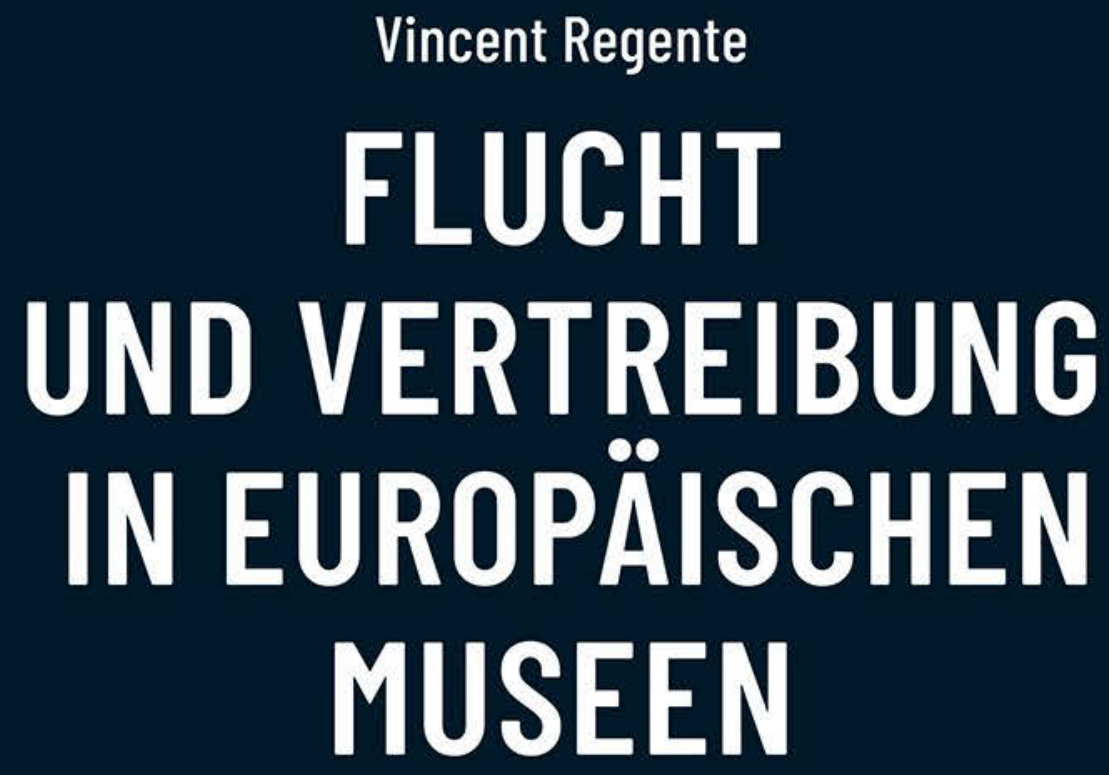

Deutsche, polnische und tschechische Perspektiven im Vergleich

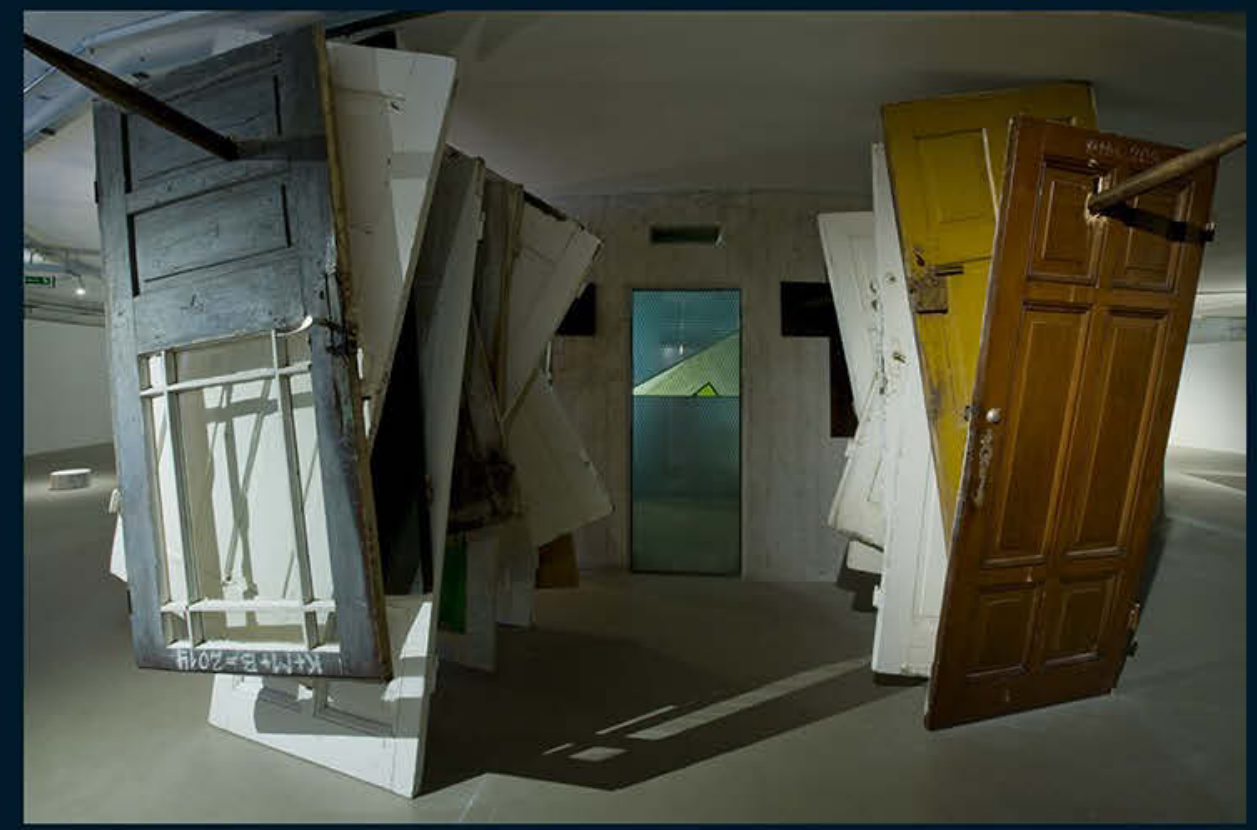

[transcript $] \begin{aligned} & \text { Public History - } \\ & \text { Angewandte Geschichte }\end{aligned}$ 
Vincent Regente

Flucht und Vertreibung in europäischen Museen

Public History - Angewandte Geschichte | Band 3 
Sine ira et studio

Vincent Regente, geb. 1987, studierte Geschichte, Sozialwissenschaften und Public History in Berlin, Wien und Warschau. Er promovierte als Stipendiat der Studienstiftung des deutschen Volkes an der Freien Universität Berlin. Seine Forschungsschwerpunkte sind Angewandte Geschichte und die Geschichte Ostmitteleuropas. 
Vincent Regente

\section{Flucht und Vertreibung in europäischen Museen}

Deutsche, polnische und tschechische Perspektiven im Vergleich 
Zugl. Dissertation, Freie Universität Berlin, 2019 mit dem Titel »Flucht und Vertreibung in europäischen Museen. Konflikte und Annäherungen in Deutschland, Polen und Tschechien«.

Die Publikation wurde ermöglicht durch eine Ko-Finanzierung für Open-Access-Monografien und -Sammelbände der Freien Universität Berlin.

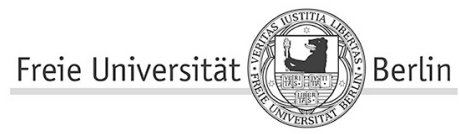

\section{Bibliografische Information der Deutschen Nationalbibliothek}

Die Deutsche Nationalbibliothek verzeichnet diese Publikation in der Deutschen Nationalbibliografie; detaillierte bibliografische Daten sind im Internet über http:// dnb.d-nb.de abrufbar.

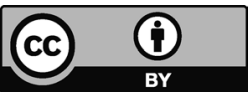

Dieses Werk ist lizenziert unter der Creative Commons Attribution 4.0 Lizenz (BY). Diese Lizenz erlaubt unter Voraussetzung der Namensnennung des Urhebers die Bearbeitung, Vervielfältigung und Verbreitung des Materials in jedem Format oder Medium für beliebige Zwecke, auch kommerziell.

(Lizenztext: https://creativecommons.org/licenses/by/4.o/deed.de)

Die Bedingungen der Creative-Commons-Lizenz gelten nur für Originalmaterial. Die Wiederverwendung von Material aus anderen Quellen (gekennzeichnet mit Quellenangabe) wie z.B. Schaubilder, Abbildungen, Fotos und Textauszüge erfordert ggf. weitere Nutzungsgenehmigungen durch den jeweiligen Rechteinhaber.

Erschienen 2020 im transcript Verlag, Bielefeld

\section{(C) Vincent Regente}

Umschlaggestaltung: Maria Arndt, Bielefeld

Umschlagabbildung: Dorota Nieznalska: Heimatvertriebene (wypędzeni z ziem ojczystych), 2014. Fotografie: Małgorzata Kujda. Mit freundlicher Genehmigung des Muzeum Współczesne Wrocław.

Druck: Majuskel Medienproduktion $\mathrm{GmbH}$, Wetzlar

Print-ISBN 978-3-8376-5169-0

PDF-ISBN 978-3-8394-5169-4

https://doi.org/10.14361/9783839451694

Gedruckt auf alterungsbeständigem Papier mit chlorfrei gebleichtem Zellstoff. Besuchen Sie uns im Internet: https://www.transcript-verlag.de Unsere aktuelle Vorschau finden Sie unter www.transcript-verlag.de/vorschau-download 


\section{Inhalt}

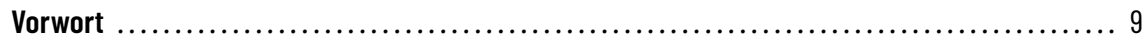

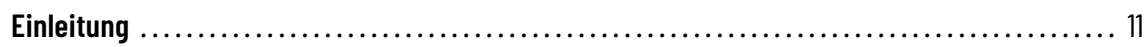

1.1 Untersuchungsansatz, Selbstverständnis des Autors und Sprache ................................... 15

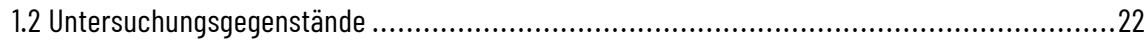

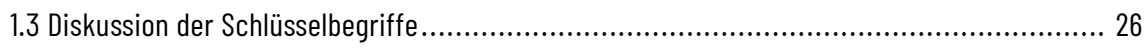

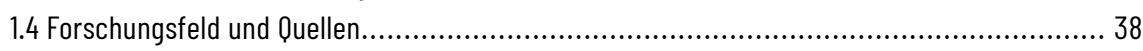

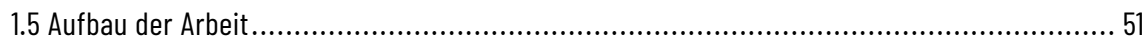

Theoretische und methodische Grundlagen ................................... 53

2.1 Vergleichende, transnationale und europäische Geschichtsschreibung............................ 53

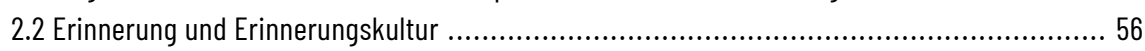

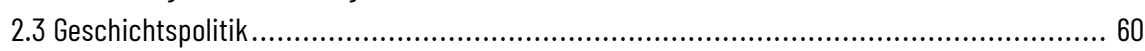

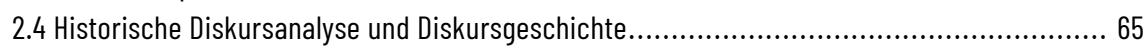

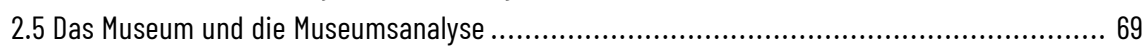

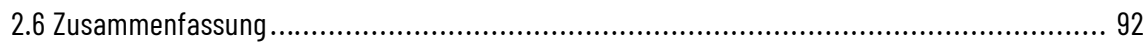

Flucht und Vertreibung der Deutschen als historisches Ereignis ................... 95

3.1 Siedlungsgeschichte bis zum modernen Nationalismus.................................................97

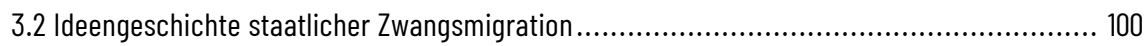

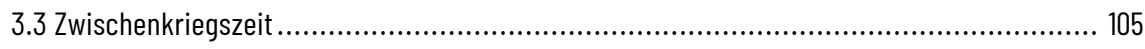

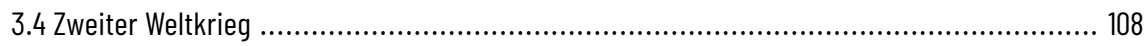

3.5 Verlauf von Flucht und Vertreibung während und nach dem Krieg.................................. 117

3.6 Integration der Vertriebenen - nach der Vertreibung in Polen und der ČSR ....................... 125

3.7 Streitpunkte: Kontext, Opferzahlen, Verantwortung und Notwendigkeit ........................... 130

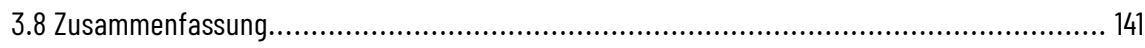

Diskurse über Flucht und Vertreibung im Kalten Krieg ........................... 145

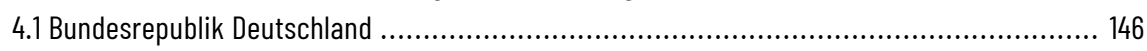

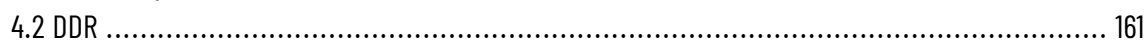

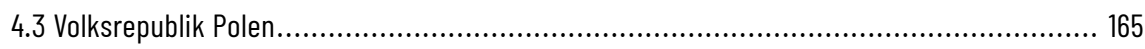


4.4 Tschechoslowakei 180

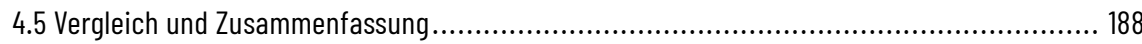

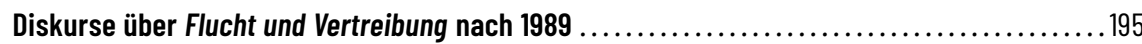

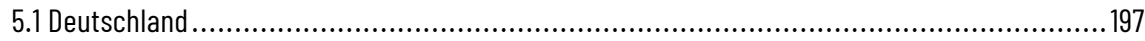

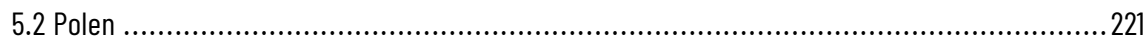

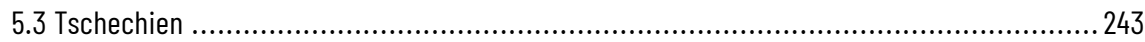

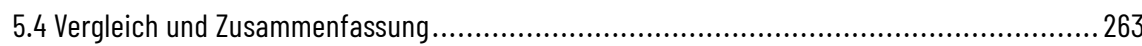

Regionalhistorische Museen .............................................. 275

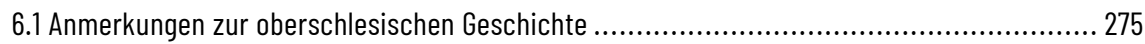

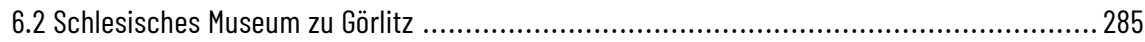

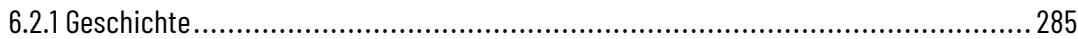

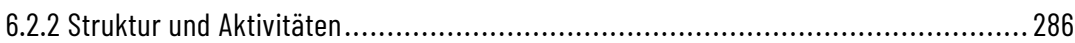

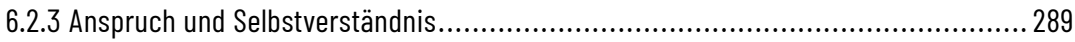

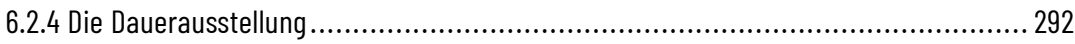

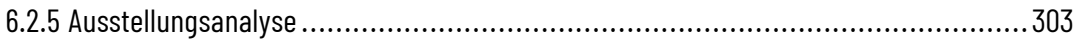

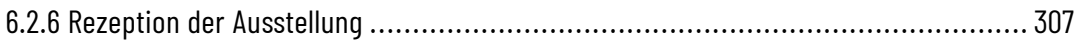

6.2.7 Zusammenführende Betrachtung ........................................................... 311

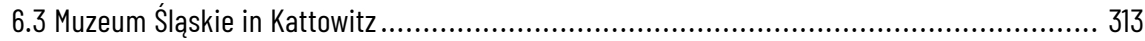

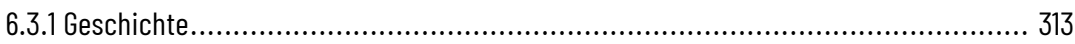

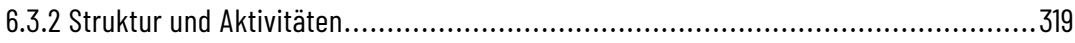

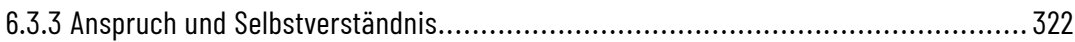

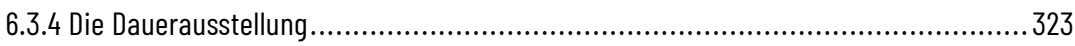

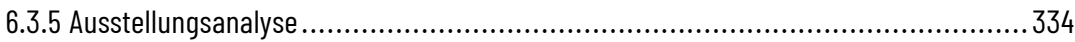

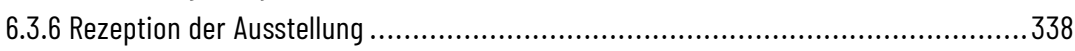

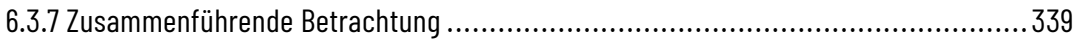

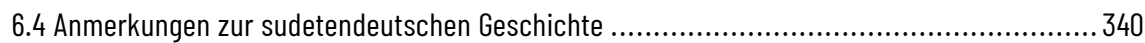

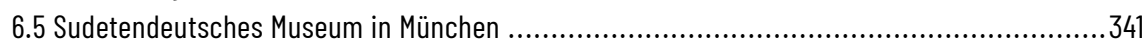

6.6 Museum der deutschsprachigen Bewohner Böhmens in Aussig .................................... 351

6.7 Vergleich der regionalhistorischen Museen ........................................................... 362

Museumsprojekte mit europäischem Anspruch im Vergleich ........................ 369

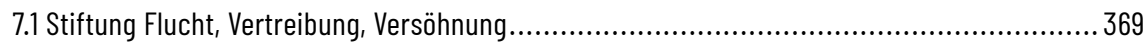

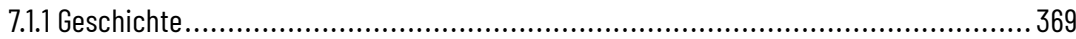

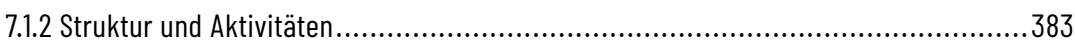

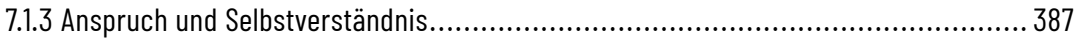

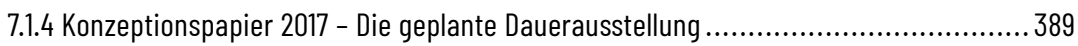

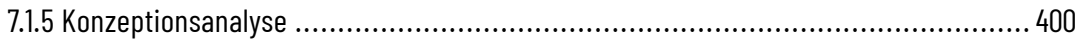

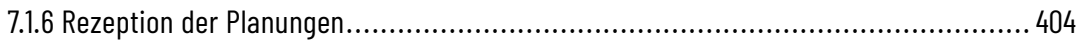

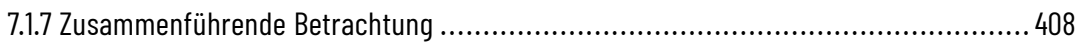

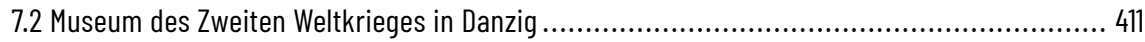

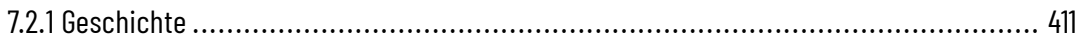

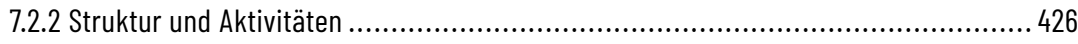

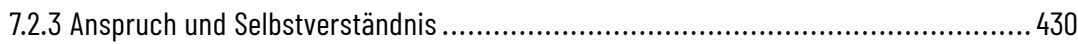




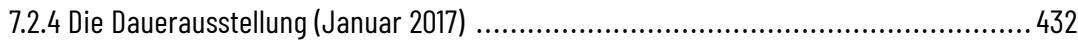

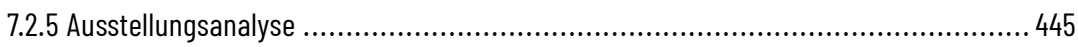

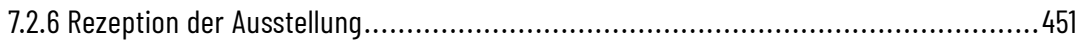

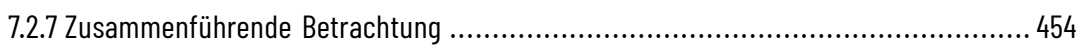

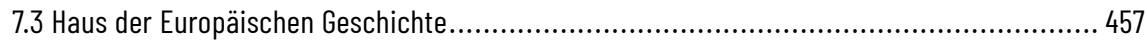

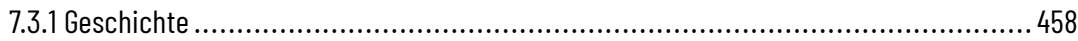

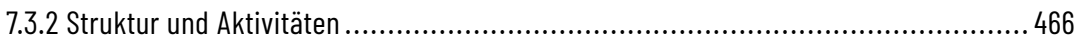

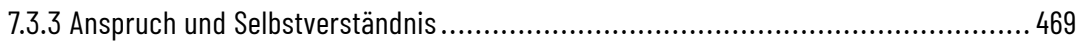

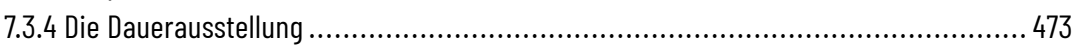

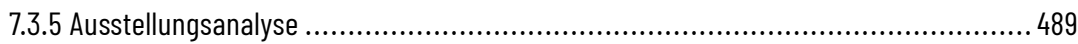

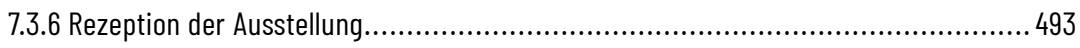

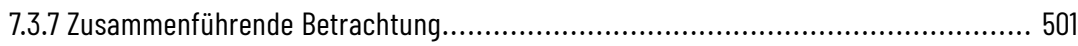

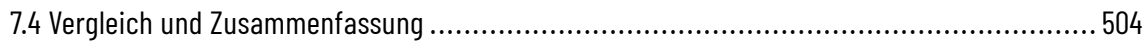

Zusammenfassung und abschließende Betrachtungen .......................... 513

\section{Anhang}

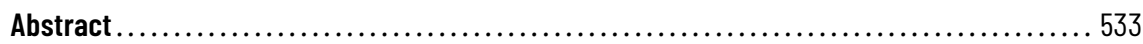

Abkürzungs- und Zeitungsverzeichnis .................................. 539

Quellen- und Literaturverzeichnis ...................................... 545

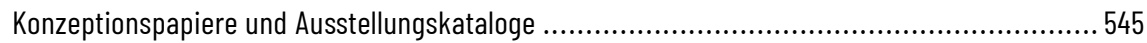

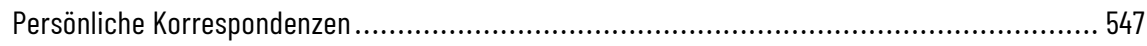

Pressemitteilungen, Berichte, Erklärungen und Manifeste ............................................. 547

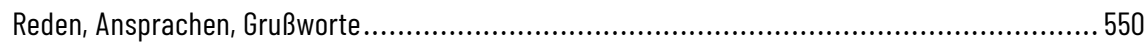

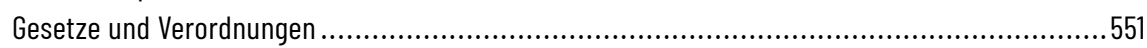

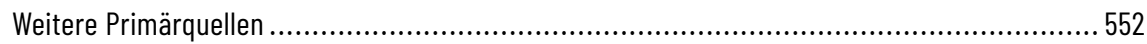

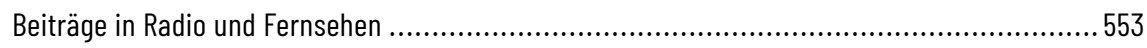

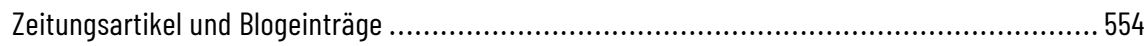

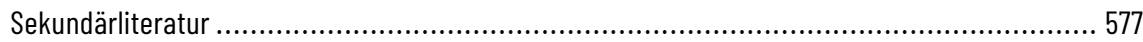

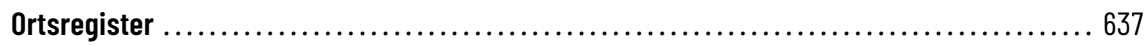

Personen-, Gruppen- und Institutionenregister ............................... 641 



\section{Vorwort}

Bei dem vorliegenden Werk handelt es sich um meine überarbeitete und aktualisierte Dissertationsschrift, die ich am 11. Juli 2019 unter dem Titel »Flucht und Vertreibung in europäischen Museen. Konflikte und Annäherungen in Deutschland, Polen und Tschechien « am Friedrich-Meinecke-Institut der Freien Universität Berlin verteidigt habe. Für die stets zugewandte Betreuung der Arbeit danke ich herzlich Professor Oliver Janz. Ein besonderer Dank gilt auch Frau Claudia Guillemin, die sehr dabei half, die ein oder andere bürokratische Hürde unter hohem Zeitdruck zu meistern. Ebenso möchte ich Professor Michael Schwartz danken, der die Arbeit von Beginn an kritisch begleitete und schließlich für das Zweitgutachten zur Verfügung stand.

Die Studienstiftung des deutschen Volkes hat die Entstehung der vorliegenden $\mathrm{Pu}$ blikation mit einem Promotionsstipendium gefördert. Für diese finanzielle und ideelle Förderung bin ich sehr dankbar. Dem Cusanuswerk möchte ich für die Förderung zu Beginn meiner Promotion danken. Der Freien Universität Berlin und ihrem Fachbereich Geschichts- und Kulturwissenschaften, die meine Auslandsaufenthalte und nicht zuletzt die Veröffentlichung der Arbeit durch den Fonds zur Ko-Finanzierung von OpenAccess-Monografien als frei zugängliches Werk unterstützten, gebührt ein besonderer Dank.

Dem transcript Verlag und namentlich Anke Poppen möchte ich für die freundliche Betreuung sowie Mirjam Galley für das schöne Angebot danken, meine Publikation in die neugeschaffene Reihe »Public History« aufzunehmen. Der Künstlerin Dorota Nieznalska, der Fotografin Małgorzata Kujda und dem Muzeum Współczesne Wrocław gebührt mein Dank dafür, dass ich ihr Werk »Heimatvertriebene« für den Umschlag des Bandes verwenden darf.

Für Inspiration und kritische Ratschläge möchte ich namentlich meinen Professoren Klaus-Peter Johne, Philipp Ther, Włodzimierz Borodziej, Hans-Jürgen Bömelburg sowie Paul Nolte danken. Für seine hilfreichen Anmerkungen darf ich auch Grzegorz Rossoliński-Liebe meine Dankbarkeit ausdrücken. Dem Militärhistorischen Museum der Bundeswehr danke ich für die Möglichkeit, an den Standorten Dresden und BerlinGatow zu arbeiten und damit Einblicke in die praktische Museumsarbeit gewinnen zu können. 
Ansgar Snethlage und Matthias Rosenthal bin ich für eine vollständige Durchsicht des Manuskriptes zu großem Dank verpflichtet. Für die kritische Lektüre einzelner Kapitel danke ich Alexander Grigoleit, Benjamin Wolff, Helge J. Pösche, Isabella Maria Engberg, Keith Buckley, Lars Lüdicke, Linn Voß, Lukas Uhde, Peter Schmidt, Sibylle Dreher, Soňa Mikulová, Sylwia Nehring und Vasco Kretschmann.

Ohne den stets inspirierenden Austausch mit vielen Kolleginnen und Kollegen, Freundinnen und Freunden wäre die Entstehung der Arbeit deutlich zäher verlaufen. Namentlich seien Christopher Spatz und Tilman Asmus Fischer genannt.

Für ihre Geduld und Unterstützung bin ich meinen Freundinnen und Freunden sehr verbunden und möchte besonders meinem Bruder Johannes und meinen Eltern Erika und Udo Regente für die stete Begleitung der Arbeit danken. 


\section{Einleitung}

In seiner Besprechung der künftigen Dauerausstellung des Museum des Zweiten Weltkrieges in Danzig befürchtete der nationalkonservative Publizist Piotr Semka, »aufdringlich von der Erinnerung an die Deutschen als Opfer bei jedem Schritt verfolgt « zu werden. ${ }^{1}$ Die vorliegende Arbeit untersucht, warum die Darstellung deutscher Opfer des Zweiten Weltkrieges im vereinten Europa auch nach Jahren der Verständigungsarbeit und Versöhnungsgesten nach wie vor umstritten und umkämpft ist. Die Auseinandersetzung mit dem Themenkomplex von Flucht und Vertreibung der Deutschen am Ende des Zweiten Weltkrieges ist dafür ein zentraler Schlüssel. Fünf Museumsvorhaben in Deutschland, Polen und auf europäischer Ebene werden auf die geschichtspolitische und erinnerungskulturelle Entwicklung dieses Themenfeldes hin untersucht. Dabei steht die Frage nach zu beobachtenden Annäherungen und fortbestehenden oder neuen Spaltungen im Fokus. Diese Studie vergleicht das 2017 eröffnete Museum des Zweiten Weltkrieges in Danzig mit dem im selben Jahr eröffneten Haus der Europäischen Geschichte in Brüssel und den Planungen der Stiftung Flucht, Vertreibung, Versöhnung in Berlin, deren Dauerausstellung 2020 eröffnen soll. Zwei regionalgeschichtliche Museen, das Schlesische Museum zu Görlitz und das Muzeum Śląskie in Kattowitz/Katowice, sind ein weiteres Untersuchungspaar. Ergänzend werden die Planungen für das Sudetendeutsche Museum in München und das Museum der deutschsprachigen Bewohner Böhmens in Aussig an der Elbe/Ústí nad Labem in Tschechien in den Blick genommen.

Das Themenfeld der Zwangsmigration hat in den letzten Jahren eine traurige Aktualität erlangt. Heute ist der Flüchtling in Europa wieder so präsent wie am Ende des Zweiten Weltkrieges. Nachdem über Jahrhunderte hinweg Menschen diesen Kontinent auf der Suche nach einem besseren Leben verlassen haben, ihre Heimat aus politischen oder religiösen Gründen aufgeben mussten oder gewaltsam aus dieser vertrieben wurden, ist in der Gegenwart Europa zum Zielort von Migrationsbewegungen geworden. Diese nahmen 2015 eine neue Dimension an, als Deutschland und Europa durch die Aufnahme von Hunderttausenden Flüchtlingen und Migranten aus verschiedenen Regionen der Welt gefordert wurden. Der Umgang mit dieser Entwicklung ist in Europa 
zu einem zentralen politischen Thema geworden und droht sowohl die nationalen Gesellschaften als auch die Union selbst zu spalten. ${ }^{2}$

In Zeiten neuer nationaler und internationaler Spannungen sind die europäischen Gesellschaften einmal mehr gefordert, das gemeinsame Haus Europa zu gestalten. Die verbindende sowie auch trennende Vergangenheit kann dafür weder ignoriert noch problemlos als Fundament genutzt werden. Fortwährende geschichtspolitische Auseinandersetzungen und historisch geglaubte Konflikte machen die Notwendigkeit einer nachhaltigen Verständigung deutlich.

Die Diskussionen um die angemessene Erinnerung und die damit verbundene politische und historische Einordnung von Flucht und Vertreibung drehten sich in Deutschland, Polen und Tschechien seit der Jahrtausendwende vor allem um die Musealisierung des historischen Geschehens und machten die geplanten Institutionen damit zum zentralen Aushandlungsort dieses Themenfeldes. Diese Auseinandersetzungen verbinden sich mit der Entwicklung, dass nach 1989 Museen als »Leitmedien« der Erinnerungskultur ebenso wie eine aktive staatliche Geschichtspolitik noch an Bedeutung gewonnen haben. ${ }^{3}$ Auch die in der vorliegenden Abhandlung diskutierten heftigen Auseinandersetzungen um die Museen sollen das Faszinosum des Museums und seiner wesentlichen Ausdrucksform, der Ausstellung, nicht verdecken. Sie besitzt die einmalige Möglichkeit, auch konfliktbeladene Erzählungen räumlich und anhand authentischer Exponate erfahrbar zu machen, Zusammenhänge zu zeigen und so eine ideale Plattform für einen vergleichenden und Verständigung ermöglichenden Blick zu sein. ${ }^{4}$

Flucht und Vertreibung sind eine der katastrophalen Folgen des Zweiten Weltkrieges. Dieses heterogene, aber verschränkte Geschehen während, am Ende und nach dem Zweiten Weltkrieg wird in Deutschland in diesem Begriffspaar zusammengefasst und bedarf weiterer Erläuterung, wie sie in Kapitel 1.3 vorgenommen wird. Der von Deutschland initiierte Zweite Weltkrieg sollte zu einer »ethnischen Neuordnung« Europas unter nationalsozialistischen Vorzeichen führen, in deren Folge die Existenz des tschechischen und polnischen Volkes in ihrer bisherigen Form ausgelöscht worden wäre. Dieses Vorhaben blieb nicht nur Planung, sondern führte zu einem beispiellosen Vernichtungskrieg mit zahllosen Verbrechen. In deren Folge wurden nach den im Holocaust ermordeten europäischen Juden, von denen etwa drei Millionen Bürger Polens waren, die nicht-jüdischen Polen und der polnische Staat zu Hauptopfern des Zweiten Weltkrieges. Insgesamt verursachte der Zweite Weltkrieg mehr als 35 Millionen Vertriebene und Flüchtlinge in Europa. ${ }^{5}$ Die Deutschen der Ostprovinzen, der Tschechoslowakei und der jahrhundertalten deutschen Siedlungsgebiete in Osteuropa waren während des Krieges Mitläufer, Täter und Opfer. Diese etwa 18 Millionen Menschen wurden am Ende des Krieges durch Flucht, Vertreibung und Deportationen ungleich härter bestraft als ihre vormaligen west- und süddeutschen >Volksgenossen 2018. Pointiert stellt er die These auf, dass die »Flüchtlingskrise sich als Europas 11. September« erwiesen habe (S. 35).

3 Makhotina; Schulze Wessel: Neue Konfliktlinien, 2015, S. 2.

4 te Heesen: Theorien des Museums zur Einführung, 2013, S. 190.

5 Suppan: Violence in Western Europe in the 20th Century, 2018, S. 179. 
Der historische Kontext von Flucht und Vertreibung scheint allein aus den Gewalttätigkeiten und den dystopischen Plänen des nationalsozialistischen Deutschland erklärbar, doch reicht der in Kapitel 3 diskutierte ideengeschichtliche Hintergrund deutlich weiter zurück. Die Vorstellungen nationaler Eindeutigkeit und eines anzustrebenden ethnisch homogenen Nationalstaates sind ein integraler Bestandteil der Moderne. Die im 19. und 20. Jahrhundert aufgekommene Idee, langfristige inner- oder zwischenstaatliche Konflikte durch organisierte >Umsiedlungen $\ll \mathrm{zu}$ befrieden, erfreut sich auch bei manchen westlichen Politikern und Intellektuellen nach einer langen Phase der Verdammung und internationaler Interventionen zur Verhinderung von Zwangsmigrationen erneuter Beliebtheit. ${ }^{6}$

Schließlich führte der Zweite Weltkrieg nicht nur zum weitgehenden Ende der Existenz deutscher Bevölkerungsgruppen in Osteuropa, sondern auch zu weiteren großflächigen Vertreibungen und Zwangsumsiedlungen. Davon bildeten die Polen aus den ehemaligen polnischen Ostgebieten, den kresy, die nächstgrößte Gruppe. Die Vernichtung des europäischen Judentums und der Sinti und Roma durch NS-Deutschland sowie das ausschließlich von Deutschland oder gemeinsam mit der Sowjetunion verursachte Ende ehemaliger multiethnischer und multikonfessioneller Kulturregionen wie Galizien änderte das bisherige Antlitz von Osteuropa vollständig und stellt einen bis heute fortwirkenden kulturellen Verlust ungeheuren Ausmaßes dar. Die genannten kresy, die jüdischen Schtetl, die von Rumänen, Ukrainern, Juden, Polen und Deutschen geprägte Bukowina und das tschechisch-jüdisch-deutsche Prag Franz Kafkas existieren nur noch in der Erinnerung. Dies ist nicht nur ein kultureller, sondern auch ein politischer Verlust - waren diese Gebiete doch bei allen, häufig erheblichen Konflikten und einer auf Ethnizität oder Konfessionalität beruhenden strukturellen Ungleichheit ${ }^{7}$ ein Beispiel für »eine lange Geschichte multikultureller und multiethnischer Kooperation [...], aus der ein gewaltiges Potenzial für gegenwärtige Orientierung und zukunftsgerichtetes Engagement gezogen werden kann. $\aleph^{8}$ Auch wenn in der vorliegenden Arbeit die Erinnerung an und die Musealisierung der Zwangsmigration der Deutschen im Mittelpunkt steht, soll diese europäische Dimension stets mitgedacht werden.

Die vorliegende Untersuchung folgt der These, dass sich erinnerungskulturelle Entwicklungen in Museumsprojekten materialisieren und anhand dieser analysiert werden können. Aus der Antwort auf die einleitend genannte Fragestellung, wie sich die geschichtspolitischen und erinnerungskulturellen Prozesse in den untersuchten Museumsvorhaben manifestiert haben, versucht die vorliegende Arbeit Schlüsse für die Entwicklung der Erinnerung an Flucht und Vertreibung in Deutschland, Polen und Tsche-

6 Vgl. Douglas: „Ordnungsgemäße Überführung«, 2012, S. 423-425, 457-459. Siehe auch: Schwartz: Ethnische »Säuberungen« in der Moderne, 2013, S. 624. Vgl. Kap. 3.7, S. 140f. und Kap. 8, S. $528 f$. Philipp Ther diskutiert kritisch die Tendenz, die »Vielsprachigkeit und [...] Multikonfessionalität« Osteuropas als Vorbild für eine multikulturelle Gesellschaft heranzuziehen, beruhte das historische Zusammenleben doch auf einer nahezu undurchlässigen und hierarchischen Zuordnung gesellschaftlicher Rollen nach Konfessionalität und Ethnie, verbunden mit einer strukturellen »soziale[n] Ungleichheit«. Ther: Die Außenseiter, 2017, S. $39 f$.

8 Kotte: Rezension zu: Beate Herget/Berit Pleitner (Hg.): Heimat im Museum? Museale Konzeptionen zu Heimat und Erinnerungskultur in Deutschland und Polen, München 2008, 2010, S. 267. 
chien zu ziehen. In Verbindung mit dem vorher untersuchten Diskurs soll dabei die Frage alter und neuer Annäherungen und Konflikte leitend sein.

Warum die hier behandelten Museumsprojekte nach wie vor umstritten und umkämpft sind, soll die Arbeit durch die Diskussion der schon existierenden und geplanten Ausstellungen sowie die ihnen vorangegangenen und sie noch begleitenden Debatten beantworten. Dafür wird die Diskursgeschichte skizziert und auf die zentralen Konfliktlinien und Argumente hin untersucht. Die in Kapitel 3 vorgenommene Diskussion des historischen Geschehens folgt der Annahme, dass Kerndissense nicht nur auf die unterschiedliche Bewertung, sondern auch auf die selektive Thematisierung einzelner Phasen der geschichtlichen Ereignisse und ihre unterschiedliche Kontextualisierung zurückzuführen sind. In den Kapiteln zur Diskursgeschichte soll folgender Fragekomplex erörtert werden: Welche diskursiven Entwicklungen führten zu einer Veränderung der Erinnerungskultur? Auf welchen Ebenen trafen sich die Diskurse? Wo scheiterten sie? Wo wurden Wege der Verständigung aufgezeigt?

Diese Arbeit prüft im Folgenden, wie die Ausstellungen und Konzeptionspapiere in dieser Diskursgeschichte agieren. Die verschiedenen Ansätze werden miteinander verglichen und auf Gemeinsamkeiten und Trennendes hin befragt. Hierbei werden die Museen nicht nur als Manifestationen, sondern auch als Akteure der Erinnerungskultur verstanden. Die Untersuchung folgt der These, dass die Unterschiede in der Darstellung von Flucht und Vertreibung stärker sind als dies auf Basis der wissenschaftlichen Literatur sowie nach dem Selbstverständnis der Museumsmacher anzunehmen wäre. Von besonderem Interesse ist die Frage, inwieweit sich demgegenüber Ansätze einer verbindenden europäischen Erzählung konkret fassen lassen. Dies soll mit der angesprochenen These abgeglichen werden, dass die älteren nationalen Narrative über eine lange unterschätzte fortlaufende Stabilität und Akzeptanz verfügen und sich auch in den Museumsprojekten wiederfinden. Eine der Annahmen des Autors besteht darin, dass besonders kontroverse Themen in den Ausstellungen aus unterschiedlichen Motivationen heraus eher vermieden als offensiv diskutiert werden. Dies wiederum könnte zu einer Unausgewogenheit der Darstellung des historischen Themas führen und damit keine ausreichende Grundlage für Verständigung sein.

Am Ende soll die Arbeit anhand der Ergebnisse der Ausstellungsuntersuchungen und der Diskursgeschichte eine Bilanz über die Erinnerungskultur an Flucht und Vertreibung in Deutschland, Polen und Tschechien sowie auf europäischer Ebene ziehen. Ein weiterführendes Ziel besteht darin, mit der Untersuchung der Auseinandersetzungen über die >richtige< Darstellung eines umstrittenen Themas im Europa des 21. Jahrhunderts auch eine Grundlage für generalisierende Überlegungen zum europäischen Umgang mit den zahlreichen umkämpften Vergangenheiten zu bieten. Grundsätzlich folgt der Autor der Argumentation, dass es unabhängig von der Gestaltung des weiteren europäischen Integrationsprozesses für das politische Zusammenleben in Europa ein Problem ist, wenn geschichtspolitische Konflikte ignoriert oder sorgsam gepflegt werden. ${ }^{9}$ Das gilt vielleicht noch mehr, wenn in Europa Nationalismus und Nationalstaat eine Renaissance erfahren sollten. Ein konstruktiver Beitrag der Geschichtswissenschaft ist für eine Verständigung notwendig, auch wenn ihr Einfluss nicht über- 
schätzt werden darf. Im besten Fall leistet auch die vorliegende Arbeit im Sinne einer engagierten Wissenschaft einen Beitrag zu diesem Einander verstehen.

\subsection{Untersuchungsansatz, Selbstverständnis des Autors und Sprache}

Für die Erläuterung des Diskurses und der Darstellung der Geschichte in den Museen ist eine Diskussion des historischen Geschehens notwendig. Auf dieser Grundlage soll der Frage nachgegangen werden, was und warum unterschiedlich erinnert wird. Dafür werden die verschiedenen Historiographien und Narrative über die Vertreibung nebeneinandergestellt und diskutiert. Unmittelbar über das Thema von Flucht und Vertreibung hinausgehend, aber für deren Verständnis in Polen und Tschechien damit untrennbar verbunden, wird auch die Besatzungs- und Kriegszeit diskutiert. Eine reine Analyse des deutschen, polnischen oder tschechischen Diskurses für sich erscheint ebenso wenig ausreichend wie eine bloße Diskussion der Museen, die so stark mit dem Diskurs und geschichtspolitischen Entwicklungen verbunden sind. Für eine Untersuchung und einen systematischen Vergleich von Erinnerungskulturen eignen sich $\mathrm{Mu}$ seen zudem besonders, auch wenn unterschiedliche Hintergründe, strukturelle Differenzen und verschiedene Ansprüche zu berücksichtigen sind..$^{10}$

Mit der Diskursgeschichte in Kapitel 4 und 5 soll, aufbauend auf dem derzeitigen Forschungsstand, eine Synthese geleistet und die verschiedenen Perspektiven und zentralen Konfliktlinien diskutiert werden. Durch die Rekonstruktion der Kernlinien des Diskurses entfällt die Notwendigkeit einer »lückenlose[n] chronologische[n] Nacherzählung der Debatte«. ${ }^{11}$ Dennoch ist der Blick auf den Diskurs im Kalten Krieg zur Herausarbeitung der erinnerungskulturellen und geschichtspolitischen Weichenstellungen beim Thema Flucht und Vertreibung geboten, wobei sich dabei eine gelegentliche Wiederholung bestimmter oder nur in Nuancen veränderter Argumentationen nicht immer vermeiden lässt. Die in Kapitel 2 thematisierte Diskursanalyse und Diskursgeschichte soll die Durchsetzung bestimmter Narrative respektive die entsprechenden Kämpfe um Deutungshoheiten erkennen und erklären. Schließlich zeichnet der Autor auf diesem Wege die Entwicklung zu den Museen nach. In Anlehnung an Stefan Troebst wird ein dreistufiges Diskurs-Modell verfolgt: der innergesellschaftliche, der zwischenstaatliche und der Diskurs auf der europäischen Ebene, wobei hier vor allem Aushandlungsprozesse im Rahmen der Europäischen Union gemeint sind. ${ }^{12}$

Für die Untersuchung der Museen, der Ausstellungen und des Konzeptionspapiers der Stiftung Flucht, Vertreibung, Versöhnung wird die in Kapitel 2.5 entwickelte Museumsanalyse herangezogen. Diese berücksichtigt die Erkenntnis, dass Ausstellungen zwar mit geschichtswissenschaftlichen Methoden, aber nicht als bloße Textquellen analysierbar sind. Zudem gilt es für eine angemessene Kritik, die spezifische »Funktionsweise 
von Ausstellungen $[\mathrm{zu}]$ verstehen und $[\mathrm{zu}]$ berücksichtigen. $\ll^{13}$ Auch wenn die Ausstellungen im Mittelpunkt der Untersuchung stehen, werden die anderen Elemente der Häuser wie Personalstruktur oder Gesetzgebung kurz erläutert und in die darauf folgenden Überlegungen einbezogen, denn schließlich limitiert die gesamte Konstruktion die Möglichkeiten der Ausstellungsmacher und sagt bereits viel über den Anspruch an das Haus oder des Hauses aus. Die Kuratoren werden in der Arbeit primär durch ihre Ausstellungen oder Konzeptionspapiere zu Wort kommen. Das stets identische Vorgehen soll die Vergleichbarkeit der untersuchten Institutionen gewährleisten. Die umfassende Ausstellungs- oder Konzeptionsanalyse bildet gemeinsam mit der Diskursgeschichte die empirische Grundlage für die abschließenden Überlegungen.

Auf Basis der in Kapitel 2.5 erörterten theoretischen Grundlagen wird ein Fragenkatalog als Leitfaden für die Untersuchung der Ausstellungen erstellt. Dieser strukturiert die Analyse und dient der Vergleichbarkeit. In diesem Katalog werden in fünf Schritten der Anspruch an das Museum und die Ausstellung (1) ebenso wie die Gestaltung (2), die konkret vermittelten Inhalte (3) und Aussagen vor allem in Hinblick auf ein oder mehrere zentrale Narrative diskutiert (4) sowie im Abgleich mit dem Anspruch des Museums Überlegungen zu dessen >Funktionieren` (5) angestellt. Die Grundlage der Analyse ist ein vom Autoren zuvor beschriebener >Ausstellungsrundgang oder eine Besprechung des Konzeptionspapieres. Diese Rundgänge und Besprechungen schaffen einen problemorientierten Überblick, der aber keinen Anspruch auf eine vollständige Erfassung der Ausstellung erhebt. Dennoch sollen deren Struktur und Grundcharakter auf diese Weise ermittelt werden.

Für die Studien vor Ort hielt der Autor besonders das räumliche Erleben und die physische Erfahrbarkeit, beispielsweise bei Geräuschkulissen, durch Notizen fest. Zudem wurden für die spätere Bearbeitung die Ausstellungen umfassend durch Fotografien dokumentiert. Erfasst wurden sowohl die Ausstellungsräume als auch Texte und Medienstationen mit dem Schwerpunkt auf den Bereichen von Flucht und Vertreibung. In allen Museen versuchte der Autor, den von den Ausstellungsmachern vorgesehenen Ausstellungsrundgang abzuschreiten, um dem intendierten räumlichen und inhaltlichen Narrativ zu folgen. In der Nachbereitung wurden die Beobachtungen in Kombination mit Ausstellungskatalogen und Ausstellungsgrundrissen, soweit vorhanden, verschriftlicht. Beim Konzeptionspapier der Stiftung Flucht, Vertreibung, Versöhnung verwendete der Autor eine an dieses Format angepasste Form der skizzierten Museumsanalyse. Die Ergebnisse und Überlegungen werden schließlich mit Pressestimmen und wissenschaftlichen Kommentaren zu den Ausstellungen abgeglichen. ${ }^{14}$ Die Resultate stellt der Autor abschließend den jeweiligen Museen der Vergleichsgruppe gegenüber.

Die Vielseitigkeit des Themas Flucht und Vertreibung, der Institution Museum und der Erinnerungskulturen Deutschlands, Polens und Tschechiens gebietet einige wesentliche Beschränkungen. Der geografische Rahmen der Arbeit begrenzt sich auf die von der 
Vertreibung der Deutschen am meisten betroffenen heutigen Staaten Deutschland, Polen und Tschechien sowie die Ebene der Europäischen Union mit dem Haus der Europäischen Geschichte. Österreich als Nachfolgestaat der Habsburgermonarchie, die über Jahrhunderte die Heimat für die Sudetendeutschen, Donauschwaben oder Siebenbürger Sachsen war, kann aus arbeitsökonomischen Gründen nicht weiter berücksichtigt werden. Das ist inhaltlich damit zu rechtfertigen, dass Österreich in der Verhandlung der Thematik nach 1945 keine zentrale Rolle einnahm. Dieses änderte sich geringfügig im Zuge der Diskussionen um die EU-Osterweiterung um die Jahrtausendwende, worauf auch einzugehen sein wird. Ebenso kann die Slowakei, die bis 1993 einen gemeinsamen Staat mit Tschechien gebildet hat und mit den Karpatendeutschen über eine eigene deutsche Minderheit verfügt, nur am Rande berücksichtigt werden.

Bei der Auswahl der Regionalmuseen erfolgt eine Beschränkung auf Schlesien mit einem Exkurs auf das Sudetenland und die Deutschen der böhmischen Länder. Nur hier liegen jeweils zwei in ihrer Form vergleichbare Museumsprojekte vor. Schlesien wird zudem auf Oberschlesien eingegrenzt, da das Museum in Kattowitz gemäß dem gängigen polnischen Verständnis von Schlesien ${ }^{15}$ einen klaren Fokus auf Oberschlesien hat und das Museum in Görlitz beide Regionen Schlesiens behandelt.

Der Fokus der Arbeit auf der staatlichen und politischen Ebene lässt es vertretbar erscheinen, auf die schwierige Frage des impacts der Museen und staatlicher Geschichtspolitik auf die Bevölkerung zu verzichten. Entsprechende punktuell vorhandene Erhebungen werden aber berücksichtigt. Da für die Ziele dieser Arbeit die Ausstellungsinhalte sowie die sie begleitenden Diskussionen im Mittelpunkt stehen, wird die Besucherrezeption keine zentrale Rolle spielen. ${ }^{16}$

Demzufolge stehen die Museen und Diskussionen im Mittelpunkt der Untersuchung. Weitere zentrale Elemente der Erinnerungskultur wie Film, Fernsehen oder Comics und digitale Formate, die die Reichweite der meisten Ausstellungen weit übersteigen, werden bis auf einige Ausnahmen nicht als Primärquellen berücksichtigt. ${ }^{17}$ Dafür kann auf eine bereits umfassende Forschung, zumindest für den Zeitraum bis in die 2000er Jahre, zurückgegriffen werden.

An verschiedenen Stellen der Arbeit werden Akteure vorgestellt und diskutiert, dennoch wird keine umfassende und vergleichende Akteursanalyse durchgeführt, wie sie bereits verschiedentlich geleistet wurde. ${ }^{18}$ Ähnlich verhält es sich mit der politischen Beziehungsgeschichte. Diese ist von Bedeutung und wird immer wieder eingebracht, dennoch handelt es sich um keine Arbeit über internationale Beziehungen, auch wenn in diesem Feld nationale und transnationale Geschichtspolitik als zunehmend wichtiger Faktor anerkannt wird. ${ }^{19}$

Die Untersuchung beschränkt sich auf aktuelle Ausstellungen und Ausstellungsprojekte. Alle untersuchten Häuser zeigen noch ihre erste Dauerausstellung und verfügen, abgesehen vom Museum in Kattowitz, über keine längere Geschichte. Ältere und weitere Musealisierungen von Flucht und Vertreibung werden nur kursorisch diskutiert.

15 Vgl. Kap. 6.1, S. 275

16 Vgl. Kap. 2.5, S. 87-89.

17 Vgl. Assmann: Das neue Unbehagen an der Erinnerungskultur, 2013, S. 42.

18 Vgl. dafür einige der in Kap. 1.4 zum Forschungsstand diskutierten Studien.

19 Vgl. Sierp; Wüstenberg: Linking the Local and the Transnational, 2015, S. 323. 
Ein gelungenes Beispiel für die Querschnittsuntersuchung eines Museums liefert themennah Vasco Kretschmann mit seiner Abhandlung zum Breslauer Stadtmuseum und seinen deutschen und polnischen Ausstellungen in 110 Jahren. ${ }^{20}$ Eine Mischform bietet die hier mehrfach herangezogene Studie von Monika Heinemann, die verschiedene polnische Museen und ihre Ausstellungen von den 1980er Jahren bis heute untersucht. ${ }^{21}$

Zeithistorische Arbeiten, die bis in die Gegenwart oder im Fall der geplanten $\mathrm{Mu}$ seumsprojekte de facto in die Zukunft reichen, unterliegen besonderen Herausforderungen und auch einer berechtigten Skepsis. Dieser soll durch die vorliegende Arbeit mit klar formulierten und mit der notwendigen Substanz beantwortbaren Fragen begegnet werden. Auf spekulative Prognosen wird verzichtet. Ansonsten steht diese wie jede wissenschaftliche Schrift der späteren Ergänzung und Falsifikation gegenüber. ${ }^{22}$ Bis zum September 2018 wurden Forschungsliteratur und Berichterstattung zum Thema Flucht und Vertreibung und zu den untersuchten Museen systematisch verfolgt. Für die überarbeitete Fassung der Studie wurden neuere Arbeiten sowie Pressemeldungen noch bis Anfang 2020 herangezogen und punktuell eingearbeitet. Das Ende des Jahres 2019 markiert damit den Endpunkt des Untersuchungszeitraumes.

Der vorliegende Untersuchungsgegenstand ist durch eine aktive Teilnahme der Geschichtswissenschaft geprägt. Ihre Aufgabe sollte darin bestehen, zu beachten, dass Museen und Politik die Thematik nicht simplifizierend dem gewünschten Narrativ unterordnen - sei es nun im Sinne einer unterschiedlich verstandenen seuropäischen oder einer nationalen Meistererzählung. Das ist nicht immer gelungen und das historische Erbe der Geschichtswissenschaft als einer Legitimationswissenschaft lässt sich auch heute nicht einfach abstreifen. Wird auf der einen Seite wieder vermehrt oder nach der wiedergewonnenen nationalen Unabhängigkeit von 1989 in Ostmitteleuropa auch nachholend klassische Nationalgeschichte geschrieben, bemühen sich auf der anderen Seite Historiker zunehmend um eine geschichtliche Fundierung der Europäischen Union. Ein prominentes Beispiel aus dem weiteren Themenfeld des vorliegenden Falles ist die >Rehabilitierung des Habsburgerreiches mit seinen komplexen Aushandlungen zwischen den Völkern und Religionen als einem historischen Vorbild der Europäischen Union. ${ }^{23}$

Eine wert- und politikfreie Arbeit ist freilich nicht möglich und auch nicht wünschenswert. Diesem Problem muss aber durch eine transparente Methodik, eine solide empirische Basis und die Darlegung der eigenen Axiome und eine damit verbundene Selbstreflexion begegnet werden. ${ }^{24}$ Der Autor versucht dafür den Ansatz zu verfolgen, dass Aushandlungen über Geschichte keine weitere Ebene internationaler Kämpfe mit Gewinnern und Verlierern sind; es geht nicht um nachträgliche Gerichtsprozesse, sondern um »Analysieren, Verstehen, Ereignisse, gesellschaftliche Mechanismen und $\mathrm{Zu}$ -

20 Kretschmann: Breslau museal, 2017.

21 Heinemann: Krieg und Kriegserinnerung im Museum, 2017.

22 Vgl. zur Problematik den Tagungsbericht zur Zeitgeschichtsforschung in Deutschland und Frankreich: Clässer: Tagungsbericht: L'histoire du temps présent et ses défis au XXle siècle/Zeitgeschichte und ihre Herausforderungen im 21. Jahrhundert, 17.10.2013-19.10.2013 Paris, 2014. 
sammenhänge, die diese bedingten und ermöglichten ${ }^{25}{ }^{25}$ Zugleich soll dem schnellen und beliebten Griff nach dem historischen Argument für politische Positionen widerstanden werden. ${ }^{26}$ Die Verständnisse und Ziele von Geschichtspolitik gehen innerhalb der Gesellschaften und zwischen den Staaten auseinander, wie in Kapitel 5 noch gezeigt wird. Existiert in Deutschland ein breiter Konsens, Geschichtspolitik als Unterstützung und Legitimation für die liberale Demokratie heranzuziehen, sehen die polnischen Nationalkonservativen in ihr einen »Generator von Patriotismus und nationaler Identitätsbildung. $\aleph^{27}$ Geschichte und Politik versteht der Autor nicht grundsätzlich als illegitime Partner, sondern sieht darin ein unter geschichtswissenschaftlicher Beteiligung oder zumindest durch sie zu begleitendes konstruktiv gestaltbares Politikfeld. ${ }^{28}$

Der Autor gehört der Generation von Deutschen an, für die Reisefreiheit und fortschreitende europäische Integration eine Selbstverständlichkeit sind und die in überwiegender Zahl ein positives Verhältnis zur Europäischen Union hat, ohne dieses in Konflikt mit nationalen Identitäten zu sehen. In den letzten Jahren, zuletzt beim Brexit, ist jedoch eine innere Spaltung Europas zunehmend offenbar geworden. Unabhängig davon, welche Vorstellungen man von der weiteren Entwicklung der Europäischen Union hat, wird die Notwendigkeit der Verständigung mit den Nachbarn über die gemeinsame Geschichte nicht verschwinden, zumindest wenn man diese eben nicht zur Konfrontation verwenden möchte.

Diese Arbeit hat die Konstruktion von Geschichte im Diskurs und im Museum zum Gegenstand. Dennoch verfolgt der Autor in Abgrenzung zu einem Radikalkonstruktivismus die Vorstellung, dass eine Annäherung an eine historische Wahrheit (wenn auch im Plural) möglich ist und dieser Anspruch unbedingt erhalten bleiben muss. ${ }^{29}$ Dass diese Wahrheit(en) aber nie abschließend geklärt werden können und stets unterschiedliche Perspektiven bestehen bleiben und müssen, ist ebenso fundamental - oder wie es der ehemalige Bundeskanzler Helmut Kohl ausdrückte:

»In einer freien Cesellschaft gibt es nach unserer Überzeugung kein geschlossenes und schon gar nicht ein amtlich verordnetes Ceschichtsbild. Niemand - niemand! - hat das Recht, anderen seine Sicht und seine Deutung der Ceschichte aufzudrängen! ${ }^{30}$

Die vorliegende Arbeit berührt die Grundfrage nach Tätern und Opfern. Auch die Museen müssen sich zu den Fragen positionieren: Werden Täter oder Opfer individualisiert oder als Kollektive dargestellt? Wie viel Raum erhalten Täter gegenüber Opfern und werden Graubereiche aufgezeigt? Der Autor folgt der Überlegung, dass eine Hierarchisierung der Opfer grundsätzlich zu vermeiden ist, was aber nicht von der Verantwortung und Notwendigkeit entbindet, auf unterschiedliche Kontexte zu verweisen. ${ }^{31}$

\footnotetext{
25 Tůma: Die Aussiedlung, 2015, S. $257 f$.

26 Ebd., S. $275 f$.

27 Saryusz-Wolska; Stach et al.: Verordnete Geschichte? 2016. Die Autorinnen beziehen sich hier auf den polnischen Politologen Aleksander Smolar.

28 Vgl. dazu und für verschiedene Positionen Kap. 2.3, S. $62 f$

29 Vgl. Rohlfes: Eine bilanzierende Einführung, 2006, S. 13.

30 Zitiert nach: Danker: Aufklärung, Identifikation oder Repräsentation? 2006, S. 215.

31 Vgl. Goschler: »Versöhnung« und »Viktimisierung«, 2005, S. 884.
} 
Damit schließt sich die Arbeit der Entwicklung an, in der die Geschichte, auch die des Zweiten Weltkrieges, nicht mehr nur durch ein starres Täter-Opfer-Schema betrachtet werden kann und so Raum für Grautöne bleibt. ${ }^{32}$ Die Diskussion über die Notwendigkeit der Vertreibungen und die Motive hinter den gewalttätigen Übergriffen wird in Kapitel 3 geführt. Der Autor folgt hier dem Verständnis, das der polnische Historiker Tomasz Strzembosz 2008 eindrücklich darlegt hat:

»Noch bevor ich zum eigentlichen Thema komme, muss ich mit einer grundlegenden Feststellung beginnen. Nichts kann Morde an irgendeiner Cruppe ziviler Opfer rechtfertigen. Es gibt nichts, was das Töten von Männern, Frauen und Kindern rechtfertigen könnte, nur weil sie zu irgendeiner gesellschaftliche Gruppe, einem bestimmten Volk oder Religion gehören. Das Üben von Gerechtigkeit muss immer individuell sein ... Genauso lehne ich grundsätzlich das Töten von Soldaten jeglicher militärischer oder polizeilicher Formationen ab, nur weil sie darin ihren Dienst tun, ganz besonders, wenn sie unbewaffnet sind und sich ergeben haben. Jeder, der einen solchen Mord begeht - und es ist ganz gleich, wen er repräsentiert - ist für mich nichts anderes als ein Mörder. ॥ $^{33}$

Die deutschen Vertriebenen betrachtet der Autor als eine Opfergruppe, deren Anspruch auf eine Erinnerung ihrer Geschichte in seiner angemessenen Dimension für Deutschland und seine Nachbarstaaten berechtigt ist. Das heißt freilich nicht, dass ihre Verbände und Positionen unkritisch gesehen werden. Schließlich gilt für die historische Bewertung, dass der spezifische Kontext des Zweiten Weltkrieges, die Beteiligung vieler Ost- und Sudetendeutscher an Krieg und Besatzungsherrschaft sie eben nicht zu einer Opfergruppe wie andere macht. Dieses Verständnis von einer besonderen Opfergruppe ist zentral, um die unterschiedlichen Bewertungsmaßstäbe für diese in Deutschland, Polen und Tschechien zu verstehen. Das stellt keineswegs in Frage, dass das vertriebene Kind oder der Greis vollständig unschuldig an ihrem Schicksal waren. Aber auch bei individuell schuldig gewordenen Menschen stellt sich die Frage, ob die Vertreibung eine rechtsstaatliche und nur damit tatsächlich gerechte Bestrafung sein kann.

Für die Untersuchung der Museen bedeutet dieses Selbstverständnis aber, dass es wissenschaftlich unsinnig wäre, diese ausschließlich aus der Perspektive zu analysieren, ob die seigene oder die im Fokus stehende Opfergruppe sangemessen wird. Diese Frage muss und kann nur im Gesamtkontext des Museums diskutiert und beantwortet werden. Dafür ist auch ein Vergleich mit der Darstellung anderer Opfergruppen sinnvoll, zum Beispiel der der polnischen Vertriebenen. Hier muss sich die Wissenschaft schließlich von einem >Opferwettbewerb < distanzieren, bei dem es darum geht »wer mehr gelitten hat, wer die meisten Opfer zu beklagen hatte.$^{34}$ Eine Möglichkeit, derartige Vorwürfe aufzufangen, besteht darin, kontroverse Themen in den $\mathrm{Mu}$ seen mit Multiperspektivität offen anzugehen und sich der Problematik auszusetzen, 
gegebenenfalls keine verbindliche Aussage treffen zu können oder diese zur Diskussion zu stellen. ${ }^{35}$ Gerade das Museum ist dafür ein geeigneter Ort.

Kaum ein Begriff ist in der engeren und weiteren Debatte um Flucht und Vertreibung unumstritten, was bei dem Terminus des historischen Geschehens selbst beginnt. Dieser und weitere Begriffe werden in der Arbeit laufend diskutiert. Ein Klassiker im deutsch-polnischen Austausch ist die Frage der Ortsbezeichnung. Der ehemals oft konfliktbeladene Umgang mit dieser Frage hat sich jedoch mittlerweile deutlich entspannt. In Polen verbindet kaum noch jemand mit der Bezeichnung von Wrocław als Breslau revanchistische Forderungen. ${ }^{36}$ Für die vorliegende Arbeit wird ein pragmatischer Umgang gewählt: Grundsätzlich werden bei der ersten Nennung im Kapitel beide Namen angegeben, bei den weiteren die deutsche Bezeichnung. Dieses auch in den bundesdeutschen Medien übliche Vorgehen stößt an seine Grenzen bei Mittel- und Kleinstädten, deren deutsche Bezeichnungen aus der Öffentlichkeit weitgehend verschwunden sind. ${ }^{37}$

Auch in dieser Arbeit fällt es schwer, den Nationenbegriff trotz der Heterogenität von Gesellschaften sowie der Komplexität von Identität konsequent zu differenzieren und damit ethnische Zuschreibungen nicht zu perpetuieren. ${ }^{38}$ Nationale Kategorien müssen zunächst als diskursive Realität zur Kenntnis genommen werden. Für den historischen Teil der vorliegenden Arbeit gilt beispielhaft, dass die Tatsache, dass die Siebenbürger Sachsen als im Mittelalter gerufene Einwanderer aus den Gebieten des Heiligen Römischen Reiches sich heute überwiegend als Deutsche verstehen, etwas mit historischen Selbst- und Fremdzuschreibungen zu tun hat. Der Fall der Sudetendeutschen ist ähnlich gelagert, gehörten diese doch trotz eines bei ihnen im 19. Jahrhundert immer stärker vorhandenen deutschen Nationalbewusstseins nach der Phase im Deutschen Bund im 19. Jahrhundert nur für sieben Jahre einem deutschen Nationalstaat an - und zwar dem nationalsozialistischen Deutschland. Vorher waren sie jahrhundertelang politisch und kulturell eng mit der Habsburger Monarchie verbunden. Besonders in den Besprechungen der Ausstellungen werden uns die Frage der Beschreibung vermeintlicher nationaler Eindeutigkeit ebenso wie nationale Indifferenzen begegnen. ${ }^{39}$

Am Beispiel der Sudetendeutschen, ein Terminus, der sich erst nach dem Zweiten Weltkrieg weitgehend durchgesetzt hat - aber auch keineswegs abschließend, wie die Benennung des Museums in Aussig zeigt - lässt sich die normative Bedeutung des Begriffes anschaulich zeigen: Wenn konsequent von der Vertreibung der tschechoslowa-

37 Ein alternativer Ansatz findet sich bei Tomann, die in ihrer historischen Untersuchung stets den jeweils vorherrschenden Stadtnamen verwendet, auch um eine historische Orientierungshilfe zu bieten: Ebd., S. 17.

38 Brunnbauer; Esch: Ethnische Säuberungen in Ostmittel- und Südosteuropa, 2006, S. 19.

39 Nach Karin Bischof stellt der »Umgang mit Minderheiten [...] eine klassische Bruchstelle nationaler Narrative dar, da Minderheiten die mit der nationalen Narration verbundene Vorstellung von Homogenität [...] häufig infrage stellen.«Bischof: Die Periode bis zur Cegenwart, 2016, S. $97 f$. 
kischen Staatsbürger deutscher Nationalität geschrieben wird, ${ }^{40}$ verbinden sich damit andere Einschätzungen, als wenn man den vermeintlichen Antagonismus von Tschechen und Sudetendeutschen repetiert. Für die Tschechoslowakei wird in dieser Arbeit der jeweils gültige Staatsname und die damit verbundene Kurzform verwendet, das heißt:

- 1918-39 und 1945-60: Tschechoslowakische Republik (ČSR; zwischen 1960-1990 Abkürzung für Tschechische Sozialistische Republik als Teilrepublik),

- 1960-1990: Tschechoslowakische Sozialistische Republik (ČSSR)

- 1990 bis 1992: Tschechische und Slowakische Föderative Republik (ČSFR).

In der Erinnerungskultur Deutschlands und Tschechiens wird häufig der tschechische und slowakische Charakter dieses Staates übersehen, auch zum Zeitpunkt der Vertreibungen. An diesen und den damit verbundenen Gewalttaten waren Slowaken auf allen Ebenen beteiligt. ${ }^{41}$

Die in der Arbeit verwendeten Übersetzungen sind, wenn nicht anders angegeben, vom Autor angefertigt worden. Bei mehrsprachigen Ausgaben wird deutschen oder englischen Texten der Vorrang gegeben. Außer wenn es gesondert angeführt ist, sind in Zitaten Hervorhebungen entsprechend der Quelle wiedergegeben.

Diese Studie verwendet ausschließlich das generische Maskulinum. Museumsmacherinnen, Kuratorinnen oder Besucherinnen seien stets mitgedacht. ${ }^{42}$

\subsection{Untersuchungsgegenstände}

Museen und Gedenkstätten sind als »Leitmedien der Erinnerung « $^{43} \mathrm{zu}$ verstehen. Durch ihre Ausstellungen und ihre Arbeit wirken sie mit einer »kreativen Eigendynamik « in die Gesellschaften hinein. ${ }^{44}$ Als Fixpunkte erinnerungskultureller Diskurse zeigen Museen und ihre Gründungen »Veränderungen, Umwidmungen und Konflikte« auf. ${ }^{45}$ An ihnen kristallisieren sich die Konfliktlinien der Auseinandersetzungen, die »Ausstellung wird zum Ort der Aushandlung, wo sich Tabus und Dissonanzen in der Geschichtsrepräsentation auftun. ${ }^{46}$ Das ganze Spektrum von Geschichtspolitik findet sich im Medium Ausstellung: "In ihnen kommen geschichtspolitische Agenden, spezifische Versuche der Funktionalisierung, Allianzen, Abgrenzungen und Umbrüche von Erinnerungsakteuren sichtbar zum Ausdruck bzw. werden kommuniziert. « ${ }^{47}$ Die

40 Das wäre freilich auch nicht vollständig korrekt, da die Sudetendeutschen die tschechoslowakische Staatsbürgerschaft nach dem Münchner Abkommen von 1938 praktisch abgelegt haben.

41 Tůma: Die Aussiedlung, 2015, S. $259 f$.

42 Vgl. Tomann: Ceschichtskultur im Strukturwandel, 2016, S. 18.

43 Makhotina; Schulze Wessel: Neue Konfliktlinien, 2015, S. 2.

44 Pieper: Resonanzräume, 2010, S. 203f.

45 Makhotina; Schulze Wessel: Neue Konfliktlinien, 2015, S. 6.

46 Pieper: Resonanzräume, 2010, S. 204.

47 Ebd. 
immanente politische Dimension zeigt sich in der Verhandlung von Identität und zentralen Fragen der Gegenwart und Zukunft im Museum. ${ }^{48}$

Die auf mehrere Jahre angelegten Dauerausstellungen sind bei ihrer Erschaffung meist vom Anspruch möglichst hoher Verbindlichkeit geprägt und wirken nach ihrer Fertigstellung häufig wiederum »kanonbildend «. ${ }^{49}$ Dies wird verstärkt durch die hohe gesellschaftliche Anerkennung, die musealisierter Geschichte entgegengebracht wird. Dennoch ist diese Autorität, gerade in der Phase der Auseinandersetzung, begrenzt und die mögliche »Absicht der Ausstellung realisiert sich [...] erst im Vorgang der Auseinandersetzung mit den Repräsentationen, in den konkurrierenden Reaktionen verschiedener Öffentlichkeiten. ${ }^{50}$

Eine genaue Definition von Möglichkeiten, Reichweite und Grenzen von Erinnerungskultur und Geschichtspolitik folgt in Kapitel 2.2 und 2.3. Dort wird die Bedeutung von staatlichen und zivilgesellschaftlichen Akteuren diskutiert, die in der vorliegenden Studie immer wieder einbezogen werden, auch wenn sie nicht im Fokus stehen. Ihre meist in langwierigen Auseinandersetzungen als Kompromisse durchgesetzten Ansprüche an die konkrete Ausformung von Geschichtspolitik und Erinnerungskultur werden in der Diskurs- sowie Vorgeschichte der Museen besprochen. Die sich anhand zentraler Konfliktlinien festmachenden Debatten zeigen zugleich die der Geschichte und Erinnerung zugeschriebene Bedeutung.

Alle in der vorliegenden Arbeit untersuchten Institutionen verbinden Gemeinsamkeiten. Sie haben als einen oder ihren zentralen Gegenstand die Flucht und Vertreibung der Deutschen am Ende des Zweiten Weltkrieges. Die untersuchten Einrichtungen sind im besonderen Maße als Ergebnis offizieller Geschichtspolitik zu verstehen, da sie zu hundert Prozent staatlich finanziert wurden und werden - teilweise auch durch die Europäische Union. Keine der Ausstellungen ist vor dem Jahr 2006 eröffnet worden. Die Konzeptions- und Gestaltungsphasen laufen folglich von den $2000 e r n$ bis in die Gegenwart. Alle Ausstellungen waren und sind umkämpft, wobei das Thema der Vertreibung im weiteren Sinne, beispielsweise bei der Darstellung der Deutschen der Region, eines der oder das Streitthema war. Bis auf das Muzeum Śląskie und das Haus der Europäischen Geschichte finden sich alle Institutionen in einem Sammelband von 2010 zur Darstellung von Flucht und Vertreibung im Museum..$^{51}$

Das 2006 eröffnete Schlesische Museum zu Görlitz (SMG ${ }^{52}$ ) und das 2015 umgezogene und um eine historische Dauerausstellung erweiterte Muzeum Śląskie in Kattowitz (MŚSK ${ }^{53}$ ) sind beides politische Leuchtturmprojekte ihrer Region. ${ }^{54}$ Die gemeinsame Bezugsre-

48 Pieper: Resonanzräume, 2010, S. 200. Vgl. Gray: The Politics of Museums, 2015, S. 170.

49 Heinemann: Krieg und Kriegserinnerung im Museum, 2017, S. 16.

50 Muttenthaler; Wonisch: Gesten des Zeigens, 2006, S. 41.

51 Dem eine entsprechende Tagung vorausging: Deutsches Historisches Museum; International Association of Museums of History et al. (Hg.): Flucht, Vertreibung, Ethnische Säuberung, 2010.

52 Die Abkürzung »SMG « wird auch vom Schlesischen Museum selbst verwendet.

53 Die Abkürzung »MŚK« wird auch vom Muzeum Śląskie selbst verwendet.

54 Die heutige schlesische Museumslandschaft ist vielfältig und wird von weiteren Museumseröffnungen in Polen begleitet. Gleichzeitig mit dem Muzeum Śląskie eröffneten zwei weitere Häuser, die die oberschlesische Geschichte behandeln: eines über die »Oberschlesischen Aufstände« in 
gion verbindet sie, auch wenn das Museum in Kattowitz sich weitgehend auf Oberschlesien beschränkt und das in Görlitz in seinem ganzheitlichen Ansatz die Geschichte Oberschlesiens miterzählt. Dennoch gibt es vielfältige Anknüpfungspunkte: sowohl die Vertreibung der Deutschen als auch damit direkt oder indirekt zusammenhängende Fragen, etwa die oberschlesische Teilung nach dem Ersten Weltkrieg, die >Begleiterscheinungen des Zwangsmigrationsgeschehens am Ende des Zweiten Weltkrieges, beispielsweise in Form der Lager, oder das Fortleben einer deutschen Minderheit in der Region. Die historische Ausstellung des Muzeum Śląskie ist auch als eine Antwort auf die deutsche und tschechische Musealisierung Oberschlesiens zu verstehen. So sah der ehemalige Direktor Leszek Jodliński in den deutschen und tschechischen Museen ein Vorbild, zumal in ihrem mehrsprachigen, auf die Nachbarländer ausgerichteten Ansatz..$^{55}$ Das MŚK hat der Autor im November 2016 besucht, das SMG im März 2017. Nach der Betrachtung der beiden Museen werden Gemeinsamkeiten und Unterschiede vergleichend erörtert. Das in der Tschechischen Republik, in Mährisch-Schlesien liegende Schlesische Landesmuseum in Troppau/Opava konnte in die vorliegende Untersuchung nicht einbezogen werden. Dieses bereits 1814 entstandene Museum war bisher aber auch weder ein Kristallisationspunkt des Vertreibungsdiskurses in Tschechien, noch berührt es aktuell mit seiner Arbeit dieses Themenfeld. Dennoch könnte das Haus in Zukunft auf die Darstellung des deutsch-tschechischen Verhältnisses hin untersucht werden. ${ }^{56}$

In zwei Exkursen werden im Kapitel 6 zudem die Planungen zum Sudetendeutschen Museum in München und zum Museum der deutschsprachigen Bewohner Böhmens in Aussig in den Blick genommen. Sie dienen als Beispiel für die Entwicklung der tschechischen und deutschen Erinnerungskultur an Flucht und Vertreibung der Sudetendeutschen. Für beide Vorhaben »lässt sich eine grenzüberschreitende Einflussgeschichte nachweisen« und beide vereint das Ziel, »das Zusammenleben in den böhmischen Ländern« darzustellen. ${ }^{57}$

2006 wurde das Collegium Bohemicum in Aussig als ein Verbundprojekt regionaler und nationaler Institutionen mit dem Auftrag gegründet, die Vergangenheit der deutschsprachigen Bewohner des Landes sowie die deutsch-tschechischen Beziehungen wissenschaftlich und kulturell aufzuarbeiten und $\mathrm{zu}$ begleiten. Auf dieser Basis wurde das Vorhaben entwickelt, ein Museum der deutschsprachigen Bewohner Böhmens zu schaffen. Diskussionen und erhebliche Verzögerungen begleiten das Projekt. Eine Eröffnung war zuletzt für 2020 vorgesehen. Für die vorliegende Arbeit kann auf

Schwientochlowitz/Świętochłowice und eines über die Deportationen von Oberschlesiern in die Sowjetunion 1945 in Radzionkau/Radzionków. Vgl. für eine knappe Darstellung der drei Institutionen Kobielska: Muzea do pamiętania/Museums for Remembering, 2016, S. 178-193. Kortko; Ostałowska: Dość całowania ręki niemieckiego pana. Gazeta Wyborcza. 26.06.2013.

56 Vgl. für eine kurze Besprechung des Schlesischen Museums in Troppau [Slezské zemské muzeum]: Táborský: Creating Silesian Identity, 2018.

57 Řezník; Schulze Wessel: Das Museum als Medium einer Verflechtungsgeschichte von Deutschen, Tschechen und Slowaken, 2017, S. $18 \mathrm{f}$. 
einen 2016 veröffentlichten »Spaziergang« durch das Ausstellungsmodell zurückgegriffen werden. ${ }^{58}$

Beim Sudetendeutschen Tag des Jahres 2006 nahm der damalige bayerische Ministerpräsident Edmund Stoiber die Idee auf, ein Sudetendeutsches Museum zu schaffen. Trotz der unmittelbar darauf beginnenden Planungen begleiteten Verzögerungen auch dieses Projekt. In der zweiten Jahreshälfte 2020 soll es eröffnen. Von allen untersuchten Häusern löste dieses Vorhaben bisher die wenigsten Kontroversen aus. Ein 355-seitiges Konzeptionspapier bildet die Grundlage für die Untersuchung. ${ }^{59}$

Die mit Beschluss des Deutschen Bundestages von der Bundesregierung 2008 ins Leben gerufene Stiftung Flucht, Vertreibung, Versöhnung $\left(\mathrm{SFVV}^{60}\right)$ war zunächst eine Reaktion auf das Projekt des Bundes der Vertriebenen (BdV), ein Zentrum gegen Vertreibungen einzurichten. Zunächst verstanden als ein Kompromiss zwischen dem Anliegen des BdV und kritischen Stimmen, die eine Gefährdung der Beziehungen zu den östlichen Nachbarstaaten sahen, war auch die weitere Entwicklung der Stiftung von fortwährenden Diskussionen geprägt. Ihre Dauerausstellung wird voraussichtlich 2021 eröffnet. Zwischenzeitlich kann auf mehrere umfassende Konzeptionspapiere, zuletzt vom Juni 2017, zurückgegriffen werden. Die SFVV versteht sich mehr als Dokumentationszentrum mit vielfältigen Aufgaben denn als Museum. Die Dauerausstellung ist nur ein, wenn auch das zentrale Element. Der Einfachheit halber wird bei der Nennung der Häuser im Plural die SFVV auch als Museum gefasst.

Der Gründungsimpuls für das Museum des Zweiten Weltkrieges (MIIW ${ }^{61}$ ) in Danzig bestand darin, eine nationalliberale, proeuropäische polnische Antwort auf das Vorhaben des BdV und später auf die Planungen der Bundesregierung zu finden. Aus der Vorstellung dieser Idee 2007 entwickelte sich rasch ein zentrales Projekt der polnischen Geschichtspolitik, um das heftigste Auseinandersetzungen entbrannten. Mittlerweile ist es zu einem Symbol des weltanschaulichen Richtungsstreits in Polen geworden. Der ursprüngliche Gründungsimpuls geriet in den Hintergrund. Dennoch ist die Darstellung von Flucht und Vertreibung an verschiedenen Stellen ein Bestandteil der Dauerausstellung geworden. Bevor das Haus im März 2017 offiziell seine Tore öffnete, konnte der Autor es im Januar 2017 bei einer vorzeitigen, temporären Öffnung besuchen. $\mathrm{Zu}$ diesem Zeitpunkt war die Ausstellung noch nicht vollständig, aber die mittlerweile fertiggestellten Bereiche zum Themenkomplex Flucht und Vertreibung konnten berücksichtigt werden, da ergänzend auf dokumentierte Berichte von Forscherkolleginnen zurückgegriffen werden konnte. ${ }^{62}$ Der Diskurs um das Museum und seine Dauerausstellung können nur in ihren Grundzügen skizziert werden und dienen vor allem als zu berücksichtigender Hintergrund für die Aushandlung von Flucht und Vertreibung im Zusammenhang mit dem MIIW. Die zeitliche Eingrenzung ist von Bedeutung, da sich

58 Mouralová; Šícha: 1500 Quadratmeter und 800 Jahre Leben, 2016.

59 Fendl: Sudetendeutsches Museum - Konzept, 2016.

60 "SFVV« ist keine offizielle Abkürzung, auch wenn sie sich in der Webadresse der Stiftung findet.

61 Muzeum II Wojny Światowej. Die Abkürzung »MIIW « wird auch von Museum in Danzig selbst verwendet, wobei die »l $\mid$ im Logo durch fallende Bomben illustriert ist.

62 Machcewicz und sein Team vermuten, dass zu diesem Zeitpunkt über 70 Prozent der Ausstellung zugänglich waren: Machcewicz: Muzeum, 2017, S. 256. 
die ursprüngliche Dauerausstellung in einem konstanten Änderungsprozess befindet. Über Änderungen an den spezifisch die Zwangsmigration betreffenden Ausstellungsteilen ist bisher noch nichts bekannt. Mit dem so gefassten Untersuchungsgegenstand lässt sich vor allem eine Aussage über das Verständnis einer angemessenen musealen Darstellung von Flucht und Vertreibung aus nationalliberaler polnischer Perspektive in den 2010er Jahren treffen.

Die Idee, ein Museum für die Geschichte Europas unter besonderer Berücksichtigung des europäischen Einigungsprozesses nach $1945 \mathrm{zu}$ schaffen, entstand bereits in den 1970er Jahren. Von verschiedenen Projekten konnte letztlich das 2007 initiierte Haus der Europäischen Geschichte $\left(\mathrm{HEH}^{63}\right)$ in Brüssel im Mai 2017 eröffnen. Das im Namen enthaltene Selbstverständnis als »Haus« soll den Anspruch widerspiegeln, ein Forum für den bürgerschaftlichen und wissenschaftlichen Austausch über die europäische Geschichte und Gegenwart zu sein. Bereits in den ersten Planungsstadien sollten Flucht und Vertreibung der Deutschen ein Ausstellungselement werden. Die spätere Realisierung dieses Teiles war dann einer von vielen verschiedenen Kritikpunkten aus dem Umfeld nationalkonservativer Kritiker des HEH aus Polen. Kurz nach der Eröffnung konnte der Autor das Haus im Juni 2017 zweimal besuchen.

\subsection{Diskussion der Schlüsselbegriffe}

Im Folgenden sollen einige der zentralen Begriffe dieser Arbeit diskutiert werden. In Kapitel 2 schließt sich die Besprechung der theoretischen und methodischen Schlüsselbegriffe von Vergleich, Erinnerungskultur, Geschichtspolitik, Museum, Ausstellung und Diskurs an.

Eine für die Diskussion der behandelten kulturhistorischen Museen fortwährend bedeutende Frage ist die der grundsätzlichen Klassifizierung. Hier soll eine schematische Skala helfen: Auf der einen Seite identifiziert der Autor einen konventionell-nationalen und konservativen, auf der anderen einen progressiven Ansatz. Monika Heinemann differenziert in ihrer Studie mit einem vergleichbaren Schema, indem sie Museen in »eher progressive oder konservative Institutionen des kollektiven Gedächtnisses« gruppiert. ${ }^{64}$ Bei progressiven Einrichtungen ist zu beobachten, dass sie bisherige Narrative hinterfragen, multiperspektivisch operieren und Inkonsistenzen zulassen, nationale Konzepte beispielsweise durch regionale, supranationale oder globale Ansätze oder eine Perspektive der Minderheiten ersetzen beziehungsweise ergänzen und von (selbst)kritischer Reflexion getragen sind. Klassische Ausstellungen zeichnen sich in diesem Schema durch zumeist nationale und sich im Kern um Nationen drehende konsistente Erzählungen aus und verwenden statische Nationenkonzepte.

Die Nähe zur politischen Sprache und zu politischen Lagern mit ihrer wertendenden Konnotation ist offensichtlich und spiegelt sich in den unterschiedlichen Positionen

House of European History. »HEH « ist keine offizielle Abkürzung, findet sich aber verschiedentlich auf den eigenen Webpräsenzen des Hauses, beispielsweise beim Mediendienst Twitter. 
zu den Museen wider, die sich häufig mit den politischen Lagern in den jeweiligen Ländern decken. Folglich soll der Begriff »progressiv« in der vorliegenden Arbeit nicht insofern missverstanden werden, dass dieser aus wissenschaftlicher Perspektive einen anzustrebenden Fortschritt bezeichnet, sondern eine bestimmte, in der Arbeit elaborierte Perspektive auf Museen beinhaltet. Wie jedes dichotome Schema ist die Aussagekraft von Kategorien wie "progressiv« und »konservativ« schließlich begrenzt. Das Haus der Europäischen Geschichte operiert zum Beispiel in einer scheinbar supranationalen Erzählung mit verschiedenen Nationalgeschichten, enthält zugleich jedoch Ansätze eines Nationalmuseums der Europäischen Union. Überkreuzungen ebenso wie unterschiedliche politische Kontexte in den verschiedenen Ländern werden folglich nicht ausgeschlossen und entsprechend thematisiert.

Flucht und Vertreibung Wie lassen sich die für diese Arbeit konstitutiven, aber heterogenen historischen Phänomene begrifflich fassen, auf die sich die Museen und Ausstellungen beziehen? Die vorliegende Untersuchung soll die vorhandene Begriffsvielfalt widerspiegeln: An erster Stelle wird der hier aufgeschlüsselte Terminus von »Flucht und Vertreibung « verwandt, ebenso wie der neutralere, wissenschaftliche Oberbegriff der "Zwangsmigration ${ }^{65}{ }^{5}$ Die Anzahl weiterer, im wissenschaftlichen Gebrauch verwendeter Begriffe ist vielfältig und eine Abgrenzung der einzelnen angesprochenen Phänomene nicht immer klar. Begriffe wie ethnische Säuberung ${ }^{66}$, Gewaltmigration, erzwungene Migration, forced removal oder population transfer haben ihre je eigenen Konnotationen und damit verbundene Vor- und Nachteile. ${ }^{67}$ Die Abgrenzung von Genozid und staatlich forcierter Zwangsmigration mag für die letztgenannten Opfergruppen, die ums Leben Gekommenen und ihre Angehörigen einen akademischen Charakter haben, dennoch ist eine Trennung aus politischer und wissenschaftlicher Sicht geboten und sinnvoll: Ist beim Genozid die physische Vernichtung einer Bevölkerungsgruppe das Ziel, ist es bei ethnischen `Säuberungen und Vertreibungen die Entfernung aus einem bestimmten Territorium. Dies schließt nicht aus, dass für letztere genozidale Metho-

65 Vgl. für ein Plädoyer für den Terminus Zwangsmigration als sinnvollem Dachbegriff: Melville; Pešek et al.: Einleitung, 2007, S. XII. Vgl. Naimark: Zwangsmigration im Europa des 20. Jahrhunderts, 2016, S. 12-14.

66 Vgl. für eine erste Einführung des Terminus, der im Zuge der ethnischen Konflikte und folgenden Kriege auf dem Balkan der 1990er Jahre entstand, den Artikel von Hans Lemberg: »Ethnische Säuberung«, 1992. Vgl. zum Begriff und zur Begriffsgeschichte auch: Schwartz: Ethnische »Säuberungen « in der Moderne, 2016, S. 29-32. Die Schreibweisen gehen dabei auseinander: Schwartz setzt nur die »Säuberungen « in Anführungszeichen, Lemberg den ganzen Begriff. Vgl. Kraft: Große Erzählungen oder dichte Beschreibungen, 2014, S. 39.

67 Vgl. zur Einführung und Diskussion des Terminus »forced removal«: Bessel; Haake: Introduction, 2009, S. 4-6. Auch Naimark diskutiert die entsprechenden Begriffe und spricht sich gegen »forced removal« aus, welches einen klinischen, »chirurgischen Beigeschmack« habe, ebenso wie der Begriff » forced population movements«(Pertti Ahonen) auch auf» Natur- und Umweltkatastrophen« zutreffen könne; der Begriff »population transfer« sei noch weniger sinnvoll, um die zu beschreibenden Ceschehnisse zu fassen. Die Verwendung des Begriffes der Vertreibung lehnt er nicht ab: Naimark: Zwangsmigration im Europa des 20. Jahrhunderts, 2016, S. 12-14. 
den angewendet und eine zumeist beträchtliche Zahl von Opfern in Kauf genommen werden. ${ }^{68}$

Der Terminus der Zwangsmigration wird sich möglicherweise als Oberbegriff durchsetzen. Ein Defizit des Begriffs des Zwanges ist allerdings seine unbestimmte Ursache. Eine Migration aufgrund einer in einem Gebiet vorherrschenden Hungersnot ist zweifellos von Zwang geprägt. Es bedarf folglich nicht eines menschlichen oder staatlichen Akteurs, der diese Form von Migration gewaltsam auslöst. ${ }^{69}$ Der Begriff der „Gewaltmigration« verdeutlicht eher das Vorhandensein eines gewalttätigen Akteurs, allerdings ermöglicht dieser keine spezifische Differenzierung von Fluchtbewegungen aufgrund unterschiedlicher Formen von Gewalt, wie das Durchrücken der Front oder die gezielte Vertreibung. Jochen Oltmer verwendet in seiner Definition einen weiten Gewaltbegriff, der die Einschränkung beziehungsweise Bedrohung von »(Über-) Lebensmöglichkeiten und körperliche[r] Unversehrtheit, Rechte[en] und Freiheit, politische[n] Partizipationschancen, Souveränität und Sicherheit « und das dadurch ausgelöste Verlassen der Herkunftsorte als Gewaltmigration fasst, welche "als eine Nötigung zur räumlichen Bewegung verstanden werden [kann], die keine realistische Handlungsalternative zuzulassen scheint. "Flucht grenzt er insofern von Vertreibungen ab, als dass erstere ein Ausweichen vor Gefahren und Diskriminierungen bedeute, Vertreibungen aber von »institutionelle[n] Akteure[n] unter Androhung und Anwendung von Gewalt « durchgeführt würden. ${ }^{70}$ Gegen den Begriff der Gewaltmigration spricht, dass diese ohne Darlegung des Kontextes als eine Migration missverstanden werden kann, die von den >Migranten mit Gewalt erzwungen wird.

Philipp Ther untergliedert Zwangsmigration in deutlicher Abgrenzung vom Genozid und den »Todeslagern der Nationalsozialisten und den Gulags der Bolschewiken«, deren Ziel die systematische Vernichtung bestimmter Gruppen war, in vier Kategorien:

1. die Flucht vor bewaffneten Auseinandersetzungen, die zu einer sethnischen Säuberung« wird, wenn die Rückkehr aufgrund von »Ethnizität oder Nationalität« verweigert wird,

2. die »Vertreibung [...], die spontan oder sogar als Racheakt erfolgen kann und nicht auf zwischenstaatlichen Vereinbarungen basiert«,

3. die ähnlich gelagerten Deportationen innerhalb oder über die Grenzen eines Staates hinweg und schließlich

4. die »Zwangsumsiedlung«, für die es eine Reihe von euphemistischen Begriffen gibt; wobei auch hier noch eine Binnendifferenzierung vorzunehmen ist. ${ }^{11}$

68 Brunnbauer; Esch: Ethnische Säuberungen in Ostmittel- und Südosteuropa, 2006, S. gf. Vgl. zur Diskussion der Trennung auch ausführlich: Kraft: Große Erzählungen oder dichte Beschreibungen, 2014, S. 41-43, 46f.

69 Naimark erscheint der Begriff Zwangsmigration zu friedlich, er klammere die notwendige Form der Gewalt aus: Naimark: Zwangsmigration im Europa des 20. Jahrhunderts, 2016, S. 12.

70 Oltmer: Deutschland und die globale Flüchtlingsfrage, 2016.

71 Ther: Die dunkle Seite der Nationalstaaten, 2011, S. 7f. In seiner Publikation von 2017 über den Flüchtling in der Geschichte untergliedert Ther wiederum vier »Idealtypen« der Flucht: die existentielle, die prädeterminierte, die proaktive und die optionale. Die Vertreibung der Deutschen 
Jenseits der wissenschaftlichen Terminologie gibt es in Deutschland, Polen und Tschechien eine eigene Begriffsgeschichte für die Zwangsmigration der Deutschen. In Polen gab und gibt es eine Reihe von meist beschönigenden Begrifflichkeiten für die Beschreibung des Geschehens. Bis heute am meisten verbreitet sind die Begriffe der »Aussiedlung« oder Zwangsaussiedlung [wysiedlenie] und »Umsiedlung« [przesiedlenie], die auch für die Zwangsmigration der Polen verwendet werden und daher entgegen dem Anschein eine weniger technisch-neutrale als negative Bedeutung in sich tragen. ${ }^{72}$ Die direkte Übersetzung des deutschen Vertreibungsbegriffs in wypędzenie funktioniert nur eingeschränkt, da dieser »wenig gebräuchlich und theologisch konnotiert ist « ${ }^{73}$ In kritischer Reaktion wird der Begriff in Polen dennoch zunehmend verwendet, allerdings dann auch bewusst für die von den Deutschen vertriebenen Polen. ${ }^{74}$ In Tschechien dominiert der Begriff des »Abschubs [odsun].${ }^{75}$ Beide beziehen sich schließlich nur auf einen Teil des historischen Geschehens. ${ }^{76}$ In allen Ländern sowie den verschiedenen betroffenen Gruppen führt der unterschiedliche Sprachgebrauch zur besonderen oder alleinigen Hervorhebung einzelner Phasen: So sind es im Deutschen die beiden Phänomene >Flucht $<$ und >Vertreibung<, im Polnischen und Tschechischen primär die Phase der vergleichsweise geregelten >Aussiedlung (der Deutschen 1946/47. ${ }^{77}$

Zur problematischen bundesrepublikanischen Tradition des Begriffes der $>$ Vertriebenen $\prec$ heißt es im Lexikon der Vertreibungen von 2010, dass dieser ein zentrales Element des bundesrepublikanischen Opferdiskurses war und ist. Er ermöglichte die Abgrenzung von den Opfern der Deutschen und behinderte die kritische Aufarbeitung des Nationalsozialismus durch eine (Über-)Betonung des deutschen Opferstatus. Zudem diente im Kalten Krieg dieses sich in dem Terminus widerspiegelnde Verständnis des Geschehens als außenpolitisches Mittel zur »Aufrechterhaltung deutscher Forderun-

betrifft vor allem die ersten beiden, kann aber zum Beispiel im Falle der als autochthon anerkannten Oberschlesier auch die letzte Kategorie betreffen: Ther: Die Außenseiter, 2017, S. 289-293. Vgl. für die Begriffsdiskussion: Stiftung Flucht, Vertreibung, Versöhnung: Konzept für die Dauerausstellung, 2017, S. $17 f$.

73 Bömelburg: Flucht und Vertreibung in der deutschen und polnischen Öffentlichkeit, 2012, S. 174.

74 Siehe: Franzen; Troebst: Vertreibung, 2010, S. $695 f$.

75 Vgl. zur komplizierten, nur als Annäherung möglichen, Übersetzung und Definition des Begriffes »odsun«: Schmidt-Hartmann: Menschen oder Nationen? 1988, S. 143-145.

76 Nach Staněk manifestieren sich in den »(...) Auseinandersetzungen um die Begriffe und ihre aktualisierten Bedeutungen (`Abschiebung` oder `Vertreibung`) nicht selten höchst unterschiedliche Sichtweisen des Bruchs in den tschechisch-deutschen Beziehungen in den $30 e r$ und 40er Jahren des 20. Jahrhunderts. Ganz offensichtlich betrachtete der überwiegende Teil der tschechischen Gesellschaft den Ausdruck >Abschiebung`(bzw. >Transfer`) als adäquate Bezeichnung für die Zwangsemigration von Deutschen aus Mittel- und Osteuropa in den Nachkriegsjahren. Allgemein gesehen gilt ungefähr das gleiche, freilich mit umgekehrten Vorzeichen (...) im deutschen Umfeld.«: Staněk: Abschiebung oder Vertreibung? 2005, S. 531. Suppan zeigt demgegenüber auf, dass bei konkreter Betrachtung die historischen Geschehnisse (auch aus Sicht beteiligter Zeitzeugen) kaum mit technischen Begriffen wie >Abschub zu fassen, sondern - den gewaltsamen und zwängenden Charakter anerkennend - als Vertreibung zu bewerten seien: Suppan: Hitler - Beneš - Tito, 2014, S. 1751.

Vgl. Linek; Lotz: Flucht, Vertreibung, Umsiedlung, 2015, S. 639-641. 
gen«, zur Abgrenzung vom `Ostblock« und der Abwehr von ausländischen Reparationsforderungen. ${ }^{78}$

Die Bezeichnung »Flucht und Vertreibung« hat trotz ihrer genannten Schwächen, ihrer politischen Instrumentalisierung und ihrer lediglich im deutschen Sprachraum existierenden Tradition auch ihre Stärken, da sie als einzige der gängigen Ausdrücke die zwei wesentlichen Bewegungen fasst. ${ }^{79}$ Die Ergänzung um weitere Begriffe wie >Evakuierung « und >Deportation « eignet sich für eine praktische Anwendung nicht. ${ }^{80}$ Eine sinnvolle Ergänzung könnte die Trias »Flucht - Vertreibung - Zwangsumsiedlung« bilden, die auch die stärker organisierten Phasen der Vertreibung einbezieht. Letztlich ist aber jeder Sammelbegriff für das historische Geschehen »zwangsläufig verkürzend « und verdeckt verschiedene Phasen und Verantwortlichkeiten des Geschehens. Damit strukturiert bereits der gewählte Begriff das Denken, den Diskurs und das politische Handeln. ${ }^{81}$

Die Verwendung des Begriffs >Vertriebeneく, in Abgrenzung zum im Sprachgebrauch der unmittelbaren Nachkriegszeit vorherrschenden Terminus >Flüchtlinge<, wird - kompatibel mit der obigen Ther'schen Kategorisierung - dadurch begründet, dass die gewünschte Rückkehr in die Heimat diesen verwehrt blieb und so aus Flüchtlingen Vertriebene wurden. ${ }^{82}$ Diese gemeinsame Erfahrung ist die Grundlage für die Verwendung der Kategorie die Vertriebenen als analytischem Dachbegriff, der mit der notwendigen Abstraktion zu lesen ist: Als vermeintlich einheitliche Großgruppe gab es sie nicht; ${ }^{83}$ es handelt sich vielmehr um eine sozial und kulturell heterogene Gruppe und die unter diesem Begriff zusammengefassten Menschen haben sehr unterschiedliche historische Erfahrungen gemacht. ${ }^{84}$ Michael Schwartz äußert sich einschränkend zum Vertriebenenbegriff, hält diesen aber gleichwohl und mangels nicht euphemistischer Alternativen für denjenigen, der den historischen Umständen am nächsten kommt. ${ }^{85}$

Eva und Hans Henning Hahn haben sich in ihrem Monumentalwerk zur Erinnerung an Flucht und Vertreibung trotz der historiographischen Unschärfe und politischen Konnotation mangels brauchbarer Alternativen und seiner festen Verankerung im deutschen Sprachgebrauch schließlich ebenfalls für die Verwendung des Begriffs der

78 Franzen: Vertriebene, 2010, S. 697f. Auch Ahonen sieht in dem in den 1950er Jahren von der Bundesrepublik geförderten Begriff der Vertreibung einen Unterschied und Komplexität reduzierenden, die östlichen Staaten anklagenden Terminus: Ahonen: On Forced Migrations, 2014, S. 602f. Vgl. Beer: Die »Flüchtlingsfrage« in Deutschland nach 1945 und heute, 2016, S. 13-22. Auch Stickler plädiert in Bezug auf Ther für die Verwendung des Begriffs »Vertreibung « und »Vertriebene« als quellennahe und die diskursive Realität prägende Begriffe: Stickler: »Ostdeutsch heißt Gesamtdeutsch«, 2004, S. $10 \mathrm{f}$.

80 Die Deutsch-Polnische Schulbuchkommission entschied sich wenigstens zeitweise für die Verwendung eines die verschiedenen Verständnisse sowie Zeitperioden abdeckenden Trialoges aus »Flucht, Vertreibung und Aussiedlung«: Ruchniewicz: Ceschichtspolitik im Schatten der Dankbarkeit und Enttäuschung, 2007/2008, S. 150.

81 Schwartz: Vertriebene im doppelten Deutschland, 2008, S. 102. Vgl. Röger: Bilder der Vertreibung, 2014, S. 263f. Siehe auch: Hahn; Hahn: Die Vertreibung im deutschen Erinnern, 2010, S. 16.

82 Lemberg: Die Vertreibung der Deutschen aus dem Osten, 2005, S. 49.

83 Schwartz: Assimilation versus Incorporation, 2016, S. 80.

84 Vgl. Kap. 3.5, S. 124.

85 Schwartz: Assimilation versus Incorporation, 2016, S. 75. 
>Vertreibung $<$ und der >Vertriebenen $<$ entschieden, verbunden mit dem Appell an die Leser, dessen problematische Begriffsgeschichte sowie die das historische Geschehen nur in Teilen fassende Verwendung fortlaufend mitzudenken. Sie verstehen Vertreibung folglich als »[...] Metapher zur Repräsentation der Geschichte der 1939-1949 heimatlos gewordenen Deutschen aus dem östlich der heutigen deutschen Grenzen gelegenen Teil Europas [...] und [...] als ein[e] historisch deskriptiv[e] Bezeichnung für jene gewaltsamen, grenzübergreifenden Ausweisungen, zu denen es in den ersten Nachkriegsmonaten vor allem entlang der neuen deutschen Ostgrenzen gekommen war. ${ }^{86}$ Diesem Appell schließt sich der Autor der vorliegenden Studie an.

Für die Verwendung des Begriffs >Vertreibungく spricht schließlich die Anerkennung der Betroffenen als Opfergruppe, auch unter Berücksichtigung des historischen Kontextes und zumal die politischen Implikationen der frühen Bundesrepublik mittlerweile entfallen sind:

»Wenn heute von >Vertriebenen gesprochen wird, geht es nicht um Revision, sondern um Anerkennung - innerhalb der deutschen Cesellschaft, aber auch seitens der osteuropäischen Nachbarn. Es geht um die nach wie vor nicht selbstverständliche Anerkennung der Tatsache, dass die Vertreibung der Deutschen nach 1945 ein Unrecht war, das mit vorangegangenen noch schlimmeren deutschen Verbrechen zweifellos erklärt, aber eben nicht gerechtfertigt werden kann. ${ }^{87}$

Europa und europäische Erinnerung Was unter »Europa« zu verstehen ist, wurde und wird in Vergangenheit und Gegenwart unterschiedlich definiert: Seien es die Grenzen des Kontinents, Europa als Kulturraum, als Idee oder als politisches Projekt. Es handelt sich um einen wirkmächtigen, vielseitig diskutierten und zumeist positiv verstandenen Begriff. ${ }^{88}$ Europa ist für alle Akteure sowohl im Diskurs über Flucht und Vertreibung als auch für die Ausrichtung der untersuchten Museen ein zentrales Motiv, auch wenn darunter Unterschiedliches verstanden wird. Vertreter der Initiative des BdV, ein Zentrum gegen Vertreibungen zu errichten, nutzten eine spezifische »Europasemantik« ebenso wie ihre Gegner. Ging es den ersteren darum, die bisherige nationale Betrachtung neu $\mathrm{zu}$ rahmen und damit zu legitimieren, forderten hingegen die Gegner, ebenfalls ohne klar ausdefinierten Europabegriff, einen vermeintlich `tatsächlichen « europäischen Ansatz ein, der vor allem die Stimmen der europäischen Nachbarländer aus Polen und Tschechien berücksichtigen sollte. ${ }^{89}$

Die in Deutschland gängige Vorstellung, dass hinter Oder und Bayerischem Wald Osteuropa beginnt, wird in Polen und Tschechien nicht geteilt. Vielmehr sieht man sich als Teil Zentraleuropas. Die Zeit des Eisernen Vorhanges gilt als unnatürliche, temporäre Verschiebung des eigenen Landes in den Ostteil Europas. Im wissenschaftlichen Sprachgebrauch in Deutschland wird bevorzugt der Begriff »Ostmitteleuropa « verwendet. In einer engeren geographischen Definition umfasst er das Gebiet zwischen Elbe/Oder, Bug, Drau und den Karpaten. Diese Ostmitteleuropadefinition schließt mit 
Ausnahme der Deutschbalten, Wolgadeutschen und der Deutschen Südosteuropas auch alle (ehemaligen) deutschen Siedlungsgebiete Osteuropas ein und eignet sich damit für die vorliegende Studie als Arbeitsbegriff. ${ }^{90}$

Differenziert betrachtet werden muss die oft unterstellte europäische Dimension von Flucht und Vertreibung, schließlich waren die Regionen und Länder Europas sehr unterschiedlich von Zwangsmigrationen betroffen. ${ }^{91}$ Besonders Ostmitteleuropa wurde während und nach dem Zweiten Weltkrieg ein "Verschiebebahnhof« der Völker, da hier die meisten Umsiedlungen, Vertreibungen und Deportationen stattfanden. ${ }^{92}$ Wenn man den Fokus jedoch auf Vertreibung und Flucht legt, wird die Bedeutung des Themas als europäisches Phänomen wesentlich deutlicher. Für die südeuropäische Dimension seien hier nur der spanische und der griechische Bürgerkrieg mit ihren erheblichen Flüchtlingszahlen, die Zwangsmigration der Algerierfranzosen oder die Aufnahme der Finno-Karelier in Finnland genannt. ${ }^{93}$

Das Heranziehen von Europa als Argument wird nicht erst seit den Vertreibungsdiskursen vorgenommen, sondern ist eng mit der Geschichte der europäischen Integration verbunden und unterliegt auch deren Konjunkturen. Dem unmittelbar nach dem Zweiten Weltkrieg in Westeuropa vorherrschenden politischen Bedarf und Willen, sich in Abgrenzung oder zumindest Ergänzung zum Nationalstaat zu verbinden und Institutionen und Wirtschaft zu europäisieren, folgten bald Re-Nationalisierungstendenzen. In den 1990er und frühen $2000 e r$ Jahren ließ sich eine neue Europaeuphorie beobachten, die mittlerweile durch starke Renationalisierungstendenzen abgelöst wurde.

In den europäischen Institutionen selbst verstärkte sich in den 1990er Jahren der Gedanke, die ökonomische und juristische Harmonisierung durch eine europäische Identitätspolitik um eine weitere Säule zu ergänzen. ${ }^{94}$ Grundlage dieses Ansatzes war die Überlegung, dass für die weitere europäische Integration eine Einigung über die gemeinsame Geschichte und Kultur notwendig sei. ${ }^{95}$ Diese Überlegung verstärkte sich noch einmal nach ökonomischen und politischen Krisen der Europäischen Union, in denen sich ein unterstelltes, aber auch tatsächliches Legitimationsdefizit der Institutionen der Europäischen Union offenbarte. ${ }^{96}$ Die in den späten 200oer Jahren ausgehandelten Kompromisse des europäischen Parlaments sehen als Fundament einer solchen intendierten gemeinsamen Erinnerung die wissenschaftlich und zivilgesellschaftlich fortgesetzte Auseinandersetzung und Abgrenzung von den totalitären Diktaturen des 20. Jahrhunderts an. ${ }^{97}$ Das Europäische Parlament ist damit zum zentralen Aus-

Vgl. Puttkamer: Ostmitteleuropa, 2014. Vgl. auch: Hackmann: Ostmitteleuropa, 2015. Siehe ebenfalls: Troebst: »Osten sind immer die anderen!« 2013. Hirsch: Flucht und Vertreibung, 2005, S. 114. 
handlungsort und Akteur der Europäischen Union in erinnerungskulturellen und geschichtspolitischen Fragen geworden. ${ }^{98}$

Manuel Becker stellt eine zielstrebige, zunehmende »Europäisierung der Memorialkultur« fest und sieht in Projekten wie dem Haus der Europäischen Geschichte »Standardisierungsbemühungen « gegenwärtiger europäischer Geschichtspolitik. ${ }^{99}$ Troebst konstatiert erste Erfolge der überwiegend im Rahmen von top-down Prozessen der EU, des Europäischen Rates, der OSZE und einiger nationaler Regierungen, aber auch durch zivilgesellschaftliche Initiativen und NGOs vorangetriebenen Projekte für eine europäische Erinnerung. Als ein zentrales Symbol dieser Entwicklung sind die polnischen, deutschen und tschechischen Museumsprojekte für die Erinnerung an unterschiedliche Zwangsmigrationen und ethnische Säuberungen des 20. Jahrhunderts anzusehen. ${ }^{100}$

Bereits in den Forschungen zu nationalen Erinnerungskulturen wird die häufig implizite Annahme, dass Gesellschaften eine Erinnerung teilen, abgelehnt und auf die auch hier vorhandene Heterogenität verwiesen. Harald Welzer stellt die Notwendigkeit eines geforderten gemeinsamen »europäischen Gedächtnisses« für einen weiteren erfolgreichen Integrationsprozess der europäischen Gemeinschaft in Frage, und zwar »ob das künftige Europa ohne eine solche mentale Gemeinschaftsstiftung auskommt bzw. auskommen muss, weil seine Erinnerungslandschaft zu heterogen und pluralistisch ist. « ${ }^{101}$ $\mathrm{Ob}$, wie, von wem ausgehend und für wen sich eine europäische Erinnerung konstituiert, bleibt eine offene Frage. Die Ebene Europas in Form von Diskussionen wie im Europäischen Parlament, aber auch die transnationaler Erinnerungsakteure, ist zudem mit den nationalen Entwicklungen unübersehbar verschränkt, sodass ein Blick auf alle drei geboten ist. ${ }^{102}$ Małgorzata Pakier und Joanna Wawrzyniak problematisieren und diskutierten die Idee Europas und einer europäischen Erinnerung anhand einer Reihe von fundierten Fragen, die die Herausforderungen zusammenfassen:

»Where are its borders? Can European societies be united - and if so, around what traditions and values? Is there a specifically European culture and tradition? How is it possible to shape a peaceful European future and to cultivate its pasts at the same time? Which pasts and which traditions should be cultivated, and which should be condemned? How is it possible to create unity and preserve the diversity of various heritages in Europe at the same time? The questions of European history and identity

Troebst: Geschichtspolitik, 2014, S. 18f. Vgl. Sierp; Wüstenberg: Linking the Local and the Transnational, 2015. Siehe auch: Dipper: Geschichtspolitik im europäischen Vergleich, 2012. Memory of Forced Migration? 2016, S. 236. Vgl. in diesem Zusammenhang auch die Arbeit von Sarah Czerney, in der sie anhand der Betrachtung dreier Museen der Frage nachgeht, ob und inwiefern sich eine »Europäisierung « europäischer Museen erkennen lässt (Deutsches Historisches Museum, Europäisches Solidarność Zentrum Gdańsk, Musée des civilisations de l'Europe et de la Méditerranée Marseille): Czerney: Zwischen Nation und Europa, 2019.

100 Troebst: Towards a European Memory of Forced Migration? 2016, S. 236.

101 Welzer: Erinnerungskultur und Zukunftsgedächtnis, 2010, S. 17.

102 Sierp: History, Memory, and Trans-European Identity, 2014, S. 145. 
have necessarily involved the need to face both the internal and external others, and definitions of who the others are. ${ }^{103}$

In der vorliegenden Studie folgt der Autor den bereits 1998 von dem Osteuropahistoriker Matthias Weber angeführten kritischen Überlegungen zur europäischen Erinnerung. Dieser warnte vor einer erneuten geschichtspolitischen und gegebenenfalls historisch verzerrenden Instrumentalisierung der historischen Region Schlesien, auch wenn diese nun für die europäische Integration genutzt werden solle. Die >Erfindung all der neuen europäischen Regionen mit ihren vermeintlich völkerverbindenden Brückenfunktionen - nachdem sie vormals >Bollwerk oder `Grenzland (waren - sei zwar politisch verständlich und auch »nicht pauschal negativ zu bewerten«. Die Wissenschaft sei hier aber gefordert, derartigen, fast »beliebig aktuellen Strömungen« und sich anpassenden Trends mit einer notwendigen Distanz zu begegnen, was auch für europäisierende Geschichtsdeutungen gelte, »die je nach Bedarf `ein Jahrtausend Kriegく zu 'tausend Jahren Nachbarschaft< werden lassen können «. ${ }^{104}$

Kritiker werfen einer solchen europäischen Rhetorik und vor allem der Geschichtspolitik der Europäischen Union eine quasi imperialistische Identitätspolitik auf Kosten der nationalen Einheiten vor, Verteidiger hingegen verweisen auf den ergänzenden Charakter einer solchen europäischen Identität. ${ }^{105}$ Die, wenn auch nicht ausschließlich, aus Ostmitteleuropa geäußerte Kritik steht allerdings in keinem Widerspruch dazu, dass die ostmitteleuropäischen Regierungen auch auf der Ebene der Europäischen Union eine sehr aktive Geschichtspolitik betreiben. Mehr als andere Regierungen haben sie erkannt, welche Bedeutung diese Ebene hat, um ihre Vorstellungen erfolgreich in die Europäische Union zu integrieren, wie das nun mit dem Holocaustgedenken auf eine vergleichbare Ebene gestellte Erinnern an die kommunistische Herrschaft über Osteuropa zeigt. ${ }^{106}$

Das Ersetzen der bisherigen nationalen Meistererzählungen durch eine neue und vereinheitlichende europäische Meistererzählung wird von den meisten Stimmen in Wissenschaft und Politik für unmöglich und aufgrund ihres potentiell exkludierenden und konfliktverschärfenden Charakters auch nicht für wünschenswert gehalten. ${ }^{107}$ Stattdessen fordert beispielsweise Aleida Assmann »die dialogische Bezogenheit und

103 Pakier; Wawrzyniak: Memory and Change in Eastern Europe, 2016, S. 5.

104 Weber: Über die Notwendigkeit, 1998, S. $22 f$.

105 So formulierten unter anderem Basil Kerski, Krzysztof Ruchniewicz, Stefan Troebst und die zeitweilige Chefentwicklerin des Museums der deutschsprachigen Bewohner Böhmens Blanka Mouralová in ihrem »Manifest für eine europäische Erinnerungskultur«: »Angesichts der zunehmenden Legitimationskrise, in der sich die >EU der 28< befindet, bedarf es einer europäischen Selbstverständigung über die gemeinsame Ceschichte. Diese Selbstverständigung soll nicht an die Stelle der jeweiligen Nationalgeschichten treten, sondern deutlich machen, wie sehr sie miteinander verflochten sind.«(Dalos; François et al.: 1914, 1989 und das Zeitalter der Extreme, 2013, S. 19).

106 Vgl. dafür beispielhaft die Auseinandersetzungen um die Einführung des 23. Augusts als EUweiten Gedenktag. Mit dem Hitler-Stalin-Pakt, in dessen Folge die beiden als gleichermaßen totalitär betrachteten Diktaturen Ostmitteleuropa unter sich aufteilten, verbindet sich für die ostmitteleuropäischen Staaten die über den Zweiten Weltkrieg hinausgehende, bis 1989 fortwährende kommunistische Diktatur: Troebst: 23 August, 2012. Vgl. Kap. 7.2.1, S. 412.

107 Rudolf Jaworski weist hier beispielsweise auf die negativen Folgen der »national exklusiv abgeschotteten Geschichtsauffassungen« besonders in Ostmitteleuropa hin, die »wie geistige Wagen- 
gegenseitige Anschlussfähigkeit nationaler Geschichtsbilder « ein. ${ }^{108} 2007$ hat sie dafür sieben »standards for a peaceful coexistence within the European Union [...] of European memories « vorgeschlagen, in denen zunächst Erinnerung vom politischen Argument getrennt werden müsse, also Geschichte nicht für gegenwärtige politische Strategien missbraucht werden dürfe. Zweitens müsse die wechselseitige Aufrechnung von Schuld aufhören und stattdessen Selbstreflektion im Mittelpunkt stehen. Daran anschließend solle auf eine ১Opferkonkurrenz`verzichtet werden; das Gedenken an die eigenen Opfer brauche und dürfe nicht durch die Marginalisierung der anderen Opfer bedingt werden. Viertens sei es erforderlich, dass Erinnerungskulturen von einer Inklusion statt Exklusion verschiedener Erinnerungen geprägt seien, was zum Beispiel heißt, dass die Erinnerung an den Holocaust die Erinnerung an die Kriegsverbrechen der Deutschen in der Sowjetunion nicht überdecken dürfe. Fünftens plädiert sie weiter dafür, dass Erinnerungen nicht auf die jeweiligen (Opfer-)Gruppen beschränkt bleiben dürfen, sondern statt einer solchen getrennten eine von Empathie geprägte geteilte Erinnerung stehen solle. Als sechsten Punkt fordert Assmann eine kontextualisierende Erinnerung, die Ursache und Wirkung des historischen Geschehens in einem weiten Horizont mitbedenkt. Schließlich sieht sie als siebten Punkt die Notwendigkeit, eine europäische Erinnerung durch gemeinsam akzeptierte Werte und eine auf diesen beruhende Identität zu rahmen. Die Berücksichtigung dieser Punkte ermögliche schließlich in Abgrenzung zum Vergessen auf der einen und einer permanenten Rückwärtsgewandheit auf der anderen Seite, "memory as a form of closure in order to open a way to the future. $\aleph^{109}$

Die vorliegende Arbeit wird weder die Konstruktion einer europäischen Erinnerung noch die Destruktion dieser Vorstellung verfolgen, sondern die Referenz auf Europa und eine »europäische Erinnerung « als eine für die vorliegende Arbeit bedeutende diskursive Realität betrachten. ${ }^{110}$ Folgen wir den Vorschlägen von Aleida Assmann, wird deutlich, dass unter einer europäischen Erinnerung, trotz mancher pathetisch-vereinfachender Äußerung, plurale, aber miteinander im Dialog stehende und aneinander anschlussfähige Erinnerungen und Erzählungen notwendig sind. Der Weg dahin ist mühevoll und erfordert eine Infragestellung der eigenen Gewissheiten. Ob sich solche Wege oder Ansätze in den Ausstellungsvorhaben finden lassen, wird zu untersuchen sein.

burgen gegenüber benachbarten Nationalitäten aufgerüstet worden sind«. Jaworski: Die historische Gedächtnis- und Erinnerungsforschung, 2009, S. 26-28.

Assmann: Auf dem Weg zu einer europäischen Cedächtniskultur? 2012, S. 62f. Bauerkämper warnt vor einer » Funktionalisierung der jüngsten Ceschichte für den Zweck der politischen Legitimation « wie der Einigung Europas, die der »Komplexität der Vergangenheit nicht gerecht«wird: Bauerkämper: Das umstrittene Gedächtnis, 2012, S. 213. Vgl. Pohl: Wann ist ein Museum »historisch korrekt«? 2006, S. $277 f$.

109 Assmann: Europe: A Community of Memory? 2007, S. 19-22. Vgl. Echternkamp; Martens: Der Weltkrieg als Wegmarke? 2007, S. 17. Siehe grundlegend zur >Opferkonkurrenz: Chaumont: Die Konkurrenz der Opfer, 2001

Feindt; Krawatzek et al.: Europäische Erinnerung? 2014, S. 11. 
Diskurs, Öffentlichkeit und Meistererzählung Der in Kapitel 2 noch auf seinen theoretischen Gehalt und damit verbundene methodische Ansätze zu befragende Begriff des Diskurses ist ein äußerst beliebter, aber auch beliebiger Terminus geworden, dessen Verwendung oft keine ausreichende Definition zugrunde liegt. Für die vorliegende Arbeit wird nach Claus Leggewie und Erik Meyer mit einer explizit geschichtspolitischen Definition unter Diskurs die Ausgestaltung der Erinnerungskultur als ein untersuchbarer politischer Aushandlungsprozess verstanden. In diesem wird die Kernfrage diskutiert: »Welche historischen Ereignisse sollen wie erinnert werden?« Für pluralistische Gesellschaften heißt das, dass durch das permanente öffentliche und von »konkurrierenden Deutungsangeboten« geprägte Ringen »um Denkmale, Gedenktage und -stätten sowie Museen « ständig Geschichtspolitik stattfindet. ${ }^{111}$

Die hier untersuchten Diskurse finden in nationalen und zeitweise transnationalen Öffentlichkeiten statt. Auch hier muss wieder der Plural unterstrichen werden, existieren und konstituieren sich doch laufend verschiedene Öffentlichkeiten. Eine Wortwahl wie: >In Deutschland war der Diskurs von Empörung geprägt‘, soll also nicht alternative Debatten und Einschätzungen, beispielsweise in der Öffentlichkeit eines beliebigen Dorfes oder Verbandes, negieren, sondern vor allem einem Öffentlichkeitsbegriff folgen, der die Argumente des jeweiligen >Mainstreamdiskurses diskutiert, der sich in den Leitmedien, bedeutenden Verbänden und Parteien konstituiert. Dass politische Aushandlungsprozesse auf dieser Ebene stattfinden, führt mit sich, dass die dafür weiterhin zentralen nationalen Öffentlichkeiten der hauptsächliche Untersuchungsgegenstand sind.

Das Fehlen einer »europäischen Öffentlichkeit« zur Förderung und als Grundlage demokratischer Aushandlungsprozesse auf europäischer Ebene wurde bereits verschiedentlich konstatiert oder als ein (noch) ausschließlicher Elitendiskurs klassifiziert. ${ }^{112}$ Dennoch ist offensichtlich, dass die nationalen Diskurse nicht unbeeinflusst sind von den Auseinandersetzungen in den Nachbarländern, aber auch von weiteren »europäische[n] und globale[n] [...] Zusammenhänge[n] «. ${ }^{113}$ Diskussionen auf europäischer Ebene werden in den einzelnen Ländern in unterschiedlichem Maße rezipiert. Für das geschichtspolitisch zwischen den Ländern weiterhin für Spannungen sorgende Themenfeld von Flucht und Vertreibung gilt dies umso mehr. Nach Becker hat sich bei dieser Diskussion ein deutsch-polnischer, wenn nicht gar ein "gesamteuropäischer Diskursraum « gebildet. ${ }^{114}$

Hier schließt sich die grundlegende Überlegung der vorliegenden Arbeit an, dass diese (temporären) nationalen oder transnationalen Diskursräume in einer »public sphere ${ }^{115}$ entstehen und als »Arena (Bernd Faulenbach, Peter Haslinger), als »politischer Kampfplatz« (Petra Bock, Edgar Wolfrum) oder als »Markt« zu verstehen sind, in

\footnotetext{
111 Leggewie; Meyer: Geschichtspolitik in der Mediengesellschaft, 2005, S. 663.

112 Vgl. Ruiz-Soler: Gibt es eine europäische Öffentlichkeit? 2017.

113 Faulenbach: Zeitenwende 1989/90, 2008, S. $94 \mathrm{f}$.

114 Becker: Geschichtspolitik in der »Berliner Republik«, 2013, S. $518 f$.

115 Sierp; Wüstenberg: Linking the Local and the Transnational, 2015, S. 322.
} 
denen mit Argumenten und mancher Polemik über zentrale Fragen wie Identität oder Schuld gestritten und für den eigenen Standpunkt geworben wird. ${ }^{116}$

Der Begriff der Meistererzählung nach Konrad Jarausch und Martin Sabrow bietet sich als Ergänzung zu kurzfristigen Aushandlungsprozessen an. Sie kann in Erweiterung der zeitweise in einem Diskurs vorherrschenden Narrative als länger gültiges und stabiles, konsistentes Verständnis eines historischen Geschehens gelten. Auch hier existieren stets Gegenerzählungen, die sich je nach politischem System stärker oder schwächer Gehör verschaffen können. Ansonsten kann sie durch ihre öffentliche Dominanz als "geschichtliche Großdeutung « mit einiger Prägekraft verstanden werden. Dem Begriff wohnt dabei auch ein gewisser simperialistischer Charakter inne, da die Erzählung nicht nur eine diskursive Hegemonie, sondern wenigstens implizit auch die Kenntnis von der einen historischen Wahrheit beansprucht. Für die wissenschaftliche Auseinandersetzung mit Meistererzählungen ist die begrenzte Vergleichbarkeit ganz unterschiedlicher politisch-gesellschaftlicher Wissenssysteme von Bedeutung, der mit der Berücksichtigung des jeweiligen Diskurskontextes zu begegnen ist. ${ }^{117}$

Versöhnung und Verständigung Zwischenstaatliche, aber auch innergesellschaftliche geschichtspolitische und erinnerungskulturelle Diskurse haben häufig Versöhnung oder - weniger pathetisch und etwas technischer - Verständigung zum Gegenstand und zum Ziel. Ein erfolgreiches Beispiel für die Beilegung eines jahrhundertelangen Konfliktes ist die deutsch-französische Aussöhnung. Der Ansicht des Autors nach erscheint der Begriff der Verständigung für den vorliegenden Fall sinnvoller, da die deutschpolnisch-tschechischen Diskurse weiter von zum Teil grundlegend unterschiedlichen Geschichtsdeutungen geprägt sind. Bei einer Erweiterung des Blickes über das >Musterbeispiek Deutschland-Frankreich hinaus ist erkennbar, dass sich bereits innergesellschaftliche Versöhnungsprozesse ebenso wie die zwischen verschiedenen Ländern zumeist durch langwierige und schwierige Verläufe auszeichnen, die zudem durch unterschiedliche kulturelle Vorstellungen von Schuld und Vergebung geprägt sind. ${ }^{118}$

Der Autor hält es daher für sinnvoll, einen Verständigungsprozess tatsächlich als einen solchen zu verstehen, der Arbeit, Zeit und Selbstkritik erfordert sowie letztlich ohne Abschluss bleibt. In Abgrenzung zu dem auch in wissenschaftlichen Schriften gelegentlich vorzufindenden »akademischen Versöhnungskitsch ${ }^{119}$ verdeutlicht der Begriff der Verständigung besser die dafür notwendigen zähen Aushandlungsprozesse. Der polnische Dissident und Intellektuelle Jan Józef Lipski formulierte 1985 die dafür notwendige Grundlage:

116 Bock; Wolfrum: Einleitung, 1999, S. 7. Haslinger: Diskurs, Sprache, Zeit, Identität, 2006, S. 42. Faulenbach: Zeitenwende 1989/90, 2008, S. 94f. Siehe auch Kap. 2.4, S. $67 f$.

117 Jarausch; Sabrow: »Meistererzählung«, 2002, S. 9, 11f., 16-18, 20-24, 30-32.

118 Tzvetkova: Apology - All is Relative, 2012, S. 110, 115. Pierre-Frédéric Weber konstatiert in seinen Ausführungen nachvollziehbar, dass der Vergleich der deutsch-polnischen mit der deutsch-französischen Versöhnung eher hemmend als produktiv ist: Weber: Ein toxischer Vergleich. Dialog Forum. 13.12.2019. Folglich dient sie auch dieser Arbeit nicht als Maßstab.

119 Grelka: Rezension zu: Stephan Lehnstaedt: Imperiale Polenpolitik in den Weltkriegen. Eine vergleichende Studie zu den Mittelmächten und zu NS-Deutschland, 2017. 
»Wir müssen uns gegenseitig alles sagen, unter der Bedingung, dass jeder über seine eigene Schuld spricht. Wenn wir dies nicht tun, erlaubt uns die Last der Vergangenheit nicht, in eine gemeinsame Zukunft aufzubrechen. $\ll^{120}$

Dieser Ansatz, tatsächliche Gesprächsfähigkeit herzustellen, deckt sich mit den ausdifferenzierten obigen Überlegungen von Aleida Assmann. Bei den untersuchten Museen bedeutet das, diese auf ihre Angebote und ihr Verständnis von Verständigung hin zu betrachten. Wie stellen sie sich zu dieser Forderung? Wie verarbeiten sie diese? Wie offensiv ist die Verständigungsrhetorik und wie gehen sie mit Kontroversen um?

\subsection{Forschungsfeld und Quellen}

Das seit den 1970er Jahren stark anwachsende mediale und wissenschaftliche Interesse an Geschichte und Erinnerungsformen hat international seinen Ausdruck in elaborierten Theorien über Formen und Techniken von Erinnerung gefunden. ${ }^{121}$ Hieran waren verschiedene Disziplinen wie die Sozialwissenschaften, die Psychologie, die Literaturwissenschaften und vor allem die Kulturwissenschaften beteiligt, welche die Vergegenwärtigung von Vergangenheit aus unterschiedlichen theoretischen und methodischen Blickwinkeln analysieren. ${ }^{122}$ Es handelt sich also um ein in hohem Maße interdisziplinäres Forschungsfeld. ${ }^{123}$

Die anfängliche Skepsis der deutschen Geschichtswissenschaft gegenüber einer historischen Erinnerungsforschung als vermeintlich wenig substantiellem Beitrag oder bloßem weiteren >Trendthema ist noch nicht überall gewichen; mittlerweile wird sie jedoch zunehmend als eine gleichberechtigte Disziplin anerkannt. ${ }^{124}$ Unterstützend kommt hinzu, dass die Bedeutung von Erinnerungskulturen in Vergangenheit und Gegenwart als ein wichtiges Element gesellschaftlicher und staatlicher Konstitution zunehmend anerkannt wird. Die geschichtswissenschaftliche Erforschung von Museen ist ein relativ neues und noch keineswegs abschließend abgestecktes Forschungsfeld, obwohl die Untersuchung von Ausstellungen als Quellen für die Untersuchung von Erinnerungskultur und Geschichtspolitik eine zunehmende Anerkennung erfährt. ${ }^{125}$

120 Entspannung und Versöhnung. Worte an Günter Grass. Text eines Vortrages, der während des Diskussionsabends mit Günter Grass im Warschauer Studentenklub »Hybrydy« am 21. Mai 1985 gehalten werden sollte; zu dieser Veranstaltung ist es dann nicht gekommen, da Grass das Einreisevisium nach Polen verweigert wurde: Lipski (Hg.): Powiedzieć sobie wszystko ... / Wir müssen uns alles sagen ..., 1998, S. 248.

121 Cornelißen: Erinnerungskulturen, 2012, S. 171f. Vgl. umfassend: Bergenthum: Geschichtswissenschaft und Erinnerungskulturen, 2005, S. 121-162. Vgl. kritisch zu einem postulierten »memory turn«: Eyal: Identity and Trauma, 2004, S. 19.

122 Vgl. Erll: Kollektives Gedächtnis und Erinnerungskulturen, 2017, S. 1f. Siehe auch: Corni: Forced Migrations and Mass Movements in the Memorialization Processes since the Second World War, 2008, S. 143.

123 Vgl. Troebst: Geschichtspolitik, 2014, S. 19.

124 Jarausch; Sabrow (Hg.): Verletztes Cedächtnis, 2002, S. 7. Vgl. Assmann: Das neue Unbehagen an der Erinnerungskultur, 2013, S. 24. Vgl. auch: Jaworski: Die historische Gedächtnis- und Erinnerungsforschung, 2009, S. $20 f ., 23$.

125 Vgl. Kaiser; Krankenhagen et al.: Europa ausstellen, 2012, S. $221 \mathrm{f}$. 
Ein beliebtes Unterthema dieses Forschungsfeldes ist die schon diskutierte Frage einer spezifischen »europäischen Erinnerung «. ${ }^{126}$ Daher wird bereits eine zunehmende Sättigung durch Forschungsliteratur zur seuropäischen Erinnerungく und der Erinnerungsforschung zum Zweiten Weltkrieg konstatiert, die alle weiteren Arbeiten in diesem Bereich unter einen besonderen Rechtfertigungsdruck setzt. ${ }^{127}$

Aus der großen Menge der hier berücksichtigten Forschungsliteratur stechen einige Arbeiten hervor, bei denen es einige Parallelen zur vorliegenden Studie gibt. Erik Meyer und Claus Leggewie haben mit ihrer viel beachteten geschichtspolitischen Untersuchung den Weg zum bundesdeutschen Holocaust-Mahnmal nachgezeichnet. ${ }^{128}$ Diese endet unter anderem mit einer knappen Besprechung der Diskussion um das Zentrum gegen Vertreibungen. An den Ansatz der Studie, den geschichtspolitischen Diskurs um die Einrichtung einer Erinnerungsstätte als Grundlage der Analyse einer Erinnerungskultur heranzuziehen, knüpft die vorliegende Arbeit an. Eine weitere vergleichbare Studie ist die von Anna Ziebińska-Witek, in der sie verschiedene Ausstellungen zum Holocaust in Museen und Gedenkstätten untersucht. ${ }^{129}$

Stephan Scholz hat in seiner Publikation von 2015 die bundesdeutsche Erinnerungslandschaft zu Flucht und Vertreibung anhand der mehreren hundert über das Land verteilten Denkmäler zur Erinnerung an die Vertreibung skizziert. ${ }^{130}$ In dem auch hier herangezogenen Sammelband »Krieg im Museum« von 2015 wird die Präsentation des Zweiten Weltkrieges in verschiedenen osteuropäischen Museen und Gedenkstätten diskutiert. Die Herausgeber Ekaterina Makhotina und Martin Schulze Wessel stellen einleitend fest, dass die vergleichende Museumsforschung in diesem Bereich noch ein Desiderat sei. ${ }^{131}$ Die Arbeit von Monika Heinemann hat hier für Polen einen wertvollen Beitrag geleistet. ${ }^{132}$ Die 2010 erschienene Studie von Thomas Thiemeyer vergleicht die Darstellung der beiden Weltkriege in elf internationalen Museen. ${ }^{133}$ Besonders auf seine im Bereich der Methodik gewonnenen Erkenntnisse wird in der vorliegenden Arbeit mehrfach zurückgegriffen. Ein ähnliches Vorgehen zeigt sich auch bei dem von Jörg Echternkamp und Stephan Jaeger 2019 herausgegebenen Sammelband »Views of Violence«, in dem die Musealisierung des Zweiten Weltkrieges in deutschen und europäischen $\mathrm{Mu}$ seen diskutiert wird. ${ }^{134}$ Für den Bereich der deutsch-polnischen Auseinandersetzungen über Flucht und Vertreibung liegt eine Vielzahl von Studien vor; ein hervorzuhebendes Beispiel ist die Untersuchung von Maren Röger über den Diskurs in Deutschland und Polen seit 1989. ${ }^{135}$ Ein aufmerksamer Beobachter und Akteur der verschiedenen Projek-

126 Vgl. Feindt; Krawatzek et al.: Europäische Erinnerung? 2014, S. 12-27.

127 Ebd., S. 11. Vgl. Makhotina; Schulze Wessel: Neue Konfliktlinien, 2015, S. 7.

128 Leggewie; Meyer: »Ein Ort, an den man gerne geht«, 2005.

129 Ziebińska-Witek: Historia w muzeach, 2011.

130 Scholz: Vertriebenendenkmäler, 2015.

131 Makhotina; Schulze Wessel: Neue Konfliktlinien, 2015, S. 7. Auch Tomann konstatiert für solche Studien im »ost(mittel)europäischen Raum« noch einen Seltenheitswert, auch wenn »sich die Forschungslandschaft langsam verändert«: Tomann: Rezension zu: Bogumił et al.: The Enemy on Display. The Second World War in Eastern European Museums. New York 2015, 2016.

132 Heinemann: Krieg und Kriegserinnerung im Museum, 2017.

133 Thiemeyer: Fortsetzung des Krieges mit anderen Mitteln, 2010.

134 Echternkamp; Jaeger (Hg.): Views of Violence, 2019.

135 Röger: Flucht, Vertreibung und Umsiedlung, 2011. 
te ist Stefan Troebst, dessen umfangreiches Oeuvre ein wertvolles Fundament bietet. Zudem gibt es eine Reihe vergleichender Studien über europäische Erinnerungskonflikte, an die verschiedentlich angeknüpft werden kann. ${ }^{136}$ Ein Beispiel für eine ausführliche vergleichende Untersuchung nationaler Erinnerungskulturen zum Zweiten Weltkrieg in verschiedenen europäischen Ländern ist die Untersuchung von Arnd Bauerkämper. ${ }^{137}$

Die Frage, inwiefern Zwangsmigration als ein Unterthema des Forschungsfeldes Migration betrachtet werden sollte, wird kontrovers diskutiert. Entsprechende Überlegungen und Ansätze, zum Beispiel im Handbuch Staat und Migration in Deutschland seit dem 17. Jahrhundert von 2016, stießen auf Widerspruch. Schwartz macht in seiner Rezension darauf aufmerksam, dass neben der Gefahr semantischer Verharmlosung die Negation spezifischer Charakteristika wie die »Opfer-Erfahrungen« von Zwangsmigranten drohe. Dennoch können auch einige Argumente für die Einordnung in das Feld der Migrationsforschung angeführt werden, so die Gemeinsamkeit einiger grundlegender Erfahrungen wie die der Entwurzelung, der Ablehnung in den Aufnahmegebieten und zum Teil erheblicher Integrationsschwierigkeiten. Letztlich sei eine angemessene Gewichtung notwendig, sodass Zwangsmigration nicht einfach als weitere >Wanderungsbewegung erscheint. ${ }^{138}$

Fast alle in dieser Arbeit behandelten Themenbereiche waren oder sind politisch umkämpft. Dies schlägt sich auch im Charakter mancher Forschungsliteratur nieder, die sich engagiert und manchmal auch polemisch in die Debatte einbringt. ${ }^{139}$ Zudem sind einige Wissenschaftler direkt oder indirekt bei den Museen involviert, zum Beispiel in den Wissenschaftlichen Beiräten, und agier(t)en dabei zum Teil selbst in erheblichem Maße politisch, in jedem Fall aber abseits des akademischen `Elfenbeinturmes‘.

Zur folgenden Besprechung des Forschungsstandes und der herangezogenen Forschungsliteratur sei einleitend noch angemerkt, dass die Sprachkenntnisse, die der Autor im Polnischen und Tschechischen erworben hat, die Bearbeitung von Quellenund einzelnen Forschungstexten erlaubt, aber dennoch eine gewisse Asymmetrie in der herangezogenen Literatur nicht zu übersehen ist. Der Autor erhebt nicht den Anspruch, den polnischen und tschechischen Forschungsstand vollständig erfasst zu

136 Vgl.z.B. folgenden umfassenden Sammelband, der sich aus theoretischen und praktischen Beiträgen zusammensetzt und europäische Erinnerungskonflikte vergleichend diskutiert: Pakier; Stråth (Hg.): A European Memory? 2010. Dem folgte 2016 ein ähnlich gelagerter Band, der sich spezifisch mit erinnerungskulturellen Fragen aus osteuropäischer Perspektive befasst: Pakier; Wawrzyniak (Hg.): Memory and Change in Europe, 2016.

137 Bauerkämper: Das umstrittene Gedächtnis, 2012.

138 Schwartz: Rezension zu: Oltmer, Jochen (Hg.): Handbuch Staat und Migration in Deutschland seit dem 17. Jahrhundert, 2016. Vgl. Ohliger: Flucht und Vertreibung als Migrationsgeschichte, 2006, S. 213; 237-239. Auch Hans Lemberg folgt unter Bezug auf Karl Schlögel dem Ansatz, »Vertreibungsgeschichte immer auch in die allgemeine Migrationsgeschichte einzuordnen «. Lemberg: Das Jahrhundert der Vertreibungen, 2003, S. 46. Vgl. Oltmer: Deutschland und die globale Flüchtlingsfrage, 2016.

139 Feindt: Flucht und Vertreibung zwischen Kaltem Krieg und Universalisierung, 2014, S. $172 f$. 
haben. Allerdings sind die zentralen Arbeiten von polnischen und tschechischen Wissenschaftlern in Deutsch oder Englisch publiziert worden oder liegen in Übersetzung vor. Dies ist besonders deshalb von Bedeutung, da in Osteuropa verschiedentlich der Einwand erhoben wird, über die dortigen Erinnerungskulturen werde im Westen ohne Beteiligung der osteuropäischen Forscher geschrieben. Dieser Kritik soll in der vorliegenden Arbeit bereits in der theoretischen Einführung wie auch im empirischen Teil durch die stete Berücksichtigung eines internationalen Autorenspektrums begegnet werden. ${ }^{140}$ Ein Beispiel für eine gelungene verbundene Geschichtsschreibung ist das 2019 erschienene österreichisch-tschechische Geschichtsbuch, das für die vorliegende Arbeit noch herangezogen werden konnte. ${ }^{141}$

Für den historischen Hintergrund sowie die damit verbundenen Kontroversen kann auf eine umfassende Historiographie zurückgegriffen werden. Bedauerlicherweise fehlt ein aktuelles Überblickswerk über die deutsche Siedlungsbewegung in Ostmitteleuropa; ${ }^{142}$ die Geschichte der deutschen Ostprovinzen ist hingegen, regional differenziert, intensiv erforscht. ${ }^{143}$ Die Forschung zum Phänomen der Zwangsmigration hat in den letzten beiden Jahrzehnten einige Standardwerke hervorgebracht, wobei diese sich meistens im Spannungsfeld von Zwangsmigration und Genozid bewegen sowie Ansätze der transnationalen und Globalgeschichte verfolgen. ${ }^{144}$ Flucht und Vertreibung der Deutschen sind in diesen häufig eines der zentralen Beispiele; zusätzlich gibt es eine Reihe aktueller regional-vergleichender Studien sowie spezifische Überblickswerke über die Zwangsmigration der Deutschen am Ende des Zweiten Weltkrieges in ihrem weiteren Kontext. ${ }^{145}$ Die Historisierungs- und Forschungsgeschichte

140 Pakier; Wawrzyniak: Memory and Change in Eastern Europe, 2016, S. 4.

141 Perzi; Schmoller et al. (Hg.): Nachbarn, 2019.

142 Eine solche Regionalgeschichte sollte heute gleichwohl stets die verschiedenen dort lebenden Bevölkerungsgruppen zusammenführend untersuchen. So stellt Seibt fest, dass es »keine sudetendeutsche Geschichte innerhalb der böhmischen Länder [gibt], es gibt nur eine böhmische Geschichte«: Seibt: Tausend Jahre Jüdische Geschichte in Böhmen und Mähren (2000), 2002, S. 49. Vgl. für einen optisch ansprechenden Überblick über »Deutsches Leben in Mittel- und Osteuropa« den Katalog zur Ausstellung »Die Gerufenen« des Zentrums gegen Vertreibungen: Zentrum gegen Vertreibungen: Die Gerufenen, 2009.

143 Vgl. z.B. das Grundlagenwerk zu Ostpreußen: Kossert: Ostpreußen, 2007.

144 Naimark: Flammender Haß, 2004. Schwartz: Ethnische»Säuberungen«in der Moderne, 2013. Ther: Die dunkle Seite der Nationalstaaten, 2011. Der Wunsch, den Diskurs durch einen systematischen Überblick zu versachlichen, hat sich u.a. in einem umfassenden Lexikonprojekt über europäische Zwangsmigrationen des 20. Jahrhunderts niedergeschlagen: Brandes; Sundhaussen et al. (Hg.): Lexikon der Vertreibungen, 2010.

145 Vgl. z.B.: Troebst; Wildt (Hg.): Zwangsmigration im Europa der Moderne, 2016. Zentral ist das neue Standardwerk des Iren Ray M. Douglas zum Vertreibungsgeschehen der Deutschen: Douglas: »Ordnungsgemäße Überführung«, 2012. Auch Beer hat ein gut komprimiertes Überblickswerk verfasst: Beer: Flucht und Vertreibung der Deutschen, 2011. Dabei kritisiert Beer, dass nach wie vor eine international anerkannte Zusammenfassung der Zwangsmigration in Ostmitteleuropa im und nach dem Zweiten Weltkrieg fehle (S. 31). Eine Reihe von entsprechend vergleichend angelegten Sammelbänden verschafft hier bereits Abhilfe: Vgl. z.B.: Ahonen; Corni et al. (Hg.): People on the Move, 2008. Ebenfalls gibt es eine Reihe von edierten, umfassenden Quellensammlungen. Für den sudetendeutschen Fall z.B. die zweisprachige und zweibändige, monumentale Veröffentlichung des Sudetendeutschen Archivs in München zum odsun: Hoffmann; Harasko: Odsun, 2000. Hoffmann; Heißig: Odsun, 2010. 
von Flucht und Vertreibung in Deutschland ist als ein eigener Untersuchungsgegenstand zu betrachten, der hier primär im Rahmen der Diskursgeschichte besprochen wird. ${ }^{146}$ Mit Andreas Kosserts »Kalter Heimat« liegt seit 2008 ein Standardwerk zur >Integrationsgeschichteく der deutschen Vertriebenen vor. ${ }^{147}$ Tomáš Staněk hat für Tschechien in zwei großen Studien sowohl das Vertreibungsgeschehen als auch das tschechoslowakische Lagerwesen aufgearbeitet. ${ }^{148}$ Für Polen existieren vergleichbare Überblickswerke und ebenso viele regionale oder thematische Studien. ${ }^{149}$

Eine Vielzahl von Abhandlungen beschäftigen sich mit der Diskursgeschichte in der Bundesrepublik während des Kalten Krieges. Neben Kosserts Buch hat sich von konservativer Seite Manfred Kittel in seiner zum Teil kontrovers besprochenen Studie »Vertreibung der Vertriebenen? « mit dieser befasst. ${ }^{150}$ Auch Eva und Hans-Henning Hahn haben sich in ihrer Publikation von 2010 umfassend mit der Erinnerungsgeschichte während des Kalten Krieges bis in die 2000er Jahre hinein beschäftigt. ${ }^{151}$ Weiter gibt es eine Reihe von Spezialpublikationen, wie die Monographie von Matthias Stickler mit der Geschichte der Vertriebenenverbände bis $1972^{152}$ oder die von Matthias Müller, die sich mit dem Verhältnis zwischen Verbänden und SPD befasst. ${ }^{153}$ Anna Jakubowska hat eine transnationale Studie über den BdV und seine Selbst- und Fremddarstellung in Polen und der Bundesrepublik Deutschland bis 2004 vorgelegt. ${ }^{154}$ Viele der Publikationen behandeln auch die Integrations- und Diskursgeschichte der DDR, außerdem gibt es eine Reihe von spezifischen oder die Bundesrepublik und die DDR vergleichenden Publikationen wie die von Arnd Bauerkämper, Michael Schwartz oder von Bill Niven,

146 Vgl. für eine knappe Zusammenfassung von Forschungsgeschichte und Forschungsstand: Beer: Flucht und Vertreibung der Deutschen, 2011, S. 23-31. Siehe auch: Suppan: Hitler - Beneš - Tito, 2014, S. 48-50. Dabei äußert sich Suppan (S. 50) verwundert darüber, dass die deutsche und österreichische akademische Geschichtsforschung dieses »Schlüsselereignis der deutschen und österreichischen Nachkriegsgeschichte für mehr als ein halbes Jahrhundert der zahlreichen Literatur aus Vertriebenenkreisen überließ.«

147 Kossert: Kalte Heimat, 2009.

148 Staněk: Verfolgung 1945, 2002. Staněk: Internierung und Zwangsarbeit, 2007. Vgl. zum Forschungsstand in Tschechien auch: Arburg: Das Katastrophenjahrzehnt 1938-1948 im Spiegel der historischen Forschung, 2011, S. 83-88.

149 Eine umfassende Besprechung aus den 1990er Jahren findet sich im Tagungsband von: Borodziej; Hajnicz (Hg.): Kompleks Wypędzenia, 1998. Eine fundierte Quellenbasis und umfassende Untersuchung liefern die vier Anfang der $2000 e r$ Jahre auf Deutsch und Polnisch erschienenen Bände von: Borodziej; Lemberg (Hg.): Die Deutschen östlich von Oder und Neiße 1945-1950. Dokumente aus polnischen Archiven. Bde. 1-4, 2000-2004. Mit den Fragen deutsch-polnischer >Nationalitätenpolitik in der Mitte des 20. Jahrhunderts beschäftigt sich z.B.: Kulczycki: Belonging to the Nation, 2016. Piskorski erzählt in seiner Studie die Geschichte der Vertreibungen Europas, in der die polnische Perspektive entsprechend berücksichtigt ist: Piskorski: Die Verjagten, 2013.

150 Kittel: Vertreibung der Vertriebenen? 2007. Vgl. sowohl kritisch zu den Publikationen von Kittel als auch von Andreas Kossert, die sich nach Feindt »mit affirmativen Publikationen im Sinne des vom BdV geplanten `Zentrums gegen Vertreibungen « hervorgetan haben: Feindt: Flucht und Vertreibung zwischen Kaltem Krieg und Universalisierung, 2014, S. 171f. Siehe auch Kap. 7.1.1, S. 372.

151 Hahn; Hahn: Die Vertreibung im deutschen Erinnern, 2010.

152 Stickler: »Ostdeutsch heißt Gesamtdeutsch«, 2004.

153 Müller: Die SPD und die Vertriebenenverbände 1949-1977, 2012.

154 Jakubowska: Der Bund der Vertriebenen in der Bundesrepublik Deutschland und Polen, 2012. 
letztere speziell zum Thema der Repräsentation von Flucht und Vertreibung in der Literatur der DDR. ${ }^{155}$ Alina Laura Tiews hat ihre vergleichend angelegte Dissertation der Darstellung dieses Themas im Spielfilm der Bundesrepublik und der DDR gewidmet, ${ }^{156}$ Kirsten Möller ihre den deutsch-polnischen »Geschlechterbildern im Vertreibungsdiskurs « in Literatur, Film und Theater. ${ }^{157}$

Mit grundsätzlichen Fragen der Erinnerungskultur und Geschichtspolitik in der späten Volksrepublik Polen befasste sich jüngst die Dissertation von Florian Peters maßgeblich. ${ }^{158}$ In den Abhandlungen zu diesem Themenfeld spielt die Frage des Umganges mit der Vertreibungsgeschichte stets eine Rolle. Piotr Madajczyk hat sich in mehreren Veröffentlichungen mit der polnischen und polnisch-deutschen Erinnerungsgeschichte zum weiteren Themenkomplex befasst sowie einen Sammelband mit herausgegeben, der den unterschiedlichsten Facetten der deutschen Minderheit im volksrepublikanischen Polen gewidmet ist. ${ }^{159}$ Burkhard Olschowsky hat sich in mehreren Studien mit dem Verhältnis der Volksrepublik Polen zur DDR und zur Bundesrepublik befasst. ${ }^{160}$ Quellenstudien wie die von Olaf Matthei über die Diskussion der Zwangsaussiedlung der Deutschen in polnischen Zeitungen zu Zeiten der Volksrepublik ergänzen den Forschungsstand durch ihren Blick auf die Komplexität des volkspolnischen Vertreibungsdiskurses. ${ }^{161}$

Die Wissenschaft begleitete die Auseinandersetzungen über Flucht und Vertreibung seit 1989 intensiv und streckenweise aktiv. ${ }^{162}$ Ein Beispiel hierfür sind mehrere Sammelbände, in denen vor allem Historiker den deutschen, polnischen und tschechischen Diskurs gemeinsam und vergleichend untersucht und den Versuch unternommen haben, die kontroversen öffentlichen Debatten zu versachlichen. ${ }^{163}$ Dabei sind zunehmend die »Akteure, Medien und Praktiken« des Vertreibungsdiskurses in den wissenschaftlichen Blick geraten. ${ }^{164}$ Eines der Ergebnisse ist das 2015 erschienene Handbuch zu Medien und Praktiken der Erinnerung an Flucht und Vertreibung in Deutschland. ${ }^{165}$ Stephan

155 Bauerkämper: Assimilationspolitik und Integrationsdynamik, 2008. Schwartz: Vertriebene im doppelten Deutschland, 2008. Niven: Representations of Flight and Expulsion in East German Prose Works, 2014.

156 Tiews: Fluchtpunkt Film, 2017.

157 Möller: Ceschlechterbilder im Vertreibungsdiskurs, 2016.

158 Peters: Revolution der Erinnerung, 2016.

159 Dziurok; Madajczyk et al. (Hg.): Die Haltung der kommunistischen Behörden gegenüber der deutschen Bevölkerung in Polen in den Jahren 1945 bis 1989, 2015. Vgl. z.B.: Madajczyk: Die Rolle antideutscher Instrumentalisierungen in Polen, 1944-1989, 2007.

160 Siehe z.B. seine Dissertation von 2002/2005: Olschowsky: Einvernehmen und Konflikt, 2005.

161 Matthei: Die Massenumsiedlungen und das Bild der Deutschen, 2006.

162 Vgl. für eine umfassende Bibliographie zum Themenkomplex »Diskurse über Zwangsmigration« in Deutschland, Polen und Tschechien: Haslinger; Franzen et al. (Hg.): Diskurse über Zwangsmigration in Zentraleuropa, 2008, S. 433-500, 533-550.

163 Vgl. z.B.: Bingen; Borodziej et al. (Hg.): Vertreibungen europäisch erinnern? 2003. Benz (Hg.): Wann ziehen wir endlich den Schlussstrich? 2004. Franzen; Schulze Wessel (Hg.): Opfernarrative, 2012. Haslinger; Franzen et al. (Hg.): Diskurse über Zwangsmigration in Zentraleuropa, 2008. Vgl. für eine internationale Auseinandersetzung mit dem deutschen Fall: Schmitz; Seidel-Arpaci (Hg.): Narratives of Trauma, 2011.

164 Scholz: >Flucht und Vertreibung< in der deutschen Erinnerungskultur, 2016, S. 155.

165 Scholz; Röger et al. (Hg.): Die Erinnerung an Flucht und Vertreibung, 2015. 
Scholz hat 2016 im Jahrbuch für Politik und Geschichte einen knappen Überblick über die jüngste wissenschaftliche Auseinandersetzung mit der deutschen Erinnerungskultur an Flucht und Vertreibung seit etwa 2010 skizziert. ${ }^{166}$ Das schon diskutierte historische Überblickswerk von Matthias Beer ebenso wie die Abhandlung von R. M. Douglas widmen sich in eigenen Kapiteln der Erinnerungsgeschichte.

Mit einem Vergleich zwischen dem polnischen und tschechischen $>$ Vertreibungsdiskurs hat sich unter anderem der spätere Vize-Direktor des MIIW und Experte der sudetendeutsch-tschechoslowakischen Geschichte Piotr M. Majewski befasst. ${ }^{167}$ Aline Sierp hat deutsche und italienische Auseinandersetzungen um die Vergangenheit in Hinblick auf transeuropäische Identitäten und die Rolle der EU als Akteur und Plattform einem Vergleich unterzogen. ${ }^{168}$ Auch die fünf Bände der Deutsch-Polnischen Erinnerungsorte streifen das Thema der Erinnerung an Flucht und Vertreibung immer wieder, zum Beispiel in Verbindung mit der kresy-Erinnerung in Polen. ${ }^{169}$ Jüngst hat Hubert Leschnik seine Dissertation zur »Erinnerungskultur und Geschichtspolitik in Polen von 1998 bis 2010 « vorgelegt, sodass diese noch punktuell berücksichtigt werden konnte. ${ }^{170}$

Philipp Ther hat sich neben seinen historischen Arbeiten bereits früh länderübergreifend mit dem Vertreibungsdiskurs beschäftigt. ${ }^{171} 2003$ und 2005 veröffentlichte er gemeinsam mit Jürgen Danyel zwei Ausgaben der Zeitschrift für Geschichtswissenschaft zum historischen Geschehen aus europäischer Perspektive sowie zur Erinnerungsgeschichte. ${ }^{172}$ Für die vorliegende Studie wird vor allem eine 2008 von ihm verfasste Streitschrift mit einem Rückblick auf die bisherigen Auseinandersetzungen herangezogen. ${ }^{173} 2017$ war Thers umfangreiches Werk zum Flüchtling in der Moderne auch ein Debattenbeitrag zur Flüchtlingskrise. ${ }^{174}$ Mehrere Dissertationen haben ebenfalls zeitnah eine Historisierung des Diskurses versucht. ${ }^{175}$

In ihrer einleitend schon angesprochenen Studie hat Maren Röger sich umfassend mit dem >Vertreibungsdiskurs in Polen und Deutschland und den darin zentralen Medien auseinandergesetzt. Diese untersucht sie in ihrer Rolle als Akteur sowie mit ihren spezifischen Regeln und Mechanismen. ${ }^{176}$ Die verschiedenen Sammelbände, die sich wahlweise dem deutschen, dem deutsch-polnischen oder deutsch-polnisch-

166 Scholz: >Flucht und Vertreibung in der deutschen Erinnerungskultur, 2016, S. 159.

167 Vgl. Majewski: Zwischen Versöhnung und Verteidigung nationaler Interessen, 2008. Vgl. auch den gemeinsam mit Piotr Buras herausgegebenen Quellenband zur deutsch-polnisch-tschechischen Vertreibungsdebatte: Buras; Majewski (Hg.): Pamieć wypedzonych, 2003.

168 Sierp: History, Memory, and Trans-European Identity, 2014.

169 Vgl. z.B.: Kleßmann; Traba: Kresy und Deutscher Osten, 2012.

170 Leschnik: Erinnerungskultur und Ceschichtspolitik in Polen, 2018.

171 Vgl. z.B.: Ther: Chance und Last der Geschichte, 1996.

172 Danyel; Ther (Hg.): Zeitschrift für Geschichtswissenschaft, 2003 (51. Jg., H. 1). Danyel; Ther (Hg.): Zeitschrift für Geschichtswissenschaft, 2005 (53. Jg., H. 10).

173 Ther: Der Diskurs um die Vertreibung, 2008.

174 Ther: Die Außenseiter, 2017.

175 Graaf: After the Expulsions, 2014. Lange: Der Erinnerungsdiskurs um Flucht und Vertreibung in Deutschland seit 1989/90, 2015.

176 Röger: Flucht, Vertreibung und Umsiedlung, 2011. 
tschechischen Rahmen widmen, wurden oben schon angesprochen. ${ }^{177}$ Bereits seit den 1970ern befasst sich die Historikerin und Politologin Anna Wolff-Powęska mit den deutsch-polnischen Beziehungen. ${ }^{178}$ Robert Traba gehört ebenso wie Hans-Jürgen Bömelburg und Krzysztof Ruchniewicz zu den wissenschaftlichen Pionieren des Diskurses in den 1990er Jahren und zu deren fortwährenden Begleitern. ${ }^{179} \mathrm{Zu}$ diesem Kreis zählt neben einigen anderen auch Włodzimierz Borodziej, der nach 1989 unter anderem an einer umfassenden Quellensammlung zu Flucht und Vertreibung mitwirkte. ${ }^{180}$ Rege Forschungsaktivitäten löste auch die Geschichtspolitik der PiS-Regierungen der Jahre 2005 bis 2007 sowie seit 2015 aus, deren Ergebnisse hier punktuell herangezogen werden. ${ }^{181}$

Für die tschechoslowakische Erinnerungskultur zur Vertreibung zwischen 1945 und 1989 kann neben den schon genannten Abhandlungen auf eine Reihe von Aufsätzen, wie die von Matěj Spurný ${ }^{182}$, Oldřich Tưma ${ }^{183}$ und Milan Ǩepa ${ }^{184}$ zurückgegriffen werden, die zudem auch noch den tschechischen >Vertreibungsdiskurs nach 1989 einschließen. Die Auseinandersetzungen nach 1989/93 über die Vertreibungen in Tschechien hat nicht zuletzt die aus diesen hervorgegangene Deutsch-Tschechische Historikerkommission mit verschiedenen Sammelbänden und Publikationen begleitet. ${ }^{185} 1999$ widmete sich ein Band dem Vergleich der Zwangsmigration aus Polen, der Tschechoslowakei, Jugoslawien und Ungarn. ${ }^{186}$ Koryphäen der deutschen Bohemistik wie Ferdinand Seibt ${ }^{187}$ und Hans Lemberg befassten sich wiederholt und in Kooperation mit tschechischen Wissenschaftlern mit dem Thema. Martin Schulze Wessel hat sich mit diesem Feld ebenfalls mehrfach beschäftigt, beispielsweise mit einer Publikation zur tschechischen

177 Vgl. zur polnischen Diskussion über das Zentrum gegen Vertreibungen den Sammelband: Lisicki; Haszczyński (Hg.): Erinnerung: europäisch oder national? Der Streit über das Zentrum gegen Vertreibungen, 2003.

178 Vgl. z.B.: Wolff-Powęska: Zur Aktualität von Dialog und Versöhnung im polnisch-deutschen Verhältnis, 2009. Siehe für einen ihrer engagierten Debattenbeiträge den Artikel in der Cazeta Wyborcza zum Schlagwort des »guten Wandels« der PiS: Wolff-Powęska: »Dobra zmiana « szuka naukowych standardów edukacji historycznej Polaków. Gazeta Wyborcza. 26.05.2018.

179 Vgl.z.B.: Bömelburg: Flucht und Vertreibung in der deutschen und polnischen Öffentlichkeit, 2012. Ein Ergebnis ihrer Arbeit der 1990er Jahre ist der Sammelband von 2000: Bömelburg; Stößinger et al. (Hg.): Vertreibung aus dem Osten, 2000. Vgl. z.B.: Ruchniewicz: Zur versöhnungspolitischen Bedeutung der Schulbuchrevision im Hinblick auf die Vertreibungsproblematik, 2006. Siehe grundlegend: Traba; Żurek: »Vertreibung« oder »Zwangsumsiedlung «? 2015.

180 Vgl. Borodziej; Hajnicz (Hg.): Kompleks Wypędzenia, 1998.

181 Vgl.z.B.: Pufelska: Raub der Clio-die polnische Geschichtspolitik und ihre Exekutoren, 2010. Florian Peters begleitet aktuelle geschichtspolitische Entwicklungen laufend auf Zeitgeschichte-online, vgl. z.B.: Peters: Patriotische Geschichtsschreibung im Staatsauftrag, 2016.

182 Spurný: Czech and German Memories of Forced Migration, 2012.

183 Tůma: Die Aussiedlung, 2015.

184 Řepa: The Czechs, Germans and Sudetenland, 2011.

185 Gemeinsame Deutsch-Tschechische Historikerkommission (Hg.): Konfliktgemeinschaft, Katastrophe, Entspannung, 1996.

186 Brandes; Ivaničková et al. (Hg.): Erzwungene Trennung, 1999.

1872002 erschien ein Sammelband mit einer Zusammenstellung aus seinem Fuvre, der in dieser Arbeit mehrfach herangezogen wird: Luft; Brenner et al. (Hg.): Deutsche, Tschechen, Sudetendeutsche, 2002. 
Zeitgeschichtsschreibung nach $1989 .{ }^{188}$ Von Claudia Kraft liegt unter anderem ein wegweisender Aufsatz zum deutsch-tschechischen »Mythos « der Beneš-Dekrete vor. ${ }^{189}$ In der tschechischen Zeitgeschichte nach 1989 findet sich neben den bereits erwähnten eine Reihe von Abhandlungen zur Diskursgeschichte, so zum Beispiel von Miroslav Kunštát ${ }^{190}$, Vladimír Handl ${ }^{191}$ oder Václav Houžvička mit seiner Geschichte über 150 Jahre tschechisch-sudetendeutsche Beziehungen. ${ }^{192}$ Michaela Witte zeichnete in ihrer 2002 veröffentlichten Dissertation die deutsch-tschechischen Auseinandersetzungen um die Vertreibung von 1984-1997 detailliert nach, so dass an diese angeknüpft werden kann. ${ }^{193}$

Für das einleitende Kapitel zur »Herausforderung oberschlesischer Geschichtsschreibung « kann maßgeblich auf den thematisch umfassenden, von polnischen und deutschen Forschern herausgebrachten Sammelband von 2011/2015 zur Geschichte Oberschlesiens zurückgegriffen werden, der sich auf vielfältige Weise den kontroversen historischen Geschehnissen aus polnischer, tschechischer und deutscher (sowie gemeinsamer) Sicht widmet. ${ }^{194}$

Die Anzahl wissenschaftlicher Untersuchungen zum Schlesischen Museum zu Görlitz beschränkt sich bisher auf eine Vielzahl von Aufsätzen sowie einige nicht veröffentlichte Masterarbeiten. ${ }^{195}$ Noch herangezogen werden konnte die Studie von Ondřej Táborský, in der dieser die schlesischen Museen in Görlitz, Kattowitz und Troppau unter der leitenden Frage untersucht hat, wie in den Häusern auf Basis der schlesischen Geschichte schlesische Identität ausgedrückt wird. ${ }^{196}$ Eine wesentliche Quelle für das SMG sind der auch einige Hintergrundaufsätze enthaltende Ausstellungskatalog des Hauses sowie verschiedene Publikationen des Museumsdirektors Markus Bauer. ${ }^{197}$

Die Debatten um das Muzeum Śląskie in Kattowitz und dessen Entwicklung hat Marcin Wiatr kenntnisreich und aufmerksam begleitet sowie dokumentiert. ${ }^{198}$ Zwei weitere einschlägige Monographien haben für die vorliegende Fragestellung wertvolle Arbeit geleistet: Juliane Tomann mit ihrer Dissertation zum Kultur- und Geschichtsraum Kattowitz sowie Peter Polak-Springer zu Oberschlesien als politisch und kulturell

188 Schulze Wessel: Tschechien - Institutionen, Methoden und Debatten in der Zeitgeschichte, 2011.

189 Kraft: Mythos »Beneš-Dekrete«, 2013.

190 Vgl. z.B.: Kunštát: Fremd- und Feindbilder der Deutschen in der tschechischen innenpolitischen Instrumentalisierung nach 1989, 2007.

191 Handl: Die Politik des wiedervereinigten Deutschland gegenüber der Tschechischen Republik, 2010.

192 Houžvička: Czechs and Cermans 1848-2004, 2015.

193 Witte: Entfremdung - Sprachlosigkeit-Aussöhnung? 2002.

194 Bahlcke; Gawrecki et al. (Hg.): Geschichte Oberschlesiens, 2015. Die polnische Fassung erschien 2011. Noch punktuell berücksichtigt werden konnte die 2019 erschienene Publikation, die sich Oberschlesien als »europäischer Ceschichtsregion«nähert: Smolorz; Kordecki: Schauplatz Oberschlesien, 2019.

195 Als Vergleich konnte die leider unveröffentlichte Masterarbeit von Johanna Adrian herangezogen werden: Adrian: Kontaktzone - Identitätsfabrik - Sehnsuchtsort, 2014.

196 Táborský: Creating Silesian Identity, 2018.

197 Der Katalog: Bauer; Brade et al. (Hg.): Schlesisches Museum zu Görlitz-Museum für eine europäische Kulturregion, 2006. Vgl. weiter z.B.: Bauer: Zwischen Denkmal und kulturpolitischem Forum, 2007.

198 Vgl. z.B.: Wiatr: Oberschlesien und sein kulturelles Erbe, 2016. 
umkämpfter Region im 20. Jahrhundert. ${ }^{199}$ Weder Polak-Springer noch Tomann konnten das neu eröffnete Schlesische Museum in ihre Untersuchungen bereits einbringen, allerdings veröffentlichte Tomann später eine Rezension, die wiederholt herangezogen wird. $^{200}$

Die Forschungsliteratur zu den Museumsprojekten in München und Aussig begrenzt sich bisher auf einige Publikationen aus dem Umfeld der Museumsmacher ${ }^{201}$ und gelegentlichen Bezugnahmen in Veröffentlichungen zur tschechischen oder sudetendeutschen Erinnerungskultur. ${ }^{202}$ In einem Aufsatz von 2017 haben Kristina Kaiserová und Miroslav Kunštát die beiden Museumsprojekte erstmals verglichen. ${ }^{203}$ Im selben Jahr widmete sich ein Sammelband der Deutsch-Tschechischen und Deutsch-Slowakischen Historikerkommission der Musealisierung der jeweiligen Beziehungsgeschichte. ${ }^{204}$ Die Planungen in München und Aussig nehmen darin folglich einen gewichtigen Platz ein und bieten einen wichtigen Bezugspunkt für die vorliegende Untersuchung.

Die Liste der Publikationen über die Stiftung Flucht, Vertreibung, Versöhnung ist noch überschaubar. Neben den von der Stiftung selbst herausgegebenen Schriften behandelt Stefan Troebst ihre Entwicklung wiederholt in seinen Veröffentlichungen. ${ }^{205}$ Ansonsten gibt es eine Reihe von Aufsätzen und Schriften über die Stiftung in ihrem weiteren historischen Zusammenhang, wie zum Beispiel Stephan Scholz' Schrift über die deutschen Vertriebenendenkmäler. ${ }^{206}$ Tim Völkering hat die Frühphase der Stiftung bis 2011 intensiv verfolgt und war zugleich am wissenschaftlichen Diskurs um ihre Ausrichtung beteiligt. ${ }^{207}$ Verschiedene polnische Publikationen widmen sich der deutschen, polnischen oder deutsch-polnischen Diskussion um die Entstehung der SFVV in den Jahren 2008/2009. ${ }^{208} \mathrm{Zu}$ einer umfassenden wissenschaftlichen Reflexion der neueren Konzeptionspapiere der Stiftung von 2012 und 2017 ist es bisher noch nicht gekommen.

199 Polak-Springer: Recovered Territory, 2015. Tomann: Geschichtskultur im Strukturwandel, 2016.

200 Tomann: Rezension zu: Das Licht der Geschichte. Oberschlesien im Wandel der Zeiten, 26.06.2015.

201 Vgl. für die ersten Überlegungen zum Sudetendeutschen Museum: Krauss: Das Sudetendeutsche Museum in München, 2010. Vgl. ebenso: Krauss: »Zusammenleben«, 2017. Vgl. für das Projekt in Aussig z.B. den Aufsatz der Verantwortlichen über das Projekt: Mouralová; Šícha: Das Museum einer nahezu abwesenden Minderheit, 2012.

202 Vgl. Spalová: Remembering the Cerman Past in the Czech Lands, 2016. Eine Ausnahme bildet das vom Autoren mehrfach herangezogene Dossier aus dem Umfeld der Rosa-Luxemburg-Stiftung, die das Münchner Vorhaben 2014 kritisch evaluierte: Hennecke: Das Sudetendeutsche Museum in München, 2014.

203 Kaiserová; Kunštát: Deutsche und Tschechen im Museum, 2017.

204 Kováč; Řezník et al. (Hg.): Erinnern - Ausstellen - Speichern, 2017

205 Vgl. z.B.: Troebst: Towards a European Memory of Forced Migration? 2016.

206 Vgl. z.B.: Czerney: Flucht, Vertreibung, Versöhnung, 2012. Ebenso: Wochnik: Non-State Actors, Political Opportunity Structures and Foreign Relations, 2014. Scholz: Vertriebenendenkmäler, 2015.

207 Vgl. z.B.: Völkering: »Flucht und Vertreibung« ausstellen - aber wie? 2011. Derzeit arbeitet Völkering an einer Dissertation unter dem Arbeitstitel: »Die Musealisierung der Themen Flucht, Vertreibung und Integration - Historische Ausstellungen seit $1950 \mathrm{im}$ Vergleich (Stand 2010).

208 Vgl. z.B.: Wagińska-Marzec: Konflikt wokół Widocznego Znaku w świetle prasy polskiej, 2009. Mazur: Widoczny Znak (2005-2009), 2009. Hajduk: Die publizistische Kontroverse um das »Zentrum gegen Vertreibungen«, 2010 
Für die Gründungsphase liegen bereits einige wissenschaftliche Qualifikationsschriften vor; weitere sind zu erwarten. ${ }^{209}$

Für das Museum des Zweiten Weltkrieges in Danzig steht derzeit nur begrenzt Forschungsliteratur zur Verfügung, dafür eine umso umfassendere polnische und internationale Presseberichterstattung sowie der schon 2016 veröffentlichte Ausstellungskatalog. ${ }^{210}$ Zur 2017 eröffneten Dauerausstellung liegen bereits einige akademische Rezensionen vor. ${ }^{211}$ Die wissenschaftliche Auseinandersetzung wurde wesentlich von Akteuren aus dem Umfeld oder direkt aus dem Team des MIIW heraus geführt. So legte der Gründungsdirektor Paweł Machcewicz im Dezember 2017 das Buch Muzeum vor, in dem er auf 300 Seiten die Entstehung des Museums umfassend dokumentiert und darin auch die Kritiker zu Wort kommen lässt. ${ }^{212}$ In ihrer 2017 erschienenen Dissertation zur polnischen Kriegserinnerung im Museum nach 1989 konnte Monika Heinemann in einem abschließenden und ausführlichen Exkurs das MIIW behandeln und bietet so eine wertvolle Referenz. ${ }^{213}$

Die Entwicklung des Hauses der Europäischen Geschichte wurde wissenschaftlich recht umfassend begleitet, auch als Teil der zunehmend erforschten Geschichtspolitik europäischer Institutionen. ${ }^{214}$ Wolfram Kaiser, Stefan Krankenhagen und Kerstin Poehls haben sich 2012 intensiv mit dem Thema »Europa ausstellen« befasst. ${ }^{215}$ Von Krankenhagen stammt auch eine der wissenschaftlichen Rezensionen der Dauerausstellung des HEH. ${ }^{216} 2011$ und 2012 erschienen zwei Sammelbände, die sich dem Haus widmen. ${ }^{217}$ Durch diese sowie weitere Publikationen haben sich die Mitglieder des Museumsteams ebenso wie des Wissenschaftlichen Beirates an der Vorstellung und auch an der kritischen Diskussion der Planungen des HEH beteiligt. ${ }^{218}$ Auch Stefan Troebst hat sich wiederholt mit dem HEH beschäftigt. ${ }^{219}$ Neben der besuchten Dauerausstellung liegen zwei Konzeptionspapiere von 2008 und 2013 zur Untersuchung vor. ${ }^{220}$ Die weitreichende und vor allem in Großbritannien und Ostmitteleuropa geäußerte konservative Kritik

209 So beschäftigt sich z.B. Jenny Graaf in ihrer Dissertation in einem Kapitel mit der SFVV: Graaf: After the Expulsions, 2014.

210 Muzeum II Wojny Światowej: Museum of the Second World War, 2016.

211 Vgl. z.B.: Hoja: An Engaged Narrative, 2017.

212 Machcewicz: Muzeum, 2017. Bereits im Sommer 2018 ist eine deutsche Übersetzung erschienen.

213 Heinemann: Krieg und Kriegserinnerung im Museum, 2017.

214 Vgl.z.B. zur Ceschichtspolitik europäischer Institutionen: Sierp; Wüstenberg: Linking the Local and the Transnational, 2015. Vgl. auch: Troebst: Die Europäische Union als »Gedächtnis und Gewissen Europas 22013.

215 Kaiser; Krankenhagen et al.: Europa ausstellen, 2012.

216 Krankenhagen: »Das andere, eigene Kap.«2017. Eine weitere Besprechung liegt von dem tschechischen Historiker Jareš vor: Jareš: The House of European History, 2017. Ebenso erschien eine Rezension in den Zeithistorischen Forschungen: Fickers: Kompromissgeschichte, serviert auf dem »Tablet«, 2018.

217 Knigge; Veen et al. (Hg.): Arbeit am europäischen Cedächtnis, 2011. Axelsson; Dupont et al. (Hg.): Entering the Minefields, 2012.

218 Vgl. z.B. den Beitrag des Mitgliedes des Wissenschaftlichen Beirates des HEH, der Direktorin des »Hauses des Terrors « in Budapest, Mária Schmidt: Schmidt: Auf dem Weg zu einem europäischen Gedächtnis? 2011.

219 Vgl. z.B.: Troebst: Eckstein einer EU-Ceschichtspolitik, 2012.

220 Committee of Experts; Borodziej et al.: Conceptual Basis for a House of European History, 2008. European Parliament: Building a House of European History, 2013. 
fasst ein Papier in Folge der Begehung des Museums durch die Platform of European Memory and Conscience zusammen. ${ }^{221}$

2012 widmete sich verschiedenen der genannten Museen eine Ausgabe des Jahrbuches zur deutsch-polnischen Beziehungsgeschichte, Inter Finitimos. Die Ausgabe behandelt das MIIW, die SFVV und das MŚK mit Beiträgen sowie das SMG in einem Querschnittsbeitrag über die schlesische Museumsgeschichte. ${ }^{222}$

Die zentralen Quellen der vorliegenden Arbeit, die Ausstellungen und Museumspapiere, wurden bereits bei der Vorstellung des Untersuchungsgegenstandes diskutiert. Wie Ausstellungen als geschichtswissenschaftliche Quelle heranziehbar sind und zugleich ihr spezifischer Charakter als komplexes kulturelles Erzeugnis berücksichtigt werden kann, wird nochmals ausführlich in Kapitel 2.5 erörtert. Bis auf wenige Ausnahmen - wie im Falle des in dieser Arbeit exkursiv behandelten Sudetendeutschen Museums in München ein nicht öffentliches Ausstellungskonzept oder der E-Mail-Austausch mit einigen der Museumsmacher - sind die Ausstellungen oder die Konzeptionspapiere öffentlich zugänglich. Sofern vorhanden, hat der Autor die digitalen oder analogen Newsletter der Museen abonniert und verfolgt.

Öffentlich verfügbar ist auch das Quellenmaterial des Diskurses. Dafür zog der Autor Zeitungsartikel sowie politische Stellungnahmen in Form von Reden und anderen Äußerungen aus den untersuchten Ländern heran. Für diese wurden die Online-Archive relevanter Tages- und Wochenzeitungen auf Basis eines laufend aktualisierten Stichwortkatalogs systematisch untersucht. Die Auswahl verschiedener Zeitungen soll unterschiedliche politische Ausrichtungen abdecken, die im Einzelnen bei der Verwendung erwähnt werden. Neben kontroversen Positionen, welche die Konfliktlinien besonders veranschaulichen, sollen besonders Zwischentöne der Debatte berücksichtigt und damit eine Repräsentativität der Quellen gewährleistet werden. Schließlich verfolgt diese Studie eine fokussierte qualitative Analyse, um die Materialmengen zu bewältigen sowie die notwendige Kontextualisierung und Einordnung des Quellenmaterials in die großen Linien des Diskurses zu erreichen. ${ }^{223}$

Für politische Reden oder Gesetztestexte kann als ein Ergebnis der geschichtswissenschaftlichen Begleitung des Diskurses auf umfangreiche Quellendokumentationen zurückgegriffen werden. ${ }^{224}$ Die Position der Vertriebenenverbände wird vor allem durch das Heranziehen der BdV-Verbandszeitung Deutscher Ostdienst in ihren Ausgaben nach 1999, der Zeitung der Sudetendeutschen Landsmannschaft, die Sudetendeutsche

221 Platform of European Memory and Conscience; Ukielski et al.: The House of European History, 2017.

222 Fischer; Kerski et al. (Hg.): Inter Finitimos, 2012.

223 Haslinger: Diskurs, Sprache, Zeit, Identität, 2006, S. 30f; 46-48.

224 Vgl.z.B. die umfassende Zusammenstellung von deutschen, polnischen, tschechischen und weiteren Dokumenten zum Themenkomplex der Zwangsmigration: Haslinger; Franzen et al. (Hg.): Diskurse über Zwangsmigration in Zentraleuropa, 2008, S. 281-429. Dieser schließt sich eine ebenso umfangreiche Bibliographie an. Siehe für eine Zusammenstellung der deutsch-polnischen Auseinandersetzungen von 2002-2006, v.a. unter dem Fokus der »Institutionalisierung « der Erinnerungskultur: Troebst (Hg.): Vertreibungsdiskurs und europäische Erinnerungskultur, 2006. 
Zeitung, von 2006-2017 sowie der Zeitung der Schlesischen Landsmannschaft, die Schlesischen Nachrichten, von 2003-2015 berücksichtigt. ${ }^{225}$

Für den Diskurs zunehmend relevante Quellenmaterialien sind eine Vielzahl von herangezogenen Websites, Blogs und auch einige Beiträge in sozialen Medien und auf der Videoplattform YouTube. Deren möglicherweise kurze Haltbarkeit, zumindest der Internetverweise, ist ein nicht zu unterschätzendes Problem. Die allermeisten zitierten Beiträge wurden vom Autoren daher nach Möglichkeit gesichert.

Trotz des hier skizzierten dichten Forschungsstandes können verschiedene Desiderata festgestellt werden. Zum einen wurden die in der vorliegenden Studie behandelten Museumsprojekte bisher noch nicht oder nur fragmentarisch wissenschaftlich untersucht und der sich in vielerlei Hinsicht anbietende Vergleich der Museumsvorhaben noch nicht oder nur im Ansatz geleistet. Hier soll erste Grundlagenarbeit geleistet werden. Zum anderen wurden der deutsch-polnische oder der deutsch-tschechische Vertreibungsdiskurs schon häufig untersucht, aber seltener in dem für die Auseinandersetzungen konstitutiven Dreieck diskutiert. Nicht nur erzielt dieses Zusammenführen einen Mehrwert, die vorliegende Studie soll darüber hinaus auch eine erste Zwischenbilanz zur Frage des Diskurses über und die Erinnerung an Flucht und Vertreibung ziehen, welche die Forschung in den 1990er und 2000er Jahren ausgiebig beschäftigten. Die Museen als Manifestationen dieser Auseinandersetzungen sind dafür als Untersuchungsgegenstand prädestiniert.

Zuletzt hat Vasco Kretschmann 2018 als Desiderat identifiziert, dass die »museale Darstellung von Flucht, Vertreibung und Aussiedlung der Deutschen im polnischen Museumswesen« weiterhin eine »Forschungslücke« darstellt. ${ }^{226}$ Der Autor der vorliegenden Studie hofft, durch die Analyse zweier polnischer Museen einen Vergleichsmaßstab für die Untersuchung weiterer lokal- und regionalhistorischer Museen in den polnischen West- und Nordgebieten anzubieten, die alle vor der Herausforderung stehen, dieses Thema zu präsentieren.

Dass die vorliegende Studie bis in die unmittelbare Gegenwart reicht, führt zu einigen Unwägbarkeiten, ermöglicht aber die Berücksichtigung der politischen Zäsur in Europa nach 2015. Der die 1990er und 2000er Jahre dominierende liberale, globalisierungsund EU-freundliche Diskurs im Westen wurde im Jahr 2016 durch die Kulmination von Brexit, der Wahl Donald Trumps zum US-Präsidenten und des großen Erfolges der PiS in Polen herausgefordert und durch diese modernen Formen von Nationalismus und alternativen Gesellschaftsentwürfen in die Defensive gedrängt. Das spiegelt sich in unterschiedlicher Intensität in den untersuchten Museumsprojekten wider und wird auch für die weitere Entwicklung des Diskurses um Flucht und Vertreibung von Bedeutung sein.

225 Die Zeiträume erklären sich durch den jeweiligen Beginn der Planungen und Umsetzungen für das Zentrum gegen Vertreibungen, das Sudetendeutsche Museum und das Schlesische Museum.

226 Kretschmann: Rezension zu: Monika Heinemann: Krieg und Kriegserinnerung im Museum. Der Zweite Weltkrieg in polnischen historischen Ausstellungen seit den 1980er-Jahren, 2017, 2018. 


\subsection{Aufbau der Arbeit}

Die folgenden sieben Kapitel untergliedern sich in vier Elemente: Das erste Element ist die Diskussion der theoretisch-methodischen Grundlagen, der als zweites die Darstellung des historischen Geschehens um Flucht und Vertreibung in seinem engeren und weiteren Kontext folgt. Anschließend wird im dritten Schritt der Diskurs über den Untersuchungsgegenstand vom Kalten Krieg bis in die Gegenwart nachgezeichnet. Diese im Wesentlichen auf der Diskussion der Forschungsliteratur und einigen veröffentlichten Primärquellen beruhenden Kapitel der Arbeit werden um eigene Gedanken und Einordnungen ergänzt. Das vierte Element ist die Untersuchung der Museen.

Die methodisch-theoretischen Grundlagen werden im zweiten Kapitel entwickelt. Zunächst erfolgt eine Besprechung der Konzepte und Anwendungsmöglichkeiten des (historischen) Vergleichs und transnationaler sowie europäischer Geschichtsschreibung. Diesem Teil schließt sich eine kurze Diskussion der sich rund um den Terminus Erinnerungskultur gruppierenden Theorien und Untersuchungsansätze an. Die Analyse von Geschichtspolitik wird verbunden mit den Überlegungen zur Historischen Diskursanalyse und dem Konzept der Diskursgeschichte. Das folgende Unterkapitel ist dem Untersuchungsansatz für die Museen und Ausstellungen gewidmet. Nach einer kurzen Definition und Differenzierung dieser beiden Termini wird detailliert die Ausstellung als zu analysierende Quelle in den Blick genommen. Auf dieser Basis entwickelt der Autor ein einheitliches Untersuchungsschema für die in der vorliegenden Studie behandelten Museen. Dafür werden zuvor einige für die Museumsanalyse zentrale Begriffe wie Exponat, Inszenierung und Szenografie erläutert und diskutiert.

In Kapitel 3 folgt die Darstellung der historischen Ereignisse von Flucht und Vertreibung, die mit einem Überblick über die Siedlungsgeschichte der Deutschen in Osteuropa bis zum Aufkommen des Nationalismus beginnt. Ein ideengeschichtlicher Exkurs zeigt, dass Planung und Umsetzung ethnischer Homogenisierungsstrategien als integraler Bestandteil moderner Staatlichkeit und damit als europäisches und globales Phänomen zu betrachten sind. In den folgenden Unterpunkten folgt das Kapitel wieder der Ereignisgeschichte und zeigt das Scheitern der Minderheitenpolitik in der Zwischenkriegszeit auf. Hieran schließen sich die beiden zentralen Elemente des Kapitels an, in denen die Ursachen und der Kontext von Flucht und Vertreibung im Zweiten Weltkrieg sowie der Verlauf dieser Zwangsmigrationsbewegungen im und nach dem Krieg diskutiert werden. Einem Blick auf die Integration der Vertriebenen in der Bundesrepublik und der DDR sowie auf die Konsequenzen der Vertreibungen für Polen und die Tschechoslowakei folgt eine Zusammenfassung der zentralen Streitpunkte sowie der gängigen Argumentation über die historischen Ereignisse in den genannten Ländern.

In den Kapiteln 4 und 5 werden die jeweiligen Diskurse über das Thema Flucht und Vertreibung in den vier und nach 1990 drei Ländern behandelt. Ein besonderes Augenmerk liegt hier auf den Phasen, in denen sich ein gemeinsamer Diskursraum aufgetan hat. Das Herausarbeiten verschiedener Abschnitte des Diskurses und zentraler Konfliktlinien leitet auf die in den folgenden Kapiteln erörterten Museen hin.

Zunächst werden die beiden schlesischen Museen in Görlitz und Kattowitz diskutiert und verglichen. Exkursorisch werden die Planungen des Sudetendeutschen $\mathrm{Mu}$ seums in München und des Museums der deutschsprachigen Bewohner Böhmens in 
Aussig besprochen. Dem folgt die Untersuchung der Museen mit europäischem Anspruch. Den schlesischen und sudetendeutschen Museen stehen jeweils Erläuterungen über die spezifischen Herausforderungen oberschlesischer und sudetendeutscher Geschichtsschreibung voran.

Zur besseren Vergleichbarkeit folgt die Besprechung der Museen oder der geplanten Ausstellungen derselben Struktur: Zu Beginn wird knapp in die Geschichte und die Diskussion um die Häuser eingeführt. Dem folgt eine kurze Ausführung zur Struktur der Institutionen, in der die gesetzliche Grundlage, Träger und Finanzierung, Dimension und Personalstruktur ebenso wie die Sammlung der Häuser sowie tatsächliche oder angestrebte Besucherzahlen und Zielgruppen zusammengefasst werden. Danach werden die von verschiedenen Gruppen oder aus den verschiedenen Ländern an die Häuser gestellten Ansprüche sowie das verlautbarte Selbstverständnis der Museen behandelt. Daran schließt sich eine kurze Besprechung bisheriger und geplanter Aktivitäten an, etwa von Sonderausstellungen, Publikationen und Veranstaltungen. Im Folgenden werden zunächst die Grundarchitektur und der Designansatz der Ausstellungen diskutiert, ehe der Ausstellungsrundgang beschrieben oder die vorliegenden Konzeptionspapiere diskutiert werden. Dafür versucht der Autor einen Gesamteindruck von Charakter, Struktur und Inhalten der Ausstellungen zu geben, fokussiert sich aber auf die Elemente, die direkt oder indirekt den Themenkomplex von Flucht und Vertreibung berühren. Auf dieser Grundlage schließt sich die in Kapitel 2.5 entwickelte Ausstellungsanalyse an. Im nächsten Schritt werden die Positionen zur Ausstellung aus Politik, Gesellschaft und Wissenschaft der verschiedenen Länder und unterschiedlicher politischer Lager untersucht. Dem folgt eine zusammenführende und bewertende Betrachtung. Die Kapitel zu den Museen schließen mit einem Vergleich der Häuser.

Im abschließenden Kapitel 8 werden auf Basis der gewonnenen Erkenntnisse die eingangs aufgeworfenen Thesen und Fragen zusammenfassend diskutiert. Nach einer Reflexion über die angewendete Methodik, die Identifizierung von Desideraten und einigen weiterführenden Überlegungen schließt die Arbeit mit einem Ausblick. 


\section{Theoretische und methodische Grundlagen}

\subsection{Vergleichende, transnationale und europäische Geschichtsschreibung}

Der historische Vergleich ist eine traditionelle Methode der Geschichtsschreibung. Es gilt: Alles kann mit allem verglichen werden. Die Vergleiche können implizit oder explizit geschehen und sie können zwischen Staaten und Systemen, aber auch zwischen verschiedenen Gesellschaftsschichten und Wirtschaftsformen, Persönlichkeiten oder Ortschaften vorgenommen werden. Ständig, ohne es klar zu formulieren, wird in der Geschichtswissenschaft chronologisch verglichen - sprich: Was hat sich in einer bestimmten Phase gegenüber einer vorherigen Phase verändert oder vice versa. ${ }^{1}$

Die transnationale Geschichte hat sich aus der Erkenntnis heraus entwickelt, dass bei dem Vergleich, der auch immer eine Abgrenzung bedeutet, stärker die Transfers und Verflechtungen untersucht werden müssen. ${ }^{2}$ Die weitere Ausdifferenzierung dieser Ansätze hat zur Folge, dass wir über ein breites Spektrum an Methoden und Theorien in diesem Bereich verfügen. ${ }^{3}$ Eine Verbindung in Form von aufeinander aufbauenden Ansätzen des Vergleichs und der transnationalen Geschichte hin zu einer histoire croisée bieten sich für den vorliegenden Fall besonders an. ${ }^{4}$

Idealerweise geht der Vergleich über Beschreibung und Erklärung hinaus hin zu einer Entwicklung von Typologien. Grundsätzliche Kategorien des Vergleichs sind »Differenz« und »Übereinstimmung«, wobei lange und besonders bei der Nationalgeschichtsschreibung die Differenz, die Suche nach dem Exzeptionellen, im Vordergrund stand. Heute, unter anderen politisch-gesellschaftlichen Vorzeichen, sucht man eher nach

Vgl. Kaelble: Historischer Vergleich, 2012, S. 1.

2 Vgl. ebd., S. 8f. Dem folgte eine differenzierende Begriffsbildung: Hadler; Middell: Auf dem Weg zu einer transnationalen Geschichte Ostmitteleuropas, 2010, S. 8. Vgl. Gassert: Transnationale Geschichte, 2012, S. 11.

Vgl. Hadler; Middell: Auf dem Weg zu einer transnationalen Geschichte Ostmitteleuropas, 2010, S. 9.

4 Vgl. Budde; Conrad et al.: Vorwort, 2006, S. 11. 
Gemeinsamkeiten. ${ }^{5}$ Dem Historiker stehen verschiedene Vorgehensweisen zur Verfügung: Eine Möglichkeit ist, alle untersuchten Fälle mit gleicher Intensität zu behandeln. Ein anderes Vorgehen besteht im asymmetrischen, um einen Kernfall gruppierten, exkursiven Vergleich. Die Anzahl der möglichen Fälle wird durch den Aufwand für die notwendige Kontextualisierung begrenzt. ${ }^{6}$

Die Kritik am historischen Vergleich hat zu einer Weiterentwicklung geführt. So wird der nach wie vor zentrale Ausgangs- und Referenzpunkt des Vergleichs, der (eigene) Nationalstaat, ebenso hinterfragt wie die Schwierigkeiten unterschiedlicher Quellenlagen und -zugänge, die von Sprachkenntnissen beeinflusst werden. Dazu sollen implizit oder explizit wertende Vergleichsmaßstäbe und Annahmen beispielsweise über $>$ Normalität $<$ und vermeintlich teleologische Entwicklungslinien nach Möglichkeit transparent gemacht werden. ${ }^{7}$

Nach Hartmut Kaelble bleibt der entsprechend problembewusste Vergleich ein zentraler Bestandteil der moderneren transnationalen Geschichtsschreibung, die selbst bis dato noch keine elaborierte Methode oder konsistente Theorie gebildet hat. Mit dem in der »transnationalen Geschichte« enthaltenen Begriff der »Nation« wird der zentrale »Referenzpunkt« (Hannes Siegrist) deutlich gemacht. Diese Kategorie wird im Gegensatz zur klassischen Nationalgeschichtsschreibung und anders als in der Geschichte der internationalen Beziehungen vornehmlich in ihre über-nationalen Vernetzungen eingeordnet und untersucht. ${ }^{8}$ Eine transnationale Geschichtsschreibung hat folglich keineswegs zwangsläufig der Idee des Endes des Nationalstaates zu folgen, auch wenn ihr gelegentlich vorgeworfen wird, die große Bedeutung des Nationalstaats als besonders relevantem »lebensgeschichtlichen Bezugsrahmen « (bis zur »letztverbindlichen Sinngebungsinstanz« im Nationalismus) allzu leichtfertig zu übergehen. ${ }^{9}$ Eher im Gegenteil wird, unter Berücksichtigung seiner Verflechtungen, der Nationalstaat als ein wesentlicher Akteur und Gestaltungsraum betrachtet. ${ }^{10}$

Eine sinnvolle und hier verfolgte Synthese von Vergleich und transnationaler Geschichte bietet das Konzept der histoire croisée von Michael Werner und Bénédicte Zimmermann an, in der mit dem historischen Vergleich und der Transfergeschichte von Beginn der Untersuchung an der »überkreuzte Blick « gewählt wird: der kontinuierliche Blick auf das >Andere ‘ oder die >Anderen bei steter Reflektion des eigenen Standpunktes und Hintergrundes. ${ }^{11}$ Dieser Ansatz betont folglich die Verflechtungen und Verschränkungen, ohne die Spezifika bestimmter Einheiten zu negieren, und bietet sich im Besonderen für die historische Untersuchung des zwar heute von starken Nationalstaa-

Kaelble: Historischer Vergleich, 2012, S. 1f. Vgl. für die gleichberechtigte Suchen nach Konvergenzen ebenso wie Divergenzen in der historischen Komparatistik: Haupt: Historische Komparatistik in der internationalen Ceschichtsschreibung, 2006, S. 139.

6 Kaelble: Historischer Vergleich, 2012, S. 2.

7 Ebd., S. 6.

8 Gassert: Transnationale Geschichte, 2012, S. 1. Gassert nimmt Bezug auf: David Thelen, Hannes Siegrist, Karl Kaiser.

9 Wehler: Transnationale Geschichte-der neue Königsweg historischer Forschung? 2006, S. 173. Vgl. Bauerkämper: Wege zur europäischen Geschichte, 2011, S. $47 f$.

10 Vgl. Mann: Globalization, Macro-Regions and Nation-States, 2006, S. $22 \mathrm{f}$.

11 Kaelble: Historischer Vergleich, 2012, S. 8f. Vgl. Werner; Zimmermann: Vergleich, Transfer, Verflechtung, 2002, S. 609, 617-619, 629, 633, 636. 
ten, in seiner Geschichte aber von übernationalen Reichen geprägten Ostmitteleuropa an. ${ }^{12}$ In der vorliegenden Arbeit soll dieses Vorgehen insofern adaptiert werden, als in allen Kapiteln kontinuierlich die verschiedenen Standpunkte sowie ihre Verbindungen eingebracht, reflektiert und schließlich unter Kenntlichmachung der eigenen Position zusammengeführt werden.

Für die Untersuchung eines pluralistisch verstandenen `europäischen Gedächtnisses liegt nach Etienne François der Ansatz in der Anerkennung der transnationalen Verschränkung nationaler Gedächtniskulturen. ${ }^{13}$ Unter Bezug auf Pierre Nora stellt er zunächst allerdings fest, dass »Bekämpfung und Abgrenzung « zumeist bedeutender sind als »Gemeinsamkeit und Verflechtung«. Wenn man das Ziel der gegenseitigen Verständigung verfolgt, ist aber gerade in diesen Fällen die Suche nach Unterschieden und Gemeinsamkeiten besonders notwendig:

»Eingedenk dieser Erkenntnis scheint mir das genaue Wissen um die einzelnen Erinnerungskulturen den Blick für das zu schärfen, was das Cemeinsame an Europa ausmacht. Nach wie vor bin ich der Auffassung, dass nur aus einem vertieften Verständnis der Unterschiede das Gefühl einer echten gemeinsamen Zugehörigkeit erwachsen kann. ${ }^{14}$

Bereits seit längerem werden die Entstehung "transnationaler Gemeinschaften und Prozesse identitärer Vergemeinschaftung jenseits nationaler Grenzen « untersucht. ${ }^{15}$ Joanna Wawrzyniak und Małgorzata Pakier sehen hier eine »[...] marriage of >memory studies« with the European identity debate. ${ }^{16}$ Viele der Wissenschaftler nehmen dabei selbst eine Doppelrolle als "scholars of memory « und »memory agents « ein. ${ }^{17}$ Der Wunsch nach einer vertieften europäischen Einigung auf Basis einer fortgesetzten historischen Verständigung tritt also durchaus in Kombination mit der Erforschung entsprechender Themen oder Phänomene auf. In Ostmitteleuropa wird von einigen Forschern die Idee einer seuropäischen Erinnerung^ und der dahinterstehenden theoretischen Konzepte als ein Ergebnis deutscher Geschichtspolitik oder aber zumindest des starken Einflusses der deutschen Erinnerungskultur auf die europäische Gemeinschaft seit den 1990er Jahren betrachtet. ${ }^{18}$ Dies ist für die vorliegende Arbeit von besonderer Relevanz und soll daher mitbedacht werden. Trotz aller Europarhetorik müssen natio-

12 Vgl. Hildermeier: Osteuropa als Gegenstand vergleichender Geschichte, 2006, S. 135. Siehe auch: Bauerkämper: Wege zur europäischen Geschichte, 2011, S. 48f. Jürgen Kocka stellte dazu schon 2000 fest: »Wer >ostmitteleuropäische Geschichte< wirklich betreibt, hat per se ein transnationales Forschungsprogramm«: Kocka: Das östliche Mitteleuropa als Herausforderung für eine vergleichende Ceschichte Europas, 2000, S. 170.

13 François : Europäische lieux de mémoire, 2006, S. $295 \mathrm{f}$.

14 Nora: Nachwort, 2001, S. 686.

15 Gassert: Transnationale Geschichte, 2012, S. 11. Transnationale >Erinnerungsgemeinschaften< sollten nicht als unrealistisches Phänomen abgetan werden, sind diese doch in der Ceschichte eher die Norm als die Ausnahme - zum Beispiel bei religiösen Erinnerungsgemeinschaften.

16 Pakier; Wawrzyniak: Memory and Change in Eastern Europe, 2016, S. 4.

17 Ebd., S. 6. Als Beispiele führen sie hier u.a. Aleida Assmann und Gesine Schwan an.

18 Ebd. 
nale Prägungen der Erinnerungsdiskurse beachtet und auch bei der Besprechung der wissenschaftlichen Literatur berücksichtigt werden.

\subsection{Erinnerung und Erinnerungskultur}

Unter dem heute in Forschung und Öffentlichkeit gängigen Dachbegriff »Erinnerungskultur« versammeln sich verschiedene Konzepte aus unterschiedlichen Disziplinen. Zentral sind die Ideen eines kollektiven Gedächtnisses nach Maurice Halbwachs ${ }^{19}$ und die dazu komplementären Begriffe des kulturellen und kommunikativen Gedächtnisses von Jan und Aleida Assmann. Eine rege Rezeption löste auch das Konzept der Erinnerungsorte von Pierre Nora aus. Der Begriff Erinnerungskultur konkurriert mit verschiedenen Begriffen wie dem der Geschichtskultur von Jörn Rüsen. ${ }^{20}$ Alle diese Konzepte wurden im Detail oder auch grundsätzlich kritisiert. Dennoch hat sich Erinnerungskultur als Leitbegriff der neuen Kulturgeschichtsschreibung in den 1990er Jahren in der Wissenschaftssprache etabliert. ${ }^{21}$ In einer umfassenden Definition steht der Terminus bei Christoph Cornelißen für einen

»formalen Oberbegriff für alle denkbaren Formen der bewussten Erinnerung an historische Ereignisse, Persönlichkeiten und Prozesse [...], seien sie ästhetischer, politischer oder kognitiver Natur. [...] Als Träger dieser Kultur treten Individuen, soziale Gruppen oder sogar Nationen in Erscheinung, teilweise in Übereinstimmung miteinander, teilweise aber auch in einem konfliktreichen Gegeneinander. ${ }^{22}$

Der funktionale Gebrauch der Vergangenheit für gegenwärtige Ziele, wie beispielsweise die historische Fundierung und Konstruktion von Gruppenidentitäten, wird hier stärker betont als bei dem sonst durchaus synonym verwendbaren Begriff der Geschichtskultur. ${ }^{23}$ Als analytischer Dachbegriff scheint »Erinnerung « zudem gängige Begriffe der historischen Forschung wie »tradition, heritage, identity and culture sinnvoll zu fassen und zugleich die Untertöne von »trauma, manipulability and multiplicity« zu integrieren. ${ }^{24}$ Auch Katrin Pieper betont die politische Dimension von Erinnerungskultur durch den ihr inhärenten »starken appellativen Charakter: Es geht immer auch um die (Streit-)Frage, wer, was und wie zu erinnern ist. ${ }^{25}$

Mit dem vielfach konstatierten >Geschichts- oder Erinnerungsboom Jahren wuchs auch das Interesse an theoretischen Fragen und mündete schließlich in

Der Soziologe und Philosoph Maurice Halbwachs stellte in der ersten Hälfte des 20. Jahrhunderts mit dem Konzept des »kollektiven Gedächtnisses« die soziale und gegenwärtige Bedingtheit von persönlicher Erinnerung heraus.

Oesterle: Einleitung, 2005, S. 11.

Cornelißen: Erinnerungskulturen, 2012, S. 166.

23 Ebd., S. 166f. Vgl. Wolff: Revising Eastern Europe, 2006, S. 115-118. Vgl. für eine theoretische und methodologische Einführung zu nationalen und europäischen Erinnerungskulturen auch: Macdonald: Memorylands, 2013, S. 1-24. 
die erinnerungskulturelle >Explosion der 1990er Jahre. ${ }^{26}$ Einen bedeutenden Anteil daran hatte der französische Historiker Pierre Nora mit seiner mehrbändigen Reihe über die französischen Erinnerungsorte, »Les Lieux de mémoire ${ }^{27}$ Noras vergleichsweise theoriearmes Konzept hat sich sowohl durch diese Offenheit als auch unter Loslösung von seinem kulturpessimistischem Impetus und durch eine weitere Dynamisierung des Ansatzes als `Exportschlager < erwiesen. ${ }^{28}$ Neben unzähligen Nachahmungen für andere Nationen sind - und dies ist für unseren Fall von Interesse - auch die transnationalen Varianten des Konzeptes ebenso wie regionale Ansätze entstanden. An erster Stelle seien hier die fünf Bände der »Deutsch-Polnischen Erinnerungsorte« (2012-2015) ${ }^{29}$, aber auch die »Schlesischen Erinnerungsorte $(2005)^{30}$ sowie die dreibändigen »Europäischen Erinnerungsorte« $(2012)^{31}$ genannt.

Ebenfalls eine große Wirkung hat das auf den Ideen von Maurice Halbwachs aufbauende und fortlaufend weiterentwickelte Konzept des kollektiven, kommunikativen und kulturellen Gedächtnisses von Jan und Aleida Assmann entfaltet. Aleida Assmann hat ein dynamisches Verständnis vom kollektiven Gedächtnis entwickelt, in dem dessen Prozesshaftigkeit und Konstruktionscharakter betont wird..$^{32}$ Ein solches Gedächtnis sei eine soziale Notwendigkeit, um Gemeinschaften »Rückversicherung und Orientierung« bieten zu können..$^{33}$ Das kulturelle Gedächtnis einer Gemeinschaft manifestiere sich weniger als das kommunikative Gedächtnis in mündlicher Tradierung, sondern vielmehr in festgesetzten Riten und Institutionen und bilde mit seinen stabilen Ausdrucksformen ein epochenübergreifendes Konstrukt. ${ }^{34}$ Mit diesem wird zumeist auf eine Vergangenheit rekurriert, um Gemeinschaft zu stiften, verbindliche Regeln und Hand-

26 Für den Erinnerungsboom bezogen auf Flucht und Vertreibung vgl. Frevert: Geschichtsvergessenheit und Geschichtsversessenheit revisited, 2003, S. 6-13. Siehe auch: Röger: Flucht, Vertreibung und Umsiedlung, 2011, S. 79.

27 In diesen skizzieren er und weitere Autoren materielle und immaterielle »Erinnerungsorte« der französischen Nation. Dabei vertritt Nora grundsätzlich einen konservativen, kulturpessimistischen Standpunkt, indem er deren lexikalische Zusammenfassung für notwendig erachtet, da durch die Moderne der früher funktionierende Transfer gesellschaftlicher Erinnerung, z.B. durch mündliche Weitergabe, bedroht sei. Siehe: Beier-de Haan: Ceschichtskultur in der Zweiten Moderne, 2000, S. 12. Vgl. Cornelißen: Erinnerungskulturen, 2012, S. $172 \mathrm{f}$.

Vgl. Erll: Kollektives Gedächtnis und Erinnerungskulturen, 2017, S. 20-23.

29 Hahn; Traba; Loew: Deutsch-polnische Erinnerungsorte, 2012-2015.

30 Czapliński; Hahn et al. (Hg.): Schlesische Erinnerungsorte, 2005.

31 Boer; Duchhardt et al. (Hg.): Europäische Erinnerungsorte, 2012. Vgl. François: Europäische lieux de mémoire, 2006. Górny und Kończal untersuchen in ihrem Aufsatz, warum Noras Konzept, abgesehen von den Deutsch-Polnischen Erinnerungsorten, vergleichsweise wenig Niederschlag in Osteuropa (und andernorts) gefunden hat: Górny; Kończal: The (Non-)Travelling Concept of Les Lieux de Mémoire, 2016.

32 Assmann: Das neue Unbehagen an der Erinnerungskultur, 2013, S. 17.

33 Ebd., S. 22.

34 Assmann: Der lange Schatten der Vergangenheit, 2006, S. 51-54. Erll: Kollektives Gedächtnis und Erinnerungskulturen, 2017, S. 24-26. Siehe für die Kritik eines elitären Kulturbegriffs in diesem Konzept sowie die schwierige analytische Trennung zwischen kommunikativem und kulturellem Gedächtnis: Hallama: Geschichtswissenschaften, Memory Studies und der passive Turn, 2012, S. 21-23. 
lungsmuster zu setzen sowie Herrschaft zu legitimieren. ${ }^{35}$ Gesellschaftliche Gruppen versuchen zumeist, ihr kulturelles Gedächtnis als alleingültiges durchzusetzen, also eine Hegemonie im Wettbewerb der konkurrierenden Erinnerungsmodelle zu erzielen. ${ }^{36}$ Woran und wie erinnert wird, ist somit Teil gesellschaftlicher Aushandlungsprozesse. ${ }^{37}$ Die Schaffung und Festigung eines gemeinsamen, in der Vergangenheit fundierten Selbstverständnisses hat zudem eine Orientierungsfunktion für Gegenwart und $\mathrm{Zu}$ kunft. $^{38}$

Trotz der bereits früh geäußerten Kritik an der Vorstellung, dass Gemeinschaften ein kollektives Gedächtnis besitzen können, ist das Bild eines homogenen Gedächtnisses von Gruppen und Nationen in der politischen und medialen Öffentlichkeit sehr beliebt. ${ }^{39}$ Nicht nur für die heutigen hochpluralisierten Gesellschaften erscheinen Vorstellungen von einheitlichen Erinnerungsgemeinschaften abwegig; $;^{40}$ Überlegungen zu einer Erinnerungskultur haben vielmehr eine Vielfalt, also Erinnerungskulturen zu berücksichtigen. ${ }^{41}$ Ein kollektives Gedächtnis kann folglich nur eingeschränkt als ein zeitweise in der (medialen) Öffentlichkeit vorherrschendes, aber grundsätzlich nie als konkurrenzloses Geschichtsbild betrachtet werden. Je nach Gesellschaft und politischem System unterscheidet sich das in der offiziellen Erinnerungskultur zugelassene Ausmaß an Vielfalt der Erzählungen und Formen der Erinnerung.

Ein vergleichsweise neues Phänomen sind die bereits diskutierte Frage eines europäischen Gedächtnisses und damit verbunden transnationale Aushandlungsprozesse

Erll: Kollektives Cedächtnis und Erinnerungskulturen, 2017, S. 4, 13, 25f., 111f. Vgl. Cornelißen: Erinnerungskulturen, 2012, S. 168. Siehe auch: Grütters: Das Gedächtnis der Deutschen, 2009, S. 67.

36 Erll: Kollektives Gedächtnis und Erinnerungskulturen, 2017, S. 114f. Vgl. Ullrich: Diskursanalyse, Diskursforschung, Diskurstheorie, 2008, S. 23f.

37 Vgl. Bauerkämper: Deutsche Flüchtlinge und Vertriebene, 2010, S. 477.

38 Assmann: Formen des Vergessens, 2016, S. 37.

39 Vgl. Assmann: Das neue Unbehagen an der Erinnerungskultur, 2013, S. 10. Tremel und Krüger schreiben hierzu: „Die Medien und insbesondere die Film- und Fernsehindustrie spiegeln und intensivieren diese rückwärtsgerichtete Identitätsmaschine und insbesondere deren nationalen Fokus, erzählt doch auch die Flut der in den letzten Jahren produzierten Geschichtsdramen und -dokus fast ausschließlich national oder gar völkisch ausgerichtete Geschichte [...].« Tremel; Krüger: Jenseits der Nation, zukünftig, 2009, S. 350f. Siehe auch: Peters: Revolution der Erinnerung, 2016, S. 28.

40 Cornelißen: Erinnerungskulturen, 2012, S. 175. Vgl. Erll: Kollektives Gedächtnis und Erinnerungskulturen, 2017, S. 13. Vgl. für die Kritik und weitere Modelle: ebd., S. 85-88.

41 Cornelißen: Erinnerungskulturen, 2012, S. 175. Zur Kritik am Konzept von Jan und Aleida Assmann vgl. Jureit; Schneider: Gefühlte Opfer, 2011, S. 12, 54-76. Siehe: Assmann (Assmann: Auf dem Weg zu einer europäischen Gedächtniskultur? 2012, S. 35f.), die in Bezug auf das Holocaustgedenken von einer europäischen und globalen Erinnerungsgemeinschaft spricht. Vgl. kritisch zu Assmann und für die Forderung nach einer stärkeren Berücksichtigung sozialer, temporaler und generationaler Differenzierung einer »kritischen Erinnerungsforschung «, die »deren Konstruktion durch die Politik, die Medien und gesellschaftliche Interessengruppen untersucht « und innere Differenzen der Gesellschaften stärker hervorhebt: Ther: Der Diskurs um die Vertreibung, 2008, S. 45f. Vgl. zur Mehrdimensionalität von offiziellem und individuellem oder marginalisiertem Gedächtnis: Bauerkämper: Das umstrittene Gedächtnis, 2012, S. $13 f$. 
über ein europäisches, respektive globales Erinnern. ${ }^{42}$ Für die vorliegende Fragestellung gilt es, zwei Möglichkeiten zu berücksichtigen: transnationale Diskurse mit dem Ziel, in die eigene nationale Erinnerungskultur hineinzuwirken, wie zum Beispiel die aktuellen polnischen Reparationsforderungen an Deutschland, die häufig als primär innenpolitisches Instrument verstanden werden, oder aber mit dem Fokus, anderen Gesellschaften die eigenen Erfahrungen und Bewertungen näher zu bringen.

Nach der intensiven Beschäftigung mit Fragen des Erinnerns und der Durchsetzung des politischen Erinnerungsgebotes in der westlichen Öffentlichkeit wird zunehmend der Frage nach der Bedeutung des Vergessens in Erinnerungskulturen nachgegangen. ${ }^{43}$ David Rieff hat ein starkes Plädoyer für das Vergessen als innergesellschaftliche sowie zwischenstaatliche Konfliktlösung oder zumindest als deren Begleitung gehalten. ${ }^{44}$ Aleida Assmann hat hierzu ebenfalls eine Monographie veröffentlicht, in der sie differenzierter als Rieff die Bedeutung des Vergessens anhand verschiedener Beispiele betrachtet. ${ }^{45}$ Erinnern und Vergessen gehören fundamental zusammen; sie lassen sich auf gesellschaftlicher Ebene zum Teil steuern, aber keineswegs zwangsläufig erfolgreich. Assmann sieht das Vergessen aber nicht als unmittelbare Konfliktlösung, sondern als mögliches Ende eines Aufarbeitungsprozesses - andernfalls droht das in der Vergangenheit inhärente Konfliktpotenzial zu einem anderen Zeitpunkt wieder hervorzudrängen oder latent die Stimmungen innerhalb und zwischen den Gruppen auf negative Weise $\mathrm{zu}$ beeinflussen. ${ }^{46}$

Bei einer erinnerungskulturellen Untersuchung kann man sich auf eine Art von Medium fokussieren, quasi >sortenrein arbeiten. ${ }^{47}$ Für die Gewinnung eines möglichst vielfältigen Bildes, besonders bei der Untersuchung snationaler Erinnerungskulturen, bietet sich aber eine um einen Schwerpunkt gruppierte Vielfalt der untersuchten Medien an, in dem hier vorliegenden Fall um den Fixpunkt der Museen und fokussiert auf die politische Ebene der Auseinandersetzungen. Schließlich wird der soziokulturelle Kontext der Erinnerungskultur getragen von verschiedenen »Medien, Symbolen und Institutionen« - und nur »die Untersuchung von Erinnerungsakten innerhalb einer bestimmten

42 Cornelißen geht hierbei jedoch mit den Akteuren hart ins Gericht und sieht in den Auseinandersetzungen auf europäischer/internationaler Ebene diese oft nur als »Forum«, welches für nationalstaatliche Erinnerungskonflikte missbraucht wird: Cornelißen: Erinnerungskulturen, 2012, S. 180. Vgl. zur Persistenz der auf die Nation fokussierten Erinnerung: Cerhards; Breuer et al.: Kollektive Erinnerungen der europäischen Bürger im Kontext von Transnationalisierungsprozessen, 2017, S. 245, 257. Vgl. Kap. 8, S. 522.

43 So ist Erinnern im Vergleich zum Vergessen die Ausnahme. Sie muss zumeist aktiv gestaltet werden, wohingegen Vergessen der natürliche Verfallsprozess ist: Assmann: Formen des Vergessens, 2016, S. 30. Nach Bergem (in Bezug auf Christa Wolfs Roman Stadt der Engel) ist »Erinnern mit dem Vergessen durch das Kriterium der Selektion verbunden«. Bergem: Ceschichtspolitik und Erinnerungskultur, 2010, S. 233.

44 Rieff: In Praise of Forgetting, 2016. Siehe besonders: S. 127-145.

45 Assmann: Formen des Vergessens, 2016.

46 Ebd., S. 66. Eine ähnliche Argumentation verfolgen: Marszałek-Kawa; Wawrzyński et al.: The Politics of Memory (Vol. II), 2017, S. 168. Vgl. ausführlich zur »friedensstiftenden Kraft des Vergessens«: König: Paradoxien der Erinnerung, 2011, S. 45-51. 
Erinnerungskultur lässt Rückschlüsse auf die Art und das Funktionieren des kollektiven Gedächtnisses zu, das sich als solches einer Untersuchung generell entzieht. $\aleph^{48}$ Dies ist insofern relevant, da moderne Medien in Form von Zeitungen, Radio und Fernsehen sowie zunehmend auch digitalen Medien ein integraler Faktor als Träger und Akteur der Erinnerungskultur sind. ${ }^{49}$ Bei der Untersuchung einzelner Elemente und der von ihnen vermittelten Narrative geht es nicht - oder nicht primär - darum, ob sie die Geschichte wahr oder falsch darstellen, sondern warum, wie und mit welchem Effekt sie erzählt wird..$^{50}$

Zur umfassenden Beschreibung von Erinnerungskulturen gehört auch die Frage des impacts von erinnerungskulturellen Institutionen und Akteuren auf individuelle Einstellungen und Wissensbestände. ${ }^{51}$ Wie bei der Museumsanalyse noch ausführlicher zu besprechen sein wird, unterliegt die Rezeptionsforschung besonderen methodischen Schwierigkeiten. Für die vorliegende Fragestellung sind jedoch primär deren Materialisierungen von Bedeutung; die Frage der darüber hinausgehenden Wirkungen ist aufgrund ihrer häufig spekulativen Basis dagegen nur als Ergänzung von Interesse. ${ }^{52}$

\subsection{Geschichtspolitik}

Erinnerungskultur und Geschichtspolitik werden häufig als Begriffspaar verwendet und sollen auch hier sinnvoll zusammengedacht werden. ${ }^{53}$ Stefan Troebst hat 2014 in einer knappen Skizze eine Definition von Geschichtspolitik formuliert, mit der er einen pragmatischen Ansatz verfolgt und diese als ein »Politikfeld ähnlich wie etwa Sozialpolitik oder Gesundheitspolitik« betrachtet. Vergleichbar mit diesen wird die Geschichtspolitik von unterschiedlichen politischen Instanzen und Akteuren geprägt und hat verschiedene Gegenstände als Handlungsfeld, darunter historische Jubiläen und Gedenktage, Denkmalbau, Gedenkstättenpflege, Einrichtung oder Steuerung von Geschichtsmuseen. Strukturelle Hintergründe wie die Staatsform sind hier einzubeziehen. Verschiedene Wissenschaftsrichtungen untersuchen dieses per definitionem interdisziplinäre Feld. ${ }^{54}$ Die immanente politische Dimension unterstreicht Edgar

48 Tomann: Ceschichtskultur im Strukturwandel, 2016, S. $78 \mathrm{f}$.

49 Vgl. Erll: Kollektives Gedächtnis und Erinnerungskulturen, 2017, S. 135-137. Siehe auch: Becker: Geschichtspolitik in der »Berliner Republik«, 2013, S. 61. Vgl. zur Bedeutung der modernen Medien für den ^Vertreibungsdiskurs : Margalit: Guilt, Suffering, and Memory, 2010, S. 268-274. Vgl. Olick: Foreword, 2016, S. IX-XI.

Vgl. Moller: Erinnerung und Gedächtnis, 2010, S. 11.

52 Vgl. in Bezug auf die Rezipientenforschung im Museum: Heinemann: Krieg und Kriegserinnerung im Museum, 2017, S. 53f.

53 Siehe: Bergem: Geschichtspolitik und Erinnerungskultur, 2010. Troebst konstatiert leicht ironisch, dass das »Tandem >Ceschichtspolitik und Erinnerungskultur < [...] seiner Komplementarität wegen [...]« derzeit en vogue sei: Troebst: Ceschichtspolitik, 2014, S. 13f. Vgl. Leschnik: Erinnerungskultur und Geschichtspolitik in Polen, 2018, S. 21-32. Vgl. die Arbeit von A. Assmann, die aus erinnerungskultureller Perspektive verschiedene geschichtspolitische Fälle diskutiert: Assmann: Der lange Schatten der Vergangenheit, 2006.

Troebst: Geschichtspolitik, 2014. Vgl. Meyer: Memory and Politics, 2010, S. 179. 
Wolfrum in seinem Lexikonartikel zu »Geschichtspolitik«, die sich um die »zentralen Kategorien« von »Interesse, Macht und Herrschaft« dreht..$^{55}$

Unstrittig ist, dass Geschichtspolitik schon immer betrieben wurde. Dies betrifft sowohl innergesellschaftliche Aushandlungsprozesse wie auch zwischenstaatliche Beziehungen, beispielsweise das Vergessensgebot im Westfälischen Frieden. ${ }^{56}$ Troebst sieht den Ursprung des Begriffes der Geschichtspolitik in der alten Bundesrepublik und dessen Entstehung im Umfeld des Historikerstreites. Sich von diesem Ursprung emanzipierend, wurde er bald als Begriff wie als Forschungsansatz übernommen, so in Polen mit dem Begriff der polityka historyczna und international mit dem der politics of history oder der politics of memory. ${ }^{57}$

Erste Maßstäbe für den zunächst spezifisch deutschen Kontext setzte Norbert Frei mit seinem 1996 erschienenen Standardwerk, in dem er Vergangenheitspolitik als abgeschlossene Epoche der politisch-juristischen Aufarbeitung in der Bundesrepublik Deutschland nach 1945 beschrieb. ${ }^{58}$ Mittlerweile ist die Begrifflichkeit hiervon gelöst und wird auch auf andere Fälle als mehr oder minder ausdefinierter Begriff für den politisch-juristischen Umgang mit diktatorischen Vergangenheiten bezogen. ${ }^{59}$ Wolfrum veröffentlichte 1999 sein Grundlagenwerk zur »Geschichtspolitik in der Bundesrepublik Deutschland.« Hierin hat er einen offeneren Begriff der Geschichtspolitik eingeführt:

»Ceschichtspolitik ist ein Handlungs- und Politikfeld, auf dem verschiedene Akteure Geschichte mit ihren spezifischen Interessen befrachten und politisch zu nutzen suchen. Sie zielt auf die Öffentlichkeit und trachtet nach legitimierenden, mobilisierenden, politisierenden, skandalisierenden, diffamierenden u.a. Wirkungen in der politischen Auseinandersetzung. « ${ }^{60}$

Bezüglich der Akteure sieht Wolfrum vor allem einen »top-down«-Ansatz, in dem politische Eliten sich historischer Argumentationen, Inszenierungen und Identitäten bedienen und damit zugleich diese sowie die politische als auch die Erinnerungskultur prägen. ${ }^{61}$

55 Wolfrum: Ceschichtspolitik, 2011, S. 207.

56 Vgl. Assmann: Formen des Vergessens, 2016, S. 57-63. Siehe auch: Becker: Geschichtspolitik in der »Berliner Republik«, 2013, S. 192.

57 Troebst: Geschichtspolitik, 2014, S. 2f. Auch hier kursieren unterschiedliche Begriffe wie »history politics«, jedoch scheint sich »politics of history« durchzusetzen. Vgl. ausführlich zur»Begriffsgeschichte der Ceschichtspolitik«: Becker: Ceschichtspolitik in der »Berliner Republik«, 2013, S. 114123. Vgl. für eine Definition der politics of memory: Marszałek-Kawa; Wawrzyński et al.: The Politics of Memory (Vol. II), 2017, S. $167 f$.

58 Frei: Vergangenheitspolitik, 2012 (1996).

59 Meyer: Memory and Politics, 2010, S. 175.

60 Wolfrum: Geschichtspolitik in der Bundesrepublik Deutschland, 1999, S. 25-26.

61 Ebd., S. 2, 26. Vgl. Troebst: Ceschichtspolitik, 2014, S. 5. Vgl. für eine knappe Besprechung des Ansatzes von Wolfrum auch: Becker: Ceschichtspolitik in der »Berliner Republik«, 2013, S. 132-134. 
Auffällig spät hat sich die Politikwissenschaft dem Themenfeld der Geschichtspolitik geöffnet. ${ }^{62}$ Der Politikwissenschaftler Manuel Becker hat 2013 eine Monographie zur »Geschichtspolitik in der >Berliner Republik« «orgelegt; darin definiert er den Begriff »Geschichtspolitik« als Oberbegriff für jede Form der Verwendung von Geschichte im Bereich der Politik. Diese untergliedert er weiter in zwei Unterkategorien: zum einen die »instrumentelle Verwendung«, vor allem zur Legitimierung politischen Handelns, zum anderen die "materielle Verwendung « - dieser ordnet er die Vergangenheitspolitik sowie die Erinnerungspolitik unter, die in Demokratien klassischerweise die Organisation von Feierlichkeiten oder von Museums- und Ausstellungsprojekten beinhaltet. ${ }^{63}$ Unterstrichen werden muss, dass geschichtspolitische Akteure durch den spezifischen gesellschaftlichen und historisch-kulturellen Rahmen und somit in ihrer Konstruktion von Geschichte beschränkt sind. ${ }^{64}$ Becker konstatiert im weiteren Zusammenhang, dass der Erfolg eines vermittelten Geschichtsbildes, dessen »Faktenarmut [...] mit einer starken Emotionalisierung [korrespondiert] «, darin bestehe, »komplexe historische Zusammenhänge und deren wertende Interpretationen auf zumeist lediglich ein verkürztes Schlag- oder Stichwort zu reduzieren. ${ }^{65}$

Reinhart Koselleck äußert sich ablehnend gegenüber der geschichtswissenschaftlichen Verwendung des Begriffs »Geschichtspolitik« - die Aufgabe der Wissenschaft sei es, sich nicht von einer solchen vereinnahmen zu lassen und dem ideologischen Betreiben von Geschichte eine ideologiekritische, politikferne Wissenschaft entgegenzusetzen. ${ }^{66}$ Anders positioniert sich Frei, der es als eine originäre Aufgabe einer »kritischen Geschichtswissenschaft [sieht], über geschichtspolitische Instrumentalisierungen aufzuklären ${ }^{67}{ }^{67}$ Ein weiteres Diskussionsfeld ist die Frage, inwieweit demokratische Staaten Geschichtspolitik betreiben dürfen oder sollen. Eine entsprechende Bewertung hängt von der Art und Weise der Geschichtspolitik ab. Nach Wolfrum kann diese neben den erwähnten machtpolitischen Zwecken auch einer politisch-pädagogischen Aufgabe dienen: Lernen über und aus der Geschichte für ein reflektiertes historisches Bewusstsein sowie das damit verbundene Diskutieren von Deutungskonkurrenzen kann in einer demokratisch strukturierten Gesellschaft als »öffentlicher Wettstreit der Erinnerungen ausgetragen « werden. ${ }^{68}$ Becker folgt hierin Wolfrum, indem er Geschichtspolitik als »naturgemäß existierendes und legitimes Mittel« demokratischer

62 Ausführlich hat sich der Politikwissenschaftler Helmut König mit dem Gedächtnisthema auseinandergesetzt und beklagt, dass dieses politisch zentrale Feld viel zu lange von der Politikwissenschaft vernachlässigt worden sei: König: Politik und Cedächtnis, 2008.

63 Becker: Ceschichtspolitik in der »Berliner Republik«, 2013, S. 198-201.

64 Kubik; Bernhard: A Theory of the Politics of Memory, 2014, S. 9. Ebenso: Becker: Geschichtspolitik in der »Berliner Republik«, 2013, S. 78. Berger/Niven unterstreichen die Bedeutung des Nationalstaates im 19. und 20. Jahrhundert bei der Definierung der Nationalgeschichte, die aber schon damals »never the only show in town « waren: Berger; Niven: Writing the History of National Memory, 2014, S. 151.

65 Becker: Ceschichtspolitik in der »Berliner Republik«, 2013, S. 90.

66 Vgl. für eine Zusammenfassung des Standpunktes von Koselleck: Troebst: Ceschichtspolitik, 2014, S. 7.

67 Frei: Rückruf der Erinnerung, 2006, S. 174f.

68 Wolfrum: Geschichtspolitik, 2011, S. $207 f$. 
Staaten beschreibt, »in deren Rahmen eine faire politische Auseinandersetzung prinzipiell möglich ist « ${ }^{69}$ Dabei dienen "geschichtspolitische Kontroversen [...] einer Gesellschaft zur Schärfung und Bewusstwerdung ihres Wertefundaments und in konkreten geschichtspolitischen Maßnahmen legt der Staat Zeugnis gegenüber seiner Vergangenheit und damit gegenüber seinem Selbstverständnis $a b . «^{70}$

Für das Verhältnis von Geschichtswissenschaft und Geschichtspolitik weist Martin Sabrow darauf hin, dass es im Zuge des »epochalen Paradigma[s] der >Aufarbeitung $\mathrm{zu}$ einer breiten wechselseitigen Anerkennung von Politik und Wissenschaft gekommen ist, dabei aber nur selten »die Risiken dieser liaison dangereuse von Geschichtspolitik, Zeitzeugenkultur und Wissenschaft [...] ins Bewusstsein treten. ${ }^{71}$ Dieses häufig »einvernehmliche Zusammenwirken « in der Bundesrepublik Deutschland wirke dem Anspruch entgegen, dass »nur und immer nur die Infragestellung des allgemein Anerkannten die Weiterentwicklung der Wissenschaft sichert. ${ }^{72}$

Aleida Assmann sieht derzeit zwei grundsätzlich unterschiedliche Arten von Geschichtspolitik als vorherrschend an. Das eine ist ein klassisches Modell, in dem die Aufgabe der Geschichtspolitik darin liegt, die »nationale Identität zu stützen und zu zelebrieren « und die dafür faktisch nur drei Rollen zulässt: die des Sieges, des heldenhaften Widerständlers oder des passiven Opfers des Bösen. Diese Rollen können vermischt werden. Eine derartige Form betont lange und positiv verstandene Kontinuitäten. Auf der anderen Seite ist eine »Politik der Reue zu sehen, die neben den eigenen Opfern verstärkt die Opfer der eigenen Nationalgeschichte in den Mittelpunkt stellt. Diese betont konsequenterweise »Bruch und Wandel«, um sich von diesen Vergangenheiten abzugrenzen. ${ }^{73}$

Becker weist darauf hin, dass das Politikfeld »Geschichte« so heterogen ist, dass »je nach konkretem $\mathrm{zu}$ untersuchendem Phänomen unterschiedliche methodische Herangehensweisen « sowie ein flexibles »theoretisches Gehäuse « erforderlich sind. ${ }^{74}$ Für die geschichtspolitische Analyse werden häufig staatliche sowie hervorgehobene Akteure herangezogen, Koselleck spricht in einer ironischen Wendung von den »sieben Ps, die darüber befinden, was kollektiv, was als Kollektiv zu erinnern sei: die Professoren, die Politiker, die Priester, die Pädagogen, die Poeten, die Publizisten und die PR-Spezialisten. Gegen dieses plurale Kollektiv gilt es, das Recht auf die eigene Erinnerung, das heißt auf die unaustauschbare Eigenerfahrung, zu schützen. «" Während Troebst anerkennt, dass Koselleck mit seiner Vorstellung dieses Kollektives »(national-) staatliche Akteure wie Präsidialverwaltungen, Regierungen, Ministerien, Behörden, Gebietskörperschaften, Kommunen, Bildungseinrichtungen u.a., desgleichen nichtstaatliche Akteure wie politische Parteien, Medien, Unternehmen, Gewerkschaften, Kirchen, Kultur- und Wissenschaftseinrichtungen, Museen, Gedenkstätten, Literaten, 
Intellektuelle etc.« einfängt, bleiben andere, zivilgesellschaftliche Akteure indes unbeachtet. Bei »Opfergruppen, Aufarbeitungsinitiativen oder Geschichtsvereine[n]«, aber auch dem »Familiengedächtnis« handele es sich aber gerade um solche Akteure, die für das Politikfeld Geschichte nicht vernachlässigt werden dürften. ${ }^{76}$

Die Akteure werden von Becker in zwei Gruppen unterteilt, die der »Akteure bzw. Konstrukteure « und die der »Adressaten bzw. Rezipienten « - die Grenzen zwischen diesen Gruppen können aber je nach Situation fließend sein und die Rollen wechseln. ${ }^{77} \mathrm{Er}$ weist weiter auf die Diskussion um die »unumgängliche Standortgebundenheit des Forschers« hin, die besonders bei gegenwärtigen geschichtspolitischen Fragen zum Tragen kommt. Diese wendet er allerdings - trotz des »in höchstem Maße normativ aufgeladene[n] und von Machtinteressen beherrschte[n] Feld[es]« - positiv:

»Der Forscher muss daher besonders vorsichtig bei der Beurteilung geschichtspolitischen Handelns vorgehen. Dennoch liegt hier als [...] Prämisse die Annahme zu Crunde, dass Geschichtspolitik wissenschaftlich seriös analysiert und nach vorab sauber definierten, objektiven Maßstäben beurteilt werden kann. Konkrete geschichtspolitische Untersuchungen sollten sich von der Maßgabe leiten lassen, dass gerade im Bewusstsein von Normativität und Standortgebundenheit des Forschers ein möglichst hoher Grad an Objektivität und Neutralität erzielt werden kann. ${ }^{78}$

Für die notwendige und gewünschte kritische Bewertung von Geschichtspolitik muss der Forscher deren Argumentation und Handlungen auf (historische) »Zulänglichkeit bzw. Unzulänglichkeit« hin prüfen. ${ }^{79}$

In einer Untersuchung, die einen transnational vergleichenden Anspruch hat, stellt sich die Frage, inwiefern auch Geschichtspolitik transnational erforscht werden kann und welche Vorarbeiten auf diesem Feld bereits geleistet worden sind. Troebst hat herausgestellt, dass eine solche Untersuchung für Ostmitteleuropa immer noch ein Forschungsdesiderat ist. Dabei böte sich gerade hier aufgrund der »Beziehungshaftigkeit der Erinnerungskulturen [...] samt ihren geschichtspolitischen Aktionsmustern « eine transnationale Perspektive an, denn diese »Beziehungshaftigkeit« sei deutlich ausgeprägter als »diejenige des südlichen, nördlichen, zentralen und westlichen Europa«. ${ }^{80}$ In dieser überwiege eine »konflikthafte« Verflechtung, die sich entsprechend immer wieder in "geschichtspolitischen Rivalitäten « niederschlage und bei der eine nachhaltige Verständigung nach wie vor die Ausnahme sei. ${ }^{81}$ Jeffrey K. Olick hat grundsätzlich darauf hingewiesen, dass die häufig als beispielhaft betrachteten Erinnerungskulturen des Westens, zum Beispiel Deutschlands und Frankreichs, herangezogen und daraus

76 Troebst: Ceschichtspolitik, 2014, S. 9.

77 Becker: Ceschichtspolitik in der »Berliner Republik«, 2013, S. 194. Becker konstatiert, dass der Fokus auf die (politischen) Eliten »in ihrer Funktion als >Sinnproduzenten< und auf deren Kontroversen [...] wertvolle Rückschlüsse auf die politische Kultur eines Cemeinwesens [verspricht].« (ebd., S. 113).

80 Troebst: Ceschichtspolitik, 2014, S. 15. Siehe für eine ähnliche Einschätzung auch: Kubik; Bernhard: A Theory of the Politics of Memory, 2014, S. 7. 
Verallgemeinerungen über die Frage der Erinnerungskultur abgeleitet werden. Bei der Betrachtung osteuropäischer Erinnerungskulturen wird aber deutlich, dass diese keineswegs paradigmatisch sind und die daraus abgeleiteten Schlussfolgerungen falsch sein können. ${ }^{82}$

In seinem Papier $\mathrm{zu} »$ Erinnerungskultur und Geschichtspolitik in der historischen Forschung zum östlichen Europa« sieht Peter Haslinger im vermeintlichen Unterschied $\mathrm{zu}$ Westeuropa, dass geschichtspolitische Fragen sowohl innerhalb der Gesellschaften als auch zwischen den Gesellschaften als Anlass von Konflikten oder konfliktverschärfend wirken. Als eine Ursache dafür notiert er den »quellengesättigten Positivismus« der heutigen ostmitteleuropäischen Geschichtswissenschaft, die auf den schematischen Marxismus-Leninismus folgte und sich mit nachholendem "nation building « verband. Trotz manch anderer Erwartungen ist auch hier zu konstatieren, dass keine simple Übernahme westlicher Forschungstraditionen und Perspektiven erfolgte, sondern komplexe Adaptionen stattfanden. Haslinger weist darauf hin, dass die geschichtspolitischen Aktivitäten in Ostmitteleuropa häufig wesentlicher direkter sind: »Initiativen [...], die das Anliegen verfolgen, auf der Deutungsfolie innenpolitischer Lagerbildung eindeutig zuzuordnende, aber national ausgestaltete Erinnerungsangebote $\mathrm{zu}$ formulieren und medialisieren. « Letztlich habe das für die kommunistischen Systeme maßgebliche »ideologiegeleitete Erinnerungsmanagement « die Transformationsphase nach 1989 überstanden und werde in gewandelter Form weiter verfolgt. ${ }^{83}$ Diese verschiedenen Hintergründe sollen in der vorliegenden Arbeit zusammen mit den weiteren hier angeführten Überlegungen mitbedacht werden.

\subsection{Historische Diskursanalyse und Diskursgeschichte}

Die Überlegungen zu Erinnerungskultur und Geschichtspolitik haben bereits die Bedeutung von Aushandlungsprozessen deutlich gemacht. Diese können im Rahmen der untrennbar mit dem Namen Michel Foucault verbundenen Diskursanalyse untersucht werden ${ }^{84}$ Die vorliegende Arbeit greift auf die für die Geschichtswissenschaft weiterentwickelten Ansätze sowie praktische Umsetzungen als Beispiele zurück. ${ }^{85}$ Hier haben sich zwei Oberbegriffe etabliert: die Diskursgeschichte und die Historische Diskursanalyse, deren inhaltliche Differenz aber nicht immer ganz klar ersichtlich ist. ${ }^{86}$ Für die vorliegende Arbeit wird dem Verständnis von Achim Landwehr gefolgt, die Diskursgeschichte als historische Forschungsrichtung aufzufassen, welche die Rekonstruktion und Unter-

82 Olick: Foreword, 2016, S. X.

83 Haslinger: Erinnerungskultur und Ceschichtspolitik in der historischen Forschung zum östlichen Europa, 2007.

84 Vgl. für die sinnvolle Verknüpfung der Theorien der Erinnerungskultur und der Diskursanalyse: Haslinger: Diskurs, Sprache, Zeit, Identität, 2006, S. 36.

85 Vgl. für die Beliebtheit von Foucault in Dissertationseinleitungen und die zumeist unklare Verwendung von diesem: Graf: Diskursanalyse und radikale Interpretation, 2006, S. 75. 
suchung vergangener Diskurse zum Gegenstand und die Historische Diskursanalyse als ihre Methode hat. ${ }^{87}$

Wissenschaftler kritisieren wiederholt, dass sich eine Beliebigkeit in der Verwendung des Diskursbegriffes eingeschlichen hat: Alles kann scheinbar als Diskurs betrachtet werden. ${ }^{88}$ Ebenso wie Erinnerungskultur und Geschichtspolitik hat sich der Begriff im allgemeinen Sprachgebrauch eingebürgert. In der Wissenschaft haben sich zwei Tendenzen herauskristallisiert: zum einen, den Diskurs als "Korpus von (schriftlichen und/oder mündlichen Texten)« zu verstehen, zum anderen »eher [als] ein Regelsystem, welches alle möglichen Aussagen hervorbringt und unmögliche verbietet. ${ }^{89}$ Eine einheitliche Auffassung gibt es nicht. Peter Ullrich sieht beispielsweise einen zweiten Strang des Diskursbegriffes in Abkehr vom »Diskursforschungsstrang Foucault'scher Prägung« eher im »traditionellen Sinne«, das heißt als »öffentliche >Diskussion<, >Debatte oder >Auseinandersetzung $« .^{90}$

Vereinfacht lässt sich nach Landwehr zusammenfassen, dass sich in Diskursen Regeln herausbilden, die das "Sagbare, Denkbare und Machbare« betreffen und so Wirklichkeit organisieren. ${ }^{91}$ Es geht um Wirklichkeits- und Wissenskonstruktionen, die mittels Sprache in Form von Texten und Bildern oder anderen Verständigungssystemen manifestiert werden. ${ }^{92}$ Bewertung und Einordnung von historischem Geschehen wie auch gesellschaftliche Wertvorstellungen und Tabus werden in Diskursen ausgehandelt und festgelegt, wobei sie dabei selbst einem steten Wandel unterliegen. Diese finden in keinem machtfreien Raum statt, sondern die verschiedenen Akteure des Diskurses haben unterschiedliche Möglichkeiten und Reichweiten, um ihre Auffassungen über Vergangenheit, Gegenwart und Zukunft im Ringen um eine Deutungshoheit zu kommunizieren. Dabei nimmt die Sprache, beispielsweise bei der Setzung von Begrifflichkeiten, einen zentralen Platz und eine rahmende Funktion in der menschlichen Realitätsdefinition ein. ${ }^{93}$ Schließlich geht es bei der Diskursanalyse darum, die "gesellschaftlichen, politischen und semantischen Vorbedingungen herauszuarbeiten, die [...] Aussagen eingeschrieben sind. ${ }^{94}$

Die nach Landwehr entwickelte Diskursgeschichte hat die Aufgabe, die dynamischen Prozesse der Diskurse zu rekonstruieren und zu beschreiben. ${ }^{95}$ Die Historische Diskursanalyse sucht nicht die >Wahrheit $<$ über die in den Diskursen behandelte Geschichte, sondern kann nur Aussagen über die historischen und gesellschaftlichen Gegeben-

87 Landwehr: Diskurs und Diskursgeschichte, 2010, S. 4, 6-9. Vgl. Pieper: Resonanzräume, 2010, S. 207f. Siehe auch: Röger: Flucht, Vertreibung und Umsiedlung, 2011, S. $13 f$.

88 Haslinger: Diskurs, Sprache, Zeit, Identität, 2006, S. 28.

89 Eder: Historische Diskurse und ihre Analyse, 2006, S. 11.

90 Ullrich: Diskursanalyse, Diskursforschung, Diskurstheorie, 2008, S. 23.

91 Landwehr: Diskurs und Diskursgeschichte, 2010, S. 4. Vgl. Schwarzenegger: Diskurs und mediale Realitätskonstruktion in der Kommunikationsgeschichte, 2017.

92 Landwehr: Diskurs und Diskursgeschichte, 2010, S. 4. Ullrich: Diskursanalyse, Diskursforschung, Diskurstheorie, 2008, S. 21. Eder: Historische Diskurse und ihre Analyse, 2006, S. $12 f$.

93 Ullrich: Diskursanalyse, Diskursforschung, Diskurstheorie, 2008, S. 21. Vgl. Landwehr: Diskurs und Diskursgeschichte, 2010, S. 6.

94 Peters: Revolution der Erinnerung, 2016, S. 32.

95 Landwehr: Diskurs und Diskursgeschichte, 2010, S. 4. 
heiten zur Zeit des Diskurses treffen. ${ }^{96}$ Die Diskursgeschichte geht davon aus, dass in Gesellschaften gültige >Wahrheiten zum ersten stets nur zeitlich begrenzt anerkannt sind und zum zweiten grundsätzlich immer (marginalisierte) Gegenerzählungen existieren, die möglicherweise zu einem späteren Zeitpunkt die Hegemonie über den Diskurs gewinnen. ${ }^{97}$ Die zeitweise vorherrschende Erzählung kann als Meistererzählung bezeichnet werden. ${ }^{98}$

Wissenschaftler sind keine objektiven, quasi außenstehenden Betrachter des Diskurses, sondern Teil desselben. ${ }^{99}$ Dies zeigt sich besonders bei der Thematik von Flucht und Vertreibung, das als zeitgeschichtliches Thema eine starke politische Konnotation hat. Historiker waren und sind im Untersuchungszeitraum selbst aktiv an den Debatten beteiligt. ${ }^{100}$ Diesem Spannungsfeld müssen die Wissenschaftler mit einem problembewussten, transparenten Vorgehen konstruktiv begegnen. Schließlich sollten Aussagen über die Gegenwart mit Vorsicht getroffen und der späteren Verifikation überlassen werden. ${ }^{101}$

Peter Haslinger plädiert für einen sparsamen Gebrauch des Diskurs-Begriffs und verweist auf andere, gegebenenfalls treffendere Begriffe wie Diskussion, Debatte, Auseinandersetzung oder auch den Terminus »Thema« und er fügt einige weitere Ergänzungen zu den Überlegungen von Landwehr im Rahmen einer »erweiterten Diskursgeschichte« an. So versteht er Diskursgeschichte als Verdeutlichung sowohl der »Zwänge« als auch der »Gestaltungsmöglichkeiten« der Diskursteilnehmer und wie Argumente »im Lauf des Kommunikationsprozesses autorisiert, hierarchisiert oder marginalisiert und dadurch Machtverhältnisse generiert, stabilisiert oder bekämpft werden.« Für ein nachvollziehbares Verstehen der »dynamischen Struktur« des Diskurses sei es unabdingbar, verschiedene Perspektiven »innerhalb des argumentativen Systems einzunehmen und die sich daraus ergebenden Unterschiede in der subjektiven Wahrnehmung stärker als bisher in das Gesamtbild einzubeziehen. ${ }^{102}$

Schließlich verweist Haslinger auf den Marktcharakter des Diskurses und plädiert für den Untersuchungsterminus »Arena«, in dem die Diskursteilnehmer um öffentliche Aufmerksamkeit sowie Zustimmung konkurrieren und für diese werben. Dabei verfügen »unterschiedliche Diskursarenen« über unterschiedliche »innere Logiken«, die Arenen können sich wiederum überschneiden und Akteure in mehreren davon aktiv

96 Landwehr: Diskurs und Diskursgeschichte, 2010, S. 5 f.

97 Eder: Historische Diskurse und ihre Analyse, 2006, S. 15. Ullrich: Diskursanalyse, Diskursforschung, Diskurstheorie, 2008, S. $23 f$.

98 Vgl. Peters: Revolution der Erinnerung, 2016, S. 32f. Siehe auch: Kap. 1.3, S. 37.

99 Landwehr: Diskurs und Diskursgeschichte, 2010, S. 5.

100 Wagner: Deutsche Erinnerungskulturen und Geschichtspolitik nach 1945, 2009, S. 18. Hallama: Geschichtswissenschaften, Memory Studies und der passive Turn, 2012, S. 10. Vgl. Kap. 1.4, S. 40.

101 Landwehr mahnt zu einem »Verzicht [auf] thematische[...] Selbstbeschränkung«: Landwehr: Diskurs und Diskursgeschichte, 2010, S. 11. Vgl. auch Cornelißen: Erinnerungskulturen, 2012, S. 169: »Folglich müssen Historiker/innen und ihre Werke als integraler Bestandteil der Erinnerungskultur moderner Cesellschaften begriffen werden, was keineswegs ihren Anspruch auf eine unabhängige Deutungshoheit beeinträchtigt«.

102 Haslinger: Diskurs, Sprache, Zeit, Identität, 2006, S. 40, 46, 27, 32. 
sein. ${ }^{103}$ Zentraler Akteur und Plattform des Diskurses sind die Massenmedien, die eigenen ökonomischen und medialen Logiken sowie Handlungszwängen unterliegen, die es zu berücksichtigen gilt. ${ }^{104}$

Nach Rüdiger Graf ist eines der Grundprobleme der Diskursanalyse die Eingrenzung der Diskurse. Welche Beiträge und welche Akteursgruppen werden berücksichtigt? Wie weit geht man bei der Berücksichtigung der jeweiligen Kontexte ${ }^{105}$ In Bezug auf die notwendige Rahmung des untersuchten Diskursbereiches konstatiert Graf, dass an sich »die ganze Welt als relevante[r] Entstehungskontext für einen Diskurs« anzugeben wäre, aber so keine Ergebnisse erzielt werden können. Folglich »müssen spezifische Kontexte definiert und in eine überprüfbare Beziehung zur Entstehung der untersuchten Diskursformationen gebracht werden«, was eine systematische, nachvollziehbare und nach Möglichkeit repräsentative Auswahl des Quellenmaterials notwendig mache. ${ }^{106}$

In Bezug auf die Frage nach den auch hier zeitweise vorliegenden transnationalen Diskursen und der erwähnten Zentralität von Sprache ist zunächst festzuhalten, dass die »linguistische Grenze« für den zumeist über Sprache vermittelten Diskurs bedeutend, aber nicht unüberwindlich ist. Weiter gilt nach Haslinger, dass, wenn »nun eine Technik zur Überwindung dieser Sprachbarriere entwickelt wird (das heißt, es werden adäquate Mittel gefunden, um Sinnbezüge und Themen des Diskurses zu >verdolmetschen ), Diskurse auch sprachübergreifend wirken können«. Um von einem tatsächlich übergreifenden Diskurs sprechen zu können, darf sich dies jedoch nicht nur punktuell vollziehen; es ist darüber hinaus »eine fortlaufende Angleichung von Begrifflichkeiten und ihren Konnotationen notwendig«. Schließlich »[ermöglicht] es erst die Beherrschung der am jeweiligen gesellschaftlichen Ort geltenden kulturellen Deutungen und Praktiken [...], Aussagen auf ihre Plausibilität hin zu prüfen und damit in den diskursiv generierten Sinnhorizont der Gruppe einbezogen zu werden. «107 Sprach- und gesellschaftsübergreifende Diskurse können schließlich sowohl konfliktreich als auch affirmativ sein, das heißt im Negativen wie auch im Positiven eng aufeinander bezogen. ${ }^{108}$

Eine sprachliche Angleichung in den hier untersuchten Diskursen hat nicht oder nur eingeschränkt stattgefunden, das Aufeinanderbeziehen ist hingegen eine integrale Komponente. Diese Überlegungen sind ebenso wie das Konzept der zeitweise und auf verschiedenen Ebenen existierenden Diskursarenen eine der Grundlagen der vorliegenden Arbeit. Dafür werden in einem Zweischrittverfahren zunächst die Diskurse in den nationalen Rahmen unter steter Berücksichtigung transnationaler Komponen-

103 Haslinger: Diskurs, Sprache, Zeit, Identität, 2006, S. 35f., 42. Fortunati und Lamberti sprechen in diesem Zusammenhang vom »battlefield«, bei dem nichts neutral und alles ständig in der Diskussion ist: Fortunati; Lamberti: Cultural Memory, 2010, S. 129.

104 Schwarzenegger: Diskurs und mediale Realitätskonstruktion in der Kommunikationsgeschichte, 2017.

105 Graf: Diskursanalyse und radikale Interpretation, 2006, S. 77 .

106 Ebd., S. 86.

107 Haslinger: Diskurs, Sprache, Zeit, Identität, 2006, S. 44.

108 Ebd. 
ten sowie im zweiten Schritt zusammenführend die Verbindungen und übergreifenden Diskurse erörtert.

\subsection{Das Museum und die Museumsanalyse}

»Das Museum ist eine dauerhafte Einrichtung - ohne Absicht der Cewinnerzielung. Im Dienst der Cesellschaft und ihrer Entwicklung, allgemein zugänglich -, die das materielle und immaterielle Erbe der Menschheit und deren Umwelt zum Zweck von Studien, der Bildung und des Cenusses sammelt, bewahrt, beforscht, ausstellt und vermittelt. $\ll^{109}$

Diese Definition des International Council of Museums formulierte für die global erfolgreiche Institution Museum ein umfassendes Aufgabenfeld. ${ }^{110}$ Für den vorliegenden Untersuchungsgegenstand ist primär der Bereich von Interesse, in dem das Museum an die Öffentlichkeit tritt und seine Rolle als Teil, Ergebnis und zentraler Akteur der Erinnerungskultur und Geschichtspolitik einnimmt. ${ }^{111}$ Museen sind als soziokulturelle Phänomene zu verstehen, deren »surrounding milieux of culture, media, and history« als Kontext zu berücksichtigen sind und deren Ausstellungen grundsätzlich bestimmte (historische) Narrative vermitteln. ${ }^{112}$ Hierfür arbeiten sie mit Relikten der Vergangenheit sowie mit inszenatorischen Techniken. ${ }^{113}$

Besonders bei der Sammel- und Repräsentationsfunktion des Museums kann man von einer »kompensatorischen Funktion« für einen wahrgenommenen Verlust der Vergangenheit sprechen, was heute ebenso zentral erscheint wie bei der Gründungswelle der ersten europäischen Museen im 18. und 19. Jahrhundert. ${ }^{114}$ Diese Funktion führt dazu, dass die Musealisierung von Objekten und von Vergangenheiten eine »Verfestigung «, das heißt eine Verengung der Vergangenheit auf eine Auswahl von Objekten und Geschichten bedeutet. ${ }^{115}$ So erklären sich die vielen Kämpfe im Vorfeld von $\mathrm{Mu}$ seumsgründungen und die teils kontroversen Diskussionen um Ausstellungen. Nach der Gründungsphase kann das Museum aber durchaus ein nur noch schwer kontrollierbares »Eigenleben« entfalten und sich von der ursprünglichen Schaffungsintention distanzieren. ${ }^{116}$

Gestaltungstechnisch lässt sich das Museum trefflich als »Gesamtkunstwerk« bezeichnen. ${ }^{117}$ Diese komplexe Institution setzt sich ebenso wie die Ausstellung aus zahl-

109 Zitiert nach: Walz: Begriffsgeschichte, Definition, Kernaufgaben, 2016, S. 10.

110 Vgl. te Heesen: Theorien des Museums zur Einführung, 2013, S. 23.

111 Vgl. Sklokina: The Politics of Remembering the Nazi Occupation in Soviet Museums, 2015, S. 131.

112 Żychlińska; Fontana: Museal Cames and Emotional Truths, 2016, S. 261.

113 Thiemeyer: Ceschichtswissenschaft: Das Museum als Quelle, 2010, S. 74.

114 Elpers; Palm: Von Grenzen und Chancen des Sammelns von Gegenwart in kulturhistorischen Museen im 21. Jahrhundert, 2014, S. 18f. Kaiser et al. zitieren in Bezug auf die (Abgrenzungs-) Funktion des Museums Niklas Luhmann: »Man braucht Institutionen der Trauer, des >nevermore«: Kaiser; Krankenhagen et al.: Europa ausstellen, 2012, S. 26.

115 Vgl. Köstlin: Die Minderheit als Kategorie der Moderne und das Museum, 2012, S. 24.

116 Pieper: Resonanzräume, 2010, S. 201.

117 Brückner; Creci: Das Museum als komplexer Erfahrungsraum, 2015, S. 88. 
losen Komponenten, inneren und äußeren Logiken und Zwängen zusammen, die sie als ergiebigen, aber auch schwer greifbaren Untersuchungsgegenstand prädestinieren.

Für die vorliegende Untersuchung stehen eine politische Definition von Museum und seine Wirkung im gesellschaftlichen Aushandlungsprozess von Geschichte im Vordergrund. Die zentrale Bedeutung von Museen für die Analyse von Geschichtspolitik zeigt sich darin, dass sie von großen Teilen der Gesellschaft - und oft auch dem eigenen Selbstverständnis nach - als objektive, neutrale und verbindliche Instanz der Information über Geschichte verstanden werden und sich dieses Vertrauen in ihnen zugesprochener Relevanz ausdrückt. ${ }^{118}$ Mit der ihnen zugeschriebenen »wissenschaftlichen Autorität« erreichen sie ein deutlich größeres und heterogeneres Publikum als die durchschnittliche wissenschaftliche Publikation. ${ }^{119}$ Verstärkend kommt hinzu, dass dem Besucher sehr selten der Entstehungsprozess einer Ausstellung sowie die dafür bedeutsamen individuellen Standpunkte der Kuratoren oder das Selbstverständnis des Museums vermittelt werden. ${ }^{120}$ Dieses zunehmend hinterfragte und kritisierte Vorgehen steht im Konflikt mit der tatsächlichen Konstruktion von Geschichte in Museen. ${ }^{121}$

Das Museum gibt es nicht. ${ }^{122}$ Zur Kategorisierung von Museen wurden die SkalenEnden »Tempel« und »Forum« eingeführt. In diesem Schema steht der »monologischautoritäre Museumstempel « dem »dialogisch-pluralen Museumsforum « gegenüber. ${ }^{123}$ Der >Museumstempek wäre beispielsweise ein Nationalmuseum, in welchem dem Besucher eine vermeintlich objektive, teleologische Erzählung unterbreitet und diese mit Exponaten sowie einer emotional-überwältigenden Szenografie belegt und ausgestaltet wird. Damit verbunden sind zumeist klare Identifikationsangebote und -zuweisungen. Das Forum würde hingegen die eigene Arbeit transparent machen, Objekte und Texte interpretationsoffen darlegen und damit den Besucher zu Kritik bis hin zum eigenen Mitwirken einladen. Hinzu käme der Versuch, verschiedene Perspektiven in die Ausstellung zu integrieren sowie Identitäten als offen bis konstruiert vorzustellen. ${ }^{124}$ Wie sich zeigen wird, ist das (ideale) Forum in der Realität kulturhistorischer Museen weitaus seltener zu finden, als es in der Wissenschaft beschrieben wird. Dennoch können

118 Bal: Kulturanalyse, 2002, S. 116. Muttenthaler; Wonisch: Gesten des Zeigens, 2006, S. 250f. Opalla: Authentisch, und deshalb...?! 2015, S. 68.

119 Thiemeyer: Politik des Zeigens, 2015, S. 18.

120 Vgl. Heinemann: Emotionalisierungsstrategien in historischen Ausstellungen am Beispiel ausgewählter Warschauer Museen, 2011, S. 213f. Siehe auch: Pohl: Der kritische Museumsführer, 2013, S. 241.

121 Vgl. Muttenthaler; Wonisch: Gesten des Zeigens, 2006, S. 21.

122 Vgl. für eine umfangreiche Erörterung weiterer kulturhistorischer Museumstypen: Baur: Was ist ein Museum? 2010, S. 16-19. Siehe auch: te Heesen: Theorien des Museums zur Einführung, 2013, S. 12.

123 Bogumił; Wawrzyniak et al. : Introduction, 2015, S. 5-8. Zechner: Rezension zu: Bogumił, Zuzanna; Wawrzyniak, Joanna; Bucher, Tim u.a.: The Enemy on Display. The Second World War in Eastern European Museums. New York/Oxford 2015, 2017.

124 Vgl. Whitehead; Eckersley et al.: Place, Identity and Migraton and European Museums, 2016, S. 51. Vgl. Schröder: Geschichte ausstellen - Geschichte verstehen, 2013, S. 447, 282f. Vgl. auch: Bogumił; Senina et al.: Conclusions, 2015, S. 149. Siehe für die Vorstellung eines partizipativen Museums: Krüger: Polen, ich komme! 2013, S. 154f. Vgl. Ziebińska-Witek: Historia w muzeach, 2011, S. 284. 
alle Formen von Museen, zum Teil auch ungewollt, eine Plattform zur gesellschaftlichen Aushandlung der Vergangenheit bieten. ${ }^{125}$

Mit diesen Voraussetzungen sowie der gekonnten Auswahl und Zusammenstellung der Objekte, mit szenografischen Inszenierungen, den erklärenden und kommentierenden Begleittexten und der Innen- wie der Außenarchitektur wird die Schaffung eines wirkmächtigen und attraktiven Narrativs ermöglicht. Daraus folgt aber keineswegs zwangsläufig, dass die intendierte Botschaft vom Besucher ohne Abstriche übernommen wird.

Nicht immer offensichtlich ist die Bedeutung der Sammlungen der jeweiligen $\mathrm{Mu}$ seen. Seit wann und mit welchen Mitteln kann das Museum Objekte sammeln? Wo liegen Sammlungsschwerpunkte? Die zentrale Objektauswahl oder die Entscheidung für einen szenografischen Ansatz hängen oft eng mit dem Sammlungsbestand zusammen, ohne dass dies offensichtlich wird. Auch wenn Museen ihre Depots zunehmend für die Öffentlichkeit (temporär) zugänglich machen, bleiben Informationen über die Sammlung dem Ausstellungsbesucher zumeist verschlossen. Dies ist insofern von Bedeutung, als die Sammlung das Narrativ der Ausstellung mitbestimmt.

Die Museumsarbeit gehört zu den international stark vernetzten Tätigkeiten, dennoch sind geographische und kulturelle Unterschiede zu beobachten und zu berücksichtigen. Folglich existiert auch kein mustergültiges Ideal für die Ausstellung und das Museum. Klaus Roth weist darauf hin, dass die unterschiedlichen Entwicklungen der Museumsarbeit im geteilten Europa vor 1989 stark nachwirken. ${ }^{126}$ Für die hier vorgenommenen Untersuchungen spielen derartige >Kulturfragen insofern eine Rolle, als damit auch unterschiedliche Vermittlungsstrategien verbunden sind, die für den späteren Vergleich entsprechend berücksichtigt werden. Ebenso von Relevanz für die Entstehungsgeschichte sowie die Bedingungen des laufenden Betriebes sind die unterschiedlichen nationalen Rechtsgrundlagen und die damit verbundenen stärkeren oder schwächeren politischen Einflüsse.

Aus diesen Erkenntnissen geht bereits hervor, warum Museen für den geschichtspolitischen Diskurs von großem Interesse sind: Da sie über eine große Autorität verfügen, werden Ausgestaltung und Führung dieser Einrichtungen von den geschichts- und gesellschaftspolitischen Akteuren als äußerst wichtig erachtet. ${ }^{127}$ Für die politische Dimension ist von besonderer Bedeutung, dass Museen zumeist Orte »kollektiver Identitätspolitiken« sind, also zentrale Fragen des gesellschaftlichen Zusammenlebens dort behandelt, moderiert oder gar >beantwortet « werden können und dieses von ihnen erwartet wird. ${ }^{128}$ Das kann mit der Konstruktion von »Erinnerungsgemeinschaften« geschehen, also der Zurschaustellung einer gemeinsamen Geschichte, sei es eine regionale,

125 Vgl. Ackermann; Boroffka et al.: Partizipative Erinnerungsräume, 2013, S. 10.

126 Roth: Ausgestellte Differenz, 2012, S. 28.

127 Siehe: Muttenthaler; Wonisch: Cesten des Zeigens, 2006, S. 28. Vgl. Pieper: Resonanzräume, 2010, S. 202.

128 Muttenthaler; Wonisch: Gesten des Zeigens, 2006, S. 14, 18f. Siehe auch: Ackermann: Das Eigene und das Fremde im Museum, 2013, S. 291. 
ethnische, nationale oder eine supranationale europäische - kurz: Im Museum wird eine immanent politische Frage verhandelt. ${ }^{129}$

Dies gilt in besonderem Maße für die Darstellung des Ersten und Zweiten Weltkrieges, die der "politischen Sinnstiftung in der Gegenwart [dient] und [...] deshalb politisch relevant « ist. ${ }^{130}$ Obwohl Museen und Ausstellungen geschichtspolitisch eine zentrale Rolle einnehmen, darf nicht einfach davon ausgegangen werden, dass diese als »mechanistische [...] Identitätsfabriken« in den Händen einiger Akteure wirken können. Obgleich das »Museum eine Institution der Anerkennung und Verhandlung von Identität par excellence « darstellt, ist es eine häufig umkämpfte. ${ }^{131}$ Museen sind also nicht nur Instrumente in erinnerungspolitischen Auseinandersetzungen, sondern zugleich Austragungsorte entsprechender Konflikte und selbstständige Akteure. ${ }^{132}$ Dabei können sie in beide Richtungen wirken: Sie können der Aufarbeitung von Konflikten dienen, diese aber auch weiter befeuern. ${ }^{133}$ Dies gilt für innergesellschaftliche Versöhnungsprozesse, aber auch für die zwischenstaatliche Verständigung. ${ }^{134}$

Verstärkend kommt hinzu, dass Museen kaum offen mit ihren ökonomischen, gesellschaftlichen und politischen Abhängigkeiten umgehen. ${ }^{135}$ Am größten ist der politische Einfluss bei der Genese der Museen, also in der Phase der Finanzierung, des Gründungskonzeptes und der ersten Personalauswahl. ${ }^{136}$ Im Gegensatz zu anderen staatlich legitimierten und finanzierten Institutionen wie beispielsweise den Universitäten gibt es durchaus einen »oftmals explizit formulierten Sinnstiftungsimperativ von Seiten der politischen Sphäre«. ${ }^{137}$ Politiktheoretisch lässt sich das Museum unter Bezugnahme auf Foucault auch als »Disziplinierungsanstalt, die Machtverhältnisse öffentlich abbildet« verstehen. ${ }^{138}$ Dabei kann es »der Beobachtung und Machtausübung dienen « und den »Besucher in seiner Wahrnehmung [lenken und kontrollieren]. ${ }^{139} \mathrm{Te}$ Heesen ist andererseits zuversichtlich, dass mittlerweile

»das Museum [...] zu einem individuellen Deutungsort geworden [ist]. In ihm werden nicht länger der allgemeine Kanon oder die Sicht der Wissenschaft dargestellt, sondern es wird in ihm vielmehr der Anspruch des individuellen Zugangs zu Geschichte und Erinnerung kultiviert. Dies geschieht zum einen in den Ausstellungen selbst,

129 Muttenthaler; Wonisch: Gesten des Zeigens, 2006, S. 42f. Wonisch: Minderheitenmuseen, 2012, S. 43. Siehe auch: Weger: Lokal- und Regionalgeschichte in der deutschen und polnischen Geschichtskultur, 2008, S. 79.

130 Thiemeyer: Fortsetzung des Krieges mit anderen Mitteln, 2010, S. $325 \mathrm{f}$.

131 Baur: Was ist ein Museum? 2010, S. 40.

132 Vgl. Makhotina; Schulze Wessel: Neue Konfliktlinien, 2015, S. 2. Siehe auch: Mittler: Neue Museen - neue Geschichte? 2007, S. 14.

133 Vgl. Bogumił; Senina et al.: Conclusions, 2015, S. 151.

134 Vgl. dazu z.B. den Tagungsband: Bojković; Stolić (Hg.): Muzeji kao mesta pomirenja, 2009.

135 Wonisch: Minderheitenmuseen, 2012, S. 37.

136 Danker: Aufklärung, Identifikation oder Repräsentation? 2006, S. 232.

137 Zechner: Rezension zu: Bogumił, Zuzanna; Wawrzyniak, Joanna; Bucher, Tim u.a.: The Enemy on Display. The Second World War in Eastern European Museums. New York/Oxford 2015, 2017.

138 Thiemeyer: Evidenzmaschine der Erlebnisgesellschaft, 2013, S. 18. Er bezieht sich hier auf Tony Bennett.

139 te Heesen: Theorien des Museums zur Einführung, 2013, S. 74. Te Heesen bezieht sich ebenfalls auf Tony Bennet und Michel Foucault. 
indem diese Deutungsangebote machen, aber keine Darstellung von Wahrheit beanspruchen. ${ }^{140}$

Demgegenüber konstatiert Thiemeyer:

»Das Museum ist eine politische Institution, weil es eine breite Zielgruppe hat, seine Vergangenheitsdeutungen besonders glaubwürdig und, dank der Objekte und Inszenierungen, evident und erinnerungsmächtig sind. Es kann Deutungen der Vergangenheit nahelegen (oder ausschließen), die zu bestimmten Schlüssen für das aktuelle Handeln führen. Es erzeugt historisches Bewusstsein, also das >Bewusstsein der Zugehörigkeit [...] zum historischen Selbstverständnis und zu den historisch erarbeiteten Wertorientierungen von Bezugsgruppen [...] «; und es generiert kollektive Identität $[\ldots] . \ll^{141}$

Es bleibt festzuhalten, dass trotz seiner geläufigen Wahrnehmung als objektiver Instanz das Museum immanenter Teil geschichtspolitischer Aushandlungsprozesse ist. Dabei kann es sowohl moderierend-versöhnend als auch konfliktverschärfend wirken. Inwieweit das Museum tatsächlich in die Gesellschaft hineinwirkt, ist allerdings schwer messbar sowie weitgehend unvorhersehbar. ${ }^{142}$ Mit Sharon Macdonald lässt sich schließen, dass Museen $z \mathrm{Zu}$ Schauplätzen [wurden], an denen einige der strittigsten und schwierigsten Fragen des späten 20. Jahrhunderts ausgefochten wurden. ${ }^{143}$ Es spricht derzeit wenig dafür, dass sich dies im 21. Jahrhundert ändern wird.

Geschichte und Theorie der Institution Museum und der Ausstellung können hier nicht vollständig erörtert werden und wurden bereits an anderer Stelle umfassend dargelegt. ${ }^{144}$ Viele der für die heutigen Entwicklungen im Ausstellungsbereich entscheidenden Grundlagen entstanden in den westlichen Gesellschaften der 1970er-Jahre, als im Zuge gesellschaftlicher Aufbrüche auch die Demokratisierung der Museen gefordert wurde. ${ }^{145}$ Mit der Abkehr von primär akademischen, objektzentrierten und vor allem das Bildungsbürgertum ansprechenden Ausstellungen, ging die Forderung nach mehr Erklärung und Attraktivität einher, um Besuchern aus möglichst allen Schichten ein verständliches und interessantes Angebot machen zu können. So rückte die Inszenierung von Ausstellungen in den Mittelpunkt, also eine ansprechende Aufmachung sowie intensivere Erläuterung historischer Vorgänge und die Erklärung von Objekten. ${ }^{146}$ Diese zunächst auf die westlichen Industrieländer beschränkte Entwicklung

140 te Heesen: Theorien des Museums zur Einführung, 2013, S. 174.

141 Thiemeyer: Politik des Zeigens, 2015, S. $18 \mathrm{f}$.

142 Vgl. Natalie Bayer im Cespräch mit Nora Sternfeld: Museen umprogrammieren, 2016, S. 134.

143 Macdonald: Museen erforschen. Für eine Museumswissenschaft in der Erweiterung, 2010, S. 55.

144 Vgl. für eine knappe Übersicht: Baur: Was ist ein Museum? 2010, S. 24-34. Thiemeyer hält zur politisch-instrumentellen Geschichte des Museums fest: »Die Praxis des Inszenierens ist so alt wie das Museum. Schon die frühen Schatz-, Kunst- und Wunderkammern präsentierten Objekte so im Raum, dass sie Deutungen nahelegten und Ordnungen visualisierten.«Thiemeyer: Inszenierung, 2015, S. 48.

145 Vgl. Muttenthaler; Wonisch: Gesten des Zeigens, 2006, S. 14, $16 \mathrm{f}$.

146 Thiemeyer: Inszenierung, 2015, S. 46, 53. 
setzte sich nach 1989 auch in den ehemaligen Staaten des Warschauer Paktes durch, auch wenn nationale und regionale Unterschiede bestehen bleiben.

Im Zuge dieser Prozesse gewann die Alltagsgeschichte für das Museum an Bedeutung. Dies zeigt sich in der zunehmenden Aufnahme von seinfachen Alltagsobjekten und der Präsentation von >Unterschichten sowie an einer generell wachsenden Thematisierung von bis dahin vernachlässigten Themen wie der Geschichte von Arbeit, Geschlecht oder Migration. ${ }^{147}$ Thiemeyer konstatiert, dass hierbei zunehmend auf die sich entwickelnde »Erlebnisgesellschaft « zugegangen werden muss(te), also »Dramaturgie und Unterhaltung« an Bedeutung gewannen und gewinnen, um den Anspruch einzulösen, breite Bevölkerungsgruppen zu erreichen. ${ }^{148}$ In diesem Zusammenhang spricht er von Museen als »manufacturer of experience[s]«, als »Erlebnisfabrik«, in denen das klassische Museumsexponat gegebenenfalls nur noch eine untergeordnete Rolle unter vielen anderen Darstellungsformen hat(te). ${ }^{149}$ In den letzten Jahren ist dennoch eine neue Konjunktur des historischen Objekts in Ausstellungen zu beobachten, wobei dieses nicht mehr als Teil eines festen enzyklopädischen Wissenskanons, sondern als bis zu einem gewissen Grad deutungsoffenes »Zeichen« oder als »Spur« historischer Vorgänge verstanden werden soll. ${ }^{150}$

Heute lässt sich eine große Bandbreite der Darstellungsweisen in historischen Ausstellungen beobachten. Die Spannweite reicht von >klassisch zu primär multimedialen oder multimedial-szenografischen Ausstellungen oder den eben genannten verbindenden Ansätzen. Hinter der Entscheidung, wie eine Ausstellung letztlich gestaltet wird, steht neben historischen Entwicklungen und ressourcentechnischen Möglichkeiten auch die Frage nach der zu erreichenden Zielgruppe. Sollen beispielsweise erneut das Bildungsbürgertum, ein stark politisiertes Publikum, internationale Gäste angesprochen werden oder soll ein besonders attraktives Angebot für jüngere Besucher entwickelt werden? In Kombination mit weiteren Zielsetzungen einer Ausstellung muss dies bei ihrer Untersuchung und Bewertung herausgefunden und berücksichtigt werden. ${ }^{151}$

Nach dieser allgemeinen Erläuterung kann das kulturhistorische Museum in Hinblick auf die in der vorliegenden Untersuchung behandelten Einrichtungen noch einmal schematisch in fünf Typen untergliedert werden: das Nationalmuseum, das Regionalund in einer weiteren Abstufung das Lokalmuseum, das Minderheitenmuseum, das thematische Geschichtsmuseum, das »Memory Museum « und Sonderformen wie etwa Wander- und Online-Museen.

147 Thiemeyer: Inszenierung, 2015, S. 46.

148 Ebd., S. 53. Bei dem Begriff »Erlebnisgesellschaft« bezieht Thiemeyer sich auf Gerhard Schulze. Pomian weist in seinem knappen Abriss über die Kriterien eines erfolgreichen Museums der Gegenwart auf die gewachsene ökonomische Bedeutung für das regionale und nationale Marketing hin, welche nicht nur ein Zugehen auf den Besucher in Hinblick auf attraktive, moderne Darstellungsformen erfordert, sondern auch die Aufgabe von Kuratoren zunehmend in den Managementbereich verlagert: Pomian: Muzeum: Kryteria sukcesu, 2009.

149 Thiemeyer: Die Sprache der Dinge, 2011, S. $7 f$.

150 Vgl. Hoffmann: Spur. Vorstellung. Ausstellung, 2000, S. 169.

151 Muttenthaler; Wonisch: Gesten des Zeigens, 2006, S. 56. 
Die vorliegende Untersuchung behandelt kein so benanntes Nationalmuseum, allerdings lässt sich das Haus der Europäischen Geschichte durchaus als ein solches bezeichnen. Freilich ist es kein klassisches Nationalmuseum, wobei es durchaus Elemente desselben, wie einen teleologischen Staats- oder Volksbildungsprozess zeigt, vor allem im Bereich nach 1945, in dem es die zunehmende Institutionalisierung der EU darstellt und nach einer gemeinsamen europäischen Identität sucht. ${ }^{152}$

Mit Regionalmuseen und ihren kulturhistorischen Ausstellungen können unterschiedliche Ziele verfolgt werden: Schaffung oder Förderung regionaler Identitäten oder die Betonung der Zugehörigkeit zum Nationalstaat sowie neuerdings die Präsentation als reuropäische Region‘. Hierzu gehören das Muzeum Śląskie in Kattowitz sowie - eingeschränkt - das Schlesische Museum in Görlitz und das Sudetendeutsche Museum in München, die beide sowohl Museen einer historischen Region sind, aber gleichzeitig auch einer bestimmten $>$ Volksgruppe $<.{ }^{153}$

Hier besteht eine Brücke zum modernen Minderheitenmuseum. Diese Museen sind zumeist als Teil der Forderungen bis dato marginalisierter Gruppen zu verstehen, die sich seit den 1960er Jahren zunehmend ihren Platz im Museum erstritten haben. $\mathrm{Zu}$ unterscheiden ist zwischen Museen, die an (weitgehend) verschwundene Minderheiten erinnern und solche, die eine aktive Minderheit präsentieren und in denen diese ein Mitspracherecht besitzt. Eine grundsätzliche Kritik an diesen Institutionen besteht darin, dass es zum einen zu einer verstärkten Ethnisierung und Klassifizierung als `Externe und damit einer Überbetonung von Differenz bei gleichzeitig gewünschter gesteigerter Anerkennung durch die >Mehrheitsgesellschaft kommen oder aber eine Vereinnahmung durch die snationale oder eine suniversalistische Sache erfolgen kann. ${ }^{154}$

Den bisher aufgeführten ist noch die Kategorie des kulturhistorischen Themenmuseums hinzuzufügen, also einer Institution, die sich einem bestimmten historischen Thema, jenseits oder in Kombination von Region, Minderheit und vor allem Nation aus einer bestimmten, zum Beispiel regionalen oder europäischen Perspektive, widmet. Hier sind das Museum des Zweiten Weltkrieges in Danzig und die Stiftung Flucht, Vertreibung, Versöhnung einzuordnen, die den Zweiten Weltkrieg aus globaler, respektive Zwangsmigration im Europa des 20. Jahrhunderts aus europäischer Perspektive zeigen. ${ }^{155}$

Zunehmend tritt eine hybride Form von Museum und Gedenkstätte auf, die sogenannten »Memory Museums $« .{ }^{156}$ Eine emotionale Ansprache wird in diesen nicht hinter einer vermeintlich sachlichen Ausstellung sversteckt‘, sondern der Besucher wird

152 Vgl. Baur: Was ist ein Museum? 2010, S. 17. Vgl. Morat; Zündorf: Ceschichtspolitik im Museum, 2019.

153 Vgl. Henkel; Scheele et al.: Lokalität als Thema, 2016, S. 107-113.

154 Vgl. Roth: Ausgestellte Differenz, 2012, S. 26. Vgl. für Vor- und Nachteile des Minderheitenmuseums: Wonisch: Minderheitenmuseen, 2012, S. 42-45. Siehe für die Gefahr der Überbetonung von Differenz und der damit möglicherweise verbundenen Steigerung gesellschaftlicher Spannung: Ackermann: Angewandte Kulturwissenschaften, 2013, S. 281, 284.

155 Vgl. Baur: Was ist ein Museum? 2010, S. 17.

156 Vgl. Schröder: Geschichte ausstellen - Geschichte verstehen, 2013, S. 103-106. Siehe auch: Echternkamp; Jaeger: Representing the Second World War, 2019, S. 4. 
mit den aus Gedenkstätten bekannten Mitteln angesprochen. Dies findet sich vor allem bei tragischen Themen, beispielsweise dem Ausstellungsteil zum Holocaust in jüdischen Museen oder im Museum des Warschauer Aufstandes in Warschau, in dem die Aufforderung zur heroischen Erinnerung ziemlich explizit ist. ${ }^{157}$ Diese »emotionalisierende Formsprache« soll die Besucher zusätzlich zur Vermittlung historischer Inhalte ansprechen und von bestimmten Narrativen überzeugen. ${ }^{158}$ Eine trennscharfe Definition ist nicht immer möglich, und so enthalten das Museum des Zweiten Weltkrieges sowie die Konzeption der Stiftung Flucht, Vertreibung, Versöhnung ebenfalls Elemente eines memory museum.

Weiterhin gibt es zahlreiche Varianten und Formen des kulturhistorischen Museums vom Wander- bis zum Onlinemuseum. Bereits jetzt expandieren die Museen in den Bereich der sozialen Medien, in den Stadtraum (beispielsweise via App) sowie in den Bereich digitaler Ausstellungen, die für ein weltweites Publikum barrierefrei zugänglich sind. ${ }^{159}$ Das Museum des Zweiten Weltkrieges in Danzig hat damit bereits begonnen. Das Haus der Europäischen Geschichte verzichtet ganz auf angebrachte Objektbeschreibungen und Informationstexte und stattet den Besucher mit einem Tablet aus, auf dem die Texte angezeigt werden. ${ }^{160}$

Für die Rezeption des Museums und der Ausstellung sind auch deren Architektur und Umgebung von Bedeutung. ${ }^{161}$ Das Gebäude, ob speziell für ein Museum errichtet (Danzig) oder mit langer Geschichte und baulich-gestalterisch umfangreich angepasst (Kattowitz), hat ebenso Einfluss wie dessen Umgebung: Erreiche ich das Museum nach einem Weg durch Industrieruinen und Hafenanlagen (Danzig) oder befindet es sich in einer lebhaften Innenstadt (Berlin)? Handelt es sich um ein Gebäude am authentischen Ort? Wie interagiert es mit der Umgebung? Die Museumsarchitektur versucht auf diese Fragen kreativ einzugehen - sie muss daher bei der Analyse berücksichtigt werden. So kann das spezifisch für die Ausstellung geschaffene Museumsgebäude oft selbst als Exponat betrachtet werden. Von den äußeren Formen abgesehen, spielt die Innenarchitektur, die zum Teil fließend in die Ausstellungsgestaltung übergeht, eine zentrale Rolle. Bei dieser wird die »Leserichtung« des Besuchers bereits durch die Innenarchitektur bestimmt: Sie kann den Besucher stark lenken oder ihm im Gegenteil weitgehende Richtungs- und Bewegungsfreiheit lassen. ${ }^{162}$

Die Ausstellung im Museum Machart, Ziele und Aufgaben von Ausstellungen können stark variieren und tun dies jenseits ihrer konkreten Inhalte mit unterschiedlichen Mitteln.

157 Pieper: Resonanzräume, 2010, S. $189 f$.

158 Makhotina; Schulze Wessel: Neue Konfliktlinien, 2015, S. 9.

159 Muttenthaler und Wonisch (Muttenthaler; Wonisch: Gesten des Zeigens, 2006, S. 252) argumentieren für die Einzigartigkeit des Museums, welches mit seiner Ortsgebundenheit und seinem speziellen räumlichen Charakter über besondere Vorzüge verfügt. Diese Äußerung muss aber in Zeiten der Digitalisierung relativiert werden.

160 Vgl. für gegenwärtige Tendenzen der Digitalisierung im Museum, v.a. in Hinblick auf die Möglichkeit des Dialoges zwischen Museum und Besucher: Gorgus: All these (museum-)communities, 2015, S. 125-137.

161 Vgl. Muttenthaler; Wonisch: Gesten des Zeigens, 2006, S. 41.

162 Buschmann: Geschichte im Raum, 2010, S. 165. Vgl. Janeke: Zeitgeschichte in Museen, 2011, S. 11. 
Soll zu einem bisherigen Narrativ - klassischerweise einer nationalen Meistererzählung - eine Ausstellung geboten werden, die dieses bestätigt und veranschaulicht? Soll etwas Neues gezeigt oder eine Debatte angestoßen werden? Hierbei sind die zumeist für zehn bis zwanzig Jahre angelegten Dauerausstellungen von den oft jährlich mehrfach wechselnden temporären Ausstellungen zu unterscheiden. ${ }^{163}$ Gerade bei tagespolitisch aktuellen Themen ist die Haltbarkeit eines bestimmten Narrativs häufig begrenzt. Wichtig ist also, die Ziele einer Ausstellung zu ermitteln, auch wenn diese nicht immer offenbar sind. Hinter den verschiedenen Zielen verbirgt sich meist ein unterschiedliches Besucherbild. Geht es um die überzeugende Darstellung eines vermeintlich objektiven Sachverhaltes oder werden dem Besucher Interpretationsangebote unterbreitet? ${ }^{164}$ Die Frage des Ausstellungsdesigns lässt so zugleich Rückschlüsse auf die politische Interpretation des Dargestellten zu. ${ }^{165}$ Nicht außer Acht zu lassen sind schließlich auch die angesprochenen kulturellen Differenzen in der Gestaltung, die ein transnationales Verstehen unter Umständen erschweren können. ${ }^{166}$

Gelegentlich wird die grundsätzliche Frage gestellt, ob Geschichte und vor allem ihr Kern, die »Prozesshaftigkeit«, überhaupt ausgestellt werden kann, »[...] ob komplexe Verläufe über Objekte, also statische Elemente, wirklich eingefangen werden können. $\ll^{167}$ Ähnlich argumentiert Sharon Macdonald mit ihrer Aussage, dass kulturhistorische Ausstellungen grundsätzlich wesentlich mehr über die Gegenwart als über die Vergangenheit aussagen. ${ }^{168}$ Als Ort des Lernens über oder von der Geschichte wären sie damit nur bedingt geeignet. Etwas optimistischer formuliert kann gesagt werden, dass eine gute Ausstellung Bildungsprozesse ermöglicht, was aber kein Automatismus ist. ${ }^{169}$ Nach Nicola Lepp liegt in der Annahme dieser Herausforderung eine besondere Chance kuratorischen Arbeitens:

»Und hier, in diesem Zwischenraum zwischen der Sprachlosigkeit und Bedeutungsoffenheit der Dinge und der Bezeichnungsmacht der Worte liegt - so meine These - das besondere Erkenntnispotenzial des Mediums Ausstellung begründet. Kuratorisches Arbeiten bedeutet, diesen Zwischenraum als Möglichkeitsraum zu begreifen, in dem Erkenntnisse erst generiert werden, neues Wissen allererst ermittelt wird. « ${ }^{170}$

Weitergedacht kann die Anerkennung der Ausstellung als ein in vielerlei Hinsicht subjektives Medium dazu führen, die Ausstellung selbst zur Verhandlung zu stellen und so eine multiperspektivische und offene Diskussion - und damit Lernprozesse - $\mathrm{zu}$ ermöglichen. ${ }^{171}$

Sowohl innerhalb der Institution Museum selbst als auch in der Wissenschaft wird gefordert und zunehmend reflektiert, dass die eigene Arbeit transparent(er) gemacht

163 Muttenthaler; Wonisch: Cesten des Zeigens, 2006, S. 20.

164 Ebd., S. 24.

165 Zabłocka-Kos: Więcej intelektu, mniej emocji/More Intellect, Less Emotion, 2013, S. 96.

166 So Zabłocka-Kos am Beispiel von polnischem und deutschem Ausstellungsdesign: ebd., S. 98.

167 Weiss: »Wir wollen nicht mehr den Standpunkt des Historikers«, 2006, S. 233. Weiss bezieht sich hier auf Hugo Borger.

168 Bogumił; Wawrzyniak et al.: Introduction, 2015, S. 11f.

169 Lepp: Ungewissheiten - Wissens(v)ermittlung im Medium Ausstellung, 2012, S. 65.

170 Ebd., S. 63.

171 Boroffka: Kulturelle Bildung und besucherorientierte Vermittlung, 2013, S. $43 f$. 
werden sollte. Damit würde dem Besucher auch vermittelt, dass in einer Ausstellung keine zeitlos gültigen Wahrheiten präsentiert werden, sondern es sich um eine Konstruktionsleistung handelt, die von konkreten Akteuren mit ihren spezifischen Hintergründen und Arbeitsweisen geschaffen wurde. Diese Darlegung, zum Beispiel am Beginn einer Ausstellung, ist aber weiterhin die Ausnahme. ${ }^{172}$ Eine selten genutzte Möglichkeit ist es, auch Forschungskontroversen in einer Ausstellung zu thematisieren. ${ }^{173}$ Hierauf und generell in Bezug auf einen offenen und reflektierten Ausstellungsansatz wird häufig eingewendet, dass dies die Besucher überfordere und diese das auch nicht wünschten. ${ }^{174}$ Diesem Einwand kann entgegengesetzt werden, dass es bei der Erschaffung einer Ausstellung nicht darum geht, ein begehbares Buch mit >Fußnoten $<\mathrm{zu}$ schaffen, sondern darum, wissenschaftliche Diskussionen - im besten Fall anhand von Objekten - anzudeuten. Allein die Botschaft, dass es dazu relevante, unterschiedliche Positionen gibt, könnte den Besucher die gesamte Ausstellung reflektierter betrachten lassen. ${ }^{175}$ Dies gilt auch, wenn man anerkennt, dass die in Museen erzählte Geschichte »Verkürzungen oder Vereinfachungen « kaum vermeiden kann. ${ }^{176}$ Schließlich ist festzuhalten, dass kulturhistorische Museen und ihre Ausstellungen stets sinnlich und wissenschaftlich operieren und folglich in der Konsequenz nie beiden Seiten abschließend gerecht werden können. ${ }^{177}$ Muttenthaler und Wonisch plädieren in Anlehnung an Irit Rogoff dafür, das Museum als »selbstreflexive Institution« zu verstehen, die ihre Arbeit und Hintergründe offenlegt und einem mündigen Besucher »Deutungsangebote« unterbreitet. ${ }^{178}$ Diese Herangehensweise erfordert gleichwohl Mut und politischen Spielraum für die Museumsmacher. ${ }^{179}$

Die Art der Informationsvermittlung einer Ausstellung ist folglich von zentraler Bedeutung, ebenso wie die transportierten und in dieser entwickelten Inhalte selbst. Die Vermittlung findet in Ausstellungen als »synästhetische Geschichtsdarstellung« statt,

»die mit mehreren Sinnen aufgenommen werden und ihre Wirkung zu einem guten Teil im unbewussten Bereich der ästhetischen Wahrnehmung entfalten, wenn der Betrachter Atmosphären spürt und intuitiv Zusammenhänge erkennt, die er nur schwer oder gar nicht verbalisieren kann. Das Museum operiert weniger mit der argumentativen Logik des Textes (sagen), sondern folgt der visuellen Logik der Evidenz (zeigen). $\aleph^{180}$

172 Vgl. Muttenthaler; Wonisch: Gesten des Zeigens, 2006, S. 24.

$173 \mathrm{Vgl}$. für die entsprechende Forderung, Kontroversität der (nicht nur wissenschaftlichen) Meinung zuzulassen: Pohl: Wann ist ein Museum »historisch korrekt«? 2006, S. 282.

174 Schärer plädiert ganz im Gegenteil dazu, dass auch intellektuell fordernde Ausstellungsinhalte mit einem attraktiven Design erfolgreich umgesetzt werden können: Schärer: National Museums - Difficulties and Possibilities, 2012, S. $39 f$.

175 Vgl. hierfür, aus einem anderen Bereich, aber dennoch treffend: »Umstrittene Forschungsfragen, wie zum Beispiel die Diskussion über Wesen und Ursprung der Kogge, werden prägnant angerissen.«Kypta: Rezension zu: Europäisches Hansemuseum, 28.05.2015 Lübeck, 2016.

176 Logemann: Die entstehende Dauerausstellung des Museums des Zweiten Weltkrieges in Danzig, 2012, S. 130. Vgl. Kula: Muzeum opowie o historii, 2017, S. 103.

177 Thiemeyer: Die Sprache der Dinge, 2011, S. 5.

178 Muttenthaler; Wonisch: Cesten des Zeigens, 2006, S. 253.

179 Vgl. Thiemeyer: Fortsetzung des Krieges mit anderen Mitteln, 2010, S. 319.

180 Thiemeyer: Politik des Zeigens, 2015, S. 16. 
Ein Beispiel sind Differenzkategorien, in denen beispielsweise in ethnologischen oder Nationalmuseen durch die zumeist vorgenommene Konstruktion von wir und sie Differenz geschaffen wird. Diese kann absichtlich oder unabsichtlich zu einer verringerten Empathie führen, besonders wenn die Darstellung des Anderen verzerrt, einseitig oder entkontextualisiert ist, eine Problemstellung, mit der die Regionalmuseen, die mit einer (historisch) großen ethnischen Differenz zu tun haben, kämpfen müssen. ${ }^{181}$ Grundsätzlich scheint eine Selbstdefinition die Definition eines Anderen zu benötigen:

»Weiße brauchen Schwarze, um sich selbst als weiß zu definieren, Männlichkeit braucht Weiblichkeit, um sich als männlich zu konstituieren etc. Bestimmte gesellschaftliche Gruppen oder Kulturen wurden von Repräsentationspraktiken entweder ausgeschlossen oder als Andere markiert, wie beispielsweise außereuropäische Kulturen in den Völkerkundemuseen $[. .]$. « $^{182}$

Interessant für die hier verfolgten Fragen ist, wie absolut beispielsweise nationale $\mathrm{Zu}$ gehörigkeiten in den Museen behandelt werden (sollen) und ob Platz für die Darstellung hybrider Identitäten ist. ${ }^{183}$

Die Museumsdidaktik hat sich seit einigen Jahrzehnten in den meisten Museen fest etabliert und versteht sich nicht als fakultatives Plus, sondern als zentrales Element des modernen Museums. ${ }^{184}$ In ihrem Anspruch hat sie im Idealfall Einfluss auf alle Elemente der Ausstellung, das heißt sie begleitet bereits deren Entstehungsprozess aus museumsdidaktischer Perspektive und entwickelt kooperativ ein entsprechend attraktives Besucherprogramm, um das Lernen im Museum zu ermöglichen. Lernen wird dabei als »individueller Vorgang der aktiven Wissenskonstruktion verstanden. ${ }^{185}$ Die museumsdidaktische Forschung hat bereits vielerlei Erkenntnisse gewonnen, beispielsweise dass es eine wichtige Bedingung für Lernprozesse ist, wenn die Besucher neu erworbenes Wissen mit bereits vorhandenen Kenntnissen verbinden können. Anderenfalls findet Lernen grundsätzlich nicht statt. ${ }^{186}$ Hinzu kommt, dass neu gewonnene Erkenntnisse für »den Lernenden anwendbar sein [...] bzw. sich auf den eigenen Lebenskontext übertragen lassen « sollten, um eine Lernwirkung zu erzielen. ${ }^{187}$ Dies schränkt bereits die Vorstellungen vieler Kuratoren, komplexe historische Sachverhalte an das breite $\mathrm{Pu}$ blikum vermitteln zu können, erheblich ein. Durchschnittliche Besucher werden

»in der Regel nicht allein die vom Kurator intendierte Narration [rezipieren] - sofern ihnen diese überhaupt deutlich wird - sondern überlagern sie mit eigenen Assoziatio-

Vgl. Bal: Kulturanalyse, 2002, S. 94. Siehe auch: Ackermann: Das Eigene und das Fremde im Museum, 2013, S. 277f.

182 Muttenthaler; Wonisch: Cesten des Zeigens, 2006, S. 14.

183 Ebd., S. 25. Die beiden Autorinnen warnen davor, dass nationale Eindeutigkeiten/alte Nationalismen heute hinter »kulturellen Identitäten « versteckt und damit weiter ausgrenzend wirken können (S. 27). Vgl. Macdonald: Nationale, postnationale, transkulturelle Identitäten und das Museum, 2000, S. 141.

184 Vgl. Grünewald Steiger: Information-Wissen-Bildung: Das Museum als Lernort, 2016, S. 278-282.

185 Boroffka: Kulturelle Bildung und besucherorientierte Vermittlung, 2013, S. $41 \mathrm{f}$.

186 Ebd.

187 Ebd. 
nen und Deutungen. Damit kreieren die Besucher eigenständig neue Sinnzusammenhänge, die jeweils individuelle Lebensweltbezüge und eine Verknüpfung mit ihrem eigenen Wissen zulassen. ${ }^{188}$

Forderungen nach differenzierter Multiperspektivität, tiefgehender kritischer Reflektion und ",dekonstruierende[r]< Rezeptionsgeschichte " von Exponaten werden daher gelegentlich als weitgehend unrealistisch, da den Besucher überfordernd, bewertet. ${ }^{189}$ Hinzu kommt, dass nach Joachim Rohlfes die meisten Besucher im Museum primär unterhalten werden wollen und »wirkliche, längerfristige Lernanstrengungen « von den wenigsten unternommen werden. ${ }^{190}$ Ähnlich kritisch argumentiert auch Volker Kirchberg in Bezug auf die Grenzen der Museumsdidaktik:

»Ausstellungen können nur vorhandene Einstellungen bekräftigen und in die schon vom Besucher gewünschte Richtung erweitern [...], was Treinens Aussage bestätigt: >Museen als Lernorte sind eine irrige Annahme.< Museumsbesuche seien durch >aktives Dösen ‘gekennzeichnet [...]. [...] Anders als die Lern- und Lehrsituation in Schulen ist der Ausstellungsbesuch in keiner Weise eine pädagogisch beeinflussbare Situation. «191

Zwischen diesen äußerst kritischen Positionen und den realistisch $\mathrm{zu}$ erwartenden Möglichkeiten der Vermittlung versucht die Museumsdidaktik, Lernerfolge zu erzielen und im Idealfall schon früh auf die Ausstellungsgestaltung einzuwirken. Eine ergänzende und damit kombinierbare Möglichkeit ist es, mit allen Mitteln der Museumsgestaltung den Besuchern durch eine anregende Präsentation Unterhaltung und Wissensgewinn zu ermöglichen. Zudem sind hier Ausstellungsführungen außer Acht gelassen, die sowohl in positiver wie negativer Hinsicht erheblichen Einfluss auf die Ausstellungsrezeption haben können.

Der Einsatz unterschiedlichster Medien und Techniken im historischen Museum ist mittlerweile stark angewachsen. Vier Oberkategorien lassen sich fassen: (1) das Originalobjekt, (2) Kunst als Intervention (in Abgrenzung $\mathrm{zu}$ den seigentlichen Objekten), (3) Video- und Audiomaterial sowie (4) die architektonisch-räumliche Gestaltung der Ausstellung. Bei der Anwendung dieser Medien ist zu differenzieren, ob diese der Präsentation von Ausstellungsobjekten wie historischen Fotografien, Filmen oder Zeitzeugenaufnahmen dienen oder ob sie zum Beispiel in Form von speziell für das Museum gedrehten Filmaufnahmen oder spielerischen Programmen selbstreferentiell sind.

Die für die moderne Ausstellungsgestaltung zentralen Begriffe von Inszenierung und Szenografie scheinen zunächst schwer voneinander abgrenzbar zu sein. Ausstellungen waren immer schon Inszenierungen. In Erweiterung dessen kann bei modernen Ausstellungen, die auf einer ausgeklügelten Dramaturgie mit Spannungselementen und Plotstruktur (durchaus analog zu Literatur und Film) basieren, von Szenogra-

188 Boroffka: Kulturelle Bildung und besucherorientierte Vermittlung, 2013, S. $41 f$.

189 Rohlfes: Eine bilanzierende Einführung, 2006, S. 17, 19.

190 Ebd., S. 19.

191 Kirchberg: Besucherforschung in Museen: Evaluation von Ausstellungen, 2010, S. 175. Kirchberg bezieht sich hier auf Heiner Treinen. 
fie gesprochen werden. ${ }^{192}$ Diese Entwicklung ging maßgeblich von den weltweit anerkannten Häusern des US Holocaust Memorial Museums und dem Yad Vashem - The World Holocaust Remembrance Center aus und erfreut sich besonders in der polnischen Museumslandschaft einer großen Popularität. ${ }^{193}$

Der zunehmende Einsatz von Innendesign, Kunst und der Arbeit von Bühnenbildnern in Ausstellungen gewann bereits seit den 1980er Jahren an Bedeutung. ${ }^{194}$ Die Herkunft aus dem Bereich des Theaters lässt es angemessen erscheinen, von Inszenierungen zu sprechen. ${ }^{195}$ Damit wird der Transport historischer Narrative in Ausstellungen als »die szenische Umsetzung eines dramatischen Werks [bezeichnet], um es zur Anschauung zu bringen « und so »erlebbar « zu machen. ${ }^{196}$ Thiemeyer definiert Inszenierung primär technisch und performativ:

»Inszenierungen sind Strategien, die in einer Ausstellung Exponate mithilfe von Ausstellungsmobiliar, audiovisuellen und atmosphärischen Medien (Licht, Töne) räumlich in Szene setzen, um Deutungen nahezulegen und Objekteigenschaften und -bedeutungen sinnlich erfahrbar zu machen. Sie sind mehr als die Summe ihrer Teile, nur partiell zu verstehen oder in Begriffe zu übersetzen, sondern vor allem erlebbar. ${ }^{197}$

Eine Erweiterung des Inszenierungsbegriffs liegt im Begriff der Szenografie: In Abkehr von der nüchternen Objektausstellung der 1990er und 2000er stellt Thiemeyer fest, dass beim Siegeszug neuer audiovisueller Techniken der Terminus Inszenierung nicht mehr ausreicht. Gleichwohl ist dieser Begriff für den Bereich der Museumswissenschaft noch nicht ausdefiniert und wird recht flexibel verwendet. Er soll hier in Abgrenzung zur Inszenierung für Ausstellungen oder Ausstellungsbereiche verwendet werden, die primär über audiovisuelle Techniken funktionieren oder die klassischen Museumsexponate gleichwertig mit diesen zeigen. Dazu gehört gegebenenfalls der in die Inszenierung integrierte Raum der Ausstellung. Pointiert formuliert kann man in Bezug auf szenografische Museen sagen:

»Primäres Ziel ist es, Ereignisse zu erzeugen. Objekte werden nur genutzt, wo sie diesem Ziel dienen. War es einst einziger Zweck des Museums, Objekte zu sammeln und auszustellen, so ist das Exponat jetzt bestenfalls eines von mehreren Mitteln, mit denen ein Museum sein Publikum unterhalten kann. Maßgeblich für die Präsentation ist nicht, was sich mit den überlieferten Dingen aus den Sammlungen machen lässt, sondern die übergreifende Cestaltungsidee, der sich alles unterordnet. ${ }^{198}$

Diese Entwicklung ist nicht unwidersprochen geblieben: Gegen szenografisch gestaltete Ausstellungen oder bestimmte Formen von diesen werden verschiedentlich Einwände

192 Schröder: Geschichte ausstellen - Geschichte verstehen, 2013, S. 47.

193 Thiemeyer: Politik des Zeigens, 2015, S. $25 f$.

194 Hoffmann: Spur. Vorstellung. Ausstellung, 2000, S. 180.

195 Thiemeyer: Inszenierung, 2015, S. 50.

196 Ebd., S. 46.

197 Ebd., S. 56.

198 Ebd., S. 59-61. 
und notwendig zu berücksichtigende Punkte genannt; so zunächst der Einspruch gegenüber der durchaus erwünschten Illusion, dass »Kulissen oder Inszenierungen Vergangenheit [realistisch] lebendig machen«, obwohl es sich bei Ausstellungen um eine Form von Geschichtskonstruktion handelt. Diese zielt nicht auf die Wiederherstellung historischen Geschehens ab, sondern auf die Erzählung einer neuen Geschichte mit Material aus der Vergangenheit. ${ }^{199}$ Joachim Baur weist darauf hin, dass inszenatorischszenografische Ansätze heute nicht mehr verpönt und entsprechende Auseinandersetzungen weitgehend beendet seien - und sich die Szenografie in Kulturmuseen »als ein Format unter anderen fest etabliert « habe. ${ }^{200}$ Die Vorzüge beschreibt er wie folgt:

»Inszenatorisch-szenografische Ansätze können die Dinge in ungewohntem Zusammenhang und deutungsleitenden Raumbildern zur Wirkung, zu ihren Möglichkeiten bringen. Sie können >die Phantasie und die Kombinationslust der Besucher stimulieren<, >Leichtigkeit und eine unverkrampfte Haltung`vermitteln und sals Strategie gegen Ermüdung, Langeweile und Überforderung des Ausstellungsbesuchers nen [...]. Nicht zuletzt können sie in besonderem Maße und auf besondere Weise komplexe, objektarme und simmaterielle< Themen anschaulich machen [...]. ${ }^{201}$

Als Konsens hat sich in der Museumsszene besonders des deutschsprachigen Raumes das sogenannte »Überwältigungsverbot « durchgesetzt, was bedeutet, dass der Besucher durch die Inszenierung der Ausstellung nicht so stark emotional angesprochen werden soll, dass seine persönliche und intellektuelle Distanz verloren geht. ${ }^{202}$ Dies ist ein Grundsatz, der in primär szenografischen Ausstellungen nicht - oder nicht in dem Maße - verfolgt wird. Schwierig ist hier eine Trennung insbesondere bei den erwähnten memory museums. Beispielhaft zeigt sich das beim Museum des Warschauer Aufstandes, wo unter anderem ein eindringliches »Herzschlag-Geräusch « zu hören ist, das als Symbol für das Leben und Sterben der Stadt Warschau gedeutet werden kann. ${ }^{203}$ Auch bei Ausstellungen, die sich einem politischen Ziel verpflichtet fühlen, hier der Ächtung von Zwangsmigrationen in der Gegenwart, ist eine emotionale Ansprache zu erwarten. Eine zu starke Szenografie birgt zudem die Gefahr, dass »historische Ereignisse und deren Interpretationen zu einer für den Besucher kaum differenzierbaren Einheit « werden. ${ }^{204}$

Ein Ausstellungselement können auch Video- oder Tonaufnahmen von Zeitzeugen sein. Deren Einsatz dient zumeist weniger der inhaltlichen Vermittlung als dazu, das

199 Thiemeyer: Geschichtswissenschaft: Das Museum als Quelle, 2010, S. 74. Siehe auch: Thiemeyer: Inszenierung, 2015, S. 61.

200 Baur: Mit Räumen sichtbar machen, 2016, S. 265. Vertreter des szenografischen Museums gehen dabei davon aus, dass nur durch Heranziehung einer »gegenwärtigen visuellen Sprache « und einer »konsistenten szenografischen Handschrift« ein »zeitgemäßes Museum« gewährleistet ist: Brückner; Creci: Das Museum als komplexer Erfahrungsraum, 2015, S. 103.

201 Baur: Mit Räumen sichtbar machen, 2016, S. 265.

202 Vgl. Pohl: Wann ist ein Museum »historisch korrekt«? 2006, S. 285. Siehe zum »Beutelsbacher Konsens«, dessen entsprechender Ansatz des Überwältigungsverbotes für die Schulbildung auch für die meisten deutschen Museen maßgeblich ist: Bundeszentrale für politische Bildung: Beutelsbacher Konsens, 2011.

203 Vgl. Peters: Polens Streitgeschichte kommt ins Museum, 2015.

204 Heinemann: Emotionalisierungsstrategien in historischen Ausstellungen am Beispiel ausgewählter Warschauer Museen, 2011, S. 234. 
Geschehen beispielhaft und emotional (besser) greifbar darzustellen. Thiemeyer weist in Bezug auf den Einsatz von Zeitzeugen in Kriegsausstellungen darauf hin, dass dieser »Empathie« fordernde und »Sympathie« fördernde Ansatz der »selektiven, fragmentarischen und weniger kritischen« Zeitzeugenerzählungen in ein »Spannungsfeld von gefühlter Geschichte und moralischem Appell« führe. ${ }^{205}$

Abgesehen von den selbst gesetzten Beschränkungen ist das Zeigen im Museum grundsätzlich beschränkt. Nach Thiemeyer können Themen wie Krieg und Gewalt in ihrer chaotischen Realität und ihrem emotionalen, persönlichen Erleben nicht tatsächlich gefasst und ausgestellt werden - zumal jede Ausstellung zwangsläufig in irgendeiner Form ordnet und arrangiert, damit das Geschehen ahistorisch einhegt und sich so entscheidende Teile der Darstellung entziehen. Damit ist sie in einem Spannungsfeld gefangen: »Zeigen bedeutet Verharmlosung, nicht zeigen heißt vergessen. «ine Annäherung an das historische Geschehen ist aber möglich und die Ausstellung dafür auch im Vergleich $\mathrm{zu}$ anderen Medien ein geeigneter Ort. ${ }^{206}$

Schließlich können unterschiedliche Ausstellungstypen - jenseits der angesprochenen technischen und inhaltlichen Darstellung - gewählt werden, zum Beispiel die offene Ausstellung als Alternative zur klassischen Narrativausstellung. Diese kann in Form von Collagen oder Montagen und inhaltlichen Fragmenten gestaltet werden und gleicht oft eher einem begehbaren Forum ohne klare Wegführung und Erzählung. Der Besucher wird mit Mehrdeutigkeiten konfrontiert und herausgefordert, sein eigenes Narrativ zu entwickeln. ${ }^{207}$ Ein Element der Inszenierung oder auch der Szenografie kann darüber hinaus der Einsatz von Kunst sein - Kunst hier nicht als historisches Objekt, sondern als 'Mittlerin<, die beispielsweise die Besucher ansprechend in die Thematik einführt oder komplexe Zusammenhänge und schwer darstellbare Konflikte und Ereignisse vermittelt. ${ }^{208}$ So ist bei der Stiftung Flucht, Vertreibung, Versöhnung geplant, im Eingangsbereich die künstlerische Darstellung eines >Hauses`, das zeitlos und übernational für Heimat und Heimatverlust stehen soll, zu installieren und so in die Thematik der Ausstellung grundlegend einzuleiten.

Der Exponateinsatz im Museum lässt sich in drei Oberformen fassen: 1. das ausstellungstechnisch hervorgehobene Einzelobjekt, das durch seine materielle oder künstlerische Besonderheit oder aber durch seinen Symbolgehalt inhaltlich hervorragt und als eine Art Leitobjekt fungiert, 2. das Exponat, das sich den Platz mit vielen anderen Exponaten teilt, die dem Besucher Sinnzusammenhänge und das Verstehen von Prozessen anbieten sowie kommunizieren sollen und individuelle sowie vom Kurator angedachte Assoziationsketten ermöglichen ${ }^{209}$ und im 3. Fall das Exponat, das gegebenenfalls in Kombination mit mehreren Objekten sowie der weiteren Ausstellungsgestaltung in ei-

205 Thiemeyer: Fortsetzung des Krieges mit anderen Mitteln, 2010, S. 325.

206 Ebd., S. 314f.

207 Muttenthaler; Wonisch: Gesten des Zeigens, 2006, S. $21 f$.

208 Vgl. Kaiser; Krankenhagen et al.: Europa ausstellen, 2012, S. 138.

209 Muttenthaler; Wonisch: Cesten des Zeigens, 2006, S. $59 f$. 
nem »atmosphärischen Zusammenhang« zu einem szenografisch erzeugten »Gesamtbild« führt, als Einzelexponat aber keine oder nur geringe Bedeutung hat. ${ }^{210}$

$\mathrm{Ob}$ als hervorgehobenes Einzelobjekt oder als Mosaikstück einer größeren Inszenierung, das Objekt ist für die eingangs angesprochene Autorität des Museums zentral, und zwar grundsätzlich unabhängig vom Museumstyp. Diese Auffassung beruht auf der Annahme, dass museale Exponate von den Besuchern häufig als unabhängige, wertfreie Quellen wahrgenommen werden, die nicht nur Geschichten, sondern auch die Geschichte erzählen können, selbst wenn die Objekte zunächst in einem Begleittext erläutert werden. ${ }^{211}$ Exponaten wird ein hohes Maß an Authentizität, das heißt eine vermittelbare Repräsentation einer (vergangenen) Epoche ebenso wie eine eigene Aura zugesprochen, die eine selbstständige Exposition des in ihm gespeicherten Wissens sowie einen emotionalen und sinnlichen Zugang ermöglichen. ${ }^{212}$ Sie sind nicht nur integraler Bestandteil der Ausstellungsinszenierung, sondern können auch eine »raumgreifende Wirkung entfalten, das heißt die Atmosphäre der Ausstellung, des Ausstellungsraumes maßgeblich beeinflussen. ${ }^{213}$ Inwieweit Exponate eine eigenständige, nicht durch ausstellungsgestalterische Kontextualisierung einzuhegende Wirkmacht besitzen, ist aber umstritten ${ }^{214}$ :

»Tatsächlich gibt es Exponate, bei denen die Texttafeln nicht den visuellen Schaustücken widersprechen. Es gibt Exponate, deren visuelle Überzeugungskraft so stark ist, dass keine Tafel ihrer Rhetorik etwas entgegensetzen kann. «215

Sicher ist, dass die Wirkung eines Objekts nur in Wechselwirkung mit dem Rezipienten entsteht. ${ }^{216}$ Die Interpretationsfähigkeit mag - je nach Exponat - begrenzt sein, dennoch erreicht das Objekt erst im Zusammenspiel mit der musealen Inszenierung in Form von Einordnung, Kontextualisierung und möglicherweise Relativierung ${ }^{217}$ sowie dem Betrachter in einem performativen Akt eine Aussage über die Vergangenheit. ${ }^{218}$

210 Siehe dazu und grundsätzlich zu den »drei Visualisierungsweisen« von Objekten: te Heesen: Theorien des Museums zur Einführung, 2013, S. 68.

211 Hoffmann: Spur. Vorstellung. Ausstellung, 2000, S. 173f.

212 Ebd., S. 169, 173. Hoffmann spricht davon, dass die Ausstellung »durch die Auratisierung des Objekts eine neue sinnliche Qualität« erlangt(e) (S. 172). Vgl. zur Auratisierung und zur Exotisierung von Alltagsobjekten im Museum auch: Muttenthaler; Wonisch: Gesten des Zeigens, 2006, S. 21. Vgl. für den emotionalen Zugang via Objekt auch: Thiemeyer: Die Sprache der Dinge, 2011, S. 4. Siehe auch: Reinhardt; Teufel: Einundzwanzig Thesen zur neuen Ausstellungsgestaltung, 2008, S. $16,18$.

213 Thiemeyer: Die Sprache der Dinge, 2012, S. 53. Thiemeyer bezieht sich hier auf den Philosophen Gernot Böhme.

214 Vgl. dazu, v.a. in Bezug, ob nicht für die öffentliche Rezeption hergestellte Objekte, also Objekte jenseits von Kunstwerken, selbstständig >wirken` können: Thiemeyer: Die Sprache der Dinge, 2011, S. 1, 6. Siehe auch: Pohl: Wann ist ein Museum »historisch korrekt«? 2006, S. 281.

215 Bal: Kulturanalyse, 2002, S. 115.

216 Vgl. te Heesen: Exponat, 2015, S. 40. Te Heesen spricht vom Objekt als »Cegenstand mit subversivem Potential « und ordnet es als Teil eines Handlungs- und Bedeutungsnetzwerkes ein.

217 Ebd., S. 44, 34. Vgl. für den eingeschränkten Blick des Besuchers auf die »Spitze des Eisberges«: Muttenthaler; Wonisch: Gesten des Zeigens, 2006, S. 59-61.

218 Thiemeyer: Die Sprache der Dinge, 2011, S. 6f. Siehe auch: Thiemeyer: Politik des Zeigens, 2015, S. 17. 
Das bedeutet aber auch, dass die Ausstellungsmacher nur einen Teil dieses Vorganges kontrollieren können. ${ }^{219}$ Anders sieht es Juliane Haubold-Stolle, die konstatiert, dass der von den Kuratoren kontrollierte Kontext ein wirkmächtiges Element sei und die »Mehrdeutigkeit der Dinge in der [gelenkten] Rezeption eindeutig« gemacht werden kann. ${ }^{220}$

Unabhängig davon, wie sehr man diesen Einschätzungen im Einzelnen folgen mag, sind der Versuch und die Art und Weise der Lenkung der Besucher zu untersuchen. Eingeschränkt wird die simple Heranziehung des Exponats als Fußnote zur vermeintlich objektiven Belegung des Ausstellungsnarrativs durch die Erkenntnis, dass Objekte häufig nicht für alle Besucher gleich definiert sind, sodass jeder Betrachter Exponate tendenziell mit einer unbegrenzten Anzahl eigener Interpretationen bewertet. Positiv gewendet wird diese »mangelnde Eindeutigkeit« aber auch als Chance für persönliche Assoziationen des Besuchers angesehen. ${ }^{221}$

Auch wenn man Exponaten keine eigene agency zuspricht, so sehen wir bei der vorliegenden Thematik doch häufig eine den Objekten zugeschriebene Brisanz, sei es als politisch umstrittene Exponatleihgabe ${ }^{222}$ oder im Rahmen einer (geplanten) Inszenierung. ${ }^{223}$ Das kritische Potenzial von Objekten, beispielsweise im Sinne von Mehrdeutigkeit und als Grundlage einer multiperspektivischen Betrachtung von Geschichte, wird in Ausstellungen nur allmählich vermehrt genutzt. ${ }^{224}$

Eine Möglichkeit der >Einhegung « und Kommentierung der Exponate sind die Ausstellungstexte. Diese lassen sich in A-, B-, C-Texte unterteilen:

A = Überblickstext, z.B. über eine in dem Ausstellungsraum vorgestellte Epoche, ein Ereignis oder eine Person (ggf. nochmals untergliedert in einen Bereichs- und Raumtext)

B = Überblickstext über einen z.B. in einer Vitrine dargestellten Sachverhalt (und/oder Objektgruppentext)

$\mathrm{C}=$ Exponatbeschreibung (ggf. mit ergänzendem Kommentar zum Objekt)

Die Texte erfüllen primär den Zweck, dem Besucher die notwendigen Informationen zum Verstehen der Objekte und gegebenenfalls tiefergehendes Wissen und Interpretationen zu übermitteln; am ehesten lassen sie sich mit einer Führung durch die Aus-

219 Thiemeyer: Die Sprache der Dinge, 2011, S. 2, 6f.

220 Haubold-Stolle: Rezension zu: Walz, Markus (Hg.): Handbuch Museum. Geschichte, Aufgaben, Perspektiven. Stuttgart 2016, 2016. Vgl. für die Argumentation ähnlich: Muttenthaler; Wonisch: Gesten des Zeigens, 2006, S. 6of.

221 Hahn: Dinge als unscharfe Zeichen, 2016, S. 16. Vgl. kritisch zum Einsatz des Exponates als Fußnote, ohne die »diskursive Praxis« der Ausstellung offenzulegen: Muttenthaler: Beredsam und wirkungsvoll, 2016, S. 43.

2222006 war die Verleihung der Schiffsglocke der Gustloff aus Polen an das ZgV ein Politikum, vgl. Kellerhoff: »Gustloff«-Glocke ist zurück in Danzig. Die Welt. 27.09.2007.

223 Der Streit um die Neukonzeption des Schlesischen Museums in Kattowitz drehte sich unter anderem um das vorgesehene Startobjekt einer als deutsch konnotierten Dampfmaschine, vgl. Kap. 6.3.1, S. 315 .

224 te Heesen: Exponat, 2015, S. 43. 
stellung vergleichen. ${ }^{225}$ Mieke Bal spricht hier vom »lernenden Spaziergänger«, der sich »im Bereich zwischen Visuellem und Verbalem sowie zwischen Informationen und Überredung fungierende[n] Zeichensystem « der Ausstellung bewegt. ${ }^{226}$ Wie das Museum grundsätzlich genießen diese Texte ein hohes Maß an Autorität und werden vom Besucher zumeist nicht hinterfragt, noch wird vom Museum dargelegt, dass es sich hierbei um ein Interpretationsangebot handelt. ${ }^{227}$ Die Narrationen in Ausstellungen funktionieren grundsätzlich über die Texte im Zusammenspiel mit den Objekten und der Szenografie. ${ }^{228}$

Die obigen Ausführungen stellen das (Konflikt-)Verhältnis von Objekt zu Objekttext dar: Auf der einen Seite ist dies die Vorstellung des quasi autonomen, kaum oder schwer seinhegbaren Objektes, auf der anderen das durch die Ausstellungsmacher durch Inszenierung und Objektbeschriftung wirksam >domestizierte Objekt. Die Argumentation für das letztere betont, dass Objekte für den Besucher »stumm« bleiben und die Wissensvermittlung sich auf die Texte beschränkt, wobei die Objekte lediglich als Beleg, als die genannten $>$ Fußnoten $<$, der Aussage dienen. ${ }^{229}$

Teil der genauen Beobachtung einer Ausstellung ist die Frage, was nicht gezeigt wird. ${ }^{230}$ Diese bewussten oder unbewussten Leerstellen können einen großen Raum einnehmen:

»Museen schaffen demnach nicht nur Bilder, die den gesellschaftlichen Normen und Werten entsprechen, sondern thematisieren auch Verborgenes. Denn sie repräsentieren nicht nur das, was zu sehen ist, sondern auch, was dem öffentlichen Diskurs und der Wahrnehmung entzogen werden soll und damit ausgeschlossen wird. ${ }^{231}$

Die Auswahl von Gezeigtem und nicht Gezeigtem, die Auswahl der Themen und Ereignisse ist also ein zentraler Prozess der Ausstellungsgestaltung. ${ }^{232}$ Dabei kann mit Leerstellen durchaus kreativ umgegangen werden. ${ }^{233}$ Für die Museumsanalyse ebenso wie für den mündigen Besucher ist zu beachten, dass man sich immer wieder von der Ausstellung, dem Dargebotenen löst und über Fehlendes oder alternative Darstellungsformen und Erzählungen nachdenkt. ${ }^{234}$ Dazu formulieren Muttenthaler und Wonisch:

»[...] gerade in den nicht-beabsichtigten Botschaften kommen gesellschaftliche Übereinkünfte oder Konflikte gleichsam symptomatisch zum Tragen. Keine Sprachäuße-

225 Vgl. Muttenthaler; Wonisch: Gesten des Zeigens, 2006, S. 40.

226 Bal: Kulturanalyse, 2002, S. 79.

227 Oder aber sogar durch Eindeutigkeit vortäuschende Formulierungen Zweifel und Skeptizismus bekämpfen. Vgl. ebd., S. 97.

228 Vgl. Muttenthaler; Wonisch: Gesten des Zeigens, 2006, S. 256.

229 Lepp: Ungewissheiten - Wissens(v)ermittlung im Medium Ausstellung, 2012, S. 62. Siehe auch: Flacke: Ausstellen als Narration, 2016, S. 256. In umgekehrter Richtung weist Opalla darauf hin, dass die »Authentifizierung des Objekts« erst maßgeblich durch die Objektbeschriftung und Inszenierung erreicht wird: Opalla: Authentisch, und deshalb...?! 2015, S. 67.

230 Bal: Kulturanalyse, 2002, S. $109 f$.

231 Muttenthaler; Wonisch: Cesten des Zeigens, 2006, S. 13.

232 Baur: Was ist ein Museum? 2010, S. 38.

233 Wonisch: Minderheitenmuseen, 2012, S. 47.

234 Thiemeyer: Ceschichtswissenschaft: Das Museum als Quelle, 2010, S. 90. 
rung, kein geschriebener Text wird rezipiert, ohne gleichzeitig individuelle Imaginationen hervorzurufen. [...] ]ede Präsentation enthält demnach einen unbewussten Anteil, der nicht zu eliminieren ist. Dennoch gilt es, dieser blinden Flecken - so weit als möglich - in der Analyse gewahr zu werden, Ausstellungsdisplays zwischen den Zeilen zu lesen, um die mitgemeinten Inhalte deutlich zu machen. « $^{235}$

Für die Ausstellung lassen sich drei zentrale `Akteure` identifizieren: der Besucher, das Objekt/die Ausstellung sowie die Ausstellungsmacher. Die letzteren stehen aber zuallermeist nicht im Vordergrund der fertigen Ausstellung, tatsächlich bleiben sie für den Besucher in der Regel unbekannt. ${ }^{236}$ Te Heesen weist auf den komplexen Charakter der Kommunikation im Museum hin, bei der die Ausstellungsmacher nur eine von mehreren Parteien sind:

»Wer spricht? [...] Es wird nicht überraschen, dass dies nicht unbedingt die Kuratoren oder anderes Museumspersonal sind, sondern ein Netz von Personen, Ausstellungsarrangements und Objekten, also ähnlich wie in der Actor-Network-Theory ein Konglomerat verschiedenster Bedingungen, die für das `Sprechen ‘ des Museums verantwortlich sind. $\ll^{237}$

Auch in dieser Arbeit wird die innere Organisation von Museen nicht im Detail thematisiert und die Kuratoren werden primär durch ihre Ausstellungen oder ihre Konzeptionen zu Wort kommen. ${ }^{238}$ Dennoch wird die Frage »Wer spricht? « im Hintergrund mitgedacht. ${ }^{239}$ Dies ist von besonderer Wichtigkeit, da die Ausstellungen ein hohes »fiktionales, subjektives « und nicht-neutrales Potenzial besitzen, das aber ebenso wie die individuelle Handschrift, Hintergründe und Positionierungen der Ausstellungsmacher durch den scheinbar neutralen und wissenschaftlichen Anspruch verdeckt wird. ${ }^{240}$

Eine für die Museumsforschung nur schwer zu beantwortende Frage ist, wie Ausstellungen durch ihre Besucher individuell wahrgenommen werden. ${ }^{241}$ Die aufwändige Besucherforschung kann tendenziell viele Fragen beantworten; dennoch ist davon auszugehen, dass es hier schwer zu beziffernde >Übersetzungsverluste< gibt. ${ }^{242}$ Die Meinungen über den >durchschnittlichen< Besucher als Leitwert für die Museumspraxis variieren teilweise erheblich. ${ }^{243}$ Ein erster angemahnter Schritt ist, die Besucher $» a l s$ vielfältig, plural und aktiv statt [als] relativ homogene und passive Masse« anzusehen,

235 Muttenthaler; Wonisch: Cesten des Zeigens, 2006, S. 43.

236 Ebd., S. 39, 250. Siehe auch: Baur: Die Musealisierung der Migration, 2009, S. 325.

237 te Heesen: Theorien des Museums zur Einführung, 2013, S. 161.

238 Vgl. für diesen Ansatz: Muttenthaler; Wonisch: Cesten des Zeigens, 2006, S. 39.

239 Bal: Kulturanalyse, 2002, S. 81.

240 Muttenthaler; Wonisch: Gesten des Zeigens, 2006, S. 250f. Siehe auch: Scholze: Kultursemiotik: Zeichenlesen in Ausstellungen, 2010, S. 141f. Vgl. Simon: The Turn to Pedagogy, 2011, S. 199.

241 Muttenthaler; Wonisch: Cesten des Zeigens, 2006, S. $55 f$.

242 Ebd., S. 44f., 252. Hierbei schränken sie ein, dass durch ein »dirigistische[s] Führungskonzept« durchaus die individuelle Zusammenstellung einer Erzählung durch den Besucher minimiert werden kann (S. 252). Vgl. auch: Schröder: Geschichte ausstellen - Geschichte verstehen, 2013, S. 31. Siehe auch: Bogumił; Senina et al.: Conclusions, 2015, S. 150.

243 Vgl. für eine Erhebung z.B.: Lindner: Soziodemographie des Museumspublikums, 2016, S. 323-329. Siehe für `den<Besucher auch: Schröder: Geschichte ausstellen-Geschichte verstehen, 2013, S. 145148. 
eine Ausstellung im Idealfall für verschiedene Besuchergruppen attraktiv und didaktisch sinnvoll zu gestalten und diese nicht nur als zu belehrende, sondern als $\mathrm{zu}$ fordernde Menschen und Gesprächspartner auf Augenhöhe zu betrachten. ${ }^{244}$ Wenn man das Leitbild des mündigen Besuchers verfolgt, sollte der »fragmentarische, konstruierte und [...] grundsätzlich gegenwartsbezogene Charakter« der Ausstellung herausgestellt und er durch die Vermittlung von Kompetenzen in die Lage zur kritischen und kreativen Betrachtung der Ausstellung versetzt werden. ${ }^{245}$

Hinzu kommt der »Eigensinn« des Besuchers: Ob er die Ausstellung für sich erst individuell »formt « und rezipiert oder - etwas schwächer formuliert - Ausstellungen grundsätzlich sehr selektiv bis hin zur Zufälligkeit und selten vollständig besucht und damit auch die einzelnen Teilstücke und Exponate mit unterschiedlicher Intensität betrachtet, unterstreicht die Problematik der Bewertung des Rezeptionsverhaltens. ${ }^{246}$ Letztlich gilt für die meisten Museen, dass für sie »fraglich bleiben [muss], was die Besucher wie verstehen. Das heißt: Museen richten ihre Kommunikation an Erwartungen über ein Publikum aus, die auf Zuschreibungen beruhen. ${ }^{247}$ Schließlich nehmen nur wenige Museen Vor- und Nacherhebungen bei ihren Besuchern vor.

Die Besucher haben zumeist keine Möglichkeit, mit den Ausstellungsmachern in einen Dialog zu treten, auch wenn sich viele Museen gerne als Plattform für Diskussionen im Sinne des eingangs beschriebenen Forums verstehen möchten. ${ }^{248}$ Der Kurator ist demzufolge im Austausch von Informationen und Meinungen mit dem Besucher strukturell im Vorteil. ${ }^{249}$ Wenn überhaupt, sind Äußerungsmöglichkeiten in Besucherbüchern oder auf Bewertungsportalen online möglich. ${ }^{250}$ Ausnahmen bilden Führungen, die aber nur selten von den Kuratoren selbst gegeben werden. Ein >Ignorieren der Besucher ist jedoch in den wenigsten Fällen möglich, gelten doch Besucherzahlen als sharte Währung` auf dem zunehmend kompetitiv verstandenen Museumsmarkt. Demzufolge werden attraktive Angebote für ein breites Publikum als notwendig erachtet, die zugleich auch in Wissenschaft und im Feuilleton Anklang finden. ${ }^{251}$ Beispielsweise betrifft dies den Wunsch vieler Besucher nach Identitätsangeboten im Museum, die nicht abgelehnt, wohl aber reflektiert gestaltet werden können. ${ }^{252}$ Daher sollte auf eine einseitige Meistererzählung verzichtet werden, denn

244 Macdonald: Museen erforschen. Für eine Museumswissenschaft in der Erweiterung, 2010, S. 61. Kirchberg: Besucherforschung in Museen: Evaluation von Ausstellungen, 2010, S. 179. Siehe auch: Tomann: Geschichtskultur im Strukturwandel, 2016, S. 407.

245 Scholze: Kultursemiotik: Zeichenlesen in Ausstellungen, 2010, S. 142. Siehe für letzteres: Pohl: Der kritische Museumsführer, 2013, S. 242.

246 te Heesen: Theorien des Museums zur Einführung, 2013, S. 137f. Schröder: Geschichte ausstellen Geschichte verstehen, 2013, S. $37 f$.

247 Ebd., S. 36.

248 Siehe: Beier-de Haan: Deutsches Historisches Museum, 2012, S. 62, 68. Vgl. Ackermann: Eine Welt, in der wir leben wollen. Sächsische Zeitung. 26.06.2018.

249 Muttenthaler; Wonisch: Cesten des Zeigens, 2006, S. 41. Siehe auch: Żychlińska; Fontana: Museal Games and Emotional Truths, 2016, S. 239f.

250 Vgl. Krüger: Polen, ich komme! 2013, S. $147 f$.

251 Vgl. Danker: Aufklärung, Identifikation oder Repräsentation? 2006, S. 230. Siehe auch: Schröder: Geschichte ausstellen - Geschichte verstehen, 2013, S. $23 \mathrm{f}$.

252 Pohl: Der kritische Museumsführer, 2013, S. 246. 
»es sollte Konkurrenz in der Interpretation geben. Zugleich aber sollten die verschiedenen Narrative so präsentiert werden, dass sie dem Besucher ein Ensemble von Zugehörigkeiten anbieten können. Sie sollen es ihm ermöglichen, sich nach kritischer Reflexion eigenständig zu positionieren, um so etwas wie einen eigenen Standort zu suchen und (vielleicht) auch zu finden. Nur so können Ergebnisoffenheit in der Aussage und zugleich Möglichkeiten der Identifikation gewährleistet werden. Nur so kann es zu einem intellektuellen und emotionalen Aushandlungsprozess im Museum kommen. Eine eigene Positionierung der Besucher ist daher geradezu erwünscht und sollte das Ziel der Museumsmacher sein. «253

Eine besondere Hürde bei der Untersuchung und Beschreibung von Museen und Ausstellungen ist die sinnliche und körperliche mehrdimensionale Erfahrbarkeit. Der Besuch der Ausstellung durch den Besucher ist schließlich als "performative Herstellung von Bedeutung durch [...] körperliche Aktivität« zu beschreiben. Nicht unerheblich ist die Entwicklung hin zu immer größeren Ausstellungen, die die Besucher körperlich und hinsichtlich ihrer Aufnahmefähigkeit fordern. ${ }^{254}$

Anwendung: Museumsanalyse Mit dieser aufzählenden und komprimierten Erläuterung der Institution Museum und der Darstellungsform Ausstellung wurde angeführt, worauf bei den folgenden Analysen zu achten sein wird. Trotz einer verstärkten Museumsforschung auch in der Geschichtswissenschaft fehlt es bislang an einer einheitlichen Methodik. Daher wird auf Basis der skizzierten Theorie und vorhandener methodischer Ansätze eine eigene Vorgehensweise zur Museumsanalyse entwickelt. Dafür orientiert sich der Autor an dem Diktum Baurs, wonach die grundsätzlich transdisziplinär ausgerichtete Museumsanalyse auf Erkenntnisse über »übergreifende gesellschaftliche, politische und kulturelle Verhältnisse« abzielt. ${ }^{255}$

Eine Möglichkeit der Ausstellungsanalyse und besonders des Vergleichs von Ausstellungen besteht darin, ein Element wie beispielsweise die Inszenierung des »Feindes«im Kriegsmuseum zu isolieren und dessen Darstellung zu untersuchen. ${ }^{256} \mathrm{Da} \mathrm{Mu-}$ seen grundsätzlich solitär sind, ist jeder Vergleich zwangsläufig asymmetrisch; entsprechende Unterschiede müssen für wertige Ergebnisse folglich berücksichtigt werden. ${ }^{257}$ Die Vorzüge eines Vergleichs gehen zumeist zu Lasten einer umfassenden Tiefenanalyse des Einzelmuseums. ${ }^{258}$ Thiemeyer hat in seinem Aufsatz "Das Museum als Quelle« herausgearbeitet, dass auch auf das Museum die historische Quellenkritik angewandt werden kann. ${ }^{259}$ Hierbei ist zu unterscheiden zwischen einer inneren Quellenkritik der

253 Pohl: Der kritische Museumsführer, 2013, S. 243.

254 Muttenthaler; Wonisch: Gesten des Zeigens, 2006, S. 41. Thiemeyer: Politik des Zeigens, 2015, S. 24f. Vgl. Thiemeyer: Inszenierung, 2015, S. $54 f$.

255 Baur: Museumsanalyse: Zur Einführung, 2010, S. 7. Siehe zur vielfachen Verwendung des Begriffes »Museumsanalyse«, ohne dass dieser bereits ausdifferenziert wäre, auch: te Heesen: Theorien des Museums zur Einführung, 2013, S. 160.

256 So bei: Bogumił; Wawrzyniak et al.: Introduction, 2015, S. 1.

257 Vgl. ebd., S. 17.

258 Vgl. für Vor- und Nachteile des Vergleichs respektive der Einzelfalluntersuchung: Thiemeyer: Geschichtswissenschaft: Das Museum als Quelle, 2010, S. 80.

259 Ebd., S. 73. 
Ausstellung und ihrer Inhalte sowie einer äußeren Quellenkritik ihrer strukturellen Verfasstheit. ${ }^{260}$ Neben der Ausstellung selbst können Konzeptpapiere, weitere Publikationen, das Veranstaltungsprogramm, Kataloge, Newsletter sowie Flyer und Webpräsenzen als Quellenbasis für die Planungen und Vorstellungen der Ausstellungsmacher herangezogen werden. ${ }^{261}$

In der vorliegenden Untersuchung sollen trotz der Fokussierung auf einzelne Themenfelder die Kernaussagen und der grundsätzliche >Charakter der Ausstellung herausgearbeitet und dadurch verhindert werden, bei diesem komplexen Untersuchungsobjekt nur die Einzelelemente herauszusuchen, die sich in die eigene Fragestellung fügen. ${ }^{262}$ Makhotina und Schulze Wessel sprechen vom »Grundton« einer Ausstellung und den damit verbundenen zentralen, möglicherweise teleologischen, Narrativen sowie davon, ob diese »Raum für Ambivalenz und Kontroverse « lässt. ${ }^{263}$

Die Schwierigkeiten der Museumsanalyse sowie der Aussagen über die Ausstellung und deren Wirkung wurden mehrfach angesprochen. Zentral ist die tausendfache, individuelle Rezeption jeder Ausstellung und jedes Objektes. ${ }^{264}$ Ebenso herausfordernd ist die Auseinandersetzung mit dem beschriebenen >Eigensinn des Kurators, des Objektes und der Besucher. ${ }^{265}$ Für die Analyse ist die nachvollziehbare Beschreibung dieses individuellen Erlebens eine Herausforderung. ${ }^{266} \mathrm{Zu}$ beachten ist zudem, dass die wissenschaftliche Analyse eines Museums, das heißt eine intensive Lektüre der Ausstellung, nicht gleichzusetzen ist mit der des durchschnittlichen Besuchers. ${ }^{267}$ Die Besprechung der Ausstellungen hat dies pragmatisch zu berücksichtigen.

Gleichfalls muss sich eine wissenschaftliche Ausstellungsanalyse vergegenwärtigen, dass Ausstellungen stets Kompromisse des Machbaren sind und finanzielle, persönliche, politische und praktische Gesichtspunkte (die vielleicht nicht erkennbar sind) eine wichtige Rolle bei der Entstehung spielen. Dabei sollte man sich auch vor übereilten oder falschen Politisierungen der Ausstellung und ihrer Entstehungsgeschichte in Acht nehmen und auch hier andere Grundlagen für Entscheidungen und Machart bedenken. $^{268}$

Das konkrete Vorgehen wird sich bei existierenden Ausstellungen auf eine >dichte Beschreibung < der Ausstellung respektive derjenigen Teile der Ausstellungen beschränken, die für meine Fragestellung relevant sind. ${ }^{269}$ Die »dichte Beschreibung« stammt aus dem Bereich der Ethnologie (Clifford Geertz, Gilbert Ryle) und ist eine Methode, umfassende Beobachtungen unter Kenntlichmachung der stets damit einhergehenden

260 Vgl. Tomann: Geschichtskultur im Strukturwandel, 2016, S. 107.

261 Thiemeyer: Geschichtswissenschaft: Das Museum als Quelle, 2010, S. 82.

262 Vgl. Tomann: Ceschichtskultur im Strukturwandel, 2016, S. 7. Vgl. ebenso: Baur: Was ist ein Museum? 2010, S. 42.

263 Makhotina; Schulze Wessel: Neue Konfliktlinien, 2015, S. 9.

264 Scholze: Kultursemiotik: Zeichenlesen in Ausstellungen, 2010, S. 145. Siehe auch: Hahn: Dinge als unscharfe Zeichen, 2016, S. 17.

265 Sternfeld: Der Objekt-Effekt, 2016, S. 25-33.

266 Thiemeyer: Die Sprache der Dinge, 2011, S. 8.

267 Vgl. Kirchberg: Das Museum als öffentlicher Raum in der Stadt, 2010, S. $174 \mathrm{f}$.

268 Thiemeyer: Geschichtswissenschaft: Das Museum als Quelle, 2010, S. 85, 83.

269 Vgl. Muttenthaler; Wonisch: Gesten des Zeigens, 2006, S. 49-53. Siehe auch: Scholze: Kultursemiotik: Zeichenlesen in Ausstellungen, 2010, S. 140. 
eigenen Interpretationen kleinteilig zu »vertexten « und so jenseits einer unreflektierten Objektivitätsbehauptung wissenschaftlich verwertbar zu machen. ${ }^{270}$ Für die Problematik der subjektiven Wahrnehmung von Ausstellungen bietet sich diese Herangehensweise daher besonders an, die durch eine offene, Eindeutigkeiten vermeidende, dennoch präzise und Interpretationen kennzeichnende Beschreibung hier aufzufangen versucht wird. ${ }^{271}$ Dabei folgt der Autor Muttenthaler und Wonisch, die dem komplexen Medium Ausstellung mit »einer möglichst genauen Erfassung, welche Themen angesprochen und in welcher Weise Objekte, Bilder, Texte, audiovisuelle Medien, Ausstellungsarchitektur und Inszenierungsmittel in einem Raum eingesetzt werden, um bestimmte Lesarten nahe zu legen«, als Analyseansatz begegnen. Ein zentrales Element ist die inhaltliche und räumliche Strukturierung der Ausstellung oder des Ausstellungsteiles »etwa nach chronologischen, regionalen, formalen oder thematischen Gesichtspunkten ${ }^{272}$ Leerstellen, also das Nicht-Erzählte, bilden einen Beobachtungsschwerpunkt der vorliegenden Untersuchung. Ausstellungen sind schließlich als "complex text « ${ }^{273}$ und als rhetorische Akte zu verstehen, die durch ein »close reading « verstanden werden können. ${ }^{274}$ Dies gilt für die verschiedenen Elemente einer Ausstellung ebenso wie für die Ausstellungskonzepte, die so dekodiert werden können. ${ }^{275}$

Die vorliegende Untersuchung versteht »Inhalt, konzeptionelle Umsetzung und ästhetische Gestaltung « als Synthese und analysiert diese daher zusammenhängend. ${ }^{276}$ Dem bestehenden Problem der Ausstellungsanalyse, der Replizierbarkeit, wird in dieser Studie durch eine nachvollziehbare Darstellung und durch eine umfassende fotografische Dokumentation zu begegnen versucht. ${ }^{277}$ In den jeweiligen Kapiteln wird die Beschreibung der Ausstellungen und ihre Analyse eingebettet in die Besprechung der jeweiligen Geschichte der Häuser, ihrer Strukturen (Personal, Finanzierung etc.) und ihrer sonstigen Aktivitäten (Veranstaltungen, Publikationen etc.). Dem folgt die Vorstellung anderer Einschätzungen des Museums und abschließend eine zusammenfassende Bewertung und Einordnung. Zur Veranschaulichung und konstruktiven Ergänzung der Kritik werden punktuell auch mögliche Darstellungsalternativen diskutiert. ${ }^{278}$

Die Beschreibung und Analyse der Ausstellung verfolgt der Autor auf Basis der skizzierten kultur- und museumswissenschaftlichen Erkenntnisse in einem selbst entwickelten Leitfaden, der eine möglichst effiziente, systematische und vergleichende Ana-

270 Der Ausdruck der »dichten Beschreibung« geht ursprünglich auf Gilbert Ryle zurück. Vgl. Geertz: Dichte Beschreibung, 1983, S. 10, 14f., 43.

271 Vgl. für den Ansatz der »dichten Beschreibung« in Heinemanns Untersuchung: Heinemann: Krieg und Kriegserinnerung im Museum, 2017, S. 57-60.

272 Muttenthaler; Wonisch: Cesten des Zeigens, 2006, S. 46.

273 Bogumił; Wawrzyniak et al. : Introduction, 2015, S. 20.

274 Scholze: Kultursemiotik: Zeichenlesen in Ausstellungen, 2010, S. 132.

275 Ebd., S. 137f.

276 Muttenthaler; Wonisch: Cesten des Zeigens, 2006, S. 250.

277 Vgl. ebd., S. 62.

278 Für ein derartiges Vorgehen plädiert Scholze in Bezug auf Bal: Scholze: Kultursemiotik: Zeichenlesen in Ausstellungen, 2010, S. 136. 
lyse ermöglichen soll. ${ }^{279}$ Dieser Katalog kann - leicht modifiziert - auch auf die noch nicht entstandenen und im Entstehen begriffenen Ausstellungen angewendet werden, indem die bisherigen Konzeptionen und Verlautbarungen als Grundlage genommen werden. $^{280}$

Der Leitfaden ist in fünf Bereiche gegliedert. In der ersten Einheit werden der Anspruch (der eigene sowie der von außen erhobene) und die angestrebte Erzählung der Ausstellung untersucht. Im zweiten Bereich werden ihre einzelnen technischen Elemente vertiefend analysiert (Objekte, Inszenierung, Texte, Besucherbild etc.). Im dritten Schritt werden die dargebotenen Inhalte ausführlich auf einige Leitfragen hin untersucht, welche die oder das Ausstellungsnarrativ/e in Hinblick auf den Komplex von Flucht und Vertreibung betreffen. Im Anschluss wird im vierten Teil die Ausstellung auf ihre zentralen Aussagen und ihre vermittelte Kernerzählung hin betrachtet und bewertet. Abschließend werden im fünften Bereich einige Überlegungen zum potentiellen >Funktionieren in Hinblick auf den Anspruch des Museums angestellt.

\begin{tabular}{|c|c|}
\hline I. Anspruch & 1. Welche Geschichte soll erzählt werden? \\
\hline \multirow[t]{5}{*}{ II. Ausstellung } & 2. Welche Objekte werden gezeigt? Wie werden sie arrangiert? \\
\hline & $\begin{array}{l}\text { 3. Wie wird die Ausstellung inszeniert? Emotional oder nüchterne Ansprache? Innen-Architektur und Cestaltung? } \\
\text { Audioeinsatz? }\end{array}$ \\
\hline & 4. Charakter der Ausstellungstexte? Sachlich? Emotional? \\
\hline & 5. Einsatz von Zeitzeugen? Wie eingesetzt? Welche Botschaften? \\
\hline & 6. Welches Besucherbild hat die Ausstellung? Partizipierender versus skonsumierender ‘ Besucher? \\
\hline \multirow[t]{3}{*}{ III. Inhalte } & 7. Darstellung von Flucht und Vertreibung? \\
\hline & 8. Kontext/Ursache(n): Vorgeschichte? Zweiter Weltkrieg? 20. Jahrhundert? Anthropologische Konstante? \\
\hline & $\begin{array}{l}\text { 9. Zusammenleben: Inwieweit wird } \text { Multikulturalität« in den Museen dargestellt? Inwieweit wird mit dem } \\
\text { Nationen begriff operiert? Werden die deutschen Minderheiten dargestellt? }\end{array}$ \\
\hline \multirow[t]{3}{*}{ IV. Aussage } & $\begin{array}{l}\text { 10. Cibt es ein zentrales Narrativ? Ein nationales? Ein regionales? Ein europäisches? Wird ein Identitätsangebot } \\
\text { unterbreitet? }\end{array}$ \\
\hline & 11. Gibt es aktuelle Bezüge? (z.B. zur»Flüchtlingskrise凶) \\
\hline & 12. Was wird eigentlich erzählt? Was wird nicht erzählt? (z.B. Notwendigkeit der Vertreibung?) \\
\hline V.) Ergebnisser & 13.) Funktionieren des Museums? (in Abgleich mit dem Anspruch) \\
\hline
\end{tabular}

Leitfaden für die Ausstellungsanalyse

\subsection{Zusammenfassung}

Der geschichtswissenschaftliche Vergleich, der die Erkenntnisse der transnationalen Geschichtsschreibung berücksichtigt, soll in dieser Arbeit dazu dienen, die verschiedenen nationalen Diskurse sowie ihre transnationalen Elemente $\mathrm{zu}$ analysieren und einzuordnen. Teil dieses Diskurses sind auch die untersuchten Museen, die alle einen über den nationalen Rahmen hinausgehenden, hier vor allem einen europäischen Anspruch haben. Die entsprechenden Interdependenzen und die Phasen, in denen sich ein gemeinsamer oder europäischer Diskursraum herausbildet, stehen im besonderen Fokus. Der überkreuzende Blick zieht sich durch die vorliegende Arbeit und verdichtet sich in den vergleichenden Zusammenfassungen der Kapitel.

279 Vgl. für einen Überblick an Fragen an eine Ausstellung, die hier zum Teil berücksichtigt, aber um einen inhaltlichen Schwerpunkt ergänzt wurden: Muttenthaler; Wonisch: Gesten des Zeigens, 2006, S. 46-49.

280 Vgl. für diesen Ansatz: Thiemeyer: Geschichtswissenschaft: Das Museum als Quelle, 2010, S. 80. 
Erinnerungskultur und Geschichtspolitik stehen in einem engen Verhältnis zueinander. Die Studie verwendet, ähnlich wie von Cornelißen vorgeschlagen, Erinnerungskultur als »formalen Oberbegriff für alle denkbaren Formen der bewussten Erinnerung an historische Ereignisse, Persönlichkeiten und Prozesse ${ }^{281}$ In diesem kulturellen und sozialen Rahmen, der ständigen Aushandlungsprozessen unterliegt, geschieht Geschichtspolitik und formt diesen gleichzeitig laufend (mit). Wenn in dieser Arbeit von einer nationalen Erinnerungskultur gesprochen wird, ist damit ein zeitweise in der (medialen) Öffentlichkeit vorherrschendes, aber grundsätzlich nie konkurrenzloses Geschichtsbild gemeint. Die Verknüpfung gewachsener historischer Diskurse mit geschichtspolitischen Entwicklungen erlaubt es, den Kontext für die untersuchten $\mathrm{Mu}$ seumsprojekte zu definieren. Das berührt im Folgenden die ab dem 4. Kapitel thematisierten Bereiche mit dem Fokus auf staatlichen, publizistischen und zivilgesellschaftlichen Akteuren.

Bei einer transnationalen Untersuchung ist neben einer Gegenüberstellung von mehr oder weniger geschlossenen nationalen Fallbeispielen gerade in Hinblick auf Ostmitteleuropa auf die komplexe Verflechtungsgeschichte der Region(en) zu achten. Um ein strukturiertes Vorgehen zu gewährleisten, wird in den Kapiteln 4 und 5 grundsätzlich ein Zweischrittverfahren angewendet, in dem zunächst die nationalen Diskurse in ihren transnationalen Verbindungen und im Anschluss gemeinsame Diskursebenen untersucht werden. Auf dieser Basis wird dann eine vergleichende Bewertung vorgenommen. Ähnlich soll bei der folgenden Betrachtung der Diskurse um die Museen vorgegangen werden.

Die Arbeit verfolgt die Vorstellung eines umkämpften >Marktes der Erinnerungen<, der erwähnten »Arena« oder den »Arenen«, in denen verschiedene Akteure um Deutungshoheiten, Aufmerksamkeit und Unterstützung ringen. ${ }^{282}$ In diesem Umfeld entstanden die hier untersuchten Museen. Zu berücksichtigen sind dabei sowohl die unterschiedlichen Kontexte und Strukturen der nationalen als auch der Diskurse auf transnationaler beziehungsweise europäischer Ebene. Im vorliegenden Fall wird der stete Kampf um die wenigstens zeitweise gültige Etablierung einer mehrheitlich anerkannten Wahrheit über den Komplex Flucht und Vertreibung als Hintergrund der Museumsprojekte verstanden und untersucht. Diese sind nicht nur Materialisierungen dieser Prozesse, sondern selbst wieder Taktgeber. Die Auseinandersetzung um die richtige Erinnerung an Flucht und Vertreibung wird in allen Teilen der Arbeit thematisiert, wobei wechselnde Deutungshoheiten ebenso von Interesse sind wie gescheiterte Impulse zur Veränderung der Erinnerungskultur.

Für die entsprechende Untersuchung der erinnerungskulturellen Entwicklungen wird die vorgestellte Diskursanalyse verwendet. Mit einem abgesteckten Korpus von Quellen werden die verschiedenen Diskursstränge und zentrale Argumentationen herausgearbeitet. ${ }^{283}$ Diese Argumente sind zumeist Teil eines bestimmten historischen Narrativs über Flucht und Vertreibung. Die zentralen Erzählungen werden daher im

281 Cornelißen: Erinnerungskulturen, 2012, S. 1.

282 Ullrich: Diskursanalyse, Diskursforschung, Diskurstheorie, 2008, S. 23. Siehe Kap. 2.4, S. $67 f$.

283 Vgl. Kap. 2.4, S. 68; Kap. 1.4, S. $49 f$. 
Kapitel 3 besprochen sowie die ihnen zugrunde liegenden diskursiven Aushandlungen in den Kapiteln 4 und 5 untersucht. Aus diesen Überlegungen ergibt sich neben dem für die Museen und Ausstellungen grundlegenden Quellenmaterial eine pragmatische, kontinuierlich weiterentwickelte und durch einen Kriterienkatalog systematisierte Quellenauswahl. ${ }^{284}$

Die vorgestellten Institutionen des Museums und der Ausstellung sowie die entsprechende Museumsanalyse sollen es ermöglichen, das Museum als geschichtspolitisches Objekt und Subjekt zu verstehen. Wie sein Kernelement, die Ausstellung, besitzt es die diskutierten Eigenlogiken, die es zu berücksichtigen gilt. Die vorliegende Studie begegnet den Ausstellungen als Gesamtkunstwerk und damit als äußerst komplexen kulturellen Erzeugnissen auf verschiedenen methodischen Ebenen, wie mit der >dichten Beschreibung . Der Vergleich der Museen ist mit der Herausforderung konfrontiert, dass sich diese ebenso wie die Ausstellungen erheblich in ihrer Machart und in ihren Zielen unterscheiden. Ein komparativer Ansatz muss solche Unterschiede berücksichtigen. Als Grundlage für ein strukturiertes Vorgehen sowohl für den Vergleich als auch für die Analyse der Museen und Ausstellungen dient der in Kapitel 2.5 entwickelte Leitfaden. 


\section{Flucht und Vertreibung der Deutschen als historisches Ereignis}

Sowohl Flucht als auch Vertreibung scheinen auf den ersten Blick anthropologische Konstanten zu sein. In der westlichen Kulturgeschichte gilt die Vertreibung der Juden in das babylonische Exil als ein frühes Beispiel für eine staatlich forcierte kollektive Zwangsumsiedlung. ${ }^{1}$ Die Flucht der Bevölkerung vor Kriegszügen und Frontverläufen aus Angst vor Übergriffen und Kriegsgewalt erscheint als eine unausweichliche Begleiterscheinung der Menschheitsgeschichte - und so scheinen sich sogar die Bilder über die unterschiedlichen Epochen bis hin in unsere Gegenwart zu gleichen. Dennoch unterscheiden sich Flucht- und Vertreibungsbewegungen sowie Genozide im 19. und 20. Jahrhundert durch verschiedene Spezifika von ihren historischen Vorläufern: Zum einen entwickelte sich das Modell des ethnisch homogenen Nationalstaates mit »einer einheitlichen Kultur und Sprache des Staatsvolkes « zu einem Sinnbild moderner Staatlichkeit. ${ }^{2}$ Zum anderen handelt es sich um eine andere Größenordnung, denn ganze Bevölkerungsgruppen - zumeist als eine Ethnie definiert - wurden geschlossen und dauerhaft aus einem Gebiet entfernt und die Möglichkeit eines Arrangements mit der neuen Herrschaft oder die Schaffung spezifischer Minderheitenrechte ausgeschlossen. ${ }^{3}$ In den letzten Jahren haben Historiker wie Michael Schwartz oder Philipp Ther den engen Zusammenhang von ethnischer Gewalt und modernem Staat hervorgehoben: „Ethnische Säuberungen sind ein Kind des Nationalstaats und damit ein zentraler Bestandteil der europäischen Moderne. $\aleph^{4}$

Vertreibungsaktionen, Flüchtlingstrecks, Deportationen, Internierungen und rethnische Säuberungen p prägten Teile des Kontinents entscheidend. Konservativ geschätzt waren etwa 40 Millionen Menschen aufgrund ihrer Nationalität, Religion oder Klasse im Europa des 20. Jahrhunderts von Zwangsmigrationsprozessen betroffen. ${ }^{5}$ In Deutsch-

1 Vgl. Várdy; Tooley: Ethnic Cleansing in History, 2003, S. $3 f$.

2 Schwartz: Ethnische »Säuberungen« in der Moderne, 2013, S. 9.

3 Vgl. Schwartz: Ethnische »Säuberungen« in der Moderne, 2013, S. 12, 638. Siehe auch: Bessel; Haake: Introduction, 2009, S. 3.

4 Ther: Die dunkle Seite der Nationalstaaten, 2011, S. 7.

$5 \quad$ Nach Schwartz kann man bei einem Einbezug der Grenzfälle noch von einer weit höheren Zahl ausgehen: Schwartz: Ethnische »Säuberungen« in der Moderne, 2013, S. 623. Piskorski setzt noch 
land wird häufig von einem »Jahrhundert der Vertreibungen « gesprochen, auch wenn es mit einigem Recht ebenso als das "Jahrhundert der Lager « oder als »Jahrhundert der Flüchtlinge« bezeichnet werden kann. ${ }^{6}$ Die Vertreibung der Deutschen zwischen 1944 und 1950 fand in der »Hochphase ethnischer Gewalt « statt und stellt die möglicherweise größte Zwangsmigration in der europäischen, je nach Kalkulation auch in der globalen Geschichte dar. ${ }^{7}$ Staatlich organisierte Vertreibungen, Deportationen und Umsiedlungen waren primär ein Phänomen Mittel- und Osteuropas, allerdings waren auch Westund Südeuropa von Massenflucht und Umsiedlung betroffen. ${ }^{8}$ Bei einer Beschränkung des Blicks auf das Europa des 20. Jahrhunderts beginnt die Phase der gewalttätigen Zwangsmigration großen Ausmaßes auf dem Balkan der Jahrhundertwende und endet ebendort mit den Zerfallskriegen Jugoslawiens in den 1990er Jahren.

Mit dem Erlebnis von Zwangsmigration sind nicht nur unzählige individuelle Schicksale verbunden, sondern auch ein unwiederbringlicher Verlust einer ehemals reichen kulturellen Vielfalt. ${ }^{9}$ Eine rethnische Säuberung in ihrer allerletzten Konsequenz führte zur industriellen und planmäßigen Vernichtung des europäischen Judentums. Die Einzigartigkeit der Shoa ist in der Forschung in diesem Zusammenhang weitgehend unbestritten. ${ }^{10}$ Ohne diese zu relativieren, werden häufig Verbindungen zur Ideengeschichte rethnischer Säuberungく gezogen. So konstatiert Aly, dass das deutsche

höhere Zahlen an und vermutet, dass »zwischen 1939 und 1942/43 « bereits »über dreißig Millionen Menschen von Umsiedlungen betroffen « waren: Piskorski: Die Verjagten, 2013, S. 215. Beer gibt die Zahl von 25 Millionen Menschen an, die sich nach dem 8. Mai »in Bewegung gesetzt«haben-»wohl die größte Bevölkerungsverschiebung der europäischen Geschichte.«Beer: Flucht und Vertreibung der Deutschen, 2011, S. 9.

6 Vgl. für den Begriff »century of expulsions « u.a.: Moeller: Germans as Victims? 2005, S. 174. Siehe auch: Esch: Zum Verhältnis, 2012, S. 78. Die Bezeichnung »]ahrhundert der Vertreibungen« wird allerdings als sehr deutsche Perspektive auf das 20. Jahrhundert betrachtet, welche kaum anschlussfähig ist an die Erfahrungen der europäischen Nachbarn: Kopernikus-Gruppe: Mitteilung über die Sitzung der Kopernikus-Gruppe am 30.11./1.12.2007, 2007. Vgl. zum »]ahrhundert der Lager«:Kreienbaum: Rezension zu: Pitzer, Andrea: One Long Night. A Global History of Concentration Camps. New York 2017, 2018. Das erste Kapitel der künftigen Dauerausstellung der Stiftung Flucht, Vertreibung, Versöhnung soll unter dem Titel »]ahrhundert der Flüchtlinge«stehen. Oltmer hat jüngst das 20. Jahrhundert aus globalgeschichtlicher Perspektive als das »]ahrhundert der Cewaltmigration« gefasst: Oltmer: Das lange 20. Jahrhundert der Cewaltmigration, 2017.

7 Schwartz: Ethnische »Säuberungen« in der Moderne, 2013, S. 23, 426. Dabei sieht Schwartz-in Abgrenzung zur Shoa: »Der deutsche Massenmord an sechs Millionen Juden war der Extremfall der Cenozid-Variante. Die Vertreibung von rund fünfzehn Millionen Deutschen war der Extremfall der Vertreibungs-Variante ethnischer Gewaltpolitik.«(S. 23). Dennoch sollten die großen Zahlen deutscher und polnischer Vertriebener nicht darüber hinwegtäuschen, dass kleinere Völker wie viele Indianervölker in den USA oder die Tschetschenen prozentual weit stärker von Zwangsmigration bis hin zur fast vollständigen Vernichtung, betroffen waren/sind: Piskorski: Zwangsmigrationen im Kontext des Zweiten Weltkriegs, 2014, S. 156.

8 Vgl. Schlögel: Die Europäisierung des »Vertreibungskomplexes«, 2005, S.130. Siehe ebenso: Hirsch: Flucht und Vertreibung, 2005, S. 114. Siehe besonders für die europäische Dimension von Zwangsmigration: Piskorski: Zwangsmigrationen im Kontext des Zweiten Weltkriegs, 2014, S. 171. Schlögel: Die Europäisierung des »Vertreibungskomplexes«, 2005, S. 127.

10 Verschiedene oder als solche wahrgenommene Versuche, Flucht und Vertreibung mit dem Holocaust zu parallelisieren, wurden vom Gros der bundesrepublikanischen Geschichtsforschung sowie Öffentlichkeit scharf zurückgewiesen. Vgl. ebd., S. 127-129. 
Vorgehen »sich auf kein historisches Vorbild stützen [konnte] - aber als äußerster, extremster Fall gehört er in den Kontext der ethnischen Entmischung Europas. «"

Die sprachliche und definitorische Begriffsvielfalt trennt sich zwischen der planmäßigen physischen Vernichtung, dem Genozid und der Vertreibung der Menschen meistens an dieser Linie. ${ }^{12}$ Das bedeutet aber nicht, dass nicht auch genozidale Methoden angewendet wurden, um das Ziel der Entfernung von Menschen aus einem bestimmten Gebiet zu erreichen. Ebenfalls kann das Ergebnis identisch sein: die Beseitigung einer Gruppe aus einem abgegrenzten Territorium. Zwangsmigration kann nach Ther in vier Kategorien aufgeteilt werden: 1. die Flucht vor bewaffneten Auseinandersetzungen, aus der eine Vertreibung wird, wenn den Flüchtlingen die Rückkehr verweigert wird; 2 . (spontane) Vertreibungen ohne internationale Vereinbarungen; 3. Deportationen und 4. staatlich organisierte und international sanktionierte Zwangsumsiedlungen. ${ }^{13}$ Die Flucht und Vertreibung der Deutschen Ostmitteleuropas berührt alle diese Kategorien.

Die bis heute immer wieder geäußerte Vorstellung, dass derartige Massenumsiedlungen human und geordnet durchführbar seien, wurde durch das historische Geschehen stets widerlegt. Im Gegenteil, ohne den Einsatz massiver Gewalt lassen sich nicht ganze Großgruppen von Menschen entwurzeln und verschieben, von den Bedingungen der konkreten Transporte ganz zu schweigen. Ray M. Douglas schließt sein Werk zur Vertreibung der Deutschen in Hinblick auf die Renaissance des >Lösungsansatzes` von Bevölkerungsverschiebungen zur vermeintlich nachhaltigen Befriedung von Konflikten mit den Worten: »Wenn diese Operationen sich nicht in Umständen ausführen lassen, in denen Brutalität, Ungerechtigkeit und sinnloses Leiden unvermeidlich sind, lassen sie sich gar nicht ausführen. $\ll^{14}$

\subsection{Siedlungsgeschichte bis zum modernen Nationalismus}

Die Regionen, aus denen Deutsche oder als Deutsche definierte Menschen am Ende des Zweiten Weltkrieges evakuiert, vertrieben oder deportiert wurden, aus denen sie flohen oder in denen sie ums Leben kamen, unterscheiden sich bezüglich des Status der deutschen Bevölkerung voneinander. Diese können in einem vereinfachten Schema in drei Gruppen aufgegliedert werden:

1. Staatsbürger des Deutschen Reiches vor dem 31.12.1937, die in den Ostprovinzen des Reiches lebten,

11 Aly: Auschwitz und die Politik der Vertreibung, 2005, S. 41. Ebenso: Leggewie: Schlachtfeld Europa, 2009, S. 168.

12 Brandes unterstreicht die notwendige Trennung von Cenozid und Vertreibung, die gelegentlich von deutschen Vertriebenenverbänden in Frage gestellt wird. Diese sei aber notwendig, um das spezifische am - z.B. - Armeniergenozid herausstellen zu können: Brandes: Das Jahrhundert der sethnischen Säuberungen<, 2007, S. 17. Vgl. Bessel; Haake: Introduction, 2009, S. 4 f.

13 Ther: Die dunkle Seite der Nationalstaaten, 2011, S. 7f. Vgl. Kap. 1.3, S. 28.

14 Douglas: »Ordnungsgemäße Überführung«, 2012, S. 460. Vgl. Schwartz: Ethnische »Säuberungen« in der Moderne, 2013, S. 409. 
2. Staatsbürger anderer Staaten, die vor den Versailler Verträgen Bürger ÖsterreichUngarns oder des Deutschen Kaiserreiches waren und sich selbst als Deutsche verstanden und/oder so von der Administration geführt wurden und

3. Staatsbürger anderer Staaten, die außerhalb des geschlossenen deutschen Siedlungsgebietes lebten, schon vor $1918 \mathrm{zu}$ anderen Staaten gehörten und deren (Selbst-) Definition als Deutsche nur zum Teil, und auch nicht immer vollständig, erst in der Moderne begann.

Die preußischen Ostprovinzen der Weimarer Republik - Schlesien, Oberschlesien, Ostpreußen, Pommern und die Grenzmark Posen-Westpreußen - gehörten seit dem Ende der sogenannten deutschen Ostsiedlung im Spätmittelalter zum weitgehend geschlossenen deutschen Siedlungsgebiet. Oberschlesien, sowie Ostpreußen und besonders die erst am Ende des 18. Jahrhunderts im Zuge der Teilungen Polens der Rzeczpospolita verloren gegangenen Territorien waren gebietsweise sprachlich-kulturelle Mischregionen, wie das Ermland in Ostpreußen, die Kaschubei in Westpreußen oder die mehrheitlich polnischsprachige Provinz Posen. In Polen ist die Erinnerung an die offensive, aber letztlich gescheiterte preußisch-deutsche Germanisierungspolitik und an den Kulturkampf unter Bismarck bis heute präsent. Nachdem der Großteil der Provinzen Posen und Westpreußen sowie Teile Oberschlesiens infolge des Ersten Weltkrieges und des Versailler Vertrages an Polen gelangten und mit Danzig ein autonomes Gebiet unter dem Mandat des Völkerbundes entstand, lebten in den bei Deutschland verbliebenen Provinzen zum allergrößten Teil sich als deutsch verstehende Menschen mit deutscher Staatsbürgerschaft.

Nach dem Ersten Weltkrieg fanden sich in den neu gegründeten Staaten Ostmitteleuropas Millionen Menschen wieder, die sich vorher der Titularnation oder im Falle der Deutschen Österreich-Ungarns vielfach einer deutschen Nation zugehörig gefühlt hatten. Die größte Gruppe unter diesen waren die Sudetendeutschen, die vor allem in den Randgebieten der vormaligen böhmischen Kronländer lebten. Sie waren zumeist Nachfahren der mittelalterlichen deutschen Ostsiedler oder in kleinerer Zahl österreichischer Beamter und Adliger, die nun die tschechoslowakische Staatsbürgerschaft erhielten. Eine deutlich kleinere, aber für den Ausbruch des Zweiten Weltkrieges mit entscheidende Gruppe waren die Deutschen in den nun zu Polen gehörenden Gebieten sowie die Danziger Deutschen. Auch wenn nach 1919 eine größere Abwanderung von ehemaligen preußischen Beamten und ihren Familien stattfand, sorgten vermeintliche und tatsächliche Übergriffe sowie Missstände der polnischen Minderheitenpolitik ebenso wie der polnische Zugriff auf Danzig für ein spannungsvolles Verhältnis. Umgekehrt beklagte Polen die Nichtanerkennung und schlechte Behandlung der polnischen Bevölkerung in Deutschland.

Eine dritte, historisch und kulturell sehr diverse Gruppe sind die nicht mit dem geschlossenen deutschen Siedlungsgebiet verbundenen Regionen, in denen sich seit dem Mittelalter bis ins 19. Jahrhundert Menschen aus West- und Mitteleuropa angesiedelt hatten. Beispielsweise zogen die Siebenbürger Sachsen im heutigen Rumänien auf Einladung des ungarischen Königs in mehreren Wellen nach Siebenbürgen und genossen dort spezielle Privilegien und Autonomie. Sie stammten nicht oder kaum aus den Regionen des heutigen Sachsen, sondern aus verschiedenen, nicht nur deutsch- 
sprachigen Gebieten des Heiligen Römischen Reiches und Westeuropas. ${ }^{15}$ Ihre Loyalität galt vorrangig den selbstverwalteten Gemeinschaften. Im 19. Jahrhundert kam es erst unter zunehmendem Magyarisierungsdruck zur Stärkung eines deutschen Bewusstseins und in anderen Teilen Ungarns auch zu einer verstärkten Assimilation. Eine andere deutschsprachige Bevölkerungsgruppe Südosteuropas sind die Donauschwaben, deren Siedlungsgebiete im 18. Jahrhundert unter den Habsburgern in der Donauregion geschaffen wurden und in der Zwischenkriegszeit an Jugoslawien fielen. In der Sowjetunion lebten 1939 etwa 1,4 Millionen Deutsche. Neben der seit dem Mittelalter ansässigen deutschen Bevölkerung im Baltikum riefen die Zaren im 18. und 19. Jahrhundert deutsche Siedler zur Entwicklung des Landes an die Wolga, nach Wolhynien und Bessarabien. ${ }^{16}$ Im Nationalsozialismus firmierten diese Deutschen ohne deutsche Staatsbürgerschaft als >Volksdeutsche . Die Sudetendeutschen gehörten offiziell nicht zu dieser Gruppe, da sie 1938 unmittelbar die Staatsbürgerschaft erhielten. ${ }^{17}$

Die Ansiedlungen des Mittelalters und der Frühen Neuzeit führten in wenigen Fällen $\mathrm{zu}$ nationalen Konflikten im heutigen Sinne, obwohl es Anzeichen für protonationalistische Auseinandersetzungen gibt. Dennoch haben diese kaum die mehrhundertjährige Beziehungsgeschichte geprägt oder sind gar als tausendjährige Auseinandersetzung zwischen `Germanen « und >Slawen zu klassifizieren. ${ }^{18}$ Vermeintlich national aufgeladene Konflikte wie die des Deutschen Ordens mit Polen oder die hussitische Reformation als eine Form des tschechischen Freiheitskampfes sind ebenso wie Vorstellungen einer spezifischen deutschen >Kulturmission tionen des 19. Jahrhunderts zu betrachten. ${ }^{19}$ Bedeutender sind in der Geschichte der ostmitteleuropäischen Gesellschaften andere Unterschiede und Gemeinsamkeiten, wie Religion und sozialer Stand. ${ }^{20}$ Dabei kam es immer wieder zu wechselseitigen, friedlichen, sprachlichen und kulturellen Assimilationen, die sowohl der Vorstellung eines permanenten Nationalitätenkampfes als auch der vermeintlichen Konstanz nationaler Zugehörigkeit widersprechen. ${ }^{21}$ Ebenso wenig sollte aber eine nachträgliche Mythisierung eines vermeintlich ausschließlich idyllischen Zusammenlebens verfolgt werden. Philipp Ther weist in diesem Zusammenhang darauf hin, dass die heute so gerne vorgebrachte Erzählung, in der »kulturelle Vielfalt gefeiert oder deren Verlust betrauert

15 Vgl. Bauer: Migration in der schlesischen Ceschichte, 2017, S. 254.

16 Vgl. für eine knape Übersicht über die deutschen Siedlungsgebiete in Ostmittel- und Osteuropa mit einer kurzen Beschreibung: Kossert: Kalte Heimat, 2009, S. 18-26.

17 Vgl. zum Begriff der >Volksdeutschen<: Kochanowski; Zwicker: Volksdeutsche, 2015, S. 667f.

18 Suppan sieht das österreichisch-deutsch-tschechische Verhältnis auf der Ebene des Zwischenmenschlichen eigentlich bis 1914 als »im Wesentlichen konfliktfrei« und verweist auf Mischehen oder Sprachwechsel: Suppan: Hitler-Beneš-Tito, 2014, S. 1725. Seibt formuliert es klar: »Die Deutung der böhmischen Geschichte als das >Ringen zweier Völker ist ein Irrtum aus Unwissenheit«: Seibt: Tausend Jahre Böhmen und Mähren (1999), 2002, S. 5. Vgl. auch: Hackmann: German East or Polish West? 2011, S. 116f.

19 Vgl. dazu: Belzyt: Ostkolonisation, 2014.

20 Vgl. Kossert: Kalte Heimat, 2009, S. 24. Konstitutiv für Böhmen ist das Überlappen der deutschen und tschechischen Kultur: Řepa: The Czechs, Germans and Sudetenland, 2011, S. 303.

21 Vgl. für Böhmen: Seibt: Die Deutschen in den Böhmischen Ländern, 2002, S. 33-47. 
wird«, zumeist die strukturell segregierende Komponente sowie die »soziale Ungleichheit«, auf der diese alten Ordnungen aufgebaut waren, ausblendet. ${ }^{22}$

Nationale Zuordnungen sind daher besonders im historischen Rückblick fragwürdig und müssen stets entsprechend kritisch bedacht werden. Selbst im vermeintlich hochnationalisierten 20. Jahrhundert bekannten sich beispielsweise etwa 30 Prozent der >Ungarndeutschen nicht zur deutschen Nation; auch in Polen und der Tschechoslowakei war eine nationale Zuordnung sowohl für die Nationalsozialisten als auch später für die polnischen und tschechoslowakischen Behörden bei vielen Personen, aufgrund hybrider oder weiter vorrangig regionaler und konfessioneller Identitäten, schwer eindeutig zu bestimmen. ${ }^{23}$

Dieser kurze und nicht vollständige Überblick zeigt zunächst die Diversität der im und nach dem Zweiten Weltkrieg auf vielfältige Weise von Zwangsmigration betroffenen deutschen Bevölkerungsgruppen. Diese Differenzierung ist für die vorliegende Arbeit insofern relevant, als dass damit unterschiedliche rechtliche und historische Hintergründe vorliegen, die das spätere Geschehen von Flucht und Vertreibung komplex machen. Neben dieser notwendigen Einordnung ist ein nun folgender Blick in die Ideengeschichte der staatlich forcierten Zwangsmigration notwendig.

\subsection{Ideengeschichte staatlicher Zwangsmigration}

Neben einer ersten Referenz auf die Französische Revolution 1789, die das Zeitalter der modernen Nationalstaaten und damit auch des Nationalismus einläutete, hat Michael Schwartz die ethnische Säuberung als Extremform staatlicher Bevölkerungspolitik für das 19. und frühe 20. Jahrhundert nachgezeichnet. ${ }^{24}$ Die moderne Bürokratie förderte nicht nur den Zwang zur eindeutigen nationalen Klassifizierung der Bevölkerung, der moderne Industriestaat schuf auch die technischen, materiellen und logistischen Mittel, um derartige Pläne für »ungleich größere Räume und ungleich größere Massen von Menschen « umzusetzen: »Der ssäubernde Zugriff wurde tendenziell totalitär ${ }^{25}$ Das früheste Beispiel international vertraglich abgesicherter Vertreibungen identifiziert Schwartz im Londoner Vertrag (1827) zwischen Russland, Großbritannien

22 Ther: Die Außenseiter, 2017, S. $39 f$.

23 Piskorski: Die Verjagten, 2013, S. 270. Vgl. zur `Erfindung/der tschechischen in Abgrenzung zu einer deutschen Nation: Řepa: The Czechs, Germans and Sudetenland, 2011, S. 322. Siehe zur völkischen Fiktion »objektiver« nationaler Zuordnung auch: Hahn; Hahn: Der »deutsche Osten«, 2010, S. 382.

24 Schwartz denkt in seinem Werk den Terminus »ethnische >Säuberung « mit Zwangsmigration zusammen.

25 Schwartz: Ethnische »Säuberungen« in der Moderne, 2013, S. 638. Schwartz: Ethnische »Säuberungen « in der Moderne, 2016, S. 36. Hahn/Hahn äußern sich hingegen skeptisch zu den langen Linien bis hin zur französischen Revolution: Hahn; Hahn: Die Vertreibung im deutschen Erinnern, 2010, S. 93. Dagegen unterstreichen Melville, Pešek und Scharf diese lange Geschichte des ethnischen Nationalismus, der auch für die ostmitteleuropäischen Nationalbewegungen maßgeblich war: Melville; Pešek et al.: Einleitung, 2007, S. XIII. Ther formuliert in Bezug auf den modernen Nationalstaat und ethnische Heterogenität: »Der Nationalstaat brachte somit einen Zwang zur Eindeutigkeit mit sich, die Existenz nationaler Minderheiten war eigentlich nicht vorgesehen.«Ther: Die Außenseiter, 2017, S. 75. 
und Frankreich, der die Vertreibung aller Muslime von der gerade befreiten Peloponnes beschloss und mit Unterstützung der französischen Armee durchgesetzt wurde. ${ }^{26}$ Das auf dem Balkan zerfallende Osmanische Reich war ebenso wie die Kolonialgebiete, vor allem in den Siedlerkolonien, ein »Experimentierfeld«, um Gebiete von unerwünschten und für nicht assimilationsfähig gehaltenen Bevölkerungsgruppen zu `befreien . Die Wurzeln der modernen Vertreibungen liegen damit also nicht, wie häufig konstatiert, in den Balkankriegen von 1912/13 und den vermeintlichen dort typischen Rückfällen in eine sarchaische Barbarei mit ihren massiven Gewalttaten und Vertreibungen, sondern weit zuvor im 19. Jahrhundert. ${ }^{27}$ Die Verdrängung der nordamerikanischen Ureinwohner war nicht nur eine >Begleiterscheinung der weißen Besiedelung Amerikas, sondern, wie im berühmten trail of tears, staatlich geplant, organisiert und gewaltsam mit hohen Opferzahlen durchgeführt. ${ }^{28}$ Einen extremen Weg ethnischer >Säuberung ‘ ging das Osmanische Reich im Ersten Weltkrieg, indem es seine armenische und aramäische Bevölkerung gewaltsam in die Wüste sumsiedelteく und so planmäßig ermordete. Schwartz betrachtet diesen Genozid allerdings nicht für sich, sondern ausführlich im wechselseitigen Zusammenhang ethnischer Gewalt und Vertreibung, dem das Osmanische Reich und die Muslime Europas im 19. und 20. Jahrhundert fortwährend ausgesetzt und die den Nationalstaatsbildungsprozessen auf dem Balkan und im Kaukasus inhärent waren. ${ }^{29}$

Oft nicht ausreichend beachtet wird die den meisten Vertreibungs- und genozidalen Politiken immanente soziale Dimension. Die »Verschränkung von Ethno- und Sozialkonflikten« ist nicht nur aus Gründen der Motivation der Akteure von entscheidender Bedeutung, sondern vermutlich auch, um die für die Vertreibung notwendige Bevölkerung zu mobilisieren. ${ }^{30}$ Dies gilt ebenfalls, wenn die Rolle der staatlichen Akteure für die Beschlüsse der Vertreibungen entscheidend sein sollte. ${ }^{31}$ In den Siedlerkolonien Europas ging es zumeist um die Aneignung und Verteilung des von den Ureinwohnern besiedelten Landes, bei der >Beseitigung ethnischer Gruppen wie der Armenier auch um die massive Verteilung von Eigentum. In der Tschechoslowakei und in Polen wurde nach dem Zweiten Weltkrieg ganz bewusst für den Zusammenhang von sozialer Revolution und den nun dafür zur Verfügung stehenden Gebieten als Experimentierfläche geworben. ${ }^{32}$ Begünstigend kam für die neuen Regime hinzu, dass das Ende des

26 Siehe: Schwartz: Ethnische »Säuberungen« in der Moderne, 2013, S. $247 f$.

27 Ebd., S. 626f.

28 Ebd., S. 189-202. Speziell zum trail of tears siehe: S. 192.

29 Ebd., S. $251 f$.

30 Vgl. ebd., S. 281, 635. Schwartz konstatiert ergänzend, dass aber auch die Vorstellung einer ausschließlich »friedlichen Bevölkerung«, der die Gewaltmaßnahmen aufgezwungen werden müssen, falsch ist.

31 Bessel; Haake: Introduction, 2009, S. 9.

32 Vgl. Classheim: Cleansing the Czechoslovak Borderlands, 2016, S. 92-94. In den meisten europäischen Ländern erwarteten und forderten weite Teile der Bevölkerung eine Nachkriegsordnung, die mit einem grundlegenden sozialen/sozialrevolutionären Wandel verbunden sein müsse; vgl. für die entsprechende Haltung der Tschechen: Kural: Tschechen, Deutsche und die sudetendeutsche Frage während des Zweiten Weltkrieges, 1999, S. 71. Siehe auch: Schwartz: Ethnische »Säuberungen« in der Moderne, 2013, S. 518. 
deutschen, polnischen und jüdischen Bürgertums und (Groß-)Bauerntums in Ostmitteleuropa ganzen Bevölkerungsschichten den sozialen Aufstieg ermöglichte. ${ }^{33}$

Wie die Beispiele schon andeuten, sind es keineswegs nur totalitäre oder autoritäre Systeme, die sich des Mittels der Zwangsmigration bedienten, sondern auch demokratische Staaten wie Großbritannien, Frankreich und die USA. ${ }^{34}$ Götz Aly betont, ähnlich wie Schwartz, dass demokratische Staaten keineswegs vor rassistischer Kategorisierung und entsprechenden Umsiedlungsplänen gefeit sind. Aly ebnet allerdings die erheblichen Differenzen von totalitären, autoritären oder demokratischen Staaten in ihren sich konkret stark unterscheidenden Vorgehen nicht ein. ${ }^{35}$

In diesem Zusammenhang lassen sich "globale Wechselwirkungen « und Lernprozesse beobachten, in deren Folge bis zum Ende des Ersten Weltkrieges »[...] ethnische `Säuberung`zu einer international immer stärker akzeptierten Sozialtechnologie großräumiger >Bevölkerungstransfers « wurde. ${ }^{36}$ Ein Charakteristikum von Zwangsmigration in der Moderne ist der in diesen Konflikten oft stattfindende Rollenwechsel vom Opfer zum Täter und umgekehrt. Die zeitlichen Abstände zwischen diesen können kurz, aber auch länger sein - besonders, wenn die Konflikte chronisch sind. ${ }^{37}$ Die soziale Deklassierung Vertriebener führt schließlich häufig zu Radikalisierung und militantem Revanchismus. ${ }^{38}$

Die Entwicklung zum weithin akzeptierten Ideal des ethnisch homogenen Nationalstaates entfaltete eine globale Wirkung. Nachdem dieses Ziel lange Zeit über eine friedliche, möglicherweise forcierte Assimilierung erreicht werden sollte, ließen entsprechende Misserfolge die Akzeptanz für >Bevölkerungstransfers`oder Grenzverschiebungen wachsen. ${ }^{39}$ Einige Verfechter der Appeasement-Politik der 1930er Jahre begründeten die nachgiebige Politik gegenüber Hitler damit, dass dieser >lediglich time Ziel verfolge, die Deutschen in einem solchen ethnisch homogenen Staat zusammenzuführen und damit das aggressive Potenzial begrenzbar bliebe. ${ }^{40}$ Die Zerschlagung der >Rest-Tschechei< zerstörte schließlich diese Hoffnungen, Hitlers Vorstellungen eines Rassenimperiums bewegten sich in anderen dystopischen Sphären. Dem Ideal der Übereinstimmung von Staat und Staatsvolk fielen allerdings im Europa des 20. Jahrhunderts noch viele Gruppen zum Opfer. Für Polen und Tschechen war es nach dem Krieg ein wichtiges Ziel, einen solchen Staat herzustellen, und sie konnten dafür auf

Siehe: Schwartz: Ethnische »Säuberungen« in der Moderne, 2013, S. 636f. In den vorherigen deutschen Planungen sollten die Unter- und Mittelschichten Deutschlands durch Landzuweisung und Versklavung zu neuen Herren werden: Aly: Auschwitz und die Politik der Vertreibung, 2005, S. 40. Vgl. Kap. 3.6, S. $129 f$.

34 Siehe: Schwartz: Ethnische »Säuberungen« in der Moderne, 2013, S. 13f. Ther konstatiert für die Phase des Zweiten Weltkrieges, »dass auch demokratische Staatsmänner für die ethnische Säuberung fast des gesamten östlichen Mitteleuropas eintraten«; »Churchill und andere Staatsmänner (...) glaubten fest an die friedensstiftende Wirkung ethnischer Säuberungen«: Ther: Ein Jahrhundert der Vertreibung, 2007, S. 35. 
den internationalen »Konsens zu einem System homogener Nationalstaaten « zählen. ${ }^{41}$ Dies betraf nicht nur die deutsche Bevölkerung: Im besetzten Polen ging der Befehlshaber der Armia Krajowa 1941 in Hinblick auf das künftige Polen davon aus, »dass die Aussiedlung der Juden aus Polen für alle Landsleute ebenso selbstverständlich sei wie die Abschiebung der Deutschen. $\aleph^{42}$

Vorhaben und Pläne zur »ethnischen Entmischung« oder zur gewaltsamen Vertreibung liefen parallel zu Entwicklungen von Minderheiten- respektive Volksgruppenrechten. Sowohl Zwangsmigrationen als auch die Verhinderung solcher, beispielsweise durch Minderheitenschutz, wurden im 19. und 20. Jahrhundert immer wieder international und rechtlich geregelt. ${ }^{43}$ Seinen vorläufigen Höhepunkt erreichte der Ansatz des Minderheitenschutzes nach dem Ersten Weltkrieg in den Pariser Vorortverträgen, die auf umfassende >Bevölkerungsaustausche`zur Lösung vermeintlicher oder tatsächlicher ethnischer Konflikte verzichteten. Stattdessen wurden international abgesicherte Minderheitenrechte, wie für die deutsche Bevölkerungsgruppe in Polen oder in der Tschechoslowakei, auch gegen den Wunsch dieser Staaten durchgesetzt, um so zur nachhaltigen Friedenssicherung beizutragen. ${ }^{44}$ Bereits kurze Zeit darauf dominierte allerdings das andere Extrem, die vollständige Vertreibung einer Ethnie in Folge des griechisch-türkischen Krieges. Der Vertrag von Lausanne (1923) sanktionierte international die >Umsiedlung< von etwa 1,5 Millionen Griechen aus Anatolien und die von ungefähr 500.000 Türken aus Griechenland und wurde im Folgenden von verschiedenen Politikern und Wissenschaftlern als nachhaltige Friedenslösung für interne und internationale ethnische Konflikte propagiert. Bezeichnend ist, dass für die nationale Zuordnung letztlich die wesentlich leichter zu identifizierende Religionszugehörigkeit entscheidend war. ${ }^{45}$

Fortwährende Konflikte gab es um die deutschen Minderheiten in Polen und der ČSR. Diese Staaten waren nicht bereit, die in den Pariser Vorortverträgen vereinbarten Minderheitenrechte in vollem Umfang zu gewährleisten und standen einer deutschen Bevölkerung gegenüber, die mit dem Verlust ihres Status als Titularnation ${ }^{46}$ haderte, zum großen Teil die neuen Staaten ablehnte, auf eine Angliederung an Deutschland hoffte und diese mindestens in Teilen politisch aktiv anstrebte. Damit war ein Teufelskreis von vorgeworfener und tatsächlicher Illoyalität und staatlicher Diskriminierung und Repression entstanden, die in abgeschwächter Form auch für die nach 1933 einzig

41 Ther: Die dunkle Seite der Nationalstaaten, 2011, S. 17. Vgl. Beer: Flucht und Vertreibung der Deutschen, 2011, S. 33-37. Vgl. auch: Suppan: Hitler-Beneš - Tito, 2014, S. 1221.

42 Madajczyk: Polnische Nation 1918-1945, 2007, S. $135 f$.

43 Vgl. für die frühen Vorläufer dazu: Schwartz: Ethnische »Säuberungen« in der Moderne, 2013, S. 261-298.

44 Vgl. umfassend: ebd., S. 325-361. Vgl. Borodziej: Geschichte Polens im 20. Jahrhundert, 2010, S. $108 \mathrm{f}$.

45 Vgl. ausführlich: Schwartz: Ethnische »Säuberungen« in der Moderne, 2013, S. 396-424.

46 Im Falle Böhmens und der Deutschböhmen handelt es sich um einen weit älteren Konflikt, war doch diese hegemoniale Stellung der Deutsch-Österreicher bereits im 19. Jahrhundert bedroht. Die Situation war in Mähren schließlich noch anders gelagert, wo noch 1905 ein Ausgleich zwischen den Gruppen erreicht werden konnte. 
verbliebene Demokratie in Ostmitteleuropa, die ČSR, galt. ${ }^{47}$ Diese scheinbar unlösbaren Konflikte bestätigten Befürworter der Idee planmäßiger sethnischer Entmischung und Gegner rechtlicher Lösungen, in denen sie eine Unterminierung des Nationalstaates sowohl durch etwaige internationale Sanktionsmächte als auch durch starke und autonome, nicht zur Titularnation gehörende Gruppen sahen.

Drei Modelle konkurrierten letztlich in der Zwischenkriegszeit: das des sich entwickelnden Minderheitenschutzes, das der sethnischen Flurbereinigung des Lausanner Modells sowie das des föderativen Nationalitätenstaates, mit dem die Sowjetunion einen ideengeschichtlich dritten Weg beschritt. ${ }^{48}$ Dieser wurde jedoch schon bald von der russischen Dominanz ausgehöhlt und schließlich durch den ethnisch konnotierten >Klassenmord ‘, den Holodomor in der Ukraine, drastisch und im Zweiten Weltkrieg durch die Deportationen seigener und >fremder Völker in zaristischer Tradition fortlaufend konterkariert. ${ }^{49}$

Nach 1945 konnte sich die rechtliche und konsequente Ächtung von Vertreibungen nur langsam durchsetzen. Über die im Westen und in der wissenschaftlichen Forschung lange nicht weiter beachteten millionenfachen Vertreibungen im Zuge der indisch-pakistanischen Staatsgründungen ${ }^{50}$ oder der gewaltsamen Teilung Zyperns 1974 bis hin zum seine muslimisch-türkischen Minderheiten verdrängenden spätkommunistischen Bulgarien in den 1980er Jahren kam es erst nach den Balkankriegen der 1990er Jahre zu einer interventionistischen, internationalen Anti-Vertreibungspolitik, deren Wirkung, bis auf wenige Ausnahmen, allerdings bisher begrenzt bleibt. ${ }^{51}$ Das nach den Balkankriegen vertraglich festgelegte Rückkehrrecht von Flüchtlingen und Vertriebenen wird aus verschiedenen Gründen, wie der Angst vor erneuter Gewalt, nur eingeschränkt angenommen. Die internationale Intervention im Kosovo-Krieg 1999 festigte schließlich die ethnisch fast vollständige Separation..$^{52}$ Die Vertreibung der muslimischen Ethnie der Rohingya in Myanmar 2017/18 löste international massive Proteste und Vermittlungsversuche aus. Bis dato konnte jedoch eine von der internationalen Gemeinschaft angestrebte Rückkehr in die von den vertreibenden Militäreinheiten häufig bewusst zerstörten Ortschaften nicht erreicht werden. ${ }^{53}$

47 Vgl. Schwartz: Ethnische »Säuberungen« in der Moderne, 2013, S. 337f., 360. Vgl. für die Verbindung des Mythos eines spezifisch tschechischen Demokratiebewusstseins mit einem exkludierenden Nationalismus: Blaive: National Narratives of Czech Identity, 2016, S. 170, 173.

48 Siehe: Schwartz: Ethnische »Säuberungen« in der Moderne, 2013, S. 323.

49 Vgl. ausführlich: ebd., S. 361-395.

50 Vgl. Elie: Histories of Refugee and Forced Migration Studies, 2014, S. $25 f$.

51 Troebst: Towards a European Memory of Forced Migration? 2016, S. 237. Siehe ausführlich: Troebst: Vom Bevölkerungstransfer zum Vertreibungsverbot, 2015. In Hinblick auf Europa ist Troebst der Überzeugung, dass tatsächlich von einem erfolgreichen Lerneffekt gesprochen werden kann (S. 188f.).

52 In Bezug auf das Rückkehrrecht von 1995 identifiziert Marie-Janine Calic die Probleme: »Haupthindernisse für die Rückkehr sind nach wie vor Diskriminierung, Sicherheitsprobleme, ungeklärte Eigentums- $u$. Staatsbürgerfragen sowie fehlende Arbeits- und Bildungsmöglichkeiten.«Calic: Dayton-Abkommen, 2010, S. 112.

53 Myanmar akzeptiert Rückkehr der Rohingya aus Bangladesch. Zeit Online. 23.11.2017. Militär macht Dörfer dem Erdboden gleich. tagesschau.de. 23.02.2018. 
Jenseits dieses global fortwirkenden Phänomens sentwickelten die Nationalsozialisten das Konzept des ethnisch homogenen Nationalstaates zum Rassenstaat 'weiter.$^{54}$ Dem schließt sich eine Diskussion an, inwieweit zwischen den angeführten älteren Traditionslinien und dem Exzeptionellen des Nationalsozialismus gewichtet werden muss. ${ }^{55}$ Dass erst die Zerstörung der europäischen Ordnung durch das Deutsche Reich die Grundlage für die Vertreibung von Millionen schuf, soll im Folgenden gezeigt werden.

\subsection{Zwischenkriegszeit}

Nach dem Ersten Weltkrieg stellte sich sowohl für die deutschen Bevölkerungen außerhalb Deutschlands und Österreichs als auch für die sie umgebenden Gesellschaften die drängende Frage der Gestaltung eines zukünftigen Zusammenlebens, auf die keine Antwort gefunden werden konnte.

Das national-föderative Konzept Piłsudskis konnte sich im neu entstandenen Staat nicht durchsetzen. Die folgenden polnischen Regierungen sahen die Polen als Hegemonialnation und verstärkten den Anpassungsdruck auf die Minderheiten. ${ }^{56}$ In Hinblick auf die Minderheitenrechte war die deutsche Bevölkerung aber - auch gedeckt und gefördert durch sihren Staat - im Vergleich zu den großen nationalen Minderheiten der II. Republik, den Ukrainern und Weißrussen, bessergestellt. ${ }^{57}$

In nationalistischen Kreisen forderte und feierte man die schnellen Erfolge der $>$ Entdeutschung der Westprovinzen, wobei die entsprechende Politik der kaiserzeitlichen Germanisierungspolitik ähnelte und auch so wahrgenommen wurde. ${ }^{58}$ Die polnische Politik war allerdings ungleich erfolgreicher, da viele Deutsche das Leben in einem deutschen Staat vorzogen und formal freiwillig emigrierten. ${ }^{59}$ Die Verbliebenen, mehrere hunderttausend Deutsche, waren eine heterogene Gruppe und bis 1939 wurde keine Vereinheitlichung ihrer Organisationen wie in der ČSR erreicht. ${ }^{60}$ Bereits in der Vorkriegszeit entstandene Pläne eines weit nach Westen expandierenden polnischen Staates, dessen Grenzen sich bis zur Oder ausdehnen sollten, wurden von Teilen der

Vgl. Schlögel: Die Europäisierung des »Vertreibungskomplexes«, 2005, S. 134. Vgl. auch: Schwartz: Ethnische »Säuberungen« in der Moderne, 2013, S. 627.

56 Siehe: Gehrke: Der polnische Westgedanke, 2001, S. 337f. Siehe auch: Madajczyk: Polnische Nation 1918-1945, 2007, S. 127-129.

57 Siehe: Borodziej: Geschichte Polens im 20. Jahrhundert, 2010, S. 131.

58 Vgl. Gehrke: Der polnische Westgedanke, 2001, S. 339-341. Vgl. Borodziej: Ceschichte Polens im 20. Jahrhundert, 2010, S. 133.

59 Vgl. ebd., S. 131. Siehe auch: Schwartz: Ethnische »Säuberungen« in der Moderne, 2013, S. 347.

60 Damit taugte die deutsche Volksgruppe nach Kittel und Möller nur bedingt zur »Fünften Kolonne«; gleichzeitig äußern sie Verständnis für die Enttäuschung der Deutschen in Polen gegenüber diesem Staat, der eine »fragwürdige >Entdeutschungspolitik« verfolgte: Kittel; Möller: Die BenešDekrete, 2006, S. 553. Vgl. zur schwierigen Kalkulation der Anzahl der Deutschen im Polen der Zwischenkriegszeit: Wissenschaftliche Dienste des Deutschen Bundestages: Deutsche Minderheiten in der Zwischenkriegszeit, 2009, S. 8f. 
polnischen Nationaldemokraten vertreten, galten aber in ihren radikalsten Forderungen als utopisch und entsprangen der nationalistischen Verklärung des Piastenstaates des Mittelalters. ${ }^{61}$ Diese Gruppen betrachteten bereits damals Schlesien, Pommern und Ostpreußen als »urpolnisches « Gebiet. ${ }^{62}$

Polen gelang es weder, ein konstruktives Verhältnis zu seinen Minderheiten noch zu seinen Nachbarn zu erreichen. Selbst mit der Tschechoslowakei befand es sich im Konflikt um das Teschener Schlesien. Dies verschärfte die Situation gegenüber den mit den gegnerischen Nachbarn vermeintlich oder tatsächlich verbundenen Minderheiten wie den der Sympathie mit der Sowjetunion verdächtigten Ukrainern, Weißrussen und Juden. Die ungeklärte Frage der Westgrenze vergiftete nicht nur das politische Verhältnis zu Deutschland; auch der Einfluss des damit verbundenen deutschen Revisionismus auf das Erstarken des deutschen Nationalismus in der Weimarer Republik ist »kaum zu überschätzen «. ${ }^{63}$

Der in Österreich-Ungarn bis zum Ende des Ersten Weltkrieges stets virulente, aber nie gelöste Konflikt zwischen der tschechischen und deutschen Bevölkerung Böhmens belastete das Klima bei der Gründung der Tschechoslowakei 1918/19 massiv. ${ }^{64}$ Die Deutschböhmen forderten das 'Selbstbestimmungsrecht nach Woodrow Wilson ein und versuchten, die Abspaltung der mehrheitlich deutsch besiedelten Gebiete an Deutschösterreich $\mathrm{zu}$ erreichen, die aber aufgrund der raschen und punktuell gewaltsamen militärischen Intervention tschechoslowakischer Kräfte nicht erfolgreich war. ${ }^{65}$ Daran änderten auch die Wahlen nichts, die den separatistischen Parteien in den Sudetengebieten zunächst klare Mehrheiten brachten. ${ }^{66}$ Für die sich durch heterogene und häufig starke lokale und regionale Identitäten auszeichnenden Deutschböhmen und Deutschmährer setzte sich nun zunehmend der Begriff der Sudetendeutschen durch. Dies ist darauf zurückzuführen, dass die neue politische Konstellation im tschechoslowakischen Staat eine solche sprachlich-politische Zusammenführung zur Behauptung der Interessen der deutschen Bevölkerungsgruppe zu gebieten schien. ${ }^{67}$ Letztlich setz-

61 Vgl. zum polnischen Westgedanken vor 1939/45: Kulczycki: Belonging to the Nation, 2016, S. 2124. Siehe ausführlich die Dissertation von: Gehrke: Der polnische Westgedanke, 2001. Siehe auch: Demshuk: Reinscribing Schlesien as Śląsk, 2012, S. 42.

62 Olschowsky: Der wenig vertraute Nachbar - Das Bild Polens in der DDR, 2009, S. 142.

63 Siehe: Borodziej: Ceschichte Polens im 20. Jahrhundert, 2010, S. 122-124, 164-169. Vgl. zum Scheitern der polnischen Minderheitenpolitik am Beispiel der sechs Millionen Ukrainer in Polen auch: Rossoliński-Liebe: Der polnisch-ukrainische Konflikt im Historikerdiskurs, 2017, S. 30. Siehe spezifisch zum polnisch-tschechoslowakischen Konflikt um das südliche Oberschlesien auch: Smolorz; Kordecki: Schauplatz Oberschlesien, 2019, S. 153-158, 249-271.

64 Vgl. ausführlich zur »Deutsch-Tschechischen Konfliktgemeinschaft« 1848-1914: Suppan: Hitler Beneš - Tito, 2014, S. 143-180. Den Begriff eingeführt hat: Křen: Die Konfliktgemeinschaft, 1996.

65 Bei separatistischen Demonstrationen kam es in verschiedenen Orten Böhmens zur Erschießung von 54 Personen und mindestens 84 Verletzten, »darunter auch Greise und Kinder«: Suppan: Hitler - Beneš - Tito, 2014, S. 355. Vgl. für eine kritische Besprechung und tschechische Perspektive auf das eingeforderte >Selbstbestimmungsrecht«: Hahn; Hahn: Die sudetendeutsche völkische Tradition, 2004, S. 51-62.

66 Suppan: Hitler - Beneš - Tito, 2014, S. 359.

67 Siehe: Classheim: Cleansing the Czechoslovak Borderlands, 2016, S. 31f. VgI. Řepa: The Czechs, Cermans and Sudetenland, 2011, S. 309. 
te sich der Terminus als Eigenbezeichnung aber erst nach 1945 weitgehend durch. ${ }^{68}$ Zusammen stellten die Deutschböhmen, Deutschmährer und Karpatendeutschen der Slowakei im tschechoslowakischen Staat mit 23,4 Prozent (und auf dem Gebiet des heutigen Tschechiens mit etwa 30 Prozent) und etwa 3,1-3,3 Millionen Menschen in ihren weitgehend geschlossenen Siedlungsgebieten im Grenzland und den Sprachinseln die größte Minderheit. In der ungefragten Aufnahme der Deutschen, Magyaren, Polen, Ukrainer und Juden in den tschechoslowakischen Nationalstaat sieht Arnold Suppan einen »Geburtsfehler « der ČSR. ${ }^{69}$ Bereits damals von »nicht nur extrem nationalistische[n] Außenseiter[n] « geäußerte Forderungen nach »Aussiedlung des deutschen Elements« sowie die Rede des Staatsgründers Tomáš G. Masaryks von den Sudetendeutschen als Kolonisten erschwerten die Situation zusätzlich. ${ }^{70}$ Versprechungen, einem föderativen Modell ähnlich dem Schweizer System zu folgen und damit diesen Minderheiten eine tatsächliche Gleichberechtigung zu gewähren, wurden nie umgesetzt. ${ }^{11}$

Die Beziehungen der ČSR zu Deutschland (bis 1933) und Österreich (bis 1938) waren »trotz der offenen sudetendeutschen Frage« relativ unproblematisch, auch wenn dieses Verhältnis letztlich entscheidend von der Tragfähigkeit des Versailler Systems abhing. ${ }^{72}$ Auf der politischen Bühne der Weimarer Republik gab es keine ernsthaften territorialen Forderungen oder Bestrebungen, die ČSR zu beseitigen. ${ }^{73}$ Die mit der Regierung kooperierenden Sudetendeutschen wurden in Berlin teilweise als Möglichkeit gesehen, die Tschechoslowakei mittelfristig als Partner zu gewinnen. ${ }^{74}$

Das demokratische, rechtstaatliche System bot den Sudetendeutschen trotz vielfältiger Diskriminierungen ein gewisses Mitbestimmungsrecht und führte von 1925 bis $1935 \mathrm{zu}$ einer anhaltenden Beteiligung deutscher Parteien an der tschechoslowakischen Regierung. ${ }^{75}$ Besonders die in Böhmen traditionell starken Sozialdemokraten setzten sich für eine Verständigung ein, gerieten jedoch nach 1933 durch die vom Deutschen Reich aus immer stärker unterstützen und aufgewiegelten Sudetendeutschen zunehmend unter Druck. Die von Konrad Henlein 1933 gegründete und geführte nationalsozialistisch ausgerichtete Sudetendeutsche Partei (SdP) erzielte stetig größere Wahlerfolge und vereinte bei den Wahlen 1935 bereits 68 Prozent der sudetendeutschen Stimmen auf sich. ${ }^{76}$ Piotr M. Majewski konstatiert weitergehend, dass ein Großteil der sudetendeutschen Bevölkerung bereits lange vor 1933 eine tiefergehende Sympathie zum au-

68 Vgl. Kap. 1.1, S. 21f. und Kap. 6.4, S. $340 f$.

69 Suppan: Hitler - Beneš - Tito, 2014, S. 332.

70 Kittel; Möller: Die Beneš-Dekrete, 2006, S. 575.

71 Siehe: Suppan: Hitler - Beneš - Tito, 2014, S. $362 f$.

72 Ebd., S. $30 f$.

73 Kubů: Die brüchigen Beziehungen, 2001, S. 84.

74 Vgl. Douglas: »Ordnungsgemäße Überführung«, 2012, S. 25.

75 Vgl. ausführlich zum sudetendeutschen Konflikt aber auch den Phasen des positiven Zusammenwirkens in der Zwischenkriegszeit: ebd., S. 20-59. Vgl. auch: Křen: Nationale Selbstbehauptung im Vielvölkerstaat, 1986, S. 42-50. Siehe ebenfalls: Seibt: Tausend Jahre Böhmen und Mähren (1999), 2002, S. 8 f. Kittel und Möller bewerten die ČSR-Sprachen- und Minderheitenpolitik hingegen weitaus kritischer und sehen hier keine sichtbaren Verbesserungen durch die Beteiligung deutscher Parteien an den Regierungen der ČSR: Kittel; Möller: Die Beneš-Dekrete, 2006, S. 557. 
toritären, totalitären und völkischen Nationalismus hatte. ${ }^{77}$ Andere Autoren sehen hingegen die staatliche Diskriminierung und die die deutschen Siedlungsgebiete besonders hart treffende Weltwirtschaftskrise als entscheidend für die Hinwendung zum nationalsozialistischen Deutschland und seinen sudetendeutschen Unterstützern. ${ }^{78}$ Die verschiedenen NS-Gegner unter den Sudetendeutschen, die schon angesprochenen Sozialdemokraten, aber auch Angehörige des Adels und der katholischen Kirche standen letztlich auf verlorenem Posten. ${ }^{79}$ Erschien für viele Sudetendeutsche und Tschechen bereits vor 1938 das Zusammenleben als schwierig bis unmöglich, so war das für die meisten Sudetendeutschen befreiende Erlebnis von >München für die Tschechen das traumatische Ereignis des 20 . Jahrhunderts. ${ }^{80}$ Unmittelbar danach wurden vorher nur theoretisch denkbare Möglichkeiten in der verbliebenen Tschechoslowakei und schließlich im Exil erörtert: die Trennung der beiden Völker.

\subsection{Zweiter Weltkrieg}

Weder gelang der Tschechoslowakei die Gewinnung der deutschsprachigen Bevölkerung noch gab es eine für alle Seiten akzeptable Lösung für die deutsche Volksgruppe in Polen und für die Danzig- und `Korridorfrage ${ }^{81}$ Alle Regierungen der Weimarer Republik strebten eine Revision der deutsch-polnischen Grenze an. ${ }^{82}$ Die Versuche der polnischen Regierungen, den Anteil der Deutschen in Polen zu senken, zeigten zwar Wirkung, führten aber zu einer weiteren Beschädigung der Verhältnisse. ${ }^{83}$ Diese ungelösten Konfliktfelder übernahm die nationalsozialistische Diktatur ab 1933. Die wirtschaftlich besonders schwierige Lage sowie ein verstärktes Bedrohungsgefühl in den Grenzgebieten verhalfen den Nationalsozialisten dort zu großen Wahlerfolgen. Mit der aggressiver werdenden NS-Außenpolitik wurden sowohl die Regierung der Freien Stadt Danzig, die bereits seit 1933 nationalsozialistisch regiert wurde, als auch die sich zur Massenbewegung entwickelnde Sudetendeutsche Partei (SdP) tatsächlich zu einer >fünften Kolonneく der deutschen Expansionspolitik. ${ }^{84}$ Mit Unterstützung der SdP begannen bereits vor dem Einmarsch der Wehrmacht mit militärischen Mitteln durchgeführte >Aufstände` gegen die ČSR.

Mit dem Münchner Abkommen von 1938, in dem Deutschland mit Großbritannien, Frankreich und Italien ohne Beteiligung der ČSR die Abtretung der Sudetengebiete durchsetzte, begann zugleich die erste Phase von Zwangsmigrationen im direkten

Vgl. die Zusammenfassung von: Majewski: »Niemcy Sudeccy«, 2007, S. 457-461. Vgl. ähnlich: Houžvička: Czechs and Germans 1848-2004, 2015, S. 478.

78 Vgl. McDermott: Communist Czechoslovakia, 1945-89, 2015, S. $9 f$.

79 Vgl. Suppan: Hitler - Beneš - Tito, 2014, S. 1220.

80 Ebd., S. 490, $1229 f$.

81 Borodziej: Ceschichte Polens im 20. Jahrhundert, 2010, S. 110. Vgl. Piskorski: Die Verjagten, 2013, S. 76. Vgl. ausführlich: Stach: Minderheitenpolitik in der Zweiten Polnischen Republik 1918-1939, 2010, S. 394-412.

82 Vgl. Hahn; Hahn: Die Vertreibung im deutschen Erinnern, 2010, S. 304.

83 Vgl. Gehrke: Der polnische Westgedanke, 2001, S. $337 f$.

84 Douglas: „Ordnungsgemäße Überführung«, 2012, S. $27 f$. 
Vorfeld des Zweiten Weltkrieges. ${ }^{85}$ Ungefähr 139.000 Tschechen sowie 37.000 Staatsangestellte mit ihren Familien wurden aus den an Deutschland gefallenen Gebieten ausgewiesen, flohen oder verließen diese >freiwillig ${ }^{86}{ }^{86}$ Etwa 290.000 Tschechen verblieben. ${ }^{87}$ Das Münchener Abkommen spielte für die spätere Rechtfertigung der Vertreibung der Deutschen eine mehrfach wichtige Rolle, da zum einen die tschechoslowakischen Staatsbürger deutscher Nationalität aus Sicht der tschechoslowakischen Regierung mit ihrem Handeln zu Hochverrätern am gemeinsamen Staat wurden und man sich zum anderen durch die befreundeten Staaten Großbritannien und Frankreich verraten und hintergangen sah. ${ }^{88}$ Diese Erfahrungen und Einschätzungen verdeutlichten tschechoslowakischen Politikern und Intellektuellen nachhaltig, dass eine große deutsche Bevölkerungsgruppe stets zu einem staatsgefährdenden Risiko werden könnte, bei dem das zwischen deutschen Siedlungsgebieten exponiert liegende Tschechien im Zweifelsfall nicht auf internationale Unterstützung hoffen konnte. Dasselbe galt in ähnlichem Maße für das 1939 von Deutschland angegriffene Polen und die Sicherung seiner zukünftigen Integrität. ${ }^{89}$

Polen wurde im September 1939 von den Alliierten nicht im Stich gelassen, auch wenn die Kriegserklärungen Frankreichs und Großbritanniens an Deutschland nach dessen Einmarsch in Polen die militärisch aussichtslose Lage nicht änderten. Die ungelöste Danzig-Frage ebenso wie die Minderheitenproblematik waren der offizielle Anlass für den Angriff; de facto musste Polen - nachdem es dem Druck, ein deutscher Satellit im Kampf gegen die Sowjetunion zu werden, widerstanden hatte - für Hitlers Lebensraumpläne im Osten beseitigt werden. ${ }^{90}$ Unmittelbar nach Kriegsausbruch kam es durch Behörden und Einheiten Polens sowie durch lokale Milizen zu einer Reihe von Erschießungen und improvisierten Evakuierungen von als politisch unzuverlässig eingeschätzten, aber auch willkürlich ausgewählten Volksdeutschen mit etwa 4500 bis 6000 Todesopfern. ${ }^{91}$ Umgekehrt kam es zu Übergriffen und Verbrechen durch volksdeutsche Milizen, wie dem »Volksdeutschen Selbstschutz« und bis heute in ihrem Ausmaß umstrittenen volksdeutschen Partisanentätigkeiten, die von polnischer Seite viel-

85 Vgl. Beer: Flucht und Vertreibung der Deutschen, 2011, S. 38.

86 Brandes: Flucht aus den Sudetengebieten 1938, 2010, S. 246. Reichel und Petrbok schreiben von »mindestens 300.000 Personen«, die »die Grenzgebiete verlassen mussten«: Reichel; Petrbok: Von »destruktiven Nationalisten«, 2019, S. 374.

87 Schwartz: Ethnische »Säuberungen« in der Moderne, 2013, S. $434 \mathrm{f}$.

88 Vgl. Suppan: Hitler-Beneš - Tito, 2014, S. 487. Siehe auch: Lemberg: »München 1938«, 2001, S. 111f.

89 Vgl. Naimark: Flammender Haß, 2004, S. $173 \mathrm{f}$.

90 Vgl. Wolf: Die deutschen Minderheiten in Polen als Instrument der expansiven Außenpolitik Berlins, 2006, S. 66. Siehe auch: Borodziej: Geschichte Polens im 20. Jahrhundert, 2010, S. 186. Vgl. zur zunehmend angespannten Lage zwischen Volksdeutschen, Polen und dem polnischen Staat unmittelbar vor dem Krieg: Kochanowski: Verräter oder Mitbürger? 2006, S. $335 f$.

91 Jastrzebski: Die deutsche Minderheit in Polen im September 1939, 2012, S. 174f. Piskorski spricht von 6000 toten Deutschen, die »während ihrer Evakuierung nach Osten ums Leben kamen oder getötet wurden. «Piskorski: Zwangsmigrationen im Kontext des Zweiten Weltkriegs, 2014, S. 156f. Vgl. zur anhaltenden Kontroversität auch innerhalb der polnischen Forschung u.a.: Krzoska: Bromberger Blutsonntag, 2014, S. 357f. Siehe dazu ausführlich auch: Machcewicz: Spory o historie 20002011, 2012, S. 232-239. 
fach als Ursache der folgenden Gewalt bewertet werden. ${ }^{92}$ In jedem Fall wurden die Ereignisse von der nationalsozialistischen Agitation unter dem Schlagwort des »Bromberger Blutsonntages ${ }^{93}$ umgehend genutzt, um massive Vergeltung an vermeintlichen Tätern zu üben und eine propagandistische Grundlage für die bereits vorher geplanten Massenmorde an gelisteten Persönlichkeiten zu haben. Bis Ende 1939 wurden so etwa 60.000 Polen, unter ihnen einige Tausend polnische Juden, ermordet. ${ }^{94}$ Gleichzeitig wurden umgehend 88.000 Polen und polnische Juden aus den für die deutsche Besiedlung vorgesehenen Gebieten ins Generalgouvernement deportiert, wobei ihr Tod unter den widrigen Bedingungen bewusst in Kauf genommen wurde. ${ }^{95}$ Letztlich sollten etwa eine Million Menschen aus den vom Reich annektierten polnischen Provinzen Pommerellen und Großpolen >umgesiedelt $<$ werden. ${ }^{96}$

Hitler skizzierte im Oktober 1939 in seiner Rede im Reichstag die »ethnographische Neuordnung « Europas nach seinen Vorstellungen. ${ }^{97}$ Auch wenn er das Lausanner Vokabular verwendete, ist nach Michael Wildt mit dieser Rede die »klassische europäische Machtpolitik « verlassen und eine spezifisch nationalsozialistische Zukunft für Europa entwickelt worden: »Die völkische Neuordnung der Nationalsozialisten hatte keine Karte von Staaten mehr im Blick, sondern von Völkern und Volksgruppen, die rassenbiologisch bewertet und dementsprechend in ihrer Existenzberechtigung und $>$ Nutzbarmachung ‘ für das deutsche >Herrenvolk $<$ hierarchisch eingestuft wurden. ${ }^{98}$ Die von Hitler geforderte und mit dem Hitler-Stalin-Pakt weitgehend erreichte >Heimholung der »Splitter deutschen Volkstums« in Ostmitteleuropa steht dabei in unmittelbarem Zusammenhang mit den stürmischen und chaotischen Vertreibungen, Ghettoisierungen und Ermordungen von Polen und Juden, um in möglichst kurzer Zeit Wohnraum und eine jjudenfreie Umgebung für die volksdeutschen Umsiedler zu schaffen. ${ }^{99} \mathrm{Im}$ Gegensatz zur Darstellung in der Propaganda war die Umsiedlung der etwa einen Million Volksdeutschen weder gut organisiert noch konnten die entsprechenden Ansiedlungsziele erreicht werden; vielmehr mussten viele Volksdeutsche jahrelang in Lagern auf ihre Ansiedlung warten. ${ }^{100}$

Das tatsächliche Handeln der nationalsozialistischen Besatzer wäre nochmals übertroffen worden, wenn es zur Umsetzung der weitreichenden Pläne, hier vor allem des Generalplan Ost, gekommen wäre. Neben der Ausbeutung, Ermordung und Massenvertreibung von 30 bis 40 Millionen >fremdrassigen Elementen<, also großer Teile der russischen/sowjetischen Bevölkerung, war nach einem siegreichen Ende und einer langfris-

92 Gerhard Wolf geht von einer großen Bedeutung der volksdeutschen Kräfte gegenüber Polen aus: Wolf: Die deutschen Minderheiten in Polen als Instrument der expansiven Außenpolitik Berlins, 2006, S. 67-69. Bromberg/Bydgoszcz war einer der zentralen Orte der über ganz Polen verteilten Ereignisse.

94 Piskorski: Die Verjagten, 2013, S. 116.

95 Wildt: »Völkische Flurbereinigung«, 2016, S. 72f.

96 Piskorski: Zwangsmigrationen im Kontext des Zweiten Weltkriegs, 2014, S. 159.

97 Siehe: Suppan: Hitler - Beneš - Tito, 2014, S. 1370f.

98 Wildt: »Völkische Flurbereinigung«, 2016, S. 68.

99 Lemberg: Das Jahrhundert der Vertreibungen, 2003, S. 49. Dabei wurde »Polen (...) zum Laboratorium der nationalsozialistischen Rassenpolitik. «(Beer: Flucht und Vertreibung der Deutschen, 2011, S. 42).

100 Piskorski: Die Verjagten, 2013, S. $160 f$. 
tigen deutschen Siedlungsgrenze am Ural keine Zukunft für die polnische oder tschechische Bevölkerung als selbstständige politische Entitäten vorgesehen. ${ }^{101}$

In den polnischen Besatzungsgebieten begann neben der systematischen Ausschaltung der Intelligenz und potenzieller Gegner der Deutschen umgehend die Reintegration der nach dem Ersten Weltkrieg verlorenen Gebiete. Die >Bevölkerungspolitik « unterschied sich in den neu geformten oder vergrößerten Gauen in der Praxis, nicht aber in der Zielsetzung. Der >Zielkonflikt « bestand darin, die Gebiete möglichst schnell >deutsch zu machen<, keine wirtschaftlichen Verluste durch etwaige Abschiebungen von Arbeitskräften zu erleiden und die deutsche Bevölkerungszahl zu stabilisieren und zu vergrößern. ${ }^{102}$ Neben der Ansiedlung der Volksdeutschen wurde hierfür die Deutsche Volksliste (DVL) genutzt. Freilich bedeutete die Eintragung in die DVL keine gleichberechtigte Anerkennung als deutscher Staatsbürger, sondern die Erwartung, sich unbedingt zum >Deutschtum $>\mathrm{zu}$ bekennen und entsprechenden Pflichten und Sanktionsmechanismen $\mathrm{zu}$ unterliegen. Die Untergliederung der Liste in vier Kategorien klassifizierte diese selbst wieder nach politischen und >rassischen $<$ Kriterien. ${ }^{103}$ Im Generalgouvernement erlitten die dort lebenden oder dorthin verbrachten Polen eine quasi koloniale Besatzungsherrschaft, die eine maximale Ausbeutung des Gebietes und der Menschen vorsah und schließlich zum wesentlichen Ort der Shoa wurde. ${ }^{104}$

Für Polen begann mit dem Hitler-Stalin-Pakt das Ende seiner seit dem Mittelalter zum polnisch-litauischen Staatenverbund und später zum Zwischenkriegspolen gehörenden Ostgebiete. ${ }^{105}$ Auch wenn diese Gebiete insgesamt nur zu etwa einem Drittel von Polen besiedelt wurden, waren (und sind) sie doch ein zentraler Bestandteil polnischer Identität und Kultur. ${ }^{106}$ Überwiegend von Polen besiedelte Städte wie Lemberg oder Wilna waren kulturell bedeutende polnische Metropolen, auch wenn die Polen im Falle Lembergs nur eine knappe Mehrheit stellten und in beiden Fällen das Umland stärker ukrainisch oder litauisch geprägt war. Neben dem großen Anteil der jüdischen Bevölkerungsgruppe handelte es sich bei den Ukrainern, Litauern und Weißrussen um aufstrebende Nationalbewegungen, die den polnischen Anspruch auf diese Städte und Gebiete zunehmend herausforderten. Als Vertreter der Interessen der Weißrussen und

101 Beer: Flucht und Vertreibung der Deutschen, 2011, S. 45f. Alle entsprechenden Pläne wurden jedoch unter das »reibungslose Funktionieren der Protektoratswirtschaft« gestellt und damit nicht umgesetzt; Hitler selbst kalkulierte für die abschließende Germanisierung des böhmischen Raumes 100 Jahre. In Folge des Heydrich-Attentates wurde gleichwohl die Marionettenregierung in Prag mit millionenfacher Umsiedlung der Tschechen bedroht: Brandes: Nationalsozialistische Tschechenpolitik im Protektorat Böhmen und Mähren, 2001, S. 122-124, 172. Suppan spricht vom geplanten »Ethnozid«: Suppan: Hitler - Beneš - Tito, 2014, S. 1759.

102 Vgl. zur unterschiedlichen Politik in den verschiedenen Besatzungsgebieten: Kochanowski; Zwicker: Volksdeutsche, 2015, S. $667 f$.

103 Vgl. dazu den Überblick von: Frackowiak: Die »Deutsche Volksliste« als Instrument der nationalsozialistischen Germanisierungspolitik in den annektierte Gebieten Polens 1939-1945, 2013. Siehe auch: Heinemann: »Deutsches Blut«, 2006, S. 169-177.

104 Vgl. Borodziej: Geschichte Polens im 20. Jahrhundert, 2010, S. 198-210.

105 Vgl. v.a. zur Ideengeschichte der kresy: Kleßmann; Traba: Kresy und Deutscher Osten, 2012, S. 3756.

106 Vgl. für die schwierige Quellenlage zur Bevölkerungsstatistik in den kresy: Ruchniewicz: Zwangsumsiedlungen von Polen, 2005, S. 164. 
Ukrainer sah sich die Sowjetunion, die damit auch den Einmarsch in Ostpolen 1939 rechtfertigte.

Den sowjetischen Terror gegen die Polen in den von der Roten Armee okkupierten Gebieten führten die Deutschen nach der Eroberung dieser Gebiete 1941 weiter. ${ }^{107}$ In Wolhynien und Ostgalizien kam es im Schatten des Krieges zu bürgerkriegsähnlichen Auseinandersetzungen und rethnischen Säuberungen zwischen ukrainischen und polnischen Kräften, die allerdings eine weit höhere Zahl ziviler polnischer Opfer forderten. ${ }^{108}$ Die verbliebene polnische Bevölkerung der kresy wurde bereits ab 1944 rausgesiedelt $<$, zumeist unter widrigsten Bedingungen. ${ }^{109}$ Insgesamt verließen in der Kriegsund Nachkriegszeit etwa 2,5 Millionen Polen als >Repatrianten $<$ die von der Sowjetunion annektierten Gebiete. Für die Bevölkerung in Weißrussland und Litauen bestand teilweise eine eingeschränkte `Optionsmöglichkeit « unter offizieller Aufgabe ihrer polnischen Identität. Schwere Kämpfe und ethnische `Säuberungen im polnisch-ukrainischen Siedlungsgebiet hatten dort bereits vorher zu einer faktischen Vertreibung geführt, wobei sich die zum Teil gewaltsame sethnische Entflechtung zwischen Polen und der Ukraine noch bis 1947 fortsetzte. ${ }^{110}$

Die deutsche Besatzungspolitik in dem im Frühjahr 1939 quasi als innereuropäische Kolonie gegründeten >Protektorat Böhmen und Mähren war von pragmatischen Erwägungen geprägt. ${ }^{111}$ Die Schwerindustrie ebenso wie das dafür notwendige Wohlwollen der tschechischen Arbeiter waren für die Rüstungsindustrie unverzichtbar. ${ }^{112}$ Durch verschiedene sozialpolitische Maßnahmen sowie durch punktuell harte - und damit immer drohende - Brutalität konnte >Ruhe aufrecht erhalten werden. ${ }^{113}$ Der tschechische Widerstand blieb in der ersten Zeit des Krieges vergleichsweise gering und passiv; so wurde auch das Attentat auf Reinhard Heydrich von eingeflogenen Kämpfern durchgeführt. ${ }^{114}$ Das mit dem Anschlag verbundene Ziel, den Widerstand des tschechischen Volkes zu verstärken, wurde allerdings verfehlt. Bis zuletzt gelang es den Deutschen

107 Vgl. für die Kooperation sowie die unterschiedlichen Formen und Ziele deutscher und sowjetischer >Polenpolitik«: Ruchniewicz: Zwangsmigration als Instrument, 2016, S. 125-140.

108 Vgl. für eine kurze Zusammenfassung des Konfliktes: Rossoliński-Liebe: Der polnisch-ukrainische Konflikt im Historikerdiskurs, 2017, S. 37-40. Vgl. Borodziej: Ceschichte Polens im 20. Jahrhundert, 2010, S. 223.

109 Vgl. Kochanowski: Repatrianten oder Expatrianten? 2007, S. 426.

110 Vgl. Ruchniewicz: Zwangsumsiedlungen von Polen, 2005, S. 178-182, 191. Vgl. Borodziej: Geschichte Polens im 20. Jahrhundert, 2010, S. 223. Vgl. auch: Madajczyk: Das zwanzigste Jahrhundert in Ostmitteleuropa, 2014, S. 67f. Siehe ebenfalls: Rossoliński-Liebe: Der polnisch-ukrainische Konflikt im Historikerdiskurs, 2017, S. $38 \mathrm{f}$.

111 Vgl. zum kolonialen Status und der damit verbundenen besonderen Demütigung der Tschechen: Schwartz: Ethnische »Säuberungen« in der Moderne, 2013, S. 229f. Vgl. ausführlich zur NSHerrschaft in der Tschechoslowakei 1939-45: Suppan: Hitler - Beneš - Tito, 2014, S. 777-923. Siehe auch: Brandes: Nationalsozialistische Tschechenpolitik im Protektorat Böhmen und Mähren, 2001, S. 119-136.

112 Vgl. Brandes: Unter deutschem Protektorat, 2005, S. $113 f$.

113 Suppan schreibt von der "geradezu perfide durchgeführten Besatzungspolitik im Protektorat«, welche die tschechische Bevölkerung in Schach hielt: Suppan: Hitler - Beneš - Tito, 2014, S. 1739.

114 Ebd., S. 804-813. Siehe für eine knappe Zusammenfassung zum tschechischen Widerstand auch: Kural: Tschechen, Deutsche und die sudetendeutsche Frage während des Zweiten Weltkrieges, 1999, S. 73-80. 
mit »kaum 2000 Beamte[n] [...] [die] tschechische Bürokratie von 350000 Menschen $\mathrm{zu}$ kontrollieren. $\ll^{115}$ Das Attentat führte zu massiven Repressionen gegen die tschechische Zivilbevölkerung, wie die Vernichtung der Ortschaften Lidice und Ležáky sowie die Ermordung eines Großteils ihrer Einwohner. All das hatte eine weitere Verbitterung und ein gesteigertes Hassempfinden der tschechischen Bevölkerung, aber auch vieler Sudetendeutscher gegenüber den Tschechen zur Folge. ${ }^{116}$ Dennoch gehörte das Protektorat aus den genannten Gründen zu den materiell vergleichsweise gutgestellten deutschen Besatzungsgebieten und blieb bis zum Ende des Krieges von direkten Kriegsfolgen weitgehend verschont. ${ }^{117}$ Auch die Shoa, der etwa 80.000 jüdische Bewohner der böhmischen Länder zum Opfer fielen, fand weitgehend außerhalb seiner Grenzen statt. ${ }^{118}$ Emilia Hrabovec hat die Vermutung angestellt, dass gerade dieses weitgehend widerstandslose Hinnehmen - so sehr der Pragmatismus den Tschechen am Ende auch geholfen habe - durch »hypernationalistisches« Verhalten am Ende des Krieges ausgeglichen werden sollte, um »die unrühmliche persönliche Vergangenheit, die Feigheit, Untätigkeit oder gar [...] die Kollaboration mit dem Feind zu kaschieren. «119 Letztlich gilt Detlef Brandes zufolge für die Besatzungspolitik: »Kurzfristig war die Tschechenpolitik sehr erfolgreich: Sie provozierte nur eine kleine Minderheit zum aktiven Widerstand und sicherte die ungehinderte Rüstungsproduktion. Langfristig führte sie in die Katastrophe: Denn sie verschärfte den Gegensatz zwischen Sudetendeutschen und Tschechen, erregte bei der überwiegenden Mehrheit der Tschechen Furcht und weckte ihren $\mathrm{Haß}$ auf alle Deutschen. « ${ }^{120}$

In einer vergleichenden Betrachtung der beiden Besatzungspolitiken lässt sich feststellen, dass sie sich letztlich in ihren Zielen glich, gleichwohl in der »kriegsbedingten Praxis« erheblich unterschied. ${ }^{121}$ Die Sicherstellung der wirtschaftlichen Funktion des böhmischen Beckens verhinderte - abgesehen von der Shoa - die Umsetzung weitreichender Pläne einer ethnischen Neuordnung des Landes und führte zu einer vergleichsweise moderaten Besatzungspolitik. Im Generalgouvernement und den polnischen Westgebieten konnte neben der wirtschaftlichen Ausbeutung zugleich die rrassische Neuordnung Europas angegangen werden. ${ }^{122}$ Der formal unabhängige Slowa-

115 Douglas: »Ordnungsgemäße Überführung«, 2012, S. 39.

116 Vgl. Suppan: Hitler - Beneš - Tito, 2014, S. 813-849.

117 Vgl. ebd., S. 1246.

118 Vgl. zum Holocaust im Protektorat und im Sudetenland: ebd., S. 855-867.

119 Hrabovec: Die Vertreibung der Deutschen und die tschechische Gesellschaft, 1994, S. 136. Deák konstatiert ähnlich: »Auch wenn es viele Tschechen gab, die Widerstand leisteten, so warteten die meisten lieber ihre Befreiung ab, anstelle sich aufzuopfern. Umso schlimmer waren die folgenden Ausschreitungen gegen die im Land lebenden Deutschen, egal, ob diese sich individuell schuldig gemacht hatten oder nicht. « Deák: Kollaboration, Widerstand und Vergeltung, 2017, S. 65. Vgl. kritisch zur >Kompensationsthese «: Kraft: Mythos »Beneš-Dekrete«, 2013, S. 246.

120 Brandes: Nationalsozialistische Tschechenpolitik im Protektorat Böhmen und Mähren, 2001, S. 136.

121 Brandes: Unter deutschem Protektorat, 2005, S. 111.

122 Brandes: National and International Planning of the sTransfer of Cermans from Czechoslovakia and Poland, 2009, S. 283. Siehe auch: Dunin-Wąsowicz: Die nationalsozialistische Okkupationspolitik, 1997, S. 238-240, 247f. Vgl. ebenfalls: Deák: Kollaboration, Widerstand und Vergeltung, 2017, S. $65 f$. Déak verweist u.a. darauf, dass eine fortgesetzte Abwanderung der Sudetendeutschen ins >Altreich< bereits nach 1938 einsetzte und die Anzahl der Tschechen sich in den Sudetengebieten 
kische Staat unter Jozef Tiso war eine dritte Form der nationalsozialistischen Europaplanung, in der unter Abspaltung der überwiegend ungarisch besiedelten Gebiete ein sslawischer Staat in Kollaboration mit Deutschland entstand.

Die sich 1939 im Londoner Exil konstituierende tschechoslowakische Exilregierung unter Edvard Beneš begann unter dem Eindruck des Münchner Abkommens mit Aussiedlungsplanungen für die Sudetendeutschen. Dabei konnte an Überlegungen von vor 1939 angeknüpft werden. Zunächst waren diese Planungen moderat und sahen eine territoriale Abgabe von einigen deutschsprachigen Gebieten sowie eine autonome Form für die verbliebenen Gebiete vor; ferner sollte ein umfassender Bevölkerungsaustausch stattfinden. Die weiteren Planungen der Tschechen hingen eng mit dem Kriegsverlauf und der Gestaltung des Verhältnisses zu und unter den Alliierten zusammen. ${ }^{123}$

Spätestens als 1941/42 eine deutsche Kriegsniederlage wieder möglich schien, radikalisierten sich die entsprechenden Pläne hin zu einer weitgehend vollständigen Aussiedlung der Deutschen. Dieser Wunsch entstand nicht nur im Exil, sondern wurde auch von der Widerstandsbewegung in Böhmen und Mähren selbst gefordert. Die angekündigte Sonderbehandlung von »loyalen« Deutschen und deutschen Antifaschisten hatte eher eine propagandistische Funktion als die tatsächliche Anerkennung einer künftigen relevanten deutschen Minderheit - wobei die Kriterien »loyal« und antifaschistisch tatsächlich nur eine sehr kleine Minderheit erfüllen konnte. In Polen verzichtete man bei den entsprechenden Plänen gleich gänzlich auf die Ausnahme antifaschistischer Deutscher. Die den Aussiedlungsplänen durchaus mit Sympathie gegenüberstehenden Westalliierten legten sich jedoch bis zum Kriegsende nicht fest. Beneš in einer vergleichsweise komfortablen Situation - konnte sich jedoch parallel mit Stalin einigen. ${ }^{124}$ In Anbetracht der Wahrscheinlichkeit, dass es für die gewaltsame Massenvertreibung der Deutschböhmen nur ein kurzes Zeitfenster der internationalen Akzep$\operatorname{tanz}$ geben würde, formulierte Beneš kurz nach der Rückkehr in die Tschechoslowakei am 28. April 1945 in Deutschendorf (Poprad):

»Unsere erste Aufgabe wird es sein, den Staat von Faschismus und Nazismus zu säubern, von den Deutschen und Magyaren. [...] Das muss gnadenlos und mit allen sich

durch den Zuzug tschechischer Immigranten aus dem Protektorat erhöhte: »Damit verschoben sich die ethnischen Verhältnisse in diesen Cebieten noch während der deutschen Herrschaft zugunsten der Tschechen."

123 Vgl. für die entsprechenden Planungen und Verhandlungen: Douglas: »Ordnungsgemäße Überführung «, 2012, S. 31-59. So wie das Problem bis in das 19. Jahrhundert zurückreicht, soweit reichen auch schon (radikale) >Lösungsvorschläge ‘ für die Trennung von Tschechen und Deutschen: Lemberg: Die Entwicklung der Pläne für die Aussiedlung der Deutschen aus der Tschechoslowakei, 2001, S. 203f. Das heißt nach Lemberg (S. 199) aber keineswegs, dass es im Cegensatz zu Behauptungen der sudetendeutschen Nachkriegspropaganda bereits konkrete Pläne für die Vertreibung der Deutschen vor 1939 gab.

124 Vgl. Suppan: Hitler - Beneš - Tito, 2014, S. 1389-1415. Siehe auch: Lemberg: Die Entwicklung der Pläne für die Aussiedlung der Deutschen aus der Tschechoslowakei, 2001, S. 197-202. Letztlich setzte sich so nach Lemberg (S. 200-202) von mehreren denkbaren und angedachten Varianten die radikalste durch: eine im Westen vollständige Wiederherstellung der ČSR mit einer vollständigen Vertreibung der deutschen Bevölkerung. 
daraus ergebenden Konsequenzen gemacht werden. Vergessen wir nicht, machen wir das nicht sofort, so wird es später keine solche Gelegenheit mehr geben. $\ll^{125}$

Die Unterschiede zu Polen sind augenfällig. ${ }^{126}$ Obwohl Polen - im Gegensatz zur ČSR - als Verbündeter militärisch vom Deutschen Reich (und der Sowjetunion) geschlagen wurde, stand die territoriale Integrität des künftigen Nachkriegsstaates von Beginn an in Zweifel. Das Streben der polnischen Exilregierung bestand daher bis zum Kriegsende darin, für eine Wiederherstellung seiner Grenzen zu kämpfen. ${ }^{127}$ Hinzu kamen >moderate<, bereits vor dem Krieg erhobene ethnisch-historische Ansprüche auf das gesamte Oberschlesien, Danzig sowie Ostpreußen oder Teile von diesem, die neben einer >Wiedergutmachung ‘ auch eine verbesserte Verteidigungsfähigkeit in der Zukunft gewährleisten sollten. ${ }^{128}$ Das vergleichsweise zurückhaltende Agieren ist damit zu erklären, dass man sich bei einer zu weitgehenden Grenzverschiebung zugunsten Polens im Westen in einer strukturell antideutschen Situation wiedergefunden hätte und zugleich die Verteidigung der Ostgrenze gegenüber der Sowjetunion diplomatisch unmöglich geworden wäre. ${ }^{129}$ Wie auch immer die Grenzgestaltung im Westen letztlich aussehen würde, sollten aus den Polen zugefallenen Gebieten die Deutschen ausgewiesen werden, um jede mit einer deutschen Minderheit verbundene Gefahr in Zukunft $\mathrm{zu}$ bannen. ${ }^{130}$ Lediglich bei dem Gesichtspunkt, »dass das Nachkriegspolen ein homogener Nationalstaat sein sollte«, bestand schließlich eine Gemeinsamkeit zwischen der Londoner Exilregierung und der kommunistischen Marionettenregierung. ${ }^{131}$

Nachdem den Westalliierten verdeutlicht wurde, dass Stalin nicht auf seine 1939/40 gewonnenen Gebiete verzichten würde, verabschiedete man sich von der territorialen Integrität Polens. ${ }^{132}$ Damit wurde eine >Kompensation` notwendig, die fraglos auf Kosten des Kriegsgegners Deutschlands erfolgen und mit der Vertreibung der dortigen Bevölkerungen einhergehen sollte. ${ }^{133}$ Die zunehmend geschwächte Position der Londoner Exilregierung wurde weiter untergraben, als Stalin im Sommer 1944 eine polnische Marionettenregierung installierte. Diese akzeptierte nicht nur umgehend die von ihm gewünschte Grenzziehung, sondern sie stimmte zugleich der Umsiedlung der Polen aus Weißrussland, der Ukraine und Litauen bis zum Frühjahr $1945 \mathrm{zu} .{ }^{134}$ Die bürgerliche Exilregierung ebenso wie alle anderen politischen Kräfte außer den Kommunisten konnten bis zuletzt nicht für einen >Kompromiss` gewonnen werden, da ein Verzicht auf Wilna und Lemberg nicht infrage kam. ${ }^{135}$ Gleichzeitig machte die Exilregierung noch

Zitiert nach: Suppan: Hitler - Beneš - Tito, 2014, S. 1242.

Vgl. für einen knappen Vergleich: Brandes: National and International Planning of the >Transfer of Cermans from Czechoslovakia and Poland, 2009, S. 284-296.

Douglas: »Ordnungsgemäße Überführung«, 2012, S. 41.

Vgl. Brandes: National and International Planning of the >Transfer< of Cermans from Czechoslovakia and Poland, 2009, S. $282 f$.

Ebd., S. 289.

Vgl. ebd., S. 292-296. Siehe für das fortlaufende Zelebrieren des serrungenen< ethnisch-homogenen Nationalstaates in der Volksrepublik Polen: Peters: Revolution der Erinnerung, 2016, S. 52.

Kochanowski: Repatrianten oder Expatrianten? 2007, S. 422.

Brandes: Die Vertreibung als negativer Lernprozess, 2005, S. $887 f$.

Vgl. Kossert: Kalte Heimat, 2009, S. 30.

Piskorski: Die Verjagten, 2013, S. 178. Ruchniewicz: Zwangsumsiedlungen von Polen, 2005, S. 179.

Siehe: Borodziej: Geschichte Polens im 20. Jahrhundert, 2010, S. 216. 
Anfang 1945 kritisch darauf aufmerksam, dass eine Oder-Neiße-Grenze »die Umsiedlung von 8 bis 10 Millionen Deutschen nötig mache. ${ }^{136}$ Mit den durch die Eroberungen der Roten Armee 1945 geschaffenen Tatsachen schwand schließlich das Interesse der Westalliierten an einem verstärkten Einsatz für Polen und sie stellten schließlich selbst die Oder-Neiße-Grenze in Frage und folglich in Potsdam unter Vorbehalt. ${ }^{137}$ Um seine territoriale Integrität zu schützen, war Polen von nun an ganz auf die Sowjetunion angewiesen. ${ }^{138}$

Neben der aggressiven nationalsozialistischen >Bevölkerungspolitik bis hin zum Holocaust wurden die Verbrechen und Ziele der deutschen Regierung nach und nach im alliierten Lager und in der Öffentlichkeit bekannt. Dies ist insofern entscheidend, als dass hauptsächlich in der britischen und US-amerikanischen Öffentlichkeit, aber auch in der Administration, Vorbehalte gegen die Vertreibung von Millionen von Deutschen überwunden werden mussten. ${ }^{139}$ So verstummten zum Ende des Krieges hin weitgehend die Stimmen, die sich für eine nachsichtige Behandlung der deutschen Zivilbevölkerung in Hinblick auf die Nachkriegsordnung einsetzten. ${ }^{140}$ Schließlich war das aktive Lobbying der tschechoslowakischen Exilregierung unter Edvard Beneš, eine internationale Zustimmung zur vollständigen Vertreibung der Deutschen zu erreichen, von Erfolg gekrönt, ebenso wie Stalin keinen Moment Zweifel an der neuen sowjetischen Westgrenze zuließ und damit die >Entschädigung« Polens durch deutsche Westgebiete als zwangsläufig erschien. ${ }^{141}$ Gezielt kalkulierte Stalin die künftige Bedrohung Polens und der ČSR durch Deutschland ein, um diese an die Sowjetunion zu binden. ${ }^{142}$ Gleichzeitig blieb für die Westalliierten das vermeintlich positive Beispiel von Lausanne zur nachhaltigen Lösung ethnischer Konflikte von Bedeutung. ${ }^{143}$

136 Brandes: Die Vertreibung als negativer Lernprozess, 2005, S. $889 f$.

137 Vgl. Brandes: National and International Planning of the sTransfer $<$ of Cermans from Czechoslovakia and Poland, 2009, S. 290f.

138 Vgl. Borodziej: Geschichte Polens im 20. Jahrhundert, 2010, S. 256.

139 Siehe dazu ausführlich: Douglas: „Ordnungsgemäße Überführung«, 2012, S. 352-371. Gleichzeitig betont Douglas, dass dies nicht bedeutet, »dass in den demokratischen Staaten je ein Konsens über die Notwendigkeit massenhafter Bevölkerungstransfers existiert« habe und weist auf entsprechend vielfältige kritische Stimmen hin (S. 51).

140 Als einer der wenigen Mahner verblieb im Februar 1945 George Orwell, der die Vertreibungen nicht nur als verbrecherisch verurteilte, sondern auch für undurchführbar hielt: Snyder: Bloodlands, 2011, S. 322.

141 Vgl. zum Verweisen auf den NS-Terror und dessen Umsiedlungspläne als Rechtfertigung für die tschechoslowakische Position in Hinblick auf die Nachkriegsplanung: Staněk: Vertreibung und Aussiedlung, 2001, S. 214. Siehe auch: Douglas: „Ordnungsgemäße Überführung«, 2012, S. 57. Siehe für die Verbindung/wechselseitige Bedingtheit von Bevölkerungsverschiebungen und der nationalistischen Agenda auch der kommunistischen Akteure ausführlich: Service: Cermans to Poles, 2013, S. 306-348. Snyder sieht eine wesentliche Ursache für die fast vollständige Durchsetzung von Stalins Interessen gegenüber den Westalliierten in dem Unterschied, dass Stalin ein klares Konzept für Osteuropa vorzuweisen hatte, wohingegen die Westalliierten noch umhertarierten: Snyder: Bloodlands, 2011, S. 319.

142 Vgl. Schwartz: Ethnische »Säuberungen« in der Moderne, 2013, S. 498.

143 Vgl. ebd., S. 424. Siehe auch: Hahn; Hahn: Die Vertreibung im deutschen Erinnern, 2010, S. 101f., 338, 346f. Diese betonen das Argument, dass der Fokus auf die Planungen der tschechischen und polnischen Exilpolitiker einer eingeschränkten Sichtweise entspringt und vielmehr in der Gesamtperspektive die Überlegungen der alliierten Großmächte betrachtet werden müssen. 
Diese Ausführungen konnten nur einen Teil der Zwangsmigrationen und Vertreibungen während des Krieges aufzeigen. Unstrittig ist, dass Deutschland zunächst selbst »Motor und Zentrum « der europäischen Zwangsmigration war. ${ }^{144}$ Auch wenn die Ideen- und Konfliktgeschichte weit länger zurückreicht, sind die radikalen Umsetzungen von Grenzverschiebungen und Massenvertreibungen unvorstellbar ohne Hitlers Angriffskriege und die in ihrer Dimension beispiellosen deutschen Verbrechen, sie sind die

»Conditio sine qua non, die unerlässliche Voraussetzung für die Vertreibung von Millionen Deutschen gegen Ende des von Deutschland begonnenen Zweiten Weltkrieges. [...] Und doch erschöpft sich die Vertreibung der Deutschen nicht im Verweis auf Hitler und die NS-Verbrecher. Sowohl die deutschen Nationalsozialisten als auch ihre alliierten Kriegsgegner verfügten bereits über Vorerfahrungen mit dem Instrumentarium ethnischer >Säuberung`, die handlungsorientierend werden sollte. $\aleph^{145}$

\subsection{Verlauf von Flucht und Vertreibung während und nach dem Krieg}

Das Geschehen, welches zur weitestgehenden Entfernung der Deutschen aus den Ostund Siedlungsgebieten führte, lässt sich in vier sich häufig überschneidende Prozesse gliedern: Evakuierung, Flucht, >wilde und `organisierte Vertreibung. ${ }^{146}$ Mit Einschränkungen unternahmen alle Länder Ostmitteleuropas und Südosteuropas entsprechende Bemühungen, ihre deutsche Bevölkerung auf diese Art und Weise zu entfernen.

Bereits 1943, und dann verstärkt 1944, wurden deutsche Siedlungsgebiete in exponierter Lage durch die NS-Administration evakuiert und/oder die Menschen wichen gemeinsam, aber halbwegs geordnet, mit der Wehrmacht zurück. Dies betraf vor allem die Karpatendeutschen in der Slowakei, das Baltikum und Südosteuropa. ${ }^{147}$ Die vermeintliche Stabilisierung der Ostfront nach der weitreichenden Sommeroffensive der Sowjetunion 1944, die die Rote Armee bis an die alte Reichsgrenze führte, brachte eine nur vorübergehende und trügerische Ruhe in Ostpreußen, Posen und Oberschlesien mit sich. Der noch verbreitete Glaube an den Endsieg sowie das Verbot oder die Verhinderung der selbstorganisierten Flucht durch die NS-Behörden führten beim folgenden massiven Durchbruch der Roten Armee im Januar $1945 \mathrm{zu}$ einer im besten Fall übereilt organisierten Flucht. ${ }^{148}$ Vorliegende Evakuierungspläne konnten nicht mehr oder erst spät umgesetzt werden und viele Evakuierungen gingen in wilde Fluchtbewegungen über. ${ }^{149}$ Eva und Hans Henning Hahn sehen die Hauptursache und Verantwortung für das Leiden der Ostdeutschen nicht in der Verhinderung oder zu späten Räumung,

144 Bade; Oltmer: Mitteleuropa, 2010, S. 155.

145 Schwartz: Ethnische »Säuberungen« in der Moderne, 2013, S. 630. Siehe auch: Lemberg: Die Entwicklung der Pläne für die Aussiedlung der Deutschen aus der Tschechoslowakei, 2001, S. 196.

146 Vgl. für eine ähnliche Gliederung unter Auslassung der Evakuierung: Eckersley: Walking the Tightrope between Memory and Diplomacy? 2016, S. 103.

147 Vgl. für Flucht und Vertreibung der Deutschen aus Südosteuropa: Beer: Flucht und Vertreibung der Deutschen, 2011, S. 86-97.

148 Vgl. ebd., S. 69f. Siehe auch: Kossert: Kalte Heimat, 2009, S. 27.

149 Vgl. Beer: Flucht und Vertreibung der Deutschen, 2011, S. 58. 
sondern gerade in dem wahnwitzigen Plan der NS-Administration, möglichst alle Deutschen (häufig unter Zwang) zu evakuieren und dem Zugriff des Feindes zu entziehen - allerdings kaum aus humanitären, sondern aus ökonomischen und rassischen Gründen. Die Evakuierung von vielen Millionen Menschen in Frontnähe durch ein zusammenbrechendes Regime musste daher in eine weitere, vom NS-Regime verantwortete, humanitäre Katastrophe und zu vielen Tausenden sinnloser Toter führen. ${ }^{150}$ Die These, dass ein Verharren der Bevölkerung in Gebieten, aus denen sie auch von den Siegermächten entfernt werden sollten, die bessere Option gewesen wäre, erscheint fraglich, selbst wenn man die Gewalttaten der Roten Armee ausblendet und lediglich auf die gleich skizzierten Nachkriegsbedingungen für die verbliebenen Deutschen schaut.

Häufig wurden Flüchtlingstrecks von der Front überrollt und mussten neben militärischen >Kollateralschäden unter massiven und systematischen Übergriffen der Roten Armee leiden. Die widrigen Wetterbedingungen des Winters taten ihr Übriges und führten unter anderem zu dem ikonischen Bild der Flucht über die zugefrorene Frische Nehrung. ${ }^{151}$ Etwa zwei Millionen Menschen konnten von der Kriegsmarine über die Ostsee evakuiert werden, wobei der Untergang der vor allem mit einigen Tausend Flüchtlingen überfüllten Wilhelm Gustloff durch Günter Grass' später geschaffenes literarisches Denkmal Im Krebsgang besondere Bekanntheit erlangte. Ein Großteil der Bevölkerung der Ostgebiete verließ so ihre Wohnorte bereits vor dem Einmarsch der Roten Armee und der Konstituierung sowjetischer oder polnischer Verwaltungsstrukturen. ${ }^{152}$

Jan Piskorski weist zu Recht auf einen in Deutschland oft zu wenig beachteten Faktor als Ursache für deutsche Vertreibungsverluste hin: den fortlaufenden und sich zum Kriegsende hin massiv verstärkenden NS-Terror gegen die eigene Bevölkerung. Vom Kampf gegen Deserteure, >Plünderer $<$, Defätisten oder illegal Fliehende waren die Ostgebiete in besonderem Maße betroffen. ${ }^{153}$ Auch die Wehrmacht zeigte sich vor Ort in ihrem abgekämpften, gehetzten und demoralisierten Zustand häufig wenig empathisch mit dem Schicksal der Zivilbevölkerung. ${ }^{154}$

Auf dem Gebiet der böhmischen Länder blieben, abgesehen von Hundertausenden durchziehender oder dorthin evakuierter deutscher Flüchtlinge, bis kurz vor Kriegsende größere Fluchtbewegungen aus, da die meisten Gebiete bis zuletzt von den Deutschen gehalten wurden und der westliche Teil um Pilsen von den Amerikanern erobert wurde, die keine Fluchtbewegungen auslösten. Abgesehen vom Osten des Sudetengaus erfolgte der Einmarsch der Roten Armee erst unmittelbar vor Kriegsende. Die schnelle Wiederherstellung tschechoslowakischer Staatlichkeit und die Rückkehr der Exilregierung führten umgehend zu einer konfrontativen Situation. In Folge der rücksichtslos geführten Kämpfe des Prager Aufstandes im Mai 1945, bei dem beide Seiten massiv gegen Zivilisten vorgingen, kam es zu Racheakten und Massakern an den Prager Deutschen. Auf dem gesamten Gebiet der Tschechoslowakei kam es zu gewalttäti-

150 Hahn; Hahn: Die Vertreibung im deutschen Erinnern, 2010, S. 261-268, $275 f$., 296.

151 Vgl. zur bereits in der NS-Zeit durchgesetzten Ikone des Treck-Bildes: Röger: Bilder der Vertreibung, 2014, S. 265-267.

152 Vgl. Schwartz: Ethnische »Säuberungen« in der Moderne, 2013, S. 539.

153 Piskorski: Die Verjagten, 2013, S. 180-182.

154 Ebd., S. 182. 
gen und mörderischen Übergriffen auf die deutsche Zivilbevölkerung sowie gefangene Wehrmachts- und SS-Angehörige durch improvisiert aufgestellte tschechoslowakische Milizen sowie Soldaten. ${ }^{155}$

Verschiedene Ereignisse, wie das Massaker von Aussig, sind bis heute in ihrem Hergang nicht restlos geklärt; beispielsweise inwiefern derartige massive Übergriffe dem sallgemeinen Volkszorn entsprangen, oder ob eher kriminelle Banden und staatliche Milizen oder geschickte Inszenierungen des tschechoslowakischen Geheimdienstes verantwortlich waren, um der Welt die Unmöglichkeit eines weiteren Zusammenlebens von Deutschen und Tschechen zu beweisen und auf die zeitgleich stattfindende Potsdamer Konferenz entsprechend Druck auszuüben. ${ }^{156}$ Vermutlich hat es in dieser Phase, mit quantitativen Unterschieden, all diese Phänomene gegeben. Für diese Ereignisse hatte sich in Abgrenzung zu den nach der Potsdamer Konferenz organisierten Vertreibungen der Terminus >Wilde Vertreibungen durchgesetzt, der aber aufgrund neuer Forschungserkenntnisse nur noch zurückhaltend verwendet wird, da nach heutigem Stand die meisten bekannten Übergriffe und Vertreibungen bereits einen geplanten Charakter hatten. ${ }^{157}$ Belegt sind Aufrufe zur Rache durch Akteure wie Beneš und andere Exilanten. ${ }^{158}$ So äußerte sich der Exil-Präsident im Oktober 1943 in einer Rundfunkansprache an die Heimat:

155 Vgl. zum Prager Aufstand und den weiteren Ausschreitungen gegenüber Deutschen im Cebiet der Tschechoslowakei: Suppan: Hitler - Beneš - Tito, 2014, S. 1243-1260. Siehe auch: Staněk: Verfolgung 1945, 2002, S. 89-98. Vgl. ebd. auch für das noch schwer zu qualifizierende und quantifizierende Ermorden/Todesfälle von gefangenen deutschen Uniformträgern: S. 103. Weiter schreibt Staněk von Taten wie dem lebendigen Begraben von Deutschen im Rahmen eines `Verhörs ( $(S .107)$ und den Vergewaltigungen durch Tschechen (S. 109). Allerdings starben die meisten Deutschen (abgesehen von der hohen Anzahl von Selbstmorden) weniger durch »unmittelbare Cewaltanwendung « als »hauptsächlich durch Erschöpfung, unzureichende Versorgung und Krankheiten alter Menschen und Kinder (S. 115). Vgl. ebenfalls: Suppan; Koura et al.: Die österreichischen und böhmischen Länder unter NS-Herrschaft 1938-1945, 2019, S. 202f. Vgl. für eine umfassende, lexikalisch-geographische Darstellung der Cewalt, v.a. der Ermordungen von deutschen Zivilisten und Kriegsgefangenen zwischen Mai und August 1945: Padevět: Krvavé léto 1945, 2016.

156 Siehe: Suppan: Hitler - Beneš - Tito, 2014, S. 1746. Ebenso: Piskorski: Die Verjagten, 2013, S. $233 f$. Vgl. auch: Kossert: Kalte Heimat, 2009, S. 32. Nach Kittel und Möller sind die »wilden Vertreibungen« schließlich der wichtigste Beleg für die »politische Verantwortung für die Zwangsaussiedlung« der tschechoslowakischen und anderer ostmitteleuropäischer Regierungen: Kittel; Möller: Die Beneš-Dekrete, 2006, S. 563. Tůma weist darauf hin, dass die Frage nach den >Tätern im Zusammenhang mit Übergriffen auf Deutsche in der ČSR oft allzu simplifizierend auf $>d i e<$ Tschechen geschoben würde; vielmehr bestehe ein Forschungsdesiderat über die konkreten Akteure. Zudem waren neben sowjetischen Soldaten auch Slowaken, schließlich handelt es sich um einen gemeinsamen Staat, an vielen Stellen mitverantwortlich: Tủma: Die Aussiedlung, 2015, S. 277.

157 Vgl. zur Diskussion des Begriffs >Wilde Vertreibung؛: Lemberg: Die Vertreibung der Deutschen aus dem Osten, 2005, S. 49. Siehe für die ,Wilden Vertreibungen in der Tschechoslowakei ausführlich: Suppan: Hitler - Beneš - Tito, 2014, S. 1415-1426.

158 Siehe: Staněk: Vertreibung und Aussiedlung, 2001, S. 126f. So verneint Staněk den spontanen Charakter unter Verweis auf die entsprechende rhetorische Vorbereitung. 
»In unserem Land wird das Kriegsende mit dem Blut geschrieben. Den Deutschen wird erbarmungslos und vielfach alles zurückgezahlt, was sie in unserem Land seit dem Jahr 1938 angerichtet haben. ${ }^{159}$

Gelegentliche Aufrufe tschechoslowakischer Autoritäten zu Mäßigung und Menschlichkeit verhallten weitgehend ungehört, ebenso wie sie durch solche aufhetzenden Äußerungen konterkariert wurden. ${ }^{160}$ Weniger stark als in Polen, aber dennoch bedeutend waren die Auswirkungen der schwachen und sich erst wieder ausbildenden tschechoslowakischen Verwaltung, die anarchisches und gewaltsames Vorgehen begünstigte. ${ }^{161}$ So hatten neben nationalistischen Soldaten und Milizen auch Individuen und Banden die Möglichkeit, nach Kriegsende weiterhin straffrei zu rauben, zu vergewaltigen und zu morden. ${ }^{162}$ Die faktische Nicht-Verfolgung derartiger Taten respektive die behördliche Duldung oder Unterstützung derselben wurde durch die spätere Gesetzgebung gestützt, die de facto alle Handlungen, wenn sie nur irgendwie »dem Wunsch nach gerechter Vergeltung « entsprachen und zwischen 1939 und Oktober 1945 geschahen, straffrei stellte - auch wenn die Opfer dieser Taten nachweislich unschuldig waren. ${ }^{163}$ Dieses Geschehen stand im drastischen Widerspruch zur Erwartung großer Teile der deutschen Zivilbevölkerung, die zwar mit einer Bestrafung rechneten, aber davon ausgingen, dass es die »Hauptschuldigen « treffen würde. ${ }^{164}$ Stattdessen wurden sie, wenn nicht unmittelbar vertrieben, vielerorts mit einer Kennzeichnungspflicht konfrontiert, ihre Bewegungsfreiheit eingeschränkt und die Arbeitspflicht eingeführt. ${ }^{165}$

Die unter sowjetischer oder der beginnenden volkspolnischen Verwaltung verbliebene deutsche Bevölkerung war lange massiven Gewaltexzessen ausgeliefert. ${ }^{166}$ Auch hier wurde ihr unmissverständlich deutlich gemacht, dass es auf den nun Polen zugeschlagenen Gebieten keine Zukunft für sie geben würde. ${ }^{167}$ Das Klima der Übergrif$\mathrm{fe}$, das weitgehende Abschneiden von jeglicher Versorgung und das Heraustreiben der Menschen aus ihren Häusern hatten vielerorts einen spontanen Anschein, waren aber dem politischen Ziel untergeordnet. ${ }^{168}$ Das Leiden wurde durch das weitgehende Fehlen staatlicher sowie jeglicher rechtsstaatlicher Strukturen noch verstärkt. ${ }^{169}$ So führte das Schicksal der deutschen Zivilbevölkerung in den von der Sowjetunion eroberten Gebieten, in Polen und der ČSR während und vor allem nach dem Ende der Kampfhandlungen zu ersten kritischen Berichten bei den alliierten Besatzungsmächten und in der westlichen Öffentlichkeit und in deren Folge zu Einsprüchen, die mit der Zeit stärker und wirksamer wurden. ${ }^{170}$

159 Zitiert nach: Staněk: Vertreibung und Aussiedlung, 2001, S. 216.

160 Vgl. ebd., S. 220.

161 Staněk: Verfolgung 1945, 2002, S. 14. Vgl. Hahn; Hahn: Die Vertreibung im deutschen Erinnern, 2010, S. 356-358.

162 Siehe: Staněk: Verfolgung 1945, 2002, S. 14.

163 Ebd., S. 16.

164 Ebd., S. 27.

165 Ebd., S. 78.

166 Vgl. Schwartz: Ethnische »Säuberungen« in der Moderne, 2013, S. 539.

167 Ebd., S. 547-550.

168 Siehe: Douglas: »Ordnungsgemäße Überführung«, 2012, S. $124 f$.

169 Piskorski: Die Verjagten, 2013, S. 242.

170 Vgl. Staněk: Vertreibung und Aussiedlung, 2001, S. 223. 
Für die Behauptung, dass die tschechische oder polnische Bevölkerung in den ethnisch gemischten Gebieten aus Rache über ihre deutschen Nachbarn herfiel, fehlen tragfähige Belege. ${ }^{171}$ Vielmehr waren die zentralen Vertreibungsakteure vor Ort meistens externe Kräfte oder Angehörige staatlicher und semistaatlicher Einheiten wie Polizei und Militär. Weniger als einen vermeintlich sspontanen Volkszorn s scheint es neben den politischen Zielen gerade unter den bewaffneten Kräften und jungen Männern einen schon erwähnten "psychologischen Hintergrund« gegeben zu haben, die erlebte Erniedrigung durch die deutsche Besatzung mit Gewalt zu kompensieren und sich an den neuen Machtgefühlen zu erfreuen. ${ }^{172}$ Schließlich galten die Deutschen sowohl in den polnisch/sowjetisch als auch tschechisch kontrollierten Gebieten als »vogelfrei« und waren weitgehend schutzlos. ${ }^{173}$

Obgleich die Bevölkerungsverschiebungen von allen Alliierten getragen wurden, wünschte man sich im Westen doch von den Exzessen der >Wilden Vertreibungen $<\mathrm{zu}$ distanzieren. Bei der Potsdamer Konferenz wurde daher der - auch in Anbetracht des folgenden Geschehens - zynische Terminus der »ordnungsgemäß und human« durchzuführenden Umsiedlungen durchgesetzt. ${ }^{174}$ Tatsächlich gab es lediglich punktuelle Verbesserungen, vor allem aufgrund der fortlaufenden Proteste der Westalliierten und später auch der Vertreter der Sowjetischen Besatzungszone in Deutschland, die von den zumeist unter widrigsten Bedingungen organisierten Transporten von Millionen Ostdeutschen bei ohnehin angespannter Versorgungslage massiv belastet wurden, besonders da es sich bei diesen zunächst primär um arbeitsunfähige und häufig unterversorgte Frauen, Kinder und Alte handelte. ${ }^{175}$

Das Potsdamer Abkommen bestätigte bereits geschaffene Fakten und Planungen, die allerdings nicht nur von Stalin und den Exilregierungen allein, sondern mit Wissen und Zustimmung der Westalliierten vereinbart und entwickelt worden waren. An diesen konnten und wollten »die in Potsdam versammelten >Großen Drei< nicht vorbeisehen«. Die dort von den Westalliierten erneut diskutierte Frage der Bevölkerungsverschiebungen betrachtet Mathias Beer lediglich als "Druckmittel« und »durchsichtiges Manöver«, um sowohl von der »eigenen Verantwortung abzulenken« als auch um andere Ziele in den Verhandlungen zu erreichen; schließlich war die Vertreibung der Deutschen für die Alliierten bei der Aushandlung der Nachkriegsordnung nicht die wichtigste Frage. ${ }^{176}$

Die Vertreibung der verbliebenen deutschen Bevölkerung erfolgte in mehreren großen Schüben mit ihrem Höhepunkt im Jahr 1946, bis diese 1949/50 de facto abgeschlossen war. ${ }^{177}$ Nach polnischen Angaben verließen so zwischen 1945 und 1949 etwa 3,6 Millionen Menschen Polen, in der deutschen Literatur wird eine höhere Angabe von 4,5

171 Douglas: »Ordnungsgemäße Überführung«, 2012, S. 450.

172 Piskorski: Die Verjagten, 2013, S. 233. Vgl. zur fragwürdigen Zusammensetzung solcher >Milizen in Polen und ihrem häufig verbrecherischen Handeln auch: Zaremba: Die große Angst, 2016, S. 435.

173 Kossert: Kalte Heimat, 2009, S. 39.

174 Vgl. ebd., S. 31-33. Siehe auch: Suppan: Hitler - Beneš - Tito, 2014, S. 1426-1430.

175 Vgl. Kossert: Kalte Heimat, 2009, S. 33.

176 Beer: Flucht und Vertreibung der Deutschen, 2011, S. $61 f$.

177 Vgl. Schwartz: Ethnische »Säuberungen« in der Moderne, 2013, S. 570 . 
Millionen sowie zusätzlich 650.000 Deutschen aus Danzig und Vorkriegspolen vorgenommen. ${ }^{178}$ Die Forderungen der Alliierten, die Menschen in ihren Besatzungszonen unter halbwegs tragfähigen Bedingungen aufnehmen zu können, führten zu häufigen Auseinandersetzungen mit der ČSR und Polen über die Anzahl und Häufigkeit der Transporte. Beide Regierungen drängten darauf, die Vertreibungen möglichst rasch abzuschließen, um damit ein fait accompli zu erreichen und bei einer erneuten Änderung der politischen Großwetterlage nicht (erneut) mit einer weiterhin im Land verbliebenen großen deutschen Minderheit konfrontiert zu sein. ${ }^{179}$ Von den Vertreibungen ausgenommen waren wenige Gruppen, wie unabdingbar benötigte Arbeitskräfte in Fabriken und vor allem im Bergwerkswesen, auch wenn diese in Polen wie in der ČSR mittelbar entfernt werden sollten. ${ }^{180}$

Ein bedeutendes und in weiten Teilen der Forschung bisher wenig beachtetes Thema ist die massenhafte Internierung von Deutschen in Lagern. ${ }^{181}$ Trotz unsicherer Zahlenlage kann angenommen werden, dass die Anzahl von dort internierten Menschen in Europa nach Kriegsende 1945 ihre absolute Höchstzahl erreichte, davon ein Großteil wiederum in Lagern für Deutsche. ${ }^{182}$ Diese erfüllten unterschiedliche und sich zumeist überschneidende Zwecke: als Zwischenstation vertriebener Deutscher, die hier auf ihre >Ausreise warten mussten, als Arbeitslager zur Ausbeutung der Arbeitskraft oder als Ort der >Verifikation`, wie zum Beispiel der möglichen Polonisierung in Oberschlesien. Diese unmittelbar nach der Wiederherstellung polnischer und tschechoslowakischer Staatlichkeit oft von den Deutschen übernommenen Lagersysteme waren aufgrund der schwierigen generellen Versorgungsbedingungen, noch verstärkt durch zum Teil extrem gewalttätige Wachmannschaften, unmenschliche Orte mit häufig hohen Todesraten und der permanenten Gefahr von Übergriffen und Vergewaltigungen. ${ }^{183}$ Tomáš Staněk kalkuliert für die tschechoslowakischen Lager zwischen 1945 und 1948 eine Zahl von mindestens 6000-7000 Sterbefällen. ${ }^{184}$ Es werden mehrere hundert Objekte vermutet, die als Internierungs- Auffangs-, Arbeits- und Abschublager sowie als Gefängnisse für bis zu etwa 350.000 vorübergehend oder länger festgehaltene Deutsche dienten. ${ }^{185}$

178 Schwartz: Ethnische »Säuberungen« in der Moderne, 2013, S. 570.

179 Vgl. Douglas: „Ordnungsgemäße Überführung«, 2012, S. 202. Siehe auch: Beer: Flucht und Vertreibung der Deutschen, 2011, S. $76 \mathrm{f}$.

180 Vgl. Beer: Flucht und Vertreibung der Deutschen, 2011, S. 83.

181 Vgl. Lemberg: Die Vertreibung der Deutschen aus dem Osten, 2005, S. 49.

182 Siehe: Douglas: »Ordnungsgemäße Überführung«, 2012, S. 174f., 199. Douglas betont nach einer ausführlichen Skizzierung der miserablen und oft grausamen Verhältnisse in den Lagern, dass es »[...] keine stichhaltige Parallele selbst zwischen den schlimmsten Nachkriegslagern und den deutschen KZ der Kriegszeit [gibt]. «Dabei nimmt er die Verhältnisse der jugoslawischen Lager aus, die den NS-Lagern durchaus stark ähnelten.

183 Vgl. für eine knappe Übersicht des tschechoslowakischen Lagerwesens: Suppan: Hitler - Beneš - Tito, 2014, S. 1260-1266. Siehe ausführlich: Douglas: »Ordnungsgemäße Überführung«, 2012, S. 168-199. Snyder verweist auf den polnischen Kommandanten des Lagers Lubraniec, in dem dieser auf einer niedergeschlagenen deutschen Frau tanzte und rief: »So legen wir den Grundstein für ein neues Polen«. Snyder: Bloodlands, 2011, S. 327.

184 Dabei schließt er eine höhere Todeszahl nicht aus: Staněk: Internierung und Zwangsarbeit, 2007, S. 353.

185 Staněk: Vertreibung und Aussiedlung, 2001, S. 221. Vgl. Dvořák; Schriffl: Am Scheideweg, 2019, S. $224 f$. 
Für Polen rechnet Piskorski 1945 mit etwa tausend Lagern von sehr unterschiedlicher Größe. Die sehr schwer zu kalkulierenden Todeszahlen werden mit ungefähr 60.000 angegeben. ${ }^{186}$ Polnische, jüdische und ausländische Zeitgenossen verglichen den Charakter vieler Lager bereits unmittelbar mit dem der Nationalsozialisten und es folgten zum Teil entsprechende Proteste. ${ }^{187}$ Erst mit der Zeit besserte sich dort die Situation durch Konsolidierung der staatlichen Organe ebenso wie durch internationale Kontrollen. ${ }^{188}$

In dem sich im Juli 1944 konstituierenden Volkspolen wurden entsprechende Handlungen und Aktionen sowie vor allem die entschädigungslose Enteignung der Deutschen in verschiedenen Dekreten und Gesetzestexten beschlossen, nicht aber jegliche Form von gewalttätigen Übergriffen gegen Deutsche legitimiert. ${ }^{189}$ Die kommunistisch dominierte Regierung war unzweifelhaft ein verlängerter Arm der stalinistischen Neuordnung Ostmitteleuropas, auch wenn diese auf nationalistische Vorkriegsideen sowie die antideutsche Stimmung in der Bevölkerung zurückgreifen konnte. Gleichzeitig war sie durch den von ihr bedingungslos akzeptierten Verlust der polnischen Ostgebiete mit der Herausforderung konfrontiert, alsbald für Hundertausende polnische kresyVertriebene Ansiedlungsmöglichkeiten zu schaffen: Das von dem späteren polnischen Parteichef der PZPR Władysław Gomułka geleitete Ministerium für die Wiedergewonnenen Gebiete war für die Organisation verantwortlich. ${ }^{190}$

In der ČSR regelten eine Reihe von Präsidentendekreten, die später sogenannten Beneš-Dekrete, die ebenso entschädigungslose Enteignung und Ausbürgerung der Deutschen. ${ }^{191}$ Eines der zentralen Elemente, das bereits nicht mehr als Dekret erlassene, sondern von der Nationalversammlung beschlossene, rückwirkende Straffreiheitsgesetz vom 8. Mai 1946, ist weiterhin in Kraft. ${ }^{192}$ Diese Erlasse ordneten die Vertreibung nicht selbst an, sondern schufen mit der entschädigungslosen Enteignung, der Massenausbürgerung oder der Straffreiheit bei Gewaltanwendung gegenüber den Sudetendeutschen nur ihre Grundlage. Daher wird manchmal geäußert, es habe kein Ver-

186 Piskorski: Die Verjagten, 2013, S. 200. Vgl. für die Todeszahlen: Habbe: Die Zeit der Abrechnung, 2011, S. 212.

187 Suppan berichtet von einem tschechisch-jüdischen Arzt, der Auschwitz und Mauthausen überlebt habe und sich über die Zustände in den tschechen Lagern deutlich empörte: Suppan: Hitler - Beneš - Tito, 2014, S. 1262. Vgl. für verschiedene zeitgenössische kritische Stimmen: Douglas: »Ordnungsgemäße Überführung«, 2012, S. 185-191.

188 Vgl. Suppan: Hitler - Beneš - Tito, 2014, S. $1264 f$.

189 In einem knappen Artikel hat Borodziej aufgezeigt, dass die die Entrechtung, Enteignung und Vertreibung regelnden verschiedenen administrativen volkspolnischen Erlasse zum einen nicht - wie in der politisch-journalistischen Rhetorik gerne getan - vereinheitlichend als »Bierut-Dekrete« analog zu den »Beneš-Dekreten« bezeichnet werden dürfen und zum anderen keinerlei rechtliche Bindung mehr haben. Dazu kommt die Suggestion, dass jedes Vorgehen gegen die Deutschen formal (wenn auch unrechtmäßig aus Sicht der Vertriebenen) geregelt war, was aber mitnichten der Fall war. Ebenso entstanden die administrativen Vorgaben (ähnlich wie in der ČSR) sowohl vor als auch nach der Potsdamer Konferenz, sind damit also auch nicht mehr oder weniger legitimiert durch diese: Borodziej: »Bierut-Dekrete«? 2002, S. $19 f$.

190 Vgl. Borodziej: Ceschichte Polens im 20. Jahrhundert, 2010, S. $264 f$.

191 Vgl. für eine umfassende Erörterung der >Beneš-Dekrete` und deren Umsetzung: Suppan: HitlerBeneš - Tito, 2014, S. 1485-1510. Siehe auch: Kittel; Möller: Die Beneš-Dekrete, 2006, S. 569-571.

192 Suppan: Hitler - Beneš - Tito, 2014, S. 1754. Vgl. Dvořák; Schriffl: Am Scheideweg, 2019, S. $227 f$. 
treibungsgesetz gegeben - dies ist aber zu kurz gedacht, denn diese Rahmenbestimmungen führten in der ČSR wie in Polen de facto zur Vertreibung. ${ }^{193}$ Ein wesentlicher Unterschied zur polnischen Administration bestand darin, dass die tschechoslowakischen Regierungen bis zum Februarumsturz 1948 von bürgerlichen Parteien mitgetragen wurden. Auch wenn die Kommunisten zentrale Stellen in den Sicherheitsbehörden übernahmen, stützte ein wesentlich breiter artikulierter politischer Konsens aller Parteien die Entscheidung zur Vertreibung der Deutschen. ${ }^{194}$

Die Exilregierung versuchte, ebenso wie die Kommunisten, die Tschechoslowakei ex-post diskursiv zur Kriegspartei zu machen und damit nicht nur die snationale Ehre $<$ zu bewahren, sondern auch als moralischer Sieger in gefestigter nationaler Einheit (von Tschechen und Slowaken) hervorzugehen. Durch Sieg und moralische Überlegenheit habe sie sich über das den Faschismus aktiv unterstützende Deutschtum erhoben und konnte damit zugleich den Ausschluss dieser Gruppe nicht nur als notwendig, sondern auch als gerecht begründen. ${ }^{195}$ Die Beseitigung der deutschen Bewohner und die Enteignung deutschen Besitzes ermöglichte darüber hinaus eine massive Umverteilung und »einen bis heute unabschätzbaren Nivellierungsprozess«, zumal die ČSR kaum eigene Flüchtlinge in den Sudetengebieten ansiedeln musste. ${ }^{196}$

Ein weiteres Phänomen des Vertreibungsgeschehens sind die Deportationen von Deutschen und Volksdeutschen in die Sowjetunion am Ende des Krieges. Hier schwankt die Zahl der Betroffenen zwischen 200.000 und einer Million. ${ }^{197}$ Als >lebende Reparationsmasse stammten sie vor allem aus den volksdeutschen Siedlungsgebieten und den deutschen Territorien, die von der Roten Armee erobert wurden.

Philipp Ther hat darauf aufmerksam gemacht, dass die deutschen Vertriebenen häufig als ein Querschnitt der Gesellschaft betrachtet werden, allerdings sei eine soziale Differenzierung notwendig. Menschen mit Besitz und Einfluss, vor allem nationalsozialistische Funktionäre, konnten sich häufig - unter Im-Stich-Lassen ihrer untergeordneten Gruppe - rechtzeitig und mit einigem Besitz absetzen und im Westen »relativ bequem und häufig ohne Entnazifizierungsverfahren ein neues Leben beginnen«. Auch die berühmte Gräfin Dönhoff, die mit ihrem Pferd zum alten Stammsitz in den Westen ritt und in der bundesdeutschen Erinnerungskultur einen prominenten Platz einnimmt, ist keineswegs repräsentativ. Vielmehr gerieten »gerade die skleinen Leute unter die Räder der voranrückenden Fronten und verloren all ihr Hab und Gut, außerdem nicht selten ihre Gesundheit oder ihr Leben." Daraus folgert Ther, dass ein genauer Blick auf die jeweiligen Vertreibungshintergründe der Individuen sinnvoll sei, denn: »Diese Unterschiede gehen verloren, wenn man sämtliche von ethnischen Säuberungen betroffenen Menschen gleichermaßen als Opfer betrachtet. ${ }^{198}$

193 Suppan: Hitler - Beneš - Tito, 2014, S. 1755. Lemberg: Die Vertreibung der Deutschen aus dem Osten, 2005, S. 54.

194 Siehe: Staněk: Vertreibung und Aussiedlung, 2001, S. 219. Vgl. zur notwendigen und gefundenen bürgerlichen Unterstützung der Vertreibung in Ostmitteleuropa: Kittel; Möller: Die BenešDekrete, 2006, S. 545.

195 Stegmann: Kriegsdeutungen, Staatsgründungen, Sozialpolitik, 2010, S. 274-278.

196 Suppan: Hitler - Beneš - Tito, 2014, S. 1222.

197 Vgl. ebd., S. 1224.

198 Ther: Die dunkle Seite der Nationalstaaten, 2011, S. 268. 
Ein Massenphänomen sind die bereits mehrfach angesprochenen Vergewaltigungen deutscher Frauen und Mädchen am Ende des Krieges, wobei man schätzt, dass etwa 1,9 Millionen Übergriffe durch Rotarmisten erleiden mussten. ${ }^{199}$ Die Vergewaltigungen wurden oft in einer solchen Häufigkeit und Brutalität durchgeführt, dass viele Opfer daran starben oder im Anschluss ermordet wurden. Eine große Anzahl der Betroffenen beging Selbstmord. Wie beispielsweise beim Lagerwesen gezeigt, vergewaltigten auch tschechische und polnische Waffenträger. Quantitativ und qualitativ war dieses Geschehen auch im Zweiten Weltkrieg und der unmittelbaren Nachkriegszeit einmalig, auch wenn sexuelle Gewalt im gesamten Zweiten Weltkrieg ein verbreitetes Phänomen war und darüber hinaus, strukturell betrachtet, »typisch für fast jede ethnische >Säuberung in Kriegskontexten « ist. ${ }^{200}$ Überproportional häufig waren Frauen auch von Zwangsarbeit und Deportation betroffen, da sie meistens den Großteil der verbliebenen arbeitsfähigen Bevölkerung bildeten.

Piskorski verwahrt sich aber in Bezug auf diese und andere Geschehnisse dagegen, die Frauen lediglich als Hauptleidtragende und passive Opfer zu betrachten: Auch wenn sie Opfer waren, hätten sich doch viele Frauen in dieser schwierigen Phase, wenn es überhaupt Spielräume gab, als besonders lebensfähig und den Männern überlegen gezeigt, vor allem wenn es galt eine Familie zu schützen. Dieses Thema werde viel zu wenig betrachtet. ${ }^{201}$

Die deutschen Vertriebenen trafen an ihren Ankunftsorten auf Millionen Displaced Persons: 10-12 Millionen von den Deutschen Verschleppte oder in Deutschland zuvor festgehaltene ehemalige Zwangsarbeiter, freigelassene KZ-Häftlinge und Kriegsgefangene, deren neu gewonnene Freiheit oft zu einer weiteren Odyssee führte. ${ }^{202}$ So waren nicht nur Deutsche über das Ende des Kriegs hinaus von Zwangsmigration betroffen; neben den erwähnten Polen aus den kresy waren es auch Italiener aus Jugoslawien, Rumänen aus Ungarn, Bulgaren oder aus Griechenland - um nur einige Beispiele zu nennen. Und sie alle glichen sich in mancherlei Hinsicht:

»The expulsions were in fact chaotic, costly, and violent. The states that expelled national minorities took every measure to ensure that all traces of the former residents were wiped clean, and the receiving states did everything to ensure that the newcomers would forget their old homelands. In the end, the suffering of the transferred populations, both during and after migration, was immeasurable. ${ }^{203}$

\subsection{Integration der Vertriebenen - nach der Vertreibung in Polen und der ČSR}

Sowohl die Westalliierten als auch die Sowjetunion standen in ihren Besatzungszonen vor der »schier unlösbaren« Herausforderung, etwa 14 Millionen Flüchtlinge und Ver-

199 Kossert: Kalte Heimat, 2009, S. 40.

200 Schwartz: Ethnische »Säuberungen« in der Moderne, 2013, S. 535f. Vgl. Zaremba: Die große Angst, 2016, S. 131-133.

201 Piskorski: Zwangsmigrationen im Kontext des Zweiten Weltkriegs, 2014, S. 168.

202 Ebd., S. 157.

203 So Siljak im Fazit zum Sammelband über sethnische Säuberung` in Ostmitteleuropa 1944-1948: Siljak: Conclusion, 2001, S. 327. 
triebene zu versorgen und langfristig unterzubringen. ${ }^{204}$ Die Alliierten achteten dabei darauf, dass die Vertriebenen nach Möglichkeit oberhalb der Familienebene verstreut angesiedelt wurden, um eine zügige Assimilation zu gewährleisten. ${ }^{205}$ Zum Teil unter Einsatz der Polizei und alliierter Kräfte wurde die Einquartierung in freizugebende Räume durchgesetzt, was den sozialen Unfrieden verstärkte. ${ }^{206}$ Diese offensive Politik, verbunden mit einer unmittelbaren rechtlichen Gleichstellung der Vertriebenen mit der einheimischen Bevölkerung, erwies sich letztlich als förderlich für die rasche Eingliederung. Sie kostete aber den Preis, die vorherigen, über die Familie hinausgehenden Bindungen der Menschen, wie alte Dorfgemeinschaften, weitgehend zu zerstören. Die verbreitete »Angst vor Überfremdung « und Diskriminierung der Vertriebenen steigerten den »Anpassungsdruck«. ${ }^{207}$ Das für die Vertriebenen zunächst verhängte Koalitionsverbot wurde bald durch kirchliche und andere Vereinigungen unterlaufen und nach den Bundestagswahlen von 1949 abgeschaff. ${ }^{208}$

Die in den Besatzungszonen gestrandeten Menschen erreichten ein vom Krieg zerstörtes Land, das bereits ohne sie unter massiven Versorgungsproblemen und Wohnungsnot litt. So erschien die erfolgreiche und dauerhafte Aufnahme der Vertriebenen den meisten Zeitgenossen als unmöglich und wird aufgrund der außerordentlichen Schwierigkeiten bis heute als herausragende Leistung der jungen Bundesrepublik bewertet. ${ }^{209}$ Die Vertriebenen ${ }^{210}$ trugen - unter nicht ausbleibenden Konflikten - durch die Ansiedlung in bis dato überwiegend monokonfessionelle Regionen sowie durch eine stärkere Mobilität entscheidend zur Modernisierung des Landes bei. ${ }^{211}$ In den 1950er Jahren gelang im Westen durch das Lastenausgleichsverfahren ${ }^{212}$ und den ökonomischen Aufschwung ihre weitgehende wirtschaftliche Integration, wobei es die Wenigsten von ihnen schafften, ihre wirtschaftliche und gesellschaftliche Position der Vorkriegszeit wieder zu erreichen. Die Bundesrepublik verfolgte eine doppelte Strategie: Zum einen sollte eine rasche "Eingliederung « zur Stabilität beitragen, zum anderen die geförderte Identitätspolitik der Vertriebenen die fortgesetzten Ansprüche auf die Ostgebiete unterstreichen und gleichzeitig die Vertriebenenverbände gewinnen. ${ }^{213}$ Stark wog jedoch für viele Vertriebene das gravierende Desinteresse der lokalen Bevölkerung und zunehmend des eigenen Nachwuchses an ihrem individuellen Schicksal und an der alten Heimat, das oftmals zu innerer Isolation führte. Die Bundesrepublik wurde

204 Kossert: Kalte Heimat, 2009, S. 32.

205 Beer: Flucht und Vertreibung der Deutschen, 2011, S. 104.

206 Ebd.

207 Ebd., S. 110.

208 Vgl. ebd., S. 105.

209 Vgl. Schwartz: Ethnische »Säuberungen« in der Moderne, 2013, S. 641. Vgl. zu einer kritischen Einschätzung des Integrationserfolges auch: Douglas: „Ordnungsgemäße Überführung«, 2012, S. 394401.

210 Schwartz weist daraufhin, dass trotz verbindendem Schicksal weiter nur mit Vorsicht von den Vertriebenen gesprochen werden solle, da auch die häufig ähnliche soziale Notlage nicht die oft großen Unterschiede zwischen den verschiedenen Herkunftsgruppen ebenso wie die sozialen Staffelungen einebnete: Schwartz: Assimilation versus Incorporation, 2016, S. 78-80.

211 Bauerkämper: Deutsche Flüchtlinge und Vertriebene, 2010, S. 481.

212 Vgl. zum Lastenausgleichsverfahren: Kossert: Kalte Heimat, 2009, S. 92-109. Siehe auch: Schwartz: Assimilation versus Incorporation, 2016, S. 87f.

213 Vgl. Schwartz: Assimilation versus Incorporation, 2016, S. 77. 
so trotz ökonomischer Erfolge für viele eine »kalte Heimat «. ${ }^{214}$ Andreas Kossert bilanziert, die bundesrepublikanische Meistererzählung der erfolgreichen Integration der Vertriebenen hinterfragend:

»Dass die Aufnahme der 14 Millionen snicht zur politischen Dauermalaise wurde, die Radikalisierung ausblieb<, dafür zahlten die Vertriebenen mit Verleugnung ihres Schmerzes und kultureller Selbstaufgabe. Schlesier, Ostpreußen, Pommern, Deutschböhmen und Banater Schwaben, die über Jahrhunderte beigetragen haben zur Vielfalt der deutschen Identität, hatten fern der Heimat nichts mehr zu melden. Sie mussten sich anpassen im Westen ihres Vaterlandes, das ihnen zur kalten Heimat werden sollte. $\ll^{215}$

In der Sowjetischen Besatzungszone und der späteren DDR gab es eine offizielle Vertriebenenpolitik lediglich bis Anfang der 1950er Jahre. ${ }^{216}$ Ab September 1945 wurden die Flüchtlinge und Vertriebenen euphemistisch »Umsiedler « genannt, um die Endgültigkeit der Vertreibung zu unterstreichen sowie die sowjetische Besatzungsmacht und später die sozialistischen Bruderländer nicht zu diskreditieren. ${ }^{217}$ Propagandistisch wurden die Bodenreform und Enteignung der »Junker « und die Verteilung von Land an die Flüchtlinge und Vertriebenen funktionalisiert und die erfolgreiche und abschließende Integration der $>$ Umsiedler in den 1950 er Jahren verkündet. ${ }^{218}$ De facto profitierte von der - später durch die Kollektivierung weitgehend obsolet gewordenen - Bodenreform vor allem die alteingesessene Bevölkerung, wohingegen die unfreiwilligen Zuwanderer ebenso wie im Westen auf starke Vorbehalte und Ablehnung stießen, die auch die staatliche Propaganda nicht überdecken konnte. ${ }^{219}$ In den 1950er Jahren verschwanden dann sowohl die »Umsiedler« als auch der alternative Begriff der »Neubürger« aus dem offiziellen Sprachgebrauch. Die Thematik von Flucht und Vertreibung konnte von da ab lediglich zeitweise in Literatur, Film und Theater behandelt werden und blieb ansonsten auf den privaten und familiären Bereich beschränkt. ${ }^{220}$ In beiden deutschen Staaten wurden die Vertriebenen schließlich zu »Trägern neuer Ordnungen des Wiederaufbaus«: in der Bundesrepublik zu »Trägern einer snivellierenden Mittelstandsgesellschaft<, in der DDR zu Säulen einer ebenfalls nivellierten Gesellschaft der >Arbeiter und Bauern und der Staats- und Partei-Angestellten. ${ }^{221}$ Trotz der unterschiedlichen

214 Vgl. zum ökonomische Erfolg: Bade; Oltmer: Mitteleuropa, 2010, S. 159. Siehe auch: Beer: Flucht und Vertreibung der Deutschen, 2011, S. $122 f$.

215 Kossert: Kalte Heimat, 2009, S. 16. Vgl. Beer: Flucht und Vertreibung der Deutschen, 2011, S. 124126.

216 Siehe zur Vertriebenenpolitik der SBZ/DDR: Bauerkämper: Assimilationspolitik und Integrationsdynamik, 2008, S. 22-39. Bauerkämper konstatiert dabei für beide deutsche Staaten ein Scheitern der »Assimilationspolitik«. Ökonomische und gesellschaftliche Trennlinien und damit verbundene Spannungen blieben bestehen (S. 36-38). Vgl. auch: Kossert: Kalte Heimat, 2009, S. 193-228.

217 Siehe: Bauerkämper: Deutsche Flüchtlinge und Vertriebene, 2010, S. $477 f$.

218 Vgl. Kossert: Kalte Heimat, 2009, S. 216f.

219 Bauerkämper: Deutsche Flüchtlinge und Vertriebene, 2010, S. 481. Vgl. Kossert: Kalte Heimat, 2009, S. $201 f$.

220 Siehe: Bauerkämper: Deutsche Flüchtlinge und Vertriebene, 2010, S. 478. Vgl. ausführlich: Kossert: Kalte Heimat, 2009, S. 193-228.

221 Schwartz: Ethnische »Säuberungen« in der Moderne, 2013, S. 644. 
Bemühungen beider Staaten verstetigte sich die ökonomische Ungleichheit der Vertriebenen gegenüber den Einheimischen noch in die nächsten Generationen hinein. ${ }^{222}$ Eine beträchtliche Zahl der deutschen Vertriebenen entschied sich für die Auswanderung nach Übersee, zum Beispiel fast alle Gottscheer Deutschen aus Slowenien.

Die in Folge der Vertreibungen angesprochenen Nivellierungsprozesse in der Bundesrepublik und der Tschechoslowakei betrafen in noch stärkerem Maße Polen. Dort führten der Zweite Weltkrieg und seine Konsequenzen zu einer beispiellosen >Mobilisierung< der Bevölkerung. Zwischen 1939 und 1946 hatten fast 70 Prozent der Polen ihren Wohnsitz geändert, wurden lang gewachsene Gemeinschaften zerstört, Familien auseinandergerissen und Akademiker zu Bauern und ehemals verarmte Bauern zu Neureichen. ${ }^{223}$

In Polen endeten die Vertreibungen offiziell 1950/51. ${ }^{224}$ Neben den materiellen deutschen Hinterlassenschaften blieben etwa eine Million Angehörige der als "autochthon « definierten Minderheiten im Land. ${ }^{225}$ Die »Masuren, Ermländer, Kaschuben und Oberschlesier « sah man als slawische Ureinwohner und damit als >repolonisierbar an und versuchte sie zu gewinnen, zumal sich die Wiederbevölkerung der Westgebiete als schwierig herausstellte; gleichwohl war damit ein offizielles und weitgehendes Bekenntnis zum Polentum verbunden, beispielsweise mit Anpassung der Namen. ${ }^{226}$ Trotz formaler Gleichstellung der Verbliebenen in den 1950er Jahren blieben >Volksdeutsche< sowie ehemalige Reichsbürger "noch lange Bürger zweiter Klasse ${ }^{227}$ Offiziell verschwand das deutsche Element bis 1989 aus der polnischen Gesellschaft, es existierte aber als Phantom sowie in der Propaganda der Volksrepublik weiter. War die Angst vor einer Rückkehr der Deutschen noch bis in die 1960er Jahre virulent, so blieb sie doch bis 1989/90 in der Gemeinschaft der Neusiedler in den polnischen Westgebieten präsent. ${ }^{228}$ Diese Angst war in der unmittelbaren Nachkriegszeit unter den kresy-Vertriebenen häufig verbunden mit der Hoffnung auf eine Revision der polnischen Ostgrenze und sowjetischen Herrschaft und damit auf die Rückkehr in ihre Heimat. ${ }^{229}$ Die polnischen >Repatrianten trafen im Westen schließlich auf vergleichbare Ankommensschwierigkeiten wie die deutschen Vertriebenen; so stießen sie an ihren neuen Wohnorten häufig auf Ablehnung und ihre polnische Herkunft wurde

222 Vgl. Mehnert: »Flucht und Vertreibung «aus den historischen deutschen Ostgebieten, 2008, S. $237 f$.

223 So prägnant formuliert es der polnische Historiker und ehemalige Mitarbeiter des MIIW Rafał Wnuk in einem Interview: Orzechowski: Czarno-biały mit Wyklętych nie ma nic wspólnego z rzeczywistością. Newsweek Polska. 05.03.2018.

224 Lemberg: Das Jahrhundert der Vertreibungen, 2003, S. $50 f$.

225 Vgl. ausführlich zur Situation der deutschen Minderheit in Volkspolen bis zum Ende der 1950er Jahre: Nitschke: Vertreibung und Aussiedlung der deutschen Bevölkerung, 2003, S. 285-311.

226 Kossert: Kalte Heimat, 2009, S. 33f. Zuvor sind die >Autochthonen< zumeist wie die Deutschen Opfer der Übergriffe durch die Rote Armee und polnischer Kräfte gewesen: Zaremba: Die große Angst, 2016, S. $425 f$.

227 Kochanowski: Verräter oder Mitbürger? 2006, S. 349. Es wird davon ausgegangen, dass bis »Ende der 1940er Jahre über eine Million ehemaliger Reichsbürger, die polnische Staatsbürgerschaft teils unter Zwang - erhielten.«(Borodziej: Geschichte Polens im 20. Jahrhundert, 2010, S. 259). 
angezweifelt. ${ }^{230}$ Die letztlich nicht vollständige Umsiedlung der Polen aus den kresy endete im Laufe der 1950er Jahre, womit nach Ruchniewicz die direkt mit dem Zweiten Weltkrieg zusammenhängenden Bevölkerungsverschiebungen abgeschlossen waren. ${ }^{231}$

Mit der Stalinisierung der Tschechoslowakei 1948 wurde diese wie Polen ein Satellit der Sowjetunion »und verlor vollständig ihre innere und äußere Unabhängigkeit«. ${ }^{232}$ Edvard Beneš war mit seinem Taktieren zwischen den Blöcken gescheitert und litt unter einem schon 1945 vorhandenen Desinteresse der Westmächte, vor allem der USA, in der Tschechoslowakei einzugreifen. ${ }^{233}$ Wesentlicher Sieger dieser Umgestaltung Ostmitteleuropas war somit schließlich die stalinistische Sowjetunion und der Preis für den gewünschten ethnisch-homogenen Nationalstaat war die Übernahme des kommunistischen Systems in der ČSR. ${ }^{234}$ Die schwer kalkulierbaren mentalen Auswirkungen des Münchner Abkommens auf die tschechoslowakische Politik nach 1945 sollten nicht unterschätzt werden. Die nach München vorgenommene Umorientierung der Außenpolitik der ČSR hin zur Sowjetunion begünstigte sicher die Machtübernahme der Kommunisten, was sich auch an deren hohen Zustimmungswerten bei den tschechoslowakischen Wahlen zeigte - ganz im Gegensatz zu Polen. ${ }^{235}$

Verbliebene Deutsche, zunächst noch einige Hunderttausend, wurden häufig innerhalb der ČSR zwangsumgesiedelt und zur Zwangsarbeit herangezogen. Auf diese Arbeitskräfte sowie binationale Familien wollte man schließlich nicht mehr verzichten. Nach 1951 verblieben etwa 150.000 Deutsche in der ČSR. Mit der Zuerkennung der tschechoslowakischen Staatsbürgerschaft an diese Gruppe im April 1953 »war das menschenrechtswidrige Kapitel von Vertreibung und Zwangsaussiedlung abgeschlossen. $\ll^{236}$

In beiden Gesellschaften dauerte es schließlich sehr lange, bis eine neue Form von Gemeinschaft und Gesellschaft sowie eine Identifikation der Bewohner mit ihrer neuen Heimat entstand, nachdem die bisherigen regionalen und religiösen Traditionen durch das Verschwinden der Deutschen wenigstens einen Bruch erfahren hatten. Die »Heimwerdung « für die Neusiedler war schließlich ein Generationenprojekt. ${ }^{237}$ Die durch die materiellen Hinterlassenschaften der Deutschen und deren Verteilung ermöglichte hohe soziale Mobilität und die vor allem den Kommunisten im Bündnis mit der Sowjet-

230 Kochanowski: Repatrianten oder Expatrianten? 2007, S. 427.

231 Siehe: Ruchniewicz: Zwangsumsiedlungen von Polen, 2005, S. 190.

232 Kamiński: Polen und die Tschechoslowakei, 1997, S. 298.

233 Ebd., S. $298 \mathrm{f}$.

234 Siehe: Beer: Flucht und Vertreibung der Deutschen, 2011, S. 48-50. Auch Ther konstatiert, dass der Konsens der Alliierten in Bezug auf die Vertreibungen schon bald schwand; tatsächlich habe damit der »deutsche Angriffskrieg und Besatzungsterror« diese »drastische Gegenreaktion« provoziert und in einem kurzen Zeitfenster ermöglicht: Ther: Die dunkle Seite der Nationalstaaten, 2011, S. 264 .

235 Siehe: Lemberg: »München 1938«, 2001, S. 111f.

236 Suppan: Hitler - Beneš - Tito, 2014, S. 1443-1446.

237 Vgl. Čapka: Parallels and Specifics of Repopulation of the Czech Border Regions and the Polish Recovered Territories after 1945, 2011, S. 29f. Vgl. zur schwierigen und nur teilweisen Wiederbesiedelung des Sudetenlandes in der ČSR und der lange mangelhaften Identifikation der neuen Bewohner mit ihrer Heimat: Glassheim: Cleansing the Czechoslovak Borderlands, 2016, S. 92-122. Siehe für eine ausführliche Darstellung der ersten Ansiedlungsphase auch: Wiedemann: »Komm mit uns das Grenzland aufbauen!«, 2007, S. 415-428. 
union zugetraute Verteidigung der neuen Besitztümer führte zu einer gewissen Unterstützung derselben. ${ }^{238}$ Sowohl in Polen als auch in der Tschechoslowakei sahen die Kommunisten in den von den Deutschen verlassenen Gebieten Experimentierfelder, in denen der "neue Mensch« und die neue Gesellschaftsordnung schnell verwirklicht werden könnten. ${ }^{239}$ Nachhaltige wirtschaftliche Erfolge waren damit nicht verbunden:

»Der beträchtliche Reichtum, welchen die deutsche Bevölkerung in der Tschechoslowakei zurückließ, wurde keineswegs effektiv genutzt oder gar vermehrt - ganz im Cegenteil. Sein wesentlicher Bestandteil wurde in den folgenden Jahrzehnten der kommunistischen Diktatur im vollen Wortsinn verwirtschaftet. « $^{240}$

Schwerer als der wirtschaftliche Verlust wiegt wahrscheinlich der moralische: Die Beseitigung der Deutschen und die damit verbundene Verteilung von Gütern und gesellschaftlichen Aufstiegsmöglichkeiten erleichterte die kommunistische Machtübernahme, führte zu einem moralischen Niedergang durch das massenhafte Erleben von straflos bleibenden Verbrechen durch die reigenen Leute und zu einem nachhaltigen ökonomischen, kulturellen und geistigen Niedergang in den Grenzgebieten, aber auch im gesamten Staat. ${ }^{241}$

\subsection{Streitpunkte: Kontext, Opferzahlen, Verantwortung und Notwendigkeit}

Ein Teil der im Folgenden diskutierten Streitpunkte bei der Beschreibung und Einordnung des Geschehens beruht auf wissenschaftlichen Differenzen und auf unterschiedlichen nationalen Narrativen. Sie sind die Grundlage der in den Kapiteln zur Diskursgeschichte und den Museen besprochenen Auseinandersetzungen. Die Konflikte rühren häufig weniger aus einer grundsätzlichen Infragestellung der historischen Ereignisse selbst, sondern eher aus unterschiedlichen Schwerpunktsetzungen und verschiedenen Kontextualisierungen. Zunächst sollen knapp die gängigen Narrative in den drei Ländern besprochen werden, darauf folgt eine Diskussion der Frage der Verantwortung für die Vertreibung und das Vertreibungsgeschehen sowie eine Erörterung der Opferzahlen und des Rachemotivs. Zum Abschluss wird die Frage der Lager sowie der Bewertung und vermeintlichen Notwendigkeit der Vertreibungen besprochen.

Die polnische Perspektive betont den unmittelbaren Zusammenhang zwischen dem Ereignis der Vertreibung und den massiven Besatzungsverbrechen der Deutschen, die etwa sechs Millionen Polen (davon über drei Millionen polnische Juden) das Leben gekostet, die vollständige Beseitigung des polnischen Volkes anvisiert und dies in Be-

238 Vgl. Beer: Flucht und Vertreibung der Deutschen, 2011, S. 50.

239 Wiedemann: »Komm mit uns das Grenzland aufbauen!«, 2007, S. 423-428.

240 Staněk: Verfolgung 1945, 2002, S. 221.

241 So das Fazit von Staněk: Staněk: Vertreibung und Aussiedlung, 2001, S. 226-229. Staněks Bilanz ist aber nicht die Mehrheitsmeinung in der tschechischen Geschichtswissenschaft und Publizistik, die mehr auf exogene Faktoren der kommunistischen Machtübernahme wie die internationale Lage verweisen: Pešek: Die 3oer und 40er Jahren in der tschechischen Erinnerung seit den 7oer Jahren, 2006, S. 132. Vgl. zu den langfristigen moralisch-politischen Folgen der Vertreibung für Tschechien: Denemarková: Shakespeare hat recht, 2019, S. $22 f$. 
zug auf die kulturelle Elite in >Kooperation $<$ mit der Sowjetunion auch beinahe erreicht hätten. ${ }^{242}$ Von dieser Perspektive aus wird die Vertreibung als vergleichsweise mildes Schicksal betrachtet, wenn auch menschliche Härten dabei nicht ausblieben. ${ }^{243}$ Dieser Kontext und damit verbunden eine Form von Kollektivschuld, die durch die besonders starke Unterstützung des Nationalsozialismus in den Ostprovinzen scheinbar ihre Bestätigung findet, prägen die Erzählung deutlich mehr als die konkreten Ereignisse und beispielsweise die gewaltsamen Übergriffe durch polnische Akteure und das angesprochene Lagerwesen. ${ }^{244}$ Verstärkend kommt hinzu, dass Polen zum einen selbst Opfer von Vertreibungen aus den kresy waren sowie durch eine kaum in der Bevölkerung verankerte sowjetische Marionettenregierung geführt wurden und die Durchsetzung der kommunistischen, als fremd wahrgenommenen, Herrschaft in langwierigen Widerstand, massive Verunsicherung und weitere Gewalt mündete. Die Flucht und Vertreibung der Deutschen aus den nunmehr polnischen Westgebieten erscheinen in diesen weiteren Zusammenhängen eher als eine minderschwere Tragödie in einer Zeit, in der Polen einmal mehr um seine Existenz zu kämpfen hatte.

In der Tschechoslowakei und in Tschechien bildeten das Münchner Abkommen, die demütigende und punktuell äußerst brutale Besatzungsherrschaft und die als real wahrgenommene Gefahr, nach einem für Deutschland siegreichen Kriegsende als Volk von der Landkarte zu verschwinden, den narrativen Kontext für die Rechtfertigung der Vertreibung der deutschsprachigen Bevölkerung, die für ihr Verhalten - ihren Verrat als tschechoslowakische Staatsbürger 1938 und die intensive Kooperation mit den nationalsozialistischen Besatzern - kollektiv bestraft wurde. ${ }^{245}$ Herausgestellt wird in diesem Zusammenhang, dass wesentliche Akteure der Besatzungsmacht im Protektorat Sudetendeutsche wie Karl Hermann Frank waren. ${ }^{246}$ Das Münchner Abkommen und die im März 1939 erfolgte `Zerschlagung der Rest-Tschechei< wären demnach undenkbar ohne die im Prinzip seit 1918/19, hauptsächlich aber nach 1933 fortgesetzte Illoyalität der Sudetendeutschen, ebenso wie durch das Im-Stich-Gelassen-Werden durch alle ihre Verbündeten.

242 Vgl. Piskorski: Zwangsmigrationen im Kontext des Zweiten Weltkriegs, 2014, S. 170. Piskorski weist auf den fundamentalen Unterschied zwischen deutscher und alliierter (und polnischer sowie tschechoslowakischer) »Nationalitätenpolitik« hin, deren gewalttätige Form sowie die Zwangsarbeit einen »völlig anderen Charakter« gehabt hätten. Darüber hinaus sei ein wesentlicher Unterschied, dass viele Handlungen aus Angst vor den Deutschen (oder den Deutschen der Zukunft) zu erklären seien und niemand auf die Idee kam »aus den Deutschen ein Volk von Sklaven zu machen«. Diese werden ggf. tiefer verortet im faschistischen und kommunistischen Totalitarismus (als Folge eines gesteigerten Nationalismus und Chauvinismus): Czerniakiewicz et al. 2005, S. 111.

243 Piskorski: Zwangsmigrationen im Kontext des Zweiten Weltkriegs, 2014, S. 170.

244 Die These einer spezifischen ostdeutschen Schuld am Nationalsozialismus wurde und wird auch an »bundesdeutschen Stammtischen bis hin zu intellektuellen Kreisen in unterschiedlicher Form« vertreten: Kittel: Vertreibung der Vertriebenen? 2007, S. 18. Vgl. für eine kritische Besprechung dieses 'Schulddiskurses< in der frühen Bundesrepublik: ebd., S. 18-23.

245 Suppan: Hitler-Beneš - Tito, 2014, S. 491. Siehe auch: Staněk: Verfolgung 1945, 2002, S. 184. Siehe zum >Argument Lidice ‘ür die Vertreibung der Sudetendeutschen: Douglas: „Ordnungsgemäße Überführung«, 2012, S. 39. Siehe zur internationalen Rezeption von Lidice auch: Suppan: Hitler Beneš - Tito, 2014, S. 1233-1235. Vgl. Lemberg: »München 1938«, 2001, S. $109 f$. 
Wenn in der Bundesrepublik Deutschland von Flucht und Vertreibung gesprochen oder geschrieben wurde, war der Kontext zumeist wesentlich enger gefasst und das Geschehen reihte sich in die Schrecken des langen Kriegsendes in ganz Deutschland ein. ${ }^{247}$ Die Fluchtbewegungen und späteren Vertreibungen erschienen fast durchweg als Einfall in eine halbwegs heile Welt, in der hauptsächlich die Zivilbevölkerung im Fokus stand. ${ }^{248}$ Die Shoa, die deutsche Besatzungsherrschaft und Kriegsverbrechen waren in diesem Narrativ zumeist nicht enthalten. ${ }^{249}$ In vielen Erzählungen tauchten nun zum ersten Mal sowjetische, polnische oder tschechische Einheiten mit der Ausübung massiver Gewalt auf. Auch in wissenschaftlichen Abhandlungen setzte sich erst seit den 1990er Jahren die Einsicht der Notwendigkeit durch, den weiteren Kontext von NS-Bevölkerungspolitik und der Shoa zu berücksichtigen. ${ }^{250}$ Im organisierten Vertriebenenmilieu sah man die Verantwortung für das Schicksal der Vertriebenen vor allem bei der Sowjetunion und den sogenannten >Vertreiberstaaten $\triangleleft$. Das entsprechende Ausklammern westalliierter Verantwortung hing zum einen mit der Blockkonfrontation des Kalten Krieges und dem neuen Status als Verbündetete wie zum anderen mit dem angesprochenen Verschleiern der alliierten Gesamtverantwortung für das Geschehen zusammen. Ebenso wurde einzelnen Akteuren, an erster Stelle Edvard Beneš, dem »Vater des Vertreibungsgedankens «, eine betont antideutsche Agenda schon für die Zeit vor 1938 unterstellt. ${ }^{251}$ Begann die Erzählung über die Vertreibung in Deutschland und besonders bei den Vertriebenenverbänden häufig erst 1944/45, so wurden gleichzeitig oft die langen Linien des polnischen, tschechischen oder panslawistischen Nationalismus betont, der seit dem 19. Jahrhundert - mehr oder weniger - die Beseitigung der Deutschen aus Osteuropa planmäßig angestrebt hätte. ${ }^{252}$

Die Frage der Verantwortung für die Geschehnisse ist ebenso von Bedeutung wie die Klassifizierung der Ereignisse. Wie eben besprochen, schwankte die entsprechende $\mathrm{Zu}$ ordnung in Deutschland zwischen einer anonymen Naturkatastrophe, der Zuweisung aller Verantwortung auf die östlichen Staaten oder aber später einer starken Fokussierung auf den vorherigen NS-Terror als Ursache der Vertreibung. ${ }^{253}$ In Tschechien und

247 Vgl. Hahn; Hahn: Flucht und Vertreibung, 2005, S. 347-350.

248 Vgl. Lüdtke: Explaining Forced Migration, 2009, S. 17.

249 Vgl. Schwartz: Vertriebene im doppelten Deutschland, 2008, S. $135 f$.

250 Suppan: Hitler - Beneš - Tito, 2014, S. 1366.

251 Hier spiegelt sich die »Legende« der Sudetendeutschen als »Fünter Kolonne« - wobei beide »ein gehöriges Element von Wahrheit«enthalten: Lemberg: Die Entwicklung der Pläne für die Aussiedlung der Deutschen aus der Tschechoslowakei, 2001, S. 191. Kraft kritisiert einen monokausalen Fokus auf die Person Beneš, die unter anderem von der Verantwortung der Alliierten ablenke: Kraft: Mythos »Beneš-Dekrete«, 2013, S. 246.

252 Besonders im Falle Böhmens ist man sich in Deutschland wie in Tschechien der langen Linie des Nationalitätenkonfliktes bewusst, verweist aber zumeist differenziert darauf, dass der Konflikt keineswegs eine Zwangsläufigkeit der Trennung impliziert. Vgl. dafür z.B. den deutsch-tschechischen Sammelband von 2003, der den Beginn des spezifisch deutsch-tschechischen Konfliktes mit 1848 ansetzt: Richter (Hg.): Bez démoů minulosti, 2003. So formulierte Erika Steinbach: »Beim Slawenkongress 1848 in Prag war das Wetterleuchten des Nationalismus und Rassismus unheilvoll sichtbar.«Steinbach: Ansprache zum Tag der Heimat des Bundes der Vertriebenen am 22. August 2009 im ICC Berlin.

253 Vgl. Hahn; Hahn: Die Vertreibung im deutschen Erinnern, 2010, S. 293, 497f. Vgl. auch: Haar: Vom »Volksgruppen-Paradigma«bis zum »Recht auf Heimat«, 2006, S. 17. 
Polen wird vor allem auf die alliierte Verantwortung der Potsdamer Konferenz hingewiesen, deren Ergebnisse man lediglich exekutiert habe. Mit Hinweis auf das Abkommen wird auch der vergleichsweise geregelte Auszug der Deutschen, bildhaft vor allem die Aussiedlungen von 1946/47, hervorgehoben.

Alle diese Perspektiven sind in hohem Maße selektiv. Die Verantwortung für die Geschehnisse verteilt sich zwischen der deutschen Führung, die den Krieg und besonders den Vernichtungskrieg im Osten begann und schließlich nicht willens oder nicht in der Lage war, die deutsche Zivilbevölkerung ausreichend zu schützen oder den Krieg durch eine vollständige Kapitulation vor dem Einmarsch der Alliierten zu beenden und - in geringerem Maße - zwischen den Westalliierten und der Sowjetunion sowie den sowohl bürgerlichen als auch kommunistischen Exil- und Nachkriegsregierungen der Tschechoslowakei und Polens. ${ }^{254}$ Dieser weitere Horizont wird häufig ebenso wenig bedacht wie die verschiedenen Dimensionen der Zwangsmigration.

Ein weiterer wesentlicher Diskussionspunkt waren und sind die Opferzahlen, die eine spezifische Funktion erfüllen:

»Alle diese Zahlen haben viel miteinander gemein: Sie sind nicht nur bestimmte quantitative Größen, sondern beinhalten vor allem eine weitere politische, moralische oder emotional motivierte Aussage, die das eigene Recht und die eigenen Leiden und zugleich das Unrecht bzw. die Brutalität des anderen nachweisen soll. « ${ }^{255}$

Die Zahlen haben, abgesehen von ihren quellenkritisch zu untersuchenden historischen Aussagen, ihren eigenen diskursiven Wert, der für die verfolgte Fragestellung wesentlicher ist als die häufig nicht abschließend zu beantwortende Frage nach ihrer tatsächlichen Höhe. Dennoch wird im Folgenden eine Übersicht der aktuellen Annäherungen geboten, um die in den Museen und Diskursen getroffenen Aussagen besser einordnen zu können. ${ }^{256}$

Realistisch erscheint die Zahl von etwa 15-18 Millionen Deutschen in den ehemaligen Ostprovinzen des Reiches sowie >Volksdeutschen $<$ in den deutschen Siedlungsgebieten Osteuropas. Hiervon sind gegen Ende des Krieges 11-14 Millionen Menschen in den Westen geflüchtet oder nach Kriegsende vertrieben oder deportiert worden. ${ }^{257}$ Unklarheiten und Debatten bestehen über die in Folge von Flucht und Vertreibung ums Leben gekommenen Deutschen. ${ }^{258}$ Die genannten Zahlen bewegen sich zwischen 500.000 bis vier Millionen, wobei sich in offiziellen bundesdeutschen Reden und im Großteil der Presse die wahrscheinlich deutlich zu hoch gegriffene Zahl von etwa zwei Millionen

254 Vgl. Douglas: „Ordnungsgemäße Überführung«, 2012, S. 90-122, hier v.a. S.122. Vgl. auch: Schwartz: Rezension zu: Piskorski, Jan M.: Die Verjagten. Flucht und Vertreibung im Europa des 20. Jahrhunderts. München 2013, 2014. Snyder weist die Gesamtverantwortung prononciert der deutschen Führung zu, die sowohl den Krieg ausgelöst als auch bei der Verteidigung ihrer Zivilbevölkerung versagt habe: Snyder: Bloodlands, 2011, S. 330. Ther bilanziert, dass die Opfer der Vertreibung »genauso auf das Konto der eigenen Regierung wie auf jenes der Kriegsgegner« gingen: Ther: Die Außenseiter, 2017, S. 109.

255 Kučera: Statistische Berechnungen der Vertreibungsverluste, 2001, S. 231.

256 Vgl. ebd., S. 231f.

257 Vgl. Bade; Oltmer: Mitteleuropa, 2010, S. 158.

258 Żurek: Wie viele Opfer forderte die Vertreibung? 2009, S. 75. 
Todesopfern durchgesetzt hat. ${ }^{259}$ Beer hat die Zahlen ebenfalls diskutiert und schließt, dass diese »vermutlich deutlich unter der Grenze von einer Million« liegen. ${ }^{260}$

Die Zahl von insgesamt 500.000 Todesopfern lässt sich im Einzelnen nachweisen, wobei etwa 1,5 Millionen ungeklärte Fälle verbleiben (nach anderer Berechnung 610.000 und 2,2 Millionen). ${ }^{261}$ Bei den Sudetendeutschen beträgt die Anzahl solcher Fälle zwischen 220.-270.000 Menschen, die gelegentlich mit den Todeszahlen gleichgesetzt wird. Tatsächlich werden bei den Sudetendeutschen 20.-30.000 Todesopfer angenommen. ${ }^{262}$ Nach Kossert verbietet es sich, die ungeklärten Fälle einfach zu den Todesfällen zu zählen. Letztlich ist auch keine weitergehende Klärung der Zahlen mehr zu erwarten, »da in den Wirren des Krieges und der Anarchie der ersten Nachkriegszeit niemand gezählt hat, wie viele Deutsche ermordet wurden, in den Lagern Hungers starben oder auf der Flucht umkamen. $\ll^{263}$ Darüber hinaus wird darauf verwiesen, dass der Begriff der »Vertreibungsverluste« häufig bewusst missverständlich diese Opfer der polnischen, tschechischen und sowjetischen Verantwortung zuordnet, obwohl in den Kalkulationen zu den Vertreibungsverlusten im Osten auch Opfer alliierter Luftangriffe, des erwähnten nationalsozialistischen Terrors gegen die eigene Bevölkerung, der massiven >Kollateralschäden` wie bei der Verteidigung von Breslau ebenso wie der chaotischen Evakuierung und Flucht einbezogen werden. ${ }^{264}$ Klaus-Peter Friedrich ergänzt in Bezug auf die Berechnungen, »dass die Zahl derjenigen, die als Opfer von vorsätzlichen verbrecherischen Handlungen bei allen Zwangsaussiedlungen Deutscher in Ostmitteleuropa zu Tode kamen, von deutschen Historikern auf 100.000 bis höchstens eine Viertel Million geschätzt wird. ${ }^{265}$

259 Siehe für die Verwendung zu hoher Opferzahlen der Vertreibung in Medien und Politik: Ther: Der Diskurs um die Vertreibung, 2008, S. 34. Vgl. für Berechnungsversuche und die Diskussion der Zahlenproblematik ausführlich: Hahn; Hahn: Die Vertreibung im deutschen Erinnern, 2010, S. 659726.

260 Zur Diskursgeschichte der Zahlen vgl. Beer: Flucht und Vertreibung der Deutschen, 2011, S. 127-134. Tůma problematisiert, dass die etwa 6000 Selbstmorde von Sudetendeutschen den Vertreibungsopfern ohne Bedenken und implizit der Verantwortung der tschechoslowakischen bzw. alliierten Politik zugerechnet werden; dies sei besonders fragwürdig, da die 100.000 Selbstmorde im deutschen Reich am Ende des Krieges für gewöhnlich nicht der alliierten Verwaltung zur Last gelegt werden: Tůma: Die Aussiedlung, 2015, S. 276f.

261 Kossert: Kalte Heimat, 2009, S. 40. Żurek: Wie viele Opfer forderte die Vertreibung? 2009, S. 75-78.

262 Suppan: Hitler - Beneš - Tito, 2014, S. 1449f. Suppan kalkuliert die Zahl höher als die von der Deutsch-Tschechischen Historikerkommission Ende 1996 ermittelte Zahl von ca. 19.000 belegten Todesfällen und sieht die von dieser als Dunkelziffer maximal angegebene Zahl von 30.000 Vertreibungsopfern als zu gering an. Vgl. Gemeinsame Deutsch-Tschechische Historikerkommission: Stellungnahme der Deutsch-Tschechischen Historikerkommission zu den Vertreibungsverlusten, 2001, S. 245-247. Siehe umfassend auch: Overmans: »Amtlich und wissenschaftlich erarbeitet«, 1999, S. 175-177.

263 Kossert: Kalte Heimat, 2009, S. 40. Auch Hahn/Hahn gehen davon aus, dass die Zahlen kaum noch konkretisiert werden können; dies sei bereits bei den militärischen Verlusten 1944/45 schwierig und wird bei den Vertreibungen durch die Verschleppungen, nationale ২Konversionen oder den Tod von nicht registrierten Neugeborenen noch erschwert, vgl. Hahn; Hahn: Die Vertreibung im deutschen Erinnern, 2010, S. 45.

264 Piskorski: Zwangsmigrationen im Kontext des Zweiten Weltkriegs, 2014, S. 157. Żurek: Wie viele Opfer forderte die Vertreibung? 2009, S. 76-78.

265 Friedrich: Erinnerungspolitische Legitimierungen des Opferstatus, 2007, S. 191. 
Die polnischen Opferzahlen im Zweiten Weltkrieg sind durch die Grenzverschiebungen, die Zerstörung der Bürokratie und die schwerwiegende demographische Umwälzung des Landes ähnlich schwer zu fassen und eine detaillierte Zählung »praktisch unmöglich «. ${ }^{266}$ Nach dem Krieg wurde von den volkspolnischen Behörden die Zahl von 6.028.000 Millionen Kriegsopfern politisch festgelegt: davon ungefähr die Hälfte polnische Juden. ${ }^{267}$ Damit sollte »eine quantitative Gleichrangigkeit zwischen polnischen und jüdischen Opfern suggeriert « werden. ${ }^{268}$ Eine Untersuchung des staatlichen polnischen Geschichtsinstituts IPN von 2009 sieht die Zahl bei 5.650.000 Opfern. ${ }^{269}$ Timothy Snyder kalkulierte 2011 die Zahl hingegen bei etwa einer Millionen nichtjüdischer Polen, die Opfer der Deutschen wurden, sowie 100.000 Opfer der sowjetischen Besatzung. Eine weitere Million »starb durch Misshandlungen und als Kriegsopfer«. Insgesamt dürfte 4,8 Millionen eine realistische Annäherung sein, die sich zudem den Zahlen von 1946 nähert, bevor diese >korrigiert « wurden. ${ }^{270}$ Die Verluste an polnischen Staatsbürgern setzten sich auf vielfältige Art zusammen: zunächst die militärischen Verluste während

266 Piskorski: Zwangsmigrationen im Kontext des Zweiten Weltkriegs, 2014, S. 157. Vgl. auch: DuninWąsowicz: Die nationalsozialistische Okkupationspolitik, 1997, S. 249.

267 Siehe: Gniazdowski: Zu den Menschenverlusten, 2007/2008, S. 71-78. Tatsächlich lag die Schätzung der demographischen Verluste bei 2,6 Millionen Polen und 3,4 Millionen Juden (S. 75). Friedrich weist in seiner Erörterung in Bezug auf Feliks Tych darauf hin, dass sowohl die sechs Millionen als auch die Zusammensetzung von jeweils 50 Prozent ein anhaltender Mythos der Volksrepublik sind; wird die Anzahl der getöteten polnischen Juden bei etwa 3 Millionen gesehen, so verweisen andere Berechnungen auf Zahlen von 1,15-1,68 Millionen nicht-jüdischer Polen bis hin zu 600.000 Opfern. Friedrich schließt damit (in Bezug auf Lucjan Dobroszycki), dass die Zahl zwischen 500.000 und 1,4 Millionen liegen dürfte: Friedrich: Erinnerungspolitische Legitimierungen des Opferstatus, 2007, S. 181-183. Vgl. Tych: Cemeinsame Geschichte-gemeinsame Aufarbeitung, 2008, S. 137. Vgl. zur politischen Erfindung und Instrumentalisierung der Zahl in der VRP ausführlich: Peters: Revolution der Erinnerung, 2016, S. 81-86.

268 Ebd., S. $82 f$.

269 Siehe: Instytut Pamięci Narodowej Główna Komisja Ścigania Zbrodni Przeciwko Narodowi Polskiemu; Materski et al. (Hg.): Polska 1939-1945, 2009. Klaus-Peter Friedrich, der sich in seinem auch hier verwendeten Aufsatz mit der bisherigen polnischen Opferzahlforschung auseinandergesetzt hat, urteilt äußerst kritisch über die erneute staatliche Fixierung der polnischen Opferzahlen: Friedrich: Erinnerungspolitische Legitimierungen des Opferstatus, 2007. Die seines Erachtens größten Verlustzahlen ethnischer Polen sind die mit den Grenzverschiebungen nach 1939/45 sich zu ukrainischen/weißrussischen/litauischen Staatsbürgern erklärten ehemaligen polnischen Staatsbürger, die hier (erneut) den von NS-Deutschland verschuldeten Bevölkerungsverlusten zugerechnet werden. Wenn diese »etwa 1,5-1,7 Millionen Personen« von der im Band angegebenen Verlustzahl von 2,77 Millionen nicht-jüdischer Polen abgezogen werden, nähert man sich den von verschiedenen polnischen Forschern nach 1989 ermittelten Zahlen von zwischen 0,5-1,7 Millionen Opfern an. Diese Forscher wurden nach Friedrich bezeichnenderweise nicht als Beiträger für die Publikation herangezogen und »so ist davon auszugehen, dass verlässlichere Berechnungen sich erst mit einer neuen Forschergeneration durchsetzen werden, deren (früher) beruflicher Werdegang mit dem kommunistischen Wissenschaftsbetrieb nicht verquickt ist und die sich den überkommenen Mythen der Volksrepublik nicht mehr verpflichtet fühlt.« - Friedrich: Rezension zu: Instytut Pamięci Narodowej Główna Komisja Ścigania Zbrodni Przeciwko Narodowi Polskiemu: Polska 1939-1945. Straty osobowe i ofiary represji pod dwiema okupacjami, Warszawa 2009, 2012. Vgl. zur gegenwärtigen Verwendung der Opferzahlen und der Kritik an der Vereinnahmung der jüdischen Opfer der Shoa: Lesser: »Sechs Millionen Polen«. Jüdische Allgemeine. 14.08.2019. Snyder: Bloodlands, 2011, S. $407 f$. 
des Krieges, die deutschen und sowjetischen Massaker an der Zivilbevölkerung und der militärischen und kulturellen Elite, die Deportationen in die Sowjetunion 1939-41 sowie die >Konversionen von ehemals polnischen Bürgern zur litauischen, weißrussischen oder ukrainischen Nationalität. Erhebliche Verluste forderte auch der Warschauer Aufstand, darunter viele Tausend durch planmäßige Erschießungen von Zivilisten. Über drei Millionen polnische Juden wurden in der Shoa von den Deutschen ermordet. ${ }^{271}$ Etwa 1,6 Millionen ethnischer Polen vertrieb die deutsche Besatzungsmacht und deportierte ungefähr drei Millionen Polen zur Zwangsarbeit. ${ }^{272}$

Die Verluste der tschechischen Zivilbevölkerung waren deutlich geringer, aber obwohl es sich um keine »demographische Katastrophe« handelte, waren sie - verbunden mit der Symbolwirkung der einzelnen deutschen Massaker wie Lidice - eine anerkannte Rechtfertigung für die Vertreibung der Deutschen. ${ }^{273}$ Miroslav Kárný geht in seinen Kalkulationen von 233.-277.000 tschechoslowakischen Opfern des Holocausts aus (davon 80.000 aus den böhmischen Ländern) und darüber hinaus von weiteren 60.-70.000 tschechoslowakischen Staatsbürgern, die der NS-Besatzungspolitik zum Opfer fielen. ${ }^{274}$ Suppan schlussfolgert, dass insgesamt $»$ Zwischen 40.000 und 45.000 Tschechen - ethnische Tschechen, nicht tschechoslowakische Staatsbürger (!) - gewaltsam ums Leben [kamen], die große Mehrheit durch Gewaltmaßnahmen des NSRegimes. ${ }^{275}$

Grundsätzlich ist der Begriff der Vertreibungsverluste zu diskutieren: Eindeutig fallen die durch Gewalttaten umgekommenen Deutschen auf dem Gebiet der ČSR am Kriegsende darunter; schwieriger wird es bei den vielen Selbstmorden. Oft ist unklar, ob Verluste infolge von Kriegs- oder Vertreibungshandlungen erfolgten. Die in den Lagern Gestorbenen oder Ermordeten kann man mit Sicherheit dazu rechnen, wobei auch hier Menschen an Ursachen wie Hunger oder Krankheiten starben, die es ebenso in anderen Regionen gab. Problematisch wird es bei den Menschen, die außerhalb der ČSR an Folgen der Vertreibung umkamen. Das zeigt nach Jaroslav Kučera, dass die Zahlen recht einfach hoch-, aber auch kleingerechnet werden können. Beides sei nicht gerechtfertigt. ${ }^{276}$

Neben genaueren Opferzahlen wird in Polen und Tschechien häufig auch eine kontextuelle Qualifizierung der deutschen und polnischen beziehungsweise tschechischen Opfer gefordert. Piskorski hält eine qualitative Unterscheidung der Schicksale von deutschen und polnischen Vertriebenen für geboten:

»Die individuelle Schicksalsgemeinschaft kann allerdings nicht die kollektive deutsche Verantwortlichkeit für den Krieg und die Art der Kriegsführung verdecken. Zwar finden

Gniazdowski weist hierzu darauf hin, »dass die nationalsozialistische Todesmaschinerie darüber befand, wer Jude war und wer nicht«: Cniazdowski: Zu den Menschenverlusten, 2007/2008, S. 88.

272 Ruchniewicz: Zwangsmigration als Instrument, 2016, S. 140.

273 Suppan: Hitler - Beneš - Tito, 2014, S. 853f. Vgl. ebd. auch zur tschechischen Opferbilanz von 19381945.

274 Kárný: Die tschechoslowakischen Opfer der deutschen Okkupation, 2001. Vgl. Cornelißen; Holec et al.: Politisch-historische Erinnerungen, 2005, S. 11f.

275 Suppan: Hitler-Beneš - Tito, 2014, S. 854.

276 Kučera: Statistische Berechnungen der Vertreibungsverluste, 2001, S. 241-244. 
wir den Begriff der Kollektivverantwortung nicht in Strafgesetzbüchern, aber wir sollten ihn in Politik und Ceschichte nicht vermeiden, wo eine Abstufung der Opfer sogar notwendig ist, auch wenn wir dabei ein gewisses Unbehagen empfinden. Für uns ist es zwar selbstverständlich, dass jede Vertreibung - selbst wenn sie international sanktioniert ist - zugleich ein Übel ist und man deshalb mit jedem Zwangsumgesiedelten Mitgefühl haben muss, aber dies ändert keineswegs etwas an der nicht weniger weitreichenden Tatsache, dass Opfer nicht immer gleich sind und die deutsch-polnische Schicksalsgemeinschaft deshalb ihre Grenzen hat. « $^{277}$

Verbunden mit der Überlegung der qualitativen Kontextualisierung des Opferstatus sind Überlegungen zur individuellen und kollektiven Schuld und ein gegebenenfalls damit verbundenes (berechtigtes) Rachemotiv. Wie besprochen, gibt es für massenhafte Rache an den deutschen Nachbarn (in den entsprechenden Mischgebieten) sowie Übergriffe durch die Zivilbevölkerung auf Deutsche wenige Belege:

»Im Gegensatz zu überhitzten Vorhersagen während des Krieges, es werde in Polen, der Tschechoslowakei und anderswo zu einem Blutbad kommen, sobald die Besatzung beendet sei, kam es nach der deutschen Kapitulation praktisch nirgends zu spontanen Gewalttaten gegen Deutsche. $\ll^{278}$

Das Motiv des aufgestauten Hasses und der eskalierenden Rache war aber besonders für die ČSR von Bedeutung, um die Trennung der beiden Völker durch die Aussiedlung der Deutschen zu rechtfertigen; außerdem ist es eine vermeintlich einfache Erklärung für brutale Exzesse. Allerdings sieht Suppan durchaus ein in Europa weit verbreitetes, »tiefes Bedürfnis« nach Vergeltung in Folge der demütigenden und rücksichtslosen Besatzungsherrschaft, die unter anderem durch Sudeten- und Volksdeutsche ausgeübt wurde. ${ }^{279}$ Verstärkend kommt für ihn hinzu, dass die Struktur der Besatzungsherrschaft und das für das Leben notwendige Operieren der Bevölkerung am Rande und jenseits der Legalität zum Verlust eines "gesunde[n] Rechtsempfinden« geführt habe, was entsprechende Ausschreitungen begünstigte. ${ }^{280}$ Ähnlich argumentiert auch Piskorski, der

277 Piskorski: Zwangsmigrationen im Kontext des Zweiten Weltkriegs, 2014, S. 172. Ther argumentiert ähnlich in Hinblick auf die große Unterstützung der Nationalsozialisten in den Sudetenund Grenzgebieten. Auch wenn diese Vorgeschichte »nach heutigem Rechtsverständnis selbstverständlich keine Grundlage für die kollektive Bestrafung einer Bevölkerungsgruppe sein (kann)« gilt, dass »die später vertriebenen Opfer (...) in vielen Fällen zugleich Täter (waren) «: Ther: Der Diskurs um die Vertreibung, 2008, S. $32 f$.

278 Douglas: »Ordnungsgemäße Überführung«, 2012, S. 450. Ebenso: Brunnbauer; Esch: Ethnische Säuberungen in Ostmittel- und Südosteuropa, 2006, S. 17. Vgl. auch: Hahn; Hahn: Die Vertreibung im deutschen Erinnern, 2010, S. 83-91. Hahn/Hahn wenden sich auch gegen den Hass-/Rachemythos, gleichzeitig lehnen sie die Vorstellung von langer Hand geplanter Gewalttaten ab.

279 Siehe: Suppan: Hitler - Beneš - Tito, 2014, S. 1215, 1218, 1752. Tůma weist zudem darauf hin, dass trotz aller Kritik an dem Vorgehen auch viele tatsächliche Täter Opfer der Rache waren: Tůma: Die Aussiedlung, 2015, S. 266, 276f. Auch Deák sieht den besonderen Status der Volksdeutschen, der sie über ihre nicht-deutschen Mitmenschen erhob, als eine Grundlage für die gewalttätige Rache; dennoch wären sie wahrscheinlich auch ohne die umfassende Kooperation mit NS-Deutschland vertrieben worden: Deák: Kollaboration, Widerstand und Vergeltung, 2017, S. 269.

Siehe: Suppan: Hitler - Beneš - Tito, 2014, S. 1219. 
ein in Europa weit verbreitetes Bedürfnis nach der Durchführung von »kollektiver Vergeltung « konstatiert, die allerdings nur in Kombination mit der sich »nach Kriegsende ausbreitenden Verwilderung « zu erklären sei, die heute als nur mehr schwer nachvollziehbar erscheint. ${ }^{281}$ Der Zusammenbruch der staatlichen und moralischen Ordnung habe solche Taten, die von einzelnen Elementen, aber mit Billigung der Bevölkerung und der Behörden durchgeführt wurden, erst ermöglicht. ${ }^{282}$ Schwartz hält schließlich fest, dass die trotz der »eigendynamische[n] Rolle der Bevölkerungsbasis bei den mit jeder `Säuberung einhergehenden Umverteilungen von Eigentum [...] scheinbar plötzlich ausgebrochene ethnische Gewalt zwischen Bevölkerungsgruppen shäufig manipuliert und organisiert war. Die Hauptverantwortung liegt in der Regel >oben<, nicht >unten [...].« Gleichzeitig schließt er, dass eine etwaige »Schlüsselbedeutung« von nichtstaatlichen Milizen noch weiter erforscht werden müsse. ${ }^{283}$ István Déak betont ebenfalls in Widerspruch zu einem monokausalen Rachemotiv den Nationalismus und Antisemitismus in Osteuropa: »Überdies bot die deutsche Besatzung den Osteuropäern nicht nur die Gelegenheit, sich der jüdischen und polnischen Landsleute zu entledigen, sondern ermöglichte es letztlich auch, die ansässige deutsche Bevölkerung zu vertreiben oder zu ermorden. « $^{284}$ Oldřich Tůma hingegen unterstreicht die unmittelbare Gewalterfahrung vor Kriegsende als einen wesentlichen (Mit-)Grund der Ausschreitungen gegen Deutsche in der ČSR; gerade in Böhmen seien die letzten Wochen der deutschen Herrschaft von einer eskalierenden Gewalt gegen die Tschechen geprägt gewesen, wie bei dem Versuch der Niederschlagung des Prager Aufstandes. Dieses Geschehen werde sowohl bei sudetendeutschen Zeitzeugen als auch im bundesdeutschen Narrativ ausgeblendet, sodass in »der deutschen Auffassung [...], kurz gesagt, die Tschechen oft mit dem 5. oder 9. Mai ohne ersichtlichen Grund zu blutrünstigen Bestien [wurden]. $\aleph^{285}$ Norman Naimark konstatiert, dass die Ursachen des die Deutschen treffenden entfesselten Nationalismus schließlich in der »Eskalation des Nationalismus« durch die Nationalsozialisten selbst lägen und »daher könnte man in gewisser Hinsicht sagen, die Deutschen hätten geerntet, was sie gesät hatten. « ${ }^{286}$

Marcin Zaremba skizziert in seinem Buch »Die große Angst« das Verhältnis der Polen zu den Deutschen und Volksdeutschen als von ehrlicher Rache geprägt, auch wenn er die gezielte Instrumentalisierung und Förderung dieser Gefühle durch die volkspolnischen Akteure beschreibt. Ebenso wirkte die Angst vor subversiven volksdeutschen Kräften nach und verhärtete das Verhältnis. Die Forderung und Durchführung von Zwangsarbeit, Internierung und Gewalt wurde sowohl von der Bevölkerung als auch in der Presse gefordert und beschrieben. Dieses - nach Zaremba verständliche, wenn auch nicht zu rechtfertigende - extrem antideutsche Gefühl ließ Entrechtung, Ausbeutung und Gewalt bis hin zu willkürlichen Morden möglich werden. Im Gegensatz zur

\footnotetext{
281 Piskorski: Die Verjagten, 2013, S. 230.

282 Siehe: Piskorski: Zwangsmigrationen im Kontext des Zweiten Weltkriegs, 2014, S. 160-162.

283 Schwartz: Ethnische »Säuberungen« in der Moderne, 2013, S. 642f. Siehe dazu auch: Naimark: Zwangsmigration im Europa des 20. Jahrhunderts, 2016, S. 21.

284 Deák: Kollaboration, Widerstand und Vergeltung, 2017, S. 268.

285 Tůma: Die Aussiedlung, 2015, S. 278f.

286 Naimark: Flammender Haß, 2004, S. 172.
} 
ČSR ging in Polen die meiste Gewalt von der Roten Armee aus, da diese zunächst alle Gebiete besetzte und so ein direktes Aufeinandertreffen von Polen und Deutschen vergleichsweise seltener und später stattfand. ${ }^{287}$

Selbst unter der Annahme, dass entsprechende spontane Racheakte in großer Zahl stattfanden und in gewisser Weise als gerechtfertigt empfunden wurden, traf es zumeist die Falschen: »Rache und Vergeltung [trafen] überwiegend deutsche Frauen, Kinder und Greise [...], kaum die politisch und strafrechtlich Verantwortlichen«, die sich vorher größtenteils abgesetzt hatten. Piskorski stellt dazu fest, dass die Frauen und Kinder »zweifellos Opfer, zweifellos nicht die richtigen Opfer [waren], aber nicht immer waren sie schuldlos «. ${ }^{288}$ Vorstellungen von kollektiver Verantwortung und weit verbreiteter individueller Schuld in der deutschen Bevölkerung waren nicht nur in Osteuropa, sondern auch im Westen oder im deutschen Exil verbreitet. ${ }^{289}$ In der frühen Bundesrepublik arbeitete man sich an einer vermeintlich von den Alliierten vertretenen deutschen Kollektivschuldthese ab. Dieser wurde nicht nur vehement widersprochen, sondern sie wurde rasch - wie Piskorski richtig konstatiert - in ihr extremes Gegenteil gewendet: die These der Kollektivunschuld, zumal die der deutschen Vertriebenen. Dabei gehe es nicht darum, sich unempathisch gegenüber dem Erlittenen zu verhalten, sondern Fragen von individueller Schuld und Verantwortung auch bei dieser Opfergruppe nicht vollständig auszuklammern. ${ }^{290}$

Unabhängig davon, wie man letztlich die Gewalttaten einordnet, gilt mit Sicherheit, dass die Vertreibungen der Deutschen aus Polen und der Tschechoslowakei dort »überaus populär« waren. Neben dem Anspruch auf Vergeltung waren »strategische, historische und wirtschaftliche Argumente« von Bedeutung:

»Durch eine radikal antideutsche Haltung konnten kommunistische wie nichtkommunistische Politiker in Prag oder Warschau ihre Erfolgschancen nur verbessern. Der Wunsch von Kommunisten und Demokraten, ihre Macht durch die Zustimmung des Volkes aufzubauen und zu konsolidieren, ließ den wenigen Stimmen kaum eine Chance, die für das Bleiben antifaschistischer Deutscher oder dem polnischen und tschechoslowakischen Staat loyal gebliebener Deutscher eintraten. ${ }^{291}$

Die massenhafte Internierung von Deutschen in Polen und Tschechien ist in Deutschland im Vergleich zu anderen Phasen und Elementen des Vertreibungsgeschehens wenig behandelt worden; bekannter sind hier noch die Deportationen in Arbeitslager der Sowjetunion. Das spätere volkspolnische Narrativ, dass in diesen Lagern primär Nationalsozialisten/SS-Leute interniert gewesen seien, stimmt mit der Realität kaum überein. Piskorski erwähnt die Brutalität der Lager, drückt sich jedoch zugleich euphemistisch aus:

»Aber auch einige polnische Lager waren als Orte ausgeklügelter Foltermethoden und regelmäßiger Gewalttaten berüchtigt, obwohl es auch andere Lager gab, die man als

287 Zaremba: Die große Angst, 2016, S. 427-438.

288 Piskorski: Zwangsmigrationen im Kontext des Zweiten Weltkriegs, 2014, S. 168.

289 Suppan: Hitler - Beneš - Tito, 2014, S. $1216 f$.

290 Piskorski: Die Verjagten, 2013, S. $192 \mathrm{f}$.

291 Naimark: Flammender Haß, 2004, S. 173. Siehe ebenso: Zaremba: Die große Angst, 2016, S. 428. 
eine Art Refugium betrachtete. Diese gewährten in schweren Zeiten und in schwieriger Umgebung ein Minimum an Sicherheit und Verpflegung, was heute allzu leichtfertig vergessen wird. $\ll^{292}$

Schwartz äußert sich in einer Besprechung des Buches von Piskorski entsprechend kritisch: „Ein echtes Skandalon aber ist, dass ein Historiker ausgerechnet die für Deutsche geschaffenen Internierungslager in Osteuropa, die Zentralorte systematischer Erniedrigung und Gewalt gewesen sind, strotz aller Drangsalierungen [...] als eine Art Refugium` verklären kann [...]. $\ll^{293}$

In seiner Monographie von 2012 hat sich R. M. Douglas ausführlich mit den tschechischen und polnischen Lagern befasst und neben verschiedenen Forschungsdesiderata, wie die oftmals bis heute unbekannten Lager, die außerordentliche Dimension des Lagerwesens dargestellt. ${ }^{294}$ Gewaltexzesse, hohe Todesraten durch mangelhafte Versorgung, Vergewaltigungen und Zwangsarbeit seien an der Tagesordnung gewesen. ${ }^{295}$ Die große Anzahl von zehntausenden zumeist willkürlich internierten Deutschen und die Präsenz der Lager und deutscher Zwangsarbeit in der polnischen und tschechoslowakischen Öffentlichkeit in der unmittelbaren Nachkriegszeit stehen in einem starken Missverhältnis zum langen und weitgehenden Ignorieren dieses Phänomens in der nationalen und internationalen öffentlichen Erinnerung und wissenschaftlichen Auseinandersetzung. ${ }^{296}$

Den Grausamkeiten zum Trotz wird immer wieder die Frage der mit einer Gesamtbewertung zusammenhängenden Notwendigkeit der Vertreibungen diskutiert. Piskorski und Staněk vertreten die Position, »dass unter den gegebenen historischen Bedingungen wesentlich andere Varianten der Lösung des Problems ausgeschlossen waren: Diese wurden fast allgemein als eine der >logischen Folgen der deutschen Niederlage wahrgenommen und empfunden. ${ }^{297}$ Oder mit Piskorski formuliert: »Die Notwendigkeit, die durch den Krieg zerstrittenen Nationen zu separieren und die europäischen Staaten national $\mathrm{zu}$ homogenisieren, wurde über viele Jahre von fast niemandem bezweifelt. ${ }^{298}$ Auch Brandes sieht es als ein verbreitetes Argument jener Zeit an, dass man die als aggressiv wahrgenommenen deutschen Minderheiten keinem mitteleuropäischen Staat mehr zumuten konnte. ${ }^{299}$ Piskorski selbst, ebenso wie Brandes, Kittel und Möller, verweisen jedoch auf zeitgleich mit der Vertreibung stattfindende alternative Lösungsmo-

292 Piskorski: Zwangsmigrationen im Kontext des Zweiten Weltkriegs, 2014, S. 161. Vgl. Piskorski: Die Verjagten, 2013, S. 232f.

293 Schwartz: Rezension zu: Piskorski, Jan M.: Die Verjagten. Flucht und Vertreibung im Europa des 20. Jahrhunderts. München 2013, 2014.

294 Douglas: »Ordnungsgemäße Überführung«, 2012, S. 174.

295 Ebd., S. 168-199. Vgl. für die Tschechoslowakei hierzu die Zusammenführung von: Staněk: Internierung und Zwangsarbeit, 2007, S. 349-354.

296 Douglas: »Ordnungsgemäße Überführung«, 2012, S. 199.

297 Staněk: Vertreibung und Aussiedlung, 2001, S. 228.

298 Piskorski: Zwangsmigrationen im Kontext des Zweiten Weltkriegs, 2014, S. 169. Schwartz verneint diese Aussage und verweist auf entsprechende zeitgenössische Stimmen: Schwartz: Rezension zu: Piskorski, Jan M.: Die Verjagten. Flucht und Vertreibung im Europa des 20. Jahrhunderts. München 2013, 2014.

299 Brandes: Die Vertreibung als negativer Lernprozess, 2005, S. 896. 
delle: So an erster Stelle die Südtirol-Frage, in der die Südtiroler - bis auf einige individuell schuldig gewordene Personen - nicht nur in ihrer Heimat verbleiben, sondern auch diejenigen zurückkehren durften, die für das Reich optiert und bereits ausgewandert waren. Ähnliches gilt für das belgische Eupen-Malmedy, das dänische Nordschleswig und auch Rumänien. ${ }^{300}$ In Polen werden solche Alternativen als unrealistisch abgelehnt. Eine mehrere Millionen umfassende deutsche Minderheit in einem kompakten Siedlungsgebiet in einer Volksrepublik Polen erscheint nicht vorstellbar. Außerdem würde in Deutschland auf die Frage nach der Alternative zur Vertreibung zumeist nur mit Schweigen oder lediglich damit reagiert, dass diese »unrechtmäßig gewesen ist «. ${ }^{301}$ Hahn/Hahn folgen dieser skeptischen Einschätzung und verweisen auf den langfristigen Erfolg der alliierten »Lösung der deutschen Frage«: Deutschland und Österreich seien gefestigte Demokratien ohne offene Grenzfragen, die deutschen Minderheiten in Polen und Tschechien "genießen die üblichen, völkerrechtlich verankerten Minderheitenrechte « und seien keine Grundlage für zwischenstaatliche Konflikte mehr. ${ }^{302}$ Gegen das geäußerte Postulat der Alternativlosigkeit und der damit verbundenen Notwendigkeit der Vertreibungen äußert sich Douglas deutlich:

»Im Lichte dieser Tatsachen erscheint es außergewöhnlich, dass die Vertreibungen immer noch von Wissenschaftlern verteidigt werden, die argumentieren, sie seien zwar unmenschlich gewesen, aber durch ihre Ergebnisse gerechtfertigt. Drei Argumente werden hier gewöhnlich genannt. Erstens wird behauptet, der Hass der jeweiligen Bevölkerungsmehrheit auf die deutschen Minderheiten habe 1945 ein solches Maß erreicht, dass eine radikale Trennung unvermeidlich gewesen sei, um ein umfassendes Massaker zu verhindern. Zweitens soll ihre Entfernung weitere europäische Konflikte verhindert haben, und drittens heißt es, die Deutschen seien als Strafe für ihr verwerfliches Verhalten vor und während des Krieges zurecht deportiert worden. Keiner dieser Punkte hält einer genauen Untersuchung stand. ${ }^{303}$

\subsection{Zusammenfassung}

Die kurze Darstellung der mittelalterlichen deutschen Ostsiedlung hat die große Diversität dieses historischen Phänomens gezeigt. Weder lässt sich ein deutscher Drang nach Osten, verbunden mit einem jahrhundertelangen germanisch-slawischen Gegensatz, in der Geschichte finden, noch kann man die Geschichte bis ins 20. Jahrhundert als eine Idylle des Zusammenlebens verklären. Eindeutige nationale Selbstzuschreibungen setzten

300 Siehe: Brandes: National and International Planning of the >Transfer of Cermans from Czechoslovakia and Poland, 2009, S. 295f. Siehe auch: Kittel; Möller: Die Beneš-Dekrete, 2006, S. 543, 545, 566f. Vgl. bei Piskorski: Die Verjagten, 2013, S. 287f. Vgl. dazu auch die Diskussion im tschechischösterreichischen Ceschichtsbuch, in der die Frage, ob die Vertreibungen unvermeidlich waren, abwägend diskutiert wird: Dvořák; Schriffl: Am Scheideweg, 2019, S. $222 f$. Kranz: Schuld und Verantwortung, Wunden und Narben, 2015, S. $70 f$.

302 Hahn; Hahn: Die Vertreibung im deutschen Erinnern, 2010, S. $427 f$.

303 Douglas: »Ordnungsgemäße Überführung«, 2012, S. 448. Zu dieser Einschätzung kamen die Westalliierten bei einer Evaluation des Geschehens bereits 1947: ebd., S. 447. 
sich in der Breite überhaupt erst im 19. und 20. Jahrhundert durch, allerdings nie vollständig. Dennoch waren die Bevölkerungen nicht nur in Europa, sondern auch weltweit mit dem zunächst elitären Projekt des ethnisch homogenen Nationalstaates konfrontiert. Neben aggressiven Assimilierungspolitiken wurden bereits im 19. Jahrhundert häufig genozidale Dimensionen annehmende Vertreibungspraktiken angewandt, um dieses Ziel herzustellen. Nach dem Ersten Weltkrieg konkurrierten im Wesentlichen zwei Ordnungsmodelle zur Lösung ethnischer Konflikte: das des sich entwickelnden Minderheitenschutzes und das der international vereinbarten `Umsiedlungen .

Trotz des Minderheitenschutzes für die deutsche Bevölkerung Polens und der demokratischen Verfasstheit der Tschechoslowakei konnte in der Zwischenkriegszeit kein befriedigendes Ergebnis für das Zusammenleben unter den Staaten und zwischen den Staaten und ihren Minderheiten gefunden werden. Die nationalsozialistische Terrorherrschaft und ihre >Massenumsiedlungen schufen schließlich die Grundlage für das weitgehende Ende der angestammten deutschen Bevölkerung in Polen und der Tschechoslowakei, ebenso wie diese Länder mit Unterstützung durch die Siegermächte ihre Nationalstaaten ethnisch homogenisieren konnten, was gleichzeitig eine zukünftige Sicherheit vor den Deutschen ebenso wie eine soziale Revolution gewährleisten sollte. Die >Westverschiebung، Polens und die Zwangsaussiedlung von annähernd zwei Millionen Polen aus den polnischen Ostgebieten ließen zudem eine Kompensation auf Kosten Deutschlands als zwingend erscheinen.

Zwangsmigrationen gewaltigen Ausmaßes in Europa begannen unter der Federführung Deutschlands und der Sowjetunion bereits 1938/39 und prägten den Kontinent in den folgenden Jahren. Waren am Anfang einige hunderttausend Volksdeutsche davon betroffen, so wurden gegen Ende des Krieges Millionen von deutscher Seite revakuiert oder flohen auf eigene Faust vor der Front. Mit Kriegsende folgten die Vertreibungen, Zwangsaussiedlungen und Deportationen sowie später die freiwilligen Ausreisen und Familienzusammenführungen.

Die Heterogenität des Geschehens und die Vielfalt der Erfahrungen sind also fundamental für den Terminus Flucht und Vertreibung. Schon im Kapitel 1 wurden die Mängel der politischen und narrativen Konnotationen der deutschen, tschechischen und polnischen Begriffe für das Geschehen diskutiert. Die vorliegende Arbeit folgt unter Berücksichtigung der Schwierigkeiten des Begriffspaares dem deutschen Begriff der Flucht und Vertreibung sowie dem wissenschaftlicheren Terminus der Zwangsmigration, versucht aber im Einzelfall, das im Diskurs oder den Museen diskutierte Geschehen begrifflich und historisch möglichst konkret zu benennen.

In den Besatzungszonen sowie anschließend in der Bundesrepublik und in der DDR wurde der mit erheblichen Herausforderungen verbundenen Integration Millionen Vertriebener schließlich auf unterschiedliche Weise begegnet. Das SED-Regime erklärte Anfang der 1950er Jahre die Umsiedlerfrage offiziell für erfolgreich abgeschlossen, wohingegen zeitgleich in der Bundesrepublik mit der Lastenausgleichsgesetzgebung die staatliche Integrationspolitik im Wesentlichen erst begann. Die 1944 und 1948 kommunistisch gewordenen Staaten Polen und Tschechoslowakei scheiterten rasch mit ihren Versuchen, die neuen Gebiete erfolgreich als soziales Experimentierfeld für die sozialistische Revolution zu nutzen. Der ökonomische Niedergang der Regionen konnte nicht aufgehalten werden. Was blieb, war die durch Angst vor einer deutschen Rückkehr ent- 
wickelte (Zwangs-)Verbundenheit vieler polnischer und tschechoslowakischer Grenzbewohner mit ihren Regierungen.

Der historischen Skizze der Geschichte und Ideengeschichte folgte eine Zusammenfassung der fortwährenden historischen und historiographischen Streitpunkte, die sich an grundsätzlich unterschiedlichen Narrativen festmachen. Die klassische deutsche Perspektive, die Flucht und Vertreibung in das lange Kriegsende einordnet, unterbelichtet die vorherige deutsche Besatzungsherrschaft, die deutschen Kriegsverbrechen und die deutschen Nachkriegsplanungen. Ähnlich wenig berücksichtigt wird die damit verbundene massiv gesunkene Empathie der Alliierten gegenüber den Deutschen und deren Fokus auf sicherheitspolitische Aspekte einer vermeintlich notwendigen rethnischen Neuordnungく Ostmitteleuropas.

In der polnischen Meistererzählung stehen zunächst das eigene Leiden unter dem doppelten deutschen und sowjetischen Besatzungsterror sowie die unmittelbar erfahrene Helotisierung des polnischen Volkes im Vordergrund. Millionen ermordeter oder unter den Kriegsbedingungen umgekommener polnischer Staatsbürger lassen das Schicksal der lediglich von >Aussiedlung betroffenen Deutschen als vergleichsweise milde erscheinen. Ebenso wird spätestens seit Ende des Kalten Krieges auf den Verlust der kresy und das Schicksal der polnischen Repatrianten verwiesen. Kontroverse Themen, wie die Übergriffe polnischer Sicherheitskräfte auf die deutsche Zivilbevölkerung, das polnische Lagerwesen, in denen deutsche oder vermeintlich deutsche Bevölkerungsanteile unter häufig widrigsten Bedingungen interniert waren, und das Heranziehen dieser Bevölkerungsgruppe zur Zwangsarbeit, führen in der polnischen Erinnerungskultur ein Schattendasein.

In der Tschechoslowakei und Tschechien stand und steht der doppelte Verrat im Vordergrund des Narrativs über Flucht und Vertreibung. Die alliierte Aufgabe ihres Verbündeten 1938 in München ließ eine größere deutsche Bevölkerungsgruppe in der ČSR als dauerhaftes Sicherheitsrisiko erscheinen, da sich das Land offenkundig nicht auf internationale Garantien verlassen konnte. Der Treuebruch der deutschen Bürger, ihre vermeintlich chronische Illoyalität und vor allem ihre massenhafte Unterstützung der Sudetendeutschen Partei, war und ist die Rechtfertigung für deren Entfernung nach Kriegsende. Die Kooperation mit dem Feind sowohl bei der Abtrennung der Sudetengebiete als auch während der Besatzungsherrschaft ließen ein Zusammenleben in $\mathrm{Zu}$ kunft als unmöglich erscheinen. Der odsun, die Abschiebung der Deutschen am Ende des Krieges, erschien als harte, aber gerechtfertigte Bestrafung, die angesichts des Vorwurfs des Hochverrates hätte schlimmer ausfallen können. Wenig Platz in dieser Erzählung haben die häufig willkürlichen Gewalttaten gegen deutsche Zivilisten und Kriegsgefangene ebenso wie das auch in der ČSR bestehende Lagerwesen für Deutsche. Eine gewisse Verklärung der Tschechoslowakei der Zwischenkriegszeit verstellt darüber hinaus den Blick auf die trotz der demokratischen Konstitution schwierige Situation für die Minderheiten des Landes.

Neben diesen kompakt zusammengefassten Meistererzählungen wurden schließlich noch die schwer zu fassenden Opferzahlen der Länder sowie der Vertreibungsopfer erörtert. Dem schloss sich eine Diskussion des $>$ Rachemotivs $<$ an, das für einige Autoren die Übergriffe auf Deutsche am Ende des Krieges erklärt, wohingegen andere konstatieren, dass sich Belege für spontanen >Volkszorn gegenüber den deutschen Nachbarn fast 
nirgends finden lassen, sondern dass es einen zentral von oben gesteuerten Prozess der Gewalt durch staatliche und semi-staatliche Gewaltakteure gab. Die Frage der Verantwortung wird unterschiedlich gewichtet. Unstrittig ist diese bei der Gewalteskalation durch die deutsche NS-Herrschaft, weniger klar ist die Zuschreibung für die Geschehnisse am Ende des Krieges und die Idee der Vertreibung: Beendete NS-Deutschland durch die katastrophalen Evakuierungen bereits vorher de facto die deutsche Besiedlung in Osteuropa? Handelte es sich um eine alleinige Entscheidung der Siegermächte, womöglich primär von Stalin, zur künftigen Sicherung seiner Herrschaft über Osteuropa? Inwieweit konnten polnische und tschechoslowakische Politiker hier ihre eigene an Vorkriegsideen anknüpfende - Agenda durchsetzen? Selten werden diese verschiedenen Verantwortungen konsequent zusammengeführt. Deren Zusammendenken ist aber für eine Annäherung an das historische Gesamtbild notwendig und könnte zugleich dem besseren Verständnis der unterschiedlichen Perspektiven dienen.

Dissens besteht auch bei der Frage der Notwendigkeit der Vertreibungen. Nicht nur vielen polnischen und tschechischen, auch deutschen Forschern fehlt heute die Fantasie, sich angesichts der historischen Umstände ein wie auch immer gestaltetes Zusammenleben mit großen deutschen Minderheiten vorzustellen. Verweise auf die Lösung der Südtirol-Frage oder den rumänischen Fall, in denen es nicht zu Vertreibungen oder gar zur Rückkehr kam, sind nur eingeschränkt überzeugend, sollten aber nicht gänzlich außer Acht gelassen werden, um sich nicht nachträglich zu sehr in einer Teleologie zu verfangen.

Erkennt man die damalige Notwendigkeit der Vertreibungen jedoch an und beklagt gegebenenfalls nur die Methoden, wird es schwerer, die nach 1945 und bis heute immer wieder stattfindenden ethnischen Säuberungen und Vertreibungen zu ächten. Unmittelbar nach dem Krieg standen in den untersuchten Gesellschaften aber zunächst gänzlich andere Fragen in Hinblick auf Flucht und Vertreibung im Mittelpunkt. Diesen ist das folgende Kapitel gewidmet. 


\section{Diskurse über Flucht und Vertreibung im Kalten Krieg}

Flucht und Vertreibung der Deutschen waren einige Jahre nach Kriegsende als historisches Geschehen abgeschlossen. Für die betroffenen Gesellschaften blieb das Thema aber auf verschiedene Art und Weise virulent: »The politics of the memory of the flight and expulsion began to take shape before the expulsion had come to an end. The participants, whether victims or the people of the states responsible for the expulsions, sought to shape collective memory to fit their interpretations. ${ }^{1}$ Die Bürger der Tschechoslowakei und Polens teilten den »kleinsten gemeinsamen Nenner« der europäischen Nachkriegsgesellschaften, die den Deutschen die »Verantwortung für den Krieg, das Leiden und die Verbrechen« zuschrieben, mit der für die Gesellschaften ebenso wie für die Regierungen komfortablen Wirkung, »andere, weniger >passende< Erinnerungen an die Kriegs- und unmittelbare Nachkriegszeit auszublenden. $\aleph^{2}$ Den innergesellschaftlichen Aushandlungen, die sich in der Bundesrepublik und der DDR zunächst primär um die Linderung der wirtschaftlichen Not und schließlich um das Ankommen der Flüchtlinge und Vertriebenen in den neuen Staaten drehten, standen auf der anderen Seite die polnische und tschechische Bevölkerung der Wiedergewonnenen Gebiete und der ehemaligen sudetendeutschen Siedlungsgebiete gegenüber, die sich der Herausforderung ausgesetzt sahen, in ihrer neuen Umgebung heimisch zu werden und ein Verhältnis zu ihrer Geschichte zu finden. Alle Nachkriegsgesellschaften mussten schließlich auf der Basis neuer Identitäten konstituiert werden. ${ }^{3}$ Die Überreste und Zeichen deutscher Vergangenheit wurden beseitigt oder ignoriert, aber die Geschichte in Form der deutschen Gefahr blieb mit Schwankungen und abnehmender Tendenz bis 1989 als Teil staatlicher Agitation, aber auch realer Ängste vor Ort präsent.

Trotz der stark eingeschränkten Möglichkeiten wurde auf die Nachbarn und dort stattfindende Entwicklungen geschaut. Gelegentlich öffnete sich die Chance für einen gemeinsamen Diskursraum, so bei dem Brief der polnischen Bischöfe an ihre deutschen Amtsbrüder 1965, beim Kniefall von Willy Brandt und den folgenden Ostverträgen. Die Sudetendeutsche Landsmannschaft und die Regierung der Tschechoslowakei

Spurný: Czech and German Memories of Forced Migration, 2012, S. 353.

Echternkamp; Martens: Der Weltkrieg als Wegmarke? 2007, S. 9.

Vgl. ebd., S. 6 . 
blieben sich über 1989 hinaus in tiefer Feindschaft verbunden. Eröffnete die >Umarmung von Kreisau< 1989 der weiteren deutsch-polnischen Versöhnung neue Horizonte, so wurde Václav Havels Verständigungsinitiative 1989 sowohl von der von diesem historischen Moment überforderten Sudetendeutschen Landsmannschaft ausgeschlagen als auch von der tschechoslowakischen Gesellschaft abgelehnt.

Für die vergleichende Gegenüberstellung muss grundsätzlich beachtet werden, dass die verschiedenen Narrative und Aushandlungen in fast gänzlich unterschiedlichen Systemkonstellationen und regulierten Öffentlichkeiten stattgefunden haben. ${ }^{4}$ Auf den ersten Blick erscheinen die verbreiteten Narrative zu Flucht und Vertreibung in den kommunistischen Staaten wesentlich statischer als in der Bundesrepublik mit ihren zum Teil eruptiven Vergangenheitskämpfen. Als diktatorische Partei war zum Beispiel die PZPR streng darauf bedacht, das Verhältnis zur Bundesrepublik als Monopol und in ihrem Interesse zu vertreten, dementsprechend heftig reagierte sie auf nichtstaatliche Initiativen wie den Bischofsbrief. ${ }^{5}$ Die im Warschauer Vertrag verbundenen Staaten waren zudem in ihrer Souveränität stark eingeschränkt, ${ }^{6}$ was sich auch in der öffentlichen Absenz von gegen die Sowjetunion gerichteten Äußerungen zeigt, bedingt durch bis zuletzt konsequente Zensur. Jüngere Forschungen befassen sich aber zunehmend mit den Spielräumen, die die jeweiligen Staatsführungen im Warschauer Pakt nutzten. ${ }^{7}$ Ein Beispiel dafür ist das Verhältnis zur Bundesrepublik, das die Länder sowohl zusammenführte als auch nach außenpolitischen Partikularinteressen spaltete. In der Bundesrepublik waren hingegen trotz Westbindung von Beginn an auch kritische Haltungen gegenüber den Westmächten möglich.

Auch wenn dieses Kapitel primär die Diskussion um Flucht und Vertreibung behandelt, so war dies nur eines und auch nur gelegentlich das zentrale Thema vieler geschichtspolitischer Auseinandersetzungen. Es ist folglich in weiteren Zusammenhängen der jeweiligen Erinnerungskulturen zu verstehen, wie zum Beispiel der Erinnerung an die kresy oder des kommunistischen Siegernarrativs nach dem Zweiten Weltkrieg. In diesen Verbindungen konnten die Erzählungen ihre politische Wirkung entfalten und nur so können sie verstanden werden. ${ }^{8}$

\subsection{Bundesrepublik Deutschland}

Die Entwicklung der gesellschaftlichen Einstellungen und Auseinandersetzungen um Flucht und Vertreibung in der Bundesrepublik bis 1989 kann in verschiedene Phasen eingeteilt werden: Zunächst gab es den Zeitraum von 1949 bis 1961 als Phase der großen Akzeptanz der Vertriebenenanliegen, dem nach dem Bau der Berliner Mauer bis 1969 eine

4 Vgl. Jakubowska: Der Bund der Vertriebenen in der Bundesrepublik Deutschland und Polen, 2012, S. 217.

5 Vgl. Bingen: Versöhnung, Aussöhnung, Normalisierung, 2009, S. 268.

6 Vgl. zur andauernden Diskussion der Charakterisierung der Volksrepublik Polen als souverän, nicht souverän, totalitär usw.: Stobiecki: Die Gegenwart der Vergangenheit, 2005, S. 432.

7 Vgl. Zimmermann: Wechselnde Bündnisse, 2010, S. 101.

8 Vgl. Madajczyk: Die Rolle antideutscher Instrumentalisierungen in Polen, 1944-1989, 2007, S. 136. 
Zeit des Übergangs folgte, in der Parteien und Kirchen die bisherigen Positionen zunehmend in Frage stellten. Danach lassen sich zwei Phasen anhand der Regierungskonstellationen definieren, der sozialliberalen Koalition von SPD und FDP zwischen 1969 bis 1982 und der Koalition aus CDU/CSU und FDP von 1982 bis 1989/98. ${ }^{9}$ Die Diskursgeschichte wird im Wechselspiel der organisierten Vertriebenenverbände und der politisch-gesellschaftlichen Entwicklung diskutiert. Dieser dichotome Überblick soll freilich nicht zeigen, dass die Vertriebenen als eine politische Einheit $\mathrm{zu}$ verstehen sind, auch wenn sich die Verbände erfolgreich so positioniert haben.

Für das Verständnis des bundesdeutschen Diskurses ist es zentral, dass dieser stets - bewusst oder unbewusst, geäußert oder nicht geäußert - im Verhältnis zum Nationalsozialismus und zur Erinnerung an die NS-Zeit und dabei primär zum Holocaust stand und steht. ${ }^{10}$ Dies spiegelt sich in ganz unterschiedlichen Facetten wider: im Verständnis der Vertriebenen als spezifische oder eben nicht spezifische Opfer des Zweiten Weltkrieges, deren Schicksal mit dem Holocaust parallelisiert wird, um damit die Verbrechen der anderen Staaten hervorzuheben oder, als gegensätzliches Argument, den Fokus von den deutschen Opfern des Krieges auf die Opfer der Deutschen zu legen. Als ein Mittelweg kann der Vorschlag von Hans Lemberg angesehen werden, der die Vertriebenen als die letzten Opfer Hitlers betrachtet und damit zugleich die deutsche Mitverantwortung für ihr Schicksal unterstreicht. ${ }^{11}$ Diese Diskurskonstellation setzt sich nach 1989 weitgehend ungebrochen fort.

Formen der Organisation der Vertriebenen setzten unmittelbar mit dem Kriegsende ein, aber zunächst standen diese ganz unter den Vorzeichen der Bewältigung der Not und dem Finden und Zusammenführen von Angehörigen. Zudem verbot die Politik der Besatzungsmächte eine politische Organisation. Die bewusst zerstreut erfolgende Ansiedlung der Vertriebenen sollte eine schnelle Assimilation gewährleisten und geschlossene Siedlungsgebiete als soziale Unruheherde und eine Radikalisierung verhindern. ${ }^{12}$ In der Öffentlichkeit der unmittelbaren deutschen Nachkriegsgesellschaft wurde die Vertreibung eingeordnet in die überall präsente und unmittelbare Erfahrung der absoluten Niederlage durch die vom Bombenkrieg zerstörten Städte, die Präsenz der Besatzungsmächte, die schwierige Versorgungslage und die betrauerten Verluste von Angehörigen im Krieg. Die Vertreibung erschien in diesem Zusammenhang überwiegend als ungerechtfertigte Grausamkeit der Siegermächte, eine Einschätzung, die bereits mit der Goebbel'schen Propaganda 1944/45 begann und sich unter anderen Vorzeichen in der Nachkriegszeit fortsetzte. ${ }^{13}$ Die deutschen Kriegsverluste, die zerstörten Städte und die Vertreibungen erfüllten eine wichtige Funktion für das Opfernarrativ der westdeutschen Gesellschaft, das zwar auf der einen Seite eine Integration der Vertriebenen begünstigte, dessen häufig funktionalistischer Gebrauch aber nicht mit einer S. 10.

10 Siehe: Beer: »Flucht und Vertreibung«, 2008, S. 268.

11 Vgl. Kittel: Vertreibung der Vertriebenen? 2007, S. 13.

12 Vgl. Stickler: Gegenspieler der Aussöhnung? 2009, S. 225. Vgl. Kap. 3.6, S. $125 f$.

13 Moeller: Cermans as Victims? 2005, S. 166. Vgl. Hahn; Hahn: Die Vertreibung im deutschen Erinnern, 2010, S. 412. 
tatsächlichen Empathie gegenüber den Schicksalen der Vertriebenen verwechselt werden darf. ${ }^{14}$

Das Arrangement mit den Westalliierten und die Angst vor der Sowjetunion ließ letztere in der westlichen Besatzungszone mit der Zeit als primären ehemaligen und künftigen Gegner und gemeinsam mit seinen tschechoslowakischen und polnischen Vasallen als Alleinverantwortlichen erscheinen. ${ }^{15}$ Seltener wurde die nationalsozialistische Führung für Krieg und somit für die in Folge der Kriegsniederlage erfolgten Vertreibungen verantwortlich gemacht, noch seltener aber die deutsche Bevölkerung in ihrer Breite. ${ }^{16}$

Unmittelbar mit den ersten Wahlen in den Besatzungszonen sprachen die Parteien die vielen Vertriebenen als Wählergruppe direkt an. Der Westpreuße Kurt Schumacher scheiterte als SPD-Kanzlerkandidat für viele Zeitgenossen überraschend bei der Bundestagswahl 1949. Die politische Zuordnung der Vertriebenen blieb noch offen und verteilte sich auf verschiedene Parteien. Die spezifische Vertriebenenpartei, der Block der Heimatvertriebenen und Entrechteten $(\mathrm{BHE})^{17}$ konnte auf Landesebene erhebliche Erfolge erzielen und bei der Bundestagswahl 1953 mit 5,9 Prozent in den Deutschen Bundestag und in die Regierung Adenauer einziehen. Aufgrund innerer Widersprüche, der veränderten und verbesserten politischen und sozialen Lage sowie einer geschickten Umarmungspolitik der CDU/CSU sank die Partei schließlich in die Bedeutungslosigkeit ab, wobei führende Protagonisten in der CDU/CSU fortwirkten. ${ }^{18}$

Mit der bis heute für die Vertriebenenverbände konstitutiven und sowohl gefeierten als auch umstrittenen »Charta der deutschen Heimatvertriebenen« setzten die Verbände im August 1950 ein erstes Ausrufungszeichen: In der Charta wurde das »Recht auf Heimat« postuliert, also der explizite Rückkehranspruch unter Verzicht auf jede Form von Rache und Vergeltung, und das Versprechen gegeben, am friedlichen Aufbau und der Einheit Europas mitzuwirken. ${ }^{19}$ Gleichzeitig wurde ein besonderer Opferstatus erhoben, denn »die Völker der Welt sollen ihre Mitverantwortung am Schicksal der Heimatvertriebenen als der vom Leid dieser Zeit am schwersten Betroffenen empfinden ${ }^{20}{ }^{20}$ Diese Einschätzung mag aus heutiger sowie auch damals schon aus internationaler Sicht befremdlich erscheinen, ebenso wie das Fehlen einer direkten Erwähnung deutscher Schuld und Verantwortung sowie die Selbstwahrnehmung der Vertriebenen, an erster Stelle in der Opferhierarchie zu stehen. ${ }^{21}$ Heute wird von den Vertriebenenverbänden und von deutschen Politikern besonders der versöhnliche Charakter der Charta

14 Vgl. Spurný: Czech and Cerman Memories of Forced Migration, 2012, S. 354. Kossert: Kalte Heimat, 2009, S. 49-54.

15 Vgl. für den entsprechenden Abschluss dieser Entwicklung in den 1950er Jahren: Schwartz: Vertriebene im doppelten Deutschland, 2008, S. 145f.

16 Vgl. Hahn; Hahn: Die Vertreibung im deutschen Erinnern, 2010, S. $423 \mathrm{f}$.

17 Nach 1952: Cesamtdeutscher Block/Bund der Heimatvertriebenen und Entrechteten (GB/BHE).

18 Siehe: Stickler: Cegenspieler der Aussöhnung? 2009, S. 227. VgI. Beer: Flucht und Vertreibung der Deutschen, 2011, S. 124.

19 Vgl. Stickler: Gegenspieler der Aussöhnung? 2009, S. 229-231.

20 Stickler: Charta der deutschen Heimatvertriebene, 2015.

21 Vgl. Hahn; Hahn: Die Vertreibung im deutschen Erinnern, 2010, S. 443-448. Siehe auch: Schwartz: Vertriebene im doppelten Deutschland, 2008, S. 144. Neben dieser Kritik historisiert Schwartz das Dokument insoweit, als er es in den kompetitiven bundesdeutschen Opferdiskurs der Zeit einord- 
hervorgehoben. ${ }^{22}$ Das in diesem Dokument und von den Vertriebenenverbänden fortwährend erhobene »Recht auf Heimat« wird allerdings nicht nur im Ausland als in der Form völkerrechtlich nicht existent betrachtet. ${ }^{23}$

Im selben Zeitraum wählte die Sudetendeutsche Landsmannschaft Rudolf Lodgman von Auen zu ihrem ersten Sprecher, welchen Ferdinand Seibt als »Sprecher der Unversöhnlichen« bezeichnet, »der von Anfang an die Vernichtung der Tschechoslowakei und seit Frühjahr 1938 auch die Vertreibung und Ausrottung ethnischer Minderheiten, vor allem der Juden, gefordert hatte ${ }^{24}$ Auch bei einer zurückhaltenderen Einschätzung Lodgman von Auens, der im nationalsozialistischen Deutschland ohne Funktion blieb und zurückgezogen lebte, sowie nach 1945 den Kontakt zum tschechoslowakischen Exil für eine friedliche Lösung der sudetendeutschen Frage suchte, passte er in die antagonistische Propaganda der kommunistischen Tschechoslowakei. ${ }^{25}$

Für die erste Legislaturperiode des Bundestages war die Klärung der Situation der Vertriebenen ein zentraler Gegenstand. Die nach langen Diskussionen verabschiedeten umfangreichen Gesetze, das Lastenausgleichsgesetz (LAG) von 1952 und das 1953 verabschiedete Bundesvertriebenengesetz (BVFG), regelten unter anderem drei zentrale Punkte: erstens materielle Unterstützung, die den Vertriebenen einen Ausgleich für ihren verlorenen Besitz gewährleisten und damit ein ökonomisches Ankommen in der Bundesrepublik ermöglichen sollte, zweitens die Übertragung des Vertriebenenstatus auf die kommenden Generationen und drittens die für die vorliegende Thematik besonders relevante Kulturförderung, die alle Ebenen des Staates zur dauerhaften Sicherung der Kulturpflege und des Kulturerbes der Vertriebenen verpflichtete. ${ }^{26}$ Der Lastenausgleich unterstützte mit 150 Milliarden DM an Eingliederungs- und Entschädigungsleistungen bis 1979 die ökonomische und gesellschaftliche Integration der Vertriebenen. ${ }^{27}$ Michael Schwartz merkt hierzu an, dass die Unterstützung letztlich finanziell als moderat zu klassifizieren und ihre symbolische Bedeutung hervorzuheben sei. Allerdings sei der Ausgleich noch unter den Vorzeichen einer angestrebten Rückkehr verabschiedet worden, was dazu geführt habe, dass "gerade die Aufrechterhaltung der RückkehrOption [...] es der einheimischen Mehrheitsgesellschaft ermöglicht [habe], >den Geschädigten einen echten Lastenausgleich vorzuenthalten $<.{ }^{28}$ Durch die Vererbung des Vertriebenenstatus stieg in der Bundesrepublik schließlich die »Zahl der Träger einer >Vertriebeneneigenschaft< von 12,8 Millionen im Jahr 1950 auf 16,2 Millionen im Jahre 1982

net: »Wer Anerkennung und Hilfe erhalten wollte, musste sich auf diesem Meinungsmarkt durchsetzen.«

22 Vgl. Schwartz: Vertriebene im doppelten Deutschland, 2008, S. 148.

23 Haar: Vom »Volksgruppen-Paradigma« bis zum »Recht auf Heimat«, 2006, S. 39.

24 Seibt: Tausend Jahre Böhmen und Mähren (1999), 2002, S. 9.

25 Vgl. für eine freundlichere biografische Einschätzung: Seubert: Lodgman von Auen, Rudolf, 2001/2002.

26 Vgl. Kittel: Vertreibung der Vertriebenen? 2007, S. 170.

27 Bauerkämper: Deutsche Flüchtlinge und Vertriebene, 2010, S. 482. Kossert sieht in dem Lastenausgleich nur einen »Tropfen auf den heißen Stein«: Kossert: Kalte Heimat, 2009, S. 14.

28 Schwartz: Vertriebene im doppelten Deutschland, 2008, S. 126f. Schwartz zitiert hier Hans Georg Lehmann. Vgl. Bösch: The Political Integration of the Expellees in Postwar West Germany, 2016, S. 161. 
an. ${ }^{29}$ Das Bundesministerium für Vertriebene, Flüchtlinge und Kriegsgeschädigte setzte sich von 1949 bis 1969 für die Interessen der Vertriebenen ein und förderte unter anderem das größte wissenschaftliche Projekt der Bonner Republik, die »Dokumentation der Vertreibung der Deutschen aus Ost-Mitteleuropa«. ${ }^{30}$

Geschichtspolitisch und in der öffentlichen sowie privaten Erinnerung waren die 1950er Jahre weiterhin von einer Selbstviktimisierung der Deutschen geprägt. ${ }^{31}$ Neben den Millionen von Kriegstoten konnten für die gesamte Gesellschaft Bombenopfer, Vertriebene und der Verlust der Ostgebiete als Strafe der Sieger reklamiert, im Zuge des Kalten Krieges instrumentalisiert und zur Entlastung herangezogen werden. ${ }^{32}$ Damit war verbunden, dass die anderen Opfer des Krieges kaum thematisiert wurden; die eigenen Täterrollen, der Holocaust und die deutschen Kriegs- und Besatzungsverbrechen wurden nur am Rande behandelt und marginalisiert. Im selben Zeitraum entwickelte sich das Bild der deutschen Vertriebenen als tatkräftige und zentrale Beiträger zum Wiederaufbau Deutschlands. ${ }^{33}$

1957/1958 konstituierte sich schließlich der Bund der Vertriebenen als Dachverband der Landsmannschaften. In seinem Selbstverständnis war er kein klassischer Lobbyverband, sondern verstand sich als überparteilicher Verband für die Interessen aller Deutschen, da seine Forderungen ein erstrebenswertes Ziel für alle Deutschen seien. Zugleich sah er sich in dieser Rolle als ein nicht übergehbarer Partner aller Bundesregierungen. ${ }^{34}$ Die deutschlandpolitischen Ziele des BdV lassen sich nach Heike Amos in vier Punkte fassen:

1. keine Anerkennung der DDR und kein Sonderstatus für Westberlin,

2. keine Anerkennung der Oder-Neiße-Grenze, keine Annullierung des Münchner Abkommens,

3. Wiederherstellung eines Deutschlands in den Grenzen von 1937 und

4. friedliches Rückkehrrecht für die Vertriebenen in die alten ost- bzw. sudetendeutschen Gebiete. ${ }^{35}$

29 Schwartz: Vertriebene im doppelten Deutschland, 2008, S. 128.

30 Auch dieses Projekt war schließlich umkämpft. Der letzte Band, der nach der umfangreichen Dokumentation der Vertreibung und der »Vertreibungsverbrechen« das Geschehen historisch kontextualisieren und damit auch deutsche Kriegs- und Besatzungsverbrechen besprochen hätte, wurde nicht mehr herausgegeben.

31 Moeller: Germans as Victims? 2005, S. 177f. Kelletat: Von der Täter- zur Opfernation? 2003/2004, S. 135f. Vgl. Wolfrum: Die beiden Deutschland, 2005, S. $156 \mathrm{f}$.

32 Ohliger: Flucht und Vertreibung als Migrationsgeschichte, 2006, S. 231f. Siehe auch: Haslinger: Von der Erinnerung zur Identität und zurück, 2005, S. 482. Esch spricht von einer »nationale[n] Vergemeinschaftung, doppelte [...] Opfer des Nationalsozialismus und des Kommunismus« zu sein. Esch: Zum Verhältnis, 2012, S. 80. Vgl. Moeller: Germans as Victims? 2005, S. 158.

33 Ebd., S. 160.

34 Stickler: Gegenspieler der Aussöhnung? 2009, S. 225-227. Jakubowska: Der Bund der Vertriebenen in der Bundesrepublik Deutschland und Polen, 2012, S. 212. Vgl. für das Engagement vertriebener Frauen in Politik, im BdV oder in Kirchenverbänden von 1945 bis 1970 ausführlich: Aubele: Vertriebene Frauen in der Bundesrepublik Deutschland, 2015, S. 385-410. 
Die Verbesserung ihres Sozialstatus führte im selben Zeitraum zu einer Erosion der Vertriebenen als Kollektivgruppe. ${ }^{36}$ Den Status als Massenorganisation konnte der BdV dennoch mit Mitte der 1960er Jahre noch etwa 2,3 Millionen Mitgliedern und durch Großkundgebungen mit oft über 100.000 Teilnehmern unterstreichen. Bei einer aus Verbandssicht zentralen Frage gingen die Meinungen bereits früh auseinander: die der Rückkehr. In zunehmender Anerkennung der politischen Realitäten und der sich durch Reiseberichte aus dem Osten verbreitendenden Erkenntnis, dass die erinnerte Heimat in jedem Fall unwiederbringlich verloren sei, wurde der Rückkehrwille unbedeutender, auch wenn er nicht gänzlich verschwand. ${ }^{37}$ Stattdessen dienten die Vertriebenentreffen und die Verbandsarbeit für die Masse der Teilnehmer - jenseits politisch markiger Reden - der >Brauchtumspflege und vor allem dem Austausch mit ehemaligen Nachbarn und Freunden über die alte Heimat. Damit erfüllten diese nach Seibt eine wichtige, nicht zu unterschätzende soziale Funktion..$^{38}$ Aber auch an dieser »ostdeutschen Kulturpflege « beteiligten sich in überwiegender Zahl bald nur noch die in den Verbänden organisierten Vertriebenen. ${ }^{39}$

Die enge politisch-personelle Parteienverbindung der Vertriebenenverbände sowie das wegen der Wählergewinnung an ihnen vorhandene Interesse führte dennoch nicht $\mathrm{zu}$ einer stets vertriebenenverbandsfreundlichen Haltung. Wie Stickler in seiner umfassenden Untersuchung herausgearbeitet hat, galt schließlich für die mit den Verbänden verbundenen Abgeordneten im »Konfliktfall [...] die höhere Loyalität in der Regel ihrer Partei« und war damit für den Verband primär von Nachteil: »Mehr als dies schadete den Vertriebenenverbänden jedoch die Verquickung der Verbandspolitik mit persönlichen Interessen bzw. mit partei- und bundespolitischen Auseinandersetzungen, boten sie dadurch doch offene Flanken und politischen Gegnern die Möglichkeit, sie gegeneinander auszuspielen und damit in der tagespolitischen Auseinandersetzung zu marginalisieren. «० $^{40}$ Stickler zufolge spielte schließlich die SPD der 1960er Jahre ein doppeltes Spiel: Ihre Vertriebenenpolitiker warben mit einigem Erfolg mit vertriebenenfreundlicher Rhetorik für den Machtwechsel, während andere Teile der Partei bereits »im Hintergrund [...] [den] >Wandel durch Annäherung< vorbereitet[en] [...]«. ${ }^{41}$ Die enge Verbindung der Vertriebenenverbände zur CDU/CSU sollte sich schließlich erst nach der Neuen Ostpolitik in den 1970er Jahren durchsetzen..$^{42}$

Pertti Ahonen bilanziert für die ersten beiden Jahrzehnte der Bonner Republik, dass Regierungen und Parteiführungen, auch wenn diese intern die Rückgewinnung der Ostgebiete von Beginn an oder zunehmend als weder möglich noch wünschenswert betrachteten, aus wahltaktischen und politischen Erwägungen den Eindruck ei-

36 Vgl. Stickler: Gegenspieler der Aussöhnung? 2009, S. $226 \mathrm{f}$.

37 Vgl. Stickler: »Ostdeutsch heißt Gesamtdeutsch«, 2004, S. 430.

38 Seibt: Eine neue Nachbarschaft? (1993), 2002, S. 97. Vgl. Hahn; Hahn: Die Vertreibung im deutschen Erinnern, 2010, S. 530.

39 Kittel: Vertreibung der Vertriebenen? 2007, S. $175 f$.

40 Stickler: »Ostdeutsch heißt Gesamtdeutsch«, 2004, S. 227, $429 f$.

41 Stickler: Gegenspieler der Aussöhnung? 2009, S. $227 \mathrm{f}$.

42 Was aber nicht bedeutet, dass sich nicht trotzdem fortlaufend viele Vertriebene - für die die Vertreibung kein zentrales Politikanliegen war - in der SPD engagierten. Siehe: Bösch: The Political Integration of the Expellees in Postwar West Germany, 2016, S. 165-167. 
ner Interessenidentität zwischen Vertriebenenverbänden und sich selbst vermittelten. ${ }^{43}$ Auch Rainer Schulze unterstreicht die Instrumentalisierung des Vertriebenenschicksals durch die westdeutsche Gesellschaft und ihre politische Führung: »The memories and experiences were instrumentalised, or functionalised, and were used, or exploited.«Die bewusst von der Regierung und auch den Westmächten offiziell lange offen gehaltene Frage einer Grenzrevision machte die Vertriebenen zu einer stark antikommunistischen Gruppe. Das tatsächliche individuelle Vertriebenen-Schicksal war dafür nicht von Interesse und wurde im westdeutschen Heimatfilm der 1950er Jahre zudem häufig zu einer "soap opera« mit gutem Ende trivialisiert. ${ }^{44}$ Ahonen sieht bei aller Kritik am politischen Diskurs zu Flucht und Vertreibung die Funktion, dass dieser für den Durchschnittsvertriebenen eine wichtige psychologische Funktion der Anerkennung erfüllte. ${ }^{45}$ Den positiven Effekt des Antikommunismus als Integrationshilfe hebt Stickler hervor, zumal dieser - wenigstens in weiten Teilen - die ethnisch konnotierten Feindschaften gegen Polen und Tschechen ersetzte und damit die Tür für eine Versöhnung mit dem Volk jenseits der Regierungen ermöglichte oder dieses sogar als potentieller Verbündeter betrachtet wurde. ${ }^{46}$ Andererseits wurde in den 1950er Jahren jede Selbstkritik an der »heilen Welt Schlesiens, Ostpreußens oder Pommerns« sowie unter dem Verdacht des Verzichtes stehende Verständigungsbereitschaft gen Osten als kommunistische Agitation angegriffen. ${ }^{47}$ Die nach Stickler kaum zu bezweifelnde Verständigungsbereitschaft der Vertriebenenverbände mit den osteuropäischen Völkern beruhte gleichwohl auf einem fortgesetzten Irrtum, bei dem die vielleicht einzige vorhandene »Interessenidentität « von Bevölkerung und Regime in Polen und der Tschechoslowakei, die als existentiell betrachtete Unveränderlichkeit der Grenzen, nicht erkannt wurde oder man diese nicht erkennen wollte. ${ }^{48}$

Aggressive Äußerungen aus den Verbänden boten in Kombination mit einer verzerrten Darstellung zunächst in den Staaten des Warschauer Paktes als auch später in der westdeutschen Öffentlichkeit die Grundlage für die »Beschwörung« eines revisionistisch-faschistischen Verbandes, der als Feindbild im Osten zur Herrschaftslegitimierung genutzt wurde. ${ }^{49}$ Versöhnungsgesten wie die der Sudetendeutschen Landsmannschaft, die 1963 um Vergebung für die im Zweiten Weltkrieg am tschechischen Volk begangenen Verbrechen bat, konnten keine nachhaltige Wirkung erzielen. ${ }^{50} \mathrm{Zu}$ dem wurde der Anspruch der Vertriebenenverbände, dass die Ursachen der Vertreibung nicht allein im Zweiten Weltkrieg, sondern auch wesentlich weiter zurücklägen, abgelehnt. ${ }^{51}$ Trotz mancher rhetorischer Eskalation blieb jedoch die von vielen in der Nachkriegszeit erwartete Radikalisierung der Vertriebenen aus. ${ }^{52}$

\footnotetext{
43 Ahonen: On Forced Migrations, 2014, S. 609.

44 Schulze: The Politics of Memory, 2006, S. $370 f$.

45 Ahonen: On Forced Migrations, 2014, S. 607.

46 Stickler: Gegenspieler der Aussöhnung? 2009, S. $230 f$.

47 Lotz: Die Landsmannschaft Schlesien, 2014, S. 104.

48 Stickler: Gegenspieler der Aussöhnung? 2009, S. 231 f., 434.

49 Ebd., S. 232.

50 Stickler: »Ostdeutsch heißt Gesamtdeutsch«, 2004, S. 101.

51 Ebd.

52 Vgl. Ahonen: On Forced Migrations, 2014, S. 608.
} 
Schwartz konstatiert bei seiner Untersuchung des ersten BdV-Präsidiums in Hinblick auf dessen NS-Verstrickung, dass die Mitglieder zu 61,6 Prozent ${ }^{53}$ der NSDAP angehört haben, eine Zahl, die sich jedoch unter Berücksichtigung der spezifischen sozialen und beruflichen Hintergründe und entsprechender Vergleichsgruppen ein Stück weit relativiert. Über die konkrete Beteiligung dieser Personen an NS-Verbrechen können nur Mutmaßungen angestellt werden, wobei die strukturelle Unterstützung des NS-Regimes und damit das Mittragen der Verbrechen direkt oder indirekt für die meisten außer Frage steht, sei es als Verwalter in den besetzten Gebieten oder bei militärischen Einsätzen. Mit dem sudetendeutschen Sozialdemokraten Wenzel Jaksch - und mit Einschränkungen dem Katholiken Linus Kather - waren zwei NS-Widerständige Mitglied des Gründungspräsidiums. ${ }^{54}$ Innen- wie außenpolitisch boten diese Besetzung des Präsidiums und die NS-Belastung weiterer BdV-Mitglieder eine fortwährende Angriffsfläche. ${ }^{55}$

Die für die Bundesrepublik konstitutive Abgrenzung vom Nationalsozialismus, deren Halbherzigkeit, besonders in personeller Hinsicht, immer wieder kritisiert wurde und wird, führte um 1960 dazu, dass unter dem Druck der DDR-Kampagnen und der weltweiten Öffentlichkeit Bundesvertriebenenminister Theodor Oberländer aufgrund seiner NS-Vergangenheit zurücktreten musste. Damit deutete sich bereits die diskursive Verschiebung der 1960er Jahre an, in der die bis dato vorherrschende Abwehrhaltung zerbrach, solche Vorwürfe als bloße kommunistische Kampagnen abzutun, und die sich ökonomisch festigende Bundesrepublik aufgrund dieses äußeren, aber auch wachsenden inneren Druckes sich zunehmend vergangenheitspolitischen und selbstkritischen Fragen zuwandte. ${ }^{56} \mathrm{Zu}$ einem weiteren entscheidenden Wandel der bundesrepublikanischen Erinnerungskultur führte die nach 1958 intensivierte juristische Aufarbeitung nationalsozialistischer Verbrechen, die schließlich im Frankfurter Auschwitz-Prozess kulminierte. ${ }^{57}$ Der Wandel wurde verstärkt durch den Bau der Berliner Mauer im August 1961, worin Kittel eine weitere Zäsur der Erinnerung an Flucht und Vertreibung sieht: Die `Stabilisierung \ der Verhältnisse in Europa und die einsetzende internationale Entspannungspolitik entzogen der Vertriebenenthematik die aktuelle Relevanz ebenso, wie es die Beschäftigung mit den eigenen, den deutschen Verbrechen voranbrachte.

Diese drei wesentlichen Faktoren begünstigten die gesellschaftliche Entwicklung hin zur Neuen Ostpolitik. Auch wenn die Vertreter der SPD, CDU/CSU und FDP weiterhin prominent $\mathrm{zu}$ den Anliegen der Vertriebenen standen und die SPD-Spitze mit Willy Brandt noch 1963 von »Verzicht ist Verrat «sprach, wurden außenpolitisch die Weichen zunehmend anders gestellt. ${ }^{58}$ So vollzog die SPD schon vor der Regierung Brandt den Wandel hin zur >Verzichtspolitik‘. Helmut Schmidt forderte im März 1968 das Eingeständnis, dass eine Aussöhnung mit Polen die Akzeptanz der gegebenen Grenzen

53 Im Vergleich dazu waren gegen Kriegsende etwa 10 Prozent der deutschen Bevölkerung in der NSDAP.

54 Schwartz: Funktionäre mit Vergangenheit, 2013, S. 521-531.

55 Vgl. Kittel: Vertreibung der Vertriebenen? 2007, S. 18.

56 Vgl. ebd., S. 13-16.

57 Vgl. ebd., S. 180.

58 Vgl. Kossert: Kalte Heimat, 2009, S. $165 f$. 
erfordere. ${ }^{59}$ Unter der ersten Großen Koalition (1966-69) wurden diplomatische Annäherungen zur VRP und zur ČSR intensiviert und eine politische Verständigung angestrebt, die an Initiativen und Interessen in diesen Ländern anknüpfen konnte. ${ }^{60}$ Denker in Kirche, Politik und unter Intellektuellen verfolgten Anfang der 1960er Jahre verstärkt Überlegungen, die Oder-Neiße-Grenze anzuerkennen. Dies ging einher mit dem wachsenden Verständnis, die Vertreibung in einem Kausalzusammenhang mit NS-Diktatur und deutschen Verbrechen zu sehen. ${ }^{61}$ Ein Resultat war die wirkmächtige Denkschrift der Evangelische Kirche in Deutschland von 1965, die in abwägendem Ton die Anerkennung der politischen Realitäten forderte. ${ }^{62}$ Ein weiterer Meilenstein im selben Jahr war, wenigstens im Nachhinein, der Brief der katholischen polnischen Bischöfe an ihre deutschen Amtsbrüder. Die erhoffte Antwort, vor allem in Hinblick auf die Anerkennung des Status Quo, konnten und wollten die deutschen Bischöfe noch nicht geben. ${ }^{63}$ Immer stärker zeigte sich in der Bundesrepublik nun der Wunsch nach einem Ausgleich mit den Nachbarn und einer Anerkennung der Kriegsverluste im Osten, der auch mit einem zunehmenden Einfluss der polnischen und tschechischen Perspektive auf die Vertreibungen einherging. ${ }^{64}$ Die Gesellschaft und die nachwachsende Generation hatten sich darüber hinaus schon so weit gewandelt, dass die Forderungen der Vertriebenen von vielen nicht nur als rückständig und ungerechtfertigt betrachtetet wurden, sondern ihr Opferstatus grundsätzlich in Frage gestellt wurde. ${ }^{65}$ So geriet die konventionelle deutsche Opfergeschichte der ersten Nachkriegszeit in den Hintergrund und blieb zunehmend der politischen Rechten überlassen. ${ }^{66}$

Nachdem die politische Funktionalisierung mit dem Regierungswechsel 1969 und der veränderten politischen Großwetterlage nicht mehr notwendig war, wurde spätestens jetzt deutlich, dass die Rolle der eben noch heftig umworbenen Vertriebenen und ihrer Verbände in der Bundesrepublik fragil war und sie ihrer zunehmenden Isolierung in der bundesrepublikanischen Erinnerungskultur weitgehend hilflos begegneten. ${ }^{67}$ In seiner ersten Regierungserklärung deutete Willy Brandt die Grundlagen für eine neue Ostpolitik an, indem er die Aufnahme von Gesprächen mit Polen und der Tschechoslowakei ankündigte. Der bald darauf folgende Warschauer (1970) und später der Prager Vertrag

59 Kosmala: Das Bild Polens in der Bundesrepublik Deutschland und die deutsch-polnischen Beziehungen, 2009, S. 134.

60 Stokłosa: Polen und die deutsche Ostpolitik, 2011, S. $527 f$.

61 Lotz: Im erinnerungspolitischen Sog, 2010, S. 340. Vgl. Kittel: Vertreibung der Vertriebenen? 2007, S. 27.

62 Ebd. Siehe auch: Kosmala: Das Bild Polens in der Bundesrepublik Deutschland und die deutschpolnischen Beziehungen, 2009, S. $132 \mathrm{f}$.

63 Vgl. Kittel: Vertreibung der Vertriebenen? 2007, S. 27. Siehe auch: Olschowsky: Versöhnungsinitiativen, 2009, S. 316. Vgl. ebenfalls umfassend: Madajczyk: Die deutsche Reaktion auf den Brief der Bischöfe in der polnischen Rezeption, 2009, S. 196-210. Vgl. Kap. 4.3, S. $171 f$.

64 Vgl. Ahonen: On Forced Migrations, 2014, S. 602.

65 Vgl. Kittel: Vertreibung der Vertriebenen? 2007, S. 28-30.

66 Vgl. ebd., S. 178f. Vgl. ebenso: Beer: »Flucht und Vertreibung«, 2008, S. 274f. Siehe auch: Lotz: Die Landsmannschaft Schlesien, 2014, S. 106-108.

67 Bauerkämper: Deutsche Flüchtlinge und Vertriebene, 2010, S. 483. Benthin: Die Vertreibung der Deutschen aus Ostmitteleuropa, 2007, S. 49. 
(1973) führten zu einer De-facto-Anerkennung der Oder-Neiße-Grenze sowie der Erklärung der Nichtigkeit des Münchner Abkommens. Die sozialliberale Koalition folgte mit diesen Verträgen aber keineswegs den Maximalpositionen der Volksrepublik Polen und der ČSSR. So wurde das Münchner Abkommen nicht als von Beginn an nichtig bewertet, die abschließende Entscheidung über die Grenzfrage unter Wahrung der Rechte der alliierten Siegermächte auf den Zeitpunkt eines Friedensvertrages verschoben und auch die innerdeutsche Grenze nicht garantiert, ebenso wie mögliche Fragen von Entschädigungen und Rechtsansprüchen von Vertriebenen in den Dokumenten nicht behandelt wurden. ${ }^{68}$ Dennoch bekämpften Vertriebenenverbände und CDU/CSU die Verträge von Anfang an heftig, was schließlich 1972 zum gescheiterten Misstrauensvotum gegen Willy Brandt führte. Bei der anschließenden Wahl erhielt die SPD/FDP Regierung eine breite plebiszitäre Mehrheit für die Fortsetzung ihres Regierungskurses. Sich den Gegnern seiner Verständigungspolitik zuwendend, argumentierte Willy Brandt bei der Vertragsunterzeichnung in Warschau:

»Was ich im August Ihnen aus Moskau gesagt habe, liebe Mitbürgerinnen und Mitbürger, gilt auch für den Vertrag mit Polen: Er gibt nichts preis, was nicht längst verspielt worden ist. Verspielt nicht von uns, die wir in der Bundesrepublik Deutschland politische Verantwortung tragen und getragen haben. Sondern verspielt von einem verbrecherischen Regime, vom Nationalsozialismus. «"

Die neue Ostpolitik verdichtet sich in einer Ikone des Kalten Krieges, dem Kniefall Willy Brandts am Denkmal des Warschauer Ghettoaufstandes, das dieser am selben Tag besuchte. Wie schon bei den Auseinandersetzungen um die Neue Ostpolitik war die deutsche Gesellschaft in Bezug auf diese Geste gespalten, die zu dem Zeitpunkt von einer Mehrheit als nicht angemessen abgelehnt wurde. Ähnlich dem polnischen Bischofsbrief von 1965 war dieser symbolische Akt in Anbetracht seiner späteren Rezeption seiner Zeit voraus. $^{70}$

Ein weiteres Beispiel für den Wandel der bundesrepublikanischen Erinnerungskultur zur Vertreibung sind die Lehrpläne und Schulbücher, in denen das zuvor umfassend thematisierte Geschehen im Laufe der 1970er Jahre zunehmend verschwand oder in einen neuen Kontext gestellt wurde: Im Prinzip wechselte ein monokausaler Standpunkt $\mathrm{zu}$ einem anderen. Nachdem vorher die >Vertreiberstaaten Kontext gebrandmarkt wurden, erschien nun die Vertreibung als »ausschließliche Konsequenz des Hitlerkrieges«. Der Standpunkt der Vertriebenenverbände, die 1973 und 1975 in ihrem Rechtsverständnis der Vorläufigkeit der Oder-Neiße-Grenze vom Bundesverfassungsgericht nochmals bestätigt wurden, sollte mit Ausnahme Bayerns bereits in den Curricula der 1970er Jahre nicht weiter behandelt werden oder erschien »als histosöhnung, Normalisierung, 2009, S. 245. Siehe auch: Suppan: Hitler - Beneš - Tito, 2014, S. 15691571. Fernsehansprache von Bundeskanzler Willy Brandt aus Warschau, 7. Dezember 1970. Vgl. Wolfrum: Die beiden Deutschland, 2005, S. 159. 
risch abgeschlossen ${ }^{71}{ }^{71}$ In den 1970er Jahren setzten die Bundesrepublik und die VRP im Zuge der Entspannungspolitik eine bis heute tätige deutsch-polnische Schulbuchkommission ein, die Empfehlungen über den Umgang mit den zwischen den Ländern umstrittenen Themen erarbeitet(e).

Rückzugsgefechte führte der BdV auch bei den Wetterkarten der Fernsehsender, von denen Anfang der 1970er Jahre schließlich Breslau und Königsberg verschwanden. Die Bedeutung mag zunächst marginal erscheinen, allerdings war das tägliche sSehen< von Breslau für ein Millionenpublikum kaum bedeutungslos. So berichtete ein ZDFIntendant 1975: „Seit Jahren sprechen uns die Polen bei jeder Gelegenheit darauf an. Das Thema Breslau in der Wetterkarte war ein echter Dauerbrenner. ${ }^{72}$ Verstärkt diskutiert wurde der 1977 durchgeführte Prozess wegen des Lagers im Lamsdorf/Łambinowice, ${ }^{73}$ von dem in der Presse ausführlich berichtet wurde und der schließlich ergebnislos endete. ${ }^{74}$ Die volkspolnische Presse berichtete äußert kritisch über diesen und sprach den Tätern von Auschwitz das Recht auf entsprechende Prozesse ab. ${ }^{75}$

Abgesehen von einigen wenigen Regionalstudien, überwiegend zur Integration der Vertriebenen oder deren Beitrag zur Entwicklung der Bundesrepublik, verlor der historische Komplex Flucht und Vertreibung in den 1970er und 1980er Jahren seinen bedeutenden Status in der Wissenschaft. ${ }^{76}$ Wesentliche Arbeiten der 1970er Jahre kamen aus dem Ausland, so die umfassende Abhandlung des US-Völkerrechtlers und Historikers Alfred de Zayas. ${ }^{77}$ Dieses Desinteresse führte letztlich dazu, dass die Geschichtswissenschaft viele umstrittene Themen, wie die genannte Diskussion um das Lager Lamsdorf, nicht fundiert begleiten konnte und so zum Teil wissenschaftlich mangelhafte Literatur die Hauptinformationsquelle für Interessierte bleiben musste. ${ }^{78}$ Auch wenn die Anzahl wissenschaftlicher Veröffentlichungen in der Bundesrepublik in den 1970ern und 1980ern stark zurückgegangen war, blieb das Thema doch ein Bestandteil des universitären Lehrangebotes. ${ }^{79}$

Getragen von den Vertriebenenverbänden und Teilen der politischen Rechten blieb die Erzählung der Vertriebenen im politischen Raum weiter präsent. ${ }^{80}$ Ebenso wurde das Thema in den Medien wiederholt aufgegriffen, so mit der im Auftrag des Bayeri-

71 Siehe: Kittel: Vertreibung der Vertriebenen? 2007, S. 135f. Siehe auch: Beer: »Flucht und Vertreibung«, 2008, S. 277. Vgl. Höpken: Das Thema der Vertreibung im deutschen Schulbuch, 2006, S. 110-112.

Zitiert nach: Kittel: Vertreibung der Vertriebenen? 2007, S. 148.

73 Vgl. Kap. 6.1, S. 282.

74 Kittel: Vertreibung der Vertriebenen? 2007, S. 156f.

75 Siehe: ebd., S. 157.

76 Vgl. Kossert: Kalte Heimat, 2009, S. 13. Ther ordnet diese Entwicklung, auch im Widerspruch zur Tabuthese, in den Rahmen ganz natürlicher wissenschaftlicher und politischer Konjunkturen ein: Ther: Der Diskurs um die Vertreibung, 2008, S. 30.

77 Zayas: Nemesis at Potsdam, 1977. De Zayas studierte und arbeitete aber in den 1970er Jahren als Wissenschaftler in der Bundesrepublik.

78 Kittel: Vertreibung der Vertriebenen? 2007, S. 163-167.

79 So Hans-Jürgen Bömelburg mündlich am 30.01.2018 während seines Kolloquiums, in dem er auf die sinkende Publikationstätigkeit der älteren Fachhistoriker dieses Feldes in jener Zeit verwies, welche aber das Thema in der Lehre fortgesetzt behandelten. 
schen Rundfunks entstandenen TV-Serie Flucht und Vertreibung von 1981. ${ }^{81}$ Diese folgte auf die von der Geschichtswissenschaft gemeinhin als zentral für die Entwicklung der bundesrepublikanischen Erinnerungskultur gesehene US-amerikanische Serie Holocaust (1979). Maren Röger hat herausgearbeitet, dass die deutsche Produktion »explizit als Korrektiv« zu der Serie gesehen wurde und zudem eine mediale Übernahme der Bildsprache der modernen Holocaustdarstellungen stattfand. ${ }^{82}$ Auf die deutsche Serie folgte umgehend eine Reaktion aus Polen, die dieser einen Rückfall in die Kampfzeiten der 1950er Jahre vorwarf und in der die sozialistischen Staaten erneut zu Unrecht an den Pranger gestellt würden. ${ }^{83}$

Im Diskurs der 1970er und 1980er setzte sich in der Nachkriegsgeneration, zumal bei den $>1968$ « Sozialisierten, zunehmend die Ansicht durch, in den Deutschen nur noch eine >Täternation $\mathrm{zu}$ sehen, die wenig oder kein Recht habe, ihre eigenen Opfer $\mathrm{zu}$ betrauern. ${ }^{84}$ Damit wurde schließlich eine Polarisierung und ein Verdrängungswettbewerb der Erinnerungen « erreicht, in der das Gedenken an eine Opfergruppe das Gedenken an eine andere scheinbar ausschloss; ${ }^{85}$ dies galt sowohl für das rechte als auch das linke Lager. ${ }^{86}$ Der Großteil der bundesdeutschen Presse, abgesehen von den Medien aus dem Axel Springer Verlag, schloss sich dem kritischen Diskurs gegenüber den Vertriebenenverbänden an. ${ }^{87}$ Auch Stimmen der anderen Vertriebenen außerhalb der Verbände konnten die »tiefen Gräben« nicht überwinden, ihre Ablehnung der Verbände und das organisatorische oder künstlerische Wirken schufen kein allgemein akzeptiertes Narrativ, auch wenn von kritischer Selbstreflexion geprägte Werke von aus den Ostgebieten stammenden Autoren wie Günter Grass, Siegfried Lenz und Horst Bienek breite Popularität genossen. ${ }^{88}$ Eine negative Einstellung gegenüber den Vertriebenen und ihren Verbänden resultierte neben den genannten Faktoren auch aus exogenen politischen Trends wie der von vielen mit Elan betriebenen Versöhnung mit den östlichen Nachbarstaaten. ${ }^{89} \mathrm{Zu}$ dem Zeitpunkt war eine ausgewogene Kombination kaum möglich und auch die politische Linke war vor einiger Ignoranz nicht gefeit, wie die 68erin Helga Hirsch 2006 selbstkritisch konstatierte:

81 Vgl. Wittlinger: Taboo or Tradition? 2006, S. 73.

82 Röger: Zeitzeugen von Flucht, Vertreibung und Heimatverlust im deutschen Ceschichtsfernsehen, 2011, S. 7.

83 Kittel: Vertreibung der Vertriebenen? 2007, S. 160.

84 Kelletat: Von der Täter- zur Opfernation? 2003/2004, S. 137. Vgl. Hirsch: Flucht und Vertreibung, 2003, S. 25.

85 Sundhaussen: Einführende Bemerkungen, 2006, S. 25f. Günter Grass formulierte dazu 2000: »Ein Unrecht verdrängte das andere. Es verbot sich, das eine mit dem anderen zu vergleichen oder gar aufzurechnen.«Zitiert nach: Assmann: Der lange Schatten der Vergangenheit, 2006, S. 199. 
»Sozialliberale Gutmenschen traten ständig in pädagogische Vorleistung gegenüber Polen und bestärkten sie damit in ihren Versuchen, ihre Geschichte erpresserisch gegenüber Deutschland einzusetzen. ${ }^{90}$

Hierbei übersahen oder ignorierten die Gegner des 1976 noch 1,5 Millionen Mitglieder zählenden BdVs und seiner Landsmannschaften sowie diese selbst, dass auch an deren Basis die sozialliberale Entspannungspolitik im Laufe der 1970er Jahre zunehmend an Unterstützung gewann und letztlich überwiegend akzeptiert wurde. ${ }^{91}$ Dieses Versäumnis führte zur weiteren wechselseitigen Distanzierung von SPD und BdV in den 1970er und 1980er Jahren, die »auf Seiten der organisierten Vertriebenen eine Verweigerungshaltung gegenüber den außenpolitischen Realitäten [förderte] und [...] deren Abdriften aus der Mitte der westdeutschen Gesellschaft in das politische Abseits und die Folklore landsmannschaftlicher Nischen [begünstigte]. ${ }^{92}$ Der politischen Marginalisierung versuchten die Vertriebenenverbände mit einer allmählichen Neuausrichtung hin zu einer deutlicheren europäischen Perspektive und dem internationalen Menschenrechtsdiskurs zu begegnen. $\mathrm{Zu}$ diesem Ansatz gehörte auch eine verstärkte Anlehnung an den mit der Holocausterinnerung verbundenen Opferdiskurs. ${ }^{93}$

Die nach dem 1982 erfolgten Regierungswechsel amtierende Regierung aus CDU/CSU und FDP unter Helmut Kohl setzte schließlich die sozialliberale Entspannungspolitik fort, und auch die ausgerufene "geistig-moralische Wende« veränderte die Position von Flucht und Vertreibung in der bundesdeutschen Erinnerungskultur nicht wesentlich. ${ }^{94}$ Kohl verzichtete auf eine Verschärfung der Rhetorik gegenüber den osteuropäischen Staaten und unterließ, trotz wechselseitiger Zusicherungen zwischen "Regierungs- und Vertriebenenpolitikern«, de facto eine Unterstützung der politischen Ziele des BdV. ${ }^{95}$ Dafür kam er den Vertriebenenverbänden auf finanziellem Wege entgegen und die Regierung schenkte ihnen insgesamt wieder mehr Beachtung. ${ }^{96}$ Die staatliche Kulturförderung der Vertriebenen, die vor seinem Regierungsantritt bei nur noch 4,2 Millionen DM lag, war 15 Jahre später wieder auf 52 Millionen DM angestiegen.$^{97}$ Nicht nur finanziell, auch in Hinblick auf Personalentscheidungen und symbolpolitische Handlungen zeigte sich Kohl - wahrscheinlich aus »taktischen Gründen« - entgegenkommend..$^{98}$ Eine ernstzunehmende politische Rolle gestand er den

90 Hirsch: Menschenrecht auf Erinnerung. Die Welt. 03.03.2006. Vgl. Kittel: Vertreibung der Vertriebenen? 2007, S. 173.

91 Ebd., S. 139. Amos: Vertriebenenverbände im Fadenkreuz, 2011, S. 277.

92 Olschowsky: Versöhnungsinitiativen, 2009, S. 324.

93 Vgl. Jakubowska: Der Bund der Vertriebenen in der Bundesrepublik Deutschland und Polen, 2012, S. $214 f$.

94 Vgl. Olschowsky: Versöhnungsinitiativen, 2009, S. 325f. Vgl. auch: Koszel: Die polnische Deutschlandpolitik in den Jahren 1970-1990, 2001, S. 918. Koszel sieht aber einige neue Akzente in der Kohlschen Außenpolitik gegenüber Polen, die konfrontativer gegenüber den Machthabern war und zunehmend die polnische Gesellschaft als Partner betrachtete.

95 Amos: Vertriebenenverbände im Fadenkreuz, 2011, S. 292.

96 Vgl. Jakubowska: Der Bund der Vertriebenen in der Bundesrepublik Deutschland und Polen, 2012, S. $215 f$.

97 Finster: »50 Jahre Bund der Vertriebenen - Das sind auch 50 Jahre deutsche Ceschichte«, 2014, S. 134. Vgl. Bergsdorf: Der Stellenwert ostdeutscher Kulturpflege in der Ära Kohl, 2005, S. 64-67. 
Vertriebenenverbänden nicht mehr zu. ${ }^{99}$ Das Schlesiertreffen 1985, bei dem Helmut Kohl zwar als Gastredner auftrat, aber zuvor eine Änderung des Mottos »40 Jahre Vertreibung - Schlesien bleibt unser« erreichte, ist vielmehr ein Beispiel, dass diese ihren Einfluss - nun sogar auf den konservativen Teil der deutschen Politik - überschätzt hatten. ${ }^{100}$ Anders sah es bei der Kohl-Regierung bezüglich ihres Engagements für die deutsche Minderheit in Polen aus, bei der einige Fortschritte erzielt werden konnten. ${ }^{101}$ Die äußerst schwache Mobilisierungsfähigkeit der Vertriebenenverbände in den späten 1980ern und frühen 1990ern wurde immer stärker deutlich, auch wenn das Selbstbild als Massenverband weiterhin besteht. ${ }^{102}$

Kohls aktive Geschichtspolitik führte zur Gründung des Hauses der Geschichte in Bonn und den Planungen für das Deutsche Historische Museum. Auf ein von Günter Grass schon 1970 gefordertes »Ostdeutsches Zentralmuseum« wurde verzichtet, vielmehr in Tradition der föderalen Vertriebenenförderung einzelne >Landesmuseen oder verstärkt gefördert. ${ }^{103}$ Die von Kohl geplanten Nationalmuseen fielen in eine Zeit der intensiven historischen Auseinandersetzungen und waren selbst Teil davon. ${ }^{104}$ Bis heute maßgeblich ist die Rede von Bundespräsident Richard von Weizsäcker zum 40. Jahrestages des Kriegsendes am 8. Mai 1985. Neben der zentralen Botschaft, das Kriegsende nicht als Niederlage, sondern in seinem Resultat als Befreiung zu betrachten, setzte sich von Weizsäcker intensiv mit den deutschen Opfern des Krieges auseinander und löste damit - nach Madlen Benthin - eine neue Beschäftigung mit deutschen Opfern des Krieges aus, die bis in die 2000 er Jahre fortreicht. ${ }^{105}$ Rainer Schulze hingegen sieht in der Rede ein vorläufiges Finale in der von ihm skizzierten Trennung der alt-westdeutschen Gesellschaft von den deutschen Vertriebenen. Auch wenn Bundespräsident von Weizsäcker diese in seiner Rede erwähne, entspreche die Vorstellung des 8. Mai als (nachträgliche) Befreiung vor allem einem westdeutschen Lebensgefühl. ${ }^{106}$

Die in den 1990ern und 2000ern von den Medien und bereits in den 1970ern aus den Vertriebenenverbänden heraus erhobene These, dass Flucht und Vertreibung in der späten Bundesrepublik zu einem Tabu wurden, ist nach der obigen Erläuterung nicht zu halten. ${ }^{107}$ Herbert Hupka sowie der Historiker und Journalist Reinhard Müller beklag-

99 Vgl. Olschowsky: Relations between the Federal Republic of Cermany and the Peoples' Republic of Poland, 2014, S. 245.

100 Schwartz: Assimilation versus Incorporation, 2016, S. 85. Vgl. Brandt: Die deutsch-polnischen Beziehungen bis 1990, 2011, S. 54.

101 Vgl. Olschowsky: Relations between the Federal Republic of Cermany and the Peoples' Republic of Poland, 2014, S. 254.

102 Finster: »50 Jahre Bund der Vertriebenen - Das sind auch 50 Jahre deutsche Ceschichte«, 2014, S. 135-143. Siehe auch: Schwartz: Vertriebene im doppelten Deutschland, 2008, S. 135.

103 Kittel: Vertreibung der Vertriebenen? 2007, S. 184. Vgl. Kap. 6.2.1, S. 285.

104 Vgl. Wolfrum: Die beiden Deutschland, 2005, S. $160 f$.

105 Benthin: Die Vertreibung der Deutschen aus Ostmitteleuropa, 2007, S. 51-57. Vgl. Schwartz: Vertriebene im doppelten Deutschland, 2008, S. 143.

106 Schulze: The Politics of Memory, 2006, S. 372.

107 Vgl. Hahn; Hahn: Flucht und Vertreibung, 2005, S. 347f. Nelhiebel konstatiert, dass die Vertriebenen sich stets benachteiligt gefühlt hätten, obwohl sie de facto von allen Opfergruppen in der Bundesrepublik die meiste Aufmerksamkeit erfahren haben: Nelhiebel: Die Entkoppelung von 
ten drastisch eine >zweite Vertreibung< der deutschen Vertriebenen aus der bundesdeutschen Erinnerung. Hupka formulierte entsprechende Worte in Bezug auf die neue Ostpolitik Brandts': »[...] es wird systematisch [...] eine zweite Vertreibung der Vertriebenen angestrebt. Zuerst hat man Millionen Deutsche aus der Heimat vertrieben, und jetzt sollen die Vertriebenen aus dem allgemeinen Bewusstsein vertrieben werden. ${ }^{108}$ Auch wenn von keinem allgemeinen gesellschaftlichen Tabu gesprochen werden kann, ist doch zu konstatieren, dass sich bestimmte politische und gesellschaftliche Verbände, wie die SPD oder die evangelische Kirche, von der Vertriebenenthematik abwandten und in bestimmten Milieus Ablehnung und Desinteresse gegenüber dem Vertreibungsthema sowie politisch nicht immer unverständliche Berührungsängste zu den Vertriebenenverbänden bestanden. ${ }^{109}$ Folglich lässt sich eher von einer diskursiven Ausgrenzung sprechen. ${ }^{110}$ Diese ist größtenteils durch den Wandel der bundesrepublikanischen Erinnerungskultur, durch die Entwicklung des BdV als eigenständigem Lobbyverband eher hemmende Verzahnung mit der politischen Landschaft sowie das Ausbleiben einer adäquaten Antwort der Verbände auf diesen Wandel zu erklären. Insgesamt war das Thema mit unterschiedlichen Konjunkturen in Intensität und Bewertung in der gesamten Bundesrepublik präsent. ${ }^{111}$ Stephan Scholz hat in seinem Werk diese Konjunkturen bundesdeutscher Erinnerung an Flucht und Vertreibung systematisch anhand der Vertriebenendenkmäler untersucht: Ein dichtes Netz von 1.584 Vertriebenendenkmälern steht stellvertretend für die große Bedeutung von Flucht und Vertreibung in der Erinnerungskultur der Bundesrepublik. Von einem Tabu könne keine Rede sein, "sie besaß vielmehr in Form von Denkmälern, Gedenksteinen und -tafeln immer eine große Präsenz im öffentlichen Raum. "112 $^{112}$ Brückenschlag in das linksliberale Milieu sollte schließlich - punktuell - erst wieder unter Erika Steinbach in den 20ooer Jahren gelingen.

Der BdV war bereits lange vor 1989 geschwächt. Durch die Urteile des Bundesverfassungsgerichtes sowie durch die vermeintliche Unterstützung durch CDU/CSU in der Grenzfrage hatten sich die führenden Verbandsvertreter letztlich »in einen Kokon von Rechtspositionen eingewoben [...], die zwar akademisch-völkerrechtlich einwandfrei waren, man darüber jedoch die Realisierbarkeit völlig aus dem Auge verloren hatte. ${ }^{113}$ Durch das Beharren auf diesen Maximalpositionen war der BdV schließlich nicht in der Lage, geschweige denn vorbereitet, 1989/90 politisch effektiv $\mathrm{zu}$ intervenieren oder als Ansprechpartner für die neuen Regierungen in Polen und Tschechien geeignet zu sein. ${ }^{114}$ Eine Anbindung der Vertriebenenverbände an den sich seit den 1960er Jah-

Krieg und Vertreibung, 2010, S. 54. Vgl. zur Tabuthese im BdV: Stratmann: »Im Krebsgang« zur Vertreibung zurückgefunden. DOD. 22.02.2002.

108 Zitiert nach: Kossert: Kalte Heimat, 2009, S. 182.

109 Vgl. ebd., S. 13, 325. Siehe auch: Douglas: »Ordnungsgemäße Überführung«, 2012, S. 434f. Vgl. zur häufig fehlenden Abgrenzung von Teilen der Vertriebenenverbände gegenüber politischem Extremismus bis in die 1990er Jahre: Streibel: Vorwort, 1994, S. 9 .

110 Vgl. Kossert: Kalte Heimat, 2009, S. 325.

111 Lotz: Im erinnerungspolitischen Sog, 2010, S. 324. Vgl. Beer: ₹Flucht und Vertreibung«, 2008, S. 273.

112 Scholz: Vertriebenendenkmäler, 2015, S. 361, 363.

113 Stickler: »Ostdeutsch heißt Gesamtdeutsch«, 2004, S. 435.

114 Stickler: Gegenspieler der Aussöhnung? 2009, S. 234f., 243. Kunštát: Die Wiedervereinigung Deutschlands und die tschechoslowakische Außenpolitik, 2010, S. 211. 
ren in der Bundesrepublik herausbildenden und zunehmend hegemonialen selbstkritischen Diskurs gelang vor 1989 nicht. ${ }^{115}$ So war der »realpolitische« Ansatz von Helmut Kohl in Hinblick auf die Grenzfrage weitgehend unbestritten. ${ }^{116}$ Freilich wäre trotz der Kohl'schen Verzögerungstaktik eine Diskussion über die Grenzfrage kaum möglich gewesen, aber Fragen von Eigentum oder Staatsbürgerschaft hätten, wie gleich gezeigt wird, durchaus verhandelt werden können.

Eva und Hans Henning Hahn betonen hingegen den Erfolg des Bundes der Vertriebenen, der es schließlich trotz einer sich demokratisierenden und pluralisierenden Öffentlichkeit über den gesamten Zeitraum hinweg geschafft habe, als legitimer und einziger Repräsentant dieser Bevölkerungsgruppe betrachtet zu werden und fortwährend eine nicht unerhebliche staatliche Förderung zu genießen. Es gelang ihm ferner, eine »Aura der Unschuld« zu erlangen, welche »von den einstigen Kriegsgegnern an der deutschen Nation [vermeintlich] verübten Unrechts umwoben ist.« Zudem gälten die Verbände des BdV oftmals als erste Ansprechpartner für Fragen der Erinnerungskultur, ohne dass deren spezifisches, selektives und nicht repräsentatives Heimatbild hinterfragt würde. ${ }^{117}$ Dies erklärt unter anderem die bis heute noch vorhandene politische Relevanz der Vertreibungsthematik für die Bundesrepublik. ${ }^{118}$ Die Vertriebenenverbände blieben aber nicht die einzigen Erben der Thematik, auch in Kunst und Kultur blieb das Thema fortwährend präsent - wenn auch häufig von anderen Standpunkten aus. ${ }^{119}$ Die Politisierung der Verbände sowie die auf diese ausgerichtete staatliche Förderung führte schließlich dazu, die tatsächliche "politische und kulturhistorische Vielfalt der Vertriebenen « eher zu verdecken und ein spezifisches Narrativ über den deutschen Osten und die Vertreibungen zu konservieren. ${ }^{120}$

\subsection{DDR}

In ihrer vom Zuzug der Vertriebenen anteilsmäßig am stärksten belasteten Besatzungszone verfolgte die Sowjetunion eine ähnliche Politik wie die westlichen Besatzungsmächte, die jede Herausbildung von Revisionismus verhindern und die immensen ökonomischen und sozialen Herausforderungen bewältigen sollte. Zunächst allerdings fiel in den 1940er Jahren nach dem Krieg selbst vielen Spitzenfunktionären der SED die >Preisgabe aller Ostgebiete schwer. ${ }^{121}$ Ohne jegliche Handlungsspielräume fügten sich diese aber schließlich der Direktive aus Moskau. Mit der Durchsetzung des Kommunismus auch in der Tschechoslowakei 1948 war die bald darauf gegründete DDR im Süden und Osten von ssozialistischen Bruderstaaten umgeben und in den folgenden

115 Vgl. Stickler: Gegenspieler der Aussöhnung? 2009, S. 243. Vgl. auch: Jakubowska: Der Bund der Vertriebenen in der Bundesrepublik Deutschland und Polen, 2012, S. 216.

116 Kossert: Kalte Heimat, 2009, S. 155.

117 Hahn; Hahn: Die Vertreibung im deutschen Erinnern, 2010, S. 517f.; siehe auch: S. 514f. Vgl. Schwartz: Assimilation versus Incorporation, 2016, S. $90 f$.

118 Naumann: Vertreibung, 2005, S. 6, 18.

119 Vgl. Kossert: Kalte Heimat, 2009, S. 269-290.

120 Hahn; Hahn: Die Vertreibung im deutschen Erinnern, 2010, S. 518.

121 Vgl. Borodziej: Geschichte Polens im 20. Jahrhundert, 2010, S. 263. Siehe auch: Mehnert: »Flucht und Vertreibung« aus den historischen deutschen Ostgebieten, 2008, S. 238. 
Jahrzehnten mehr oder minder eng mit diesen verbunden. Mit dem Görlitzer Abkommen von 1950 zwischen Polen und der DDR wurde die Oder-Neiße-Linie abschließend anerkannt und als Freundschaftsgrenze deklariert. Eine gemeinsame Erklärung mit Polen zog einen historischen Schlussstrich, in der die »durchgeführte Umsiedlung der Deutschen « als »unabänderlich, gerecht und endgültig « definiert wurde. ${ }^{122}$ Nach der Verkündigung des Abschlusses des historischen Konfliktes auf internationaler Ebene folgte 1952/53 die Feststellung der erfolgreichen ökonomischen und sozialen Lösung der Umsiedlerfrage. ${ }^{123}$ Auch wenn diese Verlautbarungen im Stile sozialistischer Planerfüllung weit entfernt von der Realität waren, darf doch nicht unterschätzt werden, dass der SED-Staat in seiner Frühphase neben seinen repressiven Maßnahmen eine forciertere Integrationspolitik betrieb als die frühe Bundesrepublik. ${ }^{124}$ Diese geschah allerdings um den Preis der weitgehenden Verdrängung der vorherigen Heimat und der eigenen Identität aus der Öffentlichkeit sowie der Anpassung an eine kommunistische Diktatur. Die SED-Führung lobte sich für ihre santifaschistische und ehrliche Aufklärungく, die den Menschen den historischen Sachverhalt erfolgreich erklärt und so dem Revanchismus in der DDR den Boden entzogen habe. ${ }^{125}$

Für die Tschechoslowakei und Polen waren diese Abkommen und Erklärungen nicht nur eine Vereinbarung mit der DDR, sondern auch eine Botschaft an die eigene Bevölkerung. Diese sollte zum einen die lange an der Endgültigkeit der neuen Grenzziehungen zweifelnde Bevölkerung beruhigen - ohne freilich das Schreckgespenst des westdeutschen Imperialismus als Instrument aus der Hand zu geben - und zum anderen die Deutschen der DDR als Freunde und Verbündete vermitteln. Dieses Vorhaben konnte aber erst mit der Zeit und mit starken Einschränkungen Früchte tragen, denn Skepsis und Ablehnung gegenüber den Deutschen blieben in der Bevölkerung lange bestehen. Umgekehrt war unter den Bürgern der DDR noch in den 1950er Jahren der Wunsch nach einer Grenzrevision stark ausgeprägt. Auch zwischen den kommunistischen Parteien wirkten die alten nationalen Konflikte gelegentlich fort. ${ }^{126}$

Sowohl die Geschichte der Deutschen in Ostmitteleuropa als auch das Schicksal der Vertreibung wurde zügig aus der Öffentlichkeit verbannt. Neben der problematischen Verwicklung der neuen Bruderstaaten in die Thematik kam die grundsätzliche Differenz zur Bundesrepublik hinzu: Die DDR sah sich weder in der Nachfolge des Dritten Reiches, noch als Opfer des Krieges, vielmehr sah man sich als Sieger der Geschichte. Auch in dieses Bild passten die Vertriebenen als Opfergruppe kaum hinein. ${ }^{127}$ Wenn die Geschichte der Deutschen Ostmitteleuropas thematisiert wurde, sah auch die DDR-Geschichtswissenschaft häufig - spiegelbildlich zum volkspolnischen Narrativ

122 Zitiert nach: Schwarz: DDR und ČSSR, 2005, S. 409. Vgl. zum Görlitzer Abkommen vom 6. Juli 1950 und der Prager Dekleration vom 23. Juni 1950: Zimmermann: Wechselnde Bündnisse, 2010, S. 89.

Amos: Vertriebenenverbände im Fadenkreuz, 2011, S. 278. Vgl. Schwartz: Vertriebene im doppelten Deutschland, 2008, S. 117.

124 Siehe: Schwartz: Tabu und Erinnerung, 2003, S. 101.

125 Schwartz: Vertriebene im doppelten Deutschland, 2008, S. 114.

126 Zimmermann: Wechselnde Bündnisse, 2010, S. 89-91. Lotz: Die Landsmannschaft Schlesien, 2014, S. 103. Siehe auch: Olschowsky: Der wenig vertraute Nachbar - Das Bild Polens in der DDR, 2009, S. 143.

Vgl. Wolfrum: Die beiden Deutschland, 2005, S. 162-166. 
- die deutsche Ostsiedlung als historische >Fehlentwicklung « und marginalisierte den deutschen Anteil an der ostmitteleuropäischen Geschichte, indem sie diesen vor allem als einen vermeintlich klassengeprägten chronischen Kriegszug der deutschen Oberschichten gen Osten betrachtete. ${ }^{128}$ Zudem überbetonte die SED-Geschichtsschreibung die fortlaufende Abwanderung der deutschen Bevölkerung aus den Ostprovinzen im 19. Jahrhundert, an deren Ende primär deutsche Großgrundbesitzer und Kapitalisten den polnischen Arbeitern gegenüberstanden. ${ }^{129}$ Abgesehen von dieser Entwicklung habe Polen sich wegen des imperialistischen Eroberungskrieges eine angemessene Kompensation verdient. ${ }^{130}$ In populären Darstellungen schien die durch die Vertreibungen erreichte neue Ordnung zum Wohle der Arbeiterklassen aller dieser Länder durchgeführt worden zu sein, und daher auch für die meisten deutschen Vertriebenen. ${ }^{131}$

Flucht und Vertreibung konnten aber nicht vollständig aus der Gesellschaft der DDR verdrängt werden, vielmehr »fehlte es keineswegs an einer in spezifischen Bahnen verlaufenden Auseinandersetzung ${ }^{132}$ Neben dem privaten Austausch und einer stark beschränkten wissenschaftlichen gab es eine durchaus kontinuierliche kulturelle Auseinandersetzung, deren Erzählung zumeist über den Subtext funktionierte oder einen stark propagandistischen, aber nicht notwendigerweise unempathischen Impuls hatte. ${ }^{133}$ Eine 1961 inszenierte Komödie des Dramatikers Heiner Müller über die Integrationsproblematik mit dem Titel Die Umsiedlerin oder Das Leben aufdem Lande wurde allerdings sogleich als »konterrevolutionäres Machwerk« mit einem Aufführungsverbot belegt, konnte aber 1976 wieder aufgeführt werden. ${ }^{134}$ Im gleichen Jahr legte Christa Wolf mit ihrem zum Teil autobiografischen Roman Kindheitsmuster ein in der Sprache zurückhaltendes, aber in den Aussagen durchaus deutliches Werk über Flucht und Vertreibung vor. ${ }^{135}$ Auch im Film der DDR war das Thema in einigen Schattierungen vergleichsweise konstant präsent. ${ }^{136}$

Trotz dieser gewissen Liberalisierung von Kultur und Wissenschaft in den 1970er und 1980er Jahren, die zu weiteren Werken und wissenschaftlichen Studien führte und die auch besonders schwierige Punkte wie die Vergewaltigungen durch die Rote Armee und die Versäumnisse der SED-Integrationspolitik ansprachen, blieb bis zuletzt de facto ein Vereinigungsverbot für die Vertriebenen bestehen. ${ }^{137}$ Diesen gelang es je-

128 Vgl. Górny: Historiographiegeschichte und marxistisches Erbe, 2008/2009, S. 32-35.

129 Lotz: Die Landsmannschaft Schlesien, 2014, S. 103.

130 Ebd.

131 Zwicker: Zur Darstellung der Sudetendeutschen, 2006, S. 403.

132 Beer: »Flucht und Vertreibung«, 2008, S. 262.

133 Siehe grundlegend für die Behandlung von Flucht und Vertreibung in der Literatur der DDR die Monografie von Bill Niven: Niven: Representations of Flight and Expulsion in East Cerman Prose Works, 2014. Hier besonders: S. 11. Vgl. auch: Mehnert: »Flucht und Vertreibung « aus den historischen deutschen Ostgebieten, 2008, S. 237-245. Siehe ebenfalls: Kossert: Kalte Heimat, 2009, S. 290-300.

134 Douglas: »Ordnungsgemäße Überführung«, 2012, S. 428. Mehnert sieht neben der Umsiedlerfrage die Darstellung der gescheiterten DDR-Agrarpolitik als eine Ursache für das Verbot: Mehnert: »Flucht und Vertreibung « aus den historischen deutschen Ostgebieten, 2008, S. $240 \mathrm{f}$.

135 Kossert: Kalte Heimat, 2009, S. 290-300.

136 Vgl. Tiews: Fluchtpunkt Film, 2017, S. 322-329.

137 Bauerkämper: Assimilationspolitik und Integrationsdynamik, 2008, S. 22. Schwartz: Tabu und Erinnerung, 2003, S. 95-97. 
doch, zum Teil inoffizielle Treffen mit dem Schwerpunkt des unpolitisch-persönlichen Austauschs durchzuführen. ${ }^{138}$ Diese Treffen wurden, wenn ermittelt, ebenso aufmerksam von Polizei und Staatssicherheit überwacht oder aufgelöst. ${ }^{139}$ Zudem konnten in den Westen reisende Rentner sowie in der DDR zirkulierende Medien der Vertriebenenverbände eine gesamtdeutsche Verbindung ein Stück weit aufrechterhalten. Die Hauptverwaltung Aufklärung verfolgte die Aktivitäten der Vertriebenenverbände in der Bundesrepublik bis 1989 nachrichtendienstlich mit unterschiedlicher Intensität. ${ }^{140}$

Im Verhältnis der DDR zu ihren Nachbarn behielten der Zweite Weltkrieg und damit verbundene, ältere nationale Konflikte - im Gegensatz zu den offiziellen Verlautbarungen - weiter große Relevanz und so blieb die erklärte Versöhnung oberflächlich. ${ }^{141}$ Die Beziehung zur Volksrepublik Polen blieb bis 1989 schwierig und von Misstrauen geprägt, wozu auch die »von Moskau erzwungene Anerkennung der Oder-Neiße-Grenze 1950 [und] die Tabuisierung der Vertreibung « beitrugen. ${ }^{142}$ Auch die besseren Beziehungen zur Tschechoslowakei waren davon beeinflusst, zumal viele Polen und Tschechen die vorgegebene Unterteilung in »gute Deutsche« in Form der DDR-Bürger und »schlechte Deutsche« in Form der bundesrepublikanischen Bürger nicht mitgehen konnten oder wollten. Nicht nur auf propagandistischer Ebene, sondern auch außenpolitisch verbanden sich die drei Staaten aber, besonders in den 1950er und 1960er Jahren, zu einer gemeinsamen Linie in Form des geteilten Feindbildes der >revanchistischen $<$ Bundesrepublik, wobei sich die DDR als entschiedener Verteidiger der Oder-Neiße-Grenze zu profilieren versuchte. ${ }^{143}$ Von einer ausschließlichen "Konfliktgeschichte dieser Staaten zu sprechen, würde die verschiedenen gemeinsamen Interessen und Kooperationen unterbewerten. ${ }^{144}$

Schließlich sollte die Verständigung sowohl durch die staatlich gelenkte Versöhnungspolitik als auch durch den zahlenmäßig sehr relevanten DDR-Tourismus in der VRP und der ČSR sowie in umgekehrter Richtung nicht unterschätzt werden. Diese Reisen ermöglichten es auch ehemaligen deutschen Bewohnern dieser Länder, ihre alte Heimat zu besuchen und führten ähnlich wie bei den bundesrepublikanischen Reisenden zum Austausch mit den neuen Bewohnern und einem wechselseitigen Abbau von Vorurteilen und Spannungen. Ein Pionier der Verständigung war die 1958 in der DDR

138 Vgl. Lotz: Die Landsmannschaft Schlesien, 2014, S. 104f. Vgl. auch: Kossert: Kalte Heimat, 2009, S. 11f., 22of. Siehe auch: Amos: Vertriebenenverbände im Fadenkreuz, 2011, S. $278 f$.

139 Vgl. Lotz: Im erinnerungspolitischen Sog, 2010, S. 334.

140 Vgl. dazu grundlegend das Fazit von Amos: Amos: Vertriebenenverbände im Fadenkreuz, 2011, S. 279-295. Vgl. Kossert: Kalte Heimat, 2009, S. 186-190. Vgl. auch: Stickler: Gegenspieler der Aussöhnung? 2009, S. 229.

141 Olschowsky: Einvernehmen und Konflikt, 2005, S. 633f. Olschowsky zieht den Vergleich zur deutsch-französischen Aussöhnung, die in einem langen und beharrlichen Prozess erfolgreich war; davon »konnte zwischen der DDR und Polen nicht die Rede sein«. Vgl. für eine knappe Zusammenfassung des Verhältnisses von DDR und ČSSR: Schwarz: DDR und ČSSR, 2005, S. 408-417.

142 Olschowsky: Einvernehmen und Konflikt, 2005, S. $633 f$.

143 Zimmermann: Wechselnde Bündnisse, 2010, S. 87-89. Vgl. Schwarz: DDR und ČSSR, 2005, S. 409. Siehe auch: Pfeil: »Brücken der Freundschaft« zwischen der DDR und Polen, 2016, S. $166 f$. 
gegründete, zunächst gesamtdeutsche zivilgesellschaftliche Initiative »Aktion Sühnezeichen ${ }^{145}$

Eine anfänglich positive Resonanz in der Bevölkerung der DDR auf die SolidarnośćBewegung wurde bald begrenzt durch die Reaktivierung alter antipolnischer Vorurteile, unterstützt durch eine entsprechende Agitation der SED sowie einen wachsenden Missmut über die wirtschaftlichen Folgen für die DDR und ein generelles Unverständnis gegenüber dem starken Nationalismus und dem großen Einfluss der katholischen Kirche. ${ }^{146}$ Interessant ist, dass im Gegensatz zu den Oppositionellen in der VRP und der ČSSR die >ostdeutsche Frage in der DDR-Opposition eine vergleichsweise kleine Rolle gespielt hat, geschweige denn, dass diese die Oder-Neiße-Grenze in Frage stellte. War schon die Frage der Wiedervereinigung für die Opposition zunächst nicht von zentraler Bedeutung, so waren die ehemaligen deutschen Ostprovinzen und Flucht und Vertreibung noch weniger ein Thema. ${ }^{147}$

Die erste frei gewählte Regierung der DDR unter Lothar de Maizière bestätigte so im April 1990 mit der Volkskammer, von einem breiten Konsens getragen, zunächst noch vor und schließlich in einer gemeinsamen Erklärung mit dem Bundestag im Juni 1990 die Unverletzbarkeit der polnischen Westgrenze. ${ }^{148}$ In politischer Hinsicht schien die SED-PDS (heute: Die Linke) in vielen Punkten die offizielle DDR-Perspektive zur Erinnerung an Flucht und Vertreibung übernommen zu haben, was sich bei den späteren Diskussionen unter anderem in einer beständigen Gegnerschaft zum Bund der Vertriebenen zeigt. Damit konnte ein auch wechselseitig wirkender Anschluss an den linksliberalen Diskurs in Westdeutschland gefunden werden, der sich verstärkt den Perspektiven der östlichen Nachbarländer öffnete. ${ }^{149}$ Die >Expansion $<$ des BdV in die neuen Bundesländer nach 1989 verlief schließlich weitgehend geräuschlos und erwirkte keine Revitalisierung des Verbandes, auch wenn über zwei Millionen Bürger der neuen Bundesländer den Vertriebenenstatus beantragten. ${ }^{150}$

\subsection{Volksrepublik Polen}

Am 22. Juli 1944 übernahmen die neuen polnischen Machthaber von Stalins Gnaden offiziell die Autorität in den von der Roten Armee eroberten Gebieten Polens westlich der von Stalin 1939 annektierten polnischen Ostgebiete. Sie waren von Beginn an gefordert, die Vertreibung der nicht-geflohenen deutschen Bevölkerung aus den polnischen und künftig polnischen Gebieten zu rechtfertigen. Dies geschah vor dem Hintergrund,

145 Olschowsky: Versöhnungsinitiativen, 2009, S. 317.

146 Holzer: Solidarność, 2014, S. 166.

147 Olschowsky: Der wenig vertraute Nachbar-Das Bild Polens in der DDR, 2009, S. 148. Olschowsky: Versöhnungsinitiativen, 2009, S. 319f. Vgl. Vilímek: Zu den Ursachen des Regimezusammenbruchs in der Tschechoslowakei und der DDR im Jahr 1989, 2010, S. 186.

148 Olschowsky: Versöhnungsinitiativen, 2009, S. 327. Vgl. Vetter: Der Preis des Wandels, 2019, S. $27 f$.

149 Siehe: Schwartz: Vertriebene im doppelten Deutschland, 2008, S. 139f. Vgl. auch: Hahn; Hahn: Die Vertreibung im deutschen Erinnern, 2010, S. 573.

150 Vgl. Danyel: Der vergangenheitspolitische Diskurs in der SBZ/DDR 1945-1989, 2005, S. 181. 
dass in der gesamten polnischen Gesellschaft die nationalsozialistische deutsche Besatzungsherrschaft als »existenzielle Bedrohung« wahrgenommen und erlebt wurde, das Land in Trümmern lag, seine Ostprovinzen verloren hatte und Hunderttausende an Menschenverlusten zu beklagen waren. Ein entsprechend hartes Vorgehen gegenüber den Deutschen traf auf breite Zustimmung. ${ }^{151}$

Die Präsenz von Deutschen nahm durch die weiteren >Aussiedlungen stetig $a b$, ebenso wie die neuen Autoritäten mit großer Energie alle Erinnerungen an die deutsche Zeit - vor allem Straßennamen, Schilder und Denkmäler - zu beseitigen versuchten, um sie durch polnische zu ersetzten. ${ }^{152}$ Nicht nur diese Symbole sollten entfernt werden, auch der Gebrauch der deutschen Sprache wurde sowohl in der Öffentlichkeit als auch im privaten Umfeld bis in die 1960er Jahre hinein verboten und in den Grenzgebieten bis in die 1980er Jahre kein fremdsprachlicher Deutschunterricht angeboten. ${ }^{153}$ Trotzdem dauerte es teilweise Jahrzehnte, bis die Bevölkerung die übernommenen Gebiete, Städte und Wohnungen als die ihren anerkannte. Das Verhältnis zur nie offiziell anerkannten deutschen Minderheit blieb angespannt. Durch eine Anerkennung fürchtete man eine Infragestellung der territorialen Nachkriegsordnung. ${ }^{154}$

Die Begründung der neuen polnischen Führung für die Entfernung der Deutschen lässt sich nach Hans-Jürgen Bömelburg in vier Argumenten zusammenfassen: Erstens seien die allermeisten Deutschen bereits 1945 geflohen, zweitens seien die >Aussiedlungen in Anbetracht der deutschen Verbrechen der Kriegszeit eine notwendige und konfliktentschärfende Lösung, drittens seien für die Entscheidung zur Aussiedlung allein die Siegermächte verantwortlich, die gemäß dem Wortlaut des Potsdamer Abkommens von den polnischen Autoritäten »ordentlich« und »human« durchgeführt wurden und viertens sei die polnische Bevölkerung in altpolnische Gebiete zurückgekehrt. Zudem wurde jede Verantwortung für Gewalttaten und Verbrechen gegen Deutsche oder derartige Vorkommnisse überhaupt rundheraus bestritten. ${ }^{155}$

Den ethnisch homogenen Nationalstaat verstanden die Kommunisten als Teil der Modernisierung in Abgrenzung zu den vormaligen Vielvölkerreichen, oder wie es im Protokoll einer Sitzung der PZPR vom Mai 1945 heißt: „Wir müssen sie hinauswerfen, da alle Länder auf nationalen, nicht multinationalen Grundlagen errichtet sind. ${ }^{156}$ In der polnischen Gesellschaft wurden die Aussiedlungen aber »nur als Randerscheinung gesehen, als Entfernung eines ethnisch und historisch fremden Elements aus angestammten polnischen Gebieten. ${ }^{157}$ Diese Argumentationen waren ebenso wie die Vorstellung von einem »Akt der historischen Gerechtigkeit« anschlussfähig an die Gefühlslage und Einschätzung vieler Polen. ${ }^{158}$ Dies dürfte in geringerem Umfang für die >Repatrianten aus den polnischen kresy gegolten haben, die über ihren Verlust schweigen

151 Vgl. Lotz: Das (Re-)Arrangieren von Feindbildern, 2007, S. 159.

152 Service: Germans to Poles, 2013, S. 346.

153 Matthei: Die Massenumsiedlungen und das Bild der Deutschen, 2006, S. 87.

154 Koszel: Die polnische Deutschlandpolitik in den Jahren 1970-1990, 2001, S. $915 f$.

155 Bömelburg: Gestörte Kommunikation, 2005, S. 38. Vgl. für eine ähnliche Systematisierung: Borodziej: Anmerkungen zur deutschen und polnischen Historiographie, 2007, S. $184 \mathrm{f}$.

156 Zitiert nach: Beer: Flucht und Vertreibung der Deutschen, 2011, S. 77.

157 Madajczyk: Die Rolle antideutscher Instrumentalisierungen in Polen, 1944-1989, 2007, S. 135.

158 Ebd., S. $134 f$. 
mussten. ${ }^{159}$ Auch die Anerkennung der Oder-Neiße-Grenze als gerechtfertigt bedeutete nicht, dass diese »auch als sicher und nachhaltig « empfunden wurde. ${ }^{160}$ Sinnbild für die volkspolnische Perspektive auf die >Aussiedlungen ist eine dokumentarische Szene an einem Breslauer Bahnhof aus der Polska Kronika Filmowa von 1946 mit dem Titel »Die Deutschen verlassen Polen«:

»Menschengruppen laden ihr keineswegs kleines Cepäck auf die Cüterwaggons, die für den Personentransport angepasst worden sind, wobei alle - vermutlich auf Aufforderung des Kameramanns - in die Kamera lächeln. Einige winken freundlich. Der Sprecher [...] stellt empathisch fest: >Wir wollen keine Rache. Wir hegen keinen Croll. Gute Fahrt - wir verabschieden uns für immer! «« ${ }^{161}$

Diese Szene steht für die Vorstellung der zivilen Aussiedlung der Deutschen: Sie können quasi unbehelligt ihre (vielen) Sachen packen und noch mit einem Lächeln auf dem Gesicht in ihre wirkliche Heimat ausreisen. Auch die Polen hegen in dieser Szenerie aus dem Jahre 1946 bereits keine Rachegefühle mehr. Die Vorstellung einer geordneten Aus- und Umsiedlung soll zudem zeigen, dass die Polen ganz andere Methoden als die NS-Besatzer verwenden und es keinerlei Grund gibt, sich für die Durchsetzung dieses Aktes zu schämen, dass man sich im Gegenteil für diese humane Durchführung loben kann. ${ }^{162}$ Das hier gezeichnete Bild steht in großem Kontrast zu den im Kapitel 3 diskutierten Verhältnissen.

Die Erzählung über den Zweiten Weltkrieg und die Aussiedlung der Deutschen bei der Etablierung des kommunistischen Staates ermöglichte es zudem, sich auf Seiten der Sieger zu verorten, die nicht nur die Überwindung des alten Feindes Deutschlands und die >Wiedergewinnung` polnischer Gebiete ermöglicht, sondern Polen auch ein modernes und gerechtes Gesellschaftssystem gebracht haben. Das Zusammenwirken von sozialer Revolution und dem Bedürfnis nach Sicherheit verdichtete sich in den polnischen Westgebieten, in denen der spätere Parteichef der PZPR Władysław Gomułka eine besondere Verbindung des Volkes mit dem System erwartete. Die Ablehnung der Deutschen ebenso wie die Furcht vor diesen war ein entscheidender Kitt für das labile Verhältnis zwischen Bevölkerung und kommunistischer Staatsmacht. ${ }^{163}$

Dieses Narrativ diente nicht nur der Legitimation, sondern auch der Diskreditierung Zwischenkriegspolens und der bürgerlichen Exilregierung in London sowie konservativer Kräfte im Land. Diese seien nicht nur entscheidend mitverantwortlich für die Niederlage Polens 1939 gewesen und hätten sich der Kollaboration mit den Deutschen schuldig gemacht, sondern gefährdeten durch die Nichtanerkennung der polnischen Ostgrenze die neu geschaffene Friedensordnung und damit direkt oder indirekt die

159 Vgl. Matthei: Die Massenumsiedlungen und das Bild der Deutschen, 2006, S. 89.

160 Hinrichsen: Oder-Neisse-Grenze, 2015, S. 510.

161 Król: Das Bild des ethnischen Deutschen im polnischen Film, 2006, S. 367. Polska Kronika Filmowa (10) (Minute 00:16-03:05): Niemcy opuszczają Polskę. 1946.

162 Król: Das Bild des ethnischen Deutschen im polnischen Film, 2006, S. $367 f$

163 Dmitrów: Polen, 2005, S. 198. Madajczyk: Die Rolle antideutscher Instrumentalisierungen in Polen, 1944-1989, 2007, S. 132-134. Opiłowska: Die Aneignung des fremden Raumes, 2013, S. 241, 245. Vgl. Kap. 3.6, S. $129 f$ 
polnischen Westgebiete. ${ }^{164}$ Abgesehen von der politischen Isolation nach 1945 war die bürgerliche Exilregierung tatsächlich in dem Dilemma gefangen, die neue Westgrenze anzuerkennen, die östliche aber nicht. Bürgerliche Konservative und Nationalisten, darunter viele >Westforscher /er Zwischenkriegszeit, wurden von den Kommunisten schließlich pragmatisch zur Mitarbeit aufgefordert. Dies war durchaus erfolgreich, sahen doch viele Polen den Status Quo eines kommunistischen Systems als mittelfristig unausweichlich an, die territoriale Gestaltung und Absicherung Polens hingegen als darüber hinausreichendes Projekt, bei dem die Mitwirkung notwendig sei. ${ }^{165}$

Das Postulat der >Rückkehr in uralte polnische Gebiete<, die >Wiedergewonnenen Gebiete , beruhte auf dem von Gomulka folgendermaßen zusammengefassten Piastenmythos:

»Die Ceschichte hat uns heute die einzige Chance gegeben, Polen in den piastischen Grenzen wiederzubeleben - Wir kehren in unsere Cebiete an der Oder, der Lausitzer Neiße und am Baltikum zurück. Wir liquidieren das Leid, welches uns vor Jahrhunderten durch die Gier der Kreuzritter angetan wurde. Wir liquidieren den Germanismus, der tief in diesen Cebieten verwurzelt ist. Wir geben sie dem Polentum zurück. $^{166}$

Die piastische Dynastie des frühen Hochmittelalters steht im nationalpolnischen Diskurs für die Westorientierung Polens. ${ }^{167}$ Das mittelalterliche Staatswesen umschloss zeitweise ungefähr die polnischen Grenzen im Jahr 1945, das heißt mit einer Grenze an der Oder, dem Besitz von Pommern, und damit einem breiten Zugang zur Ostsee, sowie die schlesischen Gebiete. Auch nach Osten reichte das Gebiet nicht viel weiter hinaus als 1945. Freilich ist die mittelalterliche, dynastische Herrschaft über dünn besiedelte Gebiete nicht mit dem modernen Territorialstaat vergleichbar, aber diese historische Diskussion spielte keine Rolle. Im Gegenteil: Die These der urpolnischen Gebiete wurde in dem gängigen Ausspruch verdichtet, den der polnische Kardinal Stefan Wyszyński anlässlich der Feierlichkeiten zum 20. Jubiläum der >Befreiung«Breslaus in Hinblick auf seine frühmittelalterliche polnische Geschichte äußerte: »Die Steine sprechen Polnisch «. ${ }^{168}$ Solche kirchlich-nationalen Positionen waren für die Kommunisten anschlussfähig und auf dieser Grundlage wurde ein einmaliger »künstlicher Raum [...] zwischen nationalistischer Reinkarnation des frühmittelalterlichen polnischen Staatswesens und kommunistischen Sieges- und Fortschrittsgedanken « konstruiert. ${ }^{169}$

In diesem Narrativ tauchen die Deutschen vor allem als hinterhältige Kreuzritter und Invasoren auf. Dass die schlesischen Herzogtümer auf friedlichem Wege in den

164 Vgl. Fend: Vom Ende des Zweiten Weltkrieges bis zum Beginn der »Wende«, 2016, S. 75f. Vgl. auch: Peters: Revolution der Erinnerung, 2016, S. 73.

165 Madajczyk: Die Rolle antideutscher Instrumentalisierungen in Polen, 1944-1989, 2007, S. 132. Strauchold: Die »Wiedergewonnenen Cebiete«, 2005, S. $310 f$.

166 Zitat und Übersetzung nach: Halicka: Polens Wilder Westen, 2013, S. $293 f$.

167 Neben der Annahme des katholischen Christentums und der Integration in den westeuropäischen Kulturraum wird im nationalkonservativen Diskurs Polens auch die Ablehnung der slawischen Orthodoxie betont.

168 Kuroczyński: Die Medialisierung der Stadt, 2011, S. $131 f$.

169 Matthei: Die Massenumsiedlungen und das Bild der Deutschen, 2006, S. 89. Vgl. Strauchold: Die »Wiedergewonnenen Cebiete«, 2005, S. 309-316. 
>deutschen Kulturkreis` übergingen, wurde ebenso ausgeblendet wie der Ruf der polnischen Fürsten nach deutschen Siedlern zur weiteren Entwicklung des Landes sowie der Hilferuf an den Deutschen Orden zur Bekämpfung der prußischen Heiden. Teil dieses Konzeptes ist die Vorstellung, dass die deutsche Präsenz in diesen Gebieten oberflächlich und begrenzt auf Ausbeutung und Vernichtung gewesen sei. ${ }^{170}$ Das auf polnischer Seite vorhandene Bild des mordenden Kreuzritters fand im deutschen Diskurs des 19. und 20. Jahrhunderts sein Spiegelbild im deutschen Kulturträger im archaischen Osten. Tatsächlich gingen die polnischen Kommunisten so weit, von einer historischen Mission zu sprechen, die seit Jahrhunderten den Polen auferlegt war: die Rückeroberung und die Rückkehr in die urpolnischen Gebiete. Sie sahen und feierten sich als Vollzieher dieses Auftrages und versuchten, damit einen heldenhaften und legitimen Platz in der polnischen Geschichte zu beanspruchen. ${ }^{171}$ Offiziell wurde das Argument vermieden, dass es sich um eine Entschädigung für die verlorenen polnischen Ostgebiete handelte, denn ein solcher Handel wäre der polnischen Bevölkerung propagandistisch schwer zu vermitteln gewesen und hätte zugleich das Bündnis mit der Sowjetunion wegen deren weitgehend tabuisierter Übernahme der kresy diskreditiert. Sowohl in Deutschland als auch in der VRP verloren diese Narrative spätestens mit der Entspannungspolitik der 1970er Jahre an Bedeutung. ${ }^{172}$ Olaf Matthei schreibt, dass Piastenmythos und nationalistische Rhetorik die strukturelle Schwäche der kommunistischen Führung bloßlegten, der es nur auf diesem Wege und auch nur eingeschränkt gelungen sei, »in der überwiegend konservativ-katholischen Bevölkerung Vertrauen zu wecken. ${ }^{173}$

Der Piastenmythos war zugleich ein Gegenentwurf zur vermeintlich fatalen Ostausrichtung der Jagiellonendynastie und ihres Vielvölkerreiches, die im strukturellen Konflikt mit dem Moskowiter Reich stand. Aus nationalkommunistisch sowjetischer und polnischer Perspektive war diese dafür verantwortlich, dass sich die slawischen Völker in einem Kampf gegeneinander aufrieben und damit ein langanhaltender Hass zwischen den >Brudervölkern gesät wurde. Die Rückkehr der Polen in ihr >angestammtes Gebiet ermöglichte es nun Polen, im Gegensatz zur Zwischenkriegszeit, in seinen 'historischen Grenzen $\measuredangle$ u stehen, die nur in einer gemeinsamen »Waffenbrüderschaft des Polnischen Heeres mit der Roten Armee« sowie im Bündnis mit den Sowjetrepubliken und der Tschechoslowakei durch den »Bau eines großen slawischen Walls« gegen den »Drang des germanischen Imperialismus« verteidigt werden könnten. ${ }^{174}$ Hinter dieser Rhetorik verbarg sich auch Stalins Plan, Polen und die Tschechoslowakei dauerhaft in eine sowjetisch dominierte Verteidigungsallianz zu zwingen. Tatsächlich war bis in die kommunistische Führung Polens hinein die nicht völlig unbegründete Angst stets präsent, ${ }^{175}$ dass sich Stalin oder seine Nachfolger erneut mit den Deutschen auf Kosten Polens einigen könnten. ${ }^{176}$ Die reale ebenso wie die propagierte Angst vor den Deutschen erfüllte neben der Legitimierung des Regimes und des Bündnisses mit der

170 Matthei: Die Massenumsiedlungen und das Bild der Deutschen, 2006, S. 90.

171 Vgl. ebd.

172 Vgl. Traba; Żytyniec: Verlorene Heimat/Wiedergewonnene Gebiete, 2015, S. 727.

173 Matthei: Die Massenumsiedlungen und das Bild der Deutschen, 2006, S. 90.

174 Manifest des Polnischen Komitees der Nationalen Befreiung vom 22. Juli 1944.

175 Koszel: Die polnische Deutschlandpolitik in den Jahren 1970-1990, 2001, S. 920.

176 Madajczyk: Die Rolle antideutscher Instrumentalisierungen in Polen, 1944-1989, 2007, S. 137. 
Sowjetunion zudem den Zweck der innenpolitischen Repression von Gegnern, denen man eine Zusammenarbeit mit diesen oder aber eine nachhaltige Schwächung gegenüber diesen unterstellte. ${ }^{177}$ Der Hitler-Stalin-Pakt, die Okkupation Ostpolens durch die Sowjetunion und das Katyń-Massaker wurden aus der Öffentlichkeit vollständig verdrängt. ${ }^{178}$

Eine erste Abschwächung der Rhetorik setzte 1949 ein, als sich mit der Gründung der DDR ein deutscher Staat an der Seite Polens in einem Bündnis unter Führung der Sowjetunion befand. Mit dem bilateralen Görlitzer Abkommen von 1950, das die Grenze zwischen der DDR und Polen bestätigte, war auf offizieller Ebene eine strittige Frage beseitigt. Das Bild der Deutschen teilte sich rhetorisch: Von nun an gab es ein $>$ fortschrittliches« Deutschland, welches jedem Revanchismus abgeschworen hatte und eine sichere Friedensgrenze gewährleistete und die Bundesrepublik als Hort des Revanchismus, in dem kapitalistische Kriegstreiber die Vertriebenen in ihrem Elend beließen und diese weiter gegen die Nachbarn hetzen konnten. ${ }^{179}$ Die Nicht-Anerkennung der polnischen Westgrenze durch die Bundesrepublik sowie das von allen Bundestagsparteien lange vertretene >Recht $<$ der Vertriebenen auf ihre Heimat boten allerdings auch so weiterhin genügend Angriffsflächen. Eine in Polen verbreitete Fotografie jener Zeit zeigte Konrad Adenauer als Ehrenritter des Deutschen Ordens. Obwohl dieser seit 1929 eine zivile, geistliche katholische Ordensgemeinschaft war, fügte sich dieses Bildmaterial gut in den behaupteten erneuten Drang der jungen Bundesrepublik nach Osten. ${ }^{180}$

Der stalinistischen Phase folgte in Polen mit der Machtübernahme des zwischenzeitlich in Ungnade gefallenen Nationalkommunisten Gomułka 1956 zunächst eine kurze Phase der scheinbaren Liberalisierung. Die nationalkommunistische Rhetorik wurde aber bereits Ende der 1950er Jahre schärfer. Klaus Bachmann spricht von »einer Art Symbiose zwischen zwei totalitären Ideologien «, die sich aus faschistischen Ansätzen der Zwischenkriegszeit und dem Sowjetkommunismus zusammensetzte. ${ }^{181}$ Borodziej schreibt etwas zurückhaltender von einer »Verlagerung des ideologischen Schwerpunktes vom international-marxistischen auf den nationalen. ${ }^{182}$ Das antideutsche Element wurde nach der Festigung des Systems weniger permanent und eher bei Bedarf ausgespielt. ${ }^{183}$ Der Prozess der Abkehr von kommunistischer Rhetorik wurde in den 1960er Jahren soweit abgeschlossen, als »die polnische Nation unweigerlich [...] [zum] beinahe unangefochtenen integrativen Leitmotiv aufstieg ${ }^{184}{ }^{184}$ Die staatlich forcierten antisemitischen Ausschreitungen im März 1968 waren ein trauriger Höhepunkt dieser nationalistischen Eskalation. ${ }^{185}$ Der vermeintliche Pioniergeist in den polnischen Westgebieten war derweil einer zunehmenden Desillusionierung gewichen, die generelle Stagnation

177 Dmitrów: Polen, 2005, S. 200.

178 Ebd., S. 203.

179 Vgl. Madajczyk: Die Rolle antideutscher Instrumentalisierungen in Polen, 1944-1989, 2007, S. 137.

180 Vgl. Adenauer und Polen. DasErste.de. 2004.

181 Bachmann: Nationalistische Einstellungen in der Volksrepublik Polen, 2013, S. 261.

182 Borodziej: Geschichte Polens im 20. Jahrhundert, 2010, S. 306.

183 Madajczyk: Die Rolle antideutscher Instrumentalisierungen in Polen, 1944-1989, 2007, S. 138.

184 Peters: Revolution der Erinnerung, 2016, S. 46.

185 Ebd. S. 90. 
jenseits der urbanen Zentren war hier durch die weiterhin für die Bevölkerung unsichere Lage der Grenze und die dadurch gehemmte Investitionsbereitschaft in den zugewiesenen Besitz besonders stark zu beobachten. ${ }^{186}$ Borodziej zieht einen Auslandspolen heran, der die Gegend besucht und eine »allgemeine Verwahrlosung und zivilisatorischen Abstieg « konstatiert. ${ }^{187}$ Die späte Gomułka-Phase endete für den Parteichef noch mit einem letzten Triumph in Form der Anerkennung der Grenze durch die Bundesrepublik. ${ }^{188}$ Nach seinem Sturz folgte unter Edward Gierek ähnlich dem kurz darauf folgenden Machtwechsel in der DDR eine Hinwendung zur Konsumgesellschaft westlicher Prägung und einem kreditfinanzierten wirtschaftlichen Aufbruch.

In die 1960er Jahre fielen auch erste bedeutende zivilgesellschaftliche Versöhnungsgesten und Versuche, einen neuen Dialog zwischen Deutschen und Polen zu schaffen. Das bis heute denkwürdigste Ereignis war im November 1965 der Brief der polnischen Bischöfe, den diese am Ende des Zweiten Vatikanischen Konzils anlässlich der Einladung zur 1000-Jahrfeier der Christianisierung Polens ihren deutschen Amtsbrüdern übergaben. In diesem nahmen sie Bezug auf den Zweiten Weltkrieg und die Zwangsumsiedlungen sowie das gegenseitige Leiden und formulierten die bis heute immer wieder zitierten Worte:

»Und wir bitten Sie, unsere Grüße und Dankesworte an die deutschen Brüder im Evangelium zu richten, die mit Ihnen und mit uns zusammenarbeiten, um eine Lösung für unsere Schwierigkeiten zu finden.

In diesem höchst christlichen und sehr menschlichen Geist reichen wir Euch, hier auf den Bänken des endenden Konzils sitzend, unsere Hände und wir gewähren Vergebung und bitten um diese. « $^{189}$

Mit dieser Geste war auch der Wunsch verbunden, dass die deutschen Amtsbrüder sich für eine Anerkennung der neuen Grenze aussprechen sollten. ${ }^{190}$ Die Antwort der deutschen Bischöfe wurde vor allem in Polen als enttäuschend wahrgenommen; ${ }^{11}$ umso schärfer war die Reaktion der kommunistischen Machthaber und

186 Borodziej: Geschichte Polens im 20. Jahrhundert, 2010, S. 339.

187 Ebd.

188 Ebd., S. $316 f$.

189 »I prosimy Was też, abyście przekazali nasze pozdrowienia i wyrazy wdzięczności niemieckim Braciom Ewangelikom, którzy wraz z Wami i z nami trudzą się nad znalezieniem rozwiązania naszych trudności. W tym jak najbardziej chrześcijańskim, ale i bardzo ludzkim duchu, wyciągamy do Was, siedzących tu, na ławach kończącego się Soboru, nasze ręce oraz udzielamy wybaczenia i prosimy o nie.« Konferencja Episkopatu Polski: Orędzie biskupów polskich do biskupów niemieckich, 1965. Bömelburg weist daraufhin, dass der Brief mitnichten als (politisches) Eingeständnis polnischer Verantwortung missverstanden werden kann (auch wenn dies häufig so gesehen wird), sondern er vielmehr in (s)einem theologischen Kontext zu verstehen sei: Bömelburg: Gestörte Kommunikation, 2005, S. 39.

191 Vgl. Felsch; Latkowska: Brief der (polnischen) Bischöfe und Willy Brandts Kniefall, 2012, S. 396. Borodziej spricht bei dem Antwortschreiben von einem »nichtssagenden Brief«: Borodziej: Ceschichte Polens im 20. Jahrhundert, 2010, S. 310. Langguth, Oberreuter und Wolffsohn sehen hingegen unter Bezug auf den polnischen Bischof Alfons Nossol die Antwort sehr wohl als eine wichtige Geste der Verständigung und Aussöhnung: Langguth; Oberreuter et al.: Zum Verständnis der deutschen Polenpolitik, 2011, S. 56. 
großer Teile der Gesellschaft. ${ }^{192}$ Abgesehen davon, dass die Regierung keine kirchliche Parallel-Außenpolitik sowie zu dem Zeitpunkt auch keine Annäherung an einen der tatsächlichen und propagandistischen Hauptfeinde im Westen wünschte, konnte das Ereignis nationalistisch sowie für eine Verschärfung der (bald gescheiterten) antikirchlichen Politik genutzt werden. ${ }^{193}$ Den meisten Polen jener Zeit schien es fragwürdig und empörend, sich bei den Deutschen entschuldigen zu müssen, sei es wegen persönlicher Erlebnisse in der Besatzungszeit oder durch die bereits zwanzig Jahre andauernde Präsenz undifferenzierter antideutscher Feind- und Geschichtsbilder in Schule, Politik und Medien. ${ }^{194}$ Auch wenn die grundsätzliche Verständigungsbereitschaft bei der Bevölkerung vorhanden war, erwartete man eine Initiative von deutscher Seite. ${ }^{195}$ Adam Krzemiński ruft zudem die emotionale Bedeutung in Erinnerung: Die Nicht-Anerkennung der Grenze durch die Bundesrepublik habe für die polnische Bevölkerung eine gegenwärtig nurmehr schwer nachvollziehbare Kränkung und das "Angewiesensein auf ein provisorisches Leben, auf sowjetische Garantien und die Solidarität der Ostblock-Staaten« und damit eine schwere Demütigung bedeutet. Eine Anerkennung der Grenze verband sich mit der »Hoffnung auf Normalität«, auf welche die in den Grenzgebieten lebenden Polen schließlich noch lange warten mussten. ${ }^{196}$ In der Nachgeschichte wird dem Hirtenbrief ähnlich Brandts Kniefall schließlich eine »ungeheure Rolle« für die Versöhnung zwischen Polen und der Bundesrepublik zugesprochen, die aber erst nach Jahren ihre volle Wirkung entfaltete. ${ }^{197}$

Mit der sozialliberalen Koalition in der Bundesrepublik und der Abkehr der SPD von ihren ehemaligen vertriebenenpolitischen Grundsätzen differenzierten sich für die VRP nicht mehr nur DDR und Bundesrepublik, sondern auch letztere selber in vergleichsweise fortschrittliche und nach wie vor revisionistische Kräfte, die zum ersten bei den Sozialdemokraten und zum zweiten in der CDU und den Vertriebenenverbänden gesehen wurden. Die faktische Anerkennung der Oder-Neiße-Grenze sowie Brandts ikonischer Kniefall vor dem Denkmal des Warschauer Ghetto-Aufstandes und die wachsende ökonomische und politische Verflechtung ließen das Feindbild des westdeutschen Revanchisten schwächer werden. ${ }^{198}$ Dies galt verstärkt nach dem gescheiterten Misstrauensvotum von 1972, da kaum mehr zu übersehen war, dass die Vertriebenenverbände in der Bundesrepublik ihren Zenit überschritten hatten. Dies führte zugleich $\mathrm{zu}$ einer differenzierteren Berichterstattung über die Vertriebenenverbände bis hin zu

192 Michnik: Trauma, Memory, and Justice, 2011, S. $209 f$.

193 Vgl. Madajczyk: Die Rolle antideutscher Instrumentalisierungen in Polen, 1944-1989, 2007, S. $138 f$. Vgl. auch: Felsch; Latkowska: Brief der (polnischen) Bischöfe und Willy Brandts Kniefall, 2012, S. 399.

194 Vgl. Borodziej: Geschichte Polens im 20. Jahrhundert, 2010, S. 310.

195 Madajczyk: Die deutsche Reaktion auf den Brief der Bischöfe in der polnischen Rezeption, 2009, S. 206.

196 Adam Krzemiński im Gespräch mit Basil Kerski: Kerski: Willy Brandt in Warschau, 2010/11, S. 31.

197 Madajczyk: Die Rolle antideutscher Instrumentalisierungen in Polen, 1944-1989, 2007, S. 139.

198 Peters: Revolution der Erinnerung, 2016, S. 57. Vgl. Madajczyk: Die Rolle antideutscher Instrumentalisierungen in Polen, 1944-1989, 2007, S. 142. 
empathischen Artikeln über deutsche Opfer des Krieges. ${ }^{199}$ Diese in der katholischen Wochenzeitung Tygodnik Powszechny erschienenen Beiträge dürfen aber nicht darüber hinwegtäuschen, dass sich das insgesamt verbesserte Verhältnis zur Bundesrepublik in der Presse spiegelte, diese aber stets den jeweils gegenwärtigen politischen Zielsetzungen der PZPR untergeordnet blieb. ${ }^{200}$ Brandts Geste versuchte man beispielsweise in der volkspolnischen Presse möglichst wenig Beachtung zu schenken, dennoch wurde sie bekannt und für viele Polen zu dem lang erhofften Symbol einer gewandelten Bundesrepublik. ${ }^{201}$

Die gesellschaftliche Modernisierung unter Edward Gierek definierte sich anstelle aggressiver Abgrenzung verstärkt über eine integrative und positive Identität. ${ }^{202}$ Diese Entwicklungen verbunden mit einem neuen Arbeitsklima zwischen Bundesrepublik und VRP auf Regierungsebene führten aber in der grundsätzlichen Bewertung des historischen Geschehens zu keinerlei oder kaum Veränderungen. Ebenso blieben in der Alltags- und Museumskultur die alten Stereotype stark präsent, auch wenn die zunehmende Reisetätigkeit zwischen DDR und VRP ebenso wie aus der Bundesrepublik zu neuen positiven Alltagserfahrungen führten. ${ }^{203}$ Das immer weniger wirksame Feindoder Angstbild des revanchistischen Deutschen wurde von der PZPR-Führung in den Hintergrund gestellt, aber nicht beseitigt. Nach Elżbieta Opiłowska lag dies daran, dass ihr schlicht ein Ersatz für den legitimierenden und integrativen Mythos der deutschen Gefahr fehlte. ${ }^{204}$ Dies änderte nichts daran, dass in der Hochphase der Entspannungspolitik 1975 in einer repräsentativen Umfrage nunmehr nur 13 Prozent der Polen angaben, mit Deutschland eine Gefahr zu assoziieren (was 1969 noch 52 Prozent taten). ${ }^{205}$

In den Oppositionskreisen der 1970er Jahre wuchs langsam ein neues Vertrauen zum veränderten (West)Deutschland heran, auch wenn viele ihrer Vertreter weiterhin davon ausgingen, dass die Teilung Deutschlands aus polnischer Sicht zu befürworten sei. Grundsätzlich ist zu beachten, dass in der »organisierten Opposition « progressive Vertreter »überrepräsentiert waren « und konservative Stimmen, die »sich der Vision eines homogenen polnischen Volkes ohne nationale Minderheiten verbunden « fühlten und »wesentlich skeptischer gegenüber Deutschland « eingestellt waren, gesamtgesellschaftlich nur scheinbar in der Minderheit waren. ${ }^{206}$ Wesentlich wichtiger als die Frage der Vertreibung der Deutschen war für die Opposition die Diskussion der tabuisierten Elemente der polnisch-sowjetischen Geschichte und eine kritische Reflektion des stalinistischen Polen und der Rolle des Landes im Zweiten Weltkrieg. Die meisten der Autoren zielten bei diesen Themen aber weniger auf Selbstkritik als auf den Widerspruch

199 Jakubowska: Der Bund der Vertriebenen in der Bundesrepublik Deutschland und Polen, 2012, S. 217-219.

200 Jarząbek: Fortsetzung oder Veränderung? 2015, S. 369.

201 Kerski: Willy Brandt in Warschau, 2010/11, S. 34.

202 Madajczyk: Die Rolle antideutscher Instrumentalisierungen in Polen, 1944-1989, 2007, S. $140 \mathrm{f}$.

203 Olschowsky: Versöhnungsinitiativen, 2009, S. 319.

204 Opiłowska: Die Aneignung des fremden Raumes, 2013, S. 245.

205 Bachmann: Nationalistische Einstellungen in der Volksrepublik Polen, 2013, S. 269.

206 Madajczyk: Die Rolle antideutscher Instrumentalisierungen in Polen, 1944-1989, 2007, S. 143. 
zum offiziellen Geschichtsbild und die richtige Darstellung der polnischen Nationalgeschichte. ${ }^{207}$

Während der Streikbewegungen der Solidarność 1980/81 ließ sich trotz fortgesetzter Versuche des Regimes das Angstbild der Deutschen kaum mehr reaktivieren. ${ }^{208}$ Für die streikenden Arbeiter, die Intellektuellen und für die Kirche war der Gegner die kommunistische Regierung und darüber hinaus die Sowjetunion. Aus Deutschland fürchtete man wenig, außer einer für die volkspolnischen Machthaber vorteilhaften Gleichgültigkeit beziehungsweise neutralen Haltung gegenüber der Solidarność. Und tatsächlich sah die sozialliberale Koalition unter Helmut Schmidt die Solidarność-Bewegung skeptisch, wollte man doch die aufgebauten Arbeitsbeziehungen zur kommunistischen Regierung nicht verschlechtern. ${ }^{209}$ Der Ausrufung des Kriegsrechts im Winter 1981 folgte dann später die Begründung des Generals und Ministerpräsidenten Wojciech Jaruzelski, dass er eine gewaltsame Besetzung der Volksrepublik durch die Rote Armee und den Warschauer Pakt unbedingt verhindern wollte. ${ }^{210}$

Die von der Solidarność wenigstens temporär geschaffenen Freiräume ebenso wie die fortbestehende illegale Presse und ein Untergrundbuchmarkt, der sogenannte zweite Umlauf [drugi obieg], schufen auch den Raum für selbstkritische Auseinandersetzungen mit der deutsch-polnischen Vergangenheit. Berühmt ist Jan Józef Lipskis 1981 erschienene umkämpfte Abrechnung mit dem extremen polnischen Nationalismus:

»Der Appell des polnischen Episkopats an den deutschen beinhaltet vor allem ein Problem, das sich nicht umgehen läßt, wenn man dem Christentum treu bleiben will: das Problem auch unserer Schuld gegenüber den Deutschen. Den Polen scheint eine solche Darstellung der Dinge unerträglich - und das ist auch unschwer zu verstehen, denn die Proportionen sind absolut unvergleichlich. Man darf sich aber nicht mit einer Bagatellisierung der eigenen Schuld abfinden, selbst dann nicht, wenn sie unvergleichlich viel geringer ist als die fremde. $\ll^{211}$

In weiteren Zeilen rechnet Lipski mit dem Piastenmythos, vermeintlicher Kollektivschuld und der angeblichen jahrhundertelangen deutsch-polnischen Erbfeindschaft ab. ${ }^{212}$ Diese primär aus dem progressiven Milieu der Opposition stammenden Stimmen waren jenseits der heftigen Bekämpfung durch die staatliche Presse aber weder innerhalb der Opposition unumstritten, noch konnten sie eine hegemoniale Stellung in der gesamtgesellschaftlichen Auseinandersetzung erlangen. ${ }^{213}$ Die Vertriebenenverbände in der Bundesrepublik missverstanden Lipskis Schrift als Bestätigung ihrer eigenen

207 Vgl. Peters: Revolution der Erinnerung, 2016, S. 91. Siehe auch: Matthei: Die Massenumsiedlungen und das Bild der Deutschen, 2006, S. $87 f$.

208 Madajczyk: Die Rolle antideutscher Instrumentalisierungen in Polen, 1944-1989, 2007, S. 144. Vgl. Matthei: Die Massenumsiedlungen und das Bild der Deutschen, 2006, S. 88.

209 Vgl. Olschowsky: Einvernehmen und Konflikt, 2005, S. 125.

210 Vgl. Urban: Tragische Gestalt der polnischen Geschichte. Süddeutsche Zeitung. 25.05.2014.

211 Lipski: Zwei Vaterländer - zwei Patriotismen, 1998, S. 192.

212 Ebd., S. 190-199.

213 Olschowsky: Einvernehmen und Konflikt, 2005, S. 310. Vgl. Gawin: Über den Nutzen und Schaden des historischen Revisionismus, 2006, S. 36-44. 
Position, wohingegen die progressive deutsche Öffentlichkeit »aus falsch verstandener Versöhnungsabsicht « den Text in Hinblick auf eine neue Nachkriegsordnung kritisch besprach. ${ }^{214}$ Die zunehmende konservativ-katholische Ausrichtung der Solidarność ebenso wie ein Fortleben des Nationalismus ließen diese selbstkritische Debatte über die eigene historische Rolle auf einen kleinen Zirkel beschränkt bleiben, deren mittelfristige Bedeutung als eine der Grundlagen für die deutsch-polnische Versöhnung dennoch nicht unterschätzt werden darf. ${ }^{215}$

Wojciech Jaruzelski äußerte in einem internen Exposé vom 12. Februar 1981, dass aufgrund der gewachsenen polnischen Schwierigkeiten revanchistische Kräfte auf eine weitere Verschuldung und Schwächung Polens hoffen würden, um so die alten deutschen Ostgebiete zurückkaufen zu können. ${ }^{216}$ Dennoch blieb die Rhetorik gegen die Bundesrepublik verhalten, zumal sich die Bundesregierung während der Niederschlagung der Solidarność mit Protesten auffällig zurückhielt. ${ }^{217}$ Interessanterweise hielten sich bis in die Führung der Volksrepublik hinein Gerüchte, dass selbst die DDR auf eine Grenzrevision spekulieren könnte und so dürfte auch das Drängen Honeckers auf einen Einmarsch in die Volksrepublik zur Niederschlagung der Solidarność wenig vertrauensbildend gewirkt haben. ${ }^{218}$

Trotz mangelhafter Resonanz wurde in der volkspolnischen Presse im Kampf gegen die Solidarność das Bild westdeutscher Einflussnahme bis hin zur Konstruktion einer Verschwörung von Revisionisten und Solidarność-Vertretern geschaffen. Die Betonung eines äußeren Feindes, der mit dem inneren Feind zum Schaden Polens kooperiert, konnte an ältere Narrative anknüpfen: Letztlich drohe die gezielte Schwächung Polens und eine Reaktivierung des deutschen >Dranges nach Osten $<$. So verzerrten volkspolnische Medien die Berichterstattung über Pro-Solidarność-Kundgebungen in Westdeutschland, in denen Polen und Deutsche vermeintlich eine Revision der Oder-NeißeGrenze gefordert hätten. Jaruzelski selbst hielt die Agitation bezüglich des deutschen Revisionismus für einen »Selbstläufer«. Das Bild der westlichen Verschwörung wurde verdichtet in einer Bildmontage der 1980er Jahre, in der einmal mehr das Bild Adenauers im Mantel des Deutschen Ordens gemeinsam mit Ronald Reagan als Cowboy und einem Kreuzritter unter dem Titel »Der Dritte Kreuzzug nach Polen« in Umlauf gebracht wurde. $^{219}$

Ansonsten verzichtete das Jaruzelski-Regime auf einen »Rollback« der Geschichtspolitik und es begann »mit der Untergrundopposition um den Titel des eifrigeren Sachverwalters der nationalen historischen Tradition zu wetteifern «, was bereits lange vor $1989 \mathrm{zu}$ einer weitgehend abschließenden Dekommunisierung der Erinnerungskultur

214 Olschowsky: Einvernehmen und Konflikt, 2005, S. 310.

215 Madajczyk: Die Rolle antideutscher Instrumentalisierungen in Polen, 1944-1989, 2007, S. 143. Vgl. Bömelburg: Cestörte Kommunikation, 2005, S. 41.

216 Koszel: Die polnische Deutschlandpolitik in den Jahren 1970-1990, 2001, S. 917f. Auch Olaszek konstatiert in Bezug auf interne Dokumente der PZPR Führung, dass man ein Wiederaufleben des westdeutschen Revanchismus fürchtete: Olaszek: Antideutsche Motive in der Propaganda gegen die Solidarność, 2013, S. $142 f$.

217 Koszel: Die polnische Deutschlandpolitik in den Jahren 1970-1990, 2001, S. 918.

218 Ebd. Vgl. Olschowsky: Einvernehmen und Konflikt, 2005, S. 310.

219 Olaszek: Antideutsche Motive in der Propaganda gegen die Solidarność, 2013, S. 142-151. 
mit der fortgesetzten Ausnahme in Hinblick auf die Sowjetunion führte. ${ }^{220}$ Erneut wurde der geschichtspolitische Fokus auf die innere und integrierende Mobilisierung der Bevölkerung gerichtet, auch wenn weiterhin »auf der Basis selbst geringfügigster Nachrichten über revanchistische Stimmen aus dem Umfeld westdeutscher Vertriebenenverbände« ein Bedrohungsszenario durch die Bundesrepublik konstruiert und aufrecht erhalten wurde. ${ }^{221}$ Die Geschichte wandelte sich zu dem zentralen Sinnhorizont des polnischen Spätsozialismus, »nachdem Zukunft und Gegenwart als Sinnhorizonte ausgefallen waren «. ${ }^{222}$ Die vermeintlich erreichten Errungenschaften der Volksrepublik wurden hervorgehoben und in einer pseudo-marxistischen und pseudo-historischen Argumentation mangels sonstiger größerer Erfolge »erklärten die Kommunisten kurzerhand die Schaffung eines ethnisch homogenen polnischen Nationalstaats an Oder und Ostsee zur zentralen historischen Errungenschaft der revolutionären Arbeiterbewegung in Polen. ${ }^{223}$ Florian Peters stellt schließlich in Bezug auf Jerzy Holzer fest, dass am Ende der Volksrepublik eine sonderbare Übereinstimmung von Gesellschaft und Regime im Verständnis Polens als auserwähltem Volk »zum gemeinsamen Nenner offizieller und alternativer Geschichtsbilder geworden« sei. ${ }^{224}$

In den oppositionellen Zirkeln intensivierte sich die Diskussion über das Verhältnis zu Deutschland und den Gegenstand von Flucht und Vertreibung. Man argumentierte rational für die Oder-Neiße-Grenze, die unabdingbar für die Existenz eines künftigen demokratischen Polens sei, zugleich wollte man nicht länger die Teilung Deutschlands verteidigen, habe Polen doch selbst schwer unter dem Schicksal seiner Teilungen gelitten. Zudem sei für die Versöhnung bedeutsam, dass sich die Polen bewusst und selbstbewusst des übernommenen und unter dem Sozialismus schwer beschädigten deutschen Kulturerbes annähmen. Außerdem verstärkte sich die Idee einer deutschpolnischen Schicksalsgemeinschaft, die sich über eine nun als gemeinsam verstandene Lokal- und Regionalgeschichte herausgebildet habe. So könnten eine eigene, angemessene Erinnerung an die ehemaligen kresy und die Zwangsaussiedlung aus diesen sowie die Bewahrung des polnischen Kulturerbes vor Ort schwerlich gefordert werden, wenn man dieses der deutschen Seite vorenthalte. ${ }^{225}$ Der Verlust der kresy selbst wurde von aus diesen Regionen stammenden polnischen Intellektuellen im Exil bereits früh als endgültig anerkannt und für künftige gute nachbarschaftliche Verhältnisse eine Abkehr von »dem Anspruch einer kulturellen Hegemonie« in der Region gefordert. ${ }^{226}$ Trotz dieser Diskurse traf eine mögliche Wiedervereinigung Deutschlands innerhalb der pol-

220 Peters: Revolution der Erinnerung, 2016, S. 12.

221 Ebd., S. 432. Madajczyk: Die Rolle antideutscher Instrumentalisierungen in Polen, 1944-1989, 2007, S. 144 .

222 Peters: Revolution der Erinnerung, 2016, S. 48.

223 Ebd., S. 51.

224 Ebd., S. 436.

225 Die Texte des »zweiten Umlaufs«, auf die hier Bezug genommen wird, sind abgedruckt bei: Thurich (Hg.): Schwierige Nachbarschaften, 1990, S. 172f., 192-194. Vgl. zum zunehmenden Bewusstsein der Verantwortung für das deutsche Kulturerbe in den 1980ern Jahren auch: Opiłowska: Die Aneignung des fremden Raumes, 2013, S. 255. Vgl. Olschowsky: Relations between the Federal Republic of Germany and the Peoples' Republic of Poland, 2014, S. 245. 
nischen Bevölkerung auch in den 1980er Jahren kaum auf Zustimmung und wurde vielmehr als Risiko eingeschätzt. ${ }^{227}$

Peters bemerkt, dass letztlich die Westverschiebung Polens ebenso wie die Frage der kresy in der Opposition »vergleichsweise selten in historischer Perspektive thematisiert wurde.«Im Text von Lipski sieht er einen Beleg für den Erfolg der volkspolnischen Propaganda, da dieser die allgemein vorherrschende Denkweise in Polen kritisierte. Letztlich gelte für die Auseinandersetzungen in der Opposition über die Geschichte, dass selbstkritische Stimmen keineswegs ausschließlich geteilt wurden und dass die in diesem Milieu entstandene »alternative Geschichtskultur [...] nicht automatisch auch eine Pluralisierung der Diskursinhalte nach sich« zog. Dennoch hätten diese schließlich zu einer Diversifizierung der Erinnerungskultur geführt. Die Übernahme westlicher Trends und der Individualismus einer neuen Generation ließen die von politischer Seite als so zentral verstandene Geschichte zudem nur noch als eines von vielen Themen erscheinen. Schließlich habe sich auch in der späten, nichtstaatlichen Erinnerungskultur der internationale Trend der stärkeren Erinnerung an das individuelle Opfer gegenüber dem heroischen Einzelkämpfer oder Kollektiv zunehmend durchgesetzt. ${ }^{228}$

Mit dem Jahr 1989 und dem sich entwickelnden Umbruch erschien für viele Polen und Deutsche überraschend wieder eine sich politisch artikulierende deutsche Minderheit. Diese nationale Minderheit, die wenigstens oberflächlich vollständig polonisiert war, musste ihre Identität und Sprache unter der kommunistischen Herrschaft bis zuletzt in der Öffentlichkeit weitgehend verstecken. Unklar war daher zunächst, wie groß die Anzahl der Menschen war, die sich selbst noch (oder teilweise) als Deutsche identifizierten. ${ }^{229}$ Die im Gegensatz zur Verschärfung des Kalten Krieges stabile deutsche Außenpolitik gegenüber Polen drehte sich in den 1980er Jahren neben dem fortwährenden Druck zur Durchführung wirtschaftlicher Reformen im Wesentlichen um die Verbesserung der Lage der deutschen Minderheit. ${ }^{230}$ Ein auffälliges und weder von deutscher noch polnischer Seite diplomatisch gewünschtes Ausrufungszeichen setzte diese Minderheit, als sie im November 1989 bei dem Treffen von Bundeskanzler Helmut Kohl und Premierminister Tadeusz Mazowiecki in Kreisau/Krzyżowa in Niederschlesien anlässlich einer Versöhnungsmesse demonstrierte und den Besuch Helmut Kohls feierte. ${ }^{231}$ Dieses Geschehen ließ für viele Polen ungute Erinnerungen wach werden, zumal die sich nun abzeichnende deutsche Einheit weiter mit Vorbehalten betrachtet wurde und die Bundesregierung einige Monate mit der Anerkennung der Oder-Neiße-Grenze zögerte. Öffentlichkeit und Regierung hatten also durchaus Grund, nervös und mit eini-

227 Madajczyk: Die Rolle antideutscher Instrumentalisierungen in Polen, 1944-1989, 2007, S. $144 \mathrm{f}$.

228 Peters: Revolution der Erinnerung, 2016, S. 433, 56, 434, 437-440, 455f., 460.

229 Vgl. Olschowsky: Versöhnungsinitiativen, 2009, S. 325. Vgl. auch: Madajczyk: Die Rolle antideutscher Instrumentalisierungen in Polen, 1944-1989, 2007, S. 135. Siehe ebenfalls: Browarek: Versuch einer Periodisierung der Politik des polnischen Staates gegenüber der deutschen Bevölkerung nach dem Zweiten Weltkrieg, 2015, S. 210-220.

230 Koszel: Die polnische Deutschlandpolitik in den Jahren 1970-1990, 2001, S. 920f. Vgl. Olschowsky: Relations between the Federal Republic of Cermany and the Peoples' Republic of Poland, 2014, S. $243 f$.

231 Franke; Kretschmann: Der Friedensgruß von Kreisau 1989, 2016, S. 145f. Siehe dazu auch das Gespräch mit dem Zelebranten der Messe, Bischof Nossol: »Es begann etwas Neues «. Kulturpolitische Korrespondenz. 12.11.2019. Vgl. auch: Kap. 6.1, S. 283. 
gen Befürchtungen auf die kommenden Zwei-plus-Vier-Verhandlungen zu blicken. ${ }^{232}$ Die Versöhnungsmesse von Kreisau ist in Polen dennoch zum Symbol der deutsch-polnischen Verständigung geworden. ${ }^{233}$

Die Jahre 1989/90 erwiesen sich als richtungsweisend für die deutsch-polnischen Beziehungen und die Verhandlung über die gemeinsame Geschichte war einer ihrer zentralen Bestandteile. In einem ausgehandelten Kompromiss mit der Solidarność war die Volksrepublik unblutig, aber auch sang- und klanglos aus der Geschichte verschwunden. Die Polen konnten die verhasste kommunistische Diktatur abschütteln und sich Westeuropa zuwenden. Inwieweit haben aber 40 Jahre kommunistische Herrschaft die Erinnerung und Einstellungen der Menschen zum Thema der Vertreibungen geprägt? Wie sich zeigen wird, sind die in diesem Zeitraum entwickelten Narrative von einer hohen Beständigkeit. Dies gelang unter anderem dadurch, dass die polnischen Kommunisten ähnlich wie die in der Tschechoslowakei eine in vielen Punkten gemeinhin akzeptierte Narration schaffen konnten, die sich dann aber von den Kommunisten als Träger derselben schließlich lösen ließ.

Eine der langen Kontinuitäten über die Volksrepublik hinaus ist die von Teilen der Gesellschaft weiter verfolgte Vorstellung der Idee der >Wiedergewonnenen Gebiete , die freilich ihre Wurzeln im nationalen und nationalistischen Diskurs des 19. und frühen 20. Jahrhunderts hat. ${ }^{234}$ Auch Peters sieht eine solche Linie der nationalen bis nationalistischen Herrschaftslegitimation, bei denen sich die Volksrepublik "großzügig aus dem ideologischen Arsenal der polnischen nationalen Tradition bis hin zum Nationalismus bediente. ${ }^{235}$ Marcin Zaremba stellt dem Erbe der Volksrepublik ein vernichtendes Urteil aus: »Durch ihre Propaganda und Minderheitenpolitik ließ die PZPR keine staatsbürgerliche, sondern eine ethnisch hermetische und fremdenfeindliche nationale Gemeinschaft entstehen, die sich nicht nur gegen die Außenwelt abgeschottet, sondern sie auch als feindlich betrachtet hat. $\ll^{236}$ Schließlich war der »Nationalismus kommunistischer Prägung [...] also ausgesprochen dümmlich und ungehobelt, xenophobisch, antideutsch und antisemitisch, dabei hochgradig traditionell, voraufklärerisch, schablonenhaft und grobschlächtig instrumentell. Es war kein Zufall, dass sich in der Niedergangsphase des Kommunismus inmitten dieser Bewegung nicht nur in Polen radikal chauvinistische Gruppierungen bildeten. Es zeigte sich, dass es unter Umständen von der roten zur braunen Politik nur ein kleiner Schritt ist. «37 Hans-Jürgen Bömelburg stellt fest, dass das innenpolitisch mit einer »erheblichen Mobilisierungskraft« versehene, nutzbare »deutsche Argument« das Ende der Volksrepublik überlebt habe ähnliches gelte für Tschechien. ${ }^{238}$ Dies ist insofern nicht verwunderlich, wurde doch in Erhebungen, die in den 1990er Jahren erfolgten, über den impact der volkspolnischen

232 Vgl. Olschowsky: Relations between the Federal Republic of Cermany and the Peoples' Republic of Poland, 2014, S. 261. Vgl. auch: Lemberg: Mitteleuropäisches Dreieck, 2002, S. 23.

233 Hartwich: Kreisau, 2015, S. 491.

234 Madajczyk: Die Rolle antideutscher Instrumentalisierungen in Polen, 1944-1989, 2007, S. 135.

235 Peters: Revolution der Erinnerung, 2016, S. 43.

236 Zaremba: Im nationalen Gewande, 2011, S. $407 f$.

237 Ebd., S. 408.

238 Bömelburg: Gestörte Kommunikation, 2005, S. 35. 
Narrative bezüglich der ehemaligen deutschen Ostgebiete festgestellt, dass diese »in großen Teilen der Bevölkerung angenommen worden waren «, primär durch die Schulbildung. ${ }^{239}$ Ein weiteres Beispiel für das populäre Fortleben volkspolnischer Narrative ist das Bild des Volksdeutschen: Auch im polnischen Fernsehen nach 1989 tauchte diese Figur durchgängig als stereotyper, grob-gezeichneter Verräter und Verbrecher auf. ${ }^{240}$ Peters ist in Bezug auf die Frage der Übernahme der staatlichen Geschichtspolitik aufgrund mangelnder »verlässlicher sozialwissenschaftlicher Daten« aus der Volksrepublik vorsichtiger, sieht jedoch einigen Grund zu der Annahme, dass »der mit großem Aufwand und außergewöhnlicher Ausdauer propagierte Mythos von den >Wiedergewonnenen Gebieten<, die als >uralte piastische Länder den Kern des polnischen Nationalstaats ausgemacht hätten« offenkundig die Bevölkerung erreichte, was »nicht zuletzt die bis heute anhaltende Akzeptanz dieses historischen Deutungsmusters « belege. ${ }^{241}$ Matthei konstatiert einen lang anhaltenden Schaden durch die nationalkommunistische Geschichtspolitik, die zur Folge gehabt habe, dass "moralische Fragen, die Beschäftigung mit der Schuldfrage und die Zweifelhaftigkeit einer völkisch motivierten historischen Kontinuitätstheorie in keiner Weise auf einer öffentlichen Ebene besprochen wurden. Das hierdurch entstandene Defizit in der Aufarbeitung der eigenen polnischen Geschichte ist groß und bis heute existiert eine Vielzahl weißer Flecken, die es $\mathrm{zu}$ füllen gilt, existiert eine Unmenge von stereotypen Geschichtsbildern, die es $\mathrm{zu}$ überwinden gilt. ${ }^{242}$

Bogdan Koszel widerspricht einer Überbewertung der volkspolnischen Agitation und betont die tiefe Verletzung der jahrhundertelangen deutsch-polnischen Beziehungen durch den Zweiten Weltkrieg, in dem das nationalsozialistische Deutschland durch seine brutale Besatzungsherrschaft das Verhältnis der Polen zu Deutschland tiefgreifend beschädigt und welche zu einem ungeheuren Vertrauensverlust geführt habe. Dies sei durch die überraschende, nicht verständliche und extreme Eskalation der durch Deutschland ausgeübten Gewalt gegenüber seinem Nachbarn verstärkt worden. Daher "wäre [es] eine starke Vereinfachung zu behaupten, dass das negative Deutschland- und Deutschenbild in Polen hauptsächlich eine Konsequenz der kommunistischen Propaganda gewesen sei. Das tief verankerte Misstrauen der Polen gegenüber ihren westlichen Nachbarn war vor allem eine Folge der historischen Erfahrungen, der Verluste und des Unrechts, das der polnischen Gesellschaft in der Zeit des Krieges widerfahren war. $\ll^{243}$

239 Matthei: Die Massenumsiedlungen und das Bild der Deutschen, 2006, S. 84.

240 Król: Das Bild des ethnischen Deutschen im polnischen Film, 2006, S. $388 f$.

241 Peters: Revolution der Erinnerung, 2016, S. 55f. Vgl. ebenso: Kraft: Der Platz der Vertreibung der Deutschen im historischen Cedächtnis Polens und der Tschechoslowakei/Tschechiens, 2005, S. 346.

242 Matthei: Die Massenumsiedlungen und das Bild der Deutschen, 2006, S. 93.

243 Koszel: Die polnische Deutschlandpolitik in den Jahren 1970-1990, 2001, S. 922. 


\subsection{Tschechoslowakei}

In Kapitel 3 wurde der umfassende Konsens der tschechoslowakischen Gesellschaft und des Exils zur Entfernung der Deutschen aus der ČSR am Ende des Krieges diskutiert. Diese Grundstimmung versuchten alle Parteien in den Wahlkämpfen für sich zu nutzen, indem sie sich über die Forderung nach einem schnellen und harten Vorgehen profilierten. Die bürgerlich-kommunistische Regierung (ab 1946 unter Führung der KSČ) setzte die Zwangsaussiedlungen sowohl der Deutschen als auch der Ungarn aus der Slowakei gemeinsam durch. Von diesem Vorgehen profitierte schließlich am meisten die Kommunistische Partei, die sich nicht nur durch ihr rigoroses Vorgehen als entschiedener Vertreter der nationalen Sache positionierte, sondern die ehemaligen deutschen Siedlungsgebiete zur Verteilung von Ämtern und attraktiven Siedlungsstellen als Machtbasis für sich nutzte. ${ }^{244}$ In den freien Wahlen von 1946, deren Ergebnisse die spätere kommunistische Machtübernahme begünstigten, schnitten die Kommunisten in den Sudetengebieten mit teilweise über 50 Prozent weit besser ab als im Landesdurchschnitt. ${ }^{245}$

Nach Matěj Spurný ist das unmittelbare Nachkriegsnarrativ über die Vertreibung der Deutschen zunächst von der Vorstellung einer historischen Gerechtigkeit geprägt, die sich unter anderem in der semantischen Parallelisierung der Ausweisung von Tschechoslowaken aus den Sudetengebieten 1938 zeige, die ebenso wie das Geschehen 1945 als odsun (Abschub) bezeichnet wurden. Die Sudetendeutschen hätten mit ihrem damaligen Verhalten nicht nur das generöse Angebot der positiv betrachteten Republik der Zwischenkriegszeit abgelehnt, sondern diese auch verraten. ${ }^{246}$ Dieses Zusammendenken von München 1938, der Besatzungszeit und der als Konsequenz dieser Ereignisse betrachteten Zwangsaussiedlung der Deutschen ist schließlich bis heute für das tschechische Narrativ konstitutiv. ${ }^{247}$ In der unmittelbaren Nachkriegszeit sowie der späteren nationalkommunistischen Literatur war zudem die in dieser Dimension kaum auf tatsächlichen Begebenheiten beruhende Vorstellung reger kämpferischer Aktivitäten verbliebener Deutscher, auf die adäquat reagiert werden musste, eine verbreitete Erzählung. ${ }^{248}$ In den Jahren 1945-1948, in denen der odsun fortlaufend stattfand, wurde das Thema in der semi-freien Tschechoslowakei durchaus offen und, abgesehen von einigen wenigen kritischen und beunruhigten Stimmen vor allem wegen der Art und Weise der >Aussiedlungen<, als sinnvoll und positiv diskutiert, ehe der Diskurs in den folgenden Jahren und Jahrzehnten jenseits kleiner oppositioneller Kreise »auf lange Zeit unterbrochen und unterdrückt« wurde. ${ }^{249}$

Die starken Wahlergebnisse der KSČ ebenso wie die gezielte Übernahme von Schlüsselpositionen in der Regierung ermöglichten 1948 den Februarumsturz, in des-

244 Vgl. Abrams: Morality, Wisdom and Revision, 1995, S. 251.

245 Vgl. McDermott: Communist Czechoslovakia, 1945-89, 2015, S. $46 \mathrm{f}$.

246 Siehe: Spurný: Czech and German Memories of Forced Migration, 2012, S. 356-358.

247 Vgl. Nižňanský: Das Münchner Abkommen in der kommunistischen Nachkriegspropaganda, 2010, S. 261.

248 Staněk: Verfolgung 1945, 2002, S. 19. Tůma: Die Aussiedlung, 2015, $273 f$.

249 Staněk: Vertreibung und Aussiedlung, 2001, S. 207. Galmiche: »Dům po Nemcich«-»von den Deutschen übernommenes Haus«, 2005, S. 954. Vgl. Tůma: Die Aussiedlung, 2015, S. 273. 
sen Folge die ČSR als kommunistischer Staat fest in das sowjetische Bündnissystem integriert wurde. Mit der vollständigen Machtübernahme passten die Kommunisten das bisherige staatliche und in der Gesellschaft etablierte Narrativ der ersten Hälfte des 20. Jahrhunderts an ihre Vorstellungen an. Zunächst wurden die Republik der Zwischenkriegszeit sowie ihre bürgerlichen Akteure wesentlich schlechter bewertet und ihr Versagen bei der Verteidigung des Staates ebenso wie der Verrat durch die bürgerlichen Regierungen Frankreichs und Großbritanniens betont. ${ }^{250}$ Das Anknüpfen an einen verbreiteten common sense der Gesellschaft erleichterte die Manipulation, dass lediglich das Bündnis mit der Sowjetunion und der Aufbau des Sozialismus die neue Friedensordnung garantieren könnten. ${ }^{251}$ Gleichzeitig bemühten sich die staatlichen Stellen nach der Gründung der DDR um eine Abschwächung antideutscher Rhetorik. Die Notwendigkeit der Vertreibung wurde nicht in Frage gestellt, aber der Fokus nun verstärkt auf die dadurch mögliche soziale Revolution gelegt. ${ }^{252}$

Ähnlich wie zur gleichen Zeit in Polen blieb unter der marxistischen »metahistory« der traditionelle, nationalistische tschechische Diskurs lebendig, wobei die Vorstellung eines tausendjährigen tschechischen »Abwehrkampfes« gegen deutsche Angriffe verfolgt wurde. ${ }^{253}$ Dieser scheinbare Widerspruch von nationalistischer Argumentation und universalistischem Marxismus konnte vermeintlich aufgelöst werden: Die deutschen Siedler des Mittelalters erschienen in diesen Darstellungen als feudale Ausbeuter des tschechischen Volkes, die Zeit des größten kulturellen deutschen Einflusses im 17. und 18. Jahrhundert als Phase des »heaviest decline« und die deutschen Sozialdemokraten wurden für die Aufspaltung der internationalen Arbeiterbewegung verantwortlich gemacht. ${ }^{254}$ Die Vertreibung der Deutschen wurde zudem als Korrektur der Folgen der Schlacht am Weißen Berg (1620) dargestellt, welche die tschechische Nationalbewegung des 19. Jahrhunderts als zentrales Ereignis für die beginnende sdeutsche Fremdherrschaft betrachtete. Ebenso wurde der vorherige >Fehler der PřemyslidenDynastie des Mittelalters ausgeglichen, unter der die >deutscheく Einwanderung nach Böhmen begann. ${ }^{255}$ Dieses Narrativ spiegelt sich in der Ansicht der Sudetendeutschen Landsmannschaft wider, dass diese Entscheidung der Přemysliden die Tschechen aus ihren rasiatischen Ursprüngen nach Europa geführt habe, was Beneš fatalerweise wieder umgekehrt habe. ${ }^{256}$ Erst später konnten im nationalkommunistischen Narrativ die mit >progressiven deutschen Kräften verbundenen Ereignisse gefeiert werden, wie die

250 Vgl. Fend: Vom Ende des Zweiten Weltkrieges bis zum Beginn der »Wende«, 2016, S. 74.

251 Vgl. ebd.

252 Siehe: Spurný: Czech and German Memories of Forced Migration, 2012, S. 356-358. Siehe auch: Nižňanský: Das Münchner Abkommen in der kommunistischen Nachkriegspropaganda, 2010, S. 262-265.

253 Řepa: The Czechs, Germans and Sudetenland, 2011, S. 316. Zwicker: Zur Darstellung der Sudetendeutschen, 2006, S. $392 f$.

254 Řepa: The Czechs, Germans and Sudetenland, 2011, S. 317.

255 Hrabovec: Politisches Dogma kontra wirtschaftliches Kalkül, 2001, S. 171. Zwicker: Zur Darstellung der Sudetendeutschen, 2006, S. 393. Vgl. Wiedemann: »Komm mit uns das Grenzland aufbauen!«, 2007, S. 421.

256 Zwicker: Zur Darstellung der Sudetendeutschen, 2006, S. 393. 
marxistisch interpretierte gemeinsame hussitische Revolution Revolte $1618-1620 .{ }^{257}$

In den staatlichen Erzählungen wurde die massive Gewalt während des odsun weitgehend ausgeblendet und mit Bezeichnungen wie »Übergriffe« oder »Ungebührlichkeiten « verharmlost und wenigen >kriminellen Elementen zugeschoben. ${ }^{258}$ Unterstrichen wurde hingegen die Notwendigkeit des Geschehens, da es sich um »eine gerechte, historisch notwendige Lösung, um einen wichtigen Bestandteil des Wegs zum sSozialismus«, um die Absicherung der nationalen und staatlichen Erfordernisse« gehandelt habe. ${ }^{259}$ Zentral blieb für diese Argumentation die Zuweisung einer Kollektivschuld an die Sudetendeutschen. ${ }^{260}$ Die schematische kommunistische Meistererzählung, in der die Deutschen die ausschließlich Bösen waren, unterstützte das gesellschaftliche Bedürfnis nach Entlastung, auch wenn es persönlichen Erfahrungen zuwiderlief. ${ }^{261}$ Von der anfänglichen Propagierung der Entfernung der Deutschen als ein zu begrüßendes Ereignis wurde diese im Laufe der 1950er und 1960er Jahre staatlicherseits abgeschwächt und zur »unfortunate historical necessity «. ${ }^{262}$

Die unmittelbare Gefahr eines deutschen Anspruchs auf die Sudetengebiete war in der ČSR, auch angesichts von der Bundesrepublik nie offiziell erhobener territorialer Ansprüche, weniger stark vermittelbar als in Polen mit seinen international nicht abgesicherten Grenzen. Auch die Vorstellung eines Rückkehrrechtes der Sudetendeutschen im Zuge eines Friedensvertrages erschien weniger realistisch als eine deutschsowjetische Einigung auf Kosten Polens. Nichtsdestoweniger konnte bis 1989 die Angst vor den Deutschen als ein Instrument der kommunistischen Herrschaftssicherung genutzt werden, zumal die Sudetendeutsche Landsmannschaft genügend propagandistisch verwertbares Material für die entsprechende Agitation lieferte. ${ }^{263}$ Stärker als die unmittelbare territoriale Bedrohung konnte der doppelte Verrat von 1938 und ein bis 1968 traditionell positives Verhältnis der Tschechen zu Russland von den Kommunisten genutzt werden - ganz im Gegensatz zur VRP, die stets mit einer tiefen Ablehnung der Bevölkerung gegenüber den Russen operieren musste.

Das Thema der deutschen Vergangenheit vieler Orte in der Tschechoslowakei blieb Thema im kommunistischen Pionierroman ebenso wie in kritischen literarischen Texten, in denen moralisch komplexe Fragen zum Teil in bemerkenswerter Offenheit diskutiert werden konnten. ${ }^{264}$ Der politischen Entstalinisierung und dem Reformweg der tschechoslowakischen kommunistischen Partei folgte 1968 der Prager Frühling sowie dessen Niederschlagung durch die Kräfte des Warschauer Paktes. Die Beteiligung der bereits in Bereitstellung gegangenen Truppen der Nationalen Volksarmee der DDR wurde kurz vor dem Einmarsch gestoppt, da sich die sowjetische Führung wohl auf

257 Řepa: The Czechs, Germans and Sudetenland, 2011, S. 318.

258 Staněk: Verfolgung 1945, 2002, S. 19. Spurný: Czech and Cerman Memories of Forced Migration, 2012, S. 357.

259 Staněk: Verfolgung 1945, 2002, S. 19.

260 Abrams: Morality, Wisdom and Revision, 1995, S. 238.

261 Spurný: Czech and Cerman Memories of Forced Migration, 2012, S. $361 \mathrm{f}$.

262 Abrams: Morality, Wisdom and Revision, 1995, S. 238.

263 Vgl. Tůma: Die Aussiedlung, 2015, S. 267.

264 Vgl. Zwicker: Zur Darstellung der Sudetendeutschen, 2006, S. 398-400. 
Anraten auch der reformfeindlichen Kommunisten der Tschechoslowakei gegen eine historische Assoziationen weckende Beteiligung deutscher Kräfte entschied, zumal die Erinnerung an die deutsche Besatzungszeit noch eine erhebliche Präsenz besaß. ${ }^{265}$

In der Phase starker Offenheit und publizistischer Freiheit »blieb die Frage der Vertreibung ein Randthema. $\ll^{266}$ Dennoch sieht Ferdinand Seibt 1968 durchaus als einen Wendepunkt, denn im Mai diesen Jahres publizierten drei tschechoslowakische Intellektuelle der Nachkriegsgeneration in der populärhistorischen Zeitschrift Host do domu ein Gespräch, in dem sie den odsun als historisch-moralisches Problem diskutierten. ${ }^{267}$ In dieser Zeit tauchte auch erstmals nach Kriegsende sowie einer temporären Phase der Offenheit in den 1950er Jahren ${ }^{268}$ die Frage einer deutschen Bevölkerung in der Tschechoslowakei wieder öffentlicher auf. Vertreter der Minderheit forderten deutschsprachige Publikationen und deutschsprachigen Unterricht. Weitreichende Reformen unterblieben schließlich, allerdings wurde mit der Verfassungsreform vom Oktober 1968 erstmals seit dem Zweiten Weltkrieg eine deutsche Minderheit anerkannt und den anderen Minderheiten gleichgestellt. ${ }^{269}$ Diese Bevölkerungsgruppe umfasste 1960 nach Angaben der Sudetendeutschen Landsmannschaft 200.000 Personen, nach denen der ČSR 140.000 Personen. Deren Zahl sank bis nach der Wende durch fortgesetzte Auswanderung und Assimilation auf 40.000. ${ }^{270}$

Während der 1968 folgenden, als normalizace bezeichneten Ära des gesellschaftlichen und ökonomischen Stillstandes verbesserte sich im Zuge der neuen Ostpolitik und der globalen Entspannungspolitik das Verhältnis zur Bundesrepublik und verlor das Feindbild des Deutschen stark an Relevanz. ${ }^{271}$ Die Verhandlungen über die Neuordnung der bilateralen Beziehungen bewegten sich entscheidend um die rechtliche Bewertung des Münchner Abkommens, das von der ČSSR als von Beginn an ungültig, von der Bundesrepublik jedoch als erst später erloschen bewertet wurde. Hierfür wurde eine Kompromissformel gefunden und die Anerkennung der Unverletzlichkeit der Grenzen festgelegt. ${ }^{272}$ Bei der schließlich erfolgreichen Unterzeichnung des Prager Vertrages 1973 versuchte Willy Brandt das deutsche und tschechoslowakische Narrativ $\mathrm{zu}$ verbinden, indem er sowohl an die auch durch diesen Vertrag nicht legitimierten Vertreibungen am Ende des Krieges ebenso wie an deren Vorgeschichte erinnerte, als die Tschechen und Slowaken Opfer der deutschen Aggression geworden waren. ${ }^{273}$

Die fortgesetzte Entspannungspolitik in den 1980ern konnte jedoch nicht die später wieder die Beziehungen belastenden Kernprobleme ausräumen, wie die Ansprüche der Vertriebenenverbände aus Deutschland und Österreich an die Tschechoslowa-

265 Vgl. Gschwend: NVA-Truppen machen halt an der tschechoslowakischen Grenze. Radio Praha. 22.08.2008.

266 Schmidt-Hartmann: Menschen oder Nationen? 1988, S. 149. Vgl. Tůma: Die Aussiedlung, 2015, S. 274.

267 Hübl; Procházka et al.: Trialog o roce 1945, 1968. Vgl. Seibt: Eine neue Nachbarschaft? (1993), 2002, S. 114.

268 Zwicker: Zur Darstellung der Sudetendeutschen, 2006, S. $397 \mathrm{f}$.

269 Pauer: 1968: Der»Prager Frühling« und die Deutschen, 2007, S. 278.

270 Zwicker: Zur Darstellung der Sudetendeutschen, 2006, S. $396 \mathrm{f}$.

271 Fend: Vom Ende des Zweiten Weltkrieges bis zum Beginn der »Wende«, 2016, S. 74.

272 Vgl. Břach: Die Bedeutung des Prager Vertrags von 1973 für die deutsche Ostpolitik, 1998, S. 189-191.

273 Niedhart: Die Ostpolitik der Bundesrepublik, 2010, S. 106. 
kei, die rechtliche Qualifikation und Negation der >Beneš-Dekrete` und des Münchner Abkommens sowie tschechoslowakische Reparationsforderungen an die Bundesrepublik. ${ }^{274}$ Eine Grundlage für die Verständigung ergab sich jedoch durch den zunehmenden Reiseverkehr zwischen den Ländern, der eingefrorenen Ängsten und Vorurteilen oft effektiv entgegenwirkte. ${ }^{275}$ In der staatlichen Propaganda, Publizistik und Schulbildung verlor im Zuge des Generationenwechsels und gefördert durch eine staatliche Tabuisierung das Thema des deutschen Anteils an der böhmischen Geschichte massiv an Bedeutung. ${ }^{276}$ Spurný spricht von einem »state-led push for forgetfulness«, welcher in den 1970ern und 1980ern seinen Zenit erreichte. ${ }^{277}$ Das Thema blieb dennoch in den Grenzgebieten sowie in den Publikationen des Untergrundes und den Debatten des Exils präsent. ${ }^{278}$ Erst in den späten 1980ern zeigte sich eine gewisse Öffnung in der offziellen Geschichtswissenschaft. ${ }^{279}$

Dienten historische Narrative zunächst primär dem Regime als Legitimation, so zeigte sich in den 1970er Jahren, dass auch die Dissidenten diese als scharfe Waffe einsetzen konnten. ${ }^{280}$ Eines der im Samizdat diskutierten Themen war die in mehreren Abhandlungen erörterte Frage der Vertreibungen, deren zentrale Bedeutung für den Aufbau des Kommunismus implizierte, dass jede Kritik an diesen das Regime direkt angriff. ${ }^{281}$ Das galt auch oder gerade, wenn in der Diskussion moralische und selbstkritische Fragen im Vordergrund standen, in der Gewalt und Anarchie verurteilt wurden, auch wenn die grundsätzliche Entscheidung zum odsun im Rahmen des internationalen Konsenses und als logische und gerechtfertigte Konsequenz des Zweiten Weltkrieges zumeist verteidigt wurde. ${ }^{282}$ Auch kritischere Stimmen lehnten das Aufkommen der Frage nach Restitution und Entschädigung der Sudetendeutschen ab; stattdessen standen die negativen Folgewirkungen des Geschehens für die tschechoslowakische Gesellschaft und die Begünstigung der kommunistischen Machtübernahme im Mittelpunkt. ${ }^{283}$ Eine These lautete, dass die Vertreibungen nach München 1938 und der Besatzungszeit das Rechtsempfinden der Tschechen endgültig und langfristig beschädigt hätten. ${ }^{284}$ Der tschechische Philosoph Erazim Kohák sah die Gründe für diese Problematik im Konzept des Nationalstaates, der ein ehemals fruchtbares multinationales Zusammenleben zerstört habe - in seiner Extremform durch den Nationalsozialismus und die Ermordung der europäischen Juden und schließlich durch die Vertreibung der Deutschen, die in der böhmischen Geschichte stets eine Brücke nach Westeuropa gewesen seien. ${ }^{285}$ Johann Wolfgang Brügel, ein tschechoslowakischer Jurist und Publizist, unterstrich die

274 Kunštát; Vilímek: Die deutsch-tschechoslowakischen Beziehungen, 2013, S. $149 f$.

275 Seibt: Eine neue Nachbarschaft? (1993), 2002, S. 111.

276 Lemberg; Křen et al.: Einleitung der Herausgeber, 1998, S. 22.

277 Spurný: Czech and German Memories of Forced Migration, 2012, S. 358.

278 Ebd., S. $358 \mathrm{f}$.

279 Pešek: Zwangsmigrationen von Tschechen und Deutschen, 2007, S. 194.

280 Seibt: Die Stunde Klios (1996), 2002, S. 317.

281 Abrams: Morality, Wisdom and Revision, 1995, S. 254.

282 Řepa: The Czechs, Germans and Sudetenland, 2011, S. 323.

283 Abrams: Morality, Wisdom and Revision, 1995, S. 235.

284 Ebd., S. 241.

285 Ebd., S. 241, 247. 
Brücke von der Vertreibung zur kommunistischen Diktatur: »From the denial of basic civil rights to almost one-quarter of the population to the confiscation of all the rights of the entire population is a comparatively small step. ${ }^{286}$

Unter dem Pseudonym »Danubius« löste der slowakische Historiker Ján Mlynárik mit seiner 1978 unter anderem in der tschechischen Exilzeitschrift Svědectví in Paris erschienenen Streitschrift über die Vertreibungen und deren Folgen eine umfassende Diskussion aus. ${ }^{287}$ In dieser Zeitschrift diskutierten weitere tschechische und deutsche Beiträge das Thema, wobei es vor allem um den Beginn einer Debatte ging, die sich im Exil und unter den Dissidenten mit unterschiedlicher Intensität bis in die 1990er Jahre fortsetzte. ${ }^{288}$ In seiner Schrift verurteilt Mlynárik nicht nur die Gewalt während des odsun, sondern die Aussiedlung der Deutschen insgesamt. Er bewertet die Vertreibung der Sudetendeutschen als ungerechte Kollektivverurteilung, als Verrat der tschechischen Werte und er sieht darin eine Übernahme nationalsozialistischer Methodik ebenso wie er die Vertreibungen als eine entscheidende Grundlage der kommunistischen Machtübernahme und der Entfernung Böhmens aus seiner klassischen Mittlerposition in Europa nach Osten betrachtet. Als einer der ersten tschechoslowakischen Autoren diskutiert Mlynárik auch explizit die Internierung der Sudetendeutschen in den Lagern und die dortigen katastrophalen Bedingungen. Die Diskussion der Vertreibung decke schließlich das kommunistische Gewaltregime auf, welches sich von dort aus gegen die gesamte Bevölkerung richtete. Damit sei die Debatte ein Schritt zur Überwindung des Totalitarismus, für die es aber eine weit über den Samizdat hinausgehende öffentliche Diskussion brauche. ${ }^{289}$ Mlynárik schließt seinen auf Slowakisch erschienenen Beitrag mit der Aufforderung, sich der eigenen Schuld zu stellen:

»Die Aussiedlung der tschechoslowakischen Deutschen ist nicht nur eine deutsche Tragödie, sondern auch unsere Tragödie. Mit ihr und ihren Folgen müssen wir uns primär und für uns selbst beschäftigen. Was deutsch ist - im Schlechten und Guten - überlassen wir den Deutschen. Wir müssen uns mit voller Verantwortung unserer Schuld widmen, wenn wir nicht auf weitere wiederkehrende Akte dieser Tragödie warten wollen. ${ }^{290}$

Die Kritiker seiner Thesen verwiesen darauf, dass er den Kontext des historischen Geschehens missachte oder unterschätze. Diesem Einwand wurde wiederum mit dem Argument begegnet, dass die Vertreibungen wohl in ihrem Kontext zu verstehen seien, dieser diese aber dennoch nicht rechtfertige. Andere Autoren des Samizdat waren der Meinung, dass die einseitige Argumentation Mlynáriks die westdeutsche Position zum

286 Zitiert nach: Abrams: Morality, Wisdom and Revision, 1995, S. 248.

287 Danubius: Tézy o vysídlení československých Nemcov, 1978.

288 Seibt: Eine neue Nachbarschaft? (1993), 2002, S. 117f.

289 Abrams: Morality, Wisdom and Revision, 1995, S. 239, 251, 248, 254. Tůma: Die Aussiedlung, 2015, S. 268f. Danubius: Tézy o vysídlení československých Nemcov, 1978, S. 105-122.

290 »Vysidlenie čs. Nemcov nie je iba nemecká tragédia, ale je to aj tragédia naša. S ňou a jej následkami sa musíme vyporiadat' predovšetkým sami v sebe a pre seba. Čo je nemecké - v zlom i dobrom - nechávame Nemcom. Našu vinu musime s plnou zodpovednost'ou riešit' my, ak sa nechceme dočkat' d'alších opakujúcich sa dejstiev tejto tragédie. ¿ Danubius: Tézy o vysídlení československých Nemcov, 1978, S. 122. 
Geschehen unterstütze und die Rechtfertigung für Revisionsforderungen liefern könne. Eine tatsächliche >Wiedergutmachungく, das heißt eine Rückkehr der Sudetendeutschen und die damit zwangsläufig verbundene Aussiedlung neuangesiedelter Tschechen der Grenzregionen sei zudem nicht nur unrealistisch, sondern eine katastrophale und gefährliche Vorstellung. Der (sudeten-)deutsche Historiker Rudolf Hilf beteiligte sich an der Diskussion und verwies auf eine mögliche demokratische Alternative, die in der individuellen juristischen Verfolgung sudetendeutscher Schuldiger hätte bestehen können. Ein solches Vorgehen hätte die Deutschen Böhmens zu loyalen Bürgern der ČSR gemacht. ${ }^{291}$

Interessant ist die internationale Rezeption der Danubius-Schrift: Der Radiosender Voice of America verbreitete Teile des Essays, ebenso erschien in der Frankfurter Rundschau eine Reportage zur Diskussion. Nach der erzwungenen Emigration Mlynáriks in die Bundesrepublik 1982 setzte er seine publizistischen Aktivitäten fort. ${ }^{292} 1985$ erschien dort eine Zusammenstellung des bisherigen Diskurses über die Vertreibung der Deutschen unter den tschechoslowakischen Dissidenten und des Exils unter dem Titel »Wir haben uns selbst aus Europa vertrieben ${ }^{293}$ Der Titel ist ein Zitat aus dem 1977 in der Schweiz erschienenen Roman Langeweile in Böhmen des tschechischen Dissidenten Alexandr Kliment, der in diesem formulierte:

»Ich glaube nach wie vor, daß dies nicht rechtens und nicht notwendig war. Der Kampf hatte doch einem Regime gegolten und nicht einem Volk. Aber das hatten wir nicht begreifen wollen und die Deutschen austreiben und ausweisen lassen. Uns selbst haben wir dadurch aus Europa vertrieben. $\ll^{294}$

Die Veröffentlichung des Sammelbandes zeigt das Interesse an dieser Diskussion in Deutschland und Österreich und mit einer Rezension des Buches in einer polnischen Zeitschrift 1988 schließt sich dies zu einem Trialog oder Quartett. ${ }^{295}$ In der polnischen Rezension wird kritisiert, dass dieser Band eine verzerrte Darstellung der Diskussion und der tschechoslowakischen Einschätzung der Vertreibungen sei, denn es würden zwar viele Schriftsteller und Intellektuelle zitiert, aber kaum Wissenschaftler, was zudem zu einer mangelhaften Berücksichtigung der realpolitischen Situation der ČSR nach Kriegsende führe. Tatsächlich wird in der Einleitung der Zusammenstellung sehr optimistisch geäußert: Die Verteidiger des bisherigen Narrativs seien in der Minderheit, hingegen sei die "Mehrheit, und hier ist es vornehmlich die junge Generation, die mit der Vertreibung nichts zu tun hatte, [...] offensichtlich willens, die dunkle Vergangenheit zu überwinden. Das soll diese Dokumentation nachweisen. ${ }^{296}$ Weder sah der Autor, dass diese selbstkritische Diskussion keine einseitige Annäherung an die (sudeten-)deutsche Argumentation bedeutete, noch erkannte er, dass es sich vor allem um einen relativ abgeschlossenen Elitendiskurs handelte, dessen Verbreitung und

291 Abrams: Morality, Wisdom and Revision, 1995, S. 240, 251f., 242.

292 Classheim: Cleansing the Czechoslovak Borderlands, 2016, S. 169.

293 Grünwald (Hg.): Wir haben uns selbst aus Europa vertrieben, 1985.

294 Ebd., S. 38.

295 Tomaszewski: Rezension zu: »Wir haben uns selbst aus Europa vertrieben. 1988.

296 Grünwald (Hg.): Wir haben uns selbst aus Europa vertrieben, 1985, S. 14, $84 f$. 
Einfluss auf die tschechische Gesellschaft und das vorherrschende Geschichtsnarrativ schließlich gering blieb. ${ }^{297}$

Mit der Samtenen Revolution im November 1989 erfolgte die politische Wende in der ČSSR. Im Dezember wurde eine Regierung aus Oppositionsangehörigen und Reformkommunisten gebildet und Ende des Jahres Václav Havel zum Staatspräsidenten gewählt. Dieser bedauerte und verurteilte im Winter 1989 die Vertreibung, unter anderem in einem Brief an Bundespräsident Richard von Weizsäcker, der die entsprechenden Zeilen in seiner Weihnachtsansprache am 24.12.1989 zitierte. ${ }^{298}$ Havels Worte konnten als Angebot an die Sudetendeutschen wahrgenommen werden, das tschechoslowakisch/tschechisch-sudetendeutsche Verhältnis neu zu bestimmen. ${ }^{299}$ Das von Havel verfolgte Denkmuster hatte seine Wurzeln im oben skizzierten oppositionellen Diskurs, dessen geringe Verbreitung nun zu einem großen Unverständnis und einer Ablehnung dieser Geste durch die tschechische Bevölkerung führte, die die Verantwortung unter anderem mit Verweis auf die Beschlüsse der alliierten Siegermächte ablehnte. ${ }^{300}$ Der Einfluss des nationalistischen Narrativs der Kommunisten in über vierzig Jahren staatlicher Propaganda führte, verbunden mit der Unsicherheit jener Zeit, zu einer schockartigen Wirkung. ${ }^{301}$ Oldřich Tůma erklärt die bis heute nicht ganz klare Geste Havels mit einer vermutlichen "Nachwendeeuphorie« und dem Hoffen auf eine rasche Verbesserung der politischen Lage sowie der Erwartung einer »reziproken« Antwort von deutscher, gerade von sudetendeutscher Seite. ${ }^{302}$

Sollte Havel auf eine solche Geste gehofft haben, so wurde er von der Sudetendeutschen Landsmannschaft enttäuscht, die seine Äußerung vielmehr als Rechtfertigung ihrer eigenen Position und als Chance verstand, ihre alten rechtlichen und vermögensrechtlichen Fragen aufs Tableau zu bringen. ${ }^{303}$ In grober Verkennung des innertschechischen Diskurses und Geschichtsverständnisses sah sie die neuen Vertreter der ČSSR in einer mehrfachen Bringschuld. ${ }^{304}$ Der deutsche Historiker Ferdinand Seibt geht mit ihr besonders hart ins Gericht, und sieht diese durch ihre undiplomatische Reaktion in ihrem Selbstverständnis als Vertreter der sudetendeutschen Volksgruppe und als Gesprächspartner der tschechoslowakischen Regierung disqualifiziert. ${ }^{305}$ Auch die bundesdeutsche Politik verzichtete auf eine entsprechende Reaktion und die freundlichen Worte des deutschen Bundespräsidenten Richard von Weizsäckers bei seinem Besuch in Prag im März 1990 gingen in den folgenden Auseinandersetzungen unter. ${ }^{306}$

In der tschechoslowakischen Öffentlichkeit wurden erneut von Sudetendeutschen erhobene Eigentumsforderungen aufgeregt und als unverständlich diskutiert, sodass

297 Vgl. Sniegoň: Between Old Animosity and New Mourning, 2016, S. 54.

298 Kunštát; Schmoller: Umbruch, Transformation und europäische Integration, 2019, S. $312 f$.

299 Vgl. Seibt: Eine neue Nachbarschaft? (1993), 2002, S. $118 f$.

300 Houžvička: Czechs and Germans 1848-2004, 2015, S. 397.

301 Tůma: Die Aussiedlung, 2015, S. 269.

302 Ebd., S. 269f.

303 Ebd. Vgl. Houžvička: Czechs and Germans 1848-2004, 2015, S. 396.

304 Houžvička: Czechs and Germans 1848-2004, 2015, S. 396.

305 Seibt: Eine neue Nachbarschaft? (1993), 2002, S. $118 f$.

306 Houžvička: Czechs and Cermans 1848-2004, 2015, S. 396. 
auch die ČSSR an einer schnellen vertraglichen Regelung interessiert war. ${ }^{307}$ Die Diskussionen zwischen Deutschland und Polen sowie »die konfusen Äußerungen einiger deutscher Politiker, namentlich Helmut Kohls, zur Oder-Neiße-Grenze« wurden in der ČSSR aufmerksam verfolgt. ${ }^{308}$ Es war ein langwieriges Diskussionsthema, ob die ČSSR, ähnlich wie Polen, auf eine Beteiligung an den Verhandlungen zum Zweiplus-Vier-Vertrag drängen sollte, was schließlich nicht erzwungen wurde. Gegen eine Beteiligung sprach, dass im Gegensatz zu Polen die ČSSR bereits über international anerkannte Grenzen verfügte und auch eine Unterstützung der fraglos folgenden Anerkennung der Oder-Neiße-Grenze durch Deutschland nicht nötig sein würde. ${ }^{309}$ In Tschechien war zudem die Angst vor Deutschland bereits deutlich gesunken, ohne dass man deshalb die ökonomische und machtpolitische Bedeutung eines wiedervereinigten Deutschlands für die künftige Gestaltung Europas unterschätzte. ${ }^{310}$

Als Erbe der kommunistischen Zeit können die jahrzehntelange Kultivierung des anfangs kommunistisch verbrämten nationalen Narrativs des Münchentraumas sowie das verfestigte Bild des sudetendeutschen Verrates gelten; diese Bilder prägen besonders im ehemaligen Sudetenland die Denkweisen bis heute. ${ }^{311}$ Muriel Blaive betont, dass trotz mancherlei Negation der Kommunismus und die Vertreibung der Sudetendeutschen ein integraler Bestandteil der tschechischen Geschichte seien und letztlich das Scheitern des nationalen Selbstbildes als besonders demokratische Nation zeigen. ${ }^{312}$ Mit diesem Hintergrund stießen die meisten Tschechoslowaken auf das ähnlich stark konservierte Geschichtsbild der Sudetendeutschen Landsmannschaft aus den 1950er Jahren. ${ }^{313}$ Die 1990er Jahre waren daher in den zwischenstaatlichen Beziehungen von den geschichtspolitisch ungelösten Fragen der 1950er Jahre geprägt. ${ }^{314}$ Der Diskurs der Dissidenten, auch wenn diese nun an der Spitze des Staates standen, konnte hier keine der notwendigen Brücken schlagen, auch wenn dieser kulturell die Grundlage für eine intensive wissenschaftliche und künstlerische Neubewertung der Geschichte legte. ${ }^{315}$

\subsection{Vergleich und Zusammenfassung}

Die Bundesrepublik und die DDR pflegten unter unterschiedlichen Vorzeichen den Mythos der erfolgreichen Integration der Vertriebenen. ${ }^{316}$ In der DDR verschwand der Um-

307 Kunštát: Die Wiedervereinigung Deutschlands und die tschechoslowakische Außenpolitik, 2010, S. 205.

308 Ebd., S. 204.

309 Vgl. ebd., S. 207-210.

310 Vgl. Kunštát: Die Wiedervereinigung Deutschlands und die tschechoslowakische Außenpolitik, 2010, S. 217.

311 Blaive: National Narratives of Czech Identity, 2016, S. 163.

312 Ebd., S. 163, 186.

313 Spurný: Czech and Cerman Memories of Forced Migration, 2012, S. 364.

314 Vgl. Kučera: »Der Hai wird nie wieder so stark sein«, 2001, S. 148.

315 Bock: Das »sudetendeutsche Thema« in der tschechischen Literatur, 2003.

316 Vgl. Schwartz: Assimilation versus Incorporation, 2016, S. 84. Vgl. auch: Hahn; Hahn: Die Vertreibung im deutschen Erinnern, 2010, S. 576-578, 582f. 
siedlermythos aus politischen Gründen bald wieder aus der Öffentlichkeit, auch wenn Flucht und Vertreibung als Thema auf unterschiedliche Weise medial präsent blieben. In der Bundesrepublik war das Gegenteil der Fall: Am Anfang stand das Elend der Vertriebenen im Mittelpunkt ebenso wie der provisorische Charakter ihres Aufenthaltes, ehe sich die Vorstellung von einer reibungslosen Integration in das Wirtschaftswunderland Deutschland entwickelte. Tatsächlich waren die Vertriebenen in beiden Staaten mit einer langfristigen sozialen Deklassierung und einem Desinteresse an ihren persönlichen Leidensgeschichten konfrontiert und von einer anfänglich starken Diskriminierung betroffen. Das Ankommen der Vertriebenen war schließlich weniger durch staatliche Integrationsmaßnahmen als durch sozioökonomische und generationelle Entwicklungen bedingt. ${ }^{317}$ Im Gegensatz zur DDR blieben Flucht und Vertreibung in der Bundesrepublik mit sehr unterschiedlichen Konjunkturen ein rewiges Thema. Die eruptiven politischen und erinnerungskulturellen Auseinandersetzungen in der Bundesrepublik, die maßgeblich die Bewertung der Zwangsmigration veränderten, fanden in der DDR kein Äquivalent. Die Vertriebenenverbände und ihre Anliegen verloren in diesem Zeitraum ihre zentrale Position in der Erinnerungskultur der Bundesrepublik. In den zwischenstaatlichen Beziehungen sah sich die DDR als progressive Kraft, die umgehend nach ihrer Gründung die Freundschaft zu den sozialistischen Bruderländern Polen und der Tschechoslowakei verkündete: eine verordnete Freundschaft, die trotz mancherlei Initiativen oberflächlich blieb. Ähnlich wie in der Bundesrepublik, die ihre Beziehungen zu Polen und der Tschechoslowakei - nicht ohne heftige innenpolitische Auseinandersetzungen - erst in den 1960ern und 1970ern verbesserte, war auch in der DDR der zunehmende Kontakt seiner Bürger mit den östlichen Nachbarn von großer Bedeutung für das Verhältnis der Gesellschaften.

In Polen und der ČSR wurden die Vertreibungen als Ergebnis alliierter Entscheidungen, der deutschen Verbrechen, des Verrates der Volks- und Sudetendeutschen an ihren Ländern sowie als Teil einer langfristigen europäischen Friedensordnung gerechtfertigt. Die kommunistischen Parteien verbanden zudem argumentativ und politisch die sozialistische Revolution und gesellschaftliche Neuordnung mit den Vertreibungen. Mit der Konstruktion einer jahrhundertelangen deutsch-polnischen, deutsch-tschechischen oder >germanisch-slawischen Konfliktgeschichte wurde an ältere nationale und nationalistische Konzepte angeknüpft, die um eine marxistische Deutung ergänzt wurden, indem diese vermeintliche ethnische Dauerkonfliktgeschichte mit einer Klassendimension versetzt wurde. In dieser beuteten die deutschen Oberschichten, häufig in Kooperation mit den korrupten eigenen Eliten, die osteuropäischen Länder aus. ${ }^{318}$ Die nationalkommunistischen Narrative blieben bis 1989 weitgehend stabil, auch wenn die pseudomarxistische Rhetorik zunehmend an Bedeutung verlor.

Die Vertreibung der Deutschen traf in Polen wie in der ČsR auf die breite Zustimmung der Bevölkerung, die diese in Anbetracht der deutschen Besatzungszeit für ei-

317 Schwartz: Assimilation versus Incorporation, 2016, S. $77 f$.

318 Solche historischen Analogien und die Nutzung älterer Feindbilder waren in dem sich neu konstituierenden Nachkriegseuropa gleichwohl »weder eine Erfindung noch eine Besonderheit der Kommunisten, sondern Teil des kurzen antifaschistischen Nachkriegskonsenses. « Fend: Vom Ende des Zweiten Weltkrieges bis zum Beginn der »Wende«, 2016, S. 66. 
ne angemessene und notwendige Reaktion erachtete. Auch die Verteilung von ehemals deutschem Eigentum sowie die Nutzung der Vertreibungen als Element einer damals in den meisten Teilen Europas angestrebten sozioökonomischen Egalisierungspolitik trugen zur Unterstützung bei. ${ }^{319}$ Die Vorstellung eines sinnvollen und gerechten Vorgehens wurde durch die staatliche Propaganda untermauert, die die Vertreibungen als zivil und human durchgeführte Aussiedlungen darstellte. ${ }^{320}$

Ein wesentlicher Unterschied zwischen Polen und der ČSR war die in der Tschechoslowakei existierende breite Unterstützung der Kommunisten durch die Bevölkerung, ebenso wie ein traditionell gutes Verhältnis zu Russland und nun zur Sowjetunion, das erst 1968 schwer beschädigt wurde. Die Polen fanden sich hingegen an der Seite ihres ehemaligen Kriegsgegners wieder, der einen Teil der polnischen Eliten ermordet und ihnen ein Drittel des Landes entrissen hatte. ${ }^{321}$ Die Entscheidungen für die Vertreibungen wurden in der ČSR sowohl vom demokratischen Exil als auch von der späteren bürgerlich-kommunistischen Regierung getragen, wohingegen Polen von Beginn an unter sowjetischem Diktat stand. ${ }^{322}$

In beiden Ländern war Geschichte nicht nur ein wichtiges Herrschaftsinstrument der kommunistischen Machthaber, auch die Opposition führte intern intensive Diskussionen um historisch-moralische Fragen und bekämpfte die Lügen und Auslassungen der staatlichen Geschichtspolitik und damit das Legitimationsfundament der Regime. Innerhalb der oppositionellen Debatten ging es mit den bekannten Ausnahmen aber zumeist weniger um eine grundsätzliche, selbstkritische Revision der nationalen Geschichtsschreibung, sondern um die Darstellung der wahren Nationalgeschichte. Kritische und provokative Schriften wie die von Ján Mlynárik oder im weiteren Sinne der polnische Bischofsbrief von 1965 zur Zwangsmigration der Deutschen wurden nicht nur staatlicherseits bekämpft, sondern auch von großen Teilen der Gesellschaft abgelehnt. Der historische Diskurs unter den Dissidenten blieb so ein heterogener Elitendiskurs, der in Bezug auf das Thema Flucht und Vertreibung vor 1989 keine hegemoniale Stellung einnehmen konnte. In der Dissidentenszene der DDR spielte die Frage der Vertreibung praktisch keine Rolle, trotz oder wegen enger Verbindungen zu oppositionellen Gruppen Polens und der Tschechoslowakei.

Die von den kommunistischen Regimes bis zuletzt genutzte Argumentation mit der deutschen Gefahr hatte sich bereits in den 1970er Jahren mangels realpolitischer Bezüge abgenutzt, was aber nicht hieß, dass die im Kern nationalistischen Narrative über die Wiedergewonnenen Gebiete oder den odsun ihre Bedeutung verloren hätten. Vielmehr war dies Teil des fortwirkenden Erbes des `Nationalkommunismus‘ dieser Länder. Gegenerzählungen, wie das vor 1989 in Dissidentenkreisen geäußerte Bedauern und Verständnis für das deutsche Leiden und das Schicksal der Vertriebenen sind aber keineswegs als einseitige Übernahme der westdeutschen Position zu verstehen.

In die stark nationalistischen Narrative der VRP und der ČSR mussten schließlich die Deutschen der DDR eingefügt werden und umgekehrt musste der Bevölkerung der

319 Fend: Vom Ende des Zweiten Weltkrieges bis zum Beginn der »Wende«, 2016, S. $65 f$.

320 Vgl. Röger: Bilder der Vertreibung, 2014, S. 269.

321 Vgl. Fend: Vom Ende des Zweiten Weltkrieges bis zum Beginn der »Wende«, 2016, S. 75-77.

322 Ebd., S. 66. 
DDR, von denen über 20 Prozent Vertriebene oder deren Nachfahren waren, der Heimatverlust erklärt werden. Als ein narrativer Kompromiss diente dafür die Vorstellung einer historischen Fehlentwicklung der deutschen Ostsiedlung, die oberflächlich war und von einer aggressiven deutschen Elite vorangetrieben wurde. Diese spiegelt sich im volkspolnischen Narrativ über die kresy, in denen vor allem polnische Magnaten die eigentliche ukrainische und weißrussische Bevölkerung unterdrückt hätten. ${ }^{323}$ Weniger als solche Rechtfertigungsnarrative zu nutzen, bemühte man sich in der staatlich kontrollierten Öffentlichkeit, die Erinnerung an die deutschen Ostgebiete und die kresy in Polen möglichst zu vermeiden und vor allem jede Kritik an dieser Ordnung zu verhindern. ${ }^{324}$

Die Beziehung zwischen DDR, VRP und ČSR/ČSSR wurde ab 1949 von einer intensiv bemühten sozialistischen Freundschaftsrhetorik begleitet, die sich in verschiedenen zwischenstaatlichen Aktivitäten, aufwändig initiierten Grenztreffen und sogenannten >Freundschaftswochen äußerte. ${ }^{325}$ Diese konnten jedoch anhaltende nationale Ressentiments nicht oder nur teilweise beseitigen, zumal eine (selbst-)kritische Aufarbeitung der Geschichte des Zweiten Weltkrieges auf Seiten der DDR ausblieb, die sich und ihre Bevölkerung als Teil der Sieger sah und jede Verantwortung in den Westen schob. ${ }^{326}$ Dennoch war eine solche Erzählung von der Bevölkerung der VRP und der ČSR/ČSSR nur schwer zu akzeptieren. Das Verhältnis verbesserte sich jedoch mit der Zeit durch den zunehmenden Reiseverkehr und intensive Kulturkontakte. ${ }^{327}$ In der politischen Führungsebene blieben nationale Vorurteile und Konflikte trotz zum Teil intensiver Kooperation und guter Verbindungen bestehen. ${ }^{328}$

Das Verhältnis der Bundesrepublik zu Polen und der Tschechoslowakei war bis in die 1970er Jahre durch die Thematik von Flucht und Vertreibung weitgehend blockiert, während die Propagierung der (bundes-)deutschen Gefahr in der weiteren Nachkriegszeit nicht nur ein Instrument der Regimestabilisierung der Kommunisten war, sondern an reale Erfahrungen aus der Besatzungszeit und damit verbundene Ängste anknüpfen konnte. ${ }^{329}$ Die Neue Ostpolitik ermöglichte hier einen Aufbruch, dem gleichwohl schon durch zivilgesellschaftliche und kirchliche Initiativen in den 1960er Jahren der Weg geebnet wurde. Der in der Bundesrepublik zunehmend isolierte Bund der Vertriebenen konnte schließlich in der Verständigungspolitik keine zentrale Rolle mehr einnehmen - auch nicht 1989 und trotz der Tatsache, dass viele Vertriebene mit ihren Reisen in die alte Heimat oft die ersten waren, die eine Verständigung vor Ort erreichten.

Aber auch bei den Verständigungswilligen blieben Missverständnisse nicht aus: Auf deutscher Seite übersahen die Vertriebenenverbände und ihr Umfeld die enge Verbindung von Regierung und polnischer und tschechischer Bevölkerung in der Frage der

323 Matthei: Die Massenumsiedlungen und das Bild der Deutschen, 2006, S. 87.

324 Vgl. Olschowsky: Versöhnungsinitiativen, 2009, S. 317.

325 Zimmermann: Wechselnde Bündnisse, 2010, S. 94.

326 Dabei handelt es sich, ggf. unter anderen ideologischen Vorzeichen, um ein durchaus gängiges Vorgehen im Europa jener Zeit: Cornelißen; Holec et al.: Politisch-historische Erinnerungen, 2005, S. 14 .

327 Vgl. Olschowsky: Versöhnungsinitiativen, 2009, S. $327 \mathrm{f}$.

328 Vgl. Zimmermann: Wechselnde Bündnisse, 2010, S. 95.

329 Vgl. Ahonen: On Forced Migrations, 2014, S. 610. 
Grenzen und sie missverstanden zum Teil auch die Äußerungen der Oppositionellen. Deren in Bezug auf die Vertreibung vor allem moralisch geprägte Diskussionen bewerteten sie in ihrem gesellschaftlichen Einfluss über und zogen sie gelegentlich fälschlicherweise zur Rechtfertigung eigener Ansprüche heran. In Deutschlands linksliberalem Spektrum kam es zum Teil zu einer unkritischen Übernahme osteuropäischer Positionen, zudem idealisierte man die dortige Dissidentenszene nach den eigenen Maßstäben und blendete den nationalen und zum Teil konservativen Charakter dieser Bewegungen aus. ${ }^{330}$ Bei der historischen Betrachtung der Verbindungslinien zwischen den untersuchten Ländern darf schließlich nicht außer Acht gelassen werden, dass die oppositionellen Diskurse, die staatliche Agitation, aber auch das Wirken der Vertriebenenverbände vor allem zunächst an die jeweiligen Gesellschaften adressiert waren. Das gilt nach Piotr Madajczyk beispielsweise auch für den Brief der polnischen Bischöfe $1965 .{ }^{331}$

Die Bewertung von und Erinnerung an Flucht und Vertreibung »became a highly contested matter, nationally and internationally, and it has remained that way, even in the era following the Cold War. ${ }^{332}$ In der pluralistischen Bundesrepublik hatte sich von allen hier betrachteten Ländern der stärkste Wandel der Erinnerungskultur vollzogen, wovon allerdings die organisierten Vertriebenen weitgehend ausgenommen waren. Ihre Erzählung traf 1989 auf ebenso lang staatlich kultivierte, ähnlich wenig offene und selbstkritische Opfererzählungen der polnischen und tschechischen Gesellschaft. ${ }^{333}$ Hier ist ein starker Kontrast zur gelegentlich als Vorbild herangezogenen deutsch-französischen Aussöhnung zu sehen, die bald nach Kriegsende im Rahmen demokratischer Gesellschaften begann und von einer geringeren Schwere der deutschen Kriegsverbrechen in Frankreich profitierte.

Der politische Umbruch 1989 traf die hier behandelten Gesellschaften erinnerungspolitisch unvorbereitet. Die von den politischen Eliten aller Länder angestrebte rasche Verständigung durch den Abwurf des historischen Ballastes konnte nicht erreicht werden. Am deutlichsten zeigt sich dies in der Tschechoslowakei, wo Václav Havels zur Verständigung und Versöhnung ausgestreckte Hand in Richtung der Sudetendeutschen auf Druck der Bevölkerung sowie aufgrund des Fehlens gleichwertiger landsmannschaftlicher Reaktionen und mangelnder Kompromissbereitschaft zurückgezogen werden musste.

Christoph Cornelißen, Roman Holec und Jiř́ Pešek konstatieren als bleibendes Erbe der kommunistischen Staaten, dass nicht nur die besonders von der »deutschen Expansions- und Vernichtungspolitik« betroffenen Menschen und ihre Nachfahren das Narrativ über die Deutschen und das wechselseitige Verhältnis in Ostmitteleuropa langfristig und auf negative Weise prägten. Auch das politisch instrumentalisierte Geden-

330 Vgl. Peters: Revolution der Erinnerung, 2016, S. 18.

331 Madajczyk: Die deutsche Reaktion auf den Brief der Bischöfe in der polnischen Rezeption, 2009, S. $207 f$.

332 Ahonen: On Forced Migrations, 2014, S. 599.

333 Seibt: Wissenschaft als Brückenschlag, 2002, S. 257. Spurný: Czech and German Memories of Forced Migration, 2012, S. 364. Fend: Vom Ende des Zweiten Weltkrieges bis zum Beginn der »Wende $\lll, 2016$, S. 88. 
ken habe bedeutenden Einfluss auf das individuelle Gedächtnis der Menschen gehabt. Eine Bekräftigung dieser Erinnerung erfolgte durch das Verschweigen der »radikale[n]

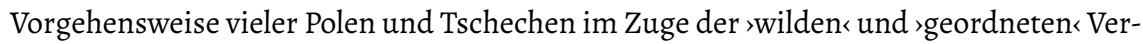
treibungen [...]«. Diese Auslassungen verstärkten das Erbe der nationalkommunistischen Erinnerungskultur: »Zugleich verhängten die Regierungen in den nach 1945 errichteten >Volksdemokratien « ein Schweigegebot über die Vorgänge um Flucht und Vertreibung. Dieses verordnete Schweigen hat sich langfristig als eine schwere politische Hypothek erwiesen. $\ll^{334}$

Die Grenzfrage, die die Beziehungen zwischen den Ländern sowie das Selbstverständnis der Vertriebenenverbände in der Bundesrepublik so lange geprägt hatte, wurde schließlich mit den Zwei-Plus-Vier-Verträgen abschließend geklärt. Offen blieb die Frage, wie in den nun freien Gesellschaften Polens und Tschechiens sowie einem sich vereinigenden Europa Flucht und Vertreibung bewertet werden sollten. 



\section{Diskurse über Flucht und Vertreibung nach 1989}

Während des Kalten Krieges entwickelte sich weder in noch zwischen den untersuchten Ländern und Gesellschaften eine anschlussfähige Erzählung über das historische Geschehen von Flucht und Vertreibung. Mit dem Ende der Blockkonfrontation schien eine Verständigung im Zuge der europäischen Integration nicht nur greifbar nah, sie schien auch dringend geboten. In der die ostmitteleuropäischen Gesellschaften bis heute beschäftigenden Erinnerung an den Zweiten Weltkrieg stellen Flucht und Vertreibung nur ein, wenn auch ein zentrales Element dar. Im Mittelpunkt der nationalen Erinnerungskulturen stehen die deutsche Besatzungsherrschaft und der eigene Widerstand. Themen wie Kollaboration oder Zwangsmigration der Deutschen werden kontrovers diskutiert, da sie das Potenzial besitzen, die gängigen Narrative in Frage zu stellen. ${ }^{1}$

Der Fall der kommunistischen Diktaturen 1989 ermöglichte eine neue Beschäftigung mit den zuvor tabuisierten Themen wie der Vertreibung der Polen aus den kresy, Katyń und der kommunistischen Herrschaft, denen sich Forschung und Zivilgesellschaft verstärkt zuwendeten. Die Auseinandersetzung mit Flucht und Vertreibung fiel oft mit der zuvor vernachlässigten Beschäftigung mit der Lokal- und Regionalgeschichte zusammen. Auch in Deutschland kündigten sich in den 1990er Jahren einige erinnerungskulturelle Verschiebungen an, die schließlich Anfang der 2000er Jahre in mehreren Ereignissen kulminierten, wie den heftigen Debatten um ein Zentrum gegen Vertreibungen. ${ }^{2}$

Mit der nach 1989 nun Mittel- und Osteuropa einbeziehenden europäischen Integration zeichnete sich nach Catherine Schilling »eine neue Spaltung der Erinnerungsdiskurse ab. Nicht nur geographisch, auch innerhalb der Gesellschaften schwinge das Gedenken an den Zweiten Weltkrieg »im östlichen und mittelöstlichen Europa zwischen Nationalisierung und Universalisierung. $\aleph^{3}$ Dies steht nur scheinbar im Widerspruch zur zunehmenden Europäisierung verschiedener Lebens- und Politikbereiche. Nationale und nationalistische Geschichtserzählungen- und politiken erleben eine Renaissance, ebenso wie sich gegenläufige Tendenzen aufzeigen lassen, beispielsweise mit 
der Erklärung der Stockholmer Holocaust-Konferenz von 2000 und der sich darin manifestierenden Internationalisierung der Holocausterinnerung als zur Bewahrung der Menschenrechte verpflichtendem Erbe der Menschheit. ${ }^{4}$

Nach Claus Leggewie und Anne Lang handelt es sich bei den Vertreibungen um ein "gesamteuropäisches Trauma «" ${ }^{5}$, welches zugleich mit weiteren ethnischen Säuberungen und "genozidalen Akte[n] « ein entscheidendes Hemmnis auf dem Weg zu einer gemeinsamen europäischen Erinnerung darstellt. ${ }^{6}$ Auch wenn die nach 1989 erneut oder neu aufgebrochenen erinnerungspolitischen Konflikte von großer Bedeutung zu sein scheinen, weisen die Autoren einschränkend darauf hin, dass eine Spaltung zwischen West- und Osteuropäern sich vielmehr auf Fragen von »Sicherheit, Energie, Freizügigkeit und dergleichen « beziehe und erinnerungskulturelle Konflikte unter Umständen »eher [der] [...] Ablenkung « dienen. ${ }^{7}$

Christoph Kleßmann hat für das Verhältnis zwischen der Bundesrepublik und der DDR den Begriff der »asymmetrisch verflochtenen Parallelgeschichte« eingeführt. Auch für das Verhältnis Deutschlands zu seinen östlichen Nachbarn ist das unterschiedlich starke Aufeinanderbeziehen stets zu berücksichtigen. So erfährt Deutschland in Medien und Politik in Polen und Tschechien eine weit größere Aufmerksamkeit als umgekehrt. Auf der einen Seite sind daher in der Breite der Bevölkerung umfassende Kenntnisse über Deutschland vorhanden, auf der anderen Seite führt der ständige Blick auf den westlichen Nachbarn gelegentlich zu einer verzerrten Wahrnehmung wie der Überschätzung des Einflusses der Vertriebenenverbände; zudem wird das Verhältnis zu Deutschland wiederholt innenpolitisch instrumentalisiert. ${ }^{8}$ Ein weiterer grundlegender Unterschied besteht in der Bedeutung von Geschichte und Erinnerung in den jeweiligen Gesellschaften. In Polen ragt nach Peter Oliver Loew »die Geschichte [...] viel unmittelbarer in die Gegenwart hinein, als dies in den meisten anderen Ländern Europas der Fall« ist. ${ }^{9}$ Ferdinand Seibt stellt Ähnliches für Tschechien fest, wo »Geschichte als Wissenschaft und als Literatur eine ungleich größere Rolle als bei uns [spielt]. $\ll^{10}$

Die folgenden Seiten diskutieren erneut vor allem die Entwicklungen auf nationaler und internationaler Ebene. Regionale Unterschiede innerhalb der Länder sind dennoch

Sierp: History, Memory, and Trans-European Identity, 2014, S. 91f. Flierl; Müller: Transitraum, 2010, S. 7.

5 Leggewie; Lang: Der Kampf um die europäische Erinnerung, 2011, S. 27-32.

6 »Erinnerungen an erzwungene, großflächige und [...] Zigtausende von Menschen betreffende $>B e-$ völkerungstransfers`dürften bei aller Unterschiedlichkeit der Motive, Begründungen und Verläufe der Deportationen im kollektiven Gedächtnis Europas am tiefsten verankert sein.«Ebd., S. 27. Auch Ther konstatierte, dass im Verhältnis von Deutschland zu Tschechien und Polen die »Aufarbeitung der jüngsten Vergangenheit, insbesondere der Vertreibung, eine Schlüsselrolle« spiele: Ther: Chance und Last der Ceschichte, 1996, S. 994.

7 Leggewie; Lang: Der Kampf um die europäische Erinnerung, 2011, S. $28 f$.

8 Ther: Der Diskurs um die Vertreibung, 2008, S. 36f. Vgl. zur Kritik an dieser auch von polnischen Intellektuellen so wahrgenommenen »Asymmetrie«, die in Form der »Unkenntnis der Deutschen« über Polen das »Konzept einer deutsch-polnischen Partnerschaft« auf Augenhöhe konterkariere: ebd., S. $39 f$. 
$\mathrm{zu}$ berücksichtigen. Erinnerungskultur und Geschichtspolitik schwanken beispielsweise sehr zwischen den von der Vertreibung der Deutschen stark und den davon kaum betroffenen Gebieten. Oberschlesien als Sonderfall wird im nächsten Kapitel einleitend diskutiert. Für die Verständigung nehmen besonders Basisinitiativen vor Ort eine bedeutende Rolle ein, oft mit überregionaler und übernationaler Wirkung, sodass verschiedentlich auf sie einzugehen sein wird.

\subsection{Deutschland}

Das vereinigte Deutschland stand vor der Herausforderung, eine neue Verständigung mit den Nachbarn Polen und der Tschechoslowakei zu finden. Politisch und ökonomisch war das Land trotz der wirtschaftlich schwierigen 1990er Jahre nun in eine kaum bestreitbare mitteleuropäische Machtposition gerückt, wobei die ökonomische Verflechtung mit Polen und Tschechien besonders stark und präsent war. Auch dies gilt es für den Diskurs zu berücksichtigen, denn Deutschland diente in Ostmitteleuropa sowohl im positiven wie negativen Sinne als Vorbild und Symbol des westlichen Wirtschaftsund Gesellschaftssystems.

Das scheinbare Schwanken Helmut Kohls bei der Grenzfrage 1989/90 wurde bereits in Kapitel 4 angesprochen. Auch wenn auf polnischer Seite zumindest heute kaum jemand mehr dessen grundsätzlich positive Haltung zum Erreichen einer raschen Aussöhnung mit Polen in Frage stellt, urteilte Adam Krzemiński 2013, dass Kohl bei der Grenzfrage lediglich »trickste [...] um den Verlust von ein paar Prozent der Stimmen von der Seite der Vertriebenen nicht zu riskieren. «" Verschiedene deutsche Autoren bewerten das zurückhaltende Vorgehen Kohls und den Verzicht auf eine sofortige Erklärung über die Endgültigkeit der Oder-Neiße-Grenze im November 1989 vielmehr als eine wichtige Leistung. Dieser längere Weg zu den Vereinbarungen von 1990/91 habe es ermöglicht, die Vertriebenen >mitzunehmen wirkt. ${ }^{12}$ Emil Nagengast sieht ebenfalls die integrative Wirkung der engen Bindung der Vertriebenenverbände an die CDU/CSU, trotz ihrer zunehmenden gesellschaftlichen Isolierung in den 1980ern Jahren und den fortbestehenden Forderungen auf ein Rückkehrrecht und umfassende Entschädigungen. In der entscheidenden Phase 1989 gab die CDU/CSU diesen Forderungen aber nicht nach. Tragisch sei für die Vertriebenen und ihre Verbände, dass die seit den 1950er Jahren von ihnen angestrebte friedliche Lösung im Rahmen einer europäischen Vereinigung jetzt am ehesten greifbar, aber politisch ohne jede Unterstützung blieb:

»The final tragedy for the expellees, however, is that after waiting decades for panEuropean integration to become a real possibility they have been abandoned - even by their own government. $\ll^{13}$ 
Aus eigener Kraft waren die Vertriebenenverbände nicht in der Lage, entscheidend Einfluss auf die innerdeutschen und auch die polnischen und tschechischen Debatten zu nehmen. Miroslav Kunštát sieht die Verbände von den Ereignissen der Wende »regelrecht überrumpelt [...] und psychologisch und politisch vorrübergehend fast raußer Betrieb $<.{ }^{14}{ }^{4}$ Angebote von tschechoslowakischer Seite, namentlich von Václav Havel, an die Sudetendeutschen zur Wiederherstellung der Staatsbürgerschaft ehemaliger tschechoslowakischer Staatsbürger, eines eingeschränkten Rückkehrrechtes ohne Restitution und einer Beteiligung an der Privatisierung waren aus heutiger Sicht die beste Offerte, die sie erhalten konnten. ${ }^{15}$ Die Sudetendeutsche Landsmannschaft blieb aber bei ihren Maximalforderungen und die Bundesregierung hatte kein Interesse, diese Thematik intensiv zu verfolgen und die weitere außenpolitische Situation $\mathrm{zu}$ verkomplizieren. Das gilt nach Kunštát auch für die Innenpolitik, fiel dieser Vorschlag einer doppelten Staatsbürgerschaft doch in die Zeit heftiger Asyldebatten in Deutschland, in der die konservativ-liberale Bundesregierung keinen »Präzedenzfall« schaffen wollte. ${ }^{16}$

Mögen die Vertriebenenverbände selbst ihre politischen Positionen nicht erfolgreich eingebracht haben, so nutzten doch ihre Untergruppen ebenso wie viele Vertriebene als Einzelpersonen oder ihre Nachfahren die Chance zur nun leichter möglichen Reise in die alte Heimat. Hier konnten sowohl alte als auch neue Bewohner abseits der Politik Verständigung auf persönlicher Ebene erreichen. ${ }^{17}$ Andreas Kossert bezeichnet die Vertriebenengruppen und Heimatvereine oft als eine "Art Avantgarde der Versöhnung", die vielfach zu dauerhaften Verbindungen kultureller und karitativer Art führte. ${ }^{18}$

In den 1990er Jahren sollten verschiedene Verträge das Verhältnis von Deutschland zu Polen und Tschechien für die Zukunft regeln. Nach dem Zwei-plus-Vier-Vertrag klärte der deutsch-polnische Grenzvertrag vom November 1990 die Grenzfrage endgültig. Der 1991 vereinbarte deutsch-polnische Nachbarschaftsvertrag widmete sich neben der Frage des Umgangs mit der deutschen Minderheit vor allem Zukunftsthemen. $23 \mathrm{Ab}$ geordnete aus der CDU/CSU, darunter viele mit Verbindungen zum BdV, wie die neugewählte Bundestagsabgeordnete Erika Steinbach, stimmten gegen den Grenzvertrag, da sie vor allem "Eigentums- und Vermögensfragen « als nicht oder nicht hinreichend geklärt ansahen. ${ }^{19}$ Die Mehrzahl von ihnen stimmte allerdings für den Nachbarschaftsvertrag. ${ }^{20}$

Bei dem zunächst noch zwischen der Tschechoslowakei und später ihrem Rechtsnachfolger, der Tschechischen Republik, ausgehandelten deutsch-tschechischen Nachbarschaftsvertrag (1992) und der Deutsch-Tschechischen Erklärung (1997) standen ähnlich wie bei den deutsch-polnischen Verträgen Fragen der Gegenwart und Zukunft im

14 Kunštát: Die Wiedervereinigung Deutschlands und die tschechoslowakische Außenpolitik, 2010, S. 211.

15 Handl: Die Politik des wiedervereinigten Deutschland gegenüber der Tschechischen Republik, 2010, S. 237.

16 Kunštát: Die Wiedervereinigung Deutschlands und die tschechoslowakische Außenpolitik, 2010, S. 212.

17 Ohliger: Flucht und Vertreibung als Migrationsgeschichte, 2006, S. 232f. Vgl. Benthin: Die Vertreibung der Deutschen aus Ostmitteleuropa, 2007, S. 128.

18 Kossert: Kalte Heimat, 2009, S. 303.

19 Nelhiebel: Die Stiftung Flucht, Vertreibung, Versöhnung, 2016, S. 524.

20 Siehe zur Position Erika Steinbachs: Steinbach: Flucht, Vertreibung, Mahnung, 2016, S. 170. 
Mittelpunkt. Das Thema von Eigentumsrechten vertriebener Sudetendeutscher wurde auf Bestreben der Bundesregierung bewusst ausgeklammert, auch wenn die tschechische Seite sich eine endgültige Klärung in ihrem Sinne gewünscht hätte. Die deutsche Seite befürchtete aber, dass in diesem Falle die Sudetendeutschen die Forderungen an die Bundesrepublik richten könnten oder aber bei Unterstützung der sudetendeutschen Forderung die deutsch-tschechischen Beziehungen nachhaltig ebenso wie das internationale Ansehen Deutschlands beschädigt worden wären. ${ }^{21}$ Den Forderungen der Sudetendeutschen Landsmannschaft, direkt an den Verhandlungen mit der Tschechoslowakei und später der Tschechischen Republik beteiligt zu werden, verweigert sich die Bundesregierung trotz verschiedentlich anderslautender Zusagen konsequent. ${ }^{22}$

$\mathrm{Zu}$ einer grundsätzlichen Neuverhandlung über das historische Geschehen kam es in der Bundesrepublik in der ersten Hälfte der 1990er Jahre nicht. ${ }^{23}$ Philipp Ther konstatierte noch 1996, dass der "sozial-liberale mainstream der Bundesrepublik « das Thema der Vertreibung »Jahrzehnte lang verdrängt « habe. ${ }^{24}$ Erst die Bilder von den Vertreibungen der Balkankriege der 1990er Jahre riefen das Vertreibungsgeschehen des Zweiten Weltkrieges bei vielen in die individuelle, aber auch in die breite öffentliche Erinnerung zurück. Eine frühe Verbindung zog Hans Lemberg 1992, der den bereits zu Beginn der Balkankriege in der Krisenregion entstandenen Begriff der »ethnischen Säuberung« diskutierte und das Geschehen mit den >Umsiedlungen Hälfte des 20. Jahrhunderts verglich. Aus seinen Beobachtungen folgerte er, dass »das Prinzip der sethnischen Säuberung « sich »wie ein roter Faden« durch »die Geschichte des mittleren und östlichen Europa im zwanzigsten Jahrhundert « ziehe. ${ }^{25}$ Der Osteuropahistoriker Karl Schlögel fasste sieben Jahre später und unter dem Eindruck des Kosovokrieges das vermeintlich so fremde Geschehen zusammen:

»Überall in Europa gibt es Menschen, die wissen, was passiert, wenn niemand mehr da ist, der einschreitet, wenn der Mob regiert. Überall gibt es Leute, die uns erzählen könnten, was das ist: ethnische Säuberung. Sie alle wissen, was Balkan ist, auch wenn sie noch nicht da gewesen sind. Europa am Ende des Jahrhunderts, das länger dauert als die Ceschichtsphilosophen vorgesehen haben, ist ein großes Déjà-vu. [...] Europa war überall Balkan. Er ist uns nicht so fremd, wie es im Augenblick des Entsetzens scheint. ${ }^{26}$

Besonders bei verschiedenen Akteuren der politischen Linken in Deutschland führte dieses Geschehen zu einer Revision der eigenen Einstellung und einer neuen Anteil2010, S. 236

Vgl. Feindt: Flucht und Vertreibung zwischen Kaltem Krieg und Universalisierung, 2014, S. 164. Ther: Chance und Last der Ceschichte, 1996, S. 995.

Lemberg: »Ethnische Säuberung«, 1992, S. 27. Lemberg plädiert mit Blick auf diese Ceschichte gegen jede Renaissance des Ansatzes, ethnisch heterogene Cebiete für eine dauerhafte Friedenslösung zu >entmischen<.

Schlögel: Kosovo ... Die Zeit. 29.04.1999. 
nahme an dem historischen Schicksal der deutschen Vertriebenen. ${ }^{27}$ Michael Schwartz spricht mit Bezug auf Klaus Naumann von einem »Kosovo->Erlebnis`, welches »eine >indirekte Aktualisierung < bewirkte und das geschichtspolitisch sensible Verhältnis zwischen Deutschland, Polen und Tschechien aufwühlte ${ }^{28}$ Die gegen erheblichen Widerstand in den eigenen Reihen durchgesetzte Intervention im Kosovokrieg 1999 stellte die rot-grüne Bundesregierung vor die Herausforderung, diesen Einsatz zu rechtfertigen und zugleich ihre Position zu verteidigen, warum die Vertreibungen von 1945 hingegen $\mathrm{zu}$ akzeptieren und mit dem aktuellen Geschehen nicht zu vergleichen seien. ${ }^{29}$ In diese sargumentative Lücke<stieß das Projekt des BdV, ein Zentrum gegen Vertreibungen einzurichten..$^{30}$ Schon zuvor hatte unter anderem die Sudetendeutsche Landsmannschaft Mitte der 1990er Jahre die Parallelisierung der damaligen Vertreibungen mit denen der Balkankriege für eine Aktualisierung ihres Anliegens und zur erneuten Verurteilung der damaligen >Vertreiberstaaten $<$ aufgegriffen. ${ }^{31}$

1998 wählte der Bund der Vertriebenen Erika Steinbach zu seiner Präsidentin, die eine Neuausrichtung und Erneuerung des Verbandes einleitete. ${ }^{32}$ Dies geschah rechtzeitig, um als relevanter Akteur bei dem gewachsenen Interesse an der Vertreibungsgeschichte mitzuwirken und dieses zu verstärken. ${ }^{33}$ Steinbach gelang es wenigstens teilweise, den BdV als akzeptierten Opferverband nach dem Muster anderer moderner Opferverbände zu positionieren. ${ }^{34}$ Unter anderem erreichte sie dies durch eine Globalisierung der Thematik, in deren Rahmen die Vertreibung weniger als exzeptionelles denn als eines der zahllosen Menschenrechtsverbrechen des Zweiten Weltkrieges und des 20. Jahrhunderts erschien..$^{35}$ Hieran knüpfte sich das neue Selbstverständnis des BdV an, der sich seitdem verstärkt als Akteur der Menschenrechtspolitik und weltweiter Mahner gegen Zwangsmigrationen betrachtet. ${ }^{36}$

27 Haslinger: Die Dynamik der aktuellen geschichtspolitischen Debatten um »Flucht und Vertreibung « in Zentraleuropa, 2006, S. 282. Vgl. für die Parallelisierung des Geschehens mit der Vertreibung der Deutschen die Zeitschrift des BdV: Ethnische Säuberungen im Kosovo müssen sofort eingestellt werden. DOD. 01.04.1999. In der Süddeutschen Zeitung sprach Gustav Seibt von einem »spezifisch altbundesrepublikanischen Hochmut gegenüber den Vertriebenen «, der durch das Geschehen auf dem Balkan abgebaut werden konnte: Seibt: Heimat und Totengedenken. Süddeutsche Zeitung. 18.07.2003.

28 Schwartz: Ethnische »Säuberungen« in der Moderne, 2013, S. 625.

29 Vgl. Wolfrum: Die beiden Deutschland, 2005, S. 153.

30 Troebst: Towards a European Memory of Forced Migration? 2016, S. $237 f$.

31 Houžvička: Czechs and Cermans 1848-2004, 2015, S. 409.

32 Vgl. Jakubowska: Der Bund der Vertriebenen in der Bundesrepublik Deutschland und Polen, 2012, S. 165 .

33 Vgl. ebd., S. 188, 197. Vgl. auch: Hahn; Hahn: Die Vertreibung im deutschen Erinnern, 2010, S. 592. 34 Der Journalist Joachim Güntner verweist auf den Historiker Michael Jeismann, der den Vertriebenen empfiehlt, ihr Schicksal als »Phänotyp« einer »fundamentalen politischen Erfahrung des 20 Jahrhunderts « zu begreifen: »Das ist die Empfehlung, sich in der internationalen Opferkultur einen Platz zu suchen und auf diese Weise aus dem Abseits des Revanchismus herauszukommen." Güntner: Opfer und Tabu. NZZ. 23.02.2002. Vgl. Ther: Der Diskurs um die Vertreibung, 2008, S. $38 f$. Vgl. Güntner: Opfer und Tabu. NZZ. 23.02.2002.

36 Siehe hierfür z.B. Erika Steinbachs Rhetorik über aktuelle Zwangsmigrationen: »Das eigene Leid, die eigene Erinnerung steht neben dem schrecklichen Erleben anderer. Diese haben unsere volle Empathie. Vielleicht ist es gerade unser Leid, das uns zu einem anderen Mitgefühl befähigt [...]«. 
Der Bund der Vertriebenen versteht sich seit seiner Gründung 1957 als der »einzige repräsentative Gesamtverband der rund 15 Millionen Deutschen, die infolge von Flucht, Vertreibung und Aussiedlung in der Bundesrepublik Aufnahme gefunden haben und noch finden. ${ }^{37}$ Er setzt sich aus 20 Landsmannschaften und 16 Landesverbänden sowie vier angeschlossenen Mitgliedsorganisationen zusammen. ${ }^{38}$ Als Dachverband der angegliederten Verbände besteht er aus dem BdV-Präsidium sowie der BdVBundesversammlung, deren Delegierte aus den verschiedenen Mitgliedsverbänden stammen. Ziel des Verbandes ist es, in Öffentlichkeit und Politik die Interessen der Vertriebenen zu vertreten, wobei man diese gleichsetzt mit den Belangen des ganzen deutschen Volkes. ${ }^{39}$ Der BdV sieht sich zudem seit seiner Gründung als der entscheidende Verwalter der Erinnerung an Flucht und Vertreibung. Lange stand hier aber eine politische und nicht die individuelle und soziale Erinnerung im Mittelpunkt. ${ }^{40}$

Trotz der fast ausschließlich auf den BdV und seine Verbände ausgerichteten staatlichen Unterstützung der Vertriebenenarbeit konnte er die von ihm angestrebte Rolle jedoch nie vollständig wahrnehmen. ${ }^{41}$ Verschiedene Stimmen in Deutschland, vor allem die politische Linke, hinterfragten und hinterfragen den Alleinvertretungsanspruch des BdV ebenso wie den von ihm postulierten, uneingeschränkten Opferstatus der Vertriebenen, den man in einem Konfliktverhältnis mit der für die reflexive Erinnerungskultur der Bundesrepublik zentralen Stellung des Holocaustgedenkens und der damit verbundenen kritischen Anerkennung deutscher Schuld und Verantwortung sieht. ${ }^{42}$ Die eingeschränkte Akzeptanz als die Vertretung >der Vertriebeneninteressen zeigt sich unter anderem in der Diskussion um die Mitgliederzahl des BdV. ${ }^{43}$ Nach eigenen Angaben von 2010 hat er zwei Millionen Mitglieder, was allerdings von wissenschaftlicher Seite ebenso wie von politischen Gegnern stark angezweifelt wird; so beträgt die Mitgliederzahl aller ihm angehörenden Landsmannschaften gemäß dem BdV-Kritiker Kurt Nelhiebel

Steinbach: Mitgefühl mit den Opfern von Flucht und Vertreibung. DOD. 2008. Vgl. dazu kritisch: Salzborn: Opfer, Tabu, Kollektivschuld, 2007, S. 33-36.

$37 \mathrm{Vgl}$. die Website des BdV: www.bund-der-vertriebenen.de/strukturen-organisation-aufgaben. html (letzter Zugriff: 12.08.2018). Von der deutschen Öffentlichkeit wird der BdV weitgehend als einziger Repräsentant der Vertriebenen akzeptiert. Siehe: Hahn; Hahn: Die Vertreibung im deutschen Erinnern, 2010, S. 517.

38 Zur Struktur des Verbandes und der Unterorganisation vgl. ebenfalls die o.g. Website des BdV.

39 Jakubowska: Der Bund der Vertriebenen in der Bundesrepublik Deutschland und Polen, 2012, S. 4f., 220. Vgl. für eine Definition des BdV als Interessenverband, »pressure« oder »lobby group«: ebd., S. 206.

40 Assmann: Der lange Schatten der Vergangenheit, 2006, S. 192.

41 Wochnik: Non-State Actors, Political Opportunity Structures and Foreign Relations, 2014, S. 226.

42 Vgl. Assmann: Der lange Schatten der Vergangenheit, 2006, S. 203.

43 So konstatiert der Historiker Erich Später in der Frankfurter Rundschau: »Nach meinen Kenntnissen ist auch die Zahl von 550.000 organisierten Vertriebenen noch weit übertrieben, da sind meiner Meinung nach höchstens noch 25.000 aktiv. Der BdV hat die Anzahl seiner Mitglieder schon immer grotesk überhöht dargestellt.« - „Konzentration auf Steinbach lenkt ab«. Frankfurter Rundschau. 11.02.2010. 
zu diesem Zeitpunkt nur 323.000 Mitglieder. ${ }^{44}$ Obgleich die Mitgliedschaft jedem an Kultur und Schicksal der deutschen Vertriebenen Interessierten offensteht, ist der BdV mit dem Problem der Überalterung seiner Führungskräfte und fehlenden Nachwuchses konfrontiert, dem auch die Übernahme der Interessenvertretung der 'Spätaussiedler<, wie der Russlanddeutschen, nur bedingt entgegenwirken konnte. ${ }^{45}$

Die komplexe Struktur des BdV wird, ebenso wie die Arbeit der Landsmannschaften und der zahllosen Ortsgruppen, oft zu wenig beachtet und stattdessen häufig die Vorstellung eines straffen konservativen Kampfverbandes verfolgt. ${ }^{46}$ Dazu haben viele konservative und nationalistische Stimmen in seinen Reihen immer wieder beigetragen. Philipp Ther verweist ebenfalls auf diese Heterogenität der Verbände, in denen es stets »Versöhner « und »Hardliner « gab. ${ }^{47}$ Jenseits der politischen Arbeit erfüllen die Verbände weiterhin eine wichtige soziale und kulturelle Funktion als Treffpunkt und Ort der Bewahrung des deutschen Kulturerbes in Osteuropa. ${ }^{48}$

1999 initiierte der BdV die Stiftung Zentrum gegen Vertreibungen (ZgV), die in Berlin an zentraler Stelle in Form eines Museums mit einer integrierten Gedenkstätte an die deutschen Opfer von Flucht und Vertreibung erinnern sollte. ${ }^{49}$ Hierbei knüpfte er an die intensiv geführten Debatte der 1990er Jahre um die Errichtung eines Denkmals für die ermordeten Juden Europas an. ${ }^{50}$ Stephan Scholz identifiziert weitere Vorbilder der Zentrumsinitiative, so das Holocaust Memorial Museum in Washington oder Yad Vashem in Israel. ${ }^{51}$ Damit schloss sich der BdV der Forderung verschiedener Opferverbände nach einem jeweiligen zentralen Erinnerungsort in der Bundeshauptstadt an. ${ }^{52}$ Das vorgesehene Zentrum sollte von Bund und Ländern finanziert, dessen Inhalte aber maßgeblich vom BdV bestimmt werden. ${ }^{53}$

44 Nelhiebel: Die Entkoppelung von Krieg und Vertreibung, 2010, S. 65. Vgl. dazu die Pressemitteilung des BdV: Bund der Vertriebenen: Der BdV hat zwei Millionen Mitglieder. 07.01.2010.

45 Vgl. Lau: Blühende Museumslandschaften. Die Zeit. 25.09.2003. Vgl. auch: Hahn; Hahn: Die Vertreibung im deutschen Erinnern, 2010, S. 516f.

46 Vgl. zur Vorstellung vom BdV als »Kampfverband « aus polnischer Sicht: Jakubowska: Der Bund der Vertriebenen in der Bundesrepublik Deutschland und Polen, 2012, S. $206 \mathrm{f}$.

47 Ther: Die Außenseiter, 2017, S. 312.

48 Vgl. das Kapitel »Mehr als Trachten und Heimattümelei. Das kulturelle Erbe der Vertriebenen« bei: Kossert: Kalte Heimat, 2009, S. 301-322.

49 Steinbach: Zentrum gegen Vertreibungen. DOD. 13.09.1999. Vgl. Stratmann: Stiftung Zentrum gegen Vertreibungen nimmt Cestalt an. DOD. 19.11.1999. Vgl. für einen chronologischen Überblick über die BdV-Initiative: Haslinger: Opferkonkurrenzen und Opferkonjunkturen, 2011, S. 178-181. Vgl. für die als äußert »unglücklich « bezeichnete Forderung nach einem Mahnmal im potentiellen ZgV: Seibt: Heimat und Totengedenken. Süddeutsche Zeitung. 18.07.2003.

50 Jakubowska: Der Bund der Vertriebenen in der Bundesrepublik Deutschland und Polen, 2012, S. 180. Haslinger: Opferkonkurrenzen und Opferkonjunkturen, 2011, S. 184f. Berg; Broder: Jedem das Seine. Der Spiegel. 2004, S.132f. Vgl. Hahn; Hahn: »The Holocaustizing of the TransferDiscourse $\ll, 2008$, S. 41.

51 Scholz: Vertriebenendenkmäler, 2015, S. 324, 350.

52 Berg; Broder: Jedem das Seine. Der Spiegel. 2004.

53 Jakubowska: Der Bund der Vertriebenen in der Bundesrepublik Deutschland und Polen, 2012, S. $176 f$. 
Kritiker vermuteten, dass das Projekt auch eine Reaktion auf die durch die neue Bundesregierung angekündigten Kürzungen im Bereich der Förderung der Vertriebenenverbände und einen damit einhergehenden Bedeutungsverlust war. ${ }^{54}$ Ein wichtiger Baustein für den Erfolg des ZgV-Projektes war die Beteiligung des langjährigen sozialdemokratischen Spitzenpolitikers Peter Glotz, der glaubhaft in das »linksliberale Meinungsspektrum « hineinwirken konnte. ${ }^{55}$ Mit seinem Tod verlor das Vorhaben nicht nur einen engagierten Verteidiger, sondern auch »massiv an Renommee« in der Öffentlichkeit. ${ }^{56}$ Abgesehen vom Mitinitiator Glotz konnten weitere prominente Unterstützer zeitweise oder dauerhaft für das Vorhaben gewonnen werden, wie zum Beispiel die Publizisten Ralph Giordano und Hellmuth Karasek, der grüne Europapolitiker Daniel Cohn-Bendit und der spätere Bundespräsident Joachim Gauck. ${ }^{57}$ Damit erreichte der $\mathrm{BdV}$ vorübergehend und öffentlichkeitswirksam den angestrebten gesamtgesellschaftlichen Rückhalt.

Bereits in den »Aufgaben und Zielen« des ZgV vom Juni 2000 hieß es: »Die Vertreibung anderer Völker, insbesondere im Europa des 20. Jahrhunderts, soll im Zentrum erfahrbar werden. $\aleph^{58}$ Diese von Beginn an vorhandene europäische Perspektive mit dem Fokus auf dem Schicksal der deutschen Vertriebenen wurde im Zuge des Diskurses ausgeweitet, ${ }^{59}$ sie entsprach allerdings auch dem Selbstverständnis des BdV, eine der anerkannten Opfergruppen des 20 . Jahrhunderts zu repräsentieren. ${ }^{60}$ Nach Erika Steinbach war der europäische Gedanke von Beginn an konstitutiv für das ZgV, auch wenn in der Forschung und Publizistik die Behauptung vertreten wird, dass die >Europäisierung erst durch äußeren Druck erfolgte. ${ }^{61}$

Die seit 1998 amtierende Bundesregierung von Sozialdemokraten und Grünen setzte zunächst erste Zeichen der Entspannung gegenüber den Vertriebenenverbänden. SPD-Innenminister Otto Schily entschuldigte sich öffentlich für das Desinteresse der politischen Linken an dem Thema. ${ }^{62}$ Seine Argumentation war, dass die klare und nicht abzuschließende selbstkritische Erinnerung an die nationalsozialistischen Verbrechen

54 Vgl. Völkering: Die Musealisierung der Themen Flucht, Vertreibung und Integration, 2010, S. 92.

55 Becker: Geschichtspolitik in der »Berliner Republik«, 2013, S. $485 f$.

56 Ebd. Vgl. für einen seiner engagierten Debattenbeiträge, der sich intensiv mit den Kritikern des Zentrums gegen Vertreibungen auseinandersetzt: Clotz: Das »Zentrum gegen Vertreibungen«soll anprangern, 2004.

57 Vgl. Douglas: „Ordnungsgemäße Überführung«, 2012, S. 444f.

58 Zentrum gegen Vertreibungen. Stiftung der deutschen Heimatvertriebenen Berlin: »Aufgaben und Ziele«. Juni 2000, 2008, S. 287.

59 Leggewie: Schlachtfeld Europa, 2009, S. 168f. Auch Becker sieht viele der zum Teil dessen Konzeption ignorierenden Vorwürfe gegen das ZgV als unbegründet an: Becker: Ceschichtspolitik in der »Berliner Republik«, 2013, S. 485.

60 Uhl: Der gegenwärtige Ort von »Flucht und Vertreibung« im deutschen und österreichischen Gedächtnisdiskurs, 2008, S. 168. Siehe auch: Esch: Zum Verhältnis, 2012, S. 83-85.

61 Der Behauptung, dass sich das ZgV erst unter Druck europäisierte, wird vom BdV entgegengehalten, dass es von Beginn an einen europäischen Zugang hatte: Ein produktiver Streit führt zu neuem Denken. DOD. 2003. Vgl. für die Einordnung von Steinbach: Steinbach: Flucht, Vertreibung, Mahnung, 2016, S. 186, 192. Vgl. zur Kritik an einer vorgeschobenen bzw. vermeintlichen Europäisierung des Vertreibungsgeschehens: Hahn; Hahn: Die Vertreibung im deutschen Erinnern, 2010, S. 103-111. Vgl. auch: Troebst: Towards a European Memory of Forced Migration? 2016, S. 246. 
nun Raum lasse für die Erinnerung an die Vertriebenen, die im weiteren Sinne auch Opfer Hitlers waren. ${ }^{63}$ Gerhard Schröder eröffnete im Jahr 2000 als erster Bundeskanzler den Tag der Heimat, allerdings ohne dem BdV inhaltliche Zugeständnisse zu machen. ${ }^{64}$ Das Verhältnis zwischen SPD und BdV verschlechterte sich bald wieder, auch wenn Vertreter wie Otto Schily und viele SPD-Lokal- und Regionalpolitiker mit den Vertriebenenverbänden weiter in einem konstruktiven Austausch stehen. ${ }^{65}$ So nahm die Bundesregierung das ZgV-Projekt zunächst noch interessiert zur Kenntnis, ehe bald die Ablehnung folgte. ${ }^{66}$ Die CDU/CSU unterstützte es hingegen während ihrer Oppositionszeit von Beginn an. Erste Reaktionen aus Wissenschaft und Politik auf die Planungen führten neben der weiteren Europäisierung des Konzeptes zu einer deutlicheren Verortung des Vertreibungsgeschehens im Kontext der NS-Verbrechen. Die baldige Abwendung der Regierung Schröder vom Zentrumsprojekt beruhte unter anderem darauf, dass die Initiative - trotz eines vergleichsweise modernen Ansatzes und der programmatischen Weite - sowohl im Ausland als auch im Inland mit dem Vorwurf konfrontiert wurde, das Erinnerungsparadigma in Deutschland ändern zu wollen. ${ }^{67}$

Der Verband der KZ-Gedenkstätten sah in dem Projekt ein Anzeichen für die »seit einiger Zeit zu beobachtende Wiederbelebung des deutschen Opfermythos «. ${ }^{68} \mathrm{Das} \mathrm{ZgV}$, so die Kritiker, würde die Deutschen in der >Opferhierarchie aufsteigen lassen und deren Leiden als ebenbürtig, wenn nicht sogar größer als die der jüdischen Opfer und anderer Nationen darstellen. ${ }^{69}$ Erika Steinbach warf man eine subtile "Form der Holocaustisierung des Flucht-und-Vertreibungs-Diskurses« und damit eine Infragestellung der Einmaligkeit der Shoa vor. ${ }^{70}$ Der Linkenpolitiker Jan Korte bemängelte, trotz der

63 Sierp: History, Memory, and Trans-European Identity, 2014, S. $88 f$.

64 Schmiese: Landsmann Schröder. Die Welt. 04.09.2000.

65 Vgl. Wochnik: Non-State Actors, Political Opportunity Structures and Foreign Relations, 2014, S. 220 .

66 So stimmten im Jahr 2002 alle im Bundestag vertretenen Parteien für die Einrichtung eines Denkmals oder Zentrums zur Erinnerung an die Vertreibung. Vgl. Haslinger: Opferkonkurrenzen und Opferkonjunkturen, 2011, S. 179. Siehe auch: Schlögel: Nach der Rechthaberei, 2003, S. 17. Vgl. Bundeskanzler Schröder steht Zentrum gegen Vertreibungen aufgeschlossen gegenüber. DOD. 28.01.2000.

67 Vgl. Franzen: Der Diskurs als Ziel? 2008, S. 16-19. Frevert sah in den Planungen des Zentrums gegen Vertreibungen lediglich eine »nationale[...] Nabelschau«statt einer angemessenen zeitlichen, räumlichen und sachlichen Kontextualisierung: Frevert: Ceschichtsvergessenheit und Ceschichtsversessenheit revisited, 2003, S. 12. Vgl. Assmann: Geschichte im Cedächtnis, 2007, S. 145-149.

68 Arbeitsgemeinschaft der KZ-Gedenkstätten in der Bundesrepublik Deutschland: Stellungnahme zum Antrag von Abgeordneten der CDU/CSU zur »Förderung von Gedenkstätten zur Diktaturgeschichte in Deutschland - Cesamtkonzept für ein würdiges Cedenken aller Opfer der beiden deutschen Diktaturen«, 2004. Vgl. auch: Franzen: Der Diskurs als Ziel? 2008, S. 19.

69 Niven: German Victimhood, 2006, S. 15.

70 Kelletat: Von der Täter- zur Opfernation? 2003/2004, S. 139. Hahn; Hahn: »The Holocaustizing of the Transfer-Discourse«, 2008, S. 55. Der das ZgV unterstützende Literaturhistoriker, Schriftsteller und SPD-Mitglied Peter Becher konstatiert in der SZ in diesem Zusammenhang: »Die deutsche Debatte zeichnet sich durch ein geradezu absurdes Ausmaß an Unterstellungen aus. «-Becher: Das Leid der Opfer nicht vergessen. Süddeutsche Zeitung. 30.10.2003. Schlögel vermerkt, dass »fast alles [an der Debatte] parteipolitisch motiviert« gewesen sei, was allerdings auf die ebenso stattfindende fachwissenschaftliche Debatte nur eingeschränkt zutrifft. Schlögel: Nach der Rechthaberei, 2003, S. 33. 
Steinbach zugestandenen klaren Position, in Bezug auf den Holocaust und die deutsche Verantwortung für den Krieg eine »veritable Verharmlosung der Shoah durch ihre sprachliche Parallelisierung mit dem Schicksal der deutschen Bevölkerung am Ende des Zweiten Weltkrieges«, auch wenn ihr selbst dies »vielleicht kaum bewusst, jedenfalls nicht begreiflich sei. $^{71}$

Unversöhnlich standen sich in der bald festgefahrenen Debatte die verschiedenen Seiten gegenüber, bei denen sich drei Positionen in der Bewertung des ZgV ausmachen lassen. ${ }^{72}$ So gab es erstens die des von der CDU/CSU unterstützten BdV, der einen auf die deutschen Opfer fokussierten Erinnerungsort in Berlin schaffen wollte, zweitens die Mittelposition der SPD sowie einiger Intellektueller und Wissenschaftler in Deutschland und im Ausland, die ein derartiges Zentrum zum Beispiel in Breslau oder Straßburg ansiedeln und einen europäischen Ansatz in Form eines Netzwerkes verfolgten wollten. Eine dritte Seite vertrat die Auffassung, dass überhaupt kein Erinnerungsort oder ein Erinnerungsnetzwerk an die Vertreibung der Deutschen erforderlich sei, da es schon genügend Einrichtungen wie das Deutsche Historische Museum oder die verschiedenen Kulturinstitutionen der Vertriebenen gäbe, die dieses Thema ausreichend behandelten. ${ }^{73}$

Im Zuge der Wahlkämpfe in Deutschland und der Tschechischen Republik im Jahre 2002 erreichte das Verhältnis zu den osteuropäischen Nachbarn durch den Vertreibungsdiskurs einen vorläufigen Tiefpunkt. Mit Sorge wurde die deutsche Debatte im Ausland aufgenommen und zum Teil politisch und medial instrumentalisiert. Die unterstellte Verbindung des BdV mit den Tätigkeiten der 2000 gegründeten Preußischen Treuhand und ihren Entschädigungsforderungen gegen Polen und Tschechien sorgte für weitere Verstimmungen und Ängste in Osteuropa sowie entsprechende Gegenreaktionen. ${ }^{74}$ Bei der Preußischen Treuhand handelt es sich um eine Forderungsgesellschaft einiger Vertriebenenfunktionäre und Privatleute, die nach Vorbild der Jewish Claims Conference Entschädigungsforderungen gegen Polen und Tschechien auf internationaljuristischem Wege erzielen wollten. Ihre Forderungen waren schließlich aussichtslos und bis heute nicht erfolgreich. ${ }^{75}$ Auch wenn die Verbandsspitze sich deutlich von der

71 Korte; Wiegel: Einleitung, 2009, S. 8.

72 Benthin: Die Vertreibung der Deutschen aus Ostmitteleuropa, 2007, S. 57. Vgl. Salzborn: Geteilte Erinnerung, 2008, S. 95-102. Vgl. Franzen: Der Diskurs als Ziel? 2008, S. 8-29.

73 Haslinger: Die Dynamik der aktuellen geschichtspolitischen Debatten um »Flucht und Vertreibung « in Zentraleuropa, 2006, S. 293-298. Vgl. auch: Franzen: Der Diskurs als Ziel? 2008, S. 14-16. Siehe für die Forderung nach einem »Europäischen Netzwerk« zur Darstellung der Zwangsmigration: Faulenbach: Überlegungen zu einer Bonner Erklärung, 2006, S. 37-40. Vgl. zum BreslauVorschlag: Traba; Żurek: »Vertreibung « oder »Zwangsumsiedlung «? 2015, S. 336. Vgl. zur Unzufriedenheit des BdV mit der Darstellung des Vertreibungsthemas in den Nationalmuseen: Der »Deutsche Osten « wird ausgeklammert. DOD. 2006.

74 Vgl. Franzen: Der Diskurs als Ziel? 2008, S. 21f. Siehe auch: Haslinger: Die Dynamik der aktuellen geschichtspolitischen Debatten um »Flucht und Vertreibung« in Zentraleuropa, 2006, S. 281f., $294 \mathrm{f}$.

Vgl. Klute: Entschädigungsklagen ohne Erfolgsaussicht? 2004, S. 6-8. 
Preußischen Treuhand distanzierte, wurden in Deutschland die kritischen Stimmen der Nachbarländer besorgt rezipiert und als Argument gegen den BdV angeführt. ${ }^{76}$

Die rot-grüne Bundesregierung initiierte und unterstützte im Folgenden das Alternativprojekt, das sie unter dem Namen Europäisches Netzwerk Erinnerung und Solidarität (ENRS) gemeinsam mit Ungarn, der Slowakei und Polen gründete und welches ein wesentlich breiteres Themenspektrum als das Zentrum abdeckte, es sollten nämlich alle Gewalterfahrungen des 20 . Jahrhunderts grenzüberschreitend thematisiert werden. ${ }^{77}$ So hieß es in der Pressemitteilung des Beauftragten der Bundesregierung für Kultur und Medien zur Gründung des Netzwerkes im September 2005:

»Die europäische Zukunft wird sich nur in Vielfalt geeint gestalten lassen, wenn es den Völkern Europas gelingt, sich gemeinsam ihrer Geschichte zu erinnern, der gemeinsamen wie der trennenden. Das allein war für die Bundesregierung Antrieb, das Netzwerk zu bauen, und nicht der Versuch, eine Alternative zum geplanten Zentrum gegen Vertreibungen zu schaffen. Diese Idee wird bei unseren Nachbarn als Provokation empfunden, weil der Blick auf das Thema Vertreibung national verengt erscheint. Wir aber wollen eine von Cemeinsamkeit getragene Aufarbeitung. ${ }^{78}$

Nach den Regierungswechseln in Polen und Deutschland 2005 verblieb das ENRS jedoch in einem Ruhezustand. Nach dessen Revitalisierung Anfang der 2010er Jahre und einer damit einhergehenden Schwerpunktverlagerung hat es bisher keinen Beitrag zum Diskurs über Flucht und Vertreibung geleistet. ${ }^{79}$

Ein vorläufiger Höhepunkt der seit der Jahrtausendwende vielfach in den Medien präsenten neuen Beschäftigung mit Flucht und Vertreibung war die Veröffentlichung von Günter Grass' Novelle Im Krebsgang im Frühjahr 2002, der sich eine längere publizistische Diskussion anschloss. ${ }^{80}$ In seinem Buch thematisiert Grass den Untergang der

76 Polen und Deutsche kritisieren »Preußische Treuhand«. FAZ. 16.12.2006. Vgl. Hirsch: Flucht und Vertreibung, 2005, S. 119f. Siehe auch: Douglas: »Ordnungsgemäße Überführung«, 2012, S. 442f. Vgl. ebenfalls: Hackmann: German East or Polish West? 2011, S. 93.

77 Vgl. Völkering: Flucht und Vertreibung im Museum, 2008, S. 57f. Siehe für eine Zusammenfassung der Entwicklung des Europäischen Netzwerks Erinnerung und Solidarität bis 2006: Troebst (Hg.): Vertreibungsdiskurs und europäische Erinnerungskultur, 2006, S. 21-29. Siehe zur Position der SPD: Griefahn: Zentrale Aspekte der Erinnerungskultur und Ceschichtspolitik des Bundes, 2009, S. 80.

78 Pressemitteilung der Beauftragten der Bundesregierung für Kultur und Medien: Kulturstaatsministerin Weiss begrüßt Vereinbarung von Projekten des »Europäischen Netzwerks Erinnerung und Solidarität«. 09.09.2005. In der FR hieß es dazu kritisch, dass das Netzwerk eine übereilte Cegenreaktion auf das Zentrum gegen Vertreibungen und ein »Schönwetterprojekt«sei, das transnationale Streitthemen wie die Zwangsmigration bewusst ausblende: Wagner: Falsche Harmonie. Frankfurter Rundschau. 11.08.2005.

79 Vgl. Regente: Europäisches Netzwerk Erinnerung und Solidarität, 2017.

80 Röger: Flucht, Vertreibung und Umsiedlung, 2011, S. 79. Vgl. Schlögel: Nach der Rechthaberei, 2003, S. 17f. Die literarische Beschäftigung mit dem Vertreibungsthema hat Tradition, allerdings erzielten die Werke von Arno Schmidt (Die Umsiedler, 1953) oder Siegfried Lenz (z.B. Heimatmuseum, 1978) keine derartige Breitenwirkung. 2002 widmete sich DerSpiegel mit einem Extraband der Vertreibung der Deutschen und postulierte, dass nun an die deutschen Opfer gedacht werden dürfe: Der Spiegel: Die Flucht, Nr. 13, 2002. Vgl. zur Aufmachung und den Inhalten des Spiegel-Magazins: Hahn; Hahn: Die Vertreibung im deutschen Erinnern, 2010, S. $590 f$. 
mit Flüchtlingen überfüllten Wilhelm Gustloff im Jahr 1945 und das Nachleben dieses Geschehens, also die vermeintliche Tabuisierung durch die Nachkriegsgeneration und die nach wie vor offenen Wunden der traumatisierten Opfer. Diese müssten endlich besprochen und geheilt werden, damit das Thema nicht den Extremisten überlassen bliebe. ${ }^{81}$ Diese - hier stark verkürzte - Botschaft des Buches entfaltete eine ausgesprochene Breitenwirkung. Ihm folgten einige weitere literarische Veröffentlichungen, die sich ebenfalls mit einer verdrängten Vergangenheit und dem Leiden deutscher Opfer befassten. ${ }^{82}$

Heidemarie Uhl stellt fest, dass durch Grass' Buch und dessen großes Medienecho eine konservative Narration der Vertreibung erfolgreich in der breiteren Öffentlichkeit verankert worden sei. ${ }^{83}$ Hierfür wird die Herausbildung eines gesellschaftlichen Konsenses über die vermeintliche Tabuisierung des Vertreibungsthemas verantwortlich gemacht: Das bisher mutmaßlich fehlende Gedenken habe das Erinnern und die Beschäftigung mit den eigenen Opfern nun nicht bloß angemessen, sondern auch geboten scheinen lassen. ${ }^{84}$ Auch Ther sieht als entscheidend an, dass dieser im Prinzip alte Opferdiskurs Anfang der 2000 er Jahre nur eine erfolgreiche Breitenwirkung erzielen konnte, weil verschiedene »Altlinke« wie »Günter Grass, Helga Hirsch und andere Publizisten « sich der Thematik unter der Postulierung eines vermeintlichen Tabubruchs zuwendeten. ${ }^{85}$

Im Kapitel 4 der vorliegenden Arbeit wurde die Entstehung der Tabuthese in den 1970er und 1980er Jahren diskutiert. Sie ist insofern fortwirkend, als dass alle Jahre erneut ein solcher >Tabubruch ausgerufen wird, wie sich zuletzt bei der Ausstrahlung des zweiteiligen TV-Spielfilms Die Flucht von 2007 zeigte, der in Deutschland 12,5 Millionen Zuschauer erreichte und mehrere Preise gewann. ${ }^{86}$ Bettina Schlüter vermutet, dass es in Bezug auf mediale >Tabubrüche nicht nur um eine Vermarktungsstrategie gehe, sondern auch um die Rechtfertigung, ein Thema immer wieder aus der gleichen Perspektive zu behandeln. ${ }^{87}$

Thomas Speckmann bezeichnet die intensive Beschäftigung der Printmedien und des Fernsehens mit dem Vertreibungsthema als »massenmediale >Erinnerungsoffensive«, welche eine außerordentliche Resonanz und ein starkes gesellschaftliches

81 Vgl. für eine Zusammenfassung: Assmann: Der lange Schatten der Vergangenheit, 2006, S. 195198. Vgl. für eine kritische Besprechung des Buches: Margalit: Guilt, Suffering, and Memory, 2010, S. 261-268.

So z.B. Tanja Dückens Himmelskörper (2003), Reinhard Jirgls Die Unvollendeten (2003) und Christoph Heins Landnahme (2004). Siehe: Kelletat: Von der Täter- zur Opfernation? 2003/2004, S. 134. Vgl. auch: Berger: On Taboos, Traumas and Other Myths, 2006, S. 211. Uhl: Deutsche Schuld, deutsches Leid, 2005, S. $167 f$.

84 Speckmann: Renaissance des Themas in den Medien, 2005, S. 177. Vgl. Margalit: Guilt, Suffering, and Memory, 2010, S. 26of.

85 Ther: Der Diskurs um die Vertreibung, 2008, S. 34

86 Vgl. Schlüter: »Politisch korrekt und auch sonst schwach«, 2012, S. 39of. Schlüter weist gleichwohl auf den »,politisch-korrekt[en] « Charakter des Filmes hin, der »gleich zu Beginn des Films diesen Verlust aus einer Perspektive der Nachkriegszeit exponiert und [...] als Ergebnis der selbstverschuldeten nationalsozialistischen Aggressionspolitik ausweist.«(S. 396). Siehe dazu auch die Besprechung im DOD: Die Flucht - Ein Film wühlt auf. DOD. 2007. 
Echo erreicht habe. ${ }^{88}$ Die ARD-Dokumentation Die Vertriebenen. Hitlers letzte Opfer (2001) bestätigte bereits durch ihren Titel, dass eine >Einreihung der deutschen Opfer in die Reihe der anderen Opfer des Nationalsozialismus erfolgen kann. ${ }^{89}$ Guido Knopps ZDF-Dokumentation Die große Flucht (2002) wurde als besonderes Medienereignis zelebriert. Obgleich die Vertriebenenverbände inhaltliche Kritik an der Dokumentation äußerten, überwog bei ihnen letztlich die Befriedigung, dass das ZDF hiermit zu einer massenmedialen Verbreitung der Thematik beitragen würde. ${ }^{90}$

Der neue Diskurs um Flucht und Vertreibung war Teil einer breiten medialen und politischen Debatte, in der neben den Vertreibungsopfern auch andere deutsche Opfergruppen des Zweiten Weltkrieges, wie die Bombenopfer und Kriegsgefangenen, intensiv thematisiert wurden. ${ }^{91}$ Kritiker dieser Debatte und einer vermeintlich einseitigen Schau auf die eigenen Opfer warnten vor einem "Neuen Deutschen Opferdiskurs «. ${ }^{92}$ Sie fühlten sich an die Selbstviktimisierung der frühen Bundesrepublik zurückerinnert und äußerten sich entsprechend alarmiert, so die Historikerin Ute Frevert: »[...] man kann geradezu von einer Rückkehr, ja von einem Rückschlag der deutschen Opfererinnerung

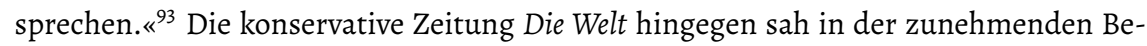
deutung globaler Menschenrechtsdiskurse eine entscheidende Ursache für die Öffnung von Teilen der politischen Linken gegenüber dem Schicksal der Vertriebenen sowie den Vertriebenenverbänden:

»Die Berührung zwischen den Sozialdemokraten [...] und der Exponentin der Vertriebenen-Verbände, die lange im Ruch des Revanchismus standen, zeigt einen fundamentalen Wandel der politischen Kultur an, einen Paradigmenwechsel, der das Thema Vertreibung aus den Bezügen des Kalten Krieges und der Entspannungspolitik weitgehend herausgelöst hat. Die Erinnerung daran ist nicht mehr Sache einer verbitterten Minderheit, sondern aller, denen das Bekenntnis zu den Menschenrechten nicht nur Lippenbekenntnis sein soll. ${ }^{94}$

Die Neue Zürcher Zeitung versuchte diesen neuen Zeitgeist der »Berliner Republik« im Jahr 2002 zu erfassen:

88 Speckmann: Renaissance des Themas in den Medien, 2005, S. 177. Vgl. zu den medialen Eigenlogiken, z.B. den kommerziellen Vermarktungstechniken: Röger: Flucht, Vertreibung und Umsiedlung, 2011, S. 109. Siehe ausführlich zu Funktion und Praxis der Medien beim Vertreibungsdiskurs seit 2002: ebd., S. 79-105.

89 Erika Steinbach begrüßte die Dokumentation und leitete daraus die Begründung für ein ZgV ab: Stratmann: ARD-Serie zu Vertriebenen zeigt, Zentrum gegen Vertreibungen wird immer dringender benötigt. DOD. 30.03.2001.

90 Salzborn: Opfer, Tabu, Kollektivschuld, 2007, S. 40. Vgl. dazu die Besprechung im DOD: Patzke: »Die große Flucht«. DOD. 16.11.2001.

91 Speckmann: Renaissance des Themas in den Medien, 2005, S. 177. Vgl. Assmann: Der lange Schatten der Vergangenheit, 2006, S. 184-189. Siehe auch: Oppen; Wolff: From the Margins to the Centre? 2006, S. 195.

92 Hahn; Hahn: Die Vertreibung im deutschen Erinnern, 2010, S. 590-592.

93 Frevert: Ceschichtsvergessenheit und Geschichtsversessenheit revisited, 2003, S. 9. Vgl. Bebenek: The Heimat Maneuver, 2007, S. 166.

94 Fuhr: Scharfe Thesen. Die Welt. 04.10.2003. Vgl. zur neuen Beschäftigung mit dem Vertreibungskomplex durch die politische Linke: Hirsch: Flucht und Vertreibung, 2003, S. 14. 
»Eine neue Unbefangenheit kennzeichnet diesen [...] Zeitgeist. Im Gewand der >Normalisierung، tritt er am liebsten auf, einem ubiquitären Dress, der als Überwurf für weitere Zeitgeistereien taugt, als da wären: Historisierung der NS-Vergangenheit, Pluralisierung der Geschichtsbilder, Aufwertung detaillierter empirischer Forschung gegenüber dem moralischen Urteil, Hebung des deutschen Selbstgefühls auf eine >partnerschaftliche، Höhe im Verhältnis zu anderen Nationen, Abschied vom Pazifismus und vom negativen Nationalismus. Manchem wird diese Aufzählung bereits genügen, um den mentalen Status quo der Berliner Republik im neuen Jahrhundert umrissen zu finden, aber die Diskussion über das Buch von Günter Grass belehrt uns darüber, dass zur deutschen >Normalisierung ein weiteres Element gehört: der Eintritt in die internationale Opferkultur. ${ }^{95}$

Interessant ist hier wie für den gesamten weiteren Verlauf des Diskurses, dass die Zeitzeugen der Vertreibung selbst kaum als Akteure präsent waren. Die Ursachen dafür liegen unter anderem im medialen Fokus auf die Person Erika Steinbach als Spitze des Dachverbandes der Vertriebenen. Gegenerzählungen von Vertriebenen, die nicht mit der Verbandspolitik des BdV einverstanden waren, fanden nur selten öffentlich Gehör. ${ }^{96}$ Ein Beispiel dafür sind die Projekte des Frauenverbandes im BdV, welche sich, häufig in deutsch-polnischer Kooperation, dem Nachwirken, den »Langen Schatten«, von Flucht und Vertreibung bei den betroffenen Menschen und in den betroffenen Ländern widmeten. ${ }^{97}$ Unabhängig von den Verbandsspitzen sieht Norman Naimark aber auch ein Interesse vieler Vertriebener nach sozialer Anerkennung in Form der Errichtung einer zentralen Dokumentations- und Gedenkstätte. ${ }^{98}$

Weltweit, besonders aber in Polen und Tschechien, verfolgte man die Diskussionen in Deutschland aufmerksam und beteiligte sich selbst aktiv an der Debatte über die Ausrichtung des ZgV. ${ }^{99}$ Die zunehmend konfrontativer werdenden Auseinandersetzungen um das $\mathrm{ZgV}$ verbanden sich mit einer Reihe weiterer Entwicklungen zu einer im Ausland inakzeptablen Melange, so der Gründung der schon erwähnten Preußischen Treuhand durch Mitglieder des rechten Flügels des BdV und der offensiv vorgetragenen Forderung nach Aufhebung der >Beneš-Dekrete` durch Edmund Stoiber gegenüber der Tschechischen Republik im Wahlkampf 2002. ${ }^{100}$ Der bayerische Ministerpräsident und Spitzenkandidat der CDU/CSU für die Bundestagswahlen 2002 beförderte dieses sudetendeutsch-tschechische Thema, was zugleich an eine verbreitete Skepsis in Deutschland gegenüber den sozialen und politischen Folgen der EU-Ostererweiterung anknüp-

95 Güntner: Opfer und Tabu. NZZ. 23.02.2002.

96 Dabei sollten »[...] die Vertriebenen nicht [...] nur als passive Gefolgschaft der Vertriebenenverbände oder als anonymes Wählerpotential der Parteien vorkommen, sondern als eigenständig agierende Subjekte wahr- und ernstgenommen werden, deren persönliche Verarbeitungsstrategien es wert sind, rekonstruiert zu werden.«-Scholz: Rezension zu: Demshuk: The Lost German East, 2012.

97 Vgl. Kellerhoff: Ehrliche Wege aus dem Schatten der Vertreibung. Die Welt. 26.04.2007.

98 Naimark: Europäische Geschichte, 2005, S. 28.

99 Vgl. Sierp: History, Memory, and Trans-European Identity, 2014, S. $87 \mathrm{f}$.

100 Vgl. Houžvička: Czechs and Cermans 1848-2004, 2015, S. $421 f$. 
fen konnte. ${ }^{101}$ Insgesamt war die Zeit geprägt von einer Verstärkung älterer Stereotype auf beiden Seiten. In Polen und Tschechien traute man der Distanzierung Erika Steinbachs von einem tatsächlichen Revanchismus nicht und befürchtete eine Umkehr von Opfern und Tätern des Zweiten Weltkrieges und damit im schlimmsten Falle eine Infragestellung der Nachkriegsordnung. In Deutschland wurden diese Ängste nicht ausreichend reflektiert, die sich noch 2004 in Umfragen zeigten, nach denen in Tschechien 30 Prozent und in Polen 60 Prozent der Menschen Sorge vor deutschen Restitutionsansprüchen hatten. ${ }^{102}$ Ein fortwährendes Problem in Deutschland war und ist zudem die mangelnde Kenntnis der polnischen und tschechischen Geschichte im Allgemeinen und der Geschichte der deutschen Besatzungsherrschaft sowie des deutschen Antipolonismus und Antislawismus im Besonderen. ${ }^{103}$ Die sich aus deutschen und polnischen Wissenschaftlern zusammensetzende Kopernikus-Gruppe fasste Ende 2004 die missliche Lage zusammen:

»In Deutschland beobachten wir eine dauerhafte Nichtbeachtung nachvollziehbarer polnischer Empfindlichkeiten, Oberflächlichkeit bei aller propolnischer Grundhaltung der wichtigsten politischen Parteien und einen Paternalismus, der die Entwicklung partnerschaftlicher, serwachsener \& Beziehungen erschwert. Auf polnischer Seite beobachten wir unkontrollierte und emotionale Reaktionen und Rückfälle in ein alt hergebrachtes Feindbild des Deutschen bis in die auflagenstärksten Printmedien und, was wir für außerordentlich beunruhigend halten, bis in die Mitte des Parlaments hinein. Gegen besseres Wissen werden in zynischer Weise oder aus Cedankenlosigkeit und schierem Nichtwissen die Errungenschaften polnischer Europa- und Deutschlandpolitik der letzten 15 Jahre aufs Spiel gesetzt. « ${ }^{104}$

Auch wenn Edmund Stoiber schließlich die Wahl verlor, blieb das Verhältnis zwischen den Ländern beschädigt. In Deutschland selbst gab es weiterhin keine Einigung, ob und wie eine Institution zur Erinnerung an die Vertreibung geschaffen werden sollte.

Der erste eigenständige Diskursbeitrag des Zentrums gegen Vertreibungen war die im Jahr 2006 öffentlichkeitswirksam präsentierte Ausstellung Erzwungene Wege im Berliner Kronprinzenpalais. ${ }^{105}$ Diese behandelte in einer breiten Zusammenstellung verschiedene Vertreibungsvorgänge im 20. Jahrhundert, darunter Flucht und Vertreibung der Deutschen, ohne dass diese als Schwerpunkt zu erkennen waren. ${ }^{106}$ Die deutsche

101 Vgl. Handl: Die Politik des wiedervereinigten Deutschland gegenüber der Tschechischen Republik, 2010, S. 234. Andere Politiker der Bundesrepublik betonten hingegen, dass die Unterstützung der EU-Osterweiterung durch Deutschland auch eine Pflicht aufgrund der deutschen Verantwortung für den Zweiten Weltkrieg sei: Sierp: History, Memory, and Trans-European Identity, 2014, S. 74. Siehe auch: Ther: Der Diskurs um die Vertreibung, 2008, S. 42.

102 Grußwort von Prof. Dr. Hermann Schäfer, 2006, S. $12 f$.

103 Ther: Der Diskurs um die Vertreibung, 2008, S. 31.

104 Kopernikus-Gruppe: Arbeitspapier IX der Kopernikus-Gruppe, Dezember 2004, S. 350.

$105 \mathrm{Vgl}$. den Ausstellungskatalog: Zentrum gegen Vertreibungen: Erzwungene Wege, 2011. Siehe für eine umfassende Diskussion der Ausstellung: Völkering: Flucht und Vertreibung im Museum, 2008, S. 86-115.

106 Assmann: Geschichte im Gedächtnis, 2007, S. 148f. Vgl. den Artikel im DOD: Pragal: »Erzwungene Wege« zum kollektiven Gedächtnis. DOD. 2006. Vgl. auch: Troebst: Towards a European Memory of Forced Migration? 2016, S. 246. 
Kriegsschuld sowie deutsche Kriegs- und Vertreibungsverbrechen fanden deutliche Berücksichtigung. ${ }^{107}$ Erstmals thematisierte in Deutschland eine Ausstellung umfassend die Vertreibungen der Polen durch NS-Deutschland sowie der Polen aus den kresy durch die Sowjetunion. Polnische Kritiker bewerteten diese Darstellung aber in der Gesamtschau als unzureichend und vielmehr als Verschleierungstaktik des eigentlichen Anliegens des BdV. ${ }^{108}$

Auch weitere Kritiker des Zentrums sahen sich in ihrer These bestätigt, dass das BdV-Projekt die deutschen Opfer von Flucht und Vertreibung, entkontextualisiert von der vorherigen NS-Terrorherrschaft über Osteuropa, in einer "großen Rundschau« von Vertreibungsvorgängen im 20. Jahrhundert in den Mittelpunkt stellen wollte. ${ }^{109}$ Weiter warfen sie der Ausstellung vor, durch die Einordnung der deutschen Vertriebenen in das Schicksal von weltweit und weitgehend unbestritten als >unschuldig` anerkannten Opfergruppen wie der Armenier den Opferstatus der deutschen Vertriebenen und damit der Deutschen zur Gänze belegen und universalisieren zu wollen. ${ }^{110}$ Dies könne aber letztlich nie gelingen, $\mathrm{da}$ - neben der Missbilligung in Deutschland selbst - bei den osteuropäischen Nachbarn der Status der ausschließlich unschuldigen Opfer in Bezug auf die deutschen Vertriebenen immer bestritten würde. ${ }^{111}$

Kritiker wie Philipp Ther und Aleida Assmann befürchteten, dass Erika Steinbach und der BdV unter dem Deckmantel der europäischen Perspektive die Geschichtspolitik der Bundesrepublik nachhaltig verändern und das Gedenken an den Holocaust als zentrales Ereignis des 20. Jahrhunderts durch ein »Jahrhundert der Vertreibungen « verdrängen wollten. ${ }^{112}$ In der Frankfurter Allgemeinen Zeitung hieß es wiederum unter Bezug auf voreilige Verurteilungen, dass »[d]ie schärfsten Kritiker« bereits vor Betreten der Ausstellung wüssten, »dass dort `Geschichte umgeschrieben` und `Täter zu Opfern gemacht würden ${ }^{113}$ Teile der Presse lobten den umfassenden europäischen Zugriff auf

107 Assmann: Geschichte im Gedächtnis, 2007, S. 148.

108 Marek A. Cichocki und Dariusz Gawin kritisieren die Darstellung der Zwangsmigration der Polen scharf, diene sie doch lediglich in der faktographischen Zusammenstellung verschiedener Vertreibungen als »Alibi«, was sich daran zeige, dass im Ausstellungsteil, in dem Verlust und Dialog thematisiert werden, Polen »überhaupt nicht« vorkomme oder lediglich als Adressat und nicht als gleichrangiger Partner: Cichocki; Gawin: Verdrehte Wege. Rzeczpospolita. 04.11.2006.

109 Assmann spricht von einer »rein parataktischen Weise, sehr unterschiedliche Ereignisse« aneinanderzureihen und so eine vermeintlich europäische Perspektive zu gewährleisten. Assmann: Geschichte im Gedächtnis, 2007, S. 149. Siehe dazu ähnlich: Boll; Kruke: Zwangsmigration in Europa im 20. Jahrhundert, 2006, S. 16.

110 Vgl. Ther: Der Diskurs um die Vertreibung, 2008, S. 33. Ebenso: Haslinger: Opferkonkurrenzen und Opferkonjunkturen, 2011, S. $188 \mathrm{f}$.

111 Ther: Der Diskurs um die Vertreibung, 2008, S. 33. Die Stimmen in Polen, die eine Berechtigung der Vorstellungen der deutschen Vertriebenenverbände und ihren Status als anzuerkennende Opfergruppe akzeptierten, waren zu dem Zeitpunkt deutlich in der Minderheit: Majewski: Zwischen Versöhnung und Verteidigung nationaler Interessen, 2008, S. 51.

112 Assmann: Geschichte im Gedächtnis, 2007, S. 149. Aleida Assmann fasste die verbreiteten Bedenken zusammen: »Die Irritation an der Sonderinitiative von Frau Steinbach konzentriert sich auf die Sorge, dass es ihr unterhalb der vergleichenden europäischen Sicht um eine nationale Perspektive geht, welche die Koordinaten der deutschen Geschichtspolitik verschiebt. « Assmann: Konstruktion von Geschichte in Museen, 2007, S. 11. Vgl. Ther: Der Diskurs um die Vertreibung, 2008, S. $33 f$. Dietrich: Unfähig zur Versöhnung. FAZ. 07.09.2006. Vgl. Kossert: Kalte Heimat, 2009, S. 346. 
die Thematik und die damit verbundene Beschäftigung mit wenig bekannten Zwangsmigrationsprozessen ebenso wie die zurückhaltende Darstellung der Vertreibung der Deutschen. ${ }^{114}$

Weitere Ausstellungen des ZgV folgten: 2009 die Ausstellung Die Gerufenen, die eine möglichst vollständige Rundschau aller deutschen Siedlungsgruppen in Südost- und Osteuropa außerhalb der ehemaligen deutschen Grenzen zeigte. 2011 behandelte dann die Ausstellung Angekommen die Integration der deutschen Vertriebenen. Als Wanderausstellungen konzipiert, sind sie ohne größere mediale Aufmerksamkeit weiterhin in Deutschland unterwegs. 2016 zeigte das ZgV erstmals die Ausstellung VerschwundenOrte, die es nicht mehr gibt. Im Oktober 2018 folgte In Lagern - Schicksale deutscher Zivilisten im östlichen Europa 1941-1955. ${ }^{115}$

Gleichzeitig mit der ersten Ausstellung des ZgV im Berliner Kronprinzenpalais war die zunächst 2005 in Bonn gezeigte Ausstellung des Hauses der Geschichte der Bundesrepublik Deutschland (HdG) mit dem Titel Flucht, Vertreibung, Integration zu Gast im gegenüberliegenden Deutschen Historischen Museum. Die Ausstellung des HdG ist als Reaktion des staatlichen Museums auf die Debatte um das $\mathrm{ZgV}$ zu verstehen. ${ }^{116}$ Im Gegensatz $\mathrm{zu}$ den Erzwungenen Wegen behielt diese einen nationalen Fokus bei und sah die Verantwortung für die Vertreibungen wesentlich in der nationalsozialistischen Politik, wohingegen die ZgV-Ausstellung mit ihrer Rundschau auch die grundsätzliche Entwicklung des Nationalismus seit dem 19. Jahrhundert für die Zwangsmigrationen verantwortlich machte. ${ }^{117}$ Die Ausstellung des HdG zählte nach eigenen Angaben in Bezug auf die Besucherzahlen zu den erfolgreichsten Ausstellungen des Hauses überhaupt. ${ }^{118}$

Letztlich ist zu konstatieren, dass die Ausstellung des $\mathrm{ZgV}$ inhaltlich und mit ihrem europäischen Ansatz innovativer war als die in dieser Frage konventionellere Ausstellung des HdG , auch wenn letztere museologisch auf einem höheren Niveau rangierte. ${ }^{119}$ Die öffentliche Kritik richtete sich am Ende jedoch vor allem gegen den Verantwortlichen der Ausstellung:

»Unabhängig davon, wie neutral, korrekt und zurückhaltend beide Ausstellungen zu agieren versuchen - die leidenschaftlichen Proteste geben doch zu denken, ob man mit der Trägerschaft [des Zentrums gegen Vertreibungen, V. R.] nicht den Bock zum Gärtner macht. Erst recht, wenn im Gästebuch der aktuellen Vertriebenen-Ausstellung

114 Völkering: Flucht und Vertreibung im Museum, 2008, S. 112-115. Vgl. für eine abwägende Einordnung durch die Presse: Weiland: Auf schmalem Grat. Spiegel Online. 10.08.2006.

115 Vgl. hierzu die verschiedenen Ausstellungskataloge: Zentrum gegen Vertreibungen: Die Gerufenen, 2009. Zentrum gegen Vertreibungen: Angekommen, 2011. Zentrum gegen Vertreibungen: Verschwunden, 2017. Zentrum gegen Vertreibungen: In Lagern, 2019.

116 Assmann: Konstruktion von Ceschichte in Museen, 2007, S. 11. Vgl. das Begleitbuch zur Ausstellung: Stiftung Haus der Ceschichte der Bundesrepublik Deutschland (Hg.): Flucht, Vertreibung, Integration, 2005. Siehe für eine Diskussion der Ausstellung: Völkering: Flucht und Vertreibung im Museum, 2008, S. 65-85.

117 Der Historiker Erich Später sieht hingegen in beiden Ausstellungen eine die deutsche Schuld relativierende Opferperspektive: »Konzentration auf Steinbach lenkt ab«. Frankfurter Rundschau. 11.02.2010.

118 Assmann: Geschichte im Gedächtnis, 2007, S. 146.

119 Becker: Ceschichtspolitik in der »Berliner Republik«, 2013, S. 490. Vgl. Schmid: Ein Draht zu den Toten. Die Welt. 27.10.2007. 
ein älterer Besucher in Krakelschrift davon träumt, im `feldgrauen Ehrenkleid` nach Polen zurückzukehren! [...]. $^{120}$

Der Diskurs um Flucht und Vertreibung sowie die Befürchtung eines möglichen Wandels der bundesrepublikanischen Geschichtskultur ebbten zunächst nicht ab, wie die Reaktionen auf eine wahrscheinlich missinterpretierte Rede des Stellvertreters des Bundesbeauftragten für Kultur und Medien Hermann Schäfer zeigte, der 2006 bei einer Gedenkveranstaltung in Buchenwald vor allem über sein Ausstellungsprojekt, die oben erwähnte Ausstellung des HdG, berichtete. Daran schloss sich eine längere Debatte an. Im Tagesspiegel hieß es:

»[...] Und Volkhard Knigge, der Leiter der Cedenkstätte Buchenwald, forderte von der Bundesregierung gar eine >Klarstellung ihres Geschichtsbildes‘. Andernfalls müsse man Schäfers Rede als Paradigmenwechsel verstehen, nach dem die deutsche Regierung nun nicht den Holocaust und seine Opfer, sondern Flucht und Vertreibung in den Mittelpunkt stellt."

Weiter schlussfolgerte der Autor des Artikels:

»Dass die deutsche Erinnerungspolitik im Wandel ist, ist unschwer zu erkennen. Das betrifft vor allem das Thema Vertreibungen. Hatte schon im Koalitionsvertrag die Ankündigung, in Berlin ein ssichtbares Zeichen< gegen Flucht und Vertreibung setzen zu wollen, vielfach für Unbehagen gesorgt, ist auch Schäfers Berufung [zum Leiter der Abteilung Kultur und Medien im Bundeskanzleramt, V. R.] als solches Zeichen zu verstehen. Schäfer ist auch Mitglied im Wissenschaftlichen Beirat der Stiftung `Zentrum gegen Vertreibungen $\iota^{121}$

Der im Kapitel 7.1.1 diskutierte Kompromiss und Weg zur Stiftung Flucht, Vertreibung, Versöhnung nach 2005 führte zu keiner Beruhigung der öffentlichen Diskussion. Anfang März 2010, als die Debatte um die Besetzung des Stiftungsrates der SFVV ihren Höhepunkt erreichte, konstatierte die FAZ resigniert, dass die Diskussion mittlerweile "groteske Züge« annehme und die "politisch Verantwortlichen« den eigentlichen Anlass, »die Geschichte von Flucht und Vertreibung von Millionen Menschen im Zweiten Weltkrieg und der Nachkriegszeit, das Versprechen, ethnische Säuberungen in Europa seit dem neunzehnten Jahrhundert im historischen Kontext mittels einer Ausstellung erfahrbar zu machen«, beinahe vollständig »aus dem Blick verloren« hätten: »Stattdessen sind sie unermüdlich damit beschäftigt, ideologisch befeuerte Schwelbrände zu löschen und alte Rechnungen $\mathrm{zu}$ begleichen. $\ll^{122}$

120 Tilmann: Wenn die Erinnerung vertrieben wird. Der Tagesspiegel. 29.08.2006. Vgl. ähnlich: Völkering: Von der privaten Stiftung »Zentrum gegen Vertreibungen« zur Bundesstiftung »Flucht, Vertreibung, Versöhnung«, 2011, S. 133. Vgl. für die Zusammenstellung weiterer Einträge des Besucherbuches: Völkering: The Musealization of >Flight, < >Expulsion, < and >Integration < in the Federal Republic of Cermany, 2011, S. 120. 
Stimmen des Ausgleichs blieben zu diesem Zeitpunkt selten. In der Zeitschrift forum erwachsenenbildung erkannte die evangelische Theologin Petra Bahr in den innerdeutschen Debatten manche westdeutsche Überheblichkeit gegenüber den Opfern von Flucht und Vertreibung und verwies auf die Komplexität von Täter- und Opferschaft:

»Leid lässt sich niemals mit Leid aufwiegen. Wer allerdings das Leid und die Greuel an Deutschen verschweigt, weil >irgendwer ja für die deutsche Barbarei< bezahlen müsste, der geht zynisch mit dem Leid Anderer um. Wer seit Cenerationen in Düsseldorf, München oder Nordhorn lebt, kann nicht ermessen, was Heimatverlust bedeutet: der Verlust von Besitz, von Sprache, von Kultur, von Vertrauen. Massenvergewaltigungen, Deportationen, Hunger, Enteignung und Vertreibung bleiben immer Unrecht, auch wenn das Unrecht manchmal Täter traf. Die Geschichte von Flucht und Vertreibung ist auch deshalb so schmutzig, weil hier nicht nur Opfer Opfer, sondern auch Täter Opfer und Opfer Täter wurden. $\aleph^{123}$

Weiter verband Bahr bereits zu diesem Zeitpunkt die Erinnerung an die Vertreibung mit einem Plädoyer für eine humanistische Flüchtlingspolitik in der Gegenwart:

»Eine Cesellschaft, die die Traumata der Vertriebenen hören will, kann auch die Vertreibungen der Gegenwart nicht achselzuckend zur Kenntnis nehmen. Sie wird anders mit Migrantinnen und Migranten umgehen, sich für Flüchtlinge in aller Welt einsetzen und die >Festung Europa $<$ durchlässig gestalten. ${ }^{124}$

Nach diesem vorerst letzten Höhepunkt der grundsätzlichen Debatte um die Erinnerung an Flucht und Vertreibung blieben die folgenden Jahre ruhiger, allerdings unterbrochen durch die teils heftigen Auseinandersetzungen um die Abberufung des Direktors der SFVV und die Neubesetzung der Position 2014/2015. Zudem verbesserte sich im Vergleich zu 2006 in einer repräsentativen Umfrage die generelle Meinung in Deutschland sowie speziell der deutschen Vertriebenen und ihrer Nachfahren gegenüber Polen. Damit schienen sich langfristige Tendenzen der Annäherung durch die europäische Integration und ein damit einhergehender allmählicher Abbau älterer Vorurteile zu zeigen. ${ }^{125} 2018$ zeigten sich schon wieder deutlich gegenläufige Neigungen, wie in Kapitel 5.2 noch diskutiert wird.

Die Umsetzung einer älteren Forderung des Bundes der Vertriebenen, einen bundesweiten Gedenktag an Flucht und Vertreibung einzurichten, gelangte 2013 in den Koalitionsvertrag. ${ }^{126}$ Die Institutionalisierung dieses 2015 erstmals durchgeführten Gedenktages war zuvor in der Wissenschaft äußerst kritisch betrachtet worden, so zum Beispiel von Stephan Scholz, der darauf hinwies, dass bisher nur die Holocaustopfer einen eigenen Gedenktag neben dem für alle Opfergruppen gedachten Volkstrauertag hätten. ${ }^{127}$ Politisch fand die Große Koalition den Kompromiss, den Gedenktag nicht am

123 Bahr: Aufrichtiges Gedenken, 2010, S. 64.

124 Ebd., S. 65.

125 Wieliński: Niemcy+Polska=WNM. Gazeta Wyborcza. 16.06.2015.

126 Vgl. zur Entwicklung bis 2015: Steinbach: Flucht, Vertreibung, Mahnung, 2016, S. 234-236.

127 Scholz: Vertriebenendenkmäler, 2015, S. 368. Vgl. zur Kritik und für eine knappe Zusammenfassung der Entwicklung bis 2015: Dräger: Ein Hoch auf Flucht und Vertreibung? 2015, S. 50-54. 
vom BdV favorisierten 5. August (Tag der Verabschiedung der Charta der Heimatvertriebenen 1950), sondern gemeinsam mit dem Weltflüchtlingstag am 20. Juni zu begehen. Die seither von der Bundesregierung organisierten zentralen Gedenkveranstaltungen im Schlüterhof des Deutschen Historischen Museums integrieren diese beiden Elemente durch Zeitzeugen und Reden zur historischen Flucht und Vertreibung sowie $\mathrm{zu}$ aktuellen Fluchtbewegungen. ${ }^{128}$ In den unter anderem bisher von Bundeskanzlerin Angela Merkel und Bundespräsident Joachim Gauck gehaltenen Reden wurden Verbindungen, aber auch Unterschiede der Schicksale gesucht. ${ }^{129}$ Die 2018 gehaltene Ansprache von Angela Merkel, in der sie die Vertreibungen als »bitteres Unrecht « beurteilte, führte zu Empörung in Tschechien, aber zu keiner weiteren Resonanz in der Bundesrepublik oder Polen. ${ }^{130}$ Die negativen Reaktionen in Tschechien überraschen insofern, als die Bundeskanzlerin nur die seit jeher von allen Bundesregierungen vertretene Position, die Vertreibungen als unrechtmäßig zu betrachten, in eigenen Worten wiederholt hatte, ohne darauf beruhende weitergehende Forderungen zu erheben. ${ }^{131}$ Abgesehen von diesem Intermezzo sind die Beziehungen zu Polen und Tschechien mittlerweile durch andere Themen belastet.

Neben weiteren kontroversen Fragen wie der künftigen Gestaltung der EU oder der Rechtsstaatlichkeit in Polen führte die sogenannte Flüchtlingskrise seit $2015 \mathrm{zu}$ einer verschärften Spaltung Europas und Verschlechterung des Verhältnisses von Deutschland zu seinen östlichen Nachbarländern. Die liberale deutsche Asyl- und Migrationspolitik traf dort auf große Ablehnung und sowohl die polnische PiS-Partei als auch Andrej Babiš in Tschechien gewannen ihre Wahlen 2015 und 2017 auch mit einer deutlichen Ablehnung der Asylpolitik Angela Merkels. ${ }^{132}$ In Deutschland wiederum traf die harte Haltung Polens und Tschechiens, keine Flüchtlinge aus dem Nahen Osten und Afrika aufzunehmen und sich einem europäischen Verteilungsmechanismus zu verweigern, auf Unverständnis und Ablehnung. ${ }^{133}$

Für den innerdeutschen Diskurs um Flucht und Vertreibung ist die schon beim Gedenktag deutlich gewordene Parallelisierung des historischen Geschehens mit den

128 Vgl. Kiesel: Die Vertriebenen von gestern und heute. Deutsche Welle. 20.06.2018.

129 Rede von Bundespräsident Joachim Gauck zum Gedenktag für die Opfer von Flucht und Vertreibung am 20.06.2015.

130 Rede von Bundeskanzlerin Merkel zum Gedenktag für die Opfer von Flucht und Vertreibung am 20. Juni 2018 in Berlin. Vgl. Kap. 5.3, S. 259.

131 Vgl. zum bundesrepublikanischen Konsens, die Vertreibungen als völkerrechtswidrig zu betrachten: Handl: Die Politik des wiedervereinigten Deutschland gegenüber der Tschechischen Republik, 2010, S. 230.

132 Vgl. für Polen: Schuller: Sprache des Hasses. FAZ. 15.10.2015. Vgl. für Tschechien: Meier: Asselborn zeigt Unverständnis für tschechischen Wahlsieger. Der Tagesspiegel. 22.10.2017. Vgl. zur Ablehnung des deutschen Umganges mit der `Flüchtlingskriseく in Tschechien: Janzer: Beziehung im Wandel. Radio Praha. 16.01.2017.

133 In Polen verwies man neben der Ablehnung sislamischer Einwanderung d darauf, dass man viele Kriegsflüchtlinge aus der Ukraine aufgenommen habe. Die Ukrainer in Polen sind jedoch zu einem Großteil mittlerweile wichtige Arbeitsmigranten für die polnische Wirtschaft. Vgl. ausführlich den Blog-Artikel über die ukrainischen Migranten in Polen: Puto: Second-hand Europe. openDemocracy. 31.05.2017. 
aktuellen Flucht- und Migrationsbewegungen ein neuer Impuls gewesen. ${ }^{134}$ In der Wissenschaft gibt es unterschiedliche Einschätzungen, inwieweit ein Parallelen betonender Vergleich sinnvoll oder angemessen ist. ${ }^{135}$ Einige Stimmen kritisieren die politische Instrumentalisierung des Vergleichs durch verschiedene politische Lager, sei es im Sinne der >Rom zerstörenden Völkerwanderungen oder im Sinne der Aufforderung zur unkritischen Unterstützung der Flüchtlingspolitik der Bundesregierung. ${ }^{136}$ Die Vertriebenenverbände und einzelne Vertriebene reagierten unterschiedlich auf diese auch in den Medien stark vertretene Zusammenführung: Es werden sowohl Parallelen als auch erhebliche Unterschiede betont. ${ }^{137}$ Viele wehren sich gegen eine Vereinnahmung durch ein Narrativ von Deutschland als Einwanderungsland, wie es die Historikerin Alina Laura Tiews formulierte, ${ }^{138}$ und betonen, dass trotz aller Eingliederungsschwierigkeiten damals zumeist Deutsche und deutsche Staatsbürger unfreiwillig und ohne Alternative in bei Deutschland verbliebene Landesteile kamen. ${ }^{139}$ Konservative Vertreter wie Erika Steinbach betonen zudem, dass viele vermeintliche Fluchtbewegungen in Wirklichkeit vor allem ökonomisch motiviert seien und daher noch weniger mit der

134 Vgl. Scholz: Willkommenskultur durch»Schicksalsvergleich«, 2016.

135 Differenziert diskutiert Matthias Beer den Vergleich und kommt dabei zu einem klaren Schluss: »Für die beliebte Gleichsetzung der Flüchtlingsfrage nach 1945 und der gegenwärtigen, für eine Analogie oder auch nur eine Anspielung, liefern die empirischen Befunde keine Grundlage. Der in der Öffentlichkeit, in der politischen Auseinandersetzung, in den Medien und auch in der Wissenschaft bemühte Vergleich führt daher nicht nur in die Irre, er ist auch falsch. Die gedeuteten, vermuteten oder angenommenen Gemeinsamkeiten der beiden Flüchtlingsfragen liegen nicht vor. Auch deshalb sollte der Criff in die Kiste der Geschichte das Urteilen und Unterscheiden nicht ersetzen, auch nicht bei der gegenwärtigen Flüchtlingsfrage.« Beer: Die »Flüchtlingsfrage« in Deutschland nach 1945 und heute, 2016. Stephan Scholz konstatiert hingegen, bei »aller gebotenen Berücksichtigung der Besonderheiten der deutschen Zwangsmigration, insbesondere auch ihrer Verursachung durch die deutsche Kriegspolitik, besitzt die migrationshistorische Perspektive ein erhebliches integratives Potential bei der Bewältigung gegenwärtiger und zukünftiger Herausforderungen«: Scholz: Willkommenskultur durch »Schicksalsvergleich«, 2016, S. 46. Vgl. auch: Meier: Die »Völkerwanderung«, 2016, S. $9 f$.

136 Der Althistoriker Mischa Meier kritisiert den Missbrauch historischer Analogien am Beispiel des in der >Flüchtlingskriseく häufig verwendeten Begriffs der `Völkerwanderungく: »Die aktuelle Suche nach vordergründigen Parallelen und Analogien droht hingegen Ceschichte zum instrumentellen Passepartout zu degradieren, um politischen oder moralischen Imperativen einen pseudolegitimatorischen Firnis zu verleihen. Cegen Vereinnahmungen dieser Art anzuarbeiten, ist eine der wichtigsten Aufgaben des Historikers. « Meier: Die »Völkerwanderung«, 2016, S. 10. Vgl. dafür die kritische Argumentation des BdV-Präsidenten Bernd Fabritius: Lehni: 70 Jahre Vertriebene in Nordrhein-Westfalen. Siebenbürgische Zeitung. 27.04.2016. Stephan Grigat, Sprecher der Landsmannschaft Ostpreußen, betonte in seiner Rede beim Jahrestreffen der Landsmannschaft 2019 die "gravierenden Unterschiede zwischen den heutigen Migranten und den deutschen Vertriebenen der Nachkriegszeit«: Grigat: »Ostpreußen ist nicht sterblich!«, 2019.

138 »Krisen in Flüchtlingslagern, die Not von Kindern, Probleme bei der Verteilung von Flüchtlingen oder auch bei der sprachlichen Verständigung spielen heute wie damals eine Rolle. Der historische Vergleich kann dabei helfen, die Geschichte von Deutschland als Einwanderungsland zu begreifen.«Tiews: 1945: Flüchtlinge in Norddeutschland. NDR. 05.12.2016. Vgl. auch den Artikel von Andreas Kossert: Böhmen, Pommern, Syrien. Die Zeit. 12.02.2015.

139 Vgl. dafür die Argumentation des BdV-Präsidenten Bernd Fabritius: Lehni: 70 Jahre Vertriebene in Nordrhein-Westfalen. Siebenbürgische Zeitung. 27.04.2016. 
Geschichte der Vertriebenen verglichen werden könnten. ${ }^{140}$ Auch der vormalige Direktor der SFVV, Manfred Kittel, äußerte sich wiederholt prononciert kritisch gegenüber der aus seiner Sicht fragwürdigen Parallelisierung von Flucht und Vertreibung am Ende des Zweiten Weltkrieges mit heutigen Flucht- und Migrationsbewegungen. ${ }^{141}$ Aleida Assmann sprach sich ebenfalls gegen simplifizierende Parallelisierungen aus, hob aber hervor, dass durch die Beschäftigung mit unterschiedlichen Erfahrungen und Geschichten von Flucht und Migration »tieferes Verständnis" gewonnen werden könne, was dem gesellschaftlichen Zusammenleben diene. ${ }^{142}$

Wie in Kapitel 7.1 gezeigt werden wird, wächst die politische Forderung beispielsweise an die Stiftung Flucht, Vertreibung, Versöhnung, die Behandlung heutiger Fluchtbewegungen in die eigene Arbeit zu übernehmen und mit dem historischen Geschehen zu verbinden. ${ }^{143}$

Die >Flüchtlingskrise ist auch ein entscheidender Mobilisierungsfaktor für die 2013 im Zuge der Eurokrise gegründete Alternative für Deutschland (AfD) geworden. Nach dem 2015 erfolgten Sturz der »Professorenführung « unter Bernd Lucke und dem Austritt zentraler Mitglieder des liberalen Flügels entwickelte sie sich zu einer primär nationalkonservativen und populistischen Partei. ${ }^{144}$ Von Anfang an waren vormals führende Vertreter oder Mitglieder aus der zweiten Reihe der Vertriebenenverbände, beispielsweise der ehemalige Vorsitzende der Landsmannschaft Ostpreußen, Wilhelm von Gottberg, in der AfD engagiert. Im Juli 2017 gründete sich der Verband »VAdM - Vertriebene, Aussiedler und deutsche Minderheiten in der AfD «. ${ }^{145}$ Diese Vereinigung steht stellvertretend dafür, dass die AfD die ehemals stark von CDU/CSU geprägten Politikfelder der Förderung der deutschen Volksgruppen im Ausland, der Russlanddeutschen und der Vertriebenen zu bearbeiten anstrebt. Für die CDU/CSU scheinen die Vertriebenenverbände trotz ihrer abnehmenden Bedeutung und geringer werdenden Mitgliederzahl weiterhin ein wichtiger Teil ihrer potentiellen Wählerschaft und des konser-

140 JU Regionalverband Heilbronn-Franken: Bundestagsabgeordnete Erika Steinbach begeistert auf Schloß Stetten. 25.10.2015. Siehe auch: Steinbach: Flucht, Vertreibung, Mahnung, 2016, S. 10.

141 In einem Artikel in der FAZ diskutierte er die falsche Schwerpunktsetzung der derzeitigen Flüchtlingspolitik auf Integration, die aber - wenn man das historische Beispiel ernst nehmen würde vielmehr auf Rückkehr ausgerichtet werden müsste: Kittel: Das kostbare Recht auf Rückkehr. FAZ. 07.01.2016.

142 Cedenktag für die Opfer von Flucht und Vertreibung am 20.06.2019. Webseite des BdVLandesverbandes Niedersachsen. 2019.

143 Kap. 7.1.1, S. 379. Vgl. für diese Diskussionen um das Museum Friedland: Spatz: Heimatlos, 2018, S. $187 f$.

144 Grimm: Bin ich denn schon rechts? 2017, S. 4. Vgl. Oppelland: Alternative für Deutschland, 2017. Im September 2018 intensivierte sich die Diskussion, ob die weitere Entwicklung der AfD mittlerweile eine Beobachtung durch den Verfassungsschutz legitimiere: Reimers: »Den Zeitpunkt für die Beobachtung verpasst«. tagesschau.de. 03.09.2018.

145 Vgl. die noch nicht sehr informative Webpräsenz: http://vadm-afd.de/ (letzter Zugriff: 09.08.2018). Aktiver ist der Verband auf Facebook: https://www.facebook.com/VAdM.AfD/ (letzter Zugriff: 09.08.2018). Vgl. zur Gründung des VAdM auch: Fischer: Auf ein Wort. Der Westpreuße. Unser Danzig. 2017. 
vativen Profils zu sein und werden daher entsprechend beachtet. ${ }^{146}$ Auf die neue Konkurrenz reagierten und reagieren die Verbandspolitiker des BdV durch eine rhetorische und praktische Abgrenzung. ${ }^{147}$ Gleichzeitig stehen die weiterhin CDU- und CSU-nahen Landsmannschaften vor der Herausforderung, dass an der Basis nicht nur die Regierungspolitik, sondern auch die vermeintlich erfolglose Verständigungspolitik gegenüber Polen und Tschechien kritisch gesehen wird: Weder wurden die >Beneš-Dekrete in Tschechien endgültig aufgehoben, noch haben sich die polnischen Regierungen auf die Vertriebenen zubewegt. ${ }^{148}$

Im BdV selbst deuten sich unter der Führung des neuen Präsidenten Bernd Fabritius seit 2014 zudem umfassende Veränderungen an: Eine 2018 diskutierte Namensergänzung des Verbandes wird gegebenenfalls den Schritt einzelner Landsmannschaften nachvollziehen, die sich wie die vormalige »Deutsch-Baltische Landsmannschaft« in »Deutsch-Baltische Gesellschaft « umbenannt und damit auch eine Schwerpunktänderung oder Erweiterung des bisherigen Selbstverständnisses vollzogen haben. ${ }^{149}$ Die vom BdV verstärkt betriebene Kooperation mit den Verbänden der deutschen Minderheiten in Ostmitteleuropa soll auch in Zukunft einen wesentlichen Kern der Verbandsarbeit darstellen. ${ }^{150}$ Für Kontinuität mit der unter Erika Steinbach eingeleiteten Ausrichtung des BdV als Akteur von gesamtgesellschaftlicher Bedeutung steht auch seine 2017 erfolgte Aufnahme in das "Deutsche Institut für Menschenrechte «. ${ }^{151}$

Mittelfristig betrachtet, kann die neue nationalkonservative Konkurrenz das Politikfeld von Flucht und Vertreibung für ihren Versuch nutzen, die bundesdeutsche Erinnerungskultur nachhaltig zu verändern. Dieses Ziel unterstrich der AfD-Landesvorsitzende von Thüringen, Björn Höcke, im Januar 2017, indem er eine »erinnerungspolitische Wende um 180 Grad« forderte und damit starke Proteste hervorrief. ${ }^{152}$ Martin Sabrow weist in seinem Artikel über diese Rede darauf hin, dass es sich trotz diverser Vorgänger um die erste »unverstellte Aufkündigung des erinnerungskulturellen Grundkonsenses der Bundesrepublik« handele. Er zieht explizit einen Vergleich dieser Rhetorik »Zur Leugnung historischer Lasten« mit Ländern wie Polen, Russland und der Türkei. ${ }^{153}$

146 Vgl. Wochnik: Non-State Actors, Political Opportunity Structures and Foreign Relations, 2014, S. 225.

147 Vgl. dafür das Interview mit Bernd Fabritius: »Das Bedürfnis nach Heimat ist Realität«. Zeit Online. 03.04.2018. Auch bei konservativen Akteuren im Bereich der Kulturförderung der Vertriebenenarbeit, zum Beispiel der Zeitschrift Kulturpolitische Korrespondenz sieht man eher Gefahren im Aufgreifen des Themas durch die AfD. Auch wenn sie auf der einen Seite berechtigte und notwendige Kritik an »Versäumnissen« in diesem Bereich äußern könne, würde gleichwohl die (erneute) Verbindung dieser Kulturarbeit durch die politische Linke und die politische Mitte mit der äußersten politischen Rechten letztlich zu ihrem Schaden sein, da sich dadurch »[d]ie in diesem Sektor tätigen Institutionen [...] in Zukunft wieder in einer Defensivlage sehen, die man längst überwunden glaubte.«-Weigelt: Eine Initiative, die weiterer bedarf, 2017, S. $4 \mathrm{f}$.

148 Vgl. Viel Gold und Silber bei den Schlesiern. Echo. 03.05.2018.

149 Breyton: Bund der Vertriebenen prüft Umbenennung. Die Welt. 18.04.2018.

150 Vgl. dazu kritisch: Salzborn: Geteilte Erinnerung, 2008, S. 90.

151 BdV nun Mitglied im Deutschen Institut für Menschenrechte. Oberhessen-live. 27.12.2017.

152 Hencke: Protokoll einer Rede. Schleswig-Holsteinischer Zeitungsverlag (shz). 18.01.2017.

153 Sabrow: Höcke und wir, 2017. 
Das bemerkenswerteste Beispiel für eine Annäherung der organisierten Vertriebenen an die AfD stellt Erika Steinbach selbst dar, die im Januar 2017 die CDU verließ und darauffolgend zur Wahl der AfD aufrief und deren Wahlkampf unterstützte. Seit März 2018 ist sie zudem die Vorsitzende der parteinahen Stiftung der AfD, der DesideriusErasmus-Stiftung. In deren Kuratorium ist auch der Rechtshistoriker Alfred-Maurice de Zayas berufen worden, der in den 1970ern zu der juristischen Bewertung sowie der angelsächsischen Beteiligung an den Vertreibungen forschte und sich seitdem zum Thema wiederholt pointiert zu Wort meldet. ${ }^{154}$ Gleichzeitig mit der Annahme dieser Position gab Steinbach den Vorsitz der Stiftung Zentrum gegen Vertreibungen ab, die nun von Christean Wagner (CDU) geleitet wird. ${ }^{155}$

Die dauerhafte Etablierung einer nationalkonservativen Partei in der Bundesrepublik ist ein Novum und wird künftige Diskussionen um Flucht und Vertreibung voraussichtlich stark beeinflussen. Dennoch ist festzuhalten, dass der Anfang der $2000 e r$ Jahre befürchtete »Neue Deutsche Opferdiskurs« und die durch diesen damals erwartete nachhaltige Veränderung der Erinnerungskultur der Bundesrepublik nicht eingetroffen ist. Sowohl die Abgrenzung vom Nationalsozialismus als auch das Gedenken an die deutschen Verbrechen stehen weiterhin im Mittelpunkt staatlicher Geschichtspolitik, in der die Erinnerung an die Shoa ihre zentrale Stelle behalten hat. ${ }^{156}$ Vielmehr lässt sich eine fortgesetzte Pluralisierung der bundesdeutschen Erinnerungskultur beobachten, in der die Vertriebenen einen Platz beanspruchen. ${ }^{157}$

Exkurs: Rechtliche Entwicklung Weitgehend von der öffentlichen Wahrnehmung unbeachtet geblieben sind die verschiedenen Institutionen in der Bundesrepublik, die sich mit Geschichte und Kultur der Heimatvertriebenen befassen. ${ }^{158}$ Paragraph 96 des im Kapitel 4 erwähnten Bundesvertriebenengesetzes von 1953 verpflichtet die Bundesregierung dazu, die Kultur der Deutschen aus Osteuropa zu pflegen und zu bewahren. ${ }^{159}$ Unter diese Förderung fallen die Landesmuseen der ehemaligen ostdeutschen Provinzen sowie Kulturinstitute für (ehemalige) deutsche Bevölkerungsgruppen in Osteuropa, wie

154 Vgl. Kap. 4.1, S. 156. Siehe dazu auch seine 2019 erschienene Schrift: Zayas; Badenheuer: 80 Thesen zur Vertreibung, 2019.

155 Vgl. Erika Steinbach leitet AfD-nahe Stiftung. Der Tagesspiegel. 04.03.2018.

156 Vgl. Bauerkämper: Das umstrittene Gedächtnis, 2012, S. 213.

157 Vgl. Völkering: Die Musealisierung der Themen Flucht, Vertreibung und Integration, 2010, S. 9395. Vgl. zur Pluralisierung der Erinnerungskultur auch: Bauerkämper: Das umstrittene Cedächtnis, 2012, S. 243.

158 Lau: Blühende Museumslandschaften. Die Zeit. 25.09.2003. Vgl. zur Entwicklung der Musealisierung von Flucht und Vertreibung in Deutschland seit 1945: Völkering: Die Musealisierung der Themen Flucht, Vertreibung und Integration, 2010, S. 81-96. Eine ähnlich geringe Beachtung erfährt die »Denkmaltopographie« mit mehr als 1000 über Deutschland verteilten Denkmälern: Scholz: Vertriebenendenkmäler, 2015, S. 12.

159 Griefahn: Zentrale Aspekte der Erinnerungskultur und Geschichtspolitik des Bundes, 2009, S. 79. Vgl. zur aktuellen Anwendung des Gesetzes kritisch: Hahn; Hahn: Die Vertreibung im deutschen Erinnern, 2010, S. 518-521. Siehe zur letzten Neukonzeption der Kulturarbeit nach § 96 BVFC: Weigelt: Gar nicht neue »neue Relevanz«, 2016. 
das Siebenbürgen-Institut in Gundelsheim oder das Institut für donauschwäbische Geschichte und Landeskunde in Tübingen. ${ }^{160}$

Diese seit den 1960er Jahren gegründeten Museen und Institute befassen sich mit der jeweiligen Regionalgeschichte, vor allem während der deutschen Besiedlungsphase. Ein Teil davon ist die Darstellung des Vertreibungsgeschehens, weshalb es verwundert, dass diese Einrichtungen sowohl bei der Debatte um das ZgV als auch bei der um die SFVV praktisch keine Rolle spielten. ${ }^{161}$ Dies mag daran liegen, dass die genannten Museen mit geringen Besucherzahlen kämpfen und aufgrund ihrer peripheren Lagen selten Impulse setzen können. Sie können als »kalte Speicher« der Vertriebenenkultur betrachtet werden. ${ }^{162}$

Auch nach Catherine Perron ist es bemerkenswert, wie wenig die Kulturförderung nach Paragraph 96 in der Forschung beachtet wird, obwohl sie ein zentrales Element für die Entwicklung der bundesrepublikanischen Erinnerungskultur sowie der Geschichtsund Nachbarschaftspolitik darstellt. Schließlich lasse sich dieser Paragraph als »als eines der ersten Erinnerungsgesetze in Europa« verstehen. Das bundesdeutsche Narrativ der 1950er Jahre wurde so wirksam durch geförderte Museen, Publikationen oder Filme kontinuiert, ehe ab 2000 ein Wandel einsetzte, der - integriert in die »auswärtige Kulturpolitik« - die Brückenfunktion der Osteuropa zugewandten Thematik mit einer Betonung des "gemeinsamen kulturellen Erbes« in einem zusammenwachsenden Europa verfolgt und verstärkt für diesen europäischen Integrationsprozess wirbt. ${ }^{163}$ Das auf dieser Basis im Jahr 2000 gegründete Deutsches Kulturforum östliches Europa in Potsdam ist dafür ein prägnantes Beispiel.

Exkurs: Bayern und die Sudetendeutschen Neben einem deutsch-polnischen und einem deutsch-tschechischen Dialog ist ebenfalls von einem spezifisch bayerisch-tschechischen Diskursraum zu sprechen. Wie Kapitel 6.4 noch zeigt, sind zum einen das Jahrhunderte bestehende sudetendeutsch-tschechische Zusammenleben und zum anderen die enge Verbindung des böhmischen und bayerischen Raumes für das Verständnis dieses Verhältnisses bedeutend. ${ }^{164}$ Nach dem Zweiten Weltkrieg fand die Mehrzahl der Sudetendeutschen eine neue dauerhafte Heimat in Bayern. Die 〉Ernennung zum vierten Stamm Bayerns neben Franken, Altbayern und Schwaben sowie die dauerhafte Liaison der Sudetendeutschen Landsmannschaft mit der bayerischen Regionalpartei CSU haben über Jahrzehnte zu einer scheinbaren und auch so verlautbarten Interessengemein-

160 Bauer: Flucht und Vertreibung in den Regionalmuseen, 2010, S. 43-49. Vgl. Kossert: Kalte Heimat, 2009, S. 340-342. Siehe für die Förderung des SMG und der SFVV durch § 96 BVFC: Kap. 6.2.2, S. 286f.; Kap. 7.1.2, S. 384.

161 So kommentiert kritisch: Lau: Blühende Museumslandschaften. Die Zeit. 25.09.2003. Dieser Sachverhalt hat sich bis heute kaum geändert.

162 So Aleida Assmann, mit Bezug auf Custav Seibt: Assmann: Der lange Schatten der Vergangenheit, 2006, S. 192. Vgl. zu den geringen Besucherzahlen: Lau: Blühende Museumslandschaften. Die Zeit. 25.09.2003.

163 Perron: § 96 Bundesvertriebenengesetz, 2016, S. 500-503, 510-513.

164 Ein Beispiel für dieses Verständnis und gleichzeitig ein Schritt der Verständigung war die bayerische Landesausstellung von 2007 »Bayern und Böhmen « mit dem Schwerpunkt »1500 Jahre bayerische-böhmische Nachbarschaft«: Luft; Hlavačka: Tschechien und Bayern, 2016, S. XVIIf. 
schaft geführt. ${ }^{165}$ So sahen und sehen sich die bayerischen Regierungen als Sachwalter der sudetendeutschen Anliegen, wobei die Sudetendeutschen in Bayern immer noch ein »nicht zu übersehendes Wählerpotenzial« darstellen. ${ }^{166}$ Die Bindung geht wesentlich tiefer als die übrigen seit den 1950er Jahren entstandenen Patenschaften von Bundesländern und anderen Gebietskörperschaften für verschiedene Landsmannschaften und sie ist vor allem - im Gegensatz zu diesen - auch weiterhin relevant.

Die Sonderstellung des Freistaats Bayerns und der CSU führen so zu einer weiteren Ebene der zwischenstaatlichen Beziehungen zwischen Deutschland und Tschechien. Bis 2010 machten die bayerischen Ministerpräsidenten einen offiziellen Besuch in Prag vom »Einlenken Tschechiens in der Vertriebenenfrage abhängig «. ${ }^{167}$ Erst 2010 beendete Ministerpräsident Horst Seehofer mit seiner Pragreise diese regionale >Eiszeit<. Bereits vorher hatte die Sudetendeutsche Landsmannschaft unter Bernd Posselt eine solche Initiative angestrebt. Der langjährige CSU-Abgeordnete des Europäischen Parlamentes prägt seit Jahren die proeuropäische Ausrichtung des Verbandes und fordert eine intensivierte Verständigung mit Tschechien. ${ }^{168}$ Ein vorheriges Entgegenkommen von tschechischer Seite war damit aber nicht verbunden. Dennoch verbesserten sich anschließend die Beziehungen und führten 2016 und 2017 zur Teilnahme tschechischer Regierungsmitglieder am Sudetendeutschen Tag. ${ }^{169}$ Ein zentraler Schritt auf dem Reformkurs der Sudetendeutschen Landsmannschaft war die gegen interne Widerstände durchgesetzte Satzungsänderung, mit der die Landmannschaft seit 2015 auf die vormalige Zielsetzung der »Wiedergewinnung der Heimat « und eine »Restitution oder gleichwertige Entschädigung « verzichtet. ${ }^{170}$

\subsection{Polen}

Die politische Landschaft in Polen unterliegt einem fortgesetzten Wandel. Die 1990er Jahre waren nach dem >neoliberalen Kälteschock der Mazowiecki-Ära von immer wieder neuen Parteigründungen und Parteienbündnissen geprägt. Mit der liberalkonservativen »Bürgerplattform« (Platforma Obywatelska, PO) und der nationalkonservativen

165 Vgl. Scholz: >Flucht und Vertreibung< in der deutschen Erinnerungskultur, 2016, S. 162. Scholz fasst hier die Ergebnisse der Studie von Erik K. Franzen zusammen, der die Beziehungsentwicklung von Sudetendeutschen und Bayern bis 1974 umfassend untersucht hat: Franzen: Der vierte Stamm Bayerns, 2010.

166 Handl: Die Politik des wiedervereinigten Deutschland gegenüber der Tschechischen Republik, 2010, S. 229.

167 Auch wenn sich schon 2006 mit Edmund Stoiber ein Richtungswechsel andeutete: Martin: Stoiber will Prag-Reise nicht allein mit Vertriebenenfrage verbinden. Radio Praha. 24.02.2006.

168 Vgl. für das Selbstverständnis der Landsmannschaft als »Brückenbauer« die Publikation: Sudetendeutsche Landsmannschaft 2015. Siehe zum Reformkurs von Posselt u.a.: Verzicht auf »Wiedergewinnung der Heimat«. FAZ. 01.03.2015.

169 Vgl. Kap. 5.3, S. 258.

170 Landsmannschaft verzichtet auf »Wiedergewinnung der Heimat«. Zeit Online. 01.03.2015. Siehe auch: Lindner: Landsmanšaft 2.0. Respekt. 08.03.2015. Vgl. zum Ende der juristischen Auseinandersetzungen um die Satzungsänderungen, an deren Ende die Reformen juristisch bestätigt wurden: Fischer: Jetzt Rückkehr zur Cemeinsamkeit! Sudetendeutsche Zeitung. 12.04.2019. Siehe auch: Reichel; Petrbok: Von »destruktiven Nationalisten«, 2019, S. $376 \mathrm{f}$. 
Partei »Recht und Gerechtigkeit« (Prawo i Sprawiedliwość, PiS) schien sich Mitte der 2000er-Jahre ein tendenziell dualistisches Parteiensystem herausgebildet zu haben, in dem gleichwohl die politische Linke marginalisiert ist. Erst zum Ende der Regierungszeit der PO in den 2010er Jahren entstanden neue liberale und linke Parteien, bisher aber ohne durchgreifenden Erfolg. Wie gleich diskutiert und anhand des MIIW und des MŚK gezeigt werden wird, ist auch die PO in ihrer Geschichtspolitik und im Diskurs von einem zum Teil konservativen polnischen Patriotismus geprägt - freilich mit einigen wesentlichen Unterschieden zu dem der PiS, wie ihr Versuch zeigt, die polnische Geschichtserzählung anschlussfähig in den europäischen Geschichtsraum einzubringen und Raum für Ambivalenz zu lassen.

Wie in Kapitel 4.3 diskutiert, war die Geschichtspolitik der späten Volksrepublik Polen bereits stark nationalisiert und nationalistisch. Die Fortsetzung älterer Traditionen, wie die Vorstellung des polnischen >Messianismus aus dem 19. Jahrhundert, war also nie völlig unterbrochen und eine patriotische Geschichtsschreibung auch in den Oppositionskreisen verbreitet, wobei selbstkritische Stimmen wie die von Jan Józef Lipski in dieser nicht hegemonial waren. ${ }^{171}$ Ein reflektiertes Geschichtsbild konnte sich so nur in Ansätzen zeigen. Alle polnischen Regierungen seit 1989 haben Geschichtspolitik mit unterschiedlicher Intensität und verschiedenen Schwerpunkten betrieben. ${ }^{172}$ Zum zentralen Faktor ist sie seit den 2000er Jahren geworden.

Polen reagierte 1989/90 mit Unverständnis auf die zögerliche Haltung der Bundesregierung zur Grenzfrage. Ministerpräsident Tadeusz Mazowiecki und Außenminister Krzysztof Skubiszewski wollten für den völkerrechtlichen Abschluss dieses Themas nicht auf die Wiedervereinigung warten, da sie das Risiko sahen, dass Deutschland nun die Grenzfrage »neu aufrollen könnte«. ${ }^{173}$ Außenpolitisch stellte sich für Polen die Situation so dar, dass erstmals die jahrzehntelange Bedrohung durch die Sowjetunion im Schwinden begriffen war, das Land aber gleichzeitig mit Deutschland einem vergrößerten und »kerngesunden Nachbarn « gegenüberstand. ${ }^{174}$ Diese im Nachhinein gesehen kurze Phase der Unsicherheit konnte mit dem Grenzvertrag vom November 1990 und dem Nachbarschaftsvertrag von 1991 schließlich zügig beendet werden. Die stets geschürte Angst vor dem deutschen Revanchismus stellte sich zum Zeitpunkt des letztmaligen Auftauchens der Grenzfrage als unbegründet heraus.

Der in Kapitel 4.3 angesprochene mögliche Konflikt, den eine sich politisierende deutsche Minderheit in Polen hätte heraufbeschwören können, nahm sich zügig selbst die Sprengkraft, da ein Großteil dieser Menschen die Auswanderung als Spätaussiedler in die Bundesrepublik wählte. ${ }^{175}$ Zugleich blieb bei manchem die Befürchtung, dass die kapitalstarken Deutschen nun ihre ehemaligen >Ländereien` nicht zurückerobern, sondern einfach nur mit der starken Deutschen Mark zurückkaufen könnten.

Im Juni 1990 stimmten sowohl der Bundestag als auch die Volkskammer der DDR mit großer Mehrheit für die Anerkennung der Grenze zu Polen. Diesem Schritt folgten

171 Vgl. Nijakowski: Die polnische Erinnerungspolitik, 2017, S. 33-37. Vgl. Kap. 4.3, S. $178 f$.

172 Ebd., S. 31.

173 Borodziej: Geschichte Polens im 20. Jahrhundert, 2010, S. 386.

174 Ebd., S. $386 f$.

175 Kap. 4.3, S. 177f. Vgl. zur weiteren Entwicklung der deutschen Minderheit in Polen: Koschyk: Heimat, Identität, Glaube, 2018, S. 272-286. 
die völkerrechtlich verbindlichen Verträge, in denen auch die Minderheitenfrage geregelt wurde. Die deutsch-polnischen Beziehungen entwickelten sich vielversprechend und in Polen galt Deutschland parteiübergreifend als Partner und Unterstützer auf dem Weg nach Europa und konkret in die EU. ${ }^{176}$

Bei seiner Wahl im Sejm am 24. August 1989 forderte der erste demokratisch gewählte Ministerpräsident Mazowiecki, einen »dicken Strich« unter die Vergangenheit zu ziehen. Damit war weniger eine Abkehr von der Geschichte gemeint, vielmehr sollte der friedliche und organisierte Transformationsprozess von der Volksrepublik Polen in die III. Republik nicht von einer Kultur der Abrechnung belastet werden. Eine offensive juristische und politische Auseinandersetzung mit der kommunistischen Vergangenheit und ihren Akteuren wurde auch später nie konsequent verfolgt. ${ }^{177}$ Daraus bildete sich eine innenpolitische Hypothek, die bis heute fortwirkt. Nach Florian Peters begann im Zuge der neoliberalen Wende, die sich in der VRP bereits vor 1989 abzeichnete und bis in die 1990er Jahre fortwirkte, eine »radikale Absage an den prägenden Einfluss historischer Narrative auf die Deutung der Gegenwart. «178

Für die polnische Bevölkerung der West- und Nordgebiete bedeutete die Akzeptanz der polnischen Grenze durch die Bundesrepublik, dass diese endgültig und nunmehr von der dritten Generation als ihre bleibende Heimat anerkannt und mit neuem Blick »die Geschichte der Orte und Städte [...] und das gemeinsame deutsch-polnische Kulturerbe entdeckt werden konnten. ${ }^{179}$ Bereits in dieser Phase entstanden viele Kooperationen und Kontakte mit deutschen Vertriebenen und mancher aufgeschlossenen Landsmannschaft. ${ }^{180}$ Ein Beispiel hierfür ist die von Robert Traba 1990 begründete Kulturgemeinschaft Borussia in Allenstein/Olsztyn, deren Ziel es ist, die »kulturelle Nachfolge« der Region aktiv anzutreten. ${ }^{181}$ Hubert Orłowski spricht in Abgrenzung von der kolonialisierenden Landnahme nach 1945 nun von einer »innovativen kulturellen Inbesitznahme«, die »[n]icht auf Exklusion fremder Kultur und Tradition [aufbaut] [...], sondern auf Inklusion, auf empathisch-achtender Einbeziehung fremder Tradition in den eigenen kulturellen $>$ Blutkreislauf $\_$${ }^{182}$ Seit 1989 lassen sich viele weitere, zumeist lokale Initiativen mit dem Ziel der Erinnerung an die vormaligen deutschen Bewohner beobachten, sei es durch die Einrichtung von Gedenktafeln, die Pflege alter deutscher Gräber oder die Diskussion des Themas in Lokalmuseen. ${ }^{183}$

176 Freudenstein: Die deutsch-polnische Streitgemeinschaft, 2003/2004, S. 39. Vgl. Garsztecki: Das Deutschlandbild im polnischen Europadiskurs, 2007, S. $293 \mathrm{f}$.

177 Wawrzyński: The Politics of Memory in Post-Authoritarian Transitions, 2017, S. 128-131. Vgl. Peters: Revolution der Erinnerung, 2016, S. 465.

178 Peters: Revolution der Erinnerung, 2016, S. 465. Vgl. Bachmann: Politische Debatten in Polen nach 1989, 2017, S. 17.

179 Halicka: Polens Wilder Westen, 2013, S. 307.

180 Traba; Żurek: »Vertreibung« oder »Zwangsumsiedlung«? 2015, S. $325 \mathrm{f}$.

181 Traba; Żytyniec: Verlorene Heimat/Wiedergewonnene Gebiete, 2015, S. 735.

182 Orłowski: Literatur, nationale Identität und kulturelles Gedächtnis, 2010, S. 88. Vgl. Bauer: Schlesien im Museum, 2012, S. $64 \mathrm{f}$.

183 Vgl. Kraft: Beschäftigung mit der Vertreibung vor Ort, 2006, S. 127-138. Ein Beispiel aus diesem weiteren Bereich sind grenzüberschreitende Wanderausstellungen wie die der Kultursoziologin Wanja W. Ronge mit dem Titel »Und dann mussten wir raus - I wtedy nas wywieźli. Von Vertreibungen der Polen und Deutschen 1939-1949«, die von 2000-2006 in verschiedenen deutschen und 
Die Geschichte schien den Beziehungen zwischen Deutschland und Polen Mitte der 1990er Jahre nicht im Weg zu stehen. Neben dem relativen Desinteresse auf politischer Ebene konnten sich, oft gemeinsam mit den erwähnten zivilgesellschaftlichen Initiativen, die Historiker des Landes seit 1989 umfassend und mit Enthusiasmus den bis dahin nicht oder nur eingeschränkt erforschbaren Themen widmen, darunter der Vertreibung der Deutschen. Eines der Ergebnisse sind die umfassenden Quellenpublikationen polnischer Dokumente über die Vertreibungen. ${ }^{184}$ Auch das Lagerwesen der unmittelbaren Nachkriegszeit, wie das von Lamsdorf/Eambinowice, wurde umfassend diskutiert, zumal im Zusammenhang mit der wieder sichtbaren deutschen Minderheit. ${ }^{185}$

Auf der Basis der politischen Entwicklungen wurde Mitte der 1990er Jahre »allenthalben über die guten deutsch-polnischen« Beziehungen gesprochen, im Gegensatz zu denen zwischen Deutschland und Tschechien. ${ }^{186}$ Neben der oben angesprochenen wissenschaftlichen Beschäftigung erfolgte eine Annäherung durch die verbesserten Reisemöglichkeiten und das starke Anwachsen der Polonia in Deutschland. Auch deutsche Vertriebene oder deren Nachfahren erschienen nun noch häufiger als vor 1989 in Polen. Praktisch niemand kam mit dem Gedanken, Land und Gut aggressiv zurück zu erwerben oder gar mit den Polen vor Ort sabzurechnen « - im Gegenteil: Die gängige Erzählung dieser Begegnungen ist, dass beim Besuch des alten Familienhauses die polnischen Bewohner ebenso wie die Deutschen häufig zunächst skeptisch waren, dann aber schnell gegenseitiges Interesse zeigten und manchmal auch langandauernde Freundschaften begründen konnten. In einer Meistererzählung der Verständigung handelt es sich bei den Bewohnern zudem selbst um vertriebene Polen. ${ }^{187}$ Das gemeinsame Schicksal der Vertreibung bietet hier eine wichtige Brücke für den deutsch-polnischen Dialog. ${ }^{188}$ Die privaten, oft aber auch von Untergliederungen des BdV durchgeführten Reisen haben auf beiden Seiten nicht unwesentlich zum Abbau von Ängsten und Vorurteilen geführt, auch wenn sie zumeist kein Ort politischer Diskussionen waren und sind. ${ }^{189}$ Aus diesen Begegnungen entwickelten sich vielmals langjährige Partnerschaften, die beispielsweise bei der Restaurierung von

polnischen Orten zu Gast war: Völkering: Die Musealisierung der Themen Flucht, Vertreibung und Integration, 2010, S. 109f.

184 Borodziej; Lemberg (Hg.): Niemcy w Polsce 1945-1950. Wybór dokumentów, Warszawa 2000-2001 (4 Bd.). Siehe auch u.a. für die deutsche Übersetzung: Kap. 1.4, S. 42 (Anmerkung 149). Vgl. zur Beschäftigung in den 1990er Jahren ebenfalls die Publikation von Maria Podlasek, in der sie verschiedene Zeitzeugenberichte, aber auch weitere grundlegende Texte der deutschen und internationalen Erinnerung und Forschung zu Flucht und Vertreibung ins Polnische übersetzte und einige polnische Presseartikel zur Diskussion versammelt hat: Podlasek: Wypedzenie Niemców z terenów na wschód od Odry i Nysy Łużyckiej, 1995.

185 Röger: Flucht, Vertreibung und Umsiedlung, 2011, S. 233-237.

186 Lemberg: Mitteleuropäisches Dreieck, 2002, S. 24. Vgl. Michnik: Trauma, Memory, and Justice, 2011, S. 210.

187 Vgl. hierfür z.B. das Gespräch mit dem Direktor des Deutschen Polen-Instituts Dieter Bingen: Warum beschäftigen Sie sich mit Polen? 2016, S. 3 f.

188 Traba; Żurek: »Vertreibung« oder »Zwangsumsiedlung«? 2015, S. 328f. Vgl. Röger: Flucht, Vertreibung und Umsiedlung, 2011, S. 239-241.

189 Vgl. Felsch: Reisen in die Vergangenheit? 2015, S. $370 f$. 
Kirchen und sonstigen Kulturdenkmälern hilfreich waren und sind. Dennoch konnten diese Kontakte an der Basis die spätere schwere Beschädigung der deutsch-polnischen Beziehungen nicht verhindern.

Von den in Gesellschaft und Wissenschaft diskutierten historischen Themen war die Vertreibung nur ein Element. In Bezug auf den Zweiten Weltkrieg lag der Schwerpunkt auf den Millionen polnischer Kriegstoten, dem Warschauer Aufstand und den bis zum Ende der VRP tabuisierten sowjetischen Verbrechen, allen voran den Massakern von Katyń. Weitere Themen waren das polnisch-ukrainische und das polnischjüdische Verhältnis. ${ }^{190}$ Die Beschäftigung mit den Zwangsmigrationen aus den kresy blieb in ihrer Größenordnung im Vergleich zur Bedeutung des Vertreibungskomplexes in der Bundesrepublik der 1950er Jahre bescheiden und ohne die Entwicklung eines umfassenden und schlagkräftigen Verbandswesens. Die Auseinandersetzung mit der Vertreibung der Polen aus dem Osten und ihrer Ansiedlung in den ehemaligen deutschen Ostgebieten lenkte häufig das Augenmerk auf die Parallelbewegung der Vertreibung der Deutschen. ${ }^{191}$ Mittelpunkt der geschichtspolitischen Debatte blieb die schon diskutierte Auseinandersetzung mit der Volksrepublik. Eine wenig konsequente Lustration und mangelhafte juristische Aufarbeitung bilden bis heute eine Angriffsfläche für konservative politische Kräfte, die die zu reibungslose Transformation der volkspolnischen Nomenklatura in Verwaltung, Gerichtswesen und vor allem in die häufig fragwürdig privatisierte Wirtschaft ebenso wie den vermeintlich bis in die Gegenwart fortwirkenden starken Einfluss der >postkommunistischen Politiker kritisieren. ${ }^{192}$

Das Verständnis von Flucht und Vertreibung in den 1990er Jahren blieb nach Traba und Żurek von dem bis heute bestehenden gesellschaftlichen Konsens geprägt, dass die »Aussiedlung der Deutschen [...] ein Übel [war] und die Opfer [...] Leid [erfuhren].« Diesem könne und solle man empathisch begegnen. Dennoch sei diese >Aussiedlung، am Ende des Krieges »unvermeidlich « gewesen, um den deutsch-polnischen Konflikt - der schließlich mit zum Ausbruch des Zweiten Weltkrieges geführt habe - zu entwirren. Verantwortlich für die Zwangsmigration seien zudem Deutschland selbst, das den Krieg begonnen habe, sowie die alliierten Siegermächte, die sich zu diesem Vorgehen entschlossen und Polen zugleich seine Ostgebiete genommen hätten. Polen sei an diesen Entscheidungen nicht beteiligt gewesen. Dennoch hätten Polen individuell Verantwortung getragen und sich auch individuell schuldig gemacht. Als polnische Gesellschaft könne man sich »für die aktive Teilnahme eines Teils der Bevölkerung bei der Erniedrigung, dem an den Deutschen begangenen Raub und den ihnen zugefügten Qualen sowie für die gleichgültige Haltung der Mehrheit der Gesellschaft gegenüber der dramatischen Lage der deutschen Bevölkerung« selbstkritisch zeigen, ohne freilich den Kontext der vorherigen NS-Besatzung zu vergessen. ${ }^{193}$

190 Borodziej: Geschichte Polens im 20. Jahrhundert, 2010, S. 405. Traba; Żurek: »Vertreibung« oder »Zwangsumsiedlung«? 2015, S. 324.

191 Borodziej: Anmerkungen zur deutschen und polnischen Historiographie, 2007, S. 188.

192 Koposov: Memory Laws, Memory Wars, 2018, S. 155. Vgl. für eine nationalkonservative Perspektive auf die Lustration und die Transformationszeit: Musiał: Die nationale Narration und ihre Entwicklung sowie die Entfaltung der europäischen Idee im Polen des 20. Jahrhunderts, 2016, S. 345, 347f. Traba; Żurek: »Vertreibung«oder »Zwangsumsiedlung«? 2015, S. 327f. Vgl. auch zur polnischen Diskussion über Vertreibungen 1993-2002: Bömelburg: Gestörte Kommunikation, 2005, S. 41-44. 
In seiner Funktion als polnischer Außenminister bedauerte Władysław Bartoszewski bei seiner vielbeachteten Rede im Deutschen Bundestag im Jahr 1995 »das Schicksal der aus Polen vertriebenen Deutschen $«{ }^{194}$ Auch wenn es sich in dieser Hochphase der deutsch-polnischen Entspannung nicht um die in Deutschland erhoffte Entschuldigung handelte (obwohl sie fälschlicherweise in Deutschland von einigen so missverstanden wurde), sondern um Worte des Bedauerns, war seine Argumentation vielmehr »sichtbares Ergebnis« der »innerpolnischen Debatte« um die Vertreibung. ${ }^{195}$ Philipp Ther konstatierte 1996, dass sich hier ein wesentlicher Unterschied zu Tschechien manifestiere, wo eine solche "Auseinandersetzung mit den dunklen Seiten der eigenen Vergangenheit« ausblieb. ${ }^{196}$

Ein Spezifikum des polnischen Diskurses in den 1990er Jahren über die Vertreibungen war die aktive Beteiligung deutscher Publizisten, Zeitzeugen und Wissenschaftler, die sich wie Helga Hirsch, Klaus Bachmann und Thomas Urban zum Teil kontrovers in den polnischen Medien einbrachten. ${ }^{197}$ Ihre Beiträge in den "auflagenstarken polnischen Tages- und Wochenzeitungen [...] erreichte[n] auf diesem Wege mehrere hunderttausende potentielle Leser. ${ }^{198}$ Durch die deutsch-polnische, aber auch weitere internationale Beteiligung besaß die Debatte nach Hans-Jürgen Bömelburg »transnationale Züge ${ }^{199}$ Ein Produkt dieser Diskussionen war eine von Klaus Bachmann und Jerzy Kranz herausgegebene Zusammenfassung der bisherigen Debatte, die in ihrer polnischen Fassung den bezeichnenden Titel »Sich für die Vertreibung entschuldigen?« trägt und in Polen kontrovers diskutiert wurde. ${ }^{200}$ Die dortigen umfassenden Auseinandersetzungen fanden trotz der deutschen Beteiligung und der auch in Deutsch erschienenen $\mathrm{Pu}$ blikation des genannten Bandes ${ }^{201}$ kaum Resonanz in der Bundesrepublik, sodass dort in der Diskussion der 2000er Jahre immer wieder der Irrtum und Vorwurf verbreitet wurde, dass man sich in Polen mit dem Thema nicht befasse. ${ }^{202}$

Włodzimierz Borodziej stellt in Hinblick auf die deutsche und polnische Geschichtsschreibung der 1990er Jahre fest, dass eine fortgesetzte volkspolnische Perspektive weiterhin das »oft unsichtbare [...] Fundament « für die Geschichtswissenschaft bilde, auch wenn sich mancher internationale Einfluss bemerkbar mache, wie etwa

194 Vgl. dafür das Interview mit Władysław Bartoszewski im Sammelband von Aust; Burgdorff: Die Flucht, 2003: »Ein Paradox der Ceschichte«, 2005, S. 186.

195 Ther: Chance und Last der Ceschichte, 1996, S. 994.

196 Ebd.

197 Bömelburg: Cestörte Kommunikation, 2005, S. 41. Majewski: Die Hauptakteure der neueren polnischen Debatten zum Thema der Zwangsmigrationen, 2008, S. 53-55. Vgl. auch den deutsch-polnischen Sammelband von 2000, der sich umfassend mit verschiedenen kontroversen Themen auseinandersetzt: Borodziej; Ziemer (Hg.): Deutsch-polnische Beziehungen 1939-1945-1949, 2000.

198 Bömelburg: Cestörte Kommunikation, 2005, S. 41.

199 Ebd.

200 Bachmann; Kranz (Hg.): Przeprosić za wypedzenie? 1997. Vgl. Bömelburg: Cestörte Kommunikation, 2005 , S. 42.

201 Bachmann; Kranz (Hg.): Verlorene Heimat, 1998. Ruchniewicz konstatiert, dass dieses Buch gerade »in Deutschland eigentlich auf große Resonanz hätte stoßen müssen«, was aber ausblieb: Ruchniewicz: Ceschichtspolitik im Schatten der Dankbarkeit und Enttäuschung, 2007/2008, S. 150.

202 Ther: Der Diskurs um die Vertreibung, 2008, S. 31f. Vgl. Bömelburg: Cestörte Kommunikation, 2005, S. 44. 
beim Wandel hin zum internationalen Opferdiskurs, in dem auch Deutsche gleichrangige Opfer darstellen. Dementsprechend sah auch die Auseinandersetzung mit dem kommunistischen Lagerwesen im Zuge der Vertreibungen aus, in der unter Personalisierung der Taten Verbrechen aufgearbeitet wurden. Wissenschaftshistorisch konstatiert Borodziej, dass der deutsch-polnische Austausch auf dieser Ebene davon profitiert habe, dass für viele junge deutsche Historiker Polen durch die Solidarność-Bewegung in den 1980er Jahren als »chic« angesehen und entsprechende Studienschwerpunkte gebildet wurden - verbunden mit einer Abkehr vom sewigen Themar der Vertreibung. Umgekehrt ließ sich bei jungen polnischen Historikern eine neue Schwerpunktsetzung auf die Vertreibungsforschung erkennen. ${ }^{203}$

Für die polnische Auseinandersetzung der 1990er Jahre machte Philipp Ther einige Probleme aus, wie die fortwirkende, weit verbreitete These des in jeder Hinsicht schuldfreien Polens, die sich nicht zuletzt aus einer 200jährigen Selbstdefinition als »Opfernation« (»Opfer von Teilungen, von Kriegen, von Russen und Deutschen«) speise. Dies sei ein Phänomen, welches sich ähnlich in Tschechien beobachten ließe. Die mangelnde Fähigkeit, die in der Tat eingeschränkte Verantwortung Polens für die Vertreibungen einzugestehen, auch die der bürgerlichen polnischen Exilregierung und ihrer Vertreibungsplanungen, erschwere den Dialog manchmal selbst unter Historikern. ${ }^{204}$ Als Beispiel für die in diesem Fall schädliche Wirkung eines falsch verstandenen politischen Verständigungswillens sieht er die von der Stiftung für deutsch-polnische Zusammenarbeit nicht gewährte finanzielle Unterstützung für ein Forschungsprojekt, welches die Zahl der Todesopfer der Vertreibungen endlich fundiert feststellen sollte. Dies hätte die in Deutschland weit verbreiteten, überhöhten Todeszahlen korrigiert und zugleich in Polen die eigene (Teil-)Beteiligung und (Teil-)Verantwortung unzweifelhaft offengelegt. Ther stellte resigniert fest: »Polen hätte also ein gehöriges Maß an Schuld eingestanden, Deutschland hätte zugeben müssen, dass die Vertreibung im Kalten Krieg auch als Propaganda missbraucht wurde. Schließlich entschied die Stiftung, dass es für beide Seiten bequemer ist, mit Halblügen weiterzuleben. Das Projekt wurde trotz vorhandener Finanzmittel nicht bewilligt. National gesinnte Polen werden also weiterhin Schuld von sich weisen, und die deutschen Vertriebenenverbände an zwei Millionen Vertreibungsopfern festhalten. ${ }^{205}$

Bömelburg konstatierte, dass der Diskurs der 1990er-Jahre in seiner Reichweite inhaltlich und gesellschaftlich letztlich beschränkt blieb, vor allem durch die »lebensweltlich und kommunikativ tiefverankert[e] Vorstellung von den Deutschen als den Tätern [...].« Dies gelte weiterhin, auch wenn die vielen Besucher der >alten Heimat « vor Ort « erfolgreich das bisherige "Opfer-Täter-Schema« in Frage stellen. ${ }^{206}$ Der Optimismus der 1990er Jahre, in dem »die meisten der strittigen Fragen zwischen den Staaten ge-

203 Borodziej: Anmerkungen zur deutschen und polnischen Historiographie, 2007, S. 186-190.

204 Ther: Chance und Last der Ceschichte, 1996, S. 996.

205 Ebd., S. 997.

206 Bömelburg: Gestörte Kommunikation, 2005, S. 43. Vgl. Hołub: Die Stiftung Flucht, Vertreibung, Versöhnung, 2014, S. 105. 
löst worden zu sein« schienen, blieb letztlich unbegründet. ${ }^{207}$ Erste Anzeichen möglicher künftiger Konflikte zeigten sich in einer noch mit der Mehrheit von CDU/CSU und FDP beschlossenen Resolution des Bundestages im Vorwahlkampf 1998, in der die bis dato bewusst ausgeklammerten "vergangenheitsbeladenen Streitfragen« offensiv angesprochen wurden. Eine darauffolgende, »in scharfem Ton gehaltene Gegenresolution« (Thomas Urban) des Sejms stellte die polnischen Selbstverständlichkeiten fest, wie die »Unantastbarkeit der polnischen Grenze ${ }^{208}$ Beobachter sprachen von einem »überflüssigen Krieg der Parlamentsresolutionen«. ${ }^{209}$

In Polen entstand Ende der 1990er Jahre die Forderung nach einer modernen und intensivierten Geschichtspolitik, die sich unter anderem in Form der Gründung beziehungsweise Neustrukturierung des Instituts für Nationales Gedenken (IPN) niederschlug. ${ }^{210}$ Innenpolitisch sollte das IPN die deutschen Kriegsverbrechen ebenso wie den Kommunismus fortgesetzt aufarbeiten, darunter auch Elemente wie verbrecherische Handlungen am Ende des Zweiten Weltkrieges. Ziel sollte es nach Auffassung konservativer Intellektueller zudem sein, die national und international vernachlässigte Bedeutung des polnischen Beitrages im Kampf gegen NS-Deutschland und am Ende des Kommunismus stärker hervorzuheben. ${ }^{211}$

Eine Infragestellung des polnischen Selbstverständnisses als heroische Opfernation ging mit der von erheblichen innerpolnischen Debatten begleiteten Veröffentlichung des Buches von Jan Tomasz Gross 2000/2001 einher, in dem dieser die Ermordung der jüdischen Einwohner des polnischen Ortes Jedwabne durch ihre christlich-polnischen Mitbewohner im Jahr 1941 schildert. ${ }^{212}$ Auch wenn das Buch wissenschaftlich bald in Details kritisiert wurde, vor allem wegen der nicht ausreichenden Beachtung der deutschen Beteiligung an dem Pogrom, wurde vielen Polen schmerzlich ins Bewusstsein gerufen, dass es eine Geschichte des gewalttätigen polnischen Antisemitismus gibt und Polen während des Zweiten Weltkrieges sowohl Opfer als auch Täter gewesen waren. $^{213}$

Nicht nur nationalistisch eingestellten Polen missfiel im Zuge der Gross-Debatte, dass diese in Deutschland vergleichsweise aufmerksam verfolgt wurde - und teilweise, so zumindest die Wahrnehmung, mit Schadenfreude, einer gewissen Genugtuung

207 Garczewski: Die Stiftung »Flucht, Vertreibung, Versöhnung« als politisches Problem in den deutsch-polnischen Beziehungen, 2011, S. 207.

208 Borodziej: Polen - Deutschland im letzten Jahrzehnt des 20. Jahrhunderts aus der Sicht des Historikers, 2000, S. 226-230. Urban: Der Verlust, 2004, S. 192. Vgl. Traba; Żurek: »Vertreibung« oder »Zwangsumsiedlung«? 2015, S. 330-334.

209 Urban: Der Verlust, 2004, S. 192. Vgl. Schmid: Die Gefahr aus Deutschland. Die Zeit. 20.08.1998.

210 Instytut Pamięci Narodowej. Traba; Żurek: »Vertreibung« oder »Zwangsumsiedlung«? 2015, S. 330334. Vgl. zur ursprünglichen Zielsetzung des IPN: Kieres: Rechtliche Aspekte der Auseinandersetzung mit der Vergangenheit, 2007, S. 78-80.

211 Kostro: The Light of History, 2012, S. 74. Vgl. Zybura: Der Kommunismus und die Polen, 2013, S. 59.

212 Cross: Nachbarn, 2001. Die polnische Ausgabe erschien 2000. Vgl. zur Diskussion den Sammelband von Robert Jankowski (Hg.): Cena »Strachu«, 2008.

213 Vgl. Majewski: Zwischen Versöhnung und Verteidigung nationaler Interessen, 2008, S. 47. 
und obendrein mit sklugen Ratschlägen`vom >Vergangenheitsbewältigungsweltmeister verbunden war. ${ }^{214}$

Bezüglich des deutsch-polnischen Verhältnisses nach der Jahrtausendwende sprechen Dieter Bingen, Peter Oliver Loew und Kazimierz Wóycicki von einer "Destruktion des Dialogs«, die die tatsächlichen und vermeintlichen Errungenschaften der Verständigung der 1990er Jahre erheblich beschädigt habe. ${ }^{215}$ Als im Jahr 2001 Günter Grass' Buch Im Krebsgang erschien, waren die Stimmen in Polen noch durchaus positiv: Dass die Deutschen nach einer intensiven Phase der Selbstkritik nun auch verstärkt ihrer eigenen Opfer gedachten, erschien durchaus verständlich. ${ }^{216}$ Der Gründung des Zentrums gegen Vertreibungen und der literarischen und medialen Rethematisierung der Vertreibung folgte der Bundestagswahlkampf 2002, in dem sich der Spitzenkandidat von CDU/CSU, der bayerische Ministerpräsident Edmund Stoiber, unter anderem mit einer Pro-Vertriebenen-Einstellung zu profilieren versuchte. Er forderte, die EUBeitrittsverhandlungen mit Polen und Tschechien zu nutzen, um diese zur Rücknahme der tatsächlichen oder nur noch vermeintlich existierenden und wirksamen anti-deutschen Gesetze und Dekrete, die als juristische Grundlage der Vertreibung dienten, zu veranlassen. ${ }^{217}$ Die Diskussion um die tschechoslowakischen $>$ Beneš-Dekrete ${ }^{218}$ wurde ebenso auf Polen übertragen, indem Stoiber den Neologismus der »Bierut-Dekrete« verwendete. Diese unzulängliche, weil sachlich falsche Parallelisierung, ${ }^{219}$ trug erheblich dazu bei, die Deutschen als selbst definierte (Haupt-)Opfergruppe des Zweiten Weltkrieges und Richter gegen seine Nachbarn zu sehen. ${ }^{20}$ Nach Claudia Kraft diente die Wortschöpfung der >Bierut-Dekrete der Funktion, die unterschiedlichen Vorgänge von Flucht und Vertreibung in Polen und Tschechien zu parallelisieren und so politisch nutzbar zu machen. ${ }^{221}$

In Polen wurde die Initiative des BdV fast einhellig abgelehnt. Nur einige Intellektuelle, die das grundsätzliche Anliegen zumindest für bedenkenswert hielten, entwickelten konstruktive Gegenvorschläge, beispielsweise in Form der vom SPD-Politiker und letzten Außenminister der DDR, Markus Meckel, als Alternative vorgeschlagenen gemeinsamen Institution zur Erinnerung an Zwangsmigrationen in Breslau. ${ }^{222}$ Äußerungen des BdV in Richtung Polen und Tschechien, die ein Eingeständnis der erheblichen

214 Vgl. Traba; Żurek: »Vertreibung« oder »Zwangsumsiedlung«? 2015, S. 333f.

215 Bingen; Loew et al.: Einleitung, 2007, S. 9.

216 Vgl. Kraft: Der Platz der Vertreibung der Deutschen im historischen Gedächtnis Polens und der Tschechoslowakei/Tschechiens, 2005, S. 350f. Vgl. auch: Majewski: Zwischen Versöhnung und Verteidigung nationaler Interessen, 2008, S. 43.

217 Vgl. Majewski: Die Hauptakteure der neueren polnischen Debatten zum Thema der Zwangsmigrationen, 2008, S. $55 f$.

218 Siehe Kap. 3.5, S. 123 f.

219 Borodziej: »Bierut-Dekrete«? 2002. Bolesław Bierut war mit seiner Leitung des kommunistisch dominierten Landesnationalrates von 1944-1947 de facto Staatsoberhaupt und nach den Wahlen von 1947 bis 1952 offiziell der erste Staatspräsident des kommunistischen Polen. Vgl. Kap. 3.5, S. 123. (Anmerkung: 189).

220 Vgl. Hajduk: Die publizistische Kontroverse um das »Zentrum gegen Vertreibungen«, 2010, S. 7.

221 Kraft: Mythos »Beneš-Dekrete«, 2013, S. $233 f$.

222 Majewski: Zwischen Versöhnung und Verteidigung nationaler Interessen, 2008, S. $46 \mathrm{f}$. 
Verantwortung für die Vertreibung und die daher notwendige Aufarbeitung forderten, zeigten die Unkenntnis - oder den Unwillen -, die vorherigen Debatten in Polen und die Charakteristika der polnischen Erinnerungskultur zur Kenntnis zu nehmen. Diese offensiv vorgetragenen Forderungen wirkten so besonders provokativ, entfalteten die gegenteilige Wirkung und trugen zur Polarisierung bei. ${ }^{223}$

Die angespannte Diskussion um das Zentrum gegen Vertreibungen, die Entstehung der Preußischen Treuhand und der Wahlkampf Edmund Stoibers wurden in Polen als eine zusammenhängende und inakzeptable Verbindung wahrgenommen, was auch die letztendliche Niederlage von Stoiber bei der Bundestagswahl 2002 und die endgültige Abkehr der rot-grünen Bundesregierung unter Gerhard Schröder von der ZgV-Initiative nicht mehr befrieden konnte. ${ }^{224}$ Mit den genannten deutschen Vorwürfen in Richtung Polen, einer vermeintlichen Neuausrichtung der deutschen Geschichtspolitik und einer drohenden Täter-Opfer-Umkehr des Zweiten Weltkrieges war auch für viele polnische Intellektuelle und Wissenschaftler, die sich in den 1990ern noch für einen selbstkritischen Umgang mit der deutsch-polnischen Geschichte eingesetzt hatten, eine rote Linie überschritten. ${ }^{225}$ Geschichtspolitisch schien offensichtlich nur eine vollständige Übernahme der »deutschen Position einschließlich derjenigen der Vertriebenenverbände« für die deutsche Seite akzeptabel zu sein. ${ }^{226}$ Symbolisch hierfür ist, dass die Verwendung des Terminus »Vertreibung«, der nach 1989 auch in der polnischen Gesellschaft verbreitet war, »erneut zu einem umstrittenen Begriff «wurde. ${ }^{227}$ Es begann eine Phase "wechselseitiger Aufrechnung«, die schließlich zu einem Tiefpunkt des deutsch-polnischen Verhältnisses führte. ${ }^{228}$

Ein Kritikpunkt polnischer Intellektueller war, dass selbst deutsche Vordenker und Historiker den Zweiten Weltkrieg primär als Hintergrund für den Holocaust und vielleicht noch von Flucht und Vertreibung sähen und damit das polnische Schicksal zwangsläufig in den Hintergrund gedrängt oder vollständig ignoriert würde. ${ }^{229}$ Dies führe zum so wahrgenommenen Paradox, dass Polen aufgefordert werde, sich der deutschen Geschichte und dem deutschen Kriegsschicksal zuzuwenden, das polnische

223 Vgl. Traba; Żurek: »Vertreibung« oder »Zwangsumsiedlung«? 2015, S. 332. Vgl. zur Forderung einer innerpolnischen Aufarbeitung des Vertreibungsgeschehens die Position des CSU-Politikers Hartmut Koschyk: »Was ich beklage ist ein Versagen breiter intellektueller Schichten von Wissenschaftlern, Publizisten und Politikern in Polen, die wenigen nationalistischen Kräften in dieser Frage das Wort überlassen und sich nicht mehr in die Debatte einmischen. (Merkel bekräftigt Idee des Zentrums. DOD. 2006, S. 8).

224 Vgl. Majewski: Zwischen Versöhnung und Verteidigung nationaler Interessen, 2008, S. 48f., 54, 56.

225 Vgl. Bömelburg: Gestörte Kommunikation, 2005, S. 48. Vgl. für die polnische Sicht auf die »Wiederentdeckung «des Themas Flucht und Vertreibung in Deutschland auch: Bebenek: The Heimat Maneuver, 2007, S. 166-170.

226 Bömelburg: Gestörte Kommunikation, 2005, S. 48.

227 Ebd., S. 49. Interessant sind hier die Ausführungen von Paweł Machcewicz, der auf einer Seite seines Buches über polnische Geschichtsdebatten im Zusammenhang mit der Vertreibung der Deutschen von der Zwangsumsiedlung spricht [przymusowe przesiedlenie] und bei den Vertreibungen der Polen von Vertreibung [wypędzenie]: Machcewicz: Spory o historie 2000-2011, 2012, S. 266.

228 Bömelburg: Gestörte Kommunikation, 2005, S. 44-50. Vgl. auch: Traba; Żurek: »Vertreibung« oder »Zwangsumsiedlung«? 2015, S. 334-341.

229 Orłowski: Literatur, nationale Identität und kulturelles Gedächtnis, 2010, S. 81. 
aber nicht weiter interessiere. ${ }^{230}$ Ein weiteres Problem stellten, nicht nur im deutschpolnischen Falle, unterschiedliche kulturelle und sprachliche Umgänge mit Fragen von Schuld und Verantwortung dar. Das Verständnis, Polen solle sich für die Vertreibungen entschuldigen, »entspricht nicht den polnischen kommunikativen Traditionen eines Umgangs mit Schuld und fand folgerichtig keine Mehrheit.«Bömelburg stellt in diesem Zusammenhang weiter und grundsätzlich fest, dass ein »reflektierter Umgang mit der Erinnerung auf europäischer Ebene [...] solche unterschiedlichen Schulddiskurse berücksichtigen und nicht versuchen [sollte], auf dem Umweg über die Europäisierung eine deutsche DIN-Norm umzusetzen. «231

Dem Wirken der Preußischen Treuhand wurde in Polen schließlich eine solche Bedeutung beigemessen, dass trotz der klaren Ablehnung ihres Tuns durch die Bundesregierung und auch der Abgrenzung der Spitze des BdV der polnische Sejm die massive öffentliche Empörung übernahm und als Folge davon, fast wie in volkspolnischen Zeiten, im Herbst 2003 einstimmig die Resolution verabschiedete, im Falle materieller deutscher Ansprüche Reparationsforderungen zu erheben. ${ }^{232}$ Piotr M. Majewski weist darauf hin, dass hier ähnliche Mechanismen wie in Tschechien wirkten, die das Abstimmungsverhalten in dieser Sache zu einem »Lackmustest in Sachen Patriotismus" gemacht hätten und auch die zurückhaltenden Stimmen des Präsidenten und der Regierung letztlich wirkungslos werden ließen. Ebenso erhielten ihre Vorschläge bei der Diskussion um das ZgV für einen Kompromiss in Form einer europäischen Institution gegen Zwangsmigration in Straßburg oder Sarajewo weder in Deutschland noch in Polen die notwendige Beachtung und Zustimmung. Auffällig sei auch das Schweigen vieler polnischer Denker zu dieser Frage, was möglicherweise als stillschweigendes Akzeptieren dieses Vorgehens zum Kontern der Forderungen aus Deutschland zu verstehen sei. $^{233}$

Ihren Teil zur Eskalation trugen auch die Medien und die Art und Weise ihrer Berichterstattung bei. ${ }^{234}$ Das berühmte Titelblatt der polnischen Zeitschrift Wprost von 2003, auf dem Erika Steinbach, als SS-Domina verkleidet, auf Bundeskanzler Gerhard Schröder reitet und das mit »Deutsches Trojanisches Pferd « unterschrieben ist, steht sowohl für die chronische Überschätzung des Einflusses der Vertriebenenverbände auf die bundesdeutsche Politik als auch für das in der polnischen Medienlandschaft besonders ausgeprägte Spiel mit Sensationen und gesellschaftlich tief verwurzelten Ängsten. ${ }^{235} \mathrm{Zu}$ -

230 Vgl. Traba: Krieg und Zwangsaussiedlungen, 2007/2008, S. 128.

231 Bömelburg: Cestörte Kommunikation, 2005, S. 52.

232 Ther: Der Diskurs um die Vertreibung, 2008, S. 37. Traba; Żurek: »Vertreibung « oder »Zwangsumsiedlung «? 2015, S. 339f. Troebst: The Discourse on Forced Migration and European Culture of Remembrance, 2012, S. 401. Horst Möller spricht von einer »völlig überzogenen Reaktion des polnischen Parlaments « auf einen unbedeutenden privaten Verein: Möller: Die Vertreibung der Deutschen aus dem Osten in der Erinnerungskultur, 2005, S. $14 \mathrm{f}$.

233 Majewski: Zwischen Versöhnung und Verteidigung nationaler Interessen, 2008, S. 52, 56f.

234 Vgl. Wolff-Powęska: Alte und neue Flecken auf dem Bild des Nachbarn in der polnischen Politik, 2007, S. 234-236.

235 Ther: Der Diskurs um die Vertreibung, 2008, S. 42. Bei aller notwendigen kritischen Analyse können die polnischen Medien als »sejsmograf « dieses Diskurses betrachtet werden: WagińskaMarzec: Konflikt wokół Widocznego Znaku w świetle prasy polskiej, 2009, S. 138. 
gleich stehen die von den Medien vertretenen populären Geschichtsdeutungen oft in der Tradition volkspolnischer Erzählungen, indem sie zum Beispiel die Vertreibungen als "gerechte Strafe« betrachten. ${ }^{236}$ Das Zusammenspiel einiger Medienorgane mit der politischen Rechten in Polen ließ in Kombination mit den genannten >Impulsen Deutschland das alte Feindbild des revanchistischen, selbstgerechten, starken Deutschen, der seine Macht als Türöffner der EU scheinbar gnadenlos auszuspielen bereit war, von Neuem entstehen. Diese Entwicklungen verstärkten sich durch den Aufstieg konservativer Kräfte wie der PiS. Bereits Anfang der $2000 e r$ Jahre »warfen die konservativen Oppositionsparteien der von den Sozialisten gestellten Regierung wiederholt vor, gegenüber deutschen erinnerungspolitischen Neuinterpretationen eine zu zurückhaltende Position zu beziehen. «37

Als Symbolfigur der deutsch-polnischen Kontroverse ist die langjährige Präsidentin des BdV, Erika Steinbach anzusehen, die in Polen höhere Bekanntheitswerte als in Deutschland hat. ${ }^{238}$ In einer Umfrage der Rzeczpospolita, welche Person bei den Polen am meisten Angst verursache, nannten die Befragten Steinbach nach Wladimir Putin an zweiter Stelle. ${ }^{239}$ Als Grund dafür führt Manuel Becker an, dass »[p]olnische Medien [...] Steinbach als dominante politische Figur der Bundesrepublik Deutschland [verzerrt darstellten]. $\aleph^{240}$ Zudem erleichterte ihre zum Teil konfrontative Sprache die Schaffung dieser medialen Gestalt. Für Empörung sorgte in Polen auch ihr angezweifeltes Vertriebenenschicksal, da sie als Tochter eines Soldaten und einer aus Bremen stammenden Luftwaffenhelferin während des Krieges in dem nach dem Ersten Weltkrieg zu Polen gefallenen Teil Westpreußens geboren und von dort am Ende des Krieges fliehen musste. ${ }^{241}$ Diese Einschätzungen erschwerten es, das $\mathrm{ZgV}$ in Polen sachlich zu betrachten, da es völlig mit der Person Steinbach gleichgesetzt wurde. Adam Hołub fasst es in ironischer Anlehnung an die in den kommunistischen Staaten übliche Wendung von »Ich sage Partei - ich denke Lenin« in »Ich sage Zentrum - ich denke Steinbach«. ${ }^{242}$

Die polnische Seite reagierte mit einer Reihe von sowohl tatsächlich ergriffenen als auch angekündigten Maßnahmen auf das ZgV, die Preußische Treuhand und den vermeintlichen Wandel der deutschen Geschichtspolitik. ${ }^{243}$ Der seit 2002 amtierende Stadtpräsident von Warschau Lech Kaczyński initiierte eine eigene Zählung der Verluste Warschaus für künftige Reparationsforderungen und auch das von ihm begründete Museum des Warschauer Aufstandes ist zum Teil als eine Reaktion auf das ZgV zu ver-

236 Feindt: Flucht und Vertreibung zwischen Kaltem Krieg und Universalisierung, 2014, S. 168.

237 Bömelburg: Die Erinnerung an die deutsche Besatzung, 2006, S. 77.

238 Machcewicz: Spory o historie 2000-2011, 2012, S. 266. Vgl. Becker: Geschichtspolitik in der »Berliner Republik«, 2013, S. 487.

239 Nur Putin macht Polen mehr Angst als Steinbach. Die Welt. 30.03.2009.

240 Becker: Geschichtspolitik in der »Berliner Republik«, 2013, S. 487.

241 Vgl. Ther: Der Diskurs um die Vertreibung, 2008, S. 38. Vgl. für ein zusammenfassendes Fazit zu Erika Steinbachs Wirken den Kommentar in der Rzeczpospolita zum Ende ihrer Amtszeit als Präsidentin des BdV: Haszczyński: Zwycięskie odejście Eriki. Rzeczpospolita. 08.07.2014.

242 Hołub: Die Stiftung Flucht, Vertreibung, Versöhnung, 2014, S. 106.

243 Vgl. für eine knappe Zusammenfassung des deutschen, polnischen und deutsch-polnischen Diskurses über das ZgV inklusive einer Diskussion der Akteure und der Rolle der Presse von 1999-2006: Hajduk: Die publizistische Kontroverse um das »Zentrum gegen Vertreibungen«, 2010, S. 209-216. 
stehen. ${ }^{244} 2004$ gründeten Vertreter der PiS eine »Polnische Treuhand«, um Ansprüche von durch das Dritte Reich geschädigten polnischen Personen zu unterstützen. ${ }^{245}$

Piotr Semka fasste 2003 in der Rzeczpospolita die polnischen Befürchtungen zusammen: »Kein Wunder, dass viele Polen von einem Alptraum heimgesucht werden, in dessen Verlauf ein ausländischer Tourist und Berlinbesucher zu dem Schluss gelangt, dass Juden und vertriebene Deutsche - fast auf gleicher Augenhöhe - die einzigen Opfer des Zweiten Weltkriegs waren. ${ }^{246}$ In einem weiteren Artikel der Rzeczpospolita hieß es, dass schließlich »junge Deutsche« nach dem Besuch eines solchen Zentrums nicht nur folgern würden, dass die Juden und die Deutschen die Hauptopfer des Krieges gewesen seien, sondern auch dass Tschechen und Polen, die besetzten Länder des Dritten Reiches, Schuld und Verantwortung trügen, mindestens für die Folgen des Krieges. ${ }^{247}$ Ganz ähnlich argumentierte 2006 der polnische Ministerpräsident Jarosław Kaczyński zur Eröffnung der Ausstellung des ZgV, die Erzwungenen Wege. Diese drohe die TäterOpfer-Rollen umzukehren und »die Geschichte des Zweiten Weltkrieges zu relativieren« und sei daher »ein sehr schlimmes, beunruhigendes und trauriges Ereignis«. ${ }^{248}$ Über den Kommentar von Kaczyński hinaus fand die Ausstellung der Erzwungenen Wege von 2006 ein breites Medienecho in Polen, allerdings waren fast alle Beurteilungen negativ. $^{249}$

Das Entstehen des ZgV und die Debatten um Jedwabne sahen die Nationalkonservativen als einen Angriff auf und eine Gefährdung von polnischen Interessen, auf die es zu reagieren gelte: »Die Angst, polnische Opfer, obwohl sie zu den Hauptleidtragenden des Krieges zählten, würden nun von innen und außen relativiert und marginalisiert, mobilisierte den nationalen Widerstand gegen jede Geschichtskritik. « ${ }^{250}$ Politisch benutzten die polnischen Europaskeptiker das ZgV als Element »ihres Propagandafeldzugs gegen die Europäische Union $\ll{ }^{251}$ Dass die politische Rechte und Teile der Medien diese Entwicklung instrumentalisieren, darf aber nicht darüber hinwegtäuschen, dass mit

244 Vgl. Ukielski: Polsko-německé dějiny v evropské omáčce. Česká pozice. 11.11.2017.

245 Majewski: Zwischen Versöhnung und Verteidigung nationaler Interessen, 2008, S. 56.

246 Zitiert und übersetzt nach: Hołub: Die Stiftung Flucht, Vertreibung, Versöhnung, 2014, S. 107.

247 So Jerzy Haszcyński in der Rzczepospolita am 15.07.2003. Zitiert und übersetzt nach: ebd.

248 Heftige Kritik aus Warschau an Ausstellung über Vertreibungen. FAZ. 11.08.2006.

249 Hajduk: Die publizistische Kontroverse um das »Zentrum gegen Vertreibungen«, 2010, S. 228-237. Das polnische Kernverständnis von Flucht und Vertreibung, dass die Vertreibungen nämlich in allererster Linie eine immanente Konsequenz des von Deutschland ausgelösten Krieges waren, sah man zudem nicht ausreichend berücksichtigt beziehungsweise durch die Ausdehnung auf ein Jahrhundert der Vertreibungen und den Nationalismus als Kernübel relativiert. (Ebd., S. 133). Grundsätzlich stellte die Mehrzahl der Stimmen auf polnischer Seite in Frage, ob das Thema der Zwangsumsiedlungen eines der wichtigsten Probleme der Ceschichte Europas im 20. Jahrhundert gewesen sei. Außerdem betonten sie die Verbindung mit dem Kontext des zweiten Weltkrieges sowie deutscher Aggression und Verbrechen, ohne welche die Umsiedlungen nicht passiert wären (Machcewicz: Spory o historie 2000-2011, 2012, S. 249). Vgl. Kap. 5.1, S. 202-206, 210-213.

250 Pufelska: Raub der Clio - die polnische Geschichtspolitik und ihre Exekutoren, 2010, S. 39. Vgl. Ruchniewicz: Geschichtspolitik im Schatten der Dankbarkeit und Enttäuschung, 2007/2008, S. 152. Katrin Steffen fasst zusammen: »]edwabne und das `Zentrum gegen Vertreibungen (ZgV) sind wichtige Faktoren, ohne die das Aufkommen der Geschichtspolitik nicht zu verstehen ist. «Steffen: Ambivalenzen des affirmativen Patriotismus, 2006, S. 224. 
der klaren Ablehnung der Initiative des Bundes der Vertriebenen, ein solches Zentrum gegen Vertreibungen einzurichten, »in Polen ein breiter, milieu- und parteienübergreifender Konsens [herrscht], was in einem ideell und politisch so stark polarisierten Land eine bemerkenswerte Ausnahme darstellt. ${ }^{252}$

Der Kritik an dem in Deutschland geäußerten Vorwurf der mangelhaften Auseinandersetzung mit Flucht und Vertreibung in Polen begegnete der konservative Historiker und Philosoph Dariusz Gawin mit dem Argument, dass man in jeder Warschauer Buchhandlung Bücher über die Vertreibung der Deutschen erwerben könne und umfassende Forschungsarbeiten darüber entstanden seien. Demgegenüber seien die Erinnerung an die kresy und die >Repatriierung der Polen aus dem Osten in Polen als »weißer Fleck« zu betrachten, woran Gawin zugleich eine Kritik an dem von Jan Józef Lipski begrifflich so gefassten »kritischen Patriotismus« der polnischen Liberalen festmacht, der vermeintlich »Fremden mehr Barmherzigkeit als den Seinen« entgegenbringe. ${ }^{253}$

Nach den vielversprechenden 1990er Jahren kehrte so nun eine breite Desillusionierung im deutsch-polnischen Diskurs ein. Klaus Bachmann sprach von einem »Versöhnungskitsch«, der schließlich die deutsch-polnische Aussöhnung an der Oberfläche belassen habe. ${ }^{254}$ Das deutsche Desinteresse an den polnischen Debatten der 1990er Jahre und das Ausblenden der Streitfragen konnte so nur überdecken, dass Fragen der Bewertung des Zweiten Weltkrieges nach wie vor von immenser Bedeutung waren. ${ }^{255}$ Trotz der hitzigen Diskussionen ergab eine repräsentative Umfrage der FAZ und der Gazeta Wyborcza im Herbst 2003, dass in Polen »etwa $70 \%$ der Befragten die deutschen Leiden des Zweiten Weltkriegs anerkennen [...]« und »dass dieses Leiden Gedenken und Mitgefühl verdient, dass jedoch die Voraussetzung dafür sei, dass die Deutschen die Verantwortung für den Zweiten Weltkrieg auf sich nähmen.«256

Eine Intervention der polnischen und deutschen Präsidenten Aleksander Kwaśniewski und Johannes Rau führte 2003 zur Danziger Erklärung, die den Konflikt um das $\mathrm{ZgV}$ zu befrieden suchte und jede Form von falscher historischer »Aufrechnung « sowie materielle Forderungen ablehnte. ${ }^{257}$ Zugleich legten die Präsidenten damit die Grundlage für das Europäische Netzwerk Erinnerung und Solidarität als für beide Seiten

252 Machcewicz: »Museum statt Stacheldrahtverhaue«, 2012, S. $81 f$.

253 Gawin: Über den Nutzen und Schaden des historischen Revisionismus, 2006, S. 58. Vgl. Ruchniewicz: Geschichtspolitik im Schatten der Dankbarkeit und Enttäuschung, 2007/2008, S. 150. In der Tat lässt sich, unabhängig von Gawins politischen Schlussfolgerungen, in Polen ein populäres Interesse an der Vertreibung feststellen, wie die bereits 2013 ins Polnische erfolgte Übersetzung des gegenüber der polnischen Verantwortung sehr kritischen und in der vorliegenden Arbeit vielfach herangezogenen Buches von Ray M. Douglas erkennen lässt: Douglas: Wypędzeni, 2013. Bezeichnenderweise ist es in der populärwissenschaftlichen Reihe »Geheimnisse der Geschichte erschienen.

254 Hajduk: Die publizistische Kontroverse um das »Zentrum gegen Vertreibungen«, 2010, S. 5. Vgl. Fehr: Vergeltende Gerechtigkeit, 2016, S. 118. Vgl. auch: Leschnik: Erinnerungskultur und Geschichtspolitik in Polen, 2018, S. 126.

255 Hajduk: Die publizistische Kontroverse um das »Zentrum gegen Vertreibungen«, 2010, S. 9.

256 Garsztecki: Das Deutschlandbild im polnischen Europadiskurs, 2007, S. 296.

257 Majewski: Die Hauptakteure der neueren polnischen Debatten zum Thema der Zwangsmigrationen, 2008 , S. $56 f$. 
tragbare Alternative zum ZgV. ${ }^{258}$ Auch die Erklärung Gerhard Schröders in Warschau im Jahr 2004, dass die Bundesregierung jegliche Eigentumsforderungen an Polen ablehne, gehört in diese Versuche der Deeskalation. ${ }^{259}$ Dennoch setzten sowohl Polen als auch Tschechien in den EU-Erweiterungsverträgen eine auch gegen die deutschen Vertriebenen gerichtete Klausel durch, die den Landerwerb von Ausländern für sieben Jahre verbot. ${ }^{260}$ Mit dem EU-Beitritt am 1. Mai 2004 sah sich Polen nun nach Jahren der Anpassung als Partner auf Augenhöhe und wurde in der Bundesrepublik parteiübergreifend in verschiedenen Politikfeldern zunehmend als »unbequem« wahrgenommen. ${ }^{261}$

Im Jahr 2005 gewann die Partei PiS die Parlaments- und Präsidentschaftswahlen und bildete bis 2007 zeitweise eine Minderheitsregierung oder regierte in einer Koalition mit der katholisch-nationalkonservativen Liga polnischer Familien (LPR) und der katholisch-konservativ orientierten Samoobrona [Selbstverteidigung]. Die nach der Bundestagswahl 2005 gebildete Große Koalition nahm das BdV-Projekt in Teilen in ihren Koalitionsvertrag auf, was in Verbindung mit der neuen nationalkonservativen polnischen Regierung zu einem geschichtspolitischen Stillstand zwischen den Ländern führte. $^{262}$

Eine auf allen Ebenen des Staates betriebene Geschichtspolitik war ein zentrales Element der PiS-Regierung. ${ }^{263}$ So wurde der polnische Terminus "polityka historyczna « zu einem politischen Kampfbegriff und die dahinterstehenden Überlegungen, »je nach politischer Präferenz als unerträgliche Manipulation oder aber als unerlässlicher Beitrag zur nationalen Identitätsstiftung bewertet $[. ..] . «^{264}$ Die nationalkonservative Rhetorik versucht, die Deutschen ebenso wie die Polen im historischen Gegensatz von Täter und Opfer der Kriegszeit zu belassen beziehungsweise diesen zu reaktualisieren. In dieser Arithmetik ist Deutschland der »ewige Schuldner Polens«, die Polen sind fortgesetzt heroische Opfer. Zugleich soll diese Argumentation die nationale Wagenburg gegen die Bedrohung von innen und außen stärken. ${ }^{265}$

PiS-Politiker und konservative Intellektuelle stellten das politische Ziel eines »affirmativen« dem Konzept des »kritischen Patriotismus« gegenüber. Letzterem wurde der Patriotismus abgesprochen und dessen selbstreflexiver Charakter nicht nur als ungeeignet, sondern auch als gefährlich für die Entwicklung der Gesellschaft angesehen. Als Vertreter dieses Narrativs gelten Personen wie der im Kapitel 4.3 diskutierte Jan Józef Lipski. Die nationalkonservative Geschichtspolitik war erfolgreich, da sie an existente Opfer- und Heldennarrative ebenso wie an das traditionelle Bild des inneren Verräters

258 Troebst: Towards a European Memory of Forced Migration? 2016, S. 239. Vgl. Traba; Żurek: »Vertreibung« oder »Zwangsumsiedlung«? 2015, S. 338, 341.

259 Vgl. Sierp: History, Memory, and Trans-European Identity, 2014, S. 90.

260 Ther: Die Außenseiter, 2017, S. 312f.

261 Garsztecki: Das Deutschlandbild im polnischen Europadiskurs, 2007, S. 294.

262 Vgl. Troebst: The Discourse on Forced Migration and European Culture of Remembrance, 2012, S. 402 .

263 Pufelska: Raub der Clio - die polnische Ceschichtspolitik und ihre Exekutoren, 2010, S. 41.

264 Peters: Revolution der Erinnerung, 2016, S. 29.

265 Wolff-Powęska: Das Deutschland-und Deutschenbild der Polen in den letzten Jahren, 2008, S. $28 f$. 
anknüpfen konnte. Im Ergebnis festigte sie das polnische Selbstverständnis als Opfernation und konnte als "Legitimationsbasis der nationalkonservativen Politik« dienen. Die PiS-Geschichtspolitik ist insofern nach außen gerichtet, als dass ein positives Polenbild gerade bei den Verbündeten als wichtig erachtet wird - und selbstkritische Diskussionen dieses gefährden könnten. Diese Direktive galt und gilt folglich auch für die von der PiS geförderten Museumsprojekte. Zudem sah und sieht man sich nicht nur geschichtspolitisch einmal mehr zwischen Deutschland und Russland eingeklammert, gegen die es sich auch auf diese Weise zu behaupten gelte. ${ }^{266}$ Für parteiübergreifende Kritik sorgt beispielsweise das deutsch-russische Nordstream-Projekt, mit welchem Deutschland scheinbar leichtfertig fundamentale Interessen Polens ignoriere. ${ }^{267}$

Feliks Tych betont die Kontinuitäten der PiS-Geschichtspolitik mit denen der Volksrepublik Polen, die vorsätzlich die Leistung von Jahrzehnten der deutsch-polnischen Verständigung »aufs Spiel« setze. ${ }^{268}$ Ein Element hiervon seien die geförderten Ausstellungen, in denen dieses Verständigungswerk und vor allem die dieser Politik gegenläufige Erkenntnis, »dass Deutschland heute ein anderes Land [...] und ein stabiler Garant der Demokratie in Europa [ist] «, nicht vermittelt werde. ${ }^{269}$

Die aktive Geschichtspolitik der polnischen Regierungen manifestiert sich seit 2004 in einem »veritablen Museumsboom«, der trotz mancherlei Kritik weiterhin ungebrochen ist. ${ }^{270}$ PiS-Politiker sprechen von einem im Vergleich zu Deutschland vorhandenen Mangel an polnischen Museen, und tatsächlich ist die Dichte an Museen im westlichen Nachbarland deutlich größer. ${ }^{271}$ Bei der langsamen Transformation der polnischen $\mathrm{Mu}$ seen nach 1989 konnten der ohnehin zumeist nur oberflächliche »dünne Firnis marxistisch-internationalistischer Traditionsinhalte« in der polnischen Erinnerungskultur insgesamt schnell beseitigt und ansonsten die in der VRP gepflegte Geschichtspolitik in Teilen fortgesetzt werden. ${ }^{272}$ Seit 1989 hat in diesem Komplex eine kritische Erzählung stets weiter mit einer heroischen Erzählung konkurriert, wobei letztere $2004 \mathrm{im}$ Museum des Warschauer Aufstands eine »Renaissance« feierte und zugleich zu dieser beisteuerte. ${ }^{273}$ Die beiden großen politischen Lager haben schließlich in den letzten

266 Pufelska: Raub der Clio - die polnische Geschichtspolitik und ihre Exekutoren, 2010, S. 36-47. Zum Gedanken, dass Polen (erneut) von Deutschland und Russland eingeklammert werde, schreibt Feliks Tych, dass die Regierung selbst für diese Entwicklung verantwortlich sei und die nach 1989 gewonnene Errungenschaft, erstmals nicht von Deutschland und Russland bedrängt zu werden, für den Effekt der inneren Mobilisierung leichtfertig riskiere: Tych: Gemeinsame Ceschichte - gemeinsame Aufarbeitung, 2008, S. 135-136. Vgl. ähnlich umfassend: Steffen: Ambivalenzen des affirmativen Patriotismus, 2006.

267 Vgl. Kellermann: Nordstream II entzweit Polen und Deutsche. Deutschlandfunk. 18.12.2017.

268 Tych: Cemeinsame Ceschichte - gemeinsame Aufarbeitung, 2008, S. 136.

269 Ebd.

270 Heinemann: Krieg und Kriegserinnerung im Museum, 2017, S. 10.

271 Muzealny »boom« i nowa historyczna narracja. tvn24. 01.05.2018. Auf 100.000 Einwohner gerechnet liegt die Museumsdichte in Polen bei 2,1, in Tschechien bei 4,9 und in Deutschland bei 8,1: Kosiewski: Zeit der Museen. Dialog Forum. 16.04.2018.

272 Boysen: Militär- und Kriegsmuseen in Deutschland und Polen, 2012, S. 38.VgI. Nijakowski: Die polnische Erinnerungspolitik, 2017, S. 33.

273 Heinemann: Krieg und Kriegserinnerung im Museum, 2017, S. 438. 
fünfzehn Jahren verschiedene `Flaggschiffe` ihres geschichtspolitischen Verständnisses geschaffen und sehen die Museen auch als Teil ihrer Außenpolitik. ${ }^{274}$

Das Aufstandsmuseum in Warschau war eines der zentralen Projekte von Lech Kaczyński als Stadtpräsident von Warschau. Der in Polen bereits in den Jahren der Volksrepublik zunehmend rehabilitierte Mythos des Warschauer Aufstandes ist lagerübergreifend anschlussfähig. Die Auslegung des Museums in Warschau zeigt und bestätigt die »Vision einer von allen Seiten unterdrückten und aufopferungsvoll für die Freiheit kämpfenden Nation [...]. $\ll^{275}$ Mag es in seinen Inhalten traditionell und patriotisch gestaltet sein, so sind seine Ausstellungsmethoden und -techniken doch modern und das Museum ein Besuchermagnet. ${ }^{276}$

Die PiS treibt eine ganze Reihe von weiteren, zum Teil umstrittenen Museumsprojekten voran. So sollen sowohl ein neues Museum für die verfemten Soldaten in Ostrołęka als auch ein Piłsudski-Museum in Sulejówek ebenso wie ein weiteres, Johannes Paul II. und der tausendjährigen Geschichte des christlichen Polen gewidmetes Museum Erinnerung und Identität in Thorn/Toruń entstehen. ${ }^{277}$ Auch die Realisierungsphase des Museums für polnische Geschichte fällt in die Ägide der PiS, welches 2006 durch die erste PiS-Regierung gegründet wurde und 2021 in Warschau eröffnen soll. ${ }^{278}$ Als Begründung, ein Museum für die kresy in Lublin zu schaffen, wird von PiS-Vertretern auf deren im Vergleich zu den deutschen Vertriebenen geringen Stellenwert in der polnischen Erinnerungskultur sowie auf die in dieser Hinsicht vorbildhafte deutsche Erinnerungskultur verwiesen. ${ }^{279}$

Die PO hat drei zentrale Museumsprojekte vorangebracht: 2014 konnten sowohl das Museum der Geschichte der polnischen Juden in Warschau als auch das Europäische Solidarność Zentrum in Danzig eröffnen, 2017 schließlich das von Donald Tusk initiierte Museum des Zweiten Weltkrieges. Nach Catherine Schilling »schicken sich [jene Museen] an, die ausgetretenen Pfade der auf das eigene Leid fixierten Narrative zu verlassen. In ihrer Erzählung gibt es gerade eben nicht ausschließlich polnische HeldInnen, polnische Opfer und wahlweise nationalsozialistische (deutsche) oder sowjetische (russische) TäterInnen. Die Ereignisse in Polen sollen außerdem in ihren europäischen Rahmen eingebettet werden; Ziel ist eine suniversale Botschaft‘, die zur gegenseitigen Verständigung

274 Vgl. Peters: Polens Streitgeschichte kommt ins Museum, 2015.

275 Pufelska: Raub der Clio - die polnische Ceschichtspolitik und ihre Exekutoren, 2010, S. 45.

276 Vgl. Schilling: Patriotismus à la PiS und die Schlüssel von Jedwabne, 2016.

277 Vgl. Muzealny »boom« i nowa historyczna narracja. tvn24. 01.05.2018.

278 Ebd. Vgl. das Interview mit dem Direktor Robert Kostro: Flieger: »W narodowej dumie nie ma nic złego«. Gazeta Wyborcza. 08.07.2018. Dieser betont in dem Gespräch, dass das Museum Raum für Kontroversen lassen und den Besucher zur Bildung einer eigenen Position anregen solle. Zudem solle die Ceschichte Polens als ehemals multi-ethnischer Staat und in Differenz zum heutigen Polen diskutiert werden.

279 So gab der PiS-Politiker Ryszard Legutko an, dass in der polnischen öffentlichen Debatte die deutschen Vertriebenen mehr Raum hätten als die ehemaligen polnischen Bewohner der kresy: Muzealny »boom« i nowa historyczna narracja. tvn24. 01.05.2018. Explizit wird auf die in dieser Hinsicht als Vorbild betrachtete deutsche Erinnerungskultur an die ehemaligen Ostgebiete und ihre Museen verwiesen: Cenckiewicz: Polityka historyczna to chaos. Dziennik. 16.02.2018. Siehe für den gegenwärtigen Stand der Planung (2019): Chrzanowska: W Lublinie będzie Muzeum Ziem Wschodnich Dawnej Rzeczypospolitej. dzieje.pl. 28.06.2019. Vgl. zur Debatte, in der 2014 unter anderem Oppeln als künftiger Museumsstandort gehandelt wurde: Leschnik: Erinnerungskultur und Geschichtspolitik in Polen, 2018, S. 442. 
beiträgt. ${ }^{280}$ Auch Florian Peters konstatiert 2015, dass die ersten beiden Museen ein bedeutender Schritt »zu einem pluralistischen und dialogorientierten Umgang mit der polnischen Geschichte [sind], vor allem aber mit ihrer Orientierung auf eine transnationale, europäische Perspektive markieren beide Museen einen qualitativen Sprung in der polnischen Geschichtskultur.« Sie verbinden sich mit ihrer »selbstkritischen und dialogorientierten Auseinandersetzung mit liebgewonnenen nationalen Geschichtsbildern« zudem mit einem »Selbstbewusstsein Polens, das sich seines Platzes in Europa neu versichern möchte. ${ }^{281}$

Neben dieser Geschichtspolitik initiierte und intensivierte die PO nach ihrem Wahlsieg von 2007 eine politische und wirtschaftliche Liberalisierung und Modernisierung des Landes. Dies blieb allerdings nicht ohne Kritik, wurde sie doch sowohl von den Nationalkonservativen als auch von linken Kräften für eine vermeintlich einseitige Politik angegriffen, die die ökonomische und gesellschaftliche Spaltung Polens verschärft und zentrale Probleme, wie die fortgesetzte Abwanderung junger Menschen, nicht in den Griff bekommen habe. ${ }^{282}$

Geschichtspolitisch blieb die neue Regierung unter Donald Tusk auf Distanz zu Deutschland und dem dort im Entstehen begriffenen "Sichtbaren Zeichen«, auch wenn die unter der PiS-Regierung gängige Polarisierung nun unterblieb. ${ }^{283}$ Statt bei den bereits weit gediehenen Planungen in Berlin zu intervenieren oder das ENRS forciert zu reaktivieren, startete Donald Tusk mit dem Projekt des Museums des Zweiten Weltkriegs eine eigene Initiative zur Lösung des geschichtspolitischen Konfliktes unter Wahrung des polnischen Interesses nach Mitbestimmung und einer ausreichenden Berücksichtigung der polnischen Geschichtserfahrungen. ${ }^{284}$ Grundlegendes Ziel war es, den polnischen Beitrag zur europäischen Geschichte aktiv und konstruktiv einzubringen, ${ }^{285}$ was die politische Rechte nicht davon abhielt, die PO-Geschichtspolitik heftig unter Beschuss zu nehmen. ${ }^{286}$ Jarosław Kaczyński unterstrich 2013 die Forderung nach einem Wandel der vermeintlich liberalen Geschichtspolitik, die eine »Pädagogik der Schande« verfolge und durch eine von »Würde und Stolz« ersetzt werden müsse. ${ }^{287}$ Auch außenpolitisch möchte die PiS Polen »von den Knien erheben « und der Welt die heroische Geschichte Polens nahelegen. ${ }^{288}$

Die deutsche Geschichtspolitik wurde in Polen weiter beständig und kritisch verfolgt. In Projektion der eigenen Vorstellung einer konzertierten Geschichtspolitik wur-

280 Schilling: Patriotismus à la PiS und die Schlüssel von Jedwabne, 2016.

281 Peters: Polens Streitgeschichte kommt ins Museum, 2015.

282 Vgl. Puto: Eine neue Generation protestiert. Süddeutsche Zeitung. 26.07.2017.

283 Politt: Alles im Zeichen von Geschichte? 2009, S. 166. Vgl. Traba; Żurek: »Vertreibung« oder »Zwangsumsiedlung «? 2015, S. 342-345.

284 Vgl. Machcewicz: Spory o historie 2000-2011, 2012, S. $252 \mathrm{f}$.

285 Vgl. Pufelska: Raub der Clio - die polnische Geschichtspolitik und ihre Exekutoren, 2010, S. $50 f$.

286 Vgl. Zybura: Der Kommunismus und die Polen, 2013, S. 56.

287 Kaczyński zapowiada aktywną politykę historyczną. dzieje.pl. 29.06.2013. Siehe auch: Kap. 7.2.1, S. 418. Der Begriff der »Pädagogik der Schande« geht zurück auf den polnischen Historiker Andrzej Nowak, der ihn bereits 2001 einführte: Wolff-Powęska: »Dobra zmiana« szuka naukowych standardów edukacji historycznej Polaków. Gazeta Wyborcza. 26.05.2018. Vgl. Pufelska: Raub der Cliodie polnische Geschichtspolitik und ihre Exekutoren, 2010, S. 51. Wóycicka: »Politik der Ewigkeit« auf Polnisch, 2019, S. 5. 
de die Ausstrahlung der in Polen unter anderem wegen der Darstellung von polnischem Antisemitismus während des Zweiten Weltkrieges umstrittenen ZDF-Serie Unsere Mütter, unsere Väter gleichzeitig mit dem Baubeginn der Stiftung Flucht, Vertreibung, Versöhnung im Jahr 2013 nicht als Zufall, sondern als Manifestation eines koordinierten geschichtspolitischen Schachzuges gesehen. ${ }^{289}$

2015 gewann die PiS sowohl die Präsidentschafts- als auch die folgenden Parlamentswahlen. Bei der Abstimmung 2019 konnte sie ihre absolute Mehrheit im Sejm verteidigen und ausbauen. Aufbauend auf dieser Stärke macht sich die Partei unter ihrem Chef Jarosław Kaczyński mit dem Schlagwort des "guten Wechsels/Wandels« [Dobra zmiana] auf allen Ebenen an den Umbau des Staates, wobei die Geschichtspolitik darin erneut ein zentrales Element ist. ${ }^{290}$ Sie kann dafür an die Regierungszeit von 20052007 anknüpfen, verfügt aber durch die Mehrheitsverhältnisse im Parlament nun über einen weitaus größeren Spielraum und sucht so seit Beginn der Regierungszeit die geschichtspolitischen Weichenstellungen der PO umzulegen. ${ }^{291}$ Das zeigt sich nicht zuletzt darin, dass - beginnend mit dem MIIW - mittlerweile verschiedene Museumsdirektoren »durch neue, linientreue Kader abgelöst« wurden. ${ }^{292}$ Im Verhältnis zu Deutschland sind andere Fragen wichtiger geworden. So verfolgen PiS-Politiker intensiver den Plan, an Deutschland Reparationsforderungen für die Zerstörungen des Zweiten Weltkrieges zu erheben. ${ }^{293}$ Geschichtspolitisch scheinen der »kritische Patriotismus« und damit der Raum für Grautöne und Ambivalenzen ganz an den Rand gedrängt worden zu sein. ${ }^{294}$

Eine praktische Funktion erfüllt das Geschichtsverständnis der PiS in aktuellen Auseinandersetzungen mit Deutschland über ganz andere Politikfelder, wie die umstritte-

289 Hołub: Die Stiftung Flucht, Vertreibung, Versöhnung, 2014, S. 113.

290 Vgl. für eine globale Einordnung des »guten Wandels/Wechsels«: Gespräch mit dem britischen Historiker Timothy Garton Ash. Dialog Forum. 23.01.2020.

291 Vgl. Bucholc: Slow-cooking Academia `à la Polonaise`, 2017. Vgl. zur weiteren geschichtspolitischen Entwicklung und ihren Einfluss auf die Erinnerungskultur: Franczak; Nowicka: Des Kaisers neue Kleider, 2016.

292 Wóycicka: »Politik der Ewigkeit« auf Polnisch, 2019, S. 5.

293 Vgl. für eine kritische Diskussion der polnischen Reparationsforderungen: Ruchniewicz: Die verspätete Rechnung, 2017. In der Newsweek Polska schrieb der Historiker Piotr Osęka, dass die Reparationsforderungen an Deutschland und das antideutsche Element keine reinen Produkte der Ablenkung von anderen Themen seien, sondern wichtige Bestandteile der permanente Mobilisierung erfordernden konservativen Revolution, die gegen die »postkommunistischen Eliten«, die »Richterkaste« oder »kriminelle Deutsche« kämpfe: Osęka: »Zły Niemiec« - PiSowska antyniemiecka ofensywa to kalka PZPR. Newsweek Polska. 06.08.2018. In der Rzeczpospolita wies auch der Historiker Andrzej Friszke darauf hin, dass die Geschichtspolitik der PiS hauptsächlich nach innen gerichtet sei, auch die Reparationsforderungen. Dies sei aber ein Spiel mit dem Feuer, da ein erneutes Aufbringen dieser Frage die internationalen Vereinbarungen mit Deutschland untergraben könne, dank derer Polen eine stabile westliche Grenze habe: Nizinkiewicz: Friszke: Samobójcza polityka historyczna PiS. Rzeczpospolita. 11.09.2017.

294 Vgl. Szeligowska: Polish Patriotism after 1989, 2016, S. 224-226. Nijakowski gibt als Beispiele für nun »verschwiegene «oder»retuschierte«Themen die Deutsche Volksliste, den Dienst in der Wehrmacht oder ein positives Verhältnis zum deutschen Kulturerbe an: Nijakowski: Die polnische Erinnerungspolitik, 2017, S. 41. 
ne Reform des Justizwesens in Polen: Deutschland habe nach dem Zweiten Weltkrieg schlicht »kein Recht«, ein Land in seinen innenpolitischen Angelegenheiten zu kritisieren, welches es überfiel und zu zerstören versuchte. Zudem kann die PiS ihre Auseinandersetzungen mit dem als vermeintlich allmächtig angesehenen Deutschland oder mit der von Deutschland angeblich dominierten EU »als eine neue Art des Kampfes um Unabhängigkeit« inszenieren. ${ }^{295}$ Die Arbeit der PiS-Geschichtspolitik an all diesen >Flanken<, die sich unter anderem in den genannten Museen, aber auch in anderen Bereichen der Kulturförderung manifestiert, hat letztlich zum Ziel, »eine breite Infrastruktur zu schaffen, um ihre Meistererzählung zu tradieren. ${ }^{296}$ Mit dieser soll ihr auch ihr eigener »Machtanspruch « dauerhaft legitimiert werden. ${ }^{297}$

Die Analogien zur Geschichtspolitik und Erinnerungskultur der Volksrepublik Polen wurden in der vorliegenden Studie schon angedeutet und von Kritikern wiederholt gegen die PiS-Regierung ins Feld geführt. Ein prominenter Vertreter dieser Einschätzung ist unter anderem der britische Polenhistoriker Norman Davies, der zur Zeit der VRP in Krakau studierte. ${ }^{298}$ Letztlich kommt aber auch die Kritik nicht umhin anzuerkennen, dass dieser Weg erfolgreich ist und der Anschluss an volkspolnische Narrative in größeren Teilen der Bevölkerung Anklang findet. Dies steht zugleich nicht im Widerspruch $\mathrm{zu}$ internationalen Entwicklungen der modernen Rechten und ihrer patriotischen bis nationalistischen Geschichtsschreibung. ${ }^{299}$

Mit steigender Intensität und unterschiedlichen Mitteln haben alle polnischen Regierungen nach 1989 das Ziel verfolgt, dem zu Recht konstatierten globalen Defizit an Geschichtskenntnissen über Polen allgemein und der Rolle Polens im Zweiten Weltkrieg im Besonderen zu begegnen. ${ }^{300}$ Der "traditionelle defensive Nationalismus« in Polen, der fest in der Gesellschaft verankert ist und sich aus einem »Gefühl der eigenen moralischen Überlegenheit speist «, ${ }^{301}$ wird von der PiS-Regierung umfassend aufgegriffen und weiterentwickelt. Es wird nicht nur an volkspolnische Mythen und deren Geschichtspolitik angeknüpft, sondern man versucht sich auch international als exzeptionelle heroische Opfernation zu präsentieren. ${ }^{302}$ Diese historisch nicht von der Hand zu

295 Schilling: Patriotismus à la PiS und die Schlüssel von Jedwabne, 2016.

296 Saryusz-Wolska; Stach et al.: Verordnete Geschichte? 2016. Die mit staatlicher Unterstützung entstandenen Filme Miasto `44 (2014) Wołyń (2016) und Smoleńsk (2016) bedienen intensiv und ohne ausgeprägte Schattierungen den polnischen Opfermythos. Vgl. Kaluza: Stolz auf Polen, 2018.

297 Wóycicka: »Politik der Ewigkeit« auf Polnisch, 2019, S. 3.

298 Hassel: Die Panzer müssen stolzer werden. Süddeutsche Zeitung. 24.10.2016. Vgl. Vetter: Die PiS und das Erbe der Volksrepublik, 2018.

299 Breitenstein: Die Liebe zum Ausnahmezustand. NZZ. 06.04.2017.

300 Vgl. Wehowski: Wie Polens Politiker die Geschichte instrumentalisieren. FAZ. 04.03.2018.

301 Bömelburg: Die Erinnerung an die deutsche Besatzung, 2006, S. 77.

302 Vgl. Peters: Revolution der Erinnerung, 2016, S. 86. Florian Peters fasst ein Ergebnis der auch hier herangezogenen Studie Monika Heinemanns zur polnischen Museumskultur zusammen: »Tatsächlich kommt Heinemann zu dem Ergebnis, dass die während des Staatssozialismus geprägten Deutungsmuster des Zweiten Weltkriegs in ihren Grundzügen eine überraschend große Beharrungskraft aufwiesen.«- Peters: Rezension zu: Heinemann, Monika: Krieg und Kriegserinnerung im Museum. Der Zweite Weltkrieg in polnischen historischen Ausstellungen seit den 1980erJahren. Göttingen 2017, 2018. 
weisende Einschätzung bleibt gleichwohl fragmentarisch und ohne Schattierungen. ${ }^{303}$ Zudem fällt Deutschland in diesem Narrativ zumeist die Rolle des ewigen Feindes zu, der sich von den Kreuzrittern weiter über Friedrich den Großen bis hin zu Bismarck und Hitler manifestierte. ${ }^{304}$ In der PiS-kritischen Presse spricht man von einer "antideutschen Obsession «, die in ihrem Einfluss auf die Medien und mit ihrer politischen Rhetorik das Verhältnis zum Nachbarn bereits geschädigt habe, wie sich in Erhebungen zeige, in denen die Sympathie gegenüber den Deutschen im Jahr 2018 auf den niedrigsten Wert seit 1993 gefallen sei. ${ }^{305}$ Intellektuelle kritisieren eine neue »Faszination für den Krieg« in der polnischen Gesellschaft, die nur durch die Gegenperspektive "wehrloser Zivilisten « gebrochen werden könne. ${ }^{306}$ Die von den Nationalkonservativen angestrebte Einigung der Nation hinter der Geschichte scheint schließlich eher zu einer gesellschaftlichen Spaltung zu führen. ${ }^{307}$

Diese Kritik deutet an, dass die Geschichtserzählung der PiS und PiS-naher Historiker, obwohl sie keineswegs unwidersprochen bleibt, dennoch bereits Wirkung zeigt. Für die kritische Behandlung und Verhandlung von Flucht und Vertreibung in der polnischen Öffentlichkeit ist diese Entwicklung schädlich. Einer solcher Auseinandersetzung steht im Weg, dass selbst euphemistische Erzählungen des historischen Geschehens von Flucht und Vertreibung das nationalkonservative Geschichtsbild einer fast ausschließlich heroischen und unschuldigen Nation herausfordern. Der Bund der Vertriebenen erfüllte in diesem Zusammenhang besonders unter Erika Steinbach die für eine nationalistische Argumentation wichtige Funktion, die Deutschen (und die deutschen Vertriebenen) weiterhin, wenn nicht als Feind, so doch als Gegner glaubhaft präsentieren zu können. Dies gelang und gelingt, da Erika Steinbach und ihr Verband aufgrund der besprochenen Logiken der polnischen Medien und Politik, aber auch wegen ihrer eigenen Politik ebenso wie der historischen Vergangenheit des BdV, als Opferverband in Polen nie breitere Glaubwürdigkeit gewinnen konnten.

Der ehemalige Direktor des MIIW, Paweł Machcewicz, geht soweit, die PiSGeschichtspolitik - hier am Beispiel der Angriffe auf den »europäischen« und »internationalen« Charakter des MIIW - als Teil einer Entwicklung zu »Isolationismus, Nationalismus und sogar Xenophobie $\mathrm{zu}$ betrachten. ${ }^{308}$ Konservative Autoren wie Bogdan Musiał hingegen weisen darauf hin, dass die jüdische Geschichte Polens ebenso wie »die bis dahin tabuisierte deutsche Geschichte in den polnischen Westgebieten [...] und die Flucht und Vertreibung der dort lebenden Deutschen « heute »ein wichtiger Bestandteil der nationalen Narration geworden « seien. ${ }^{309}$ Im September 2015 brachte

303 So sieht sich nach Philipp Ther Polen mit einigem Recht für das 18.-20. Jahrhundert als eine »Opfernation«: Ther: Der Diskurs um die Vertreibung, 2008, S. 31.

304 Michnik: Trauma, Memory, and Justice, 2011, S. 209.

305 Pacewicz: PiS: Adamowicz po stronie hitlerowców. OKO.press. 13.08.2018.

306 So die Autorin Anna Dziewit-Meller im Interview: Sowiński: Więcej dziewuch, mniej księżniczek. krytyka polityczna. 01.06.2018.

307 Szeligowska: Polish Patriotism after 1989, 2016, S. $229 f$.

308 »Myślę, że ataki na ১europejski<, >międzynarodowy< charakter Muzeum II Wojny Światowej trzeba widzieć jako część wzbierającej w ostatnich latach fali izolacjonizmu, nacjonalizmu, a nawet ksenofobii.«Machcewicz: Muzeum, 2017, S. 288.

309 Musiał: Die nationale Narration und ihre Entwicklung sowie die Entfaltung der europäischen Idee im Polen des 20. Jahrhunderts, 2016, S. 353. 
sich Jan Tomasz Gross mit einem provokativen Debattenbeitrag ein, in dem er den ostmitteleuropäischen Staaten ein Versagen in der Flüchtlingskrise vorwarf, das unter anderem darauf beruhe, dass »Osteuropa [...] seine mörderische Vergangenheit erst noch aufarbeiten [müsse]. (110 $^{310}$

Im polnischen Film differenzierte sich nach 1989 das Bild des Deutschen deutlich, auch wenn gewisse Stereotype wie die des hinterlistigen Volksdeutschen bestehen blieben. Die Thematisierung des deutschen Kriegsleidens erfolgt zugleich meist auf Kosten der Russen, die in den Filmen nun vermehrt als »Erzfeind « dargestellt werden. ${ }^{311}$ Ein Beispiel für diese Entwicklungen ist der Film Róża [Rose] von 2011, in dem der Regisseur Wojciech Smarzowski anhand des Schicksals einer masurischen Frau die nationale Indifferenz dieser Bevölkerungsgruppe und das Schicksal der Massenvergewaltigungen und der drohenden Vertreibungen am Ende des Krieges drastisch darstellt. ${ }^{312} 2017$ widmete sich der Film Zgoda [Eintracht] der schwierigen Nachkriegssituation in Oberschlesien und dem dortigen kommunistischen Lagersystem, in dem Deutsche, Schlesier und Polen interniert waren.

In der Literatur wurde sowohl das Thema von Flucht und Vertreibung als auch das der deutschen Vergangenheit vielerorts empathisch und mit einer polnischen Perspektive in all seinen Schattierungen wiederholt aufgegriffen, so von der berühmten polnischen Gegenwartsschriftstellerin und Nobelpreisträgerin Olga Tokarczuk. Auch die weitere künstlerische Auseinandersetzung mit dem Komplex führt in Polen immer wieder $\mathrm{zu}$ bemerkenswerten Werken oder Interventionen. ${ }^{313}$ So schuf der Kunststudent Jerzy Bohdan Szumczyk 2013 in Danzig vor einem sowjetischen Kriegerdenkmal eine Guerillakunst mit der Installation einer Skulptur zur Erinnerung an die von der Roten Armee vergewaltigten Frauen. Das Werk wurde bereits nach wenigen Stunden von der Polizei entfernt und führte zu russischen Protesten. ${ }^{314}$ Ein Beispiel intensiver künstlerischer Auseinandersetzung war 2015 in Breslau zu sehen: Die Ausstellung The Germans did not come diskutierte mit verschiedenartigsten Exponaten die Vertreibung der Deutschen ebenso wie die polnischen Erfahrungen und Befürchtungen. ${ }^{315}$ Ein besonders eindrucksvolles Werk mit dem Titel »Heimatvertriebene« besteht aus gesammelten historischen Breslauer Wohnungstüren, die von der Künstlerin Dorota Nieznalska mit großen Eisenspitzen durchbohrt wurden und in mehrfacher Hinsicht den gewaltsamen Akt der Vertreibung darstellen. ${ }^{316}$

310 Gross: Die Osteuropäer haben kein Schamgefühl. Die Welt. 13.09.2015.

311 Mazierska: Neighbours (Almost) Like Us, 2014, S. $86 \mathrm{f}$.

312 Vgl. das Interview mit dem Regisseur: Wojciech Smarzowski - Rose - Interview. culture.pl. 29.06.2011.

313 Vgl. für einige Werke der Literatur und des Theaters seit 2010, die sich im weiteren Sinne mit der Vertreibung befassen: Fehr: Vergeltende Gerechtigkeit, 2016, S. 123.

314 Krafczyk: Mahnmal entfacht Streit um Kriegsgräuel. Nordwest-Zeitung. 22.10.2013. Vgl. auch: Danziger Skulptur erzürnt Russland. taz. 17.10.2013.

315 Vgl. den Ausstellungskatalog: Bieniek; Miśniakiewicz et al. (Hg.): Niemcy nie przyszli, 2015. Siehe auch: Zarzycki: The Cermans Did Not Come, 2015.

316 Wypędzeniz ziem ojczystych. Siehe für eine Beschreibung: Bieniek; Miśniakiewicz et al. (Hg.): Niemcy nie przyszli, 2015, S. $68 \mathrm{f}$. 
Breslau war nicht zufällig Ort dieser Ausstellung. Als Kulturhauptstadt Europas 2016 setzte sich die Stadt auch mit ihrem deutschen Erbe auseinander und ist seit den 1990er Jahren in dieser Hinsicht generell als liberaler Vorreiter zu betrachten. Vorteilhaft dafür schien die unübersehbare Präsenz des deutschen Kulturerbes zu sein, die zum Bestandteil einer neuen lokalen Identität wurde. Die Stadtregierung betonte in der Bewerbung Breslaus zur Kulturhaupstadt ihren Charakter als europäische Metropole mit einer multikulturellen Geschichte, auch wenn das historisch nur eingeschränkt haltbar ist. Gleichzeitig wurde die eigene Erfahrung mit der schwierigen Vergangenheit eines vollständigen Bevölkerungsaustausches hervorgehoben. ${ }^{317}$

\subsection{Tschechien}

Die Frage der Vertreibung der Deutschen berührt die heutige tschechische Identität wesentlich mehr, als dies für Deutschland oder Polen gilt. ${ }^{318}$ So ist die enge deutschtschechische Verbindung seit vielen Jahrhunderten konstitutiv für die Regionen von Böhmen, Mähren und den heute tschechischen Teil Schlesiens. Der tschechische Blick auf die Deutschen ist oft auf einen vermeintlich langen Gegensatz gerichtet, in dem sich die Tschechen gegen die Deutschen - zumeist vergeblich - behaupten mussten. Eine stärkere innere und verwobene Dimension hat der Konflikt auch daher, dass im Gegensatz zum Großteil der Deutschen aus den heutigen polnischen Gebieten die Sudetendeutschen zunächst tschechoslowakische Staatsbürger deutscher Nationalität waren. Die Konflikte mit Deutschland, Österreich und den Sudetendeutschen nach der friedlichen Aufspaltung der Tschechoslowakei nach 1989/93 fielen zudem in eine Phase der Neukonstituierung einer tschechischen Identität. ${ }^{319}$ Das zeigt sich nicht zuletzt darin, dass es sich bei den Auseinandersetzungen über die Bewertung des odsun in Tschechien vor allem um einen »tschechisch-tschechischen Streit« handelt, der zu einem wichtigen, wenn nicht dem wichtigsten zeithistorischen Thema Tschechiens wurde. ${ }^{320}$ Für die interne Diskussion wie für die Streitgeschichte mit den Sudetendeutschen spielt »[d]ie Frage, wer in der Geschichte von der tragischen Entwirrung des deutsch-tschechischen Konflikts möglicherweise das (größere) Opfer und wer der (größere) Täter ist, [...] immer noch eine wichtige Rolle und ist so eines der Hauptargumente dieser nicht enden wollenden Polemik. $\ll^{321}$

Bis zu den Parlamentswahlen 2010 war das tschechische Parteiensystem vom Dualismus der liberal-konservativen ODS und der sozialdemokratischen ČSSD geprägt. Verschiedene Neugründungen wie die christdemokratische TOP o 9 und die ANO-Partei vervielfältigten das Parteienspektrum, sodass sich heute neun Parteien im tschechischen Abgeordnetenhaus befinden. Eine Besonderheit der Tschechischen Republik ist eine nicht oder kaum gewendete orthodoxe kommunistische Partei (KSČM), die nach

317 Vgl. Kretschmann: Breslau museal, 2017, S. 20, 347f., 360.

318 Kraft: Der Platz der Vertreibung der Deutschen im historischen Gedächtnis Polens und der Tschechoslowakei/Tschechiens, 2005, S. 343.

319 Vgl. Houžvička: Czechs and Cermans 1848-2004, 2015, S. $432 f$.

320 Tůma: Die Aussiedlung, 2015, S. 257f.

321 Ebd., S. 259. 
wie vor in landesweiten Wahlen zwischen 7 bis 19 Prozent der Stimmen erreicht und über lokale Hochburgen, vor allem im vormaligen `Grenzland , verfügt. Einen bedeutenden nationalen Einfluss konnte sie zuletzt 2018 gewinnen, indem sie die Minderheitenregierung aus der ursprünglich 2011 als Protestpartei gegründeten ANO von Ministerpräsident Andrej Babiš und der stark geschwächten ČSSD stützt. Bezüglich der Frage der Vertreibung der Deutschen vertritt die KSČM eine konsequent nationalistische Position; bei den anderen Parteien gab es stets unterschiedliche Stimmen, auch wenn in Grundfragen ein gleich zu besprechender parteiübergreifender Konsens besteht. ${ }^{322}$ Muriel Blaive konstatiert in diesem Zusammenhang, dass selbst die konservative ODS des damaligen Ministerpräsidenten Václav Klaus durch die informelle Unterstützung der Kommunisten die Präsidentschaftswahlen 2003 gewonnen habe, um den Gegenkandidaten und vormaligen Dissidenten Jan Sokol zu verhindern, den man einer gegenüber den Sudetendeutschen zu entgegenkommenden Einstellung verdächtigte. Dies deutet nach Blaive zugleich an, dass die sudetendeutsche Frage nach wie vor als eine der "größten Gefahren für die tschechische Nation« betrachtet wird und zumindest in den damaligen Wahlkämpfen als existentielle Frage inszeniert, aber auch wahrgenommen worden sei. ${ }^{323}$ Erik Tabery sieht Politiker wie Klaus und Zeman in der Verantwortung, die »Psychose« vor den Deutschen und vermeintlich wieder erneuerten Ansprüchen auf Land und Besitz bewusst reaktiviert zu haben, um sich zugleich als »Beschützer« anbieten zu können. ${ }^{324}$

Martin Schulze Wessel weist in seiner Abhandlung über die Entwicklung der tschechischen Zeitgeschichte auf den nuanciert anderen Charakter der >Aufarbeitungskultur in Tschechien hin. Während in Deutschland von der »Vergangenheitsbewältigung« oder »Aufarbeitung « gesprochen wird, sucht man in Tschechien den »Ausgleich mit der Geschichte« [vyrování s dějinami], der »stärker als der deutsche Begriff [...] dem Subjekt um seiner selbst willen die Pflicht auf[legt], sich um ein wahrhaftes Verhältnis zur Geschichte zu bemühen. «Auch wenn dieser Ansatz letztlich weder in der tschechischen Geschichtswissenschaft noch in der Gesellschaft eine Mehrheitsposition darstelle, habe er doch einen großen Einfluss auf die zeithistorischen Debatten seit 1989 gehabt. ${ }^{325}$

Wie schon angesprochen, verfügt die KSČM in den vormaligen sudetendeutschen Gebieten über eine überproportionale Unterstützung. In diesen Regionen sah man bis in die 200oer Jahre hinein die deutsche Gefahr in Form von Restitution als nach wie vor existent und drängend an und im Verlauf der heftigen deutsch-österreichisch-tschechischen Diskussionen bis 2003 stieg sie in der Wahrnehmung sogar noch an. Ebenso

322 Vgl. zur Entwicklung der KSČM: Blaive: The Memory of the Holocaust and of Communist Repression in a Comparative Perspective, 2011, S. 164. Siehe auch: Kunštát: Fremd- und Feindbilder der Deutschen in der tschechischen innenpolitischen Instrumentalisierung nach 1989, 2007, S. $124 f$. Kunštát konstatiert, dass die KSČM seit 1989/90 ungebrochen und durchaus erfolgreich die >deutsche Karteく als »ein Evergreen in der kommunistischen Öffentlichkeitsarbeit«nutze.

Blaive: The Memory of the Holocaust and of Communist Repression in a Comparative Perspective, 2011, S. 164. Gelegentliche Kooperationen von ODS und KSČM finden auch auf lokaler Ebene statt: vgl. ebd.

324 Tabery: Die Tschechen auf der Suche nach einem Platz in Europa, 2019, S. 53-56.

325 Schulze Wessel: Tschechien - Institutionen, Methoden und Debatten in der Zeitgeschichte, 2011. 
sanken kritische Einstellungen gegenüber den historischen Exzessen und die Sudetendeutschen wurden in Umfragen wieder in erhöhtem Maße kollektiv für die Zerstörung der ČSR verantwortlich gemacht. Die Unterstützung für diese These wuchs zwischen 1991 und 2003 von 27 auf 43 Prozent. 326

»Ich persönliche verurteile - genauso wie viele meiner Freunde - die Vertreibung der Deutschen nach dem Krieg. Ich erachtete sie stets als eine zutiefst unmoralische Tat, die nicht nur Deutschen, sondern vielleicht in noch größerem Maße Tschechen allein sowohl moralische als auch materielle Schäden zufügte. Wenn auf eine Böswilligkeit mit einer anderen Böswilligkeit geantwortet wird, bedeutet das, daß die Böswilligkeit nicht verdrängt wird, sondern sich ausdehnt. ${ }^{327}$

Diese von Václav Havel zur Jahreswende 1989/90 mehrfach geäußerten Worte des Bedauerns über die Vertreibungen stehen in der Tradition der vormaligen Auseinandersetzungen innerhalb der tschechoslowakischen Dissidentenszene. In Deutschland erhielten sie viel Zustimmung, stand Havel doch damit für einen versöhnlichen, die alten Gegensätze überwindenden Ansatz. In der Tschechoslowakei selbst nutzten die kurz zuvor entmachteten Kommunisten die Chance, gegen Havel und die sich aus den vormaligen Dissidenten formierende Regierung zu agitieren und für sich zu mobilisieren. Damit waren sie durchaus erfolgreich, trafen Havels Worte doch vor allem aus zwei Gründen auf viel Ablehnung: Zum einen fehlte ein vergleichbares, entgegenkommendes Signal von Seiten der Sudetendeutschen oder der deutschen Regierung, zum anderen war die tschechoslowakische Gesellschaft von den Diskursen der Dissidenten im Gegensatz zur Situation in Polen - fast völlig abgeschnitten und sah sich mit einer weitgehenden Neubewertung des historischen Geschehens konfrontiert und überfordert. $^{328}$

In den Diskussionen des Winters 1989/90 wurden die bis heute gängigen Argumente ausgetauscht, die eine Entschuldigung oder auch Äußerung des Bedauerns von staatlicher Seite für unangebracht hielten. Zum einen wurde auf die Entscheidung der Siegermächte verwiesen, die verantwortlich für den odsun sei, ebenso wie auf die von den Deutschen vorangetriebene Zerstörung der ersten Republik sowie die im Krieg von diesen verübten Verbrechen. Die Sudetendeutschen hätten an dieser Entwicklung stets entscheidend mitgewirkt. Zum anderen befürchtete man, dass eine Anerkennung tschechischer Schuld, auch wenn es nur ein moralisches Eingeständnis wäre, unabdinglich reale Forderungen der Deutschen nach sich ziehen könnte. ${ }^{329}$ Die selbstkritische Argumentation, dass die Vertreibungen Grundlage der kommunistischen Machtübernahme gewesen seien und nach der friedlichen Revolution ebenso wie mit dem

326 Houžvička: Czechs and Germans 1848-2004, 2015, S. $463 f$.

327 Beushausen (Hg.): Die Diskussion über die Vertreibung der Deutschen in der ČSFR, 1991, S. 298. Original in: Rudé právo, Nr. 3, 04.01.1990, S. 1: V. Havel prezidentu NSR: »Odsuzuji vyhnání Němců«.

328 Witte: Entfremdung - Sprachlosigkeit - Aussöhnung? 2002, S. 175-178. Vgl. Seibt: Deutsch-tschechischer Diskurs 1947-1999, 2002, S. 205-208.

329 Vgl. Beushausen (Hg.): Die Diskussion über die Vertreibung der Deutschen in der ČSFR, 1991, S. 298-316. 
Kommunismus nun auch mit diesem Thema kritisch abgerechnet werden müsse, fand lediglich eingeschränkt Unterstützung. ${ }^{330}$

Noch seltener waren Stimmen wie die des bereits in den 1970er Jahren mit oppositionellen Streitschriften hervorgetretenen und inzwischen demokratisch gewählten Abgeordneten Ján Mlynárik, der eine Aufhebung der »Präsidialdekrete, die die deutsche und ungarische Frage betreffen, augenblicklich und von Anfang an « forderte. ${ }^{331}$ In Teilen der slowakischen Presse ging man davon aus, dass eine Rückkehr der Sudetendeutschen letztlich nicht zu verhindern und auch natürlich sei. Helfen würde den Deutschen dabei die starke D-Mark und die Unterstützung der Bundesregierung. Dies könnte man durchaus als Chance sehen, das zerstörte und unterentwickelte Grenzland wiederaufzubauen. ${ }^{332}$ Auch in Polen wurde die Entschuldigung von Václav Havel zur Kenntnis genommen und von weiten Teilen der Gesellschaft und Politik ähnlich wie in Tschechien skeptisch und als nicht nachahmenswert betrachtet. ${ }^{333}$

Auffassungen wie von Mlynárik fanden in Tschechien kaum Unterstützung. Dazu trug auch die erwähnte Reaktion der Sudetendeutschen Landsmannschaft bei: Nach anfänglichem Schweigen und ersten verhaltenen Reaktionen folgten bald, gemäß den bisherigen Maximalforderungen der Landsmannschaft, weitergehende eigentumsrechtliche Forderungen, die dem moralischen Schuldeingeständnis zu folgen hätten. ${ }^{334}$ Vladimír Handl fasst die Forderungen der SL als einen "Komplex politischer, rechtlicher und moralischer Forderungen« zusammen, die keine Rückkehr von »Einzelpersonen [...], sondern das Recht auf Selbstbestimmung dieser Volksgruppe und die Restitution bzw. vollständige Entschädigung ihres Eigentums beinhalten. ${ }^{335}$ Dies war eine unerwartete und negative »Überraschung« für die ehemaligen Dissidenten und ein Rückschlag für diejenigen tschechoslowakischen Politiker, die einen Ausgleich mit den Sudetendeutschen anstrebten. Die Forderungen waren für die Tschechoslowakei schließlich nicht nur völlig inakzeptabel, ${ }^{336}$ sondern sie reaktivierten auch in der tschechischen Öffentlichkeit augenblicklich das dahinsiechende Schreckgespenst des >deutschen Revanchismus « ${ }^{337}$ Erschwerend für die weitere Verständigung mit der SL kam hinzu, dass deren Rhetorik in Tschechien häufig in Kontinuität der Sudetendeutschen Partei gesehen wurde, vor allem was die Kritik an der ersten tschechoslowakischen Republik betraf. $^{338}$

330 Beushausen (Hg.): Die Diskussion über die Vertreibung, 1991, S. 332.

331 Ebd., S. 368.

332 Ebd., S. 326-330.

333 Tomaszewski: Europa der Vaterländer oder Vaterland der Zwistigkeiten? Polityka. 05.05.1990, S. 141.

334 Vgl. Pauer: Zähe Erinnerung, 2005, S. $20 f$.

335 Handl: Die Politik des wiedervereinigten Deutschland gegenüber der Tschechischen Republik, 2010, S. 231.VgI. Hahn: Die Sudetendeutschen in der deutschen Gesellschaft: ein halbes Jahrhundert politischer Geschichte zwischen »Heimat« und »Zuhause«, 1998, S. 131-133.

336 Majewski: Zwischen Versöhnung und Verteidigung nationaler Interessen, 2008, S. 41.

337 Handl: Die Politik des wiedervereinigten Deutschland gegenüber der Tschechischen Republik, 2010, S. 224. Vgl. Houžvička: Czechs and Germans 1848-2004, 2015, S. 397-399.

338 Houžvička: Czechs and Cermans 1848-2004, 2015, S. 476. Auch ein direktes Gespräch zwischen dem tschechoslowakischen Ministerpräsidenten Marian Čalfa und dem Vorsitzenden der SL Franz Neubauer, in dem sie sich durch »dreihundert Jahre tschechisch-deutsche Geschichte kämpften«, führte nur zu dem Ergebnis, dass von nun an die Prager Regierung nicht länger mit der SL direkt ver- 
Havels Geste führte schließlich zum Gegenteil seiner Intention. Statt einer konstruktiven Grundlage für eine Auseinandersetzung führten die auf sie folgenden Diskussionen zu einer Verhärtung des innertschechischen und des bilateralen Verhältnisses. Seine Äußerungen bedienten unfreiwillig, aber von politischen Kräften bewusst bespielt, die Angst vor dem inneren Verrat und dem Ausverkauf gegenüber den deutschen Nachbarn und den Sudetendeutschen. ${ }^{339}$

In den tschechischen Auseinandersetzungen fungierten die Medien, ähnlich wie in Polen, weniger als Versachlicher der Diskussion, sondern mehr als Verstärker kontroverser politischer Meinungen. Damit einher ging die ebenfalls kontinuierliche Überschätzung des Einflusses der SL auf die deutschen Regierungen. So wurde ihr Verbandsorgan, die Sudetendeutsche Zeitung, ganz im Gegensatz zu Deutschland, in tschechischen Medien intensiv rezipiert, was zu einer verzerrten Wahrnehmung des bundesdeutschen Diskurses und des Einflusses der SL auf die Regierung führte. ${ }^{340}$

Nach diesem kurzen und gescheiterten Zugehen auf die Landsmannschaft fiel diese für die tschechische Regierung und weite Teile der Gesellschaft als Gesprächspartner aus. Andere sudetendeutsche Organisationen, wie die katholische Ackermann-Gemeinde oder die sozialdemokratische Seliger-Gemeinde, konnten ebenso wie der Adalbert Stifter Verein nur eingeschränkt in diese deutsch-tschechische Lücke stoßen, auch wenn sie vielfältige gemeinsame Veranstaltungen durchführten und durchführen. Sie waren schon in der Vergangenheit gegenüber Fragen sudetendeutscher Verantwortung für Verbrechen im Zweiten Weltkrieg offener als die Sudetendeutsche Landsmannschaft, haben aber ebenfalls ein kritisches Verhältnis zu den >Beneš-Dekreten und betrachten die Vertreibungen als Unrecht. Ihre Reichweite für den nationalen und zwischenstaatlichen Diskurs blieb letztlich ebenso wie die des friedlichen >Heimwehtourismus« mit seinen oft versöhnlichen Gesten beschränkt. ${ }^{341}$

In der tschechoslowakischen Geschichtswissenschaft zeigten sich bereits vor der Wende 1989 Öffnungstendenzen, wie die 1991 veröffentlichte, aber schon vorher begonnene Dissertation von Tomáš Staněk zur Vertreibung der Deutschen 1945-1947 zeigt. ${ }^{342}$ Trotz dieser Aufbrüche darf für die weitere Entwicklung der tschechischen Geschichtswissenschaft deren lange Prägung durch die kommunistische Diktatur nicht unterschätzt werden. ${ }^{343}$

handeln würde: Brunstetter: Escaping History, 2003, S. 273. Brunstetter zitiert: Ryback: Dateline Sudetenland: Hostages to History, 1996/1997, S. 171.

Majewski: Zwischen Versöhnung und Verteidigung nationaler Interessen, 2008, S. 32.

340 Vgl. Witte: Entfremdung - Sprachlosigkeit-Aussöhnung? 2002, S. 178.

341 Vgl. Seibt: Ungelebte Nachbarschaften, versäumte Gelegenheiten, 2002, S. 302. Siehe auch: Reichel; Petrbok: Von »destruktiven Nationalisten«, 2019, S. 373. Vgl. Spurný: Czech and German Memories of Forced Migration, 2012, S. 361. Vgl. ebenfalls: Houžvička: Czechs and Germans 1848-2004, 2015, S. 399-403. Erfolgreich waren Kooperationen und Initiativen von österreichischen Organisationen oder jüdischen Sudetendeutschen: Sniegoň: Between Old Animosity and New Mourning, 2016, S. 63-66.

342 Pešek: Zwangsmigrationen von Tschechen und Deutschen, 2007, S. 194.

343 Philipp Ther spricht davon, dass die »tschechische Geschichtswissenschaft [...] als Folge des rigiden tschechischen Kommunismus nicht so weit entwickelt [sei] wie in Polen«. Ther: Chance und Last der Ceschichte, 1996, S. 997. 
Wenn auch Václav Havels Worte des Bedauerns nicht die Zustimmung der Breite der Gesellschaft erreichten, waren sie doch ein wichtiger Anschub für die tschechische Zeitgeschichte, das Thema verstärkt in den Blick zu nehmen. ${ }^{344}$ Zeitgleich konnte diese mit der Öffnung der Archive und der nun freien Themenwahl einen allgemeinen Aufschwung verzeichnen. ${ }^{345}$ Im Zuge der Hinwendung zur böhmischen und mährischen Landesgeschichte gewann in der Geschichtsschreibung auch der vermehrt so wahrgenommene multiethnische und multikulturelle Charakter der Region an Bedeutung. ${ }^{346}$ Darin nahm das deutsch-tschechische Zusammenleben einen besonderen Schwerpunkt ein, wobei die Vertreibung nur eines, wenn auch ein zentrales, der behandelten Themen war. ${ }^{347}$ Inhaltlich verfolgten die Wissenschaftler verstärkt Fragen von Kontext, »lokalen Ursachen« und »den Folgen der Zwangsumsiedlung für die Tschechoslowakei« ebenso wie »die außenpolitischen Bedingungen der Umsiedlungen «. ${ }^{348}$ Die konkrete Forschung führte auf der einen Seite dazu, die in Deutschland gängigen, überhöhten Opferzahlen deutlich zu relativieren, auf der anderen Seite wurden damit einhergehend vertiefte Kenntnisse über Vertreibungsgräuel und die tschechoslowakische Beteiligung und Verantwortung gewonnen. ${ }^{349}$ Diese Arbeiten schlugen sich in einer bis heute anwachsenden Fülle an Fachliteratur nieder, oft mit einem regional- oder lokalhistorischen Schwerpunkt. ${ }^{350}$

An der historiographischen Aufarbeitung ebenso wie an der kritischen Begleitung der deutsch-tschechischen Auseinandersetzungen beteiligte sich intensiv die 1990 durch die beiden Außenminister der Länder gegründete Deutsch-Tschechoslowakische Historikerkommission (nach 1993: Deutsch-Tschechische und Deutsch-Slowakische Historikerkommission), wie sich unter anderem an der kontinuierlichen Herausgabe von auch in dieser Studie vielfach herangezogenen Sammelbänden und Stellungnahmen zeigt. ${ }^{351}$ Die Kooperation zwischen deutscher und tschechischer Geschichtswissenschaft ist als besonders eng zu betrachten und bezieht fast das gesamte politische Spektrum der Historiographie mit ein. ${ }^{352}$ Dennoch waren nicht alle Kooperationen von Erfolg gekrönt und neben fortgesetzten, auch historiographischen Differenzen ist

344 Pešek: Zwangsmigrationen von Tschechen und Deutschen, 2007, S. $195 f$.

345 Lemberg; Křen et al.: Einleitung der Herausgeber, 1998, S. $23 f$.

346 Ebd., S. 12.

347 Ebd., S. 28f. Spalová konstatiert in Bezug auf Historiker des Tschechischen Instituts für Zeitgeschichte, dass »the transfer/expulsion is undoubtedly the most discussed historical topic among Czech historians, as well as in society«. Spalová: Remembering the German Past in the Czech Lands, 2016, S. 89.

348 Schulze Wessel: Tschechien - Institutionen, Methoden und Debatten in der Zeitgeschichte, 2011.

349 Pešek: Zwangsmigrationen von Tschechen und Deutschen, 2007, S. 200.

350 Vgl. Pešek: Zwangsmigrationen von Tschechen und Deutschen, 2007, S. 197. Vgl. auch: Schulze Wessel: Tschechien - Institutionen, Methoden und Debatten in der Zeitgeschichte, 2011.

351 Vgl. Arburg: Das Katastrophenjahrzehnt 1938-1948 im Spiegel der historischen Forschung, 2011, S. $82 f$. Schulze Wessel verweist selbstkritisch auf das Format der Kommission hin, das die Gefahr berge, dass trotz »aller Annäherung « die »tief verankerte Vorstellung genährt wird, es gäbe zu bestimmten Fragen einen eigentlich tschechischen oder eigentlich deutschen Standpunkt«: Schulze Wessel: Tschechien - Institutionen, Methoden und Debatten in der Zeitgeschichte, 2011. 
zum Beispiel trotz mehrerer Anläufe ein Pendant zum deutsch-polnischen Schulbuch bisher gescheitert. ${ }^{353}$

Resignierend konstatiert Jiř́ Pešek schließlich in Hinblick auf die tschechische Zeitgeschichte eine "Schizophrenie der tschechischen Situation nach der Wende«, in der diese zwar eine große Präsenz und ihre Freiheit und Zugänglichkeit für alle gewonnen habe, zugleich »aber die Instrumentalisierung der Geschichte unbeschränkt weiter läuft und eine geschichtsorientierte Argumentation in der öffentlichen Szene mit Fortschritten und Ergebnissen der Geschichtsforschung kaum kommuniziert. «354

Die Geschichte der tschechischen und deutsch-tschechischen Aushandlungen über die Vertreibung war in den 1990er Jahren von einer Reihe von Verträgen, Reden und Erklärungen geprägt. Zunächst fanden in der Tschechoslowakei, ähnlich wie in Polen, Diskussionen über die Notwendigkeit einer Beteiligung an den Zwei-Plus-VierVerhandlungen statt. Letztlich verzichtete man auf das Erzwingen einer Beteiligung, da die tschechoslowakische Regierung von der richtigen Annahme ausging, dass die Großmächte die Beschlüsse des Potsdamer Abkommens nicht aufrollen und lediglich die dort noch offen gelassene Frage der deutschen Grenze mit Polen im Sinne des Status Quo lösen würden. ${ }^{355}$

Der im Februar 1992 in Prag unterzeichnete deutsch-tschechische Nachbarschaftsvertrag hatte zum Ziel, die Beziehungen der Nachbarstaaten auf ein neues Fundament $\mathrm{zu}$ stellen und zugleich einen Wendepunkt für die historischen Auseinandersetzungen $\mathrm{zu}$ markieren. ${ }^{356}$ Das Ausklammern von eigentumsrechtlichen und weiteren historisch umstrittenen Fragen wurde von den Vertragsparteien unterschiedlich rezipiert. Verstand man es in Deutschland als Auftakt für eine weitere konstruktive Aushandlung, sah man es in Tschechien vielmehr als einen Schlussstrich an. ${ }^{357}$ Aufgrund dieser ungelösten Streitfragen sprach der tschechische Historiker Dušan Třeštík für die folgenden 1990er Jahre von einem »kalten politischen Frieden« zwischen Deutschland und Tschechien. ${ }^{358}$

In dieser Gemengelage, die zudem den Weg zur Mitgliedschaft in der EU und der NATO zu blockieren drohte, hielt Václav Havel 1995 im Karolinum in Prag eine Rede. In dieser betonte er die fast tausend Jahre währende enge kulturelle und politische Verwobenheit von Deutschen und Tschechen, ohne die die tschechische Geschichte nicht $\mathrm{zu}$ verstehen sei. Er verwies darauf, dass seine allgemein bekannte persönliche Haltung gegenüber der Vertreibung nichts daran ändere, dass die gegenwärtige staatliche und

353 Seibt: Das Verhältnis von Tschechen und Deutschen, 2002, S. 333. Dennoch entfaltet die DeutschTschechische Schulbuchkommission vielerlei Aktivitäten. Vgl. die Webpräsenz auf der Seite des Ceorg-Eckart-Instituts: www.gei.de/abteilungen/europa/europa-und-der-nationale-faktor/ deutsch-tschechische-schulbuchkommission.html (letzter Zugriff: 02.09.2018).

354 Pešek: Die zoer und 40er Jahren in der tschechischen Erinnerung seit den 70er Jahren, 2006, S. 128.

355 Kunštát: Die Wiedervereinigung Deutschlands und die tschechoslowakische Außenpolitik, 2010, S. 207f. Vgl. ausführlich: Kučera: Mírové uspořádání s Německem, 2018, S. 230-243. 
rechtliche Ordnung für Tschechien nicht zur Disposition stehe. Dies war auch als Signal ins Inland zu verstehen, verbliebene Befürchtungen vor einem >Ausverkauf nach 1990/93 nun noch größeren Nachbarn zu zerstreuen. ${ }^{359}$ Inhaltlich betonte Havel, dass die Vertreibung in ihrem historischen Kontext und damit durch den ihr vorangehenden Terror zu verstehen sei, das heißt, dass »the evil of the transfer was just the sad outcome of the evil that preceded it. There can be no dispute over who it was who first let the djinn of real nationalist hatred out of the bottle. ${ }^{360}$ Mit dieser Rede war kein Durchbruch der deutsch-tschechischen Beziehungen erreicht, vielmehr konstatiert Piotr M. Majewski eine auf die Rede erfolgende »Abkühlung « der Beziehungen. ${ }^{361}$ Der Grundkonflikt, in Tschechien die Vertreibungen nicht als Unrecht anzusehen und lediglich dabei geschehene Ausschreitungen zu bedauern und die auf der deutschen Seite nicht vorhandene Bereitschaft, abschließend und völkerrechtlich wirksam auf jede Form von Eigentumsansprüchen zu verzichten, blieb folglich bestehen und prägte die zweijährigen Verhandlungen, die in die Deutsch-Tschechische Erklärung von 1997 mündeten. ${ }^{362}$

Die Bewertung der Erklärung in Hinblick auf den Diskurs über die Vertreibung fiel und fällt unterschiedlich aus. Auf der einen Seite »räumte die Tschechische Republik erstmals ein >Bedauern über Leid und Unrecht ein, das den Sudetendeutschen durch die Enteignung, Ausbürgerung und Vertreibung geschehen ist «, gleichwohl ohne die Vorstellung einer spezifischen kollektiven Verantwortung der Sudetendeutschen vollständig zu negieren. ${ }^{363}$ Auf der anderen Seite konnte keine Einigung bei der rechtlichen Bewertung von München, der Vertreibung und der damit einhergehenden Eigentumsansprüche gefunden und so lediglich die unterschiedlichen Rechtspositionen festgestellt werden. ${ }^{364}$ In der Frage der Entschädigung von tschechoslowakischen Zwangsarbeitern kam die Bundesregierung der tschechischen Seite entgegen, zugleich blieb aber eine von der deutschen Seite erwartete Geste gegenüber den Sudetendeutschen aus. ${ }^{365}$ Nach Jiř́ Pešek kann die Erklärung dennoch als »Meilenstein auf dem Weg der Aufarbeitung der gemeinsamen schmerzlichen Vergangenheit « betrachtet werden. ${ }^{366}$

In der tschechischen Gesellschaft fand die Erklärung nur »mäßige Unterstützung« und in Deutschland wurde sie von der Sudetendeutschen Landsmannschaft abgelehnt. Nach Jan Pauer war sie bis zuletzt von wechselseitigem Misstrauen geprägt, die sich darin versinnbildliche, dass nach Presseberichten vor ihrer Verabschiedung »die gesamte tschechische Regierung [...] mit dem deutsch-tschechischen Wörterbuch über dem Wortlaut der Erklärung [saß], um eventuelle juristische Fallstricke und Zweideutigkeiten auszuschließen. ${ }^{367}$ Ein wichtiger Aspekt war dabei die Begriffsbestimmung

359 Seibt: Deutsch-tschechischer Diskurs 1947-1999, 2002, S. 208

360 Houžvička: Czechs and Germans 1848-2004, 2015, S. 406.

361 Majewski: Zwischen Versöhnung und Verteidigung nationaler Interessen, 2008, S. 41f.

362 Witte: Entfremdung - Sprachlosigkeit - Aussöhnung? 2002, S. 284.

363 Koschyk: Heimat, Identität, Glaube, 2018, S. 324. Brunstetter: Escaping History, 2003, S. 276.

364 Majewski: Zwischen Versöhnung und Verteidigung nationaler Interessen, 2008, S. $41 \mathrm{f}$.

365 Handl: Die Politik des wiedervereinigten Deutschland gegenüber der Tschechischen Republik, 2010, S. 226.

366 Pešek: Zwangsmigrationen von Tschechen und Deutschen, 2007, S. $198 f$.

367 Pauer: Zähe Erinnerung, 2005, S. $19 f$. 
für das historische Geschehen, der letztlich in den Kompromiss einer passivischen Konstruktion im Tschechischen mündete ${ }^{368}$ :

»Die tschechische Seite bedauert, daß durch die nach dem Kriegsende erfolgte Vertreibung sowie zwangsweise Aussiedlung der Sudetendeutschen aus der damaligen Tschechoslowakei, die Enteignung und Ausbürgerung unschuldigen Menschen viel Leid und Unrecht zugefügt wurde, und dies auch angesichts des kollektiven Charakters der Schuldzuweisung. ${ }^{369}$

Das Leid und die Begleiterscheinungen der Vertreibungen wurden bedauert, eine Verurteilung der Vertreibung an sich unterblieb aber. Auch die direkte tschechische Übersetzung von Vertreibung, so der Begriff in der deutschen Fassung, wurde aufgrund der »moralischen Konnotierung « verhindert, die für viele Tschechen »unerträglich« war, da sie der Vorstellung widersprach, dass die Vertreibung letztlich zu Recht erfolgt sei. ${ }^{370}$ Die Sudetendeutsche Landsmannschaft verblieb gegenüber dem Nachbarschaftsvertrag ebenso kritisch wie sie auch die Erklärung von 1997 ablehnte. Sie fühlte sich von der deutschen Politik »übergangen « und »im Stich gelassen «. ${ }^{371}$ Auch Michaela Witte konstatiert abschließend, dass die Entwicklung letztlich immer wieder »den Interessen der Sudetendeutschen Landsmannschaft zuwiderlief «. ${ }^{372}$

Im Vergleich zu Polen war die Frage der deutschen Minderheit wesentlich weniger potentiell konflikthaft, bestand diese doch nach 1989 nurmehr aus einigen zehntausend, zumeist über das Land verteilten Personen. 2011 sollen es 19.000 Personen gewesen sein, das Auswärtige Amt schätzt die Minderheit auf etwa 40.000 Personen. ${ }^{373}$ Der Nachbarschaftsvertrag von 1992 bot nach Vladimír Handl die Grundlage für eine »liberale Minderheitenpolitik«, die sich nicht "gegen die tschechoslowakische Staatlichkeit» richten konnte, womit das »Thema innerhalb sehr kurzer Zeit seine Brisanz [verlor] und [...] von der politischen Agenda der Staaten Mitteleuropas [verschwand]. $\ll^{374}$

368 Brunstetter: Escaping History, 2003, S. 276.

369 Deutsch-tschechische Erklärung über die gegenseitigen Beziehungen und deren künftige Entwicklung, 1997. „Česká strana lituje, že poválečným vyháněním, jakož i nuceným vysídlením sudetských Němců z tehdejšího Československa, vyvlastňováním a odnímáním občanství bylo způsobeno mnoho utrpení a křivd nevinným lidem, a to i s ohledem na kolektivní charakter přisuzování viny.« - Česko-německá deklarace o vzájemných vztazích a jejich budoucím rozvoji, 1997. Die direkte Übersetzung des Begriffs »Vertreibung« wäre »vyhnání«. Die hier gewählte Variante ist die nicht-aspektive Form, die weniger definitiv ist und in diesem Fall eher als Beschreibung (einzelner) Prozesse verstanden werden kann.

370 Seibt: Deutsch-tschechischer Diskurs 1947-1999, 2002, S. 209.

371 Seibt: Das Verhältnis von Tschechen und Deutschen, 2002, S. 333. Vgl. Houžvička: Czechs and Germans 1848-2004, 2015, S. 474.

372 Witte: Entfremdung - Sprachlosigkeit - Aussöhnung? 2002, S. 286. Vgl. Seibt: Deutsch-tschechischer Diskurs 1947-1999, 2002, S. 209.

$373 \mathrm{Vgl}$. dazu und für die weitere Entwicklung der deutschen Minderheit in Tschechien: Koschyk: Heimat, Identität, Glaube, 2018, S. 319-331. Siehe für einen gegenwärtigen Eindruck auch: Osterhage: Heimat mit Hindernissen - Die deutsche Minderheit in Tschechien. Mitteldeutscher Rundfunk (mdr). 14.07.2018. Vgl. zur aktuellen Entwicklung des Verbandswesens der deutschen Minderheit auch: Jubiläum in Prag. Sudetendeutsche Zeitung. 28.06.2019.

374 Handl: Die Politik des wiedervereinigten Deutschland gegenüber der Tschechischen Republik, 2010, S. 225. 
Die tschechische Meistererzählung über die Vertreibung der Sudetendeutschen hatte sich bis Ende der 1990er Jahre nicht wesentlich verändert, allenfalls etwas differenziert. Zumeist wurden die Gewalttaten des Sommers 1945, die sogenannten >wilden Vertreibungen<, abgelehnt und kritisiert, die 1946 und folgend vermeintlich ordnungsgemäßen und im Einklang mit oder auf Forderungen der Siegermächte hin durchgeführten >Aussiedlungen aber als rechtmäßig und angemessen betrachtet. ${ }^{375}$ Für das Geschehen könne ein Bedauern sowie eine Empathie für das individuelle Leid des Heimatverlustes angemessen sein, eine Entschuldigung des tschechischen Staates aber nicht. Oldřich Tůma spricht von einer »recht einheitlichen« Perspektive der tschechischen Öffentlichkeit auf das Geschehen, in der die Vertreibung im Sinne »einer notwendigen, in Hinblick auf die Zukunft richtigen und unter Berücksichtigung der Vergangenheit zu einem gewissen Grade auch gerechten Lösung « betrachtet werde, auch wenn »die Haltung gegenüber der Gewalt, der die Deutschen ausgesetzt waren, viel differenzierter « sei. ${ }^{376}$ Die Frage der »Proportionalität von Schuld und Bestrafung für die Zerstörung der tschechoslowakischen Demokratie« ist dabei stets ein zentrales Element der tschechischen Verhandlungen über die Vertreibung. ${ }^{377}$ Der Kontextualisierung mit der Vorgeschichte des Zweiten Weltkrieges, aber auch einem vermeintlich jahrhundertelangen tschechischen Abwehrkampf gegen die Deutschen als innere Hegemonialmacht, steht die zumeist viel kürzere deutsche Betrachtung der unmittelbaren Vertreibungen und der diesen vorhergehenden Planungen entgegen. ${ }^{378}$ Der von Tschechien betonte spezifische historische Kontext, der die Vertreibungen ermöglichte und sie rechtfertigte, steht in dieser Perspektive zudem nicht im Widerspruch zur Ächtung heutiger Vertreibungen - entsprechende Vergleiche von deutscher Seite trafen und treffen daher auf Widerspruch. ${ }^{379}$

Hans Lemberg, Jan Křen und Duša Kováč konstatieren insgesamt ein breites Meinungsspektrum in den tschechischen Medien, »das von schärfster Kritik bis zu verbissener Apologetik reicht «, das heißt vom Standpunkt der SL bis hin zu kommunistischnationalen Erzählungen. ${ }^{380}$ Die kontinuierlich präsenten, vielfältigen Stimmen, welche die tschechische Meistererzählung punktuell oder im Kern kritisieren, blieben und bleiben aber in der Minderheit. Zudem kontinuiert sich das bisherige Narrativ weiter in den Museen, der Schulbildung oder den staatlichen Feiertagen. ${ }^{381}$ Initiativen aus Tschechien oder gemeinsame deutsch-tschechische Initiativen, die den Konflikt durch ein offenes Aufeinanderzugehen, beispielsweise durch direkte Verhandlungen mit der SL angehen wollen, konnten bisher keine nachhaltige Wirkung entfalten. ${ }^{382}$ Ebenso wie die vergleichbaren Entwicklungen in Polen wurden die tschechischen Diskussionen und ihre selbstkritischen Elemente in Deutschland kaum wahrgenommen. ${ }^{383}$

Vgl. Tůma: Die Aussiedlung, 2015, S. 271.

Ebd.

379 Schwartz: Ethnische »Säuberungen« in der Moderne, 2013, S. $624 \mathrm{f}$.

380 Lemberg; Křen et al.: Einleitung der Herausgeber, 1998, S. 30.

381 Spalová: Remembering the German Past in the Czech Lands, 2016, S. 94.

382 Vgl. Houžvička: Czechs and Cermans 1848-2004, 2015, S. 406.

383 Vgl. Seibt: Deutsch-tschechischer Diskurs 1947-1999, 2002, S. 210. 
Umgekehrt verhielt es sich mit dem »Neuen Deutschen Opferdiskurs«, der zwar stärker in Polen, aber auch in Tschechien skeptisch verfolgt wurde. ${ }^{384} 2002$ stand mit Parlamentswahlen in Deutschland und Tschechien ein wichtiges Wahljahr an. Eskalierte die Diskussion zwischen Deutschland und Polen vor allem anhand des Diskurses um das Zentrum gegen Vertreibungen, fokussierte sich die erst 2002 wieder intensivere Debatte zwischen Deutschland und Tschechien auf die Frage der bereits in Kapitel 3.5 diskutierten >Beneš-Dekrete.$^{385}$ Die seit 1998 in der Opposition befindliche CDU/CSU konnte ihre bisherige realpolitische Linie gegenüber der Tschechischen Republik verlassen und wählte einen konfrontativeren Kurs, der in einer Parallelisierung der Geschehnisse im Kosovo-Krieg 1999 und schließlich der ultimativen Forderung mündete, die >Beneš-Dekrete vor dem EU-Beitritt aufzuheben und den Sudetendeutschen noch weiter entgegenzukommen. Ähnlich agierte und agitierte die neue konservativ-nationalliberale Regierung von ÖVP und FPÖ in Österreich. ${ }^{386}$

Der damalige tschechische Ministerpräsident Miloš Zeman äußerte sich Anfang 2002 den Sudetendeutschen gegenüber erneut konfrontativ, indem er ihnen in der österreichischen Wochenzeitung Profil undifferenziert die Rolle einer »fünften Kolonne Hitlers « zuschrieb und damit das in Tschechien gängige Bild einer Kollektivschuld verfolgte. Bei einem Staatsbesuch in Israel im selben Jahr empfahl Zeman eine ssudetendeutsche Lösung، für den Palästinakonflikt und damit als vermeintlich beispielhaften Schlüssel zur Beendigung ethnischer Konflikte. ${ }^{387}$

Gegenüber dem ZgV, aber auch alternativen Projekten wie dem ENRS, blieben die tschechischen Regierungen auf ablehnender Distanz, da man weder die nationale noch die bilaterale oder europäische Ebene für einen geeigneten Ort zur Verhandlung der Thematik hielt und hält und dem Vorhaben eher lokale und regionale Bedeutung zumisst, wie bei dem Museum für die deutschsprachigen Bewohner Böhmens in Aussig. ${ }^{388} 2003$ formulierten Hans-Henning und Eva Hahn einen offenen Brief mit einer Kritik am Zentrum gegen Vertreibungen, der von 200 Personen unterzeichnet wurde, darunter viele tschechische Persönlichkeiten. ${ }^{389}$ Erika Steinbach verwies hingegen unter Berufung auf den ehemaligen Dissidenten und Havel-Berater Bohumil Doležal darauf, dass die gutgemeinte, überzogene Rücksichtnahme deutscher Politiker, Wissenschaftler und Publizisten auf tatsächliche oder vermeintliche tschechische >Empfindlichkeiten \dem "beharrliche[n] Kampf um eine gerechte Auffassung der Geschichte« in Tschechien schaden und reaktionären und freiheitsfeindlichen Kräften und ihren Geschichtsbildern nutzen würde. ${ }^{390}$

384 Hahn; Hahn: »The Holocaustizing of the Transfer-Discourse«, 2008, S. 45.

385 Vgl. Kap. 3.5, S. 123 f.

386 Vgl. Majewski: Zwischen Versöhnung und Verteidigung nationaler Interessen, 2008, S. 42f.

387 Ebd., S. 43. Vgl. Lang: Der Streit um die Beneš-Dekrete, 2002, S. 2. Vgl. zur problematischen Bezeichnung der Sudetendeutschen als »Fünfte Kolonne«: Pešek: Die 3oer und 40er Jahren in der tschechischen Erinnerung seit den 70er Jahren, 2006, S. 128.

390 So zitiert Steinbach Doležal: Steinbach: Flucht, Vertreibung, Mahnung, 2016, S. 194. 
Die Politik Österreichs und der CDU/CSU-Wahlkampf im Jahr 2002 lösten in Tschechien breite Empörung aus und führten zu einer politischen Querfront, in der sich die verschiedenen Parteien »in Erklärungen [übertrafen], in denen sie zur Verteidigung der nationalen Interessen angesichts der deutschen Bedrohung aufriefen. « ${ }^{391}$ Die Kommunisten stellten sich einmal mehr als die authentischen und wirksamsten Anwälte dieser Interessen dar, aber auch vormalige Dissidenten wie Präsident Havel verwahrten sich gegen die vorgetragenen Forderungen aus Deutschland und Österreich, ohne die nationalpopulistische Rhetorik mancher Politiker zu übernehmen. ${ }^{392}$ Die ablehnende Haltung der deutschen Bundesregierung zu den Ansinnen von CDU/CSU und SL konnte die Befürchtungen und die antideutschen Ressentiments nicht zerstreuen, zumal es in der tschechischen Publizistik durchaus eine Präsenz von Unterstützern der deutschen Position gab, die für Verständnis oder gar Entgegenkommen warben und sich damit als Kronzeugen für die Gefahr eines innertschechischen >Verrates d darstellen ließen. ${ }^{393}$

Das tschechische Parlament verteidigte seine Position mit verschiedenen Resolutionen und Gesetzen. ${ }^{394} 2004$ verabschiedete es ein Gesetz, die sogenannte Lex Beneš, die den Satz zum Inhalt hatte: "Edvard Beneš hat sich um den Staat verdient gemacht. « ${ }^{395}$ Zwar wurde dieser »kuriose Spross der tschechischen Gesetzgebung« weder vom tschechischen Senat gebilligt noch vom seit 2003 amtierenden Staatspräsidenten Václav Klaus unterzeichnet, besitzt jedoch »nach verbreiteter Rechtsauffassung [...] trotzdem Gültigkeit [...]. «396

Entscheidend für diese Reaktionen ist, dass die verschiedensten Präsidialdekrete der Kriegs- und unmittelbaren Nachkriegszeit, die als >Beneš-Dekrete< zusammengefasst werden, nicht nur die Vertreibung der Deutschen betrafen, sondern die zunächst demokratische Nachkriegs-Tschechoslowakei rekonstituierten und daher einen besonderen, fast als konträr zur sudetendeutschen Perspektive zu betrachtenden, positiven Mythos in Tschechien ausmachen. Angriffe auf diese werden tendenziell »in Tschechien den Blick nicht auf das individuelle Leid deutscher Vertriebener lenk[en], sondern ein Narrativ der Verteidigung der Nachkriegsordnung beförder[n].«397

In Umfragen erhielten diese Positionen breite Unterstützung, was nicht zuletzt an der wieder wahrgenommenen deutschen Bedrohung lag. ${ }^{398}$ In einer staatlich beauftragten Umfrage von 2003 machten die Teilnehmer für die Beschädigung der deutschtschechischen Beziehungen zu jeweils 90 Prozent die Forderungen der Sudetendeutschen Organisationen und die deutsche Arroganz sowie die historische Bürde mit 88,5

Majewski: Zwischen Versöhnung und Verteidigung nationaler Interessen, 2008, S. 34f. Vgl. Fehr: Vergeltende Gerechtigkeit, 2016, S. 120.

392 Majewski: Zwischen Versöhnung und Verteidigung nationaler Interessen, 2008, S. 44.

393 Vgl. ebd., S. 44f.

394 Vgl. Houžvička: Czechs and Germans 1848-2004, 2015, S. 471.

395 Vgl. zur innertschechischen Diskussion um das Gesetz: Mládková: Sondergesetz über Verdienste von Präsident Edvard Beneš. Radio Praha. 25.02.2004.

396 Kunštát: Fremd- und Feindbilder der Deutschen in der tschechischen innenpolitischen Instrumentalisierung nach 1989, 2007, S. 122.

397 Kraft: Mythos »Beneš-Dekrete«, 2013, S. 239f., $252 f$.

398 Majewski: Zwischen Versöhnung und Verteidigung nationaler Interessen, 2008, S. 44. 
Prozent verantwortlich. Der tschechische Nationalismus wurde als Ursache mit 42 Prozent beziffert, die deutsche Minderheit mit 37 sowie der Widerwille der tschechischen Regierung mit 36 Prozent. ${ }^{399}$

Das in Deutschland und Österreich verbreitete Argument, die >Beneš-Dekrete< stellten ein Hindernis zum EU-Beitritt dar, wurde von einem wiederum in Deutschland kritisierten Gutachten abgewiesen, das urteilte, dass die Dekrete nunmehr weder als Bestandteil des tschechischen Rechtssystems zu betrachten seien noch dass sie gegenwärtig einen diskriminierenden Charakter gegenüber deutschen, österreichischen oder ungarischen Staatsbürgern entfalteten. ${ }^{400}$ In seiner juristisch und historisch durchaus fragwürdigen Argumentation folgte es damit in Teilen dem Urteil des tschechischen Verfassungsgerichts von 1995, welches mit einer "widersprüchlichen Deutung« feststellte, »dass die Dekrete zwar keine Rechtswirkung mehr entfalten, jedoch weiterhin Bestandteil der geltenden Rechtsordnung seien. ${ }^{401}$ Unabhängig von dieser Rechtsprechung und den Gutachten war in Tschechien ähnlich wie in Polen die Befürchtung verbreitet, dass man mit der künftigen EU-Mitgliedschaft einem zu starken Einfluss Deutschlands gegenüber stehen würde. ${ }^{402}$

Zusammengefasst lassen sich vor dem EU-Beitritt zwei Pole der Diskussion ausmachen: Die eine Sichtweise bestand darin, dass ein EU-Beitritt zur Durchsetzung sudetendeutscher Ansprüche führen könne, da der gemeinsame Rechtsrahmen dies ermögliche. Auf der anderen Seite existierte die Vorstellung, dass mit dem Beitritt sowie durch den Verlauf der Zeit »die Mehrzahl der strittigen Fragen gelöst oder faktisch einfach kein Problem mehr darstellen würden. ${ }^{403}$ Im Europäischen Parlament stimmten derweil die sudetendeutschen Europaparlamentarier der CSU gegen den Beitritt Tschechiens zur EU, was dort als »unfreundlicher Akt« gewertet wurde. ${ }^{404}$ Bernd Posselt begründete dies mit der mangelnden Bewegung in Hinblick auf die Aufgabe der >BenešDekrete`, die sie für unvereinbar mit der europäischen Rechtsordnung hielten..$^{405}$

Der Vorsitzende der ODS Václav Klaus fasste im Zuge der Debatte um die Präsidentendekrete die vermeintliche Bedrohungslage zusammen:

»Wir sprechen von der Ansiedlung von Sudetendeutschen auf unserem Territorium, von der (tschechischen) Staatsbürgerschaft für diese Menschen, wir sprechen implizit

399 Houžvička: Czechs and Germans 1848-2004, 2015, S. 440.

400 Majewski: Zwischen Versöhnung und Verteidigung nationaler Interessen, 2008, S. 46. Vgl. zur rechtlichen Bewertung der Dekrete auch: Kraft: Mythos »Beneš-Dekrete«, 2013, S. 248f. Vgl. zu einer kritischen Besprechung der Diskussion um die Beneš-Dekrete und die EU-Osterweiterung: Salzborn: Geteilte Erinnerung, 2008, S. 115-123.

401 Kraft: Mythos »Beneš-Dekrete«, 2013, S. 251.

402 Houžvička: Czechs and Germans 1848-2004, 2015, S. 427.

403 Fiala: Deutsche und Tschechen im vereinten Europa, 2005, S. 497.

404 Houžvička: Czechs and Cermans 1848-2004, 2015, S. 475. Vgl. zur Rolle der ssudetendeutschen< EP Abgeordneten: Fiala: Deutsche und Tschechen im vereinten Europa, 2005, S. $499 f$.

405 Vgl. das Interview mit Bernd Posselt: Tschechiens EU-Beitritt und die Benes-Dekrete. Die Zeit. 25.04.2002. 
über deren politische Vertretung. Und wir sprechen über Vermögensfragen. Diese vier Dinge sind absolut offensichtlich. $«^{406}$

Diese Rhetorik konnte an drei zentrale Segmente des tschechischen Populismus anknüpfen: an eine verbreitete Europa-Skepsis, die Angst vor Deutschland und eine »Distanz zur katholischen Kirche«, was sich alles in der Diskussion um die Beneš-Dekrete und die Vertreibungen zu verdichten schien (war doch die katholische Kirche auch in starkem Maße von den Vertreibungen und Enteignungen betroffen). ${ }^{407}$ Wie angesprochen, sah man vor allem unter dem Druck äußerer Forderungen erst recht keinen Grund für eine Entschuldigung gegenüber den Sudetendeutschen, welche ein Schuldeingeständnis bedeuten würde und damit »automatisch zu einer Revision der Nachkriegsordnung und unter anderem zu einer Flut von vermögensrechtlichen Forderungen führen könnte. « ${ }^{408}$ Dass eine »symbolische Geste« vermutlich einen großen Teil der Sudetendeutschen schon zufriedenstellen würde, konnte in den Zusammenhängen kaum als eine Möglichkeit erkannt werden. ${ }^{409}$

Das vermeintlich oder tatsächlich feindliche Agieren der SL sowie die mangelnde Bereitschaft, einen Teil ihrer bisherigen Kernargumentation aufzugeben, beispielsweise gegenüber der ersten tschechoslowakischen Republik, waren hierfür ebenso wenig hilfreich. Dialogangebote der SL wie die Eröffnung eines Büros in Prag im Jahr 2003 wurden aus tschechischer Sicht konterkariert mit dem Abstimmungsverhalten im Europarlament und ließen die Verlässlichkeit als potentiellen Partner fragwürdig erscheinen. ${ }^{410}$

Als mögliche Konsequenz dieser Auseinandersetzungen stieg in der tschechischen Bevölkerung der Anteil der Menschen, die die Vertreibungen für »gerecht« hielten, von 52 Prozent (1995) auf 60 Prozent im März 2002; zugleich wurde dem Thema wesentlich mehr Relevanz als in den 1990er Jahren zugeschrieben. ${ }^{411}$ Diese Momentaufnahmen zeigten, dass sich mit der Gefahr eines »virulenten >Revanchismus « von deutscher und österreichischer Seite in Tschechien erfolgreich Wahlkämpfe bestreiten ließen. Nach Stefan Zwicker handelt es sich beim sudetendeutschen Thema weniger um ein realpolitisches Problem als um eine bedienbare »Chimäre«, ein »Schreckgespenst« des politischen Diskurses in Tschechien. ${ }^{412}$

Nationale und nationalistische Positionen treffen hier auf eine Gesellschaft, in der nach wie vor eine große Mehrheit die Vertreibungen als legitim ansieht und ein noch größerer Bevölkerungsanteil Ende der 1990er Jahre begrüßte, »dass heute deutlich weniger Deutsche in den böhmischen Ländern leben als in der Zwischenkriegszeit. « ${ }^{413}$ Ein Versuch der tschechischen Geschichtswissenschaft in Form einer »Stellungnahme der

406 Zitiert nach: Lang: Der Streit um die Beneš-Dekrete, 2002, S. 2.

407 Ebd., S. 3.

408 Ebd., S. $3 f$.

409 Ebd.

410 Houžvička: Czechs and Germans 1848-2004, 2015, S. 471.

411 Lang: Der Streit um die Beneš-Dekrete, 2002, S. 6-8.

412 Zwicker: Zur Darstellung der Sudetendeutschen, 2006, S. 398.

413 Ebd. 
Vereinigung der Historiker der Tschechischen Republik unter dem Titel >Historiker gegen die Vergewaltigung der Geschichte«", versachlichend in den Diskurs einzugreifen und sich gegen die erneute Nutzung der Geschichte als »Sturmwaffe« auszusprechen, löste eher gegenteilige Reaktionen aus, da ihr Beitrag als »autoritär« wahrgenommen und das beanspruchte Primat der Wissenschaft auf die Thematik hinterfragt wurde. ${ }^{414}$

Die Niederlage der CDU/CSU bei der Bundestagswahl 2002 brachte nur eine vorübergehende Ruhe in die Diskussion, die die tschechische Öffentlichkeit noch zwei weitere Jahre beschäftigen sollte. ${ }^{415}$ Bei den Präsidentschaftswahlen 2003 konnte sich, wie eingangs erwähnt, der eigentlich bürgerlich-konservative Václav Klaus mit Hilfe der Kommunisten mit einer prononciert antideutschen und die Beneš-Dekrete unkritisch verteidigenden Haltung durchsetzen, da seinem Gegenkandidaten erfolgreich eine indifferente Haltung in dieser Frage vorgeworfen wurde. ${ }^{416}$

Nach dem EU-Beitritt Tschechiens im Mai 2004 verschwand das Thema als Kontroverse schließlich bis 2013 aus der breiteren öffentlichen Debatte. Der Verbesserung der tschechisch-bayerischen Beziehungen mit den im Kapitel 5.1 besprochenen Prag-Reisen der bayerischen Regierung seit 2010 folgte im Februar 2013 die Rede des tschechischen Ministerpräsidenten Petr Nečas (ODS) im Bayerischen Landtag. ${ }^{417}$ In dieser setzte er deutliche Zeichen der Entspannung, indem er die Sudetendeutschen nicht nur als »unsere deutschen Landsleute« ansprach, sondern auch sein Bedauern über die Vertreibungen äußerte. ${ }^{418}$

In den erstmals als Direktwahlen durch die Bevölkerung absolvierten Präsidentschaftswahlen im Monat zuvor gewann Miloš Zeman im zweiten Wahlgang gegen seinen Gegenkandidaten Karel Schwarzenberg, der für die liberal-konservative TOP o9 antrat. Schwarzenberg war mit Äußerungen hervorgetreten, in denen er das historische Geschehen unter Ablehnung einer sudetendeutschen Kollektivschuld zu differenzieren versuchte und die Vertreibungen aus heutiger Sicht als Verletzung der Menschenrechte beurteilte, die eine strafrechtliche Verfolgung in Den Haag nach sich ziehen würde. ${ }^{419}$ Mit diesen Äußerungen sowie aufgrund seiner Herkunft aus einer alten, adeligen tschechisch-habsburgischen Familie prädestinierte er sich für eine Neuauflage eines antisudetendeutschen und nationalpopulistischen Wahlkampfes, in dem ihm als vermeintlichem Vertreter der sudetendeutschen Sache und wegen seines angeblich fremden Einflusses sein >Tschechentum che gegenübergestellt wurde. Mit allen Mitteln eines schmutzigen Wahlkampfes warfen ihm seine Gegner seine österreichische Frau, eine vermeintliche Kollaboration der Familie mit den Deutschen im Zweiten Weltkrieg und den Dienst »im >fremden In-

414 Kunštát: Fremd- und Feindbilder der Deutschen in der tschechischen innenpolitischen Instrumentalisierung nach 1989, 2007, S. 123f. Vgl. Kraft: Mythos »Beneš-Dekrete«, 2013, S. 235.

415 Majewski: Zwischen Versöhnung und Verteidigung nationaler Interessen, 2008, S. 45.

416 Blaive: National Narratives of Czech Identity, 2016, S. 185.

417 Vgl. Schwarz: Ein schwieriger Besuch beim Nachbarn. FAZ. 19.12.2010.

418 Necas bedauert Vertreibung der Sudetendeutschen. Die Welt. 21.02.2013.

419 Vgl. dafür die Berichterstattung über das Fernsehduell zwischen Zeman und Schwarzenberg: Kubita: První televizní duel. Hospodářské noviny. 17.01.2013. 
teresse vor. $^{420}$ Den zweiten Wahlgang verlor Schwarzenberg mit 45 gegen 55 Prozent. Schwarzenbergs Haltung zur sudetendeutschen Frage und deren negative Instrumentalisierung wird verschiedentlich als entscheidend für seine Wahlniederlage betrachtet. $^{421}$

Auf die Rede des tschechischen Ministerpräsidenten 2013 und die Konflikte um Schwarzenbergs Äußerungen reagierte unter anderem die Vereinigung der ehemaligen Grenzsoldaten, der Tschechische Grenzlandklub, mit einer Rücktrittsforderung, da sie seine vorsichtigen Äußerungen des Bedauerns bereits als Verzerrung der Geschichte betrachteten. Weder sei er für diese von den Tschechen gewählt worden noch seien sie in Anbetracht der Geschichte korrekt. Für die Vertreibung seien München und die Entscheidungen der Siegermächte verantwortlich, nicht die Tschechen. In ihrem Aufruf kritisierten sie zudem Schwarzenbergs Worte, mit denen er Beneš in die Nähe von Kriegsverbrechen gerückt hatte. Sie beendeten ihre Protestschrift mit Benešく Warnung für den Fall, dass irgendwann Tschechen den Sudetendeutschen die Hand reichen und sie zur Rückkehr einladen könnten: »Lasst Euch nicht täuschen und lasst sie nicht zurückkehren...« «22

Trotz dieser temporären, vor allem innertschechischen Eskalation konnte die seit 2014 amtierende Regierung von Bohuslav Sobotka aus ČSSD, ANO und Christdemokraten (KDU-ČSL) die tschechisch-bayerisch-sudetendeutsche Annäherung fortsetzen. 2016 nahm mit dem Kulturminister Daniel Herman (KDU-ČSL) zum ersten Mal ein tschechisches Regierungsmitglied am Sudetendeutschen Tag der Landsmannschaft in Nürnberg teil. Er sprach nicht nur die Sudetendeutschen erneut als »liebe Landsleute« an, sondern äußerte auch sein »tiefes Bedauern« über die Vertreibungen. Die dortige Präsenz eines tschechischen Regierungsmitgliedes ebenso wie seine Worte lösten jedoch in Tschechien bekannte Reflexe aus, so Proteste der KSČM und die Aufforderung von Präsident Zeman, dass Herman anstelle eines Besuches der Landsmannschaft die Verbände der tschechoslowakischen Grenztruppen zum »Gesprächspartner« wählen solle. ${ }^{423}$ Auch 2017 besuchte mit dem Stellvertretenden Ministerpräsidenten Pavel Bělobrádek ein Regierungsmitglied der KDU-ČSL den Sudetendeutschen Tag und verband das historische Geschehen mit einem Auftrag für die Gegenwart:

»Wir dürfen natürlich nicht die Vergangenheit vergessen, die Zeiten der Brutalität vor, während und nach dem Zweiten Weltkrieg. Das darf nie mehr wieder geschehen. Menschen dürfen nie wieder aus ihren Häusern vertrieben werden, nur weil sie anderer Nationalität sind, einen anderen Clauben haben oder aus rassistischen Cründen. ${ }^{424}$

420 Fehr: Vergeltende Gerechtigkeit, 2016, S. $120 f$.

421 Kirchick: The End of Europe, 2017, S. 67f. Vgl. Sniegoň: Between Old Animosity and New Mourning, 2016, S. 54.

422 »Nenechte se oklamat a jejich návratu nedopust'te...«: Okresní rada Českého pohraničí, Ústí nad Labem: Protestujeme proti vystoupení pana premiéra Nečase před poslanci bavorského zemského sněmu. 26.02.2013. Vgl. zum Tschechischen Grenzlandklub [Klub českého pohraničí]: Kap. 5.3, S. 262.

423 Tschechischer Minister besucht Sudetendeutschen Tag. FAZ. 15.05.2016. Ärger für Minister in Tschechien. Onetz. 18.05.2016. Vgl. Fehr: Vergeltende Gerechtigkeit, 2016, S. 127. Siehe auch: Flögel: Tschechischer Minister gewinnt »liebe Landsleute«, 2016.

424 Janzer: Sudetendeutscher Tag: Tschechische Politiker erhalten Applaus - und Kritik von Zuhause. Radio Praha. 05.06.2017. 
Diese kurze Tradition der Präsenz der tschechischen Regierung endete vorerst im Jahr 2018. Weder bei den Präsidentschaftswahlen von 2017, die Miloš Zeman erneut gewann, noch bei dem Wahlsieg der zentristisch-populistischen ANO-Partei spielte das Vertreibungsthema im engeren oder weiteren Sinne eine Rolle, ebenso wie eine aktive Geschichtspolitik keine vergleichbare Relevanz für die Parteien wie in Polen hat. Im Juli 2018 überstand die neue Minderheitenregierung von ANO und ČSSD mit Premierminister Babiš die obligatorische Vertrauensfrage wegen der vorher vertraglich ausgehandelten Duldung durch die Kommunistische Partei. Deren indirekte Rückkehr an die Regierung wird zumindest in der liberalen Presse als Tabubruch und Beginn einer neuen Ära in Abgrenzung zur postkommunistischen Politik nach 1989 betrachtet. ${ }^{425}$ Wie weit ihr tatsächlicher Einfluss auf das Regierungshandeln reichen wird, ist schließlich noch nicht absehbar. Die nach wie vor starke Verankerung der Kommunisten in der Bevölkerung der >Grenzgebiete` sowie ihre nationalkonservative historische Position lässt aber zukünftige Auseinandersetzungen um die Frage der deutschsudetendeutsch-tschechischen Beziehungen nicht einfacher erscheinen, wie die Debatten um die Rede von Bundeskanzlerin Angela Merkel am 20. Juni 2018 anlässlich des deutschen Gedenktages für die Opfer von Flucht und Vertreibung bereits aufgezeigt haben. Ihrer Aussage, dass die Vertreibungen moralisch und politisch ungerechtfertigt gewesen seien, widersprach Zeman »zutiefst«; Babiš betonte, die Argumentation reiße »alte Wunden« wieder auf »und sei für Tschechien snicht hinnehmbar«. Gleichwohl wiesen Oppositionspolitiker sowie das tschechische Außenministerium darauf hin, dass sich die Rede Merkels auf der Grundlage der deutsch-tschechischen Erklärung von 1997 und der damals konstituierten unterschiedlichen »Rechtsauffassung« bewege. ${ }^{426}$ Der Zemanschen Argumentation, dass die Verantwortung bei der Potsdamer Konferenz liege, widersprach der Historiker Tomáš Dvořák in Radio Prag bereits 2016:

»In einem Teil der tschechischen Gesellschaft hält sich der Glauben, dass die Alliierten bei der Potsdamer Konferenz die Aussiedlung entschieden hätten. Das ist aber nicht wahr. Die tschechoslowakische Regierung war entschlossen, die Aussiedlung mit jeglichen Mitteln in größtmöglichem Umfang durchzuführen, und das auch ohne internationale Zustimmung. ${ }^{427}$

Der tschechische Film hat sich in den letzten Jahren intensiv mit dem Thema der Vertreibungen befasst. Einen entscheidenden Einschnitt bedeutete der Dokumentarfilm Töten auftschechische Art von David Vondráček, der mit historischen Aufnahmen die Ermordung von Deutschen durch tschechoslowakische und sowjetische Kräfte am Ende des Krieges drastisch zeigte und 2010 im öffentlichen tschechischen Fernsehen lief. ${ }^{428}$

425 Honzejk: Stíhaný premiér, chybějící ministři a podpora nereformovaných komunistů. Hospodářské noviny. 11.07.2018.

426 Janzer: Zeman und Babiš empört über Merkel-Aussage zum Tag der Vertriebenen. Radio Praha. 20.06.2018. Janzer: Streit um Merkel-Aussagen zu Vertreibung. Radio Praha. 21.06.2018. Vgl. auch die Besprechung in der Zeitung der deutschen Minderheit in Tschechien: Schmidt: Verstörende Prager Proteste nach Merkel-Rede. LandesEcho. 22.06.2018.

427 Janzer: Streit um Merkel-Aussagen zu Vertreibung. Radio Praha. 21.06.2018.

428 Zabíjení po česku (2010). Janssen: »Töten auf Tschechisch«. Deutschlandfunk. 01.06.2010. 
Viele weitere Filme und Serien behandeln das Thema teilweise oder im Kern. ${ }^{429}$ Durch ihren Fokus auf individuellen Schicksalen gelingt es nach Marie Bettine Schwarz Empathie herzustellen, da es um den Verlust der Nachbarn und nicht um größere rechtliche und historische Fragen gehe. Derartige Erzählungen ermöglichen ein Infragestellen des ausschließlichen tschechischen Opfer- und Heldennarrativs. ${ }^{430}$

Die Vertreibung ist in Tschechien auch Thema weiterer künstlerischer Auseinandersetzungen. In die internationale Berichterstattung schaffte es das Werk von Jakub Hadrava, der im Jahr 2014 eine verlassene Kirche im ehemaligen Sudetenland mit Geisterstatuen aus Gips füllte und so auf das Verschwinden der Bewohner aufmerksam machte. ${ }^{431}$ Eine Ausstellung des jungen Fotokünstlers Lukáš Houdek im Jahr 2013 mit dem Titel »The Art of Killing«, in der er mit Barbiefiguren und Puppenhäusern die Verbrechen gegen Deutsche am Ende des Krieges darstellte, brachte ihm den Vorwurf ein, ein »Verräter« zu sein und »mit seinen Bildern die schrecklichen Taten der Nazis zu trivialisieren. $\ll^{432}$

Die tschechische Gegenwartsliteratur hat das Thema immer wieder aufgegriffen, darunter auch viele junge tschechische Schriftsteller. Noch vielschichtiger als in den Filmproduktionen ist hier Raum für Schattierungen und Prosatexte ermöglichen einen guten Zugang über individuelle Kontexte. Bei der Darstellung sudetendeutscher Lebensgeschichten sind Annäherungen an das Selbstverständnis der Sudetendeutschen und ihre Geschichtsschreibung erkennbar. Der Roman Die Vertreibung der Gerta Schnirch der Schriftstellerin Kateřina Tučková verfolgt das Narrativ, dass das »kommunistische Systém [...] nur eine logische Folge der Verhältnisse [sei], wie sie der Umgang mit den Deutschen im Jahre 1945 gebracht hat. « ${ }^{433}$ Tůma konstatiert schließlich, dass zwar bei der tschechischen Kunst eine »Revision« der »Sichtweise auf die Vergangenheit« zu beobachten sei, aber ein Äquivalent auf deutscher oder sudetendeutscher Seite fehle, was erneut sinnbildlich für die »deutliche Asymmetrie» in der wechselseitigen Empathie stehe. ${ }^{434}$

Unterhalb der nationalen politischen Ebene lässt sich mehr Bewegung und Differenz im Umgang mit der sudetendeutschen Thematik beobachten. An einigen Orten in Tschechien wird an die vormaligen deutschen Bewohner und deren Vertreibung erinnert.

429 Vgl. für einige Beispiele: Schwarz: The Postmemorial Narrative of the Expulsion of the Sudeten Germans in Czech Literature and Film, 2017, S. 23-29, 41-54.

430 Ebd., S. 6of. Vgl. zur Darstellung des Deutschen im tschechischen Film nach 1989: Hanáková: >l'm at Home Heres, 2014, S. 109f. Hanáková konstatiert, dass die Komplexität des deutsch-tschechischen Verhältnisses im Film Platz gewinne, aber immer noch ausbaufähig sei. Vgl. für ein neues »lnterpretationsschema der deutsch-tschechischen Beziehungen während des Krieges«: Tůma: Die Aussiedlung, 2015, S. 274f. Hier spricht er vom Film Habermannův mlýn (2010) [Habermanns Mühle].

431 Cable: Artist creates spooky >ghosts s that line the pews inside dilapidated village church ... turning it into global tourist attraction. Daily Mail. 05.11.2014.

432 Vgl. für die Zitate und eine Auswahl der Bilder: »Meine Landsleute nennen mich Verräter«. Süddeutsche Zeitung. 19.02.2013.

433 Kateřina Tučková: Vyhnání Gerty Schnirch, 2009. Tůma: Die Aussiedlung, 2015, S. 274f. Vgl. zum Roman und der jungen Schriftstellerin auch: Janssen: »Unsere Deutschen«. Deutschlandfunk. 18.12.2010.

434 Tůma: Die Aussiedlung, 2015, S. 275. 
Im Unterschied zur Sichtweise der kommunistischen Tschechoslowakei werden an verschiedenen Orten von Massakern die ermordeten Sudetendeutschen heute als Opfer betrachtet, was eine Erinnerung in Form von Denkmalen oder Gedenktafeln ermöglicht. Zumeist entstehen sie in Kooperation von (individuellen) Initiativen und lokalen Politikern. Dafür ist die auch in den Medien vermehrt zu beobachtende Auseinandersetzung mit den Sudetendeutschen als Individuen und nicht als problematische Großgruppe hilfreich. ${ }^{435}$

Diese Projekte werden von den Kommunisten und anderen politischen Kräften häufig kritisiert oder verhindert. ${ }^{436}$ Die Stadt Aussig hat sich mit dem in Kapitel 3.5 diskutierten »Massaker von Aussig« verschiedentlich befasst und an der Brücke, auf der ein Teil der Menschen ermordet wurde, hängt seit 2005 eine daran erinnernde Plakette. Ironischerweise trägt aber die Brücke trotz sudetendeutscher Forderungen nach Umbenennung weiter den Namen von Edvard Beneš, den ihr 1935 sudetendeutsche Sozialdemokraten als antinationalsozialistisches Bekenntnis verliehen hatten. ${ }^{437}$ Ein zentrales Ereignis für die sudetendeutsch-tschechische Versöhnung ist die Erinnerung an den >Brünner Todesmarschく. 2015 riefen die liberale Stadtregierung und das Brünner Stadtparlament zur Teilnahme an der bereits seit einigen Jahren von einer Bürgerinitiative durchgeführten »Wallfahrt der Versöhnung« auf. Zu dieser waren auch Vertreter der Landsmannschaften in Deutschland und Österreich eingeladen. Der Sprecher der SL, Bernd Posselt, nahm an der Veranstaltung teil, die bisher weiterhin jährlich stattfindet. ${ }^{438}$ Das Stadtparlament verabschiedete auf Antrag der lokalen Partei Žít Brno [Brünn leben] mit der Mehrheit von ANO, KDU-ČSL und den Grünen vorab eine »Versöhnungserklärung «, in der es die menschlichen Tragödien und die Anwendung des Prinzips der Kollektivschuld gegen die Brünner Deutschen »aufrichtig« bedauerte und die kulturellen und gesellschaftlichen Verluste durch die Vertreibungen beklagte. ${ }^{439}$ Bürgermeister Petr Vokřál (ANO) äußerte den Wunsch, dass »alles Unrecht der Vergangenheit vergeben werden könne und dass uns die Vergangenheit nicht mehr belasten möge. «40

435 Sniegoň: Between Old Animosity and New Mourning, 2016, S. 49, 63-70. Vgl. zur Entwicklung und politischen Diskussion um Denkmäler in Tschechien, die an die Vertreibung und die während dieser stattgefundenen Massaker erinnern: Luppes: Commemorating Flight and Expulsion, 2019, S. 222-228.

436 Vgl. Kunštát; Lemberg: Zur tschechischen Erinnerungskultur, 2006, S. 118.

437 Sniegoň: Between Old Animosity and New Mourning, 2016, S. 57-59.

438 Martin: „Wallfahrt der Versöhnung« erinnerte an Brünner Todesmarsch von 1945. Radio Praha. 30.05.2015. Vgl. die Website des Festivals »Meeting Brno« mit dem Programm für den Versöhnungsmarsch 2018: https://meetingbrno.cz/de/programm/gedenkveranstaltungen (letzer Zugriff: 05.09.2018). Im Dezember 2018 wurde der Initiator des »Versöhnungsmarsches«, Jaroslav Ostrčilík, mit dem Verdienstorden der Bundesrepublik Deutschland ausgezeichnet: Lothar: Begründer des Marsches der Versöhnung mit deutschem Orden geehrt. Radio Praha. 04.12.2018. Vgl. auch den Teilnahmebericht der tschechischen Autorin Kateřina Tučková, die sich in ihren Schriften mit der multiethnischen Vergangenheit Brünns beschäftigt: Tučková: Die Brünner Sudeten, 2019, S. 78-80.

439 Die Erklärung findet sich u.a. auf der Website von Žít Brno in tschechischer und deutscher Sprache: www.zitbrno.cz/deklarace-smireni-a-spolecne-budoucnosti/ (letzter Zugriff: 05.09.2018).

440 Versöhnung 70 Jahre nach »Todesmarsch« von Brünn. Deutsche Welle. 30.05.2018. »Vyjadřujeme přání, aby všechny minulé křivdy mohly být odpouštěny a nezatěžovali jsme se minulostí.«-Brno lituje »pochodu smrti« Němců po druhé světové válce. Týden. 19.05.2015. 
Auch diese Initiative traf auf Widerspruch der Kommunisten, des rechten Flügels der tschechischen Sozialdemokratie und der ehemaligen `Grenzlandkämpferく.

Der schon angesprochene »Tschechische Grenzlandklub« [Klub českého pohraničí] ist Teil einer Zivilgesellschaft mit entgegengesetzten Zielen, die sich gegen eine Verständigung mit der Landsmannschaft aussprechen, einem nationalistischen Geschichtsbild anhängen und zum Teil mit der KSČM verbunden sind. ${ }^{441}$ Weitere verständigungsskeptische Organisationen sind der »Kreis tschechischer Bürger, die aus dem tschechischen Grenzland 1938 vertrieben wurden« [Kruh občanů vyhnaných v roce 1938 z pohraničí], der »Klub tschechischer Historiker « [Sdružení historiků České republiky] oder der »Tschechische Verband der Freiheitskämpfer « [Český svaz bojovníků za svobodu]. ${ }^{442}$

Ein weiteres Beispiel für eine zivilgesellschaftliche Verständigungsinitiative ist die 1998 von tschechischen Studenten gegründete Organisation »Antikomplex «, die sich für die innertschechische Aufklärung über das vormalige deutsche und deutsch-tschechische Leben in Tschechien im Rahmen von Ausstellungen, Schulprojekten, Publikationen und Fahrten einsetzt. Inhaltlich betont sie vor allem den für das Land entstandenen Verlust durch die Vertreibungen. ${ }^{443}$ Ihr Mitgründer Ondřej Matějka fasste das Selbstverständnis und den Auftrag der Organisation 2011 zusammen:

»Wir denken darüber nach, dass auch die tschechische Gesellschaft gegen den Dämon der ethnischen Cewalt nicht immun gewesen ist. Es ist in unserem Interesse zu verstehen, warum das so war und was es für uns heute bedeutet. Unter welchen Umständen kann eine wohlgeordnete Gesellschaft so aus der Bahn geraten, dass sie Gewalt toleriert oder selbst Gewalttaten verübt? Auch heute schadet es nicht, das zu wissen. « ${ }^{444}$

Der Diskurs nach 1989 über die Vertreibung in Tschechien bewegte sich bis zuletzt im erläuterten Rahmen. Eine Distanzierung von der für die tschechische Staatlichkeit konstitutiven Nachkriegsordnung mit faktischen Konsequenzen wird bis heute von keiner relevanten politischen Gruppierung in Tschechien angestrebt. In der Diskussion bleibt, inwieweit es angemessen ist, das historische Geschehen moralisch zu verurteilen und $\mathrm{zu}$ bedauern sowie sich gegebenenfalls für tschechische Verantwortlichkeiten zu entschuldigen. Unabhängig von dieser Frage sind sich alle politischen Parteien einig, den historischen Kontext des deutsch-tschechischen Konfliktes stets zu berücksichtigen, bei dem nach tschechischer Auffassung die Sudetendeutschen schließlich einen gewichtigen Anteil an der Zerstörung der ersten Republik hatten. ${ }^{445}$

Obwohl zunächst ohne weitergehende politische Implikationen, sind lokale Initiativen ebenso wie die besprochenen Auseinandersetzungen in Kunst und Film ein nicht zu unterschätzender Teil der deutsch-tschechischen Verständigung. Von 2002 bis 2017 sank schließlich der Anteil der tschechischen Bürger, die die Vertreibungen für gerecht

441 Houžvička: Czechs and Germans 1848-2004, 2015, S. $419 f$.

442 Ebd., S. 472. Houžvička sieht in der Arbeit und Entstehung dieser Verbände auch eine Reaktion auf den fortgesetzten Revisionismus der SL nach 1989.

443 Spalová: Remembering the German Past in the Czech Lands, 2016, S. 98-100.

444 Matějka: Die Suche nach einer lebendigen Geschichte, 2011, S. 22.

445 Vgl. Tůma: Die Aussiedlung, 2015, S. 270f. Vgl. Houžvička: Czechs and Germans 1848-2004, 2015, S. $475 f$. 
halten, von 64 auf 37 Prozent; zugleich äußern 25 Prozent, dass es Zeit für das Ziehen eines Schlussstriches sei. ${ }^{446}$

Der außenpolitische Berater von Präsident Zeman, Rudolf Jindrák, konstatierte 2018, dass Tschechien für die mittlerweile stark verbesserten Beziehungen mit Bayern und Deutschland kaum eigene Positionen aufgeben musste und so letztlich erfolgreich aus den Auseinandersetzungen hervorgegangen ist:

»Heute wird uns von Angela Merkel dafür gedankt, dass wir die Beziehungen zum Freistaat in Ordnung gebracht haben. Damit das gelingen konnte, haben wir aber nicht viele Zugeständnisse machen müssen. Wir mussten den Sudetendeutschen weder ihr früheres Eigentum noch die Staatsbürgerschaft zurückgeben. Wir haben nichts gemacht, was der tschechischen Rechtsordnung widersprochen hätte. Da haben wir wirklich einen großen Fortschritt erlangt. «477

Auf lokaler, regionaler und nationaler Ebene bleibt der Komplex der Vertreibung von Bedeutung und ist weiterhin Quelle von Konflikten, wie nicht zuletzt die Auseinandersetzungen um das Museum der deutschsprachigen Bewohner Böhmens zeigen. ${ }^{448}$ Tendenzen einer Pluralisierung der tschechischen Erinnerungskultur ${ }^{449}$ steht eine von Claudia Kraft beobachtete "nationale Konsolidierung des Geschichtsbildes [...] [in den letzten Jahren], die nicht weniger homogen ist als ihr Pendant in Zeiten des Staatssozialismus«, entgegen.«450

\subsection{Vergleich und Zusammenfassung}

Die Auseinandersetzungen über Flucht und Vertreibung der Deutschen am Ende des Zweiten Weltkrieges in Deutschland, Polen und Tschechien haben sich nach 1989 mehrfach zu einem gemeinsamen Diskursraum vereint. Das Aufeinanderbeziehen und die gegenseitige Beobachtung der Nachbarländer waren zwar permanent gegeben, mündeten aber nur selten in einen tatsächlichen Dialog oder Trialog. Zum einen lag das daran, dass die mediale und politische Polarisierung ebenso wie die Stabilität antagonistischer nationaler Narrative den Austausch erschwerten. Zum anderen lässt sich eine »Ungleichzeitigkeit« der Debatten beobachten, die zur Folge hatte, dass in Deutschland die (auch selbstkritischen) polnischen Diskussionen der 1990er Jahre über die Vertreibung sowie ähnliche Entwicklungen in Tschechien kaum registriert wurden. Ähnlich verhält es sich zwischen Polen und Tschechien. So nahm man an der Weichsel bis 2002 die fortlaufende Kontroverse zwischen den Vertretern der Sudetendeutschen und der

446 Vertreibung Sudetendeutscher für immer weniger Tschechen »gerecht«. Die Presse. 12.01.2017.

447 Janzer: »Eine neue Landkarte persönlicher Kontakte«. Radio Praha. 22.03.2018.

448 Vgl. Spalová: Remembering the German Past in the Czech Lands, 2016, S. 103.

449 Volf: Shifting Attitudes Toward the Second World War Commemorations in the Czech Republic, 2016. Václav Smycka unterstützt in seiner Untersuchung u.a. der Entwicklung der deutschen und tschechischen Wikipedia-Einträge zum Thema der Vertreibung die These der Pluralisierung der Erinnerungskultur: Smycka: Das Gedächtnis der Vertreibung, 2019, S. 48-50. 
Tschechischen Republik recht gleichgültig zur Kenntnis, ehe man sich selbst in einer ähnlichen Bedrohungslage sah. ${ }^{451}$

Einen Kulminationspunkt erreichte der Diskurs innerhalb und zwischen den Ländern Anfang der 2000er Jahre. Die BdV-Initiative, einen Erinnerungsort an Flucht und Vertreibung in Form eines Zentrums gegen Vertreibungen in Berlin zu errichten, verband sich mit einem von verschiedenen Kritikern wahrgenommenen "Neuen Deutschen Opferdiskurs« und fiel mit einem das Vertreibungsthema offensiv aufgreifenden CDU/CSU-Wahlkampf zusammen. In Polen stießen vor allem die Zentrumsinitiative und die in diesem Zusammenhang vermeintlich zu beobachtende Neujustierung der deutschen Erinnerungskultur zum Nachteil des Kriegsopfers Polens auf erheblichen Widerspruch. In Tschechien fokussierte sich die Diskussion auf die vom CSUKanzlerkandidaten ebenso wie von der nationalkonservativen österreichischen Regierung forciert angegriffenen >Beneš-Dekrete . In beiden Ländern betonte man Verständnis für den deutschen Wunsch, die Vertreibungen individuell und auch als Gesellschaft zu betrauern, fühlte sich jedoch völlig zu Unrecht auf die Anklagebank gesetzt oder befürchtete dies, wenn sich der BdV mit seinem Vorhaben oder die CDU/CSU und die österreichische Regierung mit ihrem Kampf gegen die >Beneš-Dekrete` durchsetzen würden.

Für den deutschen Diskurs um Flucht und Vertreibung war das Jahr 1989 kein entscheidender Wendepunkt. Erst die Balkankriege und die Neuausrichtung des BdV mit der Zentrumsinitiative brachten die Thematik in die breite Öffentlichkeit zurück, wozu eine umfassende und dieses Anliegen unterstützende Berichterstattung, Spielfilme und Dokumentationen und nicht zuletzt literarische Werke wie Im Krebsgang von Günter Grass beitrugen. Zugleich gelang es dem BdV, für seine Initiative Unterstützer bis in das linksliberale Milieu der Bundesrepublik hinein zu gewinnen. Eine Grundlage dafür war die Aktualisierung des Vertreibungsthemas durch die Balkankriege der 1990er Jahre. Die Diskussion darüber, wie ein entsprechender Erinnerungsort schließlich aussehen sollte, war in Deutschland seit dem Jahr 2000 der Kernkonflikt im Themenfeld Flucht und Vertreibung und wird in Kapitel 7.1 weiter diskutiert.

Nach einer kurzen Phase der Unsicherheit über die Grenz- und Minderheitenfrage im Jahr 1989 waren die Vertreibung der Deutschen sowie das deutsche Kulturerbe in Polen zunächst ein Thema der Wissenschaft und Zivilgesellschaft. Erst die Debatten um das ZgV führten, neben anderen Entwicklungen wie die Jedwabne-Diskussion, zu einer Repolitisierung und weiten gesellschaftlichen Verteidigungshaltung, die eine selbstreflexive Erinnerungskultur erschwerte. Eine Antwort auf die deutsche Zentrumsinitiative und später die Stiftung Flucht, Vertreibung, Versöhnung ist das Museum des Zweiten Weltkrieges in Danzig. Das in Kapitel 7.2 untersuchte Museum ist in den 2010er Jahren zum Symbol für die heftigen innerpolnischen und geschichtspolitischen Auseinandersetzungen sowie darüber hinaus für die Polarisierung der polnischen Gesellschaft geworden.

451 Majewski: Zwischen Versöhnung und Verteidigung nationaler Interessen, 2008, S. 42, $48 f ., 57$. Vgl. zur Ungleichzeitigkeit auch: Boll: Zu historischen Missverständnissen und Versäumnissen im deutsch-polnischen Streit um Geschichtspolitik, 2008, S. 144f. 
Noch vor der Jahreswende 1989/90 äußerte der ehemalige Dissident und damalige Präsident der Tschechoslowakei, Václav Havel, Worte des Bedauerns über die Vertreibung der Deutschen und wollte einen neuen Dialog beginnen. Wie erläutert, konnte und wollte die SL nicht auf dieses Angebot eingehen. Starken Widerspruch erfuhr Havel zudem aus weiten Teilen der tschechischen Gesellschaft, die seinen Schritt für unangemessen hielten. Auch wenn in den 1990er Jahren in Tschechien eine fortlaufende wissenschaftliche Auseinandersetzung mit dem Themenfeld erfolgte, blieb die tschechisch-sudetendeutsch-bayerisch-deutsche Beziehung durch den Konflikt um die rechtliche Bewertung der Vertreibung und Entschädigungsfragen eingetrübt, woran auch die ausgehandelten Vertrags- und Erklärungswerke nichts ändern konnten. Nach der Eskalation um die >Beneš-Dekrete< Anfang der 2000er gewann das Thema in Tschechien verstärkt auch eine innenpolitische Dimension, indem es zur Diskreditierung des politischen Gegners wegen eines vermeintlichen oder tatsächlichen Entgegenkommens gegenüber den Sudetendeutschen diente. Erst Mitte der 2010er Jahre zeigten sich auf politischer Ebene Zeichen der Entspannung, welche sich unter anderem im Besuch tschechischer Regierungsmitglieder beim Sudetendeutschen Tag äußerten.

Nach der EU-Osterweiterung wurde verschiedentlich von einem "gemeineuropäischen Erinnerungsraum « gesprochen. ${ }^{452}$ Die Diskussion um die >Beneš-Dekrete ist ein Beispiel für eine Phase, in der der Diskurs auf mehreren Ebenen stattfand: innerhalb der Länder, bilateral im mitteleuropäischen Rahmen und auf der EU-Ebene. Verbreiteten Erwartungen in Westeuropa und Deutschland, dass die ostmitteleuropäischen Staaten sich neben einer fortgesetzten wirtschaftlichen und rechtlichen Angleichung auch in einem einseitigen Prozess der westlichen Erinnerungskultur annähern würden, setzten die Regierungen dieser Staaten erfolgreich eigene europaweite Initiativen entgegen. ${ }^{453}$ Bestimmte Konfliktlinien oder Argumente, wie zum Beispiel die Forderung nach einer heroischen nationalen Meistererzählung, können aber schwerlich als ein ausschließlich >osteuropäisches Phänomen betrachtet werden. ${ }^{454}$

Stefan Troebst zieht in seinem Aufsatz »Towards a European Memory of Forced Migration« das Fazit, dass die heftigen Auseinandersetzungen um die Thematik letztlich auf Deutschland, Polen und Tschechien und mit deutlichem Abstand auch auf die Slowakei und Ungarn begrenzt geblieben seien. Zudem versuchten Polen und Tschechien die Auseinandersetzungen auf die bilaterale Ebene zu beschränken. Von einem europäischen Diskurs lasse sich folglich schwerlich sprechen. Die der EU-Ostererweiterung von 2004 folgenden geschichtspolitischen Debatten hätten sich schließlich im Wesentlichen auf zwei Themen konzentriert, nämlich ob und auf welche Weise die Erinnerung an die kommunistische Herrschaft über Osteuropa Teil der gesamteuropäischen Erinnerungskultur werden und inwieweit die neuen Mitgliedsstaaten die starke westeuropäische Erinnerung an den Holocaust auch für sich adaptieren sollten. Schließlich stellt er positiv heraus, dass die Auseinandersetzung über Flucht und Vertreibung zwar andere Themen wie Holocaust und Genozid in ihrer Bedeutung herausfordere, zugleich aber

452 Kraft: Europäische Erinnerungskultur(en) als »work in progress«, 2014, S. 315.

453 Vgl. ebd., S. $315 f$.

454 Vgl. ebd., S. 315-317. 
Diskussionen um »Menschenrechte, Multikulturalität und die europäische Integration« positiv befördern könne. ${ }^{455}$

Wie bereits in diesem Kapitel gezeigt wurde und später noch mit Blick auf das Haus der europäischen Geschichte in Kapitel 7.3 zu diskutieren sein wird, ist der Vorwurf weit verbreitet, die EU sei ein Instrument hegemonialer deutscher Bestrebungen. In dieser Überspitzung sicher unzutreffend, kann ein deutscher Einfluss auf die europäischen Institutionen entsprechend der politischen und ökonomischen Bedeutung Deutschlands jedoch nicht von der Hand gewiesen werden. Auch in der Forschung wird diskutiert, dass die Deutschen von der Europäisierung der Holocaust-Erinnerung sprofitieren<, indem die Täterrollen durch die Einbeziehung der kollaborierenden oder von dem Völkermord an den europäischen Juden ökonomisch profitierenden Gesellschaften und Staaten diversifiziert werden. Zudem erscheint es durchaus zu gelingen, die Vertreibungen als zentrales Element der Erinnerung in Europa zu verankern. ${ }^{456}$

Die positiven Einflüsse der EU auf eine geschichtspolitische Verständigung, wie sie Miroslav Kunštát unter anderem für die "Krisenmomente im deutsch-tschechischen Verhältnis « ausmacht, werden herausgefordert oder konterkariert durch die politischen Auseinandersetzungen um ihre zukünftige Ausrichtung. ${ }^{457}$ Beim Aushandeln der Finanzplanung oder der künftigen Rolle der Nationalstaaten gibt es erbitterte Konflikte, die nicht selten mit ’historischen Argumenten geführt werden. ${ }^{458}$ Ähnlich verhält es sich mit den grundlegend unterschiedlichen Perspektiven auf die >Flüchtlingskrise ‘. In dem weiteren Feld der Bewertung von Nation und Nationalismus scheint in Deutschland eine Abgrenzung von diesen folgerichtig: Sie werden je nach politischem Lager teilweise oder ganz als Urheber des Schreckens des vorherigen Jahrhunderts, darunter der Vertreibung, identifiziert. Im Gegensatz dazu stößt die Kritik an Nationalismus und Nationalstaat als »Quelle allen Übels « ${ }^{459}$ in Ländern mit einem positiveren Verständnis von Nation auf Widerspruch. Das gilt besonders für Länder wie Polen und, mit Einschränkung, Tschechien und verstärkt sich nochmals, wenn die Regierungen von Nationalpopulisten gestellt werden. Verständlicherweise erscheint es den Opfern der deutschen Aggression im Zweiten Weltkrieg wohlfeil, wenn die Deutschen sich nach der verbrecherischen Eskalation des deutschen Rassennationalismus von diesem - häufig nicht ohne >Aufarbeitungsstolz « - distanzieren und heute vorwurfsvoll auf ihre Nachbarstaaten blicken, und dies sowohl in Hinblick auf eine vermeintlich ungenügende Aufarbeitung ihrer Vergangenheiten als auch ihre gegenwärtige politische Ausrichtung.

Bei einem Vergleich der Diskussionen über die Vertreibung in Polen und Tschechien zeigt sich die unterschiedliche Nähe des Themas zum nationalen Selbstverständnis.

455 Troebst: Towards a European Memory of Forced Migration? 2016, S. 235, 247.

456 Vgl. Hahn; Hahn: »The Holocaustizing of the Transfer-Discourse«, 2008, S. 48. Vgl. auch: Sierp: History, Memory, and Trans-European Identity, 2014, S. 109f.

457 Kunštát: Fremd- und Feindbilder der Deutschen in der tschechischen innenpolitischen Instrumentalisierung nach 1989, 2007, S. 128.

458 Vgl. Buras; Vegh: Stop, Brüssel! 2018.

459 Kranz: Schuld und Verantwortung, Wunden und Narben, 2015, S. 74f. So legt Jerzy Kranz die Ausrichtung des Zentrums gegen Vertreibungen und der Stiftung Flucht, Vertreibung, Versöhnung 2015 aus. 
In Tschechien »berührt [...] die Debatte das Selbstverständnis der tschechischen Gesellschaft« durch die lange, engere und innere Verwobenheit von tschechischem und deutschem Element weit mehr, als dies in Polen der Fall ist. ${ }^{460}$ Stellt die Vertreibung in Tschechien das demokratische und friedliche nationale Selbstverständnis in Frage, ist sie in Polen eine Herausforderung für die besonders unter den nationalkonservativen Regierungen prolongierte heroische Meistererzählung. Stärker als in Tschechien, wo die innere, moralische Frage der Vertreibungen in den intellektuellen Diskursen stets wichtig war, werden in Polen die »internationalen Zusammenhänge« der historischen Ereignisse betont sowie in die von den Alliierten festgelegte und erzwungene Nachkriegsordnung eingeordnet, welche zur polnischen >Westverschiebung und zur Zwangsinstallation eines kommunistischen Regimes führte. ${ }^{461}$ Der "polnisch[e] Opfermythos « macht darin »die Polen zu passiven Betrachtern des historischen Geschehens und bewirkt eine »entlastende Funktion im Inneren «. ${ }^{462}$ Diese Erzählung wird ähnlich auch in Tschechien verfolgt. Sie ist dort aber stärker gefordert durch den breiten Konsens in der tschechischen/tschechoslowakischen Gesellschaft und ihrer anfangs bürgerlich-demokratischen Konstitution während der Vertreibungen. Ein weiterer und wichtiger Unterschied für die späteren Auseinandersetzungen ist der, dass in Polen bereits ein Großteil der Deutschen geflohen war oder von der Roten Armee vertrieben wurde, ehe die polnische Verwaltung diese Gebiete übernahm. In der ČSR hingegen erfolgte ein erheblicher Teil der >Ausführung der Vertreibung durch eigene Kräfte, die zudem vormalige tschechoslowakische Staatsbürger vertrieben. ${ }^{463}$

Sowohl in Polen als auch in Tschechien sah man nach 1989 die deutschen Landsmannschaften und den BdV nicht oder nur punktuell als geeignete Ansprechpartner, wozu auch deren Politik beitrug. Sie waren 1989 und auch danach in weiten Teilen nicht in der Lage, realpolitische Kompromisse auszuhandeln und auf Offerten wie die von Václav Havel in Bezug auf ein eingeschränktes Rückkehrrecht einzugehen - ein Grund dafür waren die fehlende politische Unterstützung und der verlorene breite gesellschaftliche Rückhalt. Schädlich für die Verständigung war auch das Versäumnis von Seiten der Landsmannschaften und des BdV, die eigene historische Verantwortung als Deutsche konsequent und nicht nur punktuell zu akzeptieren und daraus resultierend Gesten der Entschuldigung anzubieten. ${ }^{464}$

Zivilgesellschaftliche Initiativen wie Borussia in Polen oder Antikomplex in Tschechien finden zwar Äquivalente in Vereinigungen wie der Jungen Aktion der AckermannGemeinde, aber nicht im BdV - der als Dachverband der Landsmannschaften trotz seiner sinkenden Mitgliederzahl nach wie vor der primäre politische Interessenvertreter

460 Schulze Wessel: Tschechien - Institutionen, Methoden und Debatten in der Zeitgeschichte, 2011.

461 Ebd.

462 Kraft: Der Platz der Vertreibung der Deutschen im historischen Gedächtnis Polens und der Tschechoslowakei/Tschechiens, 2005, S. $348 \mathrm{f}$.

463 Vgl. Schulze Wessel: Tschechien - Institutionen, Methoden und Debatten in der Zeitgeschichte, 2011. Siehe zur Problematik von »politisch-moralischer Anerkennung der Vertreibung u und der bürgerlich-demokratische[n] Regierung unter Edvard Beneš: Leggewie; Lang: Der Kampf um die europäische Erinnerung, 2011, S. 27.

464 Vgl. Schulze Wessel: Tschechien - Institutionen, Methoden und Debatten in der Zeitgeschichte, 2011. 
der deutschen Heimatvertriebenen ist. Die Bedeutung anderer zivilgesellschaftlicher und lokaler Initiativen ist ähnlich wie die des >Heimwehtourismus für die politischen Auseinandersetzungen der $2000 e r$ Jahre gering geblieben. Die langfristige Wirkung vor Ort ist aber nicht zu unterschätzen.

Piotr M. Majewski konstatiert für den Vergleich von polnischem und tschechischem Vertreibungsdiskurs, dass diese trotz »Unterschiedlichkeit von Dynamiken und Spezifika« durchaus nach einem »ähnlichen Schema« verlaufen seien. Den zunächst »freie[n] Debatten über die moralische und historische Beurteilung « folgte eine nationale Verteidigungshaltung und damit eine diskursive Verengung unter dem »Bedrohungsgefühl [...] durch Forderungen nach materieller Entschädigung von Seiten der Vertriebenen sowie durch eine in Deutschland zu beobachtende Veränderung des Geschichtsbewusstseins«. Die diesen Konflikt verschärfende politische Instrumentalisierung der Thematik durch verschiedene Kräfte sei auf allen Seiten zu beobachten gewesen. ${ }^{465}$

Friedhelm Boll diskutierte 2006, warum die Verständigung über Flucht und Vertreibung nach der "Aussöhnungseuphorie der 1980er- und 1990er-Jahre« weitgehend gescheitert sei und wo die Gründe für die Eskalation zu suchen seien. Habe es sich bei der Versöhnung der 1990er letztlich nur um einen »schmale[n] deutsch-polnische[n]« Elitendiskurs gehandelt? Sei die fortgesetzte Wirkmacht der kommunistischen Erzählung über Deutschland unterschätzt worden und welche Bedeutung habe die Konservierung des Geschichtsbildes der Vertriebenenverbände, die sich nach Willy Brandts Ostpolitik vom gesellschaftlichen mainstream entfremdeten ${ }^{466}$ Auf Grundlage der untersuchten Diskursgeschichte lassen sich fünf Probleme identifizieren, welche die Ursache für die innergesellschaftlichen und bilateralen Konflikte bilden und einer Verständigung im Wege stehen.

(1) Die schon mehrfach erwähnten mangelnden Kenntnisse der Gesellschaften über die Erinnerungskulturen und besonders die Erfahrungen ihrer Nachbarn im Zweiten Weltkrieg sind ein entscheidendes Problem. Diese schwerwiegenden und im Hintergrund selten mitgedachten Ungleichheiten erschweren die Auseinandersetzungen um das Thema von Flucht und Vertreibung. Nach Ruchniewicz war die Vertreibung in Polen, und wie in der vorliegenden Studie gezeigt, auch in Tschechien viel mehr Bestandteil innergesellschaftlicher Auseinandersetzungen als dies bis dato in Deutschland umgekehrt mit der deutschen Besatzungsherrschaft in Polen und Tschechien - abgesehen vom Holocaust - der Fall war. ${ }^{467}$ Das Übersehen der polnischen und tschechischen Auseinandersetzung in Deutschland rief Enttäuschung und schließlich auch Wut hervor, als den beiden Ländern in den 2000ern von deutscher Seite vermeintliche Ignoranz vorgeworfen wurde. ${ }^{468}$ Die asymmetrische und selektive Wahrnehmung der jeweiligen

465 Majewski: Zwischen Versöhnung und Verteidigung nationaler Interessen, 2008, S. 57.

466 Boll: Zu historischen Missverständnissen und Versäumnissen im deutsch-polnischen Streit um Geschichtspolitik, 2008, S. 143 f.

467 Ruchniewicz: Geschichtspolitik im Schatten der Dankbarkeit und Enttäuschung, 2007/2008, S. $151 \mathrm{f}$.

468 Vgl. Schulze Wessel: Tschechien - Institutionen, Methoden und Debatten in der Zeitgeschichte, 2011. 
Diskurse findet sich in Polen und Tschechien auch in dem politisch-medial grundsätzlich überschätzten Einfluss der Landsmannschaften. Umgekehrt lässt sich in der Umgebung des BdV erkennen, dass selbstkritische Stimmen aus Polen und Tschechien bevorzugt nur dann wahrgenommen werden, wenn sie in das Raster der eigenen Argumentation passen und ihr eigentlicher Kontext, beispielsweise eine innergesellschaftliche Zielrichtung, nicht erkannt wird. In Polen und Tschechien führte diese Gemengelage wiederholt zum Einspruch, dass scheinbar nur eine vollständige Übernahme der >deutschen Perspektive oder der Perspektive des BdVs diesen zufriedenstellen würde - und ein Dialog anders aussehe.

(2) Ein zweites Kernproblem ist die selektive Wahrnehmung der historischen Ereignisse. In den drei untersuchten Ländern wird an unterschiedliche Phasen und Elemente erinnert und es sind oft verschiedene Ereignisse gemeint, wenn über das Thema von Flucht und Vertreibung gesprochen wird.

(3) Das dritte Problem liegt in der politischen Instrumentalisierung und medialen Überspitzung, die sich in unterschiedlicher Intensität in allen untersuchten Ländern beobachten lässt. Erinnerte manche Berichterstattung in den bundesdeutschen Medien Anfang der 2000er an den selbstbezogenen bundesdeutschen Opferdiskurs der 1950er Jahre, so spielte die polnische Presse unter anderem mit volkspolnischen Stereotypen über die Deutschen. Auch in Tschechien erfuhr der >sudetendeutsche Nationalsozialist eine Wiederbelebung als Karikatur. ${ }^{469}$ In beiden Ländern werden diese Argumente auch für innenpolitische Kämpfe genutzt, sodass Gegnern häufig erfolgreich eine vermeintlich deutschfreundliche Haltung vorgeworfen wird. Auch wenn diese politische Wirkung oftmals die eigentliche Intention sein mag, so führt diese Wiederbelebung alter Stereotype auch zu einer gesellschaftlichen Polarisierung und der Beschädigung der bilateralen Kommunikation. ${ }^{470}$ Meistens dient die Berichterstattung in den drei Ländern zudem nicht dem Verstehen des oft nur als Projektionsfläche präsenten Gegenübers. Ein Versuch, die »Eigenlogik der jeweils fremden Auseinandersetzung« zu erfassen, unterbleibt, stattdessen nutzt man die vermeintliche Position des Gegenübers vor allem »zur Bestätigung der eigenen Position. « ${ }^{471}$

(4) Michaela Witte diskutiert in ihrer Arbeit wiederholt das sich hieran anschließende vierte Problem, dass beide Seiten (hier Sudetendeutsche und Tschechen) es für eine tatsächliche Aufarbeitung versäumt hätten, sich mit der eigenen Verantwortung und Schuld zu befassen. Stattdessen waren die Auseinandersetzungen davon geprägt, dass jeder >Angriff< sofort mit einem >Gegenangriffı gekontert worden sei. Für weite Teile der Gesellschaft sei dieser Zustand zudem komfortabel, da er Selbstkritik und ei-

469 Fehr: Vergeltende Gerechtigkeit, 2016, S. 125. Houžvička: Czechs and Germans 1848-2004, 2015, S. $424 f$.

470 Fehr: Vergeltende Gerechtigkeit, 2016, S. 125.

471 Feindt: Flucht und Vertreibung zwischen Kaltem Krieg und Universalisierung, 2014, S. 169. Die Debatten um das Zentrum gegen Vertreibungen zeigen nach Manuel Becker beispielhaft auf, wie sowohl konkrete inhaltliche Fragen als auch die Frage eines würdigen Gedenkens in den Hintergrund gerieten und wechselseitige Unterstellungen Oberhand gewannen: Becker: Ceschichtspolitik in der »Berliner Republik«, 2013, S. 505. 
ne schmerzhafte Beschäftigung mit der eigenen Geschichte erspare. ${ }^{472}$ Das verstärke die ohnehin schon chronisch selektiven nationalen Erinnerungskulturen, die »unproblematische Themen« bevorzugten, »die das nationale Ego nicht verletzten «. ${ }^{473}$

(5) Weiter hat die Untersuchung der Diskurse als fünftes Problem aufgezeigt, dass die Verbindung der moralischen Frage mit der aus Deutschland verschiedentlich immer wieder aufgebrachten Entschädigungsfrage die offene Auseinandersetzung in Polen und Tschechien blockierte.

Die diskutierten Probleme machen deutlich, warum für die drei untersuchten Länder Flucht und Vertreibung ein sperriger Gegenstand bleiben. Mit einem globalen Blick lässt sich nach Levy und Sznaider konstatieren, dass sich die Erinnerung weltweit im »Spannungsfeld von Kosmopolitisierung und Re-Nationalisierung « bewegt. ${ }^{474}$ Das zeigt sich an der Existenz unterschiedlicher, hier beschriebener Phänomene: wachsendes Interesse an lokaler und regionaler Geschichte, am deutschen Erbe und dem Selbstverständnis als beispielhafter europäischer >multikultureller Region oder einer reflektierten Geschichtsschreibung, aber auch dem Erbe und der fortgesetzten Wirkmacht der Narrative des Kalten Krieges und an einem neuem Nationalpopulismus. ${ }^{475}$ Die im Jahr 2007 verfasste optimistische Prognose von Levy und Sznaider für die künftige Entwicklung der Erinnerung scheint heute mehr denn je herausgefordert:

»Die aus dem nationalen Container befreite >Geschichte < kann daher auch keine Ruhmesgeschichte mehr sein. Ein skeptisches Geschichtsnarrativ betont plötzlich das vergangene Unrecht der eigenen Nation. Man wird schuldig. Kosmopolitische Erinnerung heißt dann auch, die Ceschichte (und die Erinnerungen) des >Anderen< anzuerkennen und in die eigene Ceschichte zu integrieren. Diese Perspektive drängt das Narrativ der selbstgerechten Nation in den Hintergrund. ${ }^{476}$

Den eben besprochenen Problemen wurde unterschiedlich begegnet. In Hinblick auf bisherige Versuche, die Verständigung zwischen den politischen und gesellschaftlichen Eliten voranzubringen, herrscht heute größere Skepsis. Der Rahmen bisheriger nationaler Erinnerungskulturen und die in ihnen vorherrschenden historischen Argumentationsmuster sind oft so resistent, dass sie sich nur selten entscheidend mit einer topdown-Initiative verschieben lassen. Václav Havels Versuch von 1989/90 ist dafür ein prägnantes Beispiel. ${ }^{477}$

Matěj Spurný schlägt vor, Raum für die (individuelle) Geschichte zu lassen, die dazu geeignet sei, mit gängigen Narrativen zu brechen und eine »Pluralisierung und Verkom-

472 Witte: Entfremdung - Sprachlosigkeit - Aussöhnung? 2002, S. 295. Auch Spalová plädiert dafür, dass einer inneren und äußeren Verständigung zunächst eine klare Anerkennung von Schuld in der eigenen nationalen Geschichte vorausgehen muss: Spalová: Remembering the German Past in the Czech Lands, 2016, S. 101.

473 Tych: Polnische Geschichtsdebatten, die es nicht gibt, 2007, S. 66.

474 Levy; Sznaider: Erinnerung im globalen Zeitalter, 2007, S. 15, 238.

475 Vgl. Steffen: Ambivalenzen des affirmativen Patriotismus, 2006, S. 221.

476 Levy; Sznaider: Erinnerung im globalen Zeitalter, 2007, S. 242.

477 Vgl. Houžvička: Czechs and Germans 1848-2004, 2015, S. 408. 
plizierung der Erinnerung « zu ermöglichen. ${ }^{478}$ Die diskutierten Bewegungen in Kunst und Literatur zeigen ebenso wie eine reflektierte, den nationalen Rahmen überwindende Geschichtswissenschaft beispielhaft, wie eine solche Komplexität erreichbar ist, die der »Erinnerungsvielfalt der Zeitzeugen und ihrer Nachfahren verschiedener Nationalitäten und sozialer Gruppen Rechnung trägt «. ${ }^{479}$

Diese Form eines >kritischen Pluralismus« scheint sich am ehesten >vor Ort « erreichen $\mathrm{zu}$ lassen, wie viele hier erwähnte lokale Initiativen veranschaulichen. Beispiele wie die Erinnerungen an den Brünner Todesmarsch zeigen zudem, dass auch ein Dialog mit der Sudetendeutschen Landsmannschaft auf dieser Ebene leichter als auf der nationalen herzustellen ist.

Um Verständigung $\mathrm{zu}$ erreichen, erscheint das konsequente Bemühen um eine transnationale Perspektive notwendig. Nach Philipp Ther ermöglicht dieser Blick für das deutsche Beispiel, dass mit dem Respektieren von Einwänden aus Polen und Tschechien diese als »Korrektiv« fungieren können. Damit wird ein gemeinsamer Diskurs möglich, der nicht nur um »unvereinbare Erinnerungen kreist, sondern in internationaler Kooperation nach Erklärungen sucht, warum das 20. Jahrhundert so viele Katastrophen hervorgebracht hat und was sich heute daraus lernen lässt." Die Bereitschaft zum wechselseitigen Korrigieren könne und müsse »unbequem« sein, sei aber notwendig. ${ }^{480}$ Das Ergebnis eines solchen Ansatzes könnte mit Manuel Becker sein, auf eine Hierarchisierung der Opfer zu verzichten, »wohl aber [zu] kontextualisieren und $[\mathrm{zu}]$ differenzieren « [...] ohne dabei die Selbstbeachtung einzelner Opfergruppen zu verletzen. ${ }^{481}$

Deutschland muss in dieser Konstellation Abstand davon nehmen, dass es ein europaweites oder gar globales Handlungsschema zur Verständigung gibt und erst recht nicht die schon zitierte »DIN-Norm« für die Aufarbeitung. ${ }^{482}$ Diese Vorstellung wirkt abstoßend auf die Länder, die von Deutschland im Zweiten Weltkrieg erobert, besetzt und terrorisiert wurden, besonders wenn dies vermengt wird mit dem »unterschwellig[en] « Vorwurf, diese Länder »hätten den Stand der Vergangenheitsbewältigung in der Bundesrepublik noch nicht erreicht. ${ }^{483}$ Aber auch vielfältige deutsche Versöhnungsgesten scheinen weniger hilfreich, als in Deutschland angenommen: Bernard Gaida, der Vorsitzende der deutschen Minderheit in Polen, konstatiert in diesem Zusammenhang, dass die »sich wiederholende[n] deutsche[n] Versöhnungsbitten ohne Reaktion « blieben: »Dagegen haben deutsche Politiker schon so oft um Verzeihung gebeten - ohne eine Antwort zu erhalten -, dass hier schon eine Devaluation des Inhaltes droht. « ${ }^{484}$ Als eine mögliche Ursache für mangelnde Reaktionen in Polen identifiziert Witold Jarusz, dass die polnischen Regierungen - trotz einer intensiven, aber vor allem nach

478 Spurný: Czech and German Memories of Forced Migration, 2012, S. 364.

479 Kolář: Vertreibung zwischen nationaler Meistererzählung und Deutungspluralität, 2005, S. 940.

480 Ther: Der Diskurs um die Vertreibung, 2008, S. $46 f$.

481 Becker: Ceschichtspolitik in der »Berliner Republik«, 2013, S. 484.

482 Bömelburg: Cestörte Kommunikation, 2005, S. 52. Vgl. Kap. 5.2, S. 231.

483 Ther: Der Diskurs um die Vertreibung, 2008, S. 36.

484 Regente: Tagungsbericht: »Vertriebene in der DDR - Zum Umgang mit einem Tabu«, 2019. 
innen gerichteten Geschichtspolitik - die Beziehungen zu Deutschland vor allem aus der Perspektive von Gegenwart und Zukunft bewerten. ${ }^{485}$

Nicht zu Unrecht wird trotz dieser Streitgeschichte wiederholt darauf hingewiesen, dass die deutsch-polnisch-tschechische Verständigung im europäischen Vergleich - beispielsweise im Vergleich mit dem Nordirland-Konflikt oder mit dem in dieser Arbeit wiederholt erwähnten polnisch-ukrainischen Konflikt um die Massaker und Vertreibungen in Wolhynien/Ostgalizien im Zweiten Weltkrieg - weder ein Sonderfall ist noch ein besonders problematischer. ${ }^{486}$ Das zeigt sich an dem letztlich in vielerlei Hinsicht guten und stabilen Verhältnis zwischen den drei Ländern. Die in der Bevölkerung verbreiteten Sichtweisen auf das Vertreibungsgeschehen sind durchaus differenzierter »als bei so manchem Politiker oder Meinungsmacher - wenn das Thema denn überhaupt noch für relevant erachtet wird. ${ }^{487}$

Die deutschen Minderheiten in Polen und Tschechien sehen sich selbst in einer Brückenfunktion zwischen den Ländern und Kulturen. In Oberschlesien haben ihre Vertreter Einfluss auf den regionalen Vertreibungsdiskurs. In Tschechien ist ihre Anzahl zu klein, um eine bedeutende Rolle zu übernehmen. Als Störfaktor oder Quelle von Konflikten werden sie seit geraumer Zeit nicht mehr wahrgenommen, auch wenn sich seit 2015 unter der PiS-Regierung eine Verschlechterung der Lage andeutet. ${ }^{488} \mathrm{Ei}$ ne >Rückwanderungsbewegung von Heimatvertriebenen oder deren Nachfahren nach 2004, wie sie noch 2001 in der Zeitschrift World Affairs erwartet wurde, blieb im Rahmen der europäischen Freizügigkeit mangels Interesses aus. ${ }^{489}$

Abschließend lässt sich für die drei Länder folgender Diskursrahmen für die entstandenen oder entstehenden Museen abstecken: Die innerdeutschen Auseinandersetzungen der 2000er über die Form eines Erinnerungsortes an Flucht und Vertreibung konnten trotz des Kompromisses der Großen Koalition noch nicht beendet werden, wie die andauernden Konflikte um die Ausrichtung der Stiftung Flucht, Vertreibung, Versöhnung zeigen. Zentral bleibt die Forderung nach einer im Einklang mit ihren Nachbarn stehenden reflektierten deutschen Erinnerungskultur, welche das Gedenken an die Shoa zum Kern hat. Die hier befürchteten fundamentalen Verschiebungen, unter anderem durch die Schaffung eines Erinnerungsortes an Flucht und Vertreibung, sind bisher nicht eingetreten..$^{40}$ Das Auftauchen neuer Akteure wie der AfD und globale Trends der Renationalisierung lassen aber darauf schließen, dass die bundesrepublikanische Erinnerungskultur in Zukunft noch mehr gefordert sein wird.

485 Jurasz: Die polnische Außenpolitik. Dialog Forum. 16.01.2020.

486 Vgl. Rigney: Transforming Memory and the European Project, 2012, S. $620 f$.

487 Becker: Geschichtspolitik in der »Berliner Republik«, 2013, S. 488. Vgl. dafür z.B. die von der SFVV beauftragte Allensbach-Studie von 2015, die eine repräsentative Umfrage in Deutschland, Polen und Tschechien zum Vertreibungsthema durchgeführt hat: Flucht, Vertreibung, Versöhnung, 2015. Unter anderem zeigt sie eine sich seit 2006 stetig verbessernde Einschätzung der Bevölkerungen in Hinblick auf die Verständigung.

488 Vgl. Hanisch; Sieradzka: Verliert die deutsche Minderheit ihre Rechte? $m d r$. 09.08.2016.

489 Vgl. Phillips: The Politics of Reconciliation Revisited, 2001, S. 187.

490 Vgl. Traba; Żurek: »Vertreibung« oder »Zwangsumsiedlung«? 2015, S. $365 f$. 
In Polen ist das Thema von Flucht und Vertreibung nach 2010 weniger von Bedeutung gewesen. Die eskalierende Geschichtspolitik der PiS-Regierung seit 2015, die zwar in einigen Punkten an die nationalliberale PO-Regierung anknüpft, kämpft neben der Schaffung und Neuausrichtung von Museen wie dem MIIW mittlerweile an verschiedenen Fronten: die erneuerten Reparationsforderungen an Deutschland, der internationale Streit um die falsche Bezeichnung spolnische Konzentrationslager und die damit verbundene Diskussion um einen historischen polnischen Antisemitismus oder eine >Neubewertung der Solidarność-Bewegung. Trotz dieser verschiedenen, großen Themenfelder werden nicht nur von nationalkonservativen Autoren die möglichen geschichtspolitischen Entwicklungen um Flucht und Vertreibung in Deutschland und Europa weiter aufmerksam verfolgt, wie zuletzt die Diskussion um das Haus der Europäischen Geschichte in Brüssel gezeigt hat.

In der Tschechischen Republik eignet sich das Thema Flucht und Vertreibung weiter für temporäre Diskussionen und Kritik an der vermeintlichen oder tatsächlichen deutschen Position. Ein Meilenstein für die Bewertung nicht nur der Vertreibung, sondern auch der jahrhundertelangen deutsch-tschechischen Gemeinschaft, wird das Museum der deutschsprachigen Bewohner Böhmens sein, wenn es nach Jahren der Verzögerung eröffnet.

Die nun siebzigjährige Diskursgeschichte um Flucht und Vertreibung in Deutschland, Polen und Tschechien zeigt, dass sich eine Annäherung der unterschiedlichen Erzählungen über das historische Geschehen nur in einzelnen Punkten oder temporär beobachten lässt. Vielmehr treffen bei diesem Thema, das alle Länder entscheidend geprägt hat, harte Gegensätze aufeinander. Wissenschaft, Kunst und Zivilgesellschaft haben viele wichtige symbolische Schritte geleistet und leisten dies weiterhin, konnten aber bisher noch keine entscheidende Annäherung bewirken. ${ }^{491}$

Die staatliche Verständigung unterlag und unterliegt politischen Konjunkturen und ihr Einfluss blieb bisher beschränkt. Im Gegenteil, öfter und leichter lässt sich ein negativer Konsens verfestigen. Das ist auch bedingt durch den diskutierten politisch-medialen Komplex, in dem die Kontroverse scheinbar schnellere politische oder ökonomische Vorteile verspricht. In Bezug auf die politische Forderung, »dass es trotz unterschiedlicher Erfahrung eine gemeinsame europäische Erinnerung geben müsse«, kam Robert Traba bereits 2007/08 zu dem Ergebnis, dass sich in der Konsequenz dieser Forderung vielmehr »vereinfacht gesagt - eine Welle von Renationalisierungen der Erinnerung und der Geschichtspolitiken in den einzelnen Ländern, auch in Polen und Deutschland« beobachten lasse. ${ }^{492}$ Daran haben auch die traditionell engen ökonomischen, aber auch gesellschaftlich stark entwickelten Kontakte zwischen Deutschland und seinen beiden östlichen Nachbarländern nur wenig ändern können.

491 Hans-Jürgen Bömelburg vertrat in seinem Kolloquium am 30.01.2018 die Ansicht, dass über Flucht und Vertreibung in Deutschland ein festes Bild vorherrsche, das wiederum im Konflikt mit ähnlich starren Vorstellungen über Besatzungszeit und Vertreibung in Polen und Tschechien stehe. Dieser Zustand lasse auch in Zukunft wenig Bewegung erwarten.

492 Traba: Krieg und Zwangsaussiedlungen, 2007/2008, S. 127. 
274 Flucht und Vertreibung in europäischen Museen

Nach Václav Houžvička kann es schließlich in der schwierigen erinnerungskulturellen und geschichtspolitischen Gemengelage nur darum gehen, einen guten und praktikablen »modus vivendi« $\mathrm{zu}$ finden. ${ }^{493}$ Aber auch um diesen zu erreichen und zu halten, ist ein fortgesetzter Einsatz für Verständigung notwendig. Die folgenden Kapitel sollen zeigen, wie die untersuchten Museen in dieser Diskursgeschichte mit den herausgearbeiteten Problemstellungen und den verschiedenen vorgeschlagenen Lösungsansätzen zu verorten sind und welchen Beitrag sie zur Verständigung über das Thema von Flucht und Vertreibung leisten können.

493 Houžvička: Czechs and Cermans 1848-2004, 2015, S. 473. 


\section{Regionalhistorische Museen}

\subsection{Anmerkungen zur oberschlesischen Geschichte}

Die Geschichte der Region Oberschlesien darzustellen ist in mehrfacher Hinsicht eine Herausforderung. Nachdem die schweren geschichtspolitischen und geschichtswissenschaftlichen Auseinandersetzungen zwischen Deutschland, Polen und auch der Tschechoslowakei nach dem Zweiten Weltkrieg und besonders nach 1989 abgeklungen sind, bleibt die Geschichtsschreibung unter anderem mit der Präsenz der oberschlesischen Autonomiebewegung und der deutschen Minderheit umstritten - umstrittener als in Niederschlesien und anderen Regionen Polens. Damit verbindet sich auch die Frage, wie Oberschlesien räumlich zu fassen ist, was es ausmacht und wer als Oberschlesier zählt. ${ }^{1}$ In Polen selbst ist das historische Oberschlesien heute hauptsächlich in die Woiwodschaften Oppeln und Schlesien aufgeteilt. Im polnischen Sprachgebrauch wird für gewöhnlich mit Schlesien (Śląsk) zumeist das im Deutschen als Oberschlesien bezeichnete Gebiet benannt und seltener spezifisch von Oberschlesien (Górny Śląsk) gesprochen. ${ }^{2}$ Einzelne Elemente der oberschlesischen Geschichte und mit ihr verbundene historiographische Diskussionen werden im Folgenden skizziert, insofern sie wenigstens mittelbar für das Verständnis der Verhältnisse in Oberschlesien am Ende des Zweiten Weltkrieges und danach von Bedeutung sind.

Besonders im 19. und in der ersten Hälfte des 20. Jahrhunderts wurde die Präsenz sslawischer < und sgermanischer S Stämme in Antike und Frühmittelalter im oberschlesischen Raum in Hinblick auf nationale Ansprüche diskutiert, ohne dass diese nationalistische und ahistorisch ethnisierende Frage beantwortet werden konnte. ${ }^{3}$ Im Mittelalter selbst ist es nie zu einer geschlossenen Herrschaftsbildung in der Region gekommen. Diese stand zumeist unter der Oberhoheit benachbarter Dynastien, wie der böhmischen Přemysliden. Die einheimischen Herrschaften verloren mit der Integration der

Vgl. für eine Diskussion der Frage aus deutsch-polnisch-tschechischer Perspektive: Baron; Michalczyk et al.: Wer ist Oberschlesier? 2015, S. 655-665. Vgl. Tomann: Geschichtskultur im Strukturwandel, 2016, S. 13-18. 
Gebiete in das Heilige Römische Reich ab Mitte des 12. Jahrhunderts den Kontakt zum mittelalterlichen polnischen Staat. ${ }^{4}$ Mit der Krone Böhmens fiel Schlesien dann im 16. Jahrhundert an die Habsburger. Die Aufteilung der Region in verschiedene Herrschaften machte die Grenzen der Region fluide, sodass bis heute eine klare Grenzziehung der Region schwerfällt. ${ }^{5}$ Entscheidend ist, dass der Begriff Oberschlesien jenseits der Verwaltungsgrenzen weiterhin lebendig ist. ${ }^{6}$

Wie bereits angesprochen, ist der Charakter der >deutschen Ostsiedlung< im Hochmittelalter zwischen der deutschen und polnischen Historiographie lange diskutiert worden. Dieses historische Phänomen war im Raum Oberschlesien deutlich schwächer als in anderen Gebieten. Inwieweit die Verhältnisse zur ursässigen Bevölkerung konfliktreich waren, lässt sich für das oberschlesische Mittelalter aufgrund einer schwachen Quellenlage kaum beantworten, angenommen wird aber, dass »ethnische oder nationale Argumente im heutigen Sinn« sowie Fragen ethnischer Identität keine Rolle spielten oder auf eine kleine Elite beschränkt waren. ${ }^{7}$ Durchaus feststellbar und im Gegensatz zur starren Vorstellung eines permanenten >Volkstumskampfesく stehend, existierte eine wechselnde sprachlich-ethnisch-lokale Zugehörigkeit, in der es im Verlauf der Jahrhunderte neben einer aktiven Mehrsprachigkeit immer wieder zu Sprachwechseln kam, für die lebenspraktische Gründe ausschlaggebend waren. ${ }^{8}$

In den Städten Oberschlesiens sowie den Oberschichten setzte sich schließlich das Deutsche durch. Die Landbevölkerung sprach mit großer Mehrheit einen polnisch-slawischen Dialekt, der unter starkem Einfluss und in regem Austausch mit dem Deutschen und dem im Süden Oberschlesiens vorherrschenden Tschechischen stand. Das Tschechische war zudem zeitweilig Kanzleisprache Oberschlesiens. ${ }^{9}$ Im 18 . Jahrhundert verblieb Oberschlesien in einer peripheren Lage. Nach der preußischen Eroberung der vormals habsburgischen Provinz bildete es gemeinsam mit Niederschlesien die Provinz Schlesien. Ob das vielfach wiedergegebene Zitat Johann Wolfgang von Goethes bei seinem Besuch der uns auch später noch beschäftigenden ${ }^{10}$ ersten Dampfmaschine Kontinentaleuropas in Tarnowitz/Tarnowskie Góry tatsächlich so negativ gemeint war, wie es heute erscheint und immer wieder bewertet wurde, kann durchaus angezweifelt und stattdessen auch als Anerkennung der wirtschaftlichen Leistungen am Vorabend der Industrialisierung bewertet werden. ${ }^{11}$

»Fern von gebildeten Menschen, am Ende des Reiches, wer hilft euch

Schätze finden und sie glücklich zu bringen an's Licht?

Bahlcke: Oberschlesien, 2015, S. 30-33, 43.

Vgl. für einen offenen Raumbegriff für Oberschlesien: ebd., S. 19.

Vgl. ebd., S. 43.

Gawrecki: Auf der Suche nach kollektiven Identitäten in Oberschlesien, 2015, S. 75.

Siehe: Rüther: Die deutschrechtliche Siedlung, 2015, S. 584f.

Vgl. Bahlcke: Oberschlesien, 2015, S. 33.

Siehe Kap. 6.3, S. 315 und S. $325 f$.

11 Vgl. für die Bedeutung der Dampfmaschine und Goethes für Oberschlesien: Kadłubek: Eine neue Minderheit? 2016, S. 88. Vgl. für eine negative Einordnung des Zitats: Bahlcke: Oberschlesien, 2015, S. 24 . 
Nur Verstand und Redlichkeit helfen; es führen die beiden

Schlüssel zu jeglichem Schatz, welchen die Erde verwahrt « ${ }^{12}$

Durch die reichen Vorkommen an Steinkohle, Eisenerz, Silber oder Blei wurde Oberschlesien zu einem der bedeutendsten Industriegebiete Europas im 19. und 20. Jahrhundert. Eine gezielte preußische Industriepolitik ließ die Region zum >Manchester Osteuropas« werden. Dies war verbunden mit allen positiven wie negativen Begleiterscheinungen: massiven sozialen Verwerfungen, Umweltverschmutzung und einem massiven Bevölkerungszuwachs sowie einer raschen Urbanisierung der Region. ${ }^{13}$ Das Dorf Kattowitz verwandelte sich so in wenigen Jahren zu einer bedeutenden Industriemetropole.

Eine oberschlesische Besonderheit war die im Vergleich zu anderen Industrieregionen des 1871 gegründeten Kaiserreichs schwache Sozialdemokratie, da der politische Katholizismus in engem Verbund mit der Interessenvertretung der polnischen Bevölkerung und ihrer Sprache sowie später in Teilen auch mit der polnischen Nationalbewegung tonangebend war. ${ }^{14}$ Der Kulturkampf Bismarcks wurde besonders in dieser Region als anti-polnisch und anti-katholisch zugleich wahrgenommen und führte bei der polnischsprachigen Bevölkerung zu einem Anwachsen des vormals schwachen Nationalbewusstseins. Diese Entwicklung wurde durch die Agitation und den Einfluss zugewanderter Polen aus den snational weiter entwickelten Regionen Posen und Galizien verstärkt. ${ }^{15}$ Trotz mahnender und vermittelnder Stimmen der Kirche und des Zentrums, dem es bis 1907 weitgehend gelang, mit polnisch-oberschlesischen Kandidaten die polnischen Oberschlesier zu vertreten, verschärfte auch die preußisch-deutsche Regierung den Germanisierungsdruck. ${ }^{16}$ Dennoch schien der Konflikt am Vorabend des Ersten Weltkrieges nicht unlösbar verschränkt. ${ }^{17}$ Nach der letzten Volkszählung vor dem Krieg im Jahr 1910 lag das Verhältnis bei etwa 53 Prozent polnisch- und 40 Prozent deutschsprachigen sowie 4 Prozent als zweisprachig klassifizierten Einwohnern. Eine klare nationale Zuordnung war damit nicht verbunden, fragten die Statistiken doch nur nach Mutter- und Umgangssprache. ${ }^{18}$ Wie sich auch in der Zwischenkriegszeit zeigen sollte, war die Anzahl der Menschen, die eine regionale oder sonstige Identifikation nationaler Eindeutigkeit vorzog, deutlich höher als von den nationalistischen Kräften behauptet, die diese freilich jeweils für ihre Seite einzunehmen versuchten. ${ }^{19}$

12 Zitiert nach: Kunicki: Schlesien, 2015, S. 220.

13 Vgl. für den Bereich der ökonomischen Entwicklung Oberschlesiens von der Frühindustrialisierung bis zum Ersten Weltkrieg: Greiner: Die Entwicklung der Wirtschaft, 2015, S. 431-449.

14 Gehrke: Vom Völkerfrühling bis zum Ersten Weltkrieg (1848-1918), 2015, S. 274-281.

15 Gawrecki: Auf der Suche nach kollektiven Identitäten in Oberschlesien, 2015, S. 83. Siehe auch: Wanatowicz: Germanisierung und großpolnische Agitation im 19. Jahrhundert, 2015, S. 602-610. Vgl. Struve: Germanisierung und großpolnische Agitation im 19. Jahrhundert, 2015, S. 593-601.

16 Vgl. zum Zentrum, den polnischen Parteien sowie der SPD ausführlich: Gehrke: Vom Völkerfrühling bis zum Ersten Weltkrieg (1848-1918), 2015, S. 265-284.

17 Vgl. Kunicki: Schlesien, 2015, S. 227.

18 Kaczmarek: Menschen, 2015, S. 65-67.

19 Masnyk: Provinz Oberschlesien (1918/19-1938/39), 2015, S. 298. Vgl. Wanatowicz: Germanisierung und großpolnische Agitation im 19. Jahrhundert, 2015, S. 610. 
Am Ende des Ersten Weltkrieges war die Zukunft Oberschlesiens unklar. Auf deutscher Seite ging man davon aus, dass die Zugehörigkeit zu Deutschland im Gegensatz $\mathrm{zu}$ anderen Gebieten nicht grundsätzlich infrage stand. Polnische Kräfte in sowie außerhalb Oberschlesiens versuchten nach Muster des erfolgreichen Posener Aufstandes mit den sogenannten drei Schlesischen Aufständen 1919, 1920 und 1921 Tatsachen zu schaffen und einen schnellen Anschluss an den neu entstandenen polnischen Staat zu erreichen. Auf Basis des Versailler Vertrages wurde 1921 ein Plebiszit durchgeführt, bei dem sich zeigte, dass das persönliche Selbstverständnis als Pole nicht automatisch in den Wunsch mündete, Teil eines polnischen Staates zu sein. ${ }^{20}$ In diesem stimmte die Mehrheit der Bewohner Oberschlesiens mit einem West-Ost- sowie Stadt-Land-Gefälle für eine Zugehörigkeit zu Deutschland. Dabei sind besondere Umstände, wie der zeitgleich stattfindende sowjetisch-polnische Krieg und wirtschaftliche Gesichtspunkte, zu berücksichtigen.

Dieses für Polen negative Ergebnis versuchten propolnische Kräfte innerhalb und außerhalb von Oberschlesien durch den letzten `Aufstand 1921 noch einmal im Sinne Polens zu entscheiden. Die wechselhaften militärischen Auseinandersetzungen wurden durch die Alliierten unterbunden und schließlich eine Teilung, rudimentär auf Basis der Abstimmungsergebnisse, zugunsten Polens durchgesetzt. Dabei verblieb der größere Teil bei Deutschland, allerdings ging das industrielle Kerngebiet mit den wichtigen Großstädten an Polen, obwohl gerade in den Städten eine große Mehrheit für den Verbleib bei Deutschland gestimmt hatte. Polak-Springer unterstreicht den offensiven und externen Charakter des polnischen Handelns im Gegensatz zum geläufigen polnischen Narrativ eines "grassroots uprising « der polnischen Oberschlesier. ${ }^{21}$ Hierin sieht er den »de facto first modern German-Polish war«, der das Klima zwischen den Staaten für den Rest der Zwischenkriegszeit vergiftete. ${ }^{22}$ Auch Tomann hinterfragt die gängige Erzählung der `schlesischen Aufstände «: »Die Bezeichnung ist insofern irreführend, als die Auseinandersetzungen vor allem von polnischen und deutschen Politikern außerhalb der Region angeheizt und von paramilitärischen Einheiten unterstützt wurden, die nur teilweise aus Oberschlesiern bestanden. ${ }^{23}$

Im Vorfeld der mit allen propagandistischen Mitteln erfolgten Abstimmung machten beide Seiten Oberschlesien Zugeständnisse. Im Deutschen Reich wurde Oberschlesien eine eigenständige preußische Provinz und in Polen erhielt die neu eingerichtete Województwo śląskie als einzige Woiwodschaft einen weitgehenden Autonomiestatus. ${ }^{24}$ Die zu jener Zeit durchgeführten Volkszählungen sind zu hinterfragen, scheinen sie doch beispielsweise im polnischen Teil ein rasches Verschwinden deutscher Bevölkerung erkennen zu lassen, obwohl dieses unter anderem mit den Wahlergebnissen für die deutschen Parteien in Dissonanz steht. ${ }^{25}$

20 Demshuk: Reinscribing Schlesien as Śląsk, 2012, S. 45.

21 Polak-Springer: Recovered Territory, 2015, S. 32.

22 Ebd.

23 Tomann: Geschichtskultur im Strukturwandel, 2016, S. 141.

24 Vgl. ausführlich zur Entwicklung der Woiwodschaft Schlesien 1922-1939: Wanatowicz: Woiwodschaft Schlesien, 2015, S. 318-333.

25 Auch wenn zu berücksichtigen ist, dass viele Oberschlesier aus Unzufriedenheit mit der polnischen Herrschaft und aktuellen politischen Entwicklungen die deutschen Parteien wählten, ohne 
Sowohl in Deutschland als auch in Polen waren Politik und Gesellschaft unzufrieden mit der Grenzziehung, woraufhin die Regierungen mit geo- und wirtschaftspolitischen Mitteln eine Revision anstrebten. ${ }^{26}$ Polak-Springer spricht von einem »territorial cold war «. ${ }^{27}$ Damit verbunden war eine intensive geschichtspolitische Kulturarbeit, in deren Folge das erste Schlesische Museum im nunmehr polnischen Katowice sowie ein Pendant auf deutscher Seite in Beuthen entstanden. ${ }^{28}$ Ein letztes Mal verschärfte sich der geschichtswissenschaftliche Kampf um die Vergangenheit Oberschlesiens nach 1933. Zugleich nahm der Druck auf die jeweiligen nationalen Minderheiten zu.

Die NS-Propaganda inszenierte am 31. August 1939 den Überfall auf den Sender Gleiwitz durch als polnische Angreifer ausgegebene SS-Kräfte und nutzte so den deutsch-polnischen Konflikt um die Zugehörigkeit Oberschlesiens als Rechtfertigung für den Krieg mit Polen. ${ }^{29}$ Im Dezember 1939 gaben bei einem von den Deutschen initiierten Zensus zur ersten `Ordnung der Provinz 95 Prozent die deutsche Volkszugehörigkeit an. ${ }^{30}$ Die hohe Zustimmung dürfte sich vor allem mit der völligen polnischen Niederlage erklären lassen, die ein Arrangement mit der neuen Herrschaft sinnvoll erscheinen ließ. ${ }^{31}$

Die Deutsche Volksliste (DVL) diente ab 1941 der Einordnung und `Germanisierung، der Bevölkerung. Über diese hatten auch Menschen mit keinem oder nur teilweisen >deutschem Hintergrund die Möglichkeit, sich zumindest im Ansatz zum >Deutschtum $>$ zu bekennen. Alle nicht in die DVL aufgenommenen Oberschlesier sollten mittelfristig in das Generalgouvernement >umgesiedelt « werden. Neben dem >Angebot an die Bevölkerung zur Anpassung wurde häufig auch Druck ausgeübt, wenn Menschen sich einem Bekenntnis zu Deutschland verweigerten. Schließlich bedeutete eine Zuordnung zur Kategorie 1 und 2 die Pflicht zum Dienst in der Wehrmacht, welcher spätestens nach Stalingrad und dem gesteigerten >Personalbedarf^ der Wehrmacht immer unbeliebter wurde. ${ }^{32}$

Die vergleichsweise moderate NS->Bevölkerungspolitik in Oberschlesien ermöglichte es den meisten polnischen Oberschlesiern und Menschen mit wechselnden nationalen Identitäten im Rahmen der DVL unterzutauchen. Dennoch wurde eine große Zahl von Polen, besonders nach 1918/19 Zugezogene, deportiert. ${ }^{33}$ Viele Mitglieder der

sich selbst unbedingt als Deutsche zu sehen: Polak-Springer: Recovered Territory, 2015, S. 38f. Vgl. Kaczmarek: Menschen, 2015, S. 67-69. Vgl. auch: Borodziej: Ceschichte Polens im 20. Jahrhundert, 2010, S. 169.

26 Mühle: Geschichtspolitik und polnischer»Westgedanke« in der Wojewodschaft Śląsk, 2003, S. 412.

27 Polak-Springer: Recovered Territory, 2015, S. 9.

28 Mühle: Ceschichtspolitik und polnischer »Westgedanke« in der Wojewodschaft Śląsk, 2003, S. $425 f$.

29 Kaczmarek: Der Zweite Weltkrieg, 2015, S. $384 f$.

30 Zwei Drittel der Bevölkerung beteiligten sich. Davon erklärten 78 Prozent Deutsch als ihre erste Sprache.

31 Vgl. Polak-Springer: Recovered Territory, 2015, S. 145f.

32 Kaczmarek: Der Zweite Weltkrieg, 2015, S. 354-357. Vgl. Gawrecki: Auf der Suche nach kollektiven Identitäten in Oberschlesien, 2015, S. 92.

33 Die geplanten Massendeportationen wurden aufgrund der Kriegslage nicht mehr durchgeführt, aber allein aus dem Regierungsbezirk Kattowitz bereits 80.000 Menschen deportiert: Kaczmarek: Der Zweite Weltkrieg, 2015, S. 355f. 
kleinen, aber für die industrielle Entwicklung besonders bedeutenden Gemeinde der oberschlesischen Juden wurden im Holocaust ermordet. ${ }^{34}$

Die Abhängigkeit von einer problemlosen Funktion der >Rüstungsschmiede des Reiches`sowie die zunehmend angespannte Kriegslage ließen alle Germanisierungspläne, den aufgenommenen Kampf gegen die katholische Kirche und weitere symbolpolitische Kämpfe im Ansatz stecken bleiben. Die Pläne für sgründliche Selektionen der Bevölkerung verschwanden für die Zeit nach dem >Endsieg` in der Schublade. So wurde der Einsatz der polnischen Sprache nicht offiziell verboten, gleichwohl propagandistisch bekämpft. ${ }^{35}$ Dennoch fielen dem nationalsozialistischen Terror im Gebiet Oberschlesiens unzählige Menschen zum Opfer, ebenso wie Oberschlesien als Industrielandschaft ein Ort brutaler Zwangsarbeit war. In dem über die Grenzen der ehemaligen Provinz hinausgehenden Gau Oberschlesien befand sich das Konzentrations- und Vernichtungslager Auschwitz.

Polnische Widerstandsgruppen der Heimatarmee organisierten sich auch in Oberschlesien, obgleich die geographische und demographische Ordnung des Raumes keine größeren militärischen Partisanenaktionen wie andernorts zuließ und sich auf Informationsdienste und Sabotage beschränkte. ${ }^{36}$ Oberschlesien blieb im Zweiten Weltkrieg zunächst weitgehend unzerstört, da es erst spät von den alliierten Bomberströmen erreicht und schließlich 1945 ohne sehr schwere Kämpfe von der Roten Armee erobert wurde. Viele der dennoch erfolgten Zerstörungen sind auf die Vernichtung von Infrastruktur durch die Wehrmacht beim Rückzug und auf Plünderungen und andere Gewaltakte der Roten Armee zurückzuführen. ${ }^{37}$

Nach Linek und Lotz lässt sich die Zwangsmigration der Deutschen aus Oberschlesien in fünf Phasen unterteilen: Evakuierung, (chaotische) Flucht, Vertreibung, Umsiedlung und Familienzusammenführung. Diese letzte Phase dauerte bis 1989 und darüber hinaus an. ${ }^{38}$ Die nationalsozialistischen Autoritäten setzten Evakuierungspläne für die deutsche Bevölkerung nur eingeschränkt um und ordneten diese der Aufrechterhaltung der Industrieproduktion unter. Dennoch konnten etwa 750.000 Menschen, zumeist mit dem Zug, Oberschlesien verlassen. Insgesamt handelte es sich wohl um 1,5 Millionen, die unter unterschiedlichsten Bedingungen nach Mittel- und Süddeutschland sowie Böhmen evakuiert wurden. ${ }^{39}$ Ein massives Überrollen der deutschen Front fand anders als in den nördlichen und westlichen Gebieten nicht statt; damit konnten Flüchtlingstrecks und Züge Oberschlesien häufig ohne sowjetische Übergriffe sowie ohne die Gefahr direkter Kampfhandlungen verlassen. Dort, wo die Rote Armee einmar-

Vgl. zur Ermordung der oberschlesischen Juden: Kaczmarek: Der Zweite Weltkrieg, 2015, S. 357359.

Siehe für die Ansätze, erstes Scheitern sowie weitere Planungen der nationalsozialistischen >Cermanisierung ( Oberschlesiens ausführlich: Polak-Springer: Recovered Territory, 2015, S. 147-175. 
schierte und auf Zivilbevölkerung traf, plünderten, mordeten und vergewaltigten die sowjetischen Soldaten oft unabhängig vom nationalen Hintergrund ihrer Opfer. ${ }^{40}$

Für die verbliebenen Oberschlesier sind diese Ereignisse als »Oberschlesische Tragödie« bekannt. Neben dem Terror der Roten Armee hat sich besonders die Deportation vieler Oberschlesier zur Zwangsarbeit in die Sowjetunion - von der Tausende nicht zurückkehrten - in das regionale Gedächtnis eingeschrieben. ${ }^{41}$ Die Sowjetunion nahm in den Gebieten, zumal in den ehemaligen Reichsgebieten Oberschlesiens, zunächst keine Rücksicht auf nationale Differenzen und behandelte die Bevölkerung so wie in anderen deutschen Gebieten auch. Bergleute als >lebendige Reparationszahlung، waren von besonderem Interesse. Das Bündnis mit der Sowjetunion verbat die Thematisierung dieser Ereignisse in Polen bis 1989, sie blieben aber regional und im Familiengedächtnis präsent.

Gemäß den Planungen Stalins und den vorläufigen Vereinbarungen der Alliierten übernahm die nun kommunistisch dominierte Verwaltung die alte Woiwodschaft Schlesien sowie die den Polen zugesprochenen Westgebiete. Bereits vor dem Potsdamer Abkommen wurde mit den >wilden Vertreibungen durch die Rote Armee und polnische Milizen begonnen und von polnischen Politikern deutlich gemacht, dass die Deutschen in diesen Gebieten keine Zukunft mehr haben würden. Als Ziel gaben die neuen polnischen Autoritäten aus, dass bis zum Juli 1945 alle Deutschen aus dem öffentlichen Leben der Region zu verschwinden hätten. Eine der dafür im Juni 1945 in Oppeln und Umgebung angeordneten Maßnahmen war die Internierung aller gesunden Männer in Lagern. ${ }^{42}$

Oberschlesien ist insofern ein Sonderfall, als dass, ähnlich wie bei den Kaschuben und Masuren in West- und Ostpreußen, die permanente Präsenz einer slawischen Bevölkerung den Anspruch Polens auf diese Gebiete international rechtfertigen sollte, ebenso wie die >deutschen Oberschlesier als Fachkräfte für die Industrie von Interesse waren. ${ }^{43}$ Daher wurde den Oberschlesiern durch ein Verifikationsverfahren die Möglichkeit des Bleibens geboten. ${ }^{44}$ Ähnlich wie bei der DVL ermöglichte dieses Verfahren den Bewohnern, abgesehen von den fraglos politisch Belasteten und zugezogenen Reichsdeutschen, das Bleiben auf Grundlage eines Bekenntnisses zum >Polentum $\prec .{ }^{45}$ Dieser Schritt erforderte freilich eine weitgehende öffentliche Verdeckung ihrer Identität und der Bindung an die >deutsche< oder deutsch-oberschlesische Kultur. Dennoch sollte die Gewalttätigkeit dieser Polonisierungsprogramme nicht unterschätzt werden. ${ }^{46}$ Bei vielen zunächst Verbliebenen setzte sich schon bald der Wunsch nach

40 Vgl. Węgrzyn: »Mikrokosmos« und »große Weltpolitik«, 2015, S. 165-167. Siehe auch: Dziurok; Linek: Im kommunistischen Polen, 2015, S. 367.

41 Vgl. Polak-Springer: Recovered Territory, 2015, S. 186.

42 Dziurok; Linek: Im kommunistischen Polen, 2015, S. 373.

43 Polak-Springer zieht hierbei wieder Parallelen zur NS-Herrschaft in Oberschlesien: PolakSpringer: Recovered Territory, 2015, S. 11.

44 Vgl. Dziurok; Linek: Im kommunistischen Polen, 2015, S. $376 \mathrm{f}$.

45 Vgl. zur Verifizierung als Gegenpart der DVL: Polak-Springer: Recovered Territory, 2015, S. 12. Siehe auch: Tomann: Geschichtskultur im Strukturwandel, 2016, S. $157 \mathrm{f}$.

Vgl. Polak-Springer: Recovered Territory, 2015, S. 12. 
Auswanderung durch, der durch den direkten und indirekten Druck bedingt war. ${ }^{47}$ Wie in den anderen Westgebieten sollten nicht nur die Deutschen in der Öffentlichkeit, sondern auch alle Spuren deutscher Kultur beseitigt werden, was bei den mit der deutschen Kultur verbundenen Oberschlesiern zu Konflikten führte und die Motivation vieler zur >freiwilligen Ausreise erhöhte. ${ }^{48}$

Neben der Diskriminierung, den Plünderungen und Ausschreitungen sowie der Ablehnung des kommunistischen Herrschaftssystems, erlangten die zumeist von den Nationalsozialisten übernommenen Lagersysteme, in denen Oberschlesier vorübergehend zur Kontrolle oder im Rahmen des Prozesses der Vertreibung interniert wurden, traurige Bekanntheit in der Region und in Deutschland. Zugleich waren sie ein Element der propagandistischen Auseinandersetzungen. ${ }^{49}$ Die hohen Todeszahlen in den Lagern sind nicht nur durch schlechte Lebensbedingungen, sondern auch durch brutale Übergriffe zu erklären. ${ }^{50}$ In den zeitgenössischen polnischen Verwaltungsquellen sprach man selbst von »Konzentrationslagern«. Bischof Bolesław Kominek, der später den Versöhnung suchenden Brief der polnischen Bischöfe von 1965 federführend verfasste, beklagte bereits im Januar 1946 nach der Beisetzung deutscher Opfer des Lagers Lamsdorf/Łambinowice in einem Brief an den schlesischen Woiwoden die Methodengleichheit von Polen und Deutschen. ${ }^{51}$ Im Gegensatz zu damaligen und späteren Behauptungen handelte es sich bei den Internierten nicht ausschließlich um Männer und NS-Täter, sondern vielfach um Unschuldige und um Frauen und Kinder aus der Umgebung. ${ }^{52}$

Die neue kommunistische Führung in Polen konnte in Bezug auf antideutsche Agitation in Oberschlesien beinahe nahtlos an die von beiden Seiten wechselhaft entwickelte und eskalierte nationalistische Vorkriegsrhetorik anschließen und sich als Vollstrecker der piastischen Idee und >Befreier ganz Oberschlesiens inszenieren. ${ }^{53}$

Nachdem die Woiwodschaft Schlesien bereits in der Zwischenkriegszeit von einer starken Zuwanderung aus anderen polnischen Gebieten geprägt war, gab es nun eine erneute Einwanderungswelle aus Zentralpolen sowie den verlorenen polnischen Ostgebieten..$^{54}$ Besonders die >Glücksritter<, die auf schnelle Beute bei den von den Deutschen verlassenen oder noch zu verlassenden Besitztümern aus waren, sorgten wie andernorts für Unmut und Angst. ${ }^{55}$

47 So wanderten viele sich selbst vorher als Polen >verifizierte`Menschen nach Westen ab: Madajczyk: Der Transfer der deutschen Bevölkerung aus dem Oppelner Schlesien, 1999, S. $283 f$., 287.

48 Vgl. Świder: Die Entgermanisierung Oberschlesiens nach 1945, 2014, S. 69-87.

49 Vgl. Kopka: Deutsche und Polen in den Arbeitslagern, 2015, S. 101-110.

50 Strauchold: Die »Wiedergewonnenen Gebiete«, 2005, S. 316.

51 Vgl. ausführlich zu den polnischen Lagern in Oberschlesien, hier v.a. das Lager Lamsdorf und deren Nachleben in der Bundesrepublik und der VRP: Linek: Lamsdorf, 2014, S. 365-377. Siehe auch: Dziurok; Linek: Im kommunistischen Polen, 2015, S. 373. Siehe zum Brief der Bischöfe: Kap. 4.3, S. $171 f$.

52 Dziurok; Linek: Im kommunistischen Polen, 2015, S. 374.

53 Polak-Springer: Recovered Territory, 2015, S. 82. Polak-Springer spricht hier prägnant von »The Communist-Nationalist Alliance (S. 190-197).

54 Vgl. Tomann: Geschichtskultur im Strukturwandel, 2016, S. $158 f$.

55 Vgl. Cołasz: Antideutsche Politik in Zabrze in den Jahren 1945 bis 1949, 2015, S. 201. 
Der stalinistischen Doktrin entsprechend, forcierten die neuen kommunistischen Autoritäten in Oberschlesien nach den ersten Wiederaufbaumaßnahmen die weitere Schwerindustrialisierung sowie die umfassende Ausbeutung aller Ressourcen. ${ }^{56}$ Die einheimischen und verbliebenen Oberschlesier mussten ihre Sonderidentitäten besonders im Stalinismus und auch danach weiterhin verstecken. Der Gebrauch der deutschen Sprache oder die Anerkennung einer regionalen oberschlesischen oder deutschen Identität war bis zum Ende der Volksrepublik unerwünscht und auf den privaten Kreis beschränkt. Die starke Zuwanderung sowie die durch den äußeren Druck häufig unterbrochene Weitergabe familiärer Traditionen führte zu einem öffentlichen und vielerorts auch zum privaten Verschwinden oberschlesischer Identität. Dies wurde nochmals verstärkt durch die zu verschiedenen Zeitpunkten ermöglichte Ausreise von Oberschlesiern zumeist in die Bundesrepublik Deutschland..$^{57}$ Der Volksrepublik gelang es schließlich nicht, der einheimischen oberschlesischen Bevölkerung ein attraktives Identitätsangebot zu machen, und in Kombination mit wirtschaftlichen und politischen Motiven entdeckten viele Menschen ihr >Deutschtum $<$ wieder. ${ }^{58}$

In der Bundesrepublik hatten sich viele Oberschlesier bereits seit 1945 organisiert, ab den 1950er Jahren in den Landsmannschaften. Jenseits der politischen Ebene halfen die unzähligen Ortsgruppen, ihre Erinnerungen und >Brauchtümer auszutauschen und weiterzuleben. Ähnlich wie die Dachorganisation des BdV erlitten die Landsmannschaften in den 1970er und 1980er Jahren einen massiven Bedeutungsverlust, sodass auch in der Bundesrepublik die Region Oberschlesien in weiten Teilen der Bevölkerung mit der Zeit zunehmend in Vergessenheit geriet. Dennoch darf nicht übersehen werden, dass Hundertausende Menschen mit oberschlesischer Identität fern der Heimat lebten und leben.

Die öffentliche Negierung der Existenz jeglicher deutscher Minderheit in der Volksrepublik ebenso wie der einer regionalen oberschlesischen Sonderidentität ließ viele Polen 1989 überrascht auf Tausende von Angehörigen der deutschen Minderheit blicken. Ablehnung und Furcht gegenüber den >Volksdeutschen dass diese ein beliebtes Instrument in Form einer negativen Projektionsfläche der volkspolnischen Propaganda waren. ${ }^{59}$ Die Minderheit zeigte sich öffentlichkeitswirksam im November 1989 anlässlich des Besuches von Helmut Kohl in Kreisau/Krzyżowa, bei dem dieser mit dem polnischen Ministerpräsidenten Tadeusz Mazowiecki eine Versöhnungsmesse feierte. Unter anderem grüßten ihn die überwiegend aus Oberschlesien kommenden Deutschen mit Plakaten wie »Helmut, Du bist auch unser Kanzler«, was leicht missverstanden werden konnte und wurde. ${ }^{60}$

Von den etwa eine Million Menschen, die sich 1989/1990 zur deutschen Bevölkerungsgruppe in Polen bekannten und die vor allem im ehemaligen Oberschlesien ansäs-

56

Vgl. für einen knappen Überblick der Wirtschaftsgeschichte Oberschlesiens vom Zweiten Weltkrieg bis heute: Greiner: Die Entwicklung der Wirtschaft, 2015, S. 459-463.

57

Dziurok; Linek: Im kommunistischen Polen, 2015, 390f.

Mühle: Geschichtspolitik und polnischer»Westgedanke« in der Wojewodschaft Śląsk, 2003, S. 426. Siehe auch: Polak-Springer: Recovered Territory, 2015, S. 219.

Vgl. Król: Das Bild des ethnischen Deutschen im polnischen Film, 2006, S. 387-389.

Wiatr: Deutsch sein in Polen, 2016, S. 61f. Vgl. zu den Implikationen des Geschehens: Kap. 4.3, S. $177 f$. 
sig waren, emigrierten allerdings viele im Laufe der folgenden Jahre in die Bundesrepublik. ${ }^{61}$ Ebenso blieb eine von manchen befürchtete politische Erneuerung des Kampfes um Oberschlesien aus, vielmehr zeichnete sich eine durchaus gut entwickelnde Zusammenarbeit im Zusammenleben von Minderheit und Mehrheit ab. Hilfreich hierfür sind eine starke regionale Identität sowie das Vorhandensein von Mehrfachidentitäten. Zusätzlich stellten die deutsch-polnischen Verträge sowie polnische Selbstverpflichtungen die Minderheitenrechte auf eine solide Grundlage. ${ }^{62}$

Gleichzeitig konnte die erneute Entstehung einer zunehmend bedeutenderen oberschlesischen Autonomiebewegung beobachtet werden, die sich wie ihre historischen Vorläufer auf eine Identität jenseits von >deutsch oder >polnisch beruft. Bei der Volkszählung von 2011 gaben auf dem historischen Gebiet Oberschlesiens 817.000 Menschen eine schlesische Nationalität an, davon etwa 362.000 nur diese, 423.000 in Verbindung mit der polnischen und 33.000 mit einer anderen, meist der deutschen Nationalität. ${ }^{63}$ Diese Zahlen sollten jedoch nicht darüber hinwegtäuschen, dass in Oberschlesien viele Polen mit keiner, einer schwachen oder einfach nur einer anderen regionalen Identifizierung in der Region leben. ${ }^{64}$ Äußerungen, wie die des ehemaligen Erzbischofs von Oppeln, Alfons Nossol, dürfen daher nicht einfach verallgemeinert werden:

»It is equally important to keep the three dimensions of Silesian culture as something to be proud of, rather than a reason to be accused of harbouring pro-Polish, pro-Czech or pro-Cerman inclinations been proven to soften the brutality of nationalistic encounters [...].

[...] For me, being a Pole is simply not enough. I have felt the beating of three hearts in my chest for a long time: Polish, German, and Moravian-Czech. ${ }^{65}$

Für Schlesien und seine Verbindung mit der deutschen, polnischen und tschechischen Geschichte gilt heute schließlich, dass die Region in Deutschland ein »imaginary land «, in Tschechien trotz der offiziellen Dreigliedrigkeit des Staates - Böhmen, Mähren und Mährisch-Schlesien - wenig beachtet und in Polen am präsentesten ist, aber aufgrund seiner Vergangenheit und seiner sich auch politisch artikulierenden Diversität ambivalent betrachtet wird. ${ }^{66}$

61 Vgl. Rogall: Die Deutschen in Polen, 2005.

62 Wiatr: Deutsch sein in Polen, 2016, S. 62-65.

63 Kaczmarek: Menschen, 2015, S. 71.

64 Vgl. für die grundsätzlichen Probleme zwischen alteingesessenen Oberschlesiern und nach 1945 zugezogenen Polen in Bezug auf die Ceschichte und Identität Oberschlesiens: Karwat: Im schlesischen Kessel brodelt es, 2013, S. 84.

65 Dialog jest językiem macierzystym ludzkości/Dialogue is the Mother Tongue of Humanity, 2016, S. 58 .

66 Táborský: Creating Silesian Identity, 2018. 


\subsection{Schlesisches Museum zu Görlitz}

\subsubsection{Geschichte}

Ein Kuriosum der schlesischen Museumsgeschichte sind die Pläne des Görlitzer Stadtrates unmittelbar nach dem Kriegsende, ein Schlesisches Museum in Görlitz einzurichten. Die politischen Verhältnisse in der SBZ machten diesen Plänen jedoch bald ein Ende und ließen die staatliche Erinnerung in der DDR an ein deutsches Schlesien bis 1989 weitgehend verschwinden. ${ }^{67}$

Im Westen begannen die Schlesier trotz der anfänglich großen Hoffnung auf Rückkehr schon bald nach Kriegsende mit der musealen Sammlung geretteter Gegenstände. Sinnbildlich hierfür sind die vielerorts entstandenen Heimatstuben. Auch wenn die Landsmannschaft den Rückkehrwillen lange nicht aufgab, erkannte man in den 1970er Jahren, dass eine Fokussierung, Modernisierung und Zentralisierung der Kulturarbeit notwendig waren. Ähnlich den Planungen anderer Landsmannschaften sollte ein die alte Heimat repräsentierendes Museum geschaffen werden. Die neue Bundesregierung aus CDU/CSU und FDP machte sich diese Vorschläge nach ihrer Regierungsübernahme 1982 in der Neujustierung der Vertriebenenförderung zu eigen. ${ }^{68}$

Langwierige Planungen für ein Schlesisches Museum in Hildesheim scheiterten 1990 an der neuen rot-grünen Landesregierung unter Gerhard Schröder in Niedersachsen. ${ }^{69}$ Die Wiedervereinigung ermöglichte es aber, das Pommersche wie das Schlesische Museum nun in den bei Deutschland verbliebenen Teilen dieser Regionen zu verwirklichen. ${ }^{70}$ Auch wenn das Görlitzer Museum die Idee eines schlesischen Zentralmuseums verwirklichen sollte, bestehen die schon existierenden Einrichtungen zur schlesischen Geschichte in der Bundesrepublik, wie das »Haus Schlesien« in Königswinter, weiter. 1998 eröffnete zudem der Neubau des seit 1983 existierenden Oberschlesischen Landesmuseums in Ratingen. ${ }^{71}$

Der anfänglichen Euphorie der 1990er Jahre folgten auch hier die Mühen der Ebene. Der dem Schlesischen Museum von der Stadt Görlitz überlassene Schönhof musste grundlegend und unter schwierigen denkmalschützerischen Bedingungen saniert werden. Auch die personelle und professionelle Ausstattung des Hauses war lange nicht ausreichend. Mit der Gründung einer Museumsstiftung 1996 und der Berufung des Gründungsdirektor Markus Bauer ${ }^{72} 1999$ konnten die Arbeiten dann entscheidend vor-

67 Bauer: Schlesien im Museum, 2012, S. 62

68 Ebd., S. 6of. Bauer: Das Schlesische Museum, 2006, S. $14 f$.

69 Bauer: Schlesien im Museum, 2012, S. 61f.

70 Görlitz wurde erst 1815 Teil einer schlesischen Region, nämlich der preußischen Provinz Schlesien. Dennoch entwickelte sich in der Stadt seitdem eine niederschlesische Identität.

71 Vgl. Bauer: Schlesien im Museum, 2012, S. 60-63. Vgl. zum Museum in Ratingen auch: PetersSchildgen: Die museale Darstellung der Geschichte Schlesiens in der Bundesrepublik Deutschland am Beispiel des Oberschlesischen Landesmuseums in Ratingen, 2008.

72 Im Tagesspiegel heißt es über den 1955 geborenen Bauer, er sei »im besten Sinn ein Kind des linksprogressiven Zeitgeistes der alten Bundesrepublik«, dessen Interesse an Schlesien durch das akademische Desinteresse der salten Bundesrepublikı geweckt wurde: Decker: Hinter den Kulissen. Der Tagesspiegel. 26.11.2017. 
angebracht und 2001 erste Ausstellungsaktivitäten entfaltet werden. ${ }^{73}$ Im Mai 2006 eröffnete schließlich die Dauerausstellung.

Die für das Museum entwickelte politische Struktur reduzierte im Vergleich zu den Hildesheimer Planungen den Einfluss der Schlesischen Landsmannschaft. Zuvor hatte der bekannte Vertriebenenpolitiker und langjährige Präsident der Landsmannschaft Herbert Hupka das Projekt seit den 1970ern »als exklusive Erinnerungs- und Wiedergutmachungsstätte der 3,2 Millionen deutschstämmigen Vertriebenen« vorangetrieben. ${ }^{74}$ Bei der Eröffnung der ersten temporären Ausstellung 2001 bedauerte er zunächst, dass es zu keinem weiteren deutschen "Bindestrich-Staat « "SachsenNiederschlesien « gekommen sei. Das Museum habe aber nun einen geeigneten Standort an der "Ader des Landes Schlesien «, der Oder, gefunden. ${ }^{75}$

Hupka vertrat die in der Dauerausstellung schließlich nur am Rande aufgegriffene Perspektive, dass im Museum das weitere Schicksal der deutschen Schlesier ebenso wie das der heutigen Bewohner der Region behandelt werden sollte. ${ }^{76}$ Bei der Eröffnung 2006 rekapitulierte er noch einmal die Diskussion um die Bezeichnung des Museums. So wurde von Seiten der Vertriebenen der Name "Landesmuseum Schlesien« bevorzugt (ähnlich dem Pommerschen oder Westpreußischen Landesmuseum), was aber auf Widerspruch von polnischer Seite stieß, die in der "Absolutheit des Namens « verdeckte oder zumindest missverständliche Ansprüche erkannte. Schließlich trägt auch das schlesische Museum in Troppau/Opava diesen Namen (Slezské zemské muzeum). Mehrheitlich entschieden die Gründungsakteure sich schließlich für den weniger umstrittenen Titel. ${ }^{77}$

Der Nachfolger an der Spitze der Landsmannschaft, Rudi Pawelka, war ebenfalls bei der Eröffnung 2006 als Ehrengast zugegen. In Polen ist dieser als Aufsichtsratsvorsitzender der Preußischen Treuhand eine umstrittene Persönlichkeit. ${ }^{78}$ So wurden Äußerungen und Einflussnahmen von Rudi Pawelka in Bezug auf das Schlesische Museum auch von polnischer Seite kritisiert, die ihm eine fortgesetzte revisionistische Agenda unterstellte. ${ }^{79}$ Markus Bauer distanzierte sich in der polnischen Presse deutlich von Pawelka: »Die Ansichten Pawelkas haben mit denen des Museums nichts gemein - betont der Direktor. ${ }^{80}$ Die Arbeit des Museums unter der fortgesetzten Leitung von Markus Bauer ist seit seiner Eröffnung ohne Kontroversen verlaufen.

\subsubsection{Struktur und Aktivitäten}

Das Schlesische Museum zu Görlitz (SMG) gehört zu den Einrichtungen, die gemäß der Kultur- und Wissenschaftsförderung nach Paragraph 96 des Bundesvertriebenengeset-

Bauer: Das Schlesische Museum, 2006, S. 15f. Bauer: Auf halbem Weg, 2001, S. 18.

Zajonz: Ein Schloss für viele Schlüssel. Der Tagesspiegel. 11.06.2006. Vgl. Bauer: Schlesien im Museum, 2012, S. $61 \mathrm{f}$.

Hupka: Grußworte, 2001, S. 9.

Ebd.

Grußwort von Dr. Herbert Hupka, 2006, S. 16.

Vgl. Zajonz: Ein Schloss für viele Schlüssel. Der Tagesspiegel. 11.06.2006. Vgl. Kap. 5.1, S. $205 f$.

Semka: O nas za nas. Wprost. 25.06.2006.

»Poglądy Pawelki nie mają z muzeum nic wspólnego - zaznacza dyrektor.« Ebd. 
zes gefördert werden. ${ }^{81}$ In diesem verpflichten sich die Bundesrepublik sowie ihre Länder und Kommunen zur dauerhaften Förderung der Kultur der Vertriebenen und ihrer Herkunftsregionen, die im Sinne einer grenzüberschreitenden Arbeit mittlerweile wesentlich weiter verstandenen wird. Dementsprechend unterliegen die geförderten Einrichtungen einer vorgegebenen politischen Rahmung. Je nach Institution unterscheidet sich diese aber, da die konkrete Aufsichts- und Führungsstruktur jeweils anders gestaltet ist. Das Team des SMG kann innerhalb der von den beteiligten Partnern festgelegten »overall parameters « in seiner Ausstellungsgestaltung autonom operieren. ${ }^{82}$ Die geförderten >ostdeutschen < Landesmuseen verstehen sich nicht als spezifische >Vertreibungsmuseen<, sondern sehen sich vielmehr einem umfassenden Ansatz verpflichtet, in dem die Vertreibung nur ein - wenn auch zentrales - Element ist. ${ }^{83}$

Der Einfluss der Landsmannschaft und ihrer Akteure auf das SMG ist vergleichsweise gering. In der Trägerstiftung des Museums sind die Bundesrepublik Deutschland, der Freistaat Sachsen, die Stadt Görlitz und die Landsmannschaft Schlesien vertreten. ${ }^{84}$ Die Parteien sind im Stiftungsrat gleichberechtigt, sodass die Landsmannschaft Schlesien über ein Viertel der Stimmen verfügt. ${ }^{85}$ Der laufende Etat des Museums wird jeweils zur Hälfte von der Bundesrepublik und vom Land Sachsen übernommen. Die Stadt Görlitz beteiligt sich durch die Bereitstellung des Museumsgebäudes und dessen baulicher Instandhaltung. ${ }^{86}$ Der Beitrag des Bundes betrug 2015 und 2016 jeweils 494.000 Euro, sodass der jährliche Gesamtetat etwa eine Millionen Euro ausmacht. ${ }^{87}$ Die Gesamtkosten bis zur Ausstellungseröffnung werden in der Rzeczpospolita mit fast 20 Millionen Euro angeben. ${ }^{88}$

Die Dauerausstellung des Schlesischen Museums verfügt über etwa 1950 Quadratmeter Ausstellungsfläche, auf der rund 1000 Objekte ausgestellt werden. ${ }^{89}$ Einschließlich des Direktors hat das Haus sechs Wissenschaftliche Mitarbeiter, darunter eine $\mathrm{Mu}$ seumspädagogin. ${ }^{90}$ Das Kulturreferat Schlesien, eine 2002 in der vom Paragraph 96 BVFG vorgegebenen Form geschaffene Einrichtung, die in Anlehnung und Kooperation mit

81 Vgl. für einen Überblick zum Paragraphen 96: Weber: Kultur- und Wissenschaftsförderung nach $\S$ 96 BVFG, 2012. Siehe auch: Kap. 5.1, S. 219f.

82 Graaf: After the Expulsions, 2014, S. 247.

83 Bauer: Flucht und Vertreibung in den Regionalmuseen, 2010, S. 43. Vgl. für einen kurzen Überblick über Heimatstuben und ostdeutsche Museen in der Bundesrepublik: Henkel; Scheele et al.: Lokalität als Thema, 2016, S. 108-110.

84 Bauer: Das Schlesische Museum, 2006, S. 13. Vgl. Táborský: Creating Silesian Identity, 2018.

85 Vgl. Graaf: After the Expulsions, 2014, S. 247. Vgl. für die aktuelle Zusammensetzung des Stiftungsrates, indem mittlerweile - nachdem man eine Mitarbeit aufgrund der Präsenz Rudi Pawelkas zunächst ablehnte (ebd.) - auch verschiedene Vertreter aus Polen mitwirken, die Website des Museums: www.schlesisches-museum.de/index.php?id=1223 (letzter Zugriff: 27.11.2017).

86 Bauer: Schlesien im Museum, 2012, S. 62.

87 Die Beauftragte der Bundesregierung für Kultur und Medien: Bericht der Bundesregierung über die Maßnahmen zur Förderung der Kulturarbeit gemäß § 96 Bundesvertriebenengesetz (BVFG) in den Jahren 2015 und 2016, 2017, S. 10.

88 Jendroszczyk: Pamięć ziem utraconych. Rzeczpospolita. 13.05.2006.

89 hg merz architekten museumsgestalter: Schlesisches Museum, 2008, S. $190 \mathrm{f}$.

90 Vgl. für die aktuelle Stellenbesetzung und die verschiedenen Aufgabenbereiche der Mitarbeiter: http://schlesisches-museum.de/index.php?id=1178 (letzter Zugriff: 16.04.2018). 
den verschiedenen nach diesem Paragraphen geförderten Einrichtungen grenzüberschreitende kulturelle Breiten- und Vernetzungsarbeit leistet, ist mit einer Stelle an das Haus angegliedert und mit eigenen Veranstaltungen oder Kooperationsveranstaltungen präsent. ${ }^{91}$

Der Wissenschaftliche Beirat, der sich derzeit aus sieben Personen zusammensetzt, soll die wissenschaftliche Qualität und weitere Entwicklung sichern. ${ }^{92}$ Zwei Vertreter kommen aus Polen, darunter Ewa Chojecka, die auch am Muzeum Śląskie in Kattowitz mitwirkt. Seit Beginn seines Bestehens kooperiert das Schlesische Museum mit Partnern in Polen und Tschechien. So werden verschiedentlich Sonder- und Wanderausstellungen des Hauses in den Nachbarländern präsentiert und gemeinsame Ausstellungsprojekte verwirklicht. ${ }^{93}$

Das Schlesische Museum musste seine Arbeit ohne eine gewachsene historische Sammlung beginnen, die eigene konnte erst ab 1999 systematisch ausgebaut werden. Dabei half die Entscheidung der Bundesregierung, schlesische Kulturgüter im Bundeseigentum aus westdeutschen Museen und Sammlungen als Dauerleihgabe in das Schlesische Museum zu überführen. ${ }^{94}$ Bis zur Eröffnung des Hauses 2006 gelang es damit und mit weiteren Zukäufen, Schenkungen und Leihgaben, die Basis für einen kulturgeschichtlichen Überblick in der Dauerausstellung zu gewährleisten. ${ }^{95}$ Schwerpunkte der Sammlung sind »Kunsthandwerk und Kunstgewerbe des 17.-19. Jahrhunderts, Objekte der Alltagskultur des 19. und frühen 20. Jahrhunderts sowie Industriekultur, Großstadtleben und Kunst in der Zwischenkriegszeit mit einem Schwerpunkt auf der Kunst der klassischen Moderne im Umkreis der Breslauer Akademie. «96 Sammlungskooperationen beschränkten sich anfangs noch auf verschiedene Häuser in Deutschland, mittlerweile findet jedoch ein reger Leihverkehr von Exponaten auch mit polnischen Museen statt. ${ }^{97}$ Zur Ausstellungseröffnung waren Häuser aus Polen und Tschechien mit >Grußobjekten präsent. $^{98}$

Das Schlesische Museum zu Görlitz organisiert in der Regel mehrfach im Jahr Sonderausstellungen aus einem breiten Spektrum kunst-, kultur- und originär historischer Themen, wobei die ersten beiden Themenbereiche einen Schwerpunkt darstellen. ${ }^{99}$ Dem von der Dauerausstellung weitgehend unberührten Bereich der Nachkriegsgeschichte Schlesiens wurde 2012 eine eigene Ausstellung gewidmet (»Schlesien nach

91 Schwarz: Kulturreferenten, 2012. Vgl. auch die Webpräsenz der Schlesischen Kulturreferentin: www.schlesisches-museum.de/index.php?id=1188 (letzter Zugriff: 16.04.2018).

92 Vgl. für die aktuelle Zusammensetzung des Wissenschaftlichen Beirates: www.schlesisches-museum.de/index.php?id=1221 (letzter Zugriff: 27.11.2017).

93 Die Beauftragte der Bundesregierung für Kultur und Medien: Bericht der Bundesregierung über die Maßnahmen zur Förderung der Kulturarbeit gemäß § 96 Bundesvertriebenengesetz (BVFC) in den Jahren 2015 und 2016, 2017, S. 10. Vgl. Seewald: Schlesisches Museum kooperiert mit Polen. Die Welt. 31.10.2014.

94 Bauer: Auf halbem Weg, 2001, S. 20.

95 Bauer: Schlesien im Museum, 2012, S. $62 \mathrm{f}$.

96 Bauer: Das Schlesische Museum, 2006, S. 16.

97 Ebd., S. 17. Vgl. Hennig: Der Schlesische Adler auf dem Weg ins Morgen. Sächsische Zeitung. 11.01.2016.

98 Spelsberg: Schlesisches Museum Görlitz. FAZ. 13.05.2006.

99 Vgl. für eine Übersicht über die bisherigen Sonderausstellungen des Schlesischen Museums zu Görlitz seit 2001: www.schlesisches-museum.de/index.php?id=6834\# (letzter Zugriff: 27.11.2017). 
1945: Wege und Wandlungen einer europäischen Region«). ${ }^{100} 2011 / 12$ wurde mit der Ausstellung »Lebenswege ins Ungewisse. Eine Ausstellung über Migration in GörlitzZgorzelec von 1933 bis heute« explizit eine deutsch-polnische sowie umfassende Perspektive auf Migration und Zwangsmigration gewählt. Die Zeit des Kriegsendes in Görlitz und Umgebung thematisierte das SMG 2015/16 mit einer Ausstellung (»Die große Not. Erinnerung an das Kriegsende 1945 und den Neubeginn in Görlitz und Zgorzelec«).

$\mathrm{Zu}$ einigen der Sonderausstellungen sind Ausstellungskataloge erschienen. Daneben ist das SMG an verschiedenen Publikationen zur schlesischen Geschichte, darunter den »Schlesischen Erinnerungsorten«, mitwirkend oder als Herausgeber beteiligt. Diese Veröffentlichungen werden durch eine rege Publikationstätigkeit des Museumsdirektors Markus Bauer ergänzt. Auch organisiert oder beteiligt sich das Schlesische Museum an Veranstaltungen und Konferenzen mit Schlesien-Bezug und führt im Haus selbst die Sonderausstellungen begleitende Veranstaltungen und weitere Formate wie Filmvorführungen durch. ${ }^{101}$

Neben der Zielgruppe der polnischen Besucher wird das, wenngleich zahlenmäßig rückläufige, aber nach wie vor bedeutende Publikum der Heimatvertriebenen und deren Nachkommen als anzusprechende Besuchergruppe genannt. ${ }^{102}$ Eine weitere Zielgruppe ist die wachsende Anzahl an Görlitztouristen. ${ }^{103}$ Nach eigenen Angaben ist das Schlesische Museum erfolgreich: Die »Veranstaltungen und Ausstellungen« zählten 2015 und 201654.400 Besucher; »Wanderausstellungen und Veranstaltungen« außerhalb von Görlitz wurden von 28.300 Menschen besucht. ${ }^{104}$ Unter den jährlich etwa 25.000 Besuchern sind ungefähr sieben bis acht Prozent aus Polen, was von Bauer als Erfolg der konsequent deutsch-polnisch gehaltenen Ausstellung sowie des mit entsprechender Sprachkompetenz ausgestatteten Personals betrachtet wird. ${ }^{105}$

\subsubsection{Anspruch und Selbstverständnis}

»Ein Schlesisches Museum zu Beginn des 21. Jahrhunderts, zumal mit einer Lage im deutsch-polnischen Grenzgebiet, kann nicht mehr ausschließlich oder auch nur hauptsächlich ein Museum für die vertriebenen Schlesier sein, sondern muss weitere Zielgruppen erschließen, darunter auch polnische Besucher, die in ihrer eigenen Sprache anzusprechen sind. Das Thema `Vertreibung ist immer noch zentral und bedeutungsvoll, aber es kommen über die Katastrophen von Krieg und Vertreibung hinweg neue Fragestellungen hinzu: Was bleibt vom alten Schlesien? Was ist historisches Erbe und Auftrag an ein neues europäisches Schlesien? $\ll^{106}$

100 Vgl. Eckersley: Walking the Tightrope between Memory and Diplomacy? 2016, S. 114.

101 Vgl. für das aktuelle Programm: www.schlesisches-museum.de/index.php?id=3606 (letzter Zugriff: 27.11.2017).

102 Bauer: Flucht und Vertreibung in den Regionalmuseen, 2010, S. $43 f$.

103 Pietsch: Das Schlesische Landesmuseum Görlitz, 2007, S. $38 \mathrm{f}$.

104 Die Beauftragte der Bundesregierung für Kultur und Medien: Bericht der Bundesregierung über die Maßnahmen zur Förderung der Kulturarbeit gemäß § 96 Bundesvertriebenengesetz (BVFG) in den Jahren 2015 und 2016, 2017, S. 10.

105 Hennig: Der Schlesische Adler auf dem Weg ins Morgen. Sächsische Zeitung. 11.01.2016.

106 Bauer: Schlesien im Museum, 2012, S. 63. 
Mit diesem Plädoyer für ein »neues europäisches Schlesien« skizziert der Direktor des Schlesischen Museum zu Görlitz-Museum für eine europäische Kulturregion den Anspruch des Hauses. Das Museum möchte weiter das gesamte historische Gebiet Schlesiens in seinen wechselnden Grenzen und in einem europäischen Kontext mit einem Schwerpunkt auf der Kulturgeschichte behandeln. Es erhebt den Anspruch, eine über das deutsche und besonders das preußische Schlesien hinausgehende Geschichte Schlesiens zu erzählen, wobei auch »der slawischen Geschichte und ihre[n] Traditionen« und »einer polnischen Perspektive auf das historische Geschehen und den polnischen Traditionen in der schlesischen Geschichte [...] Raum gegeben « werden soll. ${ }^{107}$ Mit einem Überblick von der piastischen Frühzeit bis zu »Ausblicken in die Gegenwart« sollen knapp tausend Jahre Geschichte dargestellt werden. ${ }^{108}$

Für Markus Bauer entsprechen Kooperationen mit der polnischen und tschechischen Seite dem Selbstverständnis des Hauses, das »Kulturforum, Kontakt- und Clearing-Stelle [...] für eine auf Schlesien bezogene Kulturarbeit« sein möchte. Die »historischen deutschen Kulturtraditionen [sollen] in eine europäische Perspektive« gestellt werden; dadurch erwartet er, »dass die Auseinandersetzung mit dem gemeinsamen kulturellen Erbe Deutsche, Polen und Tschechen zusammenführt und zur europäischen Verständigung beiträgt. ${ }^{109}$ Diesem Anspruch folgend, sieht es Bauer als eine der besonderen Herausforderungen an, eine multiperspektivische Betrachtung über die Grenzen hinweg zu gewährleisten, die berücksichtigt, »dass der Blick auf die Geschichte des jeweiligen Landes kein unbefangener sein kann, dass es Brechungen, vielschichtige Bedeutungen, unterschiedliche Perspektiven gibt [...]. «110

2001 definierte Bauer einen politischen Auftrag des Museums: „Es will seinen Beitrag leisten, dass der europäische Brückenschlag über die Neiße gelingt. «111 Die Region Schlesien versteht das Museum als »bedeutende Kulturlandschaft im Herzen Europas [...], die jahrhundertelang von Deutschen geprägt war und jetzt mit dem überwiegenden Teil ihres Territoriums zu Polen gehört «. ${ }^{112}$ Diese in Polen durchaus in Frage gestellte Interpretation wird durch das Bild eines weitgehend konfliktfreien Zusammenlebens unterschiedlicher Ethnien in Schlesien in einer Publikation des Museums von 2001 ergänzt, in der eine multikulturelle Vergangenheit postuliert wird, in der jahrhundertlang "nationale Gegensätze [...] kaum eine Rolle [spielten]«, ehe es im 19. Jahrhundert zum »Nationalitätenproblem « kam. ${ }^{113}$ Aus dieser Sichtweise ergibt sich, dass sich Flucht und Vertreibung trotz zunehmender Nationalitätenkonflikte nicht aus der Geschichte (Ober-)Schlesiens erklären lassen: „Sie ist eine unmittelbare Folge des Zweiten Weltkriegs. «114 Vielmehr kann man aus der Geschichte Schlesiens Erkenntnisse für die Herausforderungen unserer Zeit gewinnen:

107 Bauer: Das Schlesische Museum, 2006, S. 19. Bauer: Schlesien im Museum, 2012, S. 63.

108 Bauer: Das Schlesische Museum, 2006, S. $19 f$.

109 Ebd., S. 22.

110 Bauer: Flucht und Vertreibung in den Regionalmuseen, 2010, S. 44.

111 Bauer: Auf halbem Weg, 2001, S. 21.

112 Bauer: Das Schlesische Museum, 2006, S. $13 f$.

113 Auf der Suche nach Schlesien, 2001, S. 36.

114 Ebd., S. 58. 
»Ein zentrales Thema ist das Nebeneinander der Völker und Konfessionen auf schlesischem Boden, die Ausbildung der sprichwörtlichen sschlesischen Toleranz«. Hieraus erwachsen Perspektiven für eine neue Rolle Schlesiens in Europa nach der Epoche der Katastrophen des 20. Jahrhunderts, die geprägt war von Unterdrückung, Krieg und Vertreibung. « $^{115}$

Explizit äußert sich Bauer zur Bewertung und Einordnung von Flucht und Vertreibung im Museum, die er als »eines der einschneidensten Ereignisse in der darzustellenden Geschichte, [als] eine Art historische Wasserscheide« betrachtet. Dieser Ausstellungsabschnitt zähle zudem »sicher zu den schwierigsten und heikelsten«, sodass die Ausstellungsmacher mit dem Bewusstsein an die Arbeit gingen, dass "man ihre Texte mit besonders kritischen Augen prüfen wird. ${ }^{116}$ Er beschreibt den langen und lebhaften Aushandlungsprozess zur Darstellung des Themas zwischen Mitarbeitern und Wissenschaftlichem Beirat unter Einbeziehung »polnischer Museumskollegen«. Bei den Planungen wurde stets auch das polnische Publikum als Zielgruppe berücksichtigt. ${ }^{117}$ Für Bauer war es das Ziel, die Vertreibung in ihren »historischen Kontext einzuordnen « und damit »nicht etwa aus der Geschichte herauszulösen oder gar zu instrumentalisieren.« Dafür solle die Kriegsschuld NS-Deutschlands klar und als Bedingung für die späteren Vertreibungen herausgestellt werden. In diesem Zusammenhang werde auch die Rolle, die Schlesien und die Schlesier im nationalsozialistischen Deutschland und bei seinen Verbrechen einnahmen, diskutiert werden. Schließlich solle die »Darstellung eines historischen Ereignisses« im Mittelpunkt stehen und das Museum kein Denkmal oder eine Gedenkstätte sein. ${ }^{118}$

In Bezug auf den Charakter der Darstellung betont Bauer, dass das Geschehen der Vertreibung »nüchtern und sachlich « und »in einer für deutsche wie polnische Besucher verständlichen, nachvollziehbaren und erträglichen Art und Weise« dargestellt werden solle, »freilich ohne falsche Rücksichtnahme bei heiklen Aspekten. «119 Mögliche kontroverse Aspekte definiert er zum Beispiel in der Diskussion Schlesiens als Teil des "nationalsozialistische[n] Terror- und Vernichtungssystem[s], an die manche Vertriebene nicht gern erinnert werden «, ebenso wie in Polen umstrittene Themen, wie die »durchaus aktive und treibende Rolle polnischer staatlicher Stellen und Militärs bei der Vertreibung der Deutschen [...] oder die Existenz von polnischen Internierungslagern für Deutsche in Oberschlesien mit ihren zahlreichen Todesopfern. $\ll^{120}$

Gestalterisch setzt das SMG diesen Ansatz so um, dass sich die beiden Ausstellungsteile zum Thema >Nationalsozialismus/Zweiter Weltkrieg`sowie >Vertreibung/Schlesien und die Schlesier nach 1945< räumlich gegenüberliegen und »inhaltlich und gestalterisch vielfältig aufeinander bezogen « sind. Dadurch soll das Geschehen um 1945 vor einer etwaigen Isolierung gefeit sein und dennoch verhindert werden, dass das Erleben einer der Opfergruppen durch die Darstellung der anderen »relativiert « wird. ${ }^{121}$

115 Bauer: Das Schlesische Museum, 2006, S. 14.

116 Bauer: Flucht und Vertreibung in den Regionalmuseen, 2010, S. 44.

117 Ebd., S. $44 f$.

118 Ebd.

119 Ebd.

120 Ebd.

121 Ebd., S. 46f. 
Der Anspruch, Schlesien als europäische Region zu fassen, wird auch von polnischer Seite unterstützt. So formulierte der polnische Kunsthistoriker, Denkmalpfleger und Architekt Andrzej Tomaszewski in der Festrede zur Eröffnung des Museums: »[...] Es gibt nicht zwei Kunstgeschichten Schlesiens mehr, nicht zwei >Wahrheiten<, die polnische und die deutsche, es gibt nur die eine Wahrheit über die europäische, übernationale Kunst Schlesiens, die ein wichtiges Kapitel des gemeinsamen europäischen Erbes ist. Auf diesem Weg gilt es nun fortzuschreiten. «"22 Zugleich betonte er die integrative Kraft für die polnischen Bewohner Schlesiens, wenn diese ihre Geschichte als Teil eines "gemeinsamen europäischen Erbe[s] « betrachten. ${ }^{123}$ In diesem Zusammenhang bedauerte Tomaszewski, dass in Polen noch kein die schlesische Geschichte in ihrer ganzen Dimension fassendes Haus geschaffen wurde: »Mag sein, dass dort die Zeit noch nicht reif ist für einen übernationalen, europäischen Blick auf diese Geschichte. Görlitz [...] versucht mutig der Wegbereiter hierfür zu sein. ${ }^{124}$

Die Ansprüche der Landsmannschaft Schlesien an das Museum lassen sich in drei Punkte fassen: Es soll zum einen die verlorene Heimat und die Erinnerung an diese festhalten, zum zweiten in der gesamtdeutschen Gesellschaft das Bewusstsein für diese ehemals deutsche Region aufrecht erhalten und drittens zeigen, dass es eine polnische wie deutsche Gegenwart Schlesiens gibt. So formulierte Herbert Hupka bei der Eröffnung im Jahr 2006: »Schlesien ist hierzulande ein fernes, unbekanntes, fremdes Land geworden. Darum ist die Gründung und heutige festliche Eröffnung des Schlesischen Museums zu Görlitz ein dringendes Gebot, aus vielerlei Gründen eine Notwendigkeit. [...] In diesem unserem Landesmuseum Schlesien ist nicht etwa die Vergangenheit eingesargt, hier ist ganz Schlesien [...] Gegenwart. « ${ }^{125}$

Das Grußwort des damaligen sächsischen Ministerpräsidenten Georg Milbradt zur Eröffnung des Hauses hob die spezifischen regionalpolitischen Aspekte und Wünsche hervor: So solle das Museum mit der Vermittlung schlesischer Kultur »Brücken der Verständigung zwischen Deutschen und Polen« bauen, um damit zugleich »an wirtschaftliche Erfolge der Vergangenheit anzuknüpfen.« Oder kurz: »Wir sind eine aufstrebende Region im Herzen Europas, die aus ihren Gemeinsamkeiten im Wortsinne Kapital schlagen kann. ${ }^{126}$

\subsubsection{Die Dauerausstellung}

Das Zusammenspiel von Architektur und Ausstellung erkannten die Museumsmacher als besondere Herausforderung an. Beim Schönhof handele es sich um ein »selbstbewusstes Baudenkmal der Renaissance«, das nun in Einklang mit einer »schnell gewachsenen, heterogenen Sammlung « gebracht werden müsse, in dem die Ausstellungsinhalte »in diesem schwierigen Kontext zu ihrem Recht kommen« und dennoch ein moder-

122 Festrede von Prof. Dr. Andrzej Tomaszewski, 2006, S. 22.

123 Ebd., S. $25 f$.

124 Ebd., S. 28.

125 Grußwort von Dr. Herbert Hupka, 2006, S. 17.

126 Grußwort von Prof. Dr. Georg Milbradt, 2006, S. $8 f$. 
nes Museum geschaffen werden solle. ${ }^{127}$ Der Schönhof selbst, das älteste in Deutschland erhaltene Bürgerhaus der Renaissance, ist aus verschiedenen Bauten und Erweiterungen seit dem 13. Jahrhundert zu einem Gesamtkunstwerk zusammengewachsen. ${ }^{128}$ Das Gebäudeensemble setzt sich aus drei Teilen zusammen: Im vorderen Schönhof befinden sich auf drei Etagen der Eingang, die Zeit des Mittelalters und der frühen Neuzeit sowie die Querschnittsbereiche »Landschaft und Städte« und »Begebenheiten und Gestalten«, im Mittelhaus befindet sich auf vier Etagen die Neuzeit, im Fischmarkthaus sind die Sonderausstellungs- und Veranstaltungsräume.

Um nicht in einen Widerspruch mit der Architektur oder den Exponaten zu geraten, versuchen die Gestalter die Ausstellung mit einer dezenten »Materialität und Farbigkeit « zu versehen. ${ }^{129}$ "Leitfarben « bei und in den Vitrinen sowie bei den Hintergründen in den neun Themenbereichen dienen sowohl als zurückhaltende Orientierungshilfe wie auch als atmosphärische und inhaltliche Begleitung. ${ }^{130}$

Der Besucher erreicht das Museum durch die sanierte Altstadt von Görlitz. Nach dem Eintreten gilt es, verschiedene Wege durch das verschachtelte Gebäude zu erkennen. Das Suchen und physische Begehen der Ausstellung mit ihren vielen Treppen und Wegen bleibt charakteristisch für den weiteren Verlauf. Anhand der Raumnummerierung ist eine Orientierung aber gut möglich. Auf der linken Seite findet man an der Wand einen Übersichtsplan sowie den einführenden Text:

»[...] Wir laden Sie ein in ein faszinierendes Land mitten in Europa, mit bewegter Geschichte und vielfältiger Kultur.

Für viele Jahrhunderte bildete Schlesien einen Teil des deutschen Sprach- und Kulturraums. Heute gehört das Land zu Polen; Randgebiete liegen in Tschechien und in Deutschland. Im deutschen Landesteil ist Cörlitz die größte Stadt. Die Bundesrepublik Deutschland und der Freistaat Sachsen haben die Mittel zur Verfügung gestellt, dass hier ein Museum für Schlesien entstehen konnte. Sie haben gemeinsam mit der Stadt Cörlitz und der Landsmannschaft Schlesien eine Stiftung errichtet, die Träger des Museums ist.

Die Traditionen Schlesiens sind ein gemeinsames Erbe von Deutschen, Polen und Tschechen. Das Museum sucht nach neuen Wegen zu dieser reichen Kulturlandschaft, gemeinsam mit Partnern jenseits der Neiße.«

Der Rundgang durch das Museum beginnt im zweiten Obergeschoss des Schönhofs. Die Ausstellung gliedert sich in 17 Räume mit neun verschiedenen Themen:

Raum 1-2: Landschaften und Städte

Raum 3-6: Schlesien in der alten Zeit

Raum 7-8: Begebenheiten und Gestalten

Merz: Die Gestaltung der ständigen Ausstellung im Schlesischen Museum, 2006, S. 57. Für die Museumsgestaltung waren die hg merz architekten museumsgestalter verantwortlich: hg merz architekten museumsgestalter: Schlesisches Museum, 2008, $190 \mathrm{f.}$ 
Raum 9-11: Schlesien wird preußisch

Raum 12-13: Die Provinz im Umbruch

Raum 14: Der schwierige Weg zur Moderne

Raum 15: Vom Kaiserreich zur Republik

Raum 16: Schlesien im Nationalsozialismus und im Zweiten Weltkrieg

Raum 17: Untergang und Neubeginn

Die ersten beiden gehören ebenso wie die Räume 7-8 zu den nicht chronologisch gestalteten Räumen der Ausstellung. Im ersten Raum »Landschaften und Städte« werden zunächst neben dem einführenden A-Text auf einer statischen Karte die wichtigsten Städte und auf einem Bildschirm die wechselnde historische Zugehörigkeit der Region vorgestellt. In dem Text heißt es:

»Schlesien hat seine Besucher immer wieder überrascht. Als Goethe 1790 nach Schlesien reiste, erlebte er ein zzehnfach interessantes Land von natürlicher Schönheit und reicher Kultur. [...] Seine Künstler, Dichter und Wissenschaftler haben wichtige Beiträge zur europäischen Kultur geleistet.

Jahrhundertelang war deutsch als Landessprache vorherrschend, aber es wurde auch polnisch, mährisch, tschechisch und jiddisch gesprochen. Große europäische Handelsstraßen durchquerten das Land. Das Nebeneinander unterschiedlicher Kulturen begründete den geistigen Reichtum des Landes. Die sschlesische Toleranz wird gerühmt. [...]

Der Zweite Weltkrieg und die Vertreibung der Deutschen stellten einen tiefen, schmerzlichen Einschnitt dar. Mit der Wende 1989/90 begann eine neue Epoche: Schlesien nimmt wieder seinen angestammten Platz ein, im Herzen des geeinten Europas, als Brücke zwischen den Völkern.«

Unter den Überbegriffen »Der Fluss« (über die Oder als den schlesischen Strom), »Die Berge«, »Die romantische Landschaft«, »Die Metropole« (über Breslau), »Städte« und »Das Industrierevier« (vor allem über Oberschlesien) wird mit verschiedenen Objekten ein Überblick über die Region im Laufe ihrer Geschichte gegeben. Nationale Dimensionen spielen hier keine besondere Rolle, es werden eher die verbindenden Elemente betont, beispielsweise das des bei den tschechischen, polnischen und deutschen Schlesiern verbreiteten Rübezahlmärchens. Allerdings werden diese bei dem für Schlesien bedeutenden und später durch die nationalen Konflikte stark aufgeladenen St. Annaberg knapp skizziert.

Im Raum 2 schließt sich der Überblick »Görlitz und die schlesische Oberlausitz« an. In einer knappen Chronologie wird die Geschichte von Görlitz in der Verbundenheit der Region mit Schlesien dargestellt, darunter auch die Geschichte der jüdischen Gemeinde, Görlitz als Stadt im Nationalsozialismus sowie als Flüchtlings- und Grenzstadt nach dem Krieg sowie als Ort schlesischer Identität und Erinnerung heute.

Ebenfalls im zweiten Obergeschoss befinden sich die Räume 3-6, die dem Thema "Schlesien in der alten Zeit « gewidmet sind. Hier beginnt der chronologische Rundgang im Hochmittelalter. Einleitend wird, die Diskussion um die antike Frühgeschichte der Region beiseite lassend, formuliert: 
»Die Kulturlandschaft Schlesien formte sich in einer Epoche, in der es noch keine Nationalstaaten gab. Slawische Stämme hatten sich hier im frühen Mittelalter angesiedelt und die fruchtbaren Böden erschlossen. Das polnische Herrschaftsgeschlecht der Piasten öffnete das Land im 13. Jahrhundert nach Westen. Deutsche Siedler trieben den Landesausbau voran, brachten neue Techniken und eine fortgeschrittene Rechtskultur. In einem langen friedlichen Prozess wuchs Schlesien in den deutschen Kulturkreis hinein. [...]«

$\mathrm{Ab}$ diesem Zeitpunkt erscheint das slawische und polnische Element nurmehr am Rande. Im folgenden Bereich, unter »Land und Herrschaft, Wirtschaft und Gesellschaft» heißt es noch:

»Schlesien hatte im Laufe seiner Geschichte viele Herren. Im hohen Mittelalter gehörte das von Slawen besiedelte Land zum Herzogtum, dann Königreich Polen. Es zerfiel in zahlreiche selbstständige Fürstentümer, in denen das Ceschlecht der Piasten regiert. Seit dem Ende des 13. Jahrhunderts gelang es den böhmischen Königen, ihre Lehnshoheit über die schlesischen Fürstentümer auszudehnen [...]. Als Nebenland der böhmischen Krone gehört Schlesien jetzt zum Heiligen Römischen Reich Deutscher Nation und kam 1526 an das Haus Habsburg.

Im 13. Jahrhundert setzte ein fundamentaler kultureller Wandel ein. Deutsche Siedler wurden ins Land gerufen, zahlreiche neue Dörfer und Städte gegründet. Schlesien fand Anschluss an die fortgeschrittene Zivilisation Westeuropas. Im späten Mittelalter wuchsen die einheimische slawische Bevölkerung und die deutschen Zuwanderer zusammen. Die deutsche Sprache setzte sich in weiten Teilen des Landes durch.«

Zum Geschlecht der Piasten, denen einige Schautafeln und als Objekt unter anderem der Abguss der Grabplatte des letzten piastischen Herzogs von Breslau (Heinrich VI., 1311-1335) gewidmet sind, führt die Ausstellung an:

»[...] Bis ins 14. Jahrhundert stellte die Familie der Piasten die Herrscher Polens. Auch danach spielte sie in der Geschichte Schlesiens eine wichtige Rolle. 1675 ist der letzte schlesische Piast gestorben. Heute repräsentieren die Piasten für viele Polen ein frühes, ehemals polnisches Schlesien.

Die Piasten stehen aber auch für die Öffnung Schlesiens zum deutschen Kulturkreis. Piastische Herzöge holten im 13. Jahrhundert deutsche Siedler ins Land. Die Herrscherfamilie verband sich mit dem deutschen Hochadel und nahm dessen Kultur und Cewohnheiten an.«

Nach der herrschaftsgeschichtlichen Einführung folgen Überblicke über die Kirche des Mittelalters, die Habsburger in Schlesien, die gesellschaftliche Zusammensetzung und Entwicklung, die konfessionellen Auseinandersetzungen, Kunsthandwerk und abschließend ein vor allem kulturgeschichtlicher Überblick zum Barock in Schlesien.

Der Besucher wendet sich nun hinab in das erste Obergeschoss, in dem die nichtchronologischen Räume 7-8 unter dem Titel »Begebenheiten und Gestalten« anhand einzelner herausragender Objekte oder Objektzusammenstellungen zentrale Ereignisse und schlesische Persönlichkeiten vorstellen. Für den deutsch-polnischen Kontext ist vor allem das Andachtsbild mit dem »Jesus von Milatyń« von Interesse, das die polnischen 
Bewohner der kresy bei ihrer Zwangsmigration in die ihnen zugewiesene neue Heimat nach Zgorzelec, in den nunmehr polnischen Ostteil von Görlitz, mitnahmen. In Raum 8 erfolgt schließlich eine ausführliche Vorstellung der Baugeschichte des Schönhofs.

Im Raum 9-11 wird die chronologische Erzählung mit der Überschrift »Schlesien wird preußisch « wiederaufgenommen. Neben einem knappen ereignisgeschichtlichen Überblick (militärisch und administrativ) liegt auch hier der Fokus auf dem Kunsthandwerk. Die polnische Geschichte (Ober-)Schlesiens wird nicht mehr spezifisch erwähnt; auch nicht die polnischen Teilungen, die Schlesien zwar nicht direkt betrafen, wohl aber Preußen und später das Deutsche Reich in einen andauernden deutsch-polnischen Gegensatz führten.

Dem Rundgang folgend, verlässt der Besucher nun das Vorderhaus und bewegt sich durch den überdachten Innenhof in das erste Obergeschoss des Mittelhauses in den Bereich »Die Provinz im Umbruch« mit den verbundenen Räumen 12-13. Im einführenden A-Text begegnet uns nun auch wieder das polnische Element:

»[...] Die Industrialisierung veränderte das Gesicht des Landes. [...] Zwischen alten Zwängen und neuen Herausforderungen standen die Freiheitsbewegungen des Jahrhunderts: der Weberaufstand von 1844, die revolutionären Erhebungen von 1848 und 1849, schließlich die Arbeiterbewegung und die nationalpolnischen Bestrebungen in Oberschlesien.«

Nach einer Besprechung der preußischen Reformen und der Befreiungskriege folgt eine ausführliche Behandlung der Industrialisierung in Schlesien. Im Zusammenhang mit der Verschärfung der sozialen Lage wird auch das Entstehen der polnischen Nationalbewegung in Schlesien besprochen:

»Lange Zeit galt Schlesien als die unruhigste Provinz Preußens. Oberschlesien wurde immer wieder von Hungersnöten und Epidemien heimgesucht. [...] Die Not in Oberschlesien machte auf die Lage der dort lebenden polnischsprachigen Bevölkerung aufmerksam. Die polnische Nationalbewegung fand in Oberschlesien anfangs nur wenige Anhänger. Erst die Unterdrückung der polnischen Sprache im Bismarckreich weckte ein polnisches Kulturbewusstsein, das sich bald auch politisch artikulierte.«

Weiter widmet sich der Bereich der Arbeiterbewegung sowie bürgerlichen und adeligen Lebenswelten, ebenso wie den Entwicklungen in Literatur und Kunst. Diese Themen sind alle reichlich mit verschiedenen Objekten, vor allem mit Gemälden, Fahnen und Graphiken, gestaltet. Die Darstellung des Kulturkampfes gegen die katholische Kirche und die polnische Nationalbewegung bleiben allerdings ohne spezifische Objekte.

Der Raum 14 des zweiten Obergeschosses des Mittelhauses firmiert unter dem Titel »Der schwierige Weg zur Moderne«. Auch hier zeigt sich der kunsthistorische Schwerpunkt der Ausstellung: Mit der »Kunstlandschaft Riesengebirge«, der Breslauer Akademie oder dem »Neuen Bauen« in Breslau, um nur einige Beispiele zu nennen, wird ein Einblick in die schlesische Kunst und Architektur von ca. 1900 bis 1933 geboten.

Im dritten Obergeschoss setzt sich der Rundgang mit dem Raum 15 fort, der wieder an die politikgeschichtliche Entwicklung unter dem Titel »Vom Kaiserreich zur Republik« anknüpft. Im A-Text heißt es: 
»Der Erste Weltkrieg beendete eine lang anhaltende Phase der Prosperität und veränderte die Situation Schlesiens von Grund auf. Neue Nationalstaaten entstanden jenseits der Landesgrenzen. Österreichisch-Schlesien ging in der Tschechoslowakei auf; das östliche Oberschlesien musste nach einer Volksabstimmung an die Republik Polen abgetreten werden. Die willkürliche Teilung des Industriereviers warf das Land wirtschaftlich zurück und führte zum fortwährenden Konflikt zwischen Deutschland und Polen.

Erst 1924 begannen sich die politischen Verhältnisse zu stabilisieren. Ein wirtschaftlicher Aufschwung erfasste ganz Schlesien, einschließlich des polnischen Ostoberschlesiens. [...] Mit der Weltwirtschaftskrise 1929/30 kamen auch in Schlesien die >Coldenen Zwanzigerjahre`zu einem jähen Ende.«

Dieser Bereich zeigt anhand einiger weniger Objekte die Auswirkungen des Ersten Weltkrieges auf Schlesien sowie die Auseinandersetzung in der Region mit diesem. Neben Objekten wie Breslauer Vivatbändern werden Exponate zeitgenössischer Kunst gezeigt, die den Krieg als Katastrophe darstellen. Ein eigener Bereich ist den Auseinandersetzungen um die Zugehörigkeit Oberschlesiens gewidmet:

》Oberschlesien 1918-1921: Aufstände, Abstimmung und Teilung

Nach Deutschlands Niederlage im Ersten Weltkrieg wurden die staatlichen Verhältnisse im östlichen Mitteleuropa neu geordnet. Der Vertrag von Versailles bestimmte, dass Österreichisch-Schlesien und Randgebiete des preußischen Schlesiens an die neu entstandenen Staaten Tschechoslowakei und Polen fallen sollten. Über das Schicksal von Oberschlesien, das zwischen Deutschland und Polen umstritten war, sollte eine Volksabstimmung entscheiden.

Beide Seiten warben mit nationalistischer Propaganda um Wählerstimmen. Dreimal versuchten polnische Aufständische, mit militärischen Mitteln Fakten zu schaffen. Am 20. März 1921 votierten rund $60 \%$ der Wähler für Deutschland, 40 \% für Polen. Darauf entschieden sich die Alliierten für eine Teilung Oberschlesiens. Etwa zwei Drittel des Abstimmungsgebietes mit $58 \%$ der Bevölkerung wurden Deutschland zugesprochen. Allerdings lagen im Polen zugefallenen Landesteil die meisten Industrieanlagen und Rohstoffe.«

Mit Hilfe von Fotografien, Karten, Plakaten und Aushängen werden Akteure der Auseinandersetzung sowie die Propaganda beider Seiten dargestellt. Die für die polnischschlesische Geschichtsschreibung so bedeutenden >Schlesischen Aufstände` werden nur äußerst knapp angesprochen. Anhand von zwei Abzeichen für deutsche Freikorps bei den Kämpfen um Oberschlesien wird der letzte der drei >Aufständeく in diesem C-Text erläutert:

»Nach der Abstimmung am 20. März 1921 zögerten die Alliierten, eine endgültige Entscheidung über Oberschlesien zu treffen. Am 3. Mai begannen polnische Aufständische mit der Besetzung der oberschlesischen Gebiete rechts der Oder. Der deutsche Selbstschutz [...] ging mit Unterstützung durch Freikorps zum Cegenangriff über und erstürmte am 21. Mai den Annaberg.« 
Die oben erwähnten, sorgfältig geordneten, flachen Objekte bleiben trotz ihrer inhaltlichen Dramatik durch die aufgeräumte Darstellung eingehegt. Auf einer weiteren Schautafel heißt es unter »Die >blutende Grenze«:

»Die Teilung Oberschlesiens zerschnitt über Jahrhunderte gewachsene wirtschaftliche, kulturelle und soziale Bindungen. Ostoberschlesien wurde zur polnischen Wojewodschaft `Śląsk«mit einem großen deutschsprachigen Bevölkerungsteil, während im westlichen Landesteil auch polnischsprachige Oberschlesier lebten. Die Oberschlesienfrage blieb ein ständiger Konfliktherd. In Deutschland entstand der Mythos von der >blutenden Grenze`; die Regierungen betrieben offen die Rückgewinnung des Territoriums. Polnische Behörden verletzten immer wieder die Rechte der deutschen Minderheit. [...]«

Zwei Karten illustrieren die Teilung Schlesiens. Anhand von historischen Ansichten des Oberschlesischen Landesmuseums in Beuthen und des Muzeum Śląskie erfolgt die Darstellung des Wettbewerbes um die Deutungshoheit über die Oberschlesische Geschichte; bei der Fotografie des Kattowitzer Museums wird im Begleittext bereits ein Ausblick auf die Plünderung der Sammlung und die Zerstörung des Gebäudes durch die deutschen Eroberer nach 1939 vorgenommen. Im B-Text zum Thema des »zerschnittenen Industriereviers« wird von der "willkürlichen Grenzziehung durch die Alliierten« gesprochen, die zu einer schweren wirtschaftlichen Krise führte, die erst durch entsprechende Investitionen auf beiden Seiten abgefangen werden konnte.

Auf die symbolische und industrielle Bedeutung Oberschlesiens für das wiedergegründete Polen wird ebenso wie auf dessen Verwicklung in verschiedene Grenzkriege sowie den polnisch-sowjetischen Krieg nicht weiter eingegangen. Die weiteren Bereiche des Raumes 15 beschäftigen sich vertieft mit der Alltagskultur Schlesiens in der Zwischenkriegszeit (Religion, Landwirtschaft, Brauchtum etc.). Hier finden sich auch vereinzelt Objekte aus dem polnischen Ostoberschlesien.

Um den Rundgang abzuschließen, muss der Besucher nun in das Erdgeschoss des Mittelbaus hinabsteigen, in dem ihn zwei durch einen Gang getrennte gegenüberliegende Bereiche erwarten: auf der einen Seite Raum 16 »Schlesien im Nationalsozialismus und im Zweiten Weltkrieg « und auf der anderen Raum 17 »Untergang und Neubeginn«. Beide Seiten gleichen sich in ihrem Aufbau. Der historische Gewölbebau wird durch flache, dezent beleuchtete und den Raum länglich durchlaufende, weiße Vitrinen sowie gräulich gehaltene Wandvitrinen gefüllt. Im A-Text des Raumes 16 heißt es:

»Später als in anderen Teilen Deutschlands fand die NSDAP in Schlesien Rückhalt in der Bevölkerung. Dann aber erzielte sie hier deutliche Wahlsiege. Die Machtübernahme 1933 zerstörte auch in Schlesien die demokratischen Institutionen und bedeutete einen Bruch mit Traditionen von Freiheit und Toleranz. In zunehmenden Maße wirkte sich die Politik des NS-Regimes im Alltag aus: Kriegsvorbereitungen, Cewalt und Terror, eine totalitäre Ideologie aus Nationalismus und Rassenwahn. Tausende Deutsche - Juden und Andersdenkende - wurden interniert, vertrieben, ermordet.

Auch von Schlesien aus brachen deutsche Truppen am 1. September 1939 in Polen ein: der Zweite Weltkrieg begann. Für die deutsche Kriegsführung war Schlesien, jetzt um polnische Cebiete erweitert, von großer Bedeutung. Denn hier lagen wichtige Stand- 
orte der Rüstungsindustrie, Schutzzonen für Evakuierte aus ganz Deutschland, aber auch Konzentrationslager und Vernichtungsstätten.«

Die nationalsozialistische Anknüpfung und Verschärfung des deutsch-polnischen Konflikts um Schlesien wird im Bereich »Neue Geschichtsschreibung für Schlesien« dargestellt. Propaganda, die Gleichschaltung und die >Germanisierung〈werden zum Beispiel anhand der Umgestaltung des Breslauer Stadtwappens und nationalsozialistischer Schlesienliteratur gezeigt. Ausführlich wird auf »Widerstand und Anpassung«, »Stätten des Völkermordes« sowie »Verfolgung und Widerstand« eingegangen. Darüber hinaus werden knapp Schlesiens militärische Situation im Zweiten Weltkrieg und deren Auswirkungen auf das Alltagsleben besprochen. In einem kleinen Bereich wird »OstOberschlesien unter nationalsozialistischer Herrschaft« thematisiert. Auf einer Fotografie wird die »Vertreibung der polnischen Bevölkerung nach der Besetzung durch deutsche Truppen« dargestellt. In dem Begleittext heißt es:

»1939 wurden die nach der Volksabstimmung von 1921 an Polen abgetretenen ostoberschlesischen Cebiete [...], aber auch west-galizische, also traditionell polnische Landkreise, dem Deutschen Reich angegliedert und im neu gebildeten Regierungsbezirk Kattowitz zusammengeschlossen. Die Bevölkerung wurde in der $>$ Volksliste $<$ nach völkischen Kategorien erfasst und damit zum Objekt von Vertreibung, Zwangsarbeit oder Zwangsgermanisierung. Der Cebrauch des Polnischen in der Öffentlichkeit war verboten.«

Nachdem in den vorherigen Bereichen nur punktuell auf jüdisches Leben in Schlesien eingegangen wurde, wird nun anhand zweier jüdischer Künstler das Schicksal der schlesischen Juden behandelt. Die Verbindung von Auschwitz mit der schlesischen Geschichte verdeutlicht der Ausstellungsabschnitt mit der Darstellung des Anschlusses von Auschwitz an Schlesien sowie der Zwangsarbeit und der Nebenlager des KZ in der oberschlesischen Industrie.

Der Besucher wendet sich nun der anderen Raumhälfte zu, wo es im A-Text unter »Untergang und Neubeginn« heißt:

»Als die Front im Januar 1945 Schlesien erreichte, begann eine ungeordnete Flucht. Viele Trecks wurden von den schnell vorrückenden sowjetischen Verbänden überrollt. Zehntausende kamen ums Leben.

Die Rote Armee unterstellte die von ihr eroberten Gebiete östlich von Oder und Neiße der polnischen Verwaltung; die Westalliierten stimmten dem nachträglich zu. Die deutsche Bevölkerung wurde vertrieben. Eine jahrhundertelange historische Entwicklung erfuhr einen gewaltsamen Abbruch.

Im Laufe der Jahrzehnte entstand ein neues, polnisches Schlesien, mit einer Bevölkerung, die zu einem Teil selbst vertrieben worden war. Das zugewiesene Land blieb ihr lange fremd. Zwischen den früheren und jetzigen Bewohnern Schlesiens gab es kaum Kontakte. Erst das Ende des Kalten Krieges machte es ihnen möglich, zusammen zu kommen und sich über das kulturelle Erbe ihres Landes zu verständigen. Die Wunden, die Krieg und Vertreibung geschlagen haben, beginnen zu verheilen.« 
Am Beginn der ersten der zwei länglichen Vitrinen auf dieser Seite des Raumes heißt es unter »Kriegsende«:

»Am 12. Januar 1945 begann die Rote Armee ihren Angriff auf Schlesien. Bis zuletzt verkündeten die Behörden Durchhalteparolen und befahlen die Evakuierung der Zivilbevölkerung erst, als es schon zu spät war. Hunderttausende Menschen entschlossen sich zur Flucht über die Lausitzer Neiße oder in das Sudetenland - in der Hoffnung auf baldige Rückkehr. Das ungeschützte, eingeschlossene Breslau wurde zur »Festung « erklärt. [...]«

Dem Text schließen sich Fotografien der militärischen Auseinandersetzung und Postkarten mit entsprechenden Berichten über die Ereignisse an. In den Objektbeschriftungen wird deren Inhalt wiedergegeben und kontextualisiert. Es handelt sich um vergleichsweise zurückhaltende Berichte vom Ausharren und vom folgenden Verlust der Heimat. Die massenhaften Verbrechen der Roten Armee werden als Begleiterscheinungen beschrieben. So heißt es in dem Text zum Thema »Vertreibung«:

»Auf den Konferenzen von Teheran und Jalta hatten sich die Alliierten darauf verständigt, das polnische Staatsgebiet nach dem Sieg über Deutschland nach Westen zu verschieben. Die Sowjetunion behielt die 1939 annektierten polnischen Ostgebiete; Polen sollte mit dem Gewinn deutscher Ostprovinzen entschädigt werden. Sofort nach Kriegsende begann hier die Vertreibung der deutschen Bevölkerung, begleitet von Mord- und Cewalttaten, Zwangsarbeit und Internierungen. Auf der Potsdamer Konferenz im Juli/August 1945 legitimierten die Alliierten die >Überführung`der deutschen Bevölkerung und erkannten die polnische Verwaltung in den Cebieten östlich der Oder-Neiße-Linie an. Die endgültige Entscheidung über die deutsche Ostgrenze sollte einem Friedensvertrag vorbehalten bleiben. In der Folge setzten organisierte Massentransporte in die sowjetische und die westlichen Besatzungszonen ein. Fast die gesamte Bevölkerung Niederschlesiens und etwa die Hälfte der Bewohner des vor 1939 zu Deutschland gehörenden Teils von Oberschlesien flohen oder wurden vertrieben, rund 3,2 Millionen Menschen.«

Spezifische Akteure, beispielsweise die der »Mord- und Gewalttaten«, werden nicht genannt. Polen wird als vollständig unselbstständiger Akteur auf der internationalen Bühne dargestellt. Die das Thema begleitenden Objekte bestehen aus einem »Ausweisungsbescheid«, der Belegungsliste eines Vertreibungstransportes, dem Fluchtgepäck eines damals vierzehnjährigen Mädchens und einer Rübezahl-Figur. Der weitere Teil der Vitrine zeigt anhand von Fotografien und Aushängen Flucht- und Vertreibungsbewegungen sowie die Notlage in den aufnehmenden Orten, hier am Beispiel von Görlitz. Der Besucher trifft auch auf das Thema der Internierungslager für deutsche (Ober-)Schlesier auch anhand des Manuskriptes des Lagerarztes Heinz Esser über das Internierungslager Lamsdorf. In der Objekterklärung heißt es:

»Im Juli 1945 errichteten die polnischen Behörden im ehemaligen deutschen Kriegsgefangenenlager Lamsdorf/Oberschlesien ein Internierungslager für Deutsche. Durch Seuchen, unmenschliche Behandlungen und Cewaltexzesse kamen mehr als tausend Menschen zu Tode. [...]« 
Weitere Hintergrundinformationen zu den Motiven der Gewalt oder der Internierung gibt es in diesem knapp gehaltenen Bereich nicht. Im nächsten Bereich der Vitrine heißt es unter »Schlesien soll polnisch werden«:

»Die Regierung Polens strebte eine schnelle Integration der neuen Landesteile an. Die Vertreibung ging mit der Ansiedlung neuer Bewohner einher. Das >Land der Piasten<, die swiedergewonnenen Gebiete sollten zur Heimat für die Vertriebenen aus den ostpolnischen Gebieten werden, die nun zur Ukrainischen, Weißrussischen und Litauischen Sowjetrepublik gehörten. >Repatrianten<, Heimkehrer, war ihre offizielle Bezeichnung, doch sie kamen in ein fremdes Land. Hoffnung auf ein besseres Leben lockte Ansiedler aus dem kriegszerstörten Zentral- und Westpolen nach Schlesien, ehemalige Zwangsarbeiter aus Deutschland, polnische Rückkehrer aus Westeuropa, polnische Juden, die die Konzentrationslager überlebt hatten. Gezielt wurden Militärangehörige mit ihren Familien in Grenznähe versetzt. 1947 wurden in der Aktion Wisła Angehörige der ukrainischen Minderheit in die neuen Westgebiete deportiert. «

Der Ausführung sind in der Vitrine »Evakuierungsbescheide« aus den ehemaligen polnischen Ostgebieten und weitere entsprechende Dokumente sowie Memorabilien wie eine Tabakdose beigefügt, zudem werden die häufig katastrophalen Bedingungen der Transporte ebenso wie die beschönigende volkspolnische Propaganda aufgezeigt. Der Terminus Vertreibung wird in diesem Zusammenhang für die deutsche, polnische, ukrainische und jüdische Zwangsmigration verwandt.

In den folgenden Bereichen der Vitrine wird die Integration der Vertriebenen in die sowjetische Besatzungszone und die DDR ebenso wie die »Friedenspolitik der DDR« skizziert. Dem folgt der Bereich »Die Vertriebenen in Westdeutschland« sowie »Politisches Wirken der Vertriebenen in der Bundesrepublik«. Hier werden knapp die politische Entwicklung der entsprechenden Vertriebenenverbände und die Kontroversen und Meilensteine dargestellt, beispielsweise in Form einer Fotografie des Kniefalls von Willy Brandt sowie abschließend mit einer Abbildung von der Versöhnungsmesse in Kreisau 1989.

Ein separater Bereich geht auf»Tradition und Identität« ein. In diesem sehr kleinen Segment wird die fortlaufende Erinnerung von ehemaligen Bewohnern Schlesiens bis 1989/90 vorgestellt. Dem schließt sich in der Vitrine der Bereich "Autochthone und Aussiedler« an. Der B-Text liefert eine kurze Chronologie der Entwicklung nach 1989:

»Rund eine Million Bewohner in den schlesischen Gebieten, die vor 1939 zum Deutschen Reich gehörten, blieben im Land. Abgesehen von einigen Tausend deutschen Fachleuten, die in Industrie und Bergbau benötigt wurden, waren die übrigen in Oberschlesien ansässig. Sie galten als `Autochthoneく, als Alteingesessene, als polnischstämmig oder polonisierbar. Nach einer Prüfung ihrer Integrationsfähigkeit erhielten sie die polnische Staatsbürgerschaft.

In der Zeit der Volksrepublik wurden die ehemals zweisprachigen Gebiete Oberschlesiens rigoros polonisiert. Der öffentliche Gebrauch der deutschen Sprache war lange verboten. Zehntausende Deutsche verließen seit der Mitte der 5oer Jahre das Land. Die meisten siedelten nach Westdeutschland über. Seit den 7oer Jahren wurden Aus- 
reisegenehmigungen großzügiger erteilt. Erst seit der Errichtung des demokratischen Polen erhielten die im Land verbliebenen Deutschen kulturelle Autonomie und eine politische Vertretung im Sejm.«

Als dazugehöriges Bild dient unter anderem die Fotografie eines deutschsprachigen Gottesdienstes im Oppelner Land in den 1990er Jahren. Im nächsten Bereich der Vitrine wird noch einmal auf die Bemühungen um eine Aneignung Schlesiens durch die Kommunisten sowie auf heutige Entwicklungen verwiesen (»Schlesien - auf der Suche nach der eigenen Geschichte $\lll$ :

»Der Bevölkerungsaustausch entzog Schlesien die Kräfte für einen raschen Wiederaufbau. Die Entwicklung neuer Strukturen in Wirtschaft, Wissenschaft und Kultur ging innerhalb des sozialistischen Systems Polens langsam vonstatten. Es sollte ein Neubeginn ohne deutsche Vorgeschichte sein. Aus den polnischen Anfängen Schlesiens im Mittelalter wurde ein piastischer Mythos abgeleitet. Die neuen polnischen Westgebiete galten als >urpolnisches`, >wiedergewonnenes ‘ Land, das nach Jahrhunderten zum Mutterland zurückgekehrt sei. Doch dauerte es lange, bis die polnischen Ansiedler hier heimisch wurden. Auch ihre Vertreibung war tabuisiert, und ihr Bleiben schien jahrzehntelang nicht gewiss. Das Ende der staatlich verordneten Geschichtsdoktrin in Polen und die Anerkennung der Grenzen durch das wiedervereinigte Deutschland leiteten einen Wandel ein. Heute erforschen die Menschen im polnischen Schlesien die Ceschichte ihrer Heimat aufs Neue und legen die Spuren der deutschen Vergangenheit frei.«

Negative Beispiele der aggressiven Polonisierungspolitik in der Volksrepublik, beispielsweise die Umwidmung deutscher Kriegerdenkmäler, kontrastiert die Ausstellung mit der Wiederaufnahme deutscher Schlesier in die Galerie »Große Breslauer« in der Bürgerhalle des Breslauer Rathauses in den 1990er Jahren. Ein großes Objekt ist eine Karte von Niederschlesien von 1945 mit den neuen polnischen Ortsnamen sowie späteren handschriftlichen Korrekturen.

Kurz wird noch auf das vor allem kunsthandwerkliche Weiterleben schlesischer Traditionen eingegangen, ehe der Besucher zum Bereich der Verständigung mit dem Titel »Begegnungen in der Heimat « kommt. Hier wird beispielhaft die Geschichte zweier Familien skizziert, die noch während des Kalten Krieges eine fortdauernde Freundschaft entwickeln konnten. Es handelt sich um eine polnische Familie aus Tarnopol/Тернопіль in den ehemaligen polnischen Ostgebieten und eine deutschen Familie aus Kesselsdorf/Kotliska. Verschiedene Fotografien der Begegnungen und Veränderungen der Menschen und Häuser illustrieren diese Geschichte.

Mit den Inhalten der Wandvitrinen wird der Besucher noch einmal zu den Geschehnissen am Ende des Zweiten Weltkrieges zurückgeführt. Unter der Überschrift »Erinnerungsstücke« sind verschiedene Schlüssel und Schlüsselbünde aufgehängt. Wie bei allen folgenden Bereichen sind die Objekte hier nur eingeschränkt erkennbar, da die Sicht bewusst durch streifenweise eingesetzte undurchsichtige Folien begrenzt wird. 
Diese Gestaltung soll andeuten, »dass die Vergegenwärtigung der Ereignisse langsam zurücktritt und undeutlich wird «. ${ }^{131}$ Im entsprechenden Begleittext heißt es:

»Erfahrungen von Flucht und Vertreibung haben das Leben vieler Deutscher und Polen unauslöschlich geprägt. Die Erinnerung daran wird zuweilen verdrängt, dann wieder greift sie beherrschend in das gegenwärtige Leben ein. Die wenigen Habseligkeiten, die auf den Weg mitgenommen werden konnten, sind ihren Besitzern ans Herz gewachsen. Im Laufe der Jahrzehnte zerrannen die Hoffnungen auf eine Rückkehr, und es fielen bei den meisten die Ansprüche auf den früheren Besitz. Die Erinnerungsstücke an die verlorene Heimat blieben zurück. Manche erhielten eine neue Bestimmung: als Exponate in Heimatstuben und Museen.«

Als weitere größere Objekte folgen ein bei der Flucht verwendeter Wintermantel, ein Koffer, das Kruzifix eines evangelischen Pastors, eine aus Uniformstoff hergestellte Tragetasche, die auf den Flucht- und Vertreibungsbewegungen mitgeführt wurde, sowie ein auf der Flucht mitgenommener Schulranzen, Spielsachen und noch ein weiterer Koffer. Alle Objekte sind Personen zugeordnet und mit einer kurzen Geschichte versehen. Neben den authentischen Objekten ermöglicht die Präsentation verschiedener Biografien und Fluchtwege eine variantenreiche Darstellung. Hierbei sticht eine Stielpfanne heraus, die von Vertriebenen mitgeführt und vermutlich von Roma im Osten Polens gefertigt wurde. Die im Ausstellungsteil zur Hochphase der Industrialisierung vorgestellte Familie von Donnersmarck taucht hier bei der Präsentation von einfachen Aluminiumtellern wieder auf, von denen die Familie in ihrer Flüchtlingsunterkunft in Bayern aß. Diese stehen somit sinnbildlich auch für die materielle Seite des Heimatverlustes.

Ist auch in den letzten beiden Räumen keine klare Wegführung vorgegeben, so kann als Schlussobjekt der Ausstellung eine »Fahne aus dem KZ Buchenwald« von 1945 angesehen werden. Sie gehörte einer Gruppe von schlesischen KPD- und SPD- Mitgliedern, die im nunmehr befreiten Lager eine »Landsmannschaft Schlesien« gründeten. Interessant ist, dass die auf der Rückseite in den schlesischen Farben weiß-gelb gehaltenen Fahne in der DDR bei Aufmärschen weiter in Nutzung blieb. ${ }^{132}$ Der Rundgang der Ausstellung endet hier. Eine schriftliche Schlussbotschaft oder ein eindeutiges Schlussobjekt sind nicht vorhanden. ${ }^{133}$

\subsubsection{Ausstellungsanalyse}

Der selbst gestellte Anspruch, Schlesien als eine »europäische Kulturregion« darzustellen, ist in der Ausstellung immer wieder, wenn auch nicht kontinuierlich, erkennbar.

131 Bauer: Flucht und Vertreibung in den Regionalmuseen, 2010, S. $47 f$.

132 Die Fahne erfüllt nach Bauer auch die Funktion, darauf hinzuweisen, dass das Jahr 1945 auch ein Jahr der Befreiung war: Ebd., S. 48.

133 Laut Bauer ist die offene Cestaltung des letzten Raumes mit ihrer Sammlung von >Schlussobjekten< durchaus Intention: „Viele Besucher zeigen sich von dieser Darstellung berührt, vielleicht gerade weil sie so lapidar und unpathetisch ist und weil sie sehr unterschiedliche Interpretationen anregt und zulässt. Sie schließt die Ausstellung ab und öffnet die dargestellten Sachverhalte zugleich weiterer Auseinandersetzung und Deutung.« Ebd., S. $47 f$. 
Eine konsequente europäische Vernetzungsgeschichte wird nicht verfolgt. Der kunsthistorische Schwerpunkt in der Darstellung der Landes- und Kulturgeschichte Schlesiens ist prägend für das Haus. Letztlich zeigt sich der europäische Anspruch vor allem in einem Bemühen, die Geschichte Schlesiens dort, wo sie eine Schnittmenge mit der polnischen (oder tschechischen und russisch/sowjetischen) aufweist, besonders vorsichtig und nüchtern zu erzählen. Zwangsmigration wird nicht als europäisches oder globales Phänomen des 20. Jahrhunderts besprochen, sondern als ein weitgehend unabhängig von der (ober-)schlesischen Geschichte über die Region eingefallenes Unglück. Das Ziel, in besonderem Maße auch polnische Gäste zu erreichen, steht letztlich im Konflikt mit der nur punktuellen Sichtbarkeit des polnischen Anteils an der schlesischen Geschichte.

Die Ausstellungsgestaltung ist in Äquivalenz zur inhaltlichen Ausrichtung als zurückhaltend zu klassifizieren, ohne dass sie eintönig wirkt. Dazu trägt auch das `Ausstellungsobjekt « Schönhof, also das Museumsgebäude selbst, bei. Die allermeisten Objekte, vor allem in den für die vorliegende Arbeit relevanten Ausstellungsteilen, sind gut sortiert in Vitrinen aufgehängt oder gelegt. Dies führt dazu, dass viele Objekte eine weitgehend illustrative oder belegende Funktion übernehmen. Punktuell wird dies dort aufgebrochen, wo Lichteinsatz und das Spielen mit Blickperspektiven gezielt eingesetzt werden. Tiefe gewinnt die Ausstellung auch dann, wenn die Objekte mit kurzen persönlichen Geschichten unterlegt werden.

Die farblich aufeinander abgestimmten Themenbereiche sowie die zurückhaltende Beleuchtung tragen dazu bei, den Wandel der Themen und der Chronologie gut zu erleben und unterstreichen zugleich den dezenten Ton der Ausstellung. Szenografische Elemente finden sich nicht. Der Einsatz von Medien ist auf wenige Elemente beschränkt, wie beispielsweise Bildschirme mit historischen Filmsequenzen. Die Ausstellungstexte sind knapp und sachlich und werden lediglich durch die engagierte Europarhetorik etwas lebendiger. Dieses Bemühen um zurückhaltende Formulierungen führt dazu, dass bei schwierigen Themenlagen wie den sSchlesischen Aufständen sowie dem Kriegsund Vertreibungsgeschehen die Frage nach Akteuren und Motiven der Gewalt weniger Gewicht haben. Berichte von Zeitzeugen werden lediglich im letzten Teil der Ausstellung herangezogen, hier vor allem als Beispiel für persönliche Versöhnungsgeschichten zwischen Deutschen und Polen.

Das Besucherbild der Ausstellung ist in Hinblick auf die in Kapitel 2.5 diskutierte Skala als konventionell anzusehen. Dieser Ansatz wird erfolgreich umgesetzt und der Besucher mit einem attraktiv inszenierten sowie informativen Angebot an die schlesische Geschichte herangeführt. Die Ausstellung verfolgt keinen konsequent multiperspektivischen Ansatz, sondern basiert auf einem wissenschaftlich ausgewogenen und mit einer europäischen Rhetorik verbundenen Narrativ. In der Ausstellung wird der Besucher nicht mit alternativen Geschichtsdeutungen konfrontiert und es gibt keine partizipativen Elemente.

Die Darstellung von Flucht und Vertreibung der Deutschen am Ende des Zweiten Weltkrieges weicht nicht vom sachlichen Stil ab. Sowohl die entsprechenden Ausstellungstexte als auch die ausgestellten Objekte bleiben durch ihre Inszenierung emotional distanziert, allerdings durch die offene Darstellung der Fantasie und den Anknüpfungsmöglichkeiten der Besucher überlassen. Gleichwohl ist das Bemühen erkennbar, widerspenstige Exponate, die dem Ausstellungsnarrativ entgegenlaufen könnten, durch die 
illustrative Rahmung der Objekte und die bewusst eingeschränkte Sicht auf die Ausstellungsstücke in den Wandvitrinen einzuhegen. In diesem Ausstellungsteil erfährt der Besucher einiges über verschiedene Zwangsmigrationserfahrungen, aber wenig über Gewalterfahrungen sowohl durch die Rote Armee als auch bei den verschiedenen Phasen der folgenden Vertreibung durch polnische Akteure. Auch wenn die Ausstellung sich um eine historische Erzählung und Differenzierung der Ereignisgeschichte bemüht und die verschiedenen Stadien chronologisch zu trennen versucht, überwiegt der Eindruck einer vom Nationalsozialismus heraufbeschworenen Naturkatastrophe.

Die nationalsozialistische Vorgeschichte und die deutsche Kriegs- und Besatzungspolitik zeigt das SMG am Beispiel Schlesiens umfassend und unterstreicht diese durch die räumliche Verknüpfung als Kontext der Vertreibungen. Bei der Erzählung der Zwangsmigration aus Schlesien nach dem Zweiten Weltkrieg wird zugleich auf die Schicksale der ähnlich betroffenen Polen, Ukrainer und Juden eingegangen, die ausstellungsgestalterisch und sprachlich parallelisiert werden. Die Vertreibung erscheint also als ein entscheidendes Kriegs- und Nachkriegsphänomen, von dem nicht nur die Deutschen betroffen waren; eine gewichtende Unterscheidung der Geschehnisse wird nicht vorgenommen. Interessant ist die kurze Erwähnung des Nachkriegsinternierungslagers Lamsdorf/Łambinowice in Oberschlesien. Die zurückhaltende Darstellung zeigt sich an dem das Lager thematisierenden Objekt - das Manuskript des Berichtes des deutschen Lagerarztes. Das Papier kann leicht übersehen werden, wodurch Bedeutung und Funktion der Lager im Zusammenhang mit Vertreibung, Ausbeutung und Zwangspolonisierung von Oberschlesiern nicht deutlich wird.

Die Ausstellung entwickelt für Schlesien kein multikulturelles Narrativ und diskutiert kaum die ethnische und nationale Heterogenität und Hybridität Oberschlesiens. Die polnischen Elemente seiner Geschichte tauchen nur am Anfang der Chronologie als Spuren sowie am Ende wieder verstärkt auf, der böhmisch-tschechische Einfluss lediglich am Rande. Kurz: Mit dem postulierten Abschluss der Germanisierung Niederschlesiens im Mittelalter endet auch eine entsprechende multi-nationale Geschichte; in Oberschlesien wird diese erst wieder mit den im 19. Jahrhundert von außen hineingetragenen Einflüssen (sowohl aus dem Reich als auch aus den polnischen Teilungsgebieten) relevant. Im Zusammenhang mit den >Schlesischen Aufständen ‘ fällt neben der erwähnten betont neutralen Sprache auf, dass die Frage der Berechtigung oder NichtBerechtigung der polnischen respektive deutschen Ansprüche auf Oberschlesien auf dieses Gebiet nicht weiter besprochen wird. Es überwiegt der zurückhaltende Blick auf die Ereignisse mit einem leichten Übergewicht der deutschen Perspektive, was sich in Hinblick auf die Darstellung der Konflikte generalisieren lässt. ${ }^{134}$ Die deutsche Minderheit in Oberschlesien nach 1945 und 1989 und damit verbundene politische Fragen

134 Zu einem ähnlichen Ergebnis in Hinblick auf die Gesamterzählung kommt auch Graaf: »Although the museum's aim appears to be for openness to historical debate there is, nonetheless, a tendency for Germany to be shown as leading the way in the development of Silesia as a cultured land and also as rightful possessors of the province. [...] The impression given is that Silesia would not have developed without the Cermans who were peacefully invited into the country«. Graaf: After the Expulsions, 2014, S. 246. 
werden kurz erwähnt, ohne aktuelle Problemlagen genauer zu diskutieren. Die Oberschlesische Autonomiebewegung hat keinen Platz in der Ausstellung, was aber auch damit erklärbar ist, dass dieses Phänomen erst Ende der 2000er Jahre an Bedeutung gewann.

Ein zentrales Narrativ lässt sich für die Ausstellung schwer definieren. Die nur punktuelle Besprechung von Identitätsfragen unterliegt dem Schwerpunkt, kunsthistorisches Schaffen zu zeigen. Wenn ein bestimmendes Narrativ herausgestellt wird, ist es das selbst postulierte, dass Schlesien als bedeutende Kulturregion im »Herzen Europas« dargestellt werden soll. Dieses zieht sich aber, wie gezeigt, keineswegs durch die gesamte Ausstellung, noch werden bei jedem Thema intensiv europäische Bezüge erörtert. Es ist ein Postulat, ein Verständnis, in dem eher erkennbar wird, als was die Autoren Schlesien nicht definieren möchten: In Abgrenzung zur älteren deutschen Schlesienforschung fehlen weitgehend Vorstellungen vom deutschen >Kulturträgertum<, vom sewigen Kampf von Germanen und Slawen Osten oder einer >Brücke des Reiches $\triangleleft{ }^{135}$ Die Vermeidung dieser bei älteren Generationen durchaus noch vorhandenen und in Polen abgelehnten Erzählungen kann somit auch als ein Narrativ verstanden werden. Hier gilt einmal mehr, dass das Entscheidende unter Umständen das ist, was nicht erzählt wird. Einschränkend sei erwähnt, dass im mittelalterlichen Teil der Ausstellung und durch die sparsame Erwähnung der frühen Piastenherrschaft durchaus das Narrativ des deutschen Kulturträgers angedeutet, aber nicht weiter - und schon gar nicht mit aggressiven Tönen - ausgeführt wird.

Grundsätzlich hält sich die Ausstellung mit der Herstellung aktueller Bezüge zurück. Lediglich das Verständnis von Schlesien als europäischer Brückenregion und das postulierte Ziel der Ausstellung, zum besserem Verständnis der europäischen Nachbarn beizutragen, fällt im weiteren Sinne in diesen Rahmen. Durch den chronologischen Endpunkt 1945, der nur punktuell durch die Erinnerungs- und Versöhnungsgeschichten erweitert wird, bleiben Positionierungen zu den aktuellen Entwicklungen weitgehend aus. Eine Ausnahme ist hier die >Wiederentdeckung S Schlesiens als Teil Görlitzer Identität nach 1989.

Aus den hier angeführten Beobachtungen ergibt sich, dass das Schlesische Museum zu Görlitz die schlesische Geschichte weitgehend aus einer deutschen Perspektive erzählt, die die polnische (und tschechische) lediglich am Rande behandelt. Das Bemühen um eine europäische Erzählung wird nicht im wissenschaftlichen Sinne als Verflechtungsgeschichte verfolgt, sondern in Form einer vorsichtigen europäischen Meistererzählung, in der Schlesien ein konstitutiver und kulturell bedeutender Teil Europas ist, in dem aber auch nationale Konfliktlagen ihren Ort haben. Die Darstellung von Flucht und Vertreibung und anderen kontroversen Themen ist dabei von starker Distanz geprägt. ${ }^{136}$

135 Vgl. hierzu die Europarhetorik kritisch in die langen Linien der deutschen geschichtspolitischen Instrumentalisierung Schlesiens einordnend: Weber: Über die Notwendigkeit, 1998, S. $22 \mathrm{f}$.

136 Eckersley sieht hierin gerade einen Vorzug in Vergleich zu anderen Vertreibungsausstellungen. Die objekt-zentrierte Darstellung ist emotional und ästhetisch ansprechender als vermeintlich neutrale Präsentationen: Eckersley: Walking the Tightrope between Memory and Diplomacy? 2016, S. 111. 
Durch seine zurückhaltende Darstellung bleibt das Museum offen für verschiedene Besuchergruppen. Kunst- und Kulturinteressierte können sich hier wiederfinden, ebenso wie der schlesische Heimatkreis, dem keine dem gängigen Narrativ im Vertriebenenmilieu grundsätzlich widersprechende Darstellung, höchstens eine etwas knappe Geschichte der Vertreibung erzählt wird - die aber durch die ausgestellten Objekte für diesen trotzdem ansprechend sein kann. Polnische oder gar tschechische Besucher werden sich in der Ausstellung weniger wiederfinden, wiewohl sie gegen die Darstellung der kontroversen Themen wenig Einspruch erheben dürften. Dafür können sie ihnen unbekannte oder weniger bekannte Teile der schlesischen Geschichte kennenlernen. Umgekehrt werden deutsche Besucher nicht unbedingt die Bedeutung Schlesiens für die polnische nationale Erzählung erkennen können.

\subsubsection{Rezeption der Ausstellung}

Die deutsche Presse berichtete 2006 überregional über die Eröffnung der Ausstellung. ${ }^{137}$ Es überwogen positive Besprechungen, die sich zumeist explizit mit dem Thema der Vertreibung auseinandersetzten:

»Das schwierige Thema Vertreibung mussten Bauer und seine Mitarbeiter auf etwa 20 Quadratmetern unterbringen. Dabei lag ihnen nichts an einer breiten detailreichen Erzählung mit sentimentalen Erinnerungen. Weder eine Heimatstube noch eine Gedenkstätte sollte im Museum entstehen, sagt der Direktor. Es galt vielmehr, die Flucht der deutschen Bevölkerung nach dem Zweiten Weltkrieg, die Ansiedlung polnischer Bewohner in Schlesien und das Schicksal der Vertriebenen in Ost- und Westdeutschland nüchtern und dokumentarisch darzustellen. Sparsam werden Exponate wie Fluchtkoffer oder Kleidungsstücke von Flüchtlingen eingesetzt, um die sachlichen Texte zu illustrieren. « $^{138}$

In der Besprechung des Tagesspiegels wird der deutsch-polnische Ansatz hervorgehoben und die Ausstellung, die »mit Rhythmusgefühl, Überblick und dem Mut zur Pointe« vorgehe, insgesamt sehr positiv bewertet:

»Das Schlesische Museum vermittelt bis in die Objektbeschriftung hinein ein differenziertes Ceschichtsbild in deutscher und polnischer Sprache. Für beide Länder ein Novum. [...] Wie man die großen historischen Zusammenhänge mit den kleinen privaten Erfahrungen zusammenbringt, aus denen sich Geschichte zusammensetzt, wird in Görlitz vorbildlich vorgeführt - und das, ohne die Komplexität des Themas zu verraten. In den ersten vier Wochen kamen denn auch schon über 10000 Besucher. $\ll^{139}$

In der Frankfurter Allgemeinen Zeitung betonte man im Monat der Eröffnung das große polnische Interesse an dem Museum sowie die notwendigen und erfolgreichen Kooperationen. ${ }^{140}$ Die polnische Berichterstattung über die Eröffnung war deutlich kritischer. Der Ausstellung wurde vorgeworfen, nicht ausreichend ausgewogen zu sein,

137 Vgl. Graaf: After the Expulsions, 2014, S. $252 f$.

138 Schlesisches Museum öffnet in Cörlitz. Der Tagesspiegel. 10.05.2006.

139 Zajonz: Ein Schloss für viele Schlüssel. Der Tagesspiegel. 11.06.2006.

140 Spelsberg: Schlesisches Museum Görlitz. FAZ. 13.05.2006. 
dem Nationalsozialismus sowie generell dem polnischen Leiden zu wenig Beachtung zu schenken - und unter zu großem Einfluss der deutschen Vertriebenenverbände zu stehen. ${ }^{141}$ Auch von Seiten der liberalen Gazeta Wyborcza kam es zu Kritik, vor allem an einer vermeintlich euphemistischen Darstellung des Holocausts, der durch fröhliche Täterfotografien der SS-Wachmannschaft des schlesischen Konzentrationslagers Groß Rosen verharmlost würde. ${ }^{142}$

Der nationalkonservative Autor Piotr Semka mahnt an, dass die Darstellung der schlesischen Geschichte in Deutschland für Polen nicht irrelevant ist:

»Die Eröffnung dieser Institution am 13. Mai war in Polen fast ohne Echo. Doch die Vision der schlesischen Geschichte, die das Museum fördert, kann den Polen nicht gleichgültig sein. $\ll^{143}$

Der Autor bedauert schließlich, dass das schlesische Mittelalter, das von besonderer Bedeutung für die polnisch-schlesische Identität sei, nur am Rande behandelt wird:

»In der Bearbeitung historischer Texte zeigen sich große Anstrengungen, den polnischen Standpunkt zu berücksichtigen, aber dies betrifft vor allem das besonders sensible 20. Jahrhundert. Was die Geschichte vom 10. Jahrhundert bis zum 15. Jahrhundert betrifft (die wichtigste für die polnische nationale Identität Schlesiens), wecken rätselhafte Angaben den Wunsch nach Polemik. $\ll^{144}$

Implizit kritisiert Semka die Parallelisierung der Positionen bei der Teilung Oberschlesiens und den 'Schlesischen Aufständen ‘. Aus polnischer Perspektive ist er mit der Darstellung der Vertreibung nicht vollständig einverstanden, besonders in Bezug auf die vermeintliche Unschuld der Vertreibungsopfer:

»Ein gesondertes Thema ist die Frage der Deportation von Deutschen nach dem Zweiten Weltkrieg - hier kollidiert die polnische Sensibilität, die Deportationen als Folge des von den Deutschen begonnenen Krieges anzusehen mit der deutschen Überzeugung, die annimmt, dass es keine Rechtfertigungen für die Vertreibung geben kann. Die These der Ausstellung, die deutschen Opfer von Vertreibungen seien Opfer nationalistisch angeheizter Vergeltung für Verbrechen, die im Namen der deutschen Nation begangen worden seien, muss Besorgnis erregen. Und jeder, der ein Opfer des Nationalismus wird, ist unschuldig. ${ }^{145}$

141 So fasst Graaf die Kritik zusammen: Graaf: After the Expulsions, 2014, S. $253 f$.

142 Ebd.

143 »Otwarcie tej instytucji 13 maja przeszło w Polsce niemal bez echa. A przecież wizja historii Śląska, jaką propaguje muzeum, nie może być Polakom obojętna.« Semka: O nas za nas. Wprost. 25.06.2006.

144 »W redagowaniu tekstów dotyczących historii widać wielki wysiłek, by uwzględniać polski punkt widzenia, ale dotyczy to głównie najbardziej drażliwego XX wieku. Co do historii obejmującej okres od X wieku do XV wieku (najbardziej istotny dla polskiej tożsamości państwowej Śląska), enigmatyczne dane budzą chęć polemiki.«Ebd.

145 »Osobny temat to kwestia deportacji Niemców po Il wojnie-tu zderza się polska wrażliwość, uznająca deportacje za skutek rozpętania wojny przez Niemców, z niemiecką opcją, zakładającą, iż dla wysiedleń żadnych usprawiedliwień być nie może. Niepokój musi budzić teza wystawy, że niemieckie ofiary wypędzeń stały się ofiarami nacjonalistycznie podsycanego odwetu za zbrodnie popeł- 
Semka hätte sich eine ausführlichere Thematisierung der Verbindung von Polen und Schlesien in der frühen Neuzeit ebenso wie der `Schlesischen Aufständeく als auch der Besiedlung Schlesiens nach 1945 durch die Vertriebenen aus den kresy gewünscht. Letztlich ordnet er das Museum als deutsches Heimatmuseum ein, in dem Tschechien weitgehend außer Acht gelassen wird, sowie die polnischen Bezüge eher als höfliches `Extra<, denn als integraler Bestandteil der Ausstellung zu verstehen seien:

»Die Ausstellung präsentiert eine deutsche Sicht auf die Geschichte Schlesiens, angereichert mit Meinungen, die der polnischen historischen Sensibilität entsprechen - übrigens sind die Verweise auf die tschechischen Akzente in der Geschichte Schlesiens ungewöhnlich klein. Es ist daher eher ein deutsches Heimatmuseum als ein Museum der europäischen Kulturregion. ${ }^{146}$

Fragmente der Ausstellung, die den polnischen Standpunkt berücksichtigen, sind eher Höflichkeit als Partnerschaft, um eine Vision der Ceschichte dieses Teils Europas zu schaffen. ${ }^{147}$

Schließlich fordert er ein gemeinsames, gleichberechtigt getragenes deutsch-polnisches Schlesien-Museum, in dem beide Seiten ihre Visionen auf Augenhöhe einbringen können. Die geschichtspolitische Sprengkraft des Museums und der schlesischen Identität von Görlitz allgemein sieht er darin, dass - auch wenn die Ausstellung dies nicht hergebe - es doch eine Grundlage für einen Vorposten deutscher Schlesienansprüche werden könne:

»Das schlesische Museum in Görlitz muss selbst nicht problematisch sein, aber wenn jemand beginnt, ein schlesisches Piemont zu schaffen, einen Brückenkopf, der die Traditionen des deutschen Schlesien wieder aufleben lässt, wird das Museum für die Polen mit dem Schlimmsten assoziiert werden. $\ll^{148}$

Auch wenn diese Ausführungen sicher spitze Formulierungen sind, die dem Charakter der Zeitung Wprost und der politischen Einstellung Semkas entsprechen, zeigt die Besprechung recht zielgenau die Schwachstellen der Ausstellung respektive des gesamten Projektes aus polnischer Perspektive. In einer Besprechung der Ausstellungseröffnung in der Rzeczpospolita wird die Grundkonstruktion des Museums mit seinem Schwerpunkt auf einer deutschen Erzählung, dem vermeintlich starken Einfluss der Landsmannschaft und seiner Lage in der erst nach 1815 an Schlesien gefallenen Stadt Görlitz ebenfalls kritisiert: »Schlechter Standort, schlechte Idee «. ${ }^{149} 2013$ besuchte die polnische

niane w imieniu narodu niemieckiego. A każdy, kto staje się ofiarą nacjonalizmu, jest niewinny.« Semka: O nas za nas. Wprost. 25.06.2006.

146 »Wystawa przedstawia niemiecką wizję historii Śląska, wzbogaconą o opinie wychodzące naprzeciw polskiej wrażliwości historycznej - notabene nawiązań do czeskich akcentów w historii Śląska jest niezwykle mało. Jest to więc bardziej niemieckie Heimatmuseum niż muzeum europejskiego regionu kulturowego.«Ebd.

147 »Fragmenty ekspozycji, które uwzględniają polski punkt widzenia, to raczej grzeczność niż partnerstwo przy tworzeniu wizji historii tego rejonu Europy.«Ebd.

148 »Samo muzeum śląskie w Görlitz nie musi być konfliktogenne, ale jeśli ktoś zacznie z tego miasta tworzyć śląski Piemont, czyli przyczółek wskrzeszania tradycji niemieckiego Śląska, to także muzeum zacznie się kojarzyć Polakom jak najgorzej.«Ebd.

149 »Zła lokalizacja, zły pomysł.«Jendroszczyk: Pamięć ziem utraconych. Rzeczpospolita. 13.05.2006. 
Journalistin Anna Ładuniuk, die der anhaltenden Diskussionen um das Muzeum Śląskie in Kattowitz überdrüssig war, das Haus. ${ }^{150}$ Die Ausstellung wird von ihr als "groß, modern, multimedial« betrachtet und sie erkennt darin auf ironische Weise einen typisch deutschen Charakter:

»Allgemeiner Eindruck? Die Exponate sind systematisiert, wie bei den Deutschen üblich, sachlich, emotionslos, aber konsequent. Alle Aspekte werden erfasst: große Politik, religiöse Angelegenheiten (Reformation, Gegenreformation) und Nationalität, Handwerk, Kunst, Literatur, Alltag, Menschen. Objekte, Dokumente, dann Fotografien.... Am ausführlichsten ist der Teil der Ausstellung über die Umsiedlungen nach 1945. Alles in allem - es sind mindestens ein paar Stunden Besichtigung. ${ }^{151}$

Neben der Schilderung dieser Eindrücke beklagt sie, dass Oberschlesien (die verschiedenen Städte und auch die Aufstände) nur als Peripherie behandelt werde, was für Polen besonders problematisch sei, da für sie dort das eigentliche Schlesien liege. Ebenso wenig einverstanden ist sie mit der impliziten Darstellung, dass Schlesien ab dem 13. Jahrhundert »tylko tak« (einfach so) die ganze Zeit zum deutschen Kultur- und Sprachraum gehört habe. ${ }^{152}$

Die nationalkonservative Kritik Semkas spiegelt sich nach Auffassung Bauers in der Kritik der rechten Strömungen der Landsmannschaft Schlesien: »Während uns die einen eine Geschichtsbetrachtung aus deutscher Perspektive vorwerfen, unterstellen uns die anderen eine >polenfreundliche Sicht und >Bücklinge vor Polen. « Hier scheine es aber wesentlicher weniger um die Ausstellung zu gehen als um die Verteidigung »nationalistischer Weltbilder«. Schließlich verbindet er damit einen Arbeitsauftrag für das Schlesische Museum: »Bis ein gemeinsames, von europäischem Geist geprägtes Verständnis der Geschichte Schlesiens sich etabliert hat, bleibt noch einiges zu tun. $\ll^{153}$

Rudi Pawelka äußerte sich in der Verbandszeitschrift der Schlesischen Landsmannschaft Anfang Juli 2006 zur Ausstellung. Als generelle Einführung in Geschichte und Kultur Schlesiens eigne sie sich, kranke aber an verschiedenen, von der Landsmannschaft schon vorab kritisierten Details und einer starken politisch-pädagogischen Agenda. Die nationalsozialistische Geschichte Schlesiens sei zudem unverhältnismäßig stark gewichtet, polnische Vergehen hingegen weitgehend ausgeklammert. Um letztere sSchlagseite auszugleichen, habe man schon vorab empfohlen, einen Ausstellungsteil zur Zeit nach 1945 über Schlesien unter kommunistischer Diktatur zu integrieren und damit die doppelte Diktaturerfahrung der Region zu berücksichtigen. Die Darstellung der Vertreibung stehe in keinem Verhältnis zu ihrer tatsächlichen Bedeutung und sei zudem verharmlosend dargestellt: "In Verbindung mit den polnischen Neusiedlern erscheint die Vertreibung fast wie ein normaler Aus- und Einzug, die völkerrechtliche

150 Ładuniuk: Muzeum Śląskie, opcja niemiecka. Dziennik Zachodni. 04.03.2013.

151 »Ogólne wrażenie? Ekspozycje usystematyzowane, jak to u Niemców, rzeczowo, bez emocji, ale konsekwentnie. Uchwycone wszystkie aspekty: wielka polityka, sprawy religijne (reformacja, kontrreformacja) i narodowościowe, rzemiosło, sztuka, literatura, życie codzienne, ludzie. Przedmioty, dokumenty, potem fotografie... Najobszerniejsza jest część ekspozycji związana z przesiedleniami po 1945 roku. W sumie - co najmniej kilka godzin zwiedzania.«Ebd.

152 Ebd.

153 Bauer: Zwischen Denkmal und kulturpolitischem Forum, 2007, S. 84. 
Dimension sucht man vergeblich.« Die Darstellungen von Antike und Mittelalter sei zudem einseitig von einem polnischen Standpunkt aus geprägt. Dem Titel des Beitrages gemäß verbleibt Pawelka schließlich mit der »Hoffnung auf die Einsicht in notwendige Korrekturen. ${ }^{154}$

Im Rahmen eines multinationalen Forschungsprojektes besuchten Museologen und Erinnerungsforscher unter anderem das Schlesische Museum zu Görlitz. ${ }^{155}$ Diese lobten es für die zurückhaltende Darstellung schwieriger Themen:

»The overall positive atmosphere of the exhibition narratives, despite containing stories of hardship and trauma, can be attributed to the museum's careful balancing of emotions combined with a sensitivity to and awareness of the different perspectives on the topic. . $^{156}$

Weiter unterstreichen sie den Erfolg der Bemühungen, keine nationalen Frontstellungen in ihrer Darstellung zu wiederholen und keine simple Erzählung von »us and them « $\mathrm{zu}$ bedienen. Auch wenn sie die Intention der Museumsmacher verstehen, die Ausstellung im Jahre 1945 mit dem Ende des deutschen Schlesien zu beschließen und die Verantwortung der weiteren Darstellung der schlesischen Geschichte in Polen zu sehen, bedauern sie die nicht ergriffene Chance, die Thematik zu aktualisieren und ein gegenwärtiges, positives Schlesienbild (mit) zu schaffen. ${ }^{157}$

Positiv über die Ausstellung äußert sich auch Catherine Perron in ihrem Artikel über den Paragraph 96 als Instrument der deutsch-polnischen Versöhnung: Ein multiperspektivischer Ansatz, der »dem dialogischen Erinnern im Sinne von Assmann sehr nahe« komme, stelle verbunden mit einer klaren Präsentation von Nationalsozialismus, Besatzungsterror und der komplexen Opfer-Täter-Geschichte sowie der wechselseitigen Vertreibungsgeschichte die »traumatischen Erfahrungen des Zweiten Weltkrieges« angemessen dar. ${ }^{158}$

\subsubsection{Zusammenführende Betrachtung}

Die erwähnten polnischen Stimmen zur Ausstellung passen zu den bereits entwickelten Überlegungen, dass diese für ein polnisches Publikum nur eingeschränkt von Interesse ist - zumindest insofern, wenn sie auch etwas über >ihr Schlesien erfahren möchten und eine mehr oder minder gleichberechtigte Darstellung erwarten. Diese Anknüpfungspunkte, so zum Beispiel an die polnische Schulbildung und die populäre Geschichtskultur, sind aber von großer Bedeutung für die erfolgreiche Vermittlung. Die Herrschaft der Piasten und die Zugehörigkeit zum frühen polnischen Staatswesen hätte so beispielsweise durchaus ein größerer und eigener Bereich sein können.

154 Pawelka: Schlesisches Museum zu Görlitz - Viele Korrekturen notwendig. Schlesische Nachrichten. 01.07.2006.

155 Siehe für ihren knappen Durchgang durch die Ausstellung: Eckersley: Walking the Tightrope between Memory and Diplomacy? 2016, S. 109-112.

156 Ebd., S. 114.

157 Whitehead; Eckersley et al.: Place, Identity and Migraton and European Museums, 2016, S. 44.

158 Vgl. Perron: § 96 Bundesvertriebenengesetz, 2016, S. $514 f$. 
Interessant ist, dass sowohl Semka als auch Ładuniuk einen Schwerpunkt der Ausstellung im 20. Jahrhundert und sogar auf der Vertreibung sehen. Dies sagt mehr über die Wahrnehmung als die tatsächlichen Gegebenheiten aus, bei denen das 20. Jahrhundert nur ein Element und vor allem die Vertreibung nur einen kleinen Bereich der 1950 Quadratmeter Museumsfläche darstellen. Möglicherweise liegt dies an der Position am Ende der Ausstellung, die den Besucher mit diesem Geschehen als zentraler Empfindung zurücklässt. Ähnlich betrachten es auch Eckersley und Whitehead, die allerdings einen positiven Ausblick für wünschenswert halten. Der Artikel der Wprost zeigt sich selbst mit der äußerst zurückhaltenden Darstellung der Vertreibung in der Ausstellung unzufrieden, worin er sich unter umgekehrten Vorzeichen mit der Einschätzung Rudi Pawelkas trifft.

Dieser Punkt führt zu einer der Schwächen der Ausstellung: Die vorsichtige Darstellung kontroverser Themen vermeidet eigene Positionierungen und Wertungen der Ausstellungsmacher und zeichnet dadurch ebenso wenig die Konfliktgeschichte über die unterschiedlichen historischen Perspektiven nach, wie sie den Besucher zu seiner eigenen Positionierung einladen. Das Schlesische Museum hat mit seiner Dauerausstellung die Chance nicht ergriffen, zu einem Ort der konstruktiven Auseinandersetzung zwischen Deutschland und Polen über das Thema der Vertreibung zu werden. Dabei hätte eine Darstellung des >deutschen Standpunktes` (hier verstanden als dem der deutschsprachigen Schlesier) zur Vertreibung und dessen kritische Erörterung ebenso wie eine Darstellung polnischer und tschechischer Perspektiven hilfreich sein können. Die Zurückhaltung der Ausstellungsmacher wird auch entsprechend als »Höflichkeit« verstanden, was als Form notwendig, aber inhaltlich nicht ausreichend für eine konstruktive deutsch-polnische Auseinandersetzung über die Vergangenheit sein kann.

Dennoch sollen an das Museum keine Ansprüche und Aufgaben herangetragen werden, die es sich selbst nicht aufgetragen hat, zumal es sein Ziel ist, eben kein >Vertreibungsmuseum $<$ zu sein. Eine mögliche Option, ohne den Grundcharakter der Ausstellung zu verändern, wäre hierbei ein multiperspektivischer in Ergänzung zu dem gewählten verbindenden Ansatz. Die Wunden, die berechtigten und unberechtigten Vorwürfe und die unterschiedlichen Perspektiven auf die verschiedenen Bereiche der Geschichte hätten auch ohne das Befördern einer nationalen Dichotomisierung so dargestellt werden und im Idealfall eine grenzüberschreitende, konstruktive Diskussion voranbringen können. ${ }^{159}$

Das Schlesische Museum zu Görlitz ist ein Kind seiner Zeit. Der versöhnenden Phase der 1990er Jahre schloss sich der Weg zur EU-Osterweiterung 2004 an. Die kontroversen Debatten um das Zentrum gegen Vertreibungen machten zugleich deutlich, dass die historische Thematik nach wie vor Sprengkraft besitzt und daher eine besondere Rücksichtnahme im deutsch-polnischen Kontext notwendig ist. Die Ausstellung ist von diesem Zugehen auf die Nachbarn geprägt, sodass manche in ihr nicht aufgearbeitete Konfliktlinien lediglich überdeckt werden. Gleichzeitig schienen die Bedingungen 2006 noch nicht gegeben, eine konsequente deutsch-polnische (-tschechische) Ge-

159 Vgl. für den Vorschlag, Debatten und gegenläufigen Stimmen und Antagonismen im Museum Platz zu geben: Whitehead; Eckersley et al. (Hg.): Museums, Migration and Identity in Europe, 2016, S. 55. 
schichte Schlesiens, die zugleich die starren Nationskonzepte ein Stück weit aufbricht, in einem Museum zu zeigen, in dem auch die Vertreibung der deutschen Schlesier - in ihrem Kontext - ihren angemessenen Platz hätte.

Dennoch: Das Schlesische Museum zu Görlitz ist ein zu Recht gelobtes kulturhistorisches Museum. Zur vorliegenden Fragestellung, die in seinem Selbstverständnis nur einen Teil ausmacht, kann die Dauerausstellung nur bedingt beitragen - zu sehr ist sie in ihrer geschichtspolitischen Ausrichtung Europa sowie der besonderen Rücksichtnahme gegenüber ihren Nachbarn verhaftet. Die Sonderausstellungen und Veranstaltungen zeigen zugleich auf, dass das Museum die Dauerausstellung in ihren Inhalten weiterdenkt. $^{160}$

Ehe wir uns nun dem neun Jahre später eröffneten Muzeum Śląskie und seinen Antworten auf die schlesische Geschichte in Kattowitz zuwenden, sei noch einmal Semka zitiert. Dieser schließt seinen Artikel mit der Überlegung eines gemeinsamen deutschpolnischen Museums ab und fragt zugleich selbstkritisch, wo das polnische Pendant bleibe:

»Was würde passieren, wenn die Deutschen uns vorschlügen, ein gemeinsames Museum Schlesiens mit gleicher Kostenaufteilung zu bauen? Zum Beispiel hat das Museum ein Budget von 900.000 Euro pro Jahr. Würden die Polen zu solchen Investitionen fähig sein? Wenn Deutschland seine eigenen Museen baut, sind wir oft nicht einverstanden mit ihrer Geschichte, aber tun wir etwas, um unsere eigene schlesische Identität zu schaffen? Warum gibt es in Breslau kein Schlesisches Museum? « ${ }^{161}$

\subsection{Muzeum Śląskie in Kattowitz}

\subsubsection{Geschichte}

Vor dem Ersten Weltkrieg gab es zunächst nur Planungen für ein Oberschlesisches $\mathrm{Mu}$ seum. Das änderte sich nach dem Krieg, als Polen und Deutschland den Kampf um die Zugehörigkeit Oberschlesiens nunmehr besonders über die Kulturpolitik führten. Die Planungen der jeweiligen Gegenseite wurden stets genau beobachtet und entsprechend agiert und reagiert. ${ }^{162}$ Den polnischen Planungen für ein Muzeum Śląskie in Kattowitz standen deutsche Aktivitäten zur Errichtung eines Oberschlesischen Landesmuseums in Beuthen/Bytom gegenüber. ${ }^{163}$ Nach dem Gründungsbeschluss des Schlesischen Sejms 1929 wurde das polnische Museum zunächst Mitnutzer des gewaltigen Neubaus des

160 Siehe Kap. 6.2.2, S. $288 f$.

161 Semka: O nas za nas. Wprost. 25.06.2006. „Co by się stało, gdyby Niemcy zaproponowali nam zbudowanie wspólnego muzeum Śląska przy równym podziale kosztów. Przykładowo, muzeum ma budżet 900 tys. euro rocznie. Czy Polacy byliby zdolni do takich inwestycji? Kiedy Niemcy budują własne muzea, często nie zgadzamy się z ich ocenami historii, ale czy robimy coś dla tworzenia własnej śląskiej tożsamości? Dlaczego we Wrocławiu nie ma muzeum Śląska?«

162 Polak-Springer: Recovered Territory, 2015, S. $98 \mathrm{f}$.

163 Ebd., S. 107-109. Vgl. Weger: Museen in Schlesien, 2006, S. 39. 
Sejm, in welchem es erste Ausstellungsaktivitäten entfaltete. ${ }^{164}$ Das Museum in Beuthen ging 1932 an die Öffentlichkeit. ${ }^{165}$ Die Ausstellungstätigkeiten waren darauf gerichtet, den polnischen respektive deutschen Anspruch auf Oberschlesien museal zu untermauern. ${ }^{166}$ Der Neubau des Muzeum Śląskie im Stil der Moderne war bei Kriegsanfang fertiggestellt, das Museum konnte aber nicht mehr eröffnen. ${ }^{167}$ Nach einer zeitweisen Nutzung des Gebäudes als >Auktionshaus` für geraubtes polnisches und jüdisches Eigentum ließen es die deutschen Behörden vermutlich als nicht überschreibbares Symbol des polnischen Anspruchs auf Oberschlesien abtragen. ${ }^{168}$

Nach dem Zweiten Weltkrieg verzichteten die neuen volkspolnischen Autoritäten trotz verschiedentlich erhobener Forderungen auf die Wiedererrichtung eines Schlesischen Museums in Kattowitz, obgleich sie ansonsten in vielen Belangen an die nationalistische Kulturpolitik der Vorkriegszeit anknüpften. ${ }^{169}$ Dafür wurde allerdings das ehemalige deutsche Museum in Beuthen de facto zum Nachfolger des polnischen Zwischenkriegsmuseums, zumal die Deutschen dort einen Teil der geraubten Kattowitzer Sammlung eingelagert hatten. ${ }^{170}$

Gleichwohl blieb der Wunsch nach Wiedereinrichtung eines Regionalmuseums in Katowice bestehen. Auf Basis von Impulsen aus der Bevölkerung sowie späterem Druck der Solidarność wurden in den 1970/80er Jahren die Planungen dafür aufgenommen, die sich jedoch lange hinzogen. Schließlich konnte das Museum 1984 im für den Museumsbetrieb ungeeigneten ehemaligen Gründerzeithotel »Grand Hotel Wiener« eröffnen. Allerdings wurden primär die künstlerische Sammlung sowie einige historische Wechselausstellungen gezeigt, nicht aber eine umfassende historische Dauerausstellung. ${ }^{171}$

Ein progressiver Neustart zeigte sich im Jahre 2008 mit der Übernahme der Leitung durch Leszek Jodliński. ${ }^{172}$ Eine Innovation war die Durchführung von Veranstaltungen auch in oberschlesischer Sprache. Für den bereits seit den 1980er Jahren angedachten und mittlerweile beschlossenen Neubau des Museums entwickelte Jodliński ein Konzept für die historische Dauerausstellung. Mit einem Schwerpunkt auf authentischen

164 Vgl. Szaraniec: Muzeum Ślaskie, 2002, S. 21. Vgl. auch: Polak-Springer: Recovered Territory, 2015, S. $98 \mathrm{f}$.

165 Tomann: Geschichtskultur im Strukturwandel, 2016, S. 153f. Polak-Springer: Recovered Territory, 2015, S. 98f., 108f. Kobielska: Muzea do pamiętania/Museums for Remembering, 2016, S. $181 \mathrm{f}$.

166 Polak-Springer: Recovered Territory, 2015, S. $98 \mathrm{f}$.

167 Vgl. Galusek: Górny Śląsk/Upper Silesia, 2016, S. $22 f$.

168 Polak-Springer: Recovered Territory, 2015, S. 157.

169 Szaraniec: Muzeum Ślaskie, 2002, S. 22. Vgl. Polak-Springer: Recovered Territory, 2015, S. 98, 190197.

170 Szaraniec: Muzeum Ślaskie, 2002, S. 21f. Siehe auch: Polak-Springer: Recovered Territory, 2015, S. 196. Vgl. zur Entwicklung der polnischen Museumslandschaft in Schlesien nach 1945: Weger: Museen in Schlesien, 2006, S. $41 \mathrm{f}$.

171 Vgl. für das Museum von 1984 bis zum Neubau: Tomann: Geschichtskultur im Strukturwandel, 2016, S. 256-264. Siehe auch: Wiatr: Eine Schifffahrt ins Ungewisse, 2013, S. 69f. Siehe für die Aktivitäten des Museums von 1984 bis zur Grundsteinlegung des neuen Schlesischen Museums im Dezember 2005 auch: Szaraniec: Muzeum Ślaskie, 2006, S. 47-61.

172 Jodliński ist ein aus Gleiwitz stammender Kunsthistoriker (Jahrgang 1967). Wiatr: Oberschlesien und sein kulturelles Erbe, 2016, S. 48. 
Objekten sollte das Museum ein »identitätsstiftende[r] Lernort « der Region jenseits der "zentralstaatlich ausgerichteten Meistererzählung über Oberschlesien« werden. Dafür sollte der Ansatz eines mündigen Besuchers, der eine multiperspektivische Ausstellung besucht, verfolgt werden. Die geplante Ausstellung wollte Jodliński mit dem konstitutiven Merkmal der Region, der Industrialisierung, beginnen lassen. ${ }^{173}$ So sollte diese ein Modell der im Kapitel 6.1 erwähnten Dampfmaschine, verbunden mit einem Zitat Goethes, eröffnen. ${ }^{174}$ Die heftige Kritik an diesem >deutschen Start $<$ bezeichnete Ewa Chojecka ${ }^{175}$ als »ludicrous « und vorgeschoben, da es im Kern um den Widerstand der Vertreter eines polenzentrischen Ansatzes und die politische Kontrolle des »kollektiven Gedächtnisses « sowie die Tradition »of anti-German attitudes « ginge. ${ }^{176}$

Jodliński wollte in seinem Konzept solche historischen Erzählungen und Mythen kritisch hinterfragen und die Offenheit von Identitätsprozessen aufzeigen. Diese Ansätze wurden politisch vielfach attackiert, da er damit die zwei zentralen Elemente des klassischen polnisch-nationalen Narrativs angriff: die oberschlesische Geschichte nicht mit den Piasten im Mittelalter beginnen zu lassen sowie die antagonistische nationale Erzählung der `Schlesischen Aufstände ‘ 1919-1921 in Frage zu stellen. Mit dieser Schwerpunktsetzung würde, so die Kritik, der preußisch-deutschen Geschichte ein zu großer und positiver Raum zugestanden oder schlicht eine rein deutsche Erzählung der Region vorgenommen. ${ }^{177}$ Die Sejm-Abgeordnete Dorota Arciszewska-Mielewczyk (PiS) sprach im Parlament von einem

»verfälschenden pro-deutschen Konzept der Ausstellung, die eine antipolnische Provokation ist und zu einem besonders schmerzhaften Symbol heranwächst. «178

Verbunden mit dem bis weit in die politische Mitte der polnischen Gesellschaft verbreiteten Misstrauen gegenüber Oberschlesien, der oberschlesischen Autonomiebewegung und der deutschen Minderheit, gab es starken Widerstand gegen diese museale Ausrichtung, die immer wieder als deutschfreundlich und antipolnisch bewertet wurde. ${ }^{179}$ Zum Konzept Jodlińskis sagte der Vizewoiwode Piotr Spyra (PO):

173 Zitate und grundlegende Informationen nach: Wiatr: Eine Schifffahrt ins Ungewisse, 2013, S. 6974.

174 Die Vorgeschichte der Region sollte in einigen »Zeitkapseln«thematisiert werden: Tomann: Geschichtskultur im Strukturwandel, 2016, S. 268. Siehe auch ausführlich: Wiatr: Oberschlesien und sein kulturelles Erbe, 2016, S. 53-55. Siehe: Kap. 6.1, S. $276 \mathrm{f}$.

175 Die Kunsthistorikerin Chojecka ist Kuratorin im MŚK und Mitglied des Wissenschaftlichen Beirates des Schlesischen Museums zu Görlitz.

176 Chojecka: Górnośląskie konflikty wokół pamięci historycznej/Upper Silesian Conflicts Concerning Historical Memory, 2013, S. $43 \mathrm{f}$.

177 Tomann: »The Light of History«, 2016. Vgl. Kortko; Ostałowska: Dość całowania ręki niemieckiego pana. Gazeta Wyborcza. 26.06.2013. Siehe auch: Wiatr: Oberschlesien und sein kulturelles Erbe, 2016, S. $49 f$.

178 »zafałszowany proniemiecki scenariusz wystawy jest prowokacją antypolską i urasta do szczególnie bolesnego symbolu. « Jedlecki: Śląsk boi się Niemca. Gazeta Wyborcza. 07.01.2013.

179 Siehe dazu (und ebenfalls die Kombination mit dem Vorwurf der Kooperation mit der oberschlesischen Autonomiebewegung): Ebd. Vgl. Sander: Neueröffnung des Schlesischen Museums in Kattowitz. Deutschlandfunk Kultur. 26.06.2015. Siehe auch: Wiatr: Oberschlesien und sein kulturelles Erbe, 2016, S. 46. Vgl. ebenfalls: Karwat: Im schlesischen Kessel brodelt es, 2013, S. 84. 
»Oberschlesien wird im Ausstellungskonzept aus der Sicht der damaligen deutschen Eliten Schlesiens vorgestellt. Meiner Meinung nach sollte man sich aber auf die Entwicklung konzentrieren, die zur Herausbildung der schlesischen Identität führte. Dieser Prozess begann im Völkerfrühling des 19. Jahrhunderts in Opposition zum Deutschtum. Er führte dazu, dass Schlesien polnisch wurde. Und polnische Kulturinstitutionen dürfen das nicht außer Acht lassen - auch nicht im Namen einer deutsch-polnischen Versöhnung. « $^{180}$

Jodliński verteidigte sein Konzept im schlesischen Sejmik als europäisch und die regionalen Besonderheiten angemessen berücksichtigend und kritisierte zugleich seine Gegner als Vertreter alter volkspolnischer Narrative. Marcin Wiatr fasst seinen Widerspruch so zusammen: »Diese Codes würden vielmehr der aus der Zeit vor 1989 herrührenden nationalstaatlichen Deutungshoheit entspringen, seien vergiftet und basierten auf Mythen und Vorurteilen. ${ }^{181}$ Die für viele Polen anscheinend beängstigende Vielfalt der Region sei aber vielmehr ein Zeichen großen Reichtums: »Wie herausragend und einmalig muss denn die Geschichte einer Region sein, deren Kulturerbe nur dann erschlossen werden kann, wenn man dies ausgehend von den hier bis heute gesprochenen drei Sprachen tut? $^{182}$ Außerdem lasse sich die Geschichte Oberschlesiens auch nicht nachträglich simplifizierend polonisieren. ${ }^{183}$ Während Jodlińskis Amtszeit erfolgte 2011 die Zustimmung der Europäischen Kommission zum Bau des Muzeum Śląskie auf dem Gelände einer ehemaligen Kohlegrube. Von den zunächst veranschlagten etwa 82 Millionen Euro sollten 85 Prozent von der Europäischen Union übernommen werden. ${ }^{184}$ Diese Finanzierung nutzte Jodliński ebenfalls als offensive Rechtfertigung für sein Konzept:

»In der Gazeta Polska wurde mir vorgeworfen, wir hätten für polnisches Celd eine antipolnische Ausstellung entworfen. Da muss man schon anfügen, dass 85 Prozent des Celdes aus EU-Mitteln stammt, und natürlich sollte das ein europäisches Projekt sein, gestaltet im Geist von Minderheitenrechten und Multikulturalität. $\ll^{185}$

Letztlich musste Jodliński 2013 seinen Posten räumen. ${ }^{186}$ Nach einer Station am Schlesischen Museum im tschechischen Troppau/Opava und einer erfolglosen Kandidatur für den Sejm auf einer Liste der deutschen Minderheit, die auch für dieser nicht angehörenden Personen geöffnet war, war er von 2016 bis 2019 Direktor des Oberschlesischen Museums in Beuthen. ${ }^{187}$ Im Frühjahr 2019 wurde er aufgrund von Beschwerden eini-

180 Zitiert nach: Sander: Polen streiten über »Deutschtum« im Museum. Deutschlandfunk Kultur. 09.10.2012.

181 Wiatr: Oberschlesien und sein kulturelles Erbe, 2016, S. 50.

182 Zitiert nach: ebd., S. 51.

183 Ebd.

184324 Millionen PLN: Jest zgoda Komisji Europejskiej na budowę Muzeum Śląskiego. naszemiasto. 27.05.2011.

185 Zitiert nach: Sander: Polen streiten über »Deutschtum« im Museum. Deutschlandfunk Kultur. 09.10.2012.

186 Wiatr: Eine Schifffahrt ins Ungewisse, 2013, S. 69-74.

187 Vgl. zur Kandidatur für den Sejm: KWW Zjednoczeni dla Śląska zaprezentował kandydatów do Sejmu. onet Śląsk. 10.09.2015. 
ger Mitarbeiter entlassen, die ihm arbeitsrechtliche Vergehen vorwarfen. Er selbst hält die Gründe für vorgeschoben und sieht die Ursache in der ihm bereits 2013 in Kattowitz vorgeworfenen »Deutschfreundlichkeit $«{ }^{188}$ Die Ernennung im Jahr 2016 durch die Woiwodschaft Schlesien wurde auf die damaligen politischen Rahmenbedingungen, die Koalition von PO, PSL (Bauernpartei) und der Schlesischen Autonomiebewegung (RAŚ) zurückgeführt. ${ }^{189}$ Jodliński zeigte sich offen gegenüber bereits vorhandenen Überlegungen aus dem Umfeld der RAŚ, in Beuthen eine Ausstellung über die Vertreibungen $\mathrm{zu}$ schaffen und dafür auch die Kooperation mit der deutschen Minderheit zu suchen, er wollte aber ebenso alle anderen Minderheiten und betroffenen Gruppen wie die Vertriebenen aus den kresy ansprechen. ${ }^{190}$ Ewa Chojecka zog aus der Debatte das Fazit:

»[...] we can conclude that the unfortunate historical exhibition of Upper Silesia is a document of the present time: of the conflict of credibility between two incompatible paradigms - one of which involves national homogeneity and its primacy, a model originated in the traditions of education of the People's Republic of Poland, promoting immutability, supported by the superior authority (akin to the old cuius regio eius religio, it seems). Then a new, dynamic approach emerges, one that is in blatant opposition to it and treats cultural tradition as a means of dispute settlement and acceptance of diverse forms of memory and historical narratives, especially those implicit in all borderland regions, including Upper Silesia. The new approach to presenting history aimed at illustrating the constant development. It involved a certain fear, namely, would we dare to abandon set images, which have lost credibility, and - considering potential misjudgment - revise the ancient ideas and view ourselves from a distance, without all the heroics and with just a dash of humour? ${ }^{191}$

Diese pointierte Darstellung zeigt zwei Denkansätze auf, wobei der eine an den Nationalismus der Volksrepublik Polen anknüpft und der andere als neu und dynamisch beschrieben wird. An anderer Stelle macht Chojecka diese Dichotomie nochmals deutlich: Die Vielfalt der Region, das schwierige industrielle Erbe und Hunderte von Jahren außerhalb der polnischen Nationalgeschichte könnten entweder als "fremd und ablehnenswert« oder aber »als Vorbild für das gesamte Europa, das übersät ist mit derartigen Inkohärenzen«, und somit als kulturelle Stärke verstanden werden. ${ }^{192}$ Vertreter eines nationalpolnischen Narrativs verwiesen ihre Gegner hingegen auf die andere Oderseite:

»Wem eine solche Wahrnehmung der Ceschichte Oberschlesiens fremd sei, könne das Schlesische Museum in Cörlitz aufsuchen, das eine deutsche Sicht auf Schlesien zeige. $\ll^{193}$

188 Malinowski: Leszka Jodlińskiego najpierw odwołano za rządów PO, a teraz PiS. Gazeta Wyborcza. 09.03.2019.

189 Leszek Jodliński na czele Muzeum Górnośląskiego. Dziennik Zachodni. 05.04.2016.

190 Biły: »Na pewno nie pominę mniejszości«. Wochenblatt. 19.04.2016.

191 Chojecka: Córnośląskie konflikty wokół pamięci historycznej/Upper Silesian Conflicts Concerning Historical Memory, 2013, S. 44f.

192 Zitiert nach: Tomann: Ceschichtskultur im Strukturwandel, 2016, S. 269f. Tomann greift hier auf Chojeckas interne Bemerkungen zur Vorbereitung der Ausstellung vom Oktober 2012 zurück.

193 Wiatr: Eine Schifffahrt ins Ungewisse, 2013, S. 73. Wiatr gibt hier den Vizewoiwoden Piotr Spyra wieder. 
Dominik Abłamowicz, der ohne Ausschreibung als Nachfolger von Jodliński eingesetzt wurde, musste bereits Mitte 2014 seinen Posten wieder räumen. Der Marschall der Schlesischen Woiwodschaft, Mirosław Sekuła (PO), warf ihm unter anderem unsachgemäße Verwaltung und Organisation vor, die die für 2014 geplante Eröffnung des Museums verzögert habe. ${ }^{194} \mathrm{Ihm}$ folgte die Ausstellungsmacherin Alicja Knast, die die Arbeiten zur zügigen Eröffnung im Jahr 2015 führte. Jodliński geht von einer starken politischen Einflussnahme aus:

»Ich glaube nicht, dass diese Ausstellung in einer freien Arbeitsatmosphäre vorbereitet wurde. Ich weiß, dass es politischen Druck und Einflussnahme gab. Das ist Geschichtspolitik nach Art des kommunistischen Ancien Regime, nach der Methode: Unbemerkt ändern wir ein paar Dinge und tun dabei so, als ob es niemand merkt. $\ll^{195}$

Alicja Knast konterte derartige Vorwürfe:

»Ich bin Direktorin einer Kulturinstitution. In meiner Zeit gab es keinerlei politische Beeinflussung. Deshalb beantworte ich Ihre Frage nicht. Hinter der Kritik der Medien an unserem Konzept steht eine grobe Vereinfachung der Dinge. ${ }^{196}$

Der deutsche Journalist Martin Sander schreibt über Knast: "Alicja Knast ist erfahren in der Organisation zeitgeistgemäßer musealer Eventkultur. Beobachter sprechen ihr Geschick in der geräuschlosen Umsetzung politischer Vorgaben $\mathrm{zu.}$ « ${ }^{197}$ Die historische Dauerausstellung konnte schließlich am 26. Juni 2016 eröffnet werden. Im Herbst 2019 kündigte der neue Woiwode Jakub Chełstowski (PiS) auf Grundlage eines Kontrollberichtes die Kündigung von Knast an, da diese für eine äußerst schlechte und schädigende Haushaltsführung verantwortlich sei. ${ }^{198}$ Es kam zu verschiedenen Protesten und Petitionen von Bürgern, Künstlern und Museologen. Knast wies die Vorwürfe als falsch sowie politisch motiviert zurück. ${ }^{199}$ Die Vorwürfe gegen Knast verbinden sich nach Angaben von Oppositionellen mit den Versuchen des Woiwoden, die oberschlesische Regionalkultur noch stärker zu polonisieren. ${ }^{200}$ Im Januar 2020 stellte Kulturminister Piotr Gliński in einem Brief an den Woiwoden fest, dass es seiner Meinung nach

194 Dyrektor Muzeum Śląskiego może stracić stanowisko. Gazeta Wyborcza. 18.06.2014.

195 Zitiert nach: Sander: Neueröffnung des Schlesischen Museums in Kattowitz. Deutschlandfunk Kultur. 26.06.2015.

196 Zitiert nach: ebd.

197 Ebd.

198 Pawlik: Marszałek chce odwołać dyrektor Muzeum Śląskiego. onet. 16.11.2019.

199 Jedlecki: Artyści zainicjowali protest przeciwko odwołaniu dyrektor Muzeum Śląskiego. Gazeta Wyborcza. 17.11.2019. Jedlecki: Muzealnicy punktują marszałka. Gazeta Wyborcza. 30.11.2019.

200 Proteste rief in diesem Zusammenhang auch die geplante >Reform ‘ des bisherigen Instituts für Regionale Kultur in Kattowitz hervor, das nun »Institut für polnisches Denken Wojciech Korfanty« heißen soll. In einer Petition an den Woiwoden heißt es: »Marschall, das Denken hat keine Nationalität! Es ist nicht polnisch, schlesisch oder deutsch; es ist nicht griechisch, christlich, jüdisch oder muslimisch. Es ist alles auf einmal und kann nur durch den Austausch mit dem, was anders und was äußerlich ist, am Leben bleiben [...]. Über polnisches Denken in Schlesien zu sprechen ist nicht möglich (wenn Sie auf diesen nationalen Qualifikationen bestehen), ohne gleichzeitig deutsche, tschechische und jüdische Cedanken zu erwähnen, um nur das Wichtigste zu erwähnen.«Malinowski: Czy marszałek przedstawi swój pomysł na śląską kulturę? Gazeta Wyborcza. 07.12.2019. 
keine ausreichenden Gründe gäbe, Knast ihres Postens zu entheben, die Entscheidung darüber aber der Woiwodschaft obliege. ${ }^{201}$ Am Ende des Monats wurde Knast aufgrund der erhobenen Vorwürfe entlassen. ${ }^{202}$

\subsubsection{Struktur und Aktivitäten}

Das Muzeum Śląskie (MŚK) unterliegt dem polnischen Museumsgesetz von 1996 und dem Denkmalschutzgesetz von 2003. ${ }^{203}$ Zusammen mit der lokalen und regionalen Selbstverwaltung nach 1989 stärkten diese Gesetze »die Eigenständigkeit und Professionalität " polnischer und oberschlesischer Kultureinrichtungen. ${ }^{204}$ Der politische Einfluss bleibt aber vergleichsweise stark: Der Hauptverantwortliche hierbei ist die Woiwodschaft Schlesien mit dem Woiwoden an der Spitze. Das polnische Museumsgesetz beinhaltet keine klare Regelung in Hinblick auf die Frage nationaler Minderheiten. Formal liegt die Entscheidung, ob und wie Minderheiten in Museen dargestellt werden, bei der Museumsadministration. Wenn sich ein Museum spezifisch für Minderheitenaktivitäten einsetzen möchte, muss es die dafür notwendige finanzielle Unterstützung selbst oder über das Gesetz der nationalen Minderheiten und regionalen Sprachen sicherstellen. ${ }^{205}$

Die Kosten für den Bau des Museums von 2007-2015 lagen zwischen 63 und 80 Millionen Euro. Diese wurden zu 85 Prozent vom European Regional Development Fund finanziert, die restlichen 15 Prozent vom Ministerium für Kultur und nationales Erbe. ${ }^{206}$ Die laufenden Kosten in Höhe von insgesamt etwa 8 Millionen Euro werden zu 75 Prozent von der Woiwodschaft Schlesien und zu 25 Prozent vom Ministerium für Kultur und nationales Erbe getragen (Stand 2016). ${ }^{207}$ Zusätzlich generiert das Museum in Form von Eintrittspreisen, Raumvermietung und als Dienstleister für Kunstrestauration und -transport selbst Einnahmen. ${ }^{208}$

Die Woiwodschaftsverwaltung besetzte den Wissenschaftlichen Rat des Museums zuletzt 2016 mit fünfzehn nationalen und internationalen Wissenschaftlern und Museumsfachleuten, darunter Nicolas Wolf, Professor an der Wirtschaftswissenschaftlichen

201 Jedlecki: Minister kultury do marszałka Jakuba Chełstowskiego. Gazeta Wyborcza. 20.01.2020.

202 Babak: Zarząd woj. śląskiego odwołał dyrektor Muzeum Śląskiego. dzieje.pl. 29.01.2020. Vgl. ausführlich: Szewczuk; Pawlik: Awantura o Muzeum Śląskie. onet Śląsk. 04.02.2020.

203 Kancelaria Sejmu: Ustawa z dnia 21 listopada 1996 r. o muzeach. 07.03.2018. Kancelaria Sejmu: Ustawa z dnia 23 lipca 2003 r. o ochronie zabytków i opiece nad zabytkami. 25.01.2018.

204 Bauer: Schlesien im Museum, 2012, S. 64.

205 Golat: Problematyka mniejszości w działaności muzeów (aspekty prawne), 2017.

206 262.238.555,71 PLN. Vgl. die Website des Museums: https://muzeumslaskie.pl/en/architectureand-space/ (letzter Zugriff: 17.04.2018). Die Gazeta Wyborcza gab 2013 die Kosten mit 326 Millionen PLN an, an denen sich neben der EU und dem Kulturministerium auch die lokale Verwaltung mit einem Beitrag beteiligte: Kortko; Ostałowska: Dość całowania ręki niemieckiego pana. Gazeta Wyborcza. 26.06.2013. Wiatr kalkuliert knapp 80 Millionen Euro für den Neubau: Wiatr: Oberschlesien und sein kulturelles Erbe, 2016, S. 47.

207 34.670.000 PLN: Smyczek: Wspólne prowadzenie instytucji kultury przez samorząd województwa oraz jednostki samorządu terytorialnego i administrację rządową, 2016, S. 4.

208 https://muzeumslaskie.pl/en/commercial-offers/ (letzter Zugriff: 16.07.2018). 
Fakultät der Humboldt-Universität zu Berlin, David Fleming, Direktor des National Museum Liverpool und Sharon Heal von der Museums Association. ${ }^{209}$ Dies stellt im Vergleich zur Besetzung von 2007 eine erhebliche Internationalisierung dar. ${ }^{210}$

Das Museum besaß 2016 über 6000 Quadratmeter Ausstellungsfläche, erweitert sich aber mit der fortschreitenden Erschließung des Geländes. Es verfügt über ein Auditorium, eine Bibliothek sowie Seminarräume. Die hier im Fokus stehende historische Dauerausstellung umfasst 1364, der Bereich der Kunstausstellungen 2242 Quadratmeter. ${ }^{211}$ Die vielen Abteilungen des Hauses (Kunst, Fotografie, Ethnologie, Geschichte, Archäologie, Konservierung, Archiv etc.) führen zu einem entsprechend hohen Personalbedarf, die Vergleichbarkeit mit den anderen Museen ist daher nur eingeschränkt gegeben. So seien hier nur einige Zahlen genannt: Neben der Direktorin und einem Leitungsteam verfügt die Abteilung Geschichte über fünf Mitarbeiter, die Museumspädagogik über acht, die Bibliothek über vier. ${ }^{212}$

Das Muzeum Śląskie kann entsprechend seiner Geschichte auf eine lange Sammlungstradition zurückschauen, die gleichwohl durch Krieg und Kriegsverluste unterbrochen wurde. Von der von den Deutschen im Zweiten Weltkrieg nach Beuthen $>$ überführten Sammlung konnte mit der Wiedereinrichtung des Museums in den 1980er Jahren nur die Gemäldekollektion für Kattowitz zurückgewonnen werden. ${ }^{213}$ Das Haus verfügt über eine kunsthistorische, historische, ethnologische und naturwissenschaftliche Abteilung sowie entsprechende Sammlungen. ${ }^{214}$ Insgesamt werden in allen seinen Ausstellungsabteilungen 1400 Exponate gezeigt, davon in der historischen Ausstellung $800 .{ }^{215}$

Die erheblichen Investitionen in den Neubau des Museums sind Teil der Neuausrichtung von Kattowitz als postindustrieller Metropole. Dafür soll eine positive Selbstidentifikation der Bewohner sowohl mit der industriellen Vergangenheit der Region als auch mit einer Zukunft als internationalem Kultur-, Hightech- und Dienstleistungszentrum gefördert werden; Zielgruppen des Museums sind dementsprechend nicht nur einheimische Oberschlesier, sondern auch ein nationales und internationales $\mathrm{Pu}$ blikum. ${ }^{216}$ Die Ausstellungstexte sind dreisprachig in Polnisch, Englisch und Deutsch gehalten. Das Oberschlesische ist via Audioguide zu hören, da es keine einheitliche Schriftsprache gibt. ${ }^{217}$ Im Jahr 2017 beliefen sich die Besucherzahlen des Museums für

209 https://muzeumslaskie.pl/pl/aktualnosci/17-03-zebranie-czlonkow-rady-muzeum-slaskiegokatowicach/(letzter Zugriff: 18.04.2018). https://zarzad.slaskie.pl/content/2208_20170808215039?q=muzeum\%20\%C5\%9Bl\%C4\%85skie (letzter Zugriff: 18.04.2018). https://muzeumslaskie.pl/pl/aktualnosci/drugi-etap-przetargu-ograniczonego-na-generalnegowykonawcy-rozstrzygniety/(letzter Zugriff: 18.04.2018).

212 https://muzeumslaskie.pl/pl/zespol/ (letzter Zugriff: 17.04.2018).

213 Tomann: Ceschichtskultur im Strukturwandel, 2016, S. 263.

214 Der Bestand kann auf der Website gesichtet werden: https://muzeumslaskie.pl/pl/wyszukiwarkazbiorow/ Die Funktion ist bisher nur eingeschränkt ins Englische übersetzt: https://muzeumslaskie.pl/en/collection-search-engine/ (letzter Zugriff: 18.04.2018).

215 https://muzeumslaskie.pl/pl/architektura-i-przestrzen/ (letzter Zugriff: 18.04.2018).

216 Tomann: »The Light of History«, 2016.

217 Tomann: Rezension zu: Das Licht der Geschichte. Oberschlesien im Wandel der Zeiten, 26.06.2015. 
alle Ausstellungen und Veranstaltungen auf 211.239 Personen, dies bedeutete gegenüber 2016 eine Steigerung um etwa 35.000 Personen. ${ }^{218}$

Die regelmäßigen Sonderausstellungen aus dem gesamten Spektrum des Museums hatten seit seiner Eröffnung überwiegend kunsthistorische, naturkundliche, gesellschaftspolitische und archäologische Themen zum Gegenstand. ${ }^{219}$ Ein angekündigter Katalog zur historischen Dauerausstellung ist bis heute (2019) nicht erschienen, während zu verschiedenen Sonderausstellungen bereits Kataloge herausgegeben wurden. ${ }^{220}$ Die Bibliothek des Museums steht der Öffentlichkeit zur Verfügung. Bisherige Veranstaltungen seit 2014 (bis 2019) lassen kein besonderes Interesse an dem deutschen Element der oberschlesischen Geschichte sowie anderen erwähnten kontroversen Themen erkennen. Eine Ausnahme war die im Frühjahr 2019 durchgeführte Podiumsdiskussion zum Thema »Polen in der Wehrmacht «, das durch die deutsche Minderheit und die Nationalitätenwechsel im Zweiten Weltkrieg besonders in Oberschlesien virulent ist. ${ }^{221}$ In einer weiteren Veranstaltung wurde 2019 die deutsche und polnische Perspektive auf die Zeit nach dem Ersten Weltkrieg diskutiert. ${ }^{222}$ Zum hundertsten Jubiläum der `Schlesischen Aufstände< führte das Museum im Rahmen der Unabhängigkeitsfeierlichkeiten mit Mitteln des Ministeriums für Kultur und nationales Erbe eine landesweite »Informationskampagne« durch, mit der die Bedeutung Oberschlesiens für die polnische Geschichte popularisiert werden soll. ${ }^{223}$

In der postindustriellen Umgebung einer großen Veranstaltungshalle aus volkspolnischer Zeit wurde im Zuge der Bewerbung um die Kulturhauptstadt Europas im Jahr 2016 eine neue Kulturzone mit innovativen Neubauten angelegt, beispielsweise eine moderne Konzerthalle für das Nationale Symphonieorchester des Polnischen Rundfunks. Auf der anderen Seite des an einer achtspurigen Autobahn gelegenen Museums schließt sich das Universitätsviertel an. ${ }^{224}$ Das österreichische Architekturbüro Riewe Riegler Architekten aus Graz entwickelte ein Konzept für die stillgelegte Kohlemine, nahm damit einen "raffinierten Dialog « mit der industriellen Vergangenheit von Kattowitz auf und sicherte gleichzeitig dieses Erbe. ${ }^{225}$ Die meisten Ausstellungsbereiche liegen unterirdisch. Die oberirdischen historischen Gebäudeelemente stechen, abgesehen von dem als Aussichtsplattform begehbaren signifikanten Förderturm, wenig

218 Odziomek: Muzeum Śląskie zaprasza na nowe wystawy. Gazeta Wyborcza. 08.02.2018.

219 Vgl. dazu die Übersicht über die bisherigen Sonderausstellungen auf der Website des Museums: https://muzeumslaskie.pl/pl/archiwum-wystaw/ (letzter Zugriff: 19.08.2017). Das breite Spektrum der Arbeit des Hauses zeigt sich z.B. in einer Ausstellung über schlesischen Hiphop: Łukawska: Muzeum Śląskie przygotowuje wystawę o śląskim hip-hopie. eska. 13.06.2018.

220 Vgl. für diese und weitere Publikationen den Onlineshop des Museums: https://muzeumslaskie.pl/pl/sklep/ (letzter Zugriff: 19.04.2018).

221 »Między polityką i historią. Służba Polaków w Wehrmachcie - narracja w ostatnich 15 latach.« (https://muzeumslaskie.pl/pl/kalendarium/miedzy-polityka-historia-sluzba-polakowwehrmachcie-panel-dyskusyjny/; letzter Zugriff: 27.01.2020).

222 Po co Polsce, po co Niemcom Górny Śląsk? raciborz.com.pl. 13.03.2019.

223 Sto lat temu nikt nie mógł przewidzieć, że powstania śląskie wywrą tak duży wpływ na historię Polski. nettg.pl. 03.09.2019.

224 Galusek: Górny Śląsk/Upper Silesia, 2016, S. 33f. Siehe auch: Novotny: Das Licht unter Tage. Der Standard. 18.08.2014.

225 Galusek: Górny Śląsk/Upper Silesia, 2016, S. 34. 
hervor. In der Dunkelheit bieten beleuchtete Glaskubusinstallationen gleichwohl eine eindrucksvolle Darbietung. ${ }^{226}$ Die Außenarchitektur fügt sich in die neue Stadtlandschaft von Kattowitz ein, wobei die modernen, das historische Ensemble brechenden Elemente den gewünschten Wandel zur postindustriellen Metropole symbolisieren, die trotz aller Herausforderungen stolz auf ihr Erbe ist. ${ }^{227} 2017$ konnten weitere Gebäude der ehemaligen Kohlemine als Ausstellungsräume eröffnet werden. ${ }^{228}$ Im Jahr 2018 wurden Planungen bekannt, Wohnhochhäuser vor dem Museum zu errichten. Dagegen protestierten Museumsleitung und Museumsrat, da so die Sichtbarkeit sowie das Ensemble an sich beschränkt oder gebrochen würden. ${ }^{229}$

\subsubsection{Anspruch und Selbstverständnis}

Das Muzeum Śląskie in Kattowitz ist mit seiner Eröffnung am neuen Standort am 26. Juni 2015 der zentrale Ort für die Bestimmung und Verhandlung der Geschichte Oberschlesiens in Polen geworden. Dass die Ausrichtung dieses Museums eine erhebliche politische Bedeutung hat, zeigten die oben besprochenen Diskussionen bis zur Eröffnung des Hauses. ${ }^{230}$ Auch wenn im Zuge der Debatte um das Schlesische Museum in Görlitz nationalkonservative Stimmen die Forderung nach einer spolnischen Antwort erhoben, war dies keine entscheidende Motivation für die Schaffung der historischen Dauerausstellung in der wesentlich älteren Institution des Schlesischen Museums in Kattowitz.

Die von verschiedenen Seiten erhobenen Ansprüche widersprechen sich aus Sicht einiger der Akteure. Scheint die positive Auswirkung des Hauses auf die touristische Attraktivität von Kattowitz die Darstellung einer multikulturellen europäischen Region zu unterstützen, sehen konservative Kräfte den Auftrag primär darin, die Regionalgeschichte im Sinne einer positiven Selbstidentifikation der Kattowitzer und polnischen Oberschlesier innerhalb des klassischen polnischen Nationalnarrativs zu präsentieren und damit auch in ganz Polen akzeptiert zu sein. In diesem Sinne äußerte sich der Marschall der Woiwodschaft Schlesien Mirosław Sekuła:

»Oberschlesien fürchtet Polen und Polen fürchtet Oberschlesien. Dies ist mangelnden historischen Kenntnissen geschuldet. Wir müssen endlich zu einem sachlichen Gespräch zurückfinden. « ${ }^{231}$

Sowohl die deutsche Minderheit als auch die schlesische Autonomiebewegung haben wiederum eigene Anforderungen an das Museum und sahen diese am ehesten in der Konzeption von Jodliński berücksichtigt. So formulierte der Vorsitzende der RAŚ Jerzy Gorzelik 2013 in Bezug auf die Konzeption von Jodliński: »Ich mochte sie. Sie zeigt ein

226 Galusek: Górny Śląsk/Upper Silesia, 2016, S. 34.

227 Vgl. Tomann: Rezension zu: Das Licht der Geschichte. Oberschlesien im Wandel der Zeiten, 26.06.2015.

228 Muzeum Śląskie przygotowuje rewitalizacje kolejnych obiektów. onet. 12.02.2018.

229 Pawlik: Rada Muzeum Śląskiego przeciwko budowie bloków. onet Śląsk. 13.04.2018. Vgl. Głowacka: Wojna o mieszkaniówkę w Strefie Kultury. Silesion. 21.02.2018.

230 Vgl. Kobielska: Muzea do pamiętania/Museums for Remembering, 2016, S. 180-183.

231 Zitiert nach: Wiatr: Eine Schifffahrt ins Ungewisse, 2013, S. 69. 
neues Denken, gibt einen Impuls, eine Antwort auf die Bedürfnisse der Oberschlesier, für die Identität eine Frage der Wahl ist. «32

Robert Traba konstatierte in ähnlichem Sinne in einem Impulsreferat bei der festlichen Eröffnung des Museums 2015, dass eine Ausstellung über Oberschlesien »mit seinen multiplen Erinnerungskulturen [...] erkenntnisleitend, multiperspektivisch und kontrovers sein [solle], indem sie unterschiedliche Schichten der Erinnerung an diese Region sichtet und erläutert. Gleichzeitig [...] solle diese Erzählung so aufgebaut sein, dass niemand sich ausgeschlossen fühlt. « ${ }^{233}$

Den politischen Anspruch, entscheidender Teil des kulturellen und wirtschaftlichen Wandels Kattowitz' zu sein, sehen Vertreter des Museums als erfüllt an: »Das Schlesische Museum hat sich zu einem unverwechselbaren Symbol der Hauptstadt der Region entwickelt und ist in den letzten Jahren das unbestrittene Schaufenster der Stadt, welches ihre Geschichte erzählt. $\ll^{234}$ Auf der Website des Museums gibt das Haus als »The Mission of Museum Śląskie« an:

»Bound by the heritage of the region, its historical dynamics, its numerous cultures and the leading role of industry, and yet recognizing Silesia's intellectual and artistic background, Muzeum Śląskie provides a space for dialogue with the past and the achievements of modernity to further explore Silesia, Poland and Europe.«

Weiter wird das reiche und multikulturelle Erbe der Region unterstrichen:

»We are inspired by the heritage of Silesia: its intellectual and artistic achievements and its rich multicultural history. Our venue at the former mining site points to the significant role that the industry has played in the region. $[. ..] \ll^{235}$

Inwiefern sich die Vorstellung einer europäischen, multikulturellen Region und die weiteren erhobenen Ansprüche tatsächlich in der Ausstellung wiederfinden, soll im Folgenden aufgezeigt werden.

\subsubsection{Die Dauerausstellung}

Nachdem der Besucher die oberirdische Umgebung der ehemaligen Kohlemine und die hervorstechenden Glaskuben des Museums erkundet hat, orientiert er sich nach dem Eintritt in das Museum abwärts. In einer klaren Formensprache aus weißen Wänden, Glas und Metall sowie Sichtachsen in die tieferliegenden Teile des Museums wird zugleich offen und freundlich hell eingeladen, aber auch auf die Spur der Bergarbeiter hingewiesen. Besonders beim Hinabgehen vom Bereich der Schlesischen Kunst zur

232 »Spodobała mi się. Nowe myślenie, rozmach, odpowiedź na potrzeby Górnoślązaków, dla których tożsamość to kwestia wyboru. Kortko; Ostałowska: Dość całowania ręki niemieckiego pana. Gazeta Wyborcza. 26.06.2013.

233 So zusammengefasst von Wiatr: Oberschlesien und sein kulturelles Erbe, 2016, S. 57.

234 »Muzeum Śląskiego stał się wyraźnym i bardzo rozpoznawalnym symbolem stolicy regionu, a na przestrzeni ostatnich lat niekwestionowaną wizytówką miasta opowiadającą jego historię.«Przybytek: Muzeum Śląskie wydało oficjalne oświadczenie ws. budowy osiedla wieżowców w Strefie Kultury. Dziennik Zachodni. 21.02.2018. https://muzeumslaskie.pl/en/about-us/ (letzter Zugriff: 17.04.2018). 
historischen Ausstellung muss der Besucher eine von zwei langen Rampen passieren und kann so den räumlichen Abstieg auch physisch erfahren. Dies kann einen doppelten Zweck erfüllen: zum einen den Abstieg der Kumpel in das Bergwerk, zum anderen das Hinabsteigen in die Tiefen der Geschichte spürbar zu machen.

Im zweiten Untergeschoss befinden sich drei kunsthistorische Ausstellungen. Eine größere Auswahl zeigt die verschiedenen Kunstepochen von 1800 bis hin zu zeitgenössischen Werken. Es handelt sich hierbei weitgehend um von Polen und polnischen Schlesiern geschaffene Kunst; allerdings ist dieser Ausstellungsteil nicht regional angelegt. Die beiden Bereiche der "Hochkunst « gehen fließend zur Laienkunst über, die Werke aus der Zeit nach 1945 zeigt und einen Schwerpunkt auf den Alltag in der Industrieund Bergbauregion Oberschlesiens legt.

Nach dem Verlassen dieser Ebene bewegt sich der Zuschauer auf der langen, sich einmal um 180 Grad wendenden Rampe nach unten in das vierte Untergeschoss. Hier beginnt die historische Ausstellung mit dem Titel »Das Licht der Geschichte. Oberschlesien im Wandel der Zeiten ${ }^{236}$, die über einen eigenen Zugang in Form des nachgebildeten Einganges der Grube »Katowice« betreten wird und mit Aufnahmen von Bergleuten auf dem Weg zur Arbeit und Solidarność-Plakaten versehen ist. Sie verfügt über eine eigenständige, scheinbar nicht mit der Grundarchitektur verbundene Ausstellungsgestaltung. Ebenfalls auf dieser Ebene befindet sich die Ausstellung zu religiöser Kunst.

$\mathrm{Ab}$ hier bietet es sich an, von szenografischen Inszenierungen $\mathrm{zu}$ sprechen, da jeder Zeitraum durch eine eigene, die Zeit versinnbildlichende, Szene sowie eine entsprechende akustische Hintergrundbespielung dargestellt wird. Die Wegführung und die umgebende Gestaltung haben einen »labyrinthartigen Charakter«, verbunden mit einer scheinbar nicht sehr geradlinigen Führung. Als Besucher kann man sich dennoch kaum verlaufen. ${ }^{237}$

Vor dem Eintritt in die historische Ausstellung hat man die Möglichkeit, sich über die in der Ausstellung oder für einzelne Elemente der Ausstellung angebotenen Sprachen zu informieren, darunter »Die Schlesische Mundart«. Dabei wird auf den Charakter und die Entwicklung dieser Sprache hingewiesen. Im Dezember 2016 bestand die Möglichkeit noch nicht, die Ausstellung individualisiert mit einer wie von Bergarbeitern verwendeten »Fahrmarke« auf der Spur einzelner Oberschlesier zu besuchen.

Auf der Eröffnungstafel heißt es: »Wir beginnen unsere Reise in die Tiefen der Geschichte von Oberschlesien an einem Ort, an dem sich einst eine Kohlegrube befand.« Die »Reise durch die Jahrhunderte« beginnt mit einem szenografisch angedeuteten Umkleideraum des Jahres 1989, genauer des 4. Juni 1989. Dies war der Tag der ersten halb-freien Parlamentswahlen, der hier als Datum des Unterganges des Kommunismus und als Beginn der damit verbundenen "großen sozialen und wirtschaftlichen Veränderungen« in Polen betrachtet wird. Der Einleitungstext schließt nach einer erneuten

236 »Światło historii. Górny Śląsk na przestrzeni dziejów«. Der Titel wird unterschiedlich ins Deutsche übersetzt. Im Faltblatt der Ausstellung ist er so angegeben: »Das Licht der Geschichte. Oberschlesien im Wandel der Geschichte«. Bei Tomann finden wir »[...] im Raum der Ceschichte« oder» [...] im Wandel der Zeiten. «omann: Rezension zu: Das Licht der Geschichte. Oberschlesien im Wandel der Zeiten, 26.06.2015. 
Referenz auf die jahrhundertalte Bergbautradition Oberschlesiens mit den Leitfragen der Ausstellung:

»Wer waren die Menschen, die einst hier lebten? Welche Probleme haben deren Lebensentscheidungen nach sich gezogen? Woraus entwickelte sich die einzigartige Identität der Region?«

Nachdem die erwähnte Umkleidekabine von 1989 durchschritten ist, gelangt man in einen Raum, in dessen Mitte der angedeutete Nachbau der ältesten gemauerten oberschlesischen Kirche steht: die »Teschener Rotunde«, die St.-Nikolaus- und St.-WenzelSchlosskapelle aus »frühpiastischer Zeit« (11. Jahrhundert). An den umgebenden Wänden werden noch einige ältere Objekte bis hin zur Steinzeit sowie die verschiedenen germanischen und slawischen Siedlungsbewegungen dargestellt, ohne dass diese in die Ausstellungschronologie und ihr Narrativ eingebunden sind. In einer Reihe von szenografisch die Wand ausgestaltenden Bücherregalen hat man die Möglichkeit, sich an einem in diese eingelassenen Bildschirm mit einem digitalen Geschichtsbuch durch die mittelalterlich-frühneuzeitliche Geschichte Oberschlesiens zu klicken. Interessant ist hier, dass unter der Überschrift »Die große Modernisierung des Schlesischen Landes (13.-14. Jahrhundert)« das gezielte Anwerben deutscher Siedler durch die schlesischen Fürsten und die Gründung von Städten nach deutschem Recht als förderlich für die urbane, bürgerliche und ländliche Entwicklung angesehen, allerdings mit dem Satz geschlossen wird: »Eine negative Auswirkung war die Veränderung der nationalen Struktur, die in Niederschlesien eine Dominanz der deutschen über die polnische Bevölkerung zur Folge hatte.«

Bereits auf der nächsten Seite unter dem Titel »Der multiethnische Charakter Schlesiens « wird ein etwas anderes Bild dargestellt: »Seit dem späten Mittelalter hatte Schlesien einen multiethnischen Charakter.« Zwei Sätze später wird hingegen eine Quelle aus dem 16. Jahrhundert in Hinblick auf die Nationalitätenfrage problematisiert:

»In seinem Werk [...] schrieb er [Bartlomiej Stein, V. R.], wobei er das Problem möglicherweise zu sehr verharmloste, wie folgt: >Dieses Land ist von zwei Völkern bewohnt, die sich sowohl durch ihre Bräuche, wie auch durch den [besetzten] Raum unterscheiden: den fruchtbaren, der sich südlich und westlich erstreckt, beanspruchen die Deutschen, den stärker bewaldeten, weniger freundlichen, mit einem schlechteren Boden halten die Polen.«

Im zweiten Absatz der Seite wird noch auf das tschechische und mährische Element Schlesiens verwiesen und darauf, dass in Oberschlesien die Sprache der Elite das Tschechische oder Deutsche war, die des »einfache[n] Volk[es]« das Polnische, wobei das Polnisch Oberschlesiens durch den Einfluss der deutschen und tschechischen Sprache ebenso wie durch die zunehmende Trennung vom restlichen polnischen Sprachraum eine eigene Entwicklung nahm.

Dem Mittelalter und der Frühen Neuzeit folgt ein szenografisch gestalteter Palastraum des 18. Jahrhunderts, der Aufklärung und Entdeckungen ebenso zeigt wie den preußisch-österreichischen Konflikt um Schlesien. In der Mitte des Raumes befindet sich die in eine Glaswand eingelassene Skizze der ersten Dampfmaschine Oberschlesiens, die wiederum auf einem einen Flügel andeutenden schwarzen Tisch steht. 
»Die erste Dampfmaschine

Seit Friedrich Wilhelm von Reden zum Leiter des Oberbergamtes ernannt wurde, plante er, Oberschlesien zu einer industriellen Macht zu entwickeln. Dazu ließ er im Jahr 1788 eine Dampfmaschine aus England holen [...]. Deren Inbetriebnahme stieß damals in ganz Mitteleuropa auf starkes Interesse. Viele Vertreter der damaligen kulturellen Eliten begaben sich nach Oberschlesien, um mit eigenen Augen zu sehen, wie die >Feuermaschine< [...] funktioniert. Nach Tarnowitz (Tarnowskie Góry) kamen u. A. der preußische König Friedrich Wilhelm II und der Dichter Johann Wolfgang von Goethe.«

Der weiteren preußischen Modernisierung des Landes wird in den folgenden Bereichen viel Raum gegeben. Der Abschnitt der Industrialisierung ist in schwarzen und metallenen Farben gehalten, dazu läuft im Hintergrund eine sindustrielle Geräuschkulisse . Anschließend durchschreitet der Besucher eine angedeutete Straßenszene. Einer in Lebensgröße gehaltenen Fotowand mit der Darstellung eines Cafés um 1900 werden zwei reale Tische mit jeweils zwei weißen Figuren vorgelagert, die in gutbürgerlichem Gewand das ıschöne Leben $<$ jener Zeit darstellen. Ergänzt wird die Szenerie durch Hintergrundgeräusche, die Gesprächsfetzen auf Deutsch wiedergeben. ${ }^{238}$

Im Anschluss an diese auch optisch hell gestalteten Bereiche werden die »Sonnenund Schattenseiten des Lebens in Preußen« gezeigt, darunter besonders der Kulturkampf. Eingangs heißt es in diesem nun wesentlich dunkler gestalteten Szenario: »Die Einwohner der Länder innerhalb der Grenzen des preußischen Staates konnten die neuen technischen Erfindungen und Vorteile, die aus der Allgemeinheit der Bildung resultierten, nutzen. Der Preis hierfür war aber nicht selten immens und verlangte nach übermenschlicher Arbeit und langjährigem Dienst in der Armee.« Der Besucher steht nun vor einer größeren Leinwand, auf der auf dreißig Kacheln ein und dasselbe Bismarckportrait (mit Pickelhaube) zu sehen ist, davor das Bild eines Bismarckdenkmals als Sinnbild für den überall im Reich gepflegten Bismarckkult.

Unter dem Titel »Die politische Arena der jungen Strömungen des Nationalismus« verweist die Ausstellung auf die Grundlage der kommenden Konflikte. Anhand des Beispiels des polnischen Priesters Józef Szafranek zeigt sie, wie gering das nationale Bewusstsein in Oberschlesien zur Zeit des >Völkerfrühlings ‘ der 1848er war: Ihm und vielen anderen Konservativen sei es primär um die offizielle Anerkennung der polnischen Sprache und die damit verbundenen Konsequenzen gegangen. Von nationalen Rechten oder gar nationaler Selbstbestimmung sei - im Gegensatz zu den Teilungsgebieten Polens - lange wenig zu hören gewesen.

In diesem Rahmen wird zunächst die positive Leistung der Durchsetzung der allgemeinen Schulpflicht durch Preußen dargestellt, die den Analphabetismus wirksam beseitigte und »die zivilisatorische Entwicklung in der Region [beschleunigte]«. Die

238 Kobielska deutet in den verschiedenen Geräuschkulissen des Museums einen spezifischen »Sound of Silesia«, der die Heterogenität Oberschlesiens und damit verbundene unterschiedliche Geschichten erzählt: Kobielska: Muzea do pamiętania/Museums for Remembering, 2016. Meiner akustischen Wahrnehmung nach handelt es sich jedoch nur um deutschsprechende Stimmen. Allerdings hört auch Táborský hier die »linguistic diversity of Upper Silesia«: Táborský: Creating Silesian Identity, 2018. 
Stellwand »Im vereinigten Deutschland « thematisiert die Vergeblichkeit und schädliche Wirkung des Bismarck'schen Kulturkampfes sowie seiner anti-polnischen Politik, die in Oberschlesien zur verstärkten Entwicklung einer polnischen nationalen Identität führte. Gleichzeitig wird dargestellt, dass das parlamentarische System des Kaiserreiches eine politische Vertretung und offene Debatten um das Wesen Oberschlesiens ermöglichte. Dennoch begann die Frage der nationalen Identität an Schärfe zu gewinnen, was in einem Absatz folgendermaßen wiedergegeben ist:

$»$ Wer bin ich?

Die Antworten waren unterschiedlich. Einige zweifelten an ihrer deutschen Identität nicht. Anderen lag die Feststellung näher: Ich bin ein Oberschlesier. Viele wiederum formulierten die Antwort gemäß ihrem eigenen nationalen Cewissen und deklarierten: Ich bin ein Pole.«

Der Bereich `Germanisierung jenseits des Bismarck'schen Kulturkampfes wird auf einigen Schautafeln präsentiert. Ein B-Text verweist auf die Anpassung von Ortsnamen, um diese deutscher klingen zu lassen, ebenso wie auf die Durchsetzung des Deutschen als alleinige Amtssprache $a b$ 1876. In dem Text heißt es weiter, dass es in Preußen auch schon andere Zeiten gab, so beispielsweise mit der bis Mitte des 19. Jahrhunderts für preußische Beamte noch bestehenden Pflicht, Polnisch zu lernen. Mit »Leider war die Zeit der gegenseitigen Toleranz nun für immer vorbei.« endet die Schautafel pointiert. Daneben ist eine Grafik, die die Entwicklung der Sprachstruktur des Regierungsbezirks Oppelns und die Zunahme des Deutschen ebenso wie der Bilingualität darstellt und damit die wachsende Dominanz des Deutschen andeutet.

Eine beeindruckende begehbare Installation zeigt eine angedeutete Kirche, deren Wände komplett aus geöffneten Schulbüchern sowie einem Pult und einer Gebetsbank bestehen. Die katholische Kirche wird so als Rückzugsraum in mehrfacher Hinsicht symbolisiert, hier vor allem als »[...] Enklave der polnischen Sprache« und der polnischen Kultur im Allgemeinen. In einem weiteren Bereich »Probleme« wird »Die polnische Wesensart« beschrieben. Dabei wird - wie schon zuvor - das >nationale Erwachen durch interne Entwicklungen erklärt, aber auch durch den Zuzug von Menschen aus den anderen polnischen Teilungsgebieten, die eine längere Tradition nationalen Engagements hatten und mit Erfolg auf die polnischsprachigen Oberschlesier einwirkten. Die parlamentarische Vertretung der Polen im Reichstag wird thematisiert, aber zugleich deren Scheitern sowie das Scheitern der Minderheitenpolitik der Reichsregierungen gezeigt.

Von dieser Darstellung einer vergleichsweise heilen und aufstrebenden, wenn auch zerrissenen, Gesellschaft bewegt sich der Besucher unvermittelt in einen Schützengraben. An der Wand steht geschrieben: Wojna! [Krieg!] Auf einigen Bildern, die in die Wand des Schützengrabens eingelassen sind, kann man oberschlesische Soldaten in der preußischen Armee sehen. Nach diesem recht kurzen Ausstellungsteil muss der Besucher durch eine große Karte treten, deren >Tür $<$ das ausgebrannte Deutschland bzw. Mitteleuropa ist. Dies kann als das sprichwörtliche gewaltsame Zerreißen der alten Landschaften und Staaten verstanden werden. Eine Schautafel stellt unter dem Titel "Der Untergang der alten Welt« die neuen Grenzziehungen dar. In der Beschreibung wird Verständnis für die deutsche Perspektive geäußert: 
»Weil Deutschland den Krieg verloren hatte, musste das Land mit schweren Strafen rechnen. Im Friedensvertrag von Versailles wurde dem jungen Staat die Zahlung hoher Kriegsreparationen auferlegt, die Kolonien weggenommen und eine Berufsarmee [sic] verboten. Vor allem aber wurden umfangreiche Cebiete annektiert. Es ist kein Wunder, dass die Bestimmungen des Friedensvertrages starken Widerstand in Deutschland hervorgerufen haben.«

Nun bewegt sich der Besucher in Richtung Teilung. Dem Thema der Volksabstimmung sowie der `Schlesischen Aufständeく wird ein großer Bereich zugestanden, also der Bestimmung des Versailler Vertrages, eine Volksabstimmung über die Zugehörigkeit ganz Oberschlesiens entweder zu Polen oder Deutschland durchzuführen. Die >Schlesischen Aufständeく werden unter anderem als Antwort auf deutschen Terror ${ }^{239}$ dargestellt und ihnen insgesamt viel Sympathie entgegengebracht: »Es gelang, die gesetzten Ziele zu erreichen. Deshalb kann nach Meinung Mancher [sic] der Zweite Schlesische Aufstand als einer der wenigen Siege polnischer Volkserhebungen angesehen werden.«. Dennoch wird auch für die deutsche Perspektive Verständnis gezeigt und eine beiderseitige kompromisslose und aggressive Politik beschrieben.

Die Zeiten maximaler Polarisierung Oberschlesiens setzen Wahlplakate und eine Installation in Szene. Der Besucher wird von grob gezeichneten Köpfen förmlich angeschrien, entweder »za Polska« oder »für Deutschland« zu stimmen. Die gegenseitige Propaganda wird dem Besucher durch die Gegenüberstellung der Kampagnen dargeboten, die Gewalttätigkeit beider Seiten und die Unterstützung durch ihre jeweiligen Staaten wird auf einer Ebene bewertet. Ein typisches Beispiel der Szenografie des $\mathrm{Mu}$ seums ist hier eine kleine Ecke, die einen gestürmten Kampagnenraum darstellt, in dem eine zerstörte Schreibmaschine und zerstreute Propagandablätter umherliegen. An der Wand werden historische Bilder solcher Stürmungen gezeigt.

Die Ergebnisse des Plebiszits ${ }^{240}$ werden auf einer Tafel anhand von Diagrammen anschaulich gezeigt, die Teilung zugunsten Polens sowie der dafür notwendige militärische Einsatz angedeutet. Eindrucksvoll wird man nun in die oberschlesische Zwischenkriegszeit geleitet, für die man entweder die szenografische Installation eines polnischen oder preußisch-deutschen Grenzüberganges zu durchschreiten hat. Die Teilung wird durch einen hell-leuchtenden Streifen veranschaulicht, der sich über den Boden und die Schautafeln zieht. Die unterschiedliche Entwicklung des geteilten Oberschlesien wird auf den beiden Seiten eines szenografisch als städtische Straße gefassten Korridors jeweils für sich dargestellt und lädt zum Vergleich ein. ${ }^{241}$

Dieser Bereich zeigt die oberschlesische Autonomie im Zwischenkriegspolen ebenso wie die bedeutenden Entwicklungen der oberschlesischen Moderne. Die »Sanacja«, also die autoritäre Herrschaft unter Józef Piłsudski ab 1926, wird kritisch vorgestellt. So

239 »Die Polnische Militärorganisation von Ober Schlesien organisierte den Zweiten Schlesischen Aufstand um in erster Linie sich dem wachsenden Terror der Deutschen zu widersetzen. [...] «

24059,4 \% für Deutschland, 40,3\% für Polen; vgl. Kap. 6.1, S. 278.

241 Vgl. Táborský: Creating Silesian Identity, 2018. Táborský verweist auf dieses derzeit sehr beliebte Element im polnischen Museum, die »replica of a city street«, die uns auch im MIIW wieder begegnen wird. 
heißt es über den oberschlesischen Woiwoden Michał Grażyński, dass dieser »(...) darüber hinaus [...] die meiste Zeit während seiner Amtszeit das Prinzip der schlesischen Autonomie [kritisierte]. Er strebte eine möglichst enge und schnelle Integration mit der Zweiten Polnischen Republik an, weshalb ihm viele vorwarfen, die Oberschlesier zu diskriminieren und die national verschiedenen Einwohner zu entzweien.« Die deutsche Seite des Bereiches stellt den Nationalsozialismus und dessen zunächst politische Schwäche in Oberschlesien sowie die darauffolgende Militarisierung des öffentlichen Lebens (auf beiden Seiten) vor. Die Diskriminierung der Juden wird in dem szenografischen Ensemble mit antisemitisch beschmierten Ladenzeilen dargestellt. Eine eigene Vitrine ist dem später zerstörten Muzeum Śląskie gewidmet.

Die Zeit des Zweiten Weltkrieges beginnt mit einem angedeuteten Kinosaal, in dem historische Filmaufnahmen des Kriegsbeginns gezeigt werden. Die Wegführung wird nun eng, sodass zwei Personen kaum noch aneinander vorbeipassen; dies kann als Symbol der Ausweglosigkeit unter der Kriegssituation verstanden werden. Der Verlauf des >Polenfeldzuges 1939 wird anhand lokaler Beispiele dargestellt, durchaus mit heroischem Ton. Gleichzeitig wird die Geschichte des volksdeutschen Verrates erzählt: »In derselben Zeit, als die Aufständischen und Pfadfinder den Truppen der Wehrmacht todesmutig Widerstand leisteten, begrüßte die deutsche Minderheit die Soldaten enthusiastisch. Ein großer Teil der oberschlesischen Deutschen war an den Repressionen beteiligt, die gegen ihre polnischen Nachbarn gerichtet waren.«

Die Darstellung des breiten und heldenhaften Widerstands des polnischen Oberschlesien wird durch die gezeigte Einwohnererfassung von Ende 1939 konterkariert, in der 95 Prozent der Bewohner der ehemaligen Woiwodschaft angaben, deutscher Nationalität zu sein. Dies wird sowohl mit der verheerenden Niederlage Polens als auch mit dem nationalsozialistischen Terror erklärt. Die militärische Präsenz sowie die Durchdringung der besetzten Gebiete durch NS-Deutschland werden durch Fotografien und Inszenierungen dargestellt.

Der geplanten Germanisierung mit den dafür vorgesehenen Ansiedlungen und >Umsiedlungen wird ein größerer Bereich eingeräumt, ebenso wie der komplexen Frage der Deutschen Volksliste (DVL). Zur Veranschaulichung dieses Gegenstandes dienen hier auch Zeitzeugeninterviews. ${ }^{242}$ An einer Wand beschäftigt sich die Ausstellung ausführlich mit dem Holocaust sowie der Internierung und Ermordung polnischer Intellektueller und Widerständler sowie den Todesmärschen aus dem KZ Auschwitz-Birkenau im Jahr 1945 durch Oberschlesien. Die Darstellung des Endes des nationalsozialistischen Oberschlesien beginnt mit einer Schautafel zur Offensive der Roten Armee im Januar 1945, die zu einer raschen Eroberung Oberschlesiens führte. $\mathrm{Zu}$ den damit einhergehenden Verbrechen der Roten Armee heißt es:

»Die Kriegshandlungen wurden von zahlreichen Zerstörungen, Vergewaltigungen, Raubüberfällen und Morden auf Kosten der zivilen Bevölkerung begleitet. Die sowjetischen Soldaten behandelten Oberschlesier wie Deutsche, an denen sie sich für die Gräueltaten der nationalsozialistischen Besatzungszeit in der UdSSR rächen konnten.« 
Am chronologischen Ende der Darstellung der NS-Herrschaft steht eine Guillotine. Sie ist in einem Kasten auf nur ungefähr 1,50 m Höhe durch Sichtfenster einsehbar und wurde von den Nationalsozialisten unter anderem für die Ermordung widerständiger Polen genutzt. Zusätzlich ist das Innere des Kastens mit Repliken der Hinrichtungsbekanntmachungen ausgestaltet.

Im nächsten Bereich folgt ein Raum, an dessen einem Ende der Abschluss eines Zugwaggons szenografisch dargestellt ist und auf der anderen Seite eine einzelne, große Reisetruhe sowie diverse gestapelte Koffer. Wir befinden uns im Bereich der Zwangsmigrationen. Auf einer Schautafel heißt es zu »Die Oberschlesische Tragödie« ähnlich wie bereits vorher:

»Die Mühlen der scheinbaren, durch den Krieg geschaffenen Gerechtigkeit, die 1939 durch die Nazis zu mahlen begonnen hatten, mahlten weiter, als die Rote Armee in Oberschlesien einmarschierte. Die Russen hatten nicht vor, die komplizierte Nationalitätsstruktur der Bewohner dieser Gebiete zu analysieren. Aus ihrer Sicht waren fast alle Oberschlesier Befürworter des Nationalsozialismus. Dies war ihnen Entschuldigung genug für die Vergewaltigungen, Morde und Zwangsarbeit.«

An der im Zugwaggon eingelassenen Medienstation wird man über die Internierungen und Ausweisungen bzw. Deportationen der Zivilbevölkerung Oberschlesiens in die Sowjetunion informiert, ebenso wie über die kommunistische Machtübernahme in Oberschlesien. Im Bereich »Die Nationalitätenpolitik der Nachkriegszeit« heißt es:

»Die Kernfrage der Nationalitätenpolitik in der Woiwodschaft Schlesien war im Jahre 1945 und in den nachfolgenden Jahren das Problem mit dem Deutschtum. Die Behörden nahmen die Formel von Gen. A. Zawadzki als Grundlage ihrer Handlungen: >Wir wollen keinen einzigen Deutschen, wir geben keinen einzigen Polen ab «. Dies bedeutete in der Praxis, dass die Gesellschaft in der Woiwodschaft Schlesien einer ethnischen Segregation unterliegen sollte, um die Deutschen aus der Gesellschaft auszuschließen und dann ganz aus dem Land zu entfernen. Die Personen aus der I. Gruppe der deutschen Volksliste wurden aus dem ehemaligen polnischen Teil der Woiwodschaft vertrieben. Die Personen aus der II. Gruppe konnten sich - um dieses Vorgehen zu vermeiden - einer Rehabilitation unterziehen, d.h. in einem Gerichtsverfahren ihr Polentum beweisen (...). Die Personen aus der III. und IV. Gruppe der Volksliste wurden nach der Vorlage der Loyalitätsbescheinigung automatisch rehabilitiert. Diese Vorgehensweise galt bis Juni 1946. Im deutschen Teil Oberschlesiens der Vorkriegszeit wurden die Verifizierungsmaßnahmen bis zum Jahr 1948 vorgenommen. Personen, die als Polen verifiziert wurden, durften im Land bleiben, andere wurden - als Deutsche - vertrieben.«

Auf der nächsten Seite der Medienstation heißt es unter dem Titel »Umsiedlungen der deutschen Bevölkerung«:

»Die polnischen Behörden der Nachkriegszeit gingen besonders am Anfang davon aus, dass das Zusammenleben von Polen und Deutschen in einem Land unmöglich sei. Daher wurde beschlossen, das Problem des Deutschtums durch die Vertreibung der deutschen Bevölkerung aus Oberschlesien und durch das >Entdeutschen ‘ der Region, d.h. 
durch Eliminieren sämtlicher Spuren der deutschen Kultur zu lösen. Im Juni 1945 gab es auf Grundlage des Beschlusses von Woiwode Aleksander Zawadzki >wilde Vertreibungen der Bevölkerung aus dem ehemaligen deutschen Teil Oberschlesiens. Auch wurden schnelle Umsiedlungen von Personen aus den beiden ersten Gruppen der Volksliste aus dem ehemaligen polnischen Teil der Woiwodschaft durchgeführt. Am 17. Oktober 1945 wurde den Deutschen amtlich verboten, in den Städten der Region zu wohnen. Umsiedler wurden in Übergangslagern untergebracht und danach nach Deutschland ausgewiesen. Bis Ende 1945 wurden ca. 150 Tausend Menschen (seit der Konferenz in Potsdam im August desselben Jahres mit internationaler Anerkennung) umgesiedelt. Später wurden im Rahmen der ab dem 17. Mai 1945 durchgeführten Operation Jaskólka 21 Tausend Menschen umgesiedelt. Wie die nachfolgenden Jahre zeigten, bedeutete dies keine vollständige Vertreibung der Deutschen aus der Region.«

Offen wird das Lagersystem nach Kriegsende angesprochen, in welchem neben den sowjetischen auch polnische Lager existierten:

»Die sowjetischen und polnischen Lager, die im Jahr 1945 in Oberschlesien entstanden, dienten neben der Umsiedlung der Deutschen auch zu Repression und Zwangsarbeit. In den Lagern, die dem NKWD unterstanden, sollten potentielle politische Feinde isoliert werden. Es herrschten fatale Bedingungen und so kamen z.B. in Tost von Mai bis November 1945 ca. 3 Tausend Menschen in Tost [sic] ums Leben. Die polnischen Lager, die seit Februar 1945 zur Repression und Umsiedlung derer, die für Deutsche gehalten wurden, gegründet wurden, entstanden u.a. in Eintrachthütte und Myslowitz. Im Oppelner Teil der Woiwodschaft Schlesien war das im Juli 1945 gegründete Lager in Lamsdorf besonders berüchtigt. Die Verwaltung der Lager lag in den Händen des Sicherheitsapparats. Zum Alltag gehörten Folter, Hunger, Vergewaltigungen. Wegen der Vernachlässigung der Hygiene brachen dort Epidemien aus. In den drei genannten Lagern starben insgesamt ca. 6 Tausend Menschen. Ab Oktober 1945 wurden auch etwa 40 Lager für Zwangsarbeit in Bergwerken und anderen Betrieben gegründet. In diesen wurden ca. 35 Tausend deutsche Gefangene festgehalten, von denen ca. $10 \%$ starben. Die Lager bestanden bis zum Jahr 1949."

Auf drei darauf folgenden Seiten finden sich Informationen zum Repressionsapparat der sowjetischen Besatzer und der polnischen Sicherheitsbehörden, zum polnischen Widerstandskampf gegen die sowjetisch-kommunistische Herrschaft sowie zum »Zustrom der Bevölkerung aus den östlichen Grenzgebieten«, zu dem es heißt:

»Bereits zu Beginn des Jahres 1945 erschienen in Oberschlesien die ersten Umsiedler aus den ehemaligen östlichen Woiwodschaften der II. Republik Polen, die diese Cebiete beim Durchzug der Roten Armee oder aus Angst vor ukrainischen Nationalisten verlassen mussten. Im Frühling desselben Jahres begann der Massenexodus der Polen jenseits des Flusses Bug. [...] Die kulturellen Unterschiede der Region hatten einen eindeutig negativen Einfluss auf die Ankömmlinge, viele konnten sich nur schwer an die neue Umgebung anpassen. [...]«

Die Medienstation liefert ausführliche Informationen über die Vertreibung der Deutschen, die Vergehen an den heimatverbliebenen Oberschlesiern und benennt Akteure 
und Verbrechen sowie ausführlich das damit verbundene Lagerwesen. Auf einer separaten Tafel wird die Grenzverschiebung Polens 1944/45 unter dem Titel: „Oberschlesien - den Deutschen weggenommen« (in Englisch etwas anders: »Upper Silesia reclaimed from the Germans«/auf Polnisch: »Górny Śląsk odebrany Niemcom«) thematisiert. Hier heißt es:

„Die Potsdamer Konferenz war das letzte Treffen der Großen Drei. Vom 17. Juli bis zum 2. August 1945 fand die Zusammenkunft der Oberhäupter der UdSSR, der USA und Großbritannien [sic]: Josef Stalin, Harry S. Truman und Winston Churchill, später durch Clement Attlee vertreten, statt. Die damals getroffenen Beschlüsse entschieden u. A. über die Notwendigkeit der Aussiedlung der Deutschen aus Polen, der Tschechoslowakei und Ungarn (Pkt. 12). Die Unterzeichner hofften, dass die Aussiedlungen auf eine sgeordnete und humanitäre Art « durchgeführt werden würden. Leider war die Wirklichkeit ganz anders, als angenommen.«

Darauf folgend wird auf die Grenzverschiebungen in Mitteleuropa und die »notwendige[n] Umsiedlungsaktion[en] « eingegangen. Erneut werden die großen Leiden auf allen Seiten thematisiert, allerdings wird die Rolle polnischer Kräfte nicht benannt und die Verantwortung allein bei den drei Siegermächten gesehen:»Der Plan, dessen Durchführung zu einer ungemeinen Tragödie für die Menschen wurde, die man mit Gewalt aus ihrer Heimat vertrieb, war die Folge der Beschlüsse der Siegermächte, der sog. Großen Drei«. Die erwähnte schwere Reisetruhe neben dem angedeuteten Güterwaggon steht sinnbildlich für die Zwangsmigrationen, ebenso wie die Wand aus aufeinandergestapelten Koffern. Der Besucher folgt nun einem schmalen Gang entlang der Koffer in Richtung Nachkriegszeit. Ein Stadtschild von "Stalinogród« und ein angedeutetes abgehängtes Schild »Katowice« stehen für die stalinistische Phase, in der die Stadt den Namen des sowjetischen Diktators trug.

Die Frage »Befreiung oder neue Besatzung?« leitet diese Phase ein und erläutert die Folgen der sowjetischen Herrschaft, an der sich nur die Polen »erfreute[n] [...], die zu den Befürwortern der sowjetischen Macht zählten. Aber für diejenigen, die von der Roten Armee zum Feind erklärt wurden (z.B. aufgrund ihrer antikommunistischen Gesinnung), bedeutete die neue Ordnung den Verlust von Freiheit, Vermögen und manchmal auch den Tod «. Einen größeren Raum nimmt die Deportation von Oberschlesiern in die Sowjetunion ein, die dort überwiegend in Bergwerken eingesetzt wurden. Dieses wird als »eines der tragischsten Kapitel in der Nachkriegsgeschichte Oberschlesiens« bewertet. Die Behandlung Oberschlesiens beschreibt die Schautafel wie folgt: »Die Befreier verhielten sich oft wie Angreifer. Insbesondere in dem Teil Oberschlesiens, der vor dem Krieg zu Deutschland gehörte. Fabrikanlagen wurden massenweise beschlagnahmt, da sie von den Russen [sic] als Kriegsbeute angesehen wurden.«

Mit historischen Plakaten und Anweisungen wird auf die fortdauernden Rebellentätigkeiten hingewiesen, die von den Kommunisten pauschal als deutsch bzw. deutsche Werwolfaktionen dargestellt wurden. Dass die Deutschen immer wieder gewalttätig behandelt wurden, macht ein Zitat des Woiwoden von Schlesien-Dombrowa, Aleksander Zawadzki, deutlich: »Wir behandeln die Deutschen als lästige und schädliche Fremde. Deswegen müssen die Deutschen das polnische Land verlassen und dorthin gelangen, woher sie kamen - jenseits von Oder und Neiße«. In gestalterischer Anlehnung an 
eine der dort hängenden historischen Bekanntmachungen geht ein Text auf die Problematik der Volkslistenzugehörigkeit ein und teilt mit, dass jenseits der Angehörigen der 1. Liste oft eine einfache Treueerklärung genügte, um (wieder) als Pole anerkannt $\mathrm{zu}$ werden. Unter der größeren Tafel »Verifikation und Rehabilitierung« werden die Verfahren vereinfacht zusammengefasst:

»Die Maßnahmen der neuen Regierung im Jahr 1945 konzentrierten sich auf die Probleme, die im Zusammenhang mit der Frage der Nationalität standen. Ein Großteil der Bevölkerung wurde auf seine Volkszugehörigkeit überprüft. Die als Polen anerkannten Personen wurden rehabilitiert, die Deutschen wurden ausgesiedelt. An Stelle der zweiten traten die Übersiedler aus den früheren polnischen Ostgebieten, die von den UdSSR besetzt waren. Außerdem wurde eine geplante, großangelegte Polonisierungsaktion durchgeführt.«

Auf einer großen Schautafel werden unter "Exodus« die Bevölkerungsverschiebungen schematisch dargestellt und woher beziehungsweise wohin die verschiedenen Gruppen und Ethnien kamen oder >gingen«:

»Bevor die Kanonen an den Fronten des Zweiten Weltkrieges verstummten, begann der Exodus von Millionen Menschen, die zum Verlassen ihrer Heimat gezwungen wurden. Der Bevölkerungstransfer betraf zum großen Teil Oberschlesien. Er bedeutete Flucht, Evakuierung und anschließend Aussiedlung der Deutschen: Deren Stelle die Polen aus den früheren polnischen Ostgebieten sowie Einwanderer aus anderen Teilen des Landes einnahmen.«

Bebildert ist dieses Geschehen unter anderem mit einer polnischen Familie aus den kresy, deren Umsiedlung mit ihrem Hab und Gut fotografisch eingefangen wurde. Etwas weiter wird dann auf die schnelle Integration der Angehörigen der Oberschicht aus den kresy hingewiesen, die mit neuen Posten an den Universitäten und Fachhochschulen versorgt werden konnten. Neben recht vielen optimistischen (propagandistisch inszenierten?) Umsiedlerbildern ist die Herkunft der polnischen Siedler differenziert vermerkt:

»Polen, die nach dem Zweiten Weltkrieg nach Oberschlesien kamen, stammten hauptsächlich aus den Gebieten folgender Vorkriegs-Woiwodschaften: Lemberg, Stanisławów und Tarnopol. An zweiter Stelle waren es die ehemaligen Bewohner aus den Cebieten: Dombrowaer Kohlebecken, westlichen [sic] Kleinpolen und Zentralpolen. Und zuletzt waren es Rückkehrer aus Deutschland und Westeuropa, hauptsächlich aus Belgien und Frankreich. [...]«

In den folgenden Ausstellungsteilen werden die Phase des Hochstalinismus und die kommunistische Umgestaltung gezeigt. So wird die forcierte Fortsetzung der Industrialisierung Oberschlesiens und die dafür notwendige Zuwanderung aus anderen Gebieten Polens thematisiert, die zu Konflikten der »autochtonen Schlesier« mit den $\mathrm{Zu}$ gewanderten führte. Es folgen einige inszenierte (Wohn-)Räumlichkeiten: einfache Arbeiterschlafzimmer, Wohnzimmer, Jugendzimmer und die szenografische Darstellung eines Filmstudios mit dem typischen Polski Fiat vor einer angedeuteten Plattenbausied- 
lung. ${ }^{243}$ Die abschließenden Bereiche besprechen auf dem Weg zum Ende der Volksrepublik Polen knapp die Krisen des Spätsozialismus, die Streikbewegungen, Solidarność und das Kriegsrecht.

Die Existenz einer deutschen Minderheit wird nicht weiter thematisiert, lediglich die Konflikte zwischen einheimischen Oberschlesiern und zugewanderten Polen werden diskutiert. Die Schautafel »Stagnation in den 8oer Jahren« zeigt die großen Migrationsbewegungen aus Oberschlesien während der Zeit der Volksrepublik nach »Westeuropa« oder in die USA.

Die Ausstellung endet mit einer großen Luftaufnahme von Kattowitz. Auf einem kleinen Bildschirm kann man sich verschiedene Bewohner ansehen und anhören, die ihre Vorstellungen von Oberschlesien äußern. Auf der letzten Tafel wird die Zukunft thematisiert: »Welche Zukunft erwartet Oberschlesien?«. Hier wird nochmals die historische zentrale Lage Oberschlesiens zwischen verschiedenen Großmächten thematisiert, dessen Brückenfunktion $\mathrm{zu}$ wirtschaftlichem und kulturellem Reichtum, aber auch immer wieder zu Zerstörungen und Besetzungen führte.

Den Abschluss bildet dann ein Blick auf Oberschlesien nach 1989 als europäische Hochtechnologieregion »im Herzen von Mittel- und Osteuropa«. Als Objekt dient ein Mikrochip der Firma »Bytom«. Die Quintessenz des Abschlusstextes besteht darin, dass für eine gute Zukunft die Lage der Region und ihr Erbe beste Chancen bieten, diese müssen aber genutzt werden. Der Besucher wird zu diesem Vorhaben eingeladen: »Werden auch Sie die Zukunft Oberschlesiens mitgestalten?«

\subsubsection{Ausstellungsanalyse}

Der Anspruch der Ausstellung, die Geschichte der Menschen Oberschlesiens sowie die einzigartige Identität der Region in ihrem Wandel zu zeigen und zu erklären, wird nur eingeschränkt eingelöst. Wer die umfangreichen Inhalte der Ausstellung vollständig aufnimmt, erhält einen guten Überblick über die Geschichte Oberschlesiens - allerdings überwiegend aus national-polnischer und gelegentlich polnisch-oberschlesischer Perspektive. Die aufgrund der einleitenden Fragen und der auf der Website des Museums dargelegten Ziele durchaus zu erwartende Darstellung der für Oberschlesien so zentralen ethnischen und kulturellen Differenz wird kaum erfüllt oder wird, wenn vorhanden, sehr stark auf einen historischen deutsch-polnischen Gegensatz beschränkt.

In der Ausstellung sind Objekte weitgehend schmückendes Beiwerk. Vorrang haben szenografische Darstellungen ebenso wie Schautafeln, die überwiegend mit kurzen und prägnanten Texten sowie reichlich abgedrucktem Foto- und Kartenmaterial ansprechend gestaltet sind. Dies hat punktuell den Charakter eines >begehbaren $\mathrm{Bu}$ ches`, wird aber immer wieder durch die Szenografie aufgelockert. Die Texte haben einen überwiegend nüchternen Charakter, sind trotz ihrer Kürze durchaus komplex und stellen häufig verschiedene Standpunkte dar, was sich beispielsweise trotz einiger einseitiger Aussagen zu den `Schlesischen Aufständen oder den Ergebnissen des Versailler Vertrages zeigt. Dies gelingt jedoch nicht immer und punktuell kommt es zu historisch fragwürdigen oder anachronistischen Einschüben, beispielsweise bei der Beschreibung

Vgl. ähnlich zu dieser »somewhat nostalgic perspective«: Tomann: »The Light of History«, 2016. 
der mittelalterlichen Siedlungsgeschichte. Die Ausstellung bemüht sich um die physische Erfahrbarkeit des Dargestellten. So beinhaltet die Szenografie Geräuschkulissen und ein geschicktes Spiel mit Licht und Farben, was die an verschiedenen Stellen vorgenommene emotionale Ansprache der Besucher unterstützt, beispielsweise durch die eindrückliche Darstellung der Teilung Oberschlesiens oder durch das authentische Objekt der Guillotine. Zwangsmigration und Umsiedlung werden durch Koffer sowie das Ende eines Zugwaggons dargestellt und die Internierungslager nach dem Krieg auf Fotografien gezeigt. Der Einsatz von Zeitzeugen erfolgt punktuell, beispielsweise bei der Diskussion der Deutschen Volksliste, und dient durch das Einbringen individueller Erfahrungen der tiefergehenden Erläuterung dieses komplexen Themas. ${ }^{244}$

Festzustellen ist, dass die Ausstellung ihren Produktionsprozess und ihre Erschaffer nicht zeigt und ihre Erzählung als objektive Erzählung darbietet. Fragen an den Besucher werden nach der Einführung und schließlich am Ende kaum mehr aufgeworfen. Dieser kann daher die Ausstellung lediglich >konsumieren und ist damit nicht auf Augenhöhe mit den Erstellern.

Die Zwangsmigration am Ende des Krieges und ihre >Begleiterscheinungen matisiert die Ausstellung umfassend als Katastrophe für die Betroffenen. ${ }^{245}$ Die von ihr besonders bei der Darstellung des Zweiten Weltkrieges vorgenommene Trennung von Oberschlesiern und Deutschen hat allerdings zur Folge, dass die Flucht, Vertreibung und Internierung der deutschen Oberschlesier gleichsam als mehr oder minder externe Ereignisse betrachtet werden und in unklarer Abgrenzung zur »Oberschlesischen Tragödie« stehen. Die Frage, wer dieser Teil der oberschlesischen Bevölkerung war und welche Rolle beispielsweise der Verlust ihrer Heimat für sie nach 1945 spielte, wird nicht beantwortet. Die Entscheidung für die Grenzverschiebung sowie die Verantwortung für die Vertreibung der Deutschen wird allein bei den Siegermächten der Potsdamer Konferenz verortet. Die aktive Unterstützung sowohl der Grenzverschiebung als auch der Vertreibung der Deutschen durch die (kommunistisch dominierte) polnische Staatsführung bereits vor dem Potsdamer Abkommen wird nicht erwähnt. ${ }^{246}$ Dennoch zeigt die Ausstellung einzelne polnische Akteure, die sich hier besonders exponierten, ebenso wie sie die Internierungslager als "polnische[...] Lager « in den Händen des Sicherheitsapparates bezeichnet und ausführlich darstellt. Stimmen von deutscher oder deutsch-oberschlesischer Seite fehlen. Auf ein Referieren volkspolnischer Mythen der Lager wird verzichtet. ${ }^{247}$ Eine klare Distanzierung von der vermeintlichen Notwendigkeit, die Nationalitätsangelegenheiten »zu ordnen«, wird jenseits der kritischen Darstellung bestimmter Exzesse nicht vorgenommen oder es erfolgt eine neutrale Beschreibung der damaligen Intentionen: »Die polnischen Behörden der Nachkriegszeit gingen besonders am Anfang davon aus, dass das Zusammenleben von Deutschen und Polen in einem Land unmöglich sei.« Dass sich die kommunistische Regierung hierbei

244 Vgl. Tomann: Rezension zu: Das Licht der Geschichte. Oberschlesien im Wandel der Zeiten, 26.06.2015.

245 Tomann sieht dieses Thema (und generell die Themen des Kriegsendes) jedoch auf einem »very limited space« untergebracht: Tomann: »The Light of History«, 2016.

246 Siehe für das polnische Agieren, hier besonders bezogen auf Oberschlesien, um vollendete Tatsachen zu schaffen: Dziurok; Linek: Im kommunistischen Polen, 2015, S. 371, 373

247 Vgl. zum volkspolnischen Mythos: Linek: Lamsdorf, 2014, S. 369-374. 
auf einen breiten Konsens in der polnischen Gesellschaft stützen konnte, wird nicht weiter erwähnt. ${ }^{248}$ Anzumerken ist, dass einige der Informationen zur Vertreibung der Deutschen in einer Medienstation enthalten sind und erst durch mehrfaches $>$ Klicken erreicht werden. Diese können also leicht übergangen werden, zumal der Besucher zu diesem Zeitpunkt schon einen langen Aufenthalt in der Ausstellung hinter sich hat. Mit der Darstellung der Nationalitätenkonflikte seit dem 18. Jahrhundert legt die Ausstellung den Beginn der Geschichte des sich immer weiter steigernden Nationalismus nicht erst auf 1918 oder 1933, sondern auf das 19. Jahrhundert.

Gelegentlich variieren die Begriffe zwischen den deutschen und polnischen (und englischen) Texten. Das Museum vermeidet den in Polen umstrittenen Begriff wypęzenie [Vertreibung], ${ }^{249}$ aber auch andere gängige euphemistische Termini. Interessant ist, dass in den deutschen Texten konsequent von "Vertreibung " gesprochen wird, in den polnischen hingegen von der »(Zwangs-)Aussiedlung« [wysiedlenie]. Im Englischen werden beispielsweise die Ausdrücke »forced removal« oder »expulsions« verwendet. Die ")wilden Vertreibungen « sind in der polnischen Fassung "wwilde Deportationen« [>dzikich deportacji]. Eine Diskussion der verschiedenen Begrifflichkeiten und der damit verbundenen unterschiedlichen Perspektiven findet nicht statt; dennoch ist diese Annäherung an die jeweiligen Sprachgewohnheiten ein interessanter Befund. Im Englischen von »expulsions « zu sprechen, zeigt eine Tendenz zum deutschen und internationalen Sprachgebrauch bezüglich des Geschehens auf. Unabhängig von den Begriffen lässt die Darstellung aber kaum Zweifel an den geschehenen Verbrechen und der ausgeübten Gewalt aufkommen.

Die Ausstellung lässt sich durchaus so lesen, dass es zeitweise ein ergiebiges, wenn auch keineswegs idyllisches, Zusammenleben in Oberschlesien gegeben hat. Das >Hineintragen « des Nationalismus in das bis heute mit einer starken regionalen Identität versehene Oberschlesien durch germanisierende preußische Beamte sowie polnische Agitatoren aus den Teilungsgebieten im 19. Jahrhundert wird ausführlich thematisiert, ohne eine simple teleologische Linie von Nationalismus über Nationalsozialismus zu Krieg und Vertreibung zu zeichnen. Die Vertreibung der Deutschen wird als tragisch bewertet, aber gleichzeitig nicht als völlig unverständlich betrachtet, da die Grundlage für das Zusammenleben schließlich durch den Nationalsozialismus sowie die Kollaboration der deutschen Oberschlesier zerstört worden sei. Die tschechische oder jüdische Bevölkerung und ihre Beiträge zur Geschichte Oberschlesiens ebenso wie die stete Präsenz indifferenter, regionaler Selbstidentifikationen finden in der Darstellung nur wenig Platz.

Die zentralen Aussagen der Ausstellung basieren auf einem polnisch-nationalen Narrativ, das lediglich punktuell ethnische und religiöse Differenzen beschreibt und sich überwiegend nicht von der Vorstellung nationaler Eindeutigkeit bis zurück in das Mittelalter lösen kann. Es erfolgt eine Anerkennung der Leistungen preußisch-deutscher Zeit bei der industriell-modernen Entwicklung Oberschlesiens, ohne das volks-

248 Vgl. Madajczyk: Der Transfer der deutschen Bevölkerung aus dem Oppelner Schlesien, 1999, S. 282.

249 Vgl. die Diskussion um die Begriffsbestimmung in Polen, Deutschland und Tschechien: Kap. 1.3, S. 27-31. 
polnische Narrativ des zugezogenen deutschen Ausbeuters zu bemühen. ${ }^{250}$ Beschrieben werden die Teilung Schlesiens und die endgültige Zerstörung des Zusammenlebens durch den deutschen Nationalsozialismus. Tragik und Grausamkeit der Vertreibungen werden ebenso angesprochen wie das Lagerwesen und die sowjetischen Ausschreitungen. Hierbei werden richtigerweise nicht nur die Deutschen als Opfer benannt, sondern Teile der oberschlesischen Bevölkerung allgemein, die die Sowjets und auch polnische Akteure oft nicht mühsam >national differenzierten<. Die Zwangsaussiedlungen aus den kresy vergleicht die Ausstellung indirekt mit den Vertreibungen der Deutschen durch die Nutzung von Fotografien, die den relativ geordneten Charakter der polnischen Zwangsmigration zeigen. Dass das deutsche Bevölkerungselement nach 1945 nicht verschwand, wird angedeutet, dann allerdings in der weiteren Ausstellung ebenso wenig wie das Schicksal der Oberschlesier in der Bundesrepublik thematisiert. Ebenfalls verzichtet sie auf die Darstellung der Kontinuität von nationaler Indifferenz und das öffentlich zu beobachtende (Wieder-)Erscheinen oberschlesischer Identitäten nach 1989. Auch die Zeit zwischen 1989 und 2015 wird, jenseits des Ausblicks auf Oberschlesien als moderne europäische Technologieregion, nicht mehr thematisiert.

Letztlich hinterlässt die Ausstellung einen ambivalenten Eindruck. Immer wieder wird das klassische polnische Nationalnarrativ hinterfragt und eine ganz andere Erzählung verfolgt. Dennoch bleibt das Museum weit von einem durchgehend multiperspektivischen, kritischen und die komplexe ethnische Natur Oberschlesiens darstellenden Narrativ entfernt. Es drängt sich der Eindruck auf, dass in dem Zeitraum von 2013 bis zur Eröffnung 2015 die ursprüngliche Konzeption von Jodliński weiterhin als Grundlage genutzt, aber stark modifiziert wurde. So wären zumindest die immer wieder sichtbaren verschiedenen Charakteristika der Ausstellung erklärbar und der Konflikt um die Ausstellung durchaus zwischen den Zeilen lesbar. ${ }^{251}$ Doch sind unter dem Strich Jodlińskis ursprüngliche Ideen nur noch fragmentarisch erkennbar und die Ausstellung wird der ethnischen und kulturellen Vielfalt der oberschlesischen Geschichte in Vergangenheit und Gegenwart nur eingeschränkt gerecht. Besucher mit einem polnischen Bildungshintergrund werden viele Anknüpfungspunkte an ihr Vorwissen mit einigen neuen, das klassisch polnische Narrativ punktuell hinterfragenden Informationen finden. Besucher aus Deutschland und der Welt werden vor allem ein polnisches Oberschlesien kennenlernen.

250 So formulierte der Woiwode Piotr Spyra als Kritik auf das vermeintlich deutschfreundliche Konzept von Jodliński, welches das polnische Schicksal im 19. Jahrhundert euphemistisch ausblende, denn das Schicksal der Polen wäre dieses gewesen: »lch würde für einen Deutschen in einer Zinkhütte arbeiten und schnell sterben. (»Za Niemca harowałbym w hucie cynku i szybko bym umarł. «) So gibt ihn die Gazeta Wyborcza wieder: Kortko; Ostałowska: Dość całowania ręki niemieckiego pana. Gazeta Wyborcza. 26.06.2013.

251 Auch Kobielska bewertet die Ausstellung so, dass sie zwar kein simples Nationalnarrativ erzählt, es aber immer wieder zu einer Verwischung regionaler und polnisch-nationaler Narrative käme: Kobielska: Muzea do pamiętania/Museums for Remembering, 2016, S. $192 f$. 


\subsubsection{Rezeption der Ausstellung}

In Deutschland wurde die Eröffnung des Museums bis auf wenige Ausnahmen nicht thematisiert. ${ }^{252}$ Ebenso äußerte sich die >Vertriebenenpresse auch wenn in der Zeitschrift der deutschen Minderheit, dem »Wochenblatt « aus Oppeln/Opole, das Museum eine vernichtende Kritik erhielt. In dieser werden inhaltliche Detailfehler sowie der Ansatz der szenografischen Darstellung (»Sammelsurium an Kopien und Attrappen«) und der damit verbundene Mangel an authentischen Objekten, vor allem für die Zeit vor 1945, kritisiert. ${ }^{253}$ In Oberschlesien und Polen war die Resonanz sehr unterschiedlich und deckte sich ungefähr mit den Konfliktlinien der vorherigen Diskussion um die Schwerpunktsetzung auf einer multiethnischen Region oder einem hauptsächlich polnischen Oberschlesien sowie Kritik oder Lob an der szenografischen Inszenierung. ${ }^{254}$ Die positive und die vorherigen Diskussionen rekapitulierende Besprechung in der Polityka ist mit dem Titel »Weder zu viel Deutsch, noch zu wenig Polnisch « zusammengefasst. ${ }^{255}$

2017 erhielt das Muzeum Śląskie für seine historische Ausstellung internationale Anerkennung durch einen Sonderpreis des European Museum of the Year Awards (EMYA) "for its commitment to presenting and interpreting the dramatic history of the region, reflecting on the achievements and losses, aspirations and sorrows of generations of Silesians $«$. ${ }^{256}$

Maria Kobielska kommt in ihrer Besprechung zu einer etwas positiveren Einschätzung als der Autor: »Nonetheless, the story of Solidarity and anti-Communism is not the framework for the whole exhibition, whose labyrinthine multiplicity forces a breach in the construction of the >Polish mono-memory<, that homogenous and clichéd notion of what >our past $<$ is in today's community.« ${ }^{257}$ Wenn der Besucher entsprechende intellektuelle Bemühungen auf sich nehmen wolle, könne ein vielschichtigeres Bild Oberschlesiens entstehen als es sich auf den ersten Blick zeigt: »In [...] the Silesian Museum [...] it is possible - should the visitor so decide and make the necessary cognitive effort - to generate an image of a Silesianness that is multifaced, pluralist and enriching to Polishness, yet of which it still remains but an element. $\ll^{258}$

Juliane Tomann weist in ihrer Besprechung auf die Darstellung kontroverser Themen hin, auch wenn der »enzyklopädische« Ansatz der Ausstellung im Gegensatz zur

252 Eine Ausnahme ist zum Beispiel Martin Sander, der die Entstehung des Museums für den Deutschlandfunk verfolgte und in der vorliegenden Studie mehrfach herangezogen wurde.

253 Rasim: „Schlesisches Museum « in Kattowitz: Museum, IKEA oder Ponderosa-Ranch? Wochenblatt. 22.07.2015.

254 Vgl. für die gesamte Bandbreite an Resonanzen verschiedene Zitate oberschlesischer/polnischer Persönlichkeiten zur Ausstellung: Odziomek: »Wystawa o historii Górnego Śląska to śmietnik«. Cazeta Wyborcza. 29.06.2015. Vgl. für eine positive Besprechung die Rezension im Histmag.orgPortal von: Kartasiński: „Światło historii. Górny Śląsk na przestrzeni dziejów«-recenzja wystawy stałej Muzeum Śląskiego, 2015.

255 Dziadul: Ani za dużo Niemiec, ani za mało Polski. Polityka. 30.06.2015.

256 Vgl. die Website der Auszeichnung: www.emya2017.eu/ (letzter Zugriff: 17.07.2018).

257 Kobielska: Muzea do pamiętania/Museums for Remembering, 2016, S. 192.

258 Ebd. 
Konzeption von Jodliński letztlich durch mangelnde Thesen und Aussagekraft nur eingeschränkt den besonderen Charakter Oberschlesiens darstellen könne. ${ }^{259}$ Schließlich werde die Chance verpasst, Fragen aufzuwerfen, den Besucher zur Herausbildung eigener Positionen anzuregen und das zur Schau gestellte historische Wissen kritisch zu analysieren und zu reflektieren. Die angekündigte Diskussion um die Identität Oberschlesiens werde nur fragmentarisch geführt. ${ }^{260}$ Dass die Ausstellung praktisch im Jahre 1989 endet, sieht Tomann darin begründet, dass die Ausstellungsmacher offenkundig die schwierige und andauernde Diskussion über den politischen und kulturellen Charakter Oberschlesiens ebenso wie die für die Region zentrale Frage der marktwirtschaftlichen Umgestaltung vermeiden wollten. ${ }^{261}$

In seiner vergleichenden Besprechung der drei schlesischen Museen in Polen, Tschechien und Deutschland kritisiert Ondřej Táborský die manipulativ wirkende Auswahl der behandelten historischen Epochen und eine (Über-)Betonung von »Konflikten und Antagonismen«. Die "nationale Frage« erscheine »ausschließlich vom Standpunkt des Konfliktes, mit der offensichtlichen Intention, diese in das offizielle staatliche Narrativ einzufügen.« Dies gehe auf Kosten der spezifisch eigenständigen, schlesischen Identität der Region, die lediglich als schmückendes Beiwerk und weniger als Kern der Ausstellung dargestellt werde. ${ }^{262}$

Marcin Wiatr konstatiert, es ließen sich in Hinblick auf den Anspruch der Ausstellung und ihrer Ziele der angestrebten »Dialogfähigkeit, der Multiperspektivität und der Kontroversität - klare Schwachpunkte der Ausstellung festmachen«. Zudem sei der Schwerpunkt auf das »schwarze Oberschlesien« (also das vom Bergbau geprägte Ostoberschlesien) einseitig und unverständlich, da dies einen Großteil der Region außer Acht lasse. Außerdem vermisst Wiatr einen kontinuierlichen roten Faden, der die Identifikation mit dem Ausstellungsgegenstand erleichtern würde, was durch das plötzliche Abbrechen der Erzählung 1989 noch verstärkt werde. ${ }^{263}$ Er selbst sieht Oberschlesien und seine Geschichte in Hinblick auf aktuelle gesellschaftspolitische Fragen und Herausforderungen, beispielsweise angesichts der aktuellen >Flüchtlingskrise`, als Musterbeispiel, als Lernobjekt für die gewinnbringende Gestaltung des Zusammenlebens immer komplexer werdender Gesellschaften. ${ }^{264}$ Derartige Versuche finden in der Dauerausstellung nicht statt. Der multiethnische und kulturell vielfältige Charakter der Region verbleibt in der Vergangenheit.

\subsubsection{Zusammenführende Betrachtung}

Die Ausstellung ist ein Beispiel für die gelungene Umsetzung eines szenografischen Ansatzes. Inhaltlich fügt sie sich in den polnischen Diskurs um Flucht und Vertreibung der Deutschen ein: Die Vertreibung wird als bedauerliche Tragödie bezeichnet, ohne allerdings ihre Notwendigkeit grundsätzlich in Frage zu stellen. Ebenso werden die

259 Tomann: Rezension zu: Das Licht der Geschichte. Oberschlesien im Wandel der Zeiten, 26.06.2015.

260 Tomann: »The Light of History«, 2016.

261 Ebd.

262 Táborský: Creating Silesian Identity, 2018.

263 Wiatr: Oberschlesien und sein kulturelles Erbe, 2016, S. 56-58.

264 Wiatr: Deutsch sein in Polen, 2016, S. 71. 
Entscheidung und Verantwortung für diese nach >Potsdam^ externalisiert, auch wenn polnische Akteure vorgestellt werden. Im Muzeum Śląskie spiegelt sich außerdem der spezifische Diskurs um und in Oberschlesien wider, in dem vor allem die »Oberschlesische Tragödie« einen großen Raum bekommt. Das ist durchaus als mutig zu bewerten, denn für fast alle Polen - auch die nach 1945 in großer Zahl nach Oberschlesien zugewanderten - ist dies lange ein unbekanntes oder peripheres Thema gewesen, auch wenn es in der Ausstellung nicht konsequent mit dem Leiden der deutschen oberschlesischen Bevölkerungsgruppen verbunden wird. ${ }^{265}$

Die Ausstellung operiert schließlich mit drei verschiedenen Gruppen: mit Polen, polnischen Oberschlesiern und Deutschen. Seltener oder kaum wird deutlich, dass es vielfach eine deutsche und oberschlesische Identität gab und gibt. Diese Einschränkung wäre annehmbar, wenn der Oberschlesier in der Ausstellung noch deutlicher in seiner Vielfalt gefasst werden beziehungsweise Nation als Konstruktion stärker diskutiert würde, auch wenn das keineswegs die von manchen gefürchtete >Destruktion ‘ dieses Konzeptes bedeuten muss. Marcin Wiatr hat oben den Wert einer solchen Debatte für gegenwärtige Herausforderungen herausgestellt.

Die Ausstellung des Museums weist trotz der vielfältigen Kritik Potenziale auf. Mit einer stärkeren Betonung der Komplexität der Region und einer grundlegenderen Hinterfragung oder zumindest stärkeren Ergänzung des polnischen Nationalnarrativs, gerade auch für die Zeit nach 1945, sowie einem entsprechenden Sonderausstellungsund Veranstaltungsprogramm, könnte der selbst gestellte Anspruch des Museums, mit Oberschlesien eine bedeutende, ethnisch und konfessionell vielfältige europäische Region darzustellen, tatsächlich eingelöst werden. In Hinblick auf die zentrale Fragestellung dieser Arbeit bleibt zu konstatieren, dass die schließlich realisierte Ausstellung die Geschichte der deutschen Oberschlesier und die Entfernung eines beträchtlichen Teils der Bevölkerung Oberschlesiens um 1945 in ihrer einschneidenden Dimension für alle Betroffenen nicht ausreichend darstellt. Diese Unzufriedenheit manifestiert sich auch in dem Vorschlag der schlesischen Autonomiebewegung und der deutschen Minderheit, eine weitere Ausstellung zur Vertreibung aus Oberschlesien in Beuthen zu schaffen. ${ }^{266}$

\subsection{Anmerkungen zur sudetendeutschen Geschichte}

Die mit dem Erzählen einer sudetendeutschen Geschichte verbundenen Herausforderungen sind uns in dieser Arbeit wiederholt begegnet: Neben der grundsätzlichen Infragestellung des Begriffes »Sudetendeutsche«, der ein heterogenes Ensemble deutschsprachiger Gemeinschaften in Böhmen, Mähren und dem heute tschechischen Schlesien zu einer vermeintlichen Großgruppe zusammenfasst, ${ }^{267}$ ist doch die Abgrenzung und ein ständiger Antagonismus von Tschechen und Deutschen in der Region als historisches Kontinuum kaum haltbar. ${ }^{268}$ Die Durchsetzung des Dachbegriffs "Sudetendeutsche« in Deutschland nach dem Zweiten Weltkrieg erklärt sich unter anderem aus

265 Linek; Lotz: Flucht, Vertreibung, Umsiedlung, 2015, S. 641.

266 Siehe Kap. 6.3.1, S. 317.

267 Vgl. Kap. 3.3, S. $106 f$.

268 Vgl. Kap. 3.1, S. $99 f$. 
dem Bedürfnis, sich als Schicksals- und Interessengemeinschaft zu konstituieren. ${ }^{269}$ In Tschechien und auch bei einigen Sudetendeutschen wird diese Konstruktion aufgrund ihrer negativen Konnotation mit dem Münchner Abkommen und der Besatzungszeit hinterfragt, was sich unter anderem eindrücklich in der Arbeitsbezeichnung des $\mathrm{Mu}$ seums der deutschsprachigen Bewohner Böhmens zeigt, die auf den Terminus der Sudetendeutschen bewusst verzichtet. Auch der Bohemist Ferdinand Seibt konstatiert, dass es selbst »bei wohlwollendster Würdigung « eine »Sudetendeutsche Geschichte« nicht gibt. Es lasse sich noch von einer Geschichte der Sudetendeutschen sprechen, aber sinnvoller und ergiebiger sei eine übergreifende Geschichte Böhmens, die nationaler Indifferenz ebenso wie des Nationalismus gerecht werde. ${ }^{270}$

Wie in Kapitel 3.1 besprochen, ist die Vorstellung eines jahrhundertelangen >Volkstumskampfes« zwischen Tschechen und Deutschen, wie sie im 19. und 20. Jahrhundert auf beiden Seiten vertreten wurde, höchst problematisch - auch wenn ethnische, sprachliche und konfessionelle Konflikte integraler, aber keineswegs permanenter und alle Gesellschaftsschichten und Regionen betreffender Bestandteil dieser Geschichte sind. ${ }^{271}$ Eine solche in primär nationale Kategorien gefasste Perspektive kann nur und auch dann nur mit Einschränkung - verfolgt werden, wenn die Betrachtung auf die Zeit nach 1848 gerichtet ist. ${ }^{272}$

Das enge sudetendeutsch-bayerische Verhältnis wurde in Kapitel 5.1 diskutiert, ebenso wie auch die politisch-kulturelle Verbindung von Sudetendeutscher Landsmannschaft und bayerischer Politik, die sich in der Anerkennung der Sudetendeutschen als »vierter Stamm« Bayerns niederschlägt und weiter von Bedeutung ist. ${ }^{273}$ Heute wird auch vermehrt auf die enge bayerisch-tschechische Geschichte verwiesen. ${ }^{274}$ Die Sudetendeutsche Landsmannschaft ist im Vergleich zu den anderen Landsmannschaften mit ihrer weiterhin hohen Mitgliederzahl und ihrem politischen Einfluss noch am stärksten aufgestellt, was sich nicht zuletzt in der Federführung bei der Gestaltung des Sudetendeutschen Museums zeigt.

\subsection{Sudetendeutsches Museum in München}

Die sudetendeutsche Kulturgeschichte ist seit dem Ende des Zweiten Weltkrieges in ganz Bayern präsent. Über das Land verteilte Heimatstuben und mehrere Regionalmuseen, wie das Egerland-Museum in Marktredwitz oder das Isergebirgs-Museum in der Vertriebenengemeinde Neugablonz, sind neben den Aktivitäten der Sudetendeutschen

269 Vgl. Kap. 1.1, S. $21 \mathrm{f}$.

270 Seibt: Eine neue Nachbarschaft? (1993), 2002, S. $123 f$.

271 Kunštát: Fremd- und Feindbilder der Deutschen in der tschechischen innenpolitischen Instrumentalisierung nach 1989, 2007, S. 114f. Vgl. Bugge: »Land und Volk«-oder: Wo liegt Böhmen? 2002, S. 410 .

272 Seibt: Die Deutschen in den Böhmischen Ländern, 2002, S. 47.

273 Zwicker: Zur Darstellung der Sudetendeutschen, 2006, S. 410. Vgl. Kap. 5.1, S. $220 f$.

274 Vgl. für einen komprimierten, vergleichend-verbindenden Überblick über die bayerisch-tschechische Geschichte: Luft; Hlavačka: Tschechien und Bayern, 2016, S. XV-XXXIII. 
Landsmannschaft und ihrer Untergliederungen dafür das Fundament. ${ }^{275}$ Ähnlich wie bei den anderen >ostdeutschen Museen entstand aber auch in Bayern die Forderung nach einem zentralen sudetendeutschen Museum in Ergänzung zur bestehenden kulturellen Infrastruktur. ${ }^{276}$ Diese wurde von Edmund Stoiber aufgegriffen, indem er beim Sudetendeutschen Tag 2006 die Einrichtung eines solchen Museums in München ankündigte. ${ }^{277}$ Noch bevor das Vorhaben im Jahr 2008 in den Koalitionsvertrag von CSU und FDP gelangte, wurde die Historikerin Marita Krauss bereits 2007 von der Staatsregierung mit der Ausarbeitung eines wissenschaftlichen Konzepts für das Museum beauftragt. ${ }^{278}$

Das von Krauss entworfene Konzept stand unter der Leitidee "Zusammenleben", die bis heute den Titel des Museums bildet. Im Museumslogo sind „Zusammen« und »Leben« farblich voneinander getrennt, um eine mehrfache Deutung zu ermöglichen. Das Zusammenleben verstand Krauss als konstitutiv für die Region und der Begriff sollte die Konfliktgeschichte ebenso wie die Fragen eines europäischen Zusammenlebens in der Gegenwart ansprechen. Flucht und Vertreibung stellten in dem Konzept ein wichtiges Element dar, sollten aber nicht die künftige Ausstellung dominieren. ${ }^{279}$ Krauss formulierte retrospektiv die Grundfragen für die Planungen des Museums, wie im »Zeichen eines zusammenwachsenden Europas ein modernes Museum zu erdenken [ist], das gemäß Paragraph 96 Überlieferung bewahrt und dennoch in die Zukunft führt, das Position bezieht, alte Diskussionen sichtbar macht, sie aber gleichzeitig historisiert - ein Museum, das dabei nicht spaltet, sondern zusammenführt? ${ }^{280}$ Mit den auch für die Gegenwart relevanten Themen von Migration und Heimat wollte sie sowohl die Erlebnisgeneration der Vertriebenen als auch mit diesem Thema nicht verbundene Gruppen ansprechen. ${ }^{281}$ Ein konsequent multiperspektivischer Ansatz der Ausstellung sollte durch die stete Berücksichtigung der Perspektive deutscher, tschechischer und jüdischer Bewohner der böhmischen Länder gewährleistet werden. ${ }^{282}$

Die schwierige Begriffsgeschichte des »Sudetendeutschen« vor Augen, wurden verschiedene Alternativen für den Namen des künftigen Museums diskutiert. Letztlich entschieden sich die Akteure in Anerkennung der Durchsetzung des Terminus für "Sudetendeutsches Museum«, auch um eine Analogie zu den anderen rostdeutschen Landesmuseen, wie dem Westpreußischen Landesmuseum, zu verdeutlichen. ${ }^{283}$ Von Beginn an wurde die Planung verfolgt, den Neubau mit der bestehenden sudetendeutschen und >ostdeutschen Infrastruktur in München sinnvoll $\mathrm{zu}$ verbinden. Mit dem 1970 gegründeten Haus des Deutschen Ostens ebenso wie dem 1985 fertiggestellten Sudetendeutschen Haus, das verschiedene sudetendeutsche Institutionen beherbergt,

275 Vgl. für eine gegenwärtige Zusammenstellung von 86 Heimatstuben: Henker (Hg.): Die Heimatsammlungen der Sudeten- und Ostdeutschen in Bayern, 2009.

276 Erste Forderungen danach kamen bereits in den 1950er Jahren auf. Verstärkt artikuliert wurden sie jedoch erst seit Anfang der 200oer Jahre. Vgl. Krauss: »Zusammenleben«, 2017, S. 119.

277 Stoiber: Probleme wegdrücken ist rückwärtsgewandt. Sudetendeutsche Zeitung. 09.06.2006.

278 Krauss: Das Sudetendeutsche Museum in München, 2010, S. 115.

279 Krauss: »Zusammenleben«, 2017, S. 119; 123-125.

280 Krauss: Das Sudetendeutsche Museum in München, 2010, 113.

281 Ebd., S. 116f.

282 Ebd., S. 116.

283 Ebd., S. 114. 
soll es künftig zusammenwirken. Die Entscheidung für München als Standort erklärt sich weiter daher, dass es die Hauptstadt des Patenlandes der Sudetendeutschen ist und Bayern nach Ankunft von etwa einer Million sudetendeutscher Vertriebener deren Hauptzufluchtsland war. ${ }^{284}$

Wilfried Rogasch, der an der Schaffung der verschiedenen Ausstellungen des Zentrums gegen Vertreibungen beteiligt gewesen ist, wurde 2011 zum Gründungsbeauftragten für das Sudetendeutsche Museum berufen. ${ }^{285}$ Diese Phase blieb ein ergebnisloses Intermezzo, ${ }^{286}$ auf das 2012 als neue Gründungsbeauftragte die Volkskundlerin und Kunsthistorikerin Elisabeth Fendl folgte, die schon das Egerland-Museum in Marktredwitz geleitet hatte. ${ }^{287}$ Sie modifizierte das Konzept von Marita Krauss in einigen Punkten und stellte den zuvor gleich gewichteten Themenbereich »Heimat« stärker in den Mittelpunkt des künftigen Museums. ${ }^{288}$ Am Ende ihrer Zeit als Gründungsbeauftragte legte sie im Januar 2016 ein 355-seitiges Konzeptpapier für die geplante Ausstellung vor.

Im September 2016 konnte die Grundsteinlegung im Beisein des bayerischen Ministerpräsidenten Horst Seehofer gefeiert werden, der das Sudetendeutsche Museums als »ein Leuchtturmprojekt « der bayerischen Kulturpolitik bezeichnete. ${ }^{289}$ Auf Grundlage des Konzeptionspapieres von Elisabeth Fendl verfolgt ein mehrköpfiger Aufbaustab unter Leitung des österreichischen Museumsexperten und Historikers Michael Henker und in Kooperation mit dem Vorsitzenden der Sudetendeutschen Stiftung Ortfried Kotzian nun die Realisierung der Ausstellung. ${ }^{290}$ Durch Verzögerungen des Bauvorhabens wird mittlerweile mit einer Eröffnung in der zweiten Jahreshälfte 2020 gerechnet. ${ }^{291}$

Bis dahin war das das Sudetendeutsche Museum weder in Bayern noch in Tschechien Gegenstand einer Kontroverse. Lediglich 2014 veröffentlichte die Rosa-LuxemburgStiftung ein Papier, in dem sie die Finanzierung des Vorhabens aus dem bayerischen Sozialetat, das intransparente Vorgehen sowie das Überlassen der Gestaltungsmacht an die Sudetendeutsche Landsmannschaft kritisierte. ${ }^{292}$ Weiter vermutete die Autorin der Studie, Renate Hennecke, dass mit dem Vorhaben "notfalls [...] [ein] Korrektiv gegenüber dem >Sichtbaren Zeichen « in Berlin geschaffen werden sollte, falls dieses sich zu sehr von den Vorstellungen des BdV entferne. ${ }^{293}$ Ansonsten wurde das Vorhaben von

284 Kotzian: Ein Sudetendeutsches Museum in München? 2018, S. 15.

285 Hennecke: Das Sudetendeutsche Museum in München, 2014, S. $5 \mathrm{f}$.

286 Ebd., S. 6.

287 Vgl. Fendl; Mohr (Hg.): Heimat Geschichten, 2018, S. 200.

288 Kaiserová; Kunštát: Deutsche und Tschechen im Museum, 2017, S. 147. Vgl. für den ursprünglichen Ansatz von Krauss für ein »Themenmuseum« mit den sechs Feldern »Heimat«, »Grenze«, »Migrationen«, »Loyalitäten«, »Der Bruch« und »Austausch«: Krauss: Das Sudetendeutsche Museum in München, 2010, S. 117-119.

289 Rede des Bayerischen Ministerpräsidenten Horst Seehofer, MdL, anlässlich der Grundsteinlegung für das Sudetendeutsche Museum am 16. September 2016. Vgl. ausführlich: Fischer: Markantes Symbol der Volksgruppe mitten in München. Sudetendeutsche Zeitung. 23.09.2016.

290 Kotzian: Münchner Schatztruhe, betonbewehrt, 2017, S. 8.

291 Reichert: Klare Betrachtungsweisen. Sudetendeutsche Zeitung. 29.11.2019. Siehe für die Verzögerungen am Bau: Warum sich die Eröffnung um Jahre verzögert. Süddeutsche Zeitung. 03.07.2019.

292 Hennecke: Das Sudetendeutsche Museum in München, 2014.

293 Ebd., S. 4. 
einem breiten politischen Konsens getragen und die bayerische SPD forderte sogar eine bessere Finanzierung sowie eine Beschleunigung des Vorhabens. ${ }^{294}$

Das künftige Sudetendeutsche Museum gehört zu den nach Paragraph 96 BVFG geförderten Einrichtungen. ${ }^{295}$ Trägerin des Museums ist die 1970 durch die bayerische Landesregierung und die Sudetendeutsche Landsmannschaft gegründete Sudetendeutsche Stiftung. Die Ausstellung selbst soll durch die Stiftung in Kooperation mit der für das Bauvorhaben verantwortlichen Staatsregierung, dem Wissenschaftlichen Beirat und der Landesstelle für die nichtstaatlichen Museen in Bayern geschaffen werden. ${ }^{296} \mathrm{Im}$ Wissenschaftlichen Beirat waren 2014, neben der Direktorin des für die Entstehung des Museums der deutschsprachigen Bewohner Böhmens verantwortlichen Collegium Bohemicum in Aussig, der stellvertretende Direktor des Jüdischen Museums in Prag, jeweils ein Vertreter der Karls-Universität sowie des Kreisarchivs von Eger/Cheb, der Direktor der Stiftung Flucht, Vertreibung, Versöhnung ebenso wie der Direktor des Schlesischen Museums zu Görlitz vertreten. ${ }^{297}$ Die Kosten für den Bau und alle weiteren Schritte bis zum Beginn des Ausstellungsbetriebes sind mit etwa 30 Millionen Euro veranschlagt und werden mit 20 Millionen Euro vom Freistaat Bayern sowie 10 Millionen aus dem Bundeshaushalt gemäß Paragraph 96 des BVFG finanziert. ${ }^{298}$

Die Fläche für die künftige Dauerausstellung beträgt ungefähr 1200 Quadratmeter auf fünf Etagen. ${ }^{299}$ Für Sonderausstellungen stehen etwa 380 Quadratmeter zur Verfügung, die sich zum Teil in dem mit dem Neubau verbundenen älteren Sudetendeutschen Haus befinden werden. ${ }^{300}$ Die Sammlung für das Sudetendeutsche Museum musste neu aufgebaut werden, kann dabei aber auf einige ihr übertragene Bestände zurückgreifen. ${ }^{301}$ In der Ausstellung sollen etwa 1000 Objekte gezeigt werden. ${ }^{302}$ Als Zielgruppen definieren die Planer neben den Sudetendeutschen und ihren Nachfahren sowie den tschechischen Nachbarn auch Personen, die mit dem Thema zunächst keine Verbindung haben. Dafür soll die Ausstellung durchgängig auf Deutsch, Tschechisch und Englisch zur Verfügung stehen. ${ }^{303}$ Als weiteres Ziel wurde formuliert, sich mit ansprechenden und vielfältigen Themen im »kompetitiven Umfeld « der Münchner Kulturlandschaft zu behaupten und auch international Anerkennung zu finden. ${ }^{304}$ 2018 erschien mit »Heimat Geschichten« eine erste Publikation über die Sammlung des

294 Hennecke: Das Sudetendeutsche Museum in München, 2014, S. 2-4.

295 Vgl. zum § 96 des BVFC: Kap. 5.1, S. 219f.; Kap. 6.2.2, S. $286 f$.

296 Hennecke: Das Sudetendeutsche Museum in München, 2014, S. 1. Vgl. Kotzian: Münchner Schatztruhe, betonbewehrt, 2017, S. $7 f$.

297 Hennecke: Das Sudetendeutsche Museum in München, 2014, S. 1f., $6 \mathrm{f}$.

298 Rede des Bayerischen Ministerpräsidenten Horst Seehofer, MdL, anlässlich der Grundsteinlegung für das Sudetendeutsche Museum am 16. September 2016. Grütters: Grußwort Prof. Monika Grütters, 2018, S. 13.

299 Vgl. die Pressemitteilung der SACHER GmbH: Sudetendeutsches Museum in München, 2017.

300 Staatliches Bauamt Rosenheim: Neubau Sudetendeutsches Museum in München, 2014.

301 Krauss: Das Sudetendeutsche Museum in München, 2010, S. 120. Vgl. zum mit mehr als 25.000 Objekten bestückten Bestand des Sudetendeutschen Archives, welches dem Museum zur Arbeit zur Verfügung steht: Mohr: Die Sammlungen des Sudetendeutschen Museums, 2018, S. 17-19.

302 Reichert: Klare Betrachtungsweisen. Sudetendeutsche Zeitung. 29.11.2019.

303 Fendl: Sudetendeutsches Museum - Konzept, 2016, S. 5.

304 Ebd., S. 6. Vgl. Kotzian: Ein Sudetendeutsches Museum in München? 2018, S. 16. 
Hauses. ${ }^{305}$ Der für das Museum eigens geschaffene Neubau ${ }^{306}$ soll gemeinsam mit dem Haus des Deutschen Ostens sowie dem Sudetendeutschen Haus am Münchner Isarhangufer ein architektonisches und inhaltliches Ensemble bilden. Durch die erhöhte Lage und den auffälligen Hochbau stellt es eine Landmarke dar und ist auch vom Deutschen Museum sichtbar. ${ }^{307}$

Der Anspruch der Sudetendeutschen Landsmannschaft an das Sudetendeutsche $\mathrm{Mu}-$ seum ist bereits angeklungen: Wie die anderen Verbände sollen auch die Sudetendeutschen ein repräsentatives Zentralmuseum erhalten, das Geschichte und Kultur der Deutschen Böhmens, Mährens und Mährisch-Schlesiens zeigt. Darin soll die Vertreibung und ihre Vorgeschichte einen angemessenen Platz erhalten. Die Planungen folgen dem verständigungspolitischen Kurs des Vorsitzenden der SL, dem langjährigen CSUAbgeordneten im Europarlament, Bernd Posselt, der stets die Bedeutung der Sudetendeutschen als europäische Brückenbauer betont, wie sie sich auch in der Ausschreibung für den Bau des Museums findet:

»Das Museum soll ein Ort werden, der Ceschichte, Schicksal und Kultur der Sudetendeutschen lebendig im Bewusstsein hält - einschließlich ihrer Leistungen für die europäische Verständigung und als Brückenbauer in Europa-ein Ort der Begegnung und des Dialogs, insbesondere mit unseren tschechischen Nachbarn. « ${ }^{308}$

Horst Seehofer unterstrich diesen politischen Anspruch 2018, den er noch weiter in die Gegenwart hineintrug: »Ein zentraler Bildungsauftrag [...] ergibt sich aus dem Schicksal der Sudetendeutschen. Es soll Ausgrenzung und ethnische Verfolgung, Flucht und Vertreibung in ihren historischen Zusammenhängen erläutern und damit Bayern, Deutsche und Europäer zu Mitmenschlichkeit, Versöhnung und politischer Vernunft mahnen. $\aleph^{309}$ Ein verständigungspolitisches Ziel formulierte auch die bayerische Staatsministerin Emilia Müller, die in dem Museum künftig einen »Ort der Begegnung« sieht, "an dem sich Bayern, Tschechen und viele andere Interessierte über das Geschehene austauschen « und damit auch künftig »ein friedliches Miteinander « sichern können. ${ }^{310}$

Ortfried Kotzian, der Vorstandsvorsitzende der Sudetendeutschen Stiftung und eng involviert in die Entwicklung der Ausstellung, beschreibt den Auftrag des Museums wie folgt:

»Es wird die Ceschichte und Kultur der Sudetendeutschen anhand von Alltagsgegenständen, die gerettet werden konnten, so erzählen, dass die Fragen und Probleme, welche das Schicksal von drei Millionen Sudetendeutschen aufwerfen, verstanden werden können: so objektiv wie möglich, aus unterschiedlichen Perspektiven, ohne zu über-

305 Fendl; Mohr (Hg.): Heimat Geschichten, 2018.

306 Vgl. dafür die Ausschreibung für den Bau von 2014, bei der die Baukosten mit 24 Millionen Euro veranschlagt sind: Staatliches Bauamt Rosenheim: Neubau Sudetendeutsches Museum in München, 2014.

307 Vgl. Vick: Kunstvoller Bau an der Isarhangkante. Münchner Merkur. 20.12.2014.

308 Staatliches Bauamt Rosenheim: Neubau Sudetendeutsches Museum in München, 2014.

309 Seehofer: Grußwort, 2018, S. 8.

310 Müller: Grußwort, 2018, S. 11. 
spitzen, ohne zu dramatisieren, ohne Feindbilder aufzubauen, aber auch ohne schwierige Situationen der Geschichte zu verschweigen oder zu minimalisieren. $\ll^{311}$

Die oben schon diskutierten Vorstellungen von Marita Krauss und Elisabeth Fendl bilden weiterhin die Grundlage für das Selbstverständnis des Museums. Fendl unterstrich in ihrem Konzept von 2016, dass mit Museen grundsätzlich »Identitätspolitik betrieben« werde, die es zu reflektieren gelte - ein Beispiel dafür solle die Reflektion über den für die Ausstellung wesentlichen Begriff »Heimat « sein. ${ }^{312}$ Ein stetes Mitdenken der tschechischen, aber auch internationaler Perspektiven auf die Region von Böhmen, Mähren und Mährisch-Schlesien ebenso wie die konsequente Anerkennung der Heterogenität der Sudetendeutschen soll die dichotomen Kämpfe des 20. Jahrhunderts überwinden und historisieren. Mit seiner kulturhistorischen Aufstellung, die auch Wirtschaft, Religion und Technik beinhaltet, verfolgt es Ansätze eines Universalmuseums, das mit einer solchen Themenvielfalt das Lernen über den Menschen ermöglichen soll. Darüber hinaus wird die Ausstellung eine mehrere hundert Jahre umspannende mitteleuropäische Regionalgeschichte darstellen, in der die Sudetendeutschen heute »Brückenbauer im geeinten Europa « seien. ${ }^{313}$ Das Museum verstehen die Schöpfer nicht als isolierte Institution, sondern es soll sich in ein bayerisches, deutsches und tschechisches Netzwerk konstruktiv einfügen. Hierfür konnten schon einige Kooperationen erreicht werden, nicht zuletzt mit dem Collegium Bohemicum. ${ }^{314}$

Das im Januar 2016 von der Gründungsbeauftragten Elisabeth Fendl intern ${ }^{315}$ vorgelegte Konzept für das Sudetendeutsche Museum ist mittlerweile vom Aufbauteam weiter konkretisiert und in Teilen verändert worden. Die Untersuchung beschränkt sich hier auf das Papier von 2016 sowie einige mündliche Anmerkungen des Vorsitzenden der Sudetendeutschen Stiftung, Ortfried Kotzian, und des Leiters des Museumsaufbauteams, Michael Henker. Das Konzept ist wiederum eine Weiterentwicklung der 2008 von Marita Krauss vorgelegten Überlegungen. Auf den 355 Seiten ihres Papieres stellt Fendl anhand des geplanten chronologisch-thematischen Parcours potentiell zu zeigende Objekte, erklärungsbedürftige Ereignisse und Themen vor. Das Sudetendeutsche Museum wird als kulturhistorisches Museum entwickelt, das neben dem Schwerpunkt auf Zeit- und Politikgeschichte mit einem weiten Kulturbegriff auch Sozial- und Alltagsgeschichte integriert. ${ }^{316}$

Der Fokus der Ausstellung liegt auf der Geschichte der Deutschen in Böhmen und Mähren, wobei »deutlich gemacht werden [soll], mit wem man sich die Heimat teilte, und wann und auf welchen Feldern sich Konflikte entwickelten. «117 Sie möchte Raum

311 Kotzian: Ein Sudetendeutsches Museum in München? 2018, S. $15 f$.

312 Fendl: Sudetendeutsches Museum - Konzept, 2016, S. 8.

313 So formulierte es die bayerische Staatsministerin für Arbeit und Soziales, Familie und Integration, Emilia Müller: Grußwort, 2018, S. 10.

314 Fendl: Sudetendeutsches Museum - Konzept, 2016, S. 4f., 7.

315 Das Konzept wurde dem Autoren freundlicherweise vom Vorstandsvorsitzenden der Sudetendeutschen Stiftung Ortfried Kotzian und dem Leiter des Museumsaufbauteams Michael Henker zur Verfügung gestellt.

316 Fendl: Sudetendeutsches Museum - Konzept, 2016, S. 4.

317 Ebd., S. 8. 
für hybride Identitäten und Grautöne lassen. Das Narrativ eines idyllischen Zusammenlebens vor dem Nationalismus soll weder negiert noch unkritisch befördert werden. ${ }^{318}$ Die Ausstellung soll konsequent von einem reflektierten, multiperspektivischen Charakter getragen werden, beispielsweise bei der Herausstellung unterschiedlicher Wahrnehmungen von historischen Ereignissen. ${ }^{319}$ Die Geschichte planen die Ausstellungsmacher vor allem mit Exponaten zu erzählen und um passende Inszenierungen und audiovisuelle Elemente zu ergänzen. ${ }^{320}$ Inhaltlich verfolgt das Papier zwei Leitkategorien: Heimat und Erinnerung. Damit soll die künftige Ausstellung der besonderen Bedeutung des Sudetenlandes als erinnerter Region gerecht werden. ${ }^{321}$

Im Konzept von Marita Krauss noch stärker angelegt, aber auch im Konzept von Elisabeth Fendl enthalten ist der Ansatz, an das Gegenwartsgeschehen anzuknüpfen und einen Besuch der Ausstellung auch für nicht direkt mit dem Thema verbundene Gäste attraktiv zu machen. Als ein Beispiel wird die Diskussion des gegenwärtig in Europa wieder virulenten Themas von Flucht und Vertreibung genannt, deren politische Verbindung Fendl aber vorsichtig formuliert: „Ohne direkte Parallelen zu behaupten, gibt es Aspekte, die nebeneinandergestellt und verglichen werden können. « ${ }^{322}$

Die Ausstellung gliedert die drei Themenbereiche auf fünf Etagen und beginnt im dritten Obergeschoss: Das dritte und zweite Obergeschoss bilden den ersten Themenbereich »Heimat! «, das erste Obergeschoss und das Erdgeschoss mit »Verlust - das Ende der Selbstverständlichkeiten« den zweiten, und das erste Untergeschoss greift den Eingangstitel mit »Heimat?« als letztem Themenbereich wieder auf. Mit dieser Gliederung verbindet sich ein thematisch-chronologischer Ansatz. ${ }^{323} \mathrm{Zu}$ Beginn der Ausstellung werden dem Besucher der Konstruktionscharakter der Sammlung ebenso wie »das Museum als narratives Medium vorgestellt«. ${ }^{324}$ Die Vielfalt der heute als sudetendeutsch betrachteten Regionen soll sich auch im Museum widerspiegeln, aber die einzelnen Themen nicht mit einer Rundschau aller Regionen, sondern anhand einzelner regionaler Beispiele behandelt werden. ${ }^{325}$

Der erste Ausstellungsbereich »Heimat!« soll zunächst den Begriff Heimat und die Zeit vor dem Nationalismus diskutieren. Diesem Bereich folgen Fragen zur Begrifflichkeit "Sudetendeutsche«, in denen die deutsche und tschechische Perspektive veranschaulicht wird. Ein weiterer Bereich historisiert den Begriff »Sudetenland«, ebenso wie die Masaryk'sche Wortschöpfung »Unsere Deutschen« ${ }^{326}$ Dieses Ausstellungssegment soll nicht die von der Sudetendeutschen Landsmannschaft nach dem Zweiten Weltkrieg konstruierten statischen, verklärten »Heimatlandschaften« kontinuieren, sondern ein

\footnotetext{
318 Vgl. Fendl: Sudetendeutsches Museum - Konzept, 2016, S. 22.

319 Ebd., S. 12.

320 Ebd., S. $10 f$.

321 Ebd., S. 7-9.

322 Ebd., S. 5.

323 Ebd., S. 14

324 Ebd., S. 18.

325 Ebd., S. 80.

326 Ebd., S. 23-28. Der erste Staatspräsident der Tschechoslowakei, Tomáš Garrigue Masaryk, verwendete diese Formulierung, die ebenso integrativ wie paternalistisch zu verstehen ist.
} 
dynamisches und historisches Verständnis anbieten. ${ }^{327}$ Chronologisch bewegt sich die Ausstellung mit »Streiflichtern« durch die Geschichte der böhmischen Länder. Als Beginn sieht das Konzept die Christianisierung im 10. Jahrhundert vor und verfolgt anhand verschiedener Wegmarken die Geschichte bis ins 20. Jahrhundert, das anhand von Ereignissen wie der Gründung der Tschechoslowakei, dem sudetendeutschen Aktivismus und Negativismus, dem Münchner Abkommen, dem >Protektorat Böhmen und Mähren<, dem Massaker von Lidice, der Shoa und folgend der >wilden Vertreibungen und der Gewalt, der >Beneš-Dekrete< sowie schließlich der Charta der deutschen Heimatvertriebenen und der bayerischen Patenschaft mit den Sudetendeutschen erzählt wird. ${ }^{328}$ Mit diesem historischen Parcours soll sich eine Diskussion der damit verbundenen konfligierenden Erinnerungen in Deutschland und Tschechien verbinden, beispielsweise anhand der Frage, ob die >Beneš-Dekrete eine verständliche Reaktion auf den nationalsozialistischen Terror waren. ${ }^{329}$

Weiter folgen im ersten Ausstellungsbereich die Themen Religion ${ }^{330}$, Wirtschaft ${ }^{331}$ sowie Kultur und Lebensweise. ${ }^{332}$ Im zweiten Teil werden unter dem Titel »Verlust - das Ende der Selbstverständlichkeiten « von 1848 bis in die Zwischenkriegszeit sowohl das zunehmende nationalistische Hochschaukeln als auch beispielhafte, aber vergebliche Kompromissversuche gezeigt. ${ }^{333}$ Als nächster Abschnitt folgt der »Nationalsozialismus in den Böhmischen Ländern ${ }^{334}$, in dem die Weltwirtschaftskrise, ausführlich die Sudetendeutsche Partei, die Sudetenkrise und das Münchner Abkommen sowie dialektisch Begeisterung und Verfolgung als Folge des deutschen Einmarsches diskutiert werden. Raum erhalten auch »Widerstand und Exil«, der Alltag unter dem Nationalsozialismus, das >Protektorat Böhmen und Mähren< sowie der nationalsozialistische Terror. Diesem Bereich folgt das aufgegliederte Themenfeld von "Flucht und Vertreibung «, das in die Unterthemen von Kriegsende, »Repressalien gegen Deutsche in Form von Internierung und Arbeitspflicht, "Gewalt gegen Deutsche« und verschiedene Formen und »Wege der Vertreibung « aufgegliedert ist und die heterogenen Erfahrungen vorstellen möchte. ${ }^{335}$ Ein kleiner Abschnitt soll auch den »Heimatverbliebenen Deutschen« gewidmet werden und deren schwieriges Fortleben in der Tschechoslowakei beschreiben. In diesem Bereich plant Fendl, einen begehbaren leeren Raum einzurichten. Eine empathische Annäherung an die Vertreibung soll mit »Wortsequenzen« aus Zeitzeugengesprächen, Geräuschen von Lokomotiven oder kleinen Sichtspalten in den Wänden, wie sie bei den Güterwaggons vorkamen, ermöglicht werden. ${ }^{336}$ Der im Papier angesprochene Bereich

327 Fendl: Sudetendeutsches Museum - Konzept, 2016, S. 33.

328 Ebd., S. $41 \mathrm{f}$.

329 Ebd., S. $46 \mathrm{f}$.

330 Ebd., S. 48-79.

331 Ebd., S. 80-150.

332 Ebd., S. 151-177.

333 Ebd., S. 178. Der Abschnitt »Nationalismen im Konflikt« beinhaltet »Die »nationale Wiedergeburt der Tschechen« und verschiedene »Konfliktfelder« im Bereich Sprache, Vereinswesen oder Bildung, aber auch die politischen Lösungsansätze wie im Mährischen Ausgleich und den sudetendeutschen Aktivismus in der ersten Tschechoslowakei. Ebd., S. 179-213.

334 Ebd., S. 214-246.

335 Ebd., S. 247-278.

336 Ebd., S. 277. 
von »Vertreibung im europäischen Kontext« verweist auf den Genozid an den Armeniern, die Shoa und den Jugoslawienkrieg, sagt aber noch nichts über die konkrete Integration dieses Elementes in die Ausstellung aus. Es heißt hier lediglich, dass diese »nur aus ihren jeweiligen Kontexten heraus diskutiert werden [können]«. Der zweite Ausstellungsbereich schließt ab mit einem Ausblick auf »Die Böhmischen Länder nach der Vertreibung der Deutschen«.

Im Kellergeschoss befindet sich der letzte Teil der Ausstellung: »Heimat?«. Er ist dem Schicksal der Sudetendeutschen nach der Vertreibung gewidmet. ${ }^{337}$ Erneut verfolgt das Papier einen problemorientierten Ansatz, in dem es die Schwierigkeiten des Ankommens, des »Verstandenwerdens « und des "Nichtverstandenwerdens « beispielhaft anhand des »Konfliktfeldes Kirche« oder des Arbeitslebens zeigt. ${ }^{338}$ Im nächsten Abschnitt »Heimat Pflegen« soll es um Heimwehhaben, Heimwehtourismus, Archive der Erinnerung und das Zusammenfinden der Sudetendeutschen in Familien oder der Landsmannschaft gehen. ${ }^{339}$ Als letzte Einheit folgt der Bereich »Heimat Suchen", in dem sowohl das fortgesetzte Ankommen in Bayern als auch Beispiele tschechisch-sudetendeutscher Verständigung gezeigt werden. ${ }^{30}$ Eine Installation über Große Sudetendeutsche« soll den Anteil der Sudetendeutschen an der deutschen und europäischen Kultur veranschaulichen. ${ }^{341}$ Das Papier endet mit dem Vorschlag, »Flucht und Vertreibung heute« in Form einer Karikatur über eine "Landsmannschaft Aleppo« zu aktualisieren, auf der als syrisch zu definierende Menschen einen typisch bayerischsudetendeutschen Umzug veranstalten. ${ }^{342}$

An das Konzept schließen sich Überlegungen zu dem als Querschnittsthema verstandenen Bereich »üdisches Leben und Kultur« an, die Raimund Paleczeck verfasst hat. Die jüdische Bevölkerung soll als integraler Bestandteil der Geschichte der böhmischen Länder in der ganzen Ausstellung sinnvoll präsent sein. ${ }^{343}$

Das Konzeptionspapier lässt keine Analyse der finalen Gestaltung des Sudetendeutschen Museums zu. Als Grundlinie zeichnet sich gleichwohl die Schaffung eines kulturhistorischen Museums mit einigen Parallelen zum Schlesischen Museum zu Görlitz ab. Im Mittelpunkt des Papieres stehen die Objekte, welche die Grundlage für die Erzählung des Museums sein werden. Dieser konventionelle Ansatz soll mit einer modernen Inszenierung und zurückhaltend eingesetzten Multimediaelementen verbunden werden. Zeitzeugen dienen in dem Konzept punktuell als Ergänzung der Erzählung oder um dem Vertreibungsgeschehen eine persönliche Stimme zu geben. ${ }^{344}$ Das Papier beschreibt einen Vermittlungsansatz, der dem Besucher auf Augenhöhe zu begegnen versucht und ihm sowohl den Konstruktionscharakter musealen Sammelns als auch von Geschichte selbst vorstellt. 
Die Ausstellung will eine mehrere Jahrhunderte umfassende Geschichte der Region und der Sudetendeutschen erzählen. Das dem Museum bisher den Titel gebende »Zusammenleben « soll bereits vor dem 19. Jahrhundert vorhandene Spannungen zwischen den verschiedenen Gruppen und Religionsgemeinschaften der böhmischen Länder aufzeigen und auf die Erzählung einer multiethnischen Idylle verzichten. Bereits daraus folgt ein weiter gefasster Kontext von Flucht und Vertreibung: Als ihre Vorgeschichte wird eine jahrzehntelange Konfliktgeschichte erzählt, die aber keineswegs zwangsläufig auf die gewaltsame Trennung hinausgelaufen sei. Für die Zwischenkriegszeit sollen sowohl die zwar für Ostmitteleuropa vergleichsweise moderate, aber immer noch diskriminierende Minderheitenpolitik ebenso wie der Aufstieg des sudetendeutschen Nationalsozialismus bereits vor dem Einmarsch diskutiert werden. Damit werden sowohl die in Tschechien verbreitete Idealisierung der Zwischenkriegstschechoslowakei als auch die sudetendeutsche Meistererzählung des legitimen, eigentlich nicht faschistischen, Widerstandes gegen die ČSR hinterfragt oder destruiert. Ebenso sollen der Zweite Weltkrieg, die Rolle des Sudetenlandes, der Sudetendeutschen und des >Protektorates Böhmen und Mähren besprochen werden. Auch damit deutet sich eine Annäherung an die tschechische Erzählung an: Die Sudetendeutschen wurden am Ende des Krieges nicht aus einem vermeintlichen Idyll gerissen, sondern viele von ihnen waren aktiv an Krieg und Unterdrückung ihrer vormaligen tschechischen Nachbarn beteiligt. Daraus folgt dennoch kein simples Rechtfertigungsnarrativ der Vertreibung, die durch diese umfassende Kontextualisierung vor allem in ihren komplexen Zusammenhängen erklärt, aber eben nicht gerechtfertigt wird. Das Geschehen nach dem Kriegsende soll in seinen einzelnen Phasen erzählt werden und in der Konsequenz auch tschechische Übergriffe und Verbrechen zeigen. Inwiefern bei der Nachgeschichte des Krieges auch die Politik der Sudetendeutschen Landsmannschaft kritisch evaluiert wird, lässt das Konzept noch offen. Dies wäre eine der Forderungen aus Tschechien, die aber im Rahmen der konfrontativen Diskursgeschichte des Kalten Krieges erzählt werden könnte. Das Papier verwendet überwiegend den Begriff »Flucht und Vertreibung« oder »Vertreibung « für die Beschreibung der Zwangsmigration der Sudetendeutschen am Ende des Zweiten Weltkriegs und bleibt damit im Rahmen des konventionellen deutschen Sprachgebrauchs.

Einen Transfer in die Gegenwart nimmt das Konzept unter anderem mit der Darstellung des deutsch-tschechisch-jüdischen Zusammenlebens als ein Muster für eine europäische Region vor. Die Beschäftigung damit könne auch zum Verständnis heutiger multiethnischer Gesellschaften beitragen. Zweimal werden in dem Papier Verbindungen zur gegenwärtigen >Flüchtlingskrise gezogen. Dabei ist zu überlegen, inwieweit die Dauerausstellung für die Verhandlung eines solch komplexen und noch sehr gegenwärtigen Themas geeignet ist, oder ob dafür nicht doch eher Sonderausstellungen und Veranstaltungen sinnvoller sind.

Die Entstehung des Sudetendeutschen Museums war in Bayern von einem parteiübergreifenden Konsens geprägt. In der Regionalpresse war und ist die journalistische Begleitung bisher überwiegend positiv und konzentrierte sich auf den Bau sowie interessante künftige Exponate. Die Sudetendeutsche Zeitung begleitete aus der Verbandsperspektive der SL sihr Museum kontinuierlich, wobei vor allem Fortschrittsmeldungen im Mittelpunkt standen. Der deutsche Autor und Journalist Ralf Pasch, selbst Nach- 
komme von Deutschen aus Böhmen, weist darauf hin, dass die von der Landsmannschaft in Richtung Tschechien geforderte kritische Aufarbeitung seiner Geschichte in beide Richtungen, und damit auch für das Sudetendeutsche Museum, gelten müsse: "Wenn es das Sudetendeutsche Museum ernst meint mit der Darstellung der sganzen Geschichte<, muss es auch die politische Vergangenheit der Gründer der Landsmannschaft in den Blick nehmen. ${ }^{345}$ Der Sammlungsleiter des Collegium Bohemicum Jan Šícha zeigte sich im Vergleich zum Aussiger Museum vom schnellen Vorankommen beeindruckt und bewertet die inhaltliche Ausgestaltung als vielversprechend, auch wenn nach der Eröffnung des Hauses die obligatorischen Klagen gegen das Museum in Tschechien ebenso wie von einigen Sudetendeutschen zu erwarten seien. ${ }^{346}$

Die Planungen zum Sudetendeutschen Museum fügen sich in den Reformkurs der Landsmannschaft unter Bernd Posselt, der zu einer Verbesserung des sudetendeutschtschechischen Verhältnisses beitrug. Diese Entwicklung schlägt sich in einem vergleichsweise kritischen Ansatz der Münchner Museumsplanungen nieder, der die traditionelle Meistererzählung der Landsmannschaft reflektiert und die Kooperation und Anschlussfähigkeit mit Tschechien sucht. ${ }^{347}$ Durch seinen kulturhistorischen Anspruch ist es mit dem Schlesischen Museum zu Görlitz vergleichbar, verfolgt jedoch inhaltlich eine konservativeren Ansatz. Der prägnanteste Beleg dafür ist der Fokus auf dem Thema »Heimat«, auch wenn es komplex gefasst und diskutiert wird. Die Parallelen zu Görlitz und die Abkehr von einer konventionellen Erzählung der Landsmannschaft zeigen aber auch, dass sich das Museum im Rahmen der bundesdeutschen Erinnerungskultur und Geschichtspolitik befindet und - im Gegensatz zur 2014 geäußerten Befürchtung - kein konservatives »Korrektiv« zu einer politisch vermeintlich zu progressiven Stiftung Flucht, Vertreibung, Versöhnung werden wird. ${ }^{348}$ Nur eine deutliche Abwendung von den bisherigen Planungen könnte das noch ändern.

\subsection{Museum der deutschsprachigen Bewohner Böhmens in Aussig}

Trotz einiger bereits in den 1990er Jahren entwickelter Gedanken und der damaligen Wiederentdeckung der deutschen Geschichte »als integralem Bestandteil« der böhmischen Geschichte sehen die tschechischen Historiker Kristina Kaiserová und Miroslav Kunštát die Initiation des Museums der deutschsprachigen Bewohner Böhmens vor allem in dem »exogenen« Anstoß durch das Zentrum gegen Vertreibungen und schließlich den 2006

345 Pasch: Vorwort, 2014, S. 12.

346 Šícha: V Sudetoněmeckém muzeu. Novinky.cz. 15.01.2018. Auch Marita Krauss rechnet mit dieser Entwicklung, die zugleich eine Chance sein könne: »Ein sudetendeutsches Museum kann polarisieren, aber auch die Möglichkeit zu gemeinsamen Diskussionen eröffnen, es kann Gräben wieder aufreißen oder das Verständnis für die andere Seite vertiefen. « Krauss: »Zusammenleben«, 2017, S. 135.

347 Vgl. Kap. 5.1, S. 220f.

348 Hennecke: Das Sudetendeutsche Museum in München, 2014, S. 4. 
konkreter werdenden Planungen für ein Sudetendeutsches Museum in München. Darauf reagierte »die tschechische Politik« mit einem eigenen Museumsvorhaben. ${ }^{349}$

Im Jahr 2006 gründeten die Stadt Ústí nad Labem, ihr Stadtmuseum, die JanEvangelista-Purkyně-Universität und die Gesellschaft für die Geschichte der Deutschen in Böhmen ${ }^{350}$ das Collegium Bohemicum. ${ }^{351}$ Erste Direktorin wurde die Politikwissenschaftlerin und vormalige Leiterin des Tschechischen Zentrums in Berlin, Blanka Mouralová. 2008 trat dem Vorhaben auch der tschechische Staat in Form des Kulturministeriums bei. ${ }^{352}$ Unter Vorsitz von Mouralová entwickelte eine Expertenkommission ein erstes Konzept für eine künftige Dauerausstellung, die 2010 auf einer Tagung in Berlin vorgestellt wurde. ${ }^{353}$ Erste Besprechungen in der tschechischen Presse waren durchweg positiv. ${ }^{354}$

Der Auftrag des Collegiums besteht darin, »die Geschichte des Zusammenlebens von Deutschen und Tschechen in den böhmischen Ländern eingehend zu erforschen und einer breiteren Öffentlichkeit bekannt zu machen. «Dafür organisiert es Veranstaltungen, »die sich deutscher Kultur widmen«, und versucht, einen Beitrag zur positiven Gestaltung der deutsch-tschechischen Beziehungen zu leisten. Mit dem 1876 entstandenen Stadtmuseum soll die "Geschichte der Deutschen in den böhmischen Ländern« in Form von Forschung, Bildungsprojekten und Ausstellungen umfassend erschlossen werden. ${ }^{355}$ Aus diesem weit gefassten Auftrag entwickelte sich schließlich die zukünftige Ausstellung zur »Hauptaufgabe «. ${ }^{356}$ Inoffizieller Arbeitstitel der Ausstellung ist die Masaryk'sche Wortschöpfung »Unsere Deutschen «. ${ }^{357}$

Angesiedelt ist das Collegium Bohemicum in einem Flügel des Stadtmuseums, dem ehemaligen deutschen Gymnasium aus dem 19. Jahrhundert. In den oberen Stockwerken des um 2010 mit EU-Geldern renovierten Gebäudes soll die künftige Dauerausstellung entstehen. ${ }^{358} \mathrm{Zu}$ diesem Zeitpunkt wurde von der Leitung mit einer Eröffnung des Museums in der ersten Hälfte 2012 gerechnet. ${ }^{359}$ Die 2014 bereits als Modell vorliegen-

349 Kaiserová; Kunštát: Deutsche und Tschechen im Museum, 2017, S. 137-141. Der Deutschlandfunk sah 2010 die Planungen als eine im Vergleich zur polnischen Reaktion »positive Antwort auf das umstrittene Projekt«: Janssen: Museum als historischer Meilenstein. Deutschlandfunk Kultur. 25.10.2010.

350 Společnost pro dějiny Němců v Čechách.

351 Kaiserová; Kunštát: Deutsche und Tschechen im Museum, 2017, S. 143.

352 Ebd.

353 Mouralová: Das Collegium Bohemicum in Ústí nad Labem/Aussig, 2010. Collegium Bohemicum: Rahmenkonzeption, 2010. Vgl. Kaiserová; Kunštát: Deutsche und Tschechen im Museum, 2017, S. 143 f. Vgl. Kap. 1.2, S. 23.

354 Kaiserová; Kunštát: Deutsche und Tschechen im Museum, 2017, S. 144f.

355 Vgl. dafür die Website des Collegium Bohemicum: www.collegiumbohemicum.cz/de/clanky/7Uber-uns/ (letzter Zugriff: 16.12.2018).

356 Kaiserová; Kunštát: Deutsche und Tschechen im Museum, 2017, S. 141.

357 Mouralová; Šícha: Das Museum einer nahezu abwesenden Minderheit, 2012, S. 153. Der erste Staatspräsident der Tschechoslowakei, Tomáš Garrigue Masaryk, verwendete diese Formulierung, die ebenso integrativ wie paternalistisch zu verstehen ist. Die Ausstellungsmacher betonen hier die freundlich-integrative Variante.

358 Mouralová: Das Collegium Bohemicum in Ústí nad Labem/Aussig, 2010, S. 106.

359 Ebd. 
de Ausstellung konnte aufgrund verschiedener Hürden nicht wie geplant umgesetzt werden, unter anderem wegen der verspäteten Freigabe der vom Kulturministerium in Prag zugesagten Gelder. ${ }^{360} 2016$ veröffentlichte das Collegium ein dreizehnseitiges Papier, in dem ein fiktiver "Spaziergang« durch die künftige Ausstellung beschrieben wird. ${ }^{361}$ Kurz darauf wurde die bisherige Direktorin und Kuratorin der Ausstellung Blanka Mouralová von ihrer Funktion entbunden. ${ }^{362}$ Zwar hatte Mouralová wiederholt mit dem politischen Vorwurf zu kämpfen, dass die geplante Ausstellung »nicht tschechisch genug « sei, aber für die Abberufung schienen letztlich keine politischen Gründe ausschlaggebend gewesen zu sein. ${ }^{363}$ Das zeigt auch die Stellungnahme der im deutschtschechischen Umfeld besonders anerkannten Kristina Kaiserová und die folgende Neubesetzung der Position. ${ }^{364}$ Der im März 2017 zum neuen Direktor berufene Historiker Petr Koura ist vorher nicht als Gegner der bisherigen Ausrichtung aufgetreten und hat bereits in verschiedenen Feldern der deutsch-tschechischen Geschichte des 20. Jahrhunderts publiziert und gelehrt. ${ }^{365}$ In Bezug auf die Ausstellung spricht er davon, dass das seit 2012 kaum veränderte Konzept weiterentwickelt, ergänzt und aktualisiert werden solle. ${ }^{366}$ Die ursprünglich anvisierten Eröffnungstermine konnten nicht eingehalten werden. Im Winter 2019 kündigte Petr Koura an, dass die Ausstellung im Herbst 2020 öffnen solle. ${ }^{367}$ Für die feierliche Eröffnung sei geplant, Bundeskanzlerin Angela Merkel und die Präsidentin der Europäischen Kommission, Ursula von der Leyen, einzuladen. ${ }^{368}$ Der politische Druck, die Ausstellung $2020 \mathrm{zu}$ eröffnen, wird durch den externen Faktor gesteigert, dass andernfalls die von der Europäischen Union für den Zweck der geplanten Ausstellung eingesetzten Gelder zur Renovierung des Museumsgebäudes von der Stadt zurückgezahlt werden müssen. ${ }^{369}$ Im November 2019 erfolgte die Ausschreibung für den mit etwa 1,2 Millionen Euro veranschlagten Auftrag für die technische Umsetzung der Ausstellung, die der tschechische Ausstellungsmacher David Syrovátka Anfang 2020 gewann. ${ }^{370}$

360 Vgl. Kaiserová; Kunštát: Deutsche und Tschechen im Museum, 2017, S. 145. Vgl. auch: Mostýn: Hohe Wellen in Aussig. LandesEcho. 06.12.2016.

361 Mouralová; Šícha: 1500 Quadratmeter und 800 Jahre Leben, 2016.

362 Vgl. dazu die Pressemitteilung des Collegium Bohemicum: Die Ausstellung des Collegiums Bohemicums »Unsere Deutschen « geht in die letzte Realisationsphase. 01.11.2016. Als Cründe für die Demission gab der Verwaltungsrat an, »dass im Hinblick auf die Komplexität des Projekts eine Kumulation der Funktionen Direktor/rin und Kurator/rin der Ausstellung nicht vereinbar« sei.

363 Vgl. dazu ausführlich die Berichterstattung in der Zeitschrift der Deutschen in der Tschechischen Republik: Mostýn: Hohe Wellen in Aussig. LandesEcho. 06.12.2016.

364 Ebd.

365 Collegium Bohemicum: Das Collegium Bohemicum hat einen neuen Direktor und wissenschaftlichen Beirat. 21.03.2017.

366 Koura: Reakce ředitele Collegia Bohemika Petra Koury. Novinky.cz. 16.01.2018. Vgl. ausführlich zur Person Koura und seinen Planungen für die Ausstellung: Neumann: Der Retter für das Museum der Deutschen. Sächsische Zeitung. 10.11.2017.

367 Petr Koura: Na výstavu do Ústí by mohla prǐijet kancléŕka Merkelová. Ústecký deník. 07.12.2019.

368 Vorlíček: Výstava o Němcích? Ústecký deník. 17.09.2019.

369 Ebd.

370 Houfek: Collegium Bohemicum vypsalo výběrové rízení na zhotovení výstavy »Naši Němci«. Místní kultura. 19.11.2019. Vgl. dazu auch das Interview mit Koura: Petr Koura: Na výstavu do Ústí by mohla přijet kancléřka Merkelová. Ústecký deník. 07.12.2019. Vgl. Vorlíček: Výstava v Ústí za desítky mi- 
Das Collegium Bohemicum hat sich als gemeinnützige Gesellschaft konstituiert. Ein Verwaltungs- und Aufsichtsrat sowie ein Wissenschaftlicher Beirat strukturieren dessen Arbeit gemeinsam mit einem Rat für den Sammlungsaufbau. In den Gremien finden sich die verschiedenen Partnerinstitutionen, wie die Stadt Ústí nad Labem, die Universität oder das Kulturministerium. Elisabeth Fendl, Verantwortliche des Konzeptpapiers für das Sudetendeutsche Museum von 2016, ist ebenfalls Mitglied des Wissenschaftlichen Beirates. ${ }^{371}$ An den externen Arbeitsgruppen des Collegiums waren auch Vertreter der Zivilgesellschaft vertreten, wie die schon in Kapitel 5 angesprochene Organisation Antikomplex. ${ }^{372}$ Die Kosten für die durch Mittel der Europäischen Union getragene Renovierung des Museumsgebäudes lagen bei etwa 13 Millionen Euro. ${ }^{373}$ Der finanzielle Zuschuss des Kulturministeriums für den Aufbau des Museums betrug 2016 ungefähr zwei Millionen Euro. ${ }^{374}$ Für die laufenden Kosten plant die Stadt jährlich eine Unterstützung von bis zu 60.000 Euro ein. ${ }^{375}$ Das Collegium Bohemicum drängt auf eine Erhöhung der jährlichen städtischen Finanzmittel und eine stärkere Förderung durch den tschechischen Staat, der die weiteren Kosten tragen soll. ${ }^{376}$

Als Ausstellungsfläche werden dem künftigen Museum etwa 1500 Quadratmeter zur Verfügung stehen. ${ }^{377}$ Um den Anspruch zu erfüllen, eine exponatkonzentrierte Ausstellung zu schaffen, befasst sich das Team des Collegium Bohemicum weiter mit dem Sammlungsaufbau, der unter anderem vom Deutsch-Tschechischen Zukunftsfonds unterstützt wird. ${ }^{378}$ In der Dauerausstellung sollen schließlich etwa 500 Exponate gezeigt werden. ${ }^{379}$ Konstitutiv für das Projekt ist ein von Beginn an internationaler Ansatz, in dem deutsche Partner stets in den Gremien, aber auch bei Diskussionen und Veranstaltungen beteiligt waren. ${ }^{380}$ Als Zielgruppe wurde von Beginn an die tschechische Gesellschaft in den Mittelpunkt gerückt, der das Thema nach Jahrzehnten des Verzerrens und Verschweigens im Kommunismus als Teil der tschechischen Geschichte wieder nähergebracht werden sollte. Die Reichweite des Hauses soll aber darüber hinausgehen und die Ausstellung auch Menschen in Deutschland, Österreich und weiteren Ländern ansprechen. ${ }^{381}$ Aus der Perspektive der Stadt Ústí nad Labem, die schwer von der De-

lionů? Ústecký deník. 30.01.2020. Siehe ebenfalls: Neumann: Tschechiens Museum der Deutschen rückt näher. Sächsische Zeitung. 04.02.2020.

www.collegiumbohemicum.cz/de/clanky/31-verwaltungsstruktur/ (letzter Zugriff: 16.12.2018).

Collegium Bohemicum: Rahmenkonzeption, 2010, S. 7. Vgl. Mouralová; Šícha: Das Museum einer nahezu abwesenden Minderheit, 2012, S. $154 \mathrm{f}$.

Vgl. für eine Liste weiterer erworbener Fördermittel und veranschlagter Kosten mit dem Stand von 2010: Collegium Bohemicum: Rahmenkonzeption, 2010, S. 8

Es handelt sich um etwa 337 Millionen bzw. 50 Millionen Tschechische Kronen: Kaiserová; Kunštát: Deutsche und Tschechen im Museum, 2017, S. 143, 145.

Mostýn: Hohe Wellen in Aussig. LandesEcho. 06.12.2016.

Vorlíček: Výstava o Němcích? Ústecký deník. 17.09.2019. Neumann: Tschechiens Museum der Deutschen rückt näher. Sächsische Zeitung. 04.02.2020. Vgl. Mouralová; Šícha: 1500 Quadratmeter und 800 Jahre Leben, 2016.

Vorlíček: Výstava představí historii soužití Čechů a Němců. Ústecký deník. 12.11.2017.

Collegium Bohemicum: Rahmenkonzeption, 2010, S. 8.

Př́prava expozice o soužití Čechů a Němců finišuje šest let po termínu. iDNES. 08.03.2019.

Kaiserová; Kunštát: Deutsche und Tschechen im Museum, 2017, S. 142.

Collegium Bohemicum: Rahmenkonzeption, 2010, S. 1. 
industrialisierung betroffen ist, wird von dem Museum auch eine Stärkung des touristischen und wissenschaftlichen Profils der Stadt erwartet. ${ }^{382}$ Darüber hinaus ist Aussig historisch als eine der sudetendeutschen Industriestädte und als Ort eines der schweren Massaker nach Kriegsende zur Verhandlung des Themas mehrfach geeignet. Im Rahmen des weiten Tätigkeitsprofils des Collegium Bohemicum organisiert oder beteiligt es sich neben der Vorbereitung der künftigen Dauerausstellung an verschiedenen Veranstaltungen, wie der Ausrichtung der Deutsch-Tschechischen Kulturtage 2018.

Der Anspruch des tschechischen Staates an das Museum ist eingangs schon angesprochen worden. Die Verhandlung der Thematik des deutsch-tschechischen Zusammenlebens sowie von Flucht und Vertreibung sollen nicht allein dem deutschen Nachbarn überlassen werden. Zudem könne nach Auffassung der Museumsmacher das Museum als Instrument staatlicher Außenpolitik dienen, indem es das Thema sachlich und unvoreingenommen behandelt und so die politische Sprengkraft des Themas begrenzt. ${ }^{383}$ Weniger realpolitisch ist der Anspruch, eine Lücke in der tschechischen Erinnerungskultur zu schließen. Kenntnisse über das deutsch-tschechische Zusammenleben ebenso wie die zum Teil ausschließlich deutsche Vergangenheit mancher Ortschaften werden als notwendig erachtet, um die tschechische Geschichte zu verstehen - sodass sich daraus ein staatlicher Bildungsauftrag ergibt. Für das Collegium Bohemicum selbst formulierte Blanka Mouralová 2010 den Anspruch:

»Die Ambition [...] ist es, das Wirken und den Beitrag der deutschsprachigen Bewohner in den böhmischen Ländern aus tschechischer Perspektive, aber in europäische Zusammenhänge eingebettet, zu erforschen, darzustellen und zu bewerten. In den historisch überwiegend deutschsprachigen Regionen wie gerade der Region Ústí nad Labem geht dieses Auffinden Hand in Hand mit der Suche nach der regionalen Identität. « ${ }^{384}$

Deckungsgleich mit den verschiedenen zivilgesellschaftlichen Initiativen, die sich mit der Aufarbeitung der deutsch-tschechischen Vergangenheit befassen, sieht Mouralová mit dieser komplexen Erzählung »unsere[r] Landesgeschichte« die Gelegenheit, einen Beitrag "zur Selbstreflexion der tschechischen Gesellschaft « zu leisten. ${ }^{385}$ Zugleich interessiert die Ausstellungsmacher weniger die Konfliktgeschichte als »das frühere Zusammenleben als Inspiration für das heutige Zusammenleben in Europa. ${ }^{386}$ Ein Beispiel für Ansatz und Anspruch des Museums ist der vorgesehene Name des Hauses: Museum der deutschsprachigen Bewohner Böhmens. Der in Tschechien nach wie vor überwiegend negativ konnotierte Terminus der Sudetendeutschen würde dem Ziel widersprechen, die Deutschen des Landes als ehemaligen Teil der Gesellschaft und eben nicht als externe, feindliche Fremde zu verstehen. ${ }^{387}$ Zugleich wird die Eindeutigkeit versprechende ethnische Zuordnung von Termini wie »sudetendeutsch « durch die offenere Kategorie der Sprache ersetzt. Neben den diskursiven Konsequenzen einer solchen Ver-

382 Vgl. Mouralová; Šícha: Das Museum einer nahezu abwesenden Minderheit, 2012, S. 151.

383 Mouralová; Šícha: Das Museum einer nahezu abwesenden Minderheit, 2012, S. 153.

384 Collegium Bohemicum: Rahmenkonzeption, 2010, S. 1.

385 Ebd.

386 Herter: Was im politischen Streit liegen bleibt. Deutschlandfunk. 17.07.2013.

387 Vgl. Kap. 1.1, S. $21 \mathrm{f}$. 
wendung wird es so ermöglicht, zugleich auch alle weiteren ehemaligen deutschsprachigen Bewohner des heutigen Tschechien einzubeziehen, wie die Prager Deutschen und die häufig (auch) deutschsprachigen Juden der böhmischen Länder. ${ }^{388}$ Jenseits prominenter Persönlichkeiten wie Franz Kafka ist deren Geschichte heute häufig vergessen und soll im Museum wieder erzählt werden. ${ }^{389}$

Die folgende Besprechung der bisherigen Planungen für die künftige Ausstellung beruht auf der Rahmenkonzeption von $2010^{390}$ und dem 2016 veröffentlichten "Spaziergang « ${ }^{391}$ durch die Ausstellung, der in seiner Struktur dem Konzept von 2010 folgt und sich auch in dem bereits angefertigten Modell der Ausstellung wiederfindet. ${ }^{392}$ Wenn nicht anders vermerkt, bezieht sich die folgende Skizze auf den »Spaziergang « und die Zitate sind diesem entnommen.

Bereits im ersten geplanten Raum machen die Entwickler das ihrer Ausstellung zugrundeliegende Verständnis deutlich: Dem Besucher steht ein Quader gegenüber, auf dem ein Film gezeigt wird: In tschechischer Sprache, mit deutschen Untertiteln, erzählt eine Person von den deutschsprachigen Bewohnern Böhmens. Zum Schluss verweist sie darauf, dass auf der anderen Seite des Quaders eine weitere Person etwas zu sagen hat. Dort erzählt dann eine Person in deutscher Sprache mit tschechischen Untertiteln »eine etwas andere, seine Version der Geschichte.« Dieser Ansatz, mindestens zwei Perspektiven auf einen Sachverhalt zu zeigen, zieht sich durch die weitere Ausstellung: Der Einsatz multimedialer und szenografischer Elemente soll sinnvoll mit dem historischen Exponat kombiniert werden. ${ }^{393}$

Insgesamt sieht die Konzeption 20 Bereiche vor, die sich über zwei Etagen erstrecken. Es wird kein streng chronologischer Ansatz verfolgt und der Besucher kann wenigstens an einem Punkt den Weg selbst bestimmen. Nach dem eben beschriebenen ersten Raum, der die Frage »Wer sind >unsere Deutschen«?« einleitend diskutiert, folgt ein zweiter Raum unter dem Titel »Wo ist mein Heim, mein Vaterland?« Diese Zeilen aus der tschechoslowakischen und tschechischen Nationalhymne stehen hier für die landschaftliche Schönheit der Region und ihre Entdeckung durch die Romantiker. Im nächsten Teil der Ausstellung soll dem Besucher eine Barrikade in den Weg gestellt werden. So wird mit der Revolution von 1848 der demokratische Aufbruch ebenso wie der für die Region damit auch verbundene Beginn der nationalen Konfrontation gezeigt.

Im Folgenden soll sich der Besucher entscheiden können, ob er beim Wechsel des Stockwerkes dem Verlauf der Zeit rückläufig folgt oder einen anderen Weg wählt. Im Papier wird der erstgenannte Weg gewählt. Je weiter der Besucher nun den Verlauf der Zeit zurückverfolgt, desto mehr wird er »feststellen, dass die sprachliche Grenze immer

388 Mouralová; Šícha: 1500 Quadratmeter und 800 Jahre Leben, 2016.

389 Vgl. Řezník; Schulze Wessel: Das Museum als Medium einer Verflechtungsgeschichte von Deutschen, Tschechen und Slowaken, 2017, S. 17. Vgl. zur Geschichte und Erinnerung an die böhmischen Juden spezifisch am Beispiel der Juden aus Aussig: Wetzel: Kein Raum für Menschen zweier Kulturen, 2016, S. 246-258.

390 Collegium Bohemicum: Rahmenkonzeption, 2010.

391 Mouralová; Šícha: 1500 Quadratmeter und 800 Jahre Leben, 2016.

392 Vgl. für Eindrücke und eine Beschreibung der Modelle den Filmbeitrag auf Tschechisch ab Minute 05:45: Růžičková: Sousedé. Česká televize. 20.04.2018.

393 Vgl. dafür die Website des Collegium Bohemicums: www.collegiumbohemicum.cz/de/clanky/7Uber-uns/ (letzter Zugriff: 16.12.2018). 
weniger sichtbar ist. ${ }^{394}$ Im ersten Raum dieses Weges werden in einem Biedermeiersalon die Aufklärung in Böhmen und der Metternich'sche Polizeistaat thematisiert. Ein weiterer Schritt zurück in der Geschichte folgt im nächsten Teil mit der Darstellung der Modernisierung unter Kaiser Joseph II. Für die Sudetendeutschen ist dieser eine idealisierte Figur, für die Tschechen Symbol der mit der Modernisierung einhergehenden Germanisierung des Landes. Im Papier erhalten vor allem die damals geschaffenen Grundlagen für den modernen Staat ihren Platz. Eine weniger ambivalente Persönlichkeit der böhmischen Geschichte soll im nächsten Bereich diskutiert werden. Das Thema Frömmigkeit wird anhand des für die deutschsprachigen ebenso wie für die tschechischsprachigen Bewohner bedeutenden Heiligen Nepomuk vorgestellt, der für viele Sudetendeutsche nach der Vertreibung noch an Bedeutung gewann. Als nächstes soll der künftige Besucher den Raum »Im Habsburger Haus beheimatet « betreten. Dieser ist dem multiethnischen und multikonfessionellen Reich gewidmet, in dem Menschen aus allen Teilen des Landes, hier am Beispiel Böhmens gezeigt, Karrieren machen konnten - unter dem Primat der deutschen Sprache. Ein weiterer Schritt zurück in der Chronologie ist der Bereich, der Böhmen als Wiege der Reformation zeigt, was entgegen späteren nationalistischen Aufladungen nicht als nationale Bewegung verstanden wird. Darauf folgt Böhmen als »Teil des universellen Reiches«, in dem anhand der Person Kaiser Karls IV. die sowohl in der deutschen als auch tschechischen Geschichte verklärte mittelalterliche Phase der Region als Zentrum des Heiligen Römischen Reiches präsentiert wird. Die Darstellung der mittelalterlichen deutschsprachigen Ostsiedlung erfolgt im letzten Bereich dieses Stockwerkes. Als ein Beispiel für die verschiedenen szenografischen Elemente soll der Besucher hier durch »herunterhängende Stoffstreifen« hindurchgehen, um die Bewegung der Siedler durch die böhmischen Grenzwälder nachzuvollziehen. Die Einwanderung wird als erwünscht beschrieben und die bald folgende kulturelle Vermengung gezeigt. Migration wird als Kontinuum verstanden, die auch noch »Unternehmerfamilien im 19. Jahrhundert « nach Böhmen führte: »Wir fühlen, dass der Drang zu einer besseren Zukunft eine tiefe menschliche Eigenschaft ist.«

Im zweiten Stockwerk der Ausstellung sind drei der politischen Entwicklung nach 1848 gewidmete Räume geplant. Der erste Bereich beschäftigt sich mit den Auseinandersetzungen von 1848 bis 1919. Das zunehmend nationalistische Vereinswesen, politische Konfrontationen und Blockaden sollen ebenso wie der erste Weltkrieg mit seinen Auswirkungen für die Region angesprochen werden. Darauf folgt die Phase von 1918/19 bis 1933: Die unerwünschte und zum Teil gewalttätige Aufnahme der Sudetendeutschen in den neuen tschechoslowakischen Staat wird hier ebenso wie die folgenden Phasen politischer Annäherungen gezeigt. Die Jahre nach der Weltwirtschaftskrise sollen als komplexe Eskalation gefasst werden, unter der die deutschsprachigen Regionen besonders stark litten und die sie dadurch für die nationalsozialistische Agitation empfänglich machten. Die politische Durchsetzung der Sudetendeutschen Partei Henleins und ihre Verbindung mit der NSDAP soll der deutschen Sozialdemokratie in Böhmen entgegengestellt werden, auch wenn letztere die Auseinandersetzung verlor.

394 So formulierte Blanka Mouralová den Ansatz 2010: Gschwend: Kulturelles Erbe der deutschsprachigen Bewohner der böhmischen Länder bekommt eigenes Museum. Radio Praha. 18.09.2010. 
Der nächste Raum, der den Zeitraum 1933/38 bis 1945/47 umfassen soll, ist in drei Teile untergliedert: Der Weg zur Shoa und die Ermordung der böhmischen und europäischen Juden bilden den ersten Bereich, der zweite ist den Tschechen im vom Deutschen Reich annektierten Sudetenland und dem >Protektorat Böhmen und Mähren gewidmet. Sowohl Kollaboration als auch Zwangsarbeit und Besatzungsterror werden vorgestellt, ebenso wie Reinhard Heydrichs Rede für »die endgültige Lösung der tschechischen Frage.« Die Darstellung des tschechischen Widerstandes, des HeydrichAttentats und der Vernichtung von Lidice münden in die Präsentation einer sozialistischen »Bilderallegorie des Sieges über die Deutschen aus der Nachkriegszeit«.

Schließlich ist der dritte Teil für den »deutsche[n] Weg« vorgesehen. Die rasche Integration in den nationalsozialistischen Bewegungsstaat wird ebenso gezeigt wie in einem gesonderten Bereich Exil und Widerstand. Aus diesen drei Abschnitten führt nur ein Weg hinaus, der durch den deutschen Bereich führt. In dem folgenden, schmalen Raum wird die »Zwangsaussiedlung der Deutschen aus der Tschechoslowakei« thematisiert. Gezeigt werden sollen bei der Vertreibung getragene Trachten, Koffer und Kisten ebenso wie ein Schlüsselbund oder eine Liste von Wohnungsinventar. Die »Dekrete des Präsidenten der Republik Beneš« sollen in Schubladen einsehbar sein. Szenografisch inszeniert werden lange nach dem Krieg entdeckte Funde von verstecktem Eigentum sudetendeutscher Bewohner. Dem Raum schließt sich ein kleiner Bereich an, »wo von der Decke Texte mit unterschiedlichen Interpretationen zur Zwangsaussiedlung hängen «.

Auch diesem Teil der Ausstellung folgt ein bewusster chronologischer Bruch, denn es sollen im Folgenden noch »Reichtum und verschiedene Aspekte des gemeinsamen Lebens vor der Katastrophe« gezeigt werden. Zwei Räume sind der Industrialisierung gewidmet, die die für die Identität der Region so wichtige Produktion von Glas und das in der Form für das böhmische Grenzland spezifische »Industriedorf« zeigen. Große Innovationen und der mit der ökonomischen Entwicklung einhergehende Reichtum werden nicht ohne die Schattenseiten dargestellt. Dem schließt sich noch eine Abteilung an, die sich mit dem »Volkstumskampf auf dem Vormarsch« im 19. und 20. Jahrhundert beschäftigt. Hier soll die Diskussion des Begriffes der Sudetendeutschen und dessen weitere Nutzung nach 1945 erfolgen. Dabei möchten die Ausstellungsmacher das Verständnis vermitteln, »dass deutschsprachige Bewohner der böhmischen Länder und Sudetendeutsche nicht das Gleiche sind. Das Sudetendeutschtum ist eine der möglichen Identitäten. « Dem folgend werden der starke Regionalismus der böhmischen Länder und ihrer deutschsprachigen Bewohner gezeigt, die sich in unterschiedlichen Trachten, Bräuchen und Dialekten niederschlugen.

Der vorletzte Ausstellungsbereich steht mit drei Räumen unter dem Titel »Modernes Leben - erfüllte Hoffnungen, zerschlagene Hoffnungen«. Der Besucher wird symbolisch durch fünf Städte geführt, die beispielhaft für verschiedene Entwicklungen stehen sollen: Zunächst Elbogen/Loket mit einer szenografisch inszenierten Gaststätte, die als Ort der Auseinandersetzung begriffen wird; es folgt Brünn als Stadt der architektonischen Moderne, danach wird für Troppau/Opava das dortige Museum als Symbol bürgerschaftlichen Engagements und Selbstverständnisses szenografisch geschaffen, es folgen Reichenberg/Liberec als »inoffizielle Hauptstadt der Deutschen in den böhmischen Ländern« sowie zuletzt Prag und seine Caféhauskultur und die mit ihr verbun- 
dene deutschsprachige Weltliteratur. Dieser Teil soll mit Gemälden aus der ehemaligen deutschen Abteilung der Nationalgalerie in Prag schließen, die den damaligen Dialog der Kunstschaffenden zeigen. Damit »soll der Eindruck entstehen, dass es in Formen des modernen Lebens mit einem Nachdruck auf Reflexion, Freiheit und Demokratie ein Potenzial dafür gab, um trotz aller Katastrophen im Zusammenleben in Europa fortzufahren.«

Die Ausstellung endet in einem Flur mit einem symbolischen Aussichtsturm, der die nach 1947 auf deutscher und österreichischer Seite im Grenzland entstandenen Konstruktionen verkörpert, mit der Vertriebene in ihre alte Heimat schauen konnten. Einen vorläufigen Schlusspunkt bildet die Darstellung der Deutsch-Tschechischen Erklärung aus dem Jahr 1997. Dieses letzte Ensemble verstehen die Autoren des Papieres als eine Metaphorik,

»mit einem gewissen Abstand wie von einem Aussichtsturm in die deutsch-tschechische Geschichte zu schauen. Die alten Kämpfe müssen wir nicht aufs Neue auskämpfen. Dank einer solchen Draufsicht können wir Wege sehen, die uns am weitesten führen. Nachbarschaft als Aufgabe bleibt bestehen. Die Geschichte brachte uns sehr inspirierende Punkte und wenn uns diese durch die Ausstellung vor Augen geführt werden, hat sie ihren Zweck erfüllt.«

In der geplanten Ausstellung des Museums der deutschsprachigen Bewohner Böhmens wird eine Landesgeschichte erzählt, die durch die Verflechtung eines heterogenen deutschsprachigen Bevölkerungsanteils mit seinen tschechischen Nachbarn geprägt ist. Nur durch diese zusammenhängende Betrachtung erscheint ein Verstehen der gemeinsamen Landesgeschichte möglich, die ansonsten lückenhaft bliebe.

Demzufolge soll die geplante Ausstellung einen konsequent multiperspektivischen Ansatz verfolgen. Nicht nur eine deutsche und eine tschechische Perspektive sollen präsent sein, sondern auch die der oft deutschsprachigen Juden Böhmens. Das Konzept sieht einen nahezu gleichrangigen Einsatz von authentischem Exponat, zum Teil aufwendiger Inszenierung und spielerischer Szenografie ebenso wie moderner multimedialer Elemente vor.

Das Besucherbild ist als konventionell $\mathrm{zu}$ betrachten und weist keine dialogische Orientierung auf. Wie im Anspruch des Museums formuliert, geht es zunächst um das gut aufbereitete Informieren tschechischer Besucher über den deutschen Anteil ihrer Landesgeschichte. Internationale Besucher hingegen sollen Kenntnisse über die tschechische und deutsche Perspektive auf das historische Geschehen ebenso wie einen umfassenden Einblick in die Geschichte der Region erlangen.

Die Ausstellungsmacher planen eine Erzählung über achthundert Jahre Geschichte. Auch wenn der Schwerpunkt auf Politikgeschichte liegt, nehmen Ideen-, Wirtschaftsund Sozialgeschichte in dem Konzept eine große Rolle ein. Hierbei versuchen die Planer eine ahistorische Trennung der Themen zu vermeiden, ebenso wie sie die deutschtschechische Thematik jeweils entsprechend mitdenken. Diese weitgefasste Geschichte erzählt von keinem Jahrhunderte währenden, idyllischen Zusammenleben, jedoch bahnt erst die Entwicklung des modernen Nationalismus nach 1848 den Weg zur finalen Konfrontation im Zweiten Weltkrieg, die aber nicht als zwangsläufig erachtet wird. 
Deutlich formulieren die Planer, dass die finale Zerstörung der jahrhundertelangen Gemeinschaft trotz aller vorherigen Probleme und auch bei einer kritischen Betrachtung der ersten tschechoslowakischen Republik erst im Zweiten Weltkrieg erfolgte, in der mit sudetendeutscher Beteiligung der Nationalsozialismus die Bevölkerungen trennte und die jüdische Bevölkerung verfolgte und ermordete. ${ }^{395}$ In dieser Erzählung bildet die Vertreibung, die im Papier grundsätzlich als Zwangsaussiedlung [nucené vysídlení] und einmal als Abschub [odsun] bezeichnet wird, den Abschluss des Geschehens. Sprachlich entscheiden sich die Autoren damit für einen Mittelweg, indem sie mit der überwiegenden Verwendung des Begriffs Zwangsaussiedlung weder euphemistischen Termini noch der Übernahme der deutschen Begrifflichkeit folgen.

Auf die Frage, ob und inwiefern das tschechoslowakische Lagerwesen und die gewalttätigen Übergriffe auf die sudetendeutsche Bevölkerung nach Kriegsende thematisiert werden oder ob vor allem die vermeintlich ordentlichen, staatlich organisierten Vertreibungen im Mittelpunkt stehen sollen, lässt sich anhand des kurz gefassten Papieres noch keine Antwort geben. Mit dem Raum, der verschiedene Perspektiven auf das Geschehen der Vertreibung zeigt, wird der Besucher auch sogleich an die langwierige Auseinandersetzung über das Thema herangeführt. Bezüglich einer Aktualisierung des Themas hält sich die geplante Ausstellung zurück und beschreibt als ihren letzten wichtigen Inhalt die Deutsch-Tschechische Erklärung von 1997.

Das für die künftige Ausstellung vorgelegte Papier vertritt das ambitionierte Ziel, sowohl tschechische als auch internationale, vor allem deutsche und österreichische Besucher anzusprechen. Dafür legt es überzeugende Ansätze vor. Neben der attraktiven und vielseitigen Gestaltung verspricht vor allem die geplante und konsequent umgesetzte Multiperspektivität eine Anschlussfähigkeit an die verschiedenen Meistererzählungen zu erreichen. Dadurch entsteht die Möglichkeit, dem Besucher zugleich auch unterschiedliche Perspektiven näherzubringen. Auf diese Weise könnte eine gemeinsame Erzählung geschaffen werden, die Widersprüche und Konflikte aushält. Als eine Ausnahme erscheint die geplante Darstellung der Vertreibung, die diesen Weg nicht konsequent verfolgt. Eine angedeutete Fokussierung auf die staatlichen Zwangsaussiedlungen von 1946/47 würde ein unvollständiges Bild des Vertreibungsgeschehens bedeuten. Auch dass das Geschehen vermeintlich allein aus dem Krieg, dem vorherigen deutschen Terror und der Besatzung heraus erklärbar sei, erscheint zwar verständlich, lässt aber für die sudetendeutsche Perspektive die Bedeutung des tschechischen Nationalismus zu sehr außen vor. Diese Einschätzung dürfte aber aufgrund des knappen Charakters des bisherigen Konzeptionspapieres in Zukunft noch relativiert werden.

Die bisherigen Diskussionen zu den Planungen, ein Museum der deutschsprachigen Bewohner Böhmens zu schaffen, lassen sich schematisch in vier Perspektiven gliedern: Als erste ist die von Wissenschaftlern und Akteuren der deutsch-tschechischen Verständigung zu nennen, die ungeduldig auf die Eröffnung warten und die zögerliche politische Unterstützung - vor allem aus Prag - kritisieren. ${ }^{396}$ Die inhaltlichen Planungen

395 Das wird im Papier von 2010 noch deutlicher formuliert als in der Veröffentlichung von 2016: Collegium Bohemicum: Rahmenkonzeption, 2010, S. 5.

396 Vgl. Šícha: V Sudetoněmeckém muzeu. Novinky.cz. 15.01.2018. 
des bisherigen Teams treffen in diesen Kreisen auf breite Unterstützung, zumal sie seit Beginn an den Vorbereitungen beteiligt waren.

Das politische Zentrum um die bisherigen großen Parteien verhält sich trotz verschiedentlich geäußerter Unterstützung des Vorhabens und der von ihnen auf anderen Ebenen intensivierten sudetendeutsch-tschechischen Verständigung zögerlich und zurückhaltend. Der fehlende breite gesellschaftliche Wunsch nach einem solchen Museum und die mit einer Eröffnung möglicherweise einhergehende Brisanz für die politische Auseinandersetzung scheinen diese Haltung zu erklären.

Ohne Umschweife ablehnend gegenüber dem Vorhaben zeigen sich als dritte Gruppe die tschechischen Kommunisten, die das Projekt inhaltlich kritisieren und als Geldverschwendung betrachten - so ihr Bürgermeisterkandidat für Aussig. ${ }^{397}$ Ein Vertreter des Tschechischen Verbandes der Freiheitskämpfer kritisierte 2014 die vermeintlich falsche tschechische Selbstkritik der Ausstellung:

»In der Ausstellung wird nur das friedliche Zusammenleben gezeigt, das Ende wird übergangen. Ein tschechischer Besucher soll das Gefühl mitnehmen, dass an den schwierigen deutsch-tschechischen Beziehungen die Tschechen schuld sind. Damit sind wir nicht einverstanden, weil das nicht wahr ist. «398

Als vierte für das Projekt relevante Gruppe sind die Sudetendeutschen und die Sudetendeutsche Landsmannschaft zu betrachten, die die Planungen zum Museum aufmerksam und bis dato wohlwollend verfolgen. Bei der Demission von Blanka Mouralová wurde in der Sudetendeutschen Zeitung die These vertreten, es habe sich um die Kaltstellung eines politisch unliebsamen Projektes gehandelt und auf die gegen Mouralová von tschechischen Nationalisten wiederholt erhobenen Vorwürfe verwiesen, dass sie eine deutsche Agentin sei. ${ }^{399}$

Auch wenn derartige Anschuldigungen immer wieder geäußert werden und deren Vertreter in Tschechien nicht nur eine schrill auftretende Minderheit sind - wie gelegentliche Äußerungen des Präsidenten Miloš Zeman zum sudetendeutschen Thema zeigen -, ist das Museum stärker von der weiterhin vorherrschenden Gleichgültigkeit der tschechischen Gesellschaft gegenüber dem Thema betroffen, in deren Folge die Eröffnung nicht als politisch dringliches Anliegen erscheint. Das bisherige Konzept bewegt sich nah an den Vorstellungen der im deutsch-tschechischen Dialog tätigen Zivilgesellschaft, die beispielsweise die Vertreibung nicht nur als Verlust für die Sudetendeut-

397 Hoření: Rozhovor Haló novin s Pavlem Vodsed'álkem, kandidátem KSČM na primátora Ústí nad Labem. Haló noviny. 27.07.2018.

398 >Museum der deutschsprachigen Bewohner der böhmischen Länder in Ústí nad Labem/Aussig. Rundfunk Berlin-Brandenburg (rbb). 21.09.2014. Vgl. zum Verband auch Kap. 5.3, S. 262.

Vgl. Kubes: »Aussig gilt in Bayern als bedeutendstes tschechisches Kulturprojekt«. Sudetendeutsche Zeitung. 08.08.2014. Siehe zur Berichterstattung über die vermeintlich politische Attacke gegen das Museumsvorhaben: Šonka: Kleingeister oder das Aus für Aussig. Sudetendeutsche Zeitung. 04.11.2016. Siehe auch: Šonka: Lieber vergessen? Sudetendeutsche Zeitung. 29.07.2016. Einen politischen Hintergrund für unwahrscheinlich hält hingegen die Presse der deutschen Minderheit in Tschechien: Mostýn: Hohe Wellen in Aussig. LandesEcho. 06.12.2016. 
schen, sondern auch für die Tschechen betrachtet. ${ }^{400}$ Eine solche Perspektive kann als besonders anschlussfähig an die (sudeten-)deutsche Erzählung betrachtet werden. Dass aber auch für die tschechischen Besucher ein ebenso interessantes und verständliches Angebot gemacht werden kann, deuten die bisherigen Planungen vielversprechend an. Bis Anfang 2020 gab es keine Anzeichen, dass es zu gravierenden inhaltlichen Änderungen am oben beschriebenen Konzept kommen wird. Petr Koura sprach zu diesem Zeitpunkt von einigen technischen Aktualisierungen und inhaltlichen Ergänzungen: Die sudetendeutschen Nobelpreisträger sollen in der Ausstellung ihren Platz finden, ebenso wie die Geschichte der deutschsprachigen Juden Böhmens mehr Raum erhält. In letzterem Zusammenhang soll auch beispielhaft an die Pogrome von 1348 erinnert werden. ${ }^{401}$

Unabhängig von Detailveränderungen oder Anpassungen der Erzählstruktur setzt die Eröffnung des Museums ein Zeichen der Anerkennung der vielfältigen Geschichte der böhmischen Länder und ihrer deutschsprachigen Bewohner.

\subsection{Vergleich der regionalhistorischen Museen}

Eine zusammenführende Betrachtung der beiden schlesischen Museen sollte zunächst die erwähnten Gemeinsamkeiten und strukturellen Unterschiede diskutieren: Beiden gemein ist, dass sie als über die Region hinausreichende Vorhaben von nationaler Bedeutung entstanden sind, die darüber hinaus neben der regionalen Bevölkerung und beim SMG den deutschen Schlesiern auch ein internationales Publikum ansprechen sollen. Beiden Häusern standen ab einem gewissen Zeitpunkt erhebliche finanzielle Mittel zur Verfügung. Beide fügen sich architektonisch in - sehr unterschiedliche - historische Ensembles ein, die aufwändig für diese hergerichtet wurden. Sie standen und stehen vor der Herausforderung, sich mehreren geschichtspolitisch zwischen den Ländern und in der Region diskutierten Themen zu stellen und diesen inhaltlich und ausstellungsgestalterisch zu begegnen. Eine aufmerksame politische Beobachtung prägte beide Ausstellungen in ihren Entstehungsphasen und beide reagierten unterschiedlich auf die sie umgebenden und begleitenden Diskurse. Das äußert sich im SMG in einem liberalen Europanarrativ und im MŚK in einer nationalpolnischen Schlesienerzählung. Letztere wurde gegen die ursprüngliche Planung durchgesetzt, die dieses Narrativ durch die Präsentation Oberschlesiens als multiethnische Region stärker hinterfragt hätte.

In Hinblick auf ihren Anspruch ähneln sich die Häuser. Beide versuchen die Region in ihren Spezifika attraktiv darzustellen und verfolgen eine rhetorische Bezugnahme zu Europa - stärker in Görlitz, schwächer in Kattowitz. Der politische Gründungsimpuls war in Deutschland wesentlich mehr auf die Verständigung nach Polen hin ausgerichtet als umgekehrt in Kattowitz. Das >deutsche Element « war hier zwar eine der entscheidenden Streitfragen bei der Konzeption der historischen Ausstellung, aber nicht in Hinblick auf die Berücksichtigung der Perspektive eines potentiellen deutschen, mit

400 Vgl. Pasch: Vorwort, 2014, S. $12 f$.

401 Schneibergová: In Ústí entsteht Ausstellung »Unsere Deutschen«. Radio Praha. 31.01.2020. 
Oberschlesien verbundenen Publikums. Generell möchte das MŚK aber deutsche Besucher ansprechen, worauf auch das mehrsprachige Angebot verweist. Der Blick auf das polnische Publikum war dem gegenüber in Görlitz wesentlich wichtiger als der auf das deutsche in Kattowitz, wie die Ausführungen des Teams um Markus Bauer besonders zur Frage der Darstellung der Vertreibung gezeigt haben.

In ihrer Machart unterscheiden sich beide Ausstellungen grundsätzlich. Das Museum in Görlitz ist ein klassisches kulturhistorisches Museum, das primär kunsthistorische Objekte zur Bewunderung oder aber Objekte zur Illustration der historischen Erzählung verwendet. Die historische Ausstellung in Kattowitz ist eine szenografische, in der Objekte nur spärlich beziehungsweise schmückend zum Einsatz kommen und die Erzählung stark von den begehbaren Szenarien geprägt ist. Daher finden sich bei der Objektauswahl und ihrer Darstellung wenige Gemeinsamkeiten. Obgleich das Schlesische Museum zu Görlitz eine um etwa 600 Quadratmeter größere Ausstellungsfläche hat, sind viele historisch bedeutende Ereignisse nur knapp skizziert. Die Ausstellung in Kattowitz ist insgesamt dichter und eine Distanzierung oder ein temporäres Zurücktreten von der Ausstellung und damit aus dem szenografisch inszenierten Raum kaum möglich. In Görlitz ist dies schon fast zwangsläufig durch die immer wieder notwendigen Raumwechsel gegeben, aber auch sonst erlaubt die Gestaltung dort, sich jederzeit zurückzuziehen. Beide Ausstellungen teilen trotzdem ein ähnliches Besucherbild: Dem Besucher wird zumeist ein Narrativ angeboten, welches allerdings durch den grundsätzlich differenzierten und zurückhaltenden Charakter der Texte nicht erdrückend wirkt.

In ihrer inhaltlichen Struktur verfolgen beiden Museen einen ähnlichen Ansatz. Eine Diskussion des surpolnischen oder >urdeutschen« Charakters der Region wird vermieden, nur punktuell klingen die historiographischen Kämpfe der Vergangenheit an. Dies ist beispielsweise der Fall, wenn in Görlitz der friedliche Landesausbau betont und in Kattowitz der Zuzug der Deutschen in einem Text als negativ klassifiziert werden. Auffallend ist, dass in beiden Fällen mit einem vergleichsweise geschlossenen Nationalitätenkonzept gearbeitet wird, obwohl für Oberschlesien nationale Indifferenz konstitutiv ist. Nur das MŚK weist punktuell auf mögliche Zwischenidentitäten hin. Dass dies in Görlitz nicht weiter thematisiert wird, beruht möglicherweise auch auf dem gesamtschlesischen Anspruch und der für Niederschlesien weniger komplexen ethnischen Gliederung. In beiden Ausstellungen bleibt es bei der knappen Erwähnung des tschechischen Elementes in Geschichte und Gegenwart. Sowohl in Görlitz als auch in Kattowitz bemüht man sich bei der Darstellung der Teilung Oberschlesiens um eine symmetrische Gegenüberstellung. Bis auf wenige Ausnahmen wird eine Parteinahme und die Frage nach Recht- oder Unrechtmäßigkeit der Vertreibungen vermieden.

Beide Häuser geben der Darstellung der Geschichte vor dem Zweiten Weltkrieg und der Etablierung des nationalsozialistischen Terrorapparates sowie des anschließenden Krieges und der Besatzungsherrschaft viel Raum und zeigen die folgende Flucht- und Vertreibungsbewegung in diesem Kontext. Während in Görlitz eine betont zurückhaltende Betrachtung vorherrscht, geht Kattowitz wesentlich intensiver auf die Dramatik der Geschehnisse ein. Bei der Darstellung des Lagerwesens nennt das MŚK ausdrücklich polnische Akteure, die an Verbrechen gegen die oberschlesische oder als deutsch betrachtete Bevölkerung beteiligt waren. In einer Medienstation kann man sich über das 
die Deutschen betreffende Vertreibungsgeschehen informieren. Beide Museen treffen sich wieder in der semantischen und qualitativen Parallelisierung der Zwangsmigrationen am Ende des Zweiten Weltkrieges. Diese Vorstellung wird in Görlitz intensiver verfolgt als in Kattowitz, wo die realhistorischen Unterschiede etwas stärker zur Geltung kommen, was aber mit einer gewissen Externalisierung der deutschen Vertriebenen aus der oberschlesischen Geschichte einhergeht. Eine Ähnlichkeit besteht auch darin, dass die Hintergründe der Grenzverschiebung weitgehend ausgeblendet werden und die Verantwortung für die Zwangsmigration der Potsdamer Konferenz zugeordnet wird.

In wenigen Punkten ist das SMG in seinem Narrativ wesentlich pointierter als das MŚK. So wird das schwierige Fortleben der in Schlesien verbliebenen Deutschen nach 1945 knapp skizziert sowie auch deren gegenwärtig nicht einfache Situation angesprochen. In Kattowitz wird das Verbleiben einer deutschen Bevölkerungsgruppe in Schlesien nach dem Zweiten Weltkrieg kurz erwähnt, aber nicht weiter ausgeführt und keine explizite Verbindung mit der kontinuierlichen und massenhaften Ausreise deutscher Schlesier bis 1989 und darüber hinaus hergestellt. Spielt der versöhnende Aspekt zwischen Deutschland und Polen in Görlitz am Ende eine große Rolle, taucht dieser in Kattowitz nicht auf. Hier konzentriert sich die Ausstellung in der Darstellung der Zeit ab 1945 auf die Alltagsgeschichte im Oberschlesien der Volksrepublik und endet mit den gegenwärtigen Herausforderungen der Region. Beide Museen führen in ihrem chronologischen Rundgang schließlich nicht bis in die Gegenwart, sondern dieser endet 1945 beziehungsweise 1989. Der Blick in Gegenwart und Zukunft am Ende der Ausstellung des MŚK ist ebenso wie die Darstellung der >Wiederentdeckung Schlesiens nach 1989 im SMG nicht direkt in die Chronologie eingebunden.

Schließlich entwickelt das Museum in Kattowitz einen anderen Schwerpunkt in seinem Schlesiennarrativ, indem es für die gegenwärtige Bevölkerung des Gebietes ein Identifikationsangebot sowie eine annehmbare und anschlussfähige Geschichte der Region anbieten muss und möchte. In Görlitz überwiegt die Darstellung Schlesiens als kulturgeschichtlicher deutscher Region, deren Geschichte und Kunst bis heute von Interesse für alle Menschen sind. Dabei gelingt es Görlitz, deutsche Schlesier ebenso anzusprechen wie andere Besuchergruppen. Polen, auch aus Oberschlesien, finden aber wenige Bezugspunkte zum gängigen polnischen Kenntnisstand zu Schlesien. Umgekehrt verhält es sich ähnlich: Ein vertriebener deutscher Oberschlesier wird sich in Kattowitz, besonders bei der Erzählung über das 20. Jahrhundert, an der nationalpolnischen Perspektive stören. Beide Museen sind aber sichtbar um historische Genauigkeit, Ausgewogenheit und die Berücksichtigung des aktuellen Forschungsstandes bemüht, sodass sich die Kritik an den Häusern inhaltlich primär auf fehlende Elemente sowie auf Darstellungsformen und Kontextualisierungen bezieht.

In seiner knappen, vergleichenden Untersuchung der schlesischen Museen in Görlitz, Kattowitz und Troppau/Opava kommt Ondřej Táborský zu dem Schluss, dass trotz vielerlei positiver und technisch gut gemachter Elemente weder das MŚK noch das SMG dem Anspruch eines modernen, Reflektion und Teilhabe ermöglichenden Museums genügen und sie in ihrer Arbeit offenkundig »politischer Druck «begleitete. Abgesehen von diesem zentralen Mangel sei das Kattowitzer Haus zwar unterhaltsam, aber in seiner 
Erzählung einem selektiven und nationalpolnischen Narrativ verbunden. Die Görlitzer Ausstellung habe zudem einen nüchternen und sehr pädagogischen Ansatz, der entmündigend und ermüdend sei. ${ }^{402}$ Diese Einschätzung deckt sich in Bezug auf das MŚK mit den hier herausgearbeiteten Beobachtungen, ebenso wie beide Häuser mit einem konventionellen Besucherbild operieren. Die von Táborský beklagte >Fingerzeigpädagogik des SMG ist meines Erachtens weniger erkennbar, da die Ausstellung bei den inhaltlich schwierigen Themen vor allem auf deutliche Positionierungen verzichtet. Zudem berücksichtigt seine Kritik nicht den kunsthistorischen Charakter des SMG, der eine solche konventionelle Darstellung befördert.

Abschließend lässt sich feststellen, dass es beiden Häusern nur eingeschränkt gelingt, unbefangen, differenziert und ausgewogen von der Vertreibung der deutschen Bewohner Schlesiens und deren Kontext zu erzählen. Dem Görlitzer Museum steht ein Kontroversen überdeckendes Europanarrativ im Wege, das durch die mangelnde Bereitschaft zur Debatte einen konstruktiven Diskurs erschwert. Zugleich zeigt sich das Haus aber nicht so europäisch, als dass polnische Besucher es nicht doch als primär deutsches Museum wahrnehmen würden. Das Kattowitzer Museum ist deutlicher in der Darstellung der Vertreibungs- und Deportationsschicksale, allerdings mit einer Indifferenz bei der Zuordnung von Deutschen, Oberschlesiern und Polen, die die Unterschiede ihrer Schicksale überdeckt. Bezeichnen polnische Rezensenten die Darstellung polnischer Perspektiven in Görlitz als »höflich« und distanziert, so kann man in Kattowitz erkennen, dass ein deutscher Oberschlesier - wie auch in der Presse der deutschen Minderheit geäußert - sich schwerlich in diesem Haus wiederfinden kann.

Sowohl das Schlesische Museum zu Görlitz als auch das Muzeum Śląskie in Kattowitz weisen trotz der angeführten Kritik gelungene Umsetzungen und Potenziale auf: Zukünftige Kooperationsprojekte und gemeinsame Ausstellungen gerade über die konfliktträchtigen Themen könnten dazu beitragen, in komplizierter werdenden politischen Verhältnissen wechselseitiges Verständnis und vor allem den Dialog über die gemeinsame Region Schlesien mitsamt Licht und Schatten ihrer Geschichte weiterzuentwickeln.

Die beiden Museumsprojekte in München und Aussig sind spätestens seit der Konkretisierung der Vorhaben im Jahr 2006 miteinander verschränkt. Sie präsentieren sich als ein Beispiel für »eine grenzüberschreitende Einflussgeschichte«, die aber im Gegensatz zu den meisten der in Kapitel 4 und 5 dargestellten Auseinandersetzungen »nicht im Sinne antagonistischer Aktion und Reaktion « stattfindet, sondern trotz mancher Differenzen von den Akteuren mit einem vergleichbaren Ziel verfolgt wird: »Das $\mathrm{Zu}$ sammenleben in den böhmischen Ländern« zu zeigen. ${ }^{403}$

In ihrer Konstitution unterscheiden sich die beiden Einrichtungen insofern, als dass das Vorhaben in München von einem breiten politischen Konsens getragen und von der

402 Táborský: Creating Silesian Identity, 2018.

403 Řezník; Schulze Wessel: Das Museum als Medium einer Verflechtungsgeschichte von Deutschen, Tschechen und Slowaken, 2017, S. $18 \mathrm{f}$. 
bayerischen Regierung konsequent vorangebracht wurde. In Tschechien entstand das Projekt in einem regionalen Zusammenhang, auch wenn die nationale und weitergehende Bedeutung von Beginn an gegeben war. Die unsteten Regierungsverhältnisse in Tschechien sowie die nicht fokussierte Förderung des Vorhabens durch die tschechische Regierung haben die Eröffnung verzögert. Für beide Einrichtungen ist durch ihre Beiräte und ihr Personal eine deutsch-tschechische und internationale Ausrichtung bestimmend.

Die vorliegenden Konzeptionspapiere unterscheiden sich in ihrem Kern nicht. München verfolgt den Anspruch, die sudetendeutsche Geschichte auch in einem tschechischen Kontext zu erzählen. Aussig wählt bereits durch den Namen des Museums einen Ansatz, der die »deutschsprachigen Bewohner« als integralen Bestandteil der böhmischen Geschichte versteht. Die Ausgangspunkte sind daher die folgenden: In München soll eine sudetendeutsche Geschichte erzählt werden, ohne die für sie fundamentalen Bezüge zur tschechischen auszublenden. In Aussig soll dem Besucher eine böhmische Landesgeschichte nähergebracht werden, $\mathrm{zu}$ der deutschsprachige Bewohner gemeinsam mit ihren tschechischen Nachbarn über lange Zeit einen entscheidenden Beitrag geleistet haben.

Beide Projekte planen, die kontroversen Elemente der sudetendeutsch-tschechischen Geschichte zu reflektieren und dem Besucher multiperspektivisch näherzubringen. So soll jeweils die Definition des »Sudetendeutschen « als Konstruktion diskutiert werden, auch wenn dies in Aussig stärker als in München geplant ist. Damit verbunden ist auch die Differenz, dass in Aussig für die Darstellung des 20. Jahrhunderts die Perspektive des tschechoslowakischen Staates mit im Vordergrund steht, wohingegen in München eher die Sicht der Sudetendeutschen als ethnische Gruppe mit (legitimen) Ansprüchen gegenüber ihrem Staat verfolgt wird. ${ }^{404}$ Ein in Nuancen unterschiedlich gesetzter Schwerpunkt lässt sich auch für die Diskussion der Ursachen der Vertreibung feststellen: Wird in beiden Museen der Geschichte des zunehmenden konfrontativen Nationalismus nach 1848 viel Raum gegeben, so wird doch in Aussig die Vertreibung letztlich erst durch die Zerrüttungen des Zweiten Weltkrieges erklärt. Die Münchner Planungen fassen die Ursachen etwas weiter, auch wenn hier ebenfalls der Fokus auf der Zerstörung des Zusammenlebens in den 1930er und 1940er Jahren liegt. Diese kleineren Unterschiede zeigen sich nicht zuletzt in der verwendeten Sprache: So bleibt das Sudetendeutsche Museum bei der im deutschen Sprachgebrauch üblichen Bezeichnung als »Vertreibung«. Das Museum in Aussig verwendet in seinen Planungen hingegen den neutraleren Begriff der Zwangsaussiedlung [nucené vysídlení], verzichtet aber weitgehend auf die Verwendung der in Tschechien gängigen euphemistischen Termini.

Beide Museen bemühen sich, trotz dieser punktuellen Differenzen in ihren Darstellungen anschlussfähig an verschiedene Erzählungen zu sein. Von daher deutet sich der Erfolg an, auf einer niedrigschwelligen Ebene dem künftigen Besucher auch andere Perspektiven näherzubringen und damit Verständigung zu erreichen. Auffällig bei beiden Museen ist ein schwächerer Bezug auf Europa, was vermutlich durch den im Vergleich zu allen anderen hier untersuchten Museen stärkeren binationalen, deutsch-

404 So bewerten die bisherigen Planungen zumindest: Řezník; Schulze Wessel: Das Museum als Medium einer Verflechtungsgeschichte von Deutschen, Tschechen und Slowaken, 2017, S. 18f. 
tschechischen (und österreichisch-tschechischen) Fokus zu erklären ist. Nichtsdestoweniger schreiben beide Museen eine europäische Regionalgeschichte, die sich unaufgeregt von älteren nationalen und nationalistischen Erzählungen löst. Flucht und Vertreibung bilden in beiden Planungen den Endpunkt der Eskalation des Nationalismus, ohne bei der Geschichte von Schuld und Verantwortung stehen zu bleiben. Auf Grundlage der schon vorhandenen Kooperationen und Verbindungen können beide Institutionen in Zukunft Synergien entfalten und als Muster für eine museale Verständigung in der Mitte Europas dienen. 



\section{Museumsprojekte mit europäischem Anspruch im Vergleich}

\subsection{Stiftung Flucht, Vertreibung, Versöhnung}

\subsubsection{Geschichte}

Bereits in den 1970er Jahren kamen erste Überlegungen auf, ein Zentralmuseum für die ehemaligen deutschen Siedlungsgebiete in Osteuropa und ihr Ende durch Flucht und Vertreibung einzurichten. Diese Planungen wurden jedoch zugunsten der dezentralen Landesmuseen aufgegeben und aufgrund der politisch und kulturell stark föderalen Struktur der Bonner Republik nicht weiter verfolgt. Erst um die Jahrtausendwende erweckte der Bund der Vertriebenen mit der in Kapitel 5.1 beschriebenen Diskussion über das Zentrum gegen Vertreibungen diese Idee in neuer Form wieder zum Leben. Vorherige Überlegungen, das bereits seit den 1950er-Jahren existierende Mahnmal gegen Flucht und Vertreibung - die ewige Flamme am Theodor-Heuss-Platz in Berlin - um ein Dokumentationszentrum zu erweitern, verliefen im Sande, genauso wie die vorhandene bundesdeutsche Museums- und Denkmaltopographie an Flucht und Vertreibung in den Hintergrund geriet. ${ }^{1}$ Diese vermeintliche Leerstelle konnte der BdV daher umso prononcierter vertreten.

Die nach der Bundestagswahl 2005 gebildete Koalition aus CDU/CSU und SPD sah in ihrem Koalitionsvertrag vor, »im Geiste der Versöhnung auch in Berlin ein sichtbares Zeichen « zu setzen, um »an das Unrecht von Vertreibungen zu erinnern und Vertreibung für immer zu ächten«. Dies deckte sich mit der Position der das ZgV unterstützenden CDU/CSU-Fraktion, ein »Sichtbares Zeichen" gegen Vertreibungen in der Bundeshauptstadt zu errichten. Die SPD hingegen setzte die Zusammenarbeit mit dem von der vorherigen rot-grünen Regierung geförderten und 2004 gegründeten Europäischen Netzwerk Erinnerung und Solidarität (ENRS) durch, das eine internationale und nach Po- 
len und Tschechien anschlussfähige Gestaltung gewährleisten sollte. ${ }^{2}$ Die ursprünglich »beiden grundsätzlich gegenläufigen Positionen« fanden sich in diesem Kompromiss wieder. $^{3}$

Die folgenden zwei Jahre waren von Stillstand geprägt. ${ }^{4}$ Zum einen begleitete das von der SPD geführte Außenministerium die Planungen kritisch und zum anderen war die gewünschte Beteiligung Polens durch die neue, von der nationalkonservativen PiS geführte Regierung (2005-2007) unwahrscheinlich geworden. ${ }^{5}$ Ein zentraler Konfliktpunkt war die Beteiligung des BdV und seiner Vorsitzenden Erika Steinbach. Neben der grundsätzlichen Kritik an dem Vorhaben sahen Kritiker des Projektes in Deutschland und fast alle Stimmen aus Polen und Tschechien in Steinbach eine ungeeignete Partnerin. ${ }^{6}$ Ein fortwährender Einwand aus polnischer Perspektive war und ist, dass die Ergänzung der Berliner Erinnerungslandschaft durch ein solches »Sichtbares Zeichen« die Deutschen neben den Juden als die beiden Hauptopfer des Krieges erscheinen lassen würde. Wenn sich dies schließlich noch mit einem anklagenden Appell gegenüber Polen durch den ausschließlichen Fokus auf die Vertreibung der Deutschen verbände, in dem Polen und Tschechen zwangsläufig primär als Täter auftauchten, sei die Institution überhaupt nicht mehr hinnehmbar. ${ }^{7}$

Mit der Stiftung Zentrum gegen Vertreibungen, finanziell ausgestattet durch private Spenden sowie durch einige von der CDU/CSU regierte Bundesländer, verfügte der BdV über ein geeignetes Mittel zur politischen Einflußnahme. Die beginnenden Ausstellungsaktivitäten des $\mathrm{ZgV}$ sowie die in den Raum gestellte Ankündigung, notfalls eigenständig und ohne staatlichen Einfluss ein Museum errichten zu wollen, erhöhten den Handlungsdruck auf die Bundesregierung. Mit dem Machtwechsel in Polen 2007 und dem Vorsatz des neuen polnischen Premierministers Donald Tusk, das geschichtspolitische Verhältnis zu Deutschland zu entspannen, sah man in Deutschland die Chance für eine »wohlwollende Neutralität« - auch wenn die polnische Regierung bei ihrer Ablehnung des deutschen Projektes blieb. ${ }^{8}$ Sowohl in Polen wie auch in Tschechien äußerte man weiterhin grundsätzliche Vorbehalte. Der tschechische Vizepremierminister Alexandr Vondra ergänzte die Ablehnung einer Beteiligung der tschechischen Regierung damit, dass es sich bei der Einrichtung um »[...] kein Institut [handele], wo wir leicht einen Kompromiss finden können, der für beide Seiten ange-

2 Koalitionsvertrag von CDU, CSU und SPD, 2005, S. 114. Hesse; Purpus: Monuments and Commemorative Sites for German Expellees, 2010, S. 48f. Vgl. Benz: Zur Debatte, 2008.

3 Franzen: Der Diskurs als Ziel? 2008, S. 26.

4 Vgl. Völkering: Die Musealisierung der Themen Flucht, Vertreibung und Integration, 2010, S. 75. Völkering sieht die Ursache dafür darin, dass der Kompromiss des Koalitionsvertrages schließlich ein »begrifflich nebulöses Cebilde« geschaffen habe, dessen Ausgestaltung weitere Diskussionen nach sich ziehen musste.

5 Vgl. Troebst: The Discourse on Forced Migration and European Culture of Remembrance, 2012, S. 402 .

6 Siehe Kap. 5.1, S. 210 und Kap. 5.2, S. 232

7 Vgl. Wiliński: Stosunki polsko-niemieckie w latach 1982-1991, 2007, S. 174.

8 Siehe: Hołub: Die Stiftung Flucht, Vertreibung, Versöhnung, 2014, S. 108. Vgl. Traba; Żurek: »Vertreibung« oder »Zwangsumsiedlung«? 2015, S. 342. 
nehm ist $[. .$.$] « und dass sich die tschechische Regierung eine Kommentierung nach der$ Fertigstellung vorbehalte. ${ }^{9}$

Der polnische Premierminister Tusk schlug als gemeinsame Alternative die vom Historiker Paweł Machcewicz entwickelte Idee eines »Museums des Zweiten Weltkrieges « in Danzig vor, das zusammen mit den anderen Zwangsmigrationen des Zweiten Weltkrieges auch die der Deutschen in einem angemessenen Rahmen zeigen sollte. Andere Stimmen aus Polen empfahlen - wenn sich ein solches Zentrum schon nicht verhindern ließe - dieses gemeinsam mit Tschechien durch eine aktive Beteiligung zu überwachen und zu beeinflussen. ${ }^{10}$ In Folge der Planungen für das MIIW unterblieb die zunächst von Polen angestrebte Revitalisierung des ENRS als Alternative und erfolgte erst später unter anderen Vorzeichen. ${ }^{11}$

Eine Kooperation auf dieser Basis erschien der Bundesregierung jedoch zu weit entfernt vom Konzept des "Sichtbaren Zeichens«, sodass sie sich schließlich für ein unilaterales Vorgehen entschied. ${ }^{12}$ Im März 2008 veröffentlichte sie eine erste Konzeption für das »Sichtbare Zeichen«, die den künftigen inhaltlichen und organisatorischen Rahmen der Institution absteckte. Mit einer Dauer- und regelmäßigen Wechselausstellungen, der Durchführung von Veranstaltungen und einer internationalen Vernetzung sollte das Dokumentations- und Informationszentrum die Flucht und Vertreibung der Deutschen »vor dem Hintergrund der nationalsozialistischen Expansionsund Vernichtungspolitik ausreichend « und im Kontext »europäischer Vertreibungen im 20. Jahrhundert « darstellen. Auch aktuelle Zwangsmigrationen sollten in der Arbeit thematisiert werden. Ebenso wurde der Auftrag postuliert, die Geschichte gemeinsam mit den Nachbarn aufzuarbeiten und so »zur Versöhnung « beizutragen. ${ }^{13}$ Als eine Grundlage der künftigen Dauerausstellung sah das Papier die Ausstellung Flucht, Vertreibung, Integration des Hauses der Geschichte von 2005. ${ }^{14}$

In dem Konzept wurde weiter der organisatorische Kompromiss gefunden, die Stiftung Flucht, Vertreibung, Versöhnung als unselbstständige Einheit unter der Trägerschaft des Deutschen Historischen Museums einzurichten. Ende 2008 war der Weg frei für das Gründungsgesetz, das der Deutsche Bundestag mit den Stimmen von CDU/CSU, SPD und FDP bei Enthaltung von Bündnis 90/Die Grünen und Ablehnung der Partei Die Linke durch den Deutschen Bundestag annahm. ${ }^{15}$ Im In- und Ausland sowie vom BdV selbst wurde dieser Schritt nach den jahrelangen Kämpfen als Erfolg für den

»Chceme si ponechat svobodu to komentovat, až to bude hotové. Není to institut, kde bychom snadno nalezli kompromis komfortní pro obě strany. ¿Černý; Ehl: Německé centrum o vysidlování vznikne, Poláci a Češi vyčkávají. Hospodářské noviny. 20.03.2008.

10 Ehl: Tusk uhlazoval vztahy s Berlínem. Hospodářské noviny. 12.12.2007.

11 Vgl. Troebst: Towards a European Memory of Forced Migration? 2016, S. 240. Vgl. Kap. 5.2, S. 238.

12 Vgl. Troebst: Towards a European Memory of Forced Migration? 2016, S. 240.

13 Beauftragter der Bundesregierung für Kultur und Medien: Konzeption, 2008, S. 1.

14 Siehe Kap. 5.1, S. 212f. Vgl. Assmann: Ceschichte im Cedächtnis, 2007, S. $147 f$.

15 Deutscher Bundestag: Gesetz zur Errichtung einer Stiftung »Deutsches Historisches Museum « (DHMC). 21.12.2008, Fassung vom 14.06.2010. Die Grünen sahen den Kompromiss grundsätzlich positiv, enthielten sich jedoch aufgrund noch »ungeklärter Fragen«der Stimme. Die Linke kritisierte die Verortung der Stiftung in Berlin sowie den zu großen Einfluss des BdV auf ihre Arbeit: Beer: Flucht und Vertreibung der Deutschen, 2011, S. 155f. Siehe für die Perspektive der Partei Die Linke: Jochimsen: Die linke Gegenstimme zu: Erinnerungskultur und Geschichtspolitik, 2009, S. $90 f$. 
BdV bewertet, der sich gegen die äußeren und inneren Widerstände schließlich mit seiner Forderung nach einem zentralen Erinnerungsort durchgesetzt habe. ${ }^{16}$ Andere Stimmen wiesen daraufhin, dass mit dem »unusual step of taking responsibility« für ein solches Vorhaben durch die Bundesregierung der BdV als entscheidender Gestalter dieses Ortes ausgeschaltet wurde, wie unter anderem der in das Vorhaben involvierte damalige Vizepräsident des Deutschen Bundestages Wolfgang Thierse (SPD) konstatierte. ${ }^{17}$

Diese Erkenntnis wurde in den nächsten Jahren allerdings noch überdeckt durch die Kontroversen um die symbolpolitisch aufgeladene Frage der Mitgliedschaft Erika Steinbachs im Stiftungsrat der SFVV. Die SPD war unter Hinweis auf die im Ausland nicht vermittelbare Beteiligung Steinbachs an dem Museumsprojekt nicht bereit, ihrer Entsendung in den Stiftungsrat zuzustimmen. ${ }^{18}$ Die vom BdV nominierten Vertreter mussten laut der Gesetzesfassung von 2008 von der Bundesregierung bestätigt werden. Aus Protest und in der Hoffnung auf eine neue politische Konstellation nach den nächsten Bundestagswahlen ließ der BdV den Sitz zunächst vakant bleiben. ${ }^{19}$ In Polen wurden diese Vorgänge 2008 bis 2010 nach den langwierigen Diskussionen um das ZgV erneut intensiv und kritisch verfolgt. ${ }^{20}$

Zum Leiter der SFVV wurde 2009 der von Kritikern als nationalkonservativ eingeschätzte Regensburger Historiker Manfred Kittel berufen, dessen bisherige wissenschaftliche Arbeiten zum Themenkomplex Flucht und Vertreibung zum Teil kontrovers besprochen wurden. ${ }^{21}$ Aufsehen erregte sein 2007 erschienenes Buch zur Erinnerungskultur der Bonner Republik mit dem Titel „Vertreibung der Vertriebenen? «22 In dem auch für die vorliegende Arbeit herangezogenen Werk argumentiert er jedoch wesentlich differenzierter, als ihm vorgehalten wurde. ${ }^{23}$ Die Entscheidung für Kittel als Leiter wurde vom BdV begrüßt. ${ }^{24}$

Nach den Bundestagswahlen im Herbst 2009 bildete sich die neue Bundesregierung aus CDU/CSU und FDP. Überraschend für den BdV wandte sich der neue Außenminister Guido Westerwelle (FDP), ebenso wie vormals die SPD, unter Verweis auf die außenpolitische Wirkung gegen die Personalie Erika Steinbach. ${ }^{25}$ In Polen gilt Erika Steinbach

16 Vgl. Beer: Flucht und Vertreibung der Deutschen, 2011, S. 145.

17 Vgl. Eckersley: Walking the Tightrope between Memory and Diplomacy?2016, S. 116f. So auch: Nelhiebel: Die Stiftung Flucht, Vertreibung, Versöhnung, 2016, S. $526 \mathrm{f}$.

18 Graw: Für Polen geht es um mehr als nur um Steinbach. Die Welt. 26.02.2009.

19 Vgl. dazu die Ausführungen von Erika Steinbach und die Motivlage des BdV: Steinbach: Die Macht der Erinnerung, 2010, S. 112-115.

20 Vgl. dazu die beiden Veröffentlichungen von: Wagińska-Marzec: Konflikt wokół Widocznego Znaku w świetle prasy polskiej, 2009. Sowie: Mazur: Widoczny Znak (2005-2009), 2009.

21 Vgl. zur Person Manfred Kittels und seinem bisherigen wissenschaftlichen Wirken kritisch: Nelhiebel: Die Entkoppelung von Krieg und Vertreibung, 2010, S. 54-69.

22 Kittel: Vertreibung der Vertriebenen? 2007.

23 Vgl. beispielsweise die Bezüge auf sein Buch im Kapitel 4.1 dieser Arbeit, z.B. S. $153 f$.

24 Vgl. die Pressemitteilung: Bund der Vertriebenen: Die Weichen sind richtig gestellt. 07.07.2009.

25 Gessler: Regierung und Vertriebene einigen sich. taz. 11.02.2010. Vgl. Steinbach: Die Macht der Erinnerung, 2010, S. 115f. In Tschechien erinnerte man sich 2010 noch gut an eine Äußerung Steinbachs von 1998, dass die Tschechen im Zweiten Weltkrieg »kaum gelitten haben«: Kontroverzní šéfka Svazu vyhnanců dostane Karlovu cenu. Aktuálně.cz. 18.03.2010. Vgl. für die mediale Diskus- 
durch ihre zum Teil als aggressiv und undiplomatisch wahrgenommenen Äußerungen diesem Land gegenüber ebenso wie durch ihre Position gegen die Anerkennung der Oder-Neiße-Grenze 1990 als persona non grata, zumindest als Vertreterin für eine glaubwürdige Aussöhnung. ${ }^{26}$ Nur wenige polnische Stimmen warnten vor der kontraproduktiven Einmischung in die deutsche Debatte, da diese zum Teil als unverständlich oder überzogen wahrgenommen werden könnte. Wichtiger sei es, die Diskussion gemeinsam anhand konkreter Fragen der Geschichte mit der Zielsetzung der Versöhnung $\mathrm{zu}$ führen. ${ }^{27}$

Die folgende monatelange politische Auseinandersetzung belastete das Stiftungsprojekt erneut erheblich. Die Verweigerung eines schnellen Kompromisses durch den BdV sollte sich insofern für diesen auszahlen, als Erika Steinbach im Frühjahr 2010 durch ihren Verzicht auf einen Sitz im Stiftungsrat eine Änderung des Stiftungsgesetzes durchsetzen konnte. ${ }^{28}$ Mit dieser vergrößerte sich der Stiftungsrat von 13 auf 21 Personen und der Anteil der BdV-Vertreter überproportional von drei auf sechs. Ebenso sollten nun die Stiftungsratsmitglieder durch den Bundestag bestimmt und das Budget sowie die vorgesehene Ausstellungsfläche der Stiftung von 2200 auf 3000 Quadratmeter deutlich erweitert werden. ${ }^{29}$

Allerdings führte die sich hinziehende Kontroverse auch dazu, dass sich diverse Mitglieder aus dem Stiftungsrat und dem wissenschaftlichen Beraterkreis zurückzogen, darunter die Vertreter aus Tschechien und Polen. ${ }^{30}$ Der Zentralrat der Juden ließ seine Mitgliedschaft im Stiftungsrat ruhen, nachdem umstrittene, bereits länger zurückliegende Äußerungen zur Kriegsschuldfrage durch zwei BdV-Mitglieder des Stiftungsrates in den Medien diskutiert wurden. ${ }^{31}$ Der polnische Historiker Tomasz Szarota, der den Beraterkreis im Dezember 2009 verlassen hatte, äußerte sich pointiert kritisch:

sion um Erika Steinbach in Polen: Wagińska-Marzec: Konflikt wokół Widocznego Znaku w świetle prasy polskiej, 2009, S. 94, 119. Vgl. auch den Nachruf auf Westerwelle in der Cazeta Wyborcza, der seinen Einsatz für die deutsch-polnischen Beziehungen u.a. durch das Eintreten gegen Steinbach und das ZgV hervorhebt: Wieliński: Cdy Guido Westerwelle kierował niemiecką dyplomacją, zarzucano mu naiwność. Gazeta Wyborcza. 18.03.2016.

26 Vgl. Hołub: Die Stiftung Flucht, Vertreibung, Versöhnung, 2014, S. 108. Kap. 5.1, S. 198; Kap. 5.2, S. 241.

27 Vgl. Garczewski: Die Stiftung »Flucht, Vertreibung, Versöhnung« als politisches Problem in den deutsch-polnischen Beziehungen, 2011, S. 211.

28 Vgl. Nelhiebel: Die Stiftung Flucht, Vertreibung, Versöhnung, 2016, S. 527f. In Polen waren die Meinungen dazu zwiegespalten: Zum einen sah man den Verzicht Steinbachs als Erfolg und den Weg für eine Beruhigung der Debatte gegeben, zum anderen sahen einige Stimmen hierin vielmehr einen Triumph des BdV: Hołub: Die Stiftung Flucht, Vertreibung, Versöhnung, 2014, S. 109.

29 Cessler: Regierung und Vertriebene einigen sich. taz. 11.02.2010. Vgl. zur Sicht des BdV auf die Verhandlungsergebnisse: Steinbach: Die Macht der Erinnerung, 2010, S. 119-123.

30 Kellerhoff: Dauerstreit bei der Versöhnung. Die Welt. 14.03.2010. Vgl. zur Begründung des Rücktritts der tschechischen Historikerin Kristina Kaiserová: Češka opustila nadaci vysídleneckého centra v Berlíně. Česká televize. 09.03.2010.

31 Kellerhoff: Zentralrat stoppt Mitarbeit in Vertriebenen-Stiftung. Die Welt. 06.09.2010. Vgl. dazu die Stellungnahme der Bundesregierung: Bundesregierung: Neuer Stiftungsrat der Stiftung Flucht, Vertreibung, Versöhnung nimmt Arbeit am 25. Oktober auf. 06.09.2010. Vgl. für die Perspektive Erika Steinbachs auf die Vorgänge und Vorwürfe: Steinbach: Flucht, Vertreibung, Mahnung, 2016, S. 226-228. Siehe auch: Nelhiebel: Die Stiftung Flucht, Vertreibung, Versöhnung, 2016, S. 528-530. 
Die polnische Beteiligung im wissenschaftlichen Beraterkreis sah er als bloßes »Feigenblatt «, zumal keine tatsächliche, wissenschaftliche Diskussion über die Ausrichtung der Stiftung geführt würde und politische Erwägungen im Vordergrund stünden. Die Darstellung der polnischen Zwangsmigrationen bewertete er als eine Form von Trostpreis. Das ganze Vorhaben würde zudem gar nicht der deutsch-polnischen Versöhnung dienen, sondern den nationalen deutschen Diskurs befrieden und nicht zuletzt die zwei Millionen Wählerstimmen der Vertriebenen anvisieren. Die Beteiligung polnischer Historiker am Wissenschaftlichen Beraterkreis lehnte er daher als sinnlos und kontraproduktiv ab. ${ }^{32}$ Diese später so ähnlich wiederholte Argumentation zeigt auf, warum für polnische Historiker eine Mitgliedschaft im Wissenschaftlichen Beraterkreis schwierig ist und war, zumal auch das polnische Außenministerium umgehend mitteilte, »dass die Mitgliedschaft beider polnischer Historiker im Wissenschaftlichen Beraterkreis der Stiftung einen rein privaten Charakter habe «. ${ }^{33}$ Krzyszstof Ruchniewicz, zeitweise Mitglied des Wissenschaftlichen Beraterkreises, verteidigte hingegen die Mitgliedschaft polnischer Historiker, da man ansonsten jeglichen Einfluss verlieren würde. ${ }^{34}$

Als ein Beitrag zur inhaltlichen Diskussion und als Gegenentwurf zur geplanten Ausrichtung der SFVV wurde von einer Historikergruppe um Martin Schulze Wessel, unterstützt von der Deutsch-Polnischen Schulbuchkommission sowie der Deutsch-Tschechischen und Deutsch-Slowakischen Historikerkommission, im September 2010 ein alternatives Konzept für die Stiftung vorgestellt. ${ }^{35}$ In diesem sollten Flucht und Vertreibung zentral um die NS-Expansions- und Vernichtungspolitik gruppiert, eine klare Trennung vom Genozid vorgenommen sowie zugleich Formen von simplifizierenden Opfer-TäterMustern aufgebrochen und die Wechselwirkungen der Gewalt thematisiert werden. Ebenso betonte das Papier die kausalen Zusammenhänge der Zwangsmigrationen, so zum Beispiel die Zwangsaussiedlung der Polen aus den kresy und den damit verbundenen Vertreibungsdruck auf die deutsche Bevölkerung. Heterogenen Besuchergruppen mit ebenso unterschiedlichen Erfahrungen müsste durch eine prononciert multiperspektivische Gestaltung begegnet werden. Auch in der Vorstellung dieser Autoren sollte die Vertreibung der Deutschen der Schwerpunkt der Ausstellung sein, aber nicht ausschließlich im Fokus stehen, schließlich müsste auch hier an die Kontinuitäten zu jüngsten Zwangsmigrationsphänomenen sowie an die aktuelle Lebenswelt der Besucher angeknüpft werden. ${ }^{36}$

32 Siehe: Raabe; Velder: »Flucht, Vertreibung, Versöhnung«, 2010.

33 Ebd.

34 Ebd.

35 Schulze Wessel; Franzen et al.: Konzeptionelle Überlegungen für die Ausstellungen der »Stiftung Flucht, Vertreibung, Versöhnung«, 2010. Siehe zum Alternativkonzept kritisch: Scheliha: Forum: Diskussionsbeitrag zum Konzept für die Ausstellungen der »Stiftung Flucht, Vertreibung, Versöhnung«, 2010. Vgl. Nelhiebel: Die Stiftung Flucht, Vertreibung, Versöhnung, 2016, S. 531f. 
Kurz darauf erschien am 25. Oktober 2010 das von Kittel entworfene Eckpunktepapier für die Arbeit der Stiftung. ${ }^{37}$ Sowohl bei Historikern als auch in der medialen Berichterstattung trafen diese Überlegungen auf Kritik bis hin zu scharfem Widerspruch. ${ }^{38}$ Die Argumente gegen das Papier ähnelten über weite Strecken denen gegen das Zentrum gegen Vertreibungen, also eine vermeintlich mangelhafte Kontextualisierung des Vertreibungsgeschehens durch die nationalsozialistischen Verbrechen sowie eine Fokussierung auf deutsche Opfer. ${ }^{39}$ In Polen kritisierte man unter anderem die als unangemessen empfundene Parallelisierung der deutschen Vertreibungen mit dem Völkermord an den Armeniern. ${ }^{40}$

Die tatsächlichen inhaltlichen Unterschiede zwischen dem Alternativkonzept und Kittels Überlegungen waren allerdings bei nüchterner Betrachtung weniger eklatant und beschränkten sich hauptsächlich einerseits auf die »Eingrenzung und Fokussierung des Themas und die breitere vergleichende Darstellung andererseits«. Die Kritik an dem Eckpunktepapier ebbte wieder ab und die Diskussion endete schließlich ergebnislos. ${ }^{41}$ Der neue und erweiterte Wissenschaftliche Beraterkreis konstituierte sich unter dem Vorsitz von Stefan Troebst im Januar 2011.

Am 25. Juni 2012 verabschiedete der Stiftungsrat der SFVV einstimmig das 46seitige Konzeptionspapier für die künftige Arbeit der Stiftung und inhaltliche Ausrichtung der geplanten Dauerausstellung. ${ }^{42}$ Es sieht die Schwerpunkte der künftigen Dauerausstellung bei der Thematisierung der Zwangsmigration während des Zweiten Weltkrieges und damit verbunden »Besatzungsterror, Zwangsmigration und Völkermord als Teil der NS-Herrschaft« ebenso wie Zwangsmigrationen unter sowjetischer Herrschaft. Flucht und Vertreibung der Deutschen am Ende des Zweiten Weltkrieges bilden den Schwerpunkt. Dazu ist geplant, den Erfahrungen der Flüchtlinge nach der Vertreibung Raum zu geben und schließlich Versöhnungsinitiativen und Ideen zu einer europäischen Erinnerungskultur vorzustellen. ${ }^{43}$

Deutlich erkennbar ist aber ein möglichst umfassender und chronologischer Ansatz, der die Vertreibung der Deutschen einbettet »in den Kontext europäischer Vertreibungen im 20. Jahrhundert « und einen »allgemeinen Überblick über mehr als dreißig vertriebene ethnische Gruppen in Europa « vermittelt. ${ }^{44}$ Es sollen die Entwicklung des ethnischen Nationalismus ebenso wie die Minderheitenproblematiken des 19. und

37 Stiftung Flucht, Vertreibung, Versöhnung: Eckpunkte für die Arbeit der Stiftung Flucht, Vertreibung, Versöhnung und die geplante Dauerausstellung, 2010. Vgl. zur kritischen Diskussion des Eckpunktepapieres: Völkering: »Flucht und Vertreibung« ausstellen - aber wie? 2011, S. 10-13.

38 Rüland: Vertriebenen-Debatte treibt Keil zwischen Forscher. Die Welt. 30.09.2010.

39 Vgl. hierzu beispielsweise das wissenschaftliche Online-Diskussionsforum: H-Soz-Kult: Diskussionsforum »Vertreibungen ausstellen. Aber wie?«, 2010.

40 Siehe: Hołub: Die Stiftung Flucht, Vertreibung, Versöhnung, 2014, S. 111.

41 Raabe; Velder: »Flucht, Vertreibung, Versöhnung«, 2010. Kittel selbst konstatierte, dass es zwischen den beiden Konzepten »eine ganze Reihe von Gemeinsamkeiten« gebe - Rüland: Vertriebenen-Debatte treibt Keil zwischen Forscher. Die Welt. 30.09.2010.

42 Siehe: Bundesregierung: Inhaltliches Fundament der Stiftung Flucht, Vertreibung, Versöhnung veröffentlicht. 29.08.2012.

43 Kittel et al.: Konzeption, 2012, S. 1 f.

44 Ebd., S. 10f. 
frühen 20. Jahrhunderts als mögliche Voraussetzungen von Flucht und Vertreibung thematisiert werden, wobei die Autoren »teleologische[...] Erklärungen« vermeiden möchten. ${ }^{45}$ Hiermit bezieht Kittel den europäischen Ansatz des ZgV sowie die Betonung des Nationalismus als Ursache der Vertreibung ein und distanziert sich von einer Zwangsläufigkeit oder Rechtfertigung derselben.

In Kittels Konzept von 2012 sollen die einzelnen Vertreibungen in der Gesamtschau in ihren individuellen historischen Zusammenhängen kontextualisiert und durch die intensive Auseinandersetzung mit der Etablierung des Nationalsozialismus in Deutschland, den Auswirkungen des Antisemitismus sowie der >Volksgemeinschafts<-Idee und der expansiven Rassenideologie sowie den Besatzungs- und Kriegsverbrechen eingeordnet werden. ${ }^{46}$ Ebenso sahen die Planungen die Herausstellung von Polen als spezifischem Opfer nationalsozialistischer Rassen- und Vernichtungspolitik, verbunden mit der Vertreibung von »über eineinhalb Millionen Polen seit September 1939 durch das nationalsozialistische Deutschland «, vor. ${ }^{47}$

Flucht und Vertreibung der Deutschen sollen in ihren verschiedenen Phasen inklusive der Evakuierungen, der Deportationen und des tschechoslowakischen, polnischen und sowjetischen Lagerwesens dargestellt werden. ${ }^{48}$ Bei der Beschäftigung mit Ankunft und Integration der Flüchtlinge und Vertriebenen distanziert sich das Konzeptionspapier vom Narrativ der schnellen und unproblematischen Eingliederung, stattdessen wird im Sinne der »Kalten Heimat« auf Probleme, aber auch auf Erfolge hingewiesen. Damit verbunden wird ein Vergleich zwischen der Bundesrepublik und der DDR. ${ }^{49}$ Der im Stiftungsgesetz angelegten Aufgabe der Versöhnung im Sinne einer europäischen Einigung wird mit dem Versprechen einer »kooperativen Aufarbeitung der Geschichte « begegnet. ${ }^{50}$ Weiter sieht das Konzept vor, dass die Stiftung nicht nur die jüngsten Vertreibungen auf dem Balkan ausstellt, sondern auch gegenwärtige Zwangsmigrationen diskutiert und so an das aktuelle Zeitgeschehen anknüpft. Dabei falle ihr die Rolle eines Mahners zu. ${ }^{51}$

Im Gegensatz zu 2010 blieb eine Diskussion über das Papier in Deutschland weitgehend aus. Auch in Polen und Tschechien wurde es nicht weiter kontrovers diskutiert, was vermutlich auch durch die grundlegend gleichbleibende Argumentationslage bedingt war. In einem Interview äußerte sich der polnische Historiker Krzysztof Ruchniewicz verhalten positiv über das Konzept von 2012: Als vorteilhaft hob er hervor, dass es dem »Prinzip der Ursache-Wirkung« gerecht werden und die Vorgeschichte der Vertreibung mit den verbrecherischen, totalitären Regimes des Dritten Reiches und der Sowjetunion darstellen würde. Die Behandlung der polnischen Opfer von Vertreibung

Kittel et al.: Konzeption, 2012, S. 18, 22-25.

46 Ebd., S. 28-34. Schon 2010 machte Kittel deutlich: »Dabei ist klar, dass die jeweiligen Vertreibungsvorgänge in ganz unterschiedlichen politischen und ideologischen Kontexten mit je eigenen Ausprägungen von Gewalt standen«- Kittel: Das Ausstellungs- und Dokumentationszentrum, 2010, S. 140.

47 Kittel: Das Ausstellungs- und Dokumentationszentrum, 2010, S. 140.

48 Kittel et al.: Konzeption, 2012, S. 32-40.

49 Ebd., S. 41-44.

50 Ebd., S. 7.

51 Ebd., S. 44-46. 
und Deportation sah er als Novum für den künftigen deutschen Besucher der Ausstellung an. In Hinblick auf die Frage, ob die Ausstellung nicht doch so konstruiert sein könnte, »dass die Schuld der Deutschen minimiert « und diese zum Opfer gemacht würden, antwortete er, dass die Aufsicht durch den wissenschaftlichen Beraterkreis sowie weitere internationale Kooperationen dies verhindern sollten. ${ }^{52}$ Nelhiebel kritisierte hingegen 2016 die Konzeption von 2012 wegen einer ahistorischen, die konkreten Zusammenhänge verzerrenden Fokussierung auf die Vertreibung, einer Umkehr der Täter-Opfer-Rollen und einem Ausblenden deutscher Verbrechen. Letztlich widerspreche diese Darstellung, in der »nationale Homogenisierungsversuche «als das vermeintlich »prägende Merkmal« des 20. Jahrhunderts erscheinen, »den Lebenserfahrungen von Millionen Europäern«, deren Erinnerung an den Zweiten Weltkrieg eine ganz andere sei. ${ }^{53}$

Die Vertriebenenvertreter äußerten sich positiv über die konzeptionellen Leitlinien. ${ }^{54}$ Die Vermutung, dass nun eine Beruhigung des Diskurses eingetreten sei, war jedoch verfrüht. Zunächst aber konstatierte die linksliberale taz 2012 bezüglich einer von der SFVV veranstalteten Buchvorstellung von Ray M. Douglas' Ordnungsgemäßer Überführung:

»Das Thema deutsche Vergangenheit scheint nur noch bedingt skandalisierbar zu sein. Dass die Stiftung >Flucht, Vertreibung, Versöhnung`vor ein paar Tagen fast ohne öffentliches Echo ein Konzept für ihre lange hart umkämpfte Dauerausstellung präsentierte, passt ins Bild. Konsens überall. «5

Am 11. Juni 2013 erfolgte die Grundsteinlegung für die Umbauten am Deutschlandhaus. Bundeskanzlerin Angela Merkel äußerte sich bei ihrer Rede in Bezug auf die bundesrepublikanische Erinnerungslandschaft und Flucht und Vertreibung in Anlehnung an die Vorstellung, dass das Thema bisher nicht ausreichend berücksichtigt worden sei:

»Mit den Umbauten und der künftigen Dauerausstellung wird sich eine Leerstelle in der Museums- und Erinnerungslandschaft unseres Landes schließen. Debatten über das Thema Vertreibungen wird es auch künftig geben - und es muss sie auch geben; das ist geradezu Sinn und Zweck des Deutschlandhauses. $\ll^{56}$

$\mathrm{Zu}$ diesem Zeitpunkt war noch eine Eröffnung der Dauerausstellung für das Jahr 2015 vorgesehen. ${ }^{57}$ Im Oktober 2013 tagte der Wissenschaftliche Beraterkreis der SFVV in Danzig und besuchte gemeinsam mit Mitarbeitern der Stiftung die Geschäftsstelle des

52 Wieliński: Muzeum wyciszy spór o wypędzonych. Gazeta Wyborcza. 31.08.2012. Vgl. Hołub: Die Stiftung Flucht, Vertreibung, Versöhnung, 2014, S. 111f.

53 Nelhiebel: Die Stiftung Flucht, Vertreibung, Versöhnung, 2016, S. $533 f$.

54 Vgl. die Pressemitteilung des BdV: Bund der Vertriebenen: BdV-Präsidentin Erika Steinbach MdB begrüßt Konzeption der Stiftung Flucht, Vertreibung, Versöhnung. 31.08.2012.

55 Reinecke: Die Front weicht auf. taz. 05.09.2012.

56 Rede von Bundeskanzlerin Merkel bei Baubeginn eines Dokumentationszentrums der Stiftung Flucht, Vertreibung, Versöhnung im Deutschlandhaus am 11. Juni 2013.

57 Romaniec: Baubeginn für das Vertriebenen-Zentrum. Deutsche Welle. 12.06.2013. 
im Aufbau befindlichen Museum des Zweiten Weltkrieges mit einer Präsentation durch Paweł Machcewicz und den stellvertretenden Direktor Piotr M. Majewski. ${ }^{58}$

Im Herbst 2014 trat die Stiftung im Deutschen Historischen Museum mit einer selbst kuratierten Werkstattausstellung sowie einer griechischen und von der Europäischen Union geförderten Wanderausstellung über Zwangsmigration mit dem Titel »Twice a Stranger « an die Öffentlichkeit. Beide riefen erhebliche inhaltliche Kritik hervor. Ähnlich wie schon bei den Debatten zuvor, entzündete sich diese an einer einseitigen Fokussierung auf die Vertreibung der Deutschen, falschen Opferzahlen und einer vermeintlich mangelnden Kontextualisierung durch den von Deutschland ausgelösten Zweiten Weltkrieg. Ein weiterer Kritikpunkt waren einige der ausgestellten Fotografien: So dienten in der Ausstellung NS-Propagandaaufnahmen als vermeintlich authentische Bilder von Flucht und Vertreibung. Verantwortlich für diese Schwächen ebenso wie für ein intransparentes Vorgehen und mangelnde Kooperation mit dem Wissenschaftlichen Beraterkreis wurde der Direktor Manfred Kittel gemacht. ${ }^{59}$

Auch polnische Medien kritisierten die Ausstellung unmittelbar und sahen die Verantwortung für eine weitere Beschädigung der deutsch-polnischen Beziehungen bei Kittel:

»Eine lange Zeit in den polnisch-deutschen Beziehungen gab es keinen solchen Groll wie diesen, der von Prof. Manfred Kittel verursacht wurde, Direktor des von der Bundesregierung gegründeten Museums der Vertreibung in Berlin. Kürzlich zeigte er den Grundriss der von ihm geschaffenen Ausstellung. Daraus ergab sich, dass die vertriebenen Deutschen aus Schlesien, Pommern und dem Sudetenland die einzigen Opfer des Krieges waren. Über das, was die Deutschen vor 1945 in Polen taten, wurde kein Wort verloren. ${ }^{60}$

Jedoch wies die Gazeta Wyborcza in Hinblick auf die kritische deutsche Diskussion positiv darauf hin, dass sich die so beschriebene Darstellung in Deutschland scheinbar nicht mehr durchsetzen ließe. Daher sei es angemessen und notwendig, dass auch die polnischen Vertreter, die für ihre Tätigkeit im Wissenschaftlichen Beraterkreis in Polen angegriffen wurden, das Vorhaben weiter kritisch und aufmerksam begleiten. ${ }^{61}$

Unter Bezugnahme auf die erhobene Kritik erklärten schließlich 14 von 15 Mitgliedern des Wissenschaftlichen Beraterkreises Manfred Kittel ihr Misstrauen und fassten ihre Haltung in einem Brief an die Bundesbeauftragte für Kultur und Medien, Moni-

58 Stiftung Flucht, Vertreibung, Versöhnung: Wissenschaftlicher Beraterkreis tagt in Danzig. 18.10.2013.

59 Vgl. Nelhiebel: Die Stiftung Flucht, Vertreibung, Versöhnung, 2016, S. 535-537. Nelhiebel ist selbst einer der prononciertesten Kritiker Kittels.

60 »Dawno w stosunkach polsko-niemieckich nie było takiego zgrzytu jak ten, który wywołał prof. Manfred Kittel, dyrektor założonej przez niemiecki rząd fundacji budującej w Berlinie muzeum wypędzonych. Niedawno pokazał zarys wystawy, jaką tworzy. Wynikało z niego, że wypędzeni Niemcy ze Śląska, Pomorza czy Sudetów to wyłączne ofiary wojny. O tym, co Niemcy robili w Polsce przed 1945 r., nie padło ani słowo. « Wieliński: Bez skandalu w muzeum wypędzonych. Gazeta Wyborcza. 20.11.2014. 
ka Grütters, zusammen. ${ }^{62}$ Erneut wurde die Frage diskutiert, inwiefern »Flucht und Vertreibung der Deutschen nach dem Zweiten Weltkrieg sein` oder >der Schwerpunkt der künftigen Dauerausstellung sein solle. ${ }^{63}$ Ergänzend kam nach Troebst hinzu, dass ein fortwährendes Spannungsverhältnis zwischen dem international aufgestellten Wissenschaftlichen Beraterkreis und dem deutschen Stiftungsrat bestand. ${ }^{64}$ Im Dezember 2014 erfolgte schließlich der Rücktritt von Manfred Kittel als Direktor der SFVV.

In Folge der >Flüchtlingskriseく nach dem Spätsommer 2015 häuften sich die politischen Forderungen, die Konzeption der Stiftung in Hinblick auf die aktuellen Herausforderungen anzupassen. So äußerte sich die Abgeordnete der Partei Die Linke Sigrid Hupach am 18. Dezember 2015 im Bundestag: »Die Stiftung muss inhaltlich neu positioniert werden und die aktuellen Bezüge zu Flucht und Vertreibung aufnehmen. « ${ }^{65}$ Stimmen der Mitte verwiesen auf die notwendige Beachtung von Unterschieden ebenso wie von Gemeinsamkeiten und betonten die Chance, dass sowohl Empathie für die Notsituation der heutigen Flüchtlinge gewonnen, aber auch das historische Thema erneut stärker in der Gesellschaft diskutiert werden könnte. Das entspräche auch dem länger gehegten Wunsch vieler verbliebener Zeitzeugen und der Verbände. ${ }^{66}$

Dem Rücktritt Kittels schloss sich eine längere Interimsphase an. Die Ausschreibung der Direktorenstelle lief schließlich in der Endrunde auf zwei Kandidaten hinaus: Winfried Halder, Direktor der Stiftung Gerhart-Hauptmann-Haus in Düsseldorf, und Michael Schwartz, Mitarbeiter am Institut für Zeitgeschichte München-Berlin, der durch umfassende Publikationen sowohl zur Globalgeschichte der Zwangsmigration als auch zur Integrationsgeschichte der deutschen Vertriebenen hervorgetreten ist. ${ }^{67}$ Die Entscheidung des Stiftungsrates zugunsten Winfried Halders - mutmaßlich aufgrund der Stimmen des BdV - führte zum Rücktritt von fünf der fünfzehn Mitglieder des Wissenschaftlichen Beraterkreises, darunter dessen Vorsitzendem Stefan Troebst und der polnischen Mitglieder. ${ }^{68}$ Gründe dafür waren zum einen die vermeintlich zu große Nähe Halders zum BdV und der CDU sowie seine Vorstellungen von der künftigen Stiftungsarbeit

62 Nelhiebel: Die Stiftung Flucht, Vertreibung, Versöhnung, 2016, S. 535.

63 Kellerhoff: Streit in Vertriebenen-Stiftung endet mit Rauswurf. Die Welt. 16.12.2014. Vgl. den Artikel in dem von der CSU herausgegebenen Bayernkurier, in dem Kittel verteidigt und die gegen ihn erhobenen Vorwürfe als weitgehend konstruiert dargestellt werden: Maetzke: Wenn Historiker und Journalisten nicht lesen können. Bayernkurier. 06.12.2014.

64 Troebst: Towards a European Memory of Forced Migration? 2016, S. 240.

65 Hupach: Rede zum Bericht der Bundesregierung über die Maßnahmen zur Förderung der Kulturarbeit gemäß § 96 des Bundesvertriebenengesetzes in den Jahren 2013 und 2014, 2015.

66 Monika Grütters sprach sich ebenso wie Bernd Fabritius dafür aus, Parallelen nicht zu »überstrapazieren«, aber dennoch die Chance der Aktualisierung zu ergreifen: Brand; Plewnia: Ende des Misstrauens. FOCUS Magazin. 12.03.2016. Vgl. Ackermann: Wer kommt alles aus dem Bullenkloster? FAZ. 06.01.2016. Vgl. ausführlich für die grundsätzliche Diskussion seit 2015: Feindt: From >flight and expulsion to migration, 2017. Manfred Kittel äußerte sich mehrfach kritisch zur Parallelisierung des Geschehens, vgl. Kap. 5.1, S. 217.

67 Teile seines Fuvres zieht die vorliegende Arbeit grundlegend heran, vgl. Kap. 3 und 4.

68 Vgl. dazu die Erklärung von: Madajczyk; Ruchniewicz et al.: Stellungnahme von ehemaligen Mitgliedern des Wissenschaftlichen Beraterkreises der Stiftung Flucht, Vertreibung, Versöhnung, 2015 . 
und zum anderen eine damit verbundene grundsätzliche Kritik an dem zu starken Einfluss des Vertriebenenverbandes. ${ }^{69}$ Aufgrund von erfolglosen Vertragsverhandlungen trat Winfried Halder schließlich seinen Posten in der SFVV nicht an. Vom November 2015 bis März 2016 leitete Uwe Neumärker, Direktor der Stiftung Denkmal für die ermordeten Juden Europas, die SFVV kommissarisch. ${ }^{70}$

Auf Vorschlag einer von Monika Grütters eingerichteten Findungskommission berief sie im April 2016 Gundula Bavendamm, die bisherige Leiterin des AlliiertenMuseums Berlin, zur neuen Direktorin. Grütters begründete die Entscheidung mit den bewiesenen Erfahrungen Bavendamms im Museumsmanagement, die nun besonders gefordert seien. ${ }^{71}$ Der BdV begrüßte und unterstützte die Wahl und unterstrich dabei den Wunsch nach baldigen Ergebnissen. ${ }^{72}$ Im Oktober 2016 wurde der Wissenschaftliche Beraterkreis mit zunächst zwölf Mitgliedern neu besetzt. Bemühungen um Mitglieder aus Polen werden fortgesetzt, da ihr Beitrag für den Erfolg der Stiftung als zentral erachtet wird. ${ }^{73}$ Für den Beraterkreis konnten unter dem Vorsitz von Frank-Lothar Kroll unter anderem mit Norman Naimark eine international bekannte Koryphäe der Zwangsmigrationsforschung sowie mit Ondřej Matějka ein Wissenschaftler, der sich bereits bei der zivilgesellschaftlichen Aufarbeitung der deutsch-tschechischen Geschichte engagiert hatte, gewonnen werden. ${ }^{74}$

Im Oktober 2016 wurde auch Richtfest am Deutschlandhaus gefeiert. Aufgrund von Schwierigkeiten mit der Sanierung und dem Umbau der denkmalgeschützten Bausubstanz wurde der Bezug der für die SFVV vorgesehenen Bereiche für Ende 2018, die Eröffnung der Dauerausstellung für 2019 angesetzt. ${ }^{75}$ Im Sommer 2019 wurde der Um-

69 Kellerhoff: Chefsuche für Vertriebenenstiftung ist ein Debakel. Die Welt. 04.11.2015. Vgl. für eine Einschätzung des zurückgetretenen Vorsitzenden des Beirates: Troebst: Rettet die Vertriebenenstiftung vor der Provinz! Die Welt. 12.07.2015. Der Artikel erschien ebenso in der polnischen Presse: Troebst: Protestuję przeciwko prowincjonalizacji niemieckiej polityki historycznej. Gazeta Wyborcza. 13.07.2015. Vgl. Nelhiebel: Die Stiftung Flucht, Vertreibung, Versöhnung, 2016, S. 537f. Nelhiebel sieht schließlich die gesamte Konstruktion der Stiftung als mangelhaft an, sodass an einem Erfolg grundsätzlich zu zweifeln sei.

70 Regente: Stiftung Flucht, Vertreibung, Versöhnung, 2017.

71 Dittrich: Neue Leitung, neue Hoffnung? Deutschlandfunk. 31.03.2016.

72 Pressemitteilung vom Bund der Vertriebenen: Dr. Gundula Bavendamm wird Direktorin der »Stiftung Flucht, Vertreibung, Versöhnung«. 22.02.2016.

73 Vgl. den Eintrag auf der Website der Stiftung: www.sfvv.de/de/stiftung/chronologie (letzter Zugriff: 05.03.2018). Der polnische Historiker Krzysztof Ruchniewicz begründet das Ausbleiben einer polnischen Beteiligung weniger mit den komplizierten politischen Bedingungen in Polen als damit, dass der Beirat »nach wie vor ein Debattiergremium ohne Einfluss auf die inhaltliche Ausrichtung der Stiftung und ihrer Produkte, insbesondere auf die künftige Ausstellung« sei: Schulz: In die Mitte der Gesellschaft. Der Tagesspiegel. 17.10.2016.

74 https://www.sfvv.de/de/stiftung/wissenschaftlicher-beraterkreis (letzter Zugriff: 23.03.2018). Vgl. zu Matějka Kap. 5.3, S. 262. Auch die weitere Aufstellung des Beraterkreises stellt eine ausgewogene Zusammensetzung von nationalen und internationalen Forschern dar, wobei u.a. Jochen Oltmer und Simone Eick für einen Schwerpunkt auf aktuelle Migrationsforschung stehen. Mit Matthias Beer ist auch ein ausgewiesener, in der vorliegenden Arbeit häufig herangezogener, Kenner der deutschen Vertreibungsgeschichte Mitglied. Vgl. Beraterkreis für Stiftung Flucht und Vertreibung ohne Polen. rbb. 17.10.2016. 
und Neubau des Deutschlandhauses abgeschlossen und die Eröffnung der Dauerausstellung für das Frühjahr 2021 angekündigt. ${ }^{76} \mathrm{Im}$ Zuge der Bauarbeiten stand nach Medienangaben kurzzeitig zur Diskussion, ob der historische Name »Deutschlandhaus« weiterhin bestehen und sichtbar bleiben sollte. ${ }^{77}$ Der Präsident des BdV, Bernd Fabritius, wies dies als Falschinformation zurück. ${ }^{78}$

Die Verzögerungen ermöglichen nach Monika Grütters auch eine Nachjustierung des Projektes, sodass unter anderem die Dauerausstellung stärker »als bislang geplant in die Geschichte der Migration eingebettet werden und vor allem Bezüge zu den heutigen Flüchtlingsströmen und -schicksalen « hergestellt werden können. ${ }^{79}$ Am 20. Juni 2017 konnte das die 2012er Konzeption konkretisierende und ergänzende 46-seitige »Konzept für die Dauerausstellung « vorgestellt werden. Dessen Entstehung wurde vom Wissenschaftlichen Beraterkreis begleitet und das Ergebnis vom Stiftungsrat einstimmig angenommen. ${ }^{80}$ Der Koalitionsvertrag von CDU/CSU und SPD vom März 2018 unterstreicht nochmals eine europäische Ausrichtung der SFVV und kündigt die verstärkte Unterstützung des Europäischen Netzwerkes Erinnerung und Solidarität an, das aber inhaltlich nicht mehr in einem direkten Verhältnis zur SFVV steht. ${ }^{81}$

Im Dezember 2017 traten Vertreter der deutschen Zivilgesellschaft mit dem Vorschlag an die Öffentlichkeit, ein Denkmal für das Leiden Polens unter deutscher Herrschaft im Zweiten Weltkrieg am Askanischen Platz gegenüber dem Deutschlandhaus zu errichten. Dieser konnte schnell eine breite Unterstützung in Wissenschaft und Politik gewinnen. Die Iniitiatoren planen, diese Idee in Anerkennung der verschiedenen Hürden eines solchen Projektes langfristig zu verfolgen. ${ }^{82}$

76 Bau für Stiftung Flucht, Vertreibung, Versöhnung ist fertig. Berlin.de. 28.08.2019.

77 Ebd.

78 Fabritius: »Deutschlandhaus bleibt Deutschlandhaus«. Siebenbürgische Zeitung. 03.09.2019.

79 Eröffnung erst 2018. Der Tagesspiegel. 19.08.2016.

80 Schulz: Stiftung Flucht, Vertreibung, Versöhnung legt Ausstellungskonzept vor. Der Tagesspiegel. 21.06.2017.

81 Koalitionsvertrag zwischen CDU, CSU und SPD, 2018, S. 169f. Siehe zum ENRS: Kap. 5.2, S. 238.

82 Vgl. hier beispielsweise das Interview mit dem Unterstützer der Idee, Wolfgang Thierse: Fritz: SPDPolitiker über Mahnmal in Berlin. Berliner Zeitung. 12.11.2017. Vgl. auch: Ruchniewicz: Es gibt keine Opfer zweiter Klasse. FAZ. 05.03.2018. Ruchniewicz geht in seinem Artikel auch auf die Kritiker des Vorhabens ein, die unter anderem eine nach Nationen separierte Erinnerungskultur zum NSTerror in Osteuropa ablehnen. Siehe für die Unterstützung der Wissenschaft auch die vom Deutschen Polen Institut eigens für das Projekt eingerichtete Website: https://www.polendenkmal.de/ (letzter Zugriff: 16.10.2018). Im August 2018 plädierte Martin Aust in Anknüpfung an den Vorschlag für ein gemeinsames Denkmal für die Opfer der deutschen Vernichtungspolitik in Osteuropa »in Sichtweite des Dokumentationszentrums der Stiftung Flucht, Vertreibung und Versöhnung. «Aust: Alle Toten verdienen denselben Respekt. FAZ. 27.08.2018. Im selben Monat schlug der Historiker Stephan Lehnstaedt anstelle oder als Ergänzung eines »Polen-Denkmals« die Einrichtung eines gemeinschaftlich getragenen Deutsch-Polnischen Museums nach Vorbild des Deutsch-Russischen Museums in Berlin-Karlshorst vor, mit Dependancen in Warschau und Berlin und Kooperationen mit anderen relevanten Einrichtungen, wie der SFVV und dem MIIW. Als Argumente führte er unter anderem an, dass die Denkmalsidee zwar ehrenwert sei, aber das Kernproblem der deutschpolnischen Verständigung nicht beheben könne: die geringen Kenntnisse über die polnische und deutsch-polnische Geschichte in Deutschland und die verbreitete negative Gleichgültigkeit der 
Die Wahl des Platzes begründen die Initiatoren zum einen mit dem Bezug auf den historischen Ort: Am Anhalter Bahnhof trafen 1940 Joachim von Ribbentrop und Wjatscheslaw Michailowitsch Molotow in der Phase der deutsch-sowjetischen Allianz zusammen, in der sie Osteuropa unter sich aufgeteilt hatten. Zum anderen soll das Denkmal ganz bewusst die zukünftige Stiftung Flucht, Vertreibung, Versöhnung >kommentieren $<{ }^{83}$ Der Initiator der Idee, der Stadtplaner Florian Mausbach, äußerte sich dazu entsprechend:

»Wenn das polnische Denkmal [der Stiftung, V. R.] gegenübersteht, wird niemand zweifeln, wer das wahre Opfer war [...]. ${ }^{84}$

Von Seiten der Stiftung Flucht, Vertreibung, Versöhnung gab es bislang noch keinen offiziellen Kommentar hierzu. Der BdV positionierte sich positiv gegenüber der Einrichtung eines solchen Denkmales, fordert jedoch eine sinnvolle Integration in das Gedenkstättenkonzept des Bundes und einen vergleichbaren Gedenkort für die deutschen Nachkriegsopfer polnischer Gewalt in Polen, beispielsweise in den Lagern Lamsdorf/Łambinowice, Eintrachthütte/Zgoda oder Potulitz/Potulice. ${ }^{85}$ An der Basis des BdV reagierte man wesentlich kritischer: Die Unterstützung der Denkmalsinitiative durch Bernd Fabritius wird ebenso wie das Vorhaben an sich als eine »Provokation der Vertriebenen betrachtet. $^{86}$

Im Juli 2018 wurde die Überlegung publik, das private Exilmuseum hinter der Ruine des Anhalter Bahnhofs zu errichten. Inhaltlich steht das Exil zur Zeit des Nationalsozialismus im Mittelpunkt, auch wenn der Blick darüber hinaus unter anderem auf heutige Schicksale ausgeweitet werden soll. Nach der Vorstellung der Planer passt die räumliche Nähe zur SFVV ebenso wie zur Topographie des Terrors auch inhaltlich hervorragend. Gundula Bavendamm begrüßte den Vorschlag. ${ }^{87}$

Mit diesen Vorhaben deutet sich ein vielfältiges museales und erinnerungsarchitektonisches Ensemble um den Askanischen Platz an, das die SFVV rahmen und kommentieren wird.

Deutschen gegenüber ihrem östlichen Nachbarn Polen: Lehnstaedt: Die Nachbarn verstehen lernen. Der Tagesspiegel. 02.08.2018.

83 Vgl. Ruchniewicz: Wozu noch ein zusätzliches Denkmal in Berlin, und dann ausgerechnet ein Polen-Denkmal? Dialog Forum. 22.02.2018.

84 »Cdy naprzeciw stanie polski pomnik, nikt nie będzie miał wątpliwości, kto był prawdziwą ofiarą [...].« Wieliński: Niemcy chcą postawić pomnik Polakom zamordowanym podczas drugiej wojny światowej. Cazeta Wyborcza. 07.11.2017.

85 Pressemitteilung vom Bund der Vertriebenen: Denkmal für polnische Opfer als Mosaikstein der grenzüberschreitenden Verständigung. 15.11.2017.

86 So der Vorsitzende der Kreisgruppe Bergstraße der Landsmannschaft Schlesien Winfried Labatz: Viel Cold und Silber bei den Schlesiern. Echo. 03.05.2018.

87 Abel: Exilmuseum soll am Anhalter Bahnhof entstehen. Berliner Morgenpost. 07.07.2018. Kuhn: Wo Bertolt Brecht den Zug bestieg. Der Tagesspiegel. 19.07.2018. Vgl. Morat; Zündorf: Ceschichtspolitik im Museum, 2019. 


\subsubsection{Struktur und Aktivitäten}

Das am 30. Dezember 2008 in Kraft getretene Gesetz zur Errichtung einer Stiftung "Deutsches Historisches Museum (DHMG) bestimmt das für diesen Zweck selbst in eine rechtsfähige bundesunmittelbare Stiftung umgewandelte Deutsche Historische Museum (DHM) zum Träger der unselbstständigen Stiftung Flucht, Vertreibung, Versöhnung. ${ }^{88}$

Unter Paragraph 16, Abschnitt 2, werden der Stiftungszweck sowie die für dessen Erfüllung notwendigen Schritte formuliert. An erster Stelle soll die Einrichtung einer Dauerausstellung erfolgen, die Flucht und Vertreibung im 20. Jahrhundert in ihrem historischen Kontext und ihrer europäischen Dimension sowie die daraus resultierenden Folgen darstellt. Einzelausstellungen sollen spezielle Aspekte der Gesamtthematik beleuchten. Ebenso sollen aktuelle wissenschaftliche Erkenntnisse vorgestellt und diskutiert sowie die Sammlung und Auswertung »einschlägiger Unterlagen und Materialien, insbesondere von Zeitzeugenberichten «, durchgeführt werden. Die erwünschte Zusammenarbeit mit anderen Museen und Forschungseinrichtungen in Deutschland und in Europa ist ebenfalls im Gesetz verankert. Die Formulierung zur »europäischen Dimension « ist so offen gehalten, dass sie die Frage nicht eindeutig beantwortet, ob damit eine >Rundschau über die Zwangsmigrationsbewegungen Europas vorgenommen oder doch ein Fokus auf die europäischen Erfahrungen des Zweiten Weltkrieges und darunter die Vertreibung der Deutschen gesetzt werden soll. ${ }^{89}$

Die Unselbstständigkeit der Stiftung gewährleistet eine gewisse Kontrollfunktion des DHM. Ein in der neuen Fassung der Satzung aus 21 Persönlichkeiten bestehender Stiftungsrat soll das Erreichen der Stiftungsziele durch eine breite gesellschaftliche Aufstellung sichern. Seine Mitglieder müssen von den jeweiligen Institutionen entsandt und vom Bundestag bestätigt werden. Der Stiftungsrat setzt sich wie folgt zusammen:

- vier Mitglieder des Deutschen Bundestages,

- ein Mitglied des Auswärtigen Amtes,

- ein Mitglied des Bundesministeriums des Innern,

- die Beauftragte der Bundesregierung für Kultur und Medien,

- sechs Mitglieder des BdV,

- zwei Mitglieder der evangelischen Kirche,

- zwei Mitglieder der katholischen Kirche,

- zwei Mitglieder des Zentralrates der Juden in Deutschland,

- Präsident der Stiftung »Deutsches Historisches Museum«,

- Präsident der Stiftung »Haus der Geschichte der Bundesrepublik Deutschland «"${ }^{90}$

88 Deutscher Bundestag: Gesetz zur Errichtung einer Stiftung »Deutsches Historisches Museum« (DHMG). 21.12.2008, Fassung vom 14.06.2010.

89 Vgl. Völkering: »Flucht und Vertreibung« ausstellen - aber wie? 2011, S. 7-11.

90 Vgl. für die aktuelle Besetzung: https://www.sfvv.de/de/stiftung/stiftungsrat (letzter Zugriff: 23.03.2018). Die Präsidenten des DHM und des HdG sind geborene Mitglieder des Stiftungsrates. 
Der bis zu 15 Mitglieder umfassende Wissenschaftliche Beraterkreis soll dazu beitragen, dass »die historischen Ereignisse ausgewogen und geschichtswissenschaftlich fundiert sowie lebendig, umfassend und anschaulich« dargestellt werden. Durch eine erwünschte internationale Zusammensetzung dieses Kreises - unter anderem mit Vertretern aus Polen und Tschechien - soll eine multiperspektivische Gestaltung der Stiftungsarbeit gewährleistet werden. ${ }^{91}$ Die SFVV ist wie das Schlesische Museum zu Görlitz und das Sudetendeutsche Museum in München Teil der Kultur- und Wissenschaftsförderung nach Paragraph 96 Bundesvertriebenengesetz (BVFG). ${ }^{92}$

Die Finanzierung der Umbaukosten des Deutschlandhauses in Höhe von derzeit 53 Millionen Euro (wobei nur etwa 50 Prozent des renovierten und umgebauten Hauses von der Stiftung genutzt werden) sowie 8,6 Millionen Euro für die Initiationskosten und die Dauerausstellung trägt der Bund, ebenso wie die derzeit veranschlagten ungefähr fünf Millionen Euro für den jährlichen Haushalt der Stiftung. ${ }^{93}$

Die Fläche der Dauerausstellung wird etwa 1700 Quadratmeter betragen, für Sonderausstellungen sind ungefähr 400 Quadratmeter vorgesehen. ${ }^{94}$ Nach der Eröffnung sollen wenigstens fünf Wissenschaftliche Mitarbeiter, darunter die Direktorin, ebenso wie eine Mitarbeiterin für Öffentlichkeitsarbeit, eine Bibliothekarin, ein Archivar, ein Registrar, ein Volontär sowie ein Museumspädagoge die laufende Arbeit der Stiftung gewährleisten. Für die Ausstellungsvorbereitung sind weitere Kuratorinnen und Kuratoren engagiert. ${ }^{95}$

Die Stiftung kann auf keine ältere Sammlung zurückgreifen und befindet sich daher im Bestandsaufbau. Schenkungen, Leihgaben und Ankäufe sollen das gesamte Spektrum von Zwangsmigration abbilden, ebenso wie Zeitzeugengespräche in ganz Europa geführt und gesammelt werden. ${ }^{96}$ Das in materieller und fotografischer Hinsicht vergleichsweise schlecht bis kaum dokumentierte historische Ereignis von Flucht und Vertreibung darzustellen, stellt die Stiftung in besonderem Maße vor die Herausforderung aller Museen, die sich mit diesem Thema befassen. ${ }^{97}$

Als künftige Zielgruppen für die Arbeit der Stiftung sind alle Bevölkerungsgruppen in Deutschland ebenso wie ausländische Besucher anvisiert. Neben speziellen Angebo-

Vgl. für die aktuelle Besetzung des wissenschaftlichen Beraterkreises: https://www.sfvv.de/de/stiftung/wissenschaftlicher-beraterkreis (letzter Zugriff: 23.03.2018).

92 Vgl. Kap. 5.1, S. 219f.

93 Bei diesen geschätzten künftigen 5 Millionen Euro fällt als Haushaltsposten vor allem die Miete in Höhe von etwa 2 Millionen an die Bundesanstalt für Immobilien ins Cewicht: Beikler: Deutschlandhaus in Berlin wird 16 Millionen Euro teurer. Der Tagesspiegel. 14.10.2016. Der künftige Finanzrahmen ist aber im April 2018 noch nicht festgelegt worden; das derzeitige Haushaltsbudget ist weiter mit 2,566 Millionen Euro angesetzt.

Regente: Stiftung Flucht, Vertreibung, Versöhnung, 2017.

$95 \mathrm{Vgl}$. für die aktuelle Stellenbesetzung der SFVV: www.sfvv.de/de/stiftung/stiftungsteam (letzter Zugriff: 05.03.2018). Anfang 2020 hat sich das Team deutlich vergrößert. So stehen der Stiftung im Januar 2020 unter anderem sechs Kuratorinnen und Kuratoren, ein »Projektleiter Dauerausstellung«, zwei Mitarbeiter für den Bereich »Dokumentation und Forschung« sowie zwei Mitarbeiter für das Feld »Bildung und Vermittlung« zur Verfügung. Vgl. für den Stand am 31.12.2012: Stiftung Flucht, Vertreibung, Versöhnung: Jahresbericht 2009-2012, 2012, S. 50. 
ten für Schulen soll ein durchgängig mehrsprachiges Angebot ausländische Besucher, insbesondere aus dem osteuropäischen Raum, zum Besuch einladen. ${ }^{98}$ Verstärkt wird die Frage gestellt, wie nach dem Ableben der deutschen Zeitzeugen von Flucht und Vertreibung beispielsweise deren Nachkommen ein attraktives Angebot gemacht werden kann. ${ }^{99}$ In der Stuttgarter Zeitung hieß es Anfang 2018 in Hinblick auf die notwendige Zielsetzung der Stiftung:

»Bavendamm und ihr 23-köpfiges Team aus Historikern, Archivaren und Kuratoren müssen nun also sowohl deutlich machen, dass die Stiftung snicht der Dienstleister des Bundes der Vertriebenen< ist, als auch ihr Haus so aufstellen, dass es vor allem junge Besucher anspricht, deren Zugang zum Thema die Gegenwart und die aktuellen Wanderungsbewegungen sind. Bavendamm weiß: Der Museumsmarkt in Berlin ist heiß umkämpft. Das Dokumentationszentrum mit Dauer- und Wechselausstellung, Bibliothek und Veranstaltungsräumen muss eine einprägsame Marke werden. « ${ }^{100}$

Die gegenwärtige Planung der Stiftung identifiziert schließlich verschiedene Zielgruppen, von der »Erlebnisgeneration «, die »mit sehr fundierten Kenntnissen und gezielten Interessen« das Haus besuchen wird, bis zum 15jährigen Schüler, dem der Begriff Vertreibung vielleicht nur vom Hörensagen bekannt ist. Alle Zielgruppen sollen »jeweils adäquat« angesprochen werden. Als Richtwert für künftige Besucherzahlen, der sich an vergleichbaren Bundeseinrichtungen und »der Relevanz und der Aktualität des Themas, der zentralen Lage in der Stadt und der räumlichen Nähe zu anderen wichtigen Einrichtungen« wie der Topographie des Terrors oder dem Mahnmal für die ermordeten Juden Europas orientiert, gibt Bavendamm 150.000 an. ${ }^{101}$

Der Ort der künftigen Dauerausstellung, das Deutschlandhaus am Anhalter Bahnhof in Berlin, blickt selbst auf eine wechselhafte Geschichte seit den 1920er Jahren zurück. ${ }^{102} \mathrm{Ab}$ den $1950 e r$ Jahren beherbergte es die Büros verschiedener Landsmannschaften des BdV. Das gegenüberliegende Fragment des im Zweiten Weltkrieg zerstörten Anhalter Bahnhofs wird als symbolisch für die Vernichtungen und die mit diesem Ort verbundenen Bevölkerungsverschiebungen im Zweiten Weltkrieg betrachtet und so eine Verknüpfung des Stiftungsauftrages mit Haus und Umgebung geschaffen. ${ }^{103}$ Eine auch räumliche Verbindung mit dem NS-Kontext der Thematik ergibt sich aus der zumindest in den anfänglichen Planungen vorgesehenen Sichtachse aus der Dauerausstellung auf die Topographie des Terrors. ${ }^{104}$

98 Kittel et al.: Konzeption, 2012, S. 13.

99 Vgl. zur Zielgruppenproblematik auch: Völkering: »Flucht und Vertreibung « ausstellen - aber wie? 2011, S. 8. Helga Hirsch betont, dass auch die Kinder und Enkel der Vertriebenen noch einen Ort zur Beschäftigung mit den traumatischen Erlebnissen ihrer Vorfahren benötigen: Hirsch: Flucht und Vertreibung, 2003, S. 23.

100 Lorenz: Weiterleben ohne Heimat. Stuttgarter Zeitung. 19.01.2018.

101 Mail von Gundula Bavendamm an den Autor: Bavendamm: Stiftung Flucht, Vertreibung, Versöhnung: Antworten auf Ihre Fragen, 27.06.2018.

102 Vgl. Stiftung Flucht, Vertreibung, Versöhnung: Jahresbericht 2009-2012, S. 14.

103 Vgl. Douglas: „Ordnungsgemäße Überführung«, 2012, S. 444.

104 Kellerhoff: Vertriebenen-Stiftung blickt zur Gestapo-Zentrale. Die Welt. 30.11.2011. Siehe zur räumlichen Umgebung und der Geschichte des Hauses auch die Überlegungen im Konzeptionspapier der SFVV: Kittel et al.: Konzeption, 2012, S. 13. 
Gundula Bavendamm versteht die Stiftung Flucht, Vertreibung, Versöhnung als »eine Art von Hybrid«. Sie soll als Forschungseinrichtung und als Dokumentationszentrum ebenso wie als Ort dienen, an dem eines persönlichen Schicksals und der tragischen Ereignisse gedacht werden kann. Für letzteres ist ein geplanter »Raum der Stille« vorgesehen. ${ }^{105}$

Nach Fertigstellung der Dauerausstellung sollen jährlich mehrfach Sonderausstellungen der Stiftung aus dem weiteren Themenfeld der Zwangsmigration in Geschichte und Gegenwart erfolgen. Bisher beteiligte sich die SFVV 2012 nach einem erfolgreichen internationalen Sammlungsaufruf an der 7. Berlin Biennale mit einer Präsentation von 100 Objekten, ${ }^{106}$ 2013/14 präsentierte sie eine Open-Air-Ausstellung vor dem Deutschlandhaus, 2014/15 erfolgte die oben diskutierte Präsentation der angeworbenen Wanderausstellung zu globalen Zwangsmigrationen (»Twice a Stranger«) im Verbund mit der eigenen Werkstattausstellung (»Gewaltmigration erinnern«) im Deutschen Historischen Museum. ${ }^{107}$

Die SFVV ist bereits mit mehreren Publikationen an die Öffentlichkeit getreten. Drei Tagungsbände wurden von ihr (mit-)verantwortet, so 2010 zur Musealisierung von Zwangsmigration, ${ }^{108} 2013$ gemeinsam mit der Stiftung Denkmal für die ermordeten Juden Europas zur jüdischen Geschichte im preußischen Osten ${ }^{109}$ und 2016 zusammen mit dem Donauschwäbischen Zentralmuseum in Ulm zum Schicksal der deutschen Bevölkerungsgruppe Jugoslawiens während und nach dem Zweiten Weltkrieg ${ }^{110}$.

Die Stiftung verfügt über ein umfassendes Archiv mit einem Schwerpunkt auf Zeitzeugenberichten sowie eine wissenschaftliche Spezialbibliothek $\mathrm{zu}$ ihrem weiteren Themenkomplex. Beide Einrichtungen stehen Besuchern zur wissenschaftlichen oder persönlichen Nutzung zur Verfügung. Seit 2010 veranstaltet die SFVV Vorlesungen, Symposien, Tagungen, Zeitzeugengespräche, Buchvorstellungen und Filmvorführungen, unter anderem in Kooperation mit der Stiftung Topographie des Terrors, der Stiftung Denkmal für die ermordeten Juden Europas, der Stiftung Neue Synagoge Berlin - Centrum Judaicum und der Humboldt-Universität zu Berlin. Einige Veranstaltungen waren auch politisch aktuellen Themen wie der Situation der Krim-Tataren während der Krimkrise im Jahr 2014 gewidmet. ${ }^{111}$

105 Beraterkreis für Stiftung Flucht und Vertreibung ohne Polen. rbb. 17.10.2016.

106 Stiftung Flucht, Vertreibung, Versöhnung: Jahresbericht 2009-2012, S. 8.

107 Regente: Stiftung Flucht, Vertreibung, Versöhnung, 2017.

108 Deutsches Historisches Museum; International Association of Museums of History et al. (Hg.): Flucht, Vertreibung, Ethnische Säuberung, 2010.

109 Stiftung Flucht, Vertreibung, Versöhnung; Stiftung Denkmal für die ermordeten Juden Europas (Hg.): »Das war mal unsere Heimat ...«, 2013.

110 Stiftung Flucht, Vertreibung, Versöhnung; Donauschwäbisches Zentralmuseum (Hg.): Vom »Verschwinden« der deutschsprachigen Minderheiten, 2016.

111 Vgl. das Veranstaltungsarchiv auf der Website der SFVV: www.sfvv.de/de/veranstaltungen/archiv (letzter Zugriff: 03.03.2018). 


\subsubsection{Anspruch und Selbstverständnis}

Aus den vorherigen Diskussionen, den Einwänden und Kommentaren aus Polen und Tschechien sowie der gesetzlichen Grundlage leiten sich eine Reihe von Ansprüchen an die künftige Arbeit und das Selbstverständnis der SFVV und ihrer Dauerausstellung ab.

Von linksliberaler Seite in Deutschland wird immer wieder betont, dass die Stiftung nicht in Konfrontation zu Deutschlands Nachbarstaaten und dem zentralen Element der bundesdeutschen Erinnerungskultur, der selbstkritischen Holocaust-Erinnerung, treten darf. Dafür sei eine Beteiligung polnischer und tschechischer Wissenschaftler und die konsequente Herausstellung der deutschen Kriegsschuld und der daraus folgenden deutschen Gewaltherrschaft als Ursache der späteren Flucht- und Vertreibungsbewegungen nötig.

Aus dem Umfeld der CDU/CSU wird stärker unterstrichen, dass die deutschen Vertriebenen ein Recht auf einen eigenen Erinnerungsort haben und damit, wie Angela Merkel es 2013 formulierte, eine gesamtdeutsche Erinnerungslücke geschlossen wird. Dieses Argument betont ähnlich deutlich den NS-Kontext der Vertreibungen, auch wenn man den deutschen Vertreibungsopfern prononcierter einen eigenständigen und dadurch nicht zu relativierenden Opferstatus zugesteht. ${ }^{112}$

Die im Kapitel 5.1 diskutierte Forderung, dass die Stiftung sich verstärkt auch für Fragen gegenwärtiger Zwangsmigrationen öffnen soll, stößt bei Teilen der Vertriebenen und ihrer Nachfahren auf Kritik. ${ }^{113}$ Die AfD kritisierte im Bundestag eine vermeintliche Neuausrichtung am Beispiel eines Faltblattes der SFVV, in dem diese unter anderem auf Arabisch und Persisch für die Einsendung von Fluchtgeschichten wirbt. ${ }^{114}$

Die Vorstellungen des BdV wurden im Zuge seiner Zentrumsinitiative seit 1999 schon im Kapitel 5.1 ausführlich besprochen. Durch eine Einordnung von Flucht und Vertreibung der Deutschen in die Zwangsmigrationsgeschichte Europas sowie das Aufkommen des Ethnonationalismus wird eine multikausale Erklärung für das Geschehen konstatiert. Damit soll das Argument unterstrichen werden, dass die Vertreibungen ein Unrecht darstellen, das nicht ausschließlich mit dem vorherigen deutschen Unrecht $\mathrm{zu}$ erklären oder zu rechtfertigen ist und so die Alliierten, Polen und Tschechien erinnerungskulturell in die Verantwortung mit einbezieht. Außerdem handele es sich um ein universelles Unrecht, womit die Vertriebenenverbände ihren Status als international anerkannte Opfergruppe unterstreichen wollen. ${ }^{115}$ Überlegungen oder Befürchtungen, dass die Ausrichtung der Stiftung geändert und der Schwerpunkt auf der Vertreibung der Deutschen fallen gelassen werden könnte, verfolgt der BdV nach Bernd Fabritius

112 Vgl. hierfür nochmals: Rede von Bundeskanzlerin Merkel bei Baubeginn eines Dokumentationszentrums der Stiftung Flucht, Vertreibung, Versöhnung im Deutschlandhaus am 11. Juni 2013.

113 Vgl. Kap. 5.1, S. 215-217.

114 Vgl.die Aufzeichnung seiner Rede im Bundestag auf dem YouTube-Kanal des AfD-Abgeordneten Stephan Protschka vom 27.06.2019: Protschka: Deutsche Kultur nicht ins Museum packen! 2019. Das Faltblatt ist in seinen verschiedenen Sprachfassungen auf der Website der SFVV abrufbar: https://www.sfvv.de/de/aufruf-zur-sammlung-von-zeitzeugenberichten (letzter Zugriff: 28.01.2020)

115 Vgl. Völkering: Von der privaten Stiftung »Zentrum gegen Vertreibungen« zur Bundesstiftung »Flucht, Vertreibung, Versöhnung«, 2011, S. 132. 
aufmerksam und wird bei Verdacht »allergisch « darauf reagieren. ${ }^{116}$ Zusätzlich kommt es zu einer rhetorischen Vereinnahmung der SFVV durch den BdV. ${ }^{117}$ Nicht zu Unrecht wird die Grundlage ihrer Entstehung der Zentrumsinitiative von Erika Steinbach zugerechnet, dabei aber die im Vergleich zum ZgV starke Unabhängigkeit der SFVV vom BdV mitunter zu wenig beachtet. ${ }^{118}$

Aus der Perspektive der deutschen Regierungen seit 2002/2005 muss die Stiftung gerade in dieser Hinsicht Vorsicht walten lassen, würde ein zu großer Einfluss des BdV, ebenso wie die Verfolgung seiner oben genannten Argumentationslinie, doch einen, nicht nur außerhalb Deutschlands skeptisch betrachteten, deutschen Opferstatus hervorheben. Zudem könnten auch die Darstellung der Entscheidungen der Alliierten über die Vertreibungen sowie die Überlegungen und Handlungen der tschechoslowakischen und polnischen Regierung und Bevölkerung als anklagend verstanden werden. Daher müssten die vorherigen, gerade in Polen und Tschechien begangenen, deutschen Verbrechen in der künftigen Dauerausstellung betont und bei der Darstellung deutschen Leidens jede - im Ausland fast zwangsläufig missverstandene - einseitige Anklage vermieden werden. ${ }^{119}$

Damit sind auch die wesentlichen Anforderungen an die Arbeit der SFVV aus der Sicht Polens und Tschechiens genannt. Darüber hinaus erscheinen aus polnischer Perspektive die Hinweise auf die Vertreibungen der Polen durch Deutsche ebenso wie im Anschluss durch die Sowjetunion, als notwendiger Bestandteil einer Erzählung über Zwangsmigrationen des Zweiten Weltkrieges. Weiter wird in Polen wie in Tschechien gefordert, die nationalsozialistische Vergangenheit des BdV und der jungen Bundesrepublik zu thematisieren. ${ }^{120}$ Die Kooperation von Nationalsozialismus und Kommunismus im Rahmen des Hitler-Stalin-Paktes sowie die doppelte, beiderseitig verbrecherische Besatzungszeit Polens darzustellen, fordert auch das liberale polnische Lager. ${ }^{121}$

116 Vgl. hier die Äußerungen des BdV-Präsidenten Bernd Fabritius: Brand; Plewnia: Ende des Misstrauens. FOCUS Magazin. 12.03.2016.

117 Vgl. hier z.B. die Redebeiträge des BdV-Präsidenten Bernd Fabritius, bei denen dieser die SFVV in der »Wir«-Form vorstellt und verteidigt: Bundesinstitut für Kultur und Geschichte der Deutschen im östlichen Europa: Erinnerung bewahren - Zukunft gestalten, 2017, S. 51. Erika Steinbach formulierte es noch deutlicher: »Die Bundesstiftung [...] ist unser gemeinsames Kind. Wir werden es fürsorglich, liebevoll, aber auch streng und hartnäckig begleiten. Und wir werden sie mit Herzblut gegen alle verteidigen, die sie verwässern, banalisieren oder umdeuten wollen«: Steinbach: Die Macht der Erinnerung, 2010, S. 109.

118 In ihrer Rede zum Umbau des Deutschlandhauses betont Bundeskanzlerin Angela Merkel: „Sie, liebe Frau Steinbach, haben vor vielen Jahren [...] den Anstoß für einen zentralen Dokumentationsund Erinnerungsort gegeben. Seitdem haben Sie das Projekt beharrlich und geduldig verfolgt. Seine Umsetzung ruht nun auf einer Reihe von Schultern. Sie ist und bleibt aber vor allem Ihr Erfolg [...].«Rede von Bundeskanzlerin Merkel bei Baubeginn eines Dokumentationszentrums der Stiftung Flucht, Vertreibung, Versöhnung im Deutschlandhaus am 11. Juni 2013. Haar: Der deutsche Angriff auf Polen 1939 und die Folgen des Zweiten Weltkriegs, 2015, S. 304.

120 Wieliński: Bez skandalu w muzeum wypędzonych. Gazeta Wyborcza. 20.11.2014.

121 Wieliński: Muzeum wyciszy spór o wypędzonych. Gazeta Wyborcza. 31.08.2012. Wieliński: Niemcy+Polska=WNM. Gazeta Wyborcza. 16.06.2015. Wieliński beruft sich hier auf die von der SFVV organisierte Meinungsumfrage in Deutschland, Polen und Tschechien, in der auch aus der deutschen Bevölkerung eine Thematisierung der den Vertreibungen vorausgehenden deutschen Besatzungszeit gefordert wird. 
Die schon erörterte grundsätzliche Kritik an dem Vorhaben konnte bis dato nicht ausgeräumt werden.

Die Stiftung steht folglich vor der Herausforderung, den verschiedenen Ansprüchen gerecht zu werden und nach Polen und Tschechien hin anschlussfähig zu sein. Monika Grütters spricht in Hinblick auf die Schwerpunktsetzung der Stiftung von einer "salomonischen Lösung «, in der die Flucht und Vertreibung der Deutschen für die Stiftungsarbeit einen, in der Dauerausstellung dagegen den Schwerpunkt darstellt. ${ }^{122}$ In einem Interview verortetet Gundula Bavendamm die Stiftung an der »Nahtstelle zwischen Opfer- und Täterdiskurs«, welche sowohl innen- als auch außenpolitisch eine erhebliche »Brisanz « berge, die für die Museumsarbeit eine ganz eigene Herausforderung darstelle. ${ }^{123}$ Das Selbstverständnis der Stiftung in Bezug auf die künftige Dauerausstellung wird in den Leitlinien des Konzeptionspapieres von 2017 zusammengefasst:

»Die Präsentation erinnert besonders an Vertreibung und Flucht der Deutschen und ordnet diese doppelt ein: im ersten Ausstellungsteil mittels einer europäischen Perspektive auf Zwangsmigrationen vor allem im 20. Jahrhundert und im zweiten Ausstellungsteil durch die Einbettung in den Kontext des Zweiten Weltkriegs und die NS-Expansions- und Vernichtungspolitik. Auch der dritte Teil über die Ceschichte der Flüchtlinge und Vertriebenen nach 1945 ist einer europäischen Perspektive verpflichtet. Ein wichtiges Anliegen ist es zu zeigen, dass zwischen Zwangsmigration und Cenozid ein kategorialer Unterschied besteht. Cleichwohl macht die Ausstellung deutlich, dass beide Phänomene in ihrer historischen Cenese Verbindungen aufweisen. Die grundsätzliche Haltung der Stiftung im Hinblick auf Verständigung, Multiperspektivität und Versöhnung kommt im Ausstellungskonzept auf verschiedene Weise zum Tragen: durch eine konsequente Historisierung eines kontroversen Themas im Sinne einer ausbalancierten Cesamterzählung; durch die gegenwartsorientierte und lebensweltliche Vermittlung von Schlüsselthemen und universellen Fragen; durch die explizite Sichtbarmachung unterschiedlicher Haltungen und Kontroversen und durch die Darstellung von konkreten Beispielen für Versöhnungshandeln in Geschichte und Gegenwart. $\ll^{124}$

\subsubsection{Konzeptionspapier 2017 - Die geplante Dauerausstellung}

Die Stiftung Flucht, Vertreibung, Versöhnung empfängt den künftigen Besucher im oben beschriebenen Deutschlandhaus. Die moderne Ausstellungsarchitektur erforderte eine völlige Entkernung des Gebäudes, sodass lediglich die denkmalgeschützte Fassade erhalten geblieben ist. Der für die Stiftung vorgesehene Bereich wird unter Leitung des Marte.Marte Architekten-Büros (Weiler/Österreich) architektonisch entwickelt: Die Bauart soll sich durch Weitläufigkeit, Lichtdurchflutung sowie ein Spiel mit der Materialität

122 Brand; Plewnia: Ende des Misstrauens. FOCUS Magazin. 12.03.2016.

123 Dittrich: Neue Leitung, neue Hoffnung? Deutschlandfunk. 31.03.2016.

124 Stiftung Flucht, Vertreibung, Versöhnung: Konzept für die Dauerausstellung, 2017, S. 6. 
auszeichnen. ${ }^{125}$ Den für das Erdgeschoss geplanten »Raum der Stille« gestaltet das Büro Königs Architekten (Köln), die Ausstellungsarchitektur selbst wird gemeinsam mit dem Atelier Brückner (Stuttgart) entwickelt und umgesetzt. ${ }^{126}$

Bei der hier vorgestellten Ausstellungskonzeption von 2017 handelt es sich um eine Weiterentwicklung und Konkretisierung des Konzeptionspapieres von 2012. Eine grundlegende Verschiebung des Schwerpunktes der Dauerausstellung auf Flucht und Vertreibung der Deutschen findet nicht statt. Angepasst wird der ursprüngliche chronologische Ansatz hin zu einer »thematisch-chronologischen Struktur «. ${ }^{127}$ Einzelne Bereiche sind wiederum »geographisch-räumlich gegliedert«, um Unterschiede, aber auch Verbindungen und Parallelen aufzuzeigen. ${ }^{128}$

Die Ausstellung soll auf zwei Etagen verteilt und in drei inhaltlich und inszenatorisch miteinander verbundene Ausstellungsteile gegliedert werden. Auf der ersten Etage wird unter dem Arbeitstitel »Das Jahrhundert der Flüchtlinge - Zwangsmigrationen in Europa« (1.) mit einem historischen Überblick in das Phänomen Flucht und Vertreibung eingeführt. In Form von »Themeninseln« wird eine Diskussion von Ideen-, Begriffs-, Diskurs-, Rechts- und Ereignisgeschichte vorgenommen. Bei letzterer sollen Phänomene besprochen werden, die fast allen Zwangsmigrationsprozessen eigen sind, so Gewaltakte und verschiedene Formen des Lagerwesens. Hierfür sind 600 Quadratmeter vorgesehen. Auf der zweiten Etage werden auf 700 Quadratmetern die beiden weiteren Kapitel der Ausstellung entfaltet: 2. »Flucht und Vertreibung der Deutschen im europäischen Kontext « und 3. »Vertriebene und Flüchtlinge in Deutschland seit 1945« (beides Arbeitstitel). Im zweiten Oberkapitel werden zunächst die nationalsozialistische deutsche >Rassen $<$, Expansions- und Vernichtungspolitik sowie die sowjetischen Deportationen während des Zweiten Weltkrieges thematisiert. Darauf folgen die Planungen der Alliierten und der Exilregierungen für eine ethnische Nachkriegsordnung Europas. Evakuierungen und Flucht der Deutschen 1944/45 sollen regional untergliedert und von der anschließend behandelten »ethnisch-territorialen Neuordnung Ostmittelund Südosteuropas« getrennt dargestellt werden. Hier sind die 'wilden und organisierten Vertreibungen erneut regional oder nach Staaten angefügt. Im dritten Kapitel wird die Integrationsgeschichte der Deutschen nach 1945 ausgestellt. Die Geschichte der organisierten Vertriebenen soll hier ebenso Platz finden wie ihr individuelles Engagement und die bundesdeutsche Streitgeschichte über die ১Ostpolitik^ der Regierung Brandt. Ein Ausblick erfolgt mit der Besprechung der Erinnerungsgeschichte und ihres Wandels. $^{129}$

Der ausstellungsgestalterische Kunstgriff und gleichzeitig eine besondere Herausforderung der Museumsgestaltung wird die geplante »wechselseitige Verbindung der Ausstellungsetagen« sein. Diese Verschränkung, die Überblick und »exemplarische Vertiefung« gewährleisten soll, hat zum Ziel, die Ausstellung für ein »heterogenes Publikum« individuell besuchbar zu machen. Das bedeutet, sie möchte »den verschiedenen

Vgl. die kurze Beschreibung der Architektur auf der Website der SFVV: https://www.sfvv.de/de/k\% C3\%BCnftiges-dokumentationszentrum/architektur-martemarte (letzter Zugriff: 23.03.2018).

126 Regente: Stiftung Flucht, Vertreibung, Versöhnung, 2017.

127 Stiftung Flucht, Vertreibung, Versöhnung: Konzept für die Dauerausstellung, 2017, S. 4.

128 Ebd., S. 8.

129 Vgl. für die detaillierte Gliederung des Konzeptpapieres: ebd., S. 10. 
Zielgruppen und Interessenlagen entgegen « kommen und so Besucher oder Besuchergruppen ansprechen, die sich beispielsweise primär für einen thematischen Überblick oder vor allem für die Vertreibung der Deutschen interessieren. Dennoch soll durch die geschickte Verzahnung der verschiedenen Ausstellungsteile ein sinnvolles Ganzes konstituiert werden. Zudem will diese >mehrfache Begehbarkeit $<$ der Ausstellung modernen museumsdidaktischen Ansprüchen genügen und alle Ausstellungsteile sollen »an aktuelle schulische Lehrpläne anknüpfen«. Die Verbindung von »Überblick und exemplarischer Vertiefung « wird museumsdidaktisch als besonders wertvoll für die »historischpolitische Urteilsbildung « der Besucher erachtet. ${ }^{130}$

Gestalterisch soll sich die geplante Ausstellung aus medialen Inszenierungen (vor allem im ersten Obergeschoss), Originalobjekten (zentral im zweiten Obergeschoss) und mit diesen verbundenen biografischen, »erfahrungsgeschichtlichen Erzählansätzen« zusammensetzen und so individuelle Zugänge aufzeigen, Multiperspektivität gewährleisten und unterschiedliche »Interessen, Motive und Handlungsspielräume« herausarbeiten. Vorgestellte Biografien einzelner Menschen weisen dazu »zeitlich und thematisch über das Kernthema« hinaus. Die ausgestellten Exponate setzen sich aus »dreidimensionalen Objekten, Erinnerungsberichten, Ego-Dokumenten und Zeitzeugeninterviews « zusammen. ${ }^{131}$

Die Planungen sehen vor, dass sowohl ein multiperspektivischer Ansatz anhand einzelner Exponate verfolgt wie auch Besucher durch »interaktive Stationen [...] zum Mitmachen« angeregt werden. Zudem sollen »die Erfahrungsebene angesprochen und somit lebensweltliche Bezüge hergestellt und historische Orientierung« geboten werden. Die gesamte Ausstellung mit ihren verschiedenen Vermittlungstechniken soll dem Besucher »ein partizipatives Ausstellungserlebnis [...] ermöglichen. ${ }^{132}$

Der Besucher wird die künftige Dauerausstellung über eine in das erste Obergeschoss führende monumentale Treppe erreichen. Dort »öffnet sich ein weitläufiger, stützenloser Raum«, in dem das erste Kapitel der Ausstellung »Das Jahrhundert der Flüchtlinge - Zwangsmigrationen in Europa« mit seinen verschiedenen Themeninseln zur freien Begehung einlädt. ${ }^{133}$

Zunächst soll der Blick auf eine multimediale Installation gelenkt werden, die in Form »dynamischer Karten, Animationen und Erklärfilmen« die Dimensionen und Vielfalt von Zwangsmigrationen im Europa des 20 . Jahrhunderts darstellen wird. ${ }^{134}$ Als »konstitutives « Element europäischer Geschichte werden in diesem Überblick die verschiedenen Formen von Zwangsmigrationen präsentiert und differenziert: Evakuierungen, Flucht, Vertreibungen, Zwangsaussiedlungen und Deportationen. Hier soll der Unterschied zwischen >ethnischer Säuberung« (die als vergleichsweise neuer Terminus eingeführt wird) und Genozid aufgeschlüsselt werden, ohne die »teilweise fließenden« Grenzen auszuklammern. Dies wird anhand der Beispiele des Völkermordes an den

130 Stiftung Flucht, Vertreibung, Versöhnung: Konzept für die Dauerausstellung, 2017, S. $6 f$.

131 Ebd., S. 8f.

132 Ebd., S. 9.

133 Ebd., S. 7.

134 Ebd. Siehe als Beispiel für eine solche dynamische Karte: Imagefilm der Stiftung Flucht, Vertreibung, Versöhnung, 2017, Minute: 00:38-01:02. 
Armeniern und des Holocausts diskutiert. Es ist geplant, den räumlichen Schwerpunkt auf Europa, genauer auf Ost- und Südosteuropa inklusive des zerfallenden Osmanischen Reiches, zu setzen. Mit einzelnen "globalen Fenstern« soll die weltweite Dimension von Zwangsmigration, beispielsweise anhand des zerfallenden Britisch-Indien und dessen Nachfolgestaaten Indien und Pakistan gezeigt werden. Dieser Überblick führt schließlich mit der Thematisierung von jüngsten Flucht- und Vertreibungsbewegungen in Syrien und dem Irak in die Gegenwart. Darüber hinaus soll die mediale Installation eine laufende Aktualisierung von "Daten und Zahlen« ermöglichen und durch dieses Panorama die Botschaft vermittelt werden, dass Zwangsmigrationen eine Konstante von militärischen und staatlichen Auseinandersetzungen sind, diese zugleich aber durch den ethnischen und administratorischen Fortschritt sowie durch den gesteigerten Nationalismus im 20. Jahrhundert eine neue Dimension erreichten. ${ }^{135}$

Der Überblick ist in drei europäische »Kriegsdekaden« des 20. Jahrhunderts aufgegliedert: Die erste Dekade führt von 1912 bis 1923, fängt mit den Vertreibungen auf dem Balkan an und endet mit dem international sanktionierten griechisch-türkischen >Bevölkerungsaustausch" sowie seiner globalen Wirkung als Präzedenzfall. Die zweite Phase deckt den Zeitraum von 1938 bis 1948 ab und beginnt mit der nationalsozialistischen Expansionspolitik und den diese begleitenden Vertreibungen und Zwangsumsiedlungen, von denen die Deutschen schließlich selbst »in immenser Zahl« betroffen waren. Auch in diesem Abschnitt sollen Unterschiede nicht negiert, sondern spezifische Charakteristika, »Motivlagen « und Verbindungen aufgezeigt werden. Schließlich endet dieser Bereich mit dem verstärkten internationalen Flüchtlingsschutz in Folge des Zweiten Weltkrieges. Als »dritte Kriegsdekade« werden die Jugoslawienkriege der 1990er Jahre verstanden. Diese Phase von erneuten Massenvertreibungen und Kriegsverbrechen soll ebenso dargestellt werden wie die folgende verschärfte internationale Ächtung von Zwangsmigrationen, verbunden mit einem Interventionsrecht der internationalen Staatengemeinschaft und dem damit angestrebten Rückkehrrecht von Flüchtlingen und Vertriebenen nach Kriegsende. Insgesamt soll den »jeweiligen internationalen Machtverhältnissen«, die als entscheidend für die Zwangsmigrationen erachtet werden, viel Raum gegeben und so von Lausanne 1923 über Potsdam $1945 \mathrm{zu}$ Dayton 1995 die Verantwortungsgemeinschaften und Handlungsspielräume der Akteure zur Diskussion gestellt werden. ${ }^{136}$

Um diese im Mittelpunkt stehende umfängliche Installation gruppieren sich fünf »Themeninseln«, die als »historische Längsschnitte zu Fragestellungen, die auf das Thema Zwangsmigration gerichtet « sind, angesehen werden und eine Vertiefung der Überblicksdarstellung ermöglichen sollen. Diese zeigen nicht nur »Ursachen und Begleiterscheinungen « von Zwangsmigration in Europa, sondern auch "gesellschaftspolitische Diskurse im Europa des 20. Jahrhunderts«. Damit einher geht das Ziel, den Besucher nicht nur mit Informationen, sondern auch mit Fragen und Kontroversen zu konfrontieren: Dieser soll hier die aus der eigenen »Lebenswelt« und »aktuellen Debatten« entwickelten gegenwärtigen Perspektiven mit historischen Themen verbinden können. ${ }^{137}$

135 Stiftung Flucht, Vertreibung, Versöhnung: Konzept für die Dauerausstellung, 2017, S. $14 f$.

136 Ebd., S. $15 f$.

137 Ebd., S. $16 f$. 
In der ersten Themeninsel »Begriffe und Kontroversen« werden die für die Ausstellung konstitutiven Termini historisiert und ihre diskursive politische Konstruktivität dargelegt. Neben der bundesdeutschen und der DDR-Begriffsgeschichte von »Flucht und Vertreibung« sollen die polnischen und tschechischen Begriffe für das Geschehen vorgestellt und in ihren spezifischen Konnotationen erklärt werden. Dieser Erläuterung schließt sich ein »Glossar« der »in der Ausstellung verwendeten Begriffe« an: »Vertreibung, Deportation, Zwangsaussiedlung, Bevölkerungsaustausch, Evakuierung, ethnische Säuberungen, Transfer etc.« Mit der Diskussion derselben geht der Versuch einer transparenten Darstellung und Erklärung der von der Stiftung verwendeten Begriffe und ihrer Definitionen einher, die als Ergebnis eines Auswahlprozesses vorgestellt werden sollen. ${ }^{138}$

Die zweite Themeninsel »Nation und Nationalismus« stellt zunächst zwei grundlegende Modelle von Staatsbürgerschaft in der Moderne vor: das französische und USamerikanische Konzept der politischen Staatsbürgerschaft im Kontrast zum ethnisch definierten Volksverständnis, das in Deutschland und Ostmitteleuropa ab dem 19. Jahrhundert maßgeblich war. Besonders die Eskalation des Nationalismus in Form von Rassismus, der Angst vor vermeintlicher und tatsächlicher Illoyalität von »fremden« Staatsbürgern sowie die damit einhergehenden Konflikte zwischen Mehr- und Minderheiten bis hin zu Planungen und Durchführungen von Vertreibungen sollen hier thematisiert werden. In den Überlegungen des Papieres schließt dieser Bereich mit Fragen an die Besucher nach ihren eigenen Selbstidentifikationen. ${ }^{139}$

Unter dem Titel "Zwang und Gewalt« soll in der dritten Themeninsel die für die meisten Zwangsmigrationen konstitutive Gewalterfahrung exponiert werden. Einen besonderen Platz nehmen die "sexuelle Gewalt im Kontext ethnischer Säuberungen« sowie die zumeist folgende Tabuisierung dieses Geschehens und der damit verbundenen Traumata ein. Für die thematisierten Gewaltakte gelte, dass diese im konkreten Moment zumeist asymmetrisch seien. Dem Besucher soll aber vermittelt werden, dass häufig von einer Wechselwirkung von Gewalterfahrung und Gewaltausübung in »zwischenethnischen Konflikten« zu sprechen ist, womit sich auch die spezifische Frage nach den Akteuren und ihren Motivationen verbindet. ${ }^{140}$

Die vierte Themeninsel »Lager - Transit und Provisorium« diskutiert das Lager als weiteres konstitutives Element von Zwangsmigrationen. Dargestellt werden sollen hier verschiedene Formen von »Internierungs- und Ausweisungslager, Aufnahme- und Durchgangslager«, Gewalt, Willkür und Kontrolle ebenso wie Schutz und Hoffnung und das häufig jahrelange Leben in diesen provisorischen Unterkünften (»Das Lager als Erfahrungsraum und sozialer Mikrokosmus«). ${ }^{141}$

Die letzte Themeninsel »Völkerrecht und Menschenrechte« ist der Rechtsgeschichte der Zwangsmigration gewidmet. Vom international sanktionierten $>$ Bevölkerungsaustausch nach dem Ersten Weltkrieg bis hin zur Ächtung und strafrechtlichen Verfolgung durch den als Beispiel hier angeführten Internationalen Strafgerichtshof in Den Haag

138 Stiftung Flucht, Vertreibung, Versöhnung: Konzept für die Dauerausstellung, 2017, S. 18.

139 Ebd., S. $18 f$.

140 Ebd., S. 19.

141 Ebd., S. 20. 
seit 2002 sollen die einschneidenden Entwicklungen dargestellt werden. So könnte Den Haag dem Besucher »eventuell in der gestalterischen Form eines Gerichtssaales« plastisch nähergebracht werden. Ein weiteres Element dieser Themeninsel ist die Frage der Menschenrechte und des »Menschenrechtsdiskurses « seit 1945 und dessen Einfluss auf das Völkerrecht. Das bis heute existierende Spannungsfeld von Bürgerrecht und staatlicher Souveränität und der gelegentlich mit letzterer gerechtfertigten Diskriminierung von nationalen Minderheiten soll diskutiert und »bei jungen Besuchern« das »Bewusstsein für diese heute wieder brisante Konfliktlage« geschärft werden. Dies wird als »ein wichtiges didaktisches Ziel der Ausstellung « angesehen. ${ }^{142}$

Den Überlegungen des Konzeptionspapieres zufolge wechselt der Besucher nun in das zweite Obergeschoss zum Themenfeld »Flucht und Vertreibung der Deutschen im europäischen Kontext«. Der Beginn der Zwangsmigrationen im Zweiten Weltkrieg wird im Bereich »Totalität und Entgrenzung: Deutsche Expansionspolitik und Zweiter Weltkrieg (1938-1944)« mit der Zerschlagung der ČSR 1938/39 gesetzt. Der folgende verbrecherische »Eroberungs- und Vernichtungskrieg« gegen Polen und die Sowjetunion sowie die damit einhergehenden, von Deutschland verursachten Massenzwangsmigrationen werden hier thematisiert, wobei die NS-Politik gegenüber den >Volksdeutschen und die zeitgleich stattfindende >Heim-ins-Reich`-Bewegung in dieses Gefüge eingeordnet werden. ${ }^{143}$

Als Voraussetzungen der NS-Expansionspolitik werden der "völkische Nationalismus«, der Rassismus und die NS-Lebensraumideologie diskutiert. Das aufgezeigte verbrecherische Vorgehen ebenso wie die deutschen Planungen, beispielsweise in Form des "Generalplan Ost«, stellen die tatsächliche und drohende Gefahrenlage für die osteuropäischen Völker durch das nationalsozialistische Deutschland dar. Die antisemitische Politik des Nationalsozialismus und die damit einhergehenden Fluchtbewegungen der deutschen Juden nach 1933 sowie die Vertreibung der polnischen Juden aus Deutschland (1938) und die Deportationspläne sollen vorgestellt und schließlich die industrielle Ermordung der europäischen Juden als exzeptioneller Tiefpunkt der exterminatorischen Rassenpolitik des Nationalsozialismus eingeordnet werden. ${ }^{144}$

Darauf folgend zeigt ein Bereich die »Deutsche Germanisierungs- und >Lebensraum $<$-Politik im besetzten Osteuropa«. Thema sind hier die Fluchtbewegungen aus dem vom Deutschen Reich annektierten Sudetenland sowie die folgende Besatzungspolitik im >Protektorat Böhmen und Mähren $<$. Sowohl die Rolle der nationalsozialistischen Sudetendeutschen Partei (SdP) als auch die Minderheitenpolitik der ČSR werden als Teil der Vorgeschichte diskutiert. Daran schließt sich die Darstellung des besetzten Polen als »Hauptschauplatz« für die geplante nationalsozialistische Neuordnung Osteuropas und die unmittelbar nach der Besetzung beginnenden Vertreibungen von Polen aus den annektierten Gebieten an. Dabei werden auch die Rolle der Sowjetunion und deren Besatzungsherrschaft sowie die damit verbundenen sowjetischen Zwangsumsiedlungen von Polen diskutiert. ${ }^{145}$

142 Stiftung Flucht, Vertreibung, Versöhnung: Konzept für die Dauerausstellung, 2017, S. $21 f$.

143 Ebd., S. 24.

144 Ebd., S. $24 \mathrm{f}$.

145 Ebd., S. 25. 
Ein Schwerpunkt dieses geplanten Ausstellungsteils ist die Umsiedlung der >Volksdeutschen in die annektierten polnischen Gebiete. Sie werden »sowohl [als] Profiteure als auch [als] Opfer einer Umsiedlungspolitik im Graubereich zwischen Freiwilligkeit und Zwang « verstanden, die schließlich am Ende des Krieges alle (erneut) von Zwangsmigration betroffen waren. Anhand des Beispiels des SS->Mustersiedlungsgebietes im Kreis Zamość soll die enge Verbindung der Ansiedlung von >Volksdeutschen<, der Vertreibung von Polen und des Holocausts dargestellt werden. Als weiteres Beispiel für die exterminatorische Kriegspolitik des Nationalsozialismus in Osteuropa wird die Blockade von Leningrad herangezogen. Ein eigener Themenbereich ist die Deutsche Volksliste und deren rassistische und sozialdarwinistische Struktur. Der Blick wird auch auf die Region des von NS-Deutschland und Italien zerschlagenen Jugoslawien und des neu geschaffenen Marionettenstaates >Unabhängiger Staat Kroatien sowie seine Vertreibungs- und Vernichtungspolitik gegenüber Serben und Juden gerichtet. Die in Südosteuropa besonders enge Verbindung von Volksdeutschen und Waffen-SS nebst deren Exzessen in diesem Raum sollen ebenso thematisiert werden. ${ }^{146}$

In einem weiteren Abschnitt erfolgt die Darstellung der »Deportation ethnischer Gruppen im Zweiten Weltkrieg« durch die Sowjetunion. Die Linien der sowjetischen Bevölkerungs- und Nationalitätenpolitik werden von den 1920er Jahren bis hin zu ihrer Eskalation und Kollektivbestrafung von vermeintlich oder tatsächlich mit NSDeutschland kollaborierenden Bevölkerungsgruppen gezeigt, darunter die Deportation der Wolga- und Schwarzmeerdeutschen. ${ }^{147}$

Im nächsten Ausstellungsabschnitt sollen die »Pläne der Alliierten und der Exilregierungen für eine Nachkriegsordnung Europas durch Vertreibungen (1939-1945)« diskutiert und die verschiedenen Entwicklungen, die zu den Vertreibungen führten, zusammenführend als ein "Bedingungsgeflecht« besprochen werden. Sowohl die zu diesem Zeitpunkt anerkannte Konfliktlösung durch >Bevölkerungstransfers`als auch der weithin als Stabilität gewährleistend betrachtete ethnisch homogenisierte Nationalstaat werden angeführt, aber auch die Bestrebungen, »Vergeltung und Strafe für die aggressive Expansions- und Besatzungspolitik Deutschlands « auszuüben, sowie "partikulare staatliche Machtinteressen«. Als grundlegend für die alliierten Entscheidungen betrachtet das Papier die »Präzedenzfälle« der NS-Bevölkerungspolitik ebenso wie den griechisch-türkischen $>$ Bevölkerungsaustausch $<.{ }^{148}$

Das Konzeptionspapier von 2017 sieht die Diskussionen erster Aussiedlungspläne unmittelbar nach Kriegsbeginn 1939 über die im Kriegsverlauf zunehmend radikaler werdenden Planungen der Exil-Regierungen und der britischen Führung in die als entscheidend bewerteten Überlegungen der Siegermächte und ihre Verhandlungen übergehen. Diese Planungen seien schließlich zum großen Teil durch die Fluchtbewegungen und `wilden Vertreibungen k konterkariert oder überholt worden und die in Potsdam erhobene Forderung nach »ordnungsgemäßen und humanen« Umsiedlungen hätte sich als Illusion herausgestellt. ${ }^{149}$

146 Stiftung Flucht, Vertreibung, Versöhnung: Konzept für die Dauerausstellung, 2017, S. 25-27.

147 Ebd., S. 27.

148 Ebd., S. 28.

149 Ebd., S. $28 f$. 
Thema des folgenden Teiles sind die »Evakuierungen und Flucht der Deutschen in den letzten Kriegsmonaten (1944/45)«. Hierbei soll eine klare Differenzierung der verschiedenen Prozesse sowie die Darstellung erheblicher regionaler Unterschiede erfolgen. In diesem Ausstellungsteil zeigen biografische Darstellungen die »Bandbreite der Erfahrungen«; neben den schwerpunktmäßig dargestellten Fluchtbewegungen der Deutschen wird auch die anderer Gruppen betrachtet. Die Gestaltung dieses Ausstellungsteils durch Objekte unterschiedlicher Herkunft soll eine multiperspektivische Betrachtung ermöglichen und beispielhaft die Wirkmacht bestimmter Bilder für die bundesrepublikanische Erinnerung herausstellen. Mit der Darstellung verschiedener Ereignisse der letzten Januarwoche 1945, die hierfür beispielhaft ausführlich thematisiert wird, zeigt sich die Idee des Papieres, völlig verschiedene Erfahrungshorizonte deutlich zu machen. Neben dem Untergang der mit vielen tausend Flüchtlingen bemannten Wilhelm Gustloff sollen der weiter andauernde Massenmord an den Juden in Form eines deutschen Massakers an jüdischen KZ-Häftlingen in Ostpreußen, die Befreiung des Vernichtungslagers Auschwitz, die fortgesetzten Todesmärsche aus den Konzentrationslagern ebenso wie die in dem Zeitraum stattfindende Uraufführung des NS-Propagandafilmes Kolberg diesen Horizont aufzeigen. »Autobiographische Fluchtberichte« sollen das geschilderte Geschehen ergänzen und diese gleichzeitig kontextualisieren. ${ }^{150}$

Die regionale Untergliederung wird aufgeteilt in die Flucht

- aus Ostpreußen, Westpreußen und Danzig,

- aus Schlesien, Pommern und dem östlichen Brandenburg sowie

- die Evakuierung und Flucht aus Südosteuropa.

Anhand des ostpreußischen Erinnerungsortes »Nemmersdorf«, in dem die Rote Armee ein Massaker an der deutschen Zivilbevölkerung verübte, werden Angst und Gewalt, aber auch die propagandistische Aufwiegelung und Ausnutzung dieses Ereignisses durch die NS-Propaganda diskutiert. Ein weiteres, die Komplexität der Ereignisse unterstreichendes, Beispiel soll das Schicksal von Breslau und seiner Zivilbevölkerung sein, die bereits vor den Vertreibungen hohe Verluste durch die rücksichtslose Verteidigung der Stadt zu verzeichnen hatten. ${ }^{151}$

Im abschließenden Teil des zweiten Ausstellungskapitels »Die ethnisch-territoriale Neuordnung Ostmittel- und Südosteuropas (1944-1948)« wird mit dem »Schwerpunkt der Betrachtung « auf der Vertreibung der Deutschen »die Hauptphase der gewaltsamen Bevölkerungsverschiebungen in Europa im 20. Jahrhundert«thematisiert. Die »12 bis 14 Millionen Flüchtlinge und Vertriebenen« mit ihren »hunderttausenden Todesopfern« werden nicht als einheitliche Großgruppe verstanden, sondern in Einzelgruppen und Individuen differenziert. Die Darstellung weiterer von Vertreibung betroffener Bevölkerungsgruppen Europas in diesem Zeitraum »veranschaulicht zum einen das besondere

150 Stiftung Flucht, Vertreibung, Versöhnung: Konzept für die Dauerausstellung, 2017, S. $29 f$.

151 Ebd., S. 30-32. 
Ausmaß der Vertreibung der Deutschen und zeigt zum anderen die enge Verknüpfung einzelner Vorgänge in ihrem Ablauf auf «. ${ }^{152}$

Betont werden soll, dass die Vertreibungen zumeist nach Ende der Kampfhandlungen beziehungsweise nach Kriegsende erfolgten und so integraler Bestandteil der avisierten alliierten »Etablierung einer Nachkriegsordnung « waren. Obgleich zum großen Teil im Frieden, fand die Zwangsaussiedlung der Deutschen in durch die vorherige Besatzung und den Krieg zerrütteten Gesellschaften statt. Erschwerend kam hinzu, dass sich die staatliche und rechtliche Ordnung erst wieder etablierte. Eine Folge davon war die fast permanente Präsenz von Gewalt, auch als bewusstes Mittel zur Beschleunigung der Vertreibung. Von dieser waren nicht nur die Deutschen betroffen, sondern auch andere Gruppen wie die Polen. Gleichzeitig verbanden sich die Gewaltausbrüche auch mit länger andauernden nationalen und sozialen Konflikten. Im Falle der Deutschen hätten die "jüngsten Erfahrungen deutscher Kriegsführungen und Besatzungsherrschaft» als ein entscheidender Faktor für die Gewalt »auf der Hand« gelegen. Die Vertreibung selbst wurde als Kollektivbestrafung verstanden, gerechtfertigt und als solche in Polen und der ČSR akzeptiert. Dieser Ausstellungsteil soll neben den Erzählungen der Opfer auch einen Blick auf Akteure vor Ort und ihre Motivation ermöglichen, durch verschiedene Erfahrungsbeispiele positiver wie negativer Art »das breite Spektrum möglicher Handlungsspielräume verdeutlichen « und schließlich auch als universell verstehbare Erfahrungen aufzeigen. ${ }^{153}$

Im folgenden Bereich stellt den Planungen zufolge erneut eine »dynamische Karte« die verschiedenen Zwangsmigrationen im Zeitraum von 1944 bis 1948 dar und möchte ein Gefühl für die »zeitliche, räumliche und zahlenmäßige« Dimension vermitteln, Zusammenhänge aufzeigen sowie die »tiefgreifende und nachhaltige« Änderung der »demographischen Struktur Ostmitteleuropas « verdeutlichen. ${ }^{154}$ In der ersten der vier nach Räumen geordneten Einheiten werden die »Vertreibungen im Zusammenhang mit der Westverschiebung Polens« (1) präsentiert. Die Zwangsaussiedlung der Polen aus den kresy soll unter Berücksichtigung ihrer Spezifika in einer »vergleichenden Darstellung « die ethnische Homogenisierung »der verlorenen deutschen und polnischen Gebiete« zeigen. Im Folgenden werden die verschiedenen Stadien und Wege der Vertreibung der Deutschen dargestellt; dem Narrativ der vermeintlich organisierten und zivilen Aussiedlungen wird widersprochen. In einem Bereich ist die Zwangsassimilationspolitik gegenüber den vermeintlich autochthonen Bevölkerungsgruppen wie den Oberschlesiern und Masuren das zentrale Thema. ${ }^{155}$

Die nächste vorgestellte Region ist »das nördliche Ostpreußen unter sowjetischer Verwaltung« (2). ${ }^{156}$ Dem schließen sich als dritte behandelte Region die »Vertreibungen aus der Tschechoslowakei« (3) an. Die tschechoslowakische Regierung wird hier als Akteur hervorgehoben, ebenso die rechtliche Grundlage der durch »unter Edvard Beneš vorbereiteten und später parlamentarisch legitimierten Verordnungen (>BenešDekrete`)«. Die Vertreibung, Entrechtung, Enteignung und Internierung der Deutschen

152 Stiftung Flucht, Vertreibung, Versöhnung: Konzept für die Dauerausstellung, 2017, S. 32.

153 Ebd., S. $32 f$.

154 Ebd., S. $33 f$.

155 Ebd., S. 34f. Vgl. Kap. 6.1, S. $281 f$.

156 Ebd., S. $35 f$. 
sowie die »Gewaltexzesse« in Aussig oder der »Brünner Todesmarsch« werden als entscheidende Schritte dieser Geschichte verstanden. Dabei soll die Darstellung verdeutlichen, dass es sich »nicht um spontane Ausbrüche« von Rache handelte, sondern »dass sie [die Exzesse] fast immer organisiert auf staatlichen Befehl durchgeführt wurden«; die bewusst herbeigeführte Verschlechterung der Lebensbedingungen der deutschen Bevölkerung und die staatlich forcierten swilden Vertreibungen sollten so "noch vor einem alliierten Beschluss Fakten [...] schaffen.« Neben der Zwangsmigration der Deutschen wird auch die der Ungarn bzw. der >Bevölkerungsaustausch zwischen Ungarn und der Slowakei ebenso wie die schwierige und oftmals gescheiterte Wiederbesiedlungspolitik der ehemaligen deutschen Siedlungsgebiete der ČSR thematisiert. ${ }^{157}$

Als letzte Region wird Südosteuropa und damit »die Situation der deutschen Minderheiten in Ungarn, Jugoslawien und Rumänien bei Kriegsende« (4) in den Blick genommen. Die regional sehr unterschiedlichen Bedingungen und Zwangsmigrationsprozesse der Deutschen sollen so erfasst werden: die besonders brutale und verlustreiche Masseninternierung der Deutschen in Jugoslawien ebenso wie die letztlich nur zur Hälfte zwangsausgesiedelten Ungarndeutschen bis hin zu den Rumäniendeutschen, die trotz des Schicksals der Deportationen von 70.000 Angehörigen in die Sowjetunion »bis zum Fall des Eisernen Vorhangs [...] eine intakte deutsche Minderheit« bilden konnten. ${ }^{158}$

Im dritten Oberkapitel soll unter dem Titel »Vertriebene und Flüchtlinge in Deutschland seit 1945 « die »in der historischen Rückschau [...] schwierige und langwierige, aber letztlich gelungene« Integrationsgeschichte der deutschen Vertriebenen in der Bundesrepublik und der DDR erzählt werden. Im Gegensatz und in Ergänzung $\mathrm{zu}$ einer vereinfachten ökonomischen Erfolgsgeschichte wird auch die schwierigere immaterielle Integration diskutiert. Dabei will sich die Darstellung nicht nur auf das Ankommen der deutschen Vertriebenen nach 1945 beschränken, sondern sie zeigt auch die kontinuierliche Zuwanderung der Spätaussiedler in die Bundesrepublik und nimmt die in Osteuropa verbliebenen deutschen Minderheiten in den Blick. Außerdem soll sie die Folgen der Vertreibungen für die Staaten Ostmitteleuropas aufzeigen. Die Debatten innerhalb Deutschlands sowie sein damit verbundenes Verhältnis »zu seinen östlichen Nachbarn« werden chronologisch strukturiert und mit »entscheidenden Etappen eines langsamen Wandels«als »verflochtene Geschichte« erzählt. Weiter sollen hier Konflikte zwischen staatlicher (Geschichts-)Politik, Iniitiativen der Vertriebenen wie dem BdV und individuellen Erinnerungen (»Familiengedächtnis«) diskutiert werden. ${ }^{159}$

Der erste von vier Unterpunkten der Nachkriegsgeschichte beschäftigt sich unter dem Titel »Ein gesellschaftliches Experiment« mit den komplizierten Verhältnissen nach Kriegsende und den improvisierten, aber unter dem Strich effektiv durchgesetzten alliierten Assimilationsplänen. Die organisatorische Aufnahmegeschichte soll jedoch eher den Hintergrund für die in diesem Ausstellungsteil zentralen »Lebenswelten und Erfahrungen der Flüchtlinge und Vertriebenen« bilden. Die Schwierigkeiten unterstreichend, soll »herausgearbeitet [werden], dass damals in Deutschland keine Will-

157 Stiftung Flucht, Vertreibung, Versöhnung: Konzept für die Dauerausstellung, 2017, S. $36 f$.

158 Ebd., S. $37 f$.

159 Ebd., S. 40f. 
kommenskultur herrschte.«Der tiefgreifende demographische Wandel führte zu einer nachhaltigen (wenn auch regional unterschiedlich intensiven) Veränderung Deutschlands, wofür die »konfessionelle Landkarte« als besonders signifikantes Beispiel herangezogen wird. ${ }^{160}$

Im zweiten Bereich soll mit »Konfliktgesellschaft und deutsche Frage« die rechtliche und organisatorische Integrationsgeschichte der deutschen Vertriebenen beschrieben werden. Das Lastenausgleichsgesetz von 1952 und das Bundesvertriebenengesetz von 1953 erhalten hier ebenso Raum wie die Charta der deutschen Heimatvertriebenen und die politischen Vertretungen der Vertriebenen bis hin zur Gründung des Bundes der Vertriebenen. Am Beispiel der Charta wird anhand verschiedener Kommentare »die Bandbreite der Interpretationen dieses kontrovers diskutierten Dokuments aufgezeigt«, wie auch die Belastung des Vertriebenenministeriums, der Verbände und Parteien »vor dem Hintergrund personeller Kontinuitäten von NS-Staat und Bonner Republik« reflektiert wird. Der Einfluss der Vertriebenen und ihrer Verbände in der deutschen Innenpolitik wird ebenso wie ihre (wechselseitige) Instrumentalisierung im Kalten Krieg aufgezeigt. $^{161}$

Daran schließt sich der dritte Teil dieses Ausstellungsbereiches an: »Zwischen Polarisierung und Verständigung«. Hier soll der Weg zur neuen Ostpolitik der Regierung Brandt im Klima der internationalen Entspannungspolitik behandelt werden: Vordenker und Initiativen wie der Briefwechsel der polnischen und deutschen Bischöfe 1965 finden hier ebenso wie die Vertragswerke von Moskau (1970), Warschau und Prag (beide 1973) ihren Platz. Die heftige Bekämpfung dieser Politik durch die Vertriebenenverbände soll hier ebenfalls Raum erhalten. Zugleich soll gezeigt werden, dass die durch die Verträge erreichte Erleichterung der Reisebestimmungen vielen Vertriebenen einen ersten Besuch in ihrer alten Heimat ermöglichte und häufig alte und neue Bewohner, »Vertriebene und ihre Nachkommen durch [diese] grenzüberschreitenden Kontakte zur Verständigung« beitrugen. Die ab den 1970er Jahren verstärkt auf das Ziel der Bewahrung ausgerichtete Kulturförderung nach dem Bundesvertriebenengesetz soll hier ebenso wie der Bund der Vertriebenen aus einer historischen Perspektive betrachtet werden. ${ }^{162}$

Der geplante letzte Bereich dieses Ausstellungsteiles und der Dauerausstellung insgesamt ist unter den Titel »Erinnerung und Gedächtnis im Wandel« gefasst und behandelt die Zeit nach 1989. Der Zwei-Plus-Vier-Vertrag, die endgültige Anerkennung der Oder-Neiße-Linie und das deutsch-deutsche Zusammenwachsen auch in Fragen der Erinnerung an die Vertreibung sind Gegenstand der Diskussionen in diesem Bereich. Erneut werden Wege der Versöhnung von organisierten und nicht organisierten Vertriebenen vorgestellt, aber auch ein besonderes Augenmerk auf polnische und tschechische Initiativen gerichtet, die das deutsche Erbe ihrer Region zunehmend als Teil ihrer eigenen Identität verstehen. Für die Entwicklung der internationalen Ebene sollen »wichtige symbolpolitische Gesten der Verständigung « gezeigt werden. ${ }^{163}$

160 Stiftung Flucht, Vertreibung, Versöhnung: Konzept für die Dauerausstellung, 2017, S. 41f.

161 Ebd., S. $42 f$.

162 Ebd., S. $43 f$.

163 Ebd., S. 45. 
Einen eigenen Platz nimmt der Wandel der bundesrepublikanischen Erinnerungskultur seit den 1990ern ein. Zum einen führte ein selbstkritisches Geschichtsbewusstsein unter anderem zum Bau des Denkmals für die ermordeten Juden Europas, zum anderen lässt sich aber auch eine neue deutsche Beschäftigung mit »eigenen Verlusterfahrungen " konstatieren, die sich in Belletristik und Medien manifestiert hat. Weiter soll auf das fortdauernde »innen- und außenpolitische Konfliktpotential« des Themas anhand der Diskussion um die >Beneš-Dekrete und die Preußische Treuhand sowie nicht zuletzt um die Initiative für ein Zentrum gegen Vertreibungen von Erika Steinbach und Peter Glotz hingewiesen werden. Die Gründung der Stiftung Flucht, Vertreibung, Versöhnung 2008 »unter dem Dach des Deutschen Historischen Museums « wird schließlich als Integration »der Vertriebenen auf institutioneller Ebene in das kulturelle Gedächtnis des vereinigten Deutschlands« verstanden »und explizit in den Kontext einer auf Verständigung und Versöhnung ausgerichteten Kulturarbeit gestellt. ${ }^{164}$

In dem vorliegenden Konzeptionspapier wird als Ende und Ausblick der Ausstellung eine Diskussion von »Flucht und Vertreibungen« im »21. Jahrhundert [als bleibende] globale Herausforderung [...] auch für die deutsche Gesellschaft « angedacht und mit einem Verweis auf den »Höhepunkt der Flüchtlingsankunft in Europa« 2015 eine Aktualisierung vorgenommen: »Für viele Menschen verbindet sich die Auseinandersetzung mit den Folgen von Flucht und Vertreibung auch heute noch mit Ängsten, Vorurteilen, Empathie und Hilfsbereitschaft. ${ }^{165}$

\subsubsection{Konzeptionsanalyse}

Wenn wir uns den oben behandelten Anspruch an die Stiftung und ihr Selbstverständnis in Erinnerung rufen, wird bei Betrachtung des vorliegenden Konzeptionspapieres das Suchen nach einer ausgewogenen und den verschiedenen Forderungen gerecht werdenden Darstellung sehr deutlich. Der auf die Vertreibung der Deutschen gelegte Schwerpunkt erfüllt ebenso wie eine umfassende Behandlung der mit dieser in kausalem Zusammenhang gezeigten deutschen Aggression und Vernichtungspolitik vor dem und im Zweiten Weltkrieg sowohl die Forderungen der Vertriebenenverbände als auch die der Kritiker. Die Stiftung plant dafür zum einen die Darstellung weiterer europäischer Zwangsmigrationen des 20. Jahrhunderts, darunter die Zwangsaussiedlung der Polen aus den kresy sowie das punktuelle Aufzeigen der globalen Dimension. Zum anderen soll mit der Skizzierung der Ideengeschichte der staatlichen Massenvertreibungen auch die über die 1930er und 1940er Jahre hinausgehende Bedeutung der Thematik herausgestellt werden. Eine sinnvolle Verzahnung dieser Elemente soll eine entsprechend geschickt aufgebaute Ausstellung gewährleisten.

Dafür wird für die Ausstellung mit dem Einsatz multimedialer Installationen und dem klassischen Exponat ebenso wie mit szenografischen Elementen ein Zusammenspiel verschiedener Gestaltungstechniken angedacht. Die beschriebenen digitalen Karten, die die quantitative, europäische und globale Dimension von Flucht- und Vertrei-

164 Stiftung Flucht, Vertreibung, Versöhnung: Konzept für die Dauerausstellung, 2017, S. 45f.

165 Ebd., S. 46. 
bungsbewegungen visualisieren sollen, zeigen - wie in Kapitel 3 der vorliegenden Studie beschrieben - die für die meisten Zwangsmigrationen konstitutiven Wechselwirkungen auf. Zugleich soll die Digitaltechnik ermöglichen, zeitnah aktuelle Zwangsmigrationen in die Dauerausstellung zu integrieren und so deren Anspruch umsetzen, bis in die Gegenwart zu führen. Die Überlegung, die Rechtsgeschichte von Zwangsmigration anhand eines angedeuteten Gerichtssaales szenografisch erfassbar zu machen, unterstreicht das angestrebte Bemühen um physisch erfahrbare Elemente der Ausstellung. Die Exponate sollen unter anderem durch den Verbund mit biografischen Berichten das historische Geschehen veranschaulichen. Gerade anhand von Objekten soll aber auch Multiperspektivität ermöglicht werden, zum Beispiel in Form der Vorstellung verschiedener Betrachtungsweisen auf ein Objekt. Insgesamt deutet sich ein Wechselspiel aus sachlichen und emotionalen Zugängen an, von denen die letzteren dem Konzept zufolge aber durch die stete Kontextualisierung der historischen Ereignisse eingerahmt werden sollen. Auch für Zeitzeugen und die mit ihnen verbundene »erfahrungsgeschichtliche Dimension « wird in der Ausstellung Raum vorhanden sein. ${ }^{166}$ Ihre Berichte sollen sich aber nicht nur auf das Geschehen von Flucht und Vertreibung beschränken, sondern durch deren Einordnung in die weitere Lebensgeschichte der Menschen einen umfassenderen Blick auf die Person und die Geschichte ermöglichen.

In Hinblick auf das verfolgte Besucherbild spricht das Konzeptionspapier von einem partizipativen Ansatz, der verschiedentlich umgesetzt werden soll. Am interessantesten ist sicher das Beispiel der geplanten Diskussion wesentlicher Begriffe in der Ausstellung sowie die wenigstens punktuell oder zu Beginn vorgenommene, Transparenz schaffende Begründung des eigenen Vorgehens durch die Ausstellungsmacher. An verschiedenen Stellen soll der Besucher sowohl mit Fragen als auch Kontroversen konfrontiert und zur eigenen Positionierung aufgefordert werden. Bei der Diskussion des für die Thematik so zentralen Nationalitätsverständnisses sowie von Selbst- und Fremdzuschreibungen wird er zu einer Selbstdefinition und damit zur Reflektion eingeladen. Dennoch möchte man sich hier in keiner Beliebigkeit der Positionierung verlieren, sondern verfolgt einen den Menschen- und Bürgerrechten verpflichteten Bildungsauftrag. ${ }^{167}$

Als zentrales inhaltliches Element der Dauerausstellung sollen die Flucht und Vertreibung der Deutschen in ihren sehr unterschiedlichen Stadien, Formen und regionalen Ausprägungen differenziert und mit den damit verbundenen ganz unterschiedlichen Erzählungen und Erfahrungen gezeigt werden. Die Darstellung der besonderen Gruppe der Volksdeutschen sowohl als Opfer wie auch als Profiteure mehrfacher Zwangsmigrationen und Instrument der nationalsozialistischen ethnischen Neuordnung Osteuropas soll genutzt werden, um Schattierungen und Wechsel von Täter- und Opferschaft aufzuzeigen. Im Konzeptionspapier deutet sich eine vergleichsweise zurückhaltende Thematisierung der Gewalterfahrungen ebenso wie der Lagerinternierungen an. Letztere werden in ihrer Doppelrolle im 20. Jahrhundert gezeigt, also als Ort des Schutzes und der Unterdrückung. Offen bleibt die Diskussion der deutschen Opferzah-

166 Stiftung Flucht, Vertreibung, Versöhnung: Konzept für die Dauerausstellung, 2017, S. 8.

167 Ebd., S. 22. 
len, die im Text mit »einigen Hunderttausend « angegeben wird. ${ }^{168}$ Auf der einen Seite soll das in Kapitel 3.7 im Zusammenhang mit den vorhergehenden deutschen Verbrechen ausführlich besprochene Rachemotiv in der künftigen Dauerausstellung als eine Argumentation aufgezeigt werden, auf der anderen Seite aber auch die besonders im tschechoslowakischen Falle von staatlicher Seite organisierten sspontanen Übergriffe auf die deutsche Bevölkerung. Letztlich bleibt im Konzeptionspapier noch die Klärung offen, inwieweit das Rachemotiv als historische Erklärung trägt beziehungsweise wie dieses zu gewichten ist.

Wie oben gezeigt, soll in der Ausstellung ein doppelter Kontext von Flucht und Vertreibung verfolgt werden, wobei im Vergleich zum Konzept von 2012 verstärkt die kurze Linie, also eine Verortung im Kontext des Zweiten Weltkrieges und der deutschen Aggression, vorgenommen wird. ${ }^{169}$ Ideengeschichtliche Grundlagen, anthropologische Konstanten, Beispiele anderer europäischer und globaler Zwangsmigrationen sowie ein gegebenenfalls für die Vertreibungen relevanter tschechischer oder polnischer Nationalismus werden im ersten Obergeschoss separat diskutiert. Inwieweit hier die Vernetzung gelingt, wird sich zeigen. Unabhängig von oder ergänzend zu der Diskussion solcher Verantwortungsfragen soll mit der multiperspektivischen Darstellung der letzten Januartage des Jahres 1945 die Komplexität von deutscher Täter- und Opferschaft aufgezeigt werden, ohne Empathie gegeneinander auszuspielen oder eine Hierarchisierung der Opfer vorzunehmen. ${ }^{170}$ Die Verantwortung für die Vertreibungen wird im Papier der Stiftung überwiegend bei den alliierten Siegermächten gesehen, auf welche die ČSR und Polen nur einen geringen oder im letzteren Falle gar keinen Einfluss hatten. Die Frage nach der Notwendigkeit der Vertreibungen wird zunächst nicht diskutiert, sondern stattdessen auf die sich aus mehreren Faktoren zusammensetzenden Überlegungen der damaligen Siegermächte verwiesen, die in den stärker homogenisierten Nationalstaaten vor allem einen Friedensgaranten sahen.

Der Fokus der Stiftung lässt der deutschen Siedlungsgeschichte sowie dem multinationalen Zusammenleben in Ostmitteleuropa vor dem 20. Jahrhundert nur wenig Raum. Im Konzeptionspapier von 2017 wird in dieser Hinsicht bisher nur die Minderheitenpolitik der 1920er Jahre als Themenfeld angezeigt. Der Nationenbegriff sowie nationale Selbst- und Fremdzuschreibung sollen in der künftigen Dauerausstellung in Interaktion mit dem Besucher diskutiert werden. Es deutet sich an, dass nationale Eindeutigkeit und Konzepte von Ethnie und Volk so zu hinterfragen und die Existenz multipler Identitäten zu unterstreichen sind. Bezüglich der deutschen Minderheiten in Osteuropa fällt auf, dass die >Volksdeutschen $<$ im Papier primär als Instrument des Dritten Reiches und nicht als selbstständige Akteure betrachtet werden. ${ }^{171}$ Anders verhält es

168 Kittel et al.: Konzeption, 2012, S. 43. In der Konzeption von 2012 werden die deutschen Opferzahlen auf Basis der bisherigen Forschung diskutiert: Kittel et al.: Konzeption, 2012, S. 39. Vgl. zur Diskussion der Opferzahlen: Kap. 3.7, S. 134f.

Vgl. Stiftung Flucht, Vertreibung, Versöhnung: Konzept für die Dauerausstellung, 2017, S. $18 \mathrm{f}$.

170 Einen vergleichbaren Ansatz hat bereits Walter Kempowski in seinem 1999 erschienenen Werk Das Echolot. Fuga furiosa. Ein kollektives Tagebuch. Winter 1945 verfolgt, in dem er das Vertreibungsgeschehen derart collagierte. Vgl. dazu das Interview mit Kempowski von 2002: »Der Ärger muss raus«. Der Stern. 03.04.2002.

171 Vgl. z.B.: Stiftung Flucht, Vertreibung, Versöhnung: Konzept für die Dauerausstellung, 2017, S. 24. 
sich bei den Sudetendeutschen, deren Weg in das nationalsozialistische Deutschland und deren Beitrag zur Besatzungsherrschaft besprochen werden.

Das Konzeptionspapier sieht die künftige Ausstellung einem europäischen Narrativ verpflichtet. Diese Art der Erzählung soll sich nicht nur an den verschiedenen Fallbeispielen von Zwangsmigration im Europa des 20. Jahrhunderts zeigen, sondern auch an der multiperspektivischen Diskussion von Flucht und Vertreibung der Deutschen am Ende des Zweiten Weltkrieges, die verschiedene europäische Stimmen zu Wort kommen lässt. Kern der in dem Konzeptionspapier skizzierten Erzählung ist die des doppelten Kontextes dieses Geschehens: Zwangsmigrationen als europäische Erfahrung des 20. Jahrhunderts sowie die nationalsozialistische deutsche Herrschaft mit Gewalt, Vertreibungen und Genozid vor und während des Krieges. Dieses Narrativ ordnet sich schließlich durch eine Erweiterung der Perspektive dem doppelten Ziel unter, zum einen Wege der Versöhnung aufzuzeigen und zum anderen den Blick auf gegenwärtige Zwangsmigrationen zu lenken. Dieser umfassende Anspruch kann konsequenterweise nur mit >Mut zur Lücke< umgesetzt werden. ${ }^{172}$ Im Papier finden wir beispielsweise nicht die von Philipp Ther geforderte soziale Differenzierung der von Zwangsmigration betroffenen Gruppen und so möglicherweise eine zu starke Konstruktion von vermeintlich homogenen Gruppen wie >den $<$ Deutschbalten. ${ }^{173}$ Vergleichsweise unkonkret bleibt das Konzeptionspapier bei den Todeslagern, der Notwendigkeit der Vertreibungen und den Opferzahlen. Schließlich lässt es die Frage offen, wie die Gewichtung bei der Ursache und Verantwortung der Vertreibungen vorzunehmen ist.

Deutlich erkennbar ist der Wille zur Aktualisierung der Thematik: An verschiedenen Stellen soll durch »chronologische Längsschnitte« oder durch die Thematisierung aktueller Fluchtbewegungen ein Bogen in die Gegenwart gespannt werden. ${ }^{174}$ Ebenso wird im Konzeptionspapier der mit der >Flüchtlingskrise von 2015 eng verbundene Begriff der »Willkommenskultur« verwandt und zwar in der Weise, dass diese für die deutschen Vertriebenen nach 1945 nicht vorhanden gewesen sei. Dennoch ist insgesamt ein zurückhaltendes Vorgehen in Hinblick auf die politische Forderung nach einer stärkeren Parallelisierung der historischen und aktuellen Ereignisse erkennbar, was sich zum einen in der im Papier vorgesehenen geringen Dimension der Darstellung aktueller Zwangsmigrationen und zum anderen in der kontextualisierenden Abgrenzung der Geschehnisse zeigt.

Die SFVV begegnet mit ihren Planungen für die künftige Dauerausstellung den unterschiedlichen und umfangreichen Herausforderungen der Darstellung von Flucht und Vertreibung vor dem Hintergrund der verschiedenen Ansprüche und eines anspruchsvollen Selbstverständnisses mit kreativen, aber noch zu konkretisierenden Ansätzen. Auf dem Papier wird sie diesen Ansprüchen gerecht. Die Stiftung plant für eine erfolgreiche Umsetzung einen umfassenden ausstellungsgestalterischen Methodenmix auf

172 Vgl. für die Forderung zum »Mut zur Lücke« von Włodzimierz Borodziej in Bezug auf das HEH: Kap. 7.3.1, S. 463.

173 Vgl. Kap. 3.5, S. 124.

174 Vgl. z.B.: Stiftung Flucht, Vertreibung, Versöhnung: Konzept für die Dauerausstellung, 2017, S. 15, 46. 
der Höhe der Zeit und berücksichtigt zugleich die komplexe Historiographie, was sich in der abwägenden Diskussion der Ereignisse zeigt. Jahrzehntelangen Auseinandersetzungen innerhalb Deutschlands und mit seinen Nachbarn soll beispielsweise bei der Frage der Begriffe durch einen transparenten und den Besucher fordernden Ansatz konstruktiv begegnet werden. Diese Verbindung aus ansprechend aufbereiteter historischer Komplexität und dem Versuch, dem Besucher auf Augenhöhe zu begegnen, deuten im Sinne der eigenen und der an die Stiftung herangetragenen Ansprüche ein zukünftiges >Funktionieren der Ausstellung an.

\subsubsection{Rezeption der Planungen}

Das Konzeptionspapier von 2017 löste weder eine mediale noch eine wissenschaftliche Debatte aus. Trotz dieses Papieres, das die vorherigen Konflikte reflektiert und zusammenführt, bleiben die in Kapitel 5.1 und 7.1.1 diskutierten Grundkonflikte in der Kontinuität der Diskurse um das Zentrum gegen Vertreibungen und die die SFVV bis 2014 fortlaufend begleitenden Diskussionen bestehen, vor allem die grundsätzliche Ablehnung einer auf die Vertreibung der Deutschen als Kernpunkt ausgerichteten Institution. Dies zeigt nicht zuletzt die Ende 2017 aufgekommene Diskussion um die Errichtung des polnischen Denkmals in Sichtweite und als >Kommentar zur SFVV. In der deutschen Presse wurde das verabschiedete Konzeptionspapier, wenn es denn thematisiert wurde, positiv und nach den vorhergehenden jahrelangen Turbulenzen als wichtiger und ausgewogener Schritt zur Eröffnung des Hauses besprochen. ${ }^{175}$ In der Berliner Morgenpost hieß es:

»Fast möchte man von einem ersten kleinen Erfolg sprechen - die sStiftung Flucht, Vertreibung, Versöhnung، stellt das endgültige Konzept für die Dauerausstellung im Deutschlandhaus in Kreuzberg vor. Und was passiert? Niemand regt sich auf, keine Debatte, kein Shitstorm auf Twitter. Alles ruhig.«

In Hinblick auf eine mögliche stärkere Schwerpunktsetzung auf aktuelle Zwangsmigrationen sowie einen vermeintlichen Niedergang der Vertriebenenverbände heißt es weiter:

»Dass aktuelle Fluchtbewegungen wie aus Syrien hier auch zur Sprache kommen sollen, der berühmte Sommer 2015, passt zum Eindruck, dass der Radius der Dauerausstellung nun stark vergrößert wird: weg von der Fixierung aufs Deutsche, hin zu Europa, zur Welt. Und die Vertriebenen? Die haben sich wohl, trotz ihrer Verbände, schlicht überlebt. Sie sind nun auch Geschichte. $\ll^{176}$

Aber auch die nationalkonservative Junge Freiheit konstatierte nach dem Austritt Erika Steinbachs aus der CDU - vor der Veröffentlichung der Konzeption von 2017, aber in Hinblick auf die bereits vorher angedeuteten Veränderungen - dass Steinbachs Vorhaben, einen deutschen Erinnerungsort an Flucht und Vertreibung zu schaffen, »am

175 Schulz: Stiftung Flucht, Vertreibung, Versöhnung legt Ausstellungskonzept vor. Der Tagesspiegel. 21.06.2017.

176 Leinemann: Deutsche Vertriebene im europäischen Kontext. Berliner Morgenpost. 24.06.2017. 
Ende unter linksgrünem Dauerbeschuss bis zur Unkenntlichkeit verwässert und bis zur Parodie verzerrt werden sollte. $\aleph^{177}$ In Vertriebenenkreisen wurde das Konzeptionspapier hingegen als ein "gelungener Kompromiss« bewertet, der alle Seiten sinnvoll berücksichtige. Dennoch bleibe das abschließende Ergebnis »mit großem Interesse« abzuwarten. ${ }^{178}$

Das Papier von 2017 hat in Polen bisher kein größeres Echo ausgelöst. ${ }^{179}$ Ein Problem für die Außendarstellung der Stiftung ist, dass sie dort (und nach Auffassung des Autors nicht nur dort) vielfach als deckungsgleich mit oder unmittelbares Kontinuum des Zentrums gegen Vertreibungen betrachtet wird. ${ }^{180}$ Auch wenn das Konzept - beispielsweise in der Thematisierung der nationalsozialistischen Belastung von Teilen der Vertriebenenverbände und Ministerien - einigen Forderungen aus Polen entgegengekommen ist, bleibt eine Skepsis gegenüber dem Projekt vorhanden. Spätestens die Eröffnung der Ausstellung dürfte auf große Resonanz stoßen. ${ }^{181}$ Abgesehen davon befand sich Polen im Sommer 2017 selbst in schweren geschichtspolitischen Auseinandersetzungen, so um das Danziger Weltkriegsmuseum.

Das tschechische Nachrichtenportal České noviny widmete dem neuen Konzept einen längeren Artikel, in dem verschiedene Stimmen aus Tschechien zu Wort kamen. Die Besprechung hebt positiv hervor, dass die Verantwortung für die Vertreibungen auch in der künftigen Dauerausstellung in erster Linie bei den alliierten Siegermächten und erst in zweiter bei den ostmitteleuropäischen Staaten gesehen wird. Eine gewisse Skepsis zeigt sich gegenüber den als nicht spontan, sondern als staatlich organisiert beschriebenen Gewalttaten gegen die Deutschen in der Tschechoslowakei. Der Historiker Jaroslav Šebek unterstreicht in dem Artikel, dass die meisten Gewaltausübungen ihre direkte Ursache in der vorherigen langjährigen Gewalterfahrung durch den Nationalsozialismus sowie in dem konkreten Geschehen vor Ort gehabt hätten und überwiegend als spontane Reaktion zu klassifizieren seien. Weiter wird der Historiker Michal Stehlík zitiert, der in der avisierten Erzählung eine Kontextualisierung der tschechoslowakischen Entscheidung zur Vertreibung der Deutschen vermisst und eine einseitige Perspektive befürchtet - auch wenn in dem Artikel die im Konzeptionspapier verankerten Verweise auf das Münchner Abkommen und die NS-Verbrechen, die den Vertreibungen vorausgingen, erwähnt werden. Dabei wird unterstrichen, dass gerade das Fehlen (tschechoslowakischer) staatlicher Autorität die Gewalt befördert habe, diese auch von anderen Gruppen ausgegangen sei und auch andere Gruppen betroffen habe,

177 Paulwitz: Union in Auflösung. Junge Freiheit. 21.01.2017.

178 Fischer: Ein gelungener Kompromiss. Der Westpreuße. Unser Danzig. 2017.

179 Die polnische Historikerin und Politikerin Małgorzata Omilanowska beobachtet, dass das Ceschehen um die SFVV in Polen medial derzeit nicht besonders aufmerksam verfolgt wird: Bundesinstitut für Kultur und Geschichte der Deutschen im östlichen Europa: Erinnerung bewahren - Zukunft gestalten, 2017, S. 50.

180 So Hołub u.a. in Bezug auf Krzysztof Ruchniewicz: Hołub: Die Stiftung Flucht, Vertreibung, Versöhnung, 2014, S. 112. Vgl. Zabłocka-Kos: Więcej intelektu, mniej emocji/More Intellect, Less Emotion, 2013, S. 86.

181 Vgl. für diese Vermutung das Interview mit dem ehemaligen Direktor des MIIW, Paweł Machcewicz: Leister: Das Danziger Weltkriegsmuseum droht ein »kleinkariertes nationalistisches Zentrum«zu werden. NZZ. 13.07.2018. 
wie Russen, Ukrainer und Ungarn. Die Gewalttaten durch tschechoslowakische Einheiten oder Partisanen könnten nicht entschuldigt werden, aber die Ausweisung der deutschen Bevölkerung "war politisch und sozial unvermeidlich«, so der in dem Artikel zitierte Historiker Jiř́ Padevět. Dies scheint das Papier für ihn nicht oder nicht ausreichend herauszustellen. ${ }^{182}$

In wissenschaftlichen Publikationen wurde das Konzeptionspapier von 2017 noch nicht erörtert, einige grundsätzliche Anmerkungen gelten jedoch auch für diese Konkretisierung des Konzeptes von 2012. So ist einer der grundlegenden Punkte das sinnvolle Zusammenführen deutscher Opfer- und Täterschaft, denn nur so sei eine Anschlussfähigkeit ins Ausland und an die bundesrepublikanische Erinnerungskultur gewährleistet. Dieses Zusammenspiel könne schließlich den individuellen Erfahrungen und Traumata der Vertriebenen gerecht werden, die ihren angemessenen Raum ohne wechselseitige Negation im weiteren historischen Kontext erhalten. ${ }^{183}$

Auch viele Kritiker der Grundkonzeption der Stiftung Flucht, Vertreibung, Versöhnung wie Tim Völkering sehen eine Existenzberechtigung für einen Ort, der die verschiedensten Zwangsmigrationsprozesse »vergleichend erforscht, dokumentiert, museal präsentiert und vermittelt [...], um Vertreibung als Menschenrechtsverbrechen zu brandmarken und als politisches Mittel in Gegenwart und Zukunft zu ächten« und so national und international eine »wichtige Aufgabe [zu] erfüllen ${ }^{184}$ Völkering identifiziert allerdings als ein Problem, dass die SFVV schließlich durch die Nichtbehandlung oder nur sehr punktuelle Präsentation der Kulturgeschichte der Deutschen Osteuropas und ihres jahrhundertelangen Zusammenlebens mit den anderen Völkern ein wesentliches Element der Gesamterzählung ausspare. ${ }^{185}$

Den im Konzept von 2017 nicht mehr prononciert in der Form verfolgten Ansatz, die Zwangsmigrationen Europas in einer Zusammenschau zu zeigen, hatte Martin Schulze Wessel 2010 entschieden kritisiert, indem durch das Zeigen eines »breiten Panoramas « »in ihren Bedingungen, Folgen und Absichten [...] grundverschiedene« Ereignisse gezeigt und damit die Gefahr einer entscheidende Differenzen negierenden Parallelisierung drohe. ${ }^{186}$ Paweł Machcewicz beschreibt das grundlegende polnische Problem mit einer Einordnung der Vertreibungen der Deutschen in eine solche europäische Reihe: Abgesehen von der grundsätzlichen Gefahr des Herunterspielens der deutschen Aggressionen und Verbrechen als Vorbedingung der deutschen Zwangsmigration sehe man das Geschehen nicht auf einer Stufe mit der Vertreibung der Bosniaken und Albaner durch die Serben. Außerdem lenke die herausgestellte und vermeintlich besondere Relevanz von Zwangsmigration für Europa von der zentralen Bedeutung des Zweiten

182 Názory na poválečné výpady vưči Němcům v ČSR se liší. České noviny. 21.06.2017.

183 Eckersley: Walking the Tightrope between Memory and Diplomacy? 2016, S. 112, 118f.

184 Völkering: Die Musealisierung der Themen Flucht, Vertreibung und Integration, 2010, S. 80.

185 Ebd., S. $95 f$.

186 Schulze Wessel: Dem deutschen Opfervolke. Süddeutsche Zeitung. 18.10.2010. Weiter wird darauf hingewiesen, dass jede Ausstellung mit einer angemessenen Darstellung von 30 verschiedenen Zwangsmigrationsprozessen zwangsläufig überfordert sein müsse: Völkering: »Flucht und Vertreibung« ausstellen - aber wie? 2011, S. 36. 
Weltkrieges und des Totalitarismus für das 20. Jahrhundert $a b .{ }^{187}$ Eine ganz ähnliche Position veröffentlichte bereits 2007 die deutsch-polnische Kopernikus-Gruppe in einem Kommentar zu den Planungen des »Sichtbaren Zeichens « und des Museums des Zweiten Weltkrieges:

»Wer die Frage der >Vertreibung`als die elementare Erfahrung des 20. Jahrhunderts darstellt, verdreht das Bild von der Geschichte Europas. Außerdem werden die tatsächlichen Ursachen der Vertreibungen, die Kriege, insbesondere der vom nationalsozialistischen Deutschland verursachte Zweite Weltkrieg, und der Totalitarismus ausgeblendet. ${ }^{188}$

Der polnische Historiker Piskorski sah 2014 bereits im Titel der Stiftung einen Beleg für einen ungeschickten Ansatz, denn dieser fehle »schon im Namen die Kontextualisierung, denn wenn nicht der Krieg gewesen wäre, die Ursache allen späteren Übels, gäbe es keinen Grund, sich überhaupt zu versöhnen. ${ }^{189}$ Ein Ausweg wäre für ihn eine europäische Stiftung, welche nicht nur den historischen Kontext des Zweiten Weltkrieges, sondern auch die bedeutende Reihenfolge der chronologischen Opfer des Krieges deutlich machen würde, nämlich zuerst die Polen und Juden, dann die Russen und schließlich die Deutschen. Er betonte, dass so ein gemeinsames Projekt entstehen könnte, in dem die deutschen Opfer auch ihren Erinnerungsort erhalten. Zugleich wäre mit einem solchen deutsch-polnischen Erfolg auch Europa gestärkt. ${ }^{190}$

Mitentscheidend für den letztendlichen nationalen und internationalen Erfolg der SFVV in Form der Anerkennung als wissenschaftlich, museumsdidaktisch und politisch relevanter Institution, wird eine breite gesellschaftliche Akzeptanz innerhalb Deutschlands ebenso wie in Europa und möglicherweise weltweit sein. Das heißt freilich nicht, dass die Stiftung Kontroversen aus dem Weg gehen soll - im Gegenteil: Der Kunstgriff muss sein, beides miteinander in einem konstruktiven Spannungsfeld zu verbinden. Bereits 2012 konstatierte die taz in Hinblick auf die gewünschte Ächtung internationaler Zwangsmigration, für die die Stiftung und die Anerkennung der deutschen Vertreibungsopfer in einem sich möglicherweise herausbildenden Erinnerungskanon nicht nur sinnvoll, sondern auch notwendigerweise miteinander zusammengebracht werden:

»Was aber spricht gegen einen möglichen Erinnerungskonsens, der die zentrale Täterschaft der Deutschen als selbstverständlichen Fakt voraussetzt und alle Opfer einschließt? Nichts, gerade mit Blick auf die Zukunft. Denn die Frage ist berechtigt: Wie kann man in Deutschland ethnische Vertreibungen anderswo ächten, wenn man Zwangsumsiedlungen von mehr als zehn Millionen Deutschen stillschweigend gutheißt? «191

187 »Eine solche Perspektive verformt das tatsächliche Bild der Ceschichte.« (»Taka perspektywa deformuje rzeczywisty obraz historii.«) Machcewicz: Spory o historie 2000-2011, 2012, S. 250.

Kopernikus-Gruppe: Mitteilung über die Sitzung der Kopernikus-Gruppe am 30.11./1.12.2007, 2007.

189 Piskorski: Zwangsmigrationen im Kontext des Zweiten Weltkriegs, 2014, S. 175.

190 Ebd., S. $175 f$.

191 Reinecke: Die Front weicht auf. taz. 05.09.2012. 


\subsubsection{Zusammenführende Betrachtung}

Wenn wir die Überlegungen des Konzeptionspapieres gemeinsam mit den Erörterungen aus Kapitel 3 und den Überlegungen zu den Anforderungen eines modernen Museums Revue passieren lassen, stechen zwei Elemente der geplanten Dauerausstellung beispielhaft hervor, die der historischen Komplexität sowie einem multiperspektivischen und damit in verschiedene Richtungen anschlussfähigen Ansatz gerecht werden. Zum einen wird mit der Diskussion der thematisch entscheidenden Begriffe in ihrer sprachlichen und nationalen Vielfalt die eigene Wahl transparent, zum anderen werden verschiedene Deutungsmuster vorgestellt. So treten die Ausstellungsmacher dem Besucher als Akteur und mit Angeboten gegenüber. Am Beispiel des vielfältigen Geschehens der letzten Januarwoche 1945 können, didaktisch ansprechend, die gesamte Komplexität von Täter- und Opferschaft in ihren Graustufen, die bis zuletzt wahnhaft fortgeführten nationalsozialistischen Verbrechen, vor allem die Shoa, ebenso wie die zwiespältige Rolle der Roten Armee als Befreier, Besatzer und Täter zugleich, gezeigt werden.

Positiv fällt ebenfalls auf, dass Opfer- und Täterperspektiven zu Wort kommen und man sich so um ein tiefergehendes Verstehen jenseits simplifizierender Narrative bemüht. Sollten, wie angestrebt, eine tatsächliche Multiperspektivtät und Transparenz den Charakter der gesamten Ausstellung prägen, kann die zukünftige Stiftung nicht nur ein Ort der Information sein, sondern eine neue Ebene der Aushandlung über Flucht und Vertreibung der Deutschen erreichen. Ohne politisch vorschnelle und historisch verkürzende Gleichsetzungen vorzunehmen, kann mit der Hervorhebung der aktuellen Relevanz des Themas Zwangsmigration Empathie sowohl für die Schicksale der Flüchtlinge und Vertriebenen am Ende des Zweiten Weltkrieges und der unmittelbaren Nachkriegszeit wie auch für die gegenwärtigen Zwangslagen von Millionen von Menschen gewonnen werden.

Der gelegentlich von Kritikern des Zentrums gegen Vertreibungen oder des "Sichtbaren Zeichens « einmal geforderte und dann wieder heftig kritisierte Ansatz, ${ }^{192}$ die Vertreibung der Deutschen in einer Reihe mit weiteren Flucht- und Vertreibungsbewegungen zu zeigen, wird in dem Konzeptionspapier im Gegensatz zu den frühen Überlegungen des ZgV in einen Kompromiss gefasst: Das Zeigen anderer in Deutschland und auch anderswo oft unbekannter Zwangsmigrationen wie die der Karelier oder der Polen aus den kresy ordnet zum einen die Vertreibungen der Deutschen historisch sinnvoll in die im 20. Jahrhundert zu ihrem traurigen Höhepunkt geführte Sozialtechnologie der gewaltsamen Massentransfers von Bevölkerungen sowie in das bis zur Obsession gesteigerte Ideal des ethnisch homogenen Nationalstaates ein. Zum anderen kann die Stiftung diesen besonders für Ost- und Südosteuropa bedeutenden und eben oft zusammenhängenden Ereignissen einen festen und ihrer Bedeutung angemessenen Platz in der Mitte Europas geben. Der Kompromiss zeichnet sich dadurch aus, dass die Vertreibungen der Deutschen noch stärker als im Konzept von 2012 und beim Zentrum gegen Vertreibungen in den Kontext des Zweiten Weltkrieges eingeordnet werden, was 
den von linksliberaler Seite in Deutschland sowie allgemein in Polen und Tschechien erhobenen Forderungen entspricht. Der bereits vor 1933 und 1939 von politisch relevanten, nationalistischen Minderheiten in Polen und der Tschechoslowakei geäußerte Wunsch, in einer nahen Zukunft ohne Deutsche (und andere Minderheiten) zu leben oder deren Zahl zumindest erheblich zu reduzieren, wird wenig beachtet. ${ }^{193}$ Die Stiftung tut aber gut daran, diesen Kreislauf der Nationalismen, der schließlich von den Nationalsozialisten in einen beispiellosen exterminatorischen Rassennationalismus geführt wurde, nur im Ansatz zu thematisieren, denn unabhängig vom historischen Forschungsstand ist ein deutscher sgeschichtspolitischer Zeigefinger in den Nachbarländern nicht vermittelbar.

Zurückhaltung zeichnet sich im Konzeptionspapier auch bei der Thematisierung der Lager ab, in denen Deutsche am Ende des Krieges interniert wurden. Im Gegensatz zu der Entscheidung zur Vertreibung liegt hier unbestritten ein beträchtlicher Teil der Verantwortung für die Art und Weise der Lagerführung bei polnischen und tschechoslowakischen Akteuren vor Ort und damit in dem sensiblen erinnerungskulturellen Feld, in dem aus ehemaligen Opfern Täter wurden. Das Museum in Kattowitz hat allerdings aufgezeigt, wie man sich auch dieser Herausforderung stellen kann, indem man die Täter möglichst konkret als Personen zeigt und so Verallgemeinerungen entgeht. ${ }^{194}$ Weiter wird im Papier die Frage der Todeszahlen weitgehend ausgeklammert, nur einmal ist von »Hunderttausenden Toten« die Rede. Dies entspricht ziemlich exakt dem unzureichenden Forschungsstand. Es wäre wünschenswert, wenn die Stiftung hier noch mehr Klarheit schaffen könnte, beispielsweise mit einem Forschungsprojekt, das sich nicht auf die deutschen Opfer beschränken müsste. Dies ist angesichts der Tatsache, dass die Vertriebenenverbände (und nicht nur diese) weiterhin die Opferzahl von zwei Millionen anführen, von besonderer Relevanz. Anschlussfähig an das vorliegende Konzept und historiographisch wertvoll wäre eine Diskussion des Terminus »Vertreibungsopfer«, die anhand der verschiedenen Phasen von Flucht und Vertreibung geführt werden und auch die Heimatverbliebenen einschließen könnte.

Die notwendige Darstellung des deutschen Völkermordes an den Juden, ohne die Vertreibungen der Deutschen und anderer Gruppen unzulässig mit diesem zu parallelisieren, ist eine weitere Herausforderung der Ausstellung. Ähnlich wie in Kapitel 3 besprochen, sollen in der künftigen Dauerausstellung, gerade durch das Aufzeigen historischer Verbindungen, die Unterschiede klar verdeutlicht werden.

Eine in Kapitel 3.7 und im deutschen, polnischen und tschechischen Diskurs immer wieder erörterte Frage wird im Konzept von 2017 nicht thematisiert: die Frage nach der Notwendigkeit der Vertreibungen. Auf die Schwierigkeiten der Argumentation für eine damals vorhandene historische Notwendigkeit und die mit ihr verbundene weniger glaubwürdige Ablehnung von Vertreibungen heute wurde schon hingewiesen. Andererseits hat die Anerkennung, dass die Vertreibung der Deutschen, wenn sie denn überhaupt als Frage der eigenen Verantwortung verstanden wird, nicht notwendig war, keine Mehrheiten in Polen und Tschechien, zumal mit diesem Verständnis der Vertreibung als Unrecht und als Fehler eine Reihe von politischen Implikationen befürchtet 
werden. ${ }^{195}$ In Polen wird zudem zu Recht darauf hingewiesen, dass die Gestaltung der politischen Situation 1945 nicht nur nicht in polnischer Hand lag, sondern das Land auch - trotz des Status als vermeintlicher Kriegsgewinner - seine Ostgebiete und Millionen seiner Bürger die Heimat verloren und 44 Jahre kommunistischer Diktatur bevorstanden. Es ist folglich nur nachvollziehbar, dass die Stiftung diese Frage nicht offensiv aufwerfen will. Ob dies letztlich durchgehalten werden kann, muss sich zeigen. So wäre auch hier, dem Charakter des Konzeptionspapieres entsprechend, ein offensiver, fragender Ansatz wünschenswert. Dem Besucher wird zwar viel abverlangt, wenn er sich auch mit aktuellen Zwangsmigrationen und Bevölkerungstransfers als >Lösung< langwieriger Konflikte auseinandersetzen soll, ${ }^{196}$ aber sein Blick für aktuelle Probleme wird geschärft und auch die Perspektiven der damaligen Situation verdeutlicht.

Jenseits der künftigen Dauerausstellung hat die bisherige Arbeit der Stiftung schon unter Manfred Kittel angedeutet, wie eine sinnvolle Umsetzung des Stiftungsauftrages erfolgen kann. Synergieeffekte zeigten sich mit Institutionen, die nach Meinung einiger Kritiker eher in einem antagonistischen Verhältnis zur SFVV stehen müssten, wie in einer gemeinsamen Ringvorlesung mit der Stiftung Topographie des Terrors oder der Stiftung Denkmal für die ermordeten Juden Europas. ${ }^{197}$ Wie oben besprochen, ist es nicht nur geschichtspolitisch sinnvoll, sondern auch historisch notwendig, hier $\mathrm{Zu}$ sammenhänge und Parallelen ebenso wie Unterschiede zu suchen und aufzuzeigen. In dieser Konsequenz kann die SFVV in der Berliner Erinnerungslandschaft eine wertvolle Ergänzung in einem bereits jetzt vielstimmigen Konzert sein. Sinnbildlich dafür steht die im Deutschlandhaus und der Dauerausstellung durch ein großes Fenster angedachte Sichtachse zur Topographie des Terrors, die aus der Ausstellung heraus unmittelbar den Blick auf einen Erinnerungsort nationalsozialistischer deutscher Verbrechen lenkt. ${ }^{198}$ Ohne Frage ist für die zukünftige Arbeit der Stiftung eine weitere Internationalisierung der Kooperationen wünschenswert, durch die auch der Versöhnungsaspekt der Stiftung unterstrichen werden könnte. ${ }^{199}$

Eine Anschlussfähigkeit an die tschechischen und polnischen Erinnerungskulturen ist im Konzept gegeben. Es entspricht zwar weniger den in den Kapiteln 3 bis 5 skizzierten Meistererzählungen, aber diese werden zum Beispiel durch die negative Instrumentalisierung der Volksdeutschen und Sudetendeutschen bei der Zerstörung ihrer Staaten ebenso wie bei der Thematisierung der NS-Verbrechen in ihren Ländern

195 Vgl. Kap. 5.3, S. 244.

196 Vgl. zur Renaissance der Zwangsmigration als vermeintliche Lösung von Konflikten: Kap. 8, S. $528 f$.

197 Vgl. hierzu z.B. die Veranstaltung »Eine unglaubliche Reise. Von Ostpreußen nach New York« vom 12.12.2013, die die SFVV gemeinsam mit der Stiftung Denkmal für die ermordeten Juden Europas, der Stiftung Neue Synagoge Berlin - Centrum Judaicum und der Stiftung Topographie des Terrors durchgeführt hat (www.sfvv.de/de/veranstaltungen/zeitzeugengespr\%C3\%A 4 ch/\%C2\%BBeineunglaubliche-reise-von-ostpreu\%C3\%9Fen-nach-new-york\%C2\%AB; letzter Zugriff: 07.03.2018). Kellerhoff: Vertriebenen-Stiftung blickt zur Cestapo-Zentrale. Die Welt. 30.11.2011.

199 Vgl. Bahr: Aufrichtiges Gedenken, 2010, S. 65. Karl Schlögel wies schon 2003 im Zuge der Diskussion um das Zentrum gegen Vertreibungen skeptisch darauf hin, dass man eine museale Institution mit einem politischen Versöhnungsauftrag nicht überfordern dürfe und dies auch nicht das Ziel einer solchen Einrichtung sein könne: Schlögel: Nach der Rechthaberei, 2003, S. 32f. Das Konzept von 2017 tut daher gut daran, im Cegensatz zu dem von 2012, den Versöhnungsaspekt weniger pathetisch zu handhaben und den Fokus entsprechend auf Verständigung zu legen. 
mit einbezogen. Von einer ursprünglich tief in der Bundesrepublik verankerten und mit dem BdV verbundenen Erinnerungskultur kommend, ist das ein sich der polnischen und tschechischen Seite zuwendender Ansatz, ohne die eigene Erzählung vollständig aufzugeben.

Mit einer gelungenen Umsetzung des ambitionierten Ausstellungskonzeptes, dem erfolgreichen Brückenschlag zu den Nachbarn, auch wenn dieser von einer Vielzahl nicht von der Stiftung beeinflussbarer Faktoren abhängt, und einer sinnvollen Anknüpfung an aktuelle Flucht- und Vertreibungsbewegungen - ohne im Kielwasser schnelllebiger geschichtspolitischer Trends die Gefahr des Kenterns einzugehen -, kann die SFVV zu einem zentralen und in Anbetracht des vorhergehenden Diskurses notwendigen Aushandlungsort der Deutschen und ihrer Nachbarn über dieses die Nationen so sehr trennende und dennoch viel mehr verbindende Thema werden. Wenn sie darauf aufbaut, kann aus ihr ein europäischer und globaler Lernort für das weiter relevante Phänomen der Zwangsmigration entstehen.

\subsection{Museum des Zweiten Weltkrieges in Danzig}

\subsubsection{Geschichte}

Am 8. November 2007 begann die junge Geschichte des MIIW, als der polnische Historiker Paweł Machcewicz in der liberalen Gazeta Wyborcza erstmals die Idee formulierte, dass der neue Ministerpräsident Donald Tusk bei seinen Antrittsbesuchen in den europäischen Hauptstädten für ein internationales Museum des Zweiten Weltkrieges in Warschau werben sollte. ${ }^{200}$ Machcewicz war geschichtspolitisch kein unbeschriebenes Blatt: Er hatte unter anderem beim Aufbau des Instituts für Nationales Gedenken mitgewirkt, die Geschichtspolitik der PiS-Regierung 2004-2007 angegriffen, sich intensiv mit dem Jedwabne-Pogrom befasst und er publiziert regelmäßig für die liberale Gazeta Wyborcza. ${ }^{201}$ Ohne Umschweife führt er in seinem Artikel den Hintergrund seines Vorschlages an: das deutsche Gedenken an die Vertreibungen. Zwar sei der gerade gefundene Kompromiss in Deutschland, dass das »Sichtbare Zeichen« unter der Trägerschaft des Deutschen Historischen Museums entstünde, kein Sieg für den BdV, dennoch würden damit die Erwartungen aus Polen nicht ausreichend erfüllt. In einem kurzen Abriss skizziert Machcewicz die Problematik, dass es in weiten Teilen der deutschen Gesellschaft die Sichtweise gebe, Flucht und Vertreibung viel weniger im Kontext des Zweiten Weltkrieges als in dem der ethnisch homogenisierenden Nationalstaaten und ethnischen Säuberungen des 20. Jahrhunderts zu sehen. Mit dieser Perspektive gehe zwar zumeist einher, dass die Polen im Zweiten Weltkrieg unfraglich Opfer der Deutschen geworden seien, am Ende aber Täter wurden, die sich an unschuldigen Deutschen vergingen. Dem folge eine unzulässige Parallelisierung des Geschehens und des polnischen Handelns mit beispielsweise den serbischen Verbrechen an Bosniern und Albanern in den Balkankriegen. Dieses Narrativ »verformt aber das tatsächliche Bild

200 Machcewicz: Muzeum zamiast zasieków. Gazeta Wyborcza. 08.11.2007.

201 Pilawski: Über das Tusk-Museum, 2010, S. 68. Vgl. zum Institut: Kap. 5.2, S. 228. 
der Geschichte. Aber nicht nur das. Es relativiert auch - nicht direkt, vielmehr durch einen ganz bestimmten Blickwinkel auf das 20. Jahrhundert - die Außergewöhnlichkeit der Erfahrungen sowohl des Zweiten Weltkriegs wie auch der Totalitarismen. ${ }^{202}$ Eine derartige Erzählung stehe daher im größten Konflikt mit dem historischen Gedächtnis Polens. Aber auch der deutsche Fokus auf dieses Thema sei ein historisch falscher Schwerpunkt, denn »[...] die Erinnerungen an die Zwangsumsiedlung - der Polen und der Deutschen - sind weniger wichtig und schmerzhaft als Auschwitz und Katyń, die zivilen Opfer des Warschauer Aufstands und der seit Beginn des Krieges von den deutschen Besatzern verfolgten Ausrottungspolitik. « ${ }^{203}$

Nach den Regierungswechseln in Deutschland und Polen 2005 erstarrte die vielversprechende Gründung des gemeinsamen Europäisches Netzwerk Erinnerung und Solidarität im Jahr 2004. Die Große Koalition in Deutschland beschloss im Koalitionsvertrag, ein »Sichtbares Zeichen« für die Erinnerung an die Vertreibung in der deutschen Hauptstadt einzurichten. Machcewicz sah darin »keine freundliche Geste« gegenüber Polen, die aber auch durch das Desinteresse der PiS-Regierung an einer gemeinsamen Lösung mit bedingt war. Aber wie solle man nun darauf reagieren? Wenig vielversprechend sei eine Isolation, ein Hochziehen von »Stacheldrähten«, vielmehr solle Donald Tusk als Gegengewicht zum »Sichtbaren Zeichen« für ein Museum werben, das sich durch eine internationale Kooperation von Regierungen und Wissenschaftlern auszeichne. In diesem Museum könne schließlich ein Gesamtbild des Zweiten Weltkrieges gezeigt werden, welches weltweit noch nicht zu finden sei. Es böte gerade aus Sicht Ostmitteleuropas die Chance, auch den sowjetischen Totalitarismus ${ }^{204}$ ebenso wie die besondere Grausamkeit der deutschen Besatzungsherrschaft in Osteuropa herauszustellen. Eben genau bei diesen Themen sehe man sich in Westeuropa oft mit Unkenntnis und Missverständnissen konfrontiert ${ }^{205}$ und so sei es summa summarum eine konstruktive Antwort auf einen schon viel zu lange schwelenden deutsch-polnischen Konflikt und zugleich eine gute Chance, polnische Interessen bei der Konstitution eines gemeinsamen europäischen Gedächtnisses einzubringen.

Anfang Dezember 2007 gab Donald Tusk der FAZ ein Interview, in dem er den Vorschlag von Paweł Machcewicz aufgriff. Zunächst betonte auch er, dass für Polen

202 »Taka perspektywa deformuje rzeczywisty obraz historii. Ale nie tylko. Relatywizuje ona - nie wprost, lecz dzięki przyjętej optyce patrzenia na XX wiek - wyjątkowość doświadczenia i II wojny światowej, i totalitaryzmów [...].«Vgl. auch Kap. 7.1.6, S. $406 \mathrm{f}$.

203 »A w pamięci tej przymusowe przesiedlenia - Polaków i Niemców - są znacznie mniej istotne i bolesne od Auschwitz i Katynia, hekatomby ludności cywilnej w trakcie Powstania Warszawskiego, eksterminacyjnej polityki prowadzonej od początku wojny przez niemieckiego okupanta.«

204 Machcewicz ist die westeuropäische Totalitarismusdiskussion wohl bekannt. Die Planungen des MIIW zielen daher von Anfang darauf, die Verbrechen der Sowjetunion und NS-Deutschlands darzustellen, ohne eine Gleichsetzung vorzunehmen oder eine Diskussion zu führen, »welches der beiden Systeme verbrecherischer war und warum«, die ohnehin unlösbar oder »sogar nutzlos« sei: Machcewicz: »Museum statt Stacheldrahtverhaue«, 2012, S. 86.

205 Was sich nach Machcewicz zum Beispiel bei der deutschen und westeuropäischen Empörung über die ehemalige lettische Außenministerin und spätere EU-Kommissarin Sandra Kalniete gezeigt hat, die betonte, dass die beiden Totalitarismen, Nationalsozialismus und Kommunismus, gleichermaß verbrecherisch gewesen seien: Machcewicz: Das Museum des Zweiten Weltkrieges in Danzig, 2009, S. 2. 
die klare Verteilung von Täter und Opfer im Narrativ des Zweiten Weltkrieges unbestreitbar sei, dieses jedoch durch das Projekt von Erika Steinbach und nun durch das "Sichtbare Zeichen« sowie die damit verbundene Neujustierung der »Hierarchie der historischen Verantwortung« in Frage gestellt werde. Als eine mögliche, bessere Alternative zu einem von Polen mitgetragenen "Sichtbaren Zeichen "schlug er ein Museum des Zweiten Weltkrieges in seiner Heimatstadt Danzig vor, die sich aus historischen Gründen dafür bestens eigne. Zugleich sieht Krzysztof Pilawski in der Wahl Danzigs einen Versuch Tusks, dieses als »Hauptstadt des liberalen Polen« zu stärken und das polnische Narrativ, dass der Zweite Weltkrieg 1939 dort begann und schließlich erst in den 1980ern ebenfalls dort niedergerungen wurde, global wirksam zu bewerben. ${ }^{206}$ Es solle ein deutsch-polnisches, ein europäisches Projekt werden, nach Möglichkeit mit Beteiligung Russlands und Israels: »Alle Dimensionen dieser Weltkriegstragödie waren hier präsent. Möglicherweise können wir im Gespräch über ein solches Projekt dann auch den beschämenden und unendlichen Streit um das Gedenken an die Vertriebenen beenden. ${ }^{207}$ Die Resonanz auf Tusks Vorschlag blieb in Deutschland verhalten, wohingegen das Vorhaben in Polen schließlich mit Elan vorangetrieben wurde. ${ }^{208}$ Dem Gründungsimpuls folgten unmittelbar konkrete Aktivitäten: Machcewicz arbeitete im Beraterstab von Premierminister Tusk unter anderem an der Ausarbeitung einer ersten Konzeption, die schon 2008 vorgestellt werden konnte. ${ }^{209}$ Der sich zentral um die Frage von Flucht und Vertreibung der Deutschen drehende Gründungsimpuls des MIIW wurde bald völlig überschattet von den jahrelangen Streitigkeiten zwischen Nationalkonservativen und Nationalliberalen.

Neben der erwähnten außenpolitischen Argumentation ist das Museumsprojekt noch in zwei weitere Phänomene einzuordnen: Zum einen ist das Museum ein Teil des in Kapitel 5.2 diskutierten polnischen Museumsbooms der 2000er Jahre, zum anderen ist es auch als eine >Antwort « von PO-Ministerpräsident Donald Tusk auf das Museum des Warschauer Aufstandes zu verstehen, das der damalige Warschauer Stadtpräsident Lech Kaczyński initiierte und 2004 eröffnete. Mit modernen Mitteln und einer emotionalen Herangehensweise präesentiert dieses die Erzählung des heroischen Polen. ${ }^{210}$ Ohne Frage sind auch für die Nationalliberalen der Warschauer Aufstand und die Armia Krajowa entscheidende positive Bezugspunkte der historischen Identität. Dennoch steht das Museum des Warschauer Aufstandes für die klassische, nach innen gewandte polnische Heldenerzählung, in der die Polen nicht nur allein, sondern einmal mehr verraten und für das größere Ganze eintretend, einen Aufstand verloren. Davon unter-

206 Pilawski: Über das Tusk-Museum, 2010, S. $65 f$.

207 Schuller: »Die Ceschichte ist wieder Ballast«. FAZ. 10.12.2007.

208 Pilawski: Über das Tusk-Museum, 2010, S. 68.

209 Vgl. zu dieser Gründungsphase: Machcewicz: Muzeum, 2017, S. 57-62. Machcewicz sieht selbst die besondere politische Nähe bei diesem Vorhaben, betont aber die völlige akademische Freiheit für das Ausstellungsteam, auch wenn Donald Tusk am Vorhaben persönlich äußerst interessiert war. Vgl. Heinemann: Krieg und Kriegserinnerung im Museum, 2017, S. 10. Peters spricht von einem »Konkurrenzprojekt«zum Aufstandsmuseum in Warschau: Peters: Polens Streitgeschichte kommt ins Museum, 2015. 
schieden sich Machcewicz' Planungen für das MIIW, ähnlich der politischen Ausrichtung der Nationalliberalen um die PO, durch eine patriotische Weltzugewandtheit. ${ }^{211}$

Im ersten Konzeptionspapier formulierte Machcewicz gemeinsam mit seinem späteren Vize-Direktor und Experten für sudetendeutsche Geschichte ${ }^{212}$ Piotr M. Majewski 2008 den universellen, auf das Leiden der Zivilbevölkerung fokussierten Ansatz, der explizit die Kriegserfahrungen der Deutschen und Russen erwähnt:

»The War-time history of Poland and the Poles will understandably be the Museum's focus, both because of its location and the fact that it is being created as a Polish initiative. But this focus will not diminish the experiences of other nations, including the Cermans and the Russians. Although we would like to present Poland's war losses, military efforts and the suffering of its civilians, it is not our intention to create a museum devoted solely to either the Polish nation's martyrdom or the glory of the Polish armed struggle. Rather, it is to be a place with universal appeal in which the events that took place in Poland represent only one piece of a bigger picture. [...] « ${ }^{213}$

Mit einem vergleichenden Ansatz soll das Ausstellungsnarrativ die Unterschiede zwischen den Kriegserfahrungen in West- und denen in Osteuropa thematisieren: Beispielsweise könne so anhand der Darstellung der Okkupation Frankreichs und Polens durch NS-Deutschland der unterschiedliche Charakter der Besatzung aufgezeigt werden. ${ }^{214}$ Die zeitliche Eingrenzung auf 1939-1945 soll allerdings nicht die Vorgeschichte des Krieges in Europa (und in Asien) sowie die Nachgeschichte des Kalten Krieges als entscheidendes Resultat des Zweiten Weltkrieges ausblenden. ${ }^{215}$ Das Museum verstehe sich schließlich weniger als militärhistorisches denn als kultur- und politikhistorisches Haus, ohne dass es militärtechnische Aspekte ausblendet. ${ }^{216}$

Für die in dieser Arbeit verfolgte Fragestellung ist das in dem Papier behandelte zukünftige Ausstellungskapitel der forced migrations interessant, das separat oder ergänzend zu den Themen des Leidens der Zivilbevölkerung dargestellt werden soll. Hier beginnt die Chronologie der Vertreibungen unmittelbar nach Kriegsanfang, also mit der erzwungenen Umsiedlung bis hin zur gewaltsamen Vertreibung von Teilen der polnischen Bevölkerung in den durch Deutschland eroberten Gebieten. Ebenfalls Raum sollen die Umsiedlungen der Volksdeutschen und die sowjetischen Massendeportationen erhalten, genauso wie die radikalen `Siedlungspläne des Generalplan Ost. Auch der Transport der Juden in die Ghettos wird in diesem Rahmen behandelt. ${ }^{217}$ Diese als Hintergrund zu verstehenden Prozesse sollen um die Darstellung der während Flucht

211 Vgl. Peters: Polens Streitgeschichte kommt ins Museum, 2015.

212 Vgl. Majewski: »Niemcy Sudeccy«, 2007. Siehe Kap. 3.3, S. $107 f$.

213 Machcewicz; Majewski: The Museum of the Second World War in Poland, 2008, S. 2 f.

214 Ebd., S. 3.

215 Ebd.

216 Ebd., S. $3 f$.

217 Ebd., S. 10. Majewski betont den umfassenden Ansatz der Darstellung von Zwangsmigration im Museum: »The displacement of populations must be shown in their totality and complexity. These will include not only the displacements that usually come to mind, but also the often forgotten movements of large numbers of people [...].« Majewski: The Topic of Forced Migration in the Planned Museum of the Second World War in Cdańsk, 2010, S. 126. 
und Vertreibung weiter fortlaufenden NS-Verbrechen herum das historische Geschehen kontextualisieren. Eine solche Präambel und Einordnung ist nach den Verfassern des Papieres der unbedingt notwendige Zusammenhang, auf die Flucht und Vertreibung der Deutschen einzugehen:

»lt is only against this background that we should show the flight of Cerman civilians before the arriving Red Army and the expulsions of Cermans from Poland, Czechoslovakia, Hungary and Yugoslavia (especially the swild Conference, which will fit into the exhibition's chronological sequence). This is one of the most important sections of the exhibition: it will argue that the forcing out of Cermans after the end of the War did not stem only from the universal efforts to form nationally uniform states - as the German Federation of Expellees claims - but, above all, was a continuation of the forced migrations conducted on an unprecedented scale by the Third Reich and the USSR. In this section, we must also note that even at this most tragic moment for the Cerman civilian population - fleeing the Red Army - Cerman crimes (the death marches from Auschwitz and other camps) continued. For instance in Palmnicken, near Pilau on the Baltic coast, on 31 January 1945, the day after the sinking of the Wilhelm Custloff, 3,000 prisoners driven out of the East Prussian sub-camps of the Stutthof concentration camp were killed, while several thousand other prisoners died or were murdered during the sevacuation<. [...] These facts appear as particularly significant in view of the Museum's location in Cdańsk, and also have symbolic value since one of the main routes of escape for the Cerman civilian population from East Prussia went through the port of Pilau nearby. $\ll^{218}$

Die Formulierung, Flucht und Vertreibung der Deutschen seien »one of the most important sections of the exhibition«, ist gewiss dem Gründungsimpuls zuzuschreiben, eine umfassende Alternative zu den Berliner Planungen zu schaffen. Auch Machcewicz stellte später fest, dass die Gründungszeit von langen Diskussionen über diesen Themenbereich und mit diesem verbundenen begrifflichen Fragen geprägt war, auch wenn die Thematik im späteren Verlauf der Ausstellungsplanung in Hinblick auf die Gesamtausstellung an Bedeutung verlor. ${ }^{219}$ Interessant ist zudem Machcewicz' Kritik an den Berliner Planungen aufgrund ihrer vermeintlich ausschließlichen BdV-Perspektive. Die ihr zugeschriebene Argumentation, die Betonung des ethnischen Nationalismus von

218 Machcewicz; Majewski: The Museum of the Second World War in Poland, 2008, S. 10f.

219 »Ich erinnere mich an die langen Diskussionen über die Verortung von Zwangsumsiedlungen in der Ausstellung, ihre Definitionen und ihre Terminologie. Gemäß dem Standpunkt des Kollegiums, der auf Initiative von Włodzimierz Borodziej angenommen wurde, verwenden wir drei Konzepte, die je nach Kurs, Rechtmäßigkeit und Ausmaß der Zwangsmaßnahmen: >Umsiedlung, Deportation, Vertreibung sind.« (»Pamiętam długie dyskusje nad miejscem na wystawie przymusowych przesiedleń, ich definicji i stosowanej w odniesieniu do nich terminologii. Zgodnie ze stanowiskiem Kolegium, przyjętym z inicjatywy Włodzimierza Borodzieja, używamy trzech pojęć, w zależności od ich przebiegu, legalności, skali stosowanego przymusu: sprzesiedlenia, deportacje, wypędzeniar.« Machcewicz: Muzeum, 2017, S. 132. Machcewicz konstatierte weiter, dass nach Jahren der Arbeit und der fortlaufenden deutsch-polnischen Diskussion die Zwangsumsiedlungen weiterhin ein wichtiger Teil der Ausstellung seien, aber die emotionalen, heftigen und kontroversen Diskussionen der Gründungsphase des Museums vorbei wären: ebd., S. $24 \mathrm{f}$. 
Polen und Tschechen als Mitursache der Vertreibung der Deutschen wird so für das eigene Ausstellungsnarrativ abgelehnt und in seiner vermeintlich zentralen Bedeutung zurückgewiesen.

Als Beispiele für die Verbrechen der Roten Armee an der Zivilbevölkerung könnten dem Papier nach die Diskussion des Massakers von Nemmersdorf und die Geschehnisse beim Einmarsch der sowjetischen Streitkräfte in Oberschlesien dienen. ${ }^{220}$ Dem antitotalitären Narrativ des Museums folgend, wird Zwangsmigration als de facto ausschließliches Instrument totalitärer Regimes betrachtet. ${ }^{221}$ Diese ersten Ideen, noch entfernt von den Fragen der konkreten Umsetzung, schließen mit dem Appell, ein $\mathrm{Mu}-$ seum für die europäische und weltweite Tragödie zu schaffen und damit die Botschaft zu vertreten, dass es sich hier weniger um Konflikte von Nationen als um eine Tragödie der Menschheit handelt:

»In general, the display should not be chronological but follow its thematic axes. These will paint the picture of the Second World War as a >European (or even world) tragedy (Jerzy Holzer [...]), which shows the War as a product of totalitarian rule, under which crimes were radicalised beyond anything humanity had known until that time, and primarily through the prism of the suffering of civilian populations. ${ }^{222}$

Majewski fasste 2010 nochmals die Idee des Museums knapp zusammen:

»The museum concept [...] intends that Poland's wartime experiences will be shown in the broad context of European and world events. Its exhibition will focus on the fortunes of individuals and societies, with military history serving as the background for its narrative about the everyday lives of civilians and soldiers, the terror of occupation, genocide, diplomacy, and big power politics. $\ll^{223}$

In den Jahren 2008/2009 wurde in der polnischen Presse eine Debatte über die Ausrichtung des Museums geführt. Die Zeitschrift Przegląd Polityczny stellte das Konzept von Machcewicz und Majewski vor und zur Diskussion. ${ }^{224}$ In diesem liberalen, sozialliberalen und nationalliberalen Milieu erhielt es viel Zustimmung, auch als passende Antwort auf die deutschen Vorhaben. Der polnische Historiker, Philosoph und Museumsexperte Krzysztof Pomian betrachtete in einem ebendort erschienenen Kommentar

220 Machcewicz; Majewski: The Museum of the Second World War in Poland, 2008, S. 6.

221 Majewski spricht von »Forced migrations as an instrument of totalitarian regimes«, die dieses für die rassische oder soziale >Neuordnung von Gebieten bis hin zum Genozid nutzten: Majewski: The Topic of Forced Migration in the Planned Museum of the Second World War in Cdańsk, 2010, S. $126 f$.

222 Machcewicz; Majewski: The Museum of the Second World War in Poland, 2008, S. 13.

223 Majewski: The Topic of Forced Migration in the Planned Museum of the Second World War in Gdańsk, 2010, S. 125.

224 Machcewicz; Majewski: Muzeum II Wojny Światowej, 2008. An der Diskussion in der Przegląd Historyczny beteteiligten sich neben Machcewicz und Majewski: Władysław Bartoszewski, Tomasz Szarota, Jerzy Borejsza, Jerzy Holzer, Zbigniew Cluza, Jerzy Halbersztadt, Andrzej Chwalba, Robert Traba, Tomasz Łubieński, Krzysztof Komorowski, Piotr Kłoczowski, Grzegor Mazur, Andrzej Przewoźnik, Rafał Wnuk, Andrzej Cąsiorowski, Bogdan Chrzanowski, Andrzej Krzysztof Kunert: Wokół idei muzeum II wojny światowej, 2008. 
eine deutsche und auch russische Beteiligung am Museum als fundamental. ${ }^{225}$ In Hinblick auf die zentrale Erzählung des Museums stellte er fest, dass in der Gegenwart alle Opfer des Krieges, auch die der Deutschen, wie die eigenen zu betrachten wären. Das hieße aber nicht, die Frage der Verantwortung auszuklammern:

»Heute müssen wir deutsche Opfer behandeln, wie wir unsere behandeln. [...] Nur auf die Frage: Wessen Opfer?, lautet meine Antwort: Adolf Hitlers, und nicht die des Kapitäns, welcher die Custloff torpedierte. [...] Aber heute müssen wir zivile Opfer wie Opfer des Nationalsozialismus betrachten. ${ }^{226}$

Nationalkonservative Kritiker äußerten sich wiederholt in der Rzeczposopolita. So fassten Piotr Semka und Cesary Gmyz ihre Kritik an dem universalistischen Konzept des Museums in einem Artikel zusammen. Sie sahen in diesem die polnische und als exzeptionell verstandene Erfahrung zu wenig berücksichtigt und wiesen zugleich auf alle anderen Staaten der Welt hin, die in ihren Museen nationale Heldengeschichte erzählen - und beklagten nun, dass die Polen davon eine Ausnahme machen müssten. Ein Problem der Universalisierung sahen sie in der Entkontextualisierung der verschiedenen Opfergruppen, die aus deutscher Sicht zwar wünschenswert sei, aber aus polnischer Sicht inakzeptabel. Zugleich befürchteten sie, dass unter dem Deckmantel der »Europäisierung« vor allem die deutschen Vertriebenenverbände ihre geschichtspolitische Agenda durchsetzen könnten. Durch die vielfache Betonung der Bedeutung der Zwangsmigration im 2008er Papier sahen Semka und Gmyz den Einzug einer deutschen »Mode« über die Oder hinweg. Auch wenn man die Bedeutung der verschiedenen Zwangsmigrationen im Zweiten Weltkrieg nicht bestreite, sei diese doch für die Polen nicht das entscheidende Erinnerungsmerkmal. ${ }^{227}$ Auch Jarosław Kaczyński äußerte sich 2008 als Oppositionsführer im Sejm in diesem Sinne zu den Planungen des Museums:

»Es geht um all das, was heute in Deutschland passiert, und was im Grunde genommen eine Neudefinition des moralischen Sinns, und damit aber auch des politischen Sinns des Zweiten Weltkrieges ist. [...] Was sollte es zeigen? Das polnische Martyrium (Beifall) oder die Leiden der Deutschen? Also [...] es sollte das polnische Martyrium zeigen (Beifall), den Holocaust, der die Polen betraf, denn sonst, um das einmal deutlich zu sagen, erklären wir uns einverstanden damit, dass die Verbrechen von einigen nationalitätslosen Nazis begangen wurden, während in Polen polnische Todesfabriken existierten $[\ldots] . \ll^{228}$

225 »Ohne volle Beteiligung Deutschlands ergibt das Museum meiner Meinung nach keinen großen Sinn.« (»Bez pełnego udziału Niemiec to muzeum nie miało by moim zdaniem wielkiego sensu.«) Pomian: Muzeum pojednania, 2008, S. 63, 65.

226 »Dzisiaj musimy traktować ofiary niemieckie tak, jak traktujemy nasze.« [...] »Tylko na pytanie: czyimi ofiarami?, moja odpowiedź brzmi: Adolfa Hitlera, a nie tego sowieckiego kapitana, który wysłał torpedę i zatopił Gustloffa [...].«[...]»Ale teraz musimy patrzeć na ofiary cywilne jak na ofiary nazizmu.«Ebd., S. 65.

227 Gmyz; Semka: Przypominajmy światu polską historię. Rzeczpospolita. 03.11.2008.

228 »]est sprawa tego wszystkiego, co się dzisiaj w Niemczech dzieje, a co w istocie oznacza redefinicję sensu moralnego, a więc także politycznego drugiej wojny światowej. [...] O czym ono ma mówić? O polskiej martyrologii czy o krzywdach Niemców? Otóż [...] ono powinno mówić o polskiej martyrologii (Oklaski), o holokauście, który dotyczył Polaków, bo inaczej to, realnie rzecz biorąc, 
Im Laufe der Gedenkzeremonien zum Kriegsausbruch am 1. September 2009 auf der Danziger Westerplatte, an denen 20 Staats- und Regierungschefs teilnahmen, darunter Wladimir Putin und Angela Merkel, unterzeichnete Donald Tusk feierlich die Gründungsurkunde des Museums. ${ }^{229}$ Zeitgleich konnte eine erste dauerhafte Freiluftausstellung des MIIW auf der Westerplatte eröffnet werden. ${ }^{230}$ Im folgenden Jahr übernahm das Europäische Parlament die Schirmherrschaft über die Arbeiten an der Dauerausstellung des Museums. ${ }^{231}$ Auch wenn die öffentlichen Auseinandersetzungen über das Museum zurückgingen, äußerte sich Jarosław Kaczyński 2013 beim Kongress der PiS in aller Deutlichkeit gegen den Charakter des Vorhabens und grundsätzlich zu einer Neuausrichtung der polnischen Geschichtspolitik und kündigte an, die PiS wolle

»die Form des Museums des Zweiten Weltkriegs verändern, so dass die Ausstellung in diesem Museum den polnischen Standpunkt ausdrücken würde«

Und es ginge schließlich insgesamt darum, eine

»[...] neue, aktive, auf die Verteidigung der polnischen Würde und polnischen nationalen Interessen konzentrierte Ceschichtspolitik zu verfolgen. Es steht in engem Zusammenhang mit der Bildungspolitik, denn die Gestaltung der Identität junger Polen [...] muss nicht auf Scham basieren - wie es heute geschieht - sondern nur auf Würde und Stolz. ${ }^{232}$

Spätestens mit dieser Äußerung wurde deutlich, dass dem Museum und seinen Planern nach einer Regierungsübernahme durch die PiS ein rauer Wind entgegenwehen würde. Mit dem Doppelsieg der PiS im Jahr 2015 - zunächst bei den Präsidentschaftswahlen und schließlich bei den Parlamentswahlen - standen die Zeichen entsprechend auf Sturm. ${ }^{233}$ Zuvor konnte im Sommer 2015 eine im Europäischen Solidarność Zentrum gezeigte temporäre Ausstellung aus Anlass des 70-jährigen Jahrestages des Endes des Zweiten Weltkrieges "1945 - Das Ende des Krieges in 45 Exponaten « einen ersten Einblick in die geplante Dauerausstellung geben. ${ }^{234}$ In dieser das Kriegsende und die für Polen mit diesem verbundene Widersprüchlichkeit zwischen deutscher Besatzung und

zgadzamy się z tym, że zbrodni dokonali beznarodowi naziści, natomiast w Polsce istniały polskie fabryki śmierci [...].«Sejm Rzeczypospolitej Polskiej: Sprawozdanie Stenograficzne z 29 posiedzenia Sejmu Rzeczypospolitej Polskiej, 2008, S. 170. Vgl. Machcewicz: »Museum statt Stacheldrahtverhaue $\ll, 2012$, S. $95 f$.

229 Vgl. Musioł: Westerplatte, 2010, S. 4.

230 Vgl. für eine kritische Besprechung der Ausstellung auf der Westerplatte: Boysen: Militär- und Kriegsmuseen in Deutschland und Polen, 2012, S. $51 f$.

231 Machcewicz: »Museum statt Stacheldrahtverhaue«, 2012, S. 102.

232 „zmienić kształt Muzeum II Wojny Światowej, tak żeby wystawa w tym muzeum wyrażała polski punkt widzenia [...] nowa, aktywna, nastawiona na obronę polskiej godności i polskiego interesu narodowego polityka historyczna. Ona wiąże się ściśle z polityką oświatową, bo kształtowanie tożsamości młodych Polaków [...] musi opierać się nie o wstyd -jak to dzisiaj się robi-tylko o godność i dumę«. Kaczyński zapowiada aktywną politykę historyczną. dzieje.pl. 29.06.2013.

233 Vgl. Kap. 5.2, S. 239.

234 Ausstellungskatalog: Museum of the Second World War: 45 End of War in 45 Artefacts, 2015. Vgl. für eine Vorstellung der Ausstellung, die as »a preview of the exhibiting philosophy and the range of artefacts at the disposal «des Museums betrachtet wurde: Müller: When History Speaks Through Objects..., 2015 . 
kommunistischer Diktatur fokussierenden Ausstellung hatte »The fate of the Germans after the war « einen für sich stehenden Platz und war eines der neun behandelten Themen sowie präsent mit fünf von 45 Objekten. ${ }^{235}$

Im April 2016 erfolgte schließlich der institutionelle Angriff auf das MIIW in seiner bisherigen Form durch den Minister für Kultur und Nationales Kulturerbe, Piotr Gliński. ${ }^{236}$ Um das rechtliche Problem zu umgehen, dass Paweł Machcewicz einen gültigen Arbeitsvertrag bis 2019 hatte, entschied man sich für den Weg, das MIIW mit einem bis dato nicht existenten, zuvor gegründeten und nur auf dem Papier existierenden »Museum der Westerplatte « zusammenzulegen. ${ }^{237}$ Diese Konstruktion erlaubte es, das Team neu zu konstituieren und Machcewicz abzusetzen, dessen Museum formal nun nicht mehr existierte. Das Vorgehen wurde schließlich von Machcewicz auf dem Rechtsweg noch bis zum Frühjahr 2017 aufgehalten. ${ }^{238}$

Zuvor wurde über den Fortschritt des Museumsprojektes im Ausland wie auch in Deutschland nur gelegentlich (und wohlwollend) berichtet. ${ }^{239}$ Das aggressive Vorgehen der PiS-Administration gegenüber dem MIIW löste nun unmittelbar ein starkes internationales Medienecho aus, wobei sich der größte Teil der Stimmen der Berichterstattung mit dem Team um Paweł Machcewicz solidarisierte. ${ }^{240}$ In der Rheinischen Post hieß es in schöner Bildersprache:

»Ministerpräsidentin Beata Szydlo kündigte in ihrer Regierungserklärung an, künftig nur noch solche Projekte finanziell zu fördern, die sPolen und der Welt von unseren Helden erzählen<. In dieses Konzept, das einer Geschichtswaschmaschine ähnelt, in der alle möglichen Flecken auf der eigenen historischen Weste möglichst entfernt werden, passte das Danziger Weltkriegsmuseum von vornherein nicht hinein. Es war deshalb nur eine Frage der Zeit und der Gelegenheit, bis die PiS-Regierung den Ausstellungsmachern um Pawel Machcewicz in die Parade fahren würde. ${ }^{241}$

Timothy Snyder, Mitglied des Wissenschaftlichen Beirates des MIIW bis Januar 2018, äußerte sich an verschiedenen Stellen prononciert für die bisherige Leitung und Ausrichtung des MIIW und gegen die PiS-Politik. Die große Innovation und Einmaligkeit des Museums, sein historisch-kritischer, darum aus polnischer Perspektive aber nicht unpatriotischer Ansatz, könnte der Welt einen wichtigen Lernort geben. Zudem gebe es kein besseres Vorgehen, um der globalen Öffentlichkeit die polnische Geschichte in

235 Vgl. Vetter: Politisches Gedenken - Polen und der 8. Mai 1945, 2015.

236 Vgl. die Beschreibung bei: Machcewicz: Muzeum, 2017, S. 168-180.

237 Vgl. Puttkamer: Europäisch und polnisch zugleich, 2017, S. 4.

238 Siehe: Hassel: Die Panzer müssen stolzer werden. Süddeutsche Zeitung. 24.10.2016.

239 Vgl. z.B.: Marschall: Polens Gedächtnis wird europäisch. Der Tagesspiegel. 06.10.2014.

240 Vgl. z.B.: Donadio: A Museum Becomes a Battlefield Over Poland's History. New York Times. 09.11.2016. Die NYT sieht das Schicksal des Museums in weiteren europäischen Entwicklungszusammenhängen: »Conceived nearly a decade ago in a moment of pan-European optimism, the Museum of the Second World War here seeks to tell a story of devastation that transcended national boundaries. «Vgl. auch: Gera: Polish leaders threaten fate of nearly finished WWII museum. The Washington Post. 24.04.2016.

Krökel: Polen will Kriegsgeschichte umschreiben. Rheinische Post. 13.05.2016. 
ihren Vernetzungen darzustellen. ${ }^{242}$ Stattdessen sei die drohende »Liquidation des $\mathrm{Mu}$ seums noch vor seiner Eröffnung [...] nichts weniger als ein brutaler Schlag gegen das kulturelle Erbe dieser Welt. « ${ }^{243}$ Włodzimierz Borodziej äußerte sich weniger pathetisch, aber in dieselbe Richtung: Mit dem Angriff auf das Museum gelte es, »das Flaggschiff einer liberalen Geschichtspolitik in Ostmitteleuropa « zu versenken. ${ }^{244}$ Immer wieder wird in diesem Zusammenhang die PiS-Geschichtspolitik in die Nähe der autoritären Herrschaft Putins gerückt. ${ }^{245}$ Häufiger noch wird ein Vergleich zur Volksrepublik Polen gezogen, so unter anderem von Norman Davies, der der PiS-Regierung einen »bolschewistisch-paranoiden « Umgang in Bezug auf den internationalen Charakter des Museums und eine generelle »Rückkehr zu einer Kulturpolitik im kommunistischen Stil« unterstellt. ${ }^{246}$

Bei der Verteidigung seiner Konzeption im Kulturausschuss des Sejms im Juni 2016 wurde Machcewicz als Volksverräter und als Knecht der Deutschen beschimpft: »Ich wurde geradezu verbal gelyncht «. ${ }^{247}$ Die Kritik am Vorgehen der PiS-Regierung aus dem Ausland, zumal die aus Deutschland, traf auf umso härteren Widerstand der Nationalkonservativen. So äußerte sich der Historiker Bogdan Musiał in einem Meinungsbeitrag in einem vom polnischen Außenministerium betriebenen Onlineblog, in dem er die Verteidigung eines noch nicht eröffneten Museums kritisierte. Ebenso griff er die massiv steigenden Kosten und Verzögerungen des Projektes an, worin er den eigentlichen Skandal sah: »This is a huge scandal and a waste of taxpayer's money on a monumental scale«, wofür die Vorgängerregierung Tusk die Verantwortung zu übernehmen hätte. Abschließend verbat er sich jede Kritik aus Deutschland, welches seinen erfolgreichen Umgang mit der NS-Vergangenheit vor sich hertrage, der allerdings ein nicht auf Fakten basierender Mythos sei (»But this is a myth, which is not based on facts.«): Schließlich hätten die Deutschen - unter dem Strich - NS-Verbrecher kaum juristisch bestraft. Nach Musiał wurde darüber hinaus, seiner Kenntnis nach, kein einziger Deutscher in der Bundesrepublik wegen Massenverbrechen an ethnischen Polen verurteilt. Solange Deutschland dafür keine Verantwortung übernehme, gelte: »[...] Germany's moralistic tone and frequent demands that Poland accounts for its past are completely out of place. $\ll^{248}$

Das Vorgehen gegen das Museum begründete Gliński schließlich unter anderem mit drei umfassenden Rezensionen des Museumsprojektes. Diese hatte sein Ministerium mit dem Ziel der inhaltlichen Evaluation des Vorhabens nach der Amtsübernahme in

242 Vgl. für die entsprechende Zusammenfassung von Snyders Gedanken: Logemann: On >Polish History<, 2017.

243 Snyder: Die Tragödie verstehen lernen. taz.am Wochenende. 04.06.2016.

244 So Borodziej im Interview: Augstein: Abschied von Europa. Süddeutsche Zeitung. 19.05.2016.

245 Ebd.

246 Logemann: On >Polish Historyく, 2017. Hassel: Die Panzer müssen stolzer werden. Süddeutsche Zeitung. 24.10.2016.

247 So Machcewicz: Brandt: Das Museum des Anstosses. Tages Anzeiger. 13.10.2016. Vgl. auch den Bericht von Machcewicz in seinem Buch: Machcewicz: Muzeum, 2017, S. 189-204.

248 Musiał: German concerns about Poland's historical politics, 2016. 
Auftrag gegeben. Trotz der Heranziehung derselben als Argumentationshilfe gab er zunächst weder die Autoren noch den Inhalt preis. Für ihre Kritik zogen die Rezensenten vor allem das 75-seitige Programmkonzept des Museums von 2016 heran, das die Ausstellung aber keineswegs vollständig abbildet. Vor Ort holten sie keine Informationen ein, wobei das Museumsteam nach eigenen Aussagen gerne zur vollen Kooperation bereit gewesen wäre und die Rezensenten auch im Anschluss (vergeblich) einlud. ${ }^{249}$ Auch das Konzeptpapier selbst scheint nur selektiv gelesen worden zu sein, da beispielsweise einige kritisierte Fehlstellen darin sehr wohl erwähnt werden. ${ }^{250}$ Als Rezensenten stellten sich schließlich Piotr Semka sowie Jan Żaryn und Piotr Niwiński heraus - nationalkonservative Publizisten und Historiker, die der PiS nahestehen. ${ }^{251}$ Niwiński kritisierte, dass die positiven Eigenschaften des Krieges, wie »Patriotismus, Aufopferung, Hingabe « fehlten. ${ }^{252}$ Żaryn sieht die Aufgabe des Post-Machcewicz-Museums darin, der Welt zu zeigen, was Polen und die Polen seien:»Freiheitsliebend, katholisch, patriotisch und vor allem - stolz auf unsere Geschichte. ${ }^{253}$ Folglich forderten alle im Kern, dass die geplante Ausstellung grundsätzlich überarbeitet werden müsste. Vertreter des $\mathrm{Mu}$ seums wiesen die Kritik auch aufgrund mangelnder Kenntnisse der Rezensenten als falsch zurück. Włodzimierz Borodziej vermutet, dass der Hauptkritikpunkt der Nationalkonservativen letztlich die Tatsache sei, dass der Krieg konsequent aus Sicht der Zivilbevölkerung gezeigt werde - und dies zwangsläufig ein einseitiges Heldennarrativ hinterfragen müsse. ${ }^{254}$

Trotz aller inhaltlichen Mängel dienten die Rezensionen zusammen mit den oben angeführten Anschuldigungen der Veruntreuung und Steuergeldverschwendung als Argument gegen die bisherige Museumsführung, wobei die auch juristisch verfolgte Behauptung der Verschwendung und falschen Buchführung bis heute nicht belegt werden konnte. ${ }^{255}$ Weitere Klagen mit dem Vorwurf der Schädigung des MIIW durch Machcewicz sind bis zum Ende des Untersuchungszeitraumes 2019 im Sande verlaufen. ${ }^{256}$

Die Zusammenlegung der Museen sollte zum 1. Februar 2017 vollzogen werden. Daher präsentierte das Team um Machcewicz das Museum Ende Januar in improvisierter Form zunächst einem Fachpublikum und schließlich für zwei Tage der breiten Öffentlichkeit. Zu diesem Zeitpunkt war der Aufbau der Ausstellung zu über 70 Prozent ab-

249 Katka: Odtajnione recenzje Muzeum II Wojny. Gazeta Wyborcza. 12.07.2016. Vetter: Das Schicksal des Danziger Weltkriegsmuseums, 2016.

250 Vgl. Machcewicz: Muzeum, 2017, S. 208. Siehe auch: Logemann; Tomann: Gerichte statt Geschichte? 2019.

251 Vgl. für eine kritische Kurzvorstellung der Rezensenten: Katka: Odtajnione recenzje Muzeum II Wojny. Cazeta Wyborcza. 12.07.2016.

252 »patriotyzm, ofiarność, poświęcenie«. Niwiński: Recenzja programu funkcjonalno-użytkowego wystawy głównej przygotowanej przez Muzeum II wojny światowej w Gdańsku autorstwa prof. dr hab. Pawła Machcewicza, dr hab. Piotra M. Majewskiego, dr Janusza Marszalca, dr hab. Prof. KUL Rafała Wnuka, stan na styczeń 2016, 2016, S. 9.

253 Hassel: Die Panzer müssen stolzer werden. Süddeutsche Zeitung. 24.10.2016.

254 »Die polnischen Motive sind ausführlich dargestellt«. Deutschlandfunk Kultur. 23.01.2017.

255 Vetter: Das Schicksal des Danziger Weltkriegsmuseums, 2016, S. 6.

256 Leister: Das Danziger Weltkriegsmuseum droht ein »kleinkariertes nationalistisches Zentrum « zu werden. NZZ. 13.07.2018. 
geschlossen. ${ }^{257}$ Bei der Eröffnung solidarisierte sich das internationale Fachpublikum ebenso wie das Danziger Bürgertum mit Machcewicz und seinem Team. Die Fusion der Museen wurde dann überraschend ein letztes Mal vom Gericht aufgeschoben, sodass es noch gelang, das Museum am 23. März 2017 offiziell zu eröffnen und dem Normalbetrieb zu übergeben. Wenige Tage später konnte schließlich am 5. April 2017 nach einem Urteil des Obersten Verwaltungsgerichts die Vereinigung der beiden Museen vollzogen und damit formal die Neugründung eines Museums erreicht werden, in deren Folge Machcewicz und ein großer Teil des bisherigen Museumsteams das Haus verließen. ${ }^{258}$ Kurz vor seinem Rückzug drückte Machcewicz, nochmals den Gründungsimpuls des Museums reflektierend, seine Freude darüber aus, dass sein Haus vor der Stiftung Flucht, Vertreibung, Versöhnung eröffnet habe. Zugleich rechnete er mit einem erneuten Streit nach dessen Eröffnung. ${ }^{259}$

Zum neuen Direktor berief die PiS-Regierung Karol Nawrocki und setzte damit die allmähliche Umwandlung des Museums in ihrem Sinne in Gang. In einem in der Gazeta Wyborcza erschienenen ausführlichen Portrait wird Nawrocki wenig überraschend negativ beurteilt: Nicht seine wissenschaftliche Leistung, sondern seine politische Haltung habe zu seiner Auswahl durch die Regierung geführt. Den zu diesem Zeitpunkt erst 34-Jährigen mit einem Posten dieser Bedeutung zu betrauen, sei nach Meinung des dort zitierten Danziger Bürgermeisters Paweł Adamowicz (PO) zudem ein Affront gegen die akademische Welt. Darüber hinaus habe sein bisheriges Fachgebiet mehr im Bereich der Fußballgeschichte als der des Zweiten Weltkrieges gelegen - ganz zu schweigen von fehlender internationaler Forschungsexpertise. Veröffentlichungen habe er zur Elbinger Geschichte der Solidarność und zum polnischen Widerstand im Raum Danzig vorzuweisen. Von Vertrauten wird er als guter und ehrgeiziger Managertyp beschrieben. Bereits zu diesem Zeitpunkt wurde Nawrocki als potentieller Kandidat der PiS für die Stadtpräsidentschaft Danzigs gehandelt. ${ }^{260}$

Nawrocki sah es als seine unmittelbare Aufgabe an, das Museum an den entscheidenden Stellen $\mathrm{zu}$ `korrigieren und >notwendige Ergänzungen vorzunehmen. ${ }^{261}$ Bis Ende des Jahres 2017 waren zwölf Änderungen geplant. Die Notwendigkeit derartiger Änderungen hat Jarosław Kaczyński indirekt nochmals in einem Radiointerview mit dem nationalkonservativen, katholischen Sender Radio Maryja im Sommer 2017 unterstrichen, in dem er das Museum in seiner ursprünglichen Form als Geschenk von

257 Machcewicz: Muzeum, 2017, S. 256.

258 Heinemann: Krieg und Kriegserinnerung im Museum, 2017, S. 459. Der ehemalige Mitarbeiter Logemann konstatierte am 30.10.2017: »Inzwischen haben fast alle Kuratoren der Dauerausstellung ihren Posten geräumt, zumeist auf (zumindest passiven) Druck der neuen Leitung. Damit wurden international renommierte und hochqualifizierte Mitarbeiter durch Parteigänger der neuen Regierung ersetzt. « Logemann: Replik: D. Logemann zu S. Kleiss: Rezension zu: Dauerausstellung: Museum des Zweiten Weltkriegs, 2017.

259 Gnauck: Der lange Schatten des Krieges. FAZ. 26.03.2017.

260 Katka: Dr Nawrocki naprawi dla PiS Muzeum II Wojny Światowej. Gazeta Wyborcza. 17.04.2017. Vgl. Puttkamer: Europäisch und polnisch zugleich, 2017, S. 4. Vom Direktor des Museums der Geschichte der polnischen Juden, Dariusz Stola, wird Narowcki als »aktiver Politiker der Regierungspartei« eingeschätzt: Lesser: »Das Problem benennen«. Jüdische Allgemeine. 29.03.2018. 
Donald Tusk an Angela Merkel (»dar Donalda Tuska dla Angeli Merkel«) und als Element deutscher Geschichtspolitik bezeichnete. ${ }^{262}$ In einem Protestbrief wandten sich im November 2017500 Wissenschaftler gegen Änderungen an der Dauerausstellung. ${ }^{263}$ Ein weiteres deutliches Beispiel für die Einschätzung der ursprünglichen Konzeption erschien beispielsweise im privaten, nationalkonservativen Fernsehsender Telewizja Republika - hier eine Vorschau auf die Sendung in dem PiS-nahen Meinungsportal niezależna:

»Frühere Autoritäten des Museums des Zweiten Weltkriegs präsentierten Polen als Antisemiten und Verräter. Werden die neuen Behörden die anti-polnischen Aktivitäten der Vorgänger rückgängig machen und die Hauptausstellung wechseln? ${ }^{264}$

Im Herbst 2017 wechselte die neue Museumsleitung den bis dahin den Ausstellungsrundgang abschließenden Film aus und ersetzte ihn durch eine ausschließlich das polnische heroische Leiden des Krieges darstellende, sich in der Machtart an digitale Actionspiele anlehnende Produktion des IPN. ${ }^{265}$ Der ursprüngliche Film des Regisseurs Matt Subieta hatte mit ikonischen Aufnahmen die Geschichte des Kalten Krieges bis hin zu heutigen Kriegs- und Fluchtbewegungen dargestellt. ${ }^{266}$ Dieser Zusammenstellung wurde allgemein ein Antikriegscharakter zugesprochen und sie wurde demzufolge von verschiedenen Stimmen als gelungener Abschluss der Ausstellung eingeschätzt. ${ }^{267}$ Museumsdirektor Nawrocki drückte sich zu diesem seiner Meinung nach »antiwissenschaftlichen« und »skandalösen« Film klar aus:

»Der neue Film sammelt alle Fäden, die nicht in der Dauerausstellung erschienen sind. Er wird die gescheiterte, politisch motivierte, subjektive bestehende Produktion ersetzen, die angeblich eine Zusammenfassung unserer Ausstellung sei. « ${ }^{268}$

Nach verschiedenen weiteren Änderungen und Entfernungen sowie einige >Fehlstellen ergänzenden Sonderausstellungen kam es im März 2018 zu ersten größeren Umbauarbeiten. Museumsdirektor Nawrocki verkündete feierlich die Demolierung (»Zdemolowaliśmy«) eines Teiles der Ausstellung und ihre Ergänzung um Informationen über die Familie Ulma, die im Zweiten Weltkrieg Juden vor den Deutschen rettete und dafür

262 Prezes PiS. dzieje.pl. 27.07.2017.

263 List 500 naukowców o zmianach w Muzeum II Wojny. Dziennik Bałtycki. 03.11.2017.

264 »Poprzednie władze Muzeum II Wojny Światowej przedstawiły Polaków jako antysemitów i zdrajców. Czy nowym władzom uda się odwrócić antypolskie działania poprzedników i zmienić wystawę główną?« Czy uda się odwrócić antypolskie działania poprzednich władz Muzeum II WŚ? niezależna. 31.10.2017.

265 Hlebowicz: Duże zmiany w Muzeum II Wojny Światowej. gosc.pl. 30.10.2017. Der neue Film »Niezwyciężeni« [Die Unbesiegbaren], eine Produktion des IPN, kann auf YouTube abgerufen werden: IPNtvPL: Niezwyciężeni, 2017. Vgl. zum Film kritisch: Ruchniewicz: Das Dilemma des Historikers, 2018, S. 199-201.

266 Stawikowska: Tego filmu nie zobaczysz już w Muzeum II Wojny. Gazeta Wyborcza. 24.11.2017.

267 Vgl. dafür: List 500 naukowców o zmianach w Muzeum II Wojny. Dziennik Bałtycki. 03.11.2017.

268 »Nowy film zbiera wszystkie wątki, które nie pojawiły się na wystawie stałej. Zastąpi on nieudaną, zaangażowaną politycznie, subiektywną dotychczasową produkcję, która miała być podsumowaniem naszej wystawy. Z Zmiany w wystawie Muzeum II Wojny Światowej. tvn24. 31.10.2017. 
von den Besatzern ermordet wurde. ${ }^{269}$ Machcewicz bezeichnet die Veränderungen - die unter anderem mit Mauerdurchbrüchen einhergingen - als Vandalismus und "pseudopatriotische« Maßnahmen, die lediglich die fatale Geschichtspolitik der PiS in Bezug auf die jüngste Revision des IPN-Gesetzes und die daraus folgende Konfrontation mit Israel kaschieren sollten. ${ }^{270}$

Im Januar 2018 wurde der Wissenschaftliche Beirat des Museums ausschließlich mit nationalkonservativen bis hin $\mathrm{zu}$ fachlich und politisch umstrittenen Wissenschaftlern und Publizisten, unter anderem mit den eben besprochenen Rezensenten Piotr Semka, Jan Żaryn, Piotr Niwiński sowie Bogdan Musiał, neu besetzt. ${ }^{271}$ Der Vize-Direktor des MIIW, Grzegorz Berendt, äußerte sich dahingehend, dass die Expertise internationaler Wissenschaftler - wie vormals die der Mitglieder Snyder und Davies - nicht mehr erforderlich sei, da die internationalen Elemente der Ausstellung und Museumsarbeit nunmehr abgeschlossen seien. ${ }^{272}$ Die PiS-kritische Berichterstattung verweist darauf, dass die PiS-Führung nur eine "sehr kurze Liste von Menschen [habe], denen sie in Sachen Geschichte vertrauen « - und diese finden sich nun größtenteils im Wissenschaftlichen Beirat wieder. ${ }^{273}$

In diesem Umfeld führt die Museumsleitung weiter kleine Änderungen an der Ausstellung durch, wobei abgesehen von den rechtlichen Fragen unklar ist, ob sie es letztlich bei einigen Eingriffen belässt und ob die vorgegebene Struktur durch Architektur und Großexponate überhaupt ohne große Umbaumaßnahmen, die eine längere SchlieBung des Museums zur Folge hätten, geändert werden kann. ${ }^{274}$ Machcewicz klagt nicht nur vor polnischen Gerichten gegen die Veränderungen, sondern ist auch vor den Europäischen Gerichtshof für Menschenrechte mit der Begründung der Verletzung der Meinungsfreiheit durch Zensur, Urheberrechtsverletzungen und Beschränkung der künstlerischen und wissenschaftlichen Freiheit gezogen. ${ }^{275}$ Selbst wenn er Recht bekommen

269 Kolejne zmiany w Muzeum II Wojny Światowej. Pokazano historię rodziny Ulmów. Do Rzeczy. 17.03.2018. Der Familie Ulma ist ein eigenes Museum in ihrem Heimatort gewidmet (Muzeum Polaków Ratujących Żydów podczas II wojny światowej im. Rodziny Ulmów w Markowej). Es ist ein beliebter Ort für polnische Regierungsvertreter zum Empfang ausländischer Cäste und Journalisten und um dort in diesen Teil der polnischen Geschichte einzuführen. Von Kritikern wird eingewandt, dass die hervorgehobene Präsentation dieses Schicksales eine Verallgemeinerung auf das Verhalten der meisten Polen während des Krieges gezielt impliziert und primär der martyrologischen und heroischen Geschichtserzählung der PiS dient. Vgl. Peters: »]üdische Täter « und polnische Retter, 2018. Flieger: Z Muzeum II Wojny Światowej znikają niesłuszni partyzanci. Gazeta Wyborcza. 27.03.2018. Vgl. für eine kurze und kritische Vorstellung der neuen Mitglieder des Wissenschaftlichen Beirates: Leszczyński: Gliński powołał nową Radę Muzeum II Wojny Światowej. OKO.press. 10.02.2018.

272 Karaś: Nowa rada Muzeum II Wojny Światowej. Gazeta Wyborcza. 08.02.2018.

273 Leszczyński: Prawicowy postmodernizm. OKO.press. 21.02.2018.

274 Vgl. Logemann; Tomann: Gerichte statt Geschichte? 2019.

275 Flieger: Z Muzeum II Wojny Światowej znikają niesłuszni partyzanci. Gazeta Wyborcza. 27.03.2018. Vgl. Były dyrektor Muzeum II Wojny Światowej skarży się na Polskę. wPolityce. 27.03.2018. Schon 2016 wurde einem entsprechenden Verfahren vor dem EuCH die Möglichkeit auf Erfolg eingeräumt, zumal die gemeinsamen europäischen Richtlinien auch für Polen bindend sind: Hassel: Die Panzer müssen stolzer werden. Süddeutsche Zeitung. 24.10.2016. Vgl. ausführlich auch das Interview mit Machcewicz vom August 2018: Wróblewski: »Muzeum II Wojny Światowej, zamiast być dumą Polski, stało się miejscem politycznej cenzury«. wp opinie. 31.08.2018. 
sollte, ist zu bezweifeln, dass die PiS-Regierung einem Urteil folgen wird, welches anordnet, die Ausstellung in ihrem ursprünglichen Zustand wiederherzustellen. ${ }^{276}$ Karol Nawrocki bewertet Machcewicz' Anschuldigungen als haltlos, da es unter anderem gängige Praxis sei, an Ausstellungen im laufenden Betrieb Änderungen vorzunehmen. Außerdem sei eine klare Autorenschaft bei über zwanzig an der Schaffung der Ausstellung beteiligten Personen kaum feststellbar. ${ }^{277}$

Wahrscheinlicher ist zum jetzigen Zeitpunkt indessen, dass das MIIW unter der PiS-Regierung, zumal nach ihrem erneuten Wahlsieg 2019, ein direkt nutzbares Instrument nationalkonservativer Geschichtspolitik wird. Daraus machen die Vertreter der Regierung auch keinen Hehl: Gliński sieht in staatlichen Kulturinstitutionen »Werkzeuge« (narzędzie) der »Erinnerungskriege« (wojen pamięci), die auf nationaler und internationaler Ebene stattfinden. Es sei daher nur natürlich, wenn die vom Staat finanzierten Institutionen die Linie der gewählten Regierung unterstützen. ${ }^{278}$ In der Krytyka Polityczna heißt es dazu, dass dieses Verständnis eines Kulturministers aber auf dem Unverständnis einer liberalen Demokratie beruhe, in der Kulturinstitutionen ein autonomer Ort der Reflexion und Debatte seien. Die außerordentlichen Ambitionen der PiS im Bereich der Erinnerungspolitik könnten das demokratische Klima im Land nachhaltig schädigen, zugleich dürfte aber die Vorstellung, dass das von der PiS übernommene MIIW eine »Wunderwaffe« (Wunderwaffe) in den »Kriegen der Erinnerung mit Russland und Deutschland « ( $w$ wojnach pamięci z Rosją i Niemcami) werden könnte, täuschen. Stattdessen benötige die

»polnische raison d'état [...] keine Institutionen, die lahme historische Mythen schaffen, sondern vor allem, dass Polen von Bürgern geschaffen werden sollte, die sich ihrer Ceschichte bewusst sind. Fähig, ihre historische Erfahrung in einen globalen Kontext einzubringen und von ihrer eigenen Identität abstrahieren zu können. Das gesamte pädagogische und historische Projekt von Minister Cliński zielt auf das Cegenteil.« ${ }^{279}$

Die nationalkonservative Publizistik hingegen feiert das MIIW als neu gewonnenes Instrument. Gerade durch seine internationale Reichweite und die große Aufmerksamkeit für das Haus könnten nach einem Ende der »Marginalisierung der polnischen Opfer« in der Ausstellung die Erzählung von einer patriotischen, katholischen und heroischen Nation verfolgt, die exzeptionellen polnischen Kriegsverluste umso klarer geschildert und so unter anderem Reparationsforderungen gegenüber Deutschland eindrücklich Nachdruck verliehen werden. ${ }^{280}$

276 Vgl. Hassel: Die Panzer müssen stolzer werden. Süddeutsche Zeitung. 24.10.2016.

277 Znamy kulisy rozprawy dot. MIIWŚ! wPolityce. 14.11.2018. Vgl. Nawrocki: Mocne słowa dr Nawrockiego! Telewizja Republika. 09.06.2018.

278 Majmurek: PiS pamięci nie przepuści. krytyka polityczna. 11.09.2017.

279 »Polska racja stanu nie wymaga instytucji, tworzących kulawe historyczne mity, ale przede wszystkim tego, by Polskę tworzyli świadomi swojej historii obywatele. Zdolni wpisać swoje historyczne doświadczenie w globalny kontekst, władni abstrahować od własnych tożsamościowych obsadzeń. Cały pedagogiczno-historyczny projekt ministra Clińskiego zmierza do czegoś wprost przeciwnego.«Majmurek: PiS pamięci nie przepuści. krytyka polityczna. 11.09.2017.

280 Pospieszalski: Muzeum niemieckich zbrodni. niezależna. 09.10.2017. Auch Machcewicz verwendet den Begriff des Instruments, aber mit einem anderen Verständnis: Mit den Veränderungen des Museums beraube die Regierung »sich des Instruments des Dialogs mit der Welt. (»sam pozbawia 


\subsubsection{Struktur und Aktivitäten}

Das MIIW unterliegt dem polnischen Museumsgesetz ${ }^{281}$ und untersteht vollständig dem Kulturministerium, da die PO-Regierung 2009 »dieses Museum sehr schnell und mit sofort verfügbaren Mitteln, ohne EU-Gelder, realisieren wollte.« Nach dem Regierungswechsel von 2015 hat nun das von der PiS geführte Kulturministerium unmittelbaren "politischen Zugriff" auf das Haus. ${ }^{282}$ Machcewicz verteidigte 2017 dieses Vorgehen ohne internationale Finanzierung und Mitbestimmung. Damit sollte dem ohnehin bald aufgekommenen Vorwurf, dass es ein fremdbestimmtes Projekt sei, begegnet werden. ${ }^{283}$ Die Kosten für den Neubau und die Einrichtung des Museums betrugen etwa 100 Millionen Euro. Für den laufenden Betrieb stellte die Regierung 2017 noch unter dem Druck auf die Machcewicz-Leitung einen Jahresetat von lediglich 2,7 Millionen Euro Jahresetat zur Verfügung. ${ }^{284}$ Die Stadt Danzig ist durch die Schenkung des Grundstückes an dem Vorhaben beteiligt. ${ }^{285}$

Der Museumsrat des MIIW, hier in der Funktion eines wissenschaftlichen Beratergremiums, setzt sich aktuell aus vierzehn Mitgliedern zusammen. ${ }^{286}$ Das Gebäude verfügt über 22.000 Quadratmeter Nutzfläche, davon nimmt die Dauerausstellung im unterirdischen Bereich etwa 5000 Quadratmeter ein. Sonderausstellungen können unter anderem im weiträumigen Foyer und einem Sonderausstellungsbereich im Untergeschoss gezeigt werden. Die Mitarbeiterzahlen schwankten während der letzten Jahre: In der Aufbauphase waren vier Personen für die Entwicklung der Konzeption und des Ausstellungsdrehbuches verantwortlich, für das Kuratieren der Ausstellungssektionen 21 Personen und neun Assistenten. ${ }^{287}$ Primär haben polnische Historiker an Konzept und Programm des Hauses gearbeitet, allerdings unter ständiger Beratung und Mitarbeit internationaler Forscher »aus Deutschland, Frankreich, Großbritannien, Russland und der Ukraine, aber auch Historikern aus Israel und den USA. ${ }^{288}$ So befassten sich die beiden jungen Historiker Anna Müller und Daniel Logemann aus Deutschland unter anderem mit dem Holocaust, dem Bombenkrieg und der Zwangsmigration

się instrumentu dialogu ze światem«) - Wróblewski: »Muzeum II Wojny Światowej, zamiast być dumą Polski, stało się miejscem politycznej cenzury«. wp opinie. 31.08.2018.

Mit dem Stand vom März 2018: Kancelaria Sejmu: Ustawa z dnia 21 listopada 1996 r. o muzeach. 07.03.2018. Das Museumsgesetz unterscheidet zwischen privaten und staatlichen Museen, welche der Zuständigkeit des Ministers für Kultur und Nationales Erbe unterliegen. Diesem wird für die staatlichen Museen ein erhebliches Zugriffsrecht zugesprochen (Art. 6a (1)). Die Aufsichtspflicht und das Durchgriffsrecht des Ministers bei »groben Verletzungen der Bestimmungen des Cesetzes « werden in Art. 8.1 festgehalten.

282 So Basil Kerski, der Leiter des Europäischen Solidarność Zentrums in Danzig: Leister: »Die derzeitige Politik ist der Kampf um die Deutungshoheit der Geschichte«. NZZ. 12.09.2017.

283 Machcewicz: Muzeum, 2017, S. 18f.

284 Cnauck: Der lange Schatten des Krieges. FAZ. 26.03.2017.

285 Logemann: On >Polish History<, 2017.

286 Vgl. dafür die Website des Museums: http://muzeum1939.pl/minister-kultury-powolal-czlonkowrady-muzeum/aktualnosci/1098.html (letzter Zugriff: 29.03.2018).

287 Hoja: An Engaged Narrative, 2017. Siehe für eine namentliche Auflistung: Muzeum II Wojny Światowej: Museum of the Second World War, 2016, S. 252.

288 Machcewicz: Museum des Zweiten Weltkrieges in Danzig, 2010, S. 8. Machcewicz über das Gründungsteam: Machcewicz: Muzeum, 2017, S. 77-91. 
und engagierten sich Machcewicz zufolge lebhaft für eine ausgewogene Behandlung der Themen. ${ }^{289}$ Im Juli 2018 waren elf Wissenschaftliche Mitarbeiter einschließlich des Direktors und zweier Vize-Direktoren für den Bereich Ausstellungs-, Sammlungs- und Vermittlungsarbeit verantwortlich, davon zwei für den Bereich der Bildungsarbeit. Weiterhin verfügt das Museum über einen Sprecher und eine Bibliothekarin. ${ }^{290}$

Im Jahr 2018 umfasst die nach 2008 aufgebaute Sammlung des MIIW 50.000 Exponate, von denen etwa 2000 ausgestellt sind. ${ }^{291}$ Den objektzentrierten Ansatz der Ausstellung begründet Paweł Machcewicz damit, dass sie so »[...] gewissermaßen unseren museumspädagogischen Standpunkt zum Ausdruck [bringen], indem wir das Hauptgewicht auf authentische Gegenstände legen, weil diese mit den Erfahrungen der Menschen in Verbindung stehen und daher besser in der Lage sind, das Wichtigste zu demonstrieren, als dies etwa Multimediapräsentationen können. ${ }^{292}$ Über die Ausstellung verteilen sich etwa 240 Multimedia-Stationen, vor allem Touchscreens mit vertiefenden Informationen sowie Bild- und Kartenmaterial. ${ }^{293}$

Das MIIW möchte mit seiner Arbeit ein nationales ebenso wie ein weltweites Publikum erreichen. Die Ausstellungssprachen sind folglich Polnisch und Englisch, Audioführer liegen bisher in diesen Sprachen sowie in Deutsch, Französisch und Russisch vor. ${ }^{294}$ Machcewicz betonte stets die Notwendigkeit der Anschlussfähigkeit an andere nationale Erzählungen, um den Ausstellungsbesuch für internationale Gäste attraktiv und zugleich die spezifische polnische Kriegs- und Nachkriegserfahrung nachvollziehbar zu machen. Als besonders relevante Adressaten stellte er wiederholt Schülergruppen heraus, beispielsweise solche aus Deutschland. ${ }^{295}$ Logemann unterstreicht als Zielgruppe »zukünftige Generationen«, an die »das Gedächtnis vom Krieg« weitergereicht werden solle, dass die Ausstellung gleichzeitig »aber auch einen tragischen Zeitraum ostmitteleuropäischer Geschichte auf symbolische Weise bilanziert und abschließt. « ${ }^{296}$

Die neue Führung verfolgt eine veränderte Ausrichtung der Museumsarbeit, dennoch bleiben die Zielgruppen ähnlich, nur soll ihnen ein anderes Narrativ vermittelt werden. Sowohl die ersten Sonderausstellungstätigkeiten als auch die Öffentlichkeitsarbeit zeigen deutlich auf, dass dem nationalen und internationalen Publikum keine

289 So soll Logemann schon mal mit dem Ausruf »Wir in Polen können uns auf keinen Fall erlauben, die Deutschen so zu behandeln « (my w Polsce w żadnym razie nie możemy pozwolić Niemcom tak się traktować) auf den Tisch gehauen haben: Machcewicz: Muzeum, 2017, S. $80 f$.

290 http://muzeum1939.pl/zespol/1179.html (letzter Zugriff: 27.07.2018). Vetter schrieb im November 2016, dass das dreiköpfige Direktorium von acht Wissenschaftlichen Mitarbeitern unterstützt wird: Vetter: Das Schicksal des Danziger Weltkriegsmuseums, 2016.

291 Machcewicz: Muzeum, 2017, S. 112. Vgl. zum Sammlungsaufbau und für entsprechende nationale und internationale Bemühungen: Müller: When History Speaks Through Objects..., 2015. Vgl. für den heutigen Stand: To już rok działalności Muzeum II Wojny Światowej. niezależna. 06.04.2018.

292 Zitiert nach: Vetter: Politisches Gedenken - Polen und der 8. Mai 1945, 2015. Siehe auch: Muzeum II Wojny Światowej: Museum of the Second World War, 2016, S. 9.

293 Hoja: An Engaged Narrative, 2017.

294 Vgl. ebd.

295 Machcewicz: Muzeum, 2017, S. 13, 104, $108 \mathrm{f}$.

296 Logemann; Müller: Exponate und ihre intellektuelle und emotionale Botschaft, 2014, S. 281. 
Weltgeschichte mehr, sondern ganz überwiegend polnische Nationalgeschichte vermittelt werden soll. ${ }^{297}$

Mit seiner guten Lage in der Stadt Danzig hat das MIIW einen ausgezeichneten $\mathrm{Zu}$ gang zu nationalen und internationalen Touristenströmen. Seit seiner Eröffnung hat es sich als Besuchermagnet erwiesen: Vom 23. März bis zum 27. Dezember 2017 besuchten es 413.812 Personen. ${ }^{298}$ Unweit der historischen Altstadt gelegen, befindet es sich in der Nähe einer Fährverbindung zur Halbinsel Westerplatte sowie der Danziger Post, die im September 1939 ein zentraler Ort polnischen Widerstandes war und der Günter Grass' Blechtrommel ein bleibendes Denkmal setzte. Ebenso wie die grundlegende Bedeutung Danzigs als historischer Ort für den Ausbruch des Zweiten Weltkrieges unbestritten ist, ist auch die nähere Umgebung von Geschehnissen des Krieges geprägt: Außerhalb der Stadt befindet sich das ehemalige Konzentrationslager Stutthof, in der Nachbarstadt Gdingen/Gdynia wurde unmittelbar nach Beginn der deutschen Besatzung die polnische Bevölkerung vertrieben; 1945 waren Danzig und Umgebung schließlich Ort der Massenflucht und Vertreibung der deutschen Bevölkerung. Die Solidarność-Bewegung, die hier ihren Anfang nahm, wird gemeinhin als wichtige Etappe zur Beendigung des Kalten Krieges betrachtet. So werden daher das sich in seiner Laufweite befindende 2014 eröffnete Europäische Zentrum der Solidarnosśc und das MIIW auch als miteinander verbundene und aufeinander aufbauende Elemente verstanden. ${ }^{299}$

Den international ausgerichteten Architekturwettbewerb für die Errichtung des Museums des Zweiten Weltkrieges gewann 2010 das Architekturbüro Kwadrat aus Gdynia. ${ }^{300}$ Nach Aussage von Machcewicz sieht Daniel Libeskind, der Teil der Jury war, »in dem geplanten Bauwerk eine wahre Ikone nicht nur für Danzig, sondern auch für das historische Gedächtnis des Zweiten Weltkrieges. « ${ }^{301}$ Die Architektur des Museums soll die historische Silhouette der Danziger Altstadt nicht in den Schatten stellen, sondern diese aufgreifen: Der rötliche Ton der Fassade interpretiert die Backsteinarchitektur der Ostsee, der schräg und weit in die Höhe aufragende Museumsbau lehnt sich sowohl an die gotischen Backsteinkirchen - allen voran die Marienkirche - sowie die Kräne des Hafens an. Zugleich symbolisieren (verrostet wirkendes) Metall und das Brechen klassischer Architekturformen die Disruption und Gewalt des Krieges. In einem ehemals dicht besiedelten Teil Danzigs, der am Ende des Krieges vollständig zerstört und später in einen Busparkplatz verwandelt wurde, greift es die Geschichte des alten Viertels Eimermacherhof (Wiadrownia) in der Dauerausstellung sowie in der Architektur auf. Die alte Hauptstraße des Viertels - die Große Gasse - wird in Form der Zugangsrampe des Museums nachgezeichnet, ebenso folgt die Dauerausstellung in Teilen der Route der Straße. Die Ebenen des Hauses werden inhaltlich gedeutet: Die Vergangenheit und das Wissen über diese befinden sich im Untergeschoss, das Erd-

\footnotetext{
297 Siehe dafür zum Beispiel die Präsenz des Museums beim Mediendienst Instagram: https://www. instagram.com/muzeum1939/ (letzter Zugriff: 14.04.2018).

298 Muraszko: Muzeum II Wojny Światowej: 413812 zwiedzających. Gazeta Wyborcza. 23.01.2018.

299 Machcewicz; Majewski: The Museum of the Second World War in Poland, 2008, S. 1-3.

300 Vgl. zum Wettbewerb: Bittner: Muzeum II Wojny Światowej w Gdańsku, 2010.

301 Machcewicz: Museum des Zweiten Weltkrieges in Danzig, 2010, S. 8.
} 
geschoss verbindet das Haus mit der Umgebung und der Gegenwart, die für Bildung und Vermittlung vorgesehenen Räume im Obergeschoss verweisen auf die Zukunft. ${ }^{302}$

Neben den bereits erwähnten Sonderausstellungen sowie der dauerhaften Freiluftausstellung auf der Danziger Westerplatte entfaltet das neue Team um Nawrocki nun eine rege Ausstellungstätigkeit. Nach seiner Übernahme des Hauses installierte dieses im Oktober 2017 eine Präsentation im Foyer, in der auf großformatigen Bildern mit knappen Texten verschiedene polnische Helden des Zweiten Weltkrieges gezeigt wurden. Unter anderem wurden umstrittene Angehörige der Verstoßenen Soldaten (Żotnierze wyklęci) präsentiert, also polnische Partisanen, die nach dem Zweiten Weltkrieg fortgesetzt gegen die kommunistische Machtübernahme kämpften, darunter auch solche, die an Morden und Vergewaltigungen weißrussischer Polen beteiligt waren. ${ }^{303}$ Im Herbst/Winter 2017 zeigte das MIIW eine Sonderausstellung zur Zwangsarbeit im Dritten Reich, ${ }^{304}$ im Februar 2018 eröffnete dann für zwei Wochen eine Ausstellung über polnische Soldaten in sowjetischer Kriegsgefangenschaft. ${ }^{305}$ Anzumerken ist hier, dass es sich jeweils um kleine und kurze Sonderausstellungen handelte, wobei abzuwarten bleibt, ob sich mittelfristig ein regelmäßiges System von Sonderausstellungen einpendelt; eine erste thematische Richtung zeichnet sich jedenfalls schon ab. Am 30. März 2018 eröffnete eine Ausstellung im MIIW, in der man virtuell die Westerplatte zum Zeitpunkt des Zweiten Weltkrieges begehen konnte. ${ }^{306}$

Das MIIW hat bereits eine ganze Reihe von Forschungsliteratur in polnischer, englischer und deutscher Sprache veröffentlicht. ${ }^{307}$ In diesen Publikationen werden nicht nur historische Fragen des Zweiten Weltkrieges abgehandelt, sondern zum Beispiel auch solche der deutsch-polnischen Erinnerungskultur. ${ }^{308}$ Mit dem Thema der Vertreibungen im weiteren Sinne befassen sich zwei von ihnen: zum einen eine zur (vermeintlich großflächigen) Sabotagetätigkeit der Volksdeutschen während des Polenfeldzuges im September 1939, ${ }^{309}$ zum anderen eine über die tschechoslowakische Verteidigungskraft während der Münchenkrise $1938 .{ }^{310}$ Der russische Historiker Pavel Polian befasst

302 Ackermann: In Polen dokumentiert ein Museum die Schrecken des Zweiten Weltkriegs und blickt über dessen Ende hinaus. NZZ. 06.04.2017. Gnauck: Der lange Schatten des Krieges. FAZ. 26.03.2017. Plakatives Erinnern. BauNetz. 02.06.2017.

303 Marszalec und Wnuk, ehemalige Mitarbeter des Hauses, kritisieren diese Ausstellungsaktivität und die von der PiS angestrebte Rehabilitierung auch solcher >Verstoßener Soldaten«: »Das Museum wird zum experimentellen Übungsfeld für diese Geschichtspolitik der PiS. « (»Muzeum staje się poligonem doświadczalnym tej polityki historycznej PiS.«) - Marszalec; Wnuk: Muzeum II Wojny Światowej? Gazeta Wyborcza. 08.11.2017.

304 MIIWŚ: wystawa czasowa o pracy przymusowej i niewolniczej Polaków w III Rzeszy. gdansk.pl. 21.11.2017.

305 Sadurska: »Na nieludzkiej ziemi. Jeńcy polscy w ZSRR«. gdanskstrefa.com. 21.02.2018.

306 Gdańsk Strefa Prestiżu: Strefa wirtualna w MIIWŚ. gdanskstrefa.com. 29.03.2018. Siehe auch das für die Ausstellung werbende Video des MIIW: Muzeum II Wojny Światowej w Gdańsku: Westerplatte - polskie Pearl Harbor, 2017.

307 http://muzeum1939.pl/en/publikacje (letzter Zugriff: 30.03.2018).

308 Kałążny; Korzeniewska et al. (Hg.): Druga wojna światowa w pamięci kulturowej w Polsce i w Niemczech, 2015.

309 Chinciński: Forpoczta Hitlera, 2010.

310 Majewski: Zmarnowana szansa? 2016. 
sich in einer Publikation des MIIW mit den Deportationen in der Sowjetunion, darunter die der Wolgadeutschen. Seit 2010 veröffentlicht das MIIW ausführliche Jahresberichte, ${ }^{311}$ der Katalog zur Dauerausstellung erschien bereits 2016 vor Eröffnung des Museums.

Im Januar 2018 eröffnete schließlich die Bibliothek des Hauses für Gäste. ${ }^{312}$ Das Museumsteam um Karol Nawrocki führt regelmäßig Veranstaltungen durch - so wird unter anderem mit Buchvorstellungen, Filmvorführungen und patriotischen Konzerten vor allem das lokale und nationale Publikum angesprochen. ${ }^{313}$

\subsubsection{Anspruch und Selbstverständnis}

Der Gründungsimpuls für das Museum und sein ursprünglicher Anspruch wurden oben erörtert. Dieser von Donald Tusk und dem Gründungsteam um Paweł Machcewicz vertretene Ansatz blieb bis 2017 maßgeblich: Das Haus möchte eine "ganzheitliche« Geschichte des Zweiten Weltkrieges darstellen, was sowohl dem Verlauf als auch dem Charakter des Krieges gerecht werden soll und »die polnische Perspektive mit den Erfahrungen anderer Nationen « verbindet. ${ }^{314}$ Dieser Ansatz ist von der Vorstellung getragen, dass nur eine internationale Betrachtung des Krieges und eine gemeinsame Auseinandersetzung mit den Erzählungen der beteiligten Nationen Verständigung ermöglichen. ${ }^{315}$

Machcewicz meint damit (auch) konkret, dass das Museum dem Ziel verpflichtet sei, die »Erfahrungen Polens und anderer Länder Mittelosteuropas in die europäische und globale Erinnerungsgeschichte des Krieges zu integrieren. ${ }^{316}$ Das verdeutlicht die oben angesprochene politische Zielsetzung, für die das Museum bei der Herstellung eines europäischen Narrativs mitwirken und zugleich die Berücksichtigung der ostmitteleuropäischen Erfahrungen gewährleisten soll. ${ }^{317}$ Machcewicz schätzt, dass trotz des globalen Ansatzes etwa 50 Prozent der Ausstellungsfläche im weiteren Sinne Polen gewidmet sind. ${ }^{318}$ Die Gründer verstehen das Museum nicht als Militärmuseum, sondern als Museum des Krieges und verfolgen eine "von Grund auf pazifistische Perspektive« als universell gültige »Leitidee «. ${ }^{319}$ Auf dieser Basis soll keine Heldengeschichte des Zweiten Weltkrieges, sondern das alle Seiten verbindende Element der Kriegserfahrung durch die Zivilbevölkerung erzählt werden. Über diese gemeinsamen Erfahrungshorizonte, beispielsweise das Phänomen von Besatzung, Widerstand oder Bombenkrieg können zugleich Unterschiede - maßgeblich zwischen West und Ost - diskutiert werden. In der Formulierung der Neuen Zürcher Zeitung sollte das Museum in Donald Tusks Planung ein Symbol werden und ein

311 http://muzeum1939.pl/index.php/en/raporty-roczne (letzter Zugriff: 30.03.2018).

312 Kisicka: W Muzeum II Wojny Światowej rozpoczyna działalność biblioteka. dzieje.pl. 10.01.2018.

313 Starkowicz: Wyklęte i sprawiedliwe. gosc.pl. 26.02.2018. Wąsowicz: Wciąż biją serca dla »Inki«. niezależna. 11.03.2018.

314 Machcewicz: Museum des Zweiten Weltkrieges in Danzig, 2010, S. 8.

315 Ebd.

316 Ebd. Siehe auch: Machcewicz: Muzeum, 2017, S. 13.

317 Vgl. Muzeum II Wojny Światowej: Museum of the Second World War, 2016, S. 8, 12.

318 Leister: Museum zum Zweiten Weltkrieg - Ein Museum als Schlachtfeld. NZZ. 23.06.2017.

319 Machcewicz: Muzeum, 2017, S. 22. Machcewicz: »Museum statt Stacheldrahtverhaue«, 2012, S. 86. 
»[...] Zeichen setzen für ein modernes und liberales, weltoffenes und nachdenkliches, sprich: europäisches Polen, das die Größe hat, differenziert mit seiner Geschichte umzugehen. $\ll^{320}$

Durch das Erzählen von Lebensgeschichten in der Ausstellung soll der Besucher zum einen die damalige Realität nachempfinden können, aber zum anderen zugleich die außerordentliche Distanz spüren:

»But, above all, we want to convince visitors that the Second World War does not lie in a distant and sealed past. We believe that it is extremely important for visitors to find people similar to themselves in this exhibition, people who faced exceptionally difficult, dramatic, often extreme challenges, which most of us have not had to live through. People who made the most elemental choices that today are foreign to us, people who believed in the same values as those we hold dear. «21 $^{321}$

Von Beginn an war es kein Ziel der Museumsgründer, ein vermeintlich einheitliches europäisches Gedächtnis zu schaffen, sondern vielmehr an der Annäherung der verschiedenen europäischen Gedächtnisse mitzuwirken und so »einander zu verstehen und weniger emotional auf Unterschiede in der Bewertung der Vergangenheit zu reagieren. « ${ }^{322}$ Schließlich lohne sich »[...] der Versuch, ein Museum zu schaffen, das die unterschiedlichen historischen Erinnerungen der Europäer miteinander verknüpft. Nicht, um ein homogenes und allgemeingültiges historisches Narrativ zu schaffen - denn das wäre eine schädliche Utopie, sondern in erster Linie, um die unterschiedlichen historischen Erfahrungen zu verstehen, welche die Sensibilitäten der einzelnen Völker bis heute prägen. $\ll^{323}$ Krzysztof Pomian sah 2008 in dem Museum ein potentielles Werkzeug nicht nur der deutsch-polnischen Versöhnung (narzędziem pojednania). ${ }^{324}$

In Bezug auf die Vergleichbarkeit des Ansatzes und Anspruches betonte Piotr M. Majewski 2010, dass die Pläne des MIIW im Vergleich zu den Überlegungen der SFVV "völlig verschieden « seien. ${ }^{325}$ Machcewicz verstand das Museum als ein Instrument, um der »Dominanz des deutschen und europäischen Geschichtsgedächtnisses durch das Problem der >Vertreibungen deutsch-polnischen Streit um dieses Thema aufzuzeigen. ${ }^{326}$

Die ursprünglichen Ausstellungsmacher des MIIW verfolgten das Ideal des mündigen Besuchers. Nach Müller und Logemann sollte er »erkennen können, dass er im Museum eine Geschichtsinterpretation zu sehen bekommt«. Auch wenn er einer »durch

320 So fasst die NZZ den Anspruch des Museums zusammen: Breitenstein: Die Liebe zum Ausnahmezustand. NZZ. 06.04.2017.

321 Muzeum II Wojny Światowej: Museum of the Second World War, 2016, S. 13.

322 Machcewicz: Das Museum des Zweiten Weltkrieges in Danzig, 2009, S. $7 f$.

323 Machcewicz: Das Museum des Zweiten Weltkriegs in Danzig, 2011, S. 162. Siehe auch: Machcewicz: Das Museum des Zweiten Weltkrieges in Danzig, 2009, S. 2. Machcewicz sieht als einen wesentlichen Grund für die geschichtspolitischen Streitigkeiten weniger »bösen Willen« als dass diese »sich aus Missverständnissen und Unwissen« ergeben. 
die Ausstellungsmacher vorbereiteten Installation folgt, sollte der Besucher in der Lage sein, Fragen zu formulieren, auf die er in der Ausstellung selbstständig Antworten finden kann. ${ }^{327}$ Auch Machcewicz unterstrich 2012, dass das Museum ganz gezielt erinnerungskulturelle Dilemmata und Konflikte diskutieren wolle, wie zum Beispiel die Frage der Polen in der Wehrmacht. ${ }^{328}$ Schließlich müsste das Museum sich einer »neutralen Sprache« bedienen, die eine solche Offenheit unterstützt. ${ }^{329}$

Die neue Leitung des Museums hat noch keinen neuen, ähnlich umfassenden Anspruch formuliert. Nach der von Nawrocki geäußerten Kritik am Ursprungskonzept und den folgenden Änderungen in der Dauerausstellung lässt sich aber der Ansatz einer klassisch nationalen Meistererzählung mit ihren Heroen und der Erziehung zu einem aktiven Patriotismus im Sinne von dulce et decorum est pro patria mori deutlich erkennen. ${ }^{330}$ Die Rhetorik der nationalkonservativen Kritiker ebenso wie die von Nawrocki orientiert sich zudem in Abkehr von einem multiperspektivischen und reflektierten Vorgehen verstärkt am Terminus der einen Wahrheit, die es zu vermitteln gelte. ${ }^{331}$ Zudem zeichnen sich die veränderten Ausstellungselemente durch ihren die Besucher »überwältigenden« Charakter aus. ${ }^{332}$

\subsubsection{Die Dauerausstellung (Januar 2017)}

Für Szenografie und Visualisierung der Dauerausstellung wurde 2009 die belgische Firma NV Tempora S.A. gewonnen, die sich bereits durch die Gestaltung von Ausstellungen mit gesamteuropäischer Ausrichtung profiliert hat. ${ }^{333}$ Die Firma No Label/New Amsterdam gestaltete das audio-visuelle Material. ${ }^{334}$ Die Dauerausstellung befindet sich $14 \mathrm{Me}$ ter unter der Erde in dem bereits beschriebenen Gebäude, dessen Innenarchitektur von kaltem Sichtbeton geprägt ist. Machcewicz betrachtet den Abschluss der Ausstellung, das Heraufsteigen aus dem Keller, als Überwindung des Todes und die Rückkehr zum Leben. ${ }^{335}$

327 Logemann; Müller: Exponate und ihre intellektuelle und emotionale Botschaft, 2014, S. 285.

328 Machcewicz: Spory o historie 2000-2011, 2012, S. 262.

329 Siehe: Majewski: Muzeum II wojny światowej w Cdańsku, czyli o tym, jak opowiadać o historii w społeczeństwie o różnych wrażliwościach, 2017, S. 107.

330 So fasst es die Kulturwissenschaftlerin und Soziologin sowie Mitarbeiterin am Jüdischen Historischen Institut in Warschau, Agnieszka Haska in einem Interview: Puto: Jak zostać zdrajcą. krytyka polityczna. 07.06.2018.

331 Der stellvertretende Minister für Kultur, Jarosław Sellin sagte am Jahrestag der Fusion des MIIW: »Wir brauchen eine gute, wahrheitsgetreue historische Erzählung. Systematische Arbeit ist [dafür] sehr notwendig « (»Potrzebujemy dobrej, zgodnej z prawdą narracji historycznej. Systemowa praca jest bardzo potrzebna«) - Ważne słowa wiceministra Sellina: »Potrzebujemy dobrej, zgodnej z prawdą narracji historycznej. Systemowa praca jest bardzo potrzebna «. wPolityce. 06.04.2018. Flieger; Gałązka: Kolejna »dobra zmiana« w Muzeum II Wojny Światowej. Gazeta Wyborcza. 05.04.2018.

333 Machcewicz: Museum des Zweiten Weltkrieges in Danzig, 2010, S. 8. Das Tempora-Team ist gleichwohl sehr international geprägt und verfügt mit Krzysztof Pomian über einen polnischen Museumsexperten: Machcewicz: Muzeum, 2017, S. 86-88, 108. 
Ihre Schöpfer verstehen die Ausstellung als eine narrative, die die Geschichte des Zweiten Weltkrieges in erster Linie anhand des authentischen Exponats im Rahmen eines chronologisch-thematischen Ansatzes erzählt. ${ }^{336}$ Es soll ein multiperspektivischer Ansatz verfolgt werden, der nicht nur die Schicksale verschiedener Nationen und Bevölkerungsgruppen darstellt, sondern auch Täterperspektiven zeigt - ohne die letztlich die Geschichte des Krieges »incomplete and [...] incomprehensible« wäre. ${ }^{337}$ Auch wenn das Objekt im Fokus steht, kennzeichnet eine breite Methodenvielfalt das MIIW, dessen Ausstellungsteile vollständig und umfassend szenografisch gefasst sind. Es fügt sich zu einem Zusammenspiel von »Original und Nachbau« und »Stadtlandschaften aus Gips«, wobei dem Besucher die Unterscheidung von Original und Kopie oder digitaler Reproduktion nicht immer möglich ist. ${ }^{338}$ Weiterhin wird er zumeist von einer Soundkulisse begleitet, sei es dem Gebrüll Hitlers oder »Mozarts Requiem als Soundtrack zum Warschauer Aufstand «. ${ }^{339}$ Von Puttkamer sieht in dem Museum alle Anforderungen an eine moderne Ausstellung befriedigt: »spektakulär expressive Architektur, starke visuelle Eindrücke [...], ein sinnliches Eintauchen in imaginierte Vergangenheit, hier und da garniert mit der Einladung, an einem Bildschirm selbst tätig zu werden. «340

Die Dauerausstellung ist in drei Oberthemen und 18 Unterkapitel gegliedert (I-III, 01-18), die der thematisch-chronologischen Struktur folgen. Zusätzlich sind drei separate Ausstellungselemente vorhanden, die die Vorgeschichte des Ersten Weltkrieges und der Zwischenkriegszeit beleuchten (A), den Alltag im Krieg zeigen (B) ${ }^{341}$ und eine Kinderausstellung beinhalten (C). In einem mittlerweile abgebauten Ausstellungsteil »From Wiadrownia to our Museum. 1540-2017« wurden sowohl die Geschichte des ehemaligen, 1945 untergegangenen Stadtviertels als auch die Entstehung des Museums auf diesem Gelände dargestellt. ${ }^{342}$ Die Alltagsgeschichte zeigt die Ausstellung anhand von Exponaten in dem langen und breiten Korridor, der die verschiedenen und sich um diesen gruppierenden Ausstellungsteile miteinander verbindet. Das bedeutet, dass der Besucher immer wieder auf diese Exponate des Alltagslebens trifft. In der Kinderausstellung werden drei Räume gezeigt, die dieselbe polnische Wohnung vor, während und am Ende des Krieges zeigen. Die Dauerausstellung gliedert sich wie folgt:

A. The making of interwar Europe/Ku Europie wersalskiej

\section{The Road to War/Droga do wojny}

o1. The birth and expansion of totalitarianisms/Narodziny I ekspansja totalitarzymów

Mit dem Konzept des Narrationsmuseums sieht man sich in einer Reihe mit dem Museum des Warschauer Aufstandes oder dem Museum der Geschichte der polnischen Juden: Majewski: Muzeum II wojny światowej w Gdańsku, czyli o tym, jak opowiadać o historii w społeczeństwie o różnych wrażliwościach, 2017, S. 106.

337 Muzeum II Wojny Światowej: Museum of the Second World War, 2016, S. 12.

338 Ackermann: In Polen dokumentiert ein Museum die Schrecken des Zweiten Weltkriegs und blickt über dessen Ende hinaus. NZZ. 06.04.2017.

339 Ebd.

340 Puttkamer: Europäisch und polnisch zugleich, 2017, S. 6.

341 Vgl. die Darstellung im Katalog der Dauerausstellung: Museum of the Second World War: >45 End of War in 45 Artefacts, 2015, S. 232-241.

342 Vgl. im Katalog: Muzeum II Wojny Światowej: Museum of the Second World War, 2016, S. 243-251. 
02. Peace at any price?/Pokój za wszelką cenę?

03. So it's war, after all!/A więc wojna!

\section{Terror of War/Groza wojny}

04. The Winter War/Wojna zimowa

05. A new kind of war/Wojna nowego typu

06. Merciless war/Wojna bez litości

07. Occupation and collaboration/Okupacja I kolaboracja

08. Terror

09. The Holocaust/Zagłada

10. Ethnic purges/Czystki etniczne

11. Resistance/Opór

12. The war over secrets/Walka o tajemnicę

13. All for victory!/Wszystko dla zwcięstwa

14. Allies on the offensive/Alianci w natarciu

15. The war is over/Koniec wojny

\section{The war's long shadow/Długi cień wojny}

16. After the war/Po wojnie

17. On the two sides of the Iron Curtain/Po obu stronach żelaznej kurtyny

18. From war to freedom/Od wojny do wolności

B. Everyday life during the war and occupation/życie codzienne w czasie wojny i okupacji

C. Children's exhibition/Podróż w czasie - wystawa dla dzieci ${ }^{343}$

Nachdem der Besucher im Foyer des MIIW angekommen ist, steigt er in die Dauerausstellung hinab. In dem die gesamte Ausstellung einleitenden Text heißt es unter dem Titel: »Die größte Katastrophe der Menschheit«:

»Der Zweite Weltkrieg ist der tragischste Konflikt in der Ceschichte der Menschheit. Er wurde von totalitären Regimen entfesselt - Deutschland und der Sowjetunion, die miteinander kooperierten. Im Namen krimineller Ideologien, die elementare moralische Normen ablehnten, begingen sie unvorstellbare Grausamkeiten und Verbrechen. In Zeiten der Verachtung für das menschliche Leben erforderte Anstand oft Heldentum, der höchste Preis wurde für den Widerstand gegeben. Der Alltag ist zum Überlebenskampf und Raum für dramatische Entscheidungen geworden. Am ersten Tag in diesem Weltkonflikt - dem 1. September 1939 - stand Polen im Mittelpunkt der Ereignisse. Diese Erfahrung bleibt bis heute gültig, sie bezieht sich auf die wichtigsten Entscheidungen, denen auch heute die Menschheit und jeder von uns gegenübersteht. Damals wie heute sind Freiheit, Würde und Leben, für die Millionen von Menschen in den Jahren 1939-1945 ihre Opfer gebracht haben, universelle Werte. «344

343 Muzeum II Wojny Światowej: Museum of the Second World War, 2016, S. $2 f$.

344 »Największa katastrofa w dziejach ludzkości - II wojna światowa to najtragiczniejszy konflikt w dziejach ludzkości. Rozpętały ją reżimy totalitarne - Niemcy i współdziałający z nimi Związek Radziecki. W imię zbrodniczych ideologii, odrzucając elementarne normy moralne, dopuściły się niewyobrażalnych okrucieństw i zbrodni. W czasach pogardy dla życiu ludzkiego przyswoitość wymagała często bohaterstwa, za opór placono najwyższą cenę. Życie codzienne stało się walką o 
Im ersten Raum der Ausstellung (A) wird das Eingangsvideo »The making of interwar Europe« gezeigt und der Ausstellungsbeginn symbolisch mit 1910 angesetzt, der Beerdigung Eduards VII. in London. Bei diesem Ereignis seien noch einmal die alten Eliten und Herrscherhäuser des Kontinents zusammengekommen und es habe ein letztes Mal die Chance bestanden, den Frieden in Europa zu sichern. Letztlich sei die alte Ordnung den sozialen Problemen und dem wachsenden Nationalismus zum Opfer gefallen. Die Kriegsniederlage Deutschlands, aber auch die Ergebnisse des Krieges für die Sowjetunion, Italien und Japan ließen diese zu revanchistischen Kräften werden, die die alten Demokratien des Westens ebenso wie die neuen Staaten Ostmitteleuropas bedrohten.

Der erste Teil der Ausstellungschronologie widmet sich in separaten Räumen unter dem Titel »The birth and expansion of totalitarianisms « den Ideologien des Sowjetkommunismus, des Nationalsozialismus und des italienischen Faschismus. Es folgen der japanische Imperialismus und ein erster Blick auf das Kriegsgeschehen in Ostasien. Die hier vorherrschende Form der Präsentation von Propagandamaterial stellt die Anziehungskraft der Systeme dar; sie wird konterkariert durch kleinere, unauffällige Objekte, wie einen Handmühlenstein aus der Sowjetukraine, der symbolisch für den Holodomor steht. Der den deutschen Nationalsozialismus zeigende Raum stellt auch einige Plakate zum deutschen Revisionismus im Osten aus, wie zum Beispiel ein Plakat des »Bund Deutscher Osten«.

Nach dem Verlassen dieses Ausstellungsteils findet man sich in einer polnischen Geschäftsstraße der unmittelbaren Vorkriegszeit und damit einer Replik des untergegangenen Polen der Zweiten Republik wieder. Nicht ausgespart wird der polnische Antisemitismus, hängt doch unter anderem an einem geschlossenen Geschäft »Jüdisches Geschäft! Anständige Polen kaufen hier nicht! «. ${ }^{345}$ Diesem Ausstellungselement folgt der Bereich von »Peace at any price? « (2), in dem die »Ideological conflicts and the collapse of the Versailles order « thematisiert werden. Das Ausgreifen NS-Deutschlands nach Österreich und in die Tschechoslowakei wird anhand von Postkarten und anderen Erinnerungsstücken dargestellt. Eine Medienstation diskutiert die Geschichte vor und nach >München 1938<. Die Vorgeschichte der Sudetendeutschen beschränkt sich auf das Aufzeigen der zunehmenden Hinwendung zur Sudetendeutschen Partei und deren Umwandlung in eine >Fünfte Kolonne`, die schließlich durch immer höhere Forderungen einen Kompromiss für den sich zunächst entgegenkommend zeigenden Edvard Beneš unmöglich gemacht habe. Eine zweite Medienstation ist der Münchner Konferenz gewidmet, vor allem in Hinblick auf die fortgesetzte Aggression Hitlers und die Appeasementpolitik der Westmächte. Die »Liquidation of Czechoslovakia«, das >Protektorat Böhmen und Mähren`, Emil Hácha, der Slowakische Staat und Jozef Tiso sind Thema einer dritten Medienstation. In einer symbolischen Fensterscheibe wird anhand

przetrwanie i przestrzenią o dramatycznych decyzji. W tym światowym konflikcie już pierwszego dnia - 1.września 1939r. - Polska znalasła się w centrum wydarzeń. Tamto doswiadczenie pozostaje aktualne do dziś, odnosi się do najważniejszych wyborów, przed którymy także staje dzisiaj ludzkość i każdy z nas. Tak samo jak wtedy, również teraz uniwersalnymy wartościami pozostają wolność, godność, życie, w których obrony miliony ludzi złożyli ofiary w latach 1939-1945.« 
von vier historischen und reproduzierten Fotografien die Annexion des tschechoslowakischen Teschener Schlesiens ${ }^{346}$ durch Polen dargestellt. Auf einer historischen Gouache wird dieser Einmarsch gezeigt und die propagandistische Nutzung der Annexion für Polen im Begleittext thematisiert.

Diesem Bereich folgt ein Raum, welcher der Freien Stadt Danzig und dem polnischen Gdynia gewidmet ist. Erstere wird im Museum stets konsequent als »Wolne Miasto Gdańsk« beziehungsweise »Free City of Gdańsk« bezeichnet. Anhand von Objekten und Medienstationen werden die Entwicklungen der beiden Städte respektive Gebiete im regionalen und nationalen Rahmen besprochen, darunter die nationalsozialistische Machtübernahme in Danzig, die deutsche Judenverfolgung und die wachsenden lokalen und internationalen Spannungen. In einer Medienstation heißt es, dass »According to various estimates, the Poles accounted for from $9 \%$ to $13 \%$ of the population «, die im Jahr 1939 in der Freien Stadt Danzig 388.000 Bewohner betrug. Mit der Ablehnung jeder Konzession und Kooperation mit NS-Deutschland durch Polen schließt der Bereich. Der Besucher verlässt dieses Ausstellungssegment durch einen Flur, dessen Wand links mit drei großen Hakenkreuzen und rechts mit zehn Flaggen der Sowjetunion versehen ist.

Über den Hauptkorridor gelangt man in das dritte Element der Ausstellungschronologie: "So it's war, after all!«. Ausführlich wird der Charakter des Krieges gegen Polen als Vernichtungsfeldzug dargestellt. Neben dem polnischen militärischen Widerstand nehmen die Opfer des deutschen Bombenkrieges ebenso wie die der deutschen Verfolgungs- und Vernichtungsmaßnahmen gegen die polnischen Eliten in den besetzten Gebieten einen großen Raum ein. Im zweiten Teil dieses Bereiches wird der sowjetische Angriff auf Ostpolen als Konsequenz des Hitler-Stalin-Paktes gezeigt. Die Darstellung endet mit einer großen Karte, die das zwischen Deutschland und der Sowjetunion aufgeteilte Polen auf einer Europakarte veranschaulicht. Ein Bereich thematisiert im Zusammenhang mit den Repressionsmaßnahmen gegen die polnische Bevölkerung in den polnischen Westgebieten (dem ehemaligen Westpreußen und der Provinz Posen) auch den >Bromberger Blutsonntag« (»Bloody Sunday«, »Krwawa niedziela«). Im Wandtext heißt es:

»Polish units retreating through Bydgoszcz on 3 and 4 September 1939 were attacked by German saboteurs. About 350 members of the German minority were killed in military counterattacks and executed by local civilian kangaroo courts. After the Wehrmacht occupied Bydgoszcz, this incident was used by German propaganda to justify the mass executions of Poles."

Die zugehörige Medienstation zeigt einen Film, in dem dieses Narrativ noch um die planmäßig vorgenommene Internierung polnischer Bürger deutscher Nationalität ergänzt wird.

Der darauf folgende Bereich thematisiert die weitere sowjetische Aggression in Osteuropa, wobei ein kleiner Raum dem sowjetisch-finnischen Winterkrieg gewidmet ist (4). Einen größeren Bereich nimmt der fünfte Ausstellungsteil »A new kind of war « ein: Neben dem Kriegsverlauf 1940-1943 geht es hier vor allem um Fragen von Rekrutierung, 
Alltag der Soldaten, Frauenmobilisierung, Schützengrabenkunst, den Seekrieg und einige Uniformen und Waffen.

Im sechsten Teil »Merciless war« widmet sich die Ausstellung den Kriegsverbrechen der Deutschen, der Sowjetunion und der Japaner. Einen großen Teil nimmt die Schilderung der Behandlung von Kriegsgefangenen ein. Neben Massakern und dem durch Verhungernlassen durchgeführten Massenmord an den sowjetischen Soldaten begegnet einem auch das Schicksal der deutschen Soldaten in sowjetischer Gefangenschaft. Ein eigener Bereich ist dem Leiden der Zivilbevölkerung des belagerten Leningrads gewidmet. Ebenso wird der Bombenkrieg der deutschen, sowjetischen, japanischen und alliierten Streitkräfte dargestellt. Das Hungersterben im besetzten Europa und in den Ghettos wird mit zum Teil drastischen Bildern gezeigt.

Der siebte Bereich der Ausstellung behandelt die Themen »Occupation and collaboration«. Ausführlich werden die verschiedenen Okkupationsregime und unterschiedliche Formen der Kollaboration vorgestellt. Ein Augenmerk liegt auf der Differenzierung der Art der Besatzung zwischen West- und Osteuropa. Besondere Beachtung findet die deutsche Okkupation Polens, deren Ziele in der Versklavung der Bevölkerung sowie der Kolonialisierung und Germanisierung weiter Teile des Landes gesehen werden. Den spezifischen und besonders drastischen Charakter der deuotschen Besatzung Polens zeigt ein deutsches Plakat, das Helfern von Juden die Todesstrafe androht, ${ }^{347}$ ebenso wie das völlige Fehlen jeglicher Kollaborationspartner dargestellt wird. Im Bereich einer Medienstation werden die Deutsche Volksliste und der Dienst von Kaschuben und Oberschlesiern in der Wehrmacht knapp vorgestellt. Auch ein Mitmachelement befindet sich in diesem Ausstellungsteil: Der Besucher kann an einem Quiz teilnehmen, in dem es verschiedene Fragen zu den unterschiedlichen Okkupationsregimes zu beantworten gilt und so deren Gemeinsamkeiten und Unterschiede `spielend ‘ gelernt werden können.

Der Besucher wendet sich nun erneut dem Korridor zu. Sechs riesige Buchstaben, zwischen denen man hindurchgehen kann, bilden das Wort »Terror « und führen damit in den achten Teil der Ausstellung ein. Hinter dem Schriftzug befindet sich als großes Originalobjekt ein Zugwaggon. ${ }^{348}$ Der Bereich zeigt die Zerstörung von Ortschaften und Ermordung von Menschen durch deutsche und sowjetische Einheiten, darunter auch Lidice in der Tschechoslowakei. Auf einer großen Europawandkarte sieht man die im Krieg von deutschen Kräften vernichteten Orte und damit deutlich den auf Polen, Weißrussland und der Ukraine liegenden Schwerpunkt. In einem eigenen Bereich, der ähnlich wie bei den gleich folgenden Bilderwänden des Holocausts einen gewissen Gedenkstättencharakter hat, wird der polnischen Opfer von Katyń gedacht und ihre Schicksale anhand von Fotografien und persönlichen Gegenständen erzählt. Nun begibt man sich in einen Raum, der dem Besucher in ähnlicher Form bei den Zwangsmigrationen nach dem Krieg wiederbegegnen wird: Es geht um die vom Deutschen

347 Im >Generalgouvernment<stand auf Hilfe für Juden die Todesstrafe.

348 Vgl. zum Zugwaggon: Muzeum II Wojny Światowej: Museum of the Second World War, 2016, S. $9 f$. Er wird mit verschiedenen historischen Ereignissen des 20. Jahrhunderts in Verbindung gebracht, allerdings nicht mit der Vertreibung der Deutschen. 
Reich und der Sowjetunion initiierten Bevölkerungsverschiebungen. Den Fußboden bildet eine Karte des besetzten Europas, mit einem Hakenkreuz oder mit Hammer und Sichel versehene Pfeile deuten schematisch diese Zwangsmigrationen an. Der Raum ist umgeben von symbolischen und zum Teil originalen Türen von Angehörigen der vertriebenen Gruppen, zum Beispiel einer polnischen Familie, die aus dem nahen Gdynia ausgewiesen wurde. In diesem Bereich finden sich auch umfassende Informationen $\mathrm{zu}$ den deutschen Plänen für »Lebensraum im Osten«, unter anderem mit der Kopie einer Karte aus dem Bereich des `Generalplan Ost «. Eine Medienstation thematisiert die Zwangsausweisungen aus dem genannten Gdynia, Großpolen, Łódź, der ŻywiecRegion sowie Frankreich und Slowenien ebenso wie das deutsche Arbeits- und Internierungslager Potulice, in dem viele Polen interniert waren; darin eingeschlossen sind die ausgewiesenen oder in Ghettos deportierte Juden. Eine andere Station befasst sich mit den »Heim ins Reich«-Plänen des NS-Regimes. Ebenso ausführlich besprochen wird das »Sonderlaboratorium SS - Zamość Region«. Ein weiterer Abschnitt stellt mit Medienstationen, der Videoaufnahme eines Zeitzeugen sowie Fotografien und Originalobjekten die Deportationen durch die Sowjetunion vor und ist separiert in Deportationen vermeintlicher »Klassenfeinde« und die ganzer ethnischer Gruppen.

Es folgen Ausstellungsbereiche über die durch Deutsche durchgeführten Verschleppungen zur Zwangsarbeit, von deren Wesen und Alltagserscheinungen sowie von brutalen Exzessen der Aufseher. Dieser Bereich geht fließend in die Darstellung des expandierenden Systems der deutschen Konzentrationslager über: Eine metallene Wandkarte deutet mit möglicherweise als Einschusslöchern zu qualifizierenden Vertiefungen die Orte von Konzentrations- und Vernichtungslagern in Europa an. In einem mit Holzplanken ausgestalteten und durch die räumliche Struktur ein Engegefühl vermittelnden Raum werden ausführlich verschiedene Aspekte der deutschen Konzentrationslager thematisiert.

Der textlichen Präsentation der »Euthanasie«, der Ermordung von Menschen mit Behinderung durch die NS-Behörden in Europa, folgt unmittelbar der neunte Punkt der Ausstellung, der Holocaust. Ein Teilbereich zeigt anhand konkreter Beispiele verschiedene Reaktionsformen der polnischen Umgebung auf die deutschen Verbrechen: Hilfe, Gleichgültigkeit, Ausbeutung und Gewalt. Das Pogrom von Jedwabne wird umfassend thematisiert und zur Veranschaulichung die bei der Ausgrabung der Opfer gefundenen Schlüssel der polnischen Juden ebenso ausgestellt wie Bruchstücke einer Lenin-Statue, die im Zuge des Pogroms niedergerissen und mit den ermordeten Juden vergraben wurde. Eine gewaltige Wand an Koffern steht symbolisch für das Schicksal der deportierten und ermordeten Juden. Schließlich verlässt man diesen Bereich durch das vielleicht eindrucksvollste Element der Ausstellung, einen schmalen Gang, in dem mehrere Glasstelen mit hunderten Fotos von Opfern der Shoa den Besucher mit ihrem Schicksal konfrontieren.

Nach diesen Eindrücken folgt die zehnte Abteilung der Ausstellung, die »Ethnic purges«. In diesem knappen Bereich werden zum einen die versuchte vollständige oder regionale Beseitigung ethnischer Minderheiten durch das faschistische kroatische Ustaša-Regime (in Anlehnung an den deutschen Holocaust) sowie zum anderen die ethnischen Säuberungen durch ukrainische Nationalisten während der ukrainischpolnischen Kämpfe in Ostgalizien und Wolhynien dargestellt. Den letzteren sollen etwa 
100.000 polnische Zivilisten zum Opfer gefallen sein. Auch hier begegnen dem Besucher wieder persönliche Überbleibsel Ermordeter, die bei Exhumierungen gefunden wurden.

Als Gegenstück zum Schriftzug »Terror« wird in den elften Abschnitt der Ausstellung mit den Buchstaben Opór [Widerstand] eingeführt. Ähnlich wie im Bereich Okkupation und Kollaboration stellt dieser Bereich die in den verschiedenen Ländern existierenden Formen des Widerstandes vor; einen großen Teil der Darstellung nimmt der polnische Untergrundstaat ein. Sowohl militärische als auch zivile Formen des Widerstandes werden mit Beispielen aus verschiedenen Nationen, unter anderem aus Deutschland, umfassend gewürdigt. Der Bereich schließt mit einer Aufzählung der verschiedenen Aufstände gegen die deutschen Besatzer in den letzten Jahren des Krieges. Die Thematisierung des Prager Aufstandes spart die Massaker an der deutschen Zivilbevölkerung Prags und an deutschen Gefangenen zunächst aus. Die darauffolgenden kleinen Ausstellungsteile 12 und 13, »The War over secrets« und »All for victory!«, stellen die Entschlüsselung der Enigma durch polnische Wissenschaftler sowie Rüstungsprojekte und -produktionen wie die V2 dar.

Dem schließt sich ein eher chronologisch orientierter Teil an, in dem mit dem 14. Abschnitt unter »Allies on the offensive« die letzten beiden Kriegsjahre dargestellt werden. Ein Fokus liegt hier auf dem Beitrag der polnischen Streitkräfte an der Seite der Alliierten. Nach dem Verlassen dieses Raumes erreicht man den 15. Ausstellungsteil "The war is over", der sich trotz dieses Titels umfassend mit dem langen Weg zum Kriegsende befasst. Im englischen A-Text heißt es:

»The war is over

Joy, disenchantment and despair accompanied the end of military operations

The Great Powers prepared for the end of the war by drawing new frontiers and marking their spheres of influence. Poland and all of east-central Europe switched from Cerman occupation to Soviet control, against its will. Hundreds of thousands of Cermans fled the approaching Red Army in Panic. The Third Reich carried on its crimes until the very end. The shocking discovery of evidence of genocide, often accompanied by spontaneous acts of revenge targeting the occupier and traitors, marred the joy of liberation. [...]

Der erste Bereich widmet sich den alliierten Nachkriegsplanungen im Verlauf des Krieges, ${ }^{349}$ aber auch der Konstitution der kommunistischen polnischen Marionettenregierung. Inszeniert ist dieser Raum mit einem angedeuteten Parkettboden und einer holzvertäfelten Wand, was vermutlich die Tagungsorte der Konferenzen visualisieren soll.

Ein Raum ist der Flucht vor der Front, den deutschen Endphaseverbrechen und den Vergewaltigungen am Kriegsende gewidmet. Als erstes Ausstellungsobjekt fällt die Schiffsglocke der Wilhelm Gustloff ins Auge. Der Begleittext berichtet von dem Schicksal dieses und weiterer mit Flüchtlingen beladener Schiffe. Im A-Text heißt es:

349 Atlantik-Charta, Konferenz von Casablanca, Teheraner und Moskauer Konferenz, die Konferenz von Jalta sowie die Gründung der Vereinten Nationen. 
»Fleeing from the front

The evacuation of the German population of East Prussia in January 1945 became a panicked flight. Soon, evacuation by sea became the only possible escape route. The refugees boarded ships in the harbours of the Bay of Cdańsk, as an atmosphere of calamity loomed. The Wilhelm Gustloff, once a luxury liner used by the Nazi organization Kraft durch Freude, was the largest vessel available.«

In einer zugehörigen Medienstation wird das Geschehen um die fliehende deutsche Zivilbevölkerung mit Texten, Karten und Bildern visualisiert. Dort heißt es unter anderem, dass die Evakuierungen seit Sommer 1944 zunächst reibungslos verliefen, ehe sie im Winter 1944/45 in eine chaotische Flucht vor der herannahenden Front übergingen. Schließlich wurden »over 7 million Germans [...] evacuated from the eastern territories of the Third Reich.«Die Folie »Crimes, Propaganda, Panic« geht auf die tatsächlichen und vermeintlichen Gräueltaten der Roten Armee und der NS-Propaganda ein:

»Tohe Cerman population was terrified by news of the approaching Red Army. The panic was intensified by Nazi propaganda, which broadcast information about the Red army massacre of the inhabitants of the East Prussian village of Nemmersdorf [...] on 21st October 1944. But by exaggerating the number of victims and focusing on the shocking details, the Nazis achieved an effect opposite to the one intended. Instead of deciding to stand up and defend themselves to the bitter end, the German civilians took flight. Some committed suicide rather than face the Red Army.«

Die Fluchtbewegungen werden als »Evacuee hell« bezeichnet und als tragisch beschrieben:

»The panic-stricken flight of the Germans ahead of the approaching Red Army turned into a humanitarian disaster. Columns of evacuees wandering over snow drift covered roads became an easy target for Soviet aircraft or got caught in the firing line of opposing armies. The chaos, lack of provisions and medical care led to tragic consequences."

Die zweite Folie berichtet über die Evakuierung über die Ostsee und das Schicksal der dabei untergegangenen Schiffe. Auf einer eigenen Seite wird der sowjetische Marineoffizier Alexander Iwanowitsch Marinesko vorgestellt, der die Wilhelm Gustloff und die Steuben versenkte. In dem Raum schließt sich die Darstellung der Todesmärsche aus den Konzentrationslagern 1944/45 an, hier eindrücklich gezeigt anhand von Zeichnungen (Kopien) eines ehemaligen polnischen Lagerhäftlings. Beispielhaft wird auch das von Deutschen verübte Massaker an Häftlingen des KZ Stutthof im ostpreußischen Palmnicken erwähnt. Neben diesem Bereich befinden sich eine Medienstation sowie eine Figur und zwei Dokumente, die sich den Opfern von Vergewaltigungen am Kriegsende widmen. Im B-Text heißt es:

»As the Red Army occupied new territories its soldiers raped Cerman women. For some, it was revenge for Cerman crimes in the Soviet Union. This also happened in Cdańsk. Some of the women, trying to escape cruelty and humiliation, killed themselves, some by jumping into the Motława River. For those who lived, the experience of rape was a trauma that stayed with them forever.« 
Das an der Wand ausgestellte Objekt ist eine »Moveable erotic figurine«, die von einem Soldaten der Roten Armee geschaffen wurde und den Geschlechtsakt darstellt. »It says a lot about the needs of the millions of men in uniform. Soviet soldiers in Gdańsk and other captured cities satisfied this need by committing mass rapes on German women and often also on women of other nationalities«. Die ausgehängten, hier gezeigten Dokumente einer Frau sind der Nachweis ihrer polnischen Herkunft, um sie in Pommern vor den Vergewaltigungen durch Rotarmisten zu schützen. An der Medienstation kann man über einen Kopfhörer Erzählungen von anonymen Zeitzeuginnen über die Erfahrungen der Vergewaltigungen hören. Sowohl deutsche als auch polnische Frauen kommen zu Wort. Diese Erzählungen werden auf dem Bildschirm mit groben Zeichnungen von Hoffnungslosigkeit, Scham, Einsamkeit, Gewalt und Tod illustriert. ${ }^{350}$

Ein eigener Bereich ist dem Ende des deutschen Danzig gewidmet (»From Danzig to Gdańsk«). Als Objekte dienen unter anderem alte deutsche Laden- und Hinweisschilder sowie beim Bau des Museums ausgegrabene Alltagsobjekte. Über diesen hängt eine große Illustration des zerstörten Danzig. Eine Medienstation erzählt vom dortigen Kriegsende: Der bis zuletzt fortdauernde NS-Terror, der nun in besonderem Maße die eigene Bevölkerung und vermeintliche Deserteure betraf, wurde nach fast völliger Zerstörung des historischen Zentrums durch weiteren Terror der Roten Armee fortgesetzt. Geschildert wird unter anderem die Verbrennung von hunderten Bewohnern bei lebendigem Leibe in der St.-Josephs-Kirche durch sowjetische Soldaten (»Crimes Against the Population«).

Der nächste Teilbereich zeigt unter »Total victory, ambiguous liberation« die Einführung des Kommunismus in Polen (»The new government's terror«) und das Ereignis des unmittelbaren Kriegsendes in Deutschland und weltweit, wobei die Differenz zwischen der westlichen und östlichen Welt erneut verdeutlicht wird. Erinnerungsstücke von Angehörigen der polnischen Heimatarmee, die nach Sibirien deportiert wurden, stehen ebenso wie die Darstellung des fortgesetzten Untergrundkampfes gegen die Sowjetmacht als Beleg für die konstatierte Ambivalenz des Kriegsendes. Die mit dem Kriegsende immer deutlicher ans Tageslicht kommenden NS-Verbrechen sowie die alliierten Reaktionen werden kurz gezeigt, ebenso wie der »Spontaneous Payback«, den viele Deutsche, Kollaborateure und vermeintliche Kollaborateure ebenso wie Frauen, die Verhältnisse mit Deutschen hatten, erfahren mussten. ${ }^{351}$ Dieser Bereich schließt mit dem Bombenabwurf von Hiroshima, dargestellt durch das durch die Explosion geschmolzene Porzellan oder Glas und einem über dem Besucher schwebenden Nachbau der Bombe.

»The war's long shadow« ist der dritte und letzte Oberbereich der Ausstellung und beginnt mit der Abteilung $16 »$ After the War«. Erneut bewegt sich der Besucher in ei-

350 Mittlerweile (2018) scheinen an der Medienstation auch Filmaufnahmen der Zeitzeuginnen zu sehen zu sein.

351 Dieser Ausstellungsbereich war im Januar 2017 noch nicht abgeschlossen, im Katalog befindet sich aber die Fotografie eines von tschechischen Aufständischen gelynchten Deutschen in Prag, womit die Cewalttätigkeit des Prager Aufstandes gegen unbewaffnete Zivilisten oder Kriegsgefangene doch noch zur Sprache kommt: Muzeum II Wojny Światowej: Museum of the Second World War, 2016, S. 208. 
nem szenografisch inszenierten Stadtraum, in dem ein sowjetischer T-34-Panzer die zerstörten Häusersilhouetten bedrohlich dominiert. Im A-Text steht:

»The Second World War was one of the watersheds in world history. The borders of the countries of east-central Europe changed and many millions of people were expelled from their homes and their countries. Nazism was censured, and some important Cerman and Japanese war criminals were put on trial. But the other totalitarian empire, the Soviet Union, emerged from the conflict a winner and became a superpower, extending its domination all the way to the Elbe River. It took the nations of east-central Europe until 1989 to become free of its control. To this day, our world continues to bear the stigma of that war.«

Im einleitenden Text »After the War« heißt es unter anderem: »The victorious Allies agreed on forced migrations, especially expelling the Germans from central Europe, as a way to avert future conflicts. ${ }^{352}$ Eine Schautafel zeigt die Kriegsopferzahlen der am meisten betroffenen zehn Länder. Für Deutschland werden 4,2-5,3 Millionen gefallene Soldaten und 1,5-3,5 Millionen ums Leben gekommene Zivilisten angegeben, für Polen 0,3 Millionen gefallene Soldaten und 5,3 Millionen Zivilisten (davon 3 Millionen Juden polnischer Staatsbürgerschaft). ${ }^{353}$

Ein von dieser Szenografie abgehender Raum ist dem Bereich »Great Transformation: Migrations and Borders « gewidmet. Ähnlich wie in dem Raum, der die von der Sowjetunion und dem Deutschen Reich durchgeführten Zwangsmigrationen zeigt, ist der Boden wieder in Form einer Europakarte gestaltet, in der die mit Hakenkreuz oder Hammer und Sichel versehenen Pfeile Bevölkerungsverschiebungen darstellen. So wird die Vertreibung der Deutschen mit Hakenkreuzen veranschaulicht, die der polnischen Bewohner aus den kresy, der Ukrainer aus Polen in die Ukraine ebenso wie die Deportationen von Polen und Balten in die Sowjetunion mit dem Symbol des Kommunismus. Erneut gehen von diesem Raum verschiedene kleine Kammern ab, in denen die verschiedenen Zwangsmigrationen behandelt werden und szenografisch dargestellte Haus- und Wohnungstüren symbolisch für die verlorene Heimat stehen. An der rückwärtigen Wand des Raumes hängt - über allem und den Besucher in den Blick nehmend $^{354}$ - eine Fotografie der Potsdamer Konferenz. Der Begleittext des Bildes formuliert die Verantwortung für die Vertreibungen eindeutig:

»The last conference of the Big Three took place in July and August 1945 in Potsdam. It was to decide the future of Cermany and to resolve the issue of war reparations. It chose the Oder and Lusatian Neisse as the Polish-German border, but put off its ratification to

352 »]ednym ze sposobów zapobieżenia ponownym konfliktom miały być uzgodnione przez aliantów przymusowe migracje ludności, a przede wszystkim wysiedlenie Niemców z Europy Środkowej.«

353 Diese Karte ließ die Museumsleitung im März 2018 zur Überarbeitung entfernen. Die Angabe absoluter Zahlen soll durch prozentuale Opferzahlen ersetzt werden, mit denen Polen an erster Stelle statt an dritter hinter der Sowjetunion und Deutschland stehen würde. Vgl. Leister: Das Danziger Weltkriegsmuseum droht ein »kleinkariertes nationalistisches Zentrum« zu werden. NZZ. 13.07.2018.

Einer der Konferenzteilnehmer blickt auf der Fotografie in Richtung des Betrachters. 
the peace conference - which never took place. It also decided to remove the Germans from Poland, Czechoslovakia and Hungary.«

Eine rechts an der Wand hängende, stark vergrößerte Fotografie zeigt eine in das zerstörte Warschau zurückkehrende Frau mit ihrem Kind, die hier als Beispiel für das polnische, aber auch generell für das Schicksal des Heimatverlustes und der Zersplitterung von Familien steht. Noch nicht zum Zeitpunkt meines Besuches, aber bald darauf eingerichtet, befindet sich vor diesem Bild ein Fahrrad, mit dem eine polnische Zwangsarbeiterin von Deutschland nach Warschau fuhr. Auf der linken Seite des Bildes hängt eine historische Nachkriegskarte von 1945, die Polen in seinen neuen Grenzen zeigt, rechts daneben ein Flugblatt des polnischen Zentralbüros für vermisste Personen. ${ }^{355}$

Ion der ersten Kammer geht es um die Nachkriegswege von Polen, darunter die Rückkehr polnischer Soldaten aus dem Westen, die Heimkehr von Zwangsarbeitern aus dem Dritten Reich, die »Repatrianten « aus den ehemaligen polnischen Ostgebieten und die Migration polnischer Juden. In diesem stark verdunkelten Raum heißt es im A-Text zur »Repatriierung« der Polen:

»Poland lost sizeable territories in the east to the Soviet Union, and in return was given German lands. In the autumn of 1944 a srepatriation agreement was signed to resettle Poles from the Eastern Territories. The relocations were mandatory and were conducted in an atmosphere of terror and in appalling conditions. In 1944-1948, over 1.5 million people were moved into the new Poland.«

Die nächste Kammer zeigt die Vertreibung der Deutschen. Im A-Text ist unter »Expulsions of Germans« (Wysiedlenia Niemców) formuliert:

»Cermans were expelled from Poland and Czechoslovakia already before the Potsdam Conference. The conference decided that removals of Cermans from Poland, Czechoslovakia and Hungary would be organized, compulsory and humanitarian. About 3.5 million Cermans left Poland and over 3 million Czechoslovakia.«

In diesem ebenfalls dunklen Raum werden vier Exponate präsentiert: eine »Niemiec«Armbinde sowie eine gelbe Armbinde als zwangsverordnete Erkennungsmarken für Deutsche, die Residenzbescheinigung einer Vertriebenen für die westlichen Besatzungszonen und eine Erinnerungsmedaille eines Minenarbeiters aus Gleiwitz. In der mit Fotografien und Karten versehenen zugehörigen Medienstation werden unter "Post-war expulsion (deportation) of Germans« (Powojenne wysiedlenia Niemców) die Vertreibungen aus Polen, der Tschechoslowakei und Ungarn knapp besprochen. In der Folie zu den Vertreibungen aus Polen heißt es:

»After the end of the war, from 2.5 to 4 million Cermans lived in what were to become Polish territories. The first >wild evictions, carried out spontaneously without any international agreement, began immediately after the fighting ceased and lasted until August 1945 . They included 400,000 people and were often accompanied by robberies and acts of violence. The phase of evictions followed the Potsdam Conference of 1945

355 Bis auf das Flugblatt sind die Objekte im Katalog vorgestellt: Muzeum II Wojny Światowej: Museum of the Second World War, 2016, S. 218-221. 
and were carried out according to resolutions made by the victorious powers. The expelled were informed 24 hours before their deportation. They were only allowed to take $20 \mathrm{~kg}$ of baggage and provisions for the road. Their remaining property was confiscated. Germans were deported from Poland to the Soviet and British occupation zones in Cermany. By 1949 r. [sic] there were only some 300,000 Germans living in Poland.«

Diese Folie ist mit Fotografien von fliehenden Kindern auf Pferdetrecks unterlegt, die nächste Folie mit der Fotografie eines nicht lokalisierten tschechoslowakischen Lagers, in dem Sudetendeutsche interniert wurden, mit dem Eingangsschild Sběrné středisko [Sammellager]. Dieses ist aber nicht vollständig zu sehen, da der Text und ein weiteres Bild es teilweise überdecken. Im zugehörigen Text heißt es:

"Still during the war, the Czechoslovak President Edvard Beneš obtained tentative approval from the powers to expel Cermans. The process was begun immediately after the country was liberated, in May and June 1945, without a formal international agreement. The swild expulsions $<$ affecting around 700,000 people, were conducted with great brutality, as a result of which at least 9,000 people died. At the same time in Czechoslovakia, under Beneš's >decrees`, Germans were deprived of citizenship and had their property confiscated. As in Poland, the phase of expulsions began after the 1945 Potsdam Conference, in accordance with the international resolutions that were then made. These expulsions were conducted in a more humane manner. In total over 3 million Cermans were expelled from Czechoslovakia."

Ein weiterer Raum stellt im Verbund mit einer Medienstation die Vertreibungen beziehungsweise Umsiedlungen und Deportationen in die Sowjetunion dar. Hier wird auch die Umsiedlung der Ukrainer aus Polen oder innerhalb Polens zur Zerstreuung (»Aktion Weichsel«) besprochen, ebenso wie der andauernde militärische Widerstand von Partisanen gegen die sowjetische Herrschaft in den baltischen Staaten. In dem zugehörigen Raum stand im Januar 2017 nur eine leere Vitrine. Mittlerweile befinden sich dort zwei Koffer von in die Sowjetunion deportierten Menschen, unter anderem aus Estland, sowie der Videobericht eines Zeitzeugen und einer Zeitzeugin über die Deportation. ${ }^{356}$

Diesen eher dunklen, in Grautönen gehaltenen Bereich verlassend, betritt der Besucher nun den in helles Holz gefassten Bereich der Nachkriegsjustiz unter dem Titel »Triumph of Justice«. Umfassend werden hier sowohl die internationale strafrechtliche Verfolgung der deutschen und japanischen Kriegsverbrechen als auch die nationale juristische Aufarbeitung von Kollaboration und NS-Verbrechen vorgestellt.

Der Besucher verlässt diesen Ausstellungsbereich, indem er erneut die Ruinenlandschaft betritt. Von da aus erreicht er den vorletzten Bereich "On the two sides of the Iron Curtain«, der knapp die Spaltungen Europas und der Welt infolge des Krieges präsentiert. Zu besichtigen ist hier eine Bilderreihe von Kinderzeichnungen, die Warschau in Ruinen sowie eigene traumatische Erlebnisse darstellt. Dem folgt der 18. und letzte Teil der Ausstellung »From war to freedom«, der unter Verweis auf die SolidarnośćBewegung den Zusammenbruch des Ostblocks und die Überwindung der europäischen

356 Vgl. zum Koffer-Exponat: Muzeum II Wojny Światowej: Museum of the Second World War, 2016, S. 221. 
Teilung behandelt. Die Ausstellung endet hier in einem Raum, der durch eine Mauer getrennt ist. Für den Besucher ist sie unten durchlässig, darauf befindet sich Stacheldraht. Links der Mauer laufen Filmaufnahmen der westlichen Politik- und Kulturgeschichte des Kalten Krieges, auf der rechten Seite die entsprechenden Aufnahmen aus der kommunistischen Welt; im Hintergrund ist »The House of the Rising Sun« (1964) von The Animals zu hören. Die Aufnahmen bleiben auch bei nach 1989 entstandenen Bildern getrennt, zum Beispiel wenn der iranische Präsident Mahmud Ahmadineschād auf der einen und der israelische Ministerpräsident Benjamin Netanjahu auf der anderen Seite gezeigt werden. Es folgen Aufnahmen aus Syrien und dem Donbass, die den Krieg und das Leiden der Zivilbevölkerung und der Flüchtlinge zeigen. Erst zum Abschluss verbinden sich mit Filmaufnahmen des zerstörten Aleppos die beiden Projektionen an der Wand zu einer. ${ }^{357}$

\subsubsection{Ausstellungsanalyse}

Der eben vorgestellte Rundgang durch die Dauerausstellung des MIIW konnte nur einen Überblick geben. Dennoch wird die erfolgreiche Einlösung des Anspruches einer globalgeschichtlichen Erzählung des Zweiten Weltkrieges aus Sicht der Zivilbevölkerung und einfacher Soldaten unter besonderer Berücksichtigung der polnischen und ostmitteleuropäischen Perspektive deutlich. Viele der über die vorliegende Fragestellung hinausgehenden und zu würdigenden Elemente der Ausstellung können hier, ebenso wie die wenigen zu kritisierenden, leider nicht besprochen werden. Der für die vorliegende Untersuchung besonders relevante Gründungsimpuls - Flucht und Vertreibung der Deutschen in dem aus der Perspektive der Ausstellungsmacher entscheidenden Rahmen des Zweiten Weltkrieges darzustellen - findet sich ziemlich exakt und den damaligen Vorstellungen entsprechend wieder. Die Dauerausstellung rahmt so die Zwangsmigration der Deutschen mehrfach: durch den von Deutschland verursachten Zweiten Weltkrieg, durch die vorherige NS-Besatzungs- und Siedlungspolitik, durch die zur Zeit der Flucht- und ersten Vertreibungsbewegungen fortdauernden NSVerbrechen sowie durch das Schicksal der polnischen Zwangsarbeiter (das hier als eine Form der Zwangsmigration versanden wird) und der polnischen Vertriebenen aus den kresy, ebenso wie durch die Deportationen von Polen und Angehörigen anderer Völker in die Sowjetunion am Ende des Krieges. Flucht und Vertreibung werden räumlich in zwei Bereiche und darüber hinaus wieder in verschiedene Etappen getrennt: Evakuation und Flucht, >wilde $<$ Vertreibungen und Vertreibungen nach dem Potsdamer Abkommen. Beide Ausstellungsteile sind im Ausstellungsgefüge nicht übersehbar. Fragen sexueller Gewalt im Krieg werden anhand der Massenvergewaltigungen hauptsächlich deutscher Frauen in den von Vertreibung betroffenen Gebieten konkretisiert. Bei der Verfolgung einer globalgeschichtlichen Perspektive kann man von einer in der Gesamtschau aller möglichen und relevanten Themen überproportionalen Darstellung der

357 Vgl. Machcewicz: Muzeum, 2017, S. 137. Vgl. auch: Hoja: An Engaged Narrative, 2017. Vgl. für eine Amateuraufnahme des Filmes im Museum: Oryginalny film kończący wystawę Muzeum II Wojny Światowej w Cdańsku, 2017. 
deutschen Zwangsmigrationen sprechen. Der Präsenz des Gegenstandes kommt zugute, dass die Ausstellung immer wieder regionalgeschichtliche Fragen einbaut und mit dem Aufzeigen des Schicksals des deutschen Danzig das Vertreibungsthema im weiteren Sinne zusätzlich an Gewicht gewinnt. Die angekündigte Darstellung von Opferund Täterperspektive wird punktuell eingelöst, so in Bezug auf die hier untersuchte Thematik am Beispiel des russischen U-Boot Kommandanten, der die Gustloff versenkte.

Überzeugend wird der multimethodische Ansatz der Ausstellung, das Zusammenspiel von Exponaten, Medien und Szenografie, umgesetzt. Ob der von Machcewicz betonte besondere Schwerpunkt auf dem authentischen Exponat auch so vom Besucher wahrgenommen wird, kann aber durchaus bezweifelt werden, da die meisten Objekte stark in die Szenografie integriert sind. Hinzu kommt, dass bei der >Flachware`, wie Fotografien und Karten, nicht immer klar ist, ob es sich um Originale oder Reproduktionen handelt. Über die spezifisch militärischen Objekte und ihre Darstellung soll hier keine Aussage getroffen werden, außer, dass sie die Ausstellung nicht dominieren oder - wie der sowjetische Panzer - durch die Szenografie einer zerstörten Landschaft kritisch eingehegt sind. Bloße Objekte als Einzelstücke zur kontemplativen Betrachtung finden sich eher selten: So sind kleinere Objekte häufig mit mehreren zusammen in einer Vitrine ausgestellt oder aber bei der Schiffsglocke der Gustloff durch Fotografien und Text so gerahmt, dass der Besucher weniger von dem Objekt an sich als von dem dargebotenen Ensemble gefordert wird. Bei der Gestaltung der Räume wird das ganze Spektrum der Inszenierung verwendet: wechselnder Einsatz von Wand- und Bodenfarben, ganz unterschiedliche Beleuchtungsformen sowie verschiedene Soundkulissen. Hier reicht die Spannbreite von zurückhaltender bis hin zu aggressiver Inszenierung, beispielsweise bei der Unterlegung des Raumes zum Nationalsozialismus mit dem Versatz einer Hitlerrede und Wagners »Walkürenritt«. Dieser gemischte Gestaltungsansatz ist sehr abwechslungsreich und lässt beim Besucher keine Ermüdung aufkommen.

Bei den Einführungs-, Raum- und Objekttexten (A-C) erkennt man ein intensives und erfolgreiches Bemühen um eine präzise, einfache und knappe Sprache. ${ }^{358}$ Gelegentlich wird nach Eindruck des Autors zu selbstbewusst mit Zahlen operiert, aber das ist dem Gebot dieses Ansatzes geschuldet. Ein negatives Beispiel hierfür ist die Angabe des >polnischen Bevölkerungsanteils der Freien Stadt Danzig: Diese ist mit 9-13 Prozent weit entfernt von der letzten Vorkriegsvolkszählung vom November 1923, die über die Angabe der Muttersprache einen kaschubisch-, masurisch- oder polnischsprachigen Bevölkerungsanteil von 3,28 Prozent ergeben hat. ${ }^{359}$ Davon abgesehen werden die von den Ausstellungsmachern nicht spezifisch erwähnten Kaschuben und Masuren

358 Auch Hoja ist voll des Lobes für die Qualität der Ausstellungstexte: Hoja: An Engaged Narrative, 2017.

359 Außerdem ist ein Personenanteil von 0,44 \% der Bevölkerung verzeichnet, der sowohl Deutsch als auch Polnisch als Muttersprache angab. Der Anteil der kaschubisch-masurisch-polnischsprachigen Bevölkerung mit der Staatsbürgerschaft der Freien Stadt Danzig betrug 2,02 \%: Statistisches Landesamt der Freien Stadt Danzig (Hg.): Danziger Statistisches Taschenbuch für 1930/31, 1930, S. 18. Die deutlich höheren Angaben der Ausstellung von 9-13 \% beziehen sich vermutlich auf volkspolnische sSchätzungen«. So zum Beispiel: Drzycimski: Polacy w wolnym mieście Cdańsku (1920-1933), 1978. 
ohne Diskussion dem polnischen Bevölkerungsanteil zugeschlagen. Hier hätte es die Chance gegeben, diese Zahl, die ethnische Differenzierung, aber auch die Problematik von Volkszählungen und Schätzungen in der Zwischenkriegszeit zu erwähnen. ${ }^{360}$ Ebenso finden weitere Forschungskontroversen in der Ausstellung keinen oder kaum einen Platz und werden auch an anderer Stelle, zumindest in Hinblick auf die Zwangsmigrationen, nicht thematisiert. Deutlich hervorzuheben ist die direkte Sprache der englischen Texte, so wird von expulsions und evicitions im Zusammenhang mit Flucht und Vertreibung der Deutschen geschrieben. In den polnischen Texten bleibt es in diesem Zusammenhang bei wysiedlenie und przesiedlenie und auf die wörtliche Übersetzung von expulsion, wypędzenie wird verzichtet. Allerdings wird der Begriff wysiedlenie bei den Vertreibungen der Polen durch die Deutschen ebenfalls verwandt und so eine begriffliche Symmetrie hergestellt.

Ein Großteil der Basisinformationen befindet sich in den überall verteilten Medienstationen. Deren Gestaltung in Form einfacher Bildschirme mit lexikonartigen Überblicksinformationen wirkt schon etwas in die Jahre gekommen und wenig intuitiv; gleichzeitig ist damit eine klare Strukturierung der Informationen gewährleistet. Dennoch stellt sich gerade für das hier verfolgte Thema die Frage, inwieweit die Besucher zum Ende ihres Ausstellungsbesuches hin noch die Kapazität und Bereitschaft haben, sich an die Medienstationen zu begeben und durch die verschiedene Folien zu »klicken<. Hier sind aber die informativen A- und B-Texte durchaus ausreichend, um zumindest ein grobes Verständnis der ausgestellten Objekte und des historischen Geschehens zu erhalten. Die Frage der Aufmerksamkeitsspanne führt zu einem grundsätzlichen Problem der Ausstellung: Richtigerweise wird auch von den Ausstellungsmachern die durchschnittliche Verweildauer der Besucher in Museen mit 1,5 Stunden angesetzt. ${ }^{361}$ So kann selbst bei einem deutlich längeren Besuch die Ausstellung vom Gros der Besucher schon rein physisch nur selektiv wahrgenommen werden. Das heißt aber nicht, dass das Grundnarrativ nicht dennoch erfolgreich transportiert werden kann, da die Überblickstexte eine gute inhaltliche Orientierung sowie eine Vertiefung nach eigenen Interessen ermöglichen.

Zeitzeugen begegnen dem Besucher an verschiedenen Stellen der Ausstellung, sind aber kein tragendes Element. So gibt es die Videoaufnahme eines kresy-Vertriebenen und die angesprochenen Zeitzeugenberichte an der Medienstation zum Thema der Vergewaltigungen. Sie fungieren damit nicht als Erzähler der Ereignisgeschichte, sondern um die emotionale Dimension des Geschehens und manchmal des kaum Beschreibbaren zu vermitteln.

Das Museum spricht alle Sinne der Besucher an. Sie werden weniger zum Mitmachen als zum Staunen, Mitfühlen und Lernen angehalten. Und sie werden keineswegs geschont: Drastische Gewaltaufnahmen oder grausame Erzählungen, ohne im Vorfeld vor diesen zu warnen, scheinen das Ziel der Museumsmacher zu unterstreichen, eine

360 Vgl. zur Problematik der Volkszählungen in der Zwischenkriegszeit als Quelle: Masnyk: Provinz Oberschlesien (1918/19-1938/39), 2015, S. 313.

361 Majewski: Muzeum II wojny światowej w Cdańsku, czyli o tym, jak opowiadać o historii w społeczeństwie o różnych wrażliwościach, 2017, S. 106. 
ungeschminkte Fassung des Krieges jenseits der auch gezeigten blank geputzten Säbel, hübschen Uniformen und beeindruckender Waffentechnik zu erzählen. ${ }^{362}$

Oben wurde schon die kontextualisierende und fest gerahmte Darstellung des in der Ausstellung thematisch aufgegliederten Komplexes von Flucht und Vertreibung diskutiert. Die inhaltlich weitgehend konventionelle Erzählung fasst zentrale Begebenheiten sowie die wesentlichen Zahlen zusammen und wird in den verschiedenen das Thema berührenden Ausstellungsbereichen für sich dargestellt. Die sie umgebende Vorstellung anderer Zwangsmigrationen oder der fortlaufenden Shoa liefern einen weiteren Kontext. Die Entscheidung zur Vertreibung der Deutschen aus den Gebieten Zentralund Osteuropas wird bei den Alliierten sowie der Stalinschen Westverschiebung Polens verortet, was in den Begleittexten ebenso deutlich wird wie durch die Inszenierung im Raum der Nachkriegszwangsmigrationen, über den die Potsdamer Konferenz >wacht<. Etwas unterlaufen wird damit jedoch die ursprüngliche Aussage, dass Zwangsmigrationen in dieser Größenordnung ein typisches und ausschließliches Mittel totalitärer Regimes sind. ${ }^{363}$ In den Ansatz der Ausstellung, keine Politikgeschichte zu erzählen, fügt sich aber, dass den Entscheidungsprozessen der alliierten Staatsführer - und noch stärker den polnischen und tschechischen Exilregierungen - nicht viel Platz gegeben wird. So ist der Raum der Ausstellung, der die alliierten Konferenzen auf dem Weg zur Nachkriegsordnung thematisiert, knapp gehalten und fungiert nur als Zwischenraum. Nur bei Edvard Beneš wird kurz angedeutet, dass sein Werben für eine Entfernung der Deutschen bereits während des Krieges begann. Die Frage des Warum? wird auch in anderen Bereichen nicht tiefergehend erörtert, sondern es werden stattdessen die fatalen Auswirkungen auf das Leben der Zivilbevölkerung und so auch das Elend der deutschen Flüchtlinge und Vertriebenen thematisiert. Dies gelingt ohne Relativierung oder eine Überstrapazierung des Rachemotivs, das nicht nur in Hinblick auf die Deutschen, sondern auch auf (vermeintliche) Kollaborateure kritisch, als Beschädigung des Sieges und nicht unbedingt als zwangsläufig betrachtet wird. Die Vergewaltigungen am Ende des Krieges zeigt die Ausstellung in ihrer Dimension als Massenphänomen.

Einen überwiegend illustrativen Charakter hat die Darstellung der Gustloff-Glocke, ist sie doch durch das Ausstellungsnarrativ und die Gestaltung des Raumes eingehegt. Ähnlich wie bei den Planungen der SFVV ${ }^{364}$ wird die deutsche Opfergeschichte von Flucht und Vergewaltigungen mit den zeitgleich stattfindenden Endphaseverbrechen kontextualisiert, hier am Beispiel der Geschehnisse im Januar 1945: Der Untergang der Gustloff, das Massaker von Palmnicken und die Massenvergewaltigungen durch die Rote Armee. Das nebeneinander Erzählen dieser Ereignisse im selben Raum verhindert eine Relativierung und überlässt es dem Besucher, Verbindungen zu erkennen.

Die Objektauswahl im Raum der Vertreibung ist unter anderem mit einer »Niemiec«-Armbinde wenig originell, allerdings war die Gestaltung des Bereiches im Januar

362 Heinemann kritisiert die umfassende Darstellung drastischer Gewalt ohne Vorwarnung und verweist auf alternative Methoden, die mit diesem Vorgehen verbundenen Botschaften zu vermitteln. Zudem werde nicht reflektiert, dass die meisten Bilder eine Täterperspektive abbilden: Heinemann: Krieg und Kriegserinnerung im Museum, 2017, S. 477f. 
2017 noch nicht abgeschlossen. ${ }^{365}$ Ob die simplifizierende Darstellung der Bodenkarte mit Hakenkreuzen und Hammer und Sichel die beste Möglichkeit der Illustration auch in Hinblick auf ein Verständnis des Geschehens ist, darf bezweifelt werden. Etwas weniger Abstraktion wäre hier wünschenswert gewesen, auch wenn in den Medienstationen wesentlich besseres Kartenmaterial vorhanden ist. Nicht erzählt oder nur angedeutet wird das Schicksal der Deutschen aus Südosteuropa oder der Wolgadeutschen, was aber in Anbetracht der Notwendigkeit der Reduktion in der Gesamtbetrachtung eine verständliche Entscheidung ist.

Fast keine Rolle spielt das jahrhundertelange Zusammenleben der Ethnien in der Ausstellung, die einem recht statischen Verständnis von nationaler Zugehörigkeit folgt. Nationale Ambivalenzen deuten sich nur punktuell an, etwa bei der Diskussion der in die Wehrmacht eingezogenen Oberschlesier und Kaschuben oder aber bei der Verfolgung von Menschen als Juden, obgleich sich einige von ihnen gar nicht (mehr) als solche definierten. Warum dieses Zusammenleben der Völker scheiterte, bleibt ebenso im Unklaren wie auch der Versuch NS-Deutschlands, deutschsprachige Gebiete zurückzugewinnen, nicht weiter erklärungsbedürftig zu sein scheint. Die Deutschen der Tschechoslowakei und Polens (sowie der Freien Stadt Danzig) sind ein Ziel von Hitlers Expansion und die Deutschen dieser Regionen streben ihm entgegen: Diese gewiss korrekte Erzählung verzichtet aber weitgehend auf die ergänzende Diskussion möglicher Konstruktionsfehler der Versailler Ordnung und einer mangelnden Kompromissfähigkeit des polnischen und tschechoslowakischen Staates in dieser auch dort bedeutenden Hochphase des Nationalismus. Es wird im Gegenteil sogar der Versuch von Edvard Beneš hervorgehoben, einen Ausgleich mit den Deutschen der ČSR zu suchen - was historisch zumindest diskussionswürdig ist. ${ }^{366}$ Die Darstellung der deutschen Minderheit Polens beschränkt sich weitgehend auf die Frage des >Bromberger Blutsonntags $<$, dessen Erklärung aber eindimensional bleibt, da die Geschichte der Deutschen in Polen beziehungsweise der polnischen Bürger deutscher Abstammung nicht diskutiert wird.

Diese erneut aus der Gesamtperspektive betrachteten Detailfragen sollen nicht davon ablenken, dass sich das zentrale Narrativ konsequent durch die Ausstellung zieht: Krieg als Übel. Es gibt Menschen, Zivilisten wie Soldaten, die in dieser Zeit Übermenschliches (für andere Menschen) leisten, es gibt Millionen von Menschen, die versuchen, so gut es geht durch den Krieg zu kommen und es gibt Ausbeuter und Verbrecher - in allen Nationen. Auch auf die Deutschen so wie auf die anderen Aggressoren (Sowjetunion und Japan) fällt der Krieg unmittelbar oder am Ende in aller Brutalität zurück, auf ein simplifizierendes >Wer Wind sät, wird Sturm ernten`-Narrativ wird aber sichtlich verzichtet. In Hinblick auf Flucht und Vertreibung ist die zentrale Erzählung, dass diese nur aus dem Zweiten Weltkrieg heraus erklärbar sind. Das Wort »ethnisch homogener Nationalstaat « kommt im Ausstellungsteil der Nachkriegszwangsmigrationen und in Bezug auf die Vertreibung der Deutschen sowie nach Eindruck des Autors in der gesamten Ausstellung nicht vor - auch nicht in einfacheren Worten ausgedrückt.

365 Allerdings deuten sich auch im Katalog keine weiteren Objekte an: Muzeum II Wojny Światowej: Museum of the Second World War, 2016, S. 221. 
Eine Ideengeschichte des Nationalismus wird also nicht erzählt. Freilich erhebt das Museum diesen Anspruch auch nicht, wobei man dennoch fragen könnte, ob dies in Hinblick auf den Lerneffekt jenseits von Krieg ist schrecklich sinnvoll wäre. Nur am Anfang der Ausstellung - bei der Darstellung der Hochzeit von 1910 - wird auf die »ungelösten nationalen und sozialen Fragen« als Ursache des Ersten Weltkrieges und als deren Konsequenz auf die darauf folgenden Ideologien des Nationalsozialismus und Kommunismus verwiesen. Die Notwendigkeit der Vertreibungen wird nicht weiter erörtert und lediglich aufgezeigt, dass die Alliierten diese als eine friedensstiftende Maßnahme sahen. Es werden keine möglichen anderen Ideen oder die Frage, weshalb es keine Alternativen gab, diskutiert. Warum die Menschen flohen, stellt die Ausstellung hingegen sehr klar heraus. Bei der Thematisierung der Vergewaltigungen wird aber auf eine Zahlenangabe verzichtet. Lediglich bei der ČSR werden die infolge der brutalen Vertreibung direkt umgekommenen oder ermordeten Deutschen entsprechend dem Forschungsstand mit 9000 angegeben (die Selbstmorde und Todesfälle im weiteren $\mathrm{Zu}$ sammenhang mit dem Geschehen nicht mitgezählt). Eine tatsächliche Fehlstelle sind die nicht vorhandenen Erzählungen über die Masseninternierungen von Deutschen in Polen und der Tschechoslowakei nach dem Krieg. Dies wird in einer Medienstation, die ansonsten die Ausweisung der Deutschen aus der ČSR thematisiert, lediglich mit einem Hintergrundfoto eines tschechoslowakischen Lagers angedeutet.

Die Ausstellung stellt bis auf den nun vormaligen Abschlussfilm keine offensichtlichen Bezüge zu aktuellen Geschehnissen her. Der von der neuen Museumsführung entfernte Film endete mit Aufnahmen aus dem zerstörten Aleppo. Damit wurde nicht nur eine Verbindung zu einem virulenten und brutalen Konflikt unserer Tage gezogen, sondern auch zu der Europa entzweienden >Flüchtlingskrise . Wenn auch dieser Blick in die Gegenwart eine Ausnahme war, ist die Ausstellung von der Vorstellung getragen, dass der Zweite Weltkrieg und seine Folgen, die Menschen dieser Vergangenheit und ihre uns heute fremd erscheinenden Entscheidungen, einen unmittelbaren Bezug zu unserer Lebensrealität haben. ${ }^{367}$ Zudem unterstreicht die gesamte Ausstellung die Vorstellung von Krieg als anthropologischer Konstante, auch wenn der Zweite Weltkrieg in vielerlei und vor allem negativer Hinsicht als exzeptionell betrachtet wird.

Was lässt sich abschließend in Hinblick auf die >Funktionsfähigkeit ` des Museums sagen? Der in den Überlegungen der Konzeptionspapiere erhobene Anspruch wurde ziemlich konsequent und museal ansprechend umgesetzt. Die angestrebte narrative Ausstellung funktioniert, ohne dass dem Besucher eine Erzählung aggressiv aufgedrängt wird. Dies zeigt sich auch in dem enormen Publikumserfolg, denn es werden sowohl militär- als auch kulturgeschichtlich Interessierte und Menschen aus Polen sowie der ganzen Welt angesprochen. Es ist kein Museum der polnischen Martyrologie und Heldengeschichte, sondern auch ein Museum der polnischen Martyrologie und Heldengeschichte. Daher ist es in einem aufgeklärten Sinne patriotisch und steht in geistiger Nähe zum kritischen Patriotismus der polnischen Intellektuellen der 1980er Jahre. In Hinblick auf Flucht und Vertreibung gilt ebenso, dass die angestrebte Rahmung funktioniert: Das Thema ist kein störendes und zentrales, aber auch kein übersehbares Element. 


\subsubsection{Rezeption der Ausstellung}

Bei der Betrachtung sowohl der positiven als auch der negativen Kritik an der Dauerausstellung durch Presse, Wissenschaft und Besucher ist zunächst festzuhalten, dass die Darstellung von Flucht und Vertreibung, wie schon in dem Diskurs um das Museum in den letzten Jahren, kaum mehr und bis dato weiterhin keine Rolle spielt. Weiter ist zu konstatieren, dass die inhaltliche Auseinandersetzung um die Ausstellung bisher durch die geschichtspolitischen Debatten um das Haus eher behindert wurde. ${ }^{368}$ Dennoch sind einige Ausstellungsbesprechungen vorhanden.

Machcewicz wurde im Konflikt um die Übernahme des Museums durch die PiSRegierung vom liberalen polnischen Lager einhellig verteidigt. Dennoch äußerten auch einige ihrer Vertreter Kritik an der Dauerausstellung. So weist die polnische Kulturwissenschaftlerin Kornelia Sobczak in ihrer ausführlichen Besprechung der Dauerausstellung fragend auf einige Elemente hin, die deren vermeintlich universalen Charakter unterlaufen. Dies sei zum Beispiel bei der letztlich doch stark nach nationalen Erfahrungen sortierten Darstellung der Fall. Zudem kritisiert sie den intellektuell und historisch wenig herausfordernden Ansatz, die Ursachen des Zweiten Weltkrieges allein in den zwei oder drei Totalitarismen zu sehen. ${ }^{369}$ Den Endpunkt der Ausstellung (hier noch das ursprüngliche Ende mit dem Antikriegsfilm) sieht sie darüber hinaus als wenig einfallsreich an, indem der Besucher lediglich mit der pessimistischen und resignierenden Botschaft zurückgelassen wird, dass Krieg und Gewalt eine anthropologische Konstante seien, der man letztlich nicht ausweichen könne. Stattdessen hätte sie sich, womit sie ihre Gesamtkritik an der Ausstellung zusammenfast, hier einen wesentlich grundsätzlicheren, hinterfragenden Ansatz gewünscht:

»Es mangelt jedoch an einer soliden und ehrlichen Überlegung zu dieser Sachlage vielleicht, weil diese Reflexion die Infragestellung all unserer sicheren Konzepte und Werte erfordern würde, denen wir anhängen. So axiomatisch wie Nationalstaat, Patriotismus, Vaterland, Liberalismus. Vielleicht würde eine solche Reflexion ein kritisches Umdenken der Grundlagen unserer Kultur erfordern - im Sinne der >westlichen Zivilisation und unserer nationalen Situation. Diese Aufgabe ist nicht einfach. Aber sie drängt. $\ll^{370}$

368 Logemann; Tomann: Gerichte statt Geschichte? 2019.

369 »Zu sagen, dass der Zweite Weltkrieg von zwei schrecklichen Totalitarismen hervorgerufen wurde, ist im Grunde schon die Botschaft, die das Museum für uns hat: zwei furchtbare Systeme verursachten einen Krieg, der schrecklich war. Das ist wahr, aber flach. (Powiedzenie, że drugq wojnę światowq wywołały dwa straszliwe totalitaryzmy to w zasadzie już cały komunikat, jaki ma dla nas muzeum: dwa straszne systemy wywołały wojne, która była straszna. To prawdziwe, ale płytkie.)

»Brakuje tu jednak solidnego i uczciwego namysłu nad takim stanem rzeczy - być może dlatego, że ten namysł wymagałby zakwestionowania wszystkich naszych bezpiecznych pojęć i wartości, do których jesteśmy przywiązani. Nawet tak aksjomatycznych jak państwo narodowe, patriotyzm, ojczyzna, liberalizm. Być może taki namysł wymagałby krytycznego przemyślenia samych fundamentów naszej kultury - w rozumieniu »cywilizacji zachodniej«i naszej narodowej sytuacji. Niełatwe to zadanie. Ale palące.« Sobczak: Bezradność liberałów. Dialog. 2017. 
Die konservative Kritik ist schon vor der Ausstellungseröffnung deutlich geworden. Im Zusammenhang mit der Darstellung von Flucht und Vertreibung kann einmal mehr Piotr Semka mit seinen bildhaften Polemiken herangezogen werden, der sich 2016 darüber beklagt, dass man in der künftigen Ausstellung "aufdringlich von der Erinnerung an die Deutschen als Opfer bei jedem Schritt verfolgt würde «. ${ }^{371}$ Nach einem Besuch der Ausstellung äußerte er sich aber positiv über deren Darstellung von Terror und Besatzung durch Deutschland und die oSowjetunion. ${ }^{372}$ Im Februar 2017 erschien in der konservativen Rzeczpospolita eine Besprechung, die die humanitäre Ausrichtung mit dem polnischen Volk im Zentrum würdigte. ${ }^{373}$

Eng verknüpft ist die weltweite positive Rezeption des Museumsprojektes mit der Solidarisierung mit dem Team um Paweł Machcewicz. Kritische Stimmen gegenüber der Ausstellung gab es kaum und auch in Deutschland ist sie bisher fast ausschließlich freundlich besprochen worden. Den spezifischen Ausstellungsteil zum ehemaligen Stadtteil Eimermacherhof ordnet Gerhard Gnauck als einen neuen, offenen und interessierten Umgang mit dem deutschen Erbe ein, wie er verschiedentlich und zunehmend in Polen zu finden sei. ${ }^{374}$ Der Präsident des BdV Bernd Fabritius zeigte sich begeistert vom Museum des Zweiten Weltkrieges:

»Ich hatte die Möglichkeit, das neue nationale Museum der Ceschichte des Zweiten Weltkriegs zu besichtigen, eine Woche, bevor es eröffnet werden sollte - ein unglaublich spannendes Museum, in Danzig, mit Aussagen, die ich Polen, einem polnischen Museum, nie zugetraut hätte. Da wird die Vertreibung der Deutschen aus dem heutigen Polen Vertreibung genannt. Da ist die Glocke der >Wilhelm Gustloff Das sind Aussagen, die man, wenn man nur die Debatte über Erika Steinbach und die Kontroverse mit Polen im Gedächtnis hat, nie glauben würde. [...] ]a, es ist noch offen, nutzen Sie bitte die Gelegenheit und besuchen Sie es, solange es noch dasteht! $\ll^{375}$

In wissenschaftlichen Besprechungen wird die Ausstellung generell positiv bewertet und lediglich auf kleinere Mängel verwiesen. Eine Ausnahme ist die Kritik PiS-naher Wissenschaftler, die das Konzept grundsätzlich angreifen, und der neuen Museumsleitung unter Nawrocki, die schwere Mängel in der bisherigen Konstitution der Dauerausstellung festgestellt haben will. Spezifisch kritisch zur geplanten Darstellung der Zwangsmigration in dem Museum äußerte sich Michael Schwartz bei einer unter anderem von der Stiftung Flucht, Vertreibung, Versöhnung 2010 organisierten Tagung. Nach Piotr M. Majewskis Vorstellung des Konzeptes des Hauses in Hinblick auf die Darstellung der Zwangsmigration kritisierte Schwartz, dass diese einen »Mangel an Informationen

371 »[... nachalne przypominanie o Niemcach jako ofiarach na każdym kroku. « Semka: Recenzja dokumentu »Program funkcjonalno-użytkowy wystawy głównej«, 2016. Vgl. Machcewicz: Muzeum, 2017, S. 211.

372 Jamroż: Jak minister Gliński zapewnił gigantyczną promocję polskiej historii. Gazeta Wyborcza. 30.03.2017.

373 Stankiewicz: Antywojenny przekaz Muzeum II Wojny Światowej w Cdańsku. Rzeczpospolita. 13.02.2017.

374 Cnauck: Der lange Schatten des Krieges. FAZ. 26.03.2017.

375 Bundesinstitut für Kultur und Geschichte der Deutschen im östlichen Europa: Erinnerung bewahren-Zukunft gestalten, 2017, S. 48. 
über die intellektuelle Genese der Vertreibungen und dem damit verbundenen Aufbau von Nationalismus in Europa« zeige (so wiedergegeben von Piotr M. Majewski). Der ebenfalls anwesende Martin Schulze Wessel hingegen befand, dass die Deutschen den Polen dankbar sein sollten, dass das Museum überhaupt die »Flucht und Umsiedlung« der Deutschen berücksichtige. ${ }^{376}$

Joachim von Puttkamer zeigte sich in seiner Besprechung des MIIW von der Ausstellung sehr angetan. Zunächst konstatiert er in Hinblick auf ihre politikhistorische Tiefe, dass »auf eine politische Geschichte der Zwischenkriegszeit [...] bewusst verzichtet [wird]. $\aleph^{377}$ Zur Darstellung der Zwangsmigration der Deutschen stellt er fest: »Konzeptionell stehen Flucht und Vertreibung zwischen den Todesmärschen der letzten Kriegstage und den Nürnberger Prozessen. Sie werden nicht prominent thematisiert, aber stimmig. Auch spontane Racheakte werden angesprochen, vor allem an Frauen. Einzelne Schaustücke berichten von Vergewaltigungen durch Rotarmisten. « ${ }^{378}$

In einer umfassenden Rezension rekapituliert Andrzej Hoja den Anspruch des $\mathrm{Mu}-$ seums und vergleicht ihn mit der geschaffenen Ausstellung. Er sieht diesen als sinnvoll und die Umsetzung als sehr gelungen an. Gleichzeitig verweist er aber auch auf die Problematik, dass das - von ihm geteilte - Narrativ der grundsätzlichen Verdammung von Gewalt Besucher mit anderen Wertesystemen nicht nur nicht erreichen, sondern auch verärgern könnte. Zugleich betrachtet er die polnischen Auseinandersetzungen um das Museum als im Wesentlichen politisch motiviert und weniger dadurch bedingt, dass sie im Kern mit verschiedenen Geschichtsinterpretationen zusammenhingen. Außerdem werde bei der Kritik an der Ausstellung häufig die Frage außer Acht gelassen, was eine Ausstellung eigentlich leisten kann und wie diese funktioniert. ${ }^{379}$

Monika Heinemann zieht in ihrer Untersuchung der polnischen Museumslandschaft nach 1989 eine positive Bilanz für das MIIW. Neben einigen kleineren Kritikpunkten, wie dem zu häufig primär illustrativen Einsatz von Bildern, ohne deren Herkunft und Entstehung zu diskutieren, sieht sie in dem Haus einen geeigneten Lernort, zumal es das erste polnische Museum sei, das einem vor allem viktimologischen Ansatz verpflichtetet ist, sich also weniger auf Helden als primär die (zivilen) Opfer fokussiert. Hier könnten sowohl Polen ihr bisheriges Narrativ ergänzen und punktuell korrigieren als auch die Welt die polnische Erfahrung kennenlernen. ${ }^{380}$

376 So wiedergegeben von Piotr M. Majewski: »[...] Niemcy powinni być Polakom wdzięczni za to, że w gdańskim muzeum w ogóle planujemy upamiętnić niemieckie ucieczki i przesiedlenia.« Wąs: Niemcy powinni być wdzięczni gdańskiemu muzeum. Gazeta Wyborcza. 22.09.2010.

377 Puttkamer: Europäisch und polnisch zugleich, 2017, S. $4 \mathrm{f}$.

378 Ebd., S. 10.

379 Hoja: An Engaged Narrative, 2017. Catherine Schilling unterstreicht, dass Geschichtspolitik Machtpolitik sei und den zwei gegensätzlichen Arten, die polnische Ceschichte zu interpretieren, auch zwei unterschiedliche Arten, die polnische Gegenwart zu gestalten, gegenüberstehen: Schilling: Patriotismus à la PiS und die Schlüssel von Jedwabne, 2016.

380 Heinemann: Krieg und Kriegserinnerung im Museum, 2017, S. 466, 478-481, 486. 


\subsubsection{Zusammenführende Betrachtung}

Für die folgende Bewertung ist zunächst festzuhalten, dass mit der Untersuchung der ursprünglichen Ausstellung von 2017 vor allem eine Aussage über den Versuch der polnischen Liberalen und Liberalkonservativen getroffen werden kann, in einem Museum eine proeuropäische und patriotische Geschichte des Zweiten Weltkrieges und darin enthalten auch die Geschichte der Vertreibung der Deutschen zu erzählen. Dennoch werden für die Zusammenführung auch die erhebliche Kritik an dem Museumsprojekt von nationalkonservativer Seite sowie die nach dem Leitungswechsel vorgenommenen ersten Änderungen an der Ausstellung berücksichtigt.

Das Museum des Zweiten Weltkrieges in Danzig ist bezogen auf die im Kapitel 2 diskutierte moderne Ausstellungsgestaltung ein interessantes und ansprechendes Beispiel für eine Synthese von objektzentrierter und szenografischer Ausstellung. Das kann meines Erachtens auch einen Teil des Erfolges des Museums erklären: Es ist kompatibel für verschiedene Seh- und Erzählgewohnheiten. Anders als die meisten Häuser in Deutschland ist das MIIW weit weniger zurückhaltend, was die Präsentation von Gewalt und vor allem von Gewaltopfern anbetrifft. Nach Eindruck des Autors findet aber keine emotionale Überwältigung des Besuchers statt, da diese Konfrontationen punktuell bleiben. Das dahinterstehende und immer wieder deutlich werdende Narrativ des unschuldigen (oder wenigstens in dem Moment unschuldigen) Opfers ist in der westlichen Gegenwart allgemeingültig und erleichtert die Anschlussfähigkeit. Es hat zudem keinen anklagenden Charakter, auch wenn die deutsche oder sowjetische Aggression deutlich und eindeutig dargestellt ist.

Das MIIW konnte hier nicht in seiner Vollständigkeit dargestellt, gewürdigt oder kritisiert werden. Einige positive Auffälligkeiten, welche die Fragestellung dieser Studie berühren, sollen dennoch erörtert werden. Eine selbstkritische polnische Perspektive taucht zum Beispiel bei der Thematisierung des polnischen Anteils an der Zerschlagung der Tschechoslowakei 1938 auf, ebenso wie bei der Andeutung des polnischen Vorkriegsantisemitismus und bei der Verweigerung einer einseitigen und unwissenschaftlichen Heldengeschichte, obwohl durchaus auch Heldengeschichten erzählt werden. ${ }^{381} \mathrm{Im} \mathrm{Be}$ reich von Flucht und Vertreibung wird eine klare Sprache gewählt und Bernd Fabritius hat durchaus Recht, dieses hervorzuheben. ${ }^{382}$

Der angestrebte Versöhnungsimpuls des Museums ist weniger direkt als indirekt in die Ausstellung implementiert. Die Ausstellungsmacher sparen sich jede Form des oft beklagten »Versöhnungskitsches $\aleph^{383}$ und überlassen diese Aufgabe dem starken Narrativ: Waren die Sowjets brutale Aggressoren? Ja. Haben die Bürger der Sowjetunion ungeheuerliche und grausame Verluste im Kampf gegen NS-Deutschland erlitten? Ja. Ähnlich verhält es sich mit den Deutschen, auch wenn im Gegensatz zu Semkas Auffassung die deutschen Kriegsopfer etwas weniger präsent sind als die der Sowjets und weit weniger als die der Polen. Andererseits ist Sobczaks Kritikpunkt zu folgen, dass 
tieferes Verstehen, also die weitergehenden historischen und ideengeschichtlichen Hintergründe von Handlungen, in der Ausstellung wenig Bedeutung erfahren. Wenn etwas undifferenziert betont wird, dass die Verantwortung für die Zwangsaussiedlung der Deutschen ausschließlich bei der Potsdamer Konferenz und Stalin lag, so lässt diese Darstellung die Frage gar nicht oder nur am Rande aufkommen, warum es vielleicht für die Polen und Tschechen zu Recht unvorstellbar gewesen sein könnte, weiter mit den Deutschen zusammenzuleben. Dies wird sich möglicherweise als ein Schwachpunkt für eine künftige Auseinandersetzung mit der Stiftung Flucht, Vertreibung, Versöhnung herausstellen.

Die im Ausstellungsbereich »Ethnische Säuberungen « diskutierten Geschehnisse in Ostgalizien und Wolhynien sowie auf dem Balkan während des Krieges werden nicht mit den rethnischen Säuberungen am Ende des Krieges verbunden. ${ }^{384}$ Wie in den anderen Ausstellungsteilen auch, strebt die Ausstellung keine ideengeschichtliche Grundierung und damit Verknüpfung der verschiedenen Geschehnisse in einer horizontalen und vertikalen Chronologie an. ${ }^{385}$ Sicher sind die Gewalttaten in Ostgalizien und Wolhynien ebenso wie die Vertreibung der Deutschen am Ende des Krieges nicht allein mit dem Ideal des ethnisch homogenen Nationalstaates erklärbar. Dennoch handelt es sich um einen wichtigen Mosaikstein, um die Zwangsmigrationen des Zweiten Weltkrieges zu verstehen. Erklärungen des historischen Geschehens, die dies nicht berücksichtigen, bleiben so zwangsläufig begrenzt.

Als Alternative wären für die gesamte Ausstellung einfache A- oder B-Texte in den entsprechenden Räumen vorstellbar, in denen die Ideengeschichte knapp skizziert werden könnte - und dies nicht nur in Bezug auf Flucht und Vertreibung, sondern auch auf zentrale Fragen wie: Woher kommt der rassistische Antisemitismus? Wie entstand die Idee, gezielt Arbeiterbezirke zu bombardieren? Dies mag nach einer Überkomplexisierung klingen, würde aber auch die Kritik von Sobczak aufgreifen und dem Besucher nicht nur einen tiefergehenden Einblick in die Geschichte geben, sondern auch Ausblicke in die Gegenwart ermöglichen. Ähnlich verhält es sich mit Forschungskontroversen und der Herausforderung, eigene Positionierungen einzunehmen: Der Einschätzung des Autors nach wird dem Besucher, wie oben bereits beschrieben, ein positives und überzeugendes Narrativ angeboten, es gibt aber wenige Möglichkeiten, dieses im Grunde oder im Detail zu hinterfragen. Dennoch ist hier die Frage zu stellen, ob der vom MIIW verfolgte Ansatz, möglichst den aktuellen Forschungsstand anstelle der Wiedergabe verschiedener nationaler Positionen zu zeigen, nicht letztlich sinnvoller und $\mathrm{zu}$

384 Nach Majewski werden die Massaker in Ostgalizien und Wolhynien nicht nur als Ergebnis schon bestehender ethnischer Konflikte betrachtet, sondern auch »as a side-effect of the Holocaust, which caused the disruption of social norms and provided the radical nationalistic groups with genocidal know-how : Majewski: The Topic of Forced Migration in the Planned Museum of the Second World War in Cdańsk, 2010, S. 128.

385 Der 2012 von Logemann formulierte Ansatz wurde folglich nur abgeschwächt umgesetzt: »Der Versuch, ein ethnisch einheitliches Nachkriegspolen zu schaffen, wird als Folge des Krieges gewertet; der Anspruch des Museums ist es aber auch, durch Polen verursachtes Leid an den Deutschen sichtbar zu machen. « Logemann: Die entstehende Dauerausstellung des Museums des Zweiten Weltkrieges in Danzig, 2012, S. 128. Besonders das Letzte kommt praktisch in der Ausstellung nicht vor. 
rechtfertigen ist - kompakter ist er definitiv. Ähnlich verhält es sich mit der zwar deutlichen Positionierung in Hinblick auf die Einschätzung des Krieges als grundsätzliches Übel, ohne jedoch auf andere Sichtweisen hinzuweisen.

Die Nicht-Thematisierung beziehungsweise im besten Fall hintergründige Andeutung des Schicksals Hunderttausender Deutscher in den polnischen und tschechoslowakischen Lagern ist bedauerlich, da dies im Gesamtzusammenhang durchaus von Relevanz ist. Dessen Darstellung wäre auch gut kombinierbar mit der Diskussion der gewaltigen Migrationsströme nach Kriegsende und dem sowjetischen Gulag-System, das nach 1945 seine größte Ausdehnung erreichte. Diese Leerstelle fügt sich allerdings in die von Ray M. Douglas konstatierte internationale Unbekanntheit des Phänomens sowie die Tradition in Polen und Tschechien ein, dieses Thema stiefmütterlich zu behandeln. ${ }^{386}$

Ein konservativ-konventioneller Ansatz des Hauses zeigt sich vielleicht am deutlichsten bei der Darstellung des >Bromberger Blutsonntages $\triangleleft$, die der konventionellen, nationalpolnischen Erzählung folgt. ${ }^{387}$ Auch wenn dieses Ereignis im Vergleich zu den unmittelbar beginnenden NS-Verbrechen gegen Polen ebenso wie den Gewalttaten 'volksdeutscher< Milizen eine vergleichsweise kleine Dimension hat, fällt der gewaltsame Tod etwa 4.500 ganz überwiegend polnischer Zivilisten deutscher Herkunft in die Verantwortung der Zweiten Republik und von Teilen der polnischen Streitkräfte. Die Geschehnisse unterscheiden sich deutlich von denen der NS-Verbrechen, so dass die einseitige und rechtfertigende Erzählung über volksdeutsche Saboteure, die eine solche Reaktion provoziert hätten, zumindest multiperspektivisch ergänzt werden könnte. In Bezug auf die Freie Stadt Danzig fällt neben den diskutierten fragwürdigen Bevölkerungsangaben auf, dass diese im Englischen konsequent »Free City of Gdańsk « genannt wird. Dies ist insofern bemerkenswert, als die gängige Bezeichnung dieses historischen Staates im Englischen grundsätzlich »Free City of Danzig« lautet, was auch die historische Selbstbezeichnung widerspiegelt. ${ }^{388}$

Vertriebene Deutsche oder ihre Nachfahren ebenso wie interessierte Besucher können ihr eigenes oder das Schicksal der von Flucht und Vertreibung Betroffenen im Kontext weiterer Zwangsmigrationen und vor allem des Zweiten Weltkrieges im MIIW eindrücklich erfahren. Weitergehende Erklärungen, warum es so weit kommen musste und warum es keine Alternativen gab, werden sie nicht erhalten. Das kann aber schwerlich als Vorwurf stehen bleiben, denn es entspricht dem auch vom Autor der vorliegenden Arbeit positiv bewerteten und erfolgreich umgesetzten Grundcharakter der Ausstellung, einen umfassenden Überblick über die Geschichte des Zweiten Weltkrieges zu schaffen. Flucht und Vertreibung haben ihren Platz, wenn auch keine überragende Position, womit sich die Bewertung als eines »der wichtigsten Fragmente« der Ausstellung relativiert. Dies kann bedauert werden, wenn man sich das MIIW als eine Alternative zur Stiftung Flucht, Vertreibung, Versöhnung wünscht, denn dafür ist das Element

386 Douglas: „Ordnungsgemäße Überführung«, 2012, S. 199. Vgl. Kap. 3.7, S. 140.

387 Vgl. Kap. 3.4, S. $109 f$.

388 Vgl. dazu den Beitrag zur Freien Stadt Danzig im Oxford Public International Law: Hattenhauer: Danzig, Free City of, 2009. 
$\mathrm{zu}$ klein und zu wenig vertieft. Das Haus ist über seinen Gründungsimpuls hinausgewachsen, womit die Dauerausstellung als Aushandlungsort über Zwangsmigration im Zweiten Weltkrieg nur als Ergänzung geeignet ist.

\subsection{Haus der Europäischen Geschichte}

Das im Mai 2017 eröffnete Haus der Europäischen Geschichte (HEH) ist Teil einer seit den 1990er Jahren expandierenden Identitäts- und Erinnerungspolitik der Europäischen Union. ${ }^{389}$ Diese ist in ihrer Zielsetzung ambitioniert: "Seit Maastricht verfolgt die EU eine Kulturpolitik, deren zentraler Baustein die Behauptung einer europäischen Kultur und Geschichte bildet. $\ll^{390}$ Die Akteure der EU stehen dabei vor einer doppelten Herausforderung: Die Bürger haben nicht nur ein Problem, sich mit Europa zu identifizieren, auch die unterschiedliche Bewertung der Vergangenheit wirkt häufig trennend. Mit Initiativen wie dem $\mathrm{HEH}$ versucht man in beide Richtungen zu wirken. ${ }^{391}$ Der ehemalige Präsident des Europäischen Parlaments Hans-Gert Pöttering spricht in diesem Zusammenhang von einem gemeinsamen europäischen Bewusstsein von »human rights, democracy, liberty, legality and solidarity «, das eine solche Initiative als gemeinsame Basis befördern solle. ${ }^{392}$ Ein nach wie vor bestehendes Problem ist das schon in Kapitel 1.3 diskutierte Fehlen einer europäischen Öffentlichkeit, die eine transnationale Verbundenheit mutmaßlich stärken würde. ${ }^{393}$

Initiativen wie die des HEH sind wiederholt dem Vorwurf ausgesetzt, gleich der Harmonisierung des Binnenmarktes in der EU eine Harmonisierung der europäischen Erinnerung und in deren Folge eine Unterdrückung der nationalen Erzählungen zum Ziel zu haben. Tatsächlich befinden sich die EU-Akteure und progressive Vordenker hier in einem Zwiespalt. Eine stärkere Verbindung von Bürgern zu EU-Institutionen scheint eine positive Identifizierung mit diesen und eine aktive Identitätspolitik vorauszusetzen - zumal angesichts der nicht weniger werdenden Akteure, die alle nationalen Fehlentwicklungen nach Brüssel abzuschieben versuchen. Nicht nur Gegner sehen Analogien zu einem notwendigen nation building gleich dem des 19. Jahrhunderts, auch bei progressiven Politikern und Historikern wächst die Einsicht, dass die politischen Grenzen der EU stärker mit den kulturellen Grenzen in Einklang gebracht werden müssten. Dafür benötige sie ein verbindendes Narrativ und, kurz gesagt, eine klassische Identitätspolitik. ${ }^{394}$

Einer der Kuratoren des HEH, Martí Grau Segú, konstatiert in Bezug auf die Kritiker der EU-Geschichtspolitik: »It seems to me that Europe, and more specifically the

389 Vgl. Sierp: Drawing Lessons from the Past, 2016, S. 6. Siehe auch: Sierp; Wüstenberg: Linking the Local and the Transnational, 2015, S. 325. Vgl. Kap. 1.3, S. $32 f$.

390 Kaiser; Krankenhagen et al.: Europa ausstellen, 2012, S. 19.

391 Rigney: Transforming Memory and the European Project, 2012, 607f. Vgl. Sierp: History, Memory, and Trans-European Identity, 2014, S. 129.

392 Settele: Including Exclusion in European Memory? 2015, S. 408.

393 Sierp; Wüstenberg: Linking the Local and the Transnational, 2015, S. 325. Siehe auch: Sierp: History, Memory, and Trans-European Identity, 2014, S. 130. Vgl. Kap. 1.3, S. 36.

394 Rigney: Transforming Memory and the European Project, 2012, S. 608. Vgl. Kap. 1.3, S. $32 f$. 
European Union, has been accused at the same time and often by the same critics of not having a historical narrative of its own and of trying to get one. $\aleph^{395}$ Historische Themen bergen in Europa aber stets die Gefahr, alte Spaltungen wieder hervorzurufen. Beispielhaft zeigt sich dies im Konflikt um die Erinnerung an Kommunismus und Nationalsozialismus, bei der sich, frei nach Tony Judt, weiter ein Eiserner Vorhang der Erinnerung durch Europa zieht. ${ }^{396}$ Ähnlich wie bei ökonomischen Themenfeldern besteht zudem die Befürchtung, dass Deutschland erinnerungspolitisch eine hegemoniale Stellung entwickle und nicht nur seine Geschichtsperspektive europäisiere, sondern auch die Verantwortung für die Shoa. ${ }^{397}$

Veronika Settele betont in Hinblick auf die allgemeine Anerkennung der Institution Museum als objektiv und neutral, dass das Haus der Europäischen Geschichte mit seinem von ihm vertretenen historischen Narrativ einen schwerwiegenden und langanhaltenden Einfluss ausüben könne. Sie erkennt zudem in dem Haus die Chance, dass es "beyond the limitations of national histories « Themen wie Migration diskutieren und in der Lage sei, zu einem vielfältigen Europaverständnis beizutragen. ${ }^{398}$ Auch Wolfram Kaiser, Stefan Krankenhagen und Kerstin Poehls sehen ein weitgestecktes Potenzial des $\mathrm{HEH}$, denn nur »museale Großprojekte wie das [...] HEH können [...]« eine neue »Meistererzählung[...] europäischer Geschichte entwickeln. «399

\subsubsection{Geschichte}

Die Idee, Europa und die Geschichte der europäischen Integration und seiner Institutionen zu musealisieren, kann auf eine längere Vorgeschichte zurückblicken. Bereits 1977 entwickelte die Europäische Kommission das Konzept, in ausgewählten Museen aller Mitgliedstaaten »Europaräume« einzurichten. Diese ungefähr 60 Institutionen sollten ein Netzwerk entwickeln und »ihre lokale und regionale Geschichte in einem neuen europäischen Kontext « präsentieren. Allerdings verliefen die Planungen im Sande, auch wenn die Idee fortbestand und viele Nationalmuseen, voran das Deutsche Historische Museum, ihre Ausstellungskonzepte zunehmend europäisierten. ${ }^{400}$

Dem Haus der Europäischen Geschichte werden zumeist die Planungen des $\mathrm{Mu}-$ sée de l'Europe als Vorgeschichte zur Seite gestellt, das um 2000 auf privater Basis entstand und mit finanzieller Unterstützung verschiedener privater Sponsoren, des belgischen Staates und der Europäischen Union die Planungen für ein Museum der europäischen Geschichte und Integration voranbrachte. Dieses Vorhaben unter Federführung

395 Grau Segú: Proposing a New European Narrative, 2016, S. 58.

396 Rigney: Transforming Memory and the European Project, 2012, S. 613.

397 Ebd., S. 610-616. Auch Sierp konstatiert: »Many politival scientists are likewise convinced that the main device for generating a collective sense of identity within a complex society such as the European one lies in the mode of remembering the past and argue that Europe needs a common memory in order to build a common identity, just as nations do [...].«Sierp: History, Memory, and Trans-European Identity, 2014, S. 128.

398 Settele: Including Exclusion in European Memory? 2015, S. 406.

399 Kaiser; Krankenhagen et al.: Europa ausstellen, 2012, S. 151.

400 Vovk van Gaal; Itzel: The House of European History project in Brussels, 2012, S. 76. Vgl. zu Pomian Kap. 7.2.1, S. $416 f$. 
des schon mehrfach erwähnten Krzysztof Pomian war der Versuch, eine positive Meistergeschichte der europäischen Integration zu schaffen. ${ }^{401}$

Den weiteren Entstehungskontext sieht eine der Chefkuratorinnen des $\mathrm{HEH}$, Andrea Mork, in der beschleunigten europäischen Integration nach 1989, »mit der das allgemeine Bewusstsein der europäischen Völker kaum Schritt halten konnte« und in deren Folge die Diskrepanz zwischen europäisch gesinnten Eliten und großen Teilen der Bevölkerung sich weiter vergrößerte: »In dieser Situation war die Forderung nach einem Gemeinschaftsgefühl [...], das die Menschen jenseits von politischen Notwendigkeiten und ökonomischen Interessen miteinander verbindet, nur allzu verständlich. «402 Der eben schon erwähnte Martí Grau Segú ergänzt, dass die europäische Integration von den Menschen als selbstverständlich, und nicht mehr als täglich relevante Errungenschaft wahrgenommen werde, sodass es notwendig sei, ein historisches Bewusstsein für diese zu schaffen. Nach der europäischen Erweiterung 2004/2007 sei das paradoxerweise noch stärker der Fall, denn »the result has not always been a deeper sense of community but rather, too often, a quickly spreading feeling of disenchantment and disaffection toward the idea of Europe ${ }^{403}$

An diese Vorüberlegungen und diesen Kontext knüpfte der neu gewählte Präsident des Europäischen Parlamentes, Hans-Gert Pöttering (CDU/Europäische Volkspartei) in seiner Antrittsrede am 13. Februar 2007 an:

»Liebe Kolleginnen und Kollegen, die europäische Ceschichte wird fast immer nur national in nationalen Museen dargestellt. Ich möchte einen Ort der Erinnerung und der Zukunft anregen, in der der Cedanke der Idee Europas weiter wachsen kann. Ich möchte den Aufbau eines Hauses der Europäischen Ceschichte vorschlagen. Es soll kein langweiliges, trockenes Museum werden, sondern ein Ort, der unsere Erinnerung an die europäische Ceschichte und das europäische Einigungswerk gemeinsam pflegt und zugleich offen ist für die weitere Gestaltung der Identität Europas durch alle jetzigen und künftigen Bürger der Europäischen Union. Ein solches Haus der Europäischen Ceschichte sollte am Sitz der europäischen Institutionen gegründet und vernetzt werden mit vergleichbaren Einrichtungen in den Mitgliedsstaaten. ${ }^{404}$

Tatsächlich konnte die Initiative, deren Durchsetzung Pöttering später mehrfach als die schwerste politische Aufgabe seines Lebens beschrieb, ${ }^{405}$ zügig auf den Weg gebracht werden: Das Europäischen Parlament berief 2008 eine neunköpfige wissenschaftliche Expertenkommission unter der Leitung des Direktors des Hauses der Geschichte der

401 Krankenhagen: »Das andere, eigene Kap.« 2017, S.125f. Jeismann: Mehr als ein Projekt. FAZ. 11.12.2004. Vgl. für drei Projekte europäischer Musealisierung: Kreis: »Europa« ausstellen? 2013, S. 528-533.

402 Mork: Nach Nationalismus, Diktatur und Krieg, 2016, S. 38.

403 Grau Segú: Proposing a New European Narrative, 2016, S. 60, 71.

404 Die kursiv formatierten Worte jeweils vom Redner besonders betont: Hans-Gert Poettering's inauguration speech Feb. 2007, Minute 21:04-21:57.

405 Pöttering: Eröffnung des Hauses der Europäischen Ceschichte, 2017, S. 10. 
Bundesrepublik Deutschland, Hans Walter Hütter. ${ }^{406}$ Ein weiteres Mitglied war und ist der international anerkannte polnische Historiker Włodzimierz Borodziej, der das Projekt fortlaufend aktiv begleitet. Damit hatten, so die Formulierung von Krankenhagen, die "großen Jungs das Projekt übernommen [...].«407

Am Ende des Jahres 2008 erschien die von dieser Kommission verfasste erste »Conceptual Basis for a House of European History «, ${ }^{408}$ die mit 116 Stichpunkten eher als eine Ideensammlung zu bezeichnen ist, da sie »derart vielfältig und disparat « angelegt war und sich so der Eindruck »einer bloßen additiven Geschichtsschreibung ergab «. ${ }^{409}$ Dennoch war diesem Konzept bereits ein kritischer Charakter implizit, indem sich zum Beispiel die Besucher in der Ausstellung mit der Frage des Demokratiedefizits der EU befassen sollten. ${ }^{40}$ Auch war das Papier schon konkret genug gefasst, um erste erhebliche Kritik an der Grundausrichtung des Vorhabens hervorzurufen: Neben dem wiederkehrenden Vorwurf, eine zu westliche beziehungsweise deutsch-französische Perspektive zu verfolgen und die Geschichte Süd- und Ostmitteleuropas zu vernachlässigen, ${ }^{411}$ wurde von polnischer Seite unter anderem die fehlende Erwähnung des polnisch-sowjetischen Krieges und des polnischen Beitrages zum Ende des Kalten Krieges bemängelt. ${ }^{412}$ Die Akteure des Museumsprojektes artikulierten von Beginn an, dass es eine Herausforderung sein würde, die westliche Perspektive zu überwinden - auch wenn zum Beispiel die Direktorin Taja Vovk van Gaal selbst Slowenin ist. ${ }^{413}$ Jedoch reflektierten die Mitglieder des Planungsstabes selbst, dass die osteuropäischen Kuratoren und Wissenschaftler durch ihre akademischen Werdegänge ebenfalls bereits stark von der westlichen Wissenschaft geprägt und somit nur bedingt für eine die geschichtspolitische Spaltung Europas widerspiegelnde >osteuropäische Perspektive< geeignet seien. ${ }^{414}$ Die Doppelspitze des Hauses, bestehend aus der Deutschen Constanze Itzel und Taja Vovk van Gaal, äußerte sich 2012 dahingehend, dass es von Anfang an galt: »[...] to overcome the restraints of a Western perspective, to leave behind national historiographical paradigms and to arrive at transnational views on historical processes, to name but a few. ${ }^{415}$ Als erster ambitionierter Eröffnungstermin wurde das Jahr 2014 anvisiert.

406 Vgl. zur Zusammensetzung des Komitees mit Mitgliedern aus Polen, Italien, Belgien, Deutschland, Frankreich, Finnland, den Niederlanden, Portgual und Ungarn mit Kurzbeschreibungen: Committee of Experts; Borodziej et al.: Conceptual Basis for a House of European History, 2008, S. 27.

407 Krankenhagen: »Das andere, eigene Kap.«2017, S. 126.

408 Committee of Experts; Borodziej et al.: Conceptual Basis for a House of European History, 2008.

409 Krankenhagen: »Das andere, eigene Kap.« 2017, S. 126. Noch heftiger kritisiert Kreis das erste Papier, welchem >die Leitfragen< fehlen: Kreis: »Europa « ausstellen? 2013, S. $535 f$.

410 Committee of Experts; Borodziej et al.: Conceptual Basis for a House of European History, 2008, S. 25 .

411 Trüpel: Haus der europäischen Ceschichte, 2009, S. 187.

412 Kreis: »Europa« ausstellen? 2013, S. 536.

413 Vgl. Kaiser; Krankenhagen et al.: Europa ausstellen, 2012, S. 150. Hilmar formuliert dazu: »The fact that two Eastern European professionals were heading the respective planning teams can safely be regarded as an expression of the concern over an institutional dominance of Western professionals in the project. «Hilmar: Narrating Unity at the European Union's New History Museum, 2016, S. 309.

414 Ebd., S. $308 f$.

415 Vovk van Gaal; Itzel: The House of European History project in Brussels, 2012, S. 78. 
Das Konzeptpapier von 2008 stellt zum Zusammenhang von Nationalismus und ethnischer Säuberung zunächst fest, dass sowohl moderner Nationalismus als auch Kosmopolitismus ihre Wurzeln im 19. Jahrhundert haben und dort eine erste Blüte erlebten. ${ }^{416}$ Die Friedensordnung nach dem Ersten Weltkrieg unterminierten fortlaufende ethnische Spannungen in den neuen Nationalstaaten, deren Eliten das Ideal des ethnisch homogenen Nationalstaates anstrebten. ${ }^{417}$ Der mit der Versailler Ordnung verbundenen Schaffung von international sanktionierten Minderheitenrechten stellte das Papier das gegenteilige Extrem des multilateral vertraglich abgesicherten $>$ Bevölkerungsaustausches zwischen Griechenland und der Türkei 1923 gegenüber. ${ }^{418}$ Die alliierten Nachkriegsplanungen während des Zweiten Weltkrieges beschreiben die Autoren als Konflikt zwischen sowjetischem Expansionsstreben und der Vorstellung der Westalliierten von der Selbstbestimmung der Völker. ${ }^{419}$ Flucht und Vertreibung der Deutschen werden als die größte der vielen verschiedenen Zwangsmigrationen am Ende des Krieges unter dem 73. Punkt des Papieres gefasst:

»The end of the fighting, which had claimed more than 50 million lives in Europe alone, triggered mass migrations on the European continent. With 12 to 14 million refugees and displaced persons - primarily from areas in what had been eastern Cermany - Cermany provided the largest group. At the Potsdam Conference held in July and August 1945 the main victorious powers reached agreement not only on the transfers of population, but also on the future of Germany, which was to be divided into four occupied zones. ${ }^{420}$

Die Entscheidung zur Gründung und Finanzierung des HEH trugen die beiden großen konservativ-christlichen und sozialdemokratisch-progressiven Fraktionen des Europäischen Parlamentes gemeinsam. Im November 2008 schuf das Präsidium des Parlaments eine vorläufige Verwaltungsstruktur für das $\mathrm{HEH} .{ }^{421}$ Vovk van Gaal und Dupont beschreiben Hans-Gert Pöttering und seinen sozialdemokratischen Kollegen Miguel Ángel Martínez Martínez aus Spanien als Paten des Museumsprojektes, ohne dass darunter die politische Unabhängigkeit und Distanz der Arbeit des Museumsteams ge-

416 »The ethnic diversity of the newly founded states in Central and Eastern Europe remained a problem, since the dream of an ethnically homogenous nation-state continued to exert a strong hold on the elites in each country and, in many cases, on their majority population groups as well." Committee of Experts; Borodziej et al.: Conceptual Basis for a House of European History, 2008, S. 14.

417 Ebd., S. 15

418 »The Treaty of Lausanne signed on 24 July 1923 under the aegis of the League of Nations reflected a diametrically opposite approach. It sought to prevent future conflicts by establishing ethnically homogenous populations. «Ebd.

419 Ebd., S. 18.

420 Ebd., S. 19.

421 Es bestand aus einem Vorstand, einem akademischen Ausschuss, einem Verbindungsbüro respektive einer Kontaktgruppe und einem Aufbaukomitee: Vovk van Gaal: Comment forger un récit européen? 2016, S. 57. 
litten habe. ${ }^{422}$ Die erhebliche Kritik aus den Reihen der polnischen PiS-Abgeordneten im Europäischen Parlament konnte die Planungen des HEH kaum beeinflussen, zumal diese nicht Teil der Fraktion der Europäischen Volksparteien sind. Explizit sprachen diese im Kulturausschuss des Europaparlaments die Frage der Darstellung von Flucht und Vertreibung an:

»In dem Konzept der Projektinitiative würde der polnische Widerstand gegen den Nazi-Terror keine Rolle spielen, auch nicht der Runde Tisch, an dem die Polen 1988/1989 das Ende des Kommunismus aushandelten. Hingegen würde aber die Massenmigration der deutschen Flüchtlinge und Vertriebenen aus den Ostgebieten erwähnt, was die Missbilligung des Papiers und den Argwohn, die Deutschen würden ihre Schuld verwässern wollen, verschärfte. ${ }^{423}$

Neben der erwähnten Kritik aus Polen wurde auch im Vereinigten Königreich Widerspruch geäußert. Der unabhängige britische Thinktank »Civitas « fasste diese 2011 in einem kurzen Dossier zusammen: An erster Stelle stünden die hohen, sich möglicherweise verdoppelnden Kosten eines zunächst als 'preiswert beworbenen Projektes, die in Zeiten finanzieller Kürzungen besonders kritisch zu sehen seien. Die angebliche Amalgamierung der europäischen Nationalgeschichten sei zudem widersinnig und auch unmöglich, ebenso wie die Bewerbung einer gemeinsamen europäischen Erinnerung fragwürdig sei, hinter der sich vor allem ein unkritisches Feiern der europäischen Integration und der eigenen Institutionen verstecke. Ferner wird die osteuropäische Kritik an der bisherigen Ausrichtung referiert, die eine Marginalisierung dieser Länder beispielsweise bei ihrem Beitrag zum Fall des Kommunismus befürchten lasse. Anstelle sich mit der wahren, diversen, konfliktreichen Geschichte Europas in der Tiefe zu befassen, drohe darüber hinaus eine Oberflächlichkeit der Ausstellung, die sich nach einem Zitat des britischen Professors Frank Furedi in »leeren Werten« wie Diversität, Differenz und Nachhaltigkeit ausdrücke. ${ }^{424}$

Die Ungarin Mária Schmidt ${ }^{425}$, die von Beginn an Mitglied des Wissenschaftlichen Beirates und an der Entstehung des 2008er Papieres beteiligt war, sieht in ihrem Beitrag bei einer Tagung im Jahr 2010 in diesem Papier einen leidlichen Kompromiss, bei dem sie öfter der Auffassung der Mehrheit gegenübergestanden habe. Unter anderem beklagt sie einen zu starken Einfluss westeuropäischer »political correctness«, der sich in einer quantitativen Geringschätzung des Christentums und der Annahme des anglofranzösischen Siegernarrativs des Ersten Weltkrieges äußere. Zudem sei das Vorhaben einem westeuropäisch-marxistischen Nationenverständnis verpflichtet, in welchem die Nationen überwunden werden sollen. In der Konsequenz urteilte sie, dass das Museum

422 Vovk van Gaal; Dupont: The House of European History, 2012, S. 47. Auch der langjährige Beobachter des HEH kommt zu dem Schluss, dass der politische Einfluss auf die Ausrichtung des Hauses diese nicht »dominiert« habe: Krankenhagen: »Das andere, eigene Kap.« 2017, S. 126. Trüpel: Haus der europäischen Geschichte, 2009, S. 187.

424 Civitas: Rewriting History, 2011.

425 In der Badischen Zeitung heißt es über Mária Schmidt und ihren Einfluss auf das Projekt: »[die] Direktorin des in Ungarn hoch umstrittenen, von Victor Orban vorangetriebenen `House of Terrorı, dürfte für ganz besondere Akzente gesorgt haben. Weingärtner: Mut zur drastischen Reduktion. Badische Zeitung. 08.05.2017. 
nur erfolgreich sein könne, wenn über seine weitere Ausrichtung in einem gesamteuropäischen Meinungsaustausch diskutiert würde und es auch in Zukunft ein Ort solcher Aushandlungen sein könnte. ${ }^{426}$ Bei der Podiumsdiskussion auf dieser Tagung ergänzte Schmidt, dass man keine Scheu davor haben müsste, dass das Museum »vielen nicht gefallen könnte«, denn dies würde Diskussionen und Nachdenken auslösen, was das eigentliche Ziel des Museums sein sollte. ${ }^{427}$ Die österreichische Historikerin Heidemarie Uhl kritisierte bei derselben Diskussionsveranstaltung, dass sie das von den Planungen her durchaus vorgesehene europäische »wir [...] für höchst gefährlich [halte], weil es immer nivellierend ist, weil es genau das macht, was der Nationalstaat seit dem 19. Jahrhundert gemacht hat, nämlich Meistererzählungen zu schaffen, die auf dem Prinzip der Inklusion und Exklusion beruhen. « ${ }^{428}$

Die Abgeordnete des Europaparlaments Helga Trüpel (Bündnis 90/Die Grünen) hielt den Kritikern entgegen, dass das HEH zunächst nicht als Ersatz, sondern als Ergänzung $\mathrm{zu}$ den Nationalmuseen $\mathrm{zu}$ verstehen sei. Auf diese ebenso wie auf weitere wichtige Einrichtungen, wie das Haus des Terrors in Budapest, das Lettisches Okkupationsmuseum in Riga oder die Topographie des Terrors in Berlin könnten in der Ausstellung Verweise gesetzt werden. ${ }^{429}$ Zugleich unterstrich sie noch einmal den politischen Bedarf für eine solche Einrichtung: "Die Menschen werden sich nicht in den Binnenmarkt verlieben, sondern brauchen ein gemeinsames Verständnis der europäischen Geschichte und Geschichten. ${ }^{430}$ Borodziej konterte die Kritik der politischen Rechten, die den Initiatoren des HEH einen "paneuropäischen Treitschkismus« vorwarfen, dass es sich bei dem Haus vielmehr um ein offenes Angebot weit entfernt von jeglicher Form von Größenwahn handele, das »in absehbarerer Zeit keine nennenswerte Konkurrenz zur nationalen Erinnerung produzieren kann, hingegen optimalerweise ein willkommenes Korrektiv oder eine Ergänzung anbieten wird. $«^{431}$ Er prognostizierte weiter, dass sich jede nationale Rechte unterrepräsentiert und durch Brüssel bevormundet fühlen würde. Dabei komme diesen entgegen, dass es keine europäische Öffentlichkeit gebe und das Vorhaben so zwangsläufig den Charakter eines Elitenprojektes habe. Diesen zu erwartenden Kontroversen zum Trotz gelte dennoch: »Ohne den `Mut zur Lückeく kommt es aber nie auf die Beine. « $^{432} 2012$ lokalisierte Borodziej eine der Hauptspannungslinien des Projektes in der Frage, »ob wir stolz auf unsere Geschichte sein sollen oder uns für die schrecklichen Dinge schämen müssen, die wir einander und den Leuten außerhalb unseres Kontinents angetan haben. $\aleph^{433}$

Ebenso wie Befürworter des Projektes blieben die kritischen Stimmen aber selten, da eine umfassende Diskussion über das Vorhaben ausblieb: "In principle, the museum was created in an atmosphere of silence, even among the professionals, and without much discussion in the media. ${ }^{434}$ Dies war von Seiten der politischen und musealen

426 Schmidt: Auf dem Weg zu einem europäischen Gedächtnis? 2011, S. 165-167.

427 Niethammer; Augstein et al.: Das Haus der Europäischen Ceschichte, 2011, S. 176.

428 Ebd., S. 187.

429 Trüpel: Haus der europäischen Geschichte, 2009, S. $190 f$.

430 Ebd., S. 190.

431 Borodziej: Das Haus der Europäischen Geschichte, 2011, S. 141f., 146.

432 Ebd., S. $145 f$.

433 Busse: Stolz und Scham. FAZ. 28.01.2012.

434 Jareš: The House of European History, 2017. 
Akteure auch gewünscht, befürchtete man doch eine Beschädigung, wenn nicht gar ein Zunichtemachen des Vorhabens durch langwierige Diskussionen. ${ }^{435}$ Till Hilmar spricht in diesem Zusammenhang von einem »controlled process without significant external influences because of the absence of a public debate on the content of the museum. « ${ }^{436}$ Claus Leggewie widersprach dem von Pöttering verteidigten Ansatz, dass eine Debatte vor der ausreichenden Fundierung des Projektes diesem schade, vielmehr sei gerade ein gesamteuropäischer Diskurs eine Chance, womit das »Museum schon vor seiner Eröffnung zu einem gesamteuropäischen Erinnerungsort aufsteigen « könnte. ${ }^{437}$ Kaiser et al. sahen in dieser Strategie zudem "zahlreiche derjenigen Vorurteile gegen die EU als intransparenter bürokratischer Apparat [bestätigt], die seine neue museale Narration europäischer Integration gerade überwinden helfen soll.« ${ }^{438}$ Die Ausstellungsmacher und der Wissenschaftliche Beirat betonen gleichwohl, dass die internen Diskussionen durchaus erheblich waren und die potentiellen europäischen Debatten im Kleinen nachzeichneten. ${ }^{439}$ Weil es unweigerlich zu einem »very boring museum « führen würde, stand nach Vovk van Gaal und Dupont dabei nicht das Erarbeiten eines nach allen Seiten anschlussfähigen Kompromisses im Vordergrund, sondern das für die Ausstellung und Arbeit des Hauses erwünschte Aushalten unterschiedlicher Positionen. ${ }^{440}$

Während dieser >stillen< Phase wurde Anfang 2011 in mehreren Schritten das internationale Museumsteam berufen. Die »Kuratoren- und Teamleiterstelle« erhielt Taja Vovk van Gaal, die zuvor das Stadtmuseum Ljubljana leitete. ${ }^{441}$

2013 veröffentlichte das Europäische Parlament ein vom HEH-Team entworfenes 52seitiges Projektpapier »Building a House of European History «, ${ }^{442}$ das sowohl die Ziele und den eigenen Anspruch als auch die Gestaltung und Inhalte erstmals oder weiter konkretisierte. Im Vergleich zum Konzept von 2008 lässt sich eine Schwerpunktverlagerung mit einem stärkeren Fokus auf die Geschichte des 20. Jahrhunderts und Fragen der Gegenwart konstatieren, ${ }^{443}$ womit gleichzeitig auch einige Themenbereiche herausfallen, die dem Konzept von 2008 einen konservativeren Anstrich gaben, wie zum Beispiel die Thematisierung seuropäischer Abwehrkämpfe gegen das Osmanische Reich. Eine Diskussion dieses Papieres blieb weitgehend aus. ${ }^{444}$

435 Jareš hält diesen Ansatz für verständlich, war die Gefahr, dass nationale Lobbygruppen das Projekt zerreden könnten, doch schließlich real: Jareš: The House of European History, 2017.

436 Hilmar: Narrating Unity at the European Union's New History Museum, 2016, S. 304.

437 Leggewie; Lang: Der Kampf um die europäische Erinnerung, 2011, S. 182-188, hier: S. 186. Kreis: »Europa«ausstellen? 2013, S. 536f.

438 Kaiser; Krankenhagen et al.: Europa ausstellen, 2012, S. 182.

439 Grau Segú: Proposing a New European Narrative, 2016, S. 63.

440 Vovk van Gaal; Dupont: The House of European History, 2012, S. 48.

441 Troebst: Eckstein einer EU-Geschichtspolitik, 2012.

442 European Parliament: Building a House of European History, 2013.

443 Settele: Including Exclusion in European Memory? 2015, S. 410.

444 Vgl. für eine kritische Diskussion u.a. der Frage der Migration in dem Museum auf Basis des Papieres von 2013: ebd. Settele sieht eines der Kernprobleme in der politischen Struktur des Vorhabens, welche einer Legitimierung der Europäischen Union diene und damit zugleich kritische Fragen und »marginal voices « nur schwer oder schwerer integrieren könne, erst Recht, wenn sie dem angestrebten Narrativ widersprechen. 
Flucht und Vertreibung werden in dem Konzept nicht mehr so explizit erwähnt wie im Papier von 2008, was aber auch dem Charakter dieses bei den konkreten Inhalten nicht ins Detail gehenden broschüreartigen Projektpapiers entspricht. ${ }^{445}$ In Bezug auf das Ende des Zweiten Weltkrieges und den Beginn des Kalten Krieges heißt es lediglich: »Millions of Europeans were seeking to return to their old homes or to find new ones. « ${ }^{446}$ Stefan Troebst äußerte nach Lektüre des Papieres die Frage, ob die Thematik der forced migrations letztlich in die Dauerausstellung gelangen würde, was auch aufgrund diesbezüglich »kryptischer Aussagen« Taja Vovk van Gaals unklar bliebe. ${ }^{447}$

Nach mehrfachen Verschiebungen des Termins konnte das Haus der Europäischen Geschichte schließlich am 6. Mai 2017 eröffnen. In seiner Eröffnungsrede rekapitulierte Pöttering nochmals die Entstehungsgeschichte und die Notwendigkeit des Hauses aus seiner Perspektive. Das HEH solle nun ein Ort sein, an dem die »Idee Europas « weiter wachse und die Besucher sich an der »weiteren Gestaltung der Identität Europas beteiligen. ${ }^{448}$ Es sei in Anbetracht des Wiederauflebens von Nationalismus und politischem Radikalismus dringender denn je, für Europa, seine Werte und die aktive Beteiligung der Bürgerinnen und Bürger zu werben. ${ }^{449}$ Die Eröffnung des Hauses führte zu einem zumeist positiven internationalen Medienecho, auf das später noch kurz einzugehen sein wird.

Erst nach einem gewissen Zeitraum wurde die schon 2008 und seitdem öfter wiederholte Kritik an der inhaltlichen Ausrichtung des Hauses erneut erhoben. Nun intervenierte nicht nur die polnische Presse, auch Kulturminister Piotr Gliński äußerte sich prononciert gegen das Museum. Der polnische Historiker, ehemalige SolidarnośćAktivist und Mitglied des Europaparlaments Wojciech Roszkowski trat bereits im Mai aus dem Board of Trustees des HEH zurück und gab als Grund dafür Fehler in der Ausstellung sowie bei der Auslegung einiger der in dem Museum präsentierten Exponate an. ${ }^{450} \mathrm{Zu}$ einer von der Fraktion der European Conservatives and Reformists (ECR) und deren Mitglied Anna Fotyga von der PiS organisierten Diskussion am 5. September 2017 waren Historiker aus Dänemark, Lettland, Italien und Polen eingeladen, die zuvor das Museum besucht hatten. ${ }^{451}$ Die polnischen Historiker und Politiker beklagten die nicht gezeigte, tragische polnische Geschichte, darunter die verschiedenen Teilungen durch seine Nachbarn bis hin zum Hitler-Stalin-Pakt sowie die fehlende Thematisierung des spezifischen Charakters der deutschen Besatzungsherrschaft und die Darstellung der Einmaligkeit der polnischen Widerstandsbewegung. Ebenso fehle Polens Beitrag zur Entsetzung Wiens 1683 oder die polnische Verfassung von $1791 .{ }^{452}$ Auch wenn man akzeptiere, dass ein solches Museum kaum alle Erwartungen erfüllen könne, sei doch ein

445 Troebst: Towards a European Memory of Forced Migration? 2016, S. $244 \mathrm{f}$.

446 European Parliament: Building a House of European History, 2013, S. 34.

447 Troebst: Towards a European Memory of Forced Migration? 2016, S. $244 \mathrm{f}$.

448 Pöttering: Eröffnung des Hauses der Europäischen Geschichte, 2017, S. 6 f.

449 Ebd., S. 8f.

450 Szymańska-Borginon: Dom historii czy dom ideologii? rmf24. 04.09.2017.

451 Apelblat: Polish MEPs in Brussels want to change the narrative of the European history museum.

The Brussels Times. 12.09.2017.

452 Ebd. 
westeuropäischer Fokus zu konstatieren und eine Überbetonung des Nationalismus als "most destructive force in Europe's history, ignoring the role of the imperial powers which caused the two world wars «. ${ }^{453}$ Gliński, der sich in der Diskussion bereits mehrfach zu Wort gemeldet hatte, schrieb an den Präsidenten des Europäischen Parlamentes am 25. September 2017 einen offenen Brief, in dem er die erhobene Kritik wiederholte und beklagte, dass Polen und andere Staaten in der Ausstellung als (mit)verantwortlich für den Holocaust betrachtet, Deutschland hingegen für seine Erinnerungskultur gefeiert würde, und mahnte Änderungen an. ${ }^{454}$ Im August 2017 beging eine Delegation der Platform of European Memory and Conscience das Museum und veröffentlichte am 30. Oktober 2017 einen fünfzehnseitigen Bericht, der die bereits geäußerte Kritik noch einmal vertiefte und ergänzte. ${ }^{455}$ Dieser wird im Anschluss an die Ausstellungsanalyse noch kurz besprochen. Unmittelbar nach seinem Amtsantritt im Dezember 2017 wiederholte der polnische Ministerpräsident Mateusz Morawiecki in der Runde der Staatsund Regierungschefs der Europäischen Union die Kritik an der Gestaltung des HEH. ${ }^{456}$

\subsubsection{Struktur und Aktivitäten}

Das Haus der Europäischen Geschichte ist als Projekt des Europäischen Parlamentes in seine Verwaltungsstruktur integriert. Verschiedene Parlamentsausschüsse waren in die Realisierung des Projektes involviert. ${ }^{457}$ Ebenso trug das Europäische Parlament die Aufbaukosten. Die von den Museumsmachern 2012 selbst als sehr moderat betrachteten Kosten in Höhe von 56,15 Millionen Euro setzten sich zu diesem Zeitpunkt aus den Umbau- und Renovierungskosten für das Gebäude in Höhe von 31 Millionen Euro, dem Aufbau der Dauerausstellung für 21,4 Millionen Euro sowie Ausgaben von 3,75 Millionen Euro für die Akquise, Versicherung, Transport und Restaurierung der Sammlung zusammen. ${ }^{458}$ Das Projekt konnte nach eigenen Angaben der Museumsmacher im Finanzrahmen vollendet werden. ${ }^{459}$ Nach Fickers beliefen sich die Gesamtkosten schließlich auf 70 Millionen Euro, wovon die des Umbaus über 50 Millionen Euro betrugen. ${ }^{460}$ Die laufenden Kosten betrugen im Jahr 2017 7,4 Millionen Euro, worin auch noch Entwicklungskosten für die Dauer- und Wechselausstellung enthalten waren. Sie werden getragen vom Europäischen Parlament und ergänzt um einen Beitrag der Europäischen

453 So der polnische Historiker Marek Kornat auf der Konferenz: Apelblat: Polish MEPs in Brussels want to change the narrative of the European history museum. The Brussels Times. 12.09.2017.

454 Cliński: Cliński do szefa PE. wPolityce. 06.10.2017.

455 Platform of European Memory and Conscience; Ukielski et al.: The House of European History, 2017. Vgl. zur Platform (und dem ENRS): Büttner; Delius: World Culture in European Memory Politics? 2015.

456 Krupa: Feiert dieses Museum den Kommunismus? Die Zeit. 03.05.2018.

457 Vovk van Gaal: Comment forger un récit européen? 2016, S. 57. Vgl. European Parliament: Building a House of European History, 2013, S. 45, 47.

458 Vovk van Caal; Dupont: The House of European History, 2012, S. 47.

459 »Was uns verbindet, ist größer als das, was uns trennt«. Deutschlandfunk Kultur. 04.05.2017.

460 Fickers: Kompromissgeschichte, serviert auf dem »Tablet«, 2018. 
Kommission. ${ }^{461}$ Ziel ist es, die Finanzierung weiter zu diversifizieren, unter anderem durch weitere Institutionen und Sponsoren. ${ }^{462}$

Der Kurator Grau Segú sieht verschiedene gute Gründe, warum das Europäische Parlament die Initiative bis zur Eröffnung alleine getragen hat: „[....] doing so was a de facto acknowledgement of the potential for social transformation of historical knowledge, a transformation wanted and monitored by the ensemble of citizens. « ${ }^{463}$ Das Europäische Parlament als die einzige direkt gewählte Vertretung und supranationale europäische Institution eigne sich als Träger eines solchen europäischen Hauses besonders, gerade auch bezüglich der Repräsentanz und Anerkennung unterschiedlicher Sichtweisen. ${ }^{464}$

2009 konstituierte sich unter der Leitung von Hans-Gert Pöttering ein Board of Trustees mit 14 Mitgliedern sowie ein Academic Committee mit 12 Mitgliedern, geleitet von Włodzimierz Borodziej. ${ }^{465}$ Das Komitee setzt sich aus internationalen Experten zusammen und hat die Entstehung des Hauses in geschichtswissenschaftlichen und museologischen Fragen intensiv begleitet. Es soll die Arbeit fortwährend inhaltlich beaufsichtigen sowie die akademische Unabhängigkeit sichern. ${ }^{466}$ Das Kuratorium besteht aus Politikern europäischer Institutionen, Vertretern der Region Brüssel und weiteren Personen des öffentlichen Lebens und überwacht das general management des Projektes. $^{467}$

Das Haus verfügt mit der Kunst- und Literaturwissenschaftlerin Constanze Itzel und der Historikerin und Soziologin Taja Vovk van Gaal über eine Doppelspitze von $\mathrm{Mu}$ seum Director und Creative Director, ${ }^{468}$ auch das weitere Team ist interdisziplinär zusammengesetzt. ${ }^{469}$ Zehn Kuratoren sowie sieben Mitarbeiter für den Bereich Learning Services bilden gemeinsam mit sechs Mitarbeitern für den Bereich Sammlung, fünf für die Kommunikation sowie zwölf Mitarbeitern im Bereich der Verwaltung derzeit den Personalstamm des HEH. ${ }^{40}$ Die Dauerausstellung umfasst 4000 Quadratmeter auf fünf Etagen, der Bereich für die Wechselausstellungen liegt bei 800 Quadratmetern. ${ }^{471}$

461 Mork: RE: Questions on my PhD project about the $\mathrm{HEH}, 02.08 .2018$.

462 Vovk van Gaal; Dupont: The House of European History, 2012, S. 47.

463 Grau Segú: Proposing a New European Narrative, 2016, S. 61.

464 Ebd.

465 Settele: Including Exclusion in European Memory? 2015, S. 408. Vgl. für andere Zahlen: Troebst: Die Europäische Union als »Cedächtnis und Cewissen Europas«? 2013, S. 146. Vgl. für die aktuelle Zusammensetzung beider Gremien die HEH-Website: https://historia-europa.ep.eu/en/organisation (letzter Zugriff: 12.09.2018).

466 European Parliament: Building a House of European History, 2013, S. 46.

467 Ebd., S. 45.

468 Vgl. für eine kurze Vorstellung von Taja Vovk van Gaal: Graf: Ein Haus der Geschichte für Europa und tausend Fragen. Salzburger Nachrichten. 16.05.2017.

469 Vovk van Caal; Itzel: The House of European History project in Brussels, 2012, S. 77.

$470 \mathrm{Vgl}$. für den gegenwärtigen Stand: https://historia-europa.ep.eu/en/house-of-the-european-history-project-team (letzter Zugriff: 28.04.2018). Jareš spricht von einem »30-member curator team [...] under the leadership of the Slovene Taja Vovk van Gaal.« Jareš: The House of European History, 2017.

Vovk van Gaal; Dupont: The House of European History, 2012, S. 46. 
Die Sammeltätigkeit des zunächst nicht über eine eigene Sammlung verfügenden Museums begann nicht vor 2011. Dementsprechend sind von den ausgestellten etwa 1700 Objekten 1200 Leihgaben »von über 300 Institutionen weltweit. «72

Bereits in der Konstitution des $\mathrm{HEH}$ ist dessen internationale Ausrichtung angelegt. Der Besucher kann sich in den 24 Amtssprachen der Union durch die Dauerausstellung führen lassen, womit aber zugleich andere europäische Sprachen - darunter Russisch - zunächst noch ausgeschlossen sind. ${ }^{473}$ Menschen »of all age and of all walks of life« sollen als Besucher angesprochen werden. Die Ausstellungsmacher erwarten von den Besuchern keine umfassenden und vor allem sehr heterogene Wissensbestände, ebenso wie eine "wide range of expectations «. ${ }^{474}$ Zudem betonte Vovk van Gaal 2012, dass die Herausforderung darin bestehen wird, in einer begrenzten Zeit Besuchern und Besuchergruppen trotzdem die Hauptbotschaften des Museums vermitteln zu können. ${ }^{475}$ Constanze Itzel rechnete im Mai 2017 mit etwa 300.000 Besuchern pro Jahr. ${ }^{476}$ Das HEH soll schließlich nicht nur ein Ort der Verständigung und Vermittlung unter Europäern sein, sondern auch ein weltweites Publikum ansprechen. ${ }^{477}$

Das Museum liegt im Brüsseler Leopold-Park in unmittelbarer Nähe der europäischen Institutionen. Es befindet sich in einem Art-déco-Bau aus den 1930er Jahren, den ursprünglich George Eastman, der Gründer der Eastman Kodak Company, als Zahnklinik für arme Kinder stiftete. ${ }^{478}$ Zwischen den wenig abwechslungsreichen und eher zweckmäßigen EU-Gebäuden sticht der Bau in dem hügeligen und gepflegten Parkgelände hervor. ${ }^{479}$ Das Gebäude wurde nach einem 2009 begonnenen und 2011 abgeschlossenen Architekturwettbewerb seit 2012 für seine künftige Funktion umfassend umgestaltet. Die Architekten setzten dem Bau einen Glaskubus auf, der zugleich den Innenhof überdacht, sodass letzterer nun ein zentrales Atrium bildet, von dem die verschiedenen Bereiche des Hauses abgehen. ${ }^{400}$ Es verfügt neben den Ausstellungsbereichen über ein Auditorium für Konferenzen, Veranstaltungen und Filmvorführungen und versteht sich zusammen mit dem Europäischem Parlament und seinem Besucherzentrum Parlamentarium als Teil eines $>$ Informationsdreiecks $<.{ }^{481}$

Gemeinsam mit der Dauerausstellung eröffnete das HEH seine erste Sonderausstellung »Interactions«. Die stark kulturhistorisch-lebensweltlich-alltagshistorisch angelegte Ausstellung zeigt Verbindungslinien europäischer und globaler Entwicklungen: neben stärker historischen Fragen wie der der Entwicklung des Handels und des Krieges auch die der Kulturinstitution Café und der Küche, des Wohnzimmers und des Schlafzimmers. Mitmachelemente, hands on-Objekte sowie eine vom Besucher

472 Krankenhagen: »Das andere, eigene Kap.«2017, S. 129.

473 Ebd., S. 127.

474 Vovk van Gaal; Itzel: The House of European History project in Brussels, 2012, S. 77. Vovk van Caal; Dupont: The House of European History, 2012, S. 51.

475 Vovk van Caal; Itzel: The House of European History project in Brussels, 2012, S. 77.

476 Niehaus: Ein Haus für die Geschichte Europas. zdfheute. 07.05.2017.

477 Grau Segú: Proposing a New European Narrative, 2016, S. 71.

478 Vovk van Gaal; Itzel: The House of European History project in Brussels, 2012, S. 76.

479 Vgl. zum Cebäude und zur Umgebung: Grau Segú: Proposing a New European Narrative, 2016, S. 62 .

480 Ebd. Richters: Bauen für das Wir-Gefühl. BauNetz. 12.05.2017.

481 European Parliament: Building a House of European History, 2013, S. 15. 
nutzbare Szenografie prägen die Ausstellung. ${ }^{482}$ Das Element »Tracking my Europe« ermöglicht es, vor Ort sowie im Internet die persönliche europäische Lebensgeschichte des Besuchers $\mathrm{zu}$ visualisieren. ${ }^{483}$ Neben weiteren Sonder- und Wanderausstellungen sind Onlineausstellungen und internationale Kooperationen zur wechselseitigen Erhöhung der Reichweite der Institutionen geplant. ${ }^{484}$

In der Sparte »Publications« der Website des HEH sind noch keine eigenen Publikationen aufgelistet. ${ }^{485}$ Es existiert auch noch kein Katalog für die Dauer-oder Sonderausstellung, allerdings sind knappe Informations- und Überblicksheftchen in den 24 Amtssprachen der Europäischen Union erschienen. Bisherige Veranstaltungen des $\mathrm{HEH}$ waren unter anderem Kuratorenführungen, (akademische) Abendvorträge, Kurztagungen und Filmvorführungen. ${ }^{486}$ Einen Schwerpunkt ihrer Arbeit sehen die Macher des HEH in der pädagogischen Arbeit, die historische Reflexion und kritisches Denken fördern soll. ${ }^{487}$

\subsubsection{Anspruch und Selbstverständnis}

Der politische Impuls für die Einrichtung des HEH und der damit verbundene Anspruch an das Haus, zur Entstehung einer europäischen Identität und historischen Verständigung bis hin zur Förderung eines gemeinsamen historischen Bewusstseins beizutragen, wurde eingangs schon diskutiert. Kreis konstatiert zu dieser Ambition kritisch: »Dies setzt die Annahme voraus, dass Identität - gemeint ist eigentlich Basiszustimmung zum Elitenprojekt `Europa - über Geschichte, über die berühmten Meistererzählungen, über Wurzelnarrative produziert oder mindestens gefördert werden kann. ${ }^{488}$ Grundsätzlich sehen Akteure wie Pöttering eine europäische Identität allerdings als eine (notwendige) Ergänzung, nicht als einen Ersatz für regionale und nationale Identitäten an. ${ }^{489}$ Borodziej äußerte in Bezug auf dieses politische Erfordernis, dass für die EU als einem global player eine solche gemeinsame (historische) Identität und damit eine Institution wie das $\mathrm{HEH}$ notwendig wären: »Ohne eine reflektierte Auseinandersetzung mit den gemeinsamen Teilen der Geschichte kann in Europa kein supranationales Selbstbewusstsein entstehen. « $^{490}$ Der Präsident des Europäischen Parlamentes, Antonio Tajani, unterstrich zur Eröffnung des HEH nochmals die politische Bedeutung des Hauses:

»This is indeed not only the House of European History, it is also the Home of European Identity [...] Some say there is no clear European identity. I say our common identity lies

482 Vgl. für eine kurze Einführung auch die Präsentation auf der Website des HEH: https://historiaeuropa.ep.eu/en/interactions (letzter Zugriff: 29.04.2018).

483 www.myinteractions.eu/apps/heh-web-portal/ (letzter Zugriff: 29.04.2018).

484 Vgl. European Parliament: Building a House of European History, 2013, S. 19.

485 https://historia-europa.ep.eu/en/publications (letzter Zugriff: 29.04.2018).

486 Vgl. das Veranstaltungsarchiv auf der Website des HEH: https://historia-europa.ep.eu/en/archive (letzter Zugriff: 29.04.2018).

487 European Parliament: Building a House of European History, 2013, S. 19.

488 Kreis: »Europa« ausstellen? 2013, S. 525.

489 Theiling: Vortrag mit Hans-Cert Pöttering im Osnabrücker Rathaus. Neue Osnabrücker Zeitung. 04.11.2016.

490 Borodziej: Das Haus der Europäischen Geschichte, 2011, S. 141. 
in our shared values. Our unity for human rights and against the death penalty. Our defence of democracy and the rule of law. Our promotion of freedom and solidarity. This identity was forged through our shared history. ${ }^{491}$

Diesem Werben für eine europäische Identität stellte Vovk van Gaal 2012 die geplante Museumspraxis entgegen, die diese Anforderung in Form eines Diskussionsangebotes umzusetzen gedenkt: »If the HEH were to propose its own definition of a European identity, in a top-down movement towards the museum's visitors, this could only block any discussion instead of creating debate - which has to be central in a museum. « ${ }^{492}$ Auch Andrea Mork schreibt, das Museumsteam habe sich nach langen Diskussionen dazu entschieden, dass

»sich das Konzept der Identität als theoretische Crundlage des Museums nicht eigne. Eine allseits geteilte Definition dessen, was europäische Identität sein soll, gebe es nicht wirklich. Wolle man diese näher bestimmen, erreichten die Beschreibungen einen derartigen Grad an Allgemeinheit, dass sie jede konkrete Bedeutung verlieren würden. Das Konzept der Identität erscheint als zu statisch und beruht darüber hinaus auf einem Essentialismus, der eine Einheit voraussetzt, welche die vielfältigen Erscheinungsformen überwölbt. Vor allem aber würde der Versuch, das Haus der Europäischen Ceschichte zur Plattform für die Präsentation einer a priori gesetzten europäischen Identität zu machen, die öffentliche Diskussion über die durchaus sinnvolle Frage, worin diese bestehen solle, eher blockieren als anregen. ${ }^{493}$

Dementsprechend verfolgen die Museumsmacher die Vorstellung eines Forums anstelle eines konventionellen (National-)Museums, ähnlich wie es in Kapitel 2.5 beschrieben wurde. ${ }^{494}$ Dies unterstreicht die Namensgebung als >Haus< in Anlehnung an das als maßgeblich betrachtete bundesdeutsche Museumsprojekt der 1980er Jahre: »There is also admiration for the way the Germans transformed their museums into successful communication tools and created a forum about the country's difficult past. « ${ }^{495}$ Dieser Vorbildcharakter wird noch durch diverse personelle Überschneidungen untermauert, wie auch die schon erwähnte Beteiligung Hans Walter Hütters zeigt. ${ }^{496}$ Wolfram Kaiser spricht schließlich von einem einflussreichen westdeutschen »Catholic Micro-network for a European Integration Museum«, welches das HEH letztlich, anders als das alternative Projekt des Musée de l'Europe, durchzusetzen vermochte. ${ }^{497}$ Die internationale

491 Stur: Welcome to the House of European History. New Europe. 05.05.2017.

492 Vovk van Gaal; Dupont: The House of European History, 2012, S. 48.

493 Mork: Nach Nationalismus, Diktatur und Krieg, 2016, S. $38 \mathrm{f}$.

494 Axelsson; Dupont et al.: Entering Two Minefields, 2012, S. 9. Vgl. das Interview mit der Direktorin Constanze Itzel: Itzel: The House of European History, 2017. Kapitel 2.5, S. $66 \mathrm{f}$.

495 Axelsson; Dupont et al.: Entering Two Minefields, 2012, S. 8.

496 Ebd.

497 Bei den drei entscheidenden Personen handelt es sich um die CDU-Mitglieder Hans-Gert Pöttering, Hans Walter Hütter und Ludger Kühnhardt. Letzterer entwarf für Pöttering zwei Konzeptpapiere für eine solche Institution: Kaiser: Limits of Cultural Engineering, 2017, S. 520-522. Fickers hält die These in dieser Form jedoch für »überspitzt und wenig plausibel«: Fickers: Kompromissgeschichte, serviert auf dem »Tablet«, 2018. 
Zusammensetzung des Teams ebenso wie die erhoffte Gewährleistung einer Pluralität durch die aktive Beteiligung des Europäischen Parlamentes sowie ein international zunehmend verbreiteter >Haus $<$-Ansatz lassen aber den Vorwurf, ein deutsches Modell oder Projekt zu verfolgen, kaum nachvollziehbar erscheinen. ${ }^{498}$ Mork fasst zusammen, dass das Haus »[...] vom Ansatz her eher auf Ambivalenzen als auf Einheitlichkeit ausgerichtet [sei], auf Differenzierung statt auf Homogenität, auf kritische Aufklärung statt auf Affirmation« und somit das eigene, national geprägte Bewusstsein der Besucher erweitern solle. ${ }^{499}$

Das Team des $\mathrm{HEH}$ hat sich für einen pragmatischen Umgang mit dem »dehnbaren« Begriff beziehungsweise dem kulturellen »Konstrukt « Europa entschieden, das im Haus ebenso als offen wie als historisch, kulturell, sozial und politisch wechselhaft diskutiert wird..$^{500}$ In der Ausstellung selber greift man, wenn es thematisch geboten ist, auch über Europa hinaus. ${ }^{501}$ Der europäische Ansatz des Hauses respektiert die zentrale Bedeutung des Nationalstaates für die Entwicklung Europas. ${ }^{502}$ Die Shoa wird als »Beginn und Nukleus eines europäischen Gedächtnisses« betrachtet, »deren moralische Hinterlassenschaft konstitutiv für das Selbstverständnis eines Europas geworden ist, das sich seiner eigenen humanistischen Traditionen nicht mehr sicher sein kann. So hat sich ein spezifisch europäischer Erinnerungsstandard herausgebildet. ${ }^{503}$ Ältere Rückprojektionen europäischer Einheit möchte man in dem Museum vermeiden, denn weder das Römische Reich mit den für sein Wesen zentralen außereuropäischen Teilen noch das Staatswesens Karl des Großen würden für den Anspruch des HEH taugen. ${ }^{504}$

Auf der Website des HEH wird die »Mission \& Vision« des Hauses formuliert: Es soll dem Verstehen von gemeinsamen und unterschiedlichen Erfahrungen der europäischen Völker und dem Kennenlernen verschiedener Standpunkte ebenso wie geteilter Grundlagen der europäischen Geschichte dienen. Es soll ein Treffpunkt für alle Generationen sein. In diesem Haus soll die Auseinandersetzung mit der Vergangenheit zur Reflektion über die Gegenwart und zum Nachdenken über die Zukunft anregen. Das $\mathrm{HEH}$ hat zudem das Ziel, ein »Reservoir« der europäischen Erinnerung zu werden. Außerdem verfolgt die Institution den Anspruch, eine führende Plattform zur Verbindung europäischer Einrichtungen zu werden, die sich mit europäischer Geschichte befassen. Und schließlich soll es ein Ort sein, an dem Besucher eingebunden und mit Freude über die europäische Geschichte und den Prozess der europäischen Integration lernen können. ${ }^{505}$

Die hier genannten Punkte finden sich in den verschiedenen Äußerungen des $\mathrm{Mu}$ seumsteams wieder: Dieses betonte, dass man keiner teleologischen Perspektive und

498 Axelsson; Dupont et al.: Entering Two Minefields, 2012, S. 9. Vovk van Gaal; Dupont: The House of European History, 2012, S. 50 .

499 Mork: Nach Nationalismus, Diktatur und Krieg, 2016, S. 40.

500 Ebd., S. $44 f$.

501 Vovk van Gaal; Itzel: The House of European History project in Brussels, 2012, S. 79.

502 Mork: Nach Nationalismus, Diktatur und Krieg, 2016, S. 47.

503 Ebd., S. 53.

504 Grau Segú: Proposing a New European Narrative, 2016, S. 66.

505 https://historia-europa.ep.eu/en/mission-vision (letzter Zugriff: 24.04.2018). 
der im politischen Diskurs beliebten »out of ashes«-Rhetorik einer erfolgreichen EUIntegrationspolitik nach 1945 folgen wolle. ${ }^{506}$ Weniger als eine simple Erfolgsgeschichte möchte man vor allem die Schwierigkeiten dieses europäischen Weges nach Verlust der globalen Vormachtstellung in Folge des Ersten Weltkrieges darstellen. ${ }^{507}$ Schließlich solle das Museum im vielleicht größten Unterschied zu den klassischen Nationalmuseen des 19. Jahrhunderts ohne eine `Zielvorgabe enden, ein Fazit, das die extrem uneinheitlichen Vorstellungen über die Entwicklung der Europäischen Union in ihren Mitgliedsstaaten berücksichtigt. ${ }^{508}$ Daran anschließend müssen eine Vielfalt der Stimmen ebenso wie die grundlegende Bedeutung von kulturellen, sozialen und politischen Unterschieden für Europa respektiert und diskutiert werden. ${ }^{509}$ Eine transnationale Perspektive auf gemeinsame Entwicklungen und Erfahrungen ist also konstitutiv. ${ }^{510}$

Transparenz soll dieses Vorgehen unterstützen:»Once again it is important to make very clear to the visitor that the contents of the museums are only the product of the choices made by a team at a certain moment. ${ }^{511}$ Den scheinbaren Widerspruch zwischen einem starken, verständlichen Narrativ der Ausstellung und einem multiperspektivischen Ansatz verstehen Vovk van Gaal und Dupont vielmehr als Chance, »[...] to avoid the dangers of being static, so as to develop instead a moving and evolving approach to the history of Europe. ${ }^{512}$ Partizipative Elemente des Museums sollen diesen Ansatz unterstreichen. ${ }^{513}$ Vor allem aber soll das HEH konsequent mit Fragezeichen und offenen Erzählungen operieren, die den Besucher die Ausstellung durchgängig mit kritischem Auge betrachten lassen..$^{514}$

Ebenso möchten die Ausstellungsmacher europäische Erinnerungskonflikte bewusst diskutieren: »Therefore, the permanent exhibition will contain some points in which the visitor will be invited to take a step back and reflect on the diversity of historical interpretations and of memories on a certain topic. Thus, the visitor will be invited to reflect upon and to debate different perceptions of historical events. ${ }^{515}$ Schließlich sei »[der] Besucher des Hauses der Europäischen Geschichte [...] aufgefordert, sich anhand des Gesehenen darüber Gedanken zu machen, welche Lehren aus der Geschichte $\mathrm{zu}$ ziehen sind und welche Leitbilder und Leitmotive den gemeinsamen europäischen Kurs in Zukunft bestimmen sollen. ${ }^{16}$ Folglich verstehen die Museumsmacher das $\mathrm{HEH}$ in besonderem Maße als reflexives Museum, in dem sie die soziale und politische Konstruktion von Geschichtsbildern zur Diskussion stellen. ${ }^{517}$

506 Vovk van Gaal; Dupont: The House of European History, 2012, S. $49 f$.

507 Ebd., S. 50.

508 Rigney: Transforming Memory and the European Project, 2012, S. 608.

509 Mork: Nach Nationalismus, Diktatur und Krieg, 2016, S. $55 f$. Vovk van Gaal: Comment forger un récit européen? 2016, S. 66.

510 Grau Segú: Proposing a New European Narrative, 2016, S. 62.

511 Vovk van Gaal; Dupont: The House of European History, 2012, S. 46, 52.

512 Ebd., S. 49.

513 Itzel: The House of European History, 2017, S. 56.

514 Grau Segú: Proposing a New European Narrative, 2016, S. 62.

515 Vovk van Gaal; Itzel: The House of European History project in Brussels, 2012, S. 78.

516 Mork: Nach Nationalismus, Diktatur und Krieg, 2016, S. 55.

517 European Parliament: Building a House of European History, 2013, S. 24. 
Das Museumsteam interpretiert den politischen Auftrag des Hauses selbst weiter: Eines der Ziele müsse es sein, die Bedeutung der Errungenschaft der europäischen Integration zu verdeutlichen und aktuelle Herausforderungen aufzuzeigen. Damit könne zum Verständnis und zur Debatte beigetragen werden, »about what European unity means today, and what it brings us in light of our troubled past and the parallel effort of so many individuals to build a better world. ${ }{ }^{18}$ Als ein weiteres zentrales Ziel formuliert das Museumsteam, gegen neuen, wachsenden Extremismus und Xenophobie anzuarbeiten. ${ }^{519}$ Hans-Gert Pöttering fasste diesen Auftrag nach der Eröffnung nochmals von politischer Seite zusammen: »Gerade in einer Zeit, die herausgefordert ist durch Populismus durch wiederentstehenden Nationalismus, ist es wichtig, dass man sich an die Tragödien der europäischen Geschichte erinnert. Es hat fast in jeder Generation Kriege gegeben. Das wollen wir für alle Zeit überwinden. Das ist doch der Kern der Europäischen Einigung. ${ }^{520}$ Den Museumsmachern geht es aber weniger um eine historische Argumentation durch Überwältigung, sondern darum, dem Besucher historisch zu erklären, wie beispielsweise gesteigerter Nationalismus und Intoleranz die europäischen Demokratien der Zwischenkriegszeit relativ schnell in autoritäre Staaten verwandelten und wie die Machtmechanismen totalitärer Regime schließlich funktionieren. ${ }^{521}$

\subsubsection{Die Dauerausstellung}

Die Dauerausstellung ist in den oberen fünf Etagen des eben beschriebenen Gebäudes untergebracht. Sie gruppiert sich um den hellen Innenhof, der von den Freitreppen in die verschiedenen Etagen und dem gleich beschriebenen, die Ausstellung durchziehenden Kunstwerk geprägt ist. Der aufgesetzte gläserne Kubus bietet Raum für die drei weiteren Etagen der Dauerausstellung.

Das Ausstellungsdesign soll eine multiperspektivische Betrachtung auf die Geschichte gewährleisten und alle Sinne des Besuchers durch ein gelungenes Zusammenspiel von Exponaten und Multimedia-Elementen ansprechen. ${ }^{522} \mathrm{Ihm}$ soll über verschiedene Tiefenebenen ein möglichst individueller Besuch der Ausstellungsbereiche ermöglicht werden. ${ }^{523}$ Inhaltlich wird ein thematisch-chronologischer Ansatz verfolgt, der auf das 19. und 20. Jahrhundert sowie die Geschichte der europäischen Integration nach 1945 fokussiert ist. ${ }^{524}$ Für die in der Ausstellung behandelten Themen entwickelten die Ausstellungsmacher drei Kriterien, die schließlich auch eine Richtschnur für die Entwicklung der Dauerausstellung boten:

518 Grau Segú: Proposing a New European Narrative, 2016, S. $60 f$.

519 "Countering those trends requires putting to the forefront the values of diversity and mixture, of free thinking and life in common. «Crau Segú: Proposing a New European Narrative, 2016, S. 61.

520 Niehaus: Ein Haus für die Geschichte Europas. $z$ df heute. 07.05.2017.

521 Itzel: The House of European History, 2017, S. 59.

522 European Parliament: Building a House of European History, 2013, S. 24, 39, 41.

523 Ebd., S. 29.

524 Vovk van Gaal : Comment forger un récit européen? 2016, S. 61. 
»1) A process, event or development should have originated in Europe;

2) It should have been spread over Europe at a certain time;

3) It should still be of relevance today. ${ }^{425}$

Der Besucher erhält als zentrales Element des Ausstellungsbesuches ein Tablet mit Kopfhörern. Nur auf diesem lassen sich die Raumtexte und Objekttexte lesen beziehungsweise kann man sie sich vorlesen lassen. Für gewöhnlich wird man von dem Gerät durch die Ausstellung begleitet und es beginnt beim Voranschreiten von alleine, die nächsten Texte vorzutragen (wobei sich eine Vorleserin und ein Vorleser abwechseln). Die Vitrinen werden auf dem Tablet schematisch angezeigt und man kann dort die verschiedenen Exponate auswählen, um die zugehörigen Texte abzurufen, was bei den teilweise sehr dicht gehängten Vitrinen einiges an Bildschirmarbeit bedeutet.

Bei seinem Besuch wählte der Autor als mutmaßliche Grundlage für alle weiteren Übersetzungen Englisch als Ausgabesprache für das Tablet. Einschränkend ist daher festzuhalten, dass die Texte, die in Polnisch, Tschechisch oder Deutsch verfasst sind, abweichen könnten - wofür bisher aber keine Anzeichen zu finden sind. ${ }^{526}$ Außerdem wurden verschiedene Mitmachelemente der Ausstellung nicht oder nicht vertiefend genutzt, die aber bei den für diese Arbeit besonders relevanten Teilen auch keine Rolle spielen.

Die Ausstellung ist auf fünf der sieben Etagen des Museumsgebäudes angelegt und gliedert sich in sechs Oberthemen, die sich wiederum in 27 Unterthemen aufteilen. Der folgende Ausstellungsrundgang befasst sich schwerpunktmäßig mit den Punkten 9-12 sowie mit relevanten Einzelelementen der anderen Ausstellungsteile.

\section{Shaping Europe}

. 1. Mapping Europe

- 2. The Myth of Europe

. 3. European Heritage

. 4 . Memory

\section{Europe: A Clobal Power}

5. Political Change

. 6. Markets and People

7. Science and Technology

- 8. Imperialisms

Europe in Ruins

9. World War I

525 Vovk van Gaal; Itzel: The House of European History project in Brussels, 2012, S. 79.

526 In einem Artikel des Kölner Stadt-Anzeigers heißt es allerdings, dass nach Taja Vovk van Gal »jeder Version [...] der >Spirit ‘ des jeweiligen Landes eingewoben [sei]. «Oehlen: Haus der Europäischen Geschichte wird in Brüssel eröffnet. Kölner Stadt-Anzeiger. 05.05.2017. 
. 10. Totalitarianism versus Democracy

- 11. World War II

. 12. The Harvest of Destruction

Rebuilding a Divided Continent

. 13. Rebuilding Europe

- 14. Cold War

- 15. Creating Social Security

- 16. Milestones of European Integration I

. 17. Memory of the Shoah

\section{Shattering Certainties}

. 18. End of the Boom

- 19. Democratisation in Western Europe

- 20. Communism under Pressure

- 21. Milestones of European Integration II

- 22. Re-Mapping Europe

- 23. Milestones of European Integration III

- 24. Shared and Divided European Memory

\section{Accolades and Criticism}

- 25. Europe as seen from Abroad

- 26. Appraisal and Criticism

- 27. Brussels: A Changing Capital

Aufgrund von Sicherheitsmaßnahmen betritt der Besucher das HEH durch das Untergeschoss, von dem er via Treppenhaus in die erste Etage zum Empfangsbereich gelangt, wo ihm das Tablet ausgehändigt wird. ${ }^{527}$ Von dort kann man in das ursprüngliche Foyer des Hauses gelangen, in dem die Originalfresken aus der Gründungszeit der Zahnklinik erhalten sind. Hier befindet sich auch eine Nische, in der in deutscher Sprache das Zitat von Hans-Gert Pöttering vom 13. Februar 2007 zur Gründungsidee an der Wand angebracht ist. Darunter befindet sich in einer Vitrine das aufgeklappte Gästebuch Pötterings aus seiner Zeit als Präsident des Europäischen Parlaments. ${ }^{528}$ In der zweiten Etage beginnt die Dauerausstellung. Bereits beim Eintritt in das Treppenhaus wird der Besucher von der die gesamte Ausstellung bis zum Dach durchziehenden metallenen Skulptur in Form eines verwirbelten Spruchbandes mit dem Titel »Vortex of History»

527 Diese Form des Eintritts wird von Krankenhagen als »unübersichtlich und wenig einladend « betrachtet, über die auch die Museumsdirektorin Taja Vok van Gaal nicht glücklich sei und die sich ihm gegenüber so äußerte: »But you know: security.«-Krankenhagen: »Das andere, eigene Kap.« 2017, S. 125.

528 Aufgeschlagen sind die Seiten mit den Eintragungen der Mitglieder des Wissenschaftlichen Beirats bei ihrem ersten Treffen im Jahr 2009. 
(Der Wortwirbel der Geschichte) empfangen. ${ }^{52}$ Es setzt sich aus Buchstaben sowie bedeutenden Zitaten der europäischen Geschichte zusammen und soll die verschiedenen Ausstellungsteile miteinander verbinden. ${ }^{530}$

Im ersten Ausstellungsbereich »Shaping Europe« begegnen dem Besucher unterschiedliche künstlerische, kultisch-mythologische, religiöse und wissenschaftshistorische Exponate wie auch historische Dokumente aus allen Epochen, zum Beispiel der mit einem »J versehene Ausweis einer Jüdin. Hier finden sich unterschiedliche Ansätze für die Definition von Europa. In einem Bereich mit historischen und aktuellen Karten sowie einer Multimedia-Installation wird die politisch, zeitlich und global unterschiedliche Konstitution Europas anhand offener Fragen an den Besucher diskutiert. In Bezug auf eine potentielle europäische Erinnerungsgemeinschaft wird gefragt: „Can we say that we have a shared European past when history has affected people differently? Can we find any commonality; a reservoir of European memory?« Dem Ausstellungscharakter folgend, ist der Bereich mit sich widersprechenden Exponaten gestaltet: zum Beispiel die Darstellung der bürgerlichen Revolution als Symbol für das Freiheitsstreben Europas mit den Ketten von Sklaven oder die Gegenüberstellung eines französischen, antideutsch-revanchistischen Propaganda-Plakates aus der Zeit vor dem Ersten Weltkrieg mit einer Fotografie der Versöhnungsgeste François Mitterrands und Helmut Kohls in Verdun 1984. Eine niederländische Ausgabe von Anne Franks Tagebuch wird einem mittelalterlichen islamischen Manuskript zur Seite gestellt, das zu den wenigen geretteten Beständen der 1992 zerstörten National- und Universitätsbibliothek Bosnien-Herzegowinas zählt. Beide gehören zum Bereich »Memory and European Heritage«. Im Begleittext heißt es: »Memory has political meaning and can be a battleground. The destruction of memory is an attack against human integrity and cultural self-determination." Die Exponatpaare symbolisieren jeweils eines der Themen des Bereichs: "Rule of Law, Capitalism, State Terror, The Enlightenment, Omnipresence of Christianity, The Nation State, Revolutions, Genocide, Colonialism, Humanism, Philosophy, Democracy, Marxism, Communism \& Socialism, The Slave Trade«. Erinnerung selbst wird dem Besucher als zentral für Individuen wie auch Gesellschaften mit einer starken Bedeutung für Gegenwart und Zukunft vorgestellt, wobei gelte: "How we remember the same history constantly changes."

Versehen mit diesem ersten Eindruck begibt sich der Besucher in die dritte Etage in den Bereich »Europe: A Global Power«. Ein digitales Wanddiorama, das unter anderem den Sturm auf die Bastille und eine Karikatur mit Karl Marx als Gott zeigt, der die zehn Gebote in Form des Kapitals und des Kommunistischen Manifests an die Völker der Welt verteilt, bildet den Hintergrund zu den Exponaten, die in Revolution, Entwicklung der Menschenrechte, Demokratie oder Nationalismus einführen. Bezogen auf den ethnisch homogenen Nationalstaat heißt es: »Nationalism emerged as a revolutionary

529 Auf Deutsch wird das Kunstwerk auf der Website des HEH mit »Der Wortwirbel der Geschichte« übersetzt. Dort sind auch alle in das Werk eingearbeiteten Zitate zu finden: https://historia-europa.ep.eu/en/focus/curators-notes-vortex-history (letzter Zugriff: 29.07.2018).

530 Fickers kritisiert zu Recht, dass die einzelnen Zitate kaum lesbar seien. Dennoch gelingt meines Erachtens das Ziel, die Ausstellungsteile in Funktion eines >roten Fadens < miteinander zu verbinden. Fickers: Kompromissgeschichte, serviert auf dem »Tablet«, 2018. 
claim promising citizens more involvement in democracy, but it was exclusive, imagining a world of national territories inhabited by ethnically similar people. Some visionary Europeans, however, hoped for the unity of the continent beyond national allegiances."

Der nächste Abschnitt thematisiert die Industrielle Revolution anhand szenografisch angedeuteter und originaler Maschinen. Mit Hilfe von hands on-Elementen kann der Besucher sich hier vertiefendes Wissen aneignen. Bürgerliche Lebenswelten sind denen der Industriearbeiter direkt gegenübergestellt: Dieses sowohl als auch zeigt sich ebenfalls bei der Replik einer historischen Dampfmaschine, unter der sich eine Ausgabe des »Manifestes der Kommunistischen Partei« befindet. Dieser Bereich stellt auch die Auswanderung nach Übersee ebenso wie die interne europäische Arbeitsmigration und die jüdische Migration aus Osteuropa dar. Im daran anschließenden Abschnitt werden Exponate in einer begehbaren Stahl-Glas-Konstruktion ähnlich dem Kristallpalast der Londoner Weltausstellung von 1851 zum Feld der Wissenschaft, Technologie, Fortschritt, europäischen Überlegenheit und Europas Imperialismus im 19. Jahrhundert gezeigt. Neben positiven Beispielen wird die fortgesetzte brutale Ausbeutung und Beherrschung der Kolonien diskutiert, so anhand der britischen Konzentrationslager in Südafrika oder der deutschen Niederschlagung des Herero-Aufstandes. Charles Darwins missverstandene und politische missbrauchte Evolutionstheorie wird in Hinblick auf deren Pervertierung zu Sozialdarwinismus, Rassentheorien, Eugenik und Antisemitismus vorgestellt.

Diesen Bereich verlässt der Besucher durch eine Glastür und befindet sich nun im nächsten Themenkomplex, dem Ersten Weltkrieg. Der folgende, sich über mehrere Raumbereiche erstreckende Abschnitt versucht den Krieg in seiner europäischen Dimension darzustellen: Ein Beispiel hierfür ist eine Europakarte, die Feldpostbriefe aus fast allen Ländern Europas zeigt. Auf der einer Vitrine als Hintergrund dienenden Collage sind Soldaten unterschiedlichster Nationen und ethnischer Herkunft abgebildet, was die koloniale ebenso wie die globale Dimension des Krieges unterstreicht. Wie auch sonst mehrfach in der Ausstellung zu sehen, befinden sich eindrückliche Zitate in ihren Originalsprachen an den Wänden, hier ein Zitat von Ernst Jünger von 1920: »Das Bild des Krieges war nüchtern, grau und rot seine Farben, das Schlachtfeld eine Wüste des Irrsinns...« Trotz des begrenzten Raumes werden dem Besucher die verschiedenen Gebiete des Ersten Weltkrieges, darunter auch Afrika und der Nahe Osten vorgestellt, auch der Völkermord an den Armeniern wird in diesem Zusammenhang diskutiert: »In 1915 the Ottoman government attacked the Armenian population, a minority group within ist empire. The resulting genocide, involving mass executions of civilians and soldiers, starvation and disease, killed around a million people.«Die Präsenz von Objekten, die den Wunsch nach Heimkehr von der Front ausdrücken, ebenso wie Darstellungen der Brutalität des Krieges, zum Beispiel anhand von Gasmasken aus verschiedenen europäischen Ländern, bringen dem Besucher die grauenhaften Seiten des Krieges nahe. Eine eigene Vitrine ist der Kriegspropaganda gewidmet, in der die verschiedenen Exponate, die sich gegenseitig kommentieren, zusammengestellt sind.

Die Ausstellung verzichtet auf die Darstellung eines klaren Bruchs durch das Ende der Kriegshandlungen an der Westfront: »World War I ended on 11 November 1918, although Europe was far from being at peace, as this exhibition will show. [...] The map of Europe was about to be redrawn, but the result was far from perfect.« Hier wer- 
den unter anderem die umstrittenen Nachkriegsgrenzziehungen in Europa diskutiert, die Hoffnung auf Woodrow Wilsons »Selbstbestimmungsrecht der Völker« ebenso wie dessen Scheitern. Die umstrittenen Planungen für die polnischen Nachkriegsgrenzen werden anhand von Kartenmaterial vorgestellt ebenso wie deutsche Grafiken, die die territorialen, materiellen und demographischen Verluste darstellen. Der Kritiker des Versailler Vertragswerkes, John Maynard Keynes, ist mit seinem Buch »The Economic Consequences of the Peace « vertreten und wird unter einem Bild der Versailler Vertragsverhandlungen zitiert: »An inefficient, unemployed, disorganized Europe faces us, torn by international strife and international hate, fighting, starving, pillaging, and lying."

Mit diesen Eindrücken betritt der Besucher den Bereich »Totalitarianism versus Democracy«, der die europäische Zwischenkriegszeit als (letztlich gescheiterten) Kampf der sich zunächst fast überall durchsetzenden parlamentarischen Demokratien gegen nationalistischen Extremismus, ökonomische Krisen, Revanchismus und Autoritarismus zeigt. Die verschiedenen demokratischen Verfassungen sind zusammen mit historischen Wahlurnen und darüber schwebenden Wahlflugblättern inszeniert. Diese Zeit präsentiert sich nicht nur von der politischen Seite, sondern verstärkt mit kulturell-gesellschaftlichen Umbrüchen wie technischen Innovationen, der Emanzipation der Frau oder der neuen Filmkunst. Eine Vitrine stellt die verschiedenen Revanchismen und nationalen Auseinandersetzungen um umstrittene Gebiete vor: so zwei Wahlplakate aus dem Abstimmungskampf um die Zugehörigkeit Oberschlesiens, die für die Zugehörigkeit zu Deutschland oder Polen werben. Der Ausstellungsbereich »Obstacles and Ideals« zeigt gemäß seinem Titel auch positive Entwicklungen und Ansätze, wie eine starke Antikriegsbewegung, die Gründung des Völkerbundes oder die Paneuropa-Bewegung. Diesen sind die verschiedenen faschistischen und nationalsozialistischen Bewegungen Europas direkt gegenübergestellt, die so auch als gesamteuropäisches Phänomen verstehbar sind. Mit historischen Filmaufnahmen des brennenden Smyrna werden auch der Griechisch-Türkische Krieg und der folgende >Bevölkerungsaustausch k kurz präsentiert: »[...] a Greco-Turkish war began after the defeat of the Ottoman Empire, leading to ethnic expulsion campaigns and massacres by both sides. It was resolved by the Treaty of Lausanne (1923), which imposed a novel measure: the compulsory exchange of populations.« Der Bereich schließt mit der Darstellung des Überganges verschiedener Staaten zu autoritären und diktatorischen Regimes. In der zugehörigen Vitrine ist eine Skulptur von Józef Piłsudski neben ein Plakat des ungarischen Staatsoberhauptes Miklós Horthy und ein Heft über die jugoslawische Diktatur gestellt. In der Beschriftung zu Piłsudski steht einschränkend: »His supporters moved away from democracy by restricting political freedom, creating a relatively mild version of authoritarianism. « Auf einer digitalen Karte kann der Besucher schließlich anhand einer Zeitachse den Wandel der Regimeformen in unterschiedlichen Ländern verfolgen: Sie verwandelt sich von einer ursprünglich überwiegenden grünen der demokratischen Staaten zu einer braunblauen (autoritär-faschistisch) und roten (kommunistischen) Karte.

Im folgenden Ausstellungsbereich "Stalinism versus National Socialism« werden die beiden Systeme einander gegenübergestellt, ohne dass es zu einer offensichtlichen inhaltlichen Verknüpfung kommt. In Bezug auf den Vergleich von Stalinismus und Nationalsozialismus heißt es: »We have chosen to compare and contrast these systems, which were ideologically opposed to each other and yet so alike in their brutality and 
oppression.« Für beide Systeme werden die Spezifika totalitärer Herrschaft wie ein überbordender Personenkult, massive Propaganda, die den inneren wie äußeren Feind entmenschlicht, aber auch spezifische Elemente der Modernität, beispielsweise in der Architektur, herausgestellt. Am verbrecherischen Charakter des kommunistischen Regimes, besonders des Stalinismus, lässt die Ausstellung keinen Zweifel:

»The communist deprived people of basic freedoms and rights, subjecting them to various forms of persecution in their efforts to create the >New Soviet Man<, a vision of total compliance with the system. The system became even more repressive under Stalin. By his death in 1953 it had killed millions in the Soviet Union and other Eastern bloc states by execution, the Gulag camps, mass deportations, famine and torture.«

Auch der ökonomische Misserfolg, der selbst terroristische Züge annahm, wird besprochen: »This policy led to economic disaster but was carried out with ruthless terror leading to the deaths of millions of people.«

Die Darstellung des Nationalsozialismus hebt neben dem Terror gegen politische Gegner die zwei Hauptkriegsziele hervor: die Vernichtung der europäischen Juden mit industriellen Methoden sowie die Eroberung von >Lebensraum ‘ in Osteuropa. Verdeutlicht wird der rassistische Charakter des Regimes und der vermeintlich erfolgreichen Wirtschaft, die auf einer schuldenbasierten künftigen Ausbeutung Europas beruhte. Wie das Gulag-System der Sowjetunion wird auch das deutsche Lagersystem in seinen Spezifika gezeigt. So ist ein Ausstellungsgegenstand die Identifikationskarte eines polnischen Zwangsarbeiters. Die industrielle Vernichtung der Juden ist durch eine geöffnete Dose Zyklon B symbolisiert, ${ }^{531}$ unterlegt mit einer Texttafel, auf der das Zitat Hitlers steht, dass ein kommender Krieg zur Auslöschung des Judentums in Europa führen werde. Eine Fotografie des Planes für das Krematorium von Auschwitz-Birkenau vervollständigt die Darstellung ebenso wie die Zeichnung einer Auschwitzgefangenen, die einen Appell im Lager zeigt.

Im Übergang zum Zweiten Weltkrieg wird der Spanische Bürgerkrieg in seiner europäischen Verstrickung präsentiert. Der Einführungstext zum Zweiten Weltkrieg stellt die zivilen Opfer, den verbrecherischen Charakter von Nationalsozialismus und Stalinismus und die besondere Brutalität des Krieges in Osteuropa heraus:

»World War II is often described as a stotal war<, abandoning the distinction between soldiers and civilians. Millions of people were victims of mass execution, deportation, starvation, forced labour, concentration camps and bombing. Under Nazi rule, millions were murdered through systematic social and ethnic cleansing. In both its scale and bureaucratic form, the genocide of the European Jews became an unparalleled event in history. Caught in the crossfire between National Socialism and Stalinism, the war had a particularly brutal character in Central and Eastern Europe.«

Eine erste Vitrine zeigt Überreste von Gegenständen nach der Bombardierung Dresdens 1945: Mit verbranntem Kinderspielzeug - Militaria - wird auf der einen Seite die Militarisierung der deutschen Jugend und andererseits auch das Zurückfallen des Krieges auf 
Deutschland dargestellt. Die Szenografie des ersten Raumes ist von (kriegs-?) beschädigten Wänden geprägt, deren Fenster mit Brettern verriegelt sind. Eine einfache, lange chronologische Tafel stellt die Entwicklung des Krieges von 1938 bis 1945 überblicksartig dar, die ausgestellten Exponate, Grafiken und Ausschnitte sind auf dem Tablet wieder in knappen Sätzen erläutert. Diese Tafel setzt sich zusammen aus historischen Fotografien, Zeitungsausschnitten, Propaganda- und Kartenmaterial sowie Überschriften aus Zeitungen verschiedener europäischen Länder, die zugleich unterschiedliche Sichtweisen auf die Geschehnisse darstellen. Die Chronologie beginnt mit dem Anschluss Österreichs, dem das Münchner Abkommen und darauf die Zerschlagung der Tschechoslowakei folgen. Daran schließen sich die Darstellung des Hitler-Stalin-Paktes und des Kriegsbeginns an, bei der auch die Kooperation Deutschlands und der Sowjetunion mit einer Karikatur angedeutet und die sowjetische Aggression gegen Finnland gezeigt wird. Über die verschiedenen Wendepunkte des Krieges kommt die Übersicht schließlich zu den alliierten Verhandlungen der Nachkriegszeit, die erneut mit einer historischen Karikatur bebildert sind, in der Stalin die Westalliierten über den Tisch zieht oder zumindest eine besondere Gier an den Tag legt. Als Kriegsende wird der 08-09. Mai 1945 genannt und im Begleittext die unterschiedliche Bewertung dieses Datums beschrieben: »[...] the war ended at different times in different parts of Europe. The end of the war was also experienced differently. For some it was a true liberation; for others it meant the beginning of another occupation, further persecutions and civil war."

Unter dem Titel »The Harvest of Destruction« folgen diesem Ausstellungsteil zwei weitere Bereiche. Eine längliche Vitrine mit Objekten, Fotoreproduktionen, Zeitschriften, Orden etc. diskutiert Kollaboration, Kriegsverbrechen, Bombenkrieg, die Verfolgung der Juden (dargestellt durch verschiedene >Judenstern-Aufnäher) und nationalsozialistische Europapropaganda. In dieser äußerst dichten Hängung werden auch Fotografien von diversen deutschen Kriegsverbrechen in verschiedenen Ländern gezeigt, so die Exekution von Polen durch deutsche Polizisten 1940. Anhand eines sowjetischen, antipolnischen Propagandaplakates wird das Katyń-Massaker mit über 21.000 toten polnischen Polizei- und Armeeoffizieren dargestellt. Mit Exponaten wie einer Ausgabe des Heftes "Der Untermensch« sollen der Versuch der >rassischen Neuordnung« Europas durch das nationalsozialistische Deutschland und die ethnischen Vertreibungen durch Deutsche und Sowjets besprochen werden:

»Mass expulsions and deportation under Nazi and Soviet rule were a common war experience for people in the East. The Soviets used deportation to destroy potential opponents and presumed enemies of their system. In contrast, the Nazis expelled millions of people from their homes in order to replace them with ethnic Cermans and reorganize Eastern Europe along racial lines. Some German allies and puppet states also conducted deportations. Jews were deported to ghettos and sent to concentration camps together with other groups defined as ssubhuman«."

Mehrere Bilder zeigen die deutsche >Besiedlung polnischer Gebiete ebenso wie die Vertreibung polnischer Zivilisten aus diesen. Weitere Aufnahmen illustrieren die Deportation von Slowenen aus dem deutschen Machtbereich oder die von Serben aus Kroatien. Eine Fotografie stellt die Vertreibung polnischer Zivilisten nach der Niederschlagung des Warschauer Aufstandes dar, ein weiteres eindrückliches Exponat sind die selbst 
angefertigten Stiefel eines nach Sibirien deportierten Polen. ${ }^{532}$ Der Beginn des systematischen Bombenkrieges durch NS-Deutschland gegen Städte wird als »a practice that the Allies would also later use « diskutiert. Diese Praxis endete mit dem Atombombenabwurf auf Hiroshima und Nagasaki als »the ultimate horror of bombing strategy und wird mit geschmolzenen Münzen aus Hiroshima illustriert. Die Bombardierung Warschaus im September 1939 ist mit einer Fotografie präsent. Verschiedene Widerstandsbewegungen werden als heterogene Phänomene knapp diskutiert, »varying from largescale military encounters in Greece, Poland, Yugoslavia and the Soviet Union to civil resistance elsewhere«. Der Vitrine gegenüber hängen mehrere Leinwände, auf denen historische Aufnahmen von Bombardierungen und zerstörten Städten gezeigt werden.

Der letzte, besonders dunkel gehaltene Raum stellt die gewaltigen Verluste und Kriegsfolgen anhand individueller Objekte dar, die in die Öffnungen einer schwarzen Vitrine eingelassen sind. Im A-Text heißt es:

»An estimated 60 million people died in World War II, nearly two thirds of them civilians. Numbers alone, however, fail to convey the full extent of the personal tragedies involved or the catastrophic impact of these events on various groups of people. The objects assembled here tell the human story behind these events and challenge us all to consider how people come to terms with trauma and loss on such a scale.«

Die ersten beiden Objekte in einer der kleinen Öffnungen sind eine Fotografie von aus Polen vertriebenen Deutschen sowie ein einfacher Kleiderbügel, den ein vormaliger Bewohner Stettins 1945 mitnahm. Auch wenn hier deutsche Ausstellungsstücke verwendet werden, geht es in dem Objekttext unter dem Titel »German expellees from Poland« doch um das allgemeine Phänomen: "There were more than 40 million refugees in Europe at the end of the war, with forced migration primarily affecting civilians. This simple clothes hanger is testament to the displacement of a person who was forced to leave the former German city of Stettin, which in 1945 became the Polish city of Szczecin.«

Die weiteren Vitrinen zeigen das Schicksal der Evakuierten am Beispiel der Kinderlandverschickungen, die sowjetischen Deportationen, ${ }^{533}$ Zwangsarbeit im Deutschen Reich, Hunger und Hungersterben in Europa, ${ }^{534}$ nochmals den Bombenkrieg, ${ }^{535}$ das deutsche Konzentrationslagerwesen, ${ }^{536}$ die Kriegsgefangenschaft mit sehr unterschiedlichen Überlebenschancen, die brutale Partisanenbekämpfung, ${ }^{537}$ Kriegsverbrechen sowie Gewalt am Ende des Krieges gegen vermeintliche und tatsächliche Kollaborateure. ${ }^{538}$ Die Darstellung schließt mit dem Schicksal der displaced persons, repräsentiert durch die Fotografie einer jungen, gut gekleideten, optimistisch

532 Eine Leihgabe des Museums des Zweiten Weltkrieges in Danzig.

533 »Millions of people were affected by forced internal migrations in the Soviet Union under Stalin's regime during the war«, hier am Beispiel eines lettischen Deportierten.

534 Hier am Beispiel der Niederlande 1944/45.

535 Hier die Fotografie eines zivilen Luftschutzraumes in London.

536 »Millions of people were enslaved, starved, tortured and killed in the 1200 camps run by the Nazis across occupied Europe."

537 Hier die Erhängung einer vermeintlichen weißrussischen Partisanin durch deutsche Kräfte.

538 »At the end of the war large-scale executions without trial and spontaneous outbursts of violence, often against collaborators, were common«, hier am Beispiel eines Massengrabes mit Opfern der »Yugoslav Army«. 
schauenden Polin, die ein DP-Lager verlässt sowie einem Teddybären aus dem Besitz eines lettischen Mädchens, das mehrere DP-Lager durchlief.

Der gesamte Ausstellungsbereich endet mit zwei sich widersprechenden Zitaten, die sich auf den Umgang mit der Kriegsvergangenheit beziehen. Der erste Gedanke ist von Winston Churchill von 1946: »There must be [...] a blessed act of oblivion. We must all turn our backs upon the horrors of the past. We must look to the future.«Dem gegenüber steht eine Aussage von Elie Wiesel von 1986: »... if anything can, it is memory that will save humanity. For me, hope without memory is like memory without hope.«

Diesen dunklen, verstörend wirkenden Bereich verlässt der Besucher und befindet sich wieder im lichtdurchfluteten Innenbereich des Gebäudes, wo der Ausstellungsteil »Rebuilding a Divided Continent« beginnt. In einer langgezogenen, leicht konkaven Vitrine werden vor dem Hintergrund einer vollständig zerstörten Stadt das politische Kriegsende sowie Not und Hilfe dargestellt. Die internationalen Konsequenzen des Krieges für Europa diskutiert der einleitende Text:

»[...] The Soviet Union's decisive participation in the war against Nazi Germany led to its emergence as a new world power. Pre-war Europe lost its former dominance to the new superpowers. The Allied leaders met at Yalta in the Crimea and Potsdam in Cermany to discuss Europe's future. The outcome of these meetings had long-term consequences for Eastern Europe and resulted in Soviet control of half the continent."

In dieser Vitrine findet sich an erster Stelle die ikonische Fotografie des Potsdamer Abkommens und abermals eine Karikatur von Stalin, Truman und Churchill, in der diese eine neue Europakarte zusammenpuzzeln (»Trouble with some of the pieces«). In der Objektbeschreibung heißt es »Borders were redrawn and whole population groups were moved by force. The Western Allies accepted the westward shift of Polish borders and the Soviet Union's control of the Baltic states. Other border changes were made in Italy, Bulgaria, Romania, Hungary and Czechoslovakia. Germany and Austria were divided into occupation zones«. Daneben befinden sich das viersprachige Titelblatt des "Amtsblatt des Kontrollrats in Deutschland« sowie eine Schreibhilfe, die während der Potsdamer Konferenz genutzt wurde und in deren Begleittext auf das Auseinandergehen der alliierten Kriegskoalition eingegangen wird:

»Although the Allied leaders reached common agreement on decisions with long-term consequences for Europe at Yalta and Potsdam, their relations had deteriorated significantly by the time of the Potsdam Conference. They disagreed especially about the right of Eastern European countries to hold free elections, and concessions were granted to the Soviet Union, allowing it to assert its sphere of influence.«

Leicht mittig sind historische Fahnen der vier Siegermächte positioniert, daneben sind Care-Pakete, Rationierungskarten, eine in eine Flasche umgewandelte Gasmaske, improvisiert hergestellte (Kriegs-)Spielzeuge und eine Kaffeemühle sowie ein Fragment des zerstörten Warschauer Krasiński-Palastes ausgestellt.

Im nächsten Ausstellungsbereich sind an einem langen Halbrondell zwei große Europakarten mit vorgelagerten Vitrinen zu sehen. Auf der ersten ist das geteilte Europa mit historischen Parteimitgliedsausweisen aus verschiedenen Ländern dargestellt, 
stellvertretend für die politische Teilung des Kontinents sowie die westeuropäische Parteienentwicklung. Im Einführungstext erfährt der Besucher unter anderem:

»Countries across Europe faced the immense task of rebuilding their political structures at the end of the war, sometimes within new borders decided on by the Allies. $[\ldots] \ll$

Zur zweiten Karte der Migration und Zwangsmigration am Ende des Krieges heißt es:

»An estimated 20 million refugees and displaced persons were on the move across Europe in 1945 as a result of flight or mass expulsion. The Allied leadership believed that forced expulsions were the only way to ensure a peaceful post-war continent. Almost all areas of Central, Eastern and South-Eastern Europe were affected by mass movements and resettlements."

Auf der großen Übersichtskarte Europas sind die Migrationsbewegungen angegeben und je nach Größenordnung die Pfeile und Kreise dicker oder dünner gefasst. Neben der >Verschiebung < der Deutschen aus den verschiedenen osteuropäischen Staaten werden die Deportationen in die Sowjetunion, Fluchtbewegungen aus dem Baltikum, die Zwangsaussiedlung der Polen aus den kresy sowie die Ansiedlung der Polen in den ehemaligen deutschen Ostprovinzen grafisch dargestellt. Die Nachkriegsmigrationen in der Tschechoslowakei werden ebenso visualisiert, inklusive der etwa 1,9 Millionen Umsiedler in die ehemaligen deutschen Siedlungsgebiete sowie die Ausweisung der Ungarn. Die Karte zeigt auch die jugoslawischen Migrationsbewegungen, darunter die Zwangsaussiedlung der Italiener aus Istrien sowie die griechischen Bürgerkriegsflüchtlinge.

In der Vitrine vor den Karten ist ein großes Plakat des Kindersuchdienstes des Roten Kreuzes ausgestellt, daneben befinden sich ein »N«-Aufnäher sowie eine »Němec«Armbinde - beides Originale aus der Tschechoslowakei. Neben diesen sind ein Schlüsselbund sowie ein polnischer Ausweisungsbefehl für die deutsche Bevölkerung vom Juni 1945 mit einer detaillierten Planung sowie konkreten Anweisungen zu sehen. Ein weiteres Exponat ist ein Inventarverzeichnis [Seznam inventáře], in dem die Wohnungseinrichtung der aus der Tschechoslowakei auszuweisenden Familie Stowasser aufgelistet ist. Ebenso ist der Brief eines Ungarn ausgestellt, der aus der ČSR ausgewiesen wurde und der die erlittenen Verluste beschreibt. Neben diesem befindet sich ein Dokument, das die "Reslowakisierung« eines Ungarn und das damit verbundene Recht auf den Verbleib in der Heimat darstellt. Weitere Schriftstücke sind das Gedicht eines Ungarn über die Vertreibung sowie der Lagerausweis einer Person, die die Reslowakisierung verweigert hat. Im Begleittext zu den Němec-Identifizierungstextilien heißt es in Hinblick auf den ethnisch homogenen Nationalstaat:

»Populations were identified and expelled on the basis of their ethnicity. The aim was to create a Europe of nation states that were more ethnically similar than ever before. Many of those expelled were only given a few minutes to pack. Some were allowed to remain under forced assimilation policies."

Der Exponatreihe schließt sich unmittelbar die Darstellung der juristischen Verfolgung der NS-Verbrecher, Faschisten und Kollaborateure an. Diese wird als historisch einma- 
lig vorgestellt und die umfassende Weiterentwicklung der Menschenrechte im internationalen Recht mit der an erster Stelle kommenden UN Menschenrechtsdeklaration als deren unmittelbare Auswirkung betrachtet.

Nach dem Verlassen dieses Bereichs betritt der Besucher den Ausstellungsabschnitt zum Kalten Krieg, der in Form eines längeren Weges verläuft. Zur Linken werden die Entwicklung der USA und des westlichen Bündnisses anhand von Propaganda, Waffentechnik, Wirtschaftssystem (»Coca Cola«) und ikonischen Filmaufnahmen gezeigt, auf der rechten Seite, gewissermaßen gespiegelt, werden die Sowjetunion und der kommunistisch beherrschte Weltteil präsentiert. In der Mitte dieser Raumkonstellation befindet sich eine Eingangsstele mit einer französischen Graphik, welche die »les états.unis. d'EUROPE« in Form eines Mannes zeigt, der sich zwischen den beiden Machtblöcken selbstbewusst Raum verschafft. Dieser folgen verschiedene blau getönte, mit dem europäischen Sternenkranz sowie Jahreszahlen der europäischen Integration versehene Stelen, die den Besucher von nun an bis zum letzten Teil der Ausstellung begleiten. In diesem Bereich werden Themen wie Dekolonisation, Militärpakte und wechselseitige Propaganda diskutiert sowie in jeweils fünf westlichen und fünf östlichen »Hotspots« des Kalten Krieges gezeigt, von denen einer der Prager Frühling ist. Die europäische Integrationsgeschichte wird schrittweise durch die auf den Mittelstelen dargestellten entscheidenden Konferenzen und Verträge erzählt.

Nach Verlassen dieses Raumes steht der Besucher einer auffälligen Inszenierung gegenüber, in der in Form bühnenbildnerisch gefasster Architektur- und Werkzeugformen die »Architekten Europas« vorgestellt werden. So befinden sich in dieser Installation Büsten von Adenauer oder Schuman, aber auch mit diesen Personen assoziierte Gegenstände.

Im folgenden Ausstellungselement ist der Besucher eingeladen, sich auf typische 1950er-Jahre-Cocktailsessel zu setzen und der berühmten »Küchen-Diskussion« von Richard Nixon und Nikita Chruschtschow auf einem scheinbar alten Fernsehgerät zu folgen. Mit diesem Element beginnt das Ausstellungskapitel »Creating Social Security«, in dem der unterschiedliche Aufbau des Wohlfahrtsstaates ebenso wie die als moralisch fragwürdig problematisierte Integration der Diktaturen Portugals und Spaniens in die westliche Verteidigungsallianz, der griechische Bürgerkrieg, die österreichische und finnische Neutralität sowie die schwedische Friedenspolitik andiskutiert werden.

Etwas abseits liegend und für sich stehend, folgt der der Erinnerung an die Shoa gewidmete Ausstellungsraum. Auf der linken Seite befinden sich hier Zitate dreier deutscher und österreichischer Politiker, die sich dem Erbe des Nationalsozialismus früh kritisch stellten (Konrad Adenauer, Walter Ulbricht, Franz Vranitzky) und denen drei Zitate des polnischen Präsidenten Aleksander Kwaśniewski, des französischen Präsidenten Jacques Chirac und des ukrainischen Präsidenten Wiktor Juschtschenko gegenübergestellt sind. Kwaśniewski bittet im Namen des polnischen Volkes um Vergebung für die Verbrechen, die in Jedwabne geschahen, Chirac bedauert und verurteilt französische Beteiligungen am Holocaust und der ukrainische Präsident zieht Parallelen zwischen dem Schicksal der Juden und dem des ukrainischen Volkes, welches unter dem stalinistischen Terror und Hungersnöten sowie ebenso unter einer Negierung seiner Kultur und Sprache habe leiden müssen. 
Im Einführungstext wird das lange Verdrängen der Shoa durch die europäischen Gesellschaften hervorgehoben, das auch durch den Kalten Krieg befördert wurde. Positiv erscheinen hier die vergleichsweise frühe deutsche justizielle Aufarbeitung und die Entwicklung einer selbstkritischen Erinnerungskultur. Spätestens nach Ende des Kalten Krieges ließen die Erinnerung und Anerkennung als exzeptionelles Menschheitsverbrechen die Shoa zu einem »core of discussions about a European memory« werden. Unterhalb der Zitate werden jeweils die verschiedenen Aufarbeitungskulturen vorgestellt, unter denen sich als ein Ausstellungsgegenstand das 2001 erschienene Buch von Jan T. Gross über das Jedwabne-Pogrom befindet, zu dem es heißt: »It was not until 60 years later that heated debate about the Polish role as wartime victims or perpetrators of violence was sparked by books such as >Neighbours [...] by Jan T. Gross, published in 2001."

An der Raumwand zwischen den beiden Vitrinen hängt der Mantel eines Holocaustüberlebenden, in den sein Sohn, ein Künstler, Bilder und Erinnerungen der Kriegserfahrungen des Vaters eingestickt hat und der so zu einem Symbol wird: »The now faded and weather worn garment evokes a sense of the need to protect and preserve the memories of Shoah survivors - never allowing them simply to fade into oblivion. N Neben diesem Mantel ist ein Zitat von Tony Judt zu lesen, das die Zentralität und Bedeutung der Holocausterinnerung unterstreicht: »The recovered memory of Europe's dead Jews has become the very definition and guarantee of the continent's restored humanity."

Nach dem Verlassen dieses dunkel gehaltenen Raumes befindet sich der Besucher erneut in dem Ausstellungsteil, der die sich entwickelnde Wohlstandsgesellschaft zeigt und mit warmen Farben und freundlicher Beleuchtung eine Wohnzimmeratmosphäre herstellt, in dessen Mitte man sich an einen Tisch setzen kann. Die moderne Konsumgesellschaft des Wohlfahrtsstaates wird hier bunt und umfassend gezeigt: Urbanisierung, sozialer Wohnungsbau, moderne Möblierung, Ausstattung mit Küchengeräten und anderen Hilfen im Haushalt, die Expansion von Gesundheits- und Bildungswesen, Urlaub, Freizeit. Ein Bild europäischer Vielfalt ebenso wie die Darstellung der unterschiedlichen Bildungssysteme liefert eine Wand mit Schulklassenfotografien aus ganz Europa, für die alle zugehörigen Informationen einzeln auf dem Tablet abgerufen werden können. ${ }^{539}$ Der Ausstellungsbereich wird flankiert durch die schon bekannten Europastelen, die die weitere Entwicklung und Erweiterung um neue Mitgliedsstaaten der Europäischen Wirtschaftsgemeinschaft und den besonderen Status der deutschfranzösischen Versöhnung als Motor dieser Entwicklung darstellen.

Der Präsentation dieser vermeintlichen Überflussgesellschaft und der einer positiven Zukunft entgegengehenden politischen Gemeinschaft folgen in der Ausstellung mit der Ölkrise von 1973 die »Shattering Certainties (1970s - today)«. Auch dieser Teil wird wieder von Licht- und Schattenseiten gefasst: Der Deindustrialisierung, verbunden mit einer neuen sozialen Frage, werden positive Entwicklungen wie das Ende der Diktaturen in Griechenland, Portugal und Spanien und schließlich der Zusammenbruch des Ostblocks gegenübergestellt: »Riven by structural problems, communist countries entered a period of decline, and in 1989, the bicentenary of the French revolution, these regimes are brought crashing down through mostly peaceful revolutions. « Ausrangierte 
Kohleloren, Fotografien von stillgelegten Industrieanlagen, Streiks ebenso wie die politischen Auseinandersetzungen um die »Gastarbeiter« werden ebenso wie die heftigen Arbeitskämpfe im Großbritannien Margaret Thatchers gezeigt. Diesen Entwicklungen folgt die Diskussion der fortschreitenden Demokratisierung der westeuropäischen Gesellschaften mit Frauen-, Umwelt- und Friedensbewegungen sowie der schon erwähnten friedlichen Demokratisierung der verbliebenen südeuropäischen Diktaturen. Vier weitere Europastelen befinden sich in diesem Bereich, die die europäische Integration von 1975 bis 1986 dokumentieren.

Der folgende Teil ist »Communism under Pressure« gewidmet:

»The contradictions between communist propaganda and the realities of people's daily lives became increasingly obvious in the 1970 s and 1980s. Economic stagnation replaced former rapid growth, and debt crippled countries. Communist regimes boasted about their social justice standards. However, in some countries people were short of food and other basic commodities and in others supposedly ideal societies felt obliged to prevent their own citizens from trying to escape. Surveillance of private life and censorship of the press, arts and culture were all-embracing."

Dieser Bereich dokumentiert sozialistische Aufmärsche ebenso wie politische und künstlerische Oppositionsbewegungen, fortschreitende Repression und ökonomischen Verfall, wobei letzterer in Form einer leeren, nur mit sozialistischen Orden und Auszeichnungen gefüllten Ladentheke dargestellt ist. Die Solidarność-Bewegung in Polen wird ob ihrer Dimension als Massenbewegung als Ausnahmeerscheinung in der zumeist von kleineren Gruppen getragenen Opposition im Ostblock betrachtet. Eine Wand mit historischen Videoaufnahmen zeigt die verschiedenen ikonischen Bilder zum Ende des Kommunismus in den mittel- und osteuropäischen Ländern, darunter den >Runden Tisch rissene Mauer darstellt, zeigt die friedliche Revolution symbolisierende Exponate, darunter die Rede-Notizen von Günter Schabowski, die zum vorzeitigen Fall der Mauer führten. Als Beispiel für den blutigen Rückzug einer kommunistischen Diktatur ist der von Projektilen durchlöcherte Pullover eines während einer Demonstration von Sicherheitskräften erschossenen 17-Jährigen Rumänen zu sehen. Der Bereich endet mit einem stark vergrößerten Cover des Time-Magazins an der Wand, auf dem sich eine Fotografie von George Bush sen. und Michail Gorbatschow mit dem Titel »Building a new World « befindet.

Nun schließt sich ein großer Ausstellungsbereich zur europäischen Integration nach 1989 an. Der Einführungstext diskutiert die Herausforderungen der Integration der neuen Mitgliedsstaaten sowie die der Finanz- und Eurokrise nach 2008, die Probleme und Mängel der europäischen Integration aufzeigen und es wird festgestellt: »They are tests of European solidarity«. In diesem Bereich befinden sich auch umfassende Erklärtafeln zur Struktur und weiteren Themen der Europäischen Union.

Das Ausstellungselement »Re-Mapping Europe« behandelt auch die negativen Seiten der 1990er-Jahre. Im Einführungstext geht es um neuen Nationalismus und die ethnischen Säuberungen dieser Zeit: 
»The end of the Cold War didn't mean that all of Europe suddenly enjoyed peace and reconciliation. Many regions were still in turmoil. The former Yugoslavia, for example, descended into war in 1991 due to the aggressive nationalism of Serbia under President Milosevic and the moves by Slovenia and Croatia to achieve greater autonomy and, eventually, independence. Slovenian and Croatian declarations of independence led to armed conflict, which then spread to Bosnia and Herzegovina, where ethnic groups clashed. Cenocide and ethnic cleansing became horrific trademarks of a war that ended in 1995 with the Dayton Peace Accords. Serbia's President Milosevic and military leadership would use ethnic cleansing again in Kosovo.«

Eine ganze Vitrine mit Fotografien, Karten und Exponaten ist den Balkankriegen vorbehalten, eine weitere Vitrine widmet sich der deutschen Wiedervereinigung, hierzu formulierten Ängsten aus dem Ausland und dem Abzug der alliierten Streitkräfte aus Deutschland.

Eine große Videoinstallation an der Wand präsentiert verschiedene Filmaufnahmen von Demonstrationen und Krawallen zusammen mit einer Europakarte und Europafahne und klassifiziert die Epoche als unruhige Zeit. Der folgende Bereich zeigt die weitere europäische Integration auf: mit dem Vertrag von Maastricht (1992), der Einführung des Euro, den Aufnahmeprozessen der neuen EU-Mitgliedsstaaten, der Freizügigkeit, dem Erasmus-Programm oder der EU-Förderung regionaler und sprachlicher Diversität, aber auch die Widerstände gegen die EU generell oder gegen die EU-Fiskalpolitik im Besonderen. In der Mitte des Raumes befinden sich als Installation 80.000 Seiten EU-Gesetzestexte, die für die Europäisierung und intensivierte Konvergenz der Mitgliedsstaaten, aber auch die EU-Bürokratie stehen. Eine Tischvitrine diskutiert mit einer »Frontex«-Armbinde, einer Schwimmweste, der Fotografie eines Flüchtlingsbootes und einem aus dem Mittelmeer geborgenen Kinderschuh sowie einem kurzen Film die Fluchtbewegungen nach Europa.

Im letzten Abschnitt auf dieser fünften Etage befindet sich der kleine Bereich »Shared and divided Memory«. Im Einführungstext auf dem Tablet ist zu lesen:

»Much has changed in Europe over the past 25 years since the eclipse of Communism. Archives and files, once locked away, have been opened up to reveal the experiences and memories of people which had been repressed. This resulted in a ground-breaking change in the interpretation of history. Public monuments, memorials, street names, museums, even school books have and continue to be contested sites in the process of remembering or forgetting. The question of What is European memory? ? takes on new relevance.«

Über einer Collage mit dem Titel »The victims from Khatyn and the victims from Katyń « von Yuri Leiderman, welches die sowjetischen Massaker an den Polen in Katyń mit einem deutschen Massaker in dem weißrussischen Dorf Khatyn parallelisiert, steht ein Zitat von Jorge Semprún aus dem Jahr 2005, in dem dieser eine europäische Erinnerungsgemeinschaft als Ziel ausgibt: 
»Eine der wirksamsten Möglichkeiten, der Zukunft eines vereinten Europas [...] einen Weg zu bahnen, besteht darin, [...] unser Cedächtnis, unsere bislang getrennten Erinnerungen zu einen. ${ }^{540}$

Die diesem Themenbereich zugeordneten Vitrinen und Exponate zeigen auf der einen Seite eine ironisierende >Ostalgie anhand von mit Hammer und Sichel versehenen Tragetaschen und wieder aufgelegtem DDR-Parfum, aber auch einem Europastern, der sich aus den Symbolen der verschiedenen Weltreligionen zusammensetzt. Auf der anderen Seite werden anhand von Fotografien alte, zerstörte oder veränderte und neue Denkmäler in Osteuropa als Symbole für das Erbe des Staatssozialismus sowie mit entsprechenden Akten oder Aktenklumpen die Aufarbeitung der kommunistischen Geheimdienste präsentiert.

Zum Abschluss des Ausstellungsverlaufes begibt sich der Besucher nun in die sechste Etage und damit zum letzten Oberthema "Accolades and Criticism«. Von hier aus bietet sich nochmals ein beeindruckender Blick auf das die Ausstellung durchziehende Spruchband. In diesem lichten Ausstellungsbereich unter dem Dach werden unter anderem der an die Europäische Union verliehene Friedensnobelpreis und verschiedene, anlässlich dieses Ereignisses gesammelte Memorabilien ausgestellt. Mit dem dialektischen Charakter der Ausstellung auch weiterhin einhergehend, befinden sich auf der anderen Seite der Vitrine Protesttransparente gegen die EU-Fiskalpolitik, die bei der Verleihung des Nobelpreises von Demonstranten gezeigt wurden, ebenso wie ein T-Shirt der »Vote Leave«-Kampagne im Vorfeld des britischen Referendums über den Verbleib in der Europäischen Union; auch ein Wahlzettel und Objekte der »Remain«Kampagne werden ausgestellt. Eine weitere Vitrine ist dem Thema »Work in Progress « gewidmet. Der Begleittext richtet einmal mehr eine Reihe von Fragen an den Besucher:

»Europe faces uncertain times due to problems both within the European Union and at its borders. Will the countries of the European Union grow closer together or, on the contrary, will the nation state restore lost power again? Can the European Union enlarge further? Are the borders fixed and final, or will they continue to change? [...]«

In einem großen hölzernen Sitzkreis kann der Besucher nach dem langen Ausstellungsbesuch ausruhen und über sich eine Videoinstallation bewundern, die sich künstlerisch mit Fragen des »Facing the Future« auseinandersetzt. Weitere Mitmachelemente waren zum Zeitpunkt der Visite des Autors noch nicht oder nur eingeschränkt nutzbar.

Ebenso waren die Ausstellungsbereiche "Europe as seen from abroad« und »Brussels: A Changing Capital« zum Zeitpunkt der Begehung leider noch nicht fertiggestellt. Beim ersten Element soll laut Website ein von außen gerichteter Blick auf Europa anhand außereuropäischer Objekte und Kunstwerke aus verschiedenen Epochen, die sich mit Europa oder der Präsenz von Europäern auseinandersetzen, ermöglicht werden. Der Ausstellungsteil zu Brüssel soll schließlich die Stadt als Hauptstadt Europas vorstellen. Eine Filminstallation, die Brüssel im Wandel der Zeit zeigt, war schon zu sehen..$^{51}$ 
Diese letzten Ausstellungselemente laden zur kritischen Reflexion ein, bieten dem Besucher eine Möglichkeit der Entspannung, aber auch eine Wiederverortung in der Gegenwart des heutigen Brüssel. Mit diesen Eindrücken versehen, kann er nun wieder das Treppenhaus hinabsteigen, damit noch einmal die gesamte Ausstellung an sich vorüberziehen lassen und sich im ersten Obergeschoss die Wechselausstellung ansehen.

\subsubsection{Ausstellungsanalyse}

Die Dauerausstellung des Hauses der Europäischen Geschichte erzählt auf Basis eines offenen und wechselhaften Europabegriffes und -verständnisses eine Geschichte Europas nach der Französischen Revolution. Ergänzt wird diese durch einige wenige, historisch weiter zurückreichende Elemente. Auch wenn der Nationalstaat stets ein wichtiger Referenzpunkt ist, gelingt es, historische Entwicklungen auf einer gesamteuropäischen Ebene zu diskutieren und eine bloß parallelisierende Erzählung verschiedener Nationalgeschichten zu vermeiden. Flucht und Vertreibung der Deutschen und weitere Zwangsmigrationen erscheinen wiederholt in der Ausstellung, sind jedoch nur mit Abstrichen in die Erzählung des Hauses integriert.

Auf eine Festgeschichte Europas wird verzichtet, vermeintliche europäische Triumphe wie die lange Überlegenheit im 19. Jahrhundert, das Ende des Nationalsozialismus 1945 oder der Fall der kommunistischen Diktaturen in Mittel- und Osteuropa 1989 kontextualisieren beziehungsweise relativieren die Ausstellungsmacher stets mit positiven wie negativen Aspekten. Diese Dialektik zieht sich ziemlich konsequent durch die gesamte Ausstellung, sei es beim wissenschaftlichen Fortschritt des 19. Jahrhunderts, der zugleich zu den europäischen Rassentheorien führte, oder bei der Entstehung des modernen Nationalstaates, der einerseits zumeist mit einer Demokratisierung einherging, dem andererseits aber ebenso ein exkludierendes Element innewohnt. Die institutionelle europäische Integrationsgeschichte nach 1945 wird als positiv, wenn auch nicht als fehlerfrei dargestellt. Proteste gegen die Ausrichtung der Europäischen Union und bestimmte Elemente ihrer Politik erhalten einen nicht übersehbaren Platz. Auf ein teleologisches Narrativ verzichtet die Ausstellung und endet stattdessen mit vielen Fragen anstelle einer Vorgabe, wie ein künftiges Europa aussehen sollte.

Der überwiegend kritischen Besprechung des modernen Nationalstaates folgt schließlich auch eine negative Bewertung des Strebens der slawischen Nationen nach einem solchen, der den Ausbruch des Ersten Weltkrieges beförderte. Ebenso diskutiert die Ausstellung dieses verbreitete Streben nach ethnisch homogenen Nationalstaaten als eine der Ursachen des 'griechisch-türkischen Bevölkerungsaustausches`. Uneinheitlich bleibt sie bei der Frage nach der Grundlage der Vertreibungen am Ende des Zweiten Weltkrieges: In den meisten Texten und mit den meisten Exponaten wird die Verantwortung der Alliierten unterstrichen, die diese als vermeintliche Bedingung für einen nachhaltigen Frieden durchsetzten, sowie als ein weiterer Grund die sowjetische Westexpansion. Nur punktuell wird an dieser Stelle implizit auch das Streben der osteuropäischen Staaten und Gesellschaften nach ethnischer Homogenität thematisiert.

Ethnischer Nationalismus erscheint nach der Überlagerung durch den Kalten Krieg erst wieder in Form von neuen Spannungen der 1990er Jahre bis hin zu den ethnischen 
Säuberungen und versuchten Genoziden auf dem Balkan. Zu den abschließenden Fragen der Ausstellung gehört schließlich auch, ob Nationalismus und Nationalstaat in Europa wieder eine zunehmende Bedeutung erhalten werden.

Insgesamt ist die Ausstellung von einem ansprechenden Wechselspiel aus geschickter Inszenierung, punktueller Szenografie und einem Erzählen der Geschichte über gut ausgewählte Objekte geprägt. Dies gelingt auch oder vielleicht besonders deshalb, weil die Objekte zumeist ohne jegliche Beschriftung ausgestellt und Erläuterungen ansonsten nur auf dem Tablet zu finden sind. Der Besucher kann zunächst die Objekte erkunden und zu den ihn interessierenden den Text nachlesen. Negativ gesehen kann er sich auch ohne Lektüre nur mit dem Tablet durch das Haus bewegen und sich die Geschichte vorlesen lassen. Insgesamt liegt hier ein klarer Fokus auf Einzelobjekten, die gegebenenfalls in einer Reihung das im jeweiligen Ausstellungsteil gerade diskutierte historische Phänomen anhand verschiedener Länder mit möglicherweise unterschiedlichen Nuancen darstellen, womit die Objekte auch Element der multiperspektivischen Ausrichtung der Dauerausstellung sind. Mehrfach, so zum Beispiel bei der großen Vitrine im Bereich des Zweiten Weltkrieges, begegnet dem Besucher jedoch eine sehr starke Drängung der Objekte, die schnell überfordernd sein kann, zumal man einige Zeit darauf verwenden muss, die passende Beschreibung zum jeweiligen Exponat auf dem Tablet zu finden.

Die Inszenierung der Ausstellung unterstreicht das Narrativ des jeweiligen Bereiches, ohne die Exponate in den Hintergrund treten zu lassen. Verwendet werden alle Mittel der modernen Museumsgestaltungskunst, darunter der differenzierende Einsatz von Beleuchtung und wechselnden Hintergründen sowie zumeist unterschiedlich gestaltete Vitrinen, die den Charakter des jeweiligen Ausstellungsteiles aufgreifen. Attraktiv sind die multimedialen Elemente, mit denen die Inszenierung insgesamt sehr abwechslungsreich und ansprechend geworden ist. Demgegenüber ist der Bereich zur Zwangsmigration am Ende des Krieges nur mit Kartenmaterial und einer simplen Objektvitrine sowohl ausstellungsgestalterisch als auch inhaltlich konventionell gehalten. Die Wegführung durch die Ausstellung ist punktuell nicht immer klar: Gerade bei den eher forenartigen Elementen, die zur freien Begehung einladen, gerät der Besucher leicht in Konflikt mit der chronologischen Führung des Tablets.

Die Ausstellungstexte sind auf hohem Niveau informativ, knapp und neutral gehalten; die über die Kopfhörer vorgetragenen Texte, die entweder identisch mit den im Tablet lesbaren oder leicht angepasst sind, stellen dem Besucher zudem immer wieder - nicht nur rhetorische - Fragen, die einen das Gesehene unmittelbar reflektieren lassen. Das Bemühen um eine zurückhaltende Sprache führt nur punktuell zu einer Weichzeichnung, beispielsweise bei der Darstellung des Kommunismus in der zweiten Hälfte des 20. Jahrhunderts.

Aussagen von Zeitzeugen in Form von Medienstationen werden kaum eingesetzt, so auch nicht in den für die vorliegende Arbeit relevanten Ausstellungsteilen. Eine der Ausnahmen ist ein Beispiel aus der unmittelbaren Gegenwart, bei der ein afrikanischer Flüchtling über seinen Weg über das Mittelmeer spricht. Das weiter oben diskutierte ambitionierte Besucherbild des Museumsteams wird in Teilen umgesetzt, wobei sich dem Besucher ein durchaus starkes Narrativ präsentiert, das durch das häufige Hinterfragen aber ein Stück weit relativiert wird. So kann das HEH daher mit Einschränkung 
als ein Museum gelten, das dem Besucher immer wieder auf Augenhöhe zu begegnen und zur eigenen Meinung und Positionierung anzuregen versucht, ohne dass dieser dadurch überfordert würde. Dennoch wird darauf verzichtet, die grundsätzlich positive Haltung der Ausstellungsmacher zur europäischen Integration am Anfang der Ausstellung transparent zu machen und zur Diskussion zu stellen. Trotz der vielen an den Besucher gerichteten Fragen wird schließlich nicht deutlich, »wer spricht «, es bleibt der Eindruck eines freundlichen, wenn auch nicht allwissenden, vermeintlich neutralen Erzählers. Auch Forschungskontroversen werden, anders als angekündigt und soweit der Autor das überblicken konnte, nicht als solche herausgestellt. Letzteres wird aber dadurch etwas relativiert, dass sich mehrere Ausstellungsteile mit Erinnerungsgeschichte und -konflikten befassen.

Flucht und Vertreibung der Deutschen begegnen uns an zwei Punkten der Ausstellung direkt: Zunächst finden sich im Ausstellungsbereich, in dem Schicksale des Kriegsendes vorgestellt werden, zwei Exponate des Vertreibungsgeschehens, deren Platzierung als herausgehoben bewertet werden kann. Zweitens finden sich Flucht und Vertreibung in dem eigens den Zwangsmigrationen am Ende des Krieges gewidmeten Bereich. Auf der dort befindlichen großen Karte, die diese geographisch und quantitativ zu verorten versucht, werden zum einen die verschiedenen Zwangsmigrationen am Ende des Krieges gezeigt, zum anderen die unterschiedlichen Herkunftsgebiete der deutschen Vertriebenen. Damit wird sowohl die räumliche als auch die zahlenmäßig besondere Dimension deutlich. Die diesen Bereich flankierenden Exponate repräsentieren nur die Entfernung der Deutschen und Ungarn aus der ČSR. Die Zwangsaussiedlungen der Polen aus den ehemaligen polnischen Ostgebieten und die Ansiedlung von Polen und Tschechen in den ehemaligen deutschen Gebieten ebenso wie andere Zwangsmigrationen werden auf der Karte nur mit den entsprechenden Pfeilen thematisiert. Auch wenn diese Bewegungen schon vor dem Kriegsende begannen, sind sie Teil des Ausstellungsbereiches der unmittelbaren Nachkriegszeit.

Damit folgt die Ausstellung eher einem konventionellen und deutschen Geschichtsbild der Vertreibungen, das diese primär oder ausschließlich in den Kontext des Kriegsendes und der alliierten Nachkriegsplanungen stellt. Eine Verbindung zu den dargestellten Vergeltungsaktionen in Europa gegen vormalige Kollaborateure und NS-Verbrecher mit einem »Rachemotiv« wird nicht bewusst gezogen. Vielmehr erscheinen die Vertreibungen als fragwürdige Idee der Alliierten zur nachhaltigen Konfliktlösung, als Folge stalinistischer Expansionsbestrebungen, aber auch als Wunsch der osteuropäischen Gesellschaften und Regierungen nach ethnisch homogenen Nationalstaaten. Eine Verbindung mit dem Phänomen staatlicher Massenzwangsmigrationen wird ebenso wie bei anderen in der Ausstellung aufgezeigten Vertreibungen nicht hergestellt, auch wenn mit der Thematisierung des sgriechisch-türkischen Bevölkerungsaustausches` sowie der Balkankriege in den 1990er Jahren der Bogen eines 'Jahrhunderts der Vertreibungen lung nur indirekt, indem sie das dem Nationalstaat innewohnende exklusive Element darstellt.

Der Tatsache des Zusammenlebens verschiedener ethnischer und konfessioneller Gruppen, vor allem in den Vielvölkerreichen des 19. Jahrhunderts, wird erstaunlich wenig Raum gegeben, weder wird eine Idealisierung vorgenommen noch eine etwaige 
Vorbildfunktion aufgezeigt. Dies lässt sich vermutlich auch mit dem Vermeiden einer ethnischen Geschichte Europas oder eines >Europas der Völker erklären: Für die Ausstellung existieren in erster Linie Bürger, (National-)Staaten und die Europäische Union. Die Frage deutscher Minderheiten in Europa nach dem Zweiten Weltkrieg spielt nach Einschätzung des Verfassers ebenso wenig eine Rolle wie die anderer nationaler Minderheiten, mit Ausnahme der im späteren Verlauf der Ausstellung folgenden knappen Thematisierung der Förderung von sprachlichen und regionalen Minderheiten durch die Europäische Union.

Es fällt schwer, der Ausstellung ein zentrales Narrativ zuzuschreiben. Der Besucher bewegt sich gemeinsam mit dem Erzähler ein wenig erkundend und fragend durch die Ausstellung. Flucht und Vertreibung der Deutschen sind in der Betrachtung sowohl Teil des grauenhaften Krieges und Kriegsendes als auch der für Mittel- und Osteuropa fatalen Nachkriegsordnung. Eine etwaige Notwendigkeit oder Zwangsläufigkeit der Vertreibungen wird nicht diskutiert, sondern durch den kritischen Charakter der Beschreibung der diesbezüglichen alliierten Nachkriegsplanungen eher in Frage gestellt. Wesentlich mehr ließe sich zu den Auslassungen sagen, die noch bei den Stimmen der Kritiker besprochen werden sollen. In Anbetracht der zwangsläufig minimalistischen Darstellung der nationalen Einzelthemen fällt es auch schwer, in seriöser Weise auf einzelne Fehlstellen hinzuweisen. Da dem Schicksal der deutschen Vertriebenen ein recht großer Platz zugewiesen wird, wäre aber eine Thematisierung des Lagerwesens - zum Beispiel im Zusammenhang mit dem sowjetischen Lagersystem und dem rethnischen Regime der Sowjetunion - durchaus vorstellbar.

Die europäischen Zwangsmigrationen des 20. Jahrhunderts stellen die Ausstellungsmacher in keinen unmittelbaren Kontext mit den heutigen Flucht- und Migrationsbewegungen, auch wenn diese in der Ausstellung kritisch diskutiert werden. Weder Migration noch Zwangsmigration identifiziert die Ausstellung als konstitutives Merkmal Europas, obgleich sie für sich als einzelne historische Phänomene in der jeweiligen Epoche thematisiert werden.

Viele der zu Beginn diskutierten selbsterhobenen oder an die Dauerausstellung herangetragenen Ansprüche werden dort umgesetzt. Positiv hervorzuheben ist hier unbedingt der häufig fragende Charakter der Texte oder des Erzählers. Das Narrativ, das wesentlich von seinem chronologischen Ansatz getragen wird, führt gut durch die Ausstellung. Die Bewegungsfreiheit ist für den Besucher unterschiedlich gegeben: In manchen Bereichen, wie zum Beispiel dem des Zweiten Weltkrieges, ist eine enge Wegführung angelegt, in anderen, wie zum Beispiel dem Ausbau des Wohlfahrtsstaates nach dem Zweiten Weltkrieg, kann der Besucher sich wie in einem großen Wohnzimmer frei bewegen und seinen Blick je nach Interesse ausrichten. Eine Grundfrage bleibt allerdings, wie viele Besucher sich für den für einen möglichst umfassenden Besuch notwendigen mehrstündigen Aufenthalt in der Dauerausstellung entscheiden oder nicht doch bald ins sSpazieren ' geraten. Letzteres ist verlockend, da auch die Ausstellungsszenografie das Narrativ mitträgt und das imposante Gebäude mit dem die Ausstellung durchziehenden Schriftband zum Begehen einlädt.

Wenn man schließlich die Zielgruppe des Museums als ein an Europa und der europäischen Integration interessiertes Publikum definiert, wird dieses meines Erachtens sehr gut erreicht. Besucher, die vor allem ihre Nationalgeschichte in einem europäi- 
schen Rahmen entdecken möchten, werden hingegen enttäuscht werden, da ihre Nationen nicht in jedem Themenfeld präsent sind. Zugegebenermaßen muss man allerdings konstatieren, dass die westeuropäischen Staaten der alten Europäischen Wirtschaftsgemeinschaft in der Gesamtschau ein weit größeres Gewicht haben als zum Beispiel die südeuropäischen oder auch die skandinavischen Staaten, ganz zu schweigen von den Staaten des Balkans. Was wohl wegen ihres Anteils an der europäischen Geschichte des 20. Jahrhunderts wenig verwundert, ist die als einzige fast permanent präsente deutsche Geschichte - und mit ihr die Flucht und Vertreibung der Deutschen am Ende des Zweiten Weltkrieges.

\subsubsection{Rezeption der Ausstellung}

Die Eröffnung des Hauses der Europäischen Geschichte wurde von einer internationalen Berichterstattung begleitet, die einen zumeist informativen Charakter hatte. Politische Diskussionen fanden primär in der polnischen und in geringerem Maße auch in der britischen Presse statt. Die polnische Berichterstattung wurde in anderen Ländern mit einem unterschiedlichen Ausmaß an Verständnis rezipiert.

Wie in der Einführung beschrieben, gehörte Polen im Vorfeld der Eröffnung des HEH zu den Ländern mit der umfassendsten, aber zugleich auch kritischsten Berichterstattung über das Vorhaben, was sich nach der Eröffnung auch fortsetzte. Die staatlichen und konservativen Medien gaben zumeist die schon besprochene offizielle Kritik am Haus wieder, vor allem die von Kulturminister Gliński und polnischen Europaabgeordneten der PiS-Partei.

Die Hauptkritikpunkte, die unter anderem in verschiedenen Artikeln der Rzeczpospolita oder dem öffentlich-rechtlichen Fernsehsender Telewizja Polska (TVP) erhoben wurden, stehen direkt oder indirekt mit dem weiteren Themenfeld Flucht und Vertreibung in Zusammenhang. Die nicht nur von polnischer Seite kommende Kritik bemängelte, dass das Museum eine französisch-deutsch-linksliberale Schieflage habe, wodurch in pseudo-marxistischer Manier der Nationalstaat, das Christentum und infolgedessen auch ein Teil der positiv bewerteten polnischen Nationalgeschichte diskreditiert würden. ${ }^{542}$ Schließlich sieht der Stellvertretende Direktor des Museums des Warschauer Aufstandes, Paweł Ukielski, die Befürchtungen, dass die EU unter anderem mit dem $\mathrm{HEH}$ »ähnlich wie die Sowjets als Sozialingenieure den Homo Sovieticus« eine neue »homogene Menschenmasse schaffen « wolle, als durchaus berechtigt an. ${ }^{543}$

Die Darstellung des HEH, dass der slawische Nationalismus vor dem Ersten Weltkrieg zur Destabilisierung und damit zum Fall Europas negativ beigetragen habe, trifft

542 So die Verteidigung des >christlichen Abendlandes< vor Wien 1683 und an der Weichsel 1920, das Stellen Piłsuldskis in eine Reihe mit den Zwischenkriegszeit-Diktatoren, eine verharmlosende Darstellung des Kommunismus nach 1945/1953 und die vermeintliche Geringschätzung der Rolle der Solidarność/Polens zur Niederringung des Kommunismus: »Fałszowanie historii«. TVP. 16.08.2017. Siehe auch: Platform of European Memory and Conscience; Ukielski et al.: The House of European History, 2017, S. 13.

Ukielski: Worauf können die Europäer stolz sein? FAZ. 06.11.2017. 
in Polen auf erheblichen Widerspruch. ${ }^{54}$ Noch gravierender wiegt die immer wieder geäußerte Kritik, dass deutschen Opfern des Zweiten Weltkrieges eine bedeutende Rolle zugesprochen werde. So wird unter anderem bemängelt, dass die Darstellung der Bombardierung von Städten im Zweiten Weltkrieg prominent anhand des Beispieles deutscher Städte erfolge. ${ }^{545}$ Die Zwangsmigrationen am Ende des Krieges würden ausführlich mit Bildern von deutschen Vertriebenen und einer Beschreibung der weiteren Umstände präsentiert, wohingegen für die Zwangsmigration der Polen nur das Foto einer »jungen, elegant gekleidete(n) Frau « präsentiert werde, die lächelnd ein displaced persons-Lager verlasse: "Dies ist das ganze Bild des polnischen Leidens während des Zweiten Weltkrieges «. ${ }^{546}$ In einem Beitrag in der Rzeczpospolita sieht Marek A. Cichocki die Vertriebenen im HEH als die ersten Opfer des Zweiten Weltkrieges dargestellt. ${ }^{547}$ An anderer Stelle heißt es in diesem Blatt, dass gemäß der Ausstellung das zentrale Element des Zweiten Weltkrieges schließlich die Vertreibung sei - dabei aber leider nur die Vertreibung der Deutschen bemerkt werde. ${ }^{548}$ Zudem komme hinzu, dass der kleine, der Erinnerungsgeschichte des Holocausts gewidmete Bereich fast ebenso groß sei wie der die deutschen Opfer präsentierende und damit eine unzulässige Parallelisierung nahelege. ${ }^{549}$ In diesem Zusammenhang weist ein Autor darauf hin, dass sich durch den ausgestellten Judenstern sowie die Němec-Armbinde eine solche Analogie aufdränge. ${ }^{550}$ Als eines der wenigen positiven Elemente der Ausstellung sowie als Erfolg für die osteuropäischen Länder wird die parallelisierende Darstellung von Nationalsozialismus und Stalinismus bewertet. ${ }^{551}$ In einem Interview mit der Rzeczpospolita unterstreicht Piotr Gliński die genannten Kritikpunkte und bewertet die Ausstellung als peinlich und verfälschend, ${ }^{552}$ unter anderem zeige sie nicht die »absolute Einzigartigkeit der polnischen Erfahrung des Zweiten Weltkrieges « ${ }^{533}$ und für die Darstellung der Vertreibung gelte: »Dort werden Vertriebene vor allem durch deutsche Kriegsopfer gezeigt. Die Täter werden Opfer ...«. ${ }^{554}$

544 Słojewska: Dom Historii Europejskiej: Co najbardziej grozi Europie. Rzeczpospolita. 05.09.2017. Vgl. für eine ähnliche britische Einschätzung: Marsh: Night at the Museum. Foreign Policy. 12.09.2018.

545 Cywiński: Wykastrowany homo europeicus po elektrowstrząsach, czyli jak bardzo kocham unię i dlaczego. wPolityce. 12.11.2017.

546 »To jest cały obraz polskich cierpień w czasie II wojny światowej« - Prof. Nowak o skandalicznej wystawie w Domu Europejskiej Historii. wPolityce. 17.09.2017. Diese Kritik wird auch in der Cazeta Wyborcza erhoben: Bielecki: Nowe muzeum historii europejskiej w Brukseli wywołuje ostre kontrowersje w Polsce. Gazeta Wyborcza. 24.10.2017.

$547 »[$...] niemieccy wypędzeni pierwszymi ofiarami II wojny światowej«-Cichocki: Europeizacja pamięci. Rzeczpospolita. 15.08.2017.

548 »A centralnym elementem wojny są - według autorów wystawy - wypędzenia. Sęk w tym, że zauważono wyłącznie wypędzenie Niemców.«Szułdrzyński: Jak przez Niemców zmieniłem zdanie o reparacjach. Rzeczpospolita. 08.09.2017.

549 Słojewska: Dom Historii Europejskiej: Co najbardziej grozi Europie. Rzeczpospolita. 05.09.2017.

550 Cywiński: Wykastrowany homo europeicus po elektrowstrząsach, czyli jak bardzo kocham unię $\mathrm{i}$ dlaczego. wPolityce. 12.11.2017.

551 Słojewska: Dom Historii Europejskiej: Co najbardziej grozi Europie. Rzeczpospolita. 05.09.2017.

552 »Dzieło Parlamentu Europejskiego jest zawstydzające i fałszujące historię Europy«.

553 »absolutnej wyjątkowości polskiego doświadczenia II wojny światowej«.

554 »Tam przesiedleńcy są pokazywani głównie poprzez niemieckie ofiary wojny. Sprawcy stają się ofiarami...«. Nizinkiewicz: Piotr Gliński: Lech Wałęsa to Myszka Miki wykorzystywana w walce politycznej. Rzeczpospolita. 05.09.2017. 
Neben der unzureichenden oder vermeintlich nicht vorhandenen Darstellung des polnischen Leidens im Zweiten Weltkrieg sowie der Bemühungen der Polen, Widerstand $\mathrm{zu}$ leisten, zum Beispiel in Form des Warschauer Aufstandes, konstatiert die konservative polnische Kritik schließlich in der Konsequenz eine Täter-Opfer-Umkehr des Museums, die nicht hinzunehmen sei. Fast alle Kritiker aus dieser Richtung unterstellen dem Projekt schließlich einen spezifisch deutschen Charakter, der eine deutsche Geschichtspolitik zielgerichtet umsetze, was sich anhand der bemängelten Ausstellungselemente und des deutschen Gründungsimpulses durch Hans Gert Pöttering, der Unterstützung des Vorhabens durch seinen späteren Nachfolger Martin Schulz sowie der Mitwirkung des Präsidenten des Hauses der Geschichte der Bundesrepublik Deutschland, Hans Walter Hütter, deutlich zeige. ${ }^{555}$ Włodzimierz Borodziej wird mit seinem Beitrag zum Museum als Person diskreditiert, indem man ihn als Vertreter einer »deutschen Version der Geschichte« bezeichnet. ${ }^{556}$ Das Mitglied des Europaparlaments Zbigniew Kuźmiu (PiS) spricht von einer konzertierten Aktion der deutschen Geschichtspolitik, gegen die sich die polnische Regierung wehren müsse:

»Dies wird ein obligatorischer Aufenthaltspunkt in Brüssel sein, im Europäischen Parlament. Diesen jungen Leuten wird ein solches Bild der Geschichte und der Deutschen für diese Angelegenheit vermittelt. Sie arbeiten in einer koordinierten Art und Weise in allen Foren, um tatsächlich ihre Rolle im Zweiten Weltkrieg zu verringern, sich nicht als Nation der Henker, sondern als eine Nation der Opfer zu zeigen, und das dauert seit Jahren an. ${ }^{557}$

Die Rzeczpospolita schlägt schließlich den Bogen zum Zentrum gegen Vertreibungen. Einer "parteiübergreifenden deutsche(n) Allianz« sei es gelungen, der EU die deutsche Geschichtspolitik aufzuerlegen und nun das Zentrum in anderer Form im Haus der Europäischen Geschichte zu materialisieren: „Das Unverschämte sei, die Hauptrolle der Opfer des Zweiten Weltkrieges bei den deutschen Vertriebenen zu sehen und die Verantwortung für den Holocaust durch die Deutschen mit anderen Völkern zu teilen.«Wenn dieser deutschen Geschichtspolitik nicht auf gleiche Weise, »langfristig, entscheidend, aber ohne zu schreien und unnötige Emotionen « entgegengetreten werde, seien künftige Reparationsforderungen von deutscher Seite an Polen nicht mehr

555 Vgl. z.B. das Interview mit Mira Wszelaka, der Leiterin der polnischen Reduta Dobrego Imienia Polska Liga przeciw Zniestawieniom [Polnische Liga zur Verteidigung des guten Namens und gegen Diffamierung], mit dem Sender Telewizja Republika: Dom Historii Europejskiej to niebezpieczna, niemiecka wizja historii. Telewizja Republika. 22.08.2017. Siehe ähnlich sowie für die personelle deutsche `Verwicklung«: Słojewska: Dom Historii Europejskiej: Co najbardziej grozi Europie. Rzeczpospolita. 05.09.2017.

556 Dom Historii Europejskiej to niebezpieczna, niemiecka wizja historii. Telewizja Republika. 22.08.2017.

557 »To będzie obowiązkowy punkt pobytu w Brukseli, w Parlamencie Europejskim. Tym młodym ludziom będzie przekazywać się taki obraz historii i Niemcom o to chodzi. Działają w sposób skoordynowany na wszystkich forach, aby rzeczywiście pomniejszać swoją rolę w II wojnie światowej, pokazywać się nie jako naród katów, tylko raczej naród ofiar i to trwa od lat.« - »To jest historia Europy opowiadana z perspektywy Niemiec«. TVP. 21.08.2017. 
auszuschließen: »Und niemand in der EU würde verstehen, warum wir nicht zahlen wollen. $\aleph^{58}$

Die polnische Berichterstattung über das HEH im Jahr 2017 ist nicht aus dem Kontext der weit fortgeschrittenen medialen Polarisierung des Landes herauszulösen. Diese Kritik wurde daher nicht nur in den klassischen konservativen Medien erhoben, sondern durch das staatliche Fernsehen und die regierungsamtliche Kritik deutlich verstärkt. Aber auch Stimmen aus Polen, die dem HEH etwas Positives abgewinnen möchten, sehen grundlegende Probleme in der inhaltlichen Ausrichtung des Hauses. In der $w$ Polityce heißt es zum Beispiel, dass ein positives Narrativ fehle, Dinge, die einen stolz auf Europa machen könnten. Es sei vielmehr das Gegenteil: Nicht nur bei Themen wie dem Kolonialismus stünden Fragen der Schande [wstyd] im Vordergrund. ${ }^{559}$ Ähnlich argumentierte auch Paweł Ukielski in einem Gastbeitrag in der FAZ. ${ }^{560}$ Die Autorin Katarzyna Szymańska-Borginon widerspricht den konservativen Kritikern teilweise und weist trotz einiger eigener Kritikpunkte darauf hin, dass Polen sehr wohl in der gesamten Ausstellung (positiv) vertreten sei. ${ }^{561}$

Auf dem regierungskritischen Portal OKO.press wird schließlich die konservative Kritik ins Lächerliche gezogen. Die konservativen Lektoren würden den Polen versichern, dass

»[...] das Museum die christlichen Wurzeln Europas entfernt, in der Dauerausstellung Johannes Paul II. nicht zu sehen sei und wir nicht viel über die Polen selbst erfahren. Wenn überhaupt, dann war Piłsudski ein Faschist und Polen war einer der Haupttäter des Holocaust. Am Ende haben wir gehört, dass gemäß der Ausstellung Kommunismus gut ist, die Widerstandsbewegung gegen die Nazis vor allem von Deutschen getragen wurde, und dass Nationen nutzlos sind und in Zukunft verschwinden sollen. Fazit? Indoktrination! Und der letzte Beweis dafür, dass die Europäische Union eine neomarxistische Schöpfung ist. ${ }^{562}$

558 »Najbardziej skandaliczne jest ukazywanie w głównej roli ofiar drugiej wojny niemieckich wysiedlonych i dzielenie się przez Niemców odpowiedzialnością za Holokaust z innymi narodami.« [...] »długofalowo, stanowczo, ale bez pokrzykiwania i niepotrzebnych emocji « [...] »I nikt w UE nie zrozumie, dlaczego nie chcemy płacić. « Haszczyński: Niemcy radzą sobie ze wszystkim. Rzeczpospolita. 06.09.2017.

559 In der wPolityce werden hier vernachlässigte Themen wie die der europäischen Philosophie, Kultur, Religion aber auch des Sozialstaates genannt - schließlich würde die Frage nicht beantwortet, warum Europa eine so hegemoniale Stellung weltweit erlangte: Skwieciński: „Dom Historii Europejskiej« wykuwa nowego Europejczyka. wPolityce. 05.09.2017.

560 Ukielski: Worauf können die Europäer stolz sein? FAZ. 06.11.2017.

561 Szymańska-Borginon: Dom historii czy dom ideologii? rmf24. 04.09.2017. Für eine ähnliche Einschätzung vgl. Kiwnik Pargana: Celowe pomijanie Polski? wp opinie. 15.09.2017.

$562 »[$...] że muzeum usuwa chrześcijańskie korzenie Europy, na wystawie stałej nie zobaczymy ]ana Pawła II, a i o samych Polakach nie dowiemy się zbyt wiele. Jeżeli już, to że Piłsudski był faszystą, a Polacy jednymi z głównych sprawców Holocaustu. Na koniec usłyszelibyśmy, że według wystawy komunizm jest dobry, w ruchu oporu przeciwko nazizmowi brali przede wszystkim Niemcy, a narody są do niczego i w przyszłości powinny zniknąć. Wniosek? Indoktrynacja! I ostateczny dowód na to, że Unia Europejska to twór neomarksistowski.«Szymczak: Dom Historii Europejskiej. OKO.press. 10.12.2017. 
Der Journalist Jakub Szymczak sieht in seinem nach einer ausführlichen Begehung des Hauses entstandenen Artikel mit dem sprichwörtlichen Titel »Haus der Europäischen Geschichte. Haus der Hysterie der Polnischen Rechten ${ }^{563}$ in den Argumenten der polnischen Rechten nicht nur viele inhaltliche Fehler, sondern eine bewusste Verfälschung. Zudem weist er darauf hin, dass die historische Größe des Ausstellungsgegenstandes >Europar nicht nur die Ausstellungsmacher zwangsläufig (über)fordere, sondern auch den Besucher ob der Dimension physisch und psychisch erschöpfe. Wenn die positive Darstellung der europäischen Integration Propaganda sei, dann könne dem wohl nicht widersprochen werden, aber: »Was ist die Einmischung der derzeitigen regierenden Mannschaft in das Museum des Zweiten Weltkriegs, wenn nicht Propaganda für die martyrologische, polnisch-zentrierte Version der Geschichte? ${ }^{564}$ Schließlich bilanziert Szymczak positiv: »In Brüssel wurde versucht, die moderne Geschichte aller EU-Nationen zu erzählen und nach dem Gemeinsamen zu suchen. Auf ziemlich erfolgreiche Weise, auch wenn Fehler nicht zu vermeiden sind. ${ }^{565}$ Auch in der Gazeta Wyborcza wird der Kampf der polnischen Rechten gegen die Dauerausstellung des HEH mit dem gegen das Museum des Zweiten Weltkrieges in Danzig parallelisiert; so sieht Maciej Stasiński hier die gleichen Muster der Vorwürfe bezüglich der Geringschätzung des heroischen Beitrages Polens zur europäischen Geschichte. ${ }^{566}$

Im Juli 2018 äußerte sich die Direktorin des HEH, Constanze Itzel, in einem Interview in der polnischen Presse zur Kritik. Die bemängelten Elemente der Ausstellung verteidigte sie selbstbewusst und verwies auf das Selbstverständnis des Hauses, ein Forum für solche Diskussionen sein zu wollen. Derzeit sammle und analysiere man die vielfältigen Stimmen zur Ausstellung und plane, diese für die weitere Entwicklung $\mathrm{zu}$ berücksichtigen. Das sei jedoch nicht einfach, da sich viele in den Kommentaren vertretene Standpunkte gegenseitig ausschlössen. ${ }^{567}$

Die Presse in Tschechien hat die Entstehung des HEH nicht intensiv verfolgt. ${ }^{568}$ Das Online-Magazin Echo24 diskutierte im Dezember 2017 die polnische und ostmitteleuropäische Kritik sowie die gleich noch zu besprechenden Anmerkungen des tschechischen Historikers Jakub Jareš als Vertreter der Grünen Partei Tschechiens. ${ }^{569}$

Verschiedene internationale Stimmen äußerten sich kritisch über die mangelnde und in ihren Augen geringschätzige Behandlung der christlichen Religion als eine der von ihnen als zentral angesehenen Wurzeln Europas im HEH. ${ }^{570}$ In der britischen Boulevardzeitung Daily Mail erschien im Oktober 2017 eine ausführliche Besprechung des Hauses, deren Titel bereits die Richtung vorgibt: "Why does the EU's new £47m European history museum (part funded by UK taxes) ignore Britain's great achievements

563 »Dom Historii Europejskiej. Dom Histerii Polskiej Prawicy«.

564 »Czym jest w takim razie ingerencja obecnej ekipy rządzącej w Muzeum Drugiej Wojny Światowej, jeżeli nie propagandą na rzecz martyrologicznej, polskocentrycznej wersji historii?«

565 »W Brukseli wybrano próbę opowiedzenia nowoczesnej historii wszystkich narodów unijnych, szukając tego, co wspólne. W całkiem udany sposób, choć nie wystrzegając się błędów.« Szymczak: Dom Historii Europejskiej. OKO.press. 10.12.2017.

566 Europo! Ojczyzno moja. Po co Dom Historii Europejskiej? Cazeta Wyborcza. 16.12.2017.

567 Dyr. Domu Historii Europejskiej reaguje na krytykę. wPolityce. 09.07.2018.

568 Jareš: The House of European History, 2017.

569 Dům evropských dějin v Bruselu vyděsil historiky. Echo24. 08.12.2017.

570 Huijgen: The House of European History erases religion, 2017. 
and gloss over Germany's wartime past? « Neben der Kritik an der Missachtung des britischen Beitrages zur europäischen Geschichte bemängelt der Autor, dass im HEH zu wenig Elemente gezeigt werden, auf die Europa stolz sein könne - zum Beispiel viele technische Erfindungen oder der Tag des Sieges über den Nationalsozialismus, der nicht zelebriert werde. Mehrfach bezieht er sich auf die polnische Kritik, die er als gerechtfertigt ansieht: so die Gleichsetzung von deutschen und polnischen Opfern oder die Darstellung der verschiedenen Aufarbeitungskulturen des Holocausts, in der die Deutschen gegenüber den anderen Staaten als positives Beispiel gezeigt würden. ${ }^{571}$

In einer Replik auf die von Ukielski et al. geäußerte Kritik heißt es im Dezember 2017 in der FAZ zusammenfassend, dass von diesen Kritikern letztlich »die Darstellung einer genuin anderen europäischen Identität [gefordert wird]: christlich, nationalstaatlich, antikommunistisch«. Auch wenn das in Hinblick auf die nationale Geschichte Polens verständlich sei, könne diese Darstellung kaum umgesetzt werden: »Denn eine sausgewogene Darstellung der europäischen Geschichte gibt es nicht. Kaum eine Opfergruppe wird sich `gerecht « behandelt oder vollständig repräsentiert fühlen«; darüber hinaus hielten viele der kritisierten Punkte einer genaueren Untersuchung vor Ort nicht stand. ${ }^{572}$

Ansonsten war die Berichterstattung in Deutschland nach der Eröffnung des Hauses ganz überwiegend positiv. ${ }^{573}$ Im Tagesspiegel heißt es etwas kritischer, dass Teile der Ausstellung "arg verkürzt, überinszeniert und eurozentrisch « seien und manches "unterkomplex, harmonieselig oder effekthascherisch" wirke, dennoch lohne der Besuch. ${ }^{574}$ In einem längeren Artikel in der Zeit vom Mai 2018 wird die Kritik am HEH ausführlich diskutiert und in weiten Teilen zurückgewiesen. Dennoch konstatiert der Autor, dass diese in Teilen auf tatsächliche Schwächen in der Europäischen Union insgesamt und in einigen Bereichen des HEH selbst hinweise: »[...] der EU fällt es noch immer schwer, die Erfahrungen und die Befindlichkeiten ihrer östlichen Mitglieder zu integrieren.«Ein zentrales Beispiel dafür sei die »unterspielte« Darstellung von 1989 als »Meilenstein der europäischen Integration ${ }^{575}$ Bei den deutschen Vertriebenenverbänden fand die Eröffnung des HEH bis dato noch keine Aufmerksamkeit.

Die 2011 gegründete Platform of European Memory and Conscience, die mittlerweile »55 Institutionen aus 19 Ländern Europas, den Vereinigten Staaten und Kanada vereint, die sich mit der Erinnerung an die totalitären Systeme befassen«, begleitete das $\mathrm{HEH}$ von Beginn an skeptisch. Die Plattform ist im konservativen Spektrum anzusiedeln; Gründungsmitglieder sind unter anderem das Museum des Warschauer Aufstandes und das IPN. ${ }^{576}$ Im August 2017 führte sie eine Begehung des HEH durch. ${ }^{577}$ In dem vierzehn-

571 Hardman: Why does the EU's new $£ 47 m$ European history museum (part funded by UK taxes) ignore Britain's great achievements and gloss over Germany's wartime past? Daily Mail. 14.10.2017.

572 Ingendaay: Ist die Ceschichte Europas überhaupt darstellbar? FAZ. 02.12.2017.

573 Oehlen: Haus der Europäischen Geschichte wird in Brüssel eröffnet. Kölner Stadt-Anzeiger. 05.05.2017. Weingärtner: Mut zur drastischen Reduktion. Badische Zeitung. 08.05.2017.

574 Schröder: Erzählung eines Kontinents. Der Tagesspiegel. 08.05.2017.

575 Krupa: Feiert dieses Museum den Kommunismus? Die Zeit. 03.05.2018.

576 Dr Paweł Ukielski: Potrzebny jest międzynarodowy raport o Domu Historii Europejskiej, który wykaże szereg wypaczeń i manipulacji. wPolityce. 24.10.2017.

577 Ukielski: Worauf können die Europäer stolz sein? FAZ. 06.11.2017. Vgl. für die Teilnehmerliste: Platform of European Memory and Conscience; Ukielski et al.: The House of European History, 2017, 
seitigen Papier, das unter Federführung des schon erwähnten Paweł Ukielski verfasst und am 30. Oktober 2017 veröffentlicht wurde, sind die bereits mehrfach erwähnten Kritikpunkte nochmals zusammengefasst und ergänzt. Zunächst wird die Wirkmacht des Museums als "powerful tools to shape the remembrance of people« betont, was weniger anhand kleiner Details als bezogen auf die Gesamterzählung bewertet werden müsse. ${ }^{578}$ Das Papier kritisiert die »ideological Hegelian or neo-Marxist interpretation of European history«, die die Geschichte eines europäischen Fortschritts hin zum Ideal einer klassenlosen Gesellschaft erzähle. Dieses Narrativ sei dabei keineswegs eines von vielen, sondern »The House of European History's message is everything but diverse. « ${ }^{579}$ Der Untergang des Kommunismus 1989 werde zudem weniger als Sieg, sondern als beiläufiges Ereignis dargestellt, ohne dass die Gründe für den Niedergang des Kommunismus diskutiert würden. ${ }^{580}$ Diese grundlegende ideologische Fehlstellung sei schließlich die Ursache für »All further mistakes, omissions, misinterpretations or even distortions of facts [...]. ${ }^{581}$ Die scheinbare Abgrenzung des Kommunismus vom Stalinismus in der Dauerausstellung sei zudem eine Verharmlosung, ebenso wie die vermeintlich gleichrangige Parallelisierung des Ost-West-Konfliktes nach $1945 .{ }^{582}$ Gleichermaßen bemängeln die Autoren, dass nicht nur die Shoa deutlich zu wenig Raum erhalte, sondern auch der Holodomor und der Genozid an den Sinti und Roma »completely absent « seien. ${ }^{583}$ Insgesamt werde dem Zweiten Weltkrieg zu wenig Raum gegeben und wichtige Ereignisse wie der Warschauer Aufstand ausgelassen. ${ }^{584}$ Grundsätzlich kritisieren die Autoren einen Mangel an Daten, Zahlen, Karten und Fakten in der Ausstellung, die an verschiedenen Stellen für den notwendigen Kontext sorgen könnten. ${ }^{585}$ Schließlich konstatieren sie: »However, in our opinion the extent of omissions and gaps in the exhibition exceeds by far any acceptable compromise and it also influences the message of the exhibition and its narrative line. ${ }^{886}$

Unter die Kritik fällt auch die Vorstellung bzw. aus Sicht der Autoren fragwürdige Formulierung, dass Nationalismus und slawischer Expansionismus für den Ausbruch des Ersten Weltkrieges verantwortlich seien: »It is hard to understand what »Slavic expansionism « means and what its influence on the outbreak of WWI was. $\aleph^{587}$ Sie widersprechen der ausschließlich negativen, westlich-überheblichen Darstellung des Nationalismus grundsätzlich:

»The importance of nationalism in the transition to authoritarianism or dictatorships is overrepresented. Until today, the view from the Western part of Europe includes,

S. 2. Siehe zur unklaren Unterstützung des Papieres, besonders durch die deutschen Mitglieder der PEMC: Krupa: Feiert dieses Museum den Kommunismus? Die Zeit. 03.05.2018. 
on some occasions, certain elements of patronising. The birth and development of national states in Eastern Europe has a central place in the historical identity of many nations in Eastern Europe and that has to be taken in account. ${ }^{588}$

In Bezug auf die Potsdamer Konferenz fällt den Beobachtern der Detailfehler auf, dass mit dieser entsprechend der Darstellung in der Ausstellung die deutschen Ostgebiete formell an Polen übergingen, was aber erst nach einer künftigen internationalen Friedenskonferenz der Fall sein sollte. ${ }^{589}$ Das Papier schließt mit der Forderung nach einer Neu-Konstituierung des Museums auf breiter Basis, denn das Ergebnis der Erzählung des Hauses, das auch keine gemeinsamen Werte vermittle, sei nicht tragfähig:

»As a result, visitors get an ideologically biased, chaotic narrative line with many shortcomings or even falsifications. The main idea is missing, seems to be overshadowed by the narrow-minded Marxism-rooted concept. ${ }^{590}$

Der tschechische Historiker und Grünen-Politiker Jakub Jareš begrüßt in seiner Rezension grundsätzlich den Ansatz, eine gemeinsame europäische Erinnerung zu entwickeln und zu bewerben, stellt aber einige Schwächen in der Umsetzung fest. Positiv konstatiert er einen multiperspektivischen und selbstkritischen Ansatz des Museums, eine besondere Stärke sieht er zudem in der Gegenüberstellung von Objekten aus verschiedenen Ländern, welche die für den normalen Besucher gewohnten nationalen Entwicklungsgeschichten eindrucksvoll hinterfragen. Zugleich stellt Jareš aber zur Disposition, inwieweit die vielen Kompromisse der Darstellung - beispielsweise die Gegenüberstellung von Stalinismus und Nationalsozialismus, bei gleichzeitiger Betonung des Exzeptionellen der nationalsozialistischen Verbrechen, sich tatsächlich als »a good basis for finding a common European identity« eigne. Die Anlehnung an die deutsche Traumakultur sieht er ebenfalls als nur bedingt geeignet für die Herstellung einer positiven europäischen Identität an, ebenso wie die in der Ausstellung präsentierten Werte sich zumeist in Abgrenzung zu den negativen Erfahrungen von Diktaturen in Vergangenheit und Gegenwart zeigten, "rather than a positively formulated base on which the integrated continent should rest.«Zudem konstatiert er insgesamt eine zentraleuropäische - nicht zuletzt deutsche - Perspektive des Museums:

»However, you do not have to be an [sic] historian or politician to understand that this story was clearly presented from a Central European and especially German perspective. This impression is further strengthened by the fact that the name of the museum is taken from the German Haus der Geschichte, and that from a scenographic and exhibition viewpoint, the Brussels museum reminds visitors of its forerunners in Bonn and Leipzig.«

Trotz dieser festgestellten Schwächen sieht Jareš die Existenz des HEH positiv, es sei ein Ort »that can be further refined, criticized and built on in the future. « ${ }^{591}$

588 Platform of European Memory and Conscience; Ukielski et al.: The House of European History, 2017, S. 8.

589 Ebd., S. 12.

590 Ebd., S. 14.

591 Jareš: The House of European History, 2017. 
Der deutsche Kulturwissenschaftler Stefan Krankenhagen zieht nach seinem dreistündigen Ausstellungsrundgang sowie einem Gespräch mit der Direktorin Vovk van Gaal in seiner Besprechung ein positives Fazit, denn ausstellungsgestalterisch werde eine gelungene Mischung von klassischer musealer Vermittlung von Inhalten und moderner Gestaltung mit einigen Mitmachelementen erreicht: »Die Ausstellung will buchstäblich zur Hand sein«. Dennoch verbleibe dem Exponat seine herausragende Stellung. Aus der Wechselwirkung von »ausgestellten Dingwelten« und der Erzählung von Europa als Ideengeschichte heraus werde »Raumkunst « geschaffen, durch die sich der Besucher treiben lassen kann. Schließlich gelinge ihr die mehrfache Herausforderung, zum einen Europa erfahrbar zu machen, ohne die »sinnliche Distanz einer musealen Erzählung« zu verlieren, und zum anderen nicht in eine Teleologie oder eine Aneinanderreihung von Nationalgeschichten zu verfallen. ${ }^{592}$ Positiv hebt Krankenhagen auch den dualistischen Ansatz der Ausstellung hervor: »Auf diese Weise, ganz altmodisch dialektisch und gerade deshalb so erhellend, funktioniert das gesamte Narrativ der Ausstellungsmacher. Keine Leistung Europas, die nicht missbraucht wurde, kein technischer Fortschritt ohne Kolonialismus, keine Gewaltenteilung ohne staatlichen Terror. « ${ }^{593}$

\subsubsection{Zusammenführende Betrachtung}

Die Ausstellungsmacher haben in der von ihnen angestrebten reflektierten Weise den politischen Gründungsimpuls umgesetzt, einen gemeinsamen europäischen Ort der Erinnerung zu schaffen. Dies zeigt sich beispielhaft im Eingangsbereich der Dauerausstellung, in dem nicht nur eine offene, fragende Europadefinition gegeben wird, sondern auch in der dialektischen Anordnung der Exponate, die sich an verschiedenen Stellen weiter durch die Ausstellung zieht und Licht und Schatten der europäischen Geschichte in ihrer Verbundenheit zeigt. Das ist eine Form didaktischer Reduktion, die vereinfacht, ohne zu relativieren. Mit der in der Ausstellung mehrfach diskutierten Erinnerungsgeschichte wird nicht nur die Bedeutung der Auseinandersetzungen über die Geschichte in europäischen Gesellschaften unterstrichen, sondern auch die Zeitgebundenheit ihrer historischen Bewertungen und Betrachtungen. Dies ist ein mutiger Ansatz, der daher auch nicht ohne Grund auf Kritik stößt. Die deutsche Aufarbeitungskultur wird in der Ausstellung durchaus als ein Vorbild betrachtet, was Vertreter der Perspektive, dass Angehörige ihrer Nationen weitgehend ausschließlich Opfer und Helden waren, äußerst kritisch sehen.

Getragen wird die Ausstellung nicht nur von den Exponaten und der logischen chronologischen Struktur, sondern auch von der vorbildlichen Sprachgestaltung, der es gelingt, komplexe Sachverhalte zu vermitteln, ohne zu stark zu vereinfachen, was auch bei schwierigen Themen wie denen des Stalinismus und Nationalsozialismus funktioniert, beispielsweise bei dem Vergleich ihrer sethnischen< Deportations- und Vertreibungspolitik. Dieser informative, wenn auch fragende Ansatz verzichtet auf das Referieren komplexer Diskussionen wie die über die Wesensgleichheit von Nationalsozialismus

592 Krankenhagen: »Das andere, eigene Kap.«2017, S. 125-130.

593 Ebd., S. $127 f$. 
und Stalinismus und überlässt es dem Besucher, mögliche Zusammenhänge herzustellen.

Der Vorwurf, in der Ausstellung würden nationale Erinnerungskulturen beziehungsweise der Nationalstaat an sich diskreditiert, ist meines Erachtens unzutreffend. Es stimmt zwar, dass der Nationalstaat überwiegend kritisch betrachtet wird, aber das entspricht dem grundsätzlich kritischen Charakter der Ausstellung. Abgesehen davon erhalten die Nationalstaaten den ihrer Bedeutung angemessenen Platz. Für Nationalkonservative mag der vergleichende oder nebeneinanderstellende Ansatz, der den vermeintlich exzeptionellen Opfer- oder Heldenstatus ihrer Nation hinterfragt, beispielsweise bei den Verbrechen der Deutschen im Zweiten Weltkrieg, verstörend sein. In der Tat ist die entsprechende Vitrine durch die überbordende Vielfalt ihres Inhalts und ihre Unübersichtlichkeit unglücklich gestaltet und für Polen beispielsweise das für sie zentrale sowjetische Verbrechen der Katyń-Massaker oder die Niederschlagung des Warschauer Aufstandes nur durch leicht übersehbare Fotos oder einige Exponate unter vielen dargestellt. ${ }^{594}$ Aber auch dies entspricht dem Ansatz der Ausstellung, die Gemeinsamkeit europäischer Phänomene zu unterstreichen, und nicht gleich einer >Leistungsschau< das Exzeptionelle jeweiliger nationaler Erfahrungen auszustellen. Eine der wenigen Ausnahmen - und hier ist der Kritik zuzustimmen - ist aber in der Tat, dass sowohl die Bombardierung deutscher Städte als auch die Vertreibung der Deutschen einen hervorgehobenen Platz in der Ausstellung haben. Für die betonte Stellung der Bombardierung Dresdens mag sprechen, dass diese ein internationales Symbol der Flächenbombardierung von Städten geworden ist und bei den Zwangsmigrationen am Ende des Krieges kann man das Argument anführen, dass die deutschen Vertriebenen mit Abstand die größte betroffene Gruppe waren. Dies widerspricht aber dem Argument der Ausstellungsmacher, dass es um keine ‘Zahlenshow Hier hätte ein deutlicherer Verweis auf die verschiedenen Zwangsmigrationen am Ende des Krieges - ohne diese in irgendeiner Form zu relativieren - sowohl die $\mathrm{Zu}$ sammenhänge unterstreichen als auch der Vielfalt des Geschehens und den Kritikern gerecht werden können.

Die von einigen Kritikern unterstellte Parallelisierung von Holocaust und Vertreibung kann der Autor in der Ausstellung nicht erkennen: Es stimmt, dass das Museum den Holocaust stärker in seiner Bedeutung für die Entwicklung der europäischen Erinnerungskulturen denn als historisches Ereignis bespricht und auf die Erzählung des Holocausts als negativen Gründungsimpuls Europas verzichtet. Die Entscheidung, auf eine umfassendere Thematisierung des Holocaust zu verzichten, kann mit Recht kritisch betrachtet werden. Das Museum des Zweiten Weltkrieges in Danzig hat zudem gezeigt, dass man sich auch auf einer geringen Fläche der Bedeutung des Holocaust annähern kann. ${ }^{595}$ Ein Verweis auf die über ganz Europa verteilten Institutionen, die den Völkermord an den Juden zum Thema haben, könnte hier eine leicht zu implementierende Ergänzung sein, die zugleich die europäische Dimension des Geschehens fassen würde.

594 Die Katyń-Collage im späteren Ausstellungsteil wurde von der polnischen Kritik bisher meist nicht berücksichtigt, sie ist aber auch nicht sehr auffällig. 
Der im Bericht der Platform of European Memory and Conscience angesprochene Mangel an Zahlen, Daten, Karten und Fakten ist nicht völlig von der Hand zu weisen, auch wenn der Besucher durchaus umfassend mit Karten- und Datenmaterial versorgt wird. So erscheint der Verzicht auf klare Quantifizierungen an verschiedenen Stellen als eine vertretbare Reduktion, gerade weil das HEH ein solch breites Themenspektrum abzudecken hat. Zudem sind die von der Plattform gewünschten unbestreitbaren facts gerade in Bezug auf Zahlen zumeist gar nicht gegeben.

Die Dimension der Dauerausstellung sowie die große Menge an Informationen, die auf den Tablets abzurufen ist, lassen eine umfassende Sichtung der Ausstellung durch den durchschnittlichen Besucher als schwierig erscheinen. Er muss folglich individuelle Schwerpunkte bilden. Die Vermittlung des Ausstellungsnarrativs - der dialektische, offene, mit Licht und Schatten behaftete Weg Europas - wird meines Erachtens trotzdem über die das Narrativ ebenfalls tragende Szenografie ermöglicht.

Die wichtige Frage der Verantwortung für die Vertreibung wird an verschiedenen Stellen unterschiedlich thematisiert. Wünschenswert wäre hier gewesen, die verschiedenen genannten Ursachen - Stalins Imperialismus, alliierte Sicherheitsvorstellungen, nicht nur in Ostmitteleuropa vorhandene Wünsche nach ethnisch homogenen Nationalstaaten - klarer nebeneinander und zur Diskussion zu stellen, beispielsweise mit der Frage: »War ein gemeinsames Leben mit dem vormaligen >Herrenvolk der Deutschen noch vorstellbar? « Dies würde sich auch in den Charakter der Ausstellung fügen.

Das vom HEH verfolgte Narrativ, die negativen Aspekte des Nationalismus hervorzuheben, führt unter anderem zur Darstellung des slawischen Nationalismus als einem der Auslöser des Ersten Weltkrieges. Wahrscheinlich aber nicht intendiert ist damit, anschlussfähig an das konservative Narrativ der deutschen Vertriebenen zu sein. Auch in diesem beginnt die Erzählung mit den als aggressiv betrachteten Bestrebungen der Polen und Tschechen im 19. Jahrhundert, ihre eigene Staatlichkeit zu gewinnen und in deren Folge das Zusammenleben zu zerstören. Auch wenn dies, wie in Kapitel 3 gezeigt, ein wichtiger Teil der Geschichte ist, fehlen doch zentrale Aspekte wie die Berechtigung dieser National- und Emanzipationsbewegungen sowie Fragen des deutschen Nationalismus.

Werden bei der Frage des Nationalismus durchaus lange Linien gezogen, so wird auf eine Ideengeschichte staatlicher Zwangsmigrationen verzichtet. Diese hätten beim europäischen Siedlungskolonialismus durchaus Platz finden können. Ebenso stellt die Ausstellung keine klaren Zusammenhänge von Flucht und Vertreibung am Ende des Kriegs mit den vorherigen nationalsozialistischen und sowjetischen Zwangsmigrationen her.

Tatsächlich verbindet sich hiermit meines Erachtens die schwerwiegendste Fehlstelle: Die vom nationalsozialistischen Deutschland in Kooperation mit der Sowjetunion begonnene rethnische Neuordnung، Europas, an deren Ende Flucht und Vertreibung der Deutschen standen, die aber auch zum weitgehenden Ende des multiethnischen Osteuropa führte, wird in ihrer Bedeutung für Europa, und für Ostmitteleuropa im Besonderen, nicht ausgeführt. Dies ist besonders bedauerlich, weil damit nicht nur die Zerstörung Jahrhunderte alter Kulturgemeinschaften unterbewertet, sondern auch eine wichtige historische Grundlage für ein Verständnis aktueller politischer Entwicklungen in Ostmitteleuropa nicht genutzt wird. 
Für polnische und tschechische Besucher ist die Anschlussfähigkeit, wie unter anderem von Jareš diskutiert, durchaus stärker gegeben als für Süd- oder Nordeuropäer, dennoch bietet im Falle der Darstellung des deutschen Leidens im Zweiten Weltkrieg die Ausstellung wenig Anknüpfungspunkte an die polnischen und tschechischen Meistererzählungen, was sich auch an der Kritik zeigt. Hier fehlen Brücken, die das Thema für diese Besucher anschlussfähiger gemacht hätten. Die Integration beispielhafter multiethnischer Regionen wie Galizien, Oberschlesien oder Böhmen und Mähren in die Darstellung hätten hier Verbindungen schaffen können.

Trotz der genannten Kritikpunkte besitzt das Haus der Europäischen Geschichte alle Potenziale, ein Ort der Aushandlung über die europäische Geschichte zu werden und ist es mit den Diskussionen um seine Ausrichtung auch bereits geworden. Ein mutiges Sonderausstellungs- und Veranstaltungsprogramm könnte diesen Anspruch noch unterstreichen und diese Auseinandersetzung ermöglichen. Auch die Kritiker, deren Vorwürfe keineswegs völlig von der Hand zu weisen sind, sollten dieses Angebot annehmen und nicht in einer Fundamentalopposition verbleiben. Beide Seiten müssen im Dialog und vor allem in künftigen Projekten aufeinander zugehen. Sonst wird das Haus der Europäischen Geschichte ein weiteres Symbol für ein gespaltenes Europa werden, was die Dauerausstellung dieses Hauses nicht verdient hätte.

\subsection{Vergleich und Zusammenfassung}

Die Gründungsimpulse der in diesem Kapitel untersuchten drei Häuser in Berlin, Danzig und Brüssel, die Stiftung Flucht, Vertreibung, Versöhnung, das Museum des Zweiten Weltkrieges und das Haus der Europäischen Geschichte, liegen alle in den 2000er Jahren. Die Einrichtungen teilen die Herausforderung, verschiedene Nationalgeschichten auf einer europäischen und transnationalen Ebene zu erzählen. Sie thematisieren die Bedeutung von Nationalismus und Nationalstaat im 19. und 20. Jahrhundert, die Frage nach Verständigung und Annäherung im sich vereinigenden Europa und die der immer noch schwierigen Bewertung und Einordnung der verschiedenen Katastrophen des 20. Jahrhunderts, darunter an erster Stelle die des deutschen Völkermordes an den Juden. Die Darstellung von Flucht und Vertreibung der Deutschen war der Gründungsimpuls der SFVV und des MIIW und auch in den Planungen des HEH von Anfang an von Bedeutung. Das Gewicht dieses Komplexes für die jeweiligen Dauerausstellungen ist zwar unterschiedlich, berührt aber in Verbindung mit den eben angeführten Fragen deren Kernaussagen und fordert den selbstgestellten Anspruch der Häuser heraus.

Von den strukturellen Bedingungen her sind alle Einrichtungen als top-downInitiativen zu bezeichnen. Mit Einschränkung gilt dies für die SFVV, die von Bundesregierung und Bundestag als politischer Kompromiss iniitiert wurde. Sie ist eine Reaktion auf und ein Ergebnis der durch die vom BdV mit dem Zentrum gegen Vertreibungen erfolgreich vorgebrachte Forderung nach einem Erinnerungsort an Flucht und Vertreibung. Der Vertriebenenverband kann im Stiftungsrat auf die nun dem Deutschen Historischen Museum unterstehende SFVV weiter Einfluss nehmen, dennoch hat diese sich vom Gründungsimpuls, dem $\mathrm{ZgV}$, emanzipiert. Der politische Anlass für 
das MIIW als Antwort auf die deutschen Planungen ist auch ein Ergebnis der deutschpolnischen Streitgeschichte über Flucht und Vertreibung. Seine Initiierung durch die Regierung Tusk mit ihrem nationalliberal-patriotischen und europäischen Anspruch hat es von Beginn zu einem Angriffsobjekt der Nationalkonservativen gemacht, die einen solchen Ambivalenzen zulassenden und transnationalen Ansatz ablehnen. Das $\mathrm{HEH}$ ist eine Reaktion des Europäischen Parlamentes auf die mangelhafte Identifizierung der Bürger Europas mit den europäischen Institutionen, aber auch mit einer gemeinsamen Geschichte. Die Ausstellungsmacher sehen selbst Parallelen zu den Nationalmuseen des 19. und 20. Jahrhunderts und deren Rolle beim nation-building. Sowohl die Kuratoren als auch die politischen Auftraggeber versuchen sich davon konstruktiv $\mathrm{zu}$ distanzieren, indem sie mit einer offenen, reflektierten und multiperspektivischen Darstellung der Geschichte eine vereinheitlichende Meistererzählung vermeiden.

Strukturell sind das HEH und das MIIW mit einer Fläche ihrer Dauerausstellungen von etwa 4000 und 5000 Quadratmetern sowie einem Personalstamm von über zwanzig und über zehn Wissenschaftlichen Mitarbeitern größer als die SFVV mit etwa 1700 Quadratmetern und gegenwärtig über zehn Wissenschaftlichen Mitarbeitern (2019/2020). Die aufgrund sehr unterschiedlicher Renovierungs- oder Neubauausgaben schwer zu bemessenden Initiationskosten bewegen sich zwischen etwa 30 (SFVV), 50-70 (HEH) und 100 (MIIW) Millionen Euro. Die zu veranschlagenden laufenden jährlichen Kosten liegen bei ungefähr 5, 7 und 3 Millionen Euro. Alle Häuser mussten ihre Sammlungen noch aufbauen und sind auf Leihgaben angewiesen.

Die Dauerausstellungen dieser Häuser und die geplante Ausstellung der SFVV stehen im Fokus dieser Untersuchung. Für die Einordnung ist aber auch das übergeordnete Selbstverständnis der Institutionen wichtig, von denen sich nur das MIIW als originäres Museum versteht. Das Selbstverständnis des HEH als »Haus« steht in einer Tradition mit vergleichbaren Museumsprojekten seit den 1980er Jahren, die sich in Abgrenzung zum als sautoritär verstandenen Museum als Forum verstehen. Die Leitung der SFVV hebt den Charakter der Stiftung als Dokumentationszentrum hervor, bei dem neben der zentralen Dauerausstellung weitere Aufgaben wie die als einer Forschungseinrichtung und eines Veranstaltungsortes wichtig sind. Sowohl die SFVV als auch das MIIW besitzen Elemente eines memory museum, indem sie unter ihrem Dach auch explizite Orte der Erinnerung anbieten. ${ }^{596}$

Alle drei Institutionen erheben den Anspruch, europäische Geschichte in ihren globalen Verbindungen zu erzählen. Explizit verwahren sich die Ausstellungsmacher dagegen, eine verbindliche Meistererzählung über Europa zu schaffen oder zu befördern. Vielmehr möchten die untersuchten Einrichtungen Raum für unterschiedliche Perspektiven und Kontroversen lassen. Der zentrale Anspruch der SFVV ist die Dokumentation der europäischen Zwangsmigrationen des 20. Jahrhunderts mit einem Schwerpunkt auf Flucht und Vertreibung der Deutschen im Kontext des Zweiten Weltkrieges. Die globale Dimension dieses Phänomens soll dabei ebenso Berücksichtigung finden wie

596 Vgl. zum »Forum« und »memory museum«: Kap. 2.5, S. 7of., 75f. Als Elemente eines memory museum können bei der SFVV der geplante »Raum der Stille« und im MIIW die Stelen zur Erinnerung an die Opfer der Shoa betrachtet werden: Siehe S. 385f. und 438 
die ideengeschichtlichen Wurzeln im 19. Jahrhundert und aktuelle Flucht- und Vertreibungsbewegungen. Der ursprüngliche politische Anspruch des MIIW bestand aus zwei zusammenhängenden Aspekten: Zum einen sollte das Museum eine adäquate und international anschlussfähige polnische Antwort auf die Berliner Planungen für die SFVV sein; damit verbunden wollte es zum anderen dem polnischen, europäischen und weltweiten Publikum die besondere polnische und osteuropäische Kriegserfahrung vermitteln. Ohne Unterschiede zu negieren, deren Darstellung ja gerade einer der Gründungsimpulse in Abgrenzung zu dem vermeintlichen historisch verfälschenden egalisierenden Ansatz des $\mathrm{ZgV}$ war, sollte als verbindendes Element das Leiden der Zivilbevölkerung im Mittelpunkt stehen. Das HEH verfolgt den Anspruch, eine verbindende, aber kritische Erzählung Europas nach 1789 zu präsentieren und zu einem gemeinsamen historischen Bewusstsein beizutragen - nicht als Ersatz, sondern als Ergänzung zu den nationalen Erzählungen. Die europäische Integration soll darin als eine der Antworten auf die Katastrophen des 20. Jahrhunderts erscheinen, ohne die politisch beliebte, simplifizierende Phönix aus der Asche-Rhetorik zu verfolgen und Fehlentwicklungen auszusparen. Alle Museen haben sich implizit oder explizit einen politischen Auftrag auferlegt: Die SFVV sieht ihre Aufgabe darin, als Vermittler der historischen Konflikte und als Aufklärer über aktuelle Zwangsmigrationen zu wirken. Das MIIW versucht, in Abgrenzung zum kriegsverherrlichenden Militärmuseum eine Antikriegserzählung zu schaffen. Das HEH möchte den Weg der europäischen Integration und das mit der Europäischen Union Erreichte erklären und damit neuen europäischen Spaltungen entgegenwirken.

In Bezug auf Flucht und Vertreibung verfolgt das Konzept der SFVV den Ansatz, diese als integralen Bestandteil des von Deutschland initiierten Zweiten Weltkrieges, aber auch als Folge des im 19. Jahrhundert eskalierenden Nationalismus und des Ideals des ethnisch homogenen Nationalstaates zu erzählen. Flucht, Migration und Vertreibung werden zudem als anthropologische Konstanten betrachtet, mit denen eine fortwährende Auseinandersetzung erforderlich ist. In Abgrenzung von der SFVV folgt das MIIW einem vermeintlich gegenteiligen Ansatz, in dem Vertreibungen und gewalttätige Massenzwangsmigrationen als Strukturmerkmal totalitärer Regime definiert und damit im Wesentlichen auf die Zeit von Nationalsozialismus und Stalinismus und im engeren Sinne des Zweiten Weltkrieges beschränkt bleiben. Der Ansatz des HEH besteht darin, die verschiedenen Zwangsmigrationen nicht zusammen als ein Phänomen zu erzählen, sondern als Teil verschiedener europäischer Katastrophen oder im Fall von Flucht und Vertreibung als integralem Bestandteil des Krieges und der Nachkriegsordnung.

Ausstellungsgestalterisch verbinden alle untersuchten Ausstellungen und das Konzeptionspapier der SFVV verschiedene klassische und moderne Elemente der Darstellung. Synthetisierend werden das Exponat als Einzelobjekt oder in einer Zusammenstellung präsentiert und inszenatorische und szenografische Gestaltungsvarianten verwendet. Letztere stechen im MIIW als begehbare Stadtlandschaften oder mit dem angedachten Gerichtssaal in der SFVV hervor. Multimediaelemente spielen eine wichtige, aber keine entscheidende Rolle. Eine Ausnahme ist das für die Besichtigung der Ausstellung im $\mathrm{HEH}$ obligatorische Tablet, das aber vor allem die Funktion der Präsentation der Ausstellungstexte und die eines Audioguides erfüllt. Mit diesem kombinierten An- 
satz bewegen sich die drei Institutionen im Rahmen zeitgenössischer Geschichtsausstellungen, die die klassische Objektausstellung, die szenografische Ausstellung und die Multimediaausstellung zu verbinden suchen.

Den Anspruch, einem mündigen Besucher auf Augenhöhe zu begegnen, haben alle hier behandelten Einrichtungen in ihrer Konstituierungsphase verfolgt. Auch das Konzept der künftigen Dauerausstellung der SFVV folgt dieser Vorstellung, indem es zum Beispiel mit einer Offenlegung der gewählten Begriffe und der Sichtbarmachung der eigenen Auswahl dem Besucher eine eigene Verortung und mehrere Perspektiven anbietet. Wie sich beim HEH und dem MIIW aber gezeigt hat, finden auf dem Weg von diesem Anspruch hin zur letztendlichen Realisierung häufig erhebliche >Übersetzungsverluste statt. Der ursprünglich geplante, sehr offene Ansatz des MIIW findet sich in der realisierten Dauerausstellung nur rudimentär wieder. Auch wenn das Ausstellungsnarrativ nun stärker betont wird und nicht mit Fragezeichen versehen ist, wird dem Besucher durch eine zurückgenommene, nur gelegentlich emotional gehaltene Ausstellungsgestaltung keine Erzählung aufgedrängt. Bis dato nutzt das $\mathrm{HEH}$ den Ansatz des Dialoges mit seinen Besuchern am intensivsten dadurch, dass diese während der Führung durch die Ausstellung immer wieder mit Fragen zur Entwicklung eigener Meinungen angeregt werden. Dieser Ansatz spiegelt sich auch in der nüchtern gehaltenen Sprache im HEH und MIIW wider, die den Besucher nicht zu überwältigen versucht. Für die SFVV lässt sich dies noch nicht feststellen, aber das Konzeptpapier von 2017 deutet eine ähnliche Vorgehensweise an.

Bei der Darstellung von Flucht und Vertreibung ist das Konzept der SFVV mit Abstand am ausführlichsten, deren primärer Gegenstand dieses Thema ist. Flucht und Vertreibung sollen in ihrer regionalen und chronologischen Verschiedenheit erzählt werden und stehen nicht für sich allein, sondern werden in das lange Kriegsende und weitere Zwangsmigrationen eingeordnet. Auch das MIIW zeigt das Thema ausführlich und teilt es in Fluchtbewegung und Vertreibung auf. Die Darstellung wird hier ebenfalls durch andere Flucht- und Vertreibungsbewegungen sowie die deutschen Endphaseverbrechen gerahmt. Durch die stete Berücksichtigung der regionalen Danziger Kriegsgeschichte erhalten Flucht und Vertreibung der Deutschen in Hinblick auf die Gesamtausstellung und andere von Zwangsmigration und den damit verbundenen Schrecken wie Vergewaltigungen und Massenmorden betroffene Gruppen eine überproportionale Bedeutung. Das HEH bedient sich einer sehr klassischen Darstellung der Vertreibung mit Zahlen und Fakten und zeigt anhand einiger weniger Objekte die Erfahrung von Heimatverlust und Entrechtung.

Unterschiedlich sehen die Institutionen den Kontext und die Ursache von Flucht und Vertreibung. Das Konzept der SFVV von 2017 fokussiert stärker auf die spezifischen Bedingungen des Zweiten Weltkrieges und den vorherigen NS-Terror über Osteuropa, der die Vertreibungen erst ermöglichte, als dies vorherige Konzepte und die Planungen des ZgV mit dem Schwerpunkt auf einem `Jahrhundert der Vertreibung und der Einordnung in eine Geschichte des ethnischen Nationalismus vorgesehen hatten. Dennoch werden in dem Papier die Entwicklung des Nationalismus, das Ideal des ethnisch homogenen Nationalstaates und der polnische und tschechische Nationalismus weiterhin als Mitursachen der Vertreibung diskutiert. In der Darstellung des MIIW liegt die Entscheidung für die Vertreibungen ebenso wie bei der des $\mathrm{HEH}$ fast aus- 
schließlich bei den alliierten Siegermächten, die sich damit eine nachhaltige Friedensordnung versprachen. Beim MIIW steht dies in Widerspruch zur dort vorgenommenen Zuordnung von gewalttätigen Massenbevölkerungsverschiebungen als Sozialtechnologie ausschließlich totalitärer Regimes, denn schließlich waren an der Entscheidung zur Zwangsaussiedlung der Deutschen auch die Westalliierten beteiligt. ${ }^{597}$ Polnischer und tschechischer Nationalismus werden nur am Rande diskutiert. Im HEH wird der nach Unabhängigkeit strebende Nationalismus der sslawischen Nationen vor dem Ersten Weltkrieg mitverantwortlich für den Untergang des alten Europa gemacht - was sich einfügt in seine generell nationalismusskeptische Erzählung. Das Streben nach einem ethnisch einheitlichen Nationalstaat wird als fragwürdig betrachtet, auch wenn die sozialen Errungenschaften des modernen Nationalstaates den negativen Elementen gegenübergestellt werden. Im MIIW erscheint der Begriff des »ethnisch homogenen Nationalstaates« oder ein Synonym den Beobachtungen des Autors zufolge nicht.

Bei der Darstellung der historischen Verflechtung und Kontextualisierung von Flucht und Vertreibung bedienen sich sowohl das MIIW als auch die SFVV eines historischen Beispiels: Bei der Diskussion der Ereignisse der letzten Januartage 1945 werden die deutschen Fluchtbewegungen mit den zeitgleich und häufig in örtlicher Nähe stattfindenden Todesmärschen aus den Konzentrationslagern sowie mit weiteren Endphaseverbrechen zusammen beschrieben. Das soll keiner Relativierung des deutschen Schicksals dienen, sondern das Leiden der deutschen Zivilbevölkerung mit dem der Opfer NS-Deutschlands in eine historische Beziehung setzen. Weiter zeigen das MIIW sowie die Konzeption der SFVV anhand der >Bevölkerungsplanungen SS für die Region Zamość die Verbindung zwischen diesem deutschen Vorhaben, den Vertreibungen von Polen und der schließlichen Zwangsmigration der Deutschen auf. Als weiteres Beispiel für einen rücksichtslosen, genozidalen Krieg thematisieren beide Institutionen das deutsche Aushungern Leningrads.

Die Vorgeschichte der Deutschen in Ostmitteleuropa sowie des multiethnischen Osteuropa erhält in allen drei Einrichtungen kaum Raum. Bei der SFVV liegt das an der thematischen Beschränkung auf die Zwangsmigration, wobei die künftige Ausgestaltung abzuwarten ist. Auch beim MIIW verhindert der Fokus auf den Zweiten Weltkrieg eine intensive Auseinandersetzung mit der Vorgeschichte, da die Darstellung erst mit der Zwischenkriegszeit beginnt, in der die Minderheitenfragen bereits hochkonfrontativ waren. Das HEH verzichtet ebenfalls auf die Erzählung des multiethnischen Ostmitteleuropa, mutmaßlich, um eine ethnische Geschichte Europas zu vermeiden.

In ihrer geografischen Reichweite zeigen alle Institutionen nicht nur die europäische, sondern punktuell auch die globale Dimension der erzählten Geschichte auf. Globale wie regionale Einschübe dienen als Ausblick oder zum Verstehen des Geschehens ‘vor Ort<. Alle Ausstellungen verfolgen in ihrer Darstellung die Perspektive svon unten<, was bedeutet, dass die Ereignisgeschichte auf staatlicher und militärischer Ebene eher der Hintergrund für das Schicksal der Zivilbevölkerung ist - ohne diese lediglich als

597 Eine Erklärung dafür ist, dass Cründungsdirektor Paweł Machcewicz den in Deutschland häufig auf die alliierten Entscheidungen als Ursache für die Vertreibungen gelegten Fokus für einseitig und diese in ihrer Dimension für überbewertet hält: Vgl. Machcewicz: »Museum statt Stacheldrahtverhaue«, 2012, S. 88. 
einheitliches, passives Opfer zu betrachten. Beim HEH ist mit den vielen Elementen, die sich nicht auf den Krieg beziehen, der Horizont weiter gespannt. Bei der Erzählung der europäischen Integrationsgeschichte verlässt das $\mathrm{HEH}$ stellenweise die Perspektive >von unten

Bezüge $\mathrm{zu}$ gegenwärtigen Zwangsmigrationsbewegungen stellen direkt nur die SFVV und das HEH her. Die künftige Dauerausstellung der SFVV soll ganz bewusst auf aktuelle Fluchtbewegungen hinweisen. Auch das HEH thematisiert am Ende der Dauerausstellung das Schicksal der Bootsflüchtlinge auf dem Mittelmeer. Im Gegensatz zu den Planungen der SFVV wird aber - wie bei den meisten Themen der Ausstellung keine Querverbindung zu vergleichbaren Phänomenen in der Vergangenheit gezogen.

Die Untersuchung der Dauerausstellungen und des Konzeptionspapieres hat einige Fehl- und Leerstellen aufgezeigt. Das MIIW verzichtet, abgesehen von einem kurzen Rückgriff im Einleitungsfilm der Ausstellung, auf die Diskussion des Nationalismus als einer Mitursache des Zweiten Weltkrieges und der Vertreibungen. Beim HEH findet dies nur indirekt statt, indem Nation und Nationalismus in der Ausstellung immer wieder kritisch diskutiert werden. In den Planungen der SFVV nimmt diese Ideengeschichte der Sozialtechnologie Zwangsmigration größeren Raum ein. Die Vorgeschichte des deutschen Elementes in Ostmitteleuropa und des multiethnischen Osteuropa ist in allen drei Ausstellungen nicht oder kaum zu finden. Somit werden weder weitere Ursachen für diese Entwicklung diskutiert noch der gesamteuropäische Verlust deutlich. Kontroverse Fragen wie die des Lagerwesens und der Todeszahlen werden am ehesten im Papier der SFVV diskutiert, aber auch dort zeigt sich eher ein zurückhaltendes Vorgehen. Dies gilt bei allen Institutionen auch für die Frage der Notwendigkeit der Vertreibungen, der man im MIIW und dem HEH durch den ausschließlichen Verweis auf die alliierte Entscheidung in Potsdam aus dem Weg geht. Eine Aktualisierung der Frage auch in Hinblick darauf, was die Herausbildung ethnisch homogener Nationalstaaten nach 1945 in Ostmitteleuropa für uns heute bedeutet, zeigen weder die Ausstellungen des MIIW und des HEH noch das Papier der SFVV von 2017 auf.

Trotz dieser Defizite funktionieren die Ausstellungen des MIIW und des HEH. Ihre selbstgestellten Ansprüche konnten sie im Wesentlichen umsetzen und es wurden sehenswerte Museen geschaffen. Auch das Konzept der SFVV überzeugt. Vorbehaltlich der erfolgreichen Umsetzung ihres ambitionierten Konzeptes kann die SFVV künftig ein Verhandlungsort für Fragen von Flucht und Vertreibung werden und vielleicht doch noch eine Brücke zu den osteuropäischen Nachbarn schlagen sowie der Verständigung nach innen und außen dienen. Im MIIW sind die Ausstellungsteile zu Flucht und Vertreibung sinnvoll in die allgemein erfolgreich umgesetzte Erzählung des Krieges aus der Perspektive der Zivilbevölkerung integriert. Es zeigt das Geschehen zum Teil eindrücklich, bleibt aber eine tiefergehende Erklärung schuldig. Dies betonen Kritiker auch für andere Bereiche der Ausstellung. Das Konzept des HEH, eine vielgestaltige Geschichte Europas zu erzählen, geht mit Einschränkungen, wie einer Übergewichtung der alten EWG-Länder, ebenfalls auf. Das Besucherverständnis ist von dem des mündigen Besuchers geprägt, ohne ihn zu überfordern. Flucht und Vertreibung sind aber als Einzelthema im Gesamtnarrativ übersehbar und stehen nur in geringer Verbindung mit dem Rest der Ausstellung. 
Wie in den vorherigen Unterkapiteln gezeigt, zogen Kritiker verschiedentlich Vergleiche zwischen den hier behandelten Institutionen. Zunächst formulierte aber Karl Schlögel auf dem vorläufigen Höhepunkt der Diskussion um das Zentrum gegen Vertreibungen im Jahr 2003, dass jede Institution »vollständig« damit überfordert wäre, wenn sie "sich vornähme, eine angemessene und d.h. gerechte Darstellung zu geben, in der sich auch alle anderen wiedererkennen würden. ${ }^{598}$ Dennoch haben die hier untersuchen Einrichtungen diesen Versuch unternommen und entsprechende Ansätze erfolgreich aufgezeigt.

Ein solch europäisches Vorgehen, sei es als eine Parallelgeschichte verschiedener Nationalgeschichten oder als eine transnationale Geschichte, ist fortwährender Kritik ausgesetzt. Von konservativer polnischer Seite heißt es in Bezug auf das MIIW, das vermeintlich den Ansatz des $\mathrm{ZgV}$ übernommen habe, dass hier die »Deutschen Zutritt zum Klub der Opfer des Zweiten Weltkriegs erhielten. ${ }^{599}$ Konsequenterweise verbindet sich die Kritik am MIIW vielfach mit der am HEH. ${ }^{600}$ Nationalkonservativen sind diese Ansätze auf verschiedenen Ebenen suspekt: Sie widersprechen dem nationalen Exzeptionalismus und den für die fortlaufende gesellschaftliche Mobilisierung nötigen statischen Feindbildern. Zudem befürchten sie, dass selbstkritische Institutionen und Ausstellungen, in denen der polnische Staat oder Polen als Täter diskutiert werden, dem Ansehen des Landes in der Welt und damit auch realpolitisch schaden. Weniger heftig als in Polen wird diese Kritik auch in Tschechien geäußert, wobei man das eigene Selbstverständnis als demokratische und friedensliebende Nation infrage gestellt sieht.

Die Bewertung aller drei Institutionen spaltet sich an politischen Konfliktlinien, die auch andere gesellschaftspolitische Themen betreffen, wie beispielsweise religionspolitische Fragen. Eine Ausnahme ist bisher die SFVV, deren Planungen auch in progressiven Kreisen in Deutschland, Polen und Tschechien skeptisch verfolgt werden. Liberale Autoren bewerten das $\mathrm{HEH}$ international grundsätzlich positiv. Einen noch stärkeren Zuspruch erreichte das MIIW mit dem Team um seinen Gründungsdirektor Machcewicz als Symbol des weltoffenen, pro-europäischen und pro-westlichen Polen, das sich zeitweise erfolgreich gegen die PiS-Administration wehren konnte.

Im Falle der erfolgreichen Umsetzung des 2017 veröffentlichten Konzeptionspapieres der SFVV kann das Thema Flucht und Vertreibung mit einigen Einschränkungen anschlussfähig an die Geschichte der osteuropäischen Nachbarn erzählt und diskutiert werden. Wenn es gelingt, sich als Aushandlungsort zu positionieren, könnten nicht nur der nachbarschaftliche Diskurs wenigstens teilweise befriedet sowie auch die langjährigen innerdeutschen Auseinandersetzungen versachlicht und am historischen Gegenstand geführt werden. Mit dem Aufgreifen aktueller Flucht- und Vertreibungsbewegungen kann sie zudem auch mit dieser, die deutsche und europäische Gesellschaft

598 Schlögel: Nach der Rechthaberei, 2003, S. 33.

599 Machcewicz: »Museum statt Stacheldrahtverhaue«, 2012, S. 92. Machcewicz bezieht sich auf den Artikel von Cezary Cmyz und Piotr Semka: Gmyz; Semka: Przypominajmy światu polską historię. Rzeczpospolita. 03.11.2008.

600 Machcewicz: »Museum statt Stacheldrahtverhaue«, 2012, S. 99. 
entzweienden, Thematik einen wertvollen Beitrag in Form von Information und sachlicher Diskussion leisten - sofern sie sich nicht einseitig politisch instrumentalisieren lässt. Die SFVV wird sich zunächst auch weiterhin gegen eine erhebliche Skepsis in Deutschland, Polen und Tschechien behaupten müssen.

Das Museum des Zweiten Weltkrieges beeindruckt durch seine in vielerlei Hinsicht gelungene Erzählung des Zweiten Weltkrieges. Flucht und Vertreibung ordnen sich in der Ausstellung in die Leidensgeschichte der Zivilbevölkerung ein. Sie erhalten einen sichtbaren, jedoch keinen prominenten Platz. Mehrfach werden sie durch den NS-Terror und weitere, durch Deutschland oder die Sowjetunion verantwortete, Zwangsmigrationen kontextualisiert und gerahmt. Eine tiefergehende Erklärung folgt nicht, da die Ausstellung auf eine weitergehende Diskussion der Ursachen der Vertreibungen verzichtet. Die nationalkonservative Kritik an der Ausstellung ist in weiten Teilen ungerechtfertigt, sind doch polnisches Leiden und Heldentum permanent in der Ausstellung zu finden. Es ist auch keine ausschließlich progressive und kritisch-destruktive, sondern eine in vielerlei Hinsicht patriotische Ausstellung, welche die neue, der PiS-nahestehende Leitung seit April 2017 nun zunehmend in Richtung eines weitgehend um die eigene Nation kreisenden, heroischen Nationalmuseums verwandelt.

Beeindruckend in Dimension und Ausführung ist auch das Haus der Europäischen Geschichte. Positiv hervorzuheben ist der konsequent fragende Charakter seiner Ausstellung. Auch die dialektische Erzählung einer europäischen Geschichte nicht als Ersatz, sondern in Ergänzung zur Nationalgeschichte, gelingt. Als eine Ausnahme ist die Darstellung der Flucht und Vertreibung der Deutschen zu betrachten. Der primär der Flucht und Vertreibung der Deutschen gewidmete Ausstellungsbereich ist erstaunlich konventionell gehalten und wirkt wie ein Fremdkörper. Verstärkend kommt hinzu, dass die Phänomene von Zwangsmigration und Nationalismus in der Ausstellung nicht miteinander vernetzt sind und so das Ereignis relativ isoliert dargestellt wird. Die Begründung für die Vertreibung der Deutschen beschränkt sich auf den in der Ausstellung skeptisch gesehenen Wunsch der Alliierten, mit dieser einer nachhaltigen Friedensordnung zu zu dienen. Die nicht nur osteuropäische Kritik an der Präsentation von Flucht und Vertreibung im HEH ist daher durchaus gerechtfertigt, ist doch neben der Frage der Proportionalität diese Darstellung auch wenig anschlussfähig an die Erzählung in Polen und Tschechien. Dabei geht es nicht um ein unkritisches Zugeständnis gegenüber nationalpolnischen oder nationaltschechischen Narrativen, sondern um die Unterstreichung der Bedeutung der `ethnischen Neuordnung ( Osteuropas vor, während und nach dem Zweiten Weltkrieg für die europäische Geschichte, die diese Länder aus heutiger Sicht vielleicht noch stärker betrifft als Deutschland selbst.

Bei allen Ausstellungen wäre mehr Mut zu Kontroversen zu wünschen. Christopher Whitehead, Susannah Eckersley et al. diskutieren in ihrer Untersuchung europäischer Museen, dass sich die untersuchten Ausstellungen letztlich zumeist in einem akademisch-kosmopolitischen mainstream bewegen, der viele politische Konflikte und verbreitete Perspektiven auf die Geschichte ausblendet oder geringschätzig betrachtet. Um das Ziel des wirklich »umfassenden Verstehens « zu erreichen, müsste aber diese Vielfalt der Perspektiven, auch beispielsweise der nationalistischen, »historisierend und 
kontextualisierend « untersucht und diskutiert werden. ${ }^{601}$ Diesem Plädoyer ist auch in Hinblick auf die hier untersuchten Häuser zu folgen, gerade um die kontrovers besprochene und in Polen und Tschechien noch von einer großen Anzahl der Bürger bejahte Frage nach der Notwendigkeit der Vertreibungen - die auch viel über das heutige Verständnis von Nation, Nationalstaat und des Bildes von Europa aussagt - zu behandeln.

601 Whitehead; Eckersley et al.: Place, Identity and Migraton and European Museums, 2016, S. 46, 52. 


\section{Zusammenfassung und abschließende Betrachtungen}

Für eine wirksame Verständigung zwischen vormals verfeindeten und zerrissenen Staaten und Gesellschaften ist kontinuierliche Arbeit notwendig. Das gilt besonders für die durch den deutschen Angriffskrieg, Besatzungsterror, Völkermord und schließlich Flucht und Vertreibung zunächst scheinbar für immer geschiedenen Länder Deutschland, Polen und Tschechien. Oberflächliche Gesten der Versöhnung helfen der Verständigung ebenso wenig wie Versuche, die Vergangenheit einfach >vergangen sein zu lassen. Grundlage einer nachhaltigen Versöhnung ist die Bereitschaft, sich umfassende Kenntnisse sowohl der eigenen Geschichte als auch die der Nachbarn anzueignen. ${ }^{1}$ Die in der vorliegenden Studie untersuchten Museen, das Schlesische Museum zu Görlitz, das Muzeum Śląskie in Kattowitz/Katowice, das geplante Sudetendeutsche Museum in München, das Museum der deutschsprachigen Bewöhner Böhmens in Aussig an der Elbe/Ústí nad Labem, die Stiftung Flucht, Vertreibung, Versöhnung in Berlin, das Museum des Zweiten Weltkrieges in Danzig und das Haus der Europäischen Geschichte in Brüssel, können alle auf unterschiedliche Weise einen Beitrag zur Verständigung leisten. Sie zeigen verschiedene Erfahrungen und Perspektiven und helfen damit, einander zu verstehen.

Ziel einer solchen Verständigung ist es gleichwohl nicht, unterschiedliche Erfahrungen und Positionen zu vereinheitlichen. Es geht um einen ehrlichen Austausch, der ermöglicht, dass die Vergangenheit die Beziehungen zwischen den Ländern und innerhalb der Länder in Gegenwart und Zukunft nicht mehr negativ beeinflusst. Ein früher Wegbereiter der deutsch-polnischen Versöhnung, Stanisław Stomma, verfolgte den Gedanken, dass »die Beziehungen zwischen zwei Ländern dann als >normak zu definieren [seien], >wenn sich diese mit den Problemen von morgen befassen $\longleftarrow \aleph^{2}$ Dem ist in Anbetracht der gegenwärtigen politischen Situation in Europa zuzustimmen. Auch die Museen können neben der oben angeführten historischen Verständigungsarbeit mit Linien bis zu den Herausforderungen der Gegenwart dazu beitragen. Dabei muss aber die Gratwanderung gemeistert werden, keinem politisch genehmen Präsentismus zu 
unterliegen und auch bei Gegenwartsfragen konsequent multiperspektivisch zu operieren.

Eine Erinnerungskultur der Geschichte der Deutschen in Ostmitteleuropa sollte sich nicht auf die Vertreibungen beschränken, sondern ohne Verklärung auch die jahrhundertelange Geschichte eines überwiegend friedlichen Zusammenlebens in den Blick nehmen. ${ }^{3}$ Wie schon in Kapitel 1 angesprochen, kann gerade eine nicht idealisierte Geschichte des multiethnischen und multikonfessionellen Europa Anregungen für die Gestaltung unserer Gegenwart liefern. Diese Geschichte zeigt dabei ebenso erfolgreiche Ausgleiche ethnischer und konfessioneller Konflikte wie Wege zu scheinbar unüberwindbaren Verhärtungen auf. Antworten auf diese Fragen, wie die Gestaltungsversuche der Habsburgermonarchie, können in ihren historischen Bedingungen kein Vorbild, wohl aber ein lehrreiches Beispiel sein. ${ }^{4}$

Die vorliegende Studie untersucht die Entwicklung der Erinnerung an Flucht und Vertreibung der Deutschen am Ende des Zweiten Weltkrieges in Deutschland, Polen und Tschechien und ihre Materialisierung in den sieben genannten Museumsprojekten, die alle nach der Jahrtausendwende entstanden sind. Die Auseinandersetzungen um die historische Einordnung von Flucht und Vertreibung haben sich innerhalb der genannten Länder und zwischen den Ländern seitdem fast ausschließlich auf diese Vorhaben bezogen. Deren erhebliche geschichtspolitische Bedeutung zeigt sich sowohl durch die zeitweise die Schlagzeilen der nationalen Nachrichten füllenden Debatten als auch in dem großen staatlichen Aufwand, der für die Schaffung der Museen geleistet wurde.

In Kapitel 1 folgte nach der Einführung in den Gegenstand und einer Diskussion der Thesen eine Erörterung der in der Arbeit verwendeten Schlüsselbegriffe. Dabei wurden sowohl die politische Konnotation vieler Begrifflichkeiten als auch unterschiedliche Sprachtraditionen in Deutschland, Polen und Tschechien diskutiert, wie sie sich nicht zuletzt bei der Bezeichnung von Flucht und Vertreibung zeigen. Die vorliegende Studie verwendet trotz aller historiographischen und politischen Schwierigkeiten neben dem wissenschaftlichen Terminus der Zwangsmigration das Begriffspaar »Flucht und Vertreibung ", das von den in Deutschland, Polen und Tschechien gängigen Termini am ehesten dazu geeignet ist, das vielschichtige Geschehen zusammenzufassen. Ähnliches gilt für die Kategorisierung der Museumsprojekte anhand einer Skala von progressiv bis konservativ, die der politischen Sprache entlehnt und als schematisches Hilfsmittel definiert wurde. ${ }^{5}$

Das zweite Kapitel widmete sich den theoretischen und methodischen Grundlagen der vorliegenden Studie: dem historischen Vergleich und der transnationalen Geschichtsschreibung, der Erinnerungskultur und Geschichtspolitik sowie der Historischen Diskursanalyse und Diskursgeschichte. Umfassend wurden in Kapitel 2.5 das Museum und die Ausstellung als Untersuchungsgegenstand erörtert sowie eine $\mathrm{Mu}$ seumsanalyse als Untersuchungsansatz entwickelt. Ein auf alle Ausstellungen und - 
mit Einschränkungen - auf die Konzeptionspapiere anwendbares Analyseraster bot die Grundlage für den systematischen Vergleich der Projekte.

Kapitel 3 ordnete in einem historischen Überblick Flucht und Vertreibung zum einen in den spezifischen Kontext des Zweiten Weltkrieges ein, in dem das nationalsozialistische Deutsche Reich und die Sowjetunion massive und gewalttätige Bevölkerungsverschiebungen durchführten und Deutschland eine historisch beispiellose Besatzungsherrschaft über Ostmitteleuropa entfaltete, die eine »ethnische Neuordnung« Europas zum Ziel hatte. Zum anderen wurde herausgestellt, dass die Sozialtechnik staatlicher Vertreibungspolitik wie zur >Landnahme für Siedlerkolonien oder im Zuge des `Griechisch-Türkischen Bevölkerungsaustausches` auch von demokratisch verfassten Staaten genutzt wurde und als integraler Bestandteil des sich entwickelnden modernen Staates mit einer bis heute fortgesetzten Wirkmacht zu betrachten ist. Diese beiden Elemente identifiziert die vorliegende Arbeit als Grundlage der Vertreibung der Deutschen. Sie grenzt sich damit von zwei bis heute in Wissenschaft und Erinnerungskultur präsenten Argumentationslinien ab, entlang derer Flucht und Vertreibung entweder ausschließlich im Kontext des Zweiten Weltkrieges oder primär in dem nach ethnischer Homogenität strebenden modernen Nationalstaat zu sehen seien. Hier werden die beiden Denkansätze zusammengeführt. Dieses sowohl als auch bildet die Bewertungsgrundlage für die untersuchten Diskurse ebenso wie für die analysierten Ausstellungen und Konzeptionspapiere.

Darüber hinaus hatte Kapitel 3 die Funktion, weitere geschichtswissenschaftliche Differenzen und Desiderata sowie unterschiedliche gesellschaftliche Maßstäbe in Deutschland, Polen und Tschechien für die Bewertung von Flucht und Vertreibung herauszuarbeiten. Die unterschiedlichen Begriffe, die für das historische Geschehen verwendet werden, legen zugleich den Fokus auf lediglich einzelne Phasen des Geschehens: Während in Deutschland Flucht und Vertreibung im Mittelpunkt stehen, sind es in Polen und Tschechien die vermeintlich ordnungsgemäß abgelaufenen >Aussiedlungen oder der >Abschub<. Zudem kursieren - trotz umfassender Forschung - auch weiterhin erheblich auseinandergehende Opferzahlen. Ferner wird weiter darüber diskutiert, wer für die Gewalt während der Vertreibungen verantwortlich war. Lassen sich die Ausschreitungen auf den allgemeinen >Volkszorn` nach Jahren der Besatzung und Terrorherrschaft zurückführen oder war die Gewalt doch primär staatlich orchestriert? Im Ergebnis lässt sich feststellen, dass alle Phänomene existierten, wobei ein Primat der staatlichen Akteure erkennbar ist. Sie nutzten die Gewalt als ein Mittel, um die zügige Entfernung der deutschen Bevölkerung zu erreichen.

An diesen Streitpunkt knüpft ein weiterer an: Sowohl in der Wissenschaft als auch in den Gesellschaften gehen die Meinungen über die Notwendigkeit und Rechtmäßigkeit der Vertreibungen auseinander. Erscheinen diese in Deutschland meistens in toto als Unrecht, werden in Polen und Tschechien häufig lediglich Übergriffe und Gewalt bedauert, zugleich aber - exkulpierend - auf die Entscheidung der Siegermächte für die Vertreibung als auch auf den vorherigen deutschen Besatzungsterror verwiesen, der ein weiteres Zusammenleben unmöglich gemacht habe. Die Externalisierung der Entscheidungen auf die Alliierten ist in Polen historisch wesentlich besser zu rechtfertigen als in Tschechien, wurde Polen doch von 1944 an von einer kommunistischen Marionettenregierung mit geringer Unterstützung in der Bevölkerung regiert, wohingegen die 
Tschechoslowakei bis 1948 eine demokratisch legitimierte Regierung hatte. Zudem wird auf die Siegermächte verwiesen, die mit den Zwangsumsiedlungen die Grundlage für eine nachhaltige Friedensordnung schaffen wollten. Weiter werden die nationalsozialistischen deutschen Europaplanungen herausgestellt, bei deren Umsetzung nach einem >Endsieg ‘ den Polen und Tschechen ein wesentlich schlimmeres Schicksal gedroht hätte. In Polen wird dabei auf die Millionen Opfer der deutschen Herrschaft und der Shoa hingewiesen, in der konventionellen Meistererzählung in Tschechien zudem auf den kollektiven Hochverrat der Sudetendeutschen an ihrem Staat, der Tschechoslowakei, und ihrem Mittragen der nationalsozialistischen deutschen Besatzungsherrschaft.

Die hier angeführten und verschieden bewerteten Ereignisse markieren die Grundlage der jahrzehntelangen Auseinandersetzungen. Die nicht übereinstimmenden Erfahrungshorizonte und die nach nationalen Erinnerungskulturen differenten Bilder des Geschehens führten zu unterschiedlichen Bewertungsmaßstäben und erschweren bis heute die Verständigung.

Die Integrationsgeschichte der Vertriebenen in der Bundesrepublik und der DDR sowie die Eingliederung der vormaligen deutschen Ostprovinzen und des Sudetenlandes in die Volksrepublik Polen und die Tschechoslowakei zeigten die materiellen Hintergründe der Diskurse im Kalten Krieg auf. Das allseits erhobene Postulat der schnellen und erfolgreichen Integration sowohl der Menschen in der Bundesrepublik und der DDR als auch der Gebiete in Polen und der Tschechoslowakei ist als Mythos widerlegt, vielmehr sind langwierige Prozesse bis hin zu einem Scheitern zu konstatieren. Beispielhaft dafür steht die Rückständigkeit vieler Gebiete des ehemaligen Sudetenlandes, die vormals wirtschaftlich bedeutende Regionen waren.

Der in Kapitel 4 untersuchte Diskurs über Flucht und Vertreibung während des Kalten Krieges in der Bundesrepublik, der DDR, der Volksrepublik Polen und der Tschechoslowakei war wesentlich durch innere und äußere Frontstellungen geprägt. Die zentralen Argumentationslinien reduzierten die Komplexität des historischen Geschehens erheblich. In der Bundesrepublik wurde die Schuld für die Vertreibungen und die mit ihnen einhergehenden Verbrechen fast allein an den kommunistischen >Vertreiberstaaten und Einzelfiguren wie Edvard Beneš festgemacht, ehe sich der Diskurs in den 1960ern Jahren differenzierte. Dem Bund der Vertriebenen (BdV) und ihm nahestehenden Parteien wie CDU und CSU stellte ein immer stärker an Gewicht gewinnendes linksliberales Milieu eine eigene Geschichte entgegen, in der die deutsche Schuld im Mittelpunkt stand. In der DDR, der Volksrepublik Polen und der Tschechoslowakei wurden die Vertreibungen als eine gerechte und logische Konsequenz des Krieges betrachtet. Die Unterstützung der Vertriebenenverbände und ihrer Forderungen durch die Bundesrepublik stützte zugleich den propagandistisch intensiv genutzten Vorwurf, dass Westdeutschland eine gewaltsame Revision der Nachkriegsordnung anstrebe.

Auf beiden Seiten des geteilten Europa initiierten kleinere Gruppen neue Wege der Verständigung, indem sie für wechselseitiges Verständnis warben und sich selbstkritisch mit der eigenen Geschichte auseinandersetzten. Dennoch blieb die Reichweite solcher Initiativen auf kirchliche Kreise oder einige Intellektuelle aus der Opposition begrenzt. Daran konnten auch die verschiedenen und vermeintlichen Wendepunkte des Diskurses nichts ändern. Das prägnanteste Beispiel aus dieser Zeit ist der Brief der 
polnischen Bischöfe von 1965. Dieser ist zwar ein symbolischer Meilenstein der Verständigung, jedoch konnte er den vielleicht einzigen Konsens zwischen kommunistischer Diktatur und polnischer Bevölkerung - die Bewertung der Vertreibung als gerechtfertigt - nicht auflösen. Im Rückblick auch auf den Diskurs nach 1989 scheint vielmehr die langwierige und holzschnittartige politische Mobilisierung des Themas nicht ohne Einfluss auf die Bevölkerung geblieben zu sein.

Dieser Diskursgeschichte nach 1989 war das Kapitel 5 gewidmet. Das Ende des Kalten Krieges führte trotz vielfältiger wissenschaftlicher und politischer Initiativen und Erwartungen an eine umfassende Verständigung und dementsprechende Bemühungen nicht zu einer breiten gesellschaftlichen Infragestellung der bisherigen Narrative. Auch die Versöhnungsgesten von Václav Havel 1989/90, der vor und nach seiner Wahl zum Präsidenten der Tschechoslowakei Worte des Bedauerns über die Vertreibungen äußerte, konnten weder den tschechischen noch den Diskurs innerhalb der Gemeinschaft der Sudetendeutschen entscheidend verändern. Spätestens Anfang der 2000er Jahre schwanden die letzten Illusionen, dass nach Ende des Kalten Krieges eine erfolgreiche Verständigung über die Fragen von Flucht und Vertreibung erreicht werden könnte. Hitzige Diskussionen um das vom BdV initiierte Zentrum gegen Vertreibungen und die >Beneš-Dekrete ließen die alten Verhärtungen wieder sichtbar werden. Die am Ende des Zweiten Weltkrieges erlassenen tschechoslowakischen Präsidialdekrete rekonstituierten die Tschechoslowakei und sicherten die Vertreibungen der Deutschen rechtlich $\mathrm{ab}$. Nach der Jahrtausendwende verband der damalige Kanzlerkandidat der CDU/CSU, Edmund Stoiber, die Forderung nach Aufhebung der Dekrete mit den laufenden EU-Beitrittsverhandlungen. In Tschechien führte diese Verknüpfung zu einer Verteidigungshaltung, die kritische Stimmen über Beneš und das Vertreibungsgeschehen marginalisierte. Für Polen ebenso wie für Tschechien war die Initiative des BdV, ein Zentrum gegen Vertreibungen zu schaffen, vor allem aus zweierlei Gründen nicht akzeptabel: So sei der BdV zum einen als nicht neutrale und politisch umstrittene Instanz ungeeignet, eine solche Institution mit staatlichen Geldern, aber von ihm dominiert, umzusetzen. Zum anderen wurde befürchtet, in einem auf die Vertreibungen reduzierten und vom weiteren Kontext des Zweiten Weltkrieges gelösten Museum als alleiniger Täter dargestellt zu werden, womit eine völlige Verkehrung der Geschichte drohe. So belasteten Anfang der 200oer Jahre Flucht und Vertreibung die Beziehungen zwischen den Ländern erneut.

Eine gemeinsame und als solche artikulierte Position von Polen und Tschechien zum Vertreibungsdiskurs war und ist nur eingeschränkt gegeben. Abgesehen von einem durchaus aufmerksamen Beobachten der jeweiligen Auseinandersetzungen mit Deutschland wurde nur gelegentlich eine Interessenidentität postuliert und entsprechend kooperativ gewirkt. So war der Konflikt um das Zentrum gegen Vertreibungen eher ein deutsch-polnischer und die Diskussion um die >Beneš-Dekrete tschechischer, auch wenn dieser Fragen der Rechtmäßigkeit der Vertreibungen und Entschädigungen generell berührte. Nicht ignoriert werden darf die stete Kritik am BdV-Vorhaben durch linksliberale Stimmen in Deutschland, auch wenn es nach 2000 zeitweise gelang, in diesem Milieu einige Unterstützer zu gewinnen.

Trotz dieser fortgesetzten Streitigkeiten ist in Polen und Tschechien ein sich nach 1989 rasch entwickelnder zivilgesellschaftlicher Aufbruch festzustellen, in dem sich lo- 
kale Gruppen dem deutschen Kulturerbe ihrer Region widmen und Künstler sich empathisch mit der Vertreibung auseinandersetzen. Derartige Akteure sind von der europäischen und globalen Renaissance eines alten und neuen Nationalismus besonders betroffen, scheint doch ihre Arbeit wenig fruchtbar gewesen zu sein. Dennoch sollte ihr Wirken für die langfristige Verständigung sowohl vor Ort als auch für die Erinnerungskultur nicht unterschätzt werden.

Ein nach 2000 im Zuge der neuen Diskussion um Flucht und Vertreibung in Deutschland befürchteter entscheidender Wandel der selbstkritischen bundesrepublikanischen Erinnerungskultur ist nicht eingetreten. Mit der Alternative für Deutschland (AfD) existiert jedoch mittlerweile eine parlamentarisch etablierte Kraft, die mindestens in Teilen eine andere Erinnerungskultur anstrebt und auch im Bereich der Vertriebenenpolitik operiert.

Bis zum Ende des Untersuchungszeitraumes (2019) kam es punktuell immer wieder zur konfliktbeladenen Re-Thematisierung von Flucht und Vertreibung, so bei der Diskussion um die Stiftung Flucht, Vertreibung, Versöhnung, dem Haus der Europäischen Geschichte und zuletzt in der tschechischen Reaktion auf die Rede von Bundeskanzlerin Angela Merkel beim Gedenktag für die Opfer von Flucht und Vertreibung im Juni 2018. Wie alle bisherigen bundesdeutschen Regierungen bewertete die Bundeskanzlerin die Vertreibung als Unrecht, was bei der neuen tschechischen Regierung zu dem Reflex führte, diesen vermeintlich erneuerten Vorwurf gegenüber Tschechien rhetorisch abwehren zu müssen.

Im Anschluss an die Diskursgeschichte wurden in Kapitel 6 und 7 die verschiedenen Museumsprojekte in den drei Ländern sowie das Haus der Europäischen Geschichte in Brüssel auf ihre Darstellung von Flucht und Vertreibung hin untersucht. Dies geschah in Verbindung mit den vorher diskutierten historiographischen Problemen, der Diskursgeschichte sowie der Vorgeschichte, der Struktur und den Ansprüchen der Museen.

Zunächst wurde in Kapitel 6 das Schlesische Museum zu Görlitz (SMG) dem Muzeum Śląskie (MŚK) in Kattowitz gegenübergestellt. Das 2006 eröffnete Museum in Görlitz ist ganz dem Europadiskurs der 2000er Jahre und einem Idealismus der deutsch-polnischen Verständigung unter europäischem Vorzeichen verpflichtet. Besonders zeigt sich das bei der sehr zurückhaltenden Darstellung von Flucht und Vertreibung, die sich politisch so unangreifbar wie möglich zu machen versucht, und zwar durch eine starke historische Kontextualisierung unter Betonung der nationalsozialistischen Gewaltherrschaft, eine Unterbelichtung polnischer Verantwortung sowie eine Parallelisierung mit dem Schicksal der Polen aus den kresy. Das damit verbundene Bemühen, für Polen und Deutsche gleichermaßen ansprechend und anschlussfähig zu sein, gelingt aber nur in eingeschränktem Maße, denn polnische Besprechungen sehen in der Darstellung vor allem eine deutsche Perspektive auf Schlesien. Bereits vor der Eröffnung des Museums in Kattowitz im Jahr 2015 war eine Diskussion darüber entbrannt, welchen Anteil die deutsche Geschichte Schlesiens an der Dauerausstellung haben sollte. Die zunächst vorgesehene Konzeption wollte dem multiethnischen Oberschlesien einen größeren Raum zugestehen und die Ausstellung mit der von der polnischen Rechten als deutsch konnotierten Industrialisierung beginnen lassen. Nach dem erzwungenen Rücktritt des verantwortlichen Direktors 2013 wurde die bis dahin entwickelte progressive Konzepti- 
on wesentlich abgeändert. In der Dauerausstellung nimmt jetzt das nationalpolnische Schlesien-Narrativ wieder mehr Raum ein, was sich beispielhaft daran zeigt, dass die Ausstellung nun mit der Epoche des piastischen Schlesien beginnt. Dennoch wird an vielen Stellen ein differenzierter Umgang mit der deutschen Vergangenheit Oberschlesiens deutlich. Dies zeigt sich auch bei den Darstellungen von Vertreibung, Deportation und Internierung sowie damit einhergehender Gewalttaten, denen deutschsprachige ebenso wie polnischsprachige Oberschlesier zum Opfer fielen und die in der Ausstellung ausführlich besprochen werden. Die gelegentliche Loslösung von einem dichotomen Verständnis von Oberschlesiern als deutsch oder polnisch unterstützt die offene Darstellung des Vertreibungsgeschehens.

Der Untersuchung der beiden schlesischen Museen folgten zwei Exkurse zu den jeweils seit dem Jahr 2006 intensiv verfolgten Planungen des Sudetendeutschen Museums in München und des Museums der deutschsprachigen Bewohner Böhmens in Aussig an der Elbe/Ústí nad Labem. Die bisherige Geschichte des Vorhabens in Aussig hat die Kontroversen um die Musealisierung des Themenfeldes auch für die Tschechische Republik gezeigt. Die Planungen weisen eine Nähe zu dem verständigungspolitischen Diskurs auf, wie er bei den in Kapitel 5.3 vorgestellten zivilgesellschaftlichen Organisationen des deutsch-tschechischen Dialoges zu finden ist: Die Darstellung des Zusammenlebens verfällt keiner Idealisierung, ebenso wie der deutsche Anteil als bedeutendes und integrales Element tschechischer Geschichte gewürdigt wird. Ohne ein Schwerpunkt der Ausstellung zu werden, sollen die Vertreibungen ihre angemessene Berücksichtigung finden und die Geschehnisse multiperspektivisch diskutiert werden. Damit stehen die Planungen allerdings im Widerspruch zu einem größeren Teil der politischen Kräfte in Tschechien, die der älteren nationalen Meistererzählung verbunden sind, in der die Deutschen der böhmischen Länder vor allem eine Bedrohung darstellten. Mehr noch schien aber die Umsetzung von der verbreiteten gesellschaftlichen Gleichgültigkeit und dem politischen Desinteresse dem Thema gegenüber behindert zu werden. Die Planungen zum Sudetendeutschen Museum in München sind in ihrer inhaltlichen Grundausrichtung komplementär. Die Vertreibung wird eingebettet in eine jahrhundertelange deutsch-tschechische Kulturgeschichte und steht nicht im Mittelpunkt. Eine sowohl für Tschechen als auch für Deutsche und Sudetendeutsche anschlussfähige Erzählweise ist nicht nur gewünscht, sie soll auch ein Grundelement der Ausstellungsgestaltung sein. Ein Diskurs um das Museum fand in der Öffentlichkeit kaum statt, die Entstehung des Hauses wurde von einer breiten politischen und gesellschaftlichen Mehrheit in Bayern getragen. Personelle Verbindungen zwischen dem Münchner und Aussiger Museum sowie das nach 2010 wesentlich verbesserte bayerisch-tschechische Verhältnis bieten die Grundlage für eine ergiebige Kooperation.

Die Stiftung Flucht, Vertreibung, Versöhnung (SFVV) befindet sich nach langwierigen innerdeutschen und nachbarschaftlichen Auseinandersetzungen vor der nunmehr im Jahr 2021 geplanten Eröffnung. In den Konzeptionspapieren manifestieren sich die unterschiedlichen Forderungen und Kritikpunkte des Diskurses als Synthese. Ein europäischer Ansatz wird in Form eines Unterschiede und Gemeinsamkeiten diskutierenden Überblicks über die Zwangsmigrationen im 20. Jahrhundert verfolgt. Diese sollen zusammen mit dem ideengeschichtlichen Hintergrund staatlicher Zwangsmigrationspolitik und den nationalsozialistischen deutschen Kriegs- und Besatzungsverbrechen 
um den Ausstellungsschwerpunkt, die Flucht und Vertreibung der Deutschen, gruppiert werden. Damit finden sich sowohl Elemente des Zentrums gegen Vertreibungen des BdV als auch die Berücksichtigung der an diesem angeführten Kritikpunkte wieder, welche die Arbeit der ersten Jahre der SFVV ebenfalls begleiteten. So sollen die Vertreibungen der Deutschen weder durch eine Über-Kontextualisierung relativiert werden noch die anderen Zwangsmigrationen als bloße Ergänzung zur Hervorhebung des besonderen deutschen Schicksals dienen. Polnische Besucher können in der geplanten Ausstellung aufgrund der Darstellung der vom nationalsozialistischen Deutschland geplanten und begonnenen rethnischen Neuordnung Europas< sowie den Zwangsumsiedlungen aus den kresy Anknüpfungspunkte an entscheidende Ereignisse der polnischen Geschichte finden. Tschechischen Besuchern kann der präsentierte Zusammenhang der Vertreibungen verdeutlichen, dass es sich bei der Vertreibung der Sudetendeutschen nicht nur um ein spezifisch deutsch-tschechisches Phänomen im Kontext des Zweiten Weltkrieges handelt, sondern auch um ein bis heute fortwirkendes ideengeschichtliches Konzept. Im Unterschied zu den anderen hier diskutierten Institutionen liegt bei der SFVV auch ein Schwerpunkt auf der Darstellung jüngerer und gegenwärtiger Fluchtund Vertreibungsbewegungen. Ob mit einer erfolgreichen Umsetzung des ambitionierten Ausstellungskonzeptes ein Ende der häufig polemischen Diskussionen über die Institutionalisierung eines Erinnerungsortes an Flucht und Vertreibung einhergeht und die Stiftung eine Basis für Verständigung sein kann, hängt schließlich entscheidend von ihrer künftigen Akzeptanz in Polen und Tschechien ab.

Das 2017 eröffnete Museum des Zweiten Weltkrieges in Danzig (MIIW) wurde in der liberalen Presse weltweit gefeiert. In der Bewertung von Flucht und Vertreibung folgt es einer konventionellen und patriotischen polnischen Meistererzählung, in der Darstellung des Schicksals der Vertriebenen aber einer empathischen Perspektive. Die Vertreibung der Deutschen wird in mehreren Abschnitten behandelt. In dem ausschließlich Zwangsmigrationen am Ende des Krieges gewidmeten Raum führt eine Parallelisierung mit anderen Zwangsmigrationen dieses Zeitraumes, die Unterschiede eher negiert, zu einer gewissen Marginalisierung des Geschehens. An verschiedenen Stellen zeigt die Ausstellung jedoch auch in Hinblick auf Flucht und Vertreibung kritisches Potenzial, beispielsweise bei der Darstellung der Vergewaltigungen am Ende des Krieges sowie der Präsentation der Schiffsglocke der Wilhelm Gustloff als Symbol für die Toten der deutschen Fluchtbewegung. Die progressiven Elemente der Machcewicz-Ausstellung finden sich allerdings eher in anderen Bereichen. Dies ist auch daran erkennbar, dass die nationalkonservative Ausstellungskritik sich zu den Flucht und Vertreibung betreffenden Ausstellungsteilen nicht oder kaum geäußert hat. In Abkehr von seinem Gründungsimpuls, der deutschen Zentrumsinitiative und später der SFVV durch ein eigenes Museum zu begegnen, bleibt das Thema auch aufgrund der schieren Dimension der Ausstellung ein untergeordnetes Element. Für eine weitergehende deutsch-polnische Verständigung über Flucht und Vertreibung eignet sich die Dauerausstellung nicht. Von der im April 2017 eingesetzten PiS-nahen Museumsleitung ist nicht zu erwarten, dass sie ergänzend durch Sonderausstellungen und Veranstaltungen positive Impulse für eine deutsch-polnische Verständigung setzt.

In der lange nicht sehr lebhaft geführten Diskussion um das 2017 in Brüssel eröffnete Haus der Europäischen Geschichte (HEH) war die Darstellung von Flucht und Vertrei- 
bung der Deutschen wiederholt ein Thema. In der Ausstellung findet es sich vor allem in einem kleinen, der Zwangsmigration am Ende des Krieges gewidmeten Bereich. Dieses Element unterscheidet sich vom Rest der Ausstellung, indem es einen primär nationalgeschichtlichen, deutschen Ansatz für dieses Thema wählt, ohne aber einen gegenüber Polen oder Tschechien anklagenden Ton anzustimmen. Das Ende des für viele Regionen Ostmitteleuropas konstitutiven Elements der multiethnischen Zusammensetzung der Bevölkerung wird nicht gezeigt und damit bleibt die Chance ungenutzt, die einschneidende Dimension dieses Verlustes darzustellen. Die konventionelle deutsche Erzählung über die Vertreibung wurde von den polnischen Kritikern, die das Haus als Ganzes heftig unter Beschuss nahmen, umgehend entdeckt und polemisch angegriffen. Übersehen wurde dabei von den meisten kritischen Stimmen der besonders positiv hervorzuhebende fragende und dialektische Charakter der Brüsseler Ausstellung, die dem Besucher auf Augenhöhe zu begegnen versucht und zur eigenen Bewertung anregt. Gerade im Bereich von Flucht und Vertreibung wird diese Gelegenheit aber nicht geboten - damit bleibt die Möglichkeit für eine Anschlussfähigkeit dieser Darstellung an die Erzählungen in Polen und Tschechien ungenutzt.

In der vergleichenden Betrachtung aller untersuchten Museen lässt sich unter anderem erkennen, dass im Verlaufe der Erarbeitung eines ersten Konzepts bis hin zur tatsächlichen Realisierung im Museum oft vielversprechende Ansätze, wie etwa Multiperspektivität oder der Versuch, mit dem Besucher in der Ausstellung in einen Dialog zu treten, einem scheinbar notwendigen Pragmatismus weichen, in dessen Folge Abstriche gemacht werden. Dies gilt es bei der Bewertung der drei noch nicht fertiggestellten $\mathrm{Mu}-$ seen zu berücksichtigen. Von dem in Kapitel 2.5 skizzierten Idealtypus des Museums als demokratischem Forum, in dem Besucher und Ausstellungsmacher in einen nichthierarchisch geprägten Austausch treten, sind alle untersuchten Institutionen entfernt.

Ansätze eines solchen Museums sind aber bei allen analysierten Ausstellungen erkennbar. Im Haus der Europäischen Geschichte wird der Besucher durch einen fragend-dialektischen Charakter eingebunden, im Schlesischen Museum in Kattowitz werden mit einer streckenweise parallelen Ausstellungserzählung sowohl Differenz als auch Verschränkung zwischen den deutschen und polnischen Oberschlesiern gezeigt. Das gelingt beispielsweise über das recht einfache, aber wirkungsvolle Mittel der räumlichen Gegenüberstellung der Entwicklung des deutschen und polnischen Oberschlesien in der Zwischenkriegszeit.

Bezogen auf Flucht und Vertreibung wird ein konsequent multiperspektivischer Charakter zunächst nur durch das Konzeptionspapier der SFVV verfolgt. Ähnliches planen das Sudetendeutsche Museum in München oder das Museum der deutschsprachigen Bewohner Böhmens in Aussig, in denen verschiedene Sichtweisen dargestellt werden sollen. Das MŚK in Kattowitz verzichtet bei seiner Darstellung von Flucht und Vertreibung auf eine Diskussion über deren Notwendigkeit und unterschiedliche Einschätzungen. Ähnlich zurückhaltend ist das $\mathrm{HEH}$, wenn auch nur in diesem Teil der Ausstellung. Einen multiperspektivischen Ansatz in dem Bereich setzen das SMG und das MIIW insofern um, als sie verschiedene Erzählungen der von Vertreibung betroffenen Gruppen parallel darstellen. 
In Hinblick auf die Frage, ob und wie sich in den untersuchten Institutionen regionale, nationale oder europäische Erzählungen finden lassen, konnte festgestellt werden, dass alle Einrichtungen mit unterschiedlicher Intensität eine europäische Erzählung im Sinne von Multiperspektivität und eine über den nationalen Rahmen hinausgehende Darstellung anstreben. Alte und neue nationale Erzählungen sind dennoch weiterhin präsent oder im Falle des Hauses der Europäischen Geschichte eine - gleichwohl immer wieder selbstkritische - Meistererzählung der Europäischen Union. Flucht und Vertreibung als Teil der nationalsozialistischen und sowjetischen Zerstörung Ostmitteleuropas durch Völkermord und unzählige, zunächst von ihnen verursachte Zwangsmigrationen werden in keinem der untersuchten Häuser oder Papiere konsequent als kulturelle europäische Verlustgeschichte erzählt.

Das Phänomen, dass beim Thema der Zwangsmigration der Deutschen in den untersuchten Gesellschaften jeweils an unterschiedliche Phasen und Ereignisse erinnert wird, schlägt sich in den Museen nur eingeschränkt nieder. Alle Häuser differenzieren zwischen Flucht und Vertreibung und ergänzen diese gegebenenfalls noch um Evakuierung, Lagerinternierung, Deportation oder teilen die Vertreibung auf in swilde und >organisierte Vertreibungen. Das kann aber auch dazu führen, wie beispielhaft in Kattowitz zu beobachten, dass die Verbindung zwischen den einzelnen Geschehnissen undeutlich wird.

Die Annäherung in der Forschung, die aber auch zwischen den besonders verständigungsfreundlichen deutschen, polnischen und tschechischen Wissenschaftlern nicht in allen Feldern einen common sense hergestellt hat, findet sich insofern in den Museen wieder, als es keinerlei klare Dissonanzen zwischen den verschiedenen Ausstellungen und Konzepten gibt. Inhaltliche Unterschiede machen sich an Nuancen und vor allem daran fest, was nicht erzählt wird. Bestätigt hat sich die These, dass die Museen besonders kontroverse Themen in den Ausstellungen aus unterschiedlichen Motivationslagen heraus eher vermeiden als offensiv diskutieren. Das führt zwar nicht zur Unausgewogenheit der Darstellung, ist aber einer kritischen Auseinandersetzung nicht förderlich - die wiederum als Basis für eine erfolgreiche Verständigung anzusehen ist.

Bei der Zusammenführung aller Ergebnisse der vorliegenden Studie lässt sich erkennen, dass es im Untersuchungszeitraum nach 1989 von allen Seiten Versuche und Initiativen gab, aufeinander zuzugehen. Dies führte zu Versöhnungsgesten und weitergehenderen Schritten der Verständigung, wie sie sich nicht zuletzt auf der Ebene des alltäglichen Zusammenlebens der Nachbarn zeigten und zeigen. Im Gegensatz zu manchem Optimismus der 1990er Jahre lässt sich aber feststellen, dass in allen Ländern nationale Perspektiven und ältere Meistererzählungen persistieren und nicht vollständig überwunden werden konnten. Im Gegenteil: Zum Ende des Untersuchungszeitraumes zeichnet sich in Europa eine Renaissance von Nation und Nationalismus und damit auch heroischer Erzählungen der Nationalgeschichten ab.

Für den Zeitraum nach 1989 lassen sich drei Phasen des Vertreibungsdiskurses zwischen den Ländern ausmachen: Im deutsch-polnischen Verhältnis waren die 1990er Jahre von einem Verständigungsoptimismus geprägt und Fragen der Gegenwart standen im Mittelpunkt. Dagegen wurde diese Zeit zwischen Deutschland und Tschechien aufgrund der Diskussionen, unter anderem um Entschädigungen der Vertriebenen, 
schon als »kleine Eiszeit « bezeichnet. Anfang der 2000 er Jahre begann die zweite Phase, in der die Beziehungen zwischen Deutschland und Polen ebenso wie die zwischen Deutschland und Tschechien einen Tiefpunkt erreichten, als Vorbehalte in Deutschland in Hinblick auf die EU-Osterweiterung mit der von CDU/CSU forcierten Diskussion um die >Beneš-Dekrete « und dem Projekt des Bundes der Vertriebenen, ein Zentrum gegen Vertreibungen einzurichten, zusammenfielen. Dies gab wiederum dem polnischen und tschechischen Nationalismus Auftrieb. Die östlichen Nachbarn Deutschlands fürchteten angesichts der Initiative, ein Zentrum gegen Vertreibungen zu schaffen, einen staatlich forcierten Geschichtsrevisionismus. In der dritten Phase, von 2010 bis 2015, entspannte sich durch die bayerisch-tschechische Verständigung das deutsch-tschechische Verhältnis wieder, wohingegen das deutsch-polnische Verhältnis nach dem Regierungswechsel in Polen 2015 einen neuen Tiefpunkt erreicht hat.

Die Entwicklung der 1990er und 2000er Jahre scheint trotz aller Widrigkeiten noch im Rahmen des damals den Westen dominierenden, liberalen, globalisierungs- und EU-freundlichen Diskurses verortbar zu sein. Streitfälle wie die >Beneš-Dekrete< oder das Zentrum gegen Vertreibungen konnten noch als Anpassungsschwierigkeiten betrachtet werden, ehe das Jahr 2016 durch den Brexit, die Wahl Donald Trumps zum USPräsidenten und den doppelten Wahlsieg der PiS in Polen sowie die Etablierung der AfD als nationalpopulistische Partei in Deutschland eine entscheidende Zäsur darstellte. Alte und neue Formen des Nationalismus, das erklärte Ende des Multilateralismus und alternative Gesellschaftsentwürfe fordern die liberalen Demokratien heraus, wobei die nationalen Erinnerungskulturen einen Seismographen für diese Prozesse bilden. Das zeigt sich in unterschiedlicher Intensität an den untersuchten Museumsprojekten, die diese Entwicklungen durch die Bildung von Hybriden nachvollziehen und auf diese Weise auch die verschiedenen Positionen des >Vertreibungsdiskurses abbilden. Bisher fällt dabei kein Haus in seiner Darstellung in die Zeit des Kalten Krieges zurück; vielmehr versuchen alle Museen kompatibel mit einer europäischen Erzählung zu sein. Zugleich lassen sich in den Projekten Elemente der alten nationalen Meistererzählungen finden. Besonders auffällig ist, dass gerade das Haus der Europäischen Geschichte in dem Teil der Ausstellung, der sich mit der Vertreibung befasst, einer bundesrepublikanischen Meistererzählung folgt. Das Görlitzer Haus steht stellvertretend für die Europaeuphorie der frühen 2000er Jahre, das MIIW nach dem April 2017 für deren vorläufiges Scheitern. Ein progressives Museum, das die Kritik der deutschen und polnischen linksliberalen Intellektuellen und Wissenschaftler der 2000er Jahre widerspiegelt, ist bisher nicht zu erkennen, auch wenn die SFVV sich an diese angenähert hat. Das MIIW unter seiner neuen PiS-nahen Führung bildet hingegen einen klaren Gegenpol und steht für einen nationalistischen roll back.

Die in der vorliegenden Studie herausgearbeiteten Befunde können die in Kapitel 1 diskutierten Desiderata erfüllen: Erstmals wurden museologische Ansätze in Polen und exkursiv in Tschechien zur Darstellung von Flucht und Vertreibung an prägnanten Beispielen umfassend untersucht und dabei das für ihre Entstehung konstitutive Element des Beziehens auf die Nachbarn mit einem strukturierten Vergleich berücksichtigt. Damit konnte einem Defizit vieler deutscher Untersuchungen begegnet werden, die der Musealisierung von und dem Diskurs über Flucht und Vertreibung gewidmet sind und 
häufig bei einer bundes- und innerdeutschen Perspektive verbleiben, in der Tschechien oder Polen ohne tiefergehende Analyse als unterkomplexe Einheiten erscheinen, auf deren - nicht kritisch und historisch diskutierte - Empfindlichkeiten Rücksicht zu nehmen sei. ${ }^{6}$ Die Einbeziehung des Hauses der Europäischen Geschichte berücksichtigte schließlich die zunehmende Bedeutung der europäischen Ebene für die Aushandlung nationaler und transnationaler erinnerungskultureller Konflikte, die sich unter anderem an der Darstellung der Vertreibung im HEH festmachen lässt.

Die Untersuchung konnte nicht alle für die Diskussion der Erinnerungskultur an Flucht und Vertreibung in Ostmitteleuropa in Frage kommenden Museen behandeln, aber sie bildet für notwendige Anschlussuntersuchungen eine grundlegende Referenz. In der Gegenwart wie in der Zukunft werden sich alle Lokal-, Regional- und Nationalmuseen in Ostmitteleuropa zu ihren multiethnischen oder im Falle der polnischen Westgebiete fast ausschließlich deutschen Vergangenheiten verhalten müssen. Das gilt für das Stadtmuseum von Tallinn ebenso wie für das Nationalmuseum Moldawiens.

Die Untersuchung der Museen als Manifestationen des schwer greifbaren Gegenstandes des Diskurses ermöglichte es, auf fundierter Basis eine Bilanz der Auseinandersetzungen um Flucht und Vertreibung in Deutschland, Polen und Tschechien nach 1989 zu ziehen. In den hier untersuchten staatlichen Museen sind die Akteure gezwungen, auf die Debatten, die historiographischen Differenzen und Desiderata zu reagieren und mit den auf zehn bis zwanzig Jahre ausgelegten Dauerausstellungen mindestens mittelfristig gültige Positionen zu artikulieren. ${ }^{7}$ Trotz einiger Unwägbarkeiten gestattete es die Gegenwartsnähe der Studie, die für die Museen entscheidenden Entwicklungen nach 2015 und die oben beschriebene politische Zäsur von 2016 noch zu erfassen und $\mathrm{zu}$ erforschen. Eine zeitliche Beschränkung auf die Phase vor diesem Zeitraum wäre den Untersuchungsgegenständen daher nicht gerecht geworden, zumal das MIIW und das HEH erst 2017 eröffneten.

Die in Kapitel 4 und 5 skizzierte Diskursgeschichte baute auf einer vorherigen ausführlichen Besprechung des historischen Geschehens und den fortwährend bestehenden unterschiedlichen Sichtweisen auf. Dieses Vorgehen hat sich als sinnvoll erwiesen, um die Diskurse historisch zu fundieren und zugleich eine valide Bewertungsgrundlage zu schaffen. Die Aufgliederung der Diskursgeschichte nach Ländern mit gelegentlichen Verweisen auf die Entwicklung und Beobachtung der Nachbarstaaten wurde mit einem zusammenführenden Vergleich abgeschlossen. Diese Herangehensweise ist zwar den historischen Prozessen und dem Charakter des Diskurses gerecht geworden, hat

6 Das gilt beispielsweise auch für die in vielerlei Hinsicht ergiebige Studie von Hahn/Hahn: Hahn; Hahn: Die Vertreibung im deutschen Erinnern, 2010. Die von Völkering angekündigte Dissertation zur bundesdeutschen Musealisierung ist in ihrem Ansatz zunächst auf Deutschland beschränkt, jedoch lassen die bisherigen Schriften Völkerings erkennen, dass die Sicht Polens oder Tschechiens berücksichtigt wird: https://www.uni-muenster.de/Geschichte/hist-dida/organisation/mitarbeiter/voelkering.html (letzter Zugriff: 17.11.2018).

7 Wie sich am MIIW zeigt, kann gleichwohl durch bereits kleinere Änderungen der Charakter einer Dauerausstellung wesentlich modifiziert werden. Dennoch gilt für die uns hier beschäftigenden Institutionen, dass deren Planungen nicht auf eine flexible Veränderung je nach politischer Situation angelegt sind. 
sich aber zugleich als langwierig und Wiederholungen provozierend erwiesen. Die noch konsequentere Darstellung einer Verflechtungsgeschichte verspricht jedoch in Anbetracht der primär im nationalen Rahmen stattfindenden Diskurse wenig ergiebig zu sein. Die Arbeit versuchte die transnationalen Verbindungen und Akteure sowie die europäischen Ebene in Form der Europäischen Union als Plattform und Akteur durch ein stetes Einbeziehen konsequent zu berücksichtigen.

Die vorliegende Studie folgte bei der Verhandlung erinnerungskultureller Entwicklungen in den untersuchten Ländern einem geschichtspolitischen Schwerpunkt. Durch einen weiten Blick auf die Prozesse in Deutschland, Polen und Tschechien gelang es, die unter unterschiedlichen Rahmenbedingungen stattfindende Erinnerung an Flucht und Vertreibung nicht isoliert zu betrachten und somit in ihrem Kontext bewerten zu können. Für ergänzende Aussagen über die Erinnerungskultur böte es sich an, den Blick auf Stimmen in der Breite der Gesellschaft zu richten. Die in der Arbeit wiederholt herangezogenen Meinungsumfragen konnten hierfür nur einen sehr schematischen Einblick liefern.

Das in Kapitel 2.5 entwickelte strukturierte Vorgehen bei der Beschreibung der $\mathrm{Mu}$ seen, der Untersuchung der Ausstellungen und des Konzeptionspapieres der Stiftung Flucht, Vertreibung, Versöhnung hat sich als Methode bewährt, den komplexen Gegenstand der Ausstellung zu erfassen und klare Befunde herauszuarbeiten. Mit wenigen Einschränkungen war die Untersuchungsmaske auf alle Einrichtungen anwendbar und damit die Vergleichbarkeit gewährleistet. Ein direkter, parallelisierender Vergleich der Ausstellungen, beispielsweise nach Themen wie »Flucht « oder »Lager« wäre eine Alternative, wird aber dem Charakter des Gesamtkunstwerkes Ausstellung durch die szientistische Isolierung einzelner Elemente nicht gerecht.

In dieser Studie wurden verschiedene Fragen gestreift, für deren Beantwortung weitere Forschungen sowohl notwendig als auch vielversprechend erscheinen. Künftige Untersuchungen könnten die hier vorgelegten Ergebnisse mit archivalischen Quellen abgleichen. Dies kann sowohl auf den verschiedenen politischen Ebenen, wie denen der regionalen und nationalen Entscheidungsträger oder der Verbände, als auch auf der Ebene der Museen geschehen. Auch wenn Museen ihre Arbeit unterschiedlich dicht archivarisch dokumentieren, könnten weitere Hintergründe und Entscheidungsprozesse ergänzend analysiert werden, nachdem in dieser Arbeit die fertigen Ausstellungen oder ausgearbeitete Konzeptionspapiere im Fokus standen. Dafür bietet sich auch das Format des Interviews mit den Museumsmachern an.

Ebenso lohnend wäre eine Untersuchung der Wünsche und Vorstellungen noch lebender deutscher Vertriebener, aber auch ihrer Nachfahren in Bezug auf die Erinnerungskultur an Flucht und Vertreibung. Nicht nur diese Arbeit, auch die Debatten der letzten Jahrzehnte konzentrierten sich auf die Vertriebenenverbände und ihre Spitzenfunktionäre sowie die politisch-medialen Auseinandersetzungen und gingen damit nicht selten an den individuell Betroffenen vorbei.

Der Vorschlag von Stephan Scholz, die Erinnerung an Flucht und Vertreibung und die Erfahrungen der Vertriebenen mit »andere[n] Migrationsgeschichten zu vergleichen«, erscheint insofern sinnvoll, als damit die in Kapitel 1.4 und 5.1 besprochene Diskussion, inwieweit hier Parallelen und Unterschiede vorliegen, wissenschaftlich fun- 
diert werden kann. ${ }^{8}$ Philipp Ther hat hierzu mit seiner Studie »Die Außenseiter« über den Flüchtling in der Moderne einen wichtigen Schritt getan. Unabhängig von der Diskussion, ob oder wie Zwangsmigration unter das Dach der Migrationsforschung gehört, ${ }^{9}$ ist der Vergleich mit weiteren Erinnerungskulturen zu anderen Zwangsmigrationen erkenntnisversprechend. ${ }^{10}$

Einige Defizite der Forschung sind in der vorliegenden Studie offenbar geworden. Beispielhaft wäre hier die in der Wissenschaft häufig negative bewertete Arbeit der Vertriebenenverbände zu nennen. Durch das Abarbeiten an der nicht nur von den Verbänden vorgetragenen These der Tabuisierung des Vertreibungsthemas seit der späten Bonner Republik oder das Herausstreichen der Verantwortung der Sudetendeutschen Landsmannschaft für das Scheitern einer sudetendeutsch-tschechischen Versöhnung 1989 wird möglicherweise die durch das offensive Auftreten ihrer Verbandsspitzen verdeckte Opfererfahrung der Mitglieder unter- und der - freilich auch von den Verbandsvertretern bemühte - Charakter eines professionellen politischen Großverbands überschätzt. Die Vertriebenenverbände sind in Teilen der deutschen Gesellschaft und noch viel mehr in Polen und Tschechien keine allgemein anerkannten Vereinigungen wie andere Opferverbände des Krieges. Wesentliche Gründe dafür sind ihre historische Rolle als politische Großverbände, die ihre Ansprüche gegenüber den östlichen Staaten lange nicht aufgeben wollten, ebenso wie ihre als einseitig wahrgenommene Erzählung über das Ende des Zweiten Weltkrieges und ihre Perspektive auf Schuld und Verantwortung. Weiter konnten in der Studie wiederholt Belege für die These von Matthias Stickler gefunden werden, der die Verbindung der Vertriebenenverbände mit dem Parteienwesen, durch welche die Loyalitäten der führenden Funktionäre häufig geteilt waren, als zumindest zwiespältig für die Anliegen der Vertriebenen bewertet hat. ${ }^{11}$ Eine vertiefte Berücksichtigung der Untergliederungen des BdV, aber auch der individuellen Wahrnehmung deutscher Vertriebener zu den Entwicklungen, beispielsweise um das Jahr 1989 herum, könnte hier für ein tieferes Verständnis sorgen und die durch die geschichtspolitischen Kämpfe bedingte Schieflage der Wahrnehmung besser austarieren.

In künftigen Arbeiten könnten weitere Museen oder Museumsprojekte untersucht werden. So würde ein Einbeziehen der Museenlandschaft im heute zu Russland gehörenden Teil Ostpreußens nicht nur eine von der Europäischen Union weitgehend unbeeinflusste Museums- und Erinnerungskultur als Vergleichsfolie aufzeigen, sondern

8 Scholz: >Flucht und Vertreibung in der deutschen Erinnerungskultur, 2016, S. 167.

9 Vgl. Kap. 1.4, S. 40., Kap. 5.1, S. 215-217.

$10 \mathrm{Vgl}$. hierfür beispielhaft den 2016 erschienenen, vergleichend angelegten Sammelband zum Schicksal der Algerierfranzosen und der deutschen Vertriebenen: Borutta; Jansen et al. (Hg.): Vertriebene and Pieds-Noirs in Postwar Germany and France, 2016. Über das Themenfeld der Zwangsmigration der Deutschen hinaus, wäre ein Vergleich griechischer und türkischer Museen zum sgriechisch-türkischen Bevölkerungsaustausch v von 1923 interessant. Die europäische Dimension verlassend, bieten sich für einen globalhistorischen Ansatz Studien und ein Vergleich mit der Erinnerung an die pakistanisch-indischen Vertreibungen an, denen ebenfalls Jahrzehnte des Konfliktes, aber auch Verständigungsprozesse folgten. 
die im Diskurs wie auch in den Museen unterbelichtete, für das historische Geschehen aber zentrale sowjetisch-/russische Beteiligung an den Vertreibungen aufhellen. Im Sinne des Erkenntnisgewinns durch die Frage Was wird nicht erzählt? gilt dies auch, wenn diese in den dortigen Museen nicht oder kaum berücksichtigt ist.

Noch nicht vergleichend in den Blick genommen wurde die Darstellung von Flucht und Vertreibung in den jeweiligen Nationalmuseen. So könnte diese im Haus der Geschichte der Bundesrepublik Deutschland in Bonn und dem Deutschen Historischen Museum in Berlin mit den Darstellungen in dem im Entstehen begriffenen Museum der Polnischen Geschichte und dem renovierten Nationalmuseum in Prag verglichen werden. ${ }^{12}$ Eine künftige komparative Untersuchung des in Lublin entstehenden kresyMuseums und der SFVV bietet sich ebenfalls an. ${ }^{13}$ Insgesamt scheint ein vergleichender Gesamtüberblick über die zum Teil erhebliche Differenzen aufzeigenden Erinnerungskulturen der ostmitteleuropäischen und baltischen Länder zu Flucht und Vertreibung vielfältige Erkenntnisse zu versprechen. $\mathrm{Zu}$ diesem Kreis gehört auch Österreich, dessen enge Verbindungen zur Thematik mehrfach deutlich wurden, was sich aber nicht oder nur selten in seine notwendige Einbeziehung in die Debatten und wissenschaftlichen Auseinandersetzungen niederschlägt.

In Deutschland könnte neben den weiteren >ostdeutschen Landesmuseen auch das im seit 1945 bestehenden Grenzdurchgangslager Friedland 2016 eröffnete Museum Friedland einbezogen werden, das am authentischen und weiterhin als Aufnahmelager fungierenden Ort die Chronologie von Flucht und Vertreibung nach dem Krieg, die Kriegsheimkehrer, die DDR-Flüchtlinge und Spätaussiedler bis hin zu heutigen Fluchtbewegungen behandelt.

In der vorliegenden Studie wurden Stärken, Potenziale und Defizite der untersuchten Museen herausgearbeitet. Diese stehen stellvertretend für Verhärtungen, Missverständnisse, aber auch Wege der Verständigung im Diskurs über Flucht und Vertreibung. Die politischen Entwicklungen der letzten Jahre zeigen, dass geschichtspolitische Fragen und Konflikte innerhalb der Gesellschaften und der Europäischen Union eher zugenommen haben. Eine nachhaltige Verständigung und eine gemeinsame Sprache, die unterschiedliche Perspektiven und Erfahrungen nicht verdeckt, konnten zwischen Deutschland, Polen und Tschechien zum Komplex von Flucht und Vertreibung noch nicht gefunden werden. Das Einander verstehen ist in Hinblick auf die Zukunftsfähigkeit der Europäischen Union heute allerdings von entscheidender Relevanz. Umso bedeutender ist damit die Aufgabe der Museen, sind sie doch als Vermittler, als Orte des Verstehens und damit für das Ziel der Verständigung besonders geeignet.

Um dieses Ziel zu erreichen, muss den Museumsmachern der notwendige Freiraum für ihre Arbeit zugestanden werden. Ein mutiges Vorgehen von ihrer Seite aus

12 Die erste Ausstellung des tschechischen Nationalmuseums nach siebenjähriger Renovierungszeit hatte-zum hundertjährigen Jubiläum ihrer Gründung - die Tschechoslowakei zum Thema. In seiner Besprechung konstatiert Jakub Jareš, dass die tschechoslowakischen Minderheiten, Deutsche, Juden, Roma, Ungarn oder Ruthenen, trotz ihrer großen Bedeutung für die tschechische und slowakische Geschichte, keine Rolle spielen: Jareš: Rezension zu: Národní muzeum; Slovenské národné múzeum (Hg.): »Česko-slovenská/Slovensko-česká výstava«, 2019. 
sollte zugleich immer den mündigen Besucher als Gegenüber anerkennen. Viele der hier besprochenen Ausstellungen wären vielleicht im Vorfeld nicht so heftig diskutiert und viele Museen eher eröffnet worden, wenn die Konzeptionen und Ausstellungen nicht mit dem Ziel größtmöglicher Unangreifbarkeit und Angst vor möglichen $>$ Missdeutungen entwickelt oder vice versa von außen nicht entsprechende Forderungen und Befürchtungen geäußert worden wären. Damit ist keine unerreichbare und auch nicht wünschenswerte Politikferne gemeint: Gerade im Sinne einer Verständigung muss das Museum politische Themen diskutieren. Eine offene Herangehensweise mit Deutungsangeboten und didaktisch aufbereiteten Diskussionen der aktuellen wissenschaftlichen Forschung nähme schließlich die Last von den Ausstellungsmachern, eine allseits ausgewogene Ausstellung zu schaffen. Wenn das Haus der Europäischen Geschichte nun auf seine Kritiker zugeht und nach umfassender Reflexion eine Überarbeitung von Teilen der Ausstellung ankündigt, sollte dies nicht als Schwäche, sondern als Chance verstanden werden. ${ }^{14}$

Dieser Mut scheint besonders beim Blick auf gegenwärtige Herausforderungen von Flucht und Vertreibung erforderlich, aber auch bei der Betrachtung der Lage alter und neuer ethnischer Minderheiten. Die Verurteilung aktueller Vertreibungen fällt schwerer, wenn diese, wie im Falle der Vertreibung der Deutschen am Ende des Zweiten Weltkrieges, in einer bestimmten historischen Situation für unvermeidlich oder gerechtfertigt gehalten werden. ${ }^{15}$ Schließlich gibt es Stimmen, die einen Erfolg der Vertreibungen herausstellen - am polemischsten vielleicht die von Václav Klaus, als er den Israelis zur Lösung ihrer Minderheitenkonflikte die Vertreibung der Sudetendeutschen als Vorbild empfahl. ${ }^{16}$ Auch die weit von einem nachhaltigen Frieden und Verständigung entfernten Balkanstaaten diskutieren erneut Grenzziehungen nach ethnischen Kriterien. ${ }^{17}$

Gegenwärtige Ereignisse wie in Syrien, wo Enteignungsgesetze die Rückkehr von unliebsamen Flüchtlingen verhindern sollen, zeigen ebenso wie das Beispiel der Vertreibung der Rohingya in Myanmar, dass politische Führungen aus unterschiedlichen Gründen Vertreibungen weiter als Mittel der Politik nutzen. ${ }^{18}$ Aber nicht nur dort, auch in der westlichen Wissenschaft und Politik gibt es wieder Vertreter, die eine ethnische Segregation durch Umsiedlungen als vermeintliche Lösung unlösbarer und alter Konflikte vertreten. ${ }^{19}$

Wer die Notwendigkeit von Vertreibungen damals und in Ausnahmefällen auch heute noch sieht, darf sich aber in einer Hinsicht keine Illusionen machen: Die zwangsweise Umsiedlung von Millionen Menschen aus ihrer angestammten Heimat kann nie »ordentlich und human« durchgeführt werden: »Wenn diese Operationen sich nicht in

14 Vgl. für ein ähnliches Plädoyer gegen das Ziel der Ausstellungen als »perfekte Produkte« und stattdessen als »verhandelbare« und »wandelbare«Orte, die so ihr »kreatives Potential« entfalten können: Boroffka: Kulturelle Bildung und besucherorientierte Vermittlung, 2013, S. 44, $49 f$.

16 Vgl. ebenfalls kritisch zu der Frage nach dem `Erfolg` ethnischer Säuberungen, auch aus Perspektive der Täter: Schwartz: Ethnische »Säuberungen« in der Moderne, 2013, S. 644-646.

17 Mappes-Niediek: Die neue Balkanpolitik ist die ganz alte. Deutschlandfunk. 21.09.2018.

18 Kühntopp: Syrischen Flüchtlingen droht Enteignung. Deutschlandfunk. 27.04.2018.

19 Vgl. Schwartz: Ethnische »Säuberungen« in der Moderne, 2013, S. 624. Vgl. für ein Beispiel aus der Gegenwart des Nahostkonflikts: Hermann: Steht der Auszug der Palästinenser bevor? FAZ. 16.12.2017. 
Umständen ausführen lassen, in denen Brutalität, Ungerechtigkeit und sinnloses Leiden unvermeidlich sind, lassen sie sich gar nicht ausführen. ${ }^{20}$ Die Gefahr von Vertreibungen scheint in West- und Zentraleuropa heute gebannt zu sein, dennoch darf der fortwährende »umfassende Ordnungsanspruch des modernen Staates an sich« nicht unterschätzt werden. Auch im Zuge gegenwärtiger Integrationsdebatten stellt sich die Frage, wie viel Differenz die heute vermeintlich so aufgeklärten Gesellschaften eigentlich aushalten. ${ }^{21}$

Am aktuellen Beispiel von Klaus Johannis zeigen sich die derzeitigen Extreme der Lage der nationalen Minderheiten in Europa. Johannis ist als Angehöriger der deutschen Minderheit der Siebenbürger Sachsen in Rumänien nach Rudolf Schuster in der Slowakei der zweite osteuropäische Staatspräsident mit deutscher Herkunft nach 1989. Auf der einen Seite ist Johannis ein Symbol für die Anerkennung der deutschen Bevölkerungsgruppe als integraler und geschätzter Bestandteil der rumänischen Gesellschaft, auf der anderen Seite war er im Jahr 2018 einer seit 1989 beispiellosen Hetzkampagne der rumänischen Sozialdemokraten ausgesetzt, die ganz gezielt mit antideutschen Stereotypen seinen Kampf gegen die Korruption zu verhindern und ihn als politischen Gegner auszuschalten versuchte. ${ }^{22}$ Auch in Polen droht sich die Lage der nationalen Minderheiten nach den Wahlsiegen der PiS zu verschlechtern. ${ }^{23}$

Die Erinnerung an den Zweiten Weltkrieg, die Zerstörung Ostmitteleuropas durch den nationalsozialistischen deutschen Terror, die stalinistische Sowjetunion, aber auch die Beteiligung an der ethnischen Homogenisierung Europas durch bürgerliche Regierungen bleiben vor diesem Hintergrund eine anhaltende Mahnung gegen die fatale Wirkung von Krieg, Hass, radikalisierter Ideologie und ausuferndem Nationalismus. Der Krieg mahnt in erster Linie zum Nie wieder, aber auch zum Erhalt und Gedenken an das kulturelle Erbe des von diesem so schwer gezeichneten Ostmitteleuropa - und damit auch der Deutschen dieser Regionen. Daraus erwachsen in vielerlei Hinsicht der Wert und die Notwendigkeit, dem Thema Flucht und Vertreibung in der deutschen, polnischen, tschechischen und darüber hinaus der europäischen Erinnerungskultur einen festen Platz zu geben.

20 Douglas: »Ordnungsgemäße Überführung«, 2012, S. 460. Vgl. Kap. 3.7, S. $140 f$.

21 Brunnbauer; Esch: Ethnische Säuberungen in Ostmittel- und Südosteuropa, 2006, S. $17 f$.

22 Schwartz: »Der Deutsche ist schuld! !. Deutsche Welle. 26.08.2018.

23 Hanisch; Sieradzka: Verliert die deutsche Minderheit ihre Rechte? mdr. 09.08.2016. 

Anhang 



\section{Abstract}

This thesis has examined the development of the remembrance culture and the discourses on flight and expulsion of the Germans at the end of the Second World War in Germany, Poland, and the Czech Republic and the presentation of these topics in seven museum projects that has been conducted since 2000 . Thus the relationship of the three countries concerning the evaluation of the topic of flight and expulsion in its national as well as international context and on the European level will be analysed. The methodological basis of this study involves a historical discourse analysis and a museum analysis modified for the items examined here.

The summary of the political background of state organised forced migration and the historical events ends with a list of the decisive elements that are still assessed differently in the historical research and within the involved countries. Two fundamental points have been focused upon. Firstly, are flight and expulsions of the Germans part of a "century of expulsions « and therefore above all a consequence of the modern national state striving for ethnic homogeneity or can this be explained solely by the second world war caused by National Socialist Germany? This study combines the two approaches and uses them as the basis of assessment for the discourse and the museums. The second point is that in the three examined countries, different phases or actions of the events are remembered, which in Germany have been summarised by the term »flight and expulsion «. Whereas flight and forced removal are the centre of the remembrance culture in Germany, memories of the past events in Poland and the Czech Republic are formed by the allegedly correctly executed forced removals after the end of the war. This different way of remembrance is reflected linguistically in the different terms for the events. They form the basis of the continuing conflicts and misunderstandings on this topic.

When examining the discourse on flight and expulsion in the Cold War, both the internal and the even stronger external conflicting positions and confrontations have been analysed which conserved the antagonistic structure of discourse on this topic. Movements of smaller or bigger groups in all countries that have gone new ways to reach a better understanding internally and externally were rather limited in their influence. Only in the Federal Republic of Germany did a decisive change occur when the up to that time common national victims narrative was put into question in the 1960s. 
For the time after 1989, this study identifies how the national perspectives and old master narratives have continued to exist in all of the above-mentioned countries. The discourse on expulsion can be split up into three different phases. In the 1990s, the German-Polish relationship was determined by optimism, more specifically by understanding each other when questions of the present were in focus. In contrast, the relationship between Germany and the Czech Republic in this period of time was already called a small »ice age « because of the discussions, among other things, about compensations for the expellees. At the beginning of the 2000s, the relations between Germany and Poland and likewise those between Germany and the Czech Republic reached their low as reservations in Germany regarding the expansion of the European Union collided with the discussion on the Beneš decrees forced by the CDU/CSU and the project of the Bund der Vertriebenen (Federation of Expellees) to create a Zentrum gegen Vertreibungen (Centre against Expulsions). This again strengthened both Polish and Czech nationalism. The eastern neighbours of Germany were afraid of a state promoted revision of history by the initiative of the Bund der Vertriebenen. Whereas the German-Czech relationship improved after 2010 following the Bavarian-Czech agreement, the GermanPolish relationship reached a new low after the change of government in 2015 .

The existing historiographical differences and discourses form the background for the seven examined museums. The comparison of the Schlesisches Museum zu Görlitz (Silesian Museum in Görlitz) with the Muzeum Ślaskie w Katowicach (Silesian Museum in Katowice) led to the conclusion that the exhibition that was opened in Görlitz in 2006 was entirely dedicated to the European discourse of the 2000 s and the ideal of reaching agreements. The presentation of flight and expulsion is very reserved and tries to be as defensive as possible by forming a strong historical context with the National Socialist regime of terror and the parallelisation with the destiny of the Polish people expelled from the former Eastern parts of the Second Polish Republic (kresy). However, the effort that is linked with that, namely to be equally attractive and understandable for Germans and Polish, is only partly successful because in this presentation Polish commentators see above all a German perspective on Silesia. Already before opening the museum in Katowice in the year 2015, a discussion had been started on the structure and layout of this museum. The role that the German history of Silesia should play in this exhibition was hotly debated. After the director's forced retirement in 2013, the hitherto progressively developed concept was largely modified. Now the national Polish narrative of Silesia has once again more space in the permanent exhibition. However, in many places there is a differentiated presentation of the German past of upper Silesia. The occasional negligence of a bipolar German or Polish understanding of Upper Silesia supports the open presentation of the expulsion events.

The discussions on the Muzeum německy mluvicích obyvatel českých zemí (Museum of the German speaking citizens of Bohemia) in Ústí nad Labem showed the controversial musealisation of this topic also for the Czech Republic. The plans for the museum are close to the discourse determined by a policy of agreement similar to that found in civil organisations working on German-Czech understanding. Without becoming too idealistic, the coexistence will be presented to the same extent as the significant German part of Czech history is honoured. Equally, the expulsion of the Germans is considered in this. However, these plans form a strong contrast to a not too insignificant part of 
the political landscape in the Czech Republic. This project was stopped even more by the civil and political indifference towards it. The plan to build a Sudetendeutsches Museum in Munich (Museum of Sudeten Germans) can be regarded as complimentary concerning its basic orientation. The expulsion is integrated in a centuries old cultural history and does not form the focus. The ability to connect both for the Czechs and for the (Sudeten-) Germans is not only desired; it is a central element of the exhibition layout. A discourse on this museum hardly took place in public, and the construction of the house was supported by a broad political and civil majority in Bavaria.

After long lasting conflicts within Germany and with its neighbours, the Stiftung Flucht, Vertreibung, Versöhnung (Foundation Flight, Expulsion, Reconciliation) is now not far from its opening in the year 2021. Its concept papers contain different demands and points of criticism regarding the discourse as a synthesis. This European approach has been followed by providing an overview on forced removals in the 2oth century. It discusses differences and common aspects. These expulsions will be grouped together with the political background of state enforced migration and the National Socialist German war but also with crimes of occupation around the focus of the exhibition, the flight and expulsions of the Germans. In this way, both the elements of the Zentrum gegen Vertreibungen and the consideration of points of criticism which accompanied the first years of the Stiftung can be found in the concept. This means that neither should the expulsions of the Germans be made smaller by way of over-contextualisation nor should the other expulsions serve to highlight a special German destiny. In the planned exhibition, Polish visitors can find contacts to their past by studying the plan of the ethnic new order of Europe by the National Socialists, which hit their ancestors fatally, and by the forced removals from the kresy. Amongst other things, Czech visitors can understand from the presented context of its expulsions that expelling the Sudeten-Germans is not only a specific German-Czech phenomenon related to World War II, but also a political concept still at work today. In contrast to all the other institutions discussed here, the Stiftung also puts a focus on the presentation of current flight and expulsion movements. If the successful realisation of the ambitious exhibition concept leads to an end of the often polemic discussions on the institutionalisation of the place of memory of flight and expulsion, and if the foundation can be a basis for understanding, is highly dependent on its future acceptance in Poland and the Czech Republic.

The Museum of the Second World War in Danzig, opened in 2017, has been praised worldwide by the serious press. Its assessment of flight and expulsion follows a conventional and patriotic Polish master narrative; the presentation of the destiny of the expellees, however, an empathic perspective. The expulsion of the Germans is dealt with in several parts. In the room that is dedicated exclusively for forced migration at the end of the war, a rather neglecting parallelisation of the differences to other forced migration at this time leads to a certain marginalisation of the events. However, in several places the exhibition also reveals some critical potential concerning flight and expulsions, for example by presenting the rapes at the end of the war, and the presentation of the ship bell of the Wilhelm Gustloff as a symbol of the forcibly displaced Germans. Yet, the progressive elements of the museum's exhibition are to be found in other parts. This can also be seen by the fact that the national conservative criticism of this exhibition hardly expressed their opinion on the part of the exhibition concerning flight 
and expulsion. In contrast to its initial impulse to face the German initiative of the Zentrum gegen Vertreibungen and the Stiftung Flucht, Vertreibung, Versöhnung by their own museum, the topic remains a subordinate element because of the sheer dimension of the exhibition.

In the discussion of the House of European History, opened in Brussels in 2017, which for a long time was not very dynamic, the presentation of forced removal and the flight and expulsion of the Germans has been a constant topic. Within the exhibition it can be found above all in a small area dedicated to forced migration at the end of the war. This element is different from the rest of the exhibition because it chooses a primarily national historical German approach to this topic without, however, blaming or criticising Poland or the Czech Republic. The end of this, for many regions in Eastern Central Europe, significant elements of the multi-ethnic composition of the population is not displayed, and as a consequence the chance is not used to present the crucial dimension of this loss. Immediately, this conventional German narrative on expulsion was revealed and attacked in a polemic way by Polish critics who attacked the entire Haus severely. Most critics oversaw the especially positive, inquisitive, and dialectic character of this exhibition, which looks the visitor in the face and provokes his own assessment. Especially in the field of flight and expulsion, this opportunity is not offered, and therefore the chance to adapt this narrative to the presentations in Poland and the Czech Republic is not used.

Concerning the question if and how regional, national or European narratives can be found in the examined institutions, it can be stated that all institutions, with different intensity, are attempting European narratives in the sense of multiperspectivity and a presentation that goes beyond the national framework. Old and new narratives continue to be present, or, in the case of the Haus, to be master narratives of the European Union despite its often self-critical approach. Flight and expulsion as part of the National Socialist and Soviet destruction in Eastern Central Europe by genocide and uncountable, at first caused by themselves, forced migrations are in no consistent manner mentioned in any of the examined institutions or concept papers as a history of the loss of European culture.

Although there is as yet no complete agreement in all fields of research between German, Polish and Czech scientists who are especially keen on creating understanding each other, the coming together in science is reflected in the museums in the way that there are no clear dissonances between the different exhibitions and concepts. Differences in content can be seen in details and above all in what is left untold. The assumption that museums tend to rather avoid than offensively discuss especially controversial topics in their exhibitions out of different motives has again been confirmed. Though this does not lead to an imbalance in the presentation, it does not really promote a critical controversy which is to be regarded as the basis of a successful understanding and agreement.

In the study presented here, positive elements, potentials and deficits of the examined museums have been brought to light. They represent conflicts and misunderstandings, but also ways of understanding in the discourse on flight and expulsion. The political developments of the last years bear witness to the fact that historical-political questions and conflicts within the various societies and the European Union have in- 
creased. A sustainable understanding and a common language that does not cover up different perspectives and experiences could not be found between Germany, Poland, and the Czech Republic on the issue of flight and expulsion. However, understanding each other seems to be especially significant regarding the future of the European Union. All the more important, then, is the task of the museums. They are ideally suited as mediators and as places of understanding, and, as a result, have the capability to promote agreements between nations and people. 

Abkürzungs- und Zeitungsverzeichnis 


\begin{tabular}{|c|c|}
\hline \multicolumn{2}{|c|}{ Museen und Stiftungen } \\
\hline DHM & Deutsches Historisches Museum \\
\hline ENRS & $\begin{array}{l}\text { Europäisches Netzwerk Erinnerung und Solidarität (European Network Re- } \\
\text { membrance and Solidarity) }\end{array}$ \\
\hline $\mathrm{HdG}$ & Haus der Ceschichte der Bundesrepublik Deutschland \\
\hline $\mathrm{HEH}$ & Haus der Europäischen Ceschichte (House of European History) \\
\hline MIIW & Museum des Zweiten Weltkrieges in Danzig (Muzeum II Wojny Światowej) \\
\hline MŚK & Muzeum Śląskie (Schlesisches Museum in Kattowitz) \\
\hline SFVV & Stiftung Flucht, Vertreibung, Versöhnung \\
\hline SMG & Schlesisches Museum zu Görlitz \\
\hline ZgV & Zentrum gegen Vertreibungen \\
\hline \multicolumn{2}{|c|}{ Staaten, Ministerien und Institute } \\
\hline $\mathrm{bpb}$ & Bundeszentrale für politische Bildung \\
\hline ČSFR & $\begin{array}{l}\text { Česká a Slovenská Federativní Republika-Tschechische und Slowakische Fö- } \\
\text { derative Republik (1990-1992) }\end{array}$ \\
\hline ČSR & $\begin{array}{l}\text { Československá republika - Tschechoslowakische Republik (1918-1939; 1945- } \\
\text { 1960) }\end{array}$ \\
\hline ČSSR & $\begin{array}{l}\text { Československá socialistická republika - Tschechoslowakische Sozialistische } \\
\text { Republik (1960-1990) }\end{array}$ \\
\hline DDR & Deutsche Demokratische Republik \\
\hline EWG & Europäische Wirtschaftsgemeinschaft \\
\hline EP & Europäisches Parlament \\
\hline IPN & Instytut Pamięci Narodowej (Institut für Nationales Gedenken) \\
\hline VRP & Volksrepublik Polen (PRL - Polska Rzeczpospolita Ludowa) \\
\hline \multicolumn{2}{|c|}{ Parteien und Verbände } \\
\hline AfD & Alternative für Deutschland \\
\hline ANO & Akce nespokojených občanů (Aktion unzufriedener Bürger) \\
\hline BdV & $\begin{array}{l}\text { Bund der Vertriebenen-Vereinigte Landsmannschaften und Landesverbän- } \\
\text { de e. V. }\end{array}$ \\
\hline CDU & Christlich Demokratische Union Deutschlands \\
\hline CSU & Christlich-Soziale Union in Bayern \\
\hline ČSSD & $\begin{array}{l}\text { Česká strana sociálně demokratická (Tschechische Sozialdemokratische Par- } \\
\text { tei) }\end{array}$ \\
\hline ECR & European Conservatives and Reformists \\
\hline FDP & Freie Demokratische Partei \\
\hline $\mathrm{GB} / \mathrm{BHE}$ & Gesamtdeutscher Block/Bund der Heimatvertriebenen und Entrechteten \\
\hline KSČM & $\begin{array}{l}\text { Komunistická strana Čech a Moravy (Kommunistische Partei Böhmen und } \\
\text { Mährens) }\end{array}$ \\
\hline
\end{tabular}




\begin{tabular}{|c|c|}
\hline KDU-ČSL & $\begin{array}{l}\text { Křest'anská a demokratická unie - Československá strana lidová (Christliche } \\
\text { und Demokratische Union - Tschechoslowakische Volkspartei) }\end{array}$ \\
\hline LPR & Liga Polskich Rodzin (Liga Polnischer Familien) \\
\hline ODS & Občanská demokratická strana (Demokratische Bürgerpartei) \\
\hline PO & Platforma Obywatelska (Bürgerplattform) \\
\hline PZPR & $\begin{array}{l}\text { Polska Zjednoczona Partia Robotnicza - Polnische Vereinigte Arbeiterpartei } \\
(1948-1990)\end{array}$ \\
\hline PSL & Polskie Stronnictwo Ludow (Polnische Bauernpartei/Polnische Volkspartei) \\
\hline PiS & Prawo i Sprawiedliwość (Recht und Gerechtigkeit) \\
\hline RAŚ & Ruch Autonomii Śląska (Bewegung für die Autonomie Schlesiens) \\
\hline SdP & Sudetendeutsche Partei (1933/1935-1938) \\
\hline SED & Sozialistische Einheitspartei Deutschlands \\
\hline SPD & Sozialdemokratische Partei Deutschlands \\
\hline SRP & $\begin{array}{l}\text { Samoobrona Rzeczpospolitej Polskiej (Selbstverteidigung der Republik Po- } \\
\text { len) }\end{array}$ \\
\hline SL & Sudetendeutsche Landsmannschaft \\
\hline TOP 09 & Tradice, odpovědnost, prosperita (Tradition, Verantwortung, Wohlstand) \\
\hline \multicolumn{2}{|c|}{ Historische Begriffe } \\
\hline DVL & Deutsche Volksliste \\
\hline SBZ & Sowjetische Besatzungszone \\
\hline \multicolumn{2}{|l|}{ Gesetze } \\
\hline BVFC & Bundesvertriebenengesetz \\
\hline DHMC & Gesetz zur Errichtung einer Stiftung Deutsches Historisches Museum \\
\hline LAC & Lastenausgleichsgesetz \\
\hline \multicolumn{2}{|c|}{ Zeitungen und Medienportale } \\
\hline & Aktuálně.cz \\
\hline & Badische Zeitung \\
\hline & BauNetz \\
\hline & Bayernkurier \\
\hline & Berliner Morgenpost \\
\hline & Berliner Zeitung \\
\hline & Česká pozice \\
\hline ČT & Česká televize \\
\hline
\end{tabular}


542 Flucht und Vertreibung in europäischen Museen

\begin{tabular}{|c|c|}
\hline & České noviny \\
\hline \multirow[t]{5}{*}{ Culture.pl } & Culture.pl EN | Polish culture: literature, art, film, design \\
\hline & Daily Mail \\
\hline & Das Erste \\
\hline & Der Spiegel \\
\hline & Der Standard \\
\hline \multirow[t]{2}{*}{ TAS } & Der Tagesspiegel \\
\hline & Der Westpreuße. Unser Danzig \\
\hline DW & Deutsche Welle \\
\hline DOD & Deutscher Ostdienst \\
\hline DLF & Deutschlandfunk \\
\hline DLF Kultur & Deutschlandfunk Kultur \\
\hline Dialog & Dialog. Deutsch-Polnisches Magazin (Magazyn Polsko-Niemiecki) \\
\hline Dialog & Dialog - Miesięcznik poświęcony dramaturgii współczesnej \\
\hline \multirow{2}{*}{$\begin{array}{l}\text { Dialog } \\
\text { Forum }\end{array}$} & Dialog Forum. Perspektiven aus der Mitte Europas \\
\hline & Die Presse \\
\hline \multirow[t]{9}{*}{ taz } & Die Tageszeitung \\
\hline & Die Welt \\
\hline & Die Zeit \\
\hline & dzieje.pl \\
\hline & Dziennik \\
\hline & Dziennik Bałtycki \\
\hline & Dziennik Zachodni \\
\hline & Echo \\
\hline & Echo24 \\
\hline \multirow[t]{3}{*}{ eska } & Radio ESKA Śląsk \\
\hline & FOCUS \\
\hline & Foreign Policy \\
\hline FAZ & Frankfurter Allgemeine Zeitung \\
\hline FR & Frankfurter Rundschau \\
\hline GW & Gazeta Wyborcza \\
\hline $\begin{array}{l}\text { gdansks- } \\
\text { trefa.com }\end{array}$ & Gdańsk Strefa Prestiżu \\
\hline
\end{tabular}




\begin{tabular}{|c|c|}
\hline & gosc.pl \\
\hline & Haló noviny \\
\hline & Hospodářské noviny \\
\hline \multirow[t]{2}{*}{ iDNES } & (Internetausgabe der) Mladá fronta Dnes \\
\hline & Jüdische Allgemeine \\
\hline JF & Junge Freiheit \\
\hline \multirow[t]{2}{*}{ KSTA } & Kölner Stadt-Anzeiger \\
\hline & krytyka polityczna \\
\hline $\begin{array}{l}\text { Landes- } \\
\text { Echo }\end{array}$ & LandesEcho. Zeitschrift der Deutschen in der Tschechischen Republik \\
\hline \multirow[t]{2}{*}{$\mathrm{mdr}$} & Mitteldeutscher Rundfunk \\
\hline & Münchner Merkur \\
\hline nettg.pl & netTC.pl-Cospodarka-Ludzie \\
\hline NOZ & Neue Osnabrücker Zeitung \\
\hline \multirow[t]{2}{*}{ NZZ } & Neue Zürcher Zeitung \\
\hline & New Europe \\
\hline \multirow[t]{3}{*}{ NYT } & New York Times \\
\hline & Newsweek Polska \\
\hline & niezależna \\
\hline NDR & Norddeutscher Rundfunk \\
\hline NWZ & Nordwest-Zeitung \\
\hline \multirow[t]{8}{*}{ Novinky.cz } & Novinky \\
\hline & Oberhessen-live \\
\hline & OKO.press \\
\hline & Onet \\
\hline & Onet Śląsk \\
\hline & Polityka \\
\hline & Radio Praha \\
\hline & Respekt \\
\hline $\mathrm{RP}$ & Rheinische Post \\
\hline rmf24 & $\mathrm{rmf} 24$ \\
\hline $\mathrm{rbb}$ & Rundfunk Berlin-Brandenburg \\
\hline
\end{tabular}


544 Flucht und Vertreibung in europäischen Museen

\begin{tabular}{|l|l|}
\hline RP & Rzeczpospolita \\
\hline & Sächsische Zeitung \\
\hline & Salzburger Nachrichten \\
\hline & Schlesische Nachrichten \\
\hline & Schleswig-Holsteinischer Zeitungsverlag \\
\hline & Siebenbürgische Zeitung \\
\hline & Silesion \\
\hline & Stern \\
\hline SZ & Stuttgarter Zeitung \\
\hline & Süddeutsche Zeitung \\
\hline TVP & Sudetendeutsche Zeitung \\
\hline & Telewizja Polska \\
\hline & Telewizja Republika \\
\hline tvn24 & The Brussels Times \\
\hline & TVN24 \\
\hline & Týden \\
\hline & Washington Post \\
\hline & Wochenblatt. Zeitung der Deutschen in Polen \\
\hline WP Opinie & Wirtualna Polska - Opinie \\
\hline & wPolityce \\
\hline & Wprost \\
\hline & ZDF heute \\
\hline
\end{tabular}




\section{Quellen- und Literaturverzeichnis}

\section{Konzeptionspapiere und Ausstellungskataloge}

Auf der Suche nach Schlesien. Eine Einführung in die Ausstellung. In: BAUER, MARKuS (HG.): Auf der Suche nach Schlesien. Zwischenbilanz beim Aufbau des Schlesischen Museums zu Görlitz. Halle an der Saale 2001, S. 22-58.

Bauer, Markus; Brade, Johanna; Kügler, Martin; Pietsch, Martina (Hg.): Schlesisches Museum zu Görlitz - Museum für eine europäische Kulturregion. Muzeum Ślaskie w Görlitz - Muzeum europejskiego regionu kulturowego. Dößel 2006.

Beauftragter der Bundesregierung für Kultur und Medien: Konzeption. "Sichtbares Zeichen gegen Flucht und Vertreibung«. Ausstellungs-, Dokumentations- und Informationszentrum in Berlin. 19.03.2008. URL: www.sfvv.de/sites/default/files/downloads/ konzeption_bundesregierung_2008_sfvv_o.pdf (letzter Zugriff: 28.02.2018).

Bieniek, Michą; Miśniakiewicz, MaŁgorzata; Rewers, Ewa; Stec, Anna; Topp, Izolda (Hg.): Niemcy nie przyszli. The Germans did not come. Wrocław 2015.

Collegium Bohemicum: Rahmenkonzeption des Museums der deutschsprachigen Bewohner der böhmischen Länder. 2010. URL: www.collegiumbohemicum.cz/download/ newsletter_pyeuuloha_normecky_internet.pdf (letzter Zugriff: 16.12.2018).

Committee of Experts; Borodziej, WŁodzimierz; Cracco, Giorgio; Dumoulin, MiChel; HÜtTer, HANS WALter; Joly, MARIE-HÉlÈne et Al.: Conceptual Basis for a House of European History. Brussels 2008. URL: www.europarl.europa.eu/meetdocs/ 2004_2009/documents/dv/745/745721/745721_en.pdf (letzter Zugriff: 19.04.2018).

European Parliament: Building a House of European History. A Project of the European Parliament. Hg. v. Directorate-General for Communication. Luxembourg 2013. URL: www.europarl.europa.eu/tenders/2013/20130820b/Annex_I-Building_a_ House_of_European_History.pdf (letzter Zugriff: 02.04.2018).

FendL, Elisabeth: Sudetendeutsches Museum - Konzept. [Unveröffentlicht, im Besitz des Verfassers]. Januar 2016.

Fendl, Elisabeth; Mohr, Klaus (Hg.): Heimat Geschichten. Aus den Sammlungen des Sudetendeutschen Museums. München 2018.

Henker, Michael (Hg.): Die Heimatsammlungen der Sudeten- und Ostdeutschen in Bayern. Ein Führer zu 86 Heimatsammlungen. München 2009. 
Krauss, Marita: »Zusammenleben«. Das Sudetendeutsche Museum in München ein Konzept und ein grenzüberschreitendes Zeitzeugenprojekt. In: Kovéč, DušAN; Řezník, Miloš; Schulze Wessel, Martin (Hg.): Erinnern - Ausstellen - Speichern. Deutsch-tschechische und deutsch-slowakische Beziehungsgeschichte im Museum. Essen 2017, S. 119-135.

Machcewicz, Pawe€; Majewski, Piotr M.: Muzeum II Wojny Światowej. Zarys koncepcji programowej. In: Przegląd Polityczny (2008), H. 91/92, S. 46-51.

Machcewicz, Pawee; Majewski, Piotr M.: The Museum of the Second World War in Poland. A Concept Paper. 22.11.2008. URL: www.muzeum1939.pl/object.php/act/ sho/oid/060dace39c381925572f60c06ab61b45 (letzter Zugriff: 26.11.2016).

Mouralová, Blanka; Šícha, Jan: 1500 Quadratmeter und 800 Jahre Leben. Collegium Bohemicum 2016. URL: www.collegiumbohemicum.cz/de/clanek/344-1500quadratmeter-und-800-jahre-leben/ (letzter Zugriff: 15.12.2018).

Museum of the Second World War: 45 End of War in 45 Artefacts. Catalogue of the Exhibition. Temporary exhibition of the Museum of the Second World War. Gdańsk 2015.

Muzeum II Wojny Swiatowej: Museum of the Second World War. Catalogue of the Permanent Exhibition. Gdańsk 2016.

Schulze Wessel, Martin; Franzen, K. Erik; Kraft, Claudia; SchülerSpringorum, Stefanie; Völkering, Tim; Zimmermann, Volker; Zückert, MARTin: Konzeptionelle Überlegungen für die Ausstellungen der »Stiftung Flucht, Vertreibung, Versöhnung«. 09.09.2010. URL: https://www.hsozkult.de/debate/id/ diskussionen-1355 (letzter Zugriff: 05.03.2018).

Stiftung Flucht, Vertreibung, Versöhnung: Eckpunkte für die Arbeit der Stiftung Flucht, Vertreibung, Versöhnung und die geplante Dauerausstellung. 25.10.2010. URL: www.sfvv.de/sites/default/files/downloads/2010_10_25_eckpunkte_sfvv.pdf (letzter Zugriff: 07.04.2016).

Stiftung Flucht, Vertreibung, Versöhnung: Konzeption für die Arbeit der Stiftung Flucht, Vertreibung, Versöhnung und Leitlinien für die geplante Dauerausstellung. Berlin 2012. URL: http://sfvv.de/de/stiftung/grundlagenpapiere/konzeption-2012 (letzter Zugriff: 02.02.2014).

Stiftung Flucht, Vertreibung, Versöhnung: Konzept für die Dauerausstellung. Juni 2017. URL: www.sfvv.de/sites/default/files/2017_Konzept_Dauerausstellung_sfvv. pdf (letzter Zugriff: 29.01.2018).

Stiftung Haus der Geschichte der Bundesrepublik Deutschland (Hg.): Flucht, Vertreibung, Integration. Begleitbuch zur Ausstellung im Haus der Geschichte der Bundesrepublik Deutschland, Bonn, 3. Dezember 2005 bis 17. April 2006, im Deutschen Historischen Museum, Berlin, Mai bis August 2006, im Zeitgeschichtlichen Forum Leipzig der Stiftung Haus der Geschichte der Bundesrepublik Deutschland, 1. Dezember 2006 bis 15. April 2007; Unter Mitarbeit von Petra Rösgen. Bielefeld 2005.

VöLKERING, TIM: »Flucht und Vertreibung« ausstellen - aber wie? Konzepte für die Dauerausstellung der »Stiftung Flucht, Vertreibung, Versöhnung« in der Diskussion. Bonn 2011.

Zentrum gegen Vertreibungen: Die Gerufenen. Deutsches Leben in Mittel- und Osteuropa; Unter Mitarbeit von Katharina Klotz. Potsdam 2009 (2. Aufl.). 
Zentrum gegen Vertreibungen: Angekommen. Die Integration der Vertriebenen in Deutschland; Unter Mitarbeit von Katharina Klotz. Potsdam 2011 (2. Aufl.).

Zentrum gegen Vertreibungen: Erzwungene Wege. Flucht und Vertreibung im Europa des 20. Jahrhunderts; Unter Mitarbeit von Wilfried Rogasch, Katharina Klotz und Doris Müller-Toovey. Wiesbaden 2011 (2. Aufl.).

Zentrum gegen Vertreibungen: Verschwunden. Orte, die es nicht mehr gibt. Potsdam 2017.

Zentrum gegen Vertreibungen: In Lagern. Schicksale deutscher Zivilisten im östlichen Europa 1941-1955; Unter Mitarbeit von Wilfried Rogasch. Bonn 2019.

Zentrum gegen Vertreibungen. Stiftung der deutschen Heimatvertriebenen Berlin: »Aufgaben und Ziele«. Juni 2000. In: Haslinger, Peter; Franzen, K. Erik; WesSEL, MARTIN SCHUlZE (Hg.): Diskurse über Zwangsmigration in Zentraleuropa. Geschichtspolitik, Fachdebatten, literarisches und lokales Erinnern seit 1989. München 2008, S. 287-288.

\section{Persönliche Korrespondenzen}

BAVEndAmM, Gundula: Stiftung Flucht, Vertreibung, Versöhnung: Antworten auf Ihre Fragen. 27.06.2018 an Vincent Regente. E-Mail).

MORK, ANDREA: RE: Questions on my PhD project about the HEH. 02.08.2018 an Vincent Regente. Email).

\section{Pressemitteilungen, Berichte, Erklärungen und Manifeste}

Arbeitsgemeinschaft der KZ-Gedenkstätten in der Bundesrepublik Deutschland: Stellungnahme zum Antrag von Abgeordneten der CDU/CSU zur »Förderung von Gedenkstätten zur Diktaturgeschichte in Deutschland - Gesamtkonzept für ein würdiges Gedenken aller Opfer der beiden deutschen Diktaturen«. 2004. URL: http://hsozkult.geschichte.hu-berlin.de/index.asp?id=490\&view=pdf\&pn=forum \&type=diskussionen (letzter Zugriff: 15.08.2018).

Bund der Vertriebenen: Die Weichen sind richtig gestellt. Bundesstiftung »Flucht, Vertreibung, Versöhnung« beruft Direktor und Wissenschaftlichen Beirat. 07.07.2009. URL: $w$ ww.bund-der-vertriebenen.de/presse/index.php3?id=866 (letzter Zugriff: 02.02.2014).

Bund der Vertriebenen: Der BdV hat zwei Millionen Mitglieder. Anderweitige Spekulationen sind falsch. 07.01.2010. URL: www.bund-der-vertriebenen.de/presse/newsdetail/datum/2010/01/07/der-bdv-hat-zwei-millionen-mitglieder.html (letzter Zugriff: 15.08.2018).

Bund der Vertriebenen: BdV-Präsidentin Erika Steinbach MdB begrüßt Konzeption der Stiftung Flucht, Vertreibung, Versöhnung. 31.08.2012. URL: www.bund-dervertriebenen.de/presse/index.php3?id=1278 (letzter Zugriff: 02.02.2014).

Bund der Vertriebenen: Dr. Gundula Bavendamm wird Direktorin der »Stiftung Flucht, Vertreibung, Versöhnung«. 22.02.2016. URL: www.bund-der-vertriebenen.de/ 
presse/news-detail/datum/2016/02/22/dr-gundula-bavendamm-wird-direktorinder-stiftung-flucht-vertreibung-versoehnung.html (letzter Zugriff: 06.03.2018).

Bund der Vertriebenen: Denkmal für polnische Opfer als Mosaikstein der grenzüberschreitenden Verständigung. Bewältigung gemeinsamer Geschichte durch gegenseitige Empathie. 15.11.2017. URL: www.bund-der-vertriebenen.de/presse/ news-detail/datum/2017/11/15/denkmal-fuer-polnische-opfer-als-mosaikstein-dergrenzueberschreitenden-verstaendigung.html (letzter Zugriff: 07.03.2018).

Bundesregierung: Neuer Stiftungsrat der Stiftung Flucht, Vertreibung, Versöhnung nimmt Arbeit am 25. Oktober auf. 06.09.2010. URL: http://presseservice. pressrelations.de/standard/result_main.cfm?\%20pfach=1\&n_firmanr_=103124 \&sektor=pm\&detail=1\&r=423356\&sid=\&aktion=jour_pm\&quelle=0 (letzter Zugriff: 23.03.2018).

Bundesregierung: Inhaltliches Fundament der Stiftung Flucht, Vertreibung, Versöhnung veröffentlicht. 29.08.2012. URL: https://www.bundesregierung.de/ ContentArchiv/DE/Archiv17/Pressemitteilungen/BPA/2012/08/2012-08-29neumann-fudament-stiftung.html (letzter Zugriff: 23.03.2018).

Česko-německá deklarace o vzájemných vztazích a jejich budoucím rozvoji. 21.01.1997. URL: \#https://www.mzv.cz/jnp/cz/o_ministerstvu/historie_a_osobnosti_ceske_ diplomacie/druha_svetova_valka_a_jeji_dusledky/dokumenty/cesko_nemecka_ deklarace_o_vzajemnych.html (letzter Zugriff: 21.12.2018).

Civitas: Rewriting History. 07.04.2011. URL: www.civitas.org.uk/2011/04/07/rewritinghistory/ (letzter Zugriff: 22.04.2018).

Collegium Bohemicum: Die Ausstellung des Collegiums Bohemicums »Unsere Deutschen« geht in die letzte Realisationsphase. 01.11.2016. URL: www. collegiumbohemicum.cz/de/aktualita/81-die-ausstellung-des-collegiumsbohemicums-unsere-deutschen-geht-in-die-letzte-realisationsphase/sess_ 3421006f5bib6521bcobo6acc7dc5802/ (letzter Zugriff: 18.12.2018).

Collegium Bohemicum: Das Collegium Bohemicum hat einen neuen Direktor und wissenschaftlichen Beirat. 21.03.2017. URL: www.collegiumbohemicum.cz/de/clanek/441das-collegium-bohemicum-hat-einen-neuen-direktor-und-wissenschaftlichenbeirat/ (letzter Zugriff: 16.12.2018).

Dalos, György; François, Etienne; Kaminsky, AnNa; Kerski, Basil; Mählert, UlRICH; MeCKel, MARKUS ET AL.: 1914, 1989 und das Zeitalter der Extreme. Wer an den Ersten Weltkrieg erinnert muss über dessen Folgen sprechen. Manifest für eine europäische Erinnerungskultur. In: Inter Finitimos. Jahrbuch zur deutsch-polnischen Beziehungsgeschichte (2013/14), H. 11, S. 17-20.

Deutsch-Tschechische Erklärung über die gegenseitigen Beziehungen und deren künftige Entwicklung. 21.01.1997. URL: https://www.bundestag.de/parlament/ geschichte/gastredner/havel/havel2/244732 (letzter Zugriff: 21.12.2018).

Die Beauftragte der Bundesregierung für Kultur und Medien (13.06.2017): Bericht der Bundesregierung über die Maßnahmen zur Förderung der Kulturarbeit gemäß $\$ 96$ Bundesvertriebenengesetz (BVFG) in den Jahren 2015 und 2016. URL: https://m.bundesregierung.de/Content/DE/_Anlagen/BKM/2017/2017-06-13Bericht-\%C2\%A796-2015_2016.pdf?_blob=publicationFile\&v=1 (letzter Zugriff: 22.11.2017). 
Gemeinsame Deutsch-Tschechische Historikerkommission: Stellungnahme der DeutschTschechischen Historikerkommission zu den Vertreibungsverlusten. Pressemitteilung vom 17.12.1996. In: HoENSCH, JöRG K.; LEMBERG, HANS (HG.): Begegnung und Konflikt. Schlaglichter auf das Verhältnis von Tschechen, Slowaken und Deutschen 1815-1989. Essen 2001, S. 245-247.

Huijgen, ARnold: The House of European History erases religion. Acton Institute 14.06.2017. URL: https://acton.org/publications/transatlantic/2017/06/14/houseeuropean-history-erases-religion (letzter Zugriff: 22.04.2018).

JU Regionalverband Heilbronn-Franken: Bundestagsabgeordnete Erika Steinbach begeistert auf Schloß Stetten. 25.10.2015. URL: www.ju-heilbronn-franken.de/aktuelles/ bundestagsabgeordnete-erika-steinbach-begeistert-auf-schloss-stetten/ (letzter Zugriff: 16.08.2018).

Kopernikus-Gruppe: Mitteilung über die Sitzung der Kopernikus-Gruppe am 30.11./1.12.2007. Arbeitspapier XIV. Ein Museum der Geschichte des Zweiten Weltkriegs und der Versöhnung - Der Rahmen für das »sichtbare Zeichen«. 2007. URL: www.deutsches-polen-institut.de/politik/kopernikus-gruppe/arbeitspapierxiv/ (letzter Zugriff: 22.02.2018).

Kopernikus-Gruppe: Arbeitspapier IX der Kopernikus-Gruppe. Dezember 2004. IX Raport Grupy Kopernika. Grudzień 2004. In: Haslinger, Peter; Franzen, K. Erik; Wessel, Martin Schulze (Hg.): Diskurse über Zwangsmigration in Zentraleuropa. Geschichtspolitik, Fachdebatten, literarisches und lokales Erinnern seit 1989. München 2008, S. 346-353.

Kulturstaatsministerin Weiss begrüßt Vereinbarung von Projekten des »Europäischen Netzwerks Erinnerung und Solidarität«. 09.09.2005. URL: www. kulturforum.info/de/startseite-de/1019561-news-tipps/1000177-news/22491007432-kulturstaatsministerin-weiss-begruesst-vereinbarung-von-projektendes-europaeischen-netzwerks-erinnerung-und-solidaritaet (letzter Zugriff: 15.08.2018).

Madajczyk, Piotr; Ruchniewicz, Krzysztof; Troebst, Stefan; Wildt, Michael: Stellungnahme von ehemaligen Mitgliedern des Wissenschaftlichen Beraterkreises der Stiftung Flucht, Vertreibung, Versöhnung. 06.07.2015. URL: http:// krzysztofruchniewicz.eu/sich-konstruktiv-verhalten-heist-ernst-genommen-zuwerden/ (letzter Zugriff: 22.12.2018).

Manifest des Polnischen Komitees der Nationalen Befreiung vom 22. Juli 1944. 13.05.2018. URL: https:/www.herder-institut.de/no_cache/bestaende-digitaleangebote/e-publikationen/dokumente-und-materialien/themenmodule/quelle/ 1376/details.html, zuletzt aktualisiert am 13.05.2018.

Okresní rada Českého pohraničí, Ústí nad Labem: Protestujeme proti vystoupení pana premiéra Nečase před poslanci bavorského zemského sněmu. 26.02.2013. URL: https://www.klub-pohranici.cz/news/protestujeme-proti-vystoupeni-panapremiera-necase-pred-poslanci-bavorskeho-zemskem-snemu-/ (letzter Zugriff: 28.08.2018).

Platform of European Memory and Conscience; Ukielski, Pawe€; Kareniauskaite, Monika; Hrynko, Yana: The House of European History. Report on the Permanent Exhibition. 30.10.2017. URL: https://www.memoryandconscience.eu/wp-content/ 
uploads/2017/11/Report-on-the-HEH-by-the-Platform-of-European-Memory-

and-Conscience-30.10.2017.pdf (letzter Zugriff: 02.04.2018).

Stiftung Flucht, Vertreibung, Versöhnung: Jahresbericht 2009-2012. Berlin. 2012.

Stiftung Flucht, Vertreibung, Versöhnung: Wissenschaftlicher Beraterkreis tagt in Danzig. 18.10.2013. URL: www.sfvv.de/de/presse/wissenschaftlicher-beraterkreis-tagtdanzig-o (letzter Zugriff: 26.07.2018).

\section{Reden, Ansprachen, Grußworte}

Fernsehansprache von Bundeskanzler Willy Brandt aus Warschau, 7. Dezember 1970. URL: https://www.willy-brandt.de/fileadmin/brandt/Downloads/ Fernsehansprache_Willy_Brandt_Warschau_1970.pdf (letzter Zugriff: 02.08.2018).

Festrede von Prof. Dr. Andrzej Tomaszewski. Polnischer Generalkonservator a.D. und Vorsitzender des International Council on Monuments and Sites (ICOMOS). In: Verein der Freunde und Förderer des Schlesischen Museums zu Görlitz - Landesmuseum Schlesien e.V. (Hg.): Schlesisches Museum zu Görlitz. Eröffnung am 13. Mai 2006. Grußworte, Festrede, Predigt. Görlitz 2006, S. 22-28.

GRIGAT, STEPHAN: »Ostpreußen ist nicht sterblich!«. Die Rede des LO-Sprechers Stephan Grigat beim Jahrestreffen der Landsmannschaft Ostpreußen 2019 in Wolfsburg. 15.05.2019. URL: https://www.ostpreussen.de/lo/nachrichten/artikel/ ostpreussen-ist-nicht-sterblich.html (letzter Zugriff: 31.01.2020).

Grußwort von Dr. Herbert Hupka. Ehrenvorsitzender der Landsmannschaft Schlesien - Nieder- und Oberschlesien. In: Verein der Freunde und Förderer des Schlesischen Museums zu Görlitz - Landesmuseum Schlesien e.V. (Hg.): Schlesisches Museum zu Görlitz. Eröffnung am 13. Mai 2006. Grußworte, Festrede, Predigt. Görlitz 2006, S. 14-18.

Grußwort von Prof. Dr. Georg Milbradt. Ministerpräsident des Freistaates Sachsen. In: Verein der Freunde und Förderer des Schlesischen Museums zu Görlitz - Landesmuseum Schlesien e.V. (Hg.): Schlesisches Museum zu Görlitz. Eröffnung am 13. Mai 2006. Grußworte, Festrede, Predigt. Görlitz 2006, S. 8-9.

Grußwort von Prof. Dr. Hermann Schäfer. Abteilungsleiter beim Beauftragten der Bundesregierung für Kultur und Medien. In: Verein der Freunde und Förderer des Schlesischen Museums zu Görlitz - Landesmuseum Schlesien e.V. (Hg.): Schlesisches Museum zu Görlitz. Eröffnung am 13. Mai 2006. Grußworte, Festrede, Predigt. Görlitz 2006, S. 10-13.

Grütters, Monika: Grußwort Prof. Monika Grütters. In: Fendl, Elisabeth; Mohr, Klaus (Hg.): Heimat Geschichten. Aus den Sammlungen des Sudetendeutschen Museums. München 2018, S. 12-13.

Hans-Gert Poettering's inauguration speech as President of the European Parliament in Strasbourg. Feb. 13, 2007. EURACTIV. URL: https://www.youtube.com/watch?v= Gp2G47a-sik (letzter Zugriff: 23.04.2018).

HUPACH, SIGRID (18.12.2015): Rede zum Bericht der Bundesregierung über die Maßnahmen zur Förderung der Kulturarbeit gemäß $\$ 96$ des Bundesvertriebenengesetzes in 
den Jahren 2013 und 2014. URL: www.sigrid-hupach.de/fileadmin/btw2013hupach/ dokumente/18.12.2015_Kulturfoerderung_Bundesvertriebenengesetz_-_steno.pdf (letzter Zugriff: 06.03.2018).

Hupka, Herbert: Grußworte. In: BAuer, Markus (Hg.): Auf der Suche nach Schlesien. Zwischenbilanz beim Aufbau des Schlesischen Museums zu Görlitz. Halle an der Saale 2001, S. 9.

Müller, Emilia: Grußwort. In: Fendl, Elisabeth; Mohr, Klaus (Hg.): Heimat Geschichten. Aus den Sammlungen des Sudetendeutschen Museums. München 2018, S. 10-11.

Pöttering, Hans-Gert: Eröffnung des Hauses der Europäischen Geschichte. 04.05.2017. URL: www.kas.de/wf/de/33.48773/ (letzter Zugriff: 22.04.2018).

ProtschKa, Stephan: Deutsche Kultur nicht ins Museum packen! URL: https://www. youtube.com/watch?v=Tynil4NUCcs\&feature=youtu.be (letzter Zugriff: 15.12.2019).

Rede des Bayerischen Ministerpräsidenten Horst Seehofer, MdL, anlässlich der Grundsteinlegung für das Sudetendeutsche Museum am 16. September 2016, um $11.00 \mathrm{Uhr}$ in München. 16.09.2016. URL: www.bayern.de/wp-content/uploads/2016/09/16-09Grundsteinlegung-Sudetendeutsches-Museum.pdf (letzter Zugriff: 19.02.2018).

Rede von Bundeskanzlerin Merkel bei Baubeginn eines Dokumentationszentrums der Stiftung Flucht, Vertreibung, Versöhnung im Deutschlandhaus am 11. Juni 2013. URL: www.bundesregierung.de/ContentArchiv/DE/Archiv17/Reden/2013/06/ 2013-06-11-rede-merkel-stiftung-vertreibung.html (letzter Zugriff: 28.02.2018).

Rede von Bundeskanzlerin Merkel zum Gedenktag für die Opfer von Flucht und Vertreibung am 20. Juni 2018 in Berlin. URL: https://www.bundeskanzlerin.de/ Content/DE/Rede/2018/06/2018-06-20-rede-gedenkstunde-20-juni.html (letzter Zugriff: 12.08.2018).

Rede von Bundespräsident Joachim Gauck zum Gedenktag für die Opfer von Flucht und Vertreibung am 20.06.2015. URL: www.bundespraesident.de/SharedDocs/ Reden/DE/Joachim-Gauck/Reden/2015/06/150620-Gedenktag-Flucht-Vertreibung. html (letzter Zugriff: 12.08.2018).

SeEHOfer, Horst: Grußwort. In: Fendl, Elisabeth; MoHr, Klaus (Hg.): Heimat Geschichten. Aus den Sammlungen des Sudetendeutschen Museums. München 2018, S. 8-9.

STEINBACH, ERIKA: Ansprache zum Tag der Heimat des Bundes der Vertriebenen am 22. August 2009 im ICC Berlin. URL: www.bund-der-vertriebenen.de/presse/newsdetail/datum/2009/08/22/ansprache-zum-tag-der-heimat-des-bundes-dervertriebenen-am-22-august-2009-im-icc-berlin.html (letzter Zugriff: 12.04.2018).

StOIBER, Edmund: Probleme wegdrücken ist rückwärtsgewandt. Sudetendeutsche Zeitung. 09.06.2006 (23), S. 3-4.

\section{Gesetze und Verordnungen}

Deutscher Bundestag (21.12.2008): Gesetz zur Errichtung einer Stiftung "Deutsches Historisches Museum«(DHMG). DHMG, Fassung vom 14.06.2010. 
Kancelaria Sejmu (25.01.2018): Ustawa z dnia 23 lipca 2003 r. o ochronie zabytków i opiece nad zabytkami. URL: http://prawo.sejm.gov.pl/isap.nsf/DocDetails.xsp?id= WDU20031621568 (letzter Zugriff: 16.07.2018).

Kancelaria Sejmu (07.03.2018): Ustawa z dnia 21 listopada 1996 r. o muzeach. Dz.U. $1997 \mathrm{Nr} 5$ poz. 24. URL: http://prawo.sejm.gov.pl/isap.nsf/DocDetails.xsp?id= WDU19970050024 (letzter Zugriff: 29.03.2018).

SMYCZeK, PRzemysŁaW: Wspólne prowadzenie instytucji kultury przez samorząd województwa oraz jednostki samorządu terytorialnego i administrację rządową. Urząd Marszatkowski Województwa Śląskiego 06.10.2016. URL: sejmik.slaskie.pl/download/content/518 (letzter Zugriff: 18.04.2018).

\section{Weitere Primärquellen}

Danubius: Tézy o vysídlení československých Nemcov. In: Svědectví XV (1978), H. 57, S. 105-140.

Imagefilm der Stiftung Flucht, Vertreibung, Versöhnung. Weitere Beteiligte: Duncan McCauley. URL: https://www.sfvv.de/de/stiftung (letzter Zugriff: 22.12.2018).

Flucht, Vertreibung, Versöhnung. Zusammenfassung der wichtigsten Ergebnisse einer repräsentativen Bevölkerungsumfrage in Deutschland, Polen und Tschechien. Konzeption, Durchführung und Analyse: IfD Allensbach. 16.06.2015. URL: https:// www.sfvv.de/sites/default/files/zusammenfassung_allensbach_studie_sfvv.pdf (letzter Zugriff: 10.09.2018).

HÜBL, MILAN; ProchÁZKA, JAN; BLAŽEK, VLADIMÍR: Trialog o roce 1945. In: Host do domu 15 (1968), H. 5, S. 22-29.

IPNtvPL: Niezwyciężeni. URL: https://www.youtube.com/watch?v=M7MSG4Q-4as (letzter Zugriff: 22.12.2018).

Koalitionsvertrag von CDU, CSU und SPD. Gemeinsam für Deutschland. Mit Mut und Menschlichkeit. 11.11.2005. URL: www.kas.de/upload/ACDP/CDU/ Koalitionsvertraege/Koalitionsvertrag2005.pdf (letzter Zugriff: 28.02.2018).

Koalitionsvertrag zwischen CDU, CSU und SPD. Ein neuer Aufbruch für Europa - Eine neue Dynamik für Deutschland - Ein neuer Zusammenhalt für unser Land. 12.03.2018. URL: https://www.cdu.de/system/tdf/media/dokumente/ koalitionsvertrag_2018.pdf?file=1 (letzter Zugriff: 08.04.2018).

Konferencja Episkopatu Polski: Orędzie biskupów polskich do biskupów niemieckich. 18.11.1965. URL: https://opoka.org.pl/biblioteka/W/WE/kep/oredzie-niem_18111965. html (letzter Zugriff: 26.05.2018).

Muzeum II Wojny Światowej w Gdańsku: Westerplatte - polskie Pearl Harbor. URL: https://www.youtube.com/watch?time_continue $=185 \& v=6 \mathrm{QMj} 3 \mathrm{Ed}-\mathrm{XiU}$ (letzter $\mathrm{Zu}$ griff: 22.12.2018).

Oryginalny film kończący wystawę Muzeum II Wojny Światowej w Gdańsku. URL: http://trojmiasto.wyborcza.pl/trojmiasto/10,88290,22693627,oryginalny-filmkonczacy-wystawe-muzeum-ii-wojny-swiatowej-w.html?disableRedirects=true; 
auf YouTube: https://www.youtube.com/watch?v=fNbfTaZPdb8 (letzter Zugriff: 22.12.2018).

SACHER GmbH: Sudetendeutsches Museum in München. 22.06.2017. URL: https:// www.sacher-gmbh.com/aktuelles/detail/article/sudetendeutsches-museum-inmuenchen.html (letzter Zugriff: 15.12.2018).

Sejm Rzeczypospolitej Polskiej (Kadencja VI): Sprawozdanie Stenograficzne z 29 posiedzenia Sejmu Rzeczypospolitej Polskiej. Warszawa. 20.11.2008. URL: http://orka2. sejm.gov.pl/StenoInter6.nsf/o/535759F621D11EB3C1257508004B8E2A/\$file/29_b_ ksiazka.pdf (letzter Zugriff: 06.04.2018).

Staatliches Bauamt Rosenheim: Neubau Sudetendeutsches Museum in München - HKLSPlanung. 15.10.2014. URL: https://www.competitionline.com/de/ausschreibungen/ 181775, zuletzt aktualisiert am 09.11.2015 (letzter Zugriff: 25.10.2018).

Statistisches Landesamt der Freien Stadt Danzig (Hg.): Danziger Statistisches Taschenbuch für 1930/31. Danzig 1930.

Steinbach, ERIKa: Die Macht der Erinnerung. Wien, München 2010.

StEINBACH, ERIKA: Flucht, Vertreibung, Mahnung. Menschenrechte sind nicht teilbar. Erfahrungen meines Lebens. München 2016.

Sudetendeutsche Landsmannschaft: Brückenbauer in Europa. Die Sudetendeutschen als Wegbereiter der deutsch-tschechischen Verständigung. 2015. URL: https:// daten2.verwaltungsportal.de/dateien/seitengenerator/die_sudetendeutschen_als_ wegbereiter.pdf (letzter Zugriff: 09.08.2018).

Thurich, Eckart (Hg.): Schwierige Nachbarschaften. Deutsche und Polen - Deutsche und Tschechen im 20. Jahrhundert. Eine Darstellung in Dokumenten. Stuttgart, Berlin 1990.

\section{Beiträge in Radio und Fernsehen}

>Museum der deutschsprachigen Bewohner der böhmischen Länder in Ústí nad Labem/Aussig (Kowalski \& Schmidt). Rundfunk Berlin-Brandenburg (rbb). 21.09.2014. URL: $\quad$ www.rbb-online.de/kowalskiundschmidt/archiv/kowalski-schmidt-21-092014/museum-deutschsprachig-bewohner-boehmischer-laender.html (letzter Zugriff: 27.09.2014).

Osterhage, JÜrgen: Heimat mit Hindernissen - Die deutsche Minderheit in Tschechien (Heute im Osten. Wir und der Osten Europas). Mitteldeutscher Rundfunk (mdr). 14.07.2018. URL: https://www.mdr.de/mediathek/sendung795966_zc-89922dc9_zsdf360c07.html (letzter Zugriff: 25.07.2018).

Polska Kronika Filmowa (10): Niemcy opuszczają Polskę. 1946. URL: https://www.youtube. com/watch?v=f5Fm_nm4hHA (letzter Zugriff: 22.12.2018).

RŮŽIČKOvÁ, MARTA: Sousedé. Česká televize. 20.04.2018. URL: https://www. ceskatelevize.cz/ivysilani/11690334848-sousede/418236100111004/obsah/614992collegium-bohemicum?kvalita=auto (letzter Zugriff: 25.07.2018). 


\section{Zeitungsartikel und Blogeinträge}

Adenauer und Polen. DasErste.de. 2004. URL: https://www.deutscheundpolen.de/ themen/thema_jsp/key=adenauer_und_polen.html (letzter Zugriff: 20.12.2018).

Ärger für Minister in Tschechien. Onetz. 18.05.2016. URL: https://www. onetz.de/deutschland-und-die-welt-r/politik-de-welt/pfingsttreffen-der-

sudetendeutschen-aerger-fuer-minister-in-tschechien-d1669533.html (letzter Zugriff: 30.08.2018).

»Das Bedürfnis nach Heimat ist Realität«. Interview mit Bernd Fabritius von Vera Weidenbach. Zeit Online. 03.04.2018. URL: https://www.zeit.de/politik/ deutschland/2018-03/bernd-fabritius-aussiedlerbeauftragter-innenministeriuminterview/komplettansicht (letzter Zugriff: 16.08.2018).

»Der Ärger muss raus«. Interview mit Walter Kempowski. Der Stern. 03.04.2002. URL: https://www.stern.de/kultur/buecher/walter-kempowski-der-aerger-mussraus-3861344.html (letzter Zugriff: 03.01.2019).

»Die polnischen Motive sind ausführlich dargestellt«. Włodzimierz Borodziej im Gespräch mit Nicole Dittmer und Julius Stucke. Deutschlandfunk Kultur. 23.01.2017. URL: $\quad$ www.deutschlandradiokultur.de/museum-des-zweiten-weltkriegs-indanzig-die-polnischen.1008.de.html?dram:article_id=377139 (letzter Zugriff: 14.04.2018).

»Es begann etwas Neues«. Gespräch mit Alfons Nossol. Die Fragen stellte Markus Nowak. Kulturpolitische Korrespondenz. 12.11.2019. URL: https://kulturforum.info/de/kkmagazin/8066-es-begann-etwas-neues (letzter Zugriff: 31.01.2020).

»Fałszowanie historii«. Dom Historii Europejskiej wzbudza kontrowersje. TVP. 16.08.2017. URL: https://www.tvp.info/33618354/falszowanie-historii-dom-historiieuropejskiej-wzbudza-kontrowersje (letzter Zugriff: 22.04.2018).

»Konzentration auf Steinbach lenkt ab«. Interview mit Erich Später. Frankfurter Rundschau. 11.02.2010. URL: www.fr.de/politik/historiker-erich-spaeter-konzentrationauf-steinbach-lenkt-ab-a-1052210 (letzter Zugriff: 15.08.2018).

»Meine Landsleute nennen mich Verräter«. Süddeutsche Zeitung. 19.02.2013. URL: https://www.sueddeutsche.de/kultur/fotokuenstler-luk-houdek-meine-landsleutenennen-mich-verraeter-1.1601457 (letzter Zugriff: 05.09.2018).

»To jest historia Europy opowiadana z perspektywy Niemiec«. TVP. 21.08.2017. URL: $\quad$ https://www.tvp.info/33671106/to-jest-historia-europy-opowiadana-zperspektywy-niemiec (letzter Zugriff: 22.04.2018).

"Was uns verbindet, ist größer als das, was uns trennt«. Hans-Gert Pöttering im Gespräch mit Liane von Billerbeck. Deutschlandfunk Kultur. 04.05.2017. URL: www.deutschlandfunkkultur.de/hans-gert-poettering-ueber-europa-was-unsverbindet-ist.1008.de.html?dram:article_id=385359 (letzter Zugriff: 23.04.2018).

ABEL, ANDreas: Exilmuseum soll am Anhalter Bahnhof entstehen. Berliner Morgenpost. 07.07.2018. URL: https:/www.morgenpost.de/berlin/article214783271/ Exilmuseum-soll-am-Anhalter-Bahnhof-entstehen.html (letzter Zugriff: 26.07.2018). 
ACKermann, Felix: Wer kommt alles aus dem Bullenkloster? FAZ. 06.01.2016. URL: www.faz.net/aktuell/feuilleton/debatten/die-stiftung-flucht-und-vertreibungschlaeft-13996887.html (letzter Zugriff: 06.03.2018).

Ackermann, Felix: In Polen dokumentiert ein Museum die Schrecken des Zweiten Weltkriegs und blickt über dessen Ende hinaus. NZZ. 06.04.2017. URL: https:// www.nzz.ch/feuilleton/weltkriegsmuseum-in-danzig-in-polen-dokumentiert-einmuseum-die-schrecken-des-zweiten-weltkriegs-und-blickt-ueber-dessen-endehinaus-ld.155751 (letzter Zugriff: 30.03.2018).

ACKermanN, MARION: Eine Welt, in der wir leben wollen. Sächsische Zeitung. 26.06.2018. URL: https://www.sz-online.de/nachrichten/eine-welt-in-der-wir-leben-wollen3963194.html (letzter Zugriff: 29.06.2018).

APElblat, Mose: Polish MEPs in Brussels want to change the narrative of the European history museum. The Brussels Times. 12.09.2017. URL: www.brusselstimes.com/euaffairs/9102/polish-meps-in-brussel (letzter Zugriff: 23.04.2018).

Augstein, Franziska: Abschied von Europa. Der polnische Historiker Włodzimierz Borodziej über das Museum des Zweiten Weltkrieges in Danzig. Süddeutsche Zeitung. 19.05.2016 (114), S. 13.

Aust, Martin: Alle Toten verdienen denselben Respekt. FAZ. 27.08.2018. URL: $\quad$ www.faz.net/aktuell/feuilleton/denkmal-fuer-osteuropaeischeopfer-des-zweiten-weltkriegs-15756702.html?GEPC=s2\&premium= ox5e6bobf2dbd3f865bdod2a1co8a8bfia (letzter Zugriff: 28.08.2018).

BABAK, MAteusz: Zarząd woj. śląskiego odwołał dyrektor Muzeum Śląskiego. dzieje.pl. 29.01.2020. URL: https://dzieje.pl/rozmaitosci/premier-centrumkreatywnosci-trwale-wpisalo-sie-w-krajobraz-kultury-i-biznesu-lodzi (letzter Zugriff: 30.01.2020).

Bau für Stiftung Flucht, Vertreibung, Versöhnung ist fertig. Berlin.de. 28.08.2019. URL: https://www.berlin.de/aktuelles/berlin/5881132-958092-bau-fuer-stiftungflucht-vertreibung-ver.html (letzter Zugriff: 25.01.2020).

$\mathrm{BdV}$ nun Mitglied im Deutschen Institut für Menschenrechte. Oberhessen-live. 27.12.2017. URL: https://www.oberhessen-live.de/2017/12/27/bdv-nun-mitglied-imdeutschen-institut-fuer-menschenrechte/ (letzter Zugriff: 12.08.2018).

Becher, Peter: Das Leid der Opfer nicht vergessen. Süddeutsche Zeitung 30.10.2003.

BeIKLER, SABINE: Deutschlandhaus in Berlin wird 16 Millionen Euro teurer. Der Tagesspiegel. 14.10.2016. URL: www.tagesspiegel.de/berlin/sitz-der-bundesstiftungflucht-vertreibung-versoehnung-deutschlandhaus-in-berlin-wird-16-millioneneuro-teurer/14686334.html (letzter Zugriff: 05.03.2018).

Beraterkreis für Stiftung Flucht und Vertreibung ohne Polen. rbb. 17.10.2016. URL: www.rbb-online.de/kultur/beitrag/2016/10/Deutschlandhaus-Berlin-AusstellungFlucht-Vertreibung.html (letzter Zugriff: 01.09.2017).

Berg, Stefan; Broder, Henryk M.: Jedem das Seine. Der Spiegel. 2004 (2), S. 128-134.

BIELECKI, TOMASZ: Nowe muzeum historii europejskiej w Brukseli wywołuje ostre kontrowersje w Polsce. I na razie w żadnym innym kraju UE. Gazeta Wyborcza. 24.10.2017. URL: http://wyborcza.pl/7,75399,22558964,nowe-muzeumhistorii-europejskiej-w-brukseli-wywoluje-ostre.html?disableRedirects=true (letzter Zugriff: 23.04.2018). 
BIŁY, ŁUKASZ:»Na pewno nie pominę mniejszości«. Wochenblatt. 19.04.2016. URL: http:// wochenblatt.pl/na-pewno-nie-pomine-mniejszosci/ (letzter Zugriff: 17.07.2018).

Brand, JobstulRich; PleWnia, UlRICKe: Ende des Misstrauens. Interview mit Staatsministerin Monika Grütters und dem Präsidenten des BdV Bernd Fabritius. FOCUS Magazin. 12.03.2016 (11). URL: www.focus.de/kultur/medien/kultur-und-medienende-des-misstrauens_id_5349609.html (letzter Zugriff: 06.04.2016).

Brandt, Hans: Das Museum des Anstosses. Tages Anzeiger. 13.10.2016. URL: https://www.tagesanzeiger.ch/ausland/europa/Das-Museum-des-Anstosses/ story/10848174 (letzter Zugriff: 28.03.2018).

Breitenstein, Andreas: Die Liebe zum Ausnahmezustand. NZZ. 06.04.2017. URL: https:/www.nzz.ch/meinung/kommentare/stoerfeuer-gegen-das-neueweltkriegsmuseum-danzig-die-liebe-zum-ausnahmezustand-ld.155823 (letzter Zugriff: 28.03.2018).

BREYTON, RICARDA: Bund der Vertriebenen prüft Umbenennung. Die Welt. 18.04.2018. URL: https://www.welt.de/politik/deutschland/article175559847/JahresempfangBund-der-Vertriebenen-prueft-Umbenennung.html (letzter Zugriff: 09.08.2018).

Brno lituje "pochodu smrti« Němců po druhé světové válce. Smírení s minulostí. Týden. 19.05.2015. URL: https://www.tyden.cz/rubriky/domaci/brno-lituje-pochodusmrti-nemcu-po-druhe-svetove-valce_343387.html\#.VYO9q6bP_xw (letzter Zugriff: 19.05.2018).

Bundeskanzler Schröder steht Zentrum gegen Vertreibungen aufgeschlossen gegenüber. DOD. 28.01.2000 (4), S. 1.

BUSSE, NikOLAS: Stolz und Scham. FAZ. 28.01.2012. URL: www.faz.net/aktuell/politik/ europaeische-union/eu-museum-stolz-und-scham-11623924.html (letzter Zugriff: 22.04.2018).

Były dyrektor Muzeum II Wojny Światowej skarży się na Polskę. Prof. Machcewicz złożył pozew do Europejskiego Trybunału Praw Człowieka. wPolityce. 27.03.2018. URL: https://wpolityce.pl/polityka/387813-byly-dyrektor-muzeumii-wojny-swiatowej-skarzy-sie-na-polske-prof-machcewicz-zlozyl-pozew-doeuropejskiego-trybunalu-praw-czlowieka (letzter Zugriff: 29.03.2018).

CABLE, Simon: Artist creates spooky shosts that line the pews inside dilapidated village church ... turning it into global tourist attraction. Daily Mail. 05.11.2014. URL: www.dailymail.co.uk/travel/travel_news/article-2820404/Artist-creates-spookyghosts-line-pews-inside-dilapidated-village-church-turning-global-touristattraction.html (letzter Zugriff: 30.08.2018).

Carstens, Peter: Dinge, die von Flucht erzählen. FAZ. 27.07.2017. URL: www. faz.net/aktuell/politik/inland/gedenken-an-vertreibung-dinge-die-von-fluchterzaehlen-15118072.html (letzter Zugriff: 07.03.2018).

Cenckiewicz: Polityka historyczna to chaos. MSZ nie wie co robi IPN, IPN nie wie co robi resort kultury. [Interview mit Sławomir Cenckiewicz]. Dziennik. 16.02.2018. URL: http://wiadomosci.dziennik.pl/opinie/artykuly/568876,cenckiewicz-politykahistoryczna-w-polsce-to-chaos.html (letzter Zugriff: 22.08.2018).

ČERnÝ, ADAM; EHL, MARTIN: Německé centrum o vysidlování vznikne, Poláci a Češi vyčkávají. Hospodářské noviny. 20.03.2008. URL: https://zahranicni.ihned.cz/c123435960-berlin-se-docka-centra-pro-vyhnance (letzter Zugriff: 27.02.2018). 
Češka opustila nadaci vysídleneckého centra v Berlíně. Česká televize. 09.03.2010. URL: $\quad$ www.ceskatelevize.cz/ct24/ct24/svet/1350510-ceska-opustila-nadacivysidleneckeho-centra-v-berline (letzter Zugriff: 27.02.2018).

Chrzanowska, Renata: W Lublinie będzie Muzeum Ziem Wschodnich Dawnej Rzeczypospolitej. dzieje.pl. 28.06.2019. URL: https://dzieje.pl/aktualnosci/wlublinie-bedzie-muzeum-ziem-wschodnich-dawnej-rzeczypospolitej (letzter $\mathrm{Zu}$ griff: 31.01.2020).

CICHOCKI, MAREK A.: Europeizacja pamięci. Rzeczpospolita. 15.08.2017. URL: www.rp.pl/Felietony/308139949-Cichocki-Europeizacja-pamieci.html (letzter Zugriff: 25.04.2018).

Cichocki, Marek A.; Gawin, Dariusz: Verdrehte Wege. [Übersetzte Fassung der Konrad-Adenauer-Stiftung]. Rzeczpospolita. 04.11.2006. URL: www.kas.de/wf/doc/ kas_10147-544-1-30.pdf?070218141138 (letzter Zugriff: 05.09.2018).

CYwiński, PIOTR: Wykastrowany homo europeicus po elektrowstrząsach, czyli jak bardzo kocham unię i dlaczego. wPolityce. 12.11.2017. URL: https://wpolityce.pl/ polityka/366654-wykastrowany-homo-europeicus-po-elektrowstrzasach-czyli-jakbardzo-kocham-unie-i-dlaczego (letzter Zugriff: 23.04.2017).

Czy uda się odwrócić antypolskie działania poprzednich władz Muzeum II WŚ? »Koniec systemu«, dziś o 21:30, TV Republika. niezależna. 31.10.2017. URL: http:// niezalezna.pl/207400-czy-uda-sie-odwrocic-antypolskie-dzialania-poprzednichwladz-muzeum-ii-ws-quotkoniec-systemuquot-dzis-o-2130-tv-republika (letzter Zugriff: 28.03.2018).

Danziger Skulptur erzürnt Russland. taz. 17.10.2013. URL: www.taz.de/!5057002/ (letzter Zugriff: 19.08.2018).

DeCKer, Kerstin: Hinter den Kulissen. Der Tagesspiegel. 26.11.2017 (23306), S. 8.

Der »Deutsche Osten« wird ausgeklammert. Dauerausstellung »Deutsche Geschichte in Bildern und Zeugnissen«. DOD. 2006 (8), S. 5-7.

Die Flucht - Ein Film wühlt auf. DOD. 2007 (4), S. 5-7.

Dietrich, StEFAn: Unfähig zur Versöhnung. FAZ. 07.09.2006. URL: www.faz.net/ aktuell/politik/leitartikel-unfaehig-zur-versoehnung-1352657.html (letzter Zugriff: 16.08.2018).

DitTrich, Monika: Neue Leitung, neue Hoffnung? Stiftung Flucht, Vertreibung, Versöhnung. Deutschlandfunk. 31.03.2016. URL: www.deutschlandfunk.de/stiftungflucht-vertreibung-versoehnung-neue-leitung-neue.724.de.html?dram:article_id= 349933 (letzter Zugriff: 06.04.2016).

Dom Historii Europejskiej to niebezpieczna, niemiecka wizja historii. Telewizja Republika. 22.08.2017. URL: http://telewizjarepublika.pl/wszelaka-redutadobrego-imienia-dom-historii-europejskiej-to-niebezpieczna-niemiecka-wizjahistorii,52855.html (letzter Zugriff: 22.04.2018).

Donadio, Rachel: A Museum Becomes a Battlefield Over Poland's History. New York Times. 09.11.2016. URL: https://www.nytimes.com/2016/11/10/arts/design/museumof-the-second-world-war-in-poland-debate.html (letzter Zugriff: 04.04.2018).

Dr Paweł Ukielski: Potrzebny jest międzynarodowy raport o Domu Historii Europejskiej, który wykaże szereg wypaczeń i manipulacji. [Interview mit Paweł Ukielski]. wPolityce. 24.10.2017. URL: https://wpolityce.pl/historia/363864-nasz- 
wywiad-dr-pawel-ukielski-potrzebny-jest-miedzynarodowy-raport-o-domuhistorii-europejskiej-ktory-wykaze-szereg-wypaczen-i-manipulacji (letzter $\mathrm{Zu}$ griff: 23.04.2018).

Dům evropských dějin v Bruselu vyděsil historiky. Expozici dělali marxisté, tvrdí. Echo24. 08.12.2017. URL: https://echo24.cz/a/S7dXP/dum-evropskych-dejinv-bruselu-vydesil-historiky-expozici-delali-marxiste-tvrdi (letzter Zugriff: 23.04.2018).

Dyr. Domu Historii Europejskiej reaguje na krytykę. Weźmiemy pod uwagę opinie m.in. z Polski na temat stałej ekspozycji. Wywiad. wPolityce. 09.07.2018. URL: https://wpolityce.pl/polityka/403118-wywiad-dyr-domu-historii-europejskiejreaguje-na-krytyke (letzter Zugriff: 12.07.2018).

Dyrektor Muzeum Śląskiego może stracić stanowisko. Gazeta Wyborcza. 18.06.2014. URL: http://wyborcza.pl/1,75410,16179603,Dyrektor_Muzeum_Slaskiego_moze_ stracic_stanowisko.html (letzter Zugriff: 21.08.2017).

Dziadul, Jan: Ani za dużo Niemiec, ani za mało Polski. Polityka. 30.06.2015. URL: https:/www.polityka.pl/tygodnikpolityka/spoleczenstwo/1624453,1,muzeumslaskie-troche-polskie-troche-niemieckie.read (letzter Zugriff: 17.07.2018).

EHL, MARTin: Tusk uhlazoval vztahy s Berlínem. Hospodářské noviny. 12.12.2007. URL: https://archiv.ihned.cz/c1-22598250 (letzter Zugriff: 07.03.2018).

Ein produktiver Streit führt zu neuem Denken. Heftige Diskussionen um Zentrum gegen Vertreibungen. DOD. 2003 (8), S. 5.

Erika Steinbach leitet AfD-nahe Stiftung. Der Tagesspiegel. 04.03.2018. URL: https:// www.tagesspiegel.de/politik/desiderius-erasmus-stiftung-erika-steinbach-leitetafd-nahe-stiftung/21030422.html (letzter Zugriff: 03.09.2018).

Eröffnung erst 2018. Der Tagesspiegel. 19.08.2016. URL: https://www.tagesspiegel.de/ kultur/stiftung-flucht-vertreibung-versoehnung-eroeffnung-erst-2018/14432052. html (letzter Zugriff: 06.03.2018).

Ethnische Säuberungen im Kosovo müssen sofort eingestellt werden. DOD. 01.04.1999 (13), S. 1.

Europo! Ojczyzno moja. Po co Dom Historii Europejskiej? Gazeta Wyborcza. 16.12.2017. URL: http://wyborcza.pl/magazyn/7,124059,22790082,europo-ojczyznomoja-po-co-dom-historii-europejskiej.html (letzter Zugriff: 23.04.2018).

Fabritius: »Deutschlandhaus bleibt Deutschlandhaus«. Siebenbürgische Zeitung. 03.09.2019. URL: https://www.siebenbuerger.de/zeitung/artikel/verschiedenes/ 20236-fabritius-deutschlandhaus-bleibt.html (letzter Zugriff: 25.01.2020).

Fischer, Herbert: Markantes Symbol der Volksgruppe mitten in München. Sudetendeutsche Zeitung. 23.09.2016 (38), S. 1-3.

FISCHER, HERBERT: Jetzt Rückkehr zur Gemeinsamkeit! Sudetendeutsche Zeitung. 12.04.2019 (15), S. 1.

Fischer, Tilman Asmus: Auf ein Wort. Der Westpreuße. Unser Danzig. 2017 (5), S. 5.

Fischer, Tilman Asmus: Ein gelungener Kompromiss. Das Konzept für die Dauerausstellung im Deutschlandhaus. Der Westpreuße. Unser Danzig. 2017 (10), S. 7.

FLIEger, Estera: Z Muzeum II Wojny Światowej znikają niesłuszni partyzanci. Gazeta Wyborcza. 27.03.2018. URL: http://wyborcza.pl/7,75398,23194427,z-muzeum-iiwojny-swiatowej-znikaja-niesluszni-partyzanci.html (letzter Zugriff: 27.03.2018). 
FLIEger, Estera: »W narodowej dumie nie ma nic złego«. Rozmowa z dyrektorem Muzeum Historii Polski. Gazeta Wyborcza. 08.07.2018. URL: warszawa.wyborcza.pl/warszawa/7,54420,23644794,w-narodowej-dumie-nie-ma-nic-zlego.html (letzter Zugriff: 08.07.2018).

FLIEger, Estera; GAEĄZKA, DARIUSZ: Kolejna »dobra zmiana« w Muzeum II Wojny Światowej. Gazeta Wyborcza. 05.04.2018. URL: http://trojmiasto.wyborcza.pl/ trojmiasto/7,35612,23225824,kolejne-zmiany-w-wystawie-stalej-muzeum-iiws-przywracamy.html (letzter Zugriff: 01.06.2018).

FRITZ, PHILIPP: SPD-Politiker über Mahnmal in Berlin. "Polen muss uns allen in Deutschland nah sein«. Berliner Zeitung. 12.11.2017. URL: https://www.berlinerzeitung.de/kultur/spd-politiker-ueber-mahnmal-in-berlin-polen-muss-unsallen-in-deutschland-nah-sein-28832108 (letzter Zugriff: 13.11.2017).

FuHR, ECKHARD: Scharfe Thesen. Die Welt. 04.10.2003. URL: https://www.welt.de/printwelt/article263704/Scharfe-Thesen.html?conf (letzter Zugriff: 16.08.2018).

Gdańsk Strefa Prestiżu: Strefa wirtualna w MIIWŚ. gdanskstrefa.com. 29.03.2018 (letzter Zugriff: 01.04.2018).

Gedenktag für die Opfer von Flucht und Vertreibung am 20.06.2019. Webseite des BdV-Landesverbandes Niedersachsen. 2019. URL: https://www.bdv-ni.de/bdvniedersachsen/nachrichten-und-berichte/gedenktag-fuer-die-opfer-von-fluchtund-vertreibung (letzter Zugriff: 15.12.2019).

Gera, VANESSA: Polish leaders threaten fate of nearly finished WWII museum. The Washington Post. 24.04.2016. URL: https:/www.washingtontimes.com/news/ 2016/apr/24/polish-leaders-threaten-fate-of-nearly-finished-ww/ (letzter Zugriff: 28.03.2018).

Gespräch mit dem britischen Historiker Timothy Garton Ash. Dialog Forum. 23.01.2020. URL: https://forumdialog.eu/2020/01/23/gesprach-mit-dem-britischen-historikertimothy-garton-ash/ (letzter Zugriff: 26.01.2020).

Gessler, Philipp: Regierung und Vertriebene einigen sich. taz. 11.02.2010. URL: www. taz.de/!48219/ (letzter Zugriff: 23.03.2018).

Gliński, PIotr: Gliński do szefa PE. Wystawa w Domu Historii Europejskiej nie jest godna ani tej nazwy, ani patronatu. Wizyta $w$ tym muzeum nie wiąże się $z$ pozytywnymi emocjami. wPolityce. 06.10.2017. URL: https://wpolityce.pl/polityka/ 361125-glinski-do-szefa-pe-wystawa-w-domu-historii-europejskiej-nie-jestgodna-ani-tej-nazwy-ani-patronatu-wizyta-w-tym-muzeum-nie-wiaze-sie-zpozytywnymi-emocjami (letzter Zugriff: 23.04.2018).

GŁOWACKa, KataRzYNA: Wojna o mieszkaniówkę w Strefie Kultury. Silesion. 21.02.2018. URL: https://silesion.pl/wojna-o-mieszkania-w-strefie-kultury-w-katowicach-2102-2018 (letzter Zugriff: 19.04.2018).

Gmyz, Cesary; Semka, Piotr: Przypominajmy światu polską historię. Rzeczpospolita. 03.11.2008. URL: www.rp.pl/artykul/213790-Przypominajmy-swiatu-polskahistorie-.html (letzter Zugriff: 28.03.2018).

GNAUCK, Gerhard: Der lange Schatten des Krieges. FAZ. 26.03.2017. URL: www.faz. net/aktuell/feuilleton/polens-museum-des-zweiten-weltkriegs-14937537.html (letzter Zugriff: 28.03.2018). 
Graf, Monika: Ein Haus der Geschichte für Europa - und tausend Fragen. Salzburger Nachrichten. 16.05.2017. URL: https:/www.sn.at/kolumne/fruehstueck-in-bruessel/ ein-haus-der-geschichte-fuer-europa-und-tausend-fragen-17890483 (letzter $\mathrm{Zu}$ griff: 22.04.2018).

GraW, ANSGAR: Für Polen geht es um mehr als nur um Steinbach. Die Welt. 26.02.2009. URL: https://www.welt.de/politik/article3281142/Fuer-Polen-geht-es-um-mehr-alsnur-um-Steinbach.html (letzter Zugriff: 23.03.2018).

Gross, Jan Tomasz: Die Osteuropäer haben kein Schamgefühl. Die Welt. 13.09.2015. URL: https://www.welt.de/debatte/kommentare/article146355392/ Die-Osteuropaeer-haben-kein-Schamgefuehl.html (letzter Zugriff: 22.08.2018).

GSCHWEND, PATRICK: NVA-Truppen machen halt an der tschechoslowakischen Grenze. Radio Praha. 22.08.2008. URL: www.radio.cz/de/rubrik/sonderserie68/ nva-truppen-machen-halt-an-der-tschechoslowakischen-grenze (letzter Zugriff: 10.05.2018).

Gschwend, Patrick: Kulturelles Erbe der deutschsprachigen Bewohner der böhmischen Länder bekommt eigenes Museum. Radio Praha. 18.09.2010. URL: https:// www.radio.cz/de/print/artikel/131807 (letzter Zugriff: 18.12.2018).

GÜNTNER, JOACHIM: Opfer und Tabu. NZZ. 23.02.2002. URL: https://www.nzz.ch/ article7ZLoN-1.372861 (letzter Zugriff: 22.12.2018).

Hanisch, Dörte; SieradzKa, Monika: Verliert die deutsche Minderheit ihre Rechte? $m d r$. 09.08.2016. URL: https://www.mdr.de/heute-im-osten/opole-eingemeindungpolen-100.html (letzter Zugriff: 17.11.2018).

HARDMAN, ROBERT: Why does the EU's new £47m European history museum (part funded by UK taxes) ignore Britain's great achievements and gloss over Germany's wartime past? Daily Mail. 14.10.2017. URL: www.dailymail.co.uk/debate/article4979466/ROBERT-HARDMAN-does-EU-s-new-museum-ignore-Britain.html (letzter Zugriff: 23.04.2018).

HASSel, Florian: Die Panzer müssen stolzer werden. Süddeutsche Zeitung. 24.10.2016. URL: www.sueddeutsche.de/kultur/geschichtspolitik-die-panzer-muessen-stolzerwerden-1.3219939 (letzter Zugriff: 28.03.2018).

Haszczyński, Jerzy: Zwycięskie odejście Eriki. Komentarz Jerzego Haszczyńskiego. Rzeczpospolita. 08.07.2014. URL: https://www.rp.pl/artykul/1123982Zwycieskie-odejscie-Eriki-komentarz-Jerzego-Haszczynskiego.html (letzter Zugriff: 17.08.2018).

HASZCZYŃSKI, JERZY: Niemcy radzą sobie ze wszystkim. Także z historią. Rzeczpospolita. 06.09.2017. URL: www.rp.pl/Polityka/170909288-Jerzy-Haszczynski-Niemcy-radzasobie-ze-wszystkim-Takze-z-historia.html\#ap-1 (letzter Zugriff: 22.04.2018).

Heftige Kritik aus Warschau an Ausstellung über Vertreibungen. FAZ. 11.08.2006. URL: www.faz.net/aktuell/politik/ausland/polen-heftige-kritik-aus-warschau-anausstellung-ueber-vertreibungen-1355386.html (letzter Zugriff: 18.08.2018).

Hencke, Gerrit: Protokoll einer Rede. Björn Höcke, der Brandstifter. SchleswigHolsteinischer Zeitungsverlag (shz). 18.01.2017. URL: https://www.shz.de/deutschlandwelt/politik/protokoll-einer-rede-bjoern-hoecke-der-brandstifter-id15869041.html (letzter Zugriff: 12.08.2018). 
Hennig, Irmela: Der Schlesische Adler auf dem Weg ins Morgen. Sächsische Zeitung. 11.01.2016. URL: www.sz-online.de/nachrichten/der-schlesische-adler-aufdem-weg-ins-morgen-3294494.html (letzter Zugriff: 16.04.2018).

HERMANN, RAINER: Steht der Auszug der Palästinenser bevor? FAZ. 16.12.2017 (letzter Zugriff: 07.07.2018).

HERTER, GERWALD: Was im politischen Streit liegen bleibt. Deutschlandfunk. 17.07.2013. URL: https://www.deutschlandfunk.de/was-im-politischen-streit-liegen-bleibt. 795.de.html?dram:article_id=254363 (letzter Zugriff: 18.12.2018).

HiRsch, Helga: Menschenrecht auf Erinnerung. Die Welt. 03.03.2006. URL: https:// www.welt.de/print-welt/article201491/Menschenrecht-auf-Erinnerung.html (letzter Zugriff: 07.01.2018).

HLEBowICZ, JAN: Duże zmiany w Muzeum II Wojny Światowej. gosc.pl. 30.10.2017. URL: http://gdansk.gosc.pl/doc/4284350.Duze-zmiany-w-Muzeum-II-Wojny-Swiatowej (letzter Zugriff: 28.03.2018).

HONZEJK, PETR: Stíhaný premiér, chybějící ministři a podpora nereformovaných komunistů. Nastupuje vláda hodnotové relativizace, zmatku a nejistoty. Hospodářské noviny. 11.07.2018. URL: https://archiv.ihned.cz/c1-66189890-prichazi-ostry-startvlady-ano-cssd-a-kscm-pada-jedno-z-poslednich-velkych-tabu-polistopadovepolitiky (letzter Zugriff: 12.07.2018).

HoŘEní, Monika: Rozhovor Haló novin s Pavlem Vodsed'álkem, kandidátem KSČM na primátora Ústí nad Labem. Haló noviny. 27.07.2018. URL: www.halonoviny.cz/ articles/view/48044978 (letzter Zugriff: 28.07.2018).

HoufEK, VÁCLAV: Collegium Bohemicum vypsalo výběrové řízení na zhotovení výstavy »Naši Němci«. Místní kultura. 19.11.2019. URL: http://mistnikultura.cz/collegiumbohemicum-vypsalo-vyberove-rizeni-na-zhotoveni-vystavy-nasi-nemci (letzter $\mathrm{Zu}$ griff: 23.01.2020).

INGENDAAY, PAUL: Ist die Geschichte Europas überhaupt darstellbar? FAZ. 02.12.2017. URL: www.faz.net/aktuell/feuilleton/debatten/museum-in-bruessel-widmet-sicheuropaeischer-geschichte-15319650.html (letzter Zugriff: 23.04.2018).

JAMroż, MiChAŁ: Jak minister Gliński zapewnił gigantyczną promocję polskiej historii. Wywiad. Gazeta Wyborcza. 30.03.2017. URL: http://wyborcza.pl/ 7,75248,21566602,jak-minister-glinski-zapewnil-gigantyczna-promocje-polskiej. html (letzter Zugriff: 08.04.2018).

JANSSEN, CHRistinA: "Töten auf Tschechisch«. Deutschlandfunk. 01.06.2010. URL: https://www.deutschlandfunk.de/toeten-auf-tschechisch.691.de.html? dram:article_id=54248 (letzter Zugriff: 05.09.2018).

Janssen, Christina: Museum als historischer Meilenstein. Deutschlandfunk Kultur. 25.10.2010. URL: https://www.deutschlandfunkkultur.de/museum-alshistorischer-meilenstein.1013.de.html?dram:article_id=171088 (letzter Zugriff: 18.12.2018).

JANSSEN, Christina: »Unsere Deutschen«. Deutschlandfunk. 18.12.2010. URL: https:// www.deutschlandfunk.de/unsere-deutschen.724.de.html?dram:article_id=100047 (letzter Zugriff: 16.12.2018).

JANZer, TILl: Beziehung im Wandel. Tschechen haben meist keine Probleme mehr mit Deutschen. Radio Praha. 16.01.2017. URL: https://www.radio.cz/de/rubrik/ 
schauplatz/beziehung-im-wandel-tschechen-haben-meist-keine-probleme-mehrmit-deutschen (letzter Zugriff: 09.08.2018).

JANZER, TILL: Sudetendeutscher Tag: Tschechische Politiker erhalten Applaus - und Kritik von Zuhause. Radio Praha. 05.06.2017. URL: https://www.radio.cz/de/rubrik/ tagesecho/sudetendeutscher-tag-tschechische-politiker-erhalten-applaus-undkritik-von-zuhause (letzter Zugriff: 30.08.2018).

JANZER, Till: »Eine neue Landkarte persönlicher Kontakte«. Radio Praha. 22.03.2018. URL: https://www.radio.cz/de/rubrik/schauplatz/eine-neue-landkartepersoenlicher-kontakte (letzter Zugriff: 29.08.2018).

JANZER, Till: Zeman und Babiš empört über Merkel-Aussage zum Tag der Vertriebenen. Radio Praha. 20.06.2018. URL: https://www.radio.cz/de/rubrik/nachrichten/zemanund-babis-empoert-ueber-merkel-aussage-zum-tag-der-vertriebenen (letzter $\mathrm{Zu}$ griff: 29.08.2018).

JAnzer, Till: Streit um Merkel-Aussagen zu Vertreibung. Radio Praha. 21.06.2018. URL: https://www.radio.cz/de/rubrik/tagesecho/streit-um-merkel-aussagen-zuvertreibung (letzter Zugriff: 29.08.2018).

Jedlecki, PrzemysŁaW: Śląsk boi się Niemca. Gazeta Wyborcza. 07.01.2013. URL: http://wyborcza.pl/1,76842,13150942,Slask_boi_sie_Niemca.html (letzter Zugriff: 25.08.2017).

Jedlecki, PrzemysŁaw: Artyści zainicjowali protest przeciwko odwołaniu dyrektor Muzeum Śląskiego. Podpisało się kilkaset osób. Gazeta Wyborcza. 17.11.2019. URL: https://katowice.wyborcza.pl/katowice/7,35063,25418336,artysci-zainicjowaliprotest-przeciwko-odwolaniu-dyrektor-muzeum.html (letzter Zugriff: 27.01.2020).

Jedlecki, PrzemysŁaw: Muzealnicy punktują marszałka. Z kontroli w Muzeum Śląskim wyciągnął złe wnioski. Gazeta Wyborcza. 30.11.2019. URL: https://katowice. wyborcza.pl/katowice/7,35063,25462969,muzealnicy-punktuja-marszalka-zkontroli-w-muzeum-slaskim-wyciagnal.html (letzter Zugriff: 27.01.2020).

Jedlecki, Przemystaw: Minister kultury do marszałka Jakuba Chełstowskiego. Gazeta Wyborcza. 20.01.2020. URL: https://katowice.wyborcza.pl/katowice/ 7,35063,25616464,minister-kultury-do-marszalka-jakuba-chelstowskiego-niema.html (letzter Zugriff: 27.01.2020).

Jeismann, Michael: Mehr als ein Projekt. Das »Musée de l'Europe« in Brüssel. FAZ. 11.12.2004 (290), S. 35. URL: www.faz.net/aktuell/feuilleton/mehr-als-ein-projektdas-musee-de-l-europe-in-bruessel-1197096.html (letzter Zugriff: 30.04.2018).

Jendroszczyk, Piotr: Pamięć ziem utraconych. Rzeczpospolita. 13.05.2006. URL: www. schlesisches-museum.de/index.php?id=1566 (letzter Zugriff: 15.07.2018).

Jest zgoda Komisji Europejskiej na budowę Muzeum Śląskiego. naszemiasto. 27.05.2011. URL: http://katowice.naszemiasto.pl/artykul/krotko-jest-zgodakomisji-europejskiej-na-budowe-muzeum,925587,art,t,id,tm.html?sesja_gratka= 943a098c7cf3375cc3756270a12d3105\#42a5ff5cd784db66,1,3,9 (letzter Zugriff: 07.10.2018).

Jubiläum in Prag. 50 Jahre Kulturverbund der Deutschen. Sudetendeutsche Zeitung. 28.06.2019 (26), S. 1-2. 
JuRAsz, Witold: Die polnische Außenpolitik. Dialog Forum. 16.01.2020. URL: https://forumdialog.eu/2020/01/16/die-polnische-aussenpolitik/ (letzter Zugriff: 22.01.2020).

Kaczyński zapowiada aktywną politykę historyczną. dzieje.pl. 29.06.2013. URL: http:// dzieje.pl/aktualnosci/kaczynski-zapowiada-aktywna-polityke-historyczna (letzter Zugriff: 06.04.2018).

KARAś, Dorota: Nowa rada Muzeum II Wojny Światowej. Cenckiewicz i duszpasterz kibiców. Gazeta Wyborcza. 08.02.2018. URL: http://trojmiasto.wyborcza.pl/trojmiasto/ 7,35612,23000810,nowa-rada-muzeum-ii-wojny-swiatowej-cenckiewicz-iduszpasterz.html (letzter Zugriff: 06.04.2018).

KATKA, KRzysztzof: Odtajnione recenzje Muzeum II Wojny. Zgodnie z zamówieniem PiS są miażdżące. Bo wojna ma »hartować człowieka«. Gazeta Wyborcza. 12.07.2016. URL: http://wyborcza.pl/1,75398,20385620,odtajnione-recenzje-muzeum-ii-wojnyzgodnie-z-zamowieniem-pis.html (letzter Zugriff: 26.02.2018).

KatKa, Krzysztzof: Dr Nawrocki naprawi dla PiS Muzeum II Wojny Światowej. Gazeta Wyborcza. 17.04.2017. URL: http://trojmiasto.wyborcza.pl/trojmiasto/ 7,35612,21634834,dr-nawrocki-naprawi-dla-pis-muzeum-ii-wojny-swiatowej.html (letzter Zugriff: 26.02.2018).

KeISINGER, Florian: Historiker am Zeitgeist. Der Tagesspiegel. 12.10.2017 (23262), S. 24. URL: https:/www.pressreader.com/germany/der-tagesspiegel/20171012/ 282243780814905 (letzter Zugriff: 12.02.2018).

Kellerhoff, Sven Felix: Ehrliche Wege aus dem Schatten der Vertreibung. Die Welt. 26.04.2007. URL: https://www.welt.de/welt_print/article835100/EhrlicheWege-aus-dem-Schatten-der-Vertreibung.html (letzter Zugriff: 10.11.2018).

Kellerhoff, Sven Felix: "Gustloff«-Glocke ist zurück in Danzig. Die Welt. 27.09.2007. URL: https:/www.welt.de/welt_print/article1137305/Gustloff-Glockeist-zurueck-in-Danzig.html (letzter Zugriff: 04.04.2018).

Kellerhoff, Sven FeliX: Dauerstreit bei der Versöhnung. Die Welt. 14.03.2010. URL: www.welt.de/welt_print/politik/article6764205/Dauerstreit-bei-der-Versoehnung. html (letzter Zugriff: 28.02.2018).

Kellerhoff, Sven FeliX: Zentralrat stoppt Mitarbeit in Vertriebenen-Stiftung. Die Welt. 06.09.2010. URL: www.welt.de/politik/deutschland/article9441982/Zentralratstoppt-Mitarbeit-in-Vertriebenen-Stiftung.html (letzter Zugriff: 28.02.2018).

Kellerhoff, SVEn Felix: Vertriebenen-Stiftung blickt zur Gestapo-Zentrale. Die Welt. 30.11.2011. URL: https://www.welt.de/kultur/history/article13743614/VertriebenenStiftung-blickt-zur-Gestapo-Zentrale.html (letzter Zugriff: 07.03.2018).

Kellerhoff, Sven Felix: Streit in Vertriebenen-Stiftung endet mit Rauswurf. Die Welt. 16.12.2014. URL: https://www.welt.de/geschichte/article135435954/Streit-inVertriebenen-Stiftung-endet-mit-Rauswurf.html (letzter Zugriff: 07.03.2018).

Kellerhoff, Sven Felix: Chefsuche für Vertriebenenstiftung ist ein Debakel. Die Welt. 04.11.2015. URL: https://www.welt.de/geschichte/article148412008/Chefsuche-fuerVertriebenenstiftung-ist-ein-Debakel.html (letzter Zugriff: 07.03.2018).

Kellermann, Florian: Nordstream II entzweit Polen und Deutsche. Deutschlandfunk. 18.12.2017. URL: https://www.deutschlandfunk.de/deutsch-russische-gaspipeline- 
nordstream-ii-entzweit-polen.795.de.html?dram:article_id=406298 (letzter Zugriff: 08.12.2018).

Kiesel, HeINER: Die Vertriebenen von gestern und heute. Deutsche Welle. 20.06.2018. URL: https://p.dw.com/p/1JADJ (letzter Zugriff: 09.08.2018).

KIsICKA, ANNA: W Muzeum II Wojny Światowej rozpoczyna działalność biblioteka. dzieje.pl. 10.01.2018. URL: http://dzieje.pl/aktualnosci/w-muzeum-ii-wojnyswiatowej-rozpoczyna-dzialalnosc-biblioteka (letzter Zugriff: 06.04.2018).

KitTel, MANFRED: Das kostbare Recht auf Rückkehr. FAZ. 07.01.2016. URL: www. faz.net/aktuell/politik/staat-und-recht/fluechtlingskrise-das-kostbare-recht-aufrueckkehr-14000962.html (letzter Zugriff: 06.03.2018).

Kiwnik Pargana, Jowita: Celowe pomijanie Polski? DHE ma inny problem. wp opinie. 15.09.2017. URL: https://opinie.wp.pl/jowita-kiwnik-pargana-celowe-pomijaniepolski-dhe-ma-inny-problem-6166399214716545a (letzter Zugriff: 23.04.2018).

Kolejne zmiany w Muzeum II Wojny Światowej. Pokazano historię rodziny Ulmów. Do Rzeczy. 17.03.2018. URL: https://dorzeczy.pl/kraj/59144/Kolejne-zmiany-wMuzeum-II-Wojny-Swiatowej-Pokazano-historie-rodziny-Ulmow.html (letzter Zugriff: 18.03.2018).

Kontroverzní šéfka Svazu vyhnanců dostane Karlovu cenu. Aktuálně.cz. 18.03.2010. URL: https://zpravy.aktualne.cz/zahranici/kontroverzni-sefka-svazu-vyhnancu-dostanekarlovu-cenu/rĩ:article:663656/?redirected=1519736731 (letzter Zugriff: 27.02.2018).

Kortko, DARIUSZ; OstaŁowska, LidiA: Dość całowania ręki niemieckiego pana. Gazeta Wyborcza. 26.06.2013. URL: http://wyborcza.pl/duzyformat/ 1,127290,14172900,Dosc_calowania_reki_niemieckiego_pana.html (letzter Zugriff: 19.04.2018).

Kosiewski, Piotr: Zeit der Museen. Dialog Forum. 16.04.2018. URL: https:// forumdialog.eu/2018/04/16/zeit-der-museen/ (letzter Zugriff: 05.09.2018).

Kossert, ANDreas: Böhmen, Pommern, Syrien. Die Zeit. 12.02.2015 (5/2015). URL: https://www.zeit.de/2015/05/fluechtlinge-boehmen-pommern-nachkriegszeit (letzter Zugriff: 16.08.2018).

Koura, Petr: Reakce ředitele Collegia Bohemika Petra Koury. Novinky.cz. 16.01.2018. URL: https://www.novinky.cz/kultura/salon/460266-jan-sicha-v-sudetonemeckemmuzeu.html (letzter Zugriff: 29.10.2018).

KrAfCZYK, Eva: Mahnmal entfacht Streit um Kriegsgräuel. Nordwest-Zeitung. 22.10.2013. URL: https://www.nwzonline.de/politik/mahnmal-entfacht-streitum-kriegsgraeuel_a_9,4,600056223.html (letzter Zugriff: 19.08.2018).

KRÖKEL, UlRICH: Polen will Kriegsgeschichte umschreiben. Rheinische Post. 13.05.2016. URL: www.rp-online.de/politik/polen-will-kriegsgeschichte-umschreiben-aid-1. 5973480 (letzter Zugriff: 28.03.2018).

Krupa, Matthias: Feiert dieses Museum den Kommunismus? Die Zeit. 03.05.2018 (19/2018). URL: https:/www.zeit.de/2018/19/haus-der-europaeischen-geschichtekommunismus-polen (letzter Zugriff: 04.05.2018).

Kubes, Milan: »Aussig gilt in Bayern als bedeutendstes tschechisches Kulturprojekt«. Volksgruppensprecher Bernd Posselt im Gespräch mit der tschechischen Tageszeitung »Mladá fronta Dnes«. Sudetendeutsche Zeitung. 08.08.2014 (32), S. 1. 
Kubita, Jan: První televizní duel. Zeman se pokoušel útočit. Schwarzenbergovi se dařilo odolávat. Hospodářské noviny. 17.01.2013. URL: https://domaci.ihned.cz/c159143680-prvni-televizni-duel-zeman-se-pokousel-utocit-schwarzenbergovi-sedarilo-odolavat (letzter Zugriff: 30.08.2018).

Kuhn, Nicola: Wo Bertolt Brecht den Zug bestieg. Exil-Museum am Anhalter Bahnhof. Der Tagesspiegel. 19.07.2018. URL: https://www.tagesspiegel.de/kultur/exilmuseum-am-anhalter-bahnhof-wo-bertolt-brecht-den-zug-bestieg/22814538.html (letzter Zugriff: 26.07.2018).

KüHNTOPP, CARSTEN: Syrischen Flüchtlingen droht Enteignung. Deutschlandfunk. 27.04.2018. URL: https://www.deutschlandfunk.de/erschwerte-rueckkehr-in-dieheimat-syrischen-fluechtlingen.1766.de.html?dram:article_id=416664 (letzter Zugriff: 07.07.2018).

KWW Zjednoczeni dla Śląska zaprezentował kandydatów do Sejmu. onet Śląsk. 10.09.2015. URL: https://slask.onet.pl/kww-zjednoczeni-dla-slaska-zaprezentowalkandydatow-do-sejmu/1zok5g (letzter Zugriff: 31.07.2018).

Ładuniuk, ANna: Muzeum Śląskie, opcja niemiecka. Dziennik Zachodni. 04.03.2013. URL: $\quad$ www.dziennikzachodni.pl/artykul/775199,laduniuk-muzeum-slaskie-opcjaniemiecka,id,t.html (letzter Zugriff: 22.11.2017).

Landsmannschaft verzichtet auf »Wiedergewinnung der Heimat«. Zeit Online. 01.03.2015. URL: https://www.zeit.de/politik/deutschland/2015-03/ sudetendeutsche-landsmannschaft-heimat (letzter Zugriff: 23.01.2020).

LAU, JÖRG: Blühende Museumslandschaften. Die Zeit. 25.09.2003 (40/2003). URL: https://www.zeit.de/2003/40/Vertriebene_(letzter Zugriff: 15.08.2018).

LEHNI, RAINER: 70 Jahre Vertriebene in Nordrhein-Westfalen. Siebenbürgische Zeitung. 27.04.2016. URL: https://www.siebenbuerger.de/zeitung/artikel/verband/16575-70jahre-vertriebene-in-nordrhein.html (letzter Zugriff: 16.08.2018).

Lehnstaedt, Stephan: Die Nachbarn verstehen lernen. Plädoyer für ein polnischdeutsches Museum. Der Tagesspiegel. 02.08.2018. URL: https://www.tagesspiegel.de/ wissen/plaedoyer-fuer-ein-polnisch-deutsches-museum-die-nachbarn-verstehenlernen/22870098.html (letzter Zugriff: 04.08.2018).

LeinemanN, SusAnNe: Deutsche Vertriebene im europäischen Kontext. Berliner Morgenpost. 24.06.2017. URL: https://www.morgenpost.de/kultur/article211016063/ Deutsche-Vertriebene-im-europaeischen-Kontext.html (letzter Zugriff: 07.03.2018).

LEISTER, JUdith: Museum zum Zweiten Weltkrieg - Ein Museum als Schlachtfeld. Interview mit Paweł Machcewicz. NZZ. 23.06.2017. URL: https://www. nzz.ch/feuilleton/aktuell/danziger-tauziehen-um-die-polnische-geschichte-einmuseum-als-schlachtfeld-ld.1302384 (letzter Zugriff: 28.03.2018).

Leister, Judith: »Die derzeitige Politik ist der Kampf um die Deutungshoheit der Geschichte«. Interview mit Basil Kerski. NZZ. 12.09.2017. URL: https:// www.nzz.ch/feuilleton/kulturlandschaft-polen-politik-kampf-deutungshoheitgeschichte-ld.1315700 (letzter Zugriff: 02.04.2018).

LEISTER, JUdith: Das Danziger Weltkriegsmuseum droht ein »kleinkariertes nationalistisches Zentrum « $\mathrm{zu}$ werden. Interview mit Paweł Machcewicz. NZZ. 13.07.2018. URL: https://www.nzz.ch/feuilleton/das-danziger-weltkriegsmuseum- 
droht-ein-kleinkariertes-nationalistisches-zentrum-zu-werden-ld.1401379 (letzter Zugriff: 19.07.2018).

Lesser, Gabriele: »Das Problem benennen«. Dariusz Stola über Judenhass in Polen, das »Holocaust-Gesetz« und Eingriffe in die Kulturarbeit. Jüdische Allgemeine. 29.03.2018. URL: www.juedische-allgemeine.de/article/view/id/31213 (letzter $\mathrm{Zu}$ griff: 30.03.2018).

Lesser, Gabriele: "Sechs Millionen Polen«. Jüdische Allgemeine. 14.08.2019. URL: https://www.juedische-allgemeine.de/juedische-welt/sechs-millionen-polen/ (letzter Zugriff: 28.01.2020).

LESZCZYŃSKI, ADAM: Gliński powołał nową Radę Muzeum II Wojny Światowej. Cenckiewicz, Żaryn, duszpasterz kibiców i Semka. OKO.press. 10.02.2018. URL: https:// oko.press/glinski-powolal-nowa-rade-muzeum-ii-wojny-swiatowej-cenckiewiczzaryn-duszpasterz-kibicow-semka/ (letzter Zugriff: 06.04.2018).

LESZCZYŃSKI, ADAM: Prawicowy postmodernizm. Partia rządząca mówi, że broni prawdy historycznej, ale chodzi jej o zupełnie co innego. OKO.press. 21.02.2018. URL: https://oko.press/prawicowy-postmodernizm-partia-rzadzaca-mowi-zebroni-prawdy-historycznej-chodzi-zupelnie-o-innego/ (letzter Zugriff: 11.03.2018).

Leszek Jodliński na czele Muzeum Górnośląskiego. Dziennik Zachodni. 05.04.2016. URL: $\quad$ www.dziennikzachodni.pl/wiadomosci/bytom/a/leszek-jodlinski-na-czelemuzeum-gornoslaskiego,9830969/ (letzter Zugriff: 16.07.2018).

LINDNER, TOMÁš: Landsmanšaft 2.0. Respekt. 08.03.2015. URL: https://www.respekt.cz/ tydenik/2015/11/landsmansaft-2-o (letzter Zugriff: 31.01.2020).

List 500 naukowców o zmianach w Muzeum II Wojny. Dziennik Battycki. 03.11.2017. URL: www.dziennikbaltycki.pl/wiadomosci/gdansk/a/list-500-naukowcow-o-zmianachw-muzeum-ii-wojny,12640094/ (letzter Zugriff: 29.03.2018).

LORENZ, HiLKE: Weiterleben ohne Heimat. Was Flüchtlinge heute und damals eint. Stuttgarter Zeitung. 19.01.2018. URL: https:/www.stuttgarter-zeitung.de/inhalt.wasfluechtlinge-heute-und-damals-eint-weiterleben-ohne-heimat.7aog9a22-fdd648b5-a06c-7ffcb370b7fe.html (letzter Zugriff: 07.03.2018).

LOTHAR, MARTIN: Begründer des Marsches der Versöhnung mit deutschem Orden geehrt. Radio Praha. 04.12.2018. URL: https://radio.cz/de/rubrik/nachrichten/ begruender-des-marsches-der-versoehnung-mit-deutschem-orden-geehrt (letzter Zugriff: 16.12.2018).

ŁUKAWSKA, JoANNA: Muzeum Śląskie przygotowuje wystawę o śląskim hip-hopie. eska. 13.06.2018. URL: http://slask.eska.pl/newsy/muzeum-slaskie-przygotowujewystawe-o-slaskim-hip-hopie-audio/725633 (letzter Zugriff: 16.07.2018).

MACHCEWICZ, PAWEŁ: Muzeum zamiast zasieków. Gazeta Wyborcza. 08.11.2007. URL: https://www.pressreader.com/poland/gazeta-wyborcza/20071108/282067682579836 (letzter Zugriff: 13.03.2018).

MAetzke, HeinRICH: Wenn Historiker und Journalisten nicht lesen können. Bayernkurier. 06.12.2014. URL: https://www.bayernkurier.de/kultur/871-wenn-historikerund-journalisten-nicht-lesen-koennen/ (letzter Zugriff: 07.03.2018).

MAJMUReK, JAKUB: PiS pamięci nie przepuści. krytyka polityczna. 11.09.2017. URL: http://krytykapolityczna.pl/kultura/pis-pamieci-nie-przepusci/ (letzter Zugriff: 28.03.2018). 
Malinowski, ANNA: Leszka Jodlińskiego najpierw odwołano za rządów PO, a teraz PiS. W tle znów jest polityka. Gazeta Wyborcza. 09.03.2019. URL: https:// katowice.wyborcza.pl/katowice/7,35055,24527862,leszka-jodlinskiego-najpierwodwolano-za-rzadow-po-a-teraz.html (letzter Zugriff: 27.01.2020).

Malinowski, ANNA: Czy marszałek przedstawi swój pomysł na śląską kulturę? Petycja w sprawie Instytutu Myśli Polskiej im. Korfantego. Gazeta Wyborcza. 07.12.2019. URL: $\quad$ https://katowice.wyborcza.pl/katowice/7,35063,25488395,czy-marszalekprzedstawi-swoj-pomysl-na-slaska-kulture-petycja.html?disableRedirects=true (letzter Zugriff: 27.01.2020).

Mappes-Niediek, Norbert: Die neue Balkanpolitik ist die ganz alte. Serbien und das Kosovo sollen Gebiete tauschen. Deutschlandfunk. 21.09.2018. URL: https:// www.deutschlandfunk.de/die-neue-balkanpolitik-ist-die-ganz-alte-serbien-unddas.724.de.html?dram:article_id=428749 (letzter Zugriff: 17.11.2018).

Marschall, Christoph von: Polens Gedächtnis wird europäisch. Der Tagesspiegel. 06.10.2014. URL: https:/www.tagesspiegel.de/politik/erinnerungskultur-polensgedaechtnis-wird-europaeisch/10795660.html (letzter Zugriff: 28.03.2018).

Marsh, Katherine: Night at the Museum. Foreign Policy. 12.09.2018. URL: https:// foreignpolicy.com/2018/09/12/night-at-the-museum-european-union-brusselshistory/ (letzter Zugriff: 13.09.2018).

Marszalec, Janusz; Wnuk, Rafat: Muzeum II Wojny Światowej? Nie, Muzeum Wielkiej Polski. Śmierć wrogom ojczyzny! Gazeta Wyborcza. 08.11.2017. URL: http://wyborcza.pl/7,75968,22620819, muzeum-ii-wojny-swiatowej-nie-muzeumwielkiej-polski-smierc.html?disableRedirects=true (letzter Zugriff: 28.03.2018).

MARTIN, LOTHAR: Stoiber will Prag-Reise nicht allein mit Vertriebenenfrage verbinden. Radio Praha. 24.02.2006. URL: https://www.radio.cz/de/rubrik/nachrichten/ stoiber-will-prag-reise-nicht-allein-mit-vertriebenenfrage-verbinden (letzter $\mathrm{Zu}$ griff: 04.09.2018).

MARTIN, LOTHAR: "Wallfahrt der Versöhnung« erinnerte an Brünner Todesmarsch von 1945. Radio Praha. 30.05.2015. URL: https://www.radio.cz/de/rubrik/nachrichten/ wallfahrt-der-versoehnung-erinnerte-an-bruenner-todesmarsch-von-1945 (letzter Zugriff: 05.09.2018).

MEIER, ALBRECHT: Asselborn zeigt Unverständnis für tschechischen Wahlsieger. Der Tagesspiegel. 22.10.2017. URL: https://www.tagesspiegel.de/politik/fluechtlingspolitikasselborn-zeigt-unverstaendnis-fuer-tschechischen-wahlsieger/20486720.html (letzter Zugriff: 16.08.2018).

Merkel bekräftigt Idee des Zentrums. 60 Jahre Vertreibung - 60 Jahre Wege zur Versöhnung. DOD. 2006 (10), S. 5-8.

MIIWŚ: wystawa czasowa o pracy przymusowej i niewolniczej Polaków w III Rzeszy. gdansk.pl. 21.11.2017. URL: www.gdansk.pl/wiadomosci/MIIWS-wystawaczasowa-o-pracy-przymusowej-i-niewolniczej-Polakow-w-III-Rzeszy,a,94272 (letzter Zugriff: 06.04.2018).

Militär macht Dörfer dem Erdboden gleich. tagesschau.de. 23.02.2018 (letzter Zugriff: 12.04.2018). 
MLÁDKová, JitKa: Sondergesetz über Verdienste von Präsident Edvard Beneš. Radio Praha. 25.02.2004. URL: https://www.radio.cz/de/rubrik/tagesecho/sondergesetzueber-verdienste-von-praesident-edvard-benes (letzter Zugriff: 21.12.2018).

MÖNCH, REGINA: Unsichtbares Zeichen. FAZ. 09.03.2010. URL: www.faz.net/ aktuell/feuilleton/stiftung-flucht-vertreibung-versoehnung-unsichtbares-zeichen1955893.html (letzter Zugriff: 16.08.2018).

MostÝn, Alexandra: Hohe Wellen in Aussig. LandesEcho. 06.12.2016. URL: www. landesecho.cz/index.php/gesellschaft/101-hohe-wellen-in-aussig?highlight= WyJtdXNldWoiXQ== (letzter Zugriff: 16.12.2018).

Muraszko, MaŁgorzata: Muzeum II Wojny Światowej: 413812 zwiedzających. Gazeta Wyborcza. 23.01.2018. URL: http://trojmiasto.wyborcza.pl/trojmiasto/ 56,35611,22921002,3-muzeum-ii-wojny-swiatowej-413-812-zwiedzajacych,8.html (letzter Zugriff: 14.04.2018).

Muzealny »boom« i nowa historyczna narracja. tvn24. 01.05.2018. URL: https:// www.tvn24.pl/wiadomosci-z-kraju,3/nowe-polskie-muzea-i-ich-rola-w-politycehistorycznej,831963.html (letzter Zugriff: 02.05.2018).

Muzeum Śląskie przygotowuje rewitalizacje kolejnych obiektów. onet. 12.02.2018. URL: http://podroze.onet.pl/aktualnosci/muzeum-slaskie-przygotowuje-rewitalizacjekolejnych-obiektow/bkopph (letzter Zugriff: 19.04.2018).

Myanmar akzeptiert Rückkehr der Rohingya aus Bangladesch. Zeit Online. 23.11.2017. URL: $\quad$ www.zeit.de/politik/ausland/2017-11/myanmar-bangladesch-rohingyafluechtlinge-einigung-rueckfuehrung (letzter Zugriff: 12.04.2018).

NAwrocki, Karol: Mocne słowa dr Nawrockiego! Paweł Machcewicz reprezentuje rodzaj mentalności kastowej. Telewizja Republika. 09.06.2018. URL: http://telewizjarepublika.pl/mocne-slowa-dr-nawrockiego-pawel-machcewiczreprezentuje-rodzaj-mentalnosci-kastowej,66049.html (letzter Zugriff: 10.06.2018).

Názory na poválečné výpady vưči Němcům v ČSR se liší. České noviny. 21.06.2017. URL: www.ceskenoviny.cz/zpravy/nazory-na-povalecne-vypady-vuci-nemcum-v-csr-selisi/1499181 (letzter Zugriff: 27.02.2018).

Necas bedauert Vertreibung der Sudetendeutschen. Die Welt. 21.02.2013. URL: https:// www.welt.de/regionales/muenchen/article113807545/Necas-bedauert-Vertreibungder-Sudetendeutschen.html (letzter Zugriff: 29.08.2018).

Neumann, Steffen: Der Retter für das Museum der Deutschen. Sächsische Zeitung. 10.11.2017. URL: www.sz-online.de/nachrichten/der-retter-fuer-das-museum-derdeutschen-3814764.html (letzter Zugriff: 13.11.2017).

Neumann, Steffen: Tschechiens Museum der Deutschen rückt näher. Sächsische Zeitung. 04.02.2020. URL: https://www.saechsische.de/plus/tschechiens-museumder-deutschen-rueckt-naeher-5168811.html (letzter Zugriff: 07.02.2020).

Niehaus, Janina: Ein Haus für die Geschichte Europas. $z d f$ heute. 07.05.2017. URL: www.heute.de/in-bruesssel-eroeffnet-das-haus-der-europaeischen-geschichte(letzter Zugriff: 07.05.2017).

Nizinkiewicz, JaCek: Piotr Gliński: Lech Wałęsa to Myszka Miki wykorzystywana w walce politycznej. [Interview mit Piotr Gliński]. Rzeczpospolita. 05.09.2017. URL: www.rp.pl/Rzecz-o-polityce/309059903-Piotr-Glinski-Lech-Walesa-to-MyszkaMiki-wykorzystywana-w-walce-politycznej.html (letzter Zugriff: 22.04.2018). 
NizinkieWICZ, JACEK: Friszke: Samobójcza polityka historyczna PiS. [Interview mit Andrzej Friszke]. Rzeczpospolita. 11.09.2017. URL: https://www.rp.pl/Polityka/ 309109944-Friszke-Samobojcza-polityka-historyczna-PiS.html\#ap-1 (letzter Zugriff: 22.08.2018).

Novotny, MaIK: Das Licht unter Tage. Der Standard. 18.08.2014. URL: http:// derstandard.at/2000004450949/Das-Licht-unter-Tage (letzter Zugriff: 20.07.2017).

Nur Putin macht Polen mehr Angst als Steinbach. Die Welt. 30.03.2009. URL: https://www.welt.de/politik/article3472600/Nur-Putin-macht-Polen-mehr-Angstals-Steinbach.html (letzter Zugriff: 22.08.2018).

Odziomek, Marta: »Wystawa o historii Górnego Śląska to śmietnik«. Gazeta Wyborcza. 29.06.2015. URL: http://katowice.wyborcza.pl/katowice/1,35063,18267106,_ Wystawa_o_historii_Gornego_Slaska_to_smietnik__OPINIE_.html (letzter Zugriff: 22.12.2018).

Odziomek, Marta: Muzeum Śląskie zaprasza na nowe wystawy. Lalki, mężczyźni, młoda sztuka i polska grafika. Gazeta Wyborcza. 08.02.2018. URL: http://katowice. wyborcza.pl/katowice/7,35018,22999757,muzeum-slaskie-zaprasza-na-nowewystawy.html?disableRedirects=true (letzter Zugriff: 18.04.2018).

OeHLEN, MARTin: Haus der Europäischen Geschichte wird in Brüssel eröffnet. Kölner Stadt-Anzeiger. 05.05.2017. URL: https:/www.ksta.de/kultur/museum-in-bruesselhaus-der-europaeischen-geschichte-wird-in-bruessel-eroeffnet-26851062 (letzter Zugriff: 22.04.2018).

ORzechowski, HuberT: Czarno-biały mit Wyklętych nie ma nic wspólnego z rzeczywistością. Newsweek Polska. 05.03.2018. URL: http://m.newsweek.pl/ wiedza/historia/zolnierze-wykleci-fakty-i-mity-wywiad-z-prof-rafalemwnukiem,artykuly,424010,1.html (letzter Zugriff: 10.04.2018).

OSĘKA, PIOTR: "Zły Niemiec« - PiSowska antyniemiecka ofensywa to kalka PZPR. Newsweek Polska. 06.08.2018. URL: www.newsweek.pl/polska/polityka/-zly-niemiecpisowska-antyniemiecka-ofensywa-to-kalka-pzpr,artykuly,414282,1.html (letzter Zugriff: 22.08.2018).

Pacewicz, Piotr: PiS: Adamowicz po stronie hitlerowców. Propagandowa furia $\mathrm{w}$ odpowiedzi na samorządowe nieposłuszeństwo. OKO.press. 13.08.2018. URL: https://oko.press/pis-adamowicz-po-stronie-hitlerowcow-propagandowa-furiaw-odpowiedzi-na-samorzadowe-nieposluszenstwo/ (letzter Zugriff: 14.08.2018).

PATZKe, MARKus: »Die große Flucht«. DOD. 16.11.2001 (46), S. 11.

Paulwitz, Michael: Union in Auflösung. Junge Freiheit. 21.01.2017. URL: https:// jungefreiheit.de/debatte/kommentar/2017/union-in-aufloesung/ (letzter Zugriff: 06.03.2018).

PAWELKA, Rudi: Schlesisches Museum zu Görlitz - Viele Korrekturen notwendig. Schlesische Nachrichten. 01.07.2006, S. 1-2. URL: www.schlesisches-museum.de/index. php?id=1727 (letzter Zugriff: 15.07.2018).

PAWlik, PAWEt: Rada Muzeum Śląskiego przeciwko budowie bloków. onet Śląsk. 13.04.2018. URL: https://slask.onet.pl/rada-muzeum-slaskiego-przeciwkobudowie-blokow/qzjdmn3 (letzter Zugriff: 18.04.2018).

PAWLIK, PAWE: Marszałek chce odwołać dyrektor Muzeum Śląskiego. Poszło o kampanię PiS? onet. 16.11.2019. URL: https://wiadomosci.onet.pl/kraj/marszalek- 
chce-odwolac-dyrektor-muzeum-slaskiego-poszlo-o-kampanie-pis/bbq5x8m (letzter Zugriff: 27.01.2020).

Petr Koura: Na výstavu do Ústí by mohla přijet kancléřka Merkelová. [Interview mit Petr Koura]. Ústecký deník. 07.12.2019. URL: https://ustecky.denik.cz/zpravy_ region/petr-koura-na-vystava-rozhovor-kanclerka-merkelova-20191207.html (letzter Zugriff: 23.01.2020).

Plakatives Erinnern. Museum des Zweiten Weltkriegs in Danzig. BauNetz. 02.06.2017. URL: https://www.baunetz.de/meldungen/Meldungen-Museum_des_Zweiten_ Weltkriegs_in_Danzig_5068023.html (letzter Zugriff: 28.03.2018).

Po co Polsce, po co Niemcom Górny Śląsk? Panel dyskusyjny w Muzeum Śląskim. raciborz.com.pl. 13.03.2019. URL: https://raciborz.com.pl/2019/03/13/po-co-polsce-poco-niemcom-gorny-slask-panel-dyskusyjny-w-muzeum-slaskim.html (letzter $\mathrm{Zu}$ griff: 27.01.2020).

Polen und Deutsche kritisieren »Preußische Treuhand«. FAZ. 16.12.2006. URL: www. faz.net/aktuell/politik/vertriebene-polen-und-deutsche-kritisieren-preussischetreuhand-1385376.html (letzter Zugriff: 12.08.2018).

PosPIESZALSKI, JAN: Muzeum niemieckich zbrodni. niezależna. 09.10.2017. URL: http:// niezalezna.pl/205410-muzeum-niemieckich-zbrodni (letzter Zugriff: 28.03.2018).

Pragal, Peter: »Erzwungene Wege« zum kollektiven Gedächtnis. Ein wichtiger Baustein für ein Zentrum gegen Vertreibungen. DOD. 2006 (9), S. 5-9.

Prezes PiS. Muzeum II Wojny Światowej w Gdańsku wpisuje się w niemiecką politykę historyczną. dzieje.pl. 27.07.2017. URL: http://dzieje.pl/aktualnosci/prezes-pismuzeum-ii-wojny-swiatowej-w-gdansku-wpisuje-sie-w-niemiecka-polityke (letzter Zugriff: 28.03.2018).

Příprava expozice o soužití Čechů a Němců finišuje šest let po termínu. iDNES. 08.03.2019. URL: https://www.idnes.cz/usti/zpravy/usti-nad-labemcollegium-bohemicum-muzeum-expozice-petr-koura-cesi-nemci-souziti. A190308_462431_usti-zpravy_pakr (letzter Zugriff: 23.01.2020).

Prof. Nowak o skandalicznej wystawie w Domu Europejskiej Historii. »To jest łopatologiczne muzeum ideologiczne. Wieje nudą«. wPolityce. 17.09.2017. URL: https://wpolityce.pl/polityka/358145-prof-nowak-o-skandalicznej-wystawie-wdomu-europejskiej-historii-to-jest-lopatologiczne-muzeum-ideologiczne-wiejenuda?strona=2 (letzter Zugriff: 23.04.2018).

Przybytek, Justyna: Muzeum Śląskie wydało oficjalne oświadczenie ws. budowy osiedla wieżowców w Strefie Kultury. Dziennik Zachodni. 21.02.2018. URL: https://dziennikzachodni.pl/muzeum-slaskie-wydalo-oficjalne-oswiadczeniews-budowy-osiedla-wiezowcow-w-strefie-kultury/ar/12951461 (letzter Zugriff: 07.10.2018).

Puto, KajA: Second-hand Europe. Ukrainian immigrants in Poland. openDemocracy. 31.05.2017. URL: https:/www.opendemocracy.net/od-russia/kaja-puto/secondhand-europe-ukrainian-immigrants-in-poland (letzter Zugriff: 16.09.2018).

Puto, KajA: Eine neue Generation protestiert. Süddeutsche Zeitung. 26.07.2017. URL: https:/www.sueddeutsche.de/politik/aussenansicht-eine-neue-generationprotestiert-1.3603870 (letzter Zugriff: 23.08.2018). 
Puto, KaJA: Jak zostać zdrajcą. Wywiad z Agnieszką Haską [Interview mit Agnieszka Haska]. krytyka polityczna. 07.06.2018. URL: http://krytykapolityczna.pl/kultura/ czytaj-dalej/jak-zostac-zdrajca/ (letzter Zugriff: 28.07.2018).

RASIM, JoHANNES: „Schlesisches Museum« in Kattowitz: Museum, IKEA oder Ponderosa-Ranch? Wochenblatt. 22.07.2015. URL: http://wochenblatt.pl/schlesischemuseum-in-kattowitz-museum-ikea-oder-ponderosa-ranch/ (letzter Zugriff: 21.08.2017).

REICHERT, GÜNTER: Klare Betrachtungsweisen. Sudetendeutsche Zeitung. 29.11.2019 (48), S. 5 .

REIMERS, ARIANE: »Den Zeitpunkt für die Beobachtung verpasst«. tagesschau.de. 03.09.2018. URL: https://www.tagesschau.de/ausland/afd-verfassungsschutz-119. html (letzter Zugriff: 16.09.2018).

ReINECKe, Stefan: Die Front weicht auf. taz. 05.09.2012. URL: www.taz.de/!100967/ (letzter Zugriff: 28.02.2018).

Richters, Christian: Bauen für das Wir-Gefühl. BauNetz. 12.05.2017. URL: https:// www.baunetz.de/meldungen/Meldungen-Maison_de_l-Histoire_europeenne-_in_ Bruessel_eroeffnet_5051492.html (letzter Zugriff: 22.04.2018).

Romaniec, Rosalia: Baubeginn für das Vertriebenen-Zentrum. Deutsche Welle. 12.06.2013. URL: https://p.dw.com/p/16EoQ (letzter Zugriff: 23.03.2018).

Ruchniewicz, KrzyszToF: Wozu noch ein zusätzliches Denkmal in Berlin, und dann ausgerechnet ein Polen-Denkmal? Dialog Forum. 22.02.2018. URL: https:// forumdialog.eu/2018/02/22/wozu-noch-ein-zusaetzliches-denkmal-in-berlinund-dann-ausgerechnet-ein-polen-denkmal/ (letzter Zugriff: 23.03.2018).

Ruchniewicz, Krzysztof: Es gibt keine Opfer zweiter Klasse. FAZ. 05.03.2018. URL: www.faz.net/aktuell/feuilleton/debatten/krzysztofruchniewicz-argumentiert-fuer-polen-denkmal-15477835.html?premium= oxc7e5e722410aa4cad661499279a2b77c (letzter Zugriff: 26.07.2018).

RÜLAND, ANCHALEE: Vertriebenen-Debatte treibt Keil zwischen Forscher. Die Welt. 30.09.2010. URL: https://www.welt.de/politik/deutschland/article9977966/ Vertriebenen-Debatte-treibt-Keil-zwischen-Forscher.html (letzter Zugriff: 23.03.2018).

SADURSKA, MARIA: »Na nieludzkiej ziemi. Jeńcy polscy w ZSRR«. gdanskstrefa.com. 21.02.2018. URL: www.gdanskstrefa.com/na-nieludzkiej-ziemi-jency-polscyW-zsrr/ (letzter Zugriff: 06.04.2018).

SANDER, MARTin: Polen streiten über »Deutschtum« im Museum. Kontroverse um Schlesien-Ausstellung in Kattowitz. Deutschlandfunk Kultur. 09.10.2012. URL: www.deutschlandfunkkultur.de/polen-streiten-ueber-deutschtum-im-museum. 1013.de.html?dram:article_id=223899 (letzter Zugriff: 20.07.2017).

SANDER, Martin: Neueröffnung des Schlesischen Museums in Kattowitz. Deutschlandfunk Kultur. 26.06.2015. URL: www.deutschlandfunkkultur.de/umstrittenneueroeffnung-des-schlesischen-museums-in.1013.de.html?dram:article_id= 323757 (letzter Zugriff: 20.07.2017).

Schlesisches Museum öffnet in Görlitz. Der Tagesspiegel. 10.05.2006. URL: www. tagesspiegel.de/kultur/museen-schlesisches-museum-oeffnet-in-goerlitz/710126. html (letzter Zugriff: 21.11.2017). 
SCHLÖGEL, KARL: Kosovo ... Die Zeit. 29.04 .1999 (18/1999). URL: https:/www.zeit.de/ 1999/18/199918.schloegel_ii_.xml (letzter Zugriff: 12.08.2018).

SChmid, Klaus-Peter: Die Gefahr aus Deutschland. Die Zeit. 20.08 .1998 (35/1998). URL: https://www.zeit.de/1998/35/Die_Gefahr_aus_Deutschland/komplettansicht (letzter Zugriff: 08.12.2018).

Schmid, Thomas: Ein Draht zu den Toten. Die Welt. 27.10.2007. URL: https:// www.welt.de/debatte/kommentare/article6070409/Ein-Draht-zu-den-Toten.html (letzter Zugriff: 12.08.2018).

SCHMidT, HANS-JöRg: Verstörende Prager Proteste nach Merkel-Rede. LandesEcho. 22.06.2018. URL: www.landesecho.cz/index.php/home/706-verstoerende-pragerproteste-auf-merkel-rede (letzter Zugriff: 19.07.2018).

Schmiese, Wulf: Landsmann Schröder. Die Welt. 04.09.2000. URL: https://www. welt.de/print-welt/article531630/Landsmann-Schroeder.html (letzter Zugriff: 02.12.2018).

Schneibergová, Martina: In Ústí entsteht Ausstellung »Unsere Deutschen«. Radio Praha. 31.01.2020. URL: https://www.radio.cz/de/rubrik/tagesecho/in-ustientsteht-ausstellung-unsere-deutschen (letzter Zugriff: 31.01.2020).

Schröder, Christian: Erzählung eines Kontinents. Der Tagesspiegel. 08.05.2017. URL: https://www.tagesspiegel.de/kultur/haus-der-europaeischen-geschichte-inbruessel-erzaehlung-eines-kontinents/19766984.html (letzter Zugriff: 22.04.2018).

SCHULLER, KonRAD: "Die Geschichte ist wieder Ballast«. F.A.Z.-Gespräch mit Donald Tusk. FAZ. 10.12.2007. URL: www.faz.net/aktuell/politik/ausland/f-a-zgespraech-mit-donald-tusk-die-geschichte-ist-wieder-ballast-1491764.html? printPagedArticle=true\#void (letzter Zugriff: 15.03.2018).

SCHULLER, KonRAD: Sprache des Hasses. FAZ. 15.10.2015. URL: www.faz.net/ aktuell/politik/fluechtlingskrise/wahlkampf-in-polen-jaroslaw-kaczynski-ueberfluechtlinge-13856938.html (letzter Zugriff: 16.08.2018).

Schulz, Bernhard: In die Mitte der Gesellschaft. Der Tagesspiegel. 17.10.2016. URL: https://www.tagesspiegel.de/kultur/stiftung-flucht-vertreibung-versoehnung-indie-mitte-der-gesellschaft/14700678.html (letzter Zugriff: 07.03.2018).

SCHUlz, BERNHARD: Stiftung Flucht, Vertreibung, Versöhnung legt Ausstellungskonzept vor. Der Tagesspiegel. 21.06.2017. URL: www.tagesspiegel.de/kultur/ dauerausstellung-ueber-flucht-und-vertreibung-stiftung-flucht-vertreibungversoehnung-legt-ausstellungskonzept-vor/19957678.html (letzter Zugriff: 05.03.2018).

Schulze Wessel, MARTin: Dem deutschen Opfervolke. Süddeutsche Zeitung. 18.10.2010, S. 2.

SCHWARTZ, ROBERT: »Der Deutsche ist schuld!«. Deutsche Welle. 26.08.2018. URL: https://p.dw.com/p/33liB (letzter Zugriff: 17.11.2018).

SchWARZ, KARL-Peter: Ein schwieriger Besuch beim Nachbarn. FAZ. 19.12.2010. URL: $\quad$ www.faz.net/aktuell/politik/europaeische-union/seehofer-in-prag-einschwieriger-besuch-beim-nachbarn-1621555.html (letzter Zugriff: 30.08.2018).

Seewald, Stefan: Schlesisches Museum kooperiert mit Polen. Die Welt. 31.10.2014. URL: https://www.welt.de/sonderthemen/goerlitz/article133807657/SchlesischesMuseum-kooperiert-mit-Polen.html (letzter Zugriff: 27.11.2017). 
Seibt, Gustav: Heimat und Totengedenken. Muss es ein Mahnmal für die Vertriebenen geben? Süddeutsche Zeitung. 18.07.2003, S. 13.

SEMKA, PIOTR: O nas za nas. Wprost. 25.06.2006 (25/2006). URL: https://www.wprost.pl/ 91580/O-nas-za-nas (letzter Zugriff: 14.11.2017).

ŠíchA, JAN: V Sudetoněmeckém muzeu. Novinky.cz. 15.01.2018. URL: https://www. novinky.cz/kultura/salon/460266-jan-sicha-v-sudetonemeckem-muzeu.html (letzter Zugriff: 29.10.2018).

SKWIECIŃSKI, PIOTR: »Dom Historii Europejskiej« wykuwa nowego Europejczyka. Złożonego głównie ze wstydu. wPolityce. 05.09.2017. URL: https://wpolityce.pl/ spoleczenstwo/356342-dom-historii-europejskiej-wykuwa-nowego-europejczykazlozonego-glownie-ze-wstydu (letzter Zugriff: 22.04.2018).

SŁojewska, AnNa: Dom Historii Europejskiej: Co najbardziej grozi Europie. Rzeczpospolita. 05.09.2017. URL: www.rp.pl/Unia-Europejska/309059897-Dom-HistoriiEuropejskiej-Co-najbardziej-grozi-Europie.html\#ap-2 (letzter Zugriff: 22.04.2018).

SNyder, Timothy: Die Tragödie verstehen lernen. taz.am Wochenende. 04.06.2016, S. 1213. URL: www.taz.de/Archiv-Suche/!5306776\&s=\&SuchRahmen=Print/ (letzter Zugriff: 21.03.2018).

Sobczak, Kornelia: Bezradność liberałów. Muzeum II wojny. Dialog. 2017 (12 (733)). URL: www.dialog-pismo.pl/w-numerach/bezradnosc-liberalow-muzeum-ii-wojny (letzter Zugriff: 28.03.2018).

ŠONKA, JAROSLAV: Lieber vergessen? Sudetendeutsche Zeitung. 29.07.2016 (30), S. 1.

ŠONKA, JAROSLAV: Kleingeister oder das Aus für Aussig. Sudetendeutsche Zeitung. 04.11.2016 (44), S. 1.

SOWIŃSKI, MicHAє: Więcej dziewuch, mniej księżniczek. krytyka polityczna. 01.06.2018. URL: $\quad$ http://krytykapolityczna.pl/kultura/czytaj-dalej/dziewit-meller-wiecejdziewuch-mniej-ksiezniczek/ (letzter Zugriff: 19.08.2018).

SPELSBERG, IRMELA: Schlesisches Museum Görlitz. Wer einmal aus dem Blechnapf fraß. FAZ. 13.05 .2006 (111), S. 38. URL: www.faz.net/aktuell/feuilleton/kunst/ schlesisches-museum-goerlitz-wer-einmal-aus-dem-blechnapf-frass-1332310.

html?printPagedArticle=true\#pageIndex_o (letzter Zugriff: 21.11.2017).

Stankiewicz, Micha£: Antywojenny przekaz Muzeum II Wojny Światowej w Gdańsku. Rzeczpospolita. 13.02.2017. URL: www.rp.pl/Zycie-Pomorza/302139840Antywojenny-przekaz-Muzeum-II-Wojny-Swiatowej-w-Gdansku.html\#ap (letzter Zugriff: 07.04.2018).

STARKOWICZ, RAFAŁ: Wyklęte i sprawiedliwe. gosc.pl. 26.02.2018. URL: http://gdansk. gosc.pl/doc/4529955.Wyklete-i-sprawiedliwe (letzter Zugriff: 04.04.2018).

Stawikowska, Emilia: Tego filmu nie zobaczysz już w Muzeum II Wojny. Zamiast niego jest "polska martyrologia«. Gazeta Wyborcza. 24.11.2017 (letzter Zugriff: 06.04.2018).

STEINBACH, ERIKA: Zentrum gegen Vertreibungen. DOD. 13.09.1999 (32), S. 1.

SteInbaCH, ERIKa: Mitgefühl mit den Opfern von Flucht und Vertreibung. DOD. 2008 (11), S. 3.

Sto lat temu nikt nie mógł przewidzieć, że powstania śląskie wywrą tak duży wpływ na historię Polski. nettg.pl. 03.09.2019. URL: http://nettg.pl/news/160078/sto- 
lat-temu-nikt-nie-mogl-przewidziec-ze-powstania-slaskie-wywra-tak-duzywplyw-na-historie-polski/set/page/2 (letzter Zugriff: 27.01.2020).

StratmanN, Walter: Stiftung Zentrum gegen Vertreibungen nimmt Gestalt an. DOD. 19.11.1999 (46), S. 1.

StRATMANN, WALTER: ARD-Serie zu Vertriebenen zeigt, Zentrum gegen Vertreibungen wird immer dringender benötigt. DOD. 30.03.2001 (13), S. 1 .

STRATMANN, WALTER: »Im Krebsgang« zur Vertreibung zurückgefunden. DOD. 22.02.2002 (8), S. 1 .

Stur, Beata: Welcome to the House of European History. New Europe. 05.05.2017. URL: https://www.neweurope.eu/article/welcome-house-european-history/ (letzter Zugriff: 22.04.2018).

Szewczuk, Katarzyna; Pawlik, Pawe : Awantura o Muzeum Śląskie. »Ta historia przejdzie do podręczników«. onet Śląsk. 04.02.2020. URL: https://wiadomosci. onet.pl/tylko-w-onecie/alicja-knast-zwolniona-z-muzeum-slaskiego-o-co-chodziw-tej-historii/wjmwbse (letzter Zugriff: 05.02.2020).

SZUŁDRZYŃSKI, MichAŁ: Jak przez Niemców zmieniłem zdanie o reparacjach. Rzeczpospolita. 08.09.2017. URL: www.rp.pl/Plus-Minus/309079943-Michal-SzuldrzynskiJak-przez-Niemcow-zmienilem-zdanie-o-reparacjach.html\#ap-1 (letzter Zugriff: 22.04.2018).

SZYMAŃSKA-Borginon, Katarzyna: Dom historii czy dom ideologii? rmf24. 04.09.2017. URL: www.rmf24.pl/tylko-w-rmf24/katarzyna-szymanska-borginion/blogi/newsdom-historii-czy-dom-ideologii,nId,2436153 (letzter Zugriff: 22.04.2018).

Szymczak, Jakub: Dom Historii Europejskiej. Dom Histerii Polskiej Prawicy. OKO.press. 10.12.2017. URL: https://oko.press/dom-historii-europejskiej-domhisterii-polskiej-prawicy/ (letzter Zugriff: 23.04.2018).

Theiling, Frederik: Vortrag mit Hans-Gert Pöttering im Osnabrücker Rathaus. Werber für die europäische Idee. Neue Osnabrücker Zeitung. 04.11.2016. URL: https://www.noz.de/lokales/osnabrueck/artikel/800893/vortrag-mit-hans-gertpoettering-im-osnabruecker-rathaus (letzter Zugriff: 22.04.2018).

Tiews, Alina LaURA: 1945: Flüchtlinge in Norddeutschland. NDR. 05.12.2016. URL: https://www.ndr.de/der_ndr/unternehmen/geschichte/1945-Fluechtlinge-inNorddeutschland-,fluchtnorddeutschlandioo.html (letzter Zugriff: 16.08.2018).

Tilmann, Christina: Wenn die Erinnerung vertrieben wird. Der Tagesspiegel. 29.08.2006. URL: https://www.tagesspiegel.de/kultur/wenn-die-erinnerungvertrieben-wird/745582.html (letzter Zugriff: 16.08.2018).

To już rok działalności Muzeum II Wojny Światowej. Czas na podsumowanie. niezależna. 06.04.2018. URL: http://niezalezna.pl/221851-to-juz-rok-dzialalnosci-muzeum-iiwojny-swiatowej-czas-na-podsumowanie (letzter Zugriff: 28.05.2018).

TOMASZEWSKI, JERzY: Europa der Vaterländer oder Vaterland der Zwistigkeiten? [Europa ojczyzn czy ojczyzna swarów?] [Abgedruckt und übersetzt in: Dokumentation Ostmitteleuropa: Trauma oder Traum? Der polnische Beitrag zur MitteleuropaDiskussion (1985-1990), Jg. 17 (41), April 1991, Heft 1/2, S. 128-155]. Polityka. 05.05.1990 (18). 
Troebst, Stefan: Rettet die Vertriebenenstiftung vor der Provinz! Die Welt. 12.07.2015. URL: https://www.welt.de/geschichte/article143832676/Rettet-dieVertriebenenstiftung-vor-der-Provinz.html (letzter Zugriff: 07.03.2018).

Troebst, Stefan: Protestuję przeciwko prowincjonalizacji niemieckiej polityki historycznej. Gazeta Wyborcza. 13.07.2015. URL: http://wyborcza.pl/ 1,75968,18349376,protestuje-przeciwko-prowincjonalizacji-niemieckiej-polityki. html?disableRedirects=true (letzter Zugriff: 23.03.2018).

Tschechiens EU-Beitritt und die Benes-Dekrete. Elke Durak im Gespräch mit Bernd Posselt, Vorsitzender der Sudetendeutschen Landsmannschaft und Mitglied (CSU) im Europaparlament [Ursprünglich ein Beitrag im Deutschlandfunk, V. R.]. Die Zeit. 25.04.2002. URL: https://www.zeit.de/2002/18/200218_dlfinterview_2604_xml (letzter Zugriff: 16.09.2018).

Tschechischer Minister besucht Sudetendeutschen Tag. FAZ. 15.05.2016. URL: www. faz.net/aktuell/politik/inland/tschechischer-minister-besucht-sudetendeutschentag-14235175.html (letzter Zugriff: 30.08.2018).

UKIELSKI, PAWE:: Worauf können die Europäer stolz sein? FAZ. 06.11.2017. URL: www. faz.net/aktuell/feuilleton/worauf-koennen-die-europaeer-stolz-sein-15278563-p2. html?printPagedArticle=true\#pageIndex_I (letzter Zugriff: 23.04.2018).

Ukielski, PaWeŁ: Polsko-německé dějiny v evropské omáčce. Česká pozice. 11.11.2017. URL: http://ceskapozice.lidovky.cz/polsko-nemecke-dejiny-v-evropske-omaccefCW-/tema.aspx?c=A171107_172058_pozice-tema_lube (letzter Zugriff: 30.08.2018).

Urban, Thomas: Tragische Gestalt der polnischen Geschichte. Zum Tod von Wojciech Jaruzelski. Süddeutsche Zeitung. 25.05.2014. URL: www.sueddeutsche.de/politik/ zum-tod-von-wojciech-jaruzelski-tragische-gestalt-der-polnischen-geschichte-1. 1399662 (letzter Zugriff: 26.05.2018).

Versöhnung 70 Jahre nach »Todesmarsch« von Brünn. Deutsche Welle. 30.05.2018. URL: https://p.dw.com/p/1FZWV (letzter Zugriff: 05.09.2018).

Vertreibung Sudetendeutscher für immer weniger Tschechen »gerecht«. Die Presse. 12.01.2017. URL: https://diepresse.com/home/zeitgeschichte/5152837/VertreibungSudetendeutscher-fuer-immer-weniger-Tschechen-gerecht (letzter Zugriff: 31.08.2018).

Verzicht auf »Wiedergewinnung der Heimat«. FAZ. 01.03.2015. URL: www.faz. net/aktuell/politik/verzicht-auf-wiedergewinnung-der-heimat-13457396.html (letzter Zugriff: 29.10.2018).

VICK, KLAUS: Kunstvoller Bau an der Isarhangkante. Münchner Merkur. 20.12.2014 (293), S. 15.

Viel Gold und Silber bei den Schlesiern. Echo. 03.05.2018. URL: www.echo-online.de/ lokales/bergstrasse/kreis-bergstrasse/viel-gold-und-silber-bei-den-schlesiern_ 18727769.htm (letzter Zugriff: 28.05.2018).

VORLÍČEK, JANNI: Výstava představí historii soužití Čechů a Němců. Zabere 20 sálů. Ústecký deník. 12.11.2017. URL: https://ustecky.denik.cz/zpravy_region/vystavapredstavi-historii-souziti-cechu-a-nemcu-zabere-20-salu-20171112.html (letzter Zugriff: 31.01.2020). 
VorlíčeK, JANni: Výstava o Němcích? Ústecký deník. 17.09.2019. URL: https:// ustecky.denik.cz/zpravy_region/vystava-o-nemcich-musi-byt-za-rok-jinak-ustiprijde-0-336-5-milionu-korun-20190917.html (letzter Zugriff: 23.01.2020).

VorLíčEK, JANNI: Výstava $\mathrm{v}$ Ústí za desítky milionů? Karel IV. i ovád ze Sudet. Ústeckýdeník.30.01.2020. URL: https://ustecky.denik.cz/zpravy_region/vystavav-usti-za-desitky-milionu-karel-iv-i-ovad-ze-sudet-20200130.html (letzter Zugriff: 31.01.2020).

WAGNER, RICHARD: Falsche Harmonie. Die Vertreibung im Wahlkampf. Frankfurter Rundschau. 11.08.2005.

Warum sich die Eröffnung um Jahre verzögert. Süddeutsche Zeitung. 03.07.2019. URL: https://www.sueddeutsche.de/muenchen/muenchen-sudetendeutsches-museumeroeffnung-verzoegerung-1.4505052 (letzter Zugriff: 23.01.2020).

WĄs, MAREK: Niemcy powinni być wdzięczni gdańskiemu muzeum. Gazeta Wyborcza. 22.09.2010. URL: http://trojmiasto.wyborcza.pl/trojmiasto/ 1,35612,8408599,Niemcy_powinni_byc_wdzieczni_gdanskiemu_muzeum.html (letzter Zugriff: 25.02.2018).

WĄsowicz, JAROSŁAW: Wciąż biją serca dla »Inki«. niezależna. 11.03.2018. URL: http:// niezalezna.pl/219329-wciaz-bija-serca-dla-inki (letzter Zugriff: 06.04.2018).

Ważne słowa wiceministra Sellina: »Potrzebujemy dobrej, zgodnej z prawdą narracji historycznej. Systemowa praca jest bardzo potrzebna«. wPolityce. 06.04.2018. URL: $\quad$ https://wpolityce.pl/polityka/389169-wazne-slowa-wiceministra-sellinapotrzebujemy-dobrej-zgodnej-z-prawda-narracji-historycznej-systemowa-pracajest-bardzo-potrzebna (letzter Zugriff: 28.07.2018).

Weber, Pierre-Frédéric: Ein toxischer Vergleich. Dialog Forum. 13.12.2019. URL: https:/forumdialog.eu/2019/12/13/ein-toxischer-vergleich/ (letzter Zugriff: 31.01.2020).

Wenowski, MatthäUs: Wie Polens Politiker die Geschichte instrumentalisieren. FAZ. 04.03.2018. URL: www.faz.net/aktuell/politik/ausland/wie-polens-politikerdie-geschichte-instrumentalisieren-15474888-p3.html?printPagedArticle= true\#pageIndex_2 (letzter Zugriff: 19.08.2018).

WeILAnd, Severin: Auf schmalem Grat. Ausstellung »Erzwungene Wege«. Spiegel Online. 10.08.2006. URL: www.spiegel.de/kultur/gesellschaft/ausstellungerzwungene-wege-auf-schmalem-grat-a-431026.html (letzter Zugriff: 16.08.2018).

WeIngÄRTNER, DANIEla: Mut zur drastischen Reduktion. Badische Zeitung. 08.05.2017. URL: $\quad$ www.badische-zeitung.de/kunst-1/mut-zur-drastischen-reduktion136478314.html (letzter Zugriff: 22.04.2018).

WielińsKi, Bartosz T.: Muzeum wyciszy spór o wypędzonych. Gazeta Wyborcza. 31.08.2012. URL: http://wyborcza.pl/1,76842,12395239,Muzeum_wyciszy_spor_o_ wypedzonych.html (letzter Zugriff: 26.02.2018).

Wieliński, BARTOSz T.: Bez skandalu w muzeum wypędzonych. Gazeta Wyborcza. 20.11.2014. URL: http://wyborcza.pl/1,75968,16997635,Bez_skandalu_w_muzeum_ wypedzonych.html (letzter Zugriff: 26.02.2018).

WielińSki, BARtosz T.: Niemcy+Polska=WNM. Dobre zdanie o Polakach ma 88 proc. Niemców. Lubią nas nawet potomkowie wypędzonych. Gazeta Wyborcza. 16.06.2015. 
URL: http://wyborcza.pl/1,75399,18135014,Niemcy_Polska_WNM_Dobre_zdanie_o_ Polakach_ma_88_proc_html (letzter Zugriff: 26.02.2018).

Wieliński, BARTOSz T.: Gdy Guido Westerwelle kierował niemiecką dyplomacją, zarzucano mu naiwność. Gazeta Wyborcza. 18.03.2016. URL: http://wyborcza.pl/ 1,75968,19790419,gdy-guido-westerwelle-kierowal-niemiecka-dyplomacjazarzucano.html (letzter Zugriff: 26.02.2018).

Wieliński, BARTosz T.: Niemcy chcą postawić pomnik Polakom zamordowanym podczas drugiej wojny światowej. Gazeta Wyborcza. 07.11.2017. URL: http://wyborcza.pl/7,75399,22612024,niemcy-chca-postawic-pomnik-polakomzamordowanym-podczas-drugiej.html (letzter Zugriff: 26.02.2018).

Wojciech Smarzowski - Rose - Interview. culture.pl. 29.06.2011. URL: https:// culture.pl/en/article/wojciech-smarzowski-rose-interview (letzter Zugriff: 20.08.2018).

WolfF-PowĘSKa, ANNA: „Dobra zmiana« szuka naukowych standardów edukacji historycznej Polaków. A one już są: wystarczy nie kłamać. Gazeta Wyborcza. 26.05.2018. URL: http://wyborcza.pl/magazyn/7,124059,23451382,dobrazmiana-szuka-naukowych-standardow-edukacji.html?disableRedirects=true (letzter Zugriff: 22.08.2018).

WróblewSKI, Michą: »Muzeum II Wojny Światowej, zamiast być dumą Polski, stało się miejscem politycznej cenzury«. Prof. Paweł Machcewicz dla WP. wp opinie. 31.08.2018. URL: https://opinie.wp.pl/muzeum-ii-wojny-swiatowejzamiast-byc-duma-polski-stalo-sie-miejscem-politycznej-cenzury-prof-pawelmachcewicz-dla-wp-6290347503511169a (letzter Zugriff: 01.09.2018).

ZajonZ, Michael: Ein Schloss für viele Schlüssel. Der Tagesspiegel. 11.06.2006. URL: www.tagesspiegel.de/kultur/ein-schloss-fuer-viele-schluessel/719450.html (letzter Zugriff: 21.11.2017).

Zmiany w wystawie Muzeum II Wojny Światowej. »Nowy film zastąpił nieudaną, dotychczasową produkcję«. tvn24. 31.10.2017. URL: https://www.tvn24.pl/pomorze,42/ gdansk-zmiany-w-wystawie-muzeum-ii-wojny-swiatowej,786061.html (letzter $\mathrm{Zu-}$ griff: 28.03.2018).

Znamy kulisy rozprawy dot. MIIWŚ! Dr Nawrocki: »Wyszło, że nad wystawą główną nie pracowały 4 osoby, lecz ponad 20!« [Interview mit Karol Nawrocki]. wPolityce. 14.11.2018. URL: https://wpolityce.pl/polityka/421137-nasz-wywiad-znamykulisy-rozprawy-dot-miiws (letzter Zugriff: 16.11.2018).

\section{Sekundärliteratur}

»Ein Paradox der Geschichte«. Der Warschauer Historiker und Ex-Außenminister Władysław Bartoszewski über seine Erfahrungen als Häftling unter Nazis und Stalinisten, das Kriegs- und Vertreibungsschicksal seines Landes und den langen Weg zur deutsch-polnischen Aussöhnung. Das Gespräch führten Stephan Burgdorff und Rainer Traub. In: Aust, Stefan; Burgdorff, Stephan (Hg.): Die Flucht. Über die Vertreibung der Deutschen aus dem Osten. Bonn 2005, S. 179-188. 
ABRAMS, BradLEy F.: Morality, Wisdom and Revision. The Czech Opposition of the 1970s and the Expulsion of the Sudeten Germans. In: East European Politics and Societies 9 (1995), H. 2, S. 234-255.

Ackermann, Felix: Angewandte Kulturwissenschaften. Partizipative Wissensproduktion in Theorie und Praxis. In: Ackermann, Felix; BoroffKa, ANNA; Lersch, GreGOR H. (HG.): Partizipative Erinnerungsräume. Dialogische Wissensbildung in $\mathrm{Mu}$ seen und Ausstellungen. Bielefeld 2013, S. 51-67.

Ackermann, Felix; Boroffka, Anna; Lersch, Gregor H.: Partizipative Erinnerungsräume. In: Ackermann, Felix; Boroffka, Anna; Lersch, Gregor H. (Hg.): Partizipative Erinnerungsräume. Dialogische Wissensbildung in Museen und Ausstellungen. Bielefeld 2013, S. 9-18.

Ackermann, Jakob: Das Eigene und das Fremde im Museum. Die museale RePräsentation sozialer Differenz. In: ACKermanN, Felix; BoroffKa, ANNA; LersCH, Gregor H. (Hg.): Partizipative Erinnerungsräume. Dialogische Wissensbildung in Museen und Ausstellungen. Bielefeld 2013, S. 277-291.

ADRIAN, JoHANNA: Kontaktzone - Identitätsfabrik - Sehnsuchtsort: Schlesische Museen in Deutschland. Masterarbeit [unveröffentlicht]. Freie Universität Berlin 2014.

Ahonen, Pertti: On Forced Migrations. Transnational Realities and National Narratives in Post-1945 (West) Germany. In: German History 32 (2014), H. 4, S. 599-614.

Ahonen, Pertti; Corni, Gustavo; Kochanowski, Jerzy; Schulze, Rainer; Stark, Tamás; Stelzl-Marx, Barbara (Hg.): People on the Move. Forced Population Movements in Europe in the Second World War and its Aftermath. Oxford (UK), New York (NY) 2008.

Aly, GötZ: Auschwitz und die Politik der Vertreibung. In: Faulenbach, Bernd; HelLE, ANDREAS (Hg.): Zwangsmigration in Europa. Zur wissenschaftlichen und politischen Auseinandersetzung um die Vertreibung der Deutschen aus dem Osten. Essen 2005, S. 35-44.

Amos, HeIke: Vertriebenenverbände im Fadenkreuz. Aktivitäten der DDRStaatssicherheit 1949 bis 1989. München 2011.

ARBURG, ADRIAN von: Das Katastrophenjahrzehnt 1938-1948 im Spiegel der historischen Forschung. Desetiletí katastrof 1938-1948 v zrcadle historického výzkumu. In: Antikomplex (Hg.): Tragická místa paměti. Tragische Erinnerungsorte. Průvodce po historii jednoho regionu 1938-1945. Ein Führer durch die Geschichte einer Region 1938-1945. Praha 2011, S. 34-94.

Assmann, AleIDA: Der lange Schatten der Vergangenheit. Erinnerungskultur und Geschichtspolitik. München 2006.

Assmann, AleIDA: Europe: A Community of Memory? Twentieth Annual Lecture of the GHI, November 16, 2006. In: Bulletin of the German Historical Institute (Washington DC) (2007), H. 40, S.11-25. URL: https://www.ghi-dc.org/fileadmin/user_upload/GHI_ Washington/Publications/Bulletin40/o11.pdf (letzter Zugriff: 10.06.2018).

AssmanN, ALEIDA: Geschichte im Gedächtnis. Von der individuellen Erfahrung zur öffentlichen Inszenierung. München 2007.

Assmann, Aleida: Konstruktion von Geschichte in Museen. In: Aus Politik und Zeitgeschichte (2007), H. 49, S. 6-13.

AssmanN, AlEIDA: Auf dem Weg zu einer europäischen Gedächtniskultur? Wien 2012. 
AssmanN, Aleida: Das neue Unbehagen an der Erinnerungskultur. Eine Intervention. München 2013.

Assmann, Aleida: Ist die Zeit aus den Fugen? Aufstieg und Fall des Zeitregimes der Moderne. München 2013.

ASSMANN, ALEIDA: Formen des Vergessens. Göttingen 2016.

Aubele, Katharina: Vertriebene Frauen in der Bundesrepublik Deutschland. Göttingen 2015.

Axelsson, Bodil; Dupont, Christine; Kesteloot, Chantal (Hg.): Entering the Minefields. The Creation of New History Museums in Europe. Conference Proceedings from EuNaMus, European National Museums: Identity Politics, the Uses of the Past, and the European Citizen. Brussels 25 January 2012. Linköping 2012.

Axelsson, Bodil; Dupont, Christine; Kesteloot, Chantal: Entering Two Minefields. Research for Policy-Making and the Creation of New History Museums in Europe. In: Axelsson, Bodil; Dupont, Christine; Kesteloot, Chantal (Hg.): Entering the Minefields. The Creation of New History Museums in Europe. Conference Proceedings from EuNaMus, European National Museums: Identity Politics, the Uses of the Past, and the European Citizen. Brussels 25 January 2012. Linköping 2012, S. 1-14.

BaCHMANN, KlaUs: Nationalistische Einstellungen in der Volksrepublik Polen nach 1956 im Lichte von Meinungsumfragen. In: Frackowiak, Johannes (Hg.): Nationalistische Politik und Ressentiments. Deutsche und Polen von 1871 bis zur Gegenwart. Göttingen 2013, S. 257-283.

Bachmann, Klaus: Politische Debatten in Polen nach 1989. In: Jahrbuch Polen (2017), H. 28, S. 11-28.

Bachmann, Klaus; Kranz, Jerzy (Hg.): Przeprosić za wypedzenie? Wypowiedzi oficjalne oraz debata prasowa o wysiedleniu Niemców po II wojnie światowej. Kraków 1997.

BachmanN, Klaus; Kranz, Jerzy (Hg.): Verlorene Heimat. Die Vertreibungsdebatte in Polen. Bonn 1998.

Bade, Klaus J.; Oltmer, Jochen: Mitteleuropa. Deutschland. In: Bade, Klaus J.; EMMer, Pieter C.; LuCASSen, LeO; Oltmer, Jochen (Hg.): Enzyklopädie Migration in Europa. Vom 17. Jahrhundert bis zur Gegenwart. Paderborn, München [u.a.] 2010 (3. Aufl.), S. 141-170.

BAHLCKE, JOACHIM: Oberschlesien - eine Fallstudie zur Konstruktion geschichtlicher Räume, kultureller Identitäten und historiographischer Raumkonzepte. In: Bahlcke, Joachim; GaWrecki, Dan; Kaczmarek, Ryszard (Hg.): Geschichte Oberschlesiens. Politik, Wirtschaft und Kultur von den Anfängen bis zur Gegenwart. Berlin 2015 (2. übera. und erw. Aufl. der poln. Originalausg. von 2011), S. 17-46.

Bahlcke, JoAchim; GaWrecki, Dan; KaczMarek, Ryszard (Hg.): Geschichte Oberschlesiens. Politik, Wirtschaft und Kultur von den Anfängen bis zur Gegenwart. Berlin 2015 (2. übera. und erw. Aufl. der poln. Originalausg. von 2011).

Bahr, Petra: Aufrichtiges Gedenken. Thesen zum öffentlichen Gedenken in der Stiftung »Flucht, Vertreibung, Versöhnung«. In: forum erwachsenenbildung (2010), H. 4, S. 64-65.

BAL, Mieke: Kulturanalyse. Frankfurt a.M. 2002. 
Baron, Roman; Michalczyk, Andrzej; Witkowski, Michaє J.: Wer ist Oberschlesier? Verschiedene Antworten auf eine komplizierte Frage. In: BAHLCKE, JOACHIM; Gawrecki, Dan; Kaczmarek, Ryszard (Hg.): Geschichte Oberschlesiens. Politik, Wirtschaft und Kultur von den Anfängen bis zur Gegenwart. Berlin 2015 (2. übera. und erw. Aufl. der poln. Originalausg. von 2011), S. 655-665.

BAuER, MARkus: Auf halbem Weg. Stand und Perspektiven des Schlesischen Museums zu Görlitz. In: BAUER, MARKuS (Hg.): Auf der Suche nach Schlesien. Zwischenbilanz beim Aufbau des Schlesischen Museums zu Görlitz. Halle an der Saale 2001, S. 17-21. Bauer, Markus: Das Schlesische Museum - Entwicklung, Aufgaben, Perspektiven. In: Bauer, Markus; Brade, Johanna; Kügler, Martin; Pietsch, Martina (Hg.): Schlesisches Museum zu Görlitz - Museum für eine europäische Kulturregion. Muzeum Ślaskie w Görlitz - Muzeum europejskiego regionu kulturowego. Dößel 2006, S. 13-22.

BAuer, Markus: Zwischen Denkmal und kulturpolitischem Forum. Das Schlesische Museum zu Görlitz. In: Informationen des Sächsischen Museumsbundes e.V. (2007), H. 33, S. 77-84 (letzter Zugriff: 26.02.2018).

BAUER, MARKUS: Flucht und Vertreibung in den Regionalmuseen zu den früheren deutschen Reichs- und Siedlungsgebieten. In: Deutsches Historisches Museum; International Association of Museums of History; Stiftung Flucht, Vertreibung, Versöhnung (Hg.): Flucht, Vertreibung, Ethnische Säuberung. Eine Hausforderung für Museums- und Ausstellungsarbeit weltweit. Tagungsband zum Neunten Internationalen Symposium der International Association of Museums of History. Berlin 2010, S. 43-49.

BAUER, MARKus: Schlesien im Museum. Kultur und Geschichte Schlesiens in deutschen und polnischen Museen nach dem Zweiten Weltkrieg. In: Inter Finitimos. Jahrbuch zur deutsch-polnischen Beziehungsgeschichte (2012), H. 10, S. 53-70.

BAUER, MARKus: Migration in der schlesischen Geschichte. In: Mazurkiewicz, MareK; Franke, Annemarie; Siwek, Tadeusz; Moj, Magdalena (Hg.): Colloquium Opole 2016. Polska, Niemcy, Czechy wobec wyzwania migracji i integracji. Opole 2017, S. 253-267.

BAUERKÄMPER, ARND: Assimilationspolitik und Integrationsdynamik. Vertriebene in der SBZ/DDR in vergleichender Perspektive. In: Krauss, MARITA (Hg.): Integrationen. Vertriebene in den deutschen Ländern nach 1945. Göttingen 2008, S. 22-47.

BAUERKÄMPER, ARND: Deutsche Flüchtlinge und Vertriebene aus Ost-, Ostmittel- und Südosteuropa in Deutschland und Österreich seit dem Ende des Zweiten Weltkrieges. In: Bade, Klaus J.; Emmer, Pieter C.; Lucassen, Leo; Oltmer, Jochen (Hg.): Enzyklopädie Migration in Europa. Vom 17. Jahrhundert bis zur Gegenwart. Paderborn, München [u.a.] 2010 (3. Aufl.), S. 477-485.

BAUERKÄMPER, ARND: Wege zur europäischen Geschichte. Erträge und Perspektiven der vergleichs- und transfergeschichtlichen Forschung. In: ARNDT, AGNEs; HäBERLEN, JOACHIM C.; REINECKE, CHRISTIANE (Hg.): Vergleichen, verflechten, verwirren? Europäische Geschichtsschreibung zwischen Theorie und Praxis. Göttingen 2011, S. 33-60.

BAUERKÄMPER, ARND: Das umstrittene Gedächtnis. Die Erinnerung an Nationalsozialismus, Faschismus und Krieg in Europa seit 1945. Paderborn 2012. 
BAUR, JOACHIM: Die Musealisierung der Migration. Einwanderungsmuseen und die Inszenierung der multikulturellen Nation. Bielefeld 2009.

BAUR, JoACHIM: Museumsanalyse: Zur Einführung. In: BaUR, JOACHIM (Hg.): Museumsanalyse. Methoden und Konturen eines neuen Forschungsfeldes. Bielefeld 2010, S. 7-14.

BAUR, JOACHIM: Was ist ein Museum? Vier Umkreisungen eines widerspenstigen Gegenstands. In: BAUR, JOACHIM (Hg.): Museumsanalyse. Methoden und Konturen eines neuen Forschungsfeldes. Bielefeld 2010, S. 15-48.

BAUR, JOACHIM: Mit Räumen sichtbar machen: inszenatorisch-szenografischer Ansatz. In: Walz, Markus (Hg.): Handbuch Museum. Geschichte, Aufgaben, Perspektiven. Stuttgart 2016, S. 261-266.

BeBenek, Chris: The Heimat Maneuver. In: Transition (2007), H. 97, S. 150-171.

BECKER, MANUel: Geschichtspolitik in der »Berliner Republik«. Konzeptionen und Kontroversen. Wiesbaden 2013.

BEER, MATHIAS: »Flucht und Vertreibung «. Eine deutsche Streitgeschichte. In: HASLINger, Peter; Franzen, K. Erik; Wessel, Martin Schulze (Hg.): Diskurse über Zwangsmigration in Zentraleuropa. Geschichtspolitik, Fachdebatten, literarisches und lokales Erinnern seit 1989. München 2008, S. 261-277.

BEER, MATHIAS: Flucht und Vertreibung der Deutschen. Voraussetzungen, Verlauf, Folgen. München 2011.

BEER, MATHIAS: Die »Flüchtlingsfrage« in Deutschland nach 1945 und heute. Ein Vergleich. In: Zeitgeschichte-online (2016). URL: www.zeitgeschichte-online.de/ thema/die-fluechtlingsfrage-deutschland-nach-1945-und-heute (letzter Zugriff: 12.03.2017).

BeIER-De HaAn, Rosmarie: Geschichtskultur in der Zweiten Moderne. Eine Einführung. In: BeIER-DE HAAN, Rosmarie (Hg.): Geschichtskultur in der Zweiten Moderne. Frankfurt a.M. [u.a.] 2000, S. 11-25.

BeIER-De HaAn, Rosmarie: Deutsches Historisches Museum. Rethinking German History Against the Background of a Burdened Past and New Challenges for the $21^{\text {st }}$ Century. In: Axelsson, Bodil; Dupont, Christine; Kesteloot, Chantal (Hg.): Entering the Minefields. The Creation of New History Museums in Europe. Conference Proceedings from EuNaMus, European National Museums: Identity Politics, the Uses of the Past, and the European Citizen. Brussels 25 January 2012. Linköping 2012, S. 55-70.

Belzyt, Leszek C.: Ostkolonisation. Zivilisation aus dem Westen? In: HAHN, HaNS Henning; Traba, Robert (Hg.): Deutsch-Polnische Erinnerungsorte. Band 2: Geteilt/Gemeinsam. Unter Mitarbeit von Maciej Górny und Kornelia Kończal. Paderborn 2014, S. 227-245.

Benthin, Madlen: Die Vertreibung der Deutschen aus Ostmitteleuropa. Deutsche und tschechische Erinnerungskulturen im Vergleich. Hannover 2007.

BENZ, WolfGANG (Hg.): Wann ziehen wir endlich den Schlussstrich? Von der Notwendigkeit öffentlicher Erinnerung in Deutschland, Polen und Tschechien. Berlin 2004.

BenZ, Wolfgang: Zur Debatte. Flucht, Vertreibung, Versöhnung. In: Webseite der Bundeszentrale für Politische Bildung (12.11.2008). URL: www.bpb.de/ 
geschichte/zeitgeschichte/geschichte-und-erinnerung/39826/flucht-vertreibungversoehnung? $\mathrm{p}=$ all (letzter Zugriff: 16.03.2015).

Bergem, Wolfgang: Geschichtspolitik und Erinnerungskultur. In: FröHLICH, ClaUDia; Heinrich, Horst-Alfred; Schmid, Harald (Hg.): Jahrbuch für Politik und Geschichte 1. Historische Gerechtigkeit. Geschichtspolitik im Vergleich. Stuttgart 2010, S. 233-253.

Bergenthum, HaRtmut: Geschichtswissenschaft und Erinnerungskulturen. Bemerkungen zur neueren Theoriedebatte. In: OESTERLE, GÜNTER (Hg.): Erinnerung, Gedächtnis, Wissen. Studien zur kulturwissenschaftlichen Gedächtnisforschung. Göttingen 2005, S. 121-162.

Berger, Stefan: On Taboos, Traumas and Other Myths. Why the Debate about German Victims of the Second World War is not a Historians' Controversy. In: NIVEN, BILL (Hg.): Germans as Victims. Remembering the Past in Contemporary Germany. Basingstoke (Hampshire) [u.a.] 2006, S. 210-224.

Berger, Stefan; Niven, Bill: Writing the History of National Memory. In: Berger, Stefan; Niven, William John (Hg.): Writing the History of Memory. London 2014, S. 135-156.

BERGSDORF, WolfGANG: Der Stellenwert ostdeutscher Kulturpflege in der Ära Kohl. In: Gauger, Jörg-Dieter; Kittel, MAnfred (Hg.): Die Vertreibung der Deutschen aus dem Osten in der Erinnerungskultur. Sankt Augustin 2005, S. 53-67.

Bessel, RichARD; HAAKe, ClAudia B.: Introduction. Forced Removal in the Modern World. In: Bessel, Richard; HaAke, Claudia B. (Hg.): Removing Peoples. Forced Removal in the Modern World. Oxford (UK), New York (NY) 2009, S. 3-11.

Beushausen, Reiner (Hg.): Die Diskussion über die Vertreibung der Deutschen in der ČSFR. Marburg 1991.

Bingen, Dieter: Versöhnung, Aussöhnung, Normalisierung - Perspektiven der Entspannungspolitik in den 1960er- und 1970er-Jahren aus deutscher und polnischer Sicht. In: Boll, Friedhelm; Wysocki, WiesŁaW; Ziemer, Klaus (Hg.): Versöhnung und Politik. Polnisch-deutsche Versöhnungsinitiativen der 1960er-Jahre und die Entspannungspolitik. Unter Mitarbeit von Thomas Roth. Bonn 2009, S. 245-268.

Bingen, Dieter; Borodziej, WŁodzimierz; Troebst, Stefan (Hg.): Vertreibungen europäisch erinnern? Historische Erfahrungen, Vergangenheitspolitik, Zukunftskonzeptionen. Wiesbaden 2003.

Bingen, Dieter; Loew, Peter Oliver; Wóycicki, Kazimierz: Einleitung. In: Bingen, Dieter; Loew, Peter Oliver; Wóycicki, Kazimierz (Hg.): Die Destruktion des Dialogs. Zur innenpolitischen Instrumentalisierung negativer Fremd- und Feindbilder. Polen, Tschechien, Deutschland und die Niederlande im Vergleich, 1900-2005. Wiesbaden 2007, S. 9-11.

BISCHOF, KARIN: Die Periode bis zur Gegenwart. Kontinuitäten und Brüche der nationalen Narrative in der Transformationsphase. In: PELINKA, ANTON; BISCHOF, KARIN; Fend, Walter; Stögner, Karin; Köhler, Thomas (Hg.): Geschichtsbuch Mitteleuropa. Vom Fin de Siècle bis zur Gegenwart. Wien 2016, S. 91-105.

BitTNer, Alicja ET AL.: Muzeum II Wojny Światowej w Gdańsku. Międzynarodowy konkurs architektoniczny $=$ Museum of the Second World War: International architectural competition. Gdańsk 2010. 
Blaive, Muriel: The Memory of the Holocaust and of Communist Repression in a Comparative Perspective. The Cases of Hungary, Poland and Czechoslovakia/the Czech Republic. In: Blaive, Muriel; Gerbel, Christian; Lindenberger, Thomas (Hg.): Clashes in European Memory. The Case of Communist Repression and the Holocaust. Innsbruck 2011, S. 154-172.

Blaive, Muriel: National Narratives of Czech Identity. From the $19^{\text {th }}$ Century to the Present. In: Pelinka, Anton; Bischof, Karin; Fend, Walter; Stögner, Karin; KöHLER, Thomas (Hg.): Geschichtsbuch Mitteleuropa. Vom Fin de Siècle bis zur Gegenwart. Wien 2016, S. 161-189.

Bock, Ivo: Das "sudetendeutsche Thema in der tschechischen Literatur. Stereotype und Gegenstereotype. In: Osteuropa 53 (2003), H. 1, S. 77-93.

Bock, Petra; Wolfrum, Edgar: Einleitung. In: Bock, Petra; Wolfrum, Edgar (Hg.): Umkämpfte Vergangenheit. Geschichtsbilder, Erinnerung und Vergangenheitspolitik im internationalen Vergleich. Göttingen 1999, S. 7-14.

Boer, Pim den; Duchhardt, Heinz; Kreis, Georg; Schmale, Wolfgang (Hg.): Europäische Erinnerungsorte. Band 1: Mythen und Grundbegriffe des europäischen Selbstverständnisses. Berlin, Boston 2012.

Bogumie, Zuzanna; Senina, Maria; Wawrzyniak, Joanna; Buchen, Tim; Ganzer, Christian: Conclusions. In: Bogumie, Zuzanna; Senina, Maria; WaWrzyniak, Joanna; Buchen, Tim; Ganzer, Christian (Hg.): The Enemy on Display. The Second World War in Eastern European Museums. New York, Oxford 2015, S. 133-152.

Bogumie, Zuzanna; WaWrzyniak, Joanna; Buchen, Tim; Ganzer, Christian; Senina, MARIa: Introduction. The Enemy on Display. In: Bogumie, ZuZanna; SEnina, Maria; WaWrzyniak, JoAnna; Buchen, Tim; Ganzer, Christian (Hg.): The Enemy on Display. The Second World War in Eastern European Museums. New York, Oxford 2015, S. 1-25.

Bojković, SlaĐAna; Stolić, ANA (Hg.): Muzeji kao mesta pomirenja. Zbornik radova sa 8. kolokvijuma Međunarodne asocijacije istorijskih muzeja, Beograd, 24-27. septembar $2008=$ Museums as places of reconciliation: proceedings ot [sic] the 8th Colloquium of the International Association of Museums of History, Belgrade, September 24-27, 2008. Belgrad 2009.

BOll, Friedhelm: $\mathrm{Zu}$ historischen Missverständnissen und Versäumnissen im deutsch-polnischen Streit um Geschichtspolitik. In: BOUvIER, BEATRIX; SCHNEIDER, MiChael (Hg.): Geschichtspolitik und demokratische Kultur. Bilanz und Perspektiven. Bonn 2008, S. 143-160.

Boll, Friedhelm; KRUKe, ANJA: Zwangsmigration in Europa im 20. Jahrhundert. Erinnerungskultur auf dem Weg zur Europäisierung. In: KRUKE, ANJA (Hg.): Zwangsmigration und Vertreibung. Europa im 20. Jahrhundert. Bonn 2006, S. 9-30.

BÖMELBURG, HANS-JÜRgEN: Gestörte Kommunikation. Der polnische Monolog über Flucht und Vertreibung und seine deutsch-polnischen Ursachen. In: Mittelweg 36 (2005), H. 3, S. 35-52.

Bömelburg, HANS-Jürgen: Die Erinnerung an die deutsche Besatzung während des Zweiten Weltkrieges in Polen - Transformationen und Kontinuitäten der polnischen Erinnerungskultur 1980-2005. In: FAULENBACH, BERND; JELICH, FRANZ-JOSEF 
(HG.): »Transformationen« der Erinnerungskulturen in Europa nach 1989. Essen 2006, S. 55-78.

BömelbuRg, Hans-JÜrgen: Flucht und Vertreibung in der deutschen und polnischen Öffentlichkeit. Zwischen Medienereignis und dem Scheitern einer europäischen Erinnerung an die Zwangsmigrationen. In: Flammer, THOMAS; KARP, HANS-JÜrgeN (Hg.): Maximilian Kaller - Bischof der wandernden Kirche. Flucht und Vertreibung - Integration - Brückenbau. Münster 2012, S. 173-187.

Bömelburg, HANS-JÜrgen; StöiJInger, RenAte; Traba, Robert (Hg.): Vertreibung aus dem Osten. Deutsche und Polen erinnern sich. Olsztyn 2000.

Borodziej, WŁodzimierz: Polen - Deutschland im letzten Jahrzehnt des 20. Jahrhunderts aus der Sicht des Historikers. In: Polska - Niemcy. Tysiac lat sasiedztwa = Polen - Deutschland. Tausend Jahre Nachbarschaft. Warszawa 2000, S. 199-246.

BorodzIEJ, WŁodzIMIERz: »Bierut-Dekrete«? Gesetze, die Deutsche diskrimieren, haben in Polen längst ihre Rechtskraft verloren. In: Dialog. Deutsch-Polnisches Magazin (Magazyn Polsko-Niemiecki) (2002), H. 61, S. 19-20.

BORODZIEJ, WŁODZIMIERZ: Anmerkungen zur deutschen und polnischen Historiographie der >Vertreibung in den 1990er Jahren. In: Melville, RalPH; PešEK, JIŘí; SCHARF, Claus (Hg.): Zwangsmigrationen im mittleren und östlichen Europa. Völkerrecht - Konzeptionen - Praxis (1938-1950). Mainz 2007, S. 179-191.

Borodziej, WŁodzimierz: Geschichte Polens im 20. Jahrhundert. München 2010.

Borodziej, WŁodzimierz: Das Haus der Europäischen Geschichte. Ein Erinnerungskonzept mit dem Mut zur Lücke. In: Knigge, Volkhard; Veen, Hans-Joachim; MäHLERT, UlRICH; ET AL. (Hg.): Arbeit am europäischen Gedächtnis. Diktaturerfahrung und Demokratieentwicklung. Köln, Weimar [u. a] 2011, S. 139-146.

Borodziej, WŁodzimierz; Hajnicz, Artur (Hg.): Kompleks Wypędzenia. Kraków 1998.

Borodziej, WŁodzimierz; Lemberg, Hans (Hg.): Die Deutschen östlich von Oder und Neiße 1945-1950. Dokumente aus polnischen Archiven. Bde. 1-4. Marburg 20002004.

Borodziej, W Łodzimierz; Ziemer, Klaus (Hg.): Deutsch-polnische Beziehungen 1939-1945-1949. Eine Einführung. Osnabrück 2000.

BoroffKa, AnNa: Kulturelle Bildung und besucherorientierte Vermittlung. Theoretische Diskursfelder und die Praxis in Museen und Ausstellungen. In: AckermanN, FeliX; BoroffKA, ANNA; Lersch, Gregor H. (Hg.): Partizipative Erinnerungsräume. Dialogische Wissensbildung in Museen und Ausstellungen. Bielefeld 2013, S. 3350.

Borutta, Manuel; Jansen, Jan C.; Borutta, M.; Jansen, Jan (Hg.): Vertriebene and Pieds-Noirs in Postwar Germany and France. Comparative Perspectives. Basingstoke (Hampshire), New York (NY) 2016.

BösCH, FRANK: The Political Integration of the Expellees in Postwar West Germany. In: Borutta, Manuel; Jansen, Jan C.; Borutta, M.; Jansen, Jan (Hg.): Vertriebene and Pieds-Noirs in Postwar Germany and France. Comparative Perspectives. Basingstoke (Hampshire), New York (NY) 2016, S. 153-172.

Boysen, Jens: Militär- und Kriegsmuseen in Deutschland und Polen. In: Inter Finitimos. Jahrbuch zur deutsch-polnischen Beziehungsgeschichte (2012), H. 10, S. 36-53. 
B ̌̌ACH, RADKO: Die Bedeutung des Prager Vertrags von 1973 für die deutsche Ostpolitik. In: LEMBERG, HANS; KřEN, JAN; Kováč, DuŠAN (Hg.): Im geteilten Europa. Tschechen, Slowaken und Deutsche und ihre Staaten 1948-1989. Essen 1998, S. 169-191.

BRANDES, DETLEF: Nationalsozialistische Tschechenpolitik im Protektorat Böhmen und Mähren. In: Hoensch, Jörg K.; Lemberg, Hans (Hg.): Begegnung und Konflikt. Schlaglichter auf das Verhältnis von Tschechen, Slowaken und Deutschen 1815-1989. Essen 2001, S. 119-136.

BRANDES, DetLEF: Die Vertreibung als negativer Lernprozess. Vorbilder und Ursachen der Vertreibung der Deutschen. In: Zeitschrift für Geschichtswissenschaft 53 (2005), H. 10, S. 885-896.

BRANDES, Detlef: Unter deutschem Protektorat. In: Koschmal, Walter; Nekula, MAReK; Rogall, Joachim (Hg.): Deutsche und Tschechen. Geschichte - Kultur - Politik. Bonn 2005, S. 111-117.

BRANDES, DetLEF: Das Jahrhundert der >ethnischen Säuberungen $<$ Zwangsumsiedlungen in Europa im 20. Jahrhundert. In: MElville, RALPH; PešEK, JiŘí; SCHARF, CLAUS (HG.): Zwangsmigrationen im mittleren und östlichen Europa. Völkerrecht - Konzeptionen - Praxis (1938-1950). Mainz 2007, S. 3-18.

BRANDES, Detlef: National and International Planning of the >Transfer from Czechoslovakia and Poland. The Effects of National Socialist Policy. In: BEssEL, Richard; HAake, Claudia B. (Hg.): Removing Peoples. Forced Removal in the Modern World. Oxford (UK), New York (NY) 2009, S. 281-296.

BRANDES, DetLEF: Flucht aus den Sudetengebieten 1938. Tschechen, Juden, Antifaschisten. In: Brandes, Detlef; Sundhaussen, Holm; Troebst, Stefan (Hg.): Lexikon der Vertreibungen. Deportation, Zwangsaussiedlung und ethnische Säuberung im Europa des 20. Jahrhunderts. Wien 2010, S. 246-247.

Brandes, Detlef; Ivaničková, Edita; PeŠEK, JiŘí (Hg.): Erzwungene Trennung. Vertreibungen und Aussiedlungen in und aus der Tschechoslowakei 1938-1947 im Vergleich mit Polen, Ungarn und Jugoslawien. Essen 1999.

Brandes, Detlef; Sundhaussen, Holm; Troebst, Stefan (Hg.): Lexikon der Vertreibungen. Deportation, Zwangsaussiedlung und ethnische Säuberung im Europa des 20. Jahrhunderts. Wien 2010.

Brandt, Peter: Die deutsch-polnischen Beziehungen bis 1990 (unter Mitberücksichtigung der deutsch-russischen Beziehungen). In: Czejarek, Karol; PszczóŁKowSkiego, Tomasza G. (Hg.): Polska miedzy Niemcami a Rosja. Materiały z miedzynarodowych kolokwiów Gödelitz, 27-29 marca 2009, Pułtusk, 24-26 września $2010=$ Polen zwischen Deutschland und Russland. Materialien internationaler Colloquien Gödelitz, 27. bis 29. März 2009, Pułtusk, 24. bis 26. September 2010. Pułtusk 2011, S. 49-60.

Browarek, Tomasz: Versuch einer Periodisierung der Politik des polnischen Staates gegenüber der deutschen Bevölkerung nach dem Zweiten Weltkrieg (1945 bis 1989). In: Dziurok, Adam; Madajczyk, Piotr; Rosenbaum, Sebastian (Hg.): Die Haltung der kommunistischen Behörden gegenüber der deutschen Bevölkerung in Polen in den Jahren 1945 bis 1989. Gliwice/Gleiwitz, Opole/Oppeln 2015, S. 210-220.

BRÜCKNER, UWE R.; GRECI, LINDA: Das Museum als komplexer Erfahrungsraum. Warum Museum Szenografie braucht. In: Stieglitz, Leo von; Brune, Thomas (Hg.): 
Hin und her - Dialoge in Museen zur Alltagskultur. Aktuelle Positionen zur Besucherpartizipation. Bielefeld, Berlin 2015, S. 87-104.

Brunnbauer, Ulf; Esch, Michael G.: Ethnische Säuberungen in Ostmittel- und Südosteuropa im 20. Jahrhundert. In: BRUnNBAUER, UlF; EsCh, MichaEl G.; SUndHaussen, Holm (Hg.): Definitionsmacht, Utopie, Vergeltung. "Ethnische Säuberungen« im östlichen Europa des 20. Jahrhunderts. Berlin 2006, S. 7-20.

BRunstetTer, SCOTT: Escaping History. The Expulsion of the Sudeten Germans as a Leitmotif in German-Czech Relations. In: VÁrdy, Steven BÉLA; ToOley, T. HunT (Hg.): Ethnic Cleansing in Twentieth-Century Europe. Boulder (Colo.) 2003, S. 267280.

Bucholc, Marta: Slow-cooking Academia sà la Polonaise «. On the State of Academic Freedom in Poland. In: Cultures of History Forum (12.09.2017). URL: www.culturesof-history.uni-jena.de/focus/lex-ceu/slow-cooking-academia-a-la-polonaise-onthe-state-of-academic-freedom-in-poland/ (letzter Zugriff: 13.11.2017).

Budde, Gunilla; Conrad, Sebastian; Janz, Oliver: Vorwort. In: Budde, Gunilla; Conrad, Sebastian; Janz, Oliver (Hg.): Transnationale Geschichte. Themen, Tendenzen und Theorien. Göttingen 2006, S. 11-14.

Bugge, Peter: »Land und Volk « - oder: Wo liegt Böhmen? In: Geschichte und Gesellschaft 28 (2002), H. 3, S. 404-434.

Bundesinstitut für Kultur und Geschichte der Deutschen im östlichen Europa (Hg.): Erinnerung bewahren - Zukunft gestalten. Erinnerung bewahren - Zukunft gestalten. Berlin, 12.06.2017. Die Beauftragte der Bundesregierung für Kultur und Medien; Bundesinstitut für Kultur und Geschichte der Deutschen im östlichen Europa; Katholische Akademie in Berlin e.V. Oldenburg 2017. URL: www.bkge.de/Downloads/Veranstaltungen/Tagungen/ Broschure-Erinnerung-WEB-VERSION.pdf (letzter Zugriff: 11.03.2018).

Bundeszentrale für politische Bildung: Beutelsbacher Konsens. 07.04.2011. URL: www. bpb.de/die-bpb/51310/beutelsbacher-konsens (letzter Zugriff: 03.04.2018).

Buras, Piotr; Majewski, Piotr M. (Hg.): Pamieć wypedzonych. Grass, Beneš i środkowoeuropejskie rozrachunki. Antologia tekstów polskich, niemieckich i czeskich. Wybór i opracowanie Piotr Buras i Piotr M. Majewski. Warszawa 2003.

Buras, Piotr; Vegh, Zsuzsanna: Stop, Brüssel! Polen und Ungarn in der Europäischen Union. In: Osteuropa (2018), H. 3-5, S. 99-114.

Buschmann, Heike: Geschichte im Raum. Erzähltheorie als Museumsanalyse. In: BAUR, JoACHIM (HG.): Museumsanalyse. Methoden und Konturen eines neuen Forschungsfeldes. Bielefeld 2010, S. 149-169.

Büttner, Sebastian M.; Delius, Anna: World Culture in European Memory Politics? New European Memory Agents Between Epistemic Framing and Political Agenda Setting. In: Journal of Contemporary European Studies 23 (2015), H. 3, S. 391-404.

Calic, Marie-Janine: Dayton-Abkommen. In: Brandes, Detlef; Sundhaussen, Holm; Troebst, Stefan (Hg.): Lexikon der Vertreibungen. Deportation, Zwangsaussiedlung und ethnische Säuberung im Europa des 20. Jahrhunderts. Wien 2010, S. 111-112.

ČAPKA, FRANTIŠEK: Parallels and Specifics of Repopulation of the Czech Border Regions and the Polish Recovered Territories after 1945. In: Czech-Polish Historical and Pedagogical Journal 3 (2011), H. 1, S. 24-30. 
Chaumont, Jean-Michel: Die Konkurrenz der Opfer. Genozid, Identität und Anerkennung. Lüneburg 2001.

Chinciński, Tomasz: Forpoczta Hitlera. Niemiecka dywersja w Polsce w 1939 roku. Gdańsk 2010.

CHojeckA, EwA: Górnośląskie konflikty wokół pamięci historycznej. Nowe tożsamości in statu nascendi/Upper Silesian Conflicts Concerning Historical Memory. New Identites in Statu Nascendi. In: Herito 13 (2013), H. 4, S. 40-47.

Cichocki, Marek: Polnische Geschichtspolitik nach 1989. In: Stiftung »PolnischeDeutsche Aussöhnung«; Museum des Warschauer Aufstandes (Hg.): Wahrheit, Erinnerung, Verantwortung. Der Warschauer Aufstand im Kontext der deutsch-polnischen Beziehungen. Warszawa 2010, S. 287-295.

Corneliben, Christoph: Erinnerungskulturen. In: Bösch, Frank (Hg.): Zeitgeschichte. Konzepte und Methoden. Göttingen 2012, S. 166-184.

Corneliben, Christoph: Erinnerungskulturen. Version: 2.0. In: DocupediaZeitgeschichte (22.10.2012). URL: http://docupedia.de/zg/Erinnerungskulturen_ Version_2.0_Christoph_Corneli\%C3\%9Fen (letzter Zugriff: 22.12.2018).

Corneliben, Christoph; Holec, Roman; Pešek, JiŘí: Politisch-historische Erinnerungen in Mittel- und Ostmitteleuropa seit 1945. In: CORNELIBEN, CHRISTOPH; Holec, RoMAn; PešEK, JIŘí (Hg.): Diktatur - Krieg - Vertreibung. Erinnerungskulturen in Tschechien, der Slowakei und Deutschland seit 1945. Essen 2005, S. 9-24.

Corni, Gustavo: Forced Migrations and Mass Movements in the Memorialization Processes since the Second World War. In: Ahonen, Pertti; Corni, Gustavo; Kochanowski, Jerzy; Schulze, Rainer; Stark, Tamás; Stelzl-MarX, Barbara (Hg.): People on the Move. Forced Population Movements in Europe in the Second World War and its Aftermath. Oxford (UK), New York (NY) 2008, S. 143-145.

CZAPliński, MAREK; Hahn, HANS-JoAChim; WegER, Tobias (Hg.): Schlesische Erinnerungsorte. Gedächtnis und Identität einer mitteleuropäischen Region. Eine Veröffentlichung des Schlesischen Museums zu Görlitz. Görlitz 2005.

CZERNEY, SARAH: Flucht, Vertreibung, Versöhnung. Zwischen nationaler und europäischer Historiographie. In: Inter Finitimos. Jahrbuch zur deutsch-polnischen Beziehungsgeschichte (2012), H. 10, S. 149-158.

CZERNEY, SARAH: Zwischen Nation und Europa. Nationalmuseen als Europamedien. Berlin, Boston 2019.

Czerniakiewicz, Jan; Czerniakiewicz, Monika: Przesiedlenia ludności w Europie, 1915-1959. Warszawa 2005.

DANKer, Uwe: Aufklärung, Identifikation oder Repräsentation? Politische Motive zur Errichtung von Museen zur deutschen Landes- und Nationalgeschichte - und wie weit man ihnen folgen darf. In: Hartung, Olaf (Hg.): Museum und Geschichtskultur. Ästhetik - Politik - Wissenschaft. Bielefeld 2006, S. 211-232.

DANYel, JÜrgen: Deutscher Opferdiskurs und europäische Erinnerung. Die Debatte um das »Zentrum gegen Vertreibungen«. In: Zeitgeschichte-online (2004). URL: www. zeitgeschichte-online.de/themen/deutscher-opferdiskurs-und-europaeischeerinnerung (letzter Zugriff: 02.07.2018).

DANYEL, JÜRGEN: Der vergangenheitspolitische Diskurs in der SBZ/DDR 1945-1989. In: Corneliben, Christoph; Holec, Roman; Pešek, JiŘí (Hg.): Diktatur - Krieg - 
Vertreibung. Erinnerungskulturen in Tschechien, der Slowakei und Deutschland seit 1945. Essen 2005, S. 173-195.

DANYel, JÜRgen; Ther, PhILIPP (Hg.): Zeitschrift für Geschichtswissenschaft. Flucht und Vertreibung in europäischer Perspektive. 2003 (51. Jg., Heft 1).

DANYel, JÜRgen; Ther, PhilipP (Hg.): Zeitschrift für Geschichtswissenschaft. Nach der Vertreibung. Geschichte und Gegenwart einer kontroversen Erinnerung. 2005 (53. Jg., H. 10).

DEÁK, IsTVÁN: Kollaboration, Widerstand und Vergeltung im Europa des Zweiten Weltkrieges. Wien, Köln [u.a.] 2017.

Demshuk, ANDrew: Reinscribing Schlesien as Śląsk. Memory and Mythology in a Postwar German-Polish Borderland. In: History and Memory 24 (2012), H. 1, S. 39-86.

Denemarková, RAdKa: Shakespeare hat recht. Böhmen liegt am Meer. Das Land, in das die Schwalben zurückkehren. In: Schwarz, Wolfgang (Hg.): Mein Weg zu unseren Deutschen. Zehn tschechische Perspektiven. Viechtach 2019, S. 13-26.

Deutsches Historisches Museum; International Association of Museums of History; Stiftung Flucht, Vertreibung, Versöhnung (Hg.): Flucht, Vertreibung, Ethnische Säuberung. Eine Hausforderung für Museums- und Ausstellungsarbeit weltweit. Tagungsband zum Neunten Internationalen Symposium der International Association of Museums of History. Berlin 2010.

Dialog jest językiem macierzystym ludzkości/Dialogue is the Mother Tongue of $\mathrm{Hu}$ manity. Z księduem arcybiskupem Alfonsem Nossolem rozmawiają profesor Jacek Purchla i Łukasz Galusek/Archbishop Alfons Nossol in conversation with Professor Jacek Purchla and Łukasz Galusek. In: Herito (2016), H. 25, S. 50-59.

DipPer, Christof: Geschichtspolitik im europäischen Vergleich. Eine Bilanz. In: Neue Politische Literatur 57 (2012), H. 1, S. 33-48.

Dmitrów, Edmund: Polen. In: Knigge, Volkhard (Hg.): Verbrechen erinnern. Die Auseinandersetzung mit Holocaust und Völkermord. Bonn 2005, S. 196-204.

Douglas, RaY M.: »Ordnungsgemäße Überführung«. Die Vertreibung der Deutschen nach dem 2. Weltkrieg. München 2012 (2., durchges. Aufl.).

Douglas, RaY M.: Wypędzeni. Powojenne losy Niemców. Warszawa 2013.

DRÄGER, MARCO: Ein Hoch auf Flucht und Vertreibung? Zur Einführung des neuen Gedenktages am 20. Juni. In: Aus Politik und Zeitgeschichte (2015), H. 25, S. 49-54.

DrZYCIMSKI, ANDrZej: Polacy w wolnym mieście Gdańsku (1920-1933). Polityka senatu gdańskiego wobec ludności polskiej. Warszawa 1978.

Dunin-WĄsowicz, Krzystzof: Die nationalsozialistische Okkupationspolitik im Protektorat Böhmen und Mähren und im Generalgouvernement. Vergleichende Überlegungen. In: Heumos, Peter (Hg.): Polen und die böhmischen Länder im 19. und 20. Jahrhundert. Politik und Gesellschaft im Vergleich. München 1997, S. 233-253.

DVořák, TOMáš; Schriffl, DAvid: Am Scheideweg zwischen »Ost« und »West«. In: Perzi, Niklas; Schmoller, Hildegard; Konrád, Ota; Šmidrkal, VáclaV (Hg.): Nachbarn. Ein österreichisch-tschechisches Geschichtsbuch. Weitra 2019, S. 207233.

DziuroK, AdAM; LINEK, Bernard: Im kommunistischen Polen (1945-1989). In: Bahlcke, Joachim; Gawrecki, Dan; Kaczmarek, Ryszard (Hg.): Geschichte 
Oberschlesiens. Politik, Wirtschaft und Kultur von den Anfängen bis zur Gegenwart. Berlin 2015 (2. übera. und erw. Aufl. der poln. Originalausg. von 2011), S. 366-396.

Dziurok, Adam; Madajczyk, Piotr; Rosenbaum, Sebastian (Hg.): Die Haltung der kommunistischen Behörden gegenüber der deutschen Bevölkerung in Polen in den Jahren 1945 bis 1989. Gliwice/Gleiwitz, Opole/Oppeln 2015.

ECHTERNKAMP, JÖRG; JAEger, StePHAN: Representing the Second World War in German and European Museums and Memorials. In: ECHTERNKAMP, JöRG; JAEger, STEPHAN (HG.): Views of Violence. Representing the Second World War in German and European Museums and Memorials. New York (NY) 2019, S. 1-23.

EChTERnKAMP, Jörg; JAEger, Stephan (Hg.): Views of Violence. Representing the Second World War in German and European Museums and Memorials. New York (NY) 2019.

Echternkamp, Jörg; MARTEns, Stefan: Der Weltkrieg als Wegmarke? Die Bedeutung des Zweiten Weltkriegs für eine europäische Zeitgeschichte. In: ECHTERnKamp, Jörg; Martens, Stefan (Hg.): Der Zweite Weltkrieg in Europa. Erfahrung und Erinnerung. Paderborn 2007, S. 1-33.

ECKersley, Susannah: Walking the Tightrope between Memory and Diplomacy? Addressing the Post-Second World War Expulsions of Germans in German Museums. In: Whitehead, Christopher; Eckersley, Susannah; Lloyd, Katherine; MaSon, Rhiannon (Hg.): Museums, Migration and Identity in Europe. Peoples, Places and Identities. Florence 2016, S. 101-121.

Eder, Franz X.: Historische Diskurse und ihre Analyse. Eine Einleitung. In: EdER, Franz X. (Hg.): Historische Diskursanalysen. Genealogie, Theorie, Anwendungen. Wiesbaden 2006, S. 9-23.

Elie, JÉrôme: Histories of Refugee and Forced Migration Studies. In: FiddianQASmiyeh, Elena; Loescher, Gil; Long, Katy; Sigona, NANdo (Hg.): The Oxford Handbook of Refugee and Forced Migration Studies. Oxford (UK), New York (NY) 2014, S. 23-35.

Elpers, Sophie; Palm, ANNA: Von Grenzen und Chancen des Sammelns von Gegenwart in kulturhistorischen Museen im 21. Jahrhundert. Eine Einführung. In: ELPERS, Sophie; Palm, ANNA (Hg.): Die Musealisierung der Gegenwart. Von Grenzen und Chancen des Sammelns in kulturhistorischen Museen. Bielefeld, Berlin 2014, S. 9-28.

ERLL, AsTRID: Kollektives Gedächtnis und Erinnerungskulturen. Eine Einführung. Stuttgart 2017 (3., akt. und erw. Auflage).

EsCH, MiCHAEL: Zum Verhältnis zwischen individueller Erinnerung, öffentlichem Gedächtnis und Historiographie. Der »Komplex Vertreibung«. In: Sozial.Geschichte Online (2012), H. 7, S. 72-92. URL: http://duepublico.uni-duisburg-essen.de/ servlets/DerivateServlet/Derivate-30290/05_Esch_Vertriebene.pdf (letzter Zugriff: 22.12.2018).

Eyal, Gil: Identity and Trauma. Two Forms of the Will to Memory. In: History and Memory 16 (Spring/Summer 2004), H. 1, S. 5-36.

FAULENBACH, BERND: Überlegungen zu einer Bonner Erklärung zur Notwendigkeit eines Europäischen Netzwerkes zur Auseinandersetzung mit Vertreibungen im 20. Jahrhundert in Wissenschaft und Erinnerungskultur. In: KRUKE, ANJA (Hg.): 
Zwangsmigration und Vertreibung. Europa im 20. Jahrhundert. Bonn 2006, S. 3740.

FAUlenbaCH, BERnd: Zeitenwende 1989/90. Paradigmenwechsel in der Geschichtspolitik? In: Bouvier, Beatrix; SCHNeIder, Michael (Hg.): Geschichtspolitik und demokratische Kultur. Bilanz und Perspektiven. Bonn 2008, S. 85-95.

Fehr, Helmut: Vergeltende Gerechtigkeit - Populismus und Vergangenheitspolitik nach 1989. Leverkusen-Opladen 2016.

FEINDT, GREGor: Flucht und Vertreibung zwischen Kaltem Krieg und Universalisierung. In: Feindt, Gregor; Krawatzek, Félix; Mehler, Daniela; Pestel, FrieDEMANN; TrimçeV, Rieke (Hg.): Europäische Erinnerung als verflochtene Erinnerung. Vielstimmige und vielschichtige Vergangenheitsdeutungen jenseits der Nation. Göttingen 2014, S. 153-177.

FEINDT, GREGOR: From >flight and expulsion to migration. Contextualizing German victims of forced migration. In: European Review of History: Revue européenne d'histoire 24 (2017), H. 4, S. 552-577.

Feindt, Gregor; Krawatzek, Félix; Mehler, Daniela; Pestel, Friedemann; TRIMÇEV, RIEKE: Europäische Erinnerung? Erinnerungsforschung jenseits der Nation. In: Feindt, Gregor; Krawatzek, Félix; Mehler, Daniela; Pestel, FrieDEMANN; TRIMÇEV, RIEKE (Hg.): Europäische Erinnerung als verflochtene Erinnerung. Vielstimmige und vielschichtige Vergangenheitsdeutungen jenseits der Nation. Göttingen 2014, S. 11-36.

Felsch, Corinna: Reisen in die Vergangenheit? Westdeutsche Fahrten nach Polen 19701990. Berlin, Boston 2015.

Felsch, Corinna; Latkowska, Magdalena: Brief der (polnischen) Bischöfe und Willy Brandts Kniefall. Verfrühte Helden? In: Hahn, Hans Henning; Traba, Robert (HG.): Deutsch-Polnische Erinnerungsorte. Band 3: Parallelen. Unter Mitarbeit von Maciej Górny und Kornelia Kończal. Paderborn 2012, S. 396-414.

Fend, Walter J.: Vom Ende des Zweiten Weltkrieges bis zum Beginn der »Wende«. In: Pelinka, Anton; Bischof, Karin; Fend, Walter; Stögner, Karin; KöHler, Thomas (Hg.): Geschichtsbuch Mitteleuropa. Vom Fin de Siècle bis zur Gegenwart. Wien 2016, S. 62-90.

Fiala, Petr: Deutsche und Tschechen im vereinten Europa. In: Koschmal, Walter; Nekula, Marek; Rogall, Joachim (Hg.): Deutsche und Tschechen. Geschichte Kultur - Politik. Bonn 2005, S. 496-503.

FICKERS, ANDREAS: Kompromissgeschichte, serviert auf dem »Tablet«. Das Haus der europäischen Geschichte in Brüssel. In: Zeithistorische Forschungen/Studies in Contemporary History, Online-Ausgabe 15 (2018), H. 1, S. 173-183. URL: www.zeithistorischeforschungen.de/1-2018/id=5574 (letzter Zugriff: 23.04.2018).

FinSteR, MATthias: »50 Jahre Bund der Vertriebenen - Das sind auch 50 Jahre deutsche Geschichte«. Die Arbeit des BdV nach 1982 im Spannungsfeld von VerbandsLobbyismus und Geschichtspolitik. In: STICKLER, MATTHIAS (Hg.): Jenseits von Aufrechnung und Verdrängung. Neue Forschungen zu Flucht, Vertreibung und Vertriebenenintegration. Stuttgart 2014, S. 133-154.

Fischer, Peter; Kerski, Basil; Röskau-Rydel, Isabel; Ruchniewicz, Krzysztof; Stekel, SABInE; Deutsch-Polnische Gesellschaft Bundesverband e. V.; Willy Brandt Zen- 
trum für Deutschland- und Europastudien der Universität Wrocław (Hg.): Inter Finitimos. Jahrbuch zur deutsch-polnischen Beziehungsgeschichte. Themenschwerpunkt: $\mathrm{Mu}$ seen und Ausstellungen. Osnabrück 2012.

Flacke, Monika: Ausstellen als Narration. In: Walz, Markus (Hg.): Handbuch Museum. Geschichte, Aufgaben, Perspektiven. Stuttgart 2016, S. 253-257.

Flierl, Thomas; Müller, Elfriede: Transitraum Geschichte. In: Flierl, Thomas; MÜLLER, ElfRIEDE (HG.): Osteuropa - Schlachtfeld der Erinnerungen. Berlin 2010, S. 7-18.

FLÖGEL, UTE: Tschechischer Minister gewinnt »liebe Landsleute«. In: Kulturpolitische Korrespondenz (2016), H. 1369, S. 23-27.

Foltyn, Edelgarda M.; Rohrer, Wiebke: Germanen und Slawen in Oberschlesien. In: BAHLCKe, JoAChim; GaWrecki, Dan; Kaczmarek, Ryszard (Hg.): Geschichte Oberschlesiens. Politik, Wirtschaft und Kultur von den Anfängen bis zur Gegenwart. Berlin 2015 (2. übera. und erw. Aufl. der poln. Originalausg. von 2011), S. 565-579.

Fortunati, Vita; Lamberti, Elena: Cultural Memory. A European Perspective. In: ErLl, Astrid; NÜNNING, ANSGAR; Young, SARA B. (Hg.): A Companion to Cultural Memory Studies. Berlin 2010, S. 127-137.

FRACKOWIAK, JohANNES: Die »Deutsche Volksliste« als Instrument der nationalsozialistischen Germanisierungspolitik in den annektierte Gebieten Polens 1939-1945. In: Frackowiak, Johannes (Hg.): Nationalistische Politik und Ressentiments. Deutsche und Polen von 1871 bis zur Gegenwart. Göttingen 2013, S. 181-220.

François, ETIEnNE: Europäische lieux de mémoire. In: Budde, Gunilla; ConRad, SEBastian; JAnz, Oliver (Hg.): Transnationale Geschichte. Themen, Tendenzen und Theorien. Göttingen 2006, S. 290-303.

Franczak, Karol; Nowicka, Magdalena: Des Kaisers neue Kleider. Eine Analyse des aktuellen rechtskonservativen Geschichtsdiskurses in Polen. In: Zeitgeschichte-online (19.07.2016). URL: www.zeitgeschichte-online.de/thema/des-kaisers-neue-kleider (letzter Zugriff: 01.10.2016).

Franke, AnNemarie; Kretschmann, Dominik: Der Friedensgruß von Kreisau 1989. Eine Geste als Versprechen. In: Defrance, Corine; Pfeil, Ulrich (Hg.): Verständigung und Versöhnung nach dem »Zivilisationsbruch«? Deutschland in Europa nach 1945. Bonn 2016, S. 137-155.

FRANZEN, K. ERIK: Der Diskurs als Ziel? Anmerkungen zur deutschen Erinnerungspolitik am Beispiel der Debatte um ein »Zentrum gegen Vertreibungen« 1999-2005. In: Haslinger, Peter; Franzen, K. Erik; Wessel, Martin Schulze (Hg.): Diskurse über Zwangsmigration in Zentraleuropa. Geschichtspolitik, Fachdebatten, literarisches und lokales Erinnern seit 1989. München 2008, S. 1-29.

FRANZEN, K. ERIK: Der vierte Stamm Bayerns. Die Schirmherrschaft über die Sudetendeutschen 1954-1974. München 2010.

Franzen, K. ERIK: Vertriebene. In: Brandes, Detlef; Sundhaussen, Holm; Troebst, Stefan (Hg.): Lexikon der Vertreibungen. Deportation, Zwangsaussiedlung und ethnische Säuberung im Europa des 20. Jahrhunderts. Wien 2010, S. 696-698.

FranZEN, K. ERIK; SChUlZE WeSSEL, MARTIN (Hg.): Opfernarrative. Konkurrenzen und Deutungskämpfe in Deutschland und im östlichen Europa nach dem Zweiten Weltkrieg. München 2012. 
Franzen, K. Erik; Troebst, Stefan: Vertreibung. In: Brandes, Detlef; SundhausSen, Holm; Troebst, Stefan (Hg.): Lexikon der Vertreibungen. Deportation, Zwangsaussiedlung und ethnische Säuberung im Europa des 20. Jahrhunderts. Wien 2010, S. 693-696.

FreI, Norbert: Rückruf der Erinnerung. Geschichtspolitik nach dem »Ende der Geschichte«. In: FreI, NORbERT (Hg.): Was heißt und zu welchem Ende studiert man Geschichte des 20. Jahrhunderts? Göttingen 2006, S. 170-175.

FREI, NoRbERT: Vergangenheitspolitik. Die Anfänge der Bundesrepublik und die NSVergangenheit. München 2012 (1996) (Neuausg., 1. Aufl. in der Beck'schen Reihe/vom Autor durchges. und um ein Nachw. erw.).

Freudenstein, Roland: Die deutsch-polnische Streitgemeinschaft. In: Dialog. Deutsch-Polnisches Magazin (Magazyn Polsko-Niemiecki) (2003/2004), H. 65, S. 38-42.

FREVERT, UtE: Geschichtsvergessenheit und Geschichtsversessenheit revisited. Der jüngste Erinnerungsboom in der Kritik. In: Aus Politik und Zeitgeschichte (2003), H. 40-41, S. 6-13.

Friedrich, KlaUs-Peter: Erinnerungspolitische Legitimierungen des Opferstatus. Zur Instrumentalisierung fragwürdiger Opferzahlen in Geschichtsbildern vom Zweiten Weltkrieg in Polen und Deutschland. In: Bingen, Dieter; Loew, Peter Oliver; Wóycicki, Kazimierz (Hg.): Die Destruktion des Dialogs. Zur innenpolitischen Instrumentalisierung negativer Fremd- und Feindbilder. Polen, Tschechien, Deutschland und die Niederlande im Vergleich, 1900-2005. Wiesbaden 2007, S. 176191.

Friedrich, KLAus-Peter: Rezension zu: Instytut Pamięci Narodowej Główna Komisja Ścigania Zbrodni Przeciwko Narodowi Polskiemu: Polska 1939-1945. Straty osobowe i ofiary represji pod dwiema okupacjami. [Polen 1939-1945. Personelle Verluste und Opfer von Repressionen unter den zwei Okkupationen], Warszawa 2009. In: Jahrbücher für Geschichte Osteuropas 60 (2012), H. 2, S. 304-305. URL: https://www.dokumente.ios-regensburg.de/JGO/Rez/Friedrich_Polska_19391945.html (letzter Zugriff: 20.03.2018).

GALMICHE, XAVIER: »Di̊m po Nemcich« - »von den Deutschen übernommenes Haus«. Zur Semiotik von Kunstruktion und Zerstörung in der tschechischen Nachkriegsprosa. In: Zeitschrift für Geschichtswissenschaft 53 (2005), H. 10, S. 941-954.

GALUSEK, ŁUKASZ: Górny Śląsk/Upper Silesia. Przygoda z nowoczesnością/The Modern Adventure. In: Herito (2016), H. 25, S. 12-35.

GARCZEWSKI, KrzyszToF: Die Stiftung »Flucht, Vertreibung, Versöhnung« als politisches Problem in den deutsch-polnischen Beziehungen. In: CZEJAREK, Karol; PszCzóŁkowskiego, Tomasza G. (Hg.): Polska miedzy Niemcami a Rosja. Materiały z miedzynarodowych kolokwiów Gödelitz, 27-29 marca 2009, Pułtusk, 24-26 września $2010=$ Polen zwischen Deutschland und Russland. Materialien internationaler Colloquien Gödelitz, 27. bis 29. März 2009, Pułtusk, 24. bis 26. September 2010. Pułtusk 2011, S. 207-215.

GARSZTECKI, Stefan: Das Deutschlandbild im polnischen Europadiskurs. Rückkehr eines Feindbildes? In: Bingen, Dieter; Loew, Peter Oliver; Wóycicki, Kazimierz (Hg.): Die Destruktion des Dialogs. Zur innenpolitischen Instrumentalisierung ne- 
gativer Fremd- und Feindbilder. Polen, Tschechien, Deutschland und die Niederlande im Vergleich, 1900-2005. Wiesbaden 2007, S. 292-308.

GASSERT, PhILIPP: Transnationale Geschichte. Version 2.0. In: Docupedia-Zeitgeschichte (29.10.2012). URL: http://docupedia.de/zg/gassert_transnationale_geschichte_v2_ de_2012 (letzter Zugriff: 29.10.2017).

GAWIN, DarIUSz: Über den Nutzen und Schaden des historischen Revisionismus. In: Inter Finitimos. Jahrbuch zur deutsch-polnischen Beziehungsgeschichte 4 (2006), S. 31-60.

GAWRECKI, DAN: Auf der Suche nach kollektiven Identitäten in Oberschlesien. In: Bahlcke, Joachim; GaWrecki, Dan; Kaczmarek, Ryszard (Hg.): Geschichte Oberschlesiens. Politik, Wirtschaft und Kultur von den Anfängen bis zur Gegenwart. Berlin 2015 (2. übera. und erw. Aufl. der poln. Originalausg. von 2011), S. 74-96.

GeERTZ, Clifford: Dichte Beschreibung. Frankfurt a.M. 1983.

GEHRKE, ROLAND: Der polnische Westgedanke bis zur Wiedererrichtung des polnischen Staates nach Ende des Ersten Weltkrieges. Genese und Begründung polnischer Gebietsansprüche gegenüber Deutschland im Zeitalter des europäischen Nationalismus. Marburg 2001.

GeHRKe, Roland: Vom Völkerfrühling bis zum Ersten Weltkrieg (1848-1918). In: Bahlcke, Joachim; Gawrecki, Dan; Kaczmarek, Ryszard (Hg.): Geschichte Oberschlesiens. Politik, Wirtschaft und Kultur von den Anfängen bis zur Gegenwart. Berlin 2015 (2. übera. und erw. Aufl. der poln. Originalausg. von 2011), S. 254-289.

Gemeinsame Deutsch-Tschechische Historikerkommission (Hg.): Konfliktgemeinschaft, Katastrophe, Entspannung. Skizze einer Darstellung der deutsch-tschechischen Geschichte seit dem 19. Jahrhundert. Konfliktní společenství, katastrofa, uvolnění. Náčrt výkladu německo-českých dějin od 19. století. München 1996.

Gerhards, Jürgen; Breuer, Lars; Delius, Anna: Kollektive Erinnerungen der europäischen Bürger im Kontext von Transnationalisierungsprozessen. Deutschland, Großbritannien, Polen und Spanien im Vergleich. Wiesbaden 2017.

GläSSER, Wiebre: Tagungsbericht: Lhistoire du temps présent et ses défis au XXIe siècle/Zeitgeschichte und ihre Herausforderungen im 21. Jahrhundert, 17.10.2013 - 19.10.2013 Paris. H-Soz-Kult 22.05.2014. URL: https://www.hsozkult.de/ conferencereport/id/tagungsberichte-5380 (letzter Zugriff: 08.07.2018).

Glassheim, EAglE: Cleansing the Czechoslovak Borderlands. Migration, Environment, and Health in the Former Sudetenland. Pittsburgh (PA) 2016.

Glotz, Peter: Das »Zentrum gegen Vertreibungen« soll anprangern. Der Kampf gegen das Verbrechen der Vertreibung. In: Die Politische Meinung (2004), H. 417, S. 15-18.

GNiaZdowski, Mateusz: Zu den Menschenverlusten, die Polen während des Zweiten Weltkrieges von den Deutschen zugefügt wurden. Eine Geschichte von Forschungen und Schätzungen. In: Historie. Jahrbuch des Zentrums für Historische Forschung Berlin der Polnischen Akademie der Wissenschaften 1 (2007/2008), S. 65-92.

GoŁasz, Zbigniew: Antideutsche Politik in Zabrze in den Jahren 1945 bis 1949. Spezifik - Verlauf - Folgen. In: Dziurok, Adam; Madajczyk, Piotr; Rosenbaum, SebasTIAN (Hg.): Die Haltung der kommunistischen Behörden gegenüber der deutschen Bevölkerung in Polen in den Jahren 1945 bis 1989. Gliwice/Gleiwitz, Opole/Oppeln 2015, S. 200-210. 
Golat, Rafat: Problematyka mniejszości w działaności muzeów (aspekty prawne). In: Muzealnictwo 58 (2017), H. 1, S. 19-23.

Gorgus, NinA: All these (museum-)communities. Facebook/Twitter/Blogs. In: STIEGLitz, Leo von; Brune, Thomas (Hg.): Hin und her - Dialoge in Museen zur Alltagskultur. Aktuelle Positionen zur Besucherpartizipation. Bielefeld, Berlin 2015, S. 125-137.

GóRNY, MACIEJ: Historiographiegeschichte und marxistisches Erbe. Volksrepublik Polen, DDR und Tschechoslowakei im Vergleich. In: Historie. Jahrbuch des Zentrums für Historische Forschung Berlin der Polnischen Akademie der Wissenschaften 2 (2008/2009), S. 22-39.

Górny, Maciej; Kończal, Kornelia: The (Non-)Travelling Concept of Les Lieux de Mémoire. Central and Eastern European Perspectives. In: Pakier, Mągorzata; WaWrzyniak, JoAnNA (Hg.): Memory and Change in Europe. Eastern Perspectives. New York (NY) 2016, S. 59-76.

Goschler, Constantin: »Versöhnung« und »Viktimisierung«. Die Vertriebenen und der deutsche Opferdiskurs. In: Zeitschrift für Geschichtswissenschaft 53 (2005), H. 10, S. 873-884.

GraAf, Jenny: After the Expulsions. The lost German Heimat in Memory, Monuments and Museums. PhD thesis. University of Nottingham 2014. URL: http://eprints. nottingham.ac.uk/14478/ (letzter Zugriff: 12.04.2017).

GRAF, RÜDIGER: Diskursanalyse und radikale Interpretation. Davidsonianische Überlegungen zu Grenzen und Transformationen historischer Diskurse. In: EDER, FRANZ X. (Hg.): Historische Diskursanalysen. Genealogie, Theorie, Anwendungen. Wiesbaden 2006, S. 71-89.

Grau Segú, Martí: Proposing a New European Narrative. The House of European History Project. In: GuiXé I CoRomines, Jordi; ConesA, RicARd (Hg.): Past and Power. Public Policies on Memory. Debates, from Global to Local. Barcelona 2016, S. 57-73.

Gray, Clive: The Politics of Museums. Basingstoke (Hampshire) 2015.

Greiner, Piotr: Die Entwicklung der Wirtschaft vom 16. bis zum 20. Jahrhundert. In: Bahlcke, JoAChim; GaWrecki, Dan; Kaczmarek, Ryszard (Hg.): Geschichte Oberschlesiens. Politik, Wirtschaft und Kultur von den Anfängen bis zur Gegenwart. Berlin 2015 (2. übera. und erw. Aufl. der poln. Originalausg. von 2011), S. 427-464.

GrelKA, FrANK: Rezension zu: Stephan Lehnstaedt: Imperiale Polenpolitik in den Weltkriegen. Eine vergleichende Studie zu den Mittelmächten und zu NS-Deutschland. 2017. URL: https://www.pol-int.org/de/publikationen/imperiale-polenpolitik-denweltkriegen-eine-vergleichend-o\#r7041 (letzter Zugriff: 09.07.2018).

Griefahn, Monika: Zentrale Aspekte der Erinnerungskultur und Geschichtspolitik des Bundes. In: WAGNER, BERND (HG.): Erinnerungskulturen und Geschichtspolitik. Essen 2009, S. 75-82.

GRIMM, RICO: Bin ich denn schon rechts? Reinbek 2017.

Gross, Jan Tomasz: Nachbarn. Der Mord an den Juden von Jedwabne. Mit einem Vorwort von Adam Michnik. München 2001.

GrüNEWALd Steiger, ANDREAS: Information - Wissen - Bildung: Das Museum als Lernort. In: Walz, Markus (Hg.): Handbuch Museum. Geschichte, Aufgaben, Perspektiven. Stuttgart 2016, S. 278-282. 
GRÜNWALD, LEOPOLD (Hg.): Wir haben uns selbst aus Europa vertrieben. Tschechische Selbstkritik an der Vertreibung der Sudetendeutschen. Eine Dokumentation. München 1985.

GrütTers, MonikA: Das Gedächtnis der Deutschen. Erinnerungsarbeit - zentral für das Selbstverständnis deutscher Kulturpolitik. In: WAGNER, BERND (HG.): Erinnerungskulturen und Geschichtspolitik. Essen 2009, S. 67-73.

HAAR, INGO: Vom »Volksgruppen-Paradigma« bis zum »Recht auf Heimat«. Exklusion und Inklusion als Deutungsmuster in den Diskursen über Zwangsmigrationen vor und nach 1945. In: KochanowsKI, JerzY (HG.): Die »Volksdeutschen« in Polen, Frankreich, Ungarn und der Tschechoslowakei. Mythos und Realität. Osnabrück 2006, S. 17-39.

HAAR, INGO: Der deutsche Angriff auf Polen 1939 und die Folgen des Zweiten Weltkriegs. Geschichte und Geschichtspolitik in der Bundesrepublik Deutschland. In: KocH, CHRistoph (Hg.): War die »Vertreibung« Unrecht? Die Umsiedlungsbeschlüsse des Potsdamer Abkommens und ihre Umsetzung in ihrem völkerrechtlichen und historischen Kontext. Frankfurt a.M., Bern [u.a.] 2015, S. 301-319.

Habbe, Christian: Die Zeit der Abrechnung. In: Grobbongardt, Annette; Klubmann, Uwe; Pötzl, Norbert F. (Hg.): Die Deutschen im Osten Europas. Eroberer, Siedler, Vertriebene. Bonn 2011, S. 201-216.

HACKMANN, JöRG: German East or Polish West? Historiographical Discourses on the German-Polish Overlap between Confrontation and Reconciliation, 1772-2000. In: Frank, Tibor; HAdLER, Frank (Hg.): Disputed Territories and Shared Pasts. Overlapping National Histories in Modern Europe. Basingstoke (Hampshire) 2011, S. 92124.

HACKMANN, JöRG: Ostmitteleuropa. In: Online-Lexikon zur Kultur und Geschichte der Deutschen im östlichen Europa (29.05.2015). URL: https://ome-lexikon.uni-oldenburg.de/ begriffe/ostmitteleuropa/ (letzter Zugriff: 09.06.2018).

HAdler, Frank; Middell, Matthias: Auf dem Weg zu einer transnationalen Geschichte Ostmitteleuropas. In: HAdler, Frank; Middell, Matthias (Hg.): Verflochtene Geschichten. Ostmitteleuropa. Leipzig 2010, S. 8-29.

HAHN, Eva: Die Sudetendeutschen in der deutschen Gesellschaft: ein halbes Jahrhundert politischer Geschichte zwischen »Heimat« und »Zuhause«. In: LEMBERG, HANS; KřEN, JAN; KovÁČ, DUŠAN (Hg.): Im geteilten Europa. Tschechen, Slowaken und Deutsche und ihre Staaten 1948-1989. Essen 1998, S. 111-133.

Hahn, Eva; Hahn, Hans Henning: Die sudetendeutsche völkische Tradition. Ein tschechisches Trauma des 20. Jahrhunderts. In: BENZ, WoLfGANG (HG.): Wann ziehen wir endlich den Schlussstrich? Von der Notwendigkeit öffentlicher Erinnerung in Deutschland, Polen und Tschechien. Berlin 2004, S. 29-74.

Hahn, Eva; Hahn, Hans Henning: Flucht und Vertreibung. In: François, ÉtienNE; Schulze, Hagen (Hg.): Deutsche Erinnerungsorte. Eine Auswahl. Bonn 2005, S. 332-350.

Hahn, Eva; Hahn, Hans HenNing: »The Holocaustizing of the Transfer-Discourse«. Historical Revisionism or Old Wine in New Bottlers? In: Kopečé, Michal (Hg.): Past in the Making. Historical Revisionism in Central Europe after 1989. Budapest, New York 2008, S. 39-58. 
Hahn, Eva; Hahn, Hans Henning: Die Vertreibung im deutschen Erinnern. Legenden, Mythos, Geschichte. Paderborn, München [u.a.] 2010.

Hahn, Hans Henning; Hahn, Eva: Der »deutsche Osten« - Mythos? Realität? Verlorenes Traumland? In: Surynt, IzABela; Zybura, MareK (Hg.): Narrative des Nationalen. Deutsche und polnische Nationsdiskurse im 19. und 20. Jahrhundert. Osnabrück 2010, S. 379-396.

Hahn, Hans Peter: Dinge als unscharfe Zeichen. In: WAlz, Markus (Hg.): Handbuch Museum. Geschichte, Aufgaben, Perspektiven. Stuttgart 2016, S. 14-18.

HAJDUK, JADWIGA: Die publizistische Kontroverse um das »Zentrum gegen Vertreibungen«. Der Opfer-Täter-Diskurs in der deutschen und polnischen Presse (1999-2006). Łódź 2010.

Halicka, Beata: Polens Wilder Westen. Erzwungene Migration und die kulturelle Aneignung des Oderraums 1945-1948. Paderborn, München [u.a.] 2013.

Hallama, Peter: Geschichtswissenschaften, Memory Studies und der passive Turn. Zur Frage der Opferperspektive in der erinnerungskulturellen Forschung. In: FRANZEN, K. ERIK; SChulZe Wessel, Martin (Hg.): Opfernarrative. Konkurrenzen und Deutungskämpfe in Deutschland und im östlichen Europa nach dem Zweiten Weltkrieg. München 2012, S. 9-27.

Hanáková, Petra: >I'm at Home Here r. Sudeten Germans in Czech Postcommunist Cinema. In: Mazierska, Ewa; Kristensen, Lars; Näripea, Eva (Hg.): Postcolonial Approaches to Eastern European Cinema. Portraying Neighbours On-Screen. London 2014, S. 91-114.

HANDl, Vladimír: Die Politik des wiedervereinigten Deutschland gegenüber der Tschechischen Republik. In: BuchHEIM, CHRISTOPH; IVANičKovÁ, EdITA; KAISEROvá, Kristina; Zimmermann, Volker (Hg.): Die Tschechoslowakei und die beiden deutschen Staaten. Essen 2010, S. 219-259.

Hartwich, Mateusz J.: Kreisau. Pacta sunt servanda! In: Hahn, Hans Henning; TraBA, Robert (Hg.): Deutsch-Polnische Erinnerungsorte. Band 1: Geteilt/Gemeinsam. Unter Mitarbeit von Maciej Górny und Kornelia Kończal. Paderborn 2015, S. 485496.

HASLINGER, Peter: Von der Erinnerung zur Identität und zurück. Zur aktuellen Debatte über die Vertreibungen in Zentraleuropa. In: Corneliben, Christoph; HoleC, ROMAN; PEŠEK, JIŘí (Hg.): Diktatur - Krieg - Vertreibung. Erinnerungskulturen in Tschechien, der Slowakei und Deutschland seit 1945. Essen 2005, S. 473-486.

Haslinger, Peter: Die Dynamik der aktuellen geschichtspolitischen Debatten um »Flucht und Vertreibung« in Zentraleuropa. In: BRUNNBAUER, UlF; EsCH, MiCHAEL G.; Sundhaussen, Holm (Hg.): Definitionsmacht, Utopie, Vergeltung. »Ethnische Säuberungen« im östlichen Europa des 20. Jahrhunderts. Berlin 2006, S. 281-301.

Haslinger, Peter: Diskurs, Sprache, Zeit, Identität. Plädoyer für eine erweiterte Diskursgeschichte. In: EDER, Franz X. (HG.): Historische Diskursanalysen. Genealogie, Theorie, Anwendungen. Wiesbaden 2006, S. 27-50.

Haslinger, Peter: Erinnerungskultur und Geschichtspolitik in der historischen Forschung zum östlichen Europa. In: zeitenblicke 6 (24.12.2007), H. 2. URL: www. zeitenblicke.de/2007/2/haslinger/index_html (letzter Zugriff: 20.07.2017). 
Haslinger, Peter: Opferkonkurrenzen und Opferkonjunkturen. Das Beispiel von »Flucht und Vertreibung« in Deutschland seit 1990. In: Geschichte in Wissenschaft und Unterricht 62 (2011), H. $\frac{3}{4}$, S. 176-190.

Haslinger, Peter; Franzen, K. Erik; Wessel, Martin Schulze (Hg.): Diskurse über Zwangsmigration in Zentraleuropa. Geschichtspolitik, Fachdebatten, literarisches und lokales Erinnern seit 1989. München 2008.

Hattenhauer, Christian: Danzig, Free City of. Oxford Public International Law 2009. URL: http://opil.ouplaw.com/view/10.1093/law:epil/9780199231690/law9780199231690-e1275 (letzter Zugriff: 22.12.2018).

Haubold-Stolle, Juliane: Rezension zu: Walz, Markus (Hg.): Handbuch Museum. Geschichte, Aufgaben, Perspektiven. Stuttgart 2016. In: H-Soz-Kult (13.10.2016). URL: www.hsozkult.de/publicationreview/id/rezbuecher-21071 (letzter Zugriff: 01.09.2017).

HAUPT, HEINZ-GERHARD: Historische Komparatistik in der internationalen Geschichtsschreibung. In: Budde, Gunilla; Conrad, Sebastian; Janz, Oliver (Hg.): Transnationale Geschichte. Themen, Tendenzen und Theorien. Göttingen 2006, S. 137-149.

Heinemann, Isabel: »Deutsches Blut«. Die Rasseexperten der SS und die Volksdeutschen. Die Volksdeutschen in Hitlers Europa: Umsiedlung auf rassenpolitischer Grundlage. In: Kochanowski, Jerzy (Hg.): Die »Volksdeutschen« in Polen, Frankreich, Ungarn und der Tschechoslowakei. Mythos und Realität. Osnabrück 2006, S. 163-182.

HeInemann, Monika: Emotionalisierungsstrategien in historischen Ausstellungen am Beispiel ausgewählter Warschauer Museen. In: Heinemann, Monika; MaIschein, Hannah; Flacke, Monika; Haslinger, Peter; Wessel, Martin Schulze (Hg.): Medien zwischen Fiction-Making und Realitätsanspruch. Konstruktionen historischer Erinnerungen. München 2011, S. 213-236.

Heinemann, Monika: Krieg und Kriegserinnerung im Museum. Der Zweite Weltkrieg in polnischen historischen Ausstellungen seit den 1980er-Jahren. Göttingen 2017.

Henkel, Matthias; Scheele, Friedrich; Walz, Markus: Lokalität als Thema. Orts-. Stadt-, Regionalmuseen. In: WALZ, MARKus (Hg.): Handbuch Museum. Geschichte, Aufgaben, Perspektiven. Stuttgart 2016, S. 107-113.

Hennecke, Renate: Das Sudetendeutsche Museum in München. In: Studienreihe Zivilgesellschaftliche Bewegungen - Institutionalisierte Politik (2014), H. 27, S. 1-8. URL: https://www.rosalux.de/publikation/id/7921/ (letzter Zugriff: 12.09.2017).

Hesse, Hans; Purpus, Elke: Monuments and Commemorative Sites for German Expellees. In: Niven, Bill; Paver, Chloe (Hg.): Memorialization in Germany since 1945. Basingstoke [u.a.] 2010, S. 48-57.

hg merz architekten museumsgestalter: Schlesisches Museum. In: REINHARDT, UwE J.; TEUFel, Philipp (Hg.): Neue Ausstellungsgestaltung 01. New Exhibition Design 01. Ludwigsburg (Württemberg) 2008, S. 190-195.

Hildermeier, MANFred: Osteuropa als Gegenstand vergleichender Geschichte. In: Budde, Gunilla; Conrad, Sebastian; Janz, Oliver (Hg.): Transnationale Geschichte. Themen, Tendenzen und Theorien. Göttingen 2006, S. 117-136. 
Hilmar, Till: Narrating Unity at the European Union's New History Museum. A Cultural-Process Approach to the Study of Collective Memory. In: Arch. eur. sociol. 57 (2016), H. 2, S. 297-329.

HinRICHSEn, Kerstin: Oder-Neisse-Grenze. Bis auf Widerruf? In: Hahn, Hans HenNing; Traba, Robert (Hg.): Deutsch-Polnische Erinnerungsorte. Band 1: Geteilt/Gemeinsam. Unter Mitarbeit von Maciej Górny und Kornelia Kończal. Paderborn 2015, S. 497-517.

Hirsch, Helga: Flucht und Vertreibung. Kollektive Erinnerung im Wandel. In: Aus Politik und Zeitgeschichte (2003), H. 40-41, S. 14-26.

Hirsch, Helga: Flucht und Vertreibung. Die Rückkehr eines Themas. In: Gauger, Jörg-Dieter; Kittel, Manfred (Hg.): Die Vertreibung der Deutschen aus dem Osten in der Erinnerungskultur. Sankt Augustin 2005, S. 113-121.

Hoffmann, Detlef: Spur. Vorstellung. Ausstellung. In: Beier-de HaAn, Rosmarie (HG.): Geschichtskultur in der Zweiten Moderne. Frankfurt a.M. [u.a.] 2000, S. 167182.

Hoffmann, Roland J.; Harasko, Alois: Odsun. Die Vertreibung der Sudetendeutschen; Dokumentation zu Ursachen, Planung und Realisierung einer »ethnischen Säuberung« in der Mitte Europas, 1848/49-1945/46. München 2000.

Hoffmann, Roland J.; Heißig, Kurt: Odsun. Die Vertreibung der Sudetendeutschen; Dokumentation zu Ursachen, Planung und Realisierung einer »ethnischen Säuberung« in der Mitte Europas, 1848/49-1945/46. München 2010.

HojA, ANDRZEj: An Engaged Narrative. The Permanent Exhibition of the Museum of the Second World War in Gdańsk. In: Cultures of History Forum (24.07.2017). URL: www.cultures-of-history.uni-jena.de/exhibitions/poland/an-engaged-narrativethe-permanent-exhibition-of-the-museum-of-the-second-world-war-in-gdansk/ (letzter Zugriff: 15.08.2017).

HoŁub, AdAm: Die Stiftung Flucht, Vertreibung, Versöhnung. Was wir Polen davon wissen und darüber denken/Fundacja Ucieczka, Wypędzenie, Pojednanie. Co my Polacy o niej wiemy i sądzimy. In: Landsmannschaft Ostpreußen (Hg.): 1000 Jahre Deutsch-polnische Nachbarschaft: Gegensätze und Gemeinsamkeiten - 1000 lat niemiecko-polskiego sąsiedztwa przeciwieństwa oraz cechy wspólne. 9. DeutschPolnischer Kommunalpolitischer Kongress der Landsmannschaft Ostpreußen; 27. - 29. September 2013 Hotel Warminski Allenstein - 9 Niemiecko - Polski Kongres Polityki Komunalnej Związku Ziomkostwa Prus Wschodnich; 27 - 29 września 2013 Hotel Warmiński w Olszynie. Unter Mitarbeit von Gottfried Hufenbach. Hamburg 2014, S. 95-114.

Holzer, JERZY: Solidarność. Selbstbeschränkte Revolution. In: HAHN, HANS HeNNING; Traba, Robert (Hg.): Deutsch-Polnische Erinnerungsorte. Band 2: Geteilt/Gemeinsam. Unter Mitarbeit von Maciej Górny und Kornelia Kończal. Paderborn 2014, S. 159-177.

HÖPKEN, WolfGang: Das Thema der Vertreibung im deutschen Schulbuch. In: KRUKE, ANJA (Hg.): Zwangsmigration und Vertreibung. Europa im 20. Jahrhundert. Bonn 2006, S. 107-115.

HoužviČKA, VÁClAV: Czechs and Germans 1848-2004. The Sudeten Question and the Transformation of Central Europe. Prague 2015. 
Hrabovec, Emilia: Die Vertreibung der Deutschen und die tschechische Gesellschaft. In: Streibel, Robert (Hg.): Flucht und Vertreibung. Zwischen Aufrechnung und Verdrängung. Wien 1994, S. 134-157.

Hrabovec, Emilia: Politisches Dogma kontra wirtschaftliches Kalkül. Einige Aspekte der wirtschafts- und sozialgeschichtlichen Entwicklung in den Sudetengebieten 1945-1946. In: Heumos, Peter (Hg.): Heimat und Exil. Emigration und Rückwanderung, Vertreibung und Integration in der Geschichte der Tschechoslowakei. München 2001, S. 163-185.

H-Soz-Kult (Hg.): Diskussionsforum »Vertreibungen ausstellen. Aber wie?«. 2010. URL: https://www.hsozkult.de/debate/id/diskussionen-1351 (letzter Zugriff: 23.03.2018).

Instytut Pamięci Narodowej Gtówna Komisja Ścigania Zbrodni Przeciwko Narodowi Polskiemu; Materski, Wojciech; Szarota, Tomasz (Hg.): Polska 1939-1945. Straty osobowe i ofiary represji pod dwiema okupacjami. Warszawa 2009.

ItZel, Constanze: The House of European History. A reservoir of the diversity and complexity of the memories of Europe [Interview mit Constanze Itzel]. In: Observing Memories (2017), H. 1, S. 54-59.

Jakubowska, AnNa: Der Bund der Vertriebenen in der Bundesrepublik Deutschland und Polen (1957-2004). Selbst- und Fremddarstellung eines Vertriebenenverbandes. Marburg 2012.

JANEKE, KRISTIANE: Zeitgeschichte in Museen. Museen in der Zeitgeschichte. In: Docupedia-Zeitgeschichte (08.03.2011). URL: http://docupedia.de/zg/Zeitgeschichte_ in_Museen?oldid=84674\#cite_ref-7 (letzter Zugriff: 02.04.2018).

JANKowski, Robert (Hg.): Cena »Strachu«. Gross w oczach historyków. Wybór publicystiki. Warszawa 2008.

JARAUSCH, KonRad H.; SABrow, Martin: »Meistererzählung«. Zur Karriere eines Begriffs. In: JaRAusch, KonRad; SABrow, Martin (Hg.): Die historische Meistererzählung. Deutungslinien der deutschen Nationalgeschichte nach 1945. Göttingen 2002, S. 9-32.

Jarausch, Konrad Hugo; Sabrow, Martin (Hg.): Verletztes Gedächtnis. Erinnerungskultur und Zeitgeschichte im Konflikt. Frankfurt a.M., New York (NY) 2002.

JAREŠ, JAKUB: The House of European History. In Search of a Common History and its Future. In: Cultures of History Forum (12.10.2017). URL: www.cultures-of-history.unijena.de/exhibitions/european-union/the-house-of-european-history-in-searchof-a-common-history-and-its-future/ (letzter Zugriff: 13.11.2017).

JAREŠ, JAKUB: Rezension zu: Národní muzeum; Slovenské národné múzeum (Hg.): „Česko-slovenská/Slovensko-česká výstava«. 28.10.2018 - 30.06.2019 Praha. In: H-Soz-Kult (27.04.2019). URL: https://www.hsozkult.de/searching/id/ rezausstellungen-331?title=czech-slovak-slovak-czech-exhibition-and-2x100\&q= Jakub\%20Jare\%C5\%A1\&sort=\&fq=\&total=16\&recno=4\&subType=reex (letzter Zugriff: 31.01.2020).

JARZĄBEK, WANDA: Fortsetzung oder Veränderung? Die Propaganda der Volksrepublik Polen gegenüber den Deutschen in den Jahren 1969 bis 1975 am Beispiel der Presse. In: Dziurok, Adam; Madajczyk, Piotr; Rosenbaum, Sebastian (Hg.): Die Haltung der kommunistischen Behörden gegenüber der deutschen Bevölkerung in Polen in den Jahren 1945 bis 1989. Gliwice/Gleiwitz, Opole/Oppeln 2015, S. 362-369. 
Jastrzebski, Wøodzimierz: Die deutsche Minderheit in Polen im September 1939. (Originalausgabe: Mniejszość niemiecka w Polsce we wrześniu 1939 roku. Toruń 2010). Münster 2012.

JAWORSKI, RUDOLF: Die historische Gedächtnis- und Erinnerungsforschung als Aufgabe und Herausforderung der Geschichtswissenschaften. In: Aust, MARTin; RuchniEWicz, Krzysztof; Troebst, Stefan (Hg.): Verflochtene Erinnerungen. Polen und seine Nachbarn im 19. und 20. Jahrhundert. Köln, Wien [u.a.] 2009, S. 17-29.

JOCHIMSEN, LUKREZIA: Die linke Gegenstimme zu: Erinnerungskultur und Geschichtspolitik. In: WAGNER, BERND (HG.): Erinnerungskulturen und Geschichtspolitik. Essen 2009, S. 89-94.

JuReit, UlRike; SCHNEIder, Christian: Gefühlte Opfer. Illusionen der Vergangenheitsbewältigung. Stuttgart 2011 (2. Aufl.).

KaCZMAREK, Ryszard: Der Zweite Weltkrieg (1939-1945). In: BAHLCKe, JoACHIM; GAWReCKI, Dan; KaCzMarek, Ryszard (Hg.): Geschichte Oberschlesiens. Politik, Wirtschaft und Kultur von den Anfängen bis zur Gegenwart. Berlin 2015 (2. übera. und erw. Aufl. der poln. Originalausg. von 2011), S. 347-365.

KACZMAREK, RYSZARD: Menschen - Bevölkerungsverhältnisse, soziale Struktur, religiöse und ethnische Gliederung. In: BAHLCKE, JOACHIM; GAWreCKI, DAN; KaCZMAREK, RYSZARD (Hg.): Geschichte Oberschlesiens. Politik, Wirtschaft und Kultur von den Anfängen bis zur Gegenwart. Berlin 2015 (2. übera. und erw. Aufl. der poln. Originalausg. von 2011), S. 47-73.

KadŁubek, Zbigniew: Eine neue Minderheit? Eigensinn und Trauma der Oberschlesier. In: Jahrbuch Polen (2016), H. 27, S. 85-93.

Kaelble, Hartmut: Historischer Vergleich. In: Docupedia-Zeitgeschichte (14.08.2012). URL: http://docupedia.de/zg/kaelble_historischer_vergleich_v1_de_2012 (letzter Zugriff: 29.10.2017).

KAISER, Wolfram: Limits of Cultural Engineering. Actors and Narratives in the European Parliament's House of European History Project. In: JCMS (Journal of Common Market Studies) 55 (2017), H. 3, S. 518-534.

Kaiser, Wolfram; Krankenhagen, Stefan; Poehls, Kerstin: Europa ausstellen. Das Museum als Praxisfeld der Europäisierung. Wien, Köln, Weimar 2012.

Kaiserová, Kristina; Kunštát, Miroslav: Deutsche und Tschechen im Museum. Neue Wege der Institutionalisierung der öffentlichen Erinnerung im deutsch-tschechischen Verhältnis: das Collegium Bohemicum (Ústí nad Labem) und das Sudetendeutsche Museum (München). In: Kováč, DušAn; ŘEzník, Miloš; Schulze WesSEL, MARTIN (Hg.): Erinnern - Ausstellen - Speichern. Deutsch-tschechische und deutsch-slowakische Beziehungsgeschichte im Museum. Essen 2017, S. 137-149.

KAEĄŻNY, JERZY; KorZENIEWSKA, AMELIA; KoRZENIEWSKI, BARTOSZ (Hg.): Druga wojna światowa w pamięci kulturowej w Polsce i w Niemczech. 70 lat później (1945-2015). Gdańsk 2015.

Kaluza, ANDrZej: Stolz auf Polen. Das Ringen um das patriotische Narrativ in Polens Kulturpolitik nach 2015. In: Polen-Analysen (2018), H. 219, S. 2-8.

Kamiński, Marek Kazimierz: Polen und die Tschechoslowakei in der Politik der USA und Grossbritanniens in den Jahren 1945-1948. In: Heumos, Peter (Hg.): Polen 
und die böhmischen Länder im 19. und 20. Jahrhundert. Politik und Gesellschaft im Vergleich. München 1997, S. 273-300.

KÁRnÝ, Miroslav: Die tschechoslowakischen Opfer der deutschen Okkupation. In: HOENSCH, JÖRG K.; LEMBERG, HANS (HG.): Begegnung und Konflikt. Schlaglichter auf das Verhältnis von Tschechen, Slowaken und Deutschen 1815-1989. Essen 2001, S. 137-146.

KARTASIŃSKI, KAMIL: „Światło historii. Górny Śląsk na przestrzeni dziejów« - recenzja wystawy stałej Muzeum Śląskiego. HISTMAG.org 12.07.2015. URL: https://histmag. org/Histmag-wesprzyj-nas-9745 (letzter Zugriff: 25.08.2017).

Karwat, Krzysztof: Im schlesischen Kessel brodelt es. Neue Debatten über schlesische Geschichte. In: Dialog. Deutsch-Polnisches Magazin (Magazyn Polsko-Niemiecki) (2013), H. 103, S. 83-84.

Kelletat, Andreas F.: Von der Täter- zur Opfernation? Die Rückkehr des Themas »Flucht und Vertreibung « in den deutschen Vergangenheitsdiskurs bei Grass und anderen. In: Triangulum. Germanistisches Jahrbuch für Estland, Lettland und Litauen 10 (2003/2004), S. 132-147.

KERSKI, BASIL: Willy Brandt in Warschau. Kontinuität und Wandel in der deutschen Polen-Politik (1970-1990-2010). Basil Kerski im Gespräch mit dem Publizisten und »Polityka«-Redakteur Adam Krzemiński. In: Dialog. Deutsch-Polnisches Magazin (Magazyn Polsko-Niemiecki) (2010-2011), H. 94, S. 30-38.

KIERES, LEON: Rechtliche Aspekte der Auseinandersetzung mit der Vergangenheit. Der Fall Polen 1989-2000. In: Hofmann, AnNa; Kerski, BASIL (Hg.): Deutsche und Polen. Erinnerung im Dialog. Osnabrück 2007, S. 71-80.

KIRCHBERG, VOLKER: Besucherforschung in Museen: Evaluation von Ausstellungen. In: BAUR, JoACHIM (Hg.): Museumsanalyse. Methoden und Konturen eines neuen Forschungsfeldes. Bielefeld 2010, S. 171-184.

Kirchberg, Volker: Das Museum als öffentlicher Raum in der Stadt. In: BaUR, JoACHIM (HG.): Museumsanalyse. Methoden und Konturen eines neuen Forschungsfeldes. Bielefeld 2010, S. 231-265.

Kirchick, James: The End of Europe. Dictators, Demagogues, and the Coming Dark Age. Cumberland (UK) 2017.

Kittel, Manfred: Vertreibung der Vertriebenen? Der historische deutsche Osten in der Erinnerungskultur der Bundesrepublik (1961-1982). München 2007.

Kittel, MAnfred: Das Ausstellungs- und Dokumentationszentrum der Stiftung Flucht, Vertreibung, Versöhnung in Berlin. In: Deutsches Historisches Museum; International Association of Museums of History; Stiftung Flucht, Vertreibung, Versöhnung (Hg.): Flucht, Vertreibung, Ethnische Säuberung. Eine Hausforderung für Museums- und Ausstellungsarbeit weltweit. Tagungsband zum Neunten Internationalen Symposium der International Association of Museums of History. Berlin 2010, S. 139-144.

Kittel, Manfred; Möller, Horst: Die Beneš-Dekrete und die Vertreibung der Deutschen im europäischen Vergleich. In: Vierteljahrshefte für Zeitgeschichte (2006), H. 4, S. 541-581.

Klebmann, Christoph; Traba, Robert: Kresy und Deutscher Osten. Vom Glauben an die historische Mission - oder Wo liegt Arkadien? In: HaHN, Hans Henning; 
Traba, Robert (Hg.): Deutsch-Polnische Erinnerungsorte. Band 3: Parallelen. Unter Mitarbeit von Maciej Górny und Kornelia Kończal. Paderborn 2012, S. 37-70.

Klute, Thorsten: Entschädigungsklagen ohne Erfolgsaussicht? »Preußische Treuhand« will die Rückgabe von Vermögen an deutsche Vertriebene erreichen/Jewish Claims Conference als Vorbild. In: Dialog. Deutsch-Polnisches Magazin (Magazyn Polsko-Niemiecki) (2004), H. 66-67, S. 6-8.

KNigge, Volkhard; Veen, Hans-JoAChim; MäHlert, Ulrich; Et Al. (Hg.): Arbeit am europäischen Gedächtnis. Diktaturerfahrung und Demokratieentwicklung. Köln, Weimar [u. a] 2011.

KobielsKa, MARIA: Muzea do pamiętania/Museums for Remembering. In: Herito (2016), H. 25, S. 178-193.

Kochanowski, Jerzy: Verräter oder Mitbürger? Staat und Gesellschaft in Polen zum Problem der Volksdeutschen vor und nach 1945. In: KochANOwSKI, JERZY (HG.): Die »Volksdeutschen« in Polen, Frankreich, Ungarn und der Tschechoslowakei. Mythos und Realität. Osnabrück 2006, S. 333-352.

KochanowsKI, JeRzY: Repatrianten oder Expatrianten? Die Umsiedlung polnischer Bürger aus den ehemaligen Ostgebieten der Republik Polen (kresy) 1944-1946. In: Melville, RAlPh; PešEK, JiŘí; SCHARF, Claus (Hg.): Zwangsmigrationen im mittleren und östlichen Europa. Völkerrecht - Konzeptionen - Praxis (1938-1950). Mainz 2007, S. 421-429.

KochanowsKi, Jerzy; ZWicker, Stefan: Volksdeutsche. Rasse, Schicksal und Verrat. In: Hahn, Hans Henning; Traba, Robert (Hg.): Deutsch-Polnische Erinnerungsorte. Band 1: Geteilt/Gemeinsam. Unter Mitarbeit von Maciej Górny und Kornelia Kończal. Paderborn 2015, S. 667-687.

KockA, JÜRGEN: Das östliche Mitteleuropa als Herausforderung für eine vergleichende Geschichte Europas. In:Zeitschrift für Ostmitteleuropa-Forschung 49 (2000), H. 2, S. 159174.

KolÁř, PAVEL: Vertreibung zwischen nationaler Meistererzählung und Deutungspluralität. Der tschechische Vertreibungsdiskurs im Licht geschichtswissenschaftlicher Streitschriften. In: Zeitschrift für Geschichtswissenschaft 53 (2005), H. 10, S. 925-940.

KöNIG, Helmut: Politik und Gedächtnis. Weilerswist 2008.

KöNIG, Helmut: Paradoxien der Erinnerung. Über Wissen und Vergessen. In: Osteuropa 61 (2011), H. 4, S. 43-53.

Kopka, BogusŁaW: Deutsche und Polen in den Arbeitslagern des Ressorts für Öffentliche Sicherheit in Polen 1945 bis 1954. Terror und Arbeit. In: DzIurok, AdAM; MADajCzyK, Piotr; Rosenbaum, Sebastian (Hg.): Die Haltung der kommunistischen Behörden gegenüber der deutschen Bevölkerung in Polen in den Jahren 1945 bis 1989. Gliwice/Gleiwitz, Opole/Oppeln 2015, S. 101-110.

Koposov, Nikolay: Memory Laws, Memory Wars. The Politics of the Past in Europe and Russia. Cambridge 2018.

Korte, Jan; Wiegel, Gerd: Einleitung. In: Korte, Jan; Wiegel, Gerd (Hg.): Sichtbare Zeichen. Die neue deutsche Geschichtspolitik - Von der Tätergeschichte zur Opfererinnerung. Köln 2009, S. 7-13.

Koschyк, HARTMUT: Heimat, Identität, Glaube. Vertriebene - Aussiedler - Minderheiten im Spannungsfeld von Zeitgeschichte und Politik. St. Ottilien 2018. 
Koselleck, Reinhart: Der 8. Mai zwischen Erinnerung und Geschichte. In:THAdden, Rudolf von; KAUdelKa, STEFFEN (HG.): Erinnerung und Geschichte. 60 Jahre nach dem 8. Mai 1945. Göttingen 2006, S. 13-22.

Kosmala, Beate: Das Bild Polens in der Bundesrepublik Deutschland und die deutsch-polnischen Beziehungen. In: Kochanowski, Jerzy; Kosmala, Beate (Hg.): Deutschland, Polen und der Zweite Weltkrieg. Geschichte und Erinnerung. Eine Publikation des Deutsch-Polnischen Jugendwerks. Potsdam 2009, S. 129-141.

Kossert, ANDreas: Ostpreußen. Geschichte und Mythos. München 2007 (4. Aufl.).

KosSert, ANDreas: Kalte Heimat. Die Geschichte der deutschen Vertriebenen nach 1945. München 2009.

Köstlin, KonRad: Die Minderheit als Kategorie der Moderne und das Museum. In: Lozoviuk, Petr (Hg.): Visualisierte Minderheiten. Probleme und Möglichkeiten der musealen Präsentation von ethnischen bzw. nationalen Minderheiten. Dresden 2012, S. 13-24.

Kostro, Robert: The Light of History. Through the Lens of a Polish Museum. In:Axelsson, Bodil; Dupont, Christine; Kesteloot, Chantal (Hg.): Entering the Minefields. The Creation of New History Museums in Europe. Conference Proceedings from EuNaMus, European National Museums: Identity Politics, the Uses of the Past, and the European Citizen. Brussels 25 January 2012. Linköping 2012, S. 71-78.

Koszel, Bogdan: Die polnische Deutschlandpolitik in den Jahren 1970-1990. Von Gierek bis Jaruzelski. In: GruCZA, FrANCISZEK (Hg.): Tausend Jahre polnisch-deutsche Beziehungen. Sprache - Literatur - Kultur - Politik. Warszawa 2001, S. 913-923.

Kotte, Eugen: Rezension zu: Beate Herget/Berit Pleitner (Hg.): Heimat im Museum? Museale Konzeptionen zu Heimat und Erinnerungskultur in Deutschland und Polen, München 2008. In: Zeitschrift für Geschichtswissenschaft (2010), H. 9, S. 262-267.

Kotzian, ORTFRIED: Münchner Schatztruhe, betonbewehrt. In: Kulturpolitische Korrespondenz (25.04.2017), H. 1379, S. 6-8.

Kotzian, Ortfried: Ein Sudetendeutsches Museum in München? In: Fendl, ElisaBETH; MoHr, Klaus (Hg.): Heimat Geschichten. Aus den Sammlungen des Sudetendeutschen Museums. München 2018, S. 14-16.

Kovéč, DušAn; ŘEZník, Miloš; SCHulZE WesSEL, MARTin (Hg.): Erinnern - Ausstellen - Speichern. Deutsch-tschechische und deutsch-slowakische Beziehungsgeschichte im Museum. Essen 2017.

KRAFT, ANDREAS: Mythos "Beneš-Dekrete«. Rechtskulturen zwischen historischem Kontext und universalem Anspruch von Menschenrechten. In: IvaničKová, EDITA; Langewiesche, Dieter; Míšnová, Alena (Hg.): Mythen und Politik im 20. Jahrhundert. Deutsche - Slowaken - Tschechen. Essen 2013, S. 231-256.

KRAFT, Claudia: Der Platz der Vertreibung der Deutschen im historischen Gedächtnis Polens und der Tschechoslowakei/Tschechiens. In: CoRnelißsen, CHRISTOPH; HOLEC, ROMAN; PEŠEK, JIŘí (Hg.): Diktatur - Krieg - Vertreibung. Erinnerungskulturen in Tschechien, der Slowakei und Deutschland seit 1945. Essen 2005, S. 329-353.

KRAFT, Claudia: Beschäftigung mit der Vertreibung vor Ort. Regionale Institutionen und Initiativen der Aufarbeitung und des Gedenkens. In: KRUKe, ANJA (Hg.): Zwangsmigration und Vertreibung. Europa im 20. Jahrhundert. Bonn 2006, S. 119138. 
KRAFT, ClAUdia: Europäische Erinnerungskultur(en) als »work in progress «. In: CiUPKe, Paul; Hitze, Guido; Kenkmann, Alfons; Wolters, Astrid; Wysok, WiesŁaW (HG.): Gedenkstättenarbeit und Erinnerungskultur. Ein deutsch-polnischer Austausch $=$ Kultura pamięci i praca w muzeach-miejscach upamiętnienia. Essen 2014, S. 315-318.

KRAFT, ClAudia: Große Erzählungen oder dichte Beschreibungen. Vertreibungstopografien in der europäischen Geschichte. In: Zeitschrift für Ostmitteleuropa-Forschung 63 (2014), H. 1, S. 39-54.

Krankenhagen, Stefan: »Das andere, eigene Kap. «In Brüssel hat das House of European History eröffnet. In: Werkstatt Geschichte (2017), H. 75, S. 125-130.

KRANZ, JERZY: Schuld und Verantwortung, Wunden und Narben. War die Vertreibung Unrecht? In: КосH, CHRISTOPH (HG.): War die »Vertreibung« Unrecht? Die Umsiedlungsbeschlüsse des Potsdamer Abkommens und ihre Umsetzung in ihrem völkerrechtlichen und historischen Kontext. Frankfurt a.M., Bern [u.a.] 2015, S. 53-119.

KRĂSTEV, IvAN: Europadämmerung. Ein Essay. Berlin 2018 (4. Aufl.).

Krauss, Marita: Das Sudetendeutsche Museum in München. In: Deutsches Historisches Museum; International Association of Museums of History; Stiftung Flucht, Vertreibung, Versöhnung (Hg.): Flucht, Vertreibung, Ethnische Säuberung. Eine Hausforderung für Museums- und Ausstellungsarbeit weltweit. Tagungsband zum Neunten Internationalen Symposium der International Association of Museums of History. Berlin 2010, S. 113-122.

Kreienbaum, Jonas: Rezension zu: Pitzer, Andrea: One Long Night. A Global History of Concentration Camps. New York 2017. In: H-Soz-Kult (10.01.2018). URL: www. hsozkult.de/publicationreview/id/rezbuecher-28480 (letzter Zugriff: 10.02.2018).

KREIS, GEORG: »Europa « ausstellen? Zum Werdegang eines supranationalen Museumsprojekts. In: François, Étienne; Kończal, Kornelia; Traba, Robert; Troebst, Stefan (Hg.): Geschichtspolitik in Europa seit 1989. Deutschland, Frankreich und Polen im internationalen Vergleich. Göttingen 2013, S. 525-537.

KŘEN, JAN: Nationale Selbstbehauptung im Vielvölkerstaat. Politische Konzeptionen des tschechischen Nationalismus 1890-1938. In: Ǩ̌EN, JAN; KuRAL, VÁClaV; BRANDES, Detlef (Hg.): Integration oder Ausgrenzung. Deutsche und Tschechen 1890-1945. Bremen 1986, S. 15-65.

KřEn, JAN: Die Konfliktgemeinschaft. Tschechen und Deutsche. 1780-1918. München 1996.

Kretschmann, VAsco: Breslau museal. Deutsche und polnische Geschichtsausstellungen 1900-2010. Köln, Weimar [u.a.] 2017.

KretschmanN, Vasco: Rezension zu: Monika Heinemann: Krieg und Kriegserinnerung im Museum. Der Zweite Weltkrieg in polnischen historischen Ausstellungen seit den 1980er-Jahren, 2017. In: Polenstudien.Interdisziplinär (Pol-Int) (27.09.2018). URL: $\quad$ https://www.pol-int.org/de/publikationen/krieg-und-kriegserinnerungim-museum-der-zweite-weltkrieg\#r7203 (letzter Zugriff: 03.10.2018).

Król, Eugeniusz CeZary: Das Bild des ethnischen Deutschen im polnischen Film nach dem Zweiten Weltkrieg. In: Kochanowski, JERzY (Hg.): Die »Volksdeutschen« in Polen, Frankreich, Ungarn und der Tschechoslowakei. Mythos und Realität. Osnabrück 2006, S. 367-389. 
KRÜGer, Constance: Polen, ich komme! Gästebücher einer Ausstellung. Empirische Befunde und theoretische Überlegungen. In: AckermanN, Felix; BoroffKa, ANnA; Lersch, Gregor H. (Hg.): Partizipative Erinnerungsräume. Dialogische Wissensbildung in Museen und Ausstellungen. Bielefeld 2013, S. 147-159.

KRZOSKA, MARKUS: Bromberger Blutsonntag. Unklare Fakten, klare Interpretationen. In: Hahn, Hans Henning; Traba, Robert (Hg.): Deutsch-Polnische Erinnerungsorte. Band 2: Geteilt/Gemeinsam. Unter Mitarbeit von Maciej Górny und Kornelia Kończal. Paderborn 2014, S. 351-363.

Kubik, Jan; Bernhard, Michael H.: A Theory of the Politics of Memory. In: Bernhard, Michael H.; Kubik, Jan (Hg.): Twenty Years After Communism. The Politics of Memory and Commemoration. New York (NY) [u.a.] 2014, S. 7-34.

KubŮ, EduARD: Die brüchigen Beziehungen. Die Weimarer Republik und die Tschechoslowakei. In: Hoensch, Jörg K.; Lemberg, HANS (Hg.): Begegnung und Konflikt. Schlaglichter auf das Verhältnis von Tschechen, Slowaken und Deutschen 1815-1989. Essen 2001, S. 71-84.

KuČERA, JAROSLAV: »Der Hai wird nie wieder so stark sein«. Tschechoslowakische Deutschlandpolitik 1945-1948. Dresden 2001.

KuČERA, JAROSLAV: Statistische Berechnungen der Vertreibungsverluste - Schlußwort oder Sackgasse? In: HoENSCH, JöRG K.; LEMBERG, HANS (Hg.): Begegnung und Konflikt. Schlaglichter auf das Verhältnis von Tschechen, Slowaken und Deutschen 18151989. Essen 2001, S. 231-244.

KUČERA, JAROSLAV: Mírové uspořádání s Německem. Od protihitlerovské koalice k Česko-německé deklaraci. Praha 2018.

Kula, MARcin: Muzeum opowie o historii. In: Muzealnictwo 58 (2017), H. 1, S. 102-108.

Kulczycki, John J.: Belonging to the Nation. Inclusion and Exclusion in the PolishGerman Borderlands, 1939-1951. Cambridge (MA) 2016.

Kunicki, Wojciech: Schlesien. Mythos der Anfänge - Katastrophe des Endes - Utopie der Zukunft. In: Traba, Robert; Loew, Peter Oliver (Hg.): Deutsch-Polnische Erinnerungsorte. Band 5: Erinnerung auf Polnisch. Texte zu Theorie und Praxis des sozialen Gedächtnisses. Paderborn 2015, S. 217-233.

KunšTÁt, Miroslav: Fremd- und Feindbilder der Deutschen in der tschechischen innenpolitischen Instrumentalisierung nach 1989. In: Bingen, Dieter; Loew, Peter Oliver; Wóycicki, Kazimierz (Hg.): Die Destruktion des Dialogs. Zur innenpolitischen Instrumentalisierung negativer Fremd- und Feindbilder. Polen, Tschechien, Deutschland und die Niederlande im Vergleich, 1900-2005. Wiesbaden 2007, S. 114128.

Kunštát, Miroslav: Die Wiedervereinigung Deutschlands und die tschechoslowakische Außenpolitik. In: BuchHeim, Christoph; IvaničKová, Edita; KaISERová, Kristina; Zimmermann, Volker (Hg.): Die Tschechoslowakei und die beiden deutschen Staaten. Essen 2010, S. 201-217.

Kunštát, Miroslav; Lemberg, Hans: Zur tschechischen Erinnerungskultur. Einige Fragen von Hans Lemberg, beantwortet von Miroslav Kunštát. In: FAUlEnBACH, BERND; JELICH, FRANZ-JoSEF (Hg.): »Transformationen« der Erinnerungskulturen in Europa nach 1989. Essen 2006, S. 113-123. 
KunŠTÁt, Miroslav; SCHMoller, Hildegard: Umbruch, Transformation und europäische Integration. In: Perzi, Niklas; SCHMOller, Hildegard; Konrád, OTA; ŠMIDRKAL, VÁClAV (Hg.): Nachbarn. Ein österreichisch-tschechisches Geschichtsbuch. Weitra 2019, S. 293-325.

KunŠTát, Miroslav; Vilímek, Tomáš: Die deutsch-tschechoslowakischen Beziehungen im Zeichen der Perestroika. In: IVANičKová, Edita; ŘEzník, Miloš; ZIMmerMANN, VolKer (Hg.): Das Jahr 1989 im deutsch-tschechisch-slowakischen Kontext. Essen 2013, S. 117-150.

Kural, VÁclav: Tschechen, Deutsche und die sudetendeutsche Frage während des Zweiten Weltkrieges. In: Brandes, Detlef; IvaničKová, Edita; Pešek, Jiří (Hg.): Erzwungene Trennung. Vertreibungen und Aussiedlungen in und aus der Tschechoslowakei 1938-1947 im Vergleich mit Polen, Ungarn und Jugoslawien. Essen 1999, S. 71-94.

KuroczyŃski, Piotr: Die Medialisierung der Stadt. Analoge und digitale Stadtführer zur Stadt Breslau nach 1945. Bielefeld 2011.

KYPTA, UlLA: Rezension zu: Europäisches Hansemuseum, 28.05.2015 Lübeck. In: H-SozKult (11.06.2016). URL: www.hsozkult.de/exhibitionreview/id/rezausstellungen-239 (letzter Zugriff: 01.09.2017).

LANDWEHR, ACHIM: Diskurs und Diskursgeschichte. In: Docupedia-Zeitgeschichte (11.02.2010). URL: http://docupedia.de/zg/Diskurs_und_Diskursgeschichte (letzter Zugriff: 21.02.2017).

LANG, KaI-Olaf: Der Streit um die Beneš-Dekrete und die Folgen für das deutschtschechische Verhältnis. In: SWP-Aktuell (2002), H. 20, S. 1-8 (letzter Zugriff: 16.07.2017).

LANGE, Simon: Der Erinnerungsdiskurs um Flucht und Vertreibung in Deutschland seit 1989/90. Vertriebenenverbände, Öffentlichkeit und die Suche nach einer >normalen` Identität für die >Berliner Republik«. Dissertation. Universität Heidelberg 2015. URL: http://archiv.ub.uni-heidelberg.de/volltextserver/19300/ (letzter Zugriff: 11.04.2017).

Langguth, Gerd; Oberreuter, Heinrich; Wolffsohn, Michael: Zum Verständnis der deutschen Polenpolitik. Ein Diskussionsbeitrag zum Interview mit Adam Krzemiński »Willy Brandt in Warschau. Kontinuität und Wandel in der deutschen PolenPolitik (1970-1990-2010)« im Magazin DIALOG (Nr. 94). In: Dialog. Deutsch-Polnisches Magazin (Magazyn Polsko-Niemiecki) (2011), H. 95, S. 56-60.

LEGGEWIE, Claus: Schlachtfeld Europa. Transnationale Erinnerung und europäische Identität. In: WAGNER, BERND (HG.): Erinnerungskulturen und Geschichtspolitik. Essen 2009, S. 163-176.

Leggewie, Claus; LANG, ANNe: Der Kampf um die europäische Erinnerung. Ein Schlachtfeld wird besichtigt. München 2011.

Leggewie, Claus; Meyer, ERIK: »Ein Ort, an den man gerne geht«. Das HolocaustMahnmal und die deutsche Geschichtspolitik nach 1989. München 2005.

LegGewie, Claus; Meyer, Erik: Geschichtspolitik in der Mediengesellschaft. In: OesTERLE, GÜNTER (HG.): Erinnerung, Gedächtnis, Wissen. Studien zur kulturwissenschaftlichen Gedächtnisforschung. Göttingen 2005, S. 663-676. 
LEMberG, HANS: »Ethnische Säuberung«. Ein Mittel zur Lösung von Nationalitätenproblemen? In: Aus Politik und Zeitgeschichte (1992), H. B 46/92, S. 27-38.

LEMBERG, HANS: Die Entwicklung der Pläne für die Aussiedlung der Deutschen aus der Tschechoslowakei. In: Hoensch, Jörg K.; Lemberg, Hans (Hg.): Begegnung und Konflikt. Schlaglichter auf das Verhältnis von Tschechen, Slowaken und Deutschen 1815-1989. Essen 2001, S. 191-205.

LEMBERG, HANS: »München 1938« und die langfristigen Folgen für das Verhältnis zwischen Tschechen und Deutschen. In: Hoensch, Jörg K.; Lemberg, Hans (Hg.): Begegnung und Konflikt. Schlaglichter auf das Verhältnis von Tschechen, Slowaken und Deutschen 1815-1989. Essen 2001, S. 103-118.

LEMBERG, HANS: Mitteleuropäisches Dreieck. Ist das deutsch-polnische Verhältnis gut, das deutsch-tschechische problematisch? In: Dialog. Deutsch-Polnisches Magazin (Magazyn Polsko-Niemiecki) (2002), H. 61, S. 23-24.

Lemberg, Hans: Das Jahrhundert der Vertreibungen. In: Bingen, Dieter; BorodZiej, Weodzimierz; Troebst, Stefan (Hg.): Vertreibungen europäisch erinnern? Historische Erfahrungen, Vergangenheitspolitik, Zukunftskonzeptionen. Wiesbaden 2003, S. 44-53.

Lemberg, Hans: Die Vertreibung der Deutschen aus dem Osten. In: Faulenbach, BeRnd; Helle, ANdreas (Hg.): Zwangsmigration in Europa. Zur wissenschaftlichen und politischen Auseinandersetzung um die Vertreibung der Deutschen aus dem Osten. Essen 2005, S. 47-56.

LEMBERG, HANS; KřEN, JAN; KovÁČ, DUŠAN: Einleitung der Herausgeber. In: LEMBERG, HANS; KřEN, JAN; Kováč, DuŠAN (Hg.): Im geteilten Europa. Tschechen, Slowaken und Deutsche und ihre Staaten 1948-1989. Essen 1998, S. 9-40.

LEPP, NICOLA: Ungewissheiten - Wissens(v)ermittlung im Medium Ausstellung. In: Staupe, Gisela (Hg.): Das Museum als Lern- und Erfahrungsraum. Grundlagen und Praxisbeispiele. Wien [u.a.] 2012, S. 60-65.

Leschnik, Hubert: Erinnerungskultur und Geschichtspolitik in Polen von 1998 bis 2010. Marburg 2018.

Levy, Daniel; Sznaider, Natan: Erinnerung im globalen Zeitalter. Der Holocaust. Frankfurt a.M. 2007 (Aktual. Neuausg., 1. Aufl.).

LINDNER, BERND: Soziodemographie des Museumspublikums. In: WALZ, MARKus (Hg.): Handbuch Museum. Geschichte, Aufgaben, Perspektiven. Stuttgart 2016, S. 323-329.

LINEK, BERNARD: Lamsdorf. Können Täter Opfer werden? In: HaHn, Hans Henning; Traba, Robert (HG.): Deutsch-Polnische Erinnerungsorte. Band 2: Geteilt/Gemeinsam. Unter Mitarbeit von Maciej Górny und Kornelia Kończal. Paderborn 2014, S. 365-377.

Linek, Bernard; Lotz, Christian: Flucht, Vertreibung, Umsiedlung. In: BahlCKe, JoACHIM; GAWrecki, DaN; KaCZMAReK, Ryszard (Hg.): Geschichte Oberschlesiens. Politik, Wirtschaft und Kultur von den Anfängen bis zur Gegenwart. Berlin 2015 (2. übera. und erw. Aufl. der poln. Originalausg. von 2011), S. 639-654.

LIPSKI, JAN Józef (Hg.); Unter Mitarbeit von Georg Ziegler: Powiedzieć sobie wszystko ... / Wir müssen uns alles sagen ... Eseje o sasiedztwie polsko-niemieckim/Essays zur deutsch-polnischen Nachbarschaft. Warszawa 1998 (3. Aufl.). 
LIPSKI, JAN Józef: Zwei Vaterländer - zwei Patriotismen. Bemerkungen zum nationalen Größenwahn und zur Xenophobie der Polen. (Erstveröffentlichung: Warschau 1981). In: Lipski, JAN Józef (Hg.): Powiedzieć sobie wszystko ... / Wir müssen uns alles sagen ... Eseje o sasiedztwie polsko-niemieckim/Essays zur deutsch-polnischen Nachbarschaft. Unter Mitarbeit von Georg Ziegler. Warszawa 1998 (3. Aufl.), S. 185228.

LISICKI, PAWEŁ; HASZCZYŃSKI, JeRZY (Hg.): Erinnerung: europäisch oder national? Der Streit über das Zentrum gegen Vertreibungen. Pamięć europejska czy narodowa. Spór o Centrum przeciwko Wypędzeniom. Warszawa 2003.

Loew, Peter Oliver: Helden oder Opfer? Erinnerungskulturen in Polen nach 1989. In: Osteuropa 58 (2008), H. 6, S. 85-102.

Logemann, Daniel: Die entstehende Dauerausstellung des Museums des Zweiten Weltkrieges in Danzig. In: Inter Finitimos. Jahrbuch zur deutsch-polnischen Beziehungsgeschichte (2012), H. 10, S. 126-133.

Logemann, Daniel: On >Polish History<. Disputes over the Museum of the Second World War in Gdańsk. In: Cultures of History Forum (21.03.2017). URL: www.culturesof-history.uni-jena.de/debates/poland/on-polish-history-disputes-over-themuseum-of-the-second-world-war-in-gdansk/\#part3 (letzter Zugriff: 26.03.2017).

Logemann, DANIEL: Replik: D. Logemann zu S. Kleiss: Rezension zu: Dauerausstellung: Museum des Zweiten Weltkriegs. In: H-Soz-Kult (30.10.2017). URL: https://www. hsozkult.de/exhibitionreview/id/rezausstellungen-268 (letzter Zugriff: 15.03.2018).

Logemann, DANiel; Müller, ANNA: Exponate und ihre intellektuelle und emotionale Botschaft. Die Ausstellung über nationalsozialistische Konzentrationslager im $\mathrm{Mu}$ seum des Zweiten Weltkriegs in Gdańsk/Danzig. In: CiUPKE, PAUl; Hitze, Guido; Kenkmann, Alfons; Wolters, Astrid; WysoK, WiesŁaW (Hg.): Gedenkstättenarbeit und Erinnerungskultur. Ein deutsch-polnischer Austausch = Kultura pamięci i praca w muzeach-miejscach upamiętnienia. Essen 2014, S. 281-287.

Logemann, Daniel; Tomann, Juliane: Gerichte statt Geschichte? Das Museum des Zweiten Weltkrieges in Gdańsk. In: Zeithistorische Forschungen/Studies in Contemporary History, Online-Ausgabe (2019), H. 1. URL: https://zeithistorische-forschungen.de/12019/5685 (letzter Zugriff: 28.01.2020).

LOTZ, Christian: Das (Re-)Arrangieren von Feindbildern im geteilten Deutschland, in Polen und Bulgarien in der unmittelbaren Nachkriegszeit, 1945-1952. In: BINGEN, Dieter; Loew, Peter Oliver; Wóycicki, Kazimierz (Hg.): Die Destruktion des Dialogs. Zur innenpolitischen Instrumentalisierung negativer Fremd- und Feindbilder. Polen, Tschechien, Deutschland und die Niederlande im Vergleich, 1900-2005. Wiesbaden 2007, S. 146-161.

LOTZ, ChRISTIAN: Im erinnerungspolitischen Sog. Debatten um die Erinnerung an Flucht, Vertreibung und die Ostgebiete im geteilten Deutschland. In: Zeitschrift für Ostmitteleuropa-Forschung 59 (2010), H. 3, S. 323-343.

LOTZ, CHRISTIAN: Die Landsmannschaft Schlesien in den erinnerungspolitischen Kontroversen zwischen Ost und West. In: STICKLER, Matthias (Hg.): Jenseits von Aufrechnung und Verdrängung. Neue Forschungen zu Flucht, Vertreibung und Vertriebenenintegration. Stuttgart 2014, S. 99-108. 
LÜdTKe, AlF: Explaining Forced Migration. In: Bessel, Richard; HAAKe, Claudia B. (Hg.): Removing Peoples. Forced Removal in the Modern World. Oxford (UK), New York (NY) 2009, S. 13-32.

Luft, Robert; Brenner, Christiane; Franzen, K. Erik; Haslinger, Peter; Heumos, Peter; Weiss, Stephanie (Hg.): Deutsche, Tschechen, Sudetendeutsche. Analysen und Stellungnahmen zu Geschichte und Gegenwart aus fünf Jahrzehnten. Von Ferdinand Seibt. Festschrift zu seinem 75. Geburtstag. München 2002.

LUfT, Robert; HLAVAČKa, Milan: Tschechien und Bayern. Eine Einführung. In: HlaVAČKa, Milan; Luft, Robert; Lunow, Ulrike (Hg.): Tschechien und Bayern. Gegenüberstellungen und Vergleiche vom Mittelalter bis zur Gegenwart. Konferenzband des Collegium Carolinum, des Historický ústav AV ČR und des Hauses der Bayerischen Geschichte zur Bayerisch-Tschechischen Landesausstellung 2016/2017 in Prag und Nürnberg. München 2016, S. XV-XXXIII.

LUPPES, JefFREY: Commemorating Flight and Expulsion vor Ort. Local Expellee Monuments in Central and Eastern Europe. In: EchternkAmp, Jörg; JAEger, StEPHAN (Hg.): Views of Violence. Representing the Second World War in German and European Museums and Memorials. New York (NY) 2019, S. 215-232.

MACDONALD, SHARON: Nationale, postnationale, transkulturelle Identitäten und das Museum. In: BeIER-De HAAN, Rosmarie (Hg.): Geschichtskultur in der Zweiten Moderne. Frankfurt a.M. [u.a.] 2000, S. 123-148.

MACDONALD, Sharon: Museen erforschen. Für eine Museumswissenschaft in der Erweiterung. In: BAUR, JOACHIM (Hg.): Museumsanalyse. Methoden und Konturen eines neuen Forschungsfeldes. Bielefeld 2010, S. 49-69.

Macdonald, Sharon: Memorylands. Heritage and Identity in Europe today. London 2013.

Machcewicz, Pawet: Das Museum des Zweiten Weltkrieges in Danzig. In: PolenAnalysen (2009), H. 56, S. 2-7.

MachCeWicz, PaWeŁ: Museum des Zweiten Weltkrieges in Danzig. Der internationale Architekturwettbewerb ist entschieden. In: Dialog. Deutsch-Polnisches Magazin (Magazyn Polsko-Niemiecki) (2010), H. 93, S. 8-9.

Machcewicz, PaweŁ: Das Museum des Zweiten Weltkriegs in Danzig. In: Troebst, Stefan; Wolf, Johanna (Hg.): Erinnern an den Zweiten Weltkrieg. Mahnmale und Museen in Mittel- und Osteuropa. Leipzig 2011, S. 161-172.

MACHCEWICZ, PAWEŁ: »Museum statt Stacheldrahtverhaue«. Das Museum des Zweiten Weltkriegs in Danzig. In: Borodziej, WŁodzimierz; Puttkamer, JoAchim von (Hg.): Europa und sein Osten. Geschichtskulturelle Herausforderungen. München 2012, S. 81-103.

MACHCEWICZ, PAWE : Spory o historie 2000-2011. Kraków 2012.

MaCHCEWICZ, PAWEe: Muzeum. Kraków 2017.

MAdAJCZyK, PIOTR: Der Transfer der deutschen Bevölkerung aus dem Oppelner Schlesien nach 1945. In: BRANDES, DETLEF; IVANIČKOVÁ, EDITA; PEŠEK, JiŘí (Hg.): Erzwungene Trennung. Vertreibungen und Aussiedlungen in und aus der Tschechoslowakei 1938-1947 im Vergleich mit Polen, Ungarn und Jugoslawien. Essen 1999, S. 277-292.

MAdAJCZyK, PIOTR: Die Rolle antideutscher Instrumentalisierungen in Polen, 19441989. In: Bingen, Dieter; Loew, Peter Oliver; Wóycicki, Kazimierz (Hg.): 
Die Destruktion des Dialogs. Zur innenpolitischen Instrumentalisierung negativer Fremd- und Feindbilder. Polen, Tschechien, Deutschland und die Niederlande im Vergleich, 1900-2005. Wiesbaden 2007, S. 131-145.

MAdAJCZyK, PIOTR: Polnische Nation 1918-1945. Ansätze auf dem Weg zur Zwangsmigration. In: Melville, RAlPh; PešEK, Jiří; SCHARF, Claus (Hg.): Zwangsmigrationen im mittleren und östlichen Europa. Völkerrecht - Konzeptionen - Praxis (19381950). Mainz 2007, S. 127-138.

MADAJCZyK, Piotr: Die deutsche Reaktion auf den Brief der Bischöfe in der polnischen Rezeption. In: Boll, Friedhelm; Wysocki, WiesŁaW; Ziemer, Klaus (Hg.): Versöhnung und Politik. Polnisch-deutsche Versöhnungsinitiativen der 1960er-Jahre und die Entspannungspolitik. Unter Mitarbeit von Thomas Roth. Bonn 2009, S. 196210.

MADAJCzyK, Piotr: Das zwanzigste Jahrhundert in Ostmitteleuropa. Eine politische Geschichte. Erfurt 2014.

Majewski, Piotr M.: »Niemcy Sudeccy«. 1848-1948. Historia pewnego nacjonalizmu. Warszawa 2007.

Majewski, Piotr M.: Die Hauptakteure der neueren polnischen Debatten zum Thema der Zwangsmigrationen. In: Strobel, Thomas; MAIER, Robert (Hg.): Das Thema Vertreibung und die deutsch-polnischen Beziehungen in Forschung, Unterricht und Politik. Hannover 2008, S. 49-59.

MAJEWSKi, Piotr M.: Zwischen Versöhnung und Verteidigung nationaler Interessen. Die polnische Debatte über die Aussiedlung der deutschen Bevölkerung nach dem Zweiten Weltkrieg vor dem Hintergrund der Diskussionen in der Tschechischen Republik 1989-2003. In: Haslinger, Peter; Franzen, K. Erik; Wessel, Martin SCHUlze (Hg.): Diskurse über Zwangsmigration in Zentraleuropa. Geschichtspolitik, Fachdebatten, literarisches und lokales Erinnern seit 1989. München 2008, S. 3157.

Majewski, Piotr M.: The Topic of Forced Migration in the Planned Museum of the Second World War in Gdańsk. In: Deutsches Historisches Museum; International Association of Museums of History; Stiftung Flucht, Vertreibung, Versöhnung (Hg.): Flucht, Vertreibung, Ethnische Säuberung. Eine Hausforderung für Museums- und Ausstellungsarbeit weltweit. Tagungsband zum Neunten Internationalen Symposium der International Association of Museums of History. Berlin 2010, S. 125-129.

Majewski, Piotr M.: Zmarnowana szansa? Możliwości obrony Czechosłowacji jesienią 1938 roku. Gdańsk 2016.

Majewski, Piotr M.: Muzeum II wojny światowej w Gdańsku, czyli o tym, jak opowiadać o historii w społeczeństwie o różnych wrażliwościach. In: Muzealnictwo 58 (2017), H. 1, S. 106-108.

Makhotina, Ekaterina; Schulze Wessel, Martin: Neue Konfliktlinien in den Erinnerungen an den Zweiten Weltkrieg im östlichen Europa. Zur Einleitung. In: MAKhotina, Ekaterina; Keding, Ekaterina; Borodziej, WŁodzimierz; François, Etienne; Schulze Wessel, Martin (Hg.): Krieg im Museum. Präsentationen des Zweiten Weltkriegs in Museen und Gedenkstätten des östlichen Europa. Göttingen, Bristol (CT, USA) 2015, S. 1-14. 
MANN, Michael: Globalization, Macro-Regions and Nation-States. In: Budde, GuniLla; Conrad, Sebastian; Janz, Oliver (Hg.): Transnationale Geschichte. Themen, Tendenzen und Theorien. Göttingen 2006, S. 21-31.

MARgAlit, Gil'AD: Guilt, Suffering, and Memory. Germany remembers its Dead of World War II. Bloomington (Ind.) 2010.

Marsząek-Kawa, Joanna; Wawrzyński, Patryk; Ratke-Majewska, Anna: The Politics of Memory in Post-Authoritarian Transitions, Volume Two. Comparative Analysis. Newcastle upon Tyne, England 2017.

MaSNyK, Marek: Provinz Oberschlesien (1918/19-1938/39). In: BAHLCKe, JoaChIM; GaWRECKI, DAN; KACZMAREK, Ryszard (Hg.): Geschichte Oberschlesiens. Politik, Wirtschaft und Kultur von den Anfängen bis zur Gegenwart. Berlin 2015 (2. übera. und erw. Aufl. der poln. Originalausg. von 2011), S. 290-317.

MATĚJKA, ONDŘEJ: Die Suche nach einer lebendigen Geschichte. Hledání živé historie. In: Antikomplex (Hg.): Tragická místa paměti. Tragische Erinnerungsorte. Průvodce po historii jednoho regionu 1938-1945. Ein Führer durch die Geschichte einer Region 1938-1945. Praha 2011, S. 17-23.

Matthei, Olaf: Die Massenumsiedlungen und das Bild der Deutschen im öffentlichen Diskurs der Volksrepublik Polen am Beispiel der »Trybuna Ludu«. In: PAPPAI, ANNASophia (Hg.): Wypędzenia i co dalej? Materiały z seminarium polsko-niemieckiego dla studentów $=$ Vertreibungen und was weiter? Beiträge eines deutsch-polnischen Seminars für Studierende. Warszawa 2006, S. 82-93.

MAZIERSKA, EwA: Neighbours (Almost) Like Us. Representation of Germans, Germanness and Germany in Polish communist and Postcommunist Cinema. In: MazierSKA, EWA; Kristensen, LARS; NÄRIPEA, Eva (Hg.): Postcolonial Approaches to Eastern European Cinema. Portraying Neighbours On-Screen. London 2014, S. 67-89.

Mazur, ZbignieW: Widoczny Znak (2005-2009). Poznań 2009.

McDermott, Kevin: Communist Czechoslovakia, 1945-89. A Political and Social History. London 2015.

MEHNERT, ElKE: »Flucht und Vertreibung« aus den historischen deutschen Ostgebieten. Wenig geliebte Themen in der DDR-Literatur. In: Haslinger, Peter; Franzen, K. ERIK; Wessel, MARTIN Schulze (Hg.): Diskurse über Zwangsmigration in Zentraleuropa. Geschichtspolitik, Fachdebatten, literarisches und lokales Erinnern seit 1989. München 2008, S. 237-245.

MeIER, Mischa: Die »Völkerwanderung«. In: Aus Politik und Zeitgeschichte (2016), H. 2627, S. 3-10.

Melville, Ralph; PešEk, Jiří; Scharf, Claus: Einleitung. In: Melville, RalPh; Pešek, JIŘí; SCHARF, ClAUS (HG.): Zwangsmigrationen im mittleren und östlichen Europa. Völkerrecht - Konzeptionen - Praxis (1938-1950). Mainz 2007, S. IX-XV.

Merz, H. G.: Die Gestaltung der ständigen Ausstellung im Schlesischen Museum. In: Bauer, Markus; Brade, Johanna; Kügler, Martin; Pietsch, Martina (Hg.): Schlesisches Museum zu Görlitz - Museum für eine europäische Kulturregion. Muzeum Ślaskie w Görlitz - Muzeum europejskiego regionu kulturowego. Dößel 2006, S. 57-60.

Meyer, Erik: Memory and Politics. In: ErlL, Astrid; NÜNNING, ANSGAR; Young, SARA B. (HG.): A Companion to Cultural Memory Studies. Berlin 2010, S. 173-180. 
Michnik, AdAM: Trauma, Memory, and Justice. A Few Notes on Polish-German Historical Memory and Its Prospects. In: Beinek, Justyna; Kosicki, Piotr H. (Hg.): ReMapping Polish-German Historical Memory. Physical, Political, and Literary Spaces since World War II. Bloomington (Ind.) 2011, S. 207-215.

MitTler, GÜNTHER R.: Neue Museen - neue Geschichte? In: Aus Politik und Zeitgeschichte (2007), H. 49, S. 13-20.

Moeller, Robert G.: Germans as Victims? Thoughts on a Post-Cold War History of World War II's Legacies. In: History and Memory 17 (2005), H. 1-2; Special Issue: Histories and Memories of Twentieth-Century Germany, S. 145-194.

Mohr, Klaus: Die Sammlungen des Sudetendeutschen Museums. In: FendL, ElisaBETH; MoHr, Klaus (Hg.): Heimat Geschichten. Aus den Sammlungen des Sudetendeutschen Museums. München 2018, S. 17-19.

MOLLER, SABINE: Erinnerung und Gedächtnis. In: Docupedia-Zeitgeschichte (12.04.2010). URL: http://docupedia.de/zg/Erinnerung_und_Gedächtnis (letzter Zugriff: 24.03.2016).

MÖLLER, Horst: Die Vertreibung der Deutschen aus dem Osten in der Erinnerungskultur. Zur Einführung. In: Gauger, Jörg-Dieter; Kittel, MANFRed (Hg.): Die Vertreibung der Deutschen aus dem Osten in der Erinnerungskultur. Sankt Augustin 2005, S. 9-16.

MÖLLER, Kirsten: Geschlechterbilder im Vertreibungsdiskurs. Auseinandersetzungen in Literatur, Film und Theater nach 1945 in Deutschland und Polen. Frankfurt a.M. 2016.

MORAT, DANIEL; ZüNDORF, IRMgARD: Geschichtspolitik im Museum. In: Zeithistorische Forschungen/Studies in Contemporary History, Online-Ausgabe (2019), H. 1. URL: https:// zeithistorische-forschungen.de/1-2019/id=5682 (letzter Zugriff: 28.01.2020).

MORK, ANDREA: Nach Nationalismus, Diktatur und Krieg. Bausteine einer europäischen Geschichte der Demokratie. Das Haus der Europäischen Geschichte. In: Hertfelder, Thomas; LAPPENKÜPER, UlRICH; LILlteicher, JÜRgEN (Hg.): Erinnern an Demokratie in Deutschland. Demokratiegeschichte in Museen und Erinnerungsstätten der Bundesrepublik. Göttingen 2016, S. 37-56.

Mouralová, Blanka: Das Collegium Bohemicum in Ústí nad Labem/Aussig. In: Deutsches Historisches Museum; International Association of Museums of History; Stiftung Flucht, Vertreibung, Versöhnung (Hg.): Flucht, Vertreibung, Ethnische Säuberung. Eine Hausforderung für Museums- und Ausstellungsarbeit weltweit. Tagungsband zum Neunten Internationalen Symposium der International Association of Museums of History. Berlin 2010, S. 105-111.

MOURALOVÁ, BlANKA; Š́́CHA, JAN: Das Museum einer nahezu abwesenden Minderheit. In: Lozoviuk, Petr (Hg.): Visualisierte Minderheiten. Probleme und Möglichkeiten der musealen Präsentation von ethnischen bzw. nationalen Minderheiten. Dresden 2012, S. 151-165.

MüHLE, EduARD: Geschichtspolitik und polnischer »Westgedanke« in der Wojewodschaft Śląsk (1922-1939). In: Jahrbücher für Geschichte Osteuropas, Neue Folge 51 (2003), H. 3, S. 409-426.

MülLER, ANNA: When History Speaks Through Objects... "45: The End of the War in 45 Artefacts«. In: Cultures of History Forum (16.11.2015). URL: www.cultures- 
of-history.uni-jena.de/exhibiting-2oth-century-history/poland/when-historyspeaks-through-objects-45-the-end-of-the-war-in-45-artefacts/ (letzter Zugriff: 22.03.2016).

MüLLER, MATTHIAS: Die SPD und die Vertriebenenverbände 1949-1977. Eintracht, Entfremdung, Zwietracht. Berlin 2012.

Musiat, Bogdan: Die nationale Narration und ihre Entwicklung sowie die Entfaltung der europäischen Idee im Polen des 20. Jahrhunderts. In: PELINKA, ANTON; BISCHOF, Karin; Fend, Walter; StÖgner, Karin; KöHler, Thomas (Hg.): Geschichtsbuch Mitteleuropa. Vom Fin de Siècle bis zur Gegenwart. Wien 2016, S. 315-357.

Musiat, Bogdan: German concerns about Poland's historical politics. Hg. v. Ministry of Foreign Affairs. poland.pl 09.06.2016. URL: https://poland.pl/politics/opinions/ german-concerns-about-polands-historical-politics/ (letzter Zugriff: 28.03.2018).

MusioŁ, ANNA: Westerplatte. Gemeinsamer Erinnerungsort oder gespaltenes Symbol? Potsdam 2010.

Muttenthaler, Roswitha: Beredsam und wirkungsvoll. Dimensionen der Dinge aus museologischer Perspektive. In: Grieber, Martina; Haupt-Stummer, ChristiNe; Höllwart, Renate; Jaschke, Beatrice; Sommer, Monika; Sternfeld, Nora; ZiAjA, Luisa (Hg.): Gegen den Stand der Dinge. Objekte in Museen und Ausstellungen. Berlin, Boston 2016, S. 35-47.

Muttenthaler, Roswitha; Wonisch, Regina: Gesten des Zeigens. Zur Repräsentation von Gender und Race in Ausstellungen. Bielefeld 2006.

Nagengast, Emil: The German Expellees and European Values. In: VÁRdy, Steven BÉlA; Tooley, T. Hunt (Hg.): Ethnic Cleansing in Twentieth-Century Europe. Boulder (Colo.) 2003, S. 467-488.

NAIMARK, Norman: Europäische Geschichte im 20. Jahrhundert und die Problematik eines deutschen »Zentrums gegen Vertreibungen«. In: FAULENBACH, BERND; HELLE, ANDREAS (HG.): Zwangsmigration in Europa. Zur wissenschaftlichen und politischen Auseinandersetzung um die Vertreibung der Deutschen aus dem Osten. Essen 2005, S. 19-29.

NAIMARK, Norman: Zwangsmigration im Europa des 20. Jahrhunderts. Probleme und Verlaufsmuster. In: Troebst, Stefan; Wildt, Michael (Hg.): Zwangsmigration im Europa der Moderne. Nationale Ursachen und transnationale Wirkungen. Leipzig 2016, S. 11-27.

NAIMARK, Norman M.: Flammender Haß. Ethnische Säuberung im 20. Jahrhundert. München 2004.

Natalie Bayer im Gespräch mit Nora Sternfeld: Museen umprogrammieren. Über Dinge, Ausschlüsse und Zugänge auf dem Prüfstand der Migrationsgesellschaft. In: Grieber, Martina; Haupt-Stummer, Christine; Höllwart, Renate; Jaschke, Beatrice; Sommer, Monika; Sternfeld, Nora; Ziaja, Luisa (Hg.): Gegen den Stand der Dinge. Objekte in Museen und Ausstellungen. Berlin, Boston 2016, S. 129135.

Naumann, Klaus: Vertreibung. Ein Problem deutscher Selbstthematisierung. In: Mittelweg 36 (2005), H. 3, S. 4-18. 
Nelhiebel, Kurt: Die Entkoppelung von Krieg und Vertreibung. Zu Manfred Kittels Deutung der jüngeren europäischen Geschichte. In: Zeitschrift für Geschichtswissenschaft 58 (2010), H. 1, S. 54-69.

Nelhiebel, Kurt: Die Stiftung Flucht, Vertreibung, Versöhnung. Versuch an einem untauglichen Objekt. In: Defrance, Corine; Pfeil, Ulrich (Hg.): Verständigung und Versöhnung nach dem »Zivilisationsbruch«? Deutschland in Europa nach 1945. Bonn 2016, S. 519-538.

Niedhart, Gottfried: Die Ostpolitik der Bundesrepublik und die Normalisierung der Beziehungen zur Tschechoslowakei 1967-1973. In: BuCHHEIM, CHRISTOPH; IVANIČková, Edita; Kaiserová, Kristina; Zimmermann, Volker (Hg.): Die Tschechoslowakei und die beiden deutschen Staaten. Essen 2010, S. 103-121.

Niethammer, Lutz; Augstein, Franziska; Breier, Zsuzsa; Borodziej, WeodziMierz; Schmidt, MÁRIA; Troebst, Stefan et Al.: Das Haus der Europäischen Geschichte. Auf dem Weg zu einem europäischen Gedächtnis? Podiumsdiskussion der Referenten. In: KNIGge, Volkhard; Veen, HANS-JoACHIM; MäHLERT, UlRICH; ET AL. (Hg.): Arbeit am europäischen Gedächtnis. Diktaturerfahrung und Demokratieentwicklung. Köln, Weimar [u. a] 2011, S. 173-193.

Nijakowski, LeCH M.: Die polnische Erinnerungspolitik. In: Jahrbuch Polen (2017), H. 28, S. 29-48.

NiTSCHKE, BERNADETTA: Vertreibung und Aussiedlung der deutschen Bevölkerung aus Polen 1945 bis 1949. München 2003.

Niven, Bill: German Victimhood at the Turn of the Millennium. In: Niven, Bill (HG.): Germans as Victims. Remembering the Past in Contemporary Germany. Basingstoke (Hampshire) [u.a.] 2006, S. 1-25.

Niven, William John: Representations of Flight and Expulsion in East German Prose Works. Rochester (NY) 2014.

NiWiński, Piotr: Recenzja programu funkcjonalno-użytkowego wystawy głównej przygotowanej przez Muzeum II wojny światowej w Gdańsku autorstwa prof. dr hab. Pawła Machcewicza, dr hab. Piotra M. Majewskiego, dr Janusza Marszalca, dr hab. Prof. KUL Rafała Wnuka, stan na styczeń 2016. 2016. URL: www.cultures-of-history.uni-jena.de/fileadmin/editorial/articles/Logemann_ Museum_WWII/Recenzja_Niwinski.pdf (letzter Zugriff: 14.04.2018).

NižŇANSKÝ, EdUARD: Das Münchner Abkommen in der kommunistischen Nachkriegspropaganda (1948-1989). In: BUCHHEIM, CHRISTOPH; IVANIČKOVÁ, EDITA; KAISEROvÁ, Kristina; Zimmermann, Volker (Hg.): Die Tschechoslowakei und die beiden deutschen Staaten. Essen 2010, S. 261-277.

Nora, Pierre: Nachwort. In: François, Étienne; Schulze, Hagen (Hg.): Deutsche Erinnerungsorte III. München 2001, S. 681-686.

Oesterle, Günter: Einleitung. In: Oesterle, GüNTER (Hg.): Erinnerung, Gedächtnis, Wissen. Studien zur kulturwissenschaftlichen Gedächtnisforschung. Göttingen 2005, S. 11-23.

OHLIGER, RAINER: Flucht und Vertreibung als Migrationsgeschichte. Möglichkeiten und Grenzen einer neuen Deutung und Erinnerung. In: Brunnbauer, UlF; EsCH, MICHAel G.; Sundhaussen, Holm (Hg.): Definitionsmacht, Utopie, Vergeltung. »Eth- 
nische Säuberungen« im östlichen Europa des 20. Jahrhunderts. Berlin 2006, S. 213239.

Olaszek, JAN: Antideutsche Motive in der Propaganda gegen die Solidarność während des Kriegszustands in Polen. In: Inter Finitimos. Jahrbuch zur deutsch-polnischen Beziehungsgeschichte (2013/14), H. 11, S. 140-151.

Olick, Jeffrey Keith: Foreword. In: Pakier, MaŁgorzata; Wawrzyniak, Joanna (Hg.): Memory and Change in Europe. Eastern Perspectives. New York (NY) 2016, S. IX-XII.

Olschowsky, BuRKHARD: Einvernehmen und Konflikt. Das Verhältnis zwischen der DDR und der Volksrepublik Polen 1980-1989. Osnabrück 2005.

Olschowsky, BuRKHARD: Der wenig vertraute Nachbar - Das Bild Polens in der DDR 1949-1989. In: Kochanowski, Jerzy; Kosmala, Beate (Hg.): Deutschland, Polen und der Zweite Weltkrieg. Geschichte und Erinnerung. Eine Publikation des Deutsch-Polnischen Jugendwerks. Potsdam 2009, S. 142-153.

Olschowsky, Burkhard: Versöhnungsinitiativen, Polenpolitik und ihre Auswirkungen auf die politischen Einstellungen in den deutschen Gesellschaften. In: BoLL, Friedhelm; Wysocki, WiesŁaW; Ziemer, Klaus (Hg.): Versöhnung und Politik. Polnisch-deutsche Versöhnungsinitiativen der 1960er-Jahre und die Entspannungspolitik. Unter Mitarbeit von Thomas Roth. Bonn 2009, S. 316-328.

OlsCHOWSKY, BURKHARD: Relations between the Federal Republic of Germany and the Peoples' Republic of Poland in view of the political changes at the end of the 1980 . In: Remembrance and Solidarity Studies in 2oth Century European History (2014), H. 3, S. 243-266.

Oltmer, Jochen: Deutschland und die globale Flüchtlingsfrage. In: Zeitgeschichteonline (01.12.2016). URL: https://zeitgeschichte-online.de/thema/deutschland-unddie-globale-fluechtlingsfrage (letzter Zugriff: 12.06.2018).

Oltmer, Jochen: Das lange 20. Jahrhundert der Gewaltmigration. In: Österreichische Zeitschrift für Geschichtswissenschaften 28 (2017), H. 2, S. 24-48.

Opalla, YANNICK: Authentisch, und deshalb...?! Konzept \& Bedeutung der Authentizität im Museum. In: Stieglitz, Leo von; Brune, Thomas (Hg.): Hin und her - Dialoge in Museen zur Alltagskultur. Aktuelle Positionen zur Besucherpartizipation. Bielefeld, Berlin 2015, S. 65-71.

OpIŁOWSKA, ElżBIETA: Die Aneignung des fremden Raumes. Nationalistische Politik in den polnischen Nord- und Westgebieten nach dem Zweiten Weltkrieg. In: FrACKOWIAK, Johannes (Hg.): Nationalistische Politik und Ressentiments. Deutsche und Polen von 1871 bis zur Gegenwart. Göttingen 2013, S. 241-256.

OpPelland, Torsten: Alternative für Deutschland. Bundeszentrale für politische Bildung 05.06.2017. URL: www.bpb.de/politik/grundfragen/parteien-in-deutschland/ 211108/afd (letzter Zugriff: 12.08.2018).

Oppen, Karoline von; Wolff, Stefan: From the Margins to the Centre? The Discourse on Expellees and Victimhood in Germany. In: Niven, BILL (Hg.): Germans as Victims. Remembering the Past in Contemporary Germany. Basingstoke (Hampshire) [u.a.] 2006, S. 194-209.

OrŁoWSKI, HubERT: Literatur, nationale Identität und kulturelles Gedächtnis um die Wende des 20./21. Jahrhunderts. In: Surynt, Izabela; Zybura, Marek (Hg.): Nar- 
rative des Nationalen. Deutsche und polnische Nationsdiskurse im 19. und 20. Jahrhundert. Osnabrück 2010, S. 75-90.

OVERMANS, RÜDIGER: »Amtlich und wissenschaftlich erarbeitet«. Zur Diskussion über die Verluste während Flucht und Vertreibung der Deutschen aus der ČSR. In: BRANDEs, Detlef; IVAničKová, Edita; PešEK, JiŘí (Hg.): Erzwungene Trennung. Vertreibungen und Aussiedlungen in und aus der Tschechoslowakei 1938-1947 im Vergleich mit Polen, Ungarn und Jugoslawien. Essen 1999, S. 149-177.

PADEvĚT, JIŘí: Krvavé léto 1945. Poválečné násilí v českých zemích. Praha 2016.

Pakier, Mągorzata; Stråth, Bo (Hg.): A European Memory? Contested Histories and Politics of Remembrance. New York (NY) 2010.

Pakier, MaŁgorzata; WaWrzyniak, Joanna: Memory and Change in Eastern Europe. How Special? In: Pakier, MaŁgorzata; Wawrzyniak, Joanna (Hg.): Memory and Change in Europe. Eastern Perspectives. New York (NY) 2016, S. 1-20.

Pakier, Mazgorzata; Wawrzyniak, Joanna (Hg.): Memory and Change in Europe. Eastern Perspectives. New York (NY) 2016.

PASCH, RALF: Vorwort. In: PASCH, RALF (Hg.): Die Erben der Vertreibung. Sudetendeutsche und Tschechen heute. Halle an der Saale 2014, S. 7-14.

PAUER, JAN: Zähe Erinnerung. Der tschechisch-deutsche Dissens über die Vertreibung. In: Mittelweg 36 (2005), H. 3, S. 19-34.

PaUer, Jan: 1968: Der »Prager Frühling « und die Deutschen. In: Brandes, Detlef; KoVÁČ, DuŠAN; PEŠEK, JǏ̌í (Hg.): Wendepunkte in den Beziehungen zwischen Deutschen, Tschechen und Slowaken 1848-1989. Essen 2007, S. 263-285.

Perron, CATHERINE: $\$ 96$ Bundesvertriebenengesetz. Ein Instrument der Versöhnung Deutschlands mit seinen mittel- und osteuropäischen Nachbarn? In: DEFRANCE, Corine; Pfeil, UlRich (Hg.): Verständigung und Versöhnung nach dem »Zivilisationsbruch«? Deutschland in Europa nach 1945. Bonn 2016, S. 499-517.

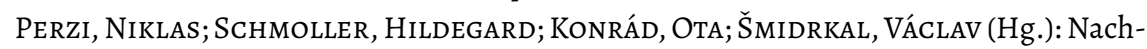
barn. Ein österreichisch-tschechisches Geschichtsbuch. Weitra 2019.

PEŠEK, JIŘí: Die 3oer und 40er Jahren in der tschechischen Erinnerung seit den 70er Jahren. In: Faulenbach, Bernd; Jelich, Franz-Josef (Hg.): »Transformationen« der Erinnerungskulturen in Europa nach 1989. Essen 2006, S. 125-137.

PEŠEK, JIŘí: Zwangsmigrationen von Tschechen und Deutschen 1938-1949 in der tschechischen Geschichtswissenschaft seit 1989. In: Melville, RalPH; PeŠEK, JiŘí; SCHARF, Claus (Hg.): Zwangsmigrationen im mittleren und östlichen Europa. Völkerrecht - Konzeptionen - Praxis (1938-1950). Mainz 2007, S. 193-201.

Peters, Florian: Polens Streitgeschichte kommt ins Museum. Wie neue Museen in Danzig und Warschau die polnische Geschichtskultur verändern. In: Zeitgeschichte-online (2015). URL: www.zeitgeschichte-online.de/geschichtskultur/polensstreitgeschichte-kommt-ins-museum (letzter Zugriff: 01.10.2016).

Peters, Florian: Revolution der Erinnerung. Der Zweite Weltkrieg in der Geschichtskultur des spätsozialistischen Polen. Berlin 2016.

Peters, Florian: Patriotische Geschichtsschreibung im Staatsauftrag. Polens neue Rechtsregierung bricht mit der historischen Legitimation des Neuanfangs von 1989. In: Zeitgeschichte-online (Mai 2016). URL: www.zeitgeschichte-online.de/thema/ patriotische-geschichtsschreibung-im-staatsauftrag (letzter Zugriff: 11.04.2017). 
Peters, Florian: »üdische Täter « und polnische Retter. In: Zeitgeschichte-online (01.03.2018). URL: https://www.zeitgeschichte-online.de/kommentar/juedischetaeter-und-polnische-retter (letzter Zugriff: 14.04.2018).

Peters, Florian: Rezension zu: Heinemann, Monika: Krieg und Kriegserinnerung im Museum. Der Zweite Weltkrieg in polnischen historischen Ausstellungen seit den 1980er-Jahren. Göttingen 2017. In: H-Soz-Kult (13.06.2018). URL: https://www. hsozkult.de/publicationreview/id/rezbuecher-26440 (letzter Zugriff: 19.08.2018).

Peters-Schildgen, Susanne: Die museale Darstellung der Geschichte Schlesiens in der Bundesrepublik Deutschland am Beispiel des Oberschlesischen Landesmuseums in Ratingen. In: Dyroff, Stefan; Krzoska, Markus (Hg.): Geschichtsbilder und ihre museale Präsentation. Ausgewählte Beiträge zur Geschichte der Deutschen in Polen in Vergangenheit und Gegenwart. München 2008, S. 191-206.

PFEIL, UlRICH: »Brücken der Freundschaft« zwischen der DDR und Polen. »Völkerfreundschaft«: eine »andere« Geste der Versöhnung? In: DefranCE, CoRINE; PfEIL, UlRICH (Hg.): Verständigung und Versöhnung nach dem »Zivilisationsbruch«? Deutschland in Europa nach 1945. Bonn 2016, S. 157-174.

Phillips, AnN L.: The Politics of Reconciliation Revisited. Germany and East-Central Europe. In: World Affairs 163 (2001), H. 4, S. 171-191.

Pickering, Michael; Keightley, Emily: Memory, Media and Methodological Footings. In: Hajek, Andrea; Lohmeier, Christine; Pentzold, Christian (Hg.): Memory in a Mediated World. Remembrance and Reconstruction. Basingstoke (Hampshire) 2016, S. 36-52.

PIEPER, KATRIN: Resonanzräume. Das Museum im Forschungsfeld Erinnerungskultur. In: BAUR, JOACHIM (Hg.): Museumsanalyse. Methoden und Konturen eines neuen Forschungsfeldes. Bielefeld 2010, S. 187-212.

Pietsch, Martina: Das Schlesische Landesmuseum Görlitz. In: Orden Pour le Mérite für Wissenschaften und Künste (Hg.): Reden und Gedenkworte. Fünfunddreissigster Band. 2006-2007. Göttingen 2007, S. 37-45.

Pilawski, KRZysztof: Über das Tusk-Museum. In: Flierl, Thomas; Müller, Elfriede (HG.): Osteuropa - Schlachtfeld der Erinnerungen. Berlin 2010, S. 65-70.

PIskorski, JAN M.: Die Verjagten. Flucht und Vertreibung im Europa des 20. Jahrhunderts. Aus dem Polnischen von Peter Oliver Loew (Originalausgabe: Wygnańcy. Przesiedlenia i uchodźcy w dwudziestowiecznej Europie, Warszawa 2010). München 2013.

PISKORSKI, JAN M.: Zwangsmigrationen im Kontext des Zweiten Weltkriegs. Zwölf ausgewählte Schwerpunkte. In: STICKLER, MATthias (HG.): Jenseits von Aufrechnung und Verdrängung. Neue Forschungen zu Flucht, Vertreibung und Vertriebenenintegration. Stuttgart 2014, S. 155-176.

Podlasek, Maria: Wypedzenie Niemców z terenów na wschód od Odry i Nysy Łużyckiej. Relacje świadków. Warszawa 1995.

PoHL, Karl HeInRICH: Wann ist ein Museum »historisch korrekt«? »Offenes Geschichtsbild«, Kontroversität, Multiperspektivität und »Überwältigungsverbot« als Grundprinzipien musealer Geschichtspräsentationen. In: HARTUNG, OlAF (Hg.): Museum und Geschichtskultur. Ästhetik - Politik - Wissenschaft. Bielefeld 2006, S. 273-286. 
Pohl, Karl Heinrich: Der kritische Museumsführer. Neun Historische Museen im Fokus. Schwalbach/Ts. 2013.

Polak-SPringer, Peter: Recovered Territory. A German-Polish Conflict over Land and Culture, 1919-1989. New York (NY), Oxford (UK) 2015.

Politt, Holger: Alles im Zeichen von Geschichte? Aktuelle Geschichtspolitik in Polen. In: Korte, Jan; Wiegel, Gerd (Hg.): Sichtbare Zeichen. Die neue deutsche Geschichtspolitik - Von der Tätergeschichte zur Opfererinnerung. Köln 2009, S. 162168.

Pomian, Krzysztof: Muzeum pojednania. In: Przegląd Polityczny (2008), H. 91/92, S. 6265.

Pomian, KRZYSZTof: Muzeum: Kryteria sukcesu. In: Muzealnictwo (2009), H. 50, S. 5764.

Pufelska, Agnieszka: Raub der Clio - die polnische Geschichtspolitik und ihre Exekutoren. In: Flierl, Thomas; MÜller, Elfriede (Hg.): Osteuropa - Schlachtfeld der Erinnerungen. Berlin 2010, S. 33-56.

Puttkamer, Joachim von: Ostmitteleuropa. In: EGO. Europäische Geschichte Online (25.03.2014). URL: http://ieg-ego.eu/de/threads/crossroads/grenzregionen/ joachim-vom-puttkamer-ostmitteleuropa (letzter Zugriff: 09.06.2018).

Puttkamer, Joachim von: Europäisch und polnisch zugleich. Das Museum des Zweiten Weltkriegs in Danzig. In: Osteuropa 67 (2017), H. 1-2, S. 3-12.

RAABE, StePhaN; Velder, ANNE:»Flucht, Vertreibung, Versöhnung«. Reaktionen in Polen auf die Besetzung des Wissenschaftlichen Beirates, Vorgeschichte und Konzepte des Stiftungsprojekts. Länderbericht: Polen. Konrad-Adenauer-Stiftung 03.12.2010. URL: www.kas.de/polen/de/publications/21385/ (letzter Zugriff: 06.04.2016).

Regente, Vincent: Stiftung Flucht, Vertreibung, Versöhnung. In: Online-Lexikon zur Kultur und Geschichte der Deutschen im östlichen Europa (2017; Aktualisierung: 15.03.2018). URL: http://ome-lexikon.uni-oldenburg.de/p32668 (letzter Zugriff: 22.03.2018).

REgENTE, VINCENT: Europäisches Netzwerk Erinnerung und Solidarität/European Network Remembrance and Solidarity. In: Online-Lexikon zur Kultur und Geschichte der Deutschen im östlichen Europa (14.12.2017). URL: https://ome-lexikon.unioldenburg.de/begriffe/europaeischesnetzwerkerinnerungundsolidaritaet/ (letzter Zugriff: 22.12.2018).

Regente, VInCEnT: Tagungsbericht: »Vertriebene in der DDR - Zum Umgang mit einem Tabu«. Leipzig, 14.11.2019. Deutsche Gesellschaft e. V. 2019. URL: https:// www.deutsche-gesellschaft-ev.de/images/pdf/2019/2019-eu-ddr-vertriebene/ Tagungsbericht_Vertriebene_in_der_DDR_4.pdf (letzter Zugriff: 30.01.2020).

Reichel, Walter; PetrboK, VÁclav: Von »destruktiven Nationalisten«, »demokratischen Patrioten« und »helfenden Cousins«. Stereotype und Narrative in der tschechisch-österreichischen Wahrnehmung. In: PERzI, NikLas; SCHMOLler, HiLDEGARD; KonRÁd, OTA; ŠMidRKAL, VÁClaV (Hg.): Nachbarn. Ein österreichischtschechisches Geschichtsbuch. Weitra 2019, S. 355-379.

Reinhardt, Uwe J.; Teufel, Philipp R.: Einundzwanzig Thesen zur neuen Ausstellungsgestaltung. Twenty-one Theses on New Exhibition Design. In: ReINHARDT, 
Uwe J.; Teufel, Philipp (Hg.): Neue Ausstellungsgestaltung o1. New Exhibition Design 01. Ludwigsburg (Württemberg) 2008, S. 10-25.

ŘEPA, MILAN: The Czechs, Germans and Sudetenland. Historiographical Dispute in the >Heart of Europer. In: Frank, Tibor; Hadler, Frank (Hg.): Disputed Territories and Shared Pasts. Overlapping National Histories in Modern Europe. Basingstoke (Hampshire) 2011, S. 303-328.

Řezník, Miloš; Schulze Wessel, Martin: Das Museum als Medium einer Verflechtungsgeschichte von Deutschen, Tschechen und Slowaken. Zur Einleitung. In: Kováč, Dušan; Řezník, Miloš; Schulze Wessel, Martin (Hg.): Erinnern - Ausstellen - Speichern. Deutsch-tschechische und deutsch-slowakische Beziehungsgeschichte im Museum. Essen 2017, S. 7-21.

Richter, Karel (Hg.): Bez démoů minulosti. Česko-německé vztahy v osudových okamžicích společné minulosti. Praha 2003.

RIEFF, DAVID: In Praise of Forgetting. Historical Memory and Its Ironies. New Haven 2016.

Rigney, ANN: Transforming Memory and the European Project. In: New Literary History 43 (2012), H. 4, S. 607-628.

Rogall, JoAchim: Die Deutschen in Polen. Bundeszentrale für politische Bildung 15.03.2005. URL: https://www.bpb.de/gesellschaft/migration/dossier-migration/ 56431/die-deutschen-in-polen?p=all (letzter Zugriff: 15.07.2018).

RÖGER, MAREN: Flucht, Vertreibung und Umsiedlung. Mediale Erinnerungen und Debatten in Deutschland und Polen seit 1989. Marburg 2011.

RÖGER, MAREN: Zeitzeugen von Flucht, Vertreibung und Heimatverlust im deutschen Geschichtsfernsehen. Funktionen und Funktionalisierungen, 1981-2010. In: KaLINKE, HeINKE M. (Hg.): Zeitzeugenberichte zur Kultur und Geschichte der Deutschen im östlichen Europa im 20. Jahrhundert. Neue Forschungen. Oldenburg 2011/12, S. 1-17.

Röger, MARen: Bilder der Vertreibung. Propagandistischer Kontext und Funktionalisierungen in erinnerungskulturellen Diskursen seit dem Ende des Zweiten Weltkrieges. In: Eder, Franz X.; Kühschelm, Oliver; Linsboth, Christina (Hg.): Bilder in historischen Diskursen. Wiesbaden 2014, S. 261-279.

Rohlfes, JoACHIM: Eine bilanzierende Einführung. Zu den Beiträgen in diesem Buch. In: HARTung, Olaf (Hg.): Museum und Geschichtskultur. Ästhetik - Politik - Wissenschaft. Bielefeld 2006, S. 11-20.

Rossoliński-Liebe, GrZEgorz: Der polnisch-ukrainische Konflikt im Historikerdiskurs. Perspektiven, Interpretationen und Aufarbeitung. Wien 2017.

Roth, Klaus: Ausgestellte Differenz. Von der Macht der Stereotypen auch im Museum. In: Lozoviuk, Petr (Hg.): Visualisierte Minderheiten. Probleme und Möglichkeiten der musealen Präsentation von ethnischen bzw. nationalen Minderheiten. Dresden 2012, S. 25-33.

RUCHNIEWICZ, KRZYSZTOF: Zur versöhnungspolitischen Bedeutung der Schulbuchrevision im Hinblick auf die Vertreibungsproblematik. In: KRUKE, ANJA (Hg.): Zwangsmigration und Vertreibung. Europa im 20. Jahrhundert. Bonn 2006, S. 151-158. 
RUCHNIEWICZ, KRZYSZTOF: Geschichtspolitik im Schatten der Dankbarkeit und Enttäuschung. In: Historie. Jahrbuch des Zentrums für Historische Forschung Berlin der Polnischen Akademie der Wissenschaften 1 (2007/2008), S. 149-152.

RUCHNIEWICZ, KRZYSZTOF: Zwangsmigration als Instrument deutscher und sowjetischer Besatzungs- und Annexionspolitik in Polen 1939-1941/45. In: Troebst, SteFAN; WiLdT, Michael (Hg.): Zwangsmigration im Europa der Moderne. Nationale Ursachen und transnationale Wirkungen. Leipzig 2016, S. 125-140.

RuCHNiEwicz, KrzyszTof: Die verspätete Rechnung. Zur polnischen Diskussion über Reparationszahlungen aus Deutschland. In: Zeitgeschichte-online (Oktober 2017). URL: www.zeitgeschichte-online.de/kommentar/die-verspaetete-rechnung (letzter Zugriff: 08.11.2017).

Ruchniewicz, Krzysztof: Das Dilemma des Historikers. Zur Geschichtspolitik der PiS. In: RosteK, ANDREAS (Hg.): POLSKA first. Über die polnische Krise. Berlin 2018, S. 199-212.

Ruchniewicz, MaŁgorzata: Zwangsumsiedlungen von Polen aus den von der Weißrussischen Sowjetrepublik annektierten Territorien (1939-1959). In: Nordost-Archiv. Zeitschrift für Regionalgeschichte (2005), H. XIV, S. 164-192.

RUIZ-SOLER, JAVIER: Gibt es eine europäische Öffentlichkeit? Forschungsstand, Befunde, Ausblicke. Bundeszentrale für politische Bildung 08.09.2017. URL: www.bpb.de/ apuz/255613/gibt-es-eine-europaeische-oeffentlichkeit-forschungsstand-befundeausblicke?p=all (letzter Zugriff: 28.05.2018).

RÜSEN, JÖRN: Die fünf Dimensionen der Geschichtskultur. In: NIEßER, JACQUELINE; Tomann, Juliane (Hg.): Angewandte Geschichte. Neue Perspektiven auf Geschichte in der Öffentlichkeit. Paderborn 2014, S. 46-57.

RÜTHER, ANDREAS: Die deutschrechtliche Siedlung. 1. Die »deutsche« Perspektive. In: BAHLCKE, JoACHIM; GAWRECKI, DAN; KACZMAREK, RYSZARD (Hg.): Geschichte Oberschlesiens. Politik, Wirtschaft und Kultur von den Anfängen bis zur Gegenwart. Berlin 2015 (2. übera. und erw. Aufl. der poln. Originalausg. von 2011), S. 580-586.

Ryваск, Тімотнy W.: Dateline Sudetenland: Hostages to History. In: Foreign Policy (1996/1997), H. 105, S. 162-178.

SABROW, MARTIN: Geschichte als Instrument. Variationen über ein schwieriges Thema. In: Aus Politik und Zeitgeschichte (2013), H. 42-43, S. 3-11.

SABROW, MARTIN: Höcke und wir. In: Zeitgeschichte-online (Januar 2017). URL: https:// zeitgeschichte-online.de/kommentar/hoecke-und-wir (letzter Zugriff: 09.08.2018).

SALZBORN, SAMUEL: Opfer, Tabu, Kollektivschuld. Über Motive deutscher Obsession. In: Klundt, Michael; Salzborn, SAmuel; Schwietring, Marc; Wiegel, Gerd (Hg.): Erinnern, verdrängen, vergessen. Geschichtspolitische Wege ins 21. Jahrhundert. Gießen 2007 (2. unverän. Nachdr. der ersten Auflage von 2003), S. 17-41.

SALZBORN, SAMUEL: Geteilte Erinnerung. Die deutsch-tschechischen Beziehungen und die sudetendeutsche Vergangenheit. Frankfurt a.M., New York (NY) 2008.

Saryusz-Wolska, Magdalena; Stach, Sabine; Stoll, Katrin: Verordnete Geschichte? Zur Dominanz nationalistischer Narrative in Polen. In: Zeitgeschichte-online (19.07.2016). URL: www.zeitgeschichte-online.de/thema/verordnete-geschichtezur-dominanz-nationalistischer-narrative-polen (letzter Zugriff: 01.10.2016). 
SCHÄRER, MARTIN R.: National Museums - Difficulties and Possibilities. A Museological Approach. In: Axelsson, Bodil; Dupont, Christine; Kesteloot, Chantal (Hg.): Entering the Minefields. The Creation of New History Museums in Europe. Conference Proceedings from EuNaMus, European National Museums: Identity Politics, the Uses of the Past, and the European Citizen. Brussels 25 January 2012. Linköping 2012, S. 37-40.

SCHELIHA, Wolfram von: Forum: Diskussionsbeitrag zum Konzept für die Ausstellungen der "Stiftung Flucht, Vertreibung, Versöhnung«. In: H-Soz-Kult (22.09.2010). URL: http://hsozkult.geschichte.hu-berlin.de/forum/id=1371\&type= diskussionen (letzter Zugriff: 23.03.2018).

Schilling, Catherine: Patriotismus à la PiS und die Schlüssel von Jedwabne. In: Erinnerungskulturen. Erinnerung und Geschichtspolitik im östlichen und südöstlichen Europa (14.10.2016). URL: https://erinnerung.hypotheses.org/873 (letzter Zugriff: 12.04.2017).

SCHLÖGEL, KARL: Nach der Rechthaberei. Umsiedlung und Vertreibung als europäisches Problem. In: Bingen, Dieter; Borodziej, WŁodzimierz; Troebst, Stefan (HG.): Vertreibungen europäisch erinnern? Historische Erfahrungen, Vergangenheitspolitik, Zukunftskonzeptionen. Wiesbaden 2003, S. 11-38.

SCHLÖGEL, KARL: Die Europäisierung des »Vertreibungskomplexes«. In: GAUGER, JöRGDieter; Kittel, Manfred (Hg.): Die Vertreibung der Deutschen aus dem Osten in der Erinnerungskultur. Sankt Augustin 2005, S. 123-138.

SCHLÜTER, BETtina: »Politisch korrekt und auch sonst schwach«. Die mediale >Reaktualisierung von Flucht und Vertreibung. In: Fischer, ERIK; MÜlLER, GERHARD; Kleinschrodt, Alexander (Hg.): Deutsche Musikkultur im östlichen Europa. Konstellationen - Metamorphosen - Desiderata - Perspektiven. Stuttgart 2012, S. 390-408.

SCHMIDT, MÁRIA: Auf dem Weg zu einem europäischen Gedächtnis? Eine ungarische Sicht auf das geplante Haus der Europäischen Geschichte. In: KNIGGE, VolKHARD; VeEN, HaNS-JoAChim; MäHLERT, UlRich; ET AL. (Hg.): Arbeit am europäischen Gedächtnis. Diktaturerfahrung und Demokratieentwicklung. Köln, Weimar [u. a] 2011, S. 165-167.

Schmidt-Hartmann, Eva: Menschen oder Nationen? Die Vertreibung der Deutschen aus tschechischer Sicht. In: Auerbach, Hellmuth; Benz, Wolfgang (Hg.): Die Vertreibung der Deutschen aus dem Osten. Ursachen, Ereignisse, Folgen. Frankfurt a.M. 1988, S. 143-157.

Schmitz, Helmut; Seidel-Arpaci, Annette (Hg.): Narratives of Trauma. Discourses of German Wartime Suffering in National and International Perspective. Amsterdam, New York (NY) 2011.

Scholz, Stephan: Rezension zu: Demshuk, Andrew: The Lost German East. Forced Migration and the Politics of Memory, 1945-1970. Cambridge 2012. In: H-Soz-Kult (08.11.2012). URL: https://www.hsozkult.de/publicationreview/id/rezbuecher-19191 (letzter Zugriff: 16.08.2018).

ScHOLZ, STEPHAN: Vertriebenendenkmäler. Topographie einer deutschen Erinnerungslandschaft. Paderborn 2015. 
SCHOLZ, STEPHAN: >Flucht und Vertreibung in der deutschen Erinnerungskultur. In: Fröhlich, Claudia; Schmid, Harald (Hg.): Jahrbuch für Politik und Geschichte 6. Geschichtspolitiken und Erinnerungskulturen global. Stuttgart 2016, S. 153-170.

SCHOLZ, STEPHAN: Willkommenskultur durch »Schicksalsvergleich«. Die deutsche Vertreibungserinnerung in der Flüchtlingsdebatte. In: Aus Politik und Zeitgeschichte (2016), H. 26-27, S. 40-46.

Scholz, Stephan; Röger, Maren; Niven, Bill (Hg.): Die Erinnerung an Flucht und Vertreibung. Ein Handbuch der Medien und Praktiken. Paderborn 2015.

Scholze, JANA: Kultursemiotik: Zeichenlesen in Ausstellungen. In: BAUR, JoACHIM (Hg.): Museumsanalyse. Methoden und Konturen eines neuen Forschungsfeldes. Bielefeld 2010, S. 121-148.

SCHRÖDER, VANESSA: Geschichte ausstellen - Geschichte verstehen. Wie Besucher im Museum Geschichte und historische Zeit deuten. Bielefeld 2013.

SChulze, RAINER: The Politics of Memory. Flight and Expulsion of German Populations after the Second World War and German Collective Memory. In: National Identities 8 (2006), H. 4, S. 367-382.

Schulze Wessel, Martin: Tschechien - Institutionen, Methoden und Debatten in der Zeitgeschichte. In: Docupedia-Zeitgeschichte (19.09.2011). URL: https:// docupedia.de/zg/Tschechien_-_Institutionen,_Methoden_und_Debatten_in_der_ Zeitgeschichte (letzter Zugriff: 04.04.2017).

Schwartz, Michael: Tabu und Erinnerung. Zur Vertriebenen-Problematik in Politik und literarischer Öffentlichkeit der DDR. In: Zeitschrift für Geschichtswissenschaft 51 (2003), H. 1, S. 85-101.

SCHWARTZ, MiCHAEL: Vertriebene im doppelten Deutschland. Integrations- und Erinnerungspolitik in der DDR und in der Bundesrepublik. In: Vierteljahrshefte für Zeitgeschichte 56 (2008), H. 1, S. 101-151.

SCHWARTZ, MICHAEL: Ethnische »Säuberungen« in der Moderne. Globale Wechselwirkungen nationalistischer und rassistischer Gewaltpolitik im 19. und 20. Jahrhundert. München 2013.

SCHWARTZ, MichaEL: Funktionäre mit Vergangenheit. Das Gründungspräsidium des Bundesverbandes der Vertriebenen und das »Dritte Reich«; Unter Mitarbeit von Michael Buddrus, Martin Holler und Alexander Post. München 2013.

SchWARTZ, Michael: Rezension zu: Piskorski, Jan M.: Die Verjagten. Flucht und Vertreibung im Europa des 20. Jahrhunderts. München 2013. In: H-SozKult (28.03.2014). URL: https://www.hsozkult.de/publicationreview/id/rezbuecher20415 (letzter Zugriff: 17.12.2017).

Schwartz, Michael: Assimilation versus Incorporation. Expellee Integration Policies in East and West Germany after 1945. In: Borutta, MANuel; JANSEN, Jan C.; Borutta, M.; Jansen, JAN (Hg.): Vertriebene and Pieds-Noirs in Postwar Germany and France. Comparative Perspectives. Basingstoke (Hampshire), New York (NY) 2016, S. 73-94.

SCHWARTZ, MICHAEL: Ethnische »Säuberungen« in der Moderne. Globale Wechselwirkungen einer Politik der Gewalt. In: Troebst, Stefan; Wildt, Michael (Hg.): Zwangsmigration im Europa der Moderne. Nationale Ursachen und transnationale Wirkungen. Leipzig 2016, S. 28-48. 
Schwartz, Michael: Rezension zu: Oltmer, Jochen (Hg.): Handbuch Staat und Migration in Deutschland seit dem 17. Jahrhundert. Berlin 2016. In: H-Soz-Kult (25.11.2016). URL: https://www.hsozkult.de/publicationreview/id/rezbuecher-24996 (letzter Zugriff: 14.06.2018).

Schwarz, Marie Bettine: The Postmemorial Narrative of the Expulsion of the Sudeten Germans in Czech Literature and Film. MA dissertation. University College London; Charles University in Prague. Prag, London 2017. School for Slavonic and Eastern European Studies; Faculty of Social Sciences. URL: https://is.cuni.cz/webapps/zzp/ download/120277918 (letzter Zugriff: 21.02.2018).

SCHWARZ, WOLFGANG: DDR und ČSSR. Eine sozialistische Vernunftehe mit Beziehungskrisen. In: Koschmal, Walter; Nekula, Marek; Rogall, Joachim (Hg.): Deutsche und Tschechen. Geschichte - Kultur - Politik. Bonn 2005, S. 408-417.

SchWARZ, WolfGANG: Kulturreferenten. In: Online-Lexikon zur Kultur und Geschichte der Deutschen im östlichen Europa (24.09.2012). URL: https://ome-lexikon.unioldenburg.de/begriffe/kulturreferenten/ (letzter Zugriff: 16.04.2018).

SchWARZENEgGer, Christian: Diskurs und mediale Realitätskonstruktion in der Kommunikationsgeschichte. In: H-Soz-Kult (15.06.2017). URL: www.hsozkult.de/ event/id/termine-34418 (letzter Zugriff: 22.11.2017).

SeibT, Ferdinand: Das Verhältnis von Tschechen und Deutschen. Wo liegt das Problem? (1997). In: Luft, Robert; Brenner, Christiane; Franzen, K. Erik; HaslinGer, Peter; Heumos, Peter; Weiss, Stephanie (Hg.): Deutsche, Tschechen, Sudetendeutsche. Analysen und Stellungnahmen zu Geschichte und Gegenwart aus fünf Jahrzehnten. Von Ferdinand Seibt. Festschrift zu seinem 75. Geburtstag. München 2002, S. 333-336.

SeIbT, Ferdinand: Deutsch-tschechischer Diskurs 1947-1999. Ein Lesedrama in sieben Akten (2000). In: Ebd., S. 195-210.

SEIBT, FERDINAND: Die Deutschen in den Böhmischen Ländern. Geschichte, Wirtschaft, Kultur (1994). In: Ebd., S. 33-47.

SeIBT, FerdinAnd: Die Stunde Klios (1996). In: Ebd., S. 311-325.

SEIBT, FERdinAND: Eine neue Nachbarschaft? (1993). In: Ebd., S. 91-123.

SEIBT, FERDINAND: Tausend Jahre Böhmen und Mähren (1999). In: Ebd., S. 3-9.

SEIBT, FERDINAND: Tausend Jahre Jüdische Geschichte in Böhmen und Mähren (2000). In: Ebd., S. 49-62.

SEIBT, FERDINAND: Ungelebte Nachbarschaften, versäumte Gelegenheiten. Tschechen, Deutsche und Slowaken (1994). In: Ebd., S. 291-303.

SEIBT, FERdinAND: Wissenschaft als Brückenschlag. Deutsche, tschechische und slowakische Historiker suchen nach gemeinsamer Geschichte (1991). In: Ebd., S. 255-261.

SEMKA, PIOTR: Recenzja dokumentu »Program funkcjonalno-użytkowy wystawy głównej« przygotowanej przez Muzeum II wojny światowej w Gdańsku przez zespół: prof. dr hab. Paweł Machcewicz, dr hab. Piotr M. Majewski, dr Janusz Marszalec, dr hab. Prof. KUL Rafał Wnuk. 2016. URL: www.cultures-of-history.uni-jena.de/ fileadmin/editorial/articles/Logemann_Museum_WWII/Recenzja_Semka.pdf (letzter Zugriff: 28.09.2018).

Service, Hugo: Germans to Poles. Communism, Nationalism and Ethnic Cleansing after the Second World War. Cambridge (UK) 2013. 
Settele, Veronika: Including Exclusion in European Memory? Politics of Remembrance at the House of European History. In: Journal of Contemporary European Studies 23 (2015), H. 3, S. 405-416.

SEUBERT, HARALD: Lodgman von Auen, Rudolf. Kulturportal West-Ost 2001/2002. URL: https://kulturportal-west-ost.eu/biographien/lodgman-von-auen-rudolf-2 (letzter Zugriff: 26.09.2018).

SIERP, Aline: History, Memory, and Trans-European Identity. Unifying Divisions. Hoboken (NJ) 2014.

Sierp, Aline: Drawing Lessons from the Past. Mapping Change in Central and SouthEastern Europe. In: East European Politics \& Societies 30 (2016), H. 1, S. 3-9.

Sierp, Aline; Wüstenberg, Jenny: Linking the Local and the Transnational. Rethinking Memory Politics in Europe. In: Journal of Contemporary European Studies 23 (2015), H. 3, S. 321-329.

Siljak, Ana: Conclusion. In: Ther, Philipp; Siljak, ANa (Hg.): Redrawing Nations. Ethnic Cleansing in East-Central Europe, 1944-1948. Lanham (Md.) 2001, S. 327-335.

Simon, Roger I.: The Turn to Pedagogy. A Needed Conversation on the Practice of Curating Difficult Knowledge. In: Lehrer, Erica T.; Milton, Cynthia E.; Patterson, Monica (Hg.): Curating Difficult Knowledge. Violent Pasts in Public Places. Basingstoke (Hampshire), New York (NY) 2011, S. 193-209.

Sklokina, Iryna: The Politics of Remembering the Nazi Occupation in Soviet Museums. The Case of the Kharkiv Historical Museum (1943-1985). In: MaKhotina, Ekaterina; Keding, Ekaterina; Borodziej, WŁodzimierz; François, Etienne; Schulze Wessel, Martin (Hg.): Krieg im Museum. Präsentationen des Zweiten Weltkriegs in Museen und Gedenkstätten des östlichen Europa. Göttingen, Bristol (CT, USA) 2015, S. 131-156.

SMOLORZ, DAWID; KORDECKI, MARCIN: Schauplatz Oberschlesien. Eine europäische Geschichtsregion neu entdecken. Paderborn 2019.

SMYCKA, VÁCLAV: Das Gedächtnis der Vertreibung. Interkulturelle Perspektiven auf deutsche und tschechische Gegenwartsliteratur und Erinnerungskulturen. Bielefeld 2019.

SNIEgoŇ, Tomáš: Between Old Animosity and New Mourning. Meanings of Czech PostCommunist Memorials of Mass Killings of the Sudeten Germans. In: TöRnQUISTPlewa, Barbara (Hg.): Whose Memory? Which Future? Remembering Ethnic Cleansing and Lost Cultural Diversity in Eastern, Central and Southeastern Europe. New York, Oxford 2016, S. 49-72.

SNyder, Timothy: Bloodlands. Europa zwischen Hitler und Stalin (Original: Bloodlands. Europe between Hitler and Stalin, New York 2010). Bonn 2011.

Spalová, BARbora: Remembering the German Past in the Czech Lands. A Key Moment Between Communicative and Cultural Memory. In: History and Anthropology 28 (2016), H. 1, S. 84-109.

Spatz, Christopher: Heimatlos. Friedland und die langen Schatten von Krieg und Vertreibung. Mit Fotografien von Fritz Paul. Hamburg 2018.

SPeckmanN, Thomas: Renaissance des Themas in den Medien. In: Stiftung Haus der Geschichte der Bundesrepublik Deutschland (Hg.): Flucht, Vertreibung, Integration. Begleitbuch zur Ausstellung im Haus der Geschichte der Bundesrepublik 
Deutschland, Bonn, 3. Dezember 2005 bis 17. April 2006, im Deutschen Historischen Museum, Berlin, Mai bis August 2006, im Zeitgeschichtlichen Forum Leipzig der Stiftung Haus der Geschichte der Bundesrepublik Deutschland, 1. Dezember 2006 bis 15. April 2007. Unter Mitarbeit von Petra Rösgen. Bielefeld 2005, S. 175179.

SPETH, Rudolf: Europäische Geschichtsbilder heute. In: Bock, Petra; Wolfrum, EdGAR (HG.): Umkämpfte Vergangenheit. Geschichtsbilder, Erinnerung und Vergangenheitspolitik im internationalen Vergleich. Göttingen 1999, S. 159-175.

SPURNÝ, MATĚj: Czech and German Memories of Forced Migration. In: The Hungarian Historical Review 1 (2012), H. $\frac{3}{4}$, S. 353-367.

Stach, Stephan: Minderheitenpolitik in der Zweiten Polnischen Republik 1918-1939. In: Zeitschrift für Ostmitteleuropa-Forschung 59 (2010), H. 3, S. 394-412.

STANĚK, Tomás: Verfolgung 1945. Die Stellung der Deutschen in Böhmen, Mähren und Schlesien (außerhalb der Lager und Gefängnisse). Wien [u.a.] 2002 (Erw. und überarb. dt.-sprachige Version der ersten tschech. Aufl. von 1996).

STANĚK, ToMÁš: Vertreibung und Aussiedlung der Deutschen aus der Tschechoslowakei 1945-1948. In: HoensCH, JÖRg K.; Lemberg, HANS (Hg.): Begegnung und Konflikt. Schlaglichter auf das Verhältnis von Tschechen, Slowaken und Deutschen 1815-1989. Essen 2001, S. 207-229.

STANĚK, TOMÁš: Abschiebung oder Vertreibung? In: Koschmal, WALTER; NeKUla, MAReK; Rogall, JoAchim (Hg.): Deutsche und Tschechen. Geschichte - Kultur - Politik. Bonn 2005, S. 528-535.

STANĚK, ToMÁš: Internierung und Zwangsarbeit. Das Lagersystem in den böhmischen Ländern 1945-1948. Mit einer Einführung von Andreas R. Hofmann. München 2007.

Steffen, Katrin: Ambivalenzen des affirmativen Patriotismus. Geschichtspolitik in Polen. In: Osteuropa 56 (2006), H. 11-12, S. 219-233.

Stegmann, Natali: Kriegsdeutungen, Staatsgründungen, Sozialpolitik. Der Heldenund Opferdiskurs in der Tschechoslowakei. 1918-1948. München 2010.

STEINBACH, Peter: Erinnerung - Gedenken - Geschichtspolitik. In: HAHN, HANS HeNNing; Traba, Robert (Hg.): Deutsch-Polnische Erinnerungsorte. Band 4: Reflexionen. Unter Mitarbeit von Maciej Górny und Kornelia Kończal. Paderborn 2013, S. 315-336.

Sternfeld, Nora: Der Objekt-Effekt. In: Grieiber, Martina; Haupt-Stummer, Christine; Höllwart, Renate; Jaschke, Beatrice; Sommer, Monika; SternFeld, Nora; Ziaja, Luisa (Hg.): Gegen den Stand der Dinge. Objekte in Museen und Ausstellungen. Berlin, Boston 2016, S. 25-33.

STICKLER, MATthias: »Ostdeutsch heißt Gesamtdeutsch«. Organisation, Selbstverständnis und heimatpolitische Zielsetzungen der deutschen Vertriebenenverbände 1949-1972. Düsseldorf 2004.

STICKLER, MATTHIAS: Gegenspieler der Aussöhnung? Die Haltung der Vertriebenenverbände zur deutsch-polnischen Verständigung 1949 bis 1969. In: BOLL, FRIEDHELM; Wysocki, WiesŁaw; Ziemer, Klaus (Hg.): Versöhnung und Politik. Polnisch-deutsche Versöhnungsinitiativen der 1960er-Jahre und die Entspannungspolitik. Unter Mitarbeit von Thomas Roth. Bonn 2009, S. 224-244. 
STICKLER, MatThias: Charta der deutschen Heimatvertriebene. In: Online-Lexikon zur Kultur und Geschichte der Deutschen im östlichen Europa (02.06.2015). URL: https://omelexikon.uni-oldenburg.de/begriffe/charta-der-deutschen-heimatvertriebenen/ (letzter Zugriff: 04.11.2018).

Stiftung Flucht, Vertreibung, Versöhnung; Donauschwäbisches Zentralmuseum (Hg.): Vom »Verschwinden« der deutschsprachigen Minderheiten. Ein schwieriges Kapitel in der Geschichte Jugoslawiens 1941-1955; Unter Mitarbeit von Zoran Janjetović, Marianne Graumann, Wolfgang Kessler, Anka Lück, Leonie Mechelhoff und Leni Perenčević. Ulm 2016.

Stiftung Flucht, Vertreibung, Versöhnung; Stiftung Denkmal für die ermordeten Juden Europas (Hg.): »Das war mal unsere Heimat ...«. Jüdische Geschichte im preußischen Osten. Begleitband zur Internationalen Tagung am 2. und 3. November 2011 in Berlin; Unter Mitarbeit von Uwe Neumärker und Andreas Kossert. Berlin 2013.

Stobiecki, RAfaє: Die Gegenwart der Vergangenheit. Kommunismus und Volksrepublik in der öffentlichen Debatte Polens nach 1989. In: CoRneliben, CHRISTOPH; HOLEC, ROMAN; PEŠEK, JIŘí (Hg.): Diktatur - Krieg - Vertreibung. Erinnerungskulturen in Tschechien, der Slowakei und Deutschland seit 1945. Essen 2005, S. 429-451. StokŁosa, Katarzyna: Polen und die deutsche Ostpolitik. 1945-1990. Göttingen 2011.

STRAUCHOLD, GRZEGORZ: Die »Wiedergewonnenen Gebiete« und das »Piastische Schlesien«. In: CZAPlińsKi, MAREK; Hahn, HANS-JOACHIM; Weger, Tobias (Hg.): Schlesische Erinnerungsorte. Gedächtnis und Identität einer mitteleuropäischen Region. Eine Veröffentlichung des Schlesischen Museums zu Görlitz. Görlitz 2005, S. 306322.

Streibel, Robert: Vorwort. In: Streibel, Robert (Hg.): Flucht und Vertreibung. Zwischen Aufrechnung und Verdrängung. Wien 1994, S. 9-19.

StruVE, KaI: Germanisierung und großpolnische Agitation im 19. Jahrhundert. Die »deutsche« Perspektive. In: BAHLCKe, JoACHIM; GAWRECKI, DAN; KACZMAREK, RYsZARD (HG.): Geschichte Oberschlesiens. Politik, Wirtschaft und Kultur von den Anfängen bis zur Gegenwart. Berlin 2015 (2. übera. und erw. Aufl. der poln. Originalausg. von 2011), S. 593-601.

Strzembosz, Tomasz: Przemilczana kolaboracja. Rzeczpospolita 27.01.2001. In: JANKOWSKI, ROBERT (Hg.): Cena »Strachu«. Gross w oczach historyków. Wybór publicystiki. Warszawa 2008, S. 53-78.

Sundhaussen, Holm: Einführende Bemerkungen. Wider Vertreibung als nationalen Erinnerungsort. In: Brunnbauer, Ulf; Esch, Michael G.; Sundhaussen, Holm (Hg.): Definitionsmacht, Utopie, Vergeltung. »Ethnische Säuberungen« im östlichen Europa des 20. Jahrhunderts. Berlin 2006, S. 21-31.

SuPPAN, ARNOLD: Hitler - Beneš - Tito. Konflikt, Krieg und Völkermord in Ostmittelund Südosteuropa. Wien 2014 (2., korrigierte Aufl.).

SUPPAN, ARNOLD: Violence in Western Europe in the 2oth Century. In: Remembrance and Solidarity Studies in 2oth Century European History (2018), H. 6, S. 179-189.

Suppan, Arnold; Koura, Petr; Perzi, Niklas: Die österreichischen und böhmischen Länder unter NS-Herrschaft 1938-1945. In: PERZI, NikLAS; SCHMOLLER, HILDEGARD; KonRÁD, OTA; ŠMIDRKAL, VÁClAV (HG.): Nachbarn. Ein österreichisch-tschechisches Geschichtsbuch. Weitra 2019, S. 167-205. 
Świder, MAŁgorzata: Die Entgermanisierung Oberschlesiens nach 1945. In: STICKLER, Matthias (Hg.): Jenseits von Aufrechnung und Verdrängung. Neue Forschungen zu Flucht, Vertreibung und Vertriebenenintegration. Stuttgart 2014, S. 65-87.

SzARANIEC, LECH: Muzeum Ślaskie w Katowicach 1924-2002. Das Schlesische Museum in Katowice 1924-2002. Katowice 2002 (4. Aufl.).

SzARANIEC, LECH: Muzeum Ślaskie. 1924-2005 = Silesian Museum $=$ Museè de Silesie $=$ Schlesisches Museum. Katowice 2006.

Szeligowska, Dorota: Polish Patriotism after 1989. Concepts, Debates, Identities. Oxford (UK) 2016.

TABERY, ERIK: Die Tschechen auf der Suche nach einem Platz in Europa. In: ScHWARZ, Wolfgang (Hg.): Mein Weg zu unseren Deutschen. Zehn tschechische Perspektiven. Viechtach 2019, S. 47-61.

TÁBORSKÝ, ONDǨEJ: Creating Silesian Identity. A Comparative Review of Three Regional Museums. In: Cultures of History Forum (21.06.2018). URL: www.cultures-of-history. uni-jena.de/exhibitions/czech-republic/creating-silesian-identity-a-comparativereview-of-three-regional-museums/ (letzter Zugriff: 12.09.2018).

te Heesen, ANKe: Theorien des Museums zur Einführung. Hamburg 2013 (2. unveränd. Aufl.).

te Heesen, Anke: Exponat. In: Gfrereis, Heike; Thiemeyer, Thomas; Tschofen, Bernhard (Hg.): Museen verstehen. Begriffe der Theorie und Praxis. Göttingen 2015, S. 33-44.

Ther, PhILIPp: Chance und Last der Geschichte. Vergleich des deutsch-polnischen und deutsch-tschechischen Dialogs zur Vertreibung. In: Die Neue Gesellschaft/Frankfurter Hefte 48 (1996), H. 11, S. 994-997.

Ther, Philipp: Ein Jahrhundert der Vertreibung. Die Ursachen von ethnischen Säuberungen im 20. Jahrhundert. In: MELville, RALPH; PEŠEK, JIŘí; SCHARF, ClAuS (Hg.): Zwangsmigrationen im mittleren und östlichen Europa. Völkerrecht - Konzeptionen - Praxis (1938-1950). Mainz 2007, S. 19-37.

Ther, PhILIPp: Der Diskurs um die Vertreibung und die Falle der Erinnerung. In: STRoBel, Thomas; MaIer, Robert (Hg.): Das Thema Vertreibung und die deutsch-polnischen Beziehungen in Forschung, Unterricht und Politik. Hannover 2008, S. 29-47.

Ther, Philipp: Die dunkle Seite der Nationalstaaten. »Ethnische Säuberungen« im modernen Europa. Göttingen 2011.

Ther, PhILIPP: Die Außenseiter. Flucht, Flüchtlinge und Integration im modernen Europa. Berlin 2017.

Thiemeyer, Thomas: Fortsetzung des Krieges mit anderen Mitteln. Die beiden Weltkriege im Museum. Paderborn 2010.

Thiemeyer, Thomas: Geschichtswissenschaft: Das Museum als Quelle. In: BAur, JoACHIM (HG.): Museumsanalyse. Methoden und Konturen eines neuen Forschungsfeldes. Bielefeld 2010, S. 73-94.

Thiemeyer, Thomas: Die Sprache der Dinge. Museumsobjekte zwischen Zeichen und Erscheinung. In: Museen für Geschichte (Hg.): Online-Publikation der Beiträge des Symposiums »Geschichtsbilder im Museum « im Deutschen Historischen Museum Berlin (Februar 2011). URL: www.museenfuergeschichte.de/downloads/news/Thomas_ThiemeyerDie_Sprache_der_Dinge.pdf (letzter Zugriff: 25.10.2016). 
Thiemeyer, Thomas: Die Sprache der Dinge. Museumsobjekte zwischen Zeichen und Erscheinung. In: Staupe, Gisela (Hg.): Das Museum als Lern- und Erfahrungsraum. Grundlagen und Praxisbeispiele. Wien [u.a.] 2012, S. 51-59.

ThIEMEyer, Thomas: Evidenzmaschine der Erlebnisgesellschaft. Die Museumsausstellung als Hort und Ort der Geschichte. In: FröHlich, Claudia; Schmid, Harald; SCHWElling, Birgit (Hg.): Jahrbuch für Politik und Geschichte 4. Geschichte ausstellen. Stuttgart 2013, S. 13-29.

Thiemeyer, Thomas: Inszenierung. In: Gfrereis, Heike; Thiemeyer, Thomas; Tschofen, Bernhard (Hg.): Museen verstehen. Begriffe der Theorie und Praxis. Göttingen 2015, S. 45-62.

Thiemeyer, Thomas: Politik des Zeigens. Das Museum als Medium der WeltkriegsErinnerung. In: Makhotina, Ekaterina; Keding, Ekaterina; Borodziej, WŁodzimierz; François, Etienne; SChulze Wessel, Martin (Hg.): Krieg im Museum. Präsentationen des Zweiten Weltkriegs in Museen und Gedenkstätten des östlichen Europa. Göttingen, Bristol (CT, USA) 2015, S. 15-27.

Thiemeyer, Thomas: Multi-Voiced and Personal. Second World War Remembrance in German Museums. In: EchternKAMP, Jörg; JAEger, StePHAN (Hg.): Views of Violence. Representing the Second World War in German and European Museums and Memorials. New York (NY) 2019, S. 27-51.

TiEws, Alina LaURa: Fluchtpunkt Film. Integrationen von Flüchtlingen und Vertriebenen durch den deutschen Nachkriegsfilm 1945-1990. Berlin 2017.

TOMANN, JulianE: Rezension zu: Das Licht der Geschichte. Oberschlesien im Wandel der Zeiten, 26.06.2015 Katowice. In: H-Soz-Kult (31.10.2015). URL: www.hsozkult.de/ exhibitionreview/id/rezausstellungen-229 (letzter Zugriff: 20.07.2017).

TOMANN, JulianE: Geschichtskultur im Strukturwandel. Öffentliche Geschichte in Katowice nach 1989. Berlin, Boston 2016.

Tomann, Juliane: Rezension zu: Bogumił, Zuzanna; Wawrzyniak, Joanna; Buchen, Tim; Ganzer, Christian; Senina, Maria: The Enemy on Display. The Second World War in Eastern European Museums. New York 2015. In: H-Soz-Kult (17.02.2016). URL: www.hsozkult.de/publicationreview/id/rezbuecher-24000 (letzter Zugriff: 07.09.2017).

Tomann, JUliane: »The Light of History«. The First Permanent Exhibition on Upper Silesian History in Poland Avoids Sensitive Issues and Focuses on Ostensible Consensus. In: Cultures of History Forum (01.03.2016). URL: www.cultures-ofhistory.uni-jena.de/exhibitions/poland/the-light-of-history-the-first-permanentexhibition-on-upper-silesian-history-in-poland-avoids-sensitive-issues-andfocuses-on-ostensible-consensus/ (letzter Zugriff: 20.07.2017).

TOMASZEWSKI, JERZY: Rezension zu: »Wir haben uns selbst aus Europa vertrieben.«. Tschechische Selbstkritik an der Vertreibung der Sudetendeutschen. Eine Dokumentation von Leopold Grünwald, München 1985. In: Przegląd Historyczny (1988), H. 79/2, S. 396-397.

Traba, Robert: Krieg und Zwangsaussiedlungen. Ein Beispiel für die Asymmetrie des kulturellen Gedächtnisses in Polen und Deutschland. In: Historie. Jahrbuch des Zentrums für Historische Forschung Berlin der Polnischen Akademie der Wissenschaften 1 (2007/2008), S. 126-128. 
TrAbA, Robert; ŻUReK, Robert: "Vertreibung« oder "Zwangsumsiedlung«? Die deutsch-polnische Auseinandersetzung um Termini, das Gedächtnis und den Zweck der Erinnerungspolitk. In: KocH, CHRIsTOPH (Hg.): War die »Vertreibung« Unrecht? Die Umsiedlungsbeschlüsse des Potsdamer Abkommens und ihre Umsetzung in ihrem völkerrechtlichen und historischen Kontext. Frankfurt a.M., Bern [u.a.] 2015, S. 321-372.

TrabA, Robert; Żytyniec, RAfAє: Verlorene Heimat/Wiedergewonnene Gebiete. Menschliche Dramen und politische Konjunkturen. In: HAHN, HaNs HeNNING; Traba, Robert (Hg.): Deutsch-Polnische Erinnerungsorte. Band 1: Geteilt/Gemeinsam. Unter Mitarbeit von Maciej Górny und Kornelia Kończal. Paderborn 2015, S. 715-739.

TREMEL, LUISE; KRÜGER, ThOMAS: Jenseits der Nation, zukünftig. Erinnerungskultur und politische Bildung. In: WAGNER, BERND (HG.): Erinnerungskulturen und Geschichtspolitik. Essen 2009, S. 349-356.

Troebst, Stefan (Hg.): Vertreibungsdiskurs und europäische Erinnerungskultur. Deutsch-polnische Initiativen zur Institutionalisierung seit 2002. Eine Dokumentation. Osnabrück 2006.

Troebst, Stefan: 23 August. The Genesis of a Euro-Atlantic Day of Remembrance. In: Remembrance and Solidarity Studies in 2oth Century European History (2012), H. 1, S. 1551.

Troebst, Stefan: The Discourse on Forced Migration and European Culture of Remembrance. In: Hungarian Historical Review (2012), H. 3-4, S. 397-414.

Troebst, Stefan: Eckstein einer EU-Geschichtspolitik. Das Museumsprojekt »Haus der Europäischen Geschichte« in Brüssel. Bundeszentrale für politische Bildung 26.10.2012. URL: www.bpb.de/geschichte/zeitgeschichte/deutschlandarchiv/144616/ eckstein-einer-eu-geschichtspolitik?p=all (letzter Zugriff: 28.05.2018).

Troebst, Stefan: Die Europäische Union als »Gedächtnis und Gewissen Europas«? Zur EU-Geschichtspolitik seit der Osterweiterung. In: François, Étienne; Kończal, Kornelia; Traba, Robert; Troebst, Stefan (Hg.): Geschichtspolitik in Europa seit 1989. Deutschland, Frankreich und Polen im internationalen Vergleich. Göttingen 2013, S. 94-155.

Troebst, Stefan: »Osten sind immer die anderen!«. Mitteleuropa als exklusionistisches Konzept (2012). In: Troebst, Stefan (Hg.): Erinnerungskultur - Kulturgeschichte - Geschichtsregion. Ostmitteleuropa in Europa. Stuttgart 2013, S. 43-50.

Troebst, Stefan: Geschichtspolitik. In: Docupedia-Zeitgeschichte (04.08.2014). URL: https://docupedia.de/zg/Geschichtspolitik (letzter Zugriff: 23.03.2016).

TRoebst, Stefan: Vom Bevölkerungstransfer zum Vertreibungsverbot. Eine europäische Erfolgsgeschichte? In: Koch, CHRIstoph (Hg.): War die »Vertreibung« Unrecht? Die Umsiedlungsbeschlüsse des Potsdamer Abkommens und ihre Umsetzung in ihrem völkerrechtlichen und historischen Kontext. Frankfurt a.M., Bern [u.a.] 2015, S. 169-194.

Troebst, StEFAn: Towards a European Memory of Forced Migration? Processes of Institutionalization and Musealization in Germany and Poland. In: Borutta, Manuel; JANSEn, Jan C.; Borutta, M.; JANSEN, JAN (Hg.): Vertriebene and Pieds-Noirs in 
Postwar Germany and France. Comparative Perspectives. Basingstoke (Hampshire), New York (NY) 2016, S. 233-251.

Troebst, Stefan; Wildt, Michael (Hg.): Zwangsmigration im Europa der Moderne. Nationale Ursachen und transnationale Wirkungen. Leipzig 2016.

TRÜPel, Helga: Haus der europäischen Geschichte. In: WAgner, BeRnd (Hg.): Erinnerungskulturen und Geschichtspolitik. Essen 2009, S. 185-191.

TuČKová, Kateřina: Die Brünner Sudeten. In: SchwarZ, Wolfgang (Hg.): Mein Weg zu unseren Deutschen. Zehn tschechische Perspektiven. Viechtach 2019, S. 63-81.

TŮmA, OLDřich: Die Aussiedlung der Deutschen aus der Tschechoslowakei. Ihre Geschichte und die Entwicklung ihrer Wahrnehmung im tschechischen nationalen Gedächtnis. In: КосH, CHRIstopH (HG.): War die »Vertreibung« Unrecht? Die Umsiedlungsbeschlüsse des Potsdamer Abkommens und ihre Umsetzung in ihrem völkerrechtlichen und historischen Kontext. Frankfurt a.M., Bern [u.a.] 2015, S. 257282.

Tych, Feliks: Polnische Geschichtsdebatten, die es nicht gibt. In: Hofmann, Anna; Kerski, BAsil (Hg.): Deutsche und Polen. Erinnerung im Dialog. Osnabrück 2007, S. 63-69.

Tych, Feliks: Gemeinsame Geschichte - gemeinsame Aufarbeitung. Ein Beitrag zur Verständigung zwischen Deutschen und Polen. In: Bouvier, BEATRIX; SCHNEIDER, Michael (Hg.): Geschichtspolitik und demokratische Kultur. Bilanz und Perspektiven. Bonn 2008, S. 135-141.

Tzvetkova, Gergana: Apology - All is Relative. Stories of Acknowledgement, Hesitation and Denial after Communism. In: Remembrance and Solidarity Studies in 2oth Century European History (2012), H. 1, S. 105-123.

Uhl, Heidemarie: Deutsche Schuld, deutsches Leid. Eine österreichische Perspektive auf neue Tendenzen der deutschen Erinnerungskultur. In: Tel Aviver Jahrbuch für deutsche Geschichte (2005), H. 33, S. 160-180.

Uhl, HeIdemarie: Der gegenwärtige Ort von »Flucht und Vertreibung« im deutschen und österreichischen Gedächtnisdiskurs. In: Haslinger, Peter; Franzen, K. ERIK; Wessel, Martin Schulze (Hg.): Diskurse über Zwangsmigration in Zentraleuropa. Geschichtspolitik, Fachdebatten, literarisches und lokales Erinnern seit 1989. München 2008, S. 157-174.

UllRich, Peter: Diskursanalyse, Diskursforschung, Diskurstheorie. Ein- und Überblick. In: Freikamp, UlRIKe (Hg.): Kritik mit Methode? Forschungsmethoden und Gesellschaftskritik. Berlin 2008, S. 19-32.

Urban, Thomas: Der Verlust. Die Vertreibung der Deutschen und Polen im 20. Jahrhundert. München 2004.

VÁrdy, Steven BÉla; ToOley, T. Hunt: Ethnic Cleansing in History. In: VÁRdy, STEVeN BÉla; Tooley, T. Hunt (Hg.): Ethnic Cleansing in Twentieth-Century Europe. Boulder (Colo.) 2003, S. 1-10.

Vetter, Reinhold: Politisches Gedenken - Polen und der 8. Mai 1945. Bundeszentrale für politische Bildung 26.05.2015. URL: www.bpb.de/internationales/europa/ polen/207253/analyse-politisches-gedenken-polen-und-der-8-mai-1945 (letzter $\mathrm{Zu}$ griff: 01.10.2016). 
Vetter, Reinhold: Das Schicksal des Danziger Weltkriegsmuseums. Die polnische Regierung und die europäische Ausrichtung des Projekts. In: Polen-Analysen (06.12.2016), H. 192, S. 2-7.

Vetter, Reinhold: Die PiS und das Erbe der Volksrepublik. In: Polen-Analysen (06.03.2018), H. 214, S. 2-7.

Vetter, Reinhold: Der Preis des Wandels. Geschichte des europäischen Ostens seit 1989. Bonn 2019.

VilímEK, Tomáš: Zu den Ursachen des Regimezusammenbruchs in der Tschechoslowakei und der DDR im Jahr 1989. Ein Vergleich. In: BuCHHEIM, CHRISTOPH; IVANIČKová, Edita; Kaiserová, Kristina; Zimmermann, Volker (Hg.): Die Tschechoslowakei und die beiden deutschen Staaten. Essen 2010, S. 163-200.

Volf, Darina: Shifting Attitudes Toward the Second World War Commemorations in the Czech Republic. In: Cultures of History Forum (01.03.2016). URL: www.culturesof-history.uni-jena.de/debating-2oth-century-history/czech-republic/shiftingattitudes-toward-the-second-world-war-commemorations-in-the-czech-republic/ (letzter Zugriff: 22.03.2016).

VöLKERING, TIM: Flucht und Vertreibung im Museum. Zwei aktuelle Ausstellungen und ihre geschichtskulturellen Hintergründe im Vergleich. Münster 2008.

VölKERING, TIM: Die Musealisierung der Themen Flucht, Vertreibung und Integration. Analysen zur Debatte um einen neuen musealen Gedenkort und zu historischen Ausstellungen seit 1950. In: FendL, Elisabeth (Hg.): Zur Ästhetik des Verlusts. Bilder von Heimat, Flucht und Vertreibung. Referate der Tagung des Johannes-KünzigInstituts für ostdeutsche Volkskunde 8. bis 10. Juli 2009. Münster 2010, S. 71-124.

VöLKERING, TIM: The Musealization of >Flight, < >Expulsion, $<$ and >Integration $<$ in the Federal Republic of Germany. Institutional Trends - Conceptual Approaches - Controversial Receptions. In: Beinek, Justyna; Kosicki, Piotr H. (Hg.): Re-Mapping Polish-German Historical Memory. Physical, Political, and Literary Spaces since World War II. Bloomington (Ind.) 2011, S. 105-126.

VöLKERING, TIM: Von der privaten Stiftung »Zentrum gegen Vertreibungen« zur Bundesstiftung »Flucht, Vertreibung, Versöhnung«. In: Łuczewski, Micha£; WiedMANN, JutTA; Muzeum Powstania Warszawskiego (Hg.): Erinnerungskultur des 20. Jahrhunderts. Analysen deutscher und polnischer Erinnerungsorte. Frankfurt a.M. 2011, S. 129-137.

VOVK VAN GAAL, TAJA: Comment forger un récit européen? La Maison de l'histoire européenne: Travaux en cours. In: ArJAkovsky, ANTOINE (Hg.): Histoire de la conscience européenne. Préface de Herman Van Rompuy, postface de Rown Williams. Paris 2016, S. 57-66.

Vovk van GaAl, TAJA; Dupont, Christine: The House of European History. In: AXelsson, Bodil; Dupont, Christine; Kesteloot, Chantal (Hg.): Entering the Minefields. The Creation of New History Museums in Europe. Conference Proceedings from EuNaMus, European National Museums: Identity Politics, the Uses of the Past, and the European Citizen. Brussels 25 January 2012. Linköping 2012, S. 43-53.

Vovk van GaAl, Taja; ItZel, Constanze: The House of European History project in Brussels. In: Borodziej, WŁodzimierz; PutTKAmer, JoACHim von (Hg.): Europa und sein Osten. Geschichtskulturelle Herausforderungen. München 2012, S. 75-80. 
WAGińSKa-MARZEC, MARIA: Konflikt wokół Widocznego Znaku w świetle prasy polskiej. Poznań 2009.

WAGNER, BERND: Deutsche Erinnerungskulturen und Geschichtspolitik nach 1945. In: WAGNER, BERND (HG.): Erinnerungskulturen und Geschichtspolitik. Essen 2009, S. 17-30.

Walz, MARKus: Begriffsgeschichte, Definition, Kernaufgaben. In: Walz, Markus (Hg.): Handbuch Museum. Geschichte, Aufgaben, Perspektiven. Stuttgart 2016, S. 8-14.

WANATOWICZ, MARIA W.: Germanisierung und großpolnische Agitation im 19. Jahrhundert. Die "polnische« Perspektive. In: Bahlcke, JoAchim; Gawrecki, Dan; KaczMAREK, Ryszard (Hg.): Geschichte Oberschlesiens. Politik, Wirtschaft und Kultur von den Anfängen bis zur Gegenwart. Berlin 2015 (2. übera. und erw. Aufl. der poln. Originalausg. von 2011), S. 602-610.

WANATOWICZ, MARIA W.: Woiwodschaft Schlesien (1922-1939). In: BAHLCKE, JOACHIM; Gawrecki, Dan; Kaczmarek, Ryszard (Hg.): Geschichte Oberschlesiens. Politik, Wirtschaft und Kultur von den Anfängen bis zur Gegenwart. Berlin 2015 (2. übera. und erw. Aufl. der poln. Originalausg. von 2011), S. 318-333.

Warum beschäftigen Sie sich mit Polen? Jan Strękowski im Gespräch mit Dieter Bingen. In: Bingen, Dieter; HaŁub, Marek; Weber, Matthias (Hg.): Mein Polen - meine Polen. Zugänge und Sichtweisen. Wiesbaden 2016, S. 3-14.

Wawrzyński, Patryk: The Politics of Memory in Post-Authoritarian Transitions. The Case of the Republic of Poland. In: Marszatek-Kawa, Joanna; PiechowiakLamparska, Joanna; Ratke-Majewska, Anna; Wawrzyński, Patryk (Hg.): The Politics of Memory in Post-Authoritarian Transitions, Volume One. Case Studies. Newcastle upon Tyne (UK) 2017, S. 98-160.

Weber, MATthIAS: Über die Notwendigkeit einer Standortbestimmung der historischen Schlesienforschung in Deutschland. Zur Konzeption dieses Buches. In: WEBer, Matthias (Hg.): Silesiographia. Stand und Perspektiven der historischen Schlesienforschung. Festschrift für Norbert Conrads zum 60. Geburtstag. Würzburg 1998, S. 13-25.

Weber, Matthias: Kultur- und Wissenschaftsförderung nach $\$ 96$ BVFG. In: OnlineLexikon zur Kultur und Geschichte der Deutschen im östlichen Europa (2012; letzte Aktualisierung: 03.06.2015). URL: https://ome-lexikon.uni-oldenburg.de/begriffe/kulturund-wissenschaftsfoerderung-nach-96-bvfg/ (letzter Zugriff: 16.04.2018).

Weger, Tobias: Museen in Schlesien - gestern und heute. In: BaUer, Markus; BraDe, Johanna; Kügler, Martin; Pietsch, Martina (Hg.): Schlesisches Museum zu Görlitz - Museum für eine europäische Kulturregion. Muzeum Ślaskie w Görlitz Muzeum europejskiego regionu kulturowego. Dößel 2006, S. 35-44.

WEgER, ToBias: Lokal- und Regionalgeschichte in der deutschen und polnischen Geschichtskultur. Schwerpunkt: Museen. In: Herget, Beate; Pleitner, Berit (Hg.): Heimat im Museum? Museale Konzeptionen zu Heimat und Erinnerungskultur in Deutschland und Polen. München 2008, S. 79-101.

WĘGRZYN, DARIUSZ: »Mikrokosmos« und "große Weltpolitik«. Oberschlesien angesichts der Entwicklung der sowjetischen Politik gegenüber der deutschen und als deutsch betrachteten Bevölkerung zwischen 1941 und 1945. In: DzIUROK, ADAM; MA- 
DajCzyK, Piotr; Rosenbaum, Sebastian (Hg.): Die Haltung der kommunistischen Behörden gegenüber der deutschen Bevölkerung in Polen in den Jahren 1945 bis 1989. Gliwice/Gleiwitz, Opole/Oppeln 2015, S. 156-175.

WeHLER, HANS-UlRICH: Transnationale Geschichte - der neue Königsweg historischer Forschung? In: Budde, Gunilla; ConRad, Sebastian; Janz, Oliver (Hg.): Transnationale Geschichte. Themen, Tendenzen und Theorien. Göttingen 2006, S. 161-174.

Weigelt, Klaus: Gar nicht neue »neue Relevanz«. In: Kulturpolitische Korrespondenz (2016), H. 1366, S. 3-6.

Weigelt, Klaus: Eine Initiative, die weiterer bedarf. In: Kulturpolitische Korrespondenz (2017), H. 1385, S. 3-5.

WEISS, GISELA: »Wir wollen nicht mehr den Standpunkt des Historikers«. Zum spannungsvollen Verhältnis zwischen Museumsdisziplin und Geschichtswissenschaften im 19. und 20. Jahrhundert. In: HARTUNG, Olaf (Hg.): Museum und Geschichtskultur. Ästhetik - Politik - Wissenschaft. Bielefeld 2006, S. 233-259.

Welzer, Harald: Erinnerungskultur und Zukunftsgedächtnis. In: Aus Politik und Zeitgeschichte (2010), H. 25-26, S. 16-23.

Werner, Michael; Zimmermann, Bénédicte: Vergleich, Transfer, Verflechtung. Der Ansatz der Histoire croisée und die Herausforderung des Transnationalen. In: Geschichte und Gesellschaft 28 (2002), H. 4, S. 607-636.

Wetzel, Frauke: Kein Raum für Menschen zweier Kulturen. Das Beispiel Ústí nad Labem nach 1945. In: SCHOOR, Kerstin; SCHÜlER-SPRINGORUM, STEFANIE (Hg.): Gedächtnis und Gewalt. Nationale und transnationale Erinnerungsräume im östlichen Europa. Bonn 2016, S. 245-258.

Whitehead, Christopher; Eckersley, Susannah; Lloyd, Katherine; Mason, RhiANNON (Hg.): Museums, Migration and Identity in Europe. Peoples, Places and Identities. Florence 2016.

Whitehead, Christopher; Eckersley, Susannah; Lloyd, Katherine; Mason, RhianNon: Place, Identity and Migraton and European Museums. In: WhiteHEAd, Christopher; Eckersley, Susannah; Lloyd, Katherine; Mason, Rhiannon (Hg.): Museums, Migration and Identity in Europe. Peoples, Places and Identities. Florence 2016, S. 7-59.

Wiatr, MARcin: Eine Schifffahrt ins Ungewisse. Zum Streit um die geplante Oberschlesien-Ausstellung des Schlesischen Museums in Kattowitz. In: Dialog. Deutsch-Polnisches Magazin (Magazyn Polsko-Niemiecki) (2013), H. 103, S. 68-74.

Wiatr, Marcin: Deutsch sein in Polen. In: Jahrbuch Polen (2016), H. 27, S. 61-71.

WIATR, MARCIN: Oberschlesien und sein kulturelles Erbe. Erinnerungspolitische Befunde, bildungspolitische Impulse und didaktische Innovationen. Göttingen 2016.

WiedemanN, ANDREAS: »Komm mit uns das Grenzland aufbauen!«. Ansiedlung und neue Strukturen in den ehemaligen Sudetengebieten 1945-1952. Essen 2007.

WILDT, MichaEL: „Völkische Flurbereinigung«. Vertreibungen im Nationalsozialismus. In: Troebst, Stefan; Wildt, Michael (Hg.): Zwangsmigration im Europa der Moderne. Nationale Ursachen und transnationale Wirkungen. Leipzig 2016, S. 63-76. WILIŃSKI, MATEUSZ: Stosunki polsko-niemieckie w latach 1982-1991. Katowice 2007. 
WILKENS, ANDREAS: Kniefall vor der Geschichte. Willy Brandt in Warschau 1970. In: DeFRANCE, CORINE; PfEIL, Ulrich (Hg.): Verständigung und Versöhnung nach dem »Zivilisationsbruch«? Deutschland in Europa nach 1945. Bonn 2016, S. 83-102.

Wissenschaftliche Dienste des Deutschen Bundestages: Deutsche Minderheiten in der Zwischenkriegszeit. 31.07.2009. URL: https://www.bundestag.de/blob/411708/ 72a5544c10ee7ae5fi3d3aee9badbb80/wd-1-093-09-pdf-data.pdf (letzter Zugriff: 02.11.2018).

Witte, Michaela: Entfremdung - Sprachlosigkeit - Aussöhnung? Deutsch-tschechische Verständigungsprobleme in der Vertreibungsfrage (vyhnání a odsun) der Sudetendeutschen im Spiegel ausgewählter deutscher und tschechischer Presseorgane (1984-1997). Norderstedt 2002.

Wittlinger, Ruth: Taboo or Tradition? The >German as Victims Theme in the Federal Republic until the mid-1990s. In: Niven, BILL (Hg.): Germans as Victims. Remembering the Past in Contemporary Germany. Basingstoke (Hampshire) [u.a.] 2006, S. 62-75.

Wochnik, Alexander: Non-State Actors, Political Opportunity Structures and Foreign Relations. The Case of Germany's Federation of Expellees and the >Foundation Flight, Expulsion and Reconciliation<. In: German Politics 23 (2014), H. 3, S. 213-230.

Wokół idei muzeum II wojny światowej. In: Przegląd Polityczny (2008), H. 91/92, S. 52-62. Wolf, Gerhard: Die deutschen Minderheiten in Polen als Instrument der expansiven Außenpolitik Berlins. In: Kochanowski, Jerzy (Hg.): Die »Volksdeutschen« in Polen, Frankreich, Ungarn und der Tschechoslowakei. Mythos und Realität. Osnabrück 2006, S. 41-75.

WolfF, LARrY: Revising Eastern Europe. Memory and the Nation in Recent Historiography. In: The Journal of Modern History 78 (2006), H. 1, S. 93-118.

WOLFF-PowĘSKA, ANNA: Alte und neue Flecken auf dem Bild des Nachbarn in der polnischen Politik. In: Bingen, Dieter; Loew, Peter Oliver; Wóycicki, Kazimierz (Hg.): Die Destruktion des Dialogs. Zur innenpolitischen Instrumentalisierung negativer Fremd- und Feindbilder. Polen, Tschechien, Deutschland und die Niederlande im Vergleich, 1900-2005. Wiesbaden 2007, S. 231-246.

Wolff-Powęska, Anna: Das Deutschland- und Deutschenbild der Polen in den letzten Jahren. In: Dyroff, Stefan; Krzoska, Markus (Hg.): Geschichtsbilder und ihre museale Präsentation. Ausgewählte Beiträge zur Geschichte der Deutschen in Polen in Vergangenheit und Gegenwart. München 2008, S. 25-51.

WolfF-PowĘSKA, ANNA: Zur Aktualität von Dialog und Versöhnung im polnisch-deutschen Verhältnis. In: Boll, FriedHelm; WySOCKI, WiesŁaW; Ziemer, KlaUS (Hg.): Versöhnung und Politik. Polnisch-deutsche Versöhnungsinitiativen der 1960erJahre und die Entspannungspolitik. Unter Mitarbeit von Thomas Roth. Bonn 2009, S. 388-402.

WolfRum, Edgar: Geschichtspolitik in der Bundesrepublik Deutschland. Der Weg zur bundesrepublikanischen Erinnerung 1948-1990. Darmstadt 1999.

Wolfrum, Edgar: Die beiden Deutschland. In: Knigge, Volkhard (Hg.): Verbrechen erinnern. Die Auseinandersetzung mit Holocaust und Völkermord. Bonn 2005, S. 153-169. 
Wolfrum, Edgar: Geschichtspolitik. In: Nohlen, Dieter (Hg.): Kleines Lexikon der Politik. Bonn 2011, S. 207-210.

Wonisch, Regina: Minderheitenmuseen. Möglichkeiten und Grenzen von Gegenerzählungen im Museum. In: Lozoviuk, Petr (Hg.): Visualisierte Minderheiten. Probleme und Möglichkeiten der musealen Präsentation von ethnischen bzw. nationalen Minderheiten. Dresden 2012, S. 35-50.

WóYCiCKA, ZofiA: »Politik der Ewigkeit« auf Polnisch. Zu der aktuellen polnischen Geschichtspolitik. In: informationen. Wissenschaftliche Zeitschrift des Studienkreises Deutscher Widerstand 1933-1945 44 (2019), H. 89, S. 3-7.

ZabŁockA-Kos, AgniEszka: Więcej intelektu, mniej emocji/More Intellect, Less Emotion. $\mathrm{W}$ poszukiwaniu równowagi narracji w muzeach historycznych $\mathrm{w}$ Polsce/In Search of a Balanced Narrative in Historical Museums in Poland. In: Herito 13 (2013), H. 4, S. 82-99.

ZAREMBA, MARCIN: Im nationalen Gewande. Strategien kommunistischer Herrschaftslegitimation in Polen 1944-1980. Mit einer Einführung von Robert Brier. Osnabrück 2011.

Zaremba, Marcin: Die große Angst. Polen 1944-1947: Leben im Ausnahmezustand. Paderborn 2016.

ZARZYCKI, JAKUB: The Germans Did Not Come, or History as Material for Contemporary Art. In: Cultures of History Forum (26.10.2015). URL: www.cultures-of-history.unijena.de/exhibiting-2oth-century-history/poland/the-germans-did-not-comeor-history-as-material-for-contemporary-art/ (letzter Zugriff: 22.03.2016).

Zayas, Alfred de: Nemesis at Potsdam. The Anglo-Americans and the Expulsion of the Germans. Background, Execution, Consequences. Foreword by Robert Murphy. London, Henley [u.a.] 1977.

ZAYAS, AlfRED de; BADENHEUER, KonRAD: 80 Thesen zur Vertreibung. Aufarbeiten statt verdrängen. Berlin 2019.

ZeChneR, Johannes: Rezension zu: Bogumił, Zuzanna; Wawrzyniak, Joanna; Bucher, Tim u.a.: The Enemy on Display. The Second World War in Eastern European Museums. New York/Oxford 2015. In: Archiv für Sozialgeschichte (online) (2017), H. 57. URL: http://library.fes.de/pdf-files/afs/81782.pdf (letzter Zugriff: 07.09.2017).

ZiebińsKa-Witek, ANNA: Historia w muzeach. Studium ekspozycji Holokaustu. Lublin 2011.

Zimmermann, Volker: Wechselnde Bündnisse. Die DDR und ihre Beziehungen zur Tschechoslowakei und zu Polen in den 1950er und 1960er Jahren. In: BuchHeim, Christoph; IVAničKová, Edita; Kaiserová, Kristina; Zimmermann, Volker (Hg.): Die Tschechoslowakei und die beiden deutschen Staaten. Essen 2010, S. 87102.

ŻUrek, Robert: Wie viele Opfer forderte die Vertreibung? In: Dialog. Deutsch-Polnisches Magazin (Magazyn Polsko-Niemiecki) (2009-2010), H. 90, S. 74-78.

ZWicker, Stefan: Zur Darstellung der Sudetendeutschen in Literatur, Publizistik und Film der Nachkriegszeit in der Tschechoslowakei und Deutschland. In: KocHaNowSKI, JERZY (HG.): Die »Volksdeutschen« in Polen, Frankreich, Ungarn und der Tschechoslowakei. Mythos und Realität. Osnabrück 2006, S. 391-411. 
636 Flucht und Vertreibung in europäischen Museen

Zybura, Marek: Der Kommunismus und die Polen. In: Knigge, Volkhard (Hg.): Kommunismusforschung und Erinnerungskulturen in Ostmittel- und Westeuropa. Unter Mitarbeit von Manuel Leppert. Köln, Wien 2013, S. 49-60.

ŻYCHLIŃSKA, MONIKA; FonTANA, ERICA: Museal Games and Emotional Truths. Creating Polish National Identity at the Warsaw Rising Museum. In: East European Politics and Societies and Cultures 30 (May 2016), H. 2, S. 235-269. 


\section{Ortsregister}

A

Aleppo, S. $349,445,450$

Auschwitz, S. 153, 156, 280, 299, 329, 396, 412, 415, 479

Aussig an der Elbe/Ústí nad La-

bem, S. 11, 21, 24, 47, 52, 119, 253,

$261,344,351,355,361,365-366,398,513$,

519,521

B

Balkan, S. 27, 96, 101, 199-200, 376, 392, 455

Baltijsk/Pillau (Ostpreußen), S. 415

Baltikum, S. 99, 117, 168, 483

Bessarabien, S. 99

Beuthen/Bytom, S. 279, 298, 313-314, $316-317,320,340$

Bosnien-Herzegowina, S. 476

Breslau/Wrocław, S. 18, 21, 134, 156, 167, 205, 229, 242-243, 288, 294-297, 299, $300,302,313,396$

Bromberg/Bydgoszcz, S. $110,436,449$, 456

Buchenland/Bukowina, S. 13

Bukowina/Buchenland, s. Buchenland

Bydgoszcz/Bromberg, s. Bromberg

Bytom/Beuthen, s. Beuthen

C

Chebsko/Egerland, S. 341, 343

D

Dąbrowa Górnicza/Dombrowa,
Dayton, S. 392, 486

Den Haag, S. 257, 393-394

Dombrowa/Dąbrowa Górnicza, s. Dąbrowa Górnicza

Donbass, S. 445

Dresden, S. 479, 502

E

Egerland/Chebsko, s. Chebsko

Eintrachthütte/Zgoda, S. 331, 382

Elbląg/Elbing, S. 422

Elbing/Elbląg, s. Elbląg

Elbogen/Loket, S. 358

Ermland/Warmia, S. 98, 128

Estland, S. 444

Eupen-Malmedy, S. 141

$\mathbf{F}$

Friedland, S. 217, 527

G

Galizien, S. 13, 277, 299, 504

Gdingen/Gdynia, S. 428, 436, 438

Gdynia/Gdingen, s. Gdingen

Gleiwitz/Gliwice, S. 279, 314, 443

Gliwice/Gleiwitz, s. Gleiwitz

Góra Świętej Anny/St. Anna-

$$
\text { berg, S. } 294
$$

Grenzmark Posen-Westpreußen, S. 98

Griechenland, S. 32, 103, 125, 392, 395, $461,478,483-485,489,491,515,526$

Groß Rosen/Rogoźnica (Strze-

gom), S. 08

Großpolen/Wielkopolska, S. 110, 438 
H

Hiroshima, S. 441, 480

\section{I}

Indien, S. 392, 526

Irak, S. 392

Istrien, S. 483

\section{J}

Jalta (Krim), S. 300, 439

Jantarny/Palmnicken (Ostpreu-

ßen), S. $415,440,448$

Jedwabne, S. $228,233,264,411,438,484$

Jugoslawien, S. 45, 99, 125, 395, 398

\section{K}

Kaschubei/Kaszëbë, S. 98

Kaszëbë/Kaschubei, s. Kaschubei

Katyn/Katyń, S. 170, 195, 225, 412, 437, $480,487,502$

Kesselsdorf/Kotliska, S. 302

Kleinpolen/Małopolska, S. 333

Königsberg, S. 156

Kosovo, S. 104, 200, 253, 486

Kotliska/Kesselsdorf, s. Kesselsdorf

Kreisau/Krzyżowa, S. 146, 177, 178, 283, 301

Krim, S. 386

Kroatien, S. 395,480

Krzyżowa/Kreisau, s. Kreisau

\section{L}

Łambinowice/Lamsdorf, S. 156, 224, $282,300,305,331,382$

Lamsdorf/Łambinowice, s. Łambinowice

Lausanne, S. 103-104, 110, 116, 392, 461, 478

Lemberg/Lwów/Lwiw, S. 111, 115, 333

Leningrad, S. $395,437,508$

Ležáky, S. 113

Liberec/Reichenberg, S. 358

Lidice, S. 113, 131, 136, 348, 358, 437

Litauen, S. 111-112, 115, 135-136, 301

Loket/Elbogen, s. Elbogen

Lublin, S. 237, 527

Lubraniec, S. 122
M

Mährisch-Schlesien, S. 24, 284, 345-346

Majakowskoje/Nemmersdorf, s. Nemmersdorf

Małopolska/Kleinpolen, s. Kleinpolen

Mauthausen, S. 123

Moldawien, S. 524

Myanmar, S. 104, 528

Mysłowice/Myslowitz, S. 331

Myslowitz/Mysłowice, s. Mysłowice

$\mathbf{N}$

Nemmersdorf/Majakowskoje, S. 396, 416,440

Nordirland, S. 272

Nordschleswig/Nordslesvig, S. 141

\section{0}

Oberlausitz, S. 294

Opava/Troppau, S. 24, 46, 286, 316, 358, 364

Opole/Oppeln, S. 237, 273, 281-282, 284, 302, 327, 331, 336, 338

Oppeln/Opole, s. Opole

Osmanisches Reich, S. 101, 392, 464

Österreich, S. 17, 41, 42, 99, 105-107, 141, 183, 186, 243-244, 247, 253-256, 261, $264,354,359-360,367,435,479,484$, 527

Österreich-Ungarn, S. 98, 103, 106

Ostgalizien, S. 112, 272, 438, 455

Ostpreußen, S. 41, 98, 106, 115, 117, 127, $216,281,396,397,410$

\section{$\mathbf{P}$}

Pakistan, S. 392, 526

Palmnicken (Ostpreußen)/Jantarny, s. Jantarny

Peloponnes, S. 101

Pillau (Ostpreußen)/Baltijsk, s. Baltijsk Pilsen/Plzeň, S. 118

Plzeň/Pilsen, s. Pilsen

Pommerellen, S. 110

Pommern, S. 98, 106, 127, 152, 168, 378, 396, 441

Posen (Provinz), S. 98, 117, 277-278, 436

Potulice/Potulitz, S. 382,438 
Potulitz/Potulice, s. Potulice

Protektorat Böhmen und Mäh-

ren, S. $112-114,131,348,358,394,435$

\section{$\mathbf{R}$}

Radzionkau/Radzionków, S. 24

Radzionków/Radzionkau, s. Radzionkau

Reichenberg/Liberec, s. Liberec

Rogoźnica (Strzegom)/Groß Rosen, s. Groß Rosen

Rumänien, S. 98, 141, 398, 529

\section{S}

Sarajewo, S. 231

Schwientochlowitz/Świętochłowice, S. 24

Siebenbürgen, S. 98

Smyrna, S. 478

St. Annaberg/Góra Świętej Anny, s. Góra Świętej Anny

Stalingrad, S. 279

Stalinogród, S. 332

Stanisławów, S. 333

Stettin/Szczecin, S. 481

Straßburg, S. 205, 231

Stutthof/Sztutowo, S. $415,428,440$

Südtirol, S. 141, 144

Świętochłowice/Schwientochlowitz, s. Schwientochlowitz

Syrien, S. 216, 392, 404, 445, 528

Szczecin/Stettin, s. Stettin

Sztutowo/Stutthof, s. Stutthof

\section{$\mathbf{T}$}

Tarnopol/Ternopil, S. 302, S. 333

Tarnowitz/Tarnowskie Góry, S. 276, 326

Tarnowskie Góry/Tarnowitz, s. Tarnowitz

Teschener Schlesien, S. 106, 325, 436, 454

Tost/Toszek, S. 331

Toszek/Tost, s. Tost

Troppau/Opava, s. Opava

Türkei, S. 103-104, 218, 392, 395, 461, $478,489,491,515,526$

\section{$\mathbf{U}$}

Ukraine, S. 104, 111-112, 115, 135-136, 191, $215,225,272,301,331,426,437-438$, 442,484

Ungarn, S. 45, 125, 180, 206, 265, 332, 398, 406, 443, 460, 462, 483, 491, 527

Ústí nad Labem/Aussig an der Elbe, s. Aussig an der Elbe

W

Warmia/Ermland, s. Ermland

Weißrussland, S. 112, 115, 135-136, 301, 437, 481, 487

Westerplatte, S. 418-419, 428-429

Westpreußen, S. 98, 281, 396, 436

Wielkopolska/Großpolen, s. Großpolen

Wilna/Wilno/Vilnius, S. 111, 115

Wolhynien/Wołyń/Volýn', S. 99, 112, 272, 438, 455

Wrocław/Breslau, s. Breslau

\section{$\mathbf{Z}$}

Zamość, S. 395, 438, 508

Zgoda/Eintrachthütte, s. Eintrachthütte 



\section{Personen-, Gruppen- und Institutionenregister}

A

Abłamowicz, Dominik, S. 318

Ackermann-Gemeinde, S. 247, 267

Adalbert Stifter Verein, S. 247

Adamowicz, Paweł, S. 422

Adenauer, Konrad, S. 148, 170, 175, 484

Ahmadineschād, Mahmud, S. 445

AlliiertenMuseum (Berlin), S. 380

Antikomplex, S. 262, 267, 354

Arciszewska-Mielewczyk, Doro-

ta, S. 315

Armenier, S. 97, 101, 211, 349, 375, 391, 477

Atelier Brückner (Stuttgart), S. 390

Attlee, Clement, S. 332

Auen, Rudolf Lodgman von, S. 149

\section{B}

Babiš, Andrej, S. 215, 244, 259

Bartoszewski, Władysław, S. 226, 416

Bauer, Markus, S. 46, 285-286, 289-291, $303,307,363$

Bavendamm, Gundula, S. 380,382 , 385-386, 389

Becher, Peter, S. 204

Bělobrádek, Pavel, S. 258

Beneš, Edvard, S. 114, 116, 119, 129, 132, 181, 254, 258, 261, 358, 397, 435, 444, 448-449, 516-517

Berendt, Grzegorz, S. 424

Bienek, Horst, S. 157

Bierut, Bolesław, S. 123, 229

Bismarck, Otto von, S. 98, 231, 326, 327

Bosniaken, S. 406
Brandt, Willy, S. 145, 153-155, 183, 301, 390, 399

Bush, George H. W., S. 486

C

Čalfa, Marian, S. 246

Chełstowski, Jakub, S. 318

Chirac, Jacques, S. 484

Chojecka, Ewa, S. 288, 315, 317

Chruschtschow, Nikita Sergejewitsch, S. 484

Churchill, Winston, S. 102, 332, 481, 482

Civitas: Institute for the Study of Civil Society, S. 462

Cohn-Bendit, Daniel, S. 203

D

Davies, Norman, S. $240,420,424$

Deutschbalten, S. 32, 403

Deutsch-Baltische Gesellschaft, S. 218

Deutsch-Baltische Landsmannschaft, S. 218

Deutsch-Polnische Schulbuchkommission, S. 30, 156, 374

Deutsch-Slowakische Historikerkommission, S. 47, 248, 374

Deutsch-Tschechische Historikerkommission, S. 45, 47, 134, 248, 374

Deutsch-Tschechische Schulbuchkommission, S. 249

Doležal, Bohumil, S. 253

Donauschwaben, S. 17, 99

Donauschwäbisches Zentralmuseum

(Ulm), S. 386 
Dönhoff, Marion Hedda Ilse Grä-

fin, S. 124

Dücken, Tanja, S. 207

Dupont, Christine, S. $461,464,472$

\section{E}

Eduard VII. (Vereinigtes Königreich), S. 435

Egerland-Museum Marktredwitz, S. 341, 343

Ermländer, S. 128

Europäische Kommission, S. 316, 353, 458, 466

Europäisches Netzwerk Erinnerung und

Solidarität (ENRS), S. 206, 234, 238, $253,369,371,381,412,466$

Europäisches Zentrum der

Solidarność, S. 33, 237, 418, 426, 428

\section{$\mathbf{F}$}

Fabritius, Bernd, S. 216, 218, 379, 381$382,387-388,452,454$

Fendl, Elisabeth, S. 343, 346-348, 354

Fotyga, Anna, S. 465

Foucault, Michel, S. 65, 72

Frank, Karl Hermann, S. 131

Friedrich der Große， S. 241

Friedrich Wilhelm II., S. 326

\section{G}

Gaal, Taja Vovk van, S. 460-461, 464$468,470,472,475,500$

Gauck, Joachim, S. 203, 215

Gawin, Dariusz, S. 211, 234

Gedenkstätte Buchenwald, S. 213, 303

Gesellschaft für die Geschichte der Deutschen in Böhmen, S. 352

Gierek, Edward, S. 171, 173

Giordano, Ralph, S. 203

Gliński, Piotr, S. 318, 419-420, 424-425, 465-466, 493-494

Glotz, Peter, S. 203, 400

Gmyz, Cesary, S. 417, 510

Goethe, Wolfgang von, S. 276, 294, 315, 326

Gomułka, Władysław, S. 123, 167-168, 170-171
Gorbatschow, Michail Sergeje-

witsch, S. 486

Gorzelik, Jerzy, S. 322

Gottberg, Wilhelm von, S. 217

Gottscheer Deutsche, S. 128

Grass, Günter, S. 38, 118, 157, 159, 206207, 209, 229, 264, 428

Grażyński, Michał, S. 329

Grigat, Stephan, S. 216,

Gross, Jan Tomasz, S. 228, 242, 484-485

Grütters, Monika, S. 344, 379-381, 389

\section{H}

Hadrava, Jakub, S. 260

Halder, Winfried, S. 379-380

Haus des Terrors (Budapest), S. 48, 463

Haus Schlesien (Königswinter), S. 285

Havel, Václav, S. 146, 187, 192, 198, 245250, 253-254, 265, 267, 270, 517

Hein, Christoph, S. 207

Heinrich VI. (Schlesien), S. 295

Henker, Michael, S. 343, 346

Henlein, Konrad, S. 107, 357

Herman, Daniel, S. 258

Heydrich, Reinhard, S. 111-112, 358

hg merz architekten museumsgestalter, S. 287, 293

Hirsch, Helga, S. 157-158, 207-208, 226, 385

Hitler, Adolf, S. 102, 109-111, 117, 147, 155, 204, 208, 241, 253, 388, 417, 433, 435, 449, 479

Höcke, Björn, S. 218

Honecker, Erich, S. 175

Horthy, Miklós, S. 478

Houdek, Lukáš, S. 260

Hupach, Sigrid, S. 379

Hupka, Herbert, S. 159-160, 286, 292

Hütter, Hans Walter, S. 460, 470, 495

\section{I}

Institut für donauschwäbische Geschichte und Landeskunde (Tübingen), S. 220

Isergebirgs-Museum Neugablonz, S. 341

Itzel, Constanze, S. 460, 467-468, 497 
$\mathrm{J}$

Jaksch, Wenzel, S. 153

Jareš, Jakub, S. 464, 497, 500, 503, 527

Jaruzelski, Wojciech, S. 174-175

Jewish Claims Conference, S. 205

Jindrák, Rudolf, S. 263

Jirgl, Reinhard, S. 207

Jodliński, Leszek, S. 24, 314-318, 322, 337, 339

Johannes Paul II., S. 237, 496

Johannis, Klaus, S. 529

Joseph II., S. 357

Judt, Tony, S. 458,485

Jünger, Ernst, S. 477

Juschtschenko, Wiktor, S. 484

\section{K}

Kaczyński, Jarosław, S. 233, 238-239, 417-418, 422

Kaczyński, Lech, S. 232, 237, 413

Kafka, Franz, S. 13, 356

Kalniete, Sandra, S. 412

Karasek, Hellmuth, S. 203

Karelier, S. 32, 408

Karl IV. (HRR), S. 357

Karpatendeutsche, S. 17, 107, 117

Kaschuben, S. 128, 281, 437, 446, 449

Kather, Linus, S. 153

Kempowski, Walter, S. 402

Keynes, John Maynard, S. 477

Kittel, Manfred, S. 42, 105, 107, 119, 123124, 131, 140-141, 147, 149, 151, 153-154, 156-159, 217, 372, 375-376, 378-379, 385, 402, 410, 514

Klaus, Václav, S. 244, 254-255, 257, 528

Kliment, Alexandr, S. 186

Knast, Alicja, S. 318-319

Knigge, Volkhard, S. 213

Knopp, Guido, S. 208

Kohák, Erazim, S. 184

Kohl, Helmut, S. 19, 158-159, 161, 177, 188, 197, 283, 476

Kominek, Bolesław, S. 282

Königs Architekten (Köln), S. 390

Kopernikus-Gruppe, S. 96, 210, 407

Korte, Jan, S. 204
Koschyk, Hartmut, S. 222, 230, 250-251

Kotzian, Ortfried, S. 343-346

Koura, Petr, S. 353, 362

Krastev, Ivan, S. 12

Krauss, Marita, S. 47, 342-344, 346-347, 351

Krim-Tataren, S. 386

Kroll, Frank-Lothar, S. 380

Kuźmiu, Zbigniew, S. 495

Kwadrat (Gdynia), S. 428

Kwaśniewski, Aleksander, S. 234, 484

$\mathbf{L}$

Landsmannschaft Ostpreußen, S. 216-217

Landsmannschaft Schlesien, S. 50, 285287, 292-293, 303, 309-310, 341, 382

Latvijas Okupācijas muzejs/Lettisches Okkupationsmuseum (Riga), S. 463

Legutko, Ryszard, S. 237

Leiderman, Yuri, S. 487

Lenz, Siegfried, S. 157, 206

Lettisches Okkupationsmuseum, s. Latvijas Okupācijas muzejs (Riga)

Leyen, Ursula von der, S. 353

Libeskind, Daniel, S. 428

Lipski, Jan Józef, S. 37, 174, 177, 222, 234-235

M

Machcewicz, Pawel, S. 25, 48, 109, 230, 232-234, 238, 241, 371, 378, 405-407, 411-416, 418-422, 424-428, 430-433, $445-446,451-452,508,510,520$

Maizière, Lothar de, S. 165

Marte.Marte Architekten (Weiler/Österreich), S. 389

Martínez, Miguel Ángel Martínez, S. 461

Marx, Karl (Marxismus), S. 170, 176, 181-182, 189, 236, 462, 476, 500

Masaryk, Tomáš G., S. 107, 347, 352

Masuren, S. 128, 281, 397, 446

Matějka, Ondřej, S. 262, 380

Mausbach, Florian, S. 382

Mazowiecki, Tadeusz, S. 177, 221-223, 283

Meckel, Markus, S. 229 
Merkel, Angela, S. 215, 230, 259, 263, $353,377,387-388,418,423,518$

Metternich, Klemens Wenzel Lothar von, S. 357

Milbradt, Georg, S. 292

Milošević, Slobodan, S. 486

Mitterrand, François, S. 476

Mlynárik, Jan, S. 185-186, 190, 246

Molotow, Wjatscheslaw Michailowitsch, S. 382

Morawiecki, Mateusz, S. 466

Mork, Andrea, S. 459, 466, 470-472

Mouralová, Blanka, S. 25, 34, 47, 352357, 361

Müller, Emilia, S. 345-346

Müller, Heiner, S. 163

Museum des Warschauer Aufstandes, S. 76, 82, 232, 236, 413, 433, 498

Musial, Bogdan, S. 225, 241, 420, 424

\section{$\mathbf{N}$}

Naimark, Norman, S. 27-28, 41, 105, 109, 138-139, 209, 380

Nawrocki, Karol, $\quad$ S. 422-423, 425, 429430, 432, 452

Nečas, Petr, S. 257

Nepomuk, Johannes, S. 357

Netanjahu, Benjamin, S. 445

Neubauer, Franz, S. 246

Neumärker, Uwe, S. 380

Nieznalska, Dorota, S. 242

Niwiński, Piotr, S. 421, 424

Nixon, Richard, S. 484

Nossol, Alfons, S. 171, 177, 284

Nowak, Andrzej, S. 238, 494

NV Tempora S.A. (Belgien), S. 432

\section{o}

Oberländer, Theodor, S. 153

Oberschlesisches Landesmuseum (Ratingen), S. 285

Orbán, Victor, S. 462

Orwell, George, S. 116

Ostrčilík, Jaroslav, S. 261

\section{$\mathbf{P}$}

Pasch, Ralf, S. 350-351

Pawelka, Rudi, S. 268, 286-287, 310-312

Piłsudski, Józef, S. 105, 237, 328, 478, 496

Platform of European Memory and Conscience, S. 49, 466, 493, 498-500, 502

Posselt, Bernd, S. 221, 255, 261, 345, 351

Pomian, Krzysztof, S. 74, 416-417, 431432, 458-459

Pommersches Landesmuseum (Greifswald), S. 285-286

Pöttering, Hans-Gert, S. $457,459,461$, 464-465, 467, 469-470, 473, 475, 494

Preußische Treuhand, S. 205-206, 209, 230-232, 286, 400

Putin, Wladimir Wladimirowitsch, S. 232, 418, 420

\section{$\mathbf{R}$}

Rau, Johannes, S. 234

Reagan, Ronald, S. 175

Ribbentrop, Joachim von, S. 382

Riewe Riegler Architekten (Graz), S. 321

Rogasch, Wilfried, S. 343

Rohingya, S. 104, 528

Rosa-Luxemburg-Stiftung, S. 47, 343

Roszkowski, Wojciech, S. 465

Rumäniendeutsche, S. 398

\section{S}

Schabowski, Günter, S. 486

Schäfer, Hermann, S. 210, 213

Schily, Otto, S. 203, 204

Schlesisches Landesmuseum/Slezské zemské muzeum (Opava/Troppau), S. 24, 286

Schmidt, Arno, S. 206

Schmidt, Helmut, S. 153,174

Schmidt, Mária, S. 48, 462-463

Schröder, Gerhard, S. 204, 230-231, 235, 285

Schulz, Martin, S. 495

Schumacher, Kurt, S. 148

Schuman, Robert, S. 484

Schuster, Rudolf, S. 529

Schwan, Gesine, S. 55 
Schwarzenberg, Karel, S. 257-258

Schwarzmeerdeutsche, S. 395

Seehofer, Horst, ～S. 221, 343-345

Sekuła, Mirosław, S. 318, 322

Seliger-Gemeinde (Gesinnungsgemeinschaft sudetendeutscher Sozialdemokraten), S. 247

Sellin, Jarosław, S. 432

Semka, Piotr, S. 11, 233, 286, 308-310, $312-313,417,421,424,452,454,510$

Semprún, Jorge, S. 487

Serben, S. $395,406,480$

Šícha, Jan, S. 25, 47, 351-356, 360

Siebenbürgen-Institut (Gundelsheim), S. 220

Siebenbürger Sachsen, S. 17, 21, 98, 529

Sinti und Roma, S. 13, 499

Skubiszewski, Krzysztof, S. 222

Smarzowski, Wojciech, S. 242

Snyder, Timothy, S. 116, 122, 133, 135, 419-420, 424

Sobotka, Bohuslav, S. 258

Sokol, Jan, S. 242

Spyra, Piotr, S. 315, 317, 337

Stalin, Josef Wissarionowitsch, S. 114$116,121,144,165,169,281,332,455,478$, $480,482,503$

Steinbach, Erika, S. $132,160,198,200-$ 205, 208-212, 214, 216-219, 231-232, $241,253,370,372-373,377,388,400$, 404, 413, 452

Stiftung für deutsch-polnische Zusammenarbeit, S. 227

Stiftung Gerhart-Hauptmann-Haus (Düsseldorf), S. 379

Stoiber, Edmund, S. 25, 209-210, 221, 229-230, 342, 517

Stola, Dariusz, S. 422

Stomma, Stanisław, S. 513

Subieta, Matt, S. 423

Sudetendeutsche Landsmannschaft, S. 49, $145-146,149,152,181-183,187-188$, 198200, 220-221, 246-247, 250-251, 258, $262,271,341-345,347,349-351,361,526$

Sudetendeutsche Partei (SdP), S. 107-108, 348

Sudetendeutsche Stiftung, S. 344
Szumczyk, Jerzy Bohdan, S. 242

Szydło, Beata, S. 419

\section{$\mathbf{T}$}

Tajani, Antonio, S. 469

Thierse, Wolfgang, S. 372, 381

Tiso, Jozef, S. 114, 435

Tokarczuk, Olga, S. 242

Topographie des Terrors (Berlin), S. 382, 385-386, 410, 463

Truman, Harry $\quad$ S., S. 332,482

Trump, Donald, S. 50, 523

Trüpel, Helga, S. 460, 462-463

Tučková, Kateřina, S. 260-261

Tusk, Donald, S. 237-238, 370-371, 411$413,420,423,430-431,504$

U

Ukielski, Paweł, S. 493, 496

Ulbricht, Walter, S. 484

Ulma (Familie), S. 423-424

Ungarndeutsche, S. 100, S. 398

\section{V}

Vokřál, Petr, S. 261

Vondra, Alexandr, S. 370

Vondráček, David, S. 259

Vranitzky, Franz, S. 484

W

Wagner, Christean, S. 219

Wagner, Richard, S. 446

Weiss, Christina, S. 206

Weizsäcker, Richard von, S. 159, 187

Westerwelle, Guido, S. 372-373

Westpreußisches Landesmuseum (Warendorf), S. 286, 342

Wiesel, Elie, S. 481

Wilson, Woodrow, S. 106, 477

Wolf, Christa, S. 59, 163

Wolgadeutsche, S. 32, 430, 449

Wszelaka, Mira, S. 495

Wyszyński, Stefan, S. 168

\section{$\mathbf{Z}$}

Żaryn, Jan, S. 421, 424

Zawadzki, Aleksander, S. 330-332 
646 Flucht und Vertreibung in europäischen Museen

Zayas, Alfred de, S. 156, 219

Zeman, Miloš, S. 244, 253, 257-259, 263, 361

Zentralrat der Juden in Deutschland, S. 373,383 


\section{Geschichtswissenschaft}

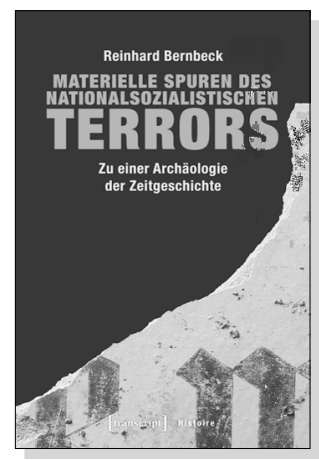

Reinhard Bernbeck

Materielle Spuren

des nationalsozialistischen Terrors

Zu einer Archäologie der Zeitgeschichte

2017, 520 S., kart., 33 SW-Abbildungen, 33 Farbabbildungen $39,99 €(D E), 978-3-8376-3967-4$

E-Book: 39,99 € (DE), ISBN 978-3-8394-3967-8

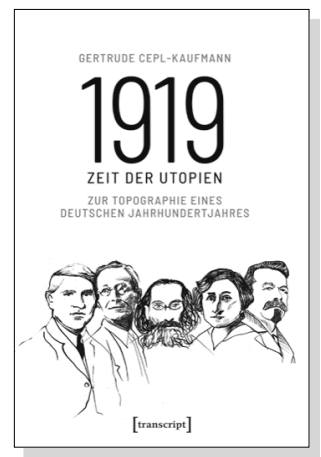

Gertrude Cepl-Kaufmann

1919 - Zeit der Utopien

Zur Topographie eines deutschen Jahrhundertjahres

2018, 382 S., Hardcover, 39 SW-Abbildungen,

35 Farbabbildungen

$39,99 €(D E), 978-3-8376-4654-2$

E-Book: 39,99 € (DE), ISBN 978-3-8394-4654-6

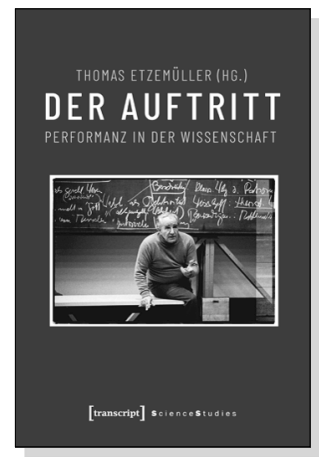

Thomas Etzemüller (Hg.)

\section{Der Auftritt}

Performanz in der Wissenschaft

2019, 428 S., kart., 42 SW-Abbildungen, 44 Farbabbildungen $44,99 €(D E), 978-3-8376-4659-7$

E-Book: 44,99€ (DE), ISBN 978-3-8394-4659-1 


\section{Geschichtswissenschaft}

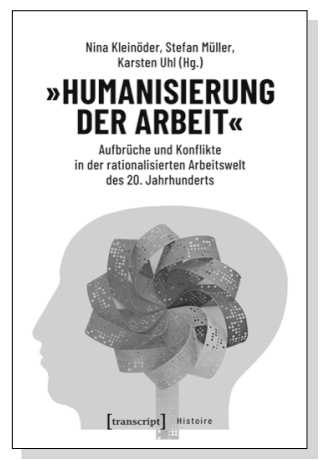

Nina Kleinöder, Stefan Müller, Karsten Uhl (Hg.)

"Humanisierung der Arbeit"

Aufbrüche und Konflikte

in der rationalisierten Arbeitswelt des 20. Jahrhunderts

2019, 336 S., kart., 1 Farbabbildung

$34,99 €(D E), 978-3-8376-4653-5$

E-Book: 34,99 € (DE), ISBN 978-3-8394-4653-9

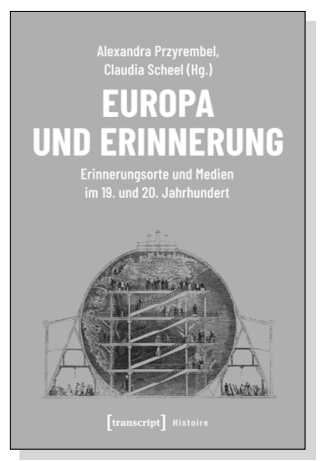

Alexandra Przyrembel, Claudia Scheel (Hg.)

\section{Europa und Erinnerung}

Erinnerungsorte und Medien im 19. und 20. Jahrhundert

2019, 260 S., kart., 10 SW-Abbildungen, 2 Farbabbildungen $24,99 €(D E), 978-3-8376-4876-8$

E-Book: 21,99€ (DE), ISBN 978-3-8394-4876-2

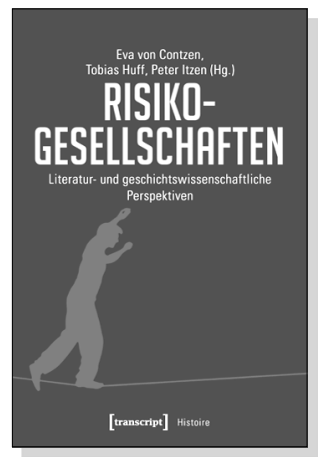

Eva von Contzen, Tobias Huff, Peter Itzen (Hg.)

\section{Risikogesellschaften}

Literatur- und geschichtswissenschaftliche Perspektiven

2018, 272 S., kart.

$29,99 €(D E), 978-3-8376-4323-7$

E-Book: 26,99 € (DE), ISBN 978-3-8394-4323-1 

